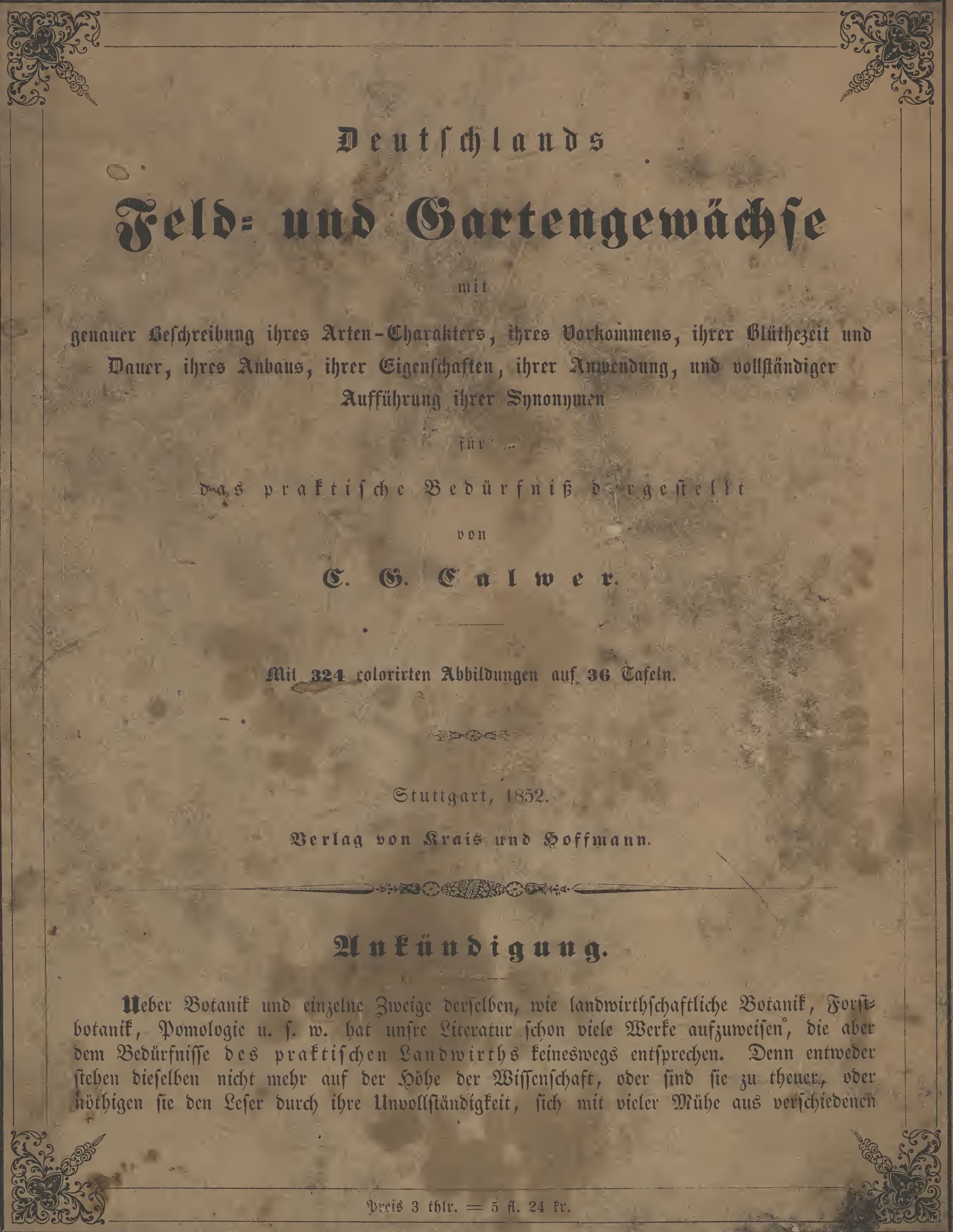




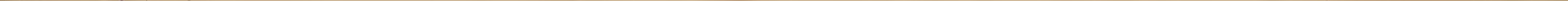




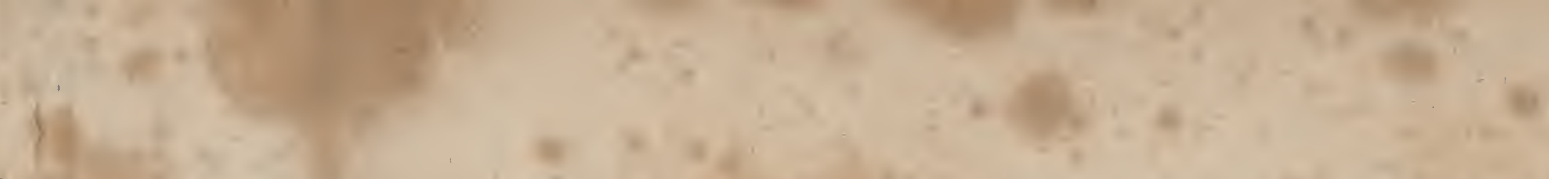

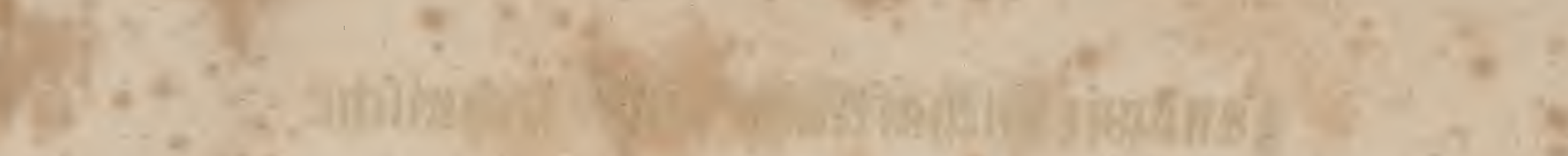

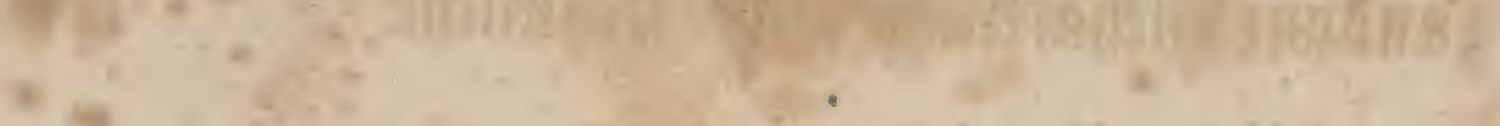

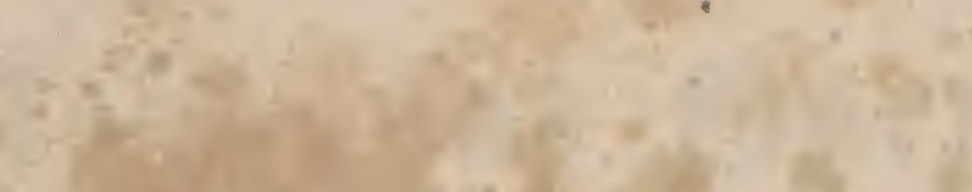

s.

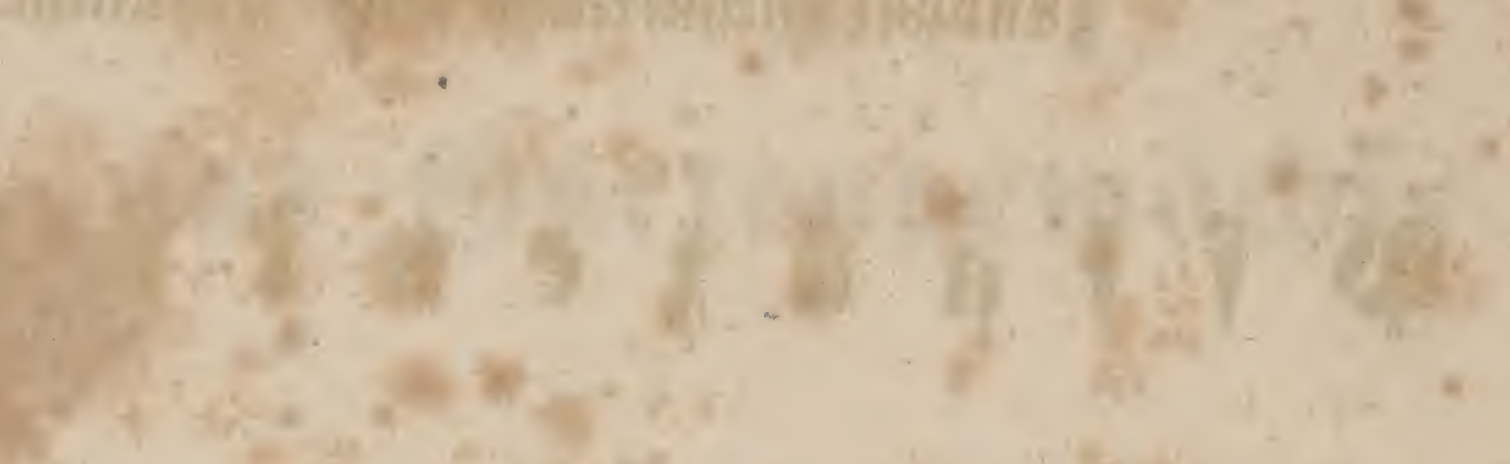

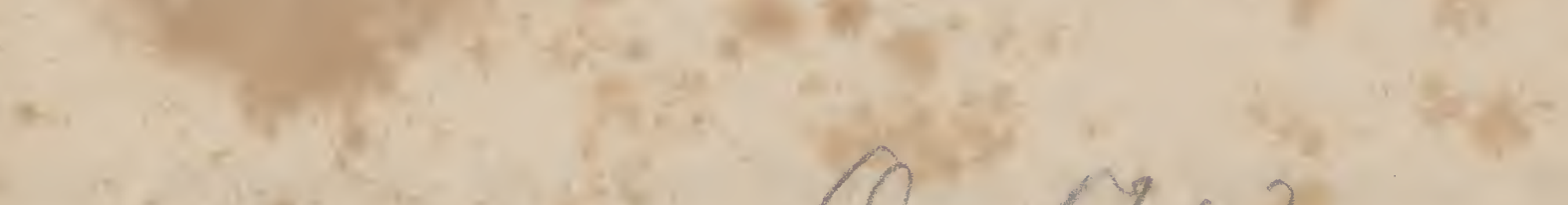

$$
\text { at is atot. }
$$

4.

.

v

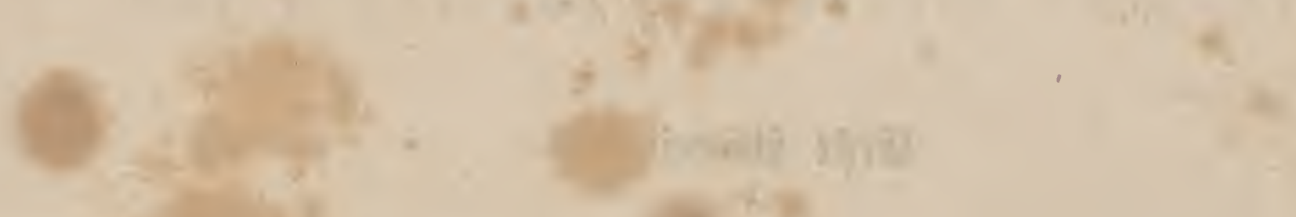
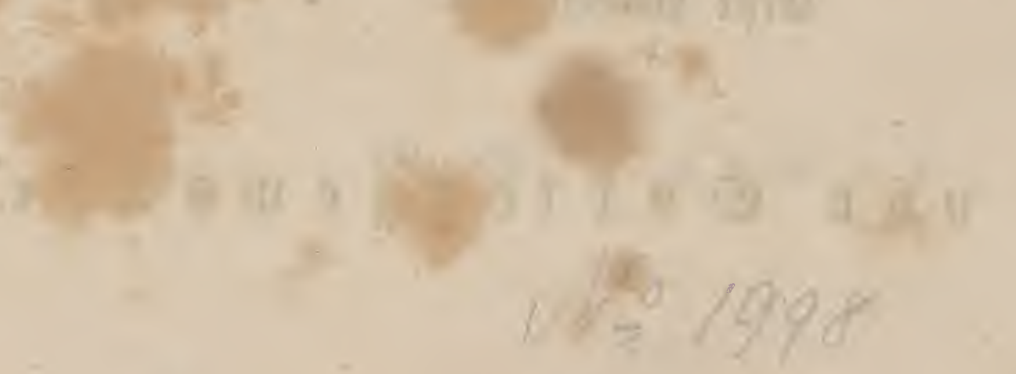

v

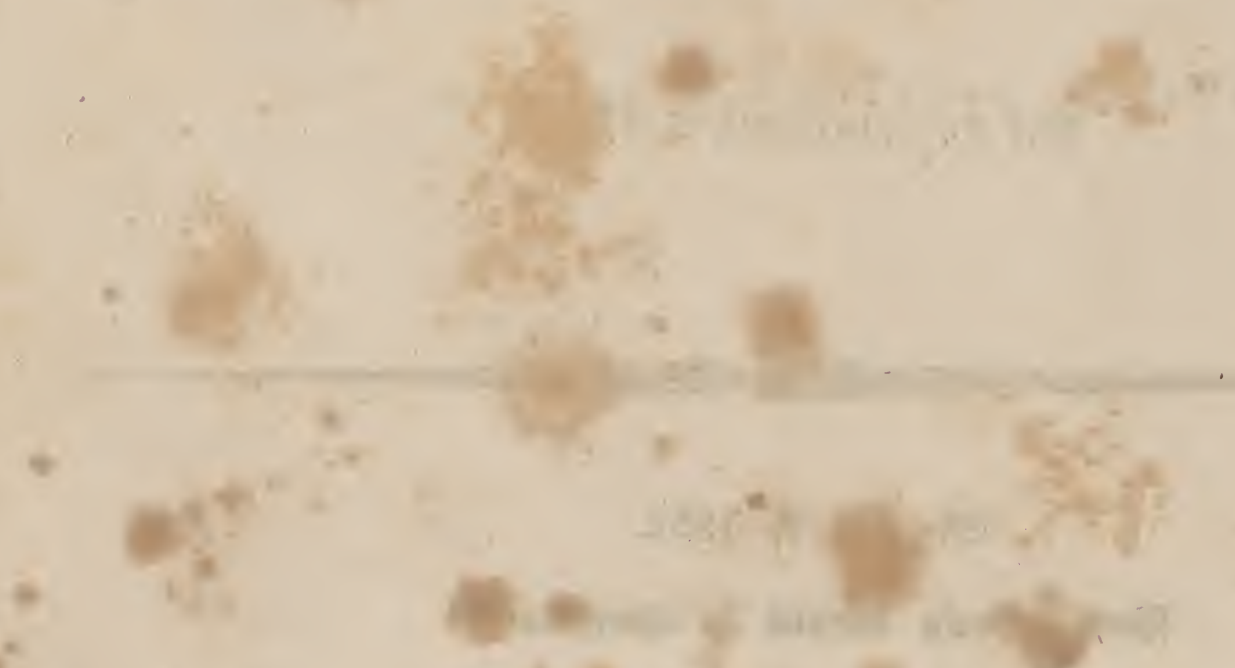




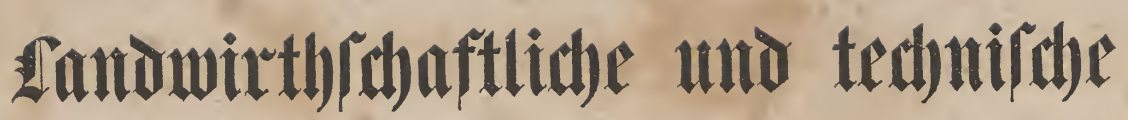

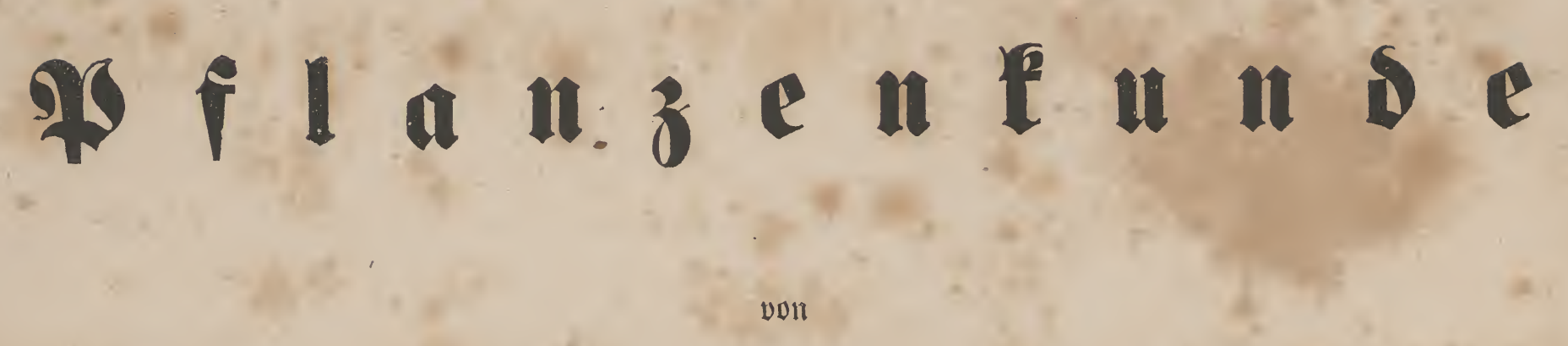

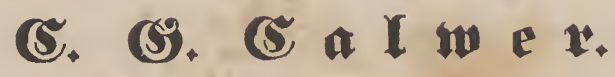

$-\infty 8300$

Erffe 2(rbtheilung:

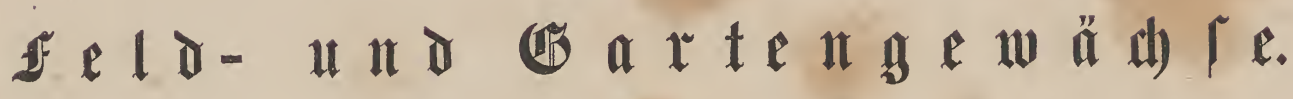

$-0300$

Mit 36 coloriten afern.

Stuttgart, 1852.

SYexlag vou Rrais \& Soffmaut. 


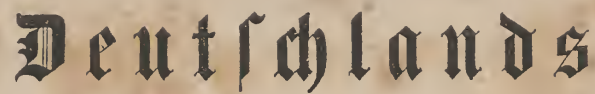

\section{Feld = und Gartengewädhie}

mit

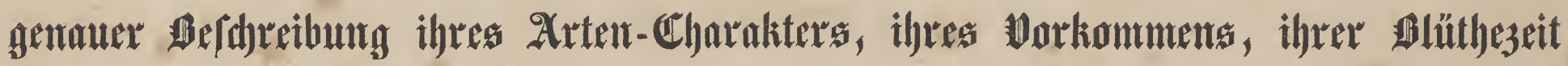

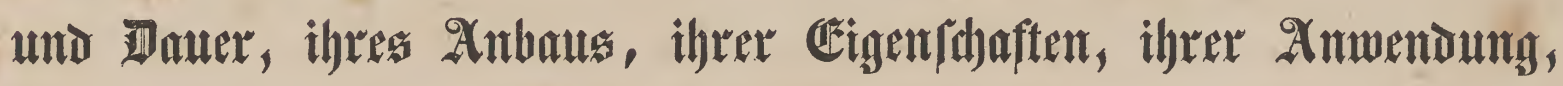
und vollftündiger Auffỉuhrum ihrer Sinnonymen

für

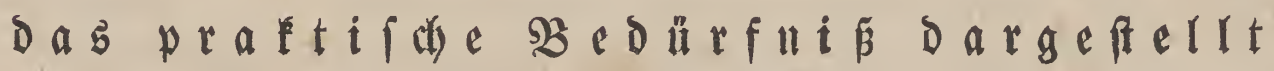

Uon

(5.) (ङ). (5) $\mathfrak{a} \mathfrak{l} \mathfrak{w} \mathfrak{x}$.

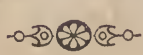

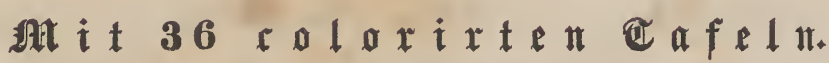

\section{Stuttgart, 1852 .}

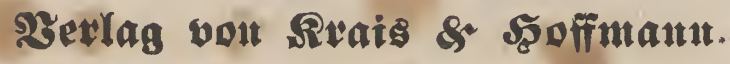




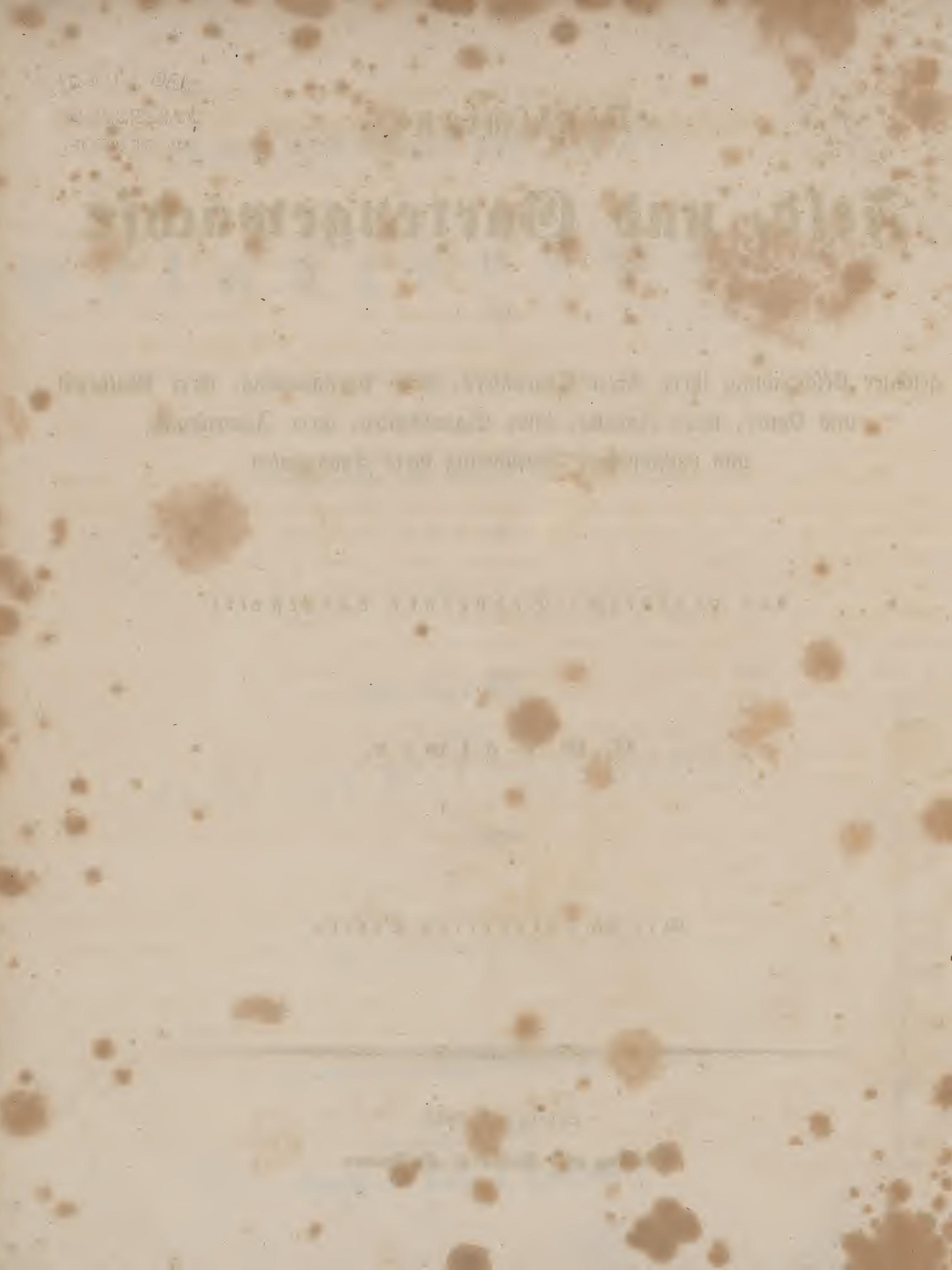




\section{$\mathfrak{y} \mathfrak{O} \mathfrak{i} \mathfrak{i} \mathfrak{e} \mathfrak{d} \mathfrak{e}$.}

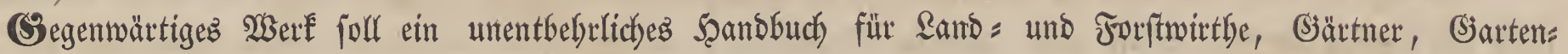

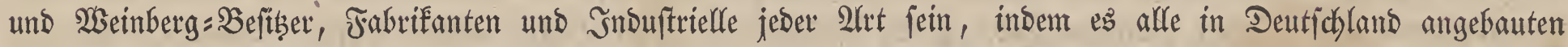

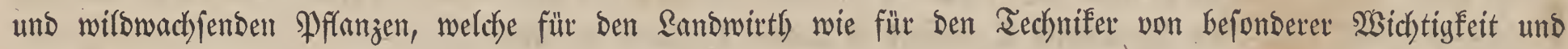

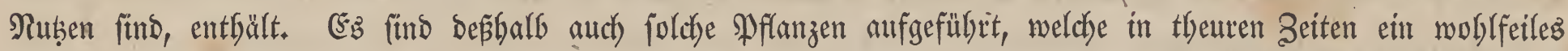
Surrogat für manche andere - im Preife geftiegene Pflanzen abgeben folfen, und ith habe von biejen Sur=

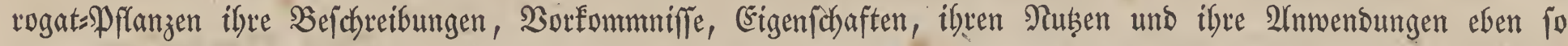
genau bearbeitet, als biez bee ben fulyon feit einer Reibe von Jabren angebauten Pflanzen ber Jall ift.

Die in biejem $\mathfrak{B}_{\text {erfe }}$ aufgefübrten Pflanzen habe ich in verfichiedene Scaupt: und Unterabtheilungen ges

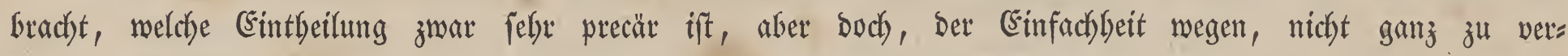

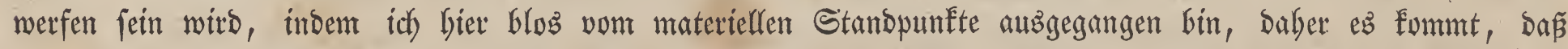

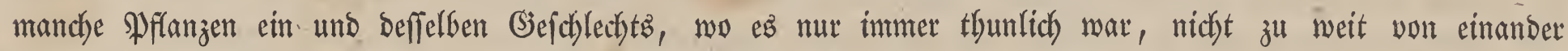
entrülett worden find.

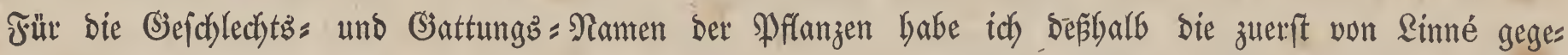

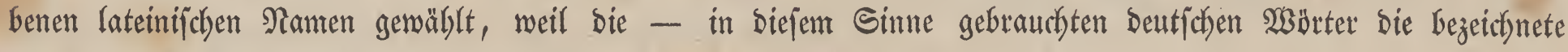
Pflange nicht immer genau charafterifitren.

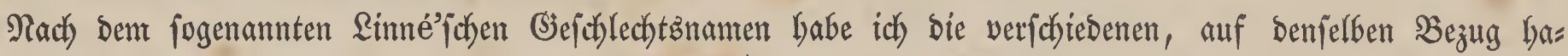

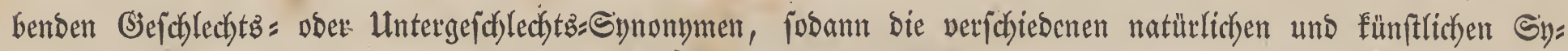

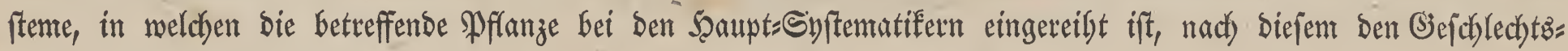
(Sharafter folgen laffen.

Bet ber 2luffübrung jeber einzelnen Pflanze ift ber für fie von Simné gegebene lateinijche Name ges

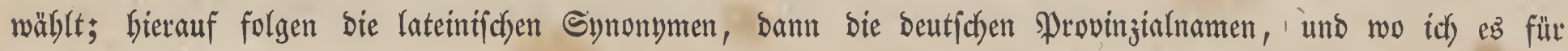

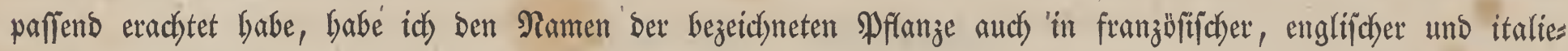
nijather Sprache gegeben.

Damit man bie gegebene Pflanze genau Eennen lernen Fann, babe ich Den 2lrtene(E)arafter, fo genau alz

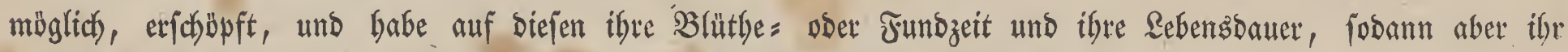
Borfommen folgen lafien. 


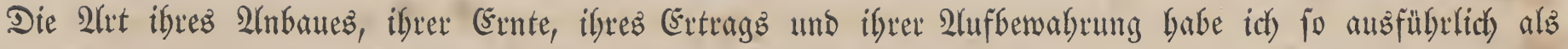

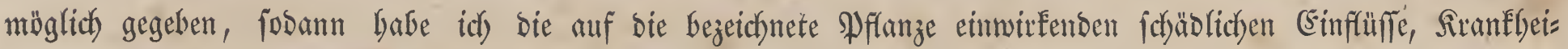

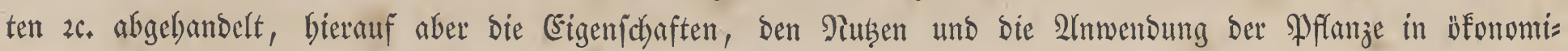

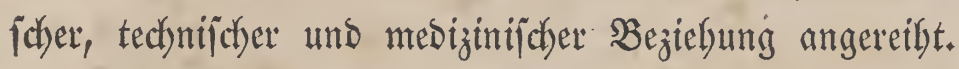

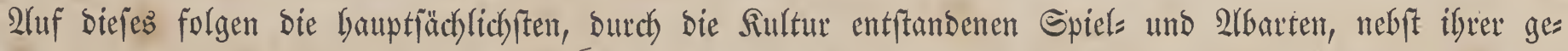

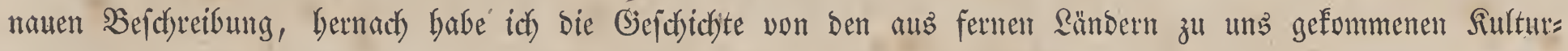

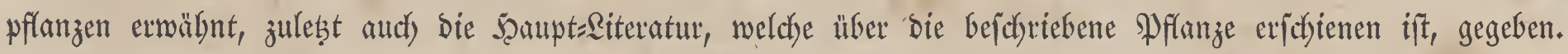

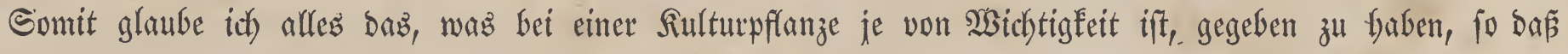

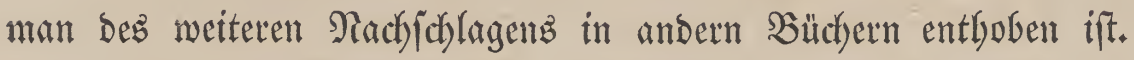

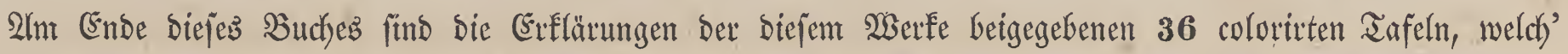

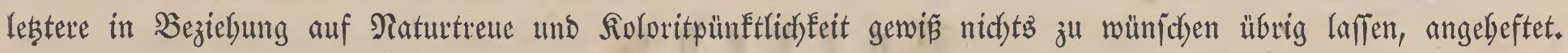

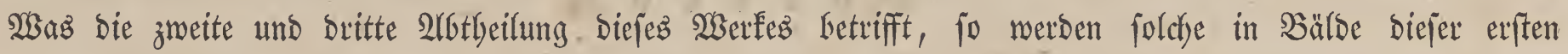
2lbtheilung nachfolgen, bauptfächlich ba baz Manufcript und bie Driginaltafeln volfendet find.

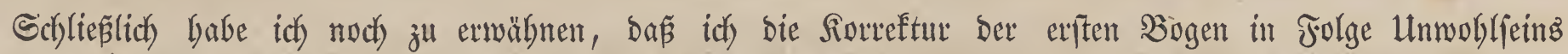

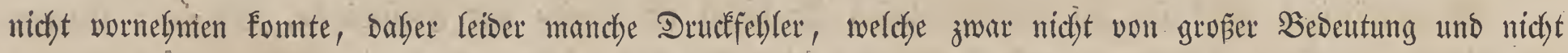

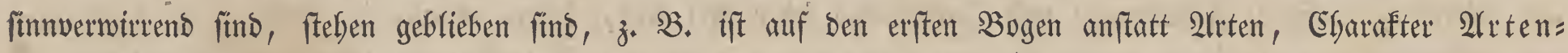
Sharafter und auf Seite 8, Spalte 7 anftatt 3 Sabre Jabre ju lepert.

Stuttgat im Softober 1851 .

Det Betfatiex. 


\section{(E) $\mathfrak{i} \mathfrak{n} \mathfrak{l} \mathfrak{e} \mathfrak{i} \mathfrak{t} \mathfrak{t} \mathfrak{n} \mathfrak{g}$.}

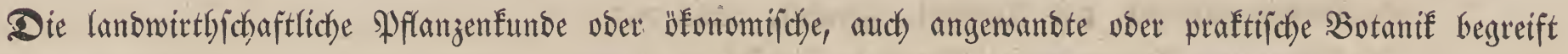

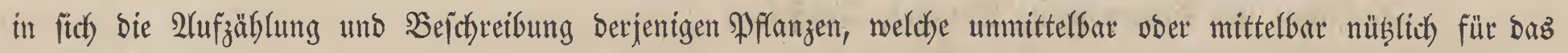

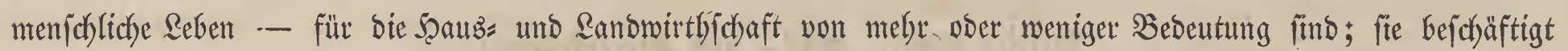

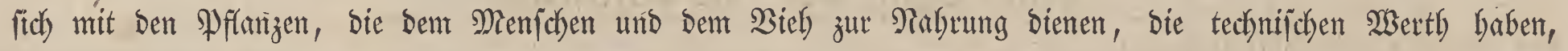

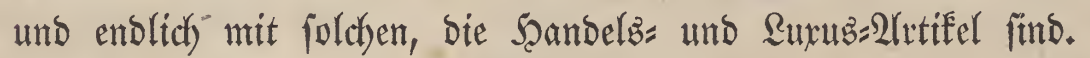

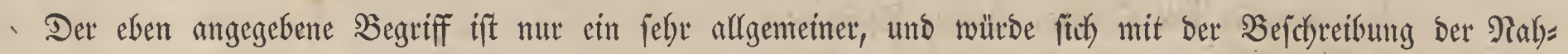

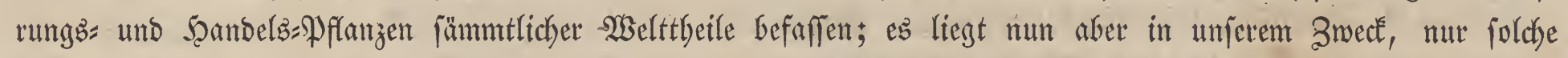

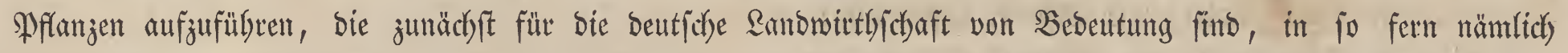

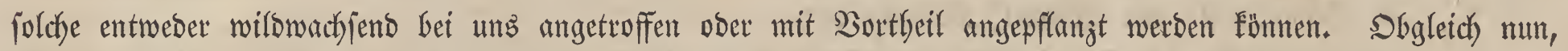

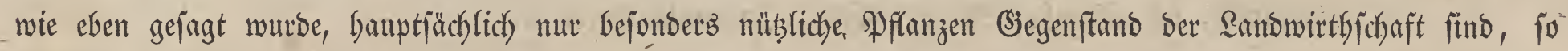

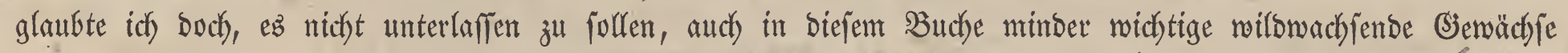
anzufülyren, bie zun Theil ftatt anberer fultivirten Gènächje benuţ̧ merben fönnten.

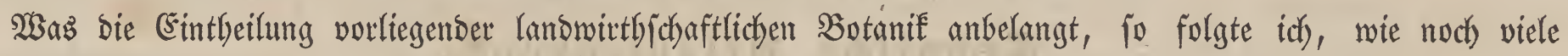

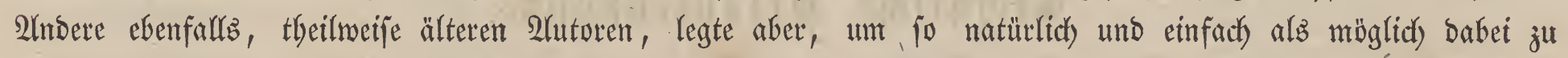

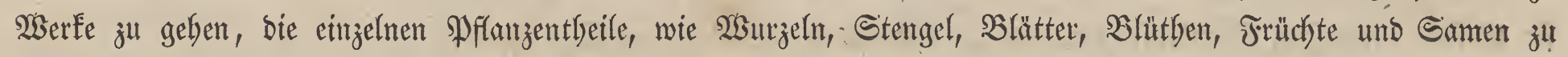

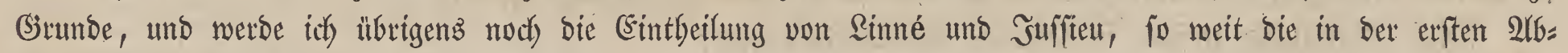

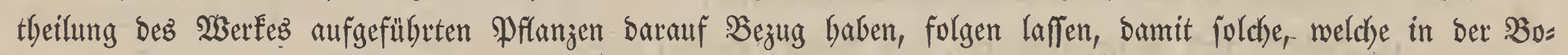

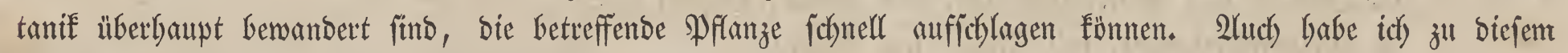
Zwecké bie Seitenzahl binter jeber einzelnen Pflanze beigefügt.

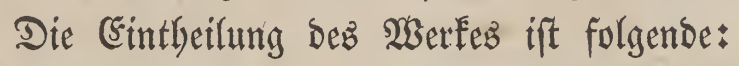

\section{- Grite Abtbeilung. \\ (1)ekonomifde planzenkunde:}

fie umfä́t foldye Pflanjen, weldye bem Menjdyen und Den Thteren zur Mabrung bienert.

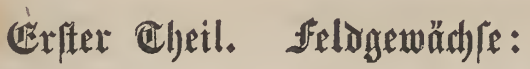

Diejer Theil jerfällt in nachjtebende Unterabtheilungen:

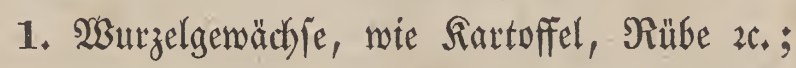

2. Sornfrüchte, wie Weizén, Roggen, Błerite, Scafer, Matz zc. ; 


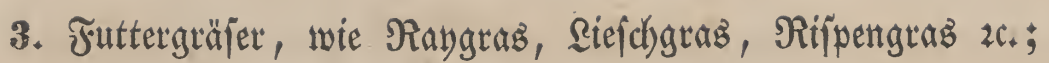

4. Jutterfräuter, wie Flee, Ëparjette, $2 c_{*}$;

5. Şüljenfrücbte, wie Bolgne, Ervfle, Simfe 26.

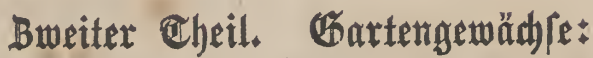

Die Unterabtheilungen fitro:

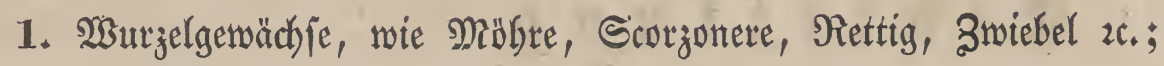

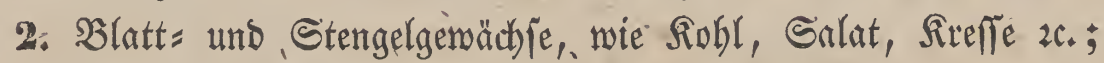

3. Fruchtgenächje, wie Guurf́e, Melone, Fürbiz;

4. đènürzpflanzen, wie Sünmel, Fendhel, 2lntis zc.;

5. Pilze, wie Ehampignon, Mordhel, Trüffel.

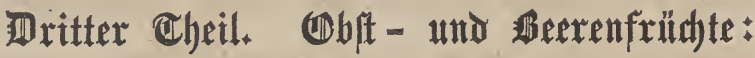

hat folgenbe Utnterabtheilungen:

1. Sernobft, wie Quitte, Birne, $\mathfrak{L}(\mathfrak{p} f \mathfrak{e l} 2 \mathfrak{c}$.;

2. Steinobft, wie Sitiche, Pflaume, Pfirlich $2 c$;

3. Salbfteinobft, wie Mifpel, Speierling;

4. Sidalendbft, wie Mandel, Raftanie 2c.;

5. Beerentobft, wie Traube, Mauls,

\section{3weite 2rbtbeifung.}

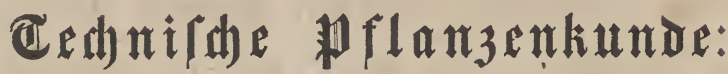

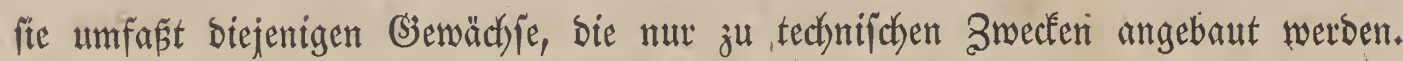

Dieje 2lbtheilung zerfällt in folgende Unterabtheilungen:

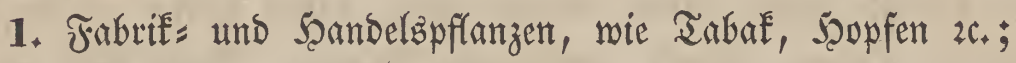

2. Siefpinmftpflanzen, wie F̂lucha und Şanf;

3. Selpflanjen, wie Reps, Molnn $2 C_{*}$;

4. Jartbpflanzen, wie Sirapp, $\mathfrak{B a u}, \mathfrak{B a t b}$;

5. Gierbpflanzen, wie Eithe 2 . 


\section{Syftem von Iithé.}

\section{Monandria.}

\section{Digynia.}

Blitum capitatum. L. ङ. 195. virgatum. L. ङ. 195. Bonus Henricus. Mey. S. 196.

\section{Diandria.}

\section{Monogynia.}

Verouica Beccabunga. L. S. 210. Rnsmarinus officinalis. L. G. 220. Salvia officinalis. L. S. 221 . pratensis. L. S. 120.

Digynia.

Anthoxanthum odoratum. L. S. 113 .

\section{Triandria.}

Monogynia,

Valerianella olitoria. Moench. S. 206. Crocus sativus. L. S. 232.

Cyperus esculentus. L. S. 20.

\section{Digynia.}

Alopecurus pratensis. L. S. 88. agrestis. L. S. 88. geniculatus. L. S. 88. fulvus. Smitl. S. 88 . Cynodon Dactylon. Rich. G. 89. Phalaris arundinacea. L. 5. 90. Phleum pratense, L. S. 90 Milium effusum. L. S. 94. Agrostis Spica-venti. L. S. 95 . vulgaris. With. 5. 95. alba. Schrad. S. 95.

Arundo Epigejos. L. 5. 96 . Psamma arenaria. Beauv. ङ. 249.

Hordeum murinum. L. S. 112 pratense. Huds. 5. 112. vulgare. L. S. 62. distichon. L. S. 68 . hexastichon. L. S. 67 . zeocriton. L. S. 70.

Secale cereale. L. S. 57.

Koeleria cristata. Pers. G. 101.

Aira caespitosa. L. S. 98 . canescens. L. S. 98.

Melica ciliata. L. ฐ. 100 .
Melica nutans, L. S. 100. uniflora. L. S. 100.

Molinia coerulea. Moench. S. 102. Arrhenatherum avenaceum. Beauv. ธ. 96.

Holcus mollis. L. S. 97. lanatus. L. S. 97.

Panicum italicunı. L. S. 80. crus-galli, L. S. 89. miliaceum. L. 5. 79.

Sorghum vulgare. Pers. ․ 80. saccharatum. Moench. S. 81

Lolium perenne. L. S. 111. arvense. With. S. 112.

Glyceria fluitans. R. Br. S. 93. spectabilis. M. et K. S. 94

Poa annua. L. S. 91. bulbosa. L. S. 92. compressa. L. S. 93. nemoralis. L. G. 91 . fertilis. Host. S. 93 pratensis. L. S. 92. trivialis. L, S. 92 .

Dactylis glomerata. L. S. 105. Cynosurus cristatus. L. S, 105. Festuca Myurus, L. S. 110. ovina. L. S. 106. duriuscula. L. S. 106. glauca. Schrad. ङ. 106. rubra. L. S. 106. heterophylla. Haenk. G. 107. sylvatica. Vill. S. 108. montana. Savi, S. 109. arundinacea. Schreb. S. 108. pratensis. Huds. S. 108. inermis. DeC. S. 109 gigantea. Vill. ङ. 108. aspera. M. et K. 5. 109 . loliacea. L. S. 108.

Bromus tectorum. L. S. 105. sterilis. L. ङ. 104. arvensis. L. ธ. 104. racemosus, L, S. 103. mollis. L. G. 103. secalinus. L. S. 103 . grossus. Desf. 5. 103. Brachypodium pinnatum. R. S. S. 110. Avena argentea. Willd. 5. 78. flavescens. L. 5. 99 . pratensis. L. S. 99. pubescens. L. S. 99. brevis. Roth. S. 77. nuda. L, 厅. 78 .
Avena strigosa. Schreb. S. 77. fatua. L. S. 99 sativa. L. S. 71 . orientalis. Schreb. S. 76.

Triticum caninum. Schreb. S. 111. repens. L. S. 110 vulgare. Cill. S. 32. turgidum. L. S. 40 . durum. Desf. S. 44. polonicum. L. 5. 48. Spelta. L. S. 50. amyleum. Sering. S. 52 monococcum. L. ङ. 56 .

Briza media. L. S. 102.

Elymus arenarius. L. S. 113.

\section{Trigynia.}

Montia rivuláris. Gm. S. 250

\section{Tetrandria.}

\section{Monogynia.}

Trichera arvensis. Schirad. S. 118 Sanguisorba officinalis. L. S. 118 . Plantago lanceolata. L. S. 116. major. L. S. 117. media. L. S. 117

Alchemilla vulgaris. L. F. 138.

\section{Pentandria.}

\section{Monogynia.}

Symphytùm officinale. L. S. 249 Borago officinalis. L. ๔. 209.

Solanum tuberosum. L. S. 1. Capsicum annuum. L. S. 233

\section{Digynia.}

Chenopodiun album. L. S. 195. Atriplex hortensis. L. ङ. 196. Halimus. L. S. 197. portulacoides, L. S. 197. angustifolia. Smith. S. 197.

Beta vulgaris. L. S. 29 .

Cicla. L. S. 30. 196.

Daucus Carota. L. S. 153.

Coriandrum sativum. L. S. 234. Heracleum Sphondylium. L. S. 121. Pastinaca sativa. L. 5. 156. Anethum graveolens. L. S. 236.
Meum athamanthicum. Jacq. S. 138. Foeniculum vulgare. Gaertn. S. 235. Sium sisarum. L. S. 159.

Pimpinella magna. L. S. 139. anisum. L. S. 237.

Carum Bulbocastanun. Koch. S. 23. Carvi. L. ऽ. 234.

Aegopodium Podagraria. L. 5.139. Petroselinum sativum. Hoffm. S.161. 211.

Apium graveolens. L. S. 162. 211. Chaerophyllum bulbosum. L. S. 160. Anthriscus sylvestris. Hoffm. S. 106. Cerefolium. Hoffm. S. 211.

Myrrhis odorata. Scop. G. 160.

\section{Fexandria.}

\section{Monogynia.}

Allium ascalonicum. L. S. 169. Cepa. L. S. 168.

proliferum. Schrad. S. 172 Scorodoprasum. L. S. 172. sativum. L. S. 171.

Porrum. L. S. 170. Schoenoprasum. L. S. 171 . fistulosum. L. S. 169."

Asparagus officinalis. L. G. 198.

\section{Trigynia.}

Rumex Patientia. L. S. 193. Acetosa. L. S. 194. scutatus. L. S. 194.

\section{Detandria.}

Monogynia

Oenothera biennis. L. ङ. 163.

Trigynia.

Polygonum aviculare. L. ऽ. 120. Convolvulus. L. S. 119 .

Fagopyrum. L. 5. 85 . tataricum. L. ङ. 87. Bistorta, L. S. 119 .

\section{Decandria.}

Digynia.

Scleranthus annuus, L. ऽ. 137. 
Pentagynia.

Spergula arvensis. L. S. 121. Sedum reflexum. L. S. 212.

\section{Dodecandria.}

Monogynia.

Portulaca oleracea. L. S. 198

\section{Icosandria.}

Pentagynia.

Tetragonia expansa. Ait. S. 193.

\section{Polyandria.}

Pentagynia.

Nigella śativa. L. G. 237.

\section{Didynamia.}

Gymnospermia.

Satureją hortensis. L. G. 230. montana. L. G. 230

Hyssopus officinalis. L. ऽ. 229.

Lavandula Spica. L. ङ. 231 .

Mentha piperita. L. S. 227. crispa. L. G. 227.

Pulegium. L. S. 228.

Origanum majorana. L. S. 219. vulgare. L. S. 219. creticum. L. S. 220.

Thymus vulgaris. L. S. 225. Serpyllum. L. G. 225. angustifolius. Schreb. §. 226

Calamintha officinalis. Moench. $\mathfrak{G}$. 226.

Melissa officinalis. L. S. 229.

Ocimum Basilicum. L. S. 223. minimum. L. ऽ. 224.

\section{Tetradynamia.}

Synclistae.

Crambe maritima. L. G. 186. Raphanus sativus. L. S. 164.

\section{Siliculosae.}

Lepidium sativum. L. S. 207. latifolium. L. S. 231.

Cochlearia Armoracia. L. ऽ. 166. officinalis. L. S. 210 .

\section{Siliquosae.}

Cardamine pratensis. L. S. 208.

Nasturtium officinale. R. Br. S. 207. Brassica Rapa. L. 5. 24.

Napus. L. G. 27. 185. oleracea. L. S. 172

\section{Diadelphia.}

\section{Decandrìa.}

Anthyllis Vulneraria. L. S. 122.

Phaseolus vulgaris. L. S. 140 .

nanus. L. S. 142 .

multiflorus. Lam. ๔. 143.

Apios tuberosa. Moench, S. 23.

Orobus tuberosus. L. S. 22.

Lathyrus Aphaca. L. S. 134.

sativus. L. ङ. 149.

tuberosus. L. S. 22.

pratensis. L. S. 135.

Pisum sativum. L. G. 143.

arvense. L. S. 147.

Vicia Cracca. L. S. 135.

sativa. L. G. 149.

Sepium. L. S. 135.

Faba. L, ๙. 150.

Ervum Lens. L. G. 148.

Ervilia: L. G. 137.

tetraspernum. L. S. 137.

hirsutum. L. 5. 137.

Cicer arietinum, L. S. 148.
Coronilla varia. L. S. 123. Onobrychis sativa. L. S. I24.

Galega officinalis. L. S. 124.

Astragalus glycyphyllos. L. S. 122. cicer. L. S. 122.

Melilotus officinalis. Lam. S. 128. alba. Desr. S. 128.

Petitpierreana. Willd. S. 129. dentata. Willd. S. 129. coerulea, Lam. ఠ. 129.

Trifolium fragiferum. L. S. 134 stellatum. L. S. 133 . arvense. L. S. 133. incarnatum. L. S. 132 pratense. L. - - 130. medium. L. S. 133. rubens. L. ङ. 132. montanum. L. S. 133. repens. L. S. 132. hybridum. L. ఠ. 132. filiforme. I. S. 134 . agrarium. L. S. 134.

Tetragonolobus siliquosus, Roth. ธ. 152.

Lotus corniculatus. L. S. 125.

Trigonella Foenum-graecum. L. ธ. 136.

Medicago lupulina. L. ङ. 127. falcata. L. 127. sativa. L. ङ. 126.

\section{Syngenesia.}

Polygamia aequalis.

Tragopogon pratensis. L. S. 158. porrifolius. L. F. 158.

Scorzonera hispanica. L. ๑. 157. glastifolia. Willd. S. 158.

Sonchus oleraceus. Willd. S. 191.

Lactuca sativa. L. S. 200.

Cichorium Intybus. L. 5. 205. Endivia. L. S. 204.

Lappa major. Gaertn. G. 191.

Carduus nutans. L. S. 188.
Carduus crispus. L. G. 188 Cirsium palustrc. Scop. ङ. 187. lanceolatum. Scop. S. 187. oleraceum. All. G, 187. Onopordon Acanthium. L. E. 190. Cynara Cardunculus. L. S. 188. Scolymus. L. S. 189.

Polygamia superflua.

Artemisia Abrotanum. L. S. 223 vulgaris. L. S. 222

Dracunculus. L. S. 222 Georgina variabilis. Willd. S. 19. Achillea Millefolium. L. S. 114.

Polygamia frustranea.

Helianthus tuberosus, L. S. 17. Centaurca Jacea. L. ङ. 115. Scabiosa. L. S. 115 .

\section{Monoecia.}

Triandria.

Zea Mays. L. G. 81 .

Polyandria.

Poterium Sanguisorba, L. G. 119. Monadelphia.

Cucumis sativus. L. S. 213 flexuosus. L. G. 214. Dudaim. L. S. 214. Citrullus. Sering. ऽ. 214. Melo. L. ఠ. 215.

Trichosanthes Anguina, L. G. 217. Cucurbita Pepo. L. 217. maxima. Duches. ऽ. 218 . Melopepo. L. ङ. 218.

\section{Dioecia.}

Pentandria.

Spinacia oleracea. Willd. S. 192.

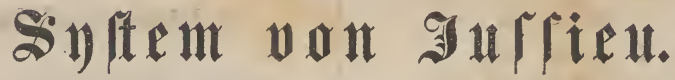

\section{Hanunculaceae.}

Helleboreae.

Nigella sativa. L. S. 237.

\section{Cruciferae.}

Siliquosae.

Arabideae.

Nasturtium officinale. R. Br. G. 207. Cardamine pratensis. L. S. 208.

\section{Brassiceae.}

Brassica oleracea. L. S. 172. Napus. L. S. 27, 185. Rapa. L. S. 24.

\section{Latiseptae.}

Alyssineae.

Cochlearia Armoracia. L. S. 166. officinalis. L. S. 210.

Angustiseptae.

Lepidineae.

Lepidium sativum. L. S. 207. latifolium.' L. S. 231 .

Lomentaceae.

Raphaneae.

Crambe maritima. L. ङ. 186. Raphanus sativus. L. ङ. 164.
Alsineae.

Spergula arvensis. L. S. 121.

\section{Papilionaceac.}

Loteae.

Anthyllideae.

Anthyllis Vulneraria. T. ङ. 122

\section{Trifolieae.}

Medicago sativa. L. 5.126.

falcata. L. S. 127.

lupulina. L, S. 127.

Trigonella Foenum-graecum. L. ธ. 136 .
Melilotus coerulea. Lam, 5. 129 alba. Desr. 5. 128 Petitpierreana. Willd. S. 129. dentata. Willd. S. 129. officinalis. Lam. S. 128.

Trifolium fragiferum. L. S. 134. stellatum. L. S. 133. arvense. L. 5. 133 . incarnatum. L. S. 132. pratense. L. S. 130. medium, L, 厅. 133. rubens. L. ङ. 132. montanun. L. S. 133 . repens. L. S. 132. hybridum. L, S. 132 . filiforme. L. S. 134. agrarium. L. S. 134.

Lotus corniculatus. L. $\mathfrak{~}$. 125 . 
Tetragonolobus siliquosus, Roth. ธ. 152 .

Galegeae.

Galega officinalis. L. S. 124 .

\section{Astragaleae.}

Astragalus glycyphyllos. L. S. 122. Cicer. L. ङ. 122.

\section{Hedysareae. \\ Coronilleae.}

Coronilla varia. L 5.123.

\section{Euhedysareae.}

Onobrychis sativa. L. S. 124.

\section{Vicieae.}

Cicer arietinum. L. 5. 148.

Vicia Cracea. L. 5. 135. sativa. L. S. 149. Sepium. L. S. 135. Faba, L. 5. 150.

Ervum Lens. L. S. 148. Ervilia, L. S. 137. tetraspermum. L. S. 137. hirsutum. L. S. 137.

Pisum sativum. L. S. 143. arvense: L. S. 147.

Lathyrus aphaca. L. S. 134. sativus. L. S. 149. tuberosus. L. S. 22. pratensis. L. S. 135 .

Orobus tuberosus. L. S. 22.

\section{Phaseoleae.}

Phaseolus vulgaris. L. S. 140 . nanus. L. S. 142.

multiflorus. Lam. S. I43.

Apios tuberosa. Moench. S. 23.

\section{Rosaceae.}

Dryadeae.

\section{Sanguisorbeae.}

Alchemilla vulgaris. L, S. 138 . Sanguisorba officinalis. L. 5.118 . Poterium Sanguisorba. L. E. 119.

\section{Dnagrariae.}

Epilobieae.

Oenothera biennis. L. S. 163.

\section{Cucuxbitaceae.}

\section{Cucurbiteae.}

Cucurbita Pepo. L. ๔. 217. maxima. Duches. S. 218. Melopepo. L. G. 218.

Cucumis sativus. L. 5. 213. flexuosus. L. S. 214.

Dudaim. L. S. 214.

Citrullus. Sesing. ธ. 214.
Cucumis Melo. L. 5. 215 Trichosanthes Anguina. L. S. 217.

\section{Portulacaceae.}

Tetragonieae.

Tetragonia expansa. Ait. S. 193

Sesuvieae.

Portulaca oleracea. L. S. 198.

Calandrinieae.

Montia rivularis. Gm. S. 250.

\section{Paronichiaceae.}

Sclerantheae.

Scleranthus anuuus. L. S. 137.

\section{Crassulaceae.}

Crassuleae.

\section{Diplostemones.}

Sedum reflexum, L. S. 212 .

\section{Umbelliferae.}

Orthospermae.

\section{Ammineae.}

Apium graveolens. L. S. 162, 211 Petroselinum sativum. Hoffm. S. 161, 211.

Aegopodium Podagraria. L. S. 139. Carum Bulbocastanum. Koch. S. 23. Carvi. L. S. 234.

Pimpinella magna. L. S. 139.

Anisum. L. S. 237.

Sium Sisarum. L. 5. 159

\section{Seselineae.}

Foeniculam vulgare. Gaertn. S. 235. Meum athamanticum. Jacq. 5.138.

\section{Peucedaneae.}

Anethum graveolens. L. S. 236. Pastinaca sativa. L. S. I56.

Heracleum Sphondylium. L. S. 121.

\section{Daucineae.}

Dancus Carota. L. ऽ. 153.

\section{Cambylospermae.}

\section{Scandicineae.}

Anthriscus sylvestris. Hoffm. S. 116. Cerefolium. Hoffm. S. 211.

Chaerophyllum bulbosum. L. S. 160. Myrrhis odorata. Scop. S. 160.

\section{Coriandreae.}

Coriandrum sativum, L. S. 234.

\section{Valerianeae.}

Valerianella olitoria. Moench, G.206.

\section{Dipsaceae.}

Scabioseae.

Trichera arvensis. Schrad. S. 118.

\section{Compositae.}

Tubuliflorae.

\section{Asteroideae.}

\section{Ecliptea}

Georgina variabilis. Willd. S. 19.

\section{Senecionideae.}

Helian thea e.

Helianthus tuberosus. L. $\subseteq$. 17. Anthemydeae.

Artemisia Abrotanum. L. S. 223. vulgaris, L. ๔. 222.

Dracunculus. I. S. 222. Achillea Millefolium. L. S. 114.

\section{Cynareae.} Cardineae.

Cirsium palustre. Scop. S. 187. lanceolatum. Scop. S. 187 oleraceum. All. G. 187.

Cynara Cardunculus. L. S. 188 Scolymus. L. S. 189.

Carduus nutans. L. Б. 188. crispus. L. S. 188.

Onopordon Acanthium. L. G. 190Lappa major. Gaertn. S. 191.

$$
\text { Centaureac. }
$$

Centaurea Jácea. L. S. 115. Scabiosa, L. S. 115.

\section{Liguliflorae.}

Cichorieae.

Cichorium Intybus. L. G. 205. Endivia. L. S. 204.

\section{Scorzonereae.}

Tragopogon pratensis. L. S. 158. porrifolius. L. S. 158.

Scorzonera hispanica. L. S. 157. glastifolia. Wild. G. 158.

\section{Lactucaceae.}

Lactuca sativa. L. S. 200.

Sonchus oleraceus. Willd. S. 191.

\section{Boxragineae.}

\section{Anchuseae.}

Borrago officinalis. L. S. 209.

Symphytum officinale. I. S. 249.

\section{Solanaceae.}

Solanum tuberosum. L. S. 1. Capsicum annuum. L. ๔. 233.

\section{Scrofularineae.}

Antirrhineae.

Veronica Beccabunga. L. S. 210.

\section{uabiatae.}

0cimoideae.

Ocimum Basilicum. L. S. 223. minimum. L. S. 224 .

Lavandula Spica. L. S. 231.

Menthoideae.

Mentha piperita. L. S. 227\% crispa. L. S. 227.

Pulegium. L. S. 228.

\section{Monardeae.}

Rosmarinus officinalis. L. S. 220. Salvia officinalis. L. S. 221. pratensis, L. S. 120.

\section{- Satureineae}

Origanum majorana. L. ఠ. 219. crispa. L. S. 219. creticum. L. S. 220.

Thymus vulgaris. L. S. 225. serpyllum. L. E. 225. angustifolius. Schreb. S. 226.

Satureja hortensis. L. S. 230. montana. L. G. 230.

Calamintha of ficinalis.Moench. S.226.

Melissineae.

Melissa officinalis. L. S. 229. Hyssopus officinalis. L. S. 229.

\section{Plantagineae.}

Plantago lanceolata. L. S. 116. major. L. ङ. 117 . media. L. S. 117 .

\section{Chenopodiaceae.}

Cyclolobeae.

Chenopodieae.

Chenopodium album. L. S. 195 Blitum capitatum. L. S. 195. virgatum. L. ङ. 195 . Bonus Henricus. L. G. 196.

Beta vulgaris. L. S. 29. Cicla. L.- 5. 30. 196.

\section{Atripliceae.}

Spinacia oleracea. Willd. S. 192. Atriplex hortensis. L. S. 196. Halimus. L. S. 197. portulacoides. L. S. 197. angustifolia. Smith. S. 197.

\section{Polygoneae.}

Rumex Patientia. L. S. 193 acetosa. L. S. 194. scutatus. L. S. 194

Polygonum aviculare. L. S. 120. Convolvulus. L. S. 119 Fagopyrum. L. S. 85 . tataricum. L. S. 87. Bistorta. L. G. 119.

\section{Iridene.}

Crocus sativus. L. G. 232 


\section{Liliaceae.}

Asphodeleae.

Allium ascalonicum. L. ङ. 169. Cepa. L. S. 168. proliferum. Schrad. S. 172. Scorodoprasum. L. S. 172. sativum. L. ऽ. 171.

Porrum. L. S. 170.

Schoenoprasum. L. S. 171.

fistulosum. L. S. 169.'

\section{Asparageae.}

Asparagus officinalis. L. S. 198.

\section{Cyperaceae.}

Cypereae.

Cyperus esculentus. L. S. 20.

\section{Gramineae.}

0lyreae.

, Zea Mays. L. G. 81.

\section{Andropogoneae.}

Sorghum vulgare. Pers. ङ. 80. saccharatum. Moench. 5. 81.

\section{Paniceae.}

Panicum miliaceum. L. 5. 79. italicum. L. 5. 80. Crus-galli. L. ฐ. 89.

\section{Phalarideae.}

Phalaris arundinacea. L. G. 90. Anthoxanthum odoratum. L. S. 113.

\section{Alopecuroideae.}

Alopecurus pratensis. L. G. 88, agrestis. L. S. 88. geniculatus. L. S. 88. fulvus. Smith. ‥ 88.

Phleum pratense. L. Б. 90.

\section{Chloridéae.}

Cynodon Dăctylon. L. 厅. 89.

\section{- Agrostideae.}

Agrostis Spica-venti. L. S. 95. vulgaris. With. S. 95. alba. Schrad. S. 95.

Arundo Epigejos. L. ङ. 96.

Psamma arenaria. Beauv. ङ. 249.

\section{Stypaceae.}

Milium effusum. L, S. 94 .

\section{Avenaceae.}

Koeleria cristata. Pers. ๔. 101.

Aira caespitosa. L. 5. 98. cănescens. L. S. 98.

Holcus mollis. L. S. 97. lanatus. L. S. 97.

Arrhenatherum avenaceum. Beauv. ธ. 96 .

Avena argentea. Willd. ङ. 78.
Avena flavescens. L. S. 99. pratensis. L. S. 99. pubescens. L. S. 99. brevis. Roth. S. 77. nuda. L. S. 78. strigosa. Schreb. 5. 77. fatua. L. S. 99. sativa. L. S. 71 . orientalis. Schreb. S. 76.

Melica ciliata. L. S. 100. nutans. L. S. 100. uniflora. L. S. 100.

\section{Festucaceae.}

Briza media. L. F. 102. Poa annua. L. 5. 91. bulbosa. L. S. 92. compressa. L. ङ. 93. nemoralis. L. S. 91. fertilis. Host. G. 93. pratensis. L. S. 92. trivialis. L. S. 92.

Glyceria fluitans. R. Br. S. 93. spectabilis. M. et K. S. 94 .

Molinia coerulea. Moench. G. 102. Dactylis glomerata. L. ङ. 105.

Cynosurus eristatus. L. ङ. 105.

Festuca Myurus. L. S. 110. ovina. L. S. 106.! duriuscula. L. S. 106.

glauca. Schrad. S. 106. rubra. L. S. 106.

heterophylla. Haenk. S. 107. sylvatica. Vill. ङ. 108. montana. Savi. S. 109. arundinacea. Schreb. S. 108.
Festuca pratensis. Huds. S. 108. inermis. DeC. S. 109. gigantea. Vill. S. 108. aspera. M. et K. S. 109. loliacea. L. S. 108.

Brachypodium pinnatum. R. S. ธ. 110 .

Bromus tectorum. L. S. 105. sterilis. L. S. 104. arvensis. L. S. 104. racemosus. L. ธ. 103. mollis. L. S. 103. secalinus. L. S. 103. grossus. Desf. ऽ. 103.

\section{Hordeaceae.}

Triticum caninum. Schreb. ऽ. 111. repens. L. G. 110. vulgare. Cill. G. 32. turgidum. L. S. 40 . durum. Desf. ⿷. 44. polonicum. L. S. 48. Spelta, L. ङ. 50. amyleum. Sering. 5. 52 monococcum. L. S. 56.

Secale cereale. L. S. 57.

Elymus arenarius. L. S. 113.

Hordeum murinum. L. ङ. 112. pratense. Huds. S. 112. vulgare. L. 5. 62. disticlıon. L. S. 68. hexastichon. L. 5. 67. zeocriton. L. S. 70.

Lolium perenne. L. S. 111. arvense. With. ङ. 112.

(-) bedentet, onß die $\mathfrak{P}$ frnnze einjührig,

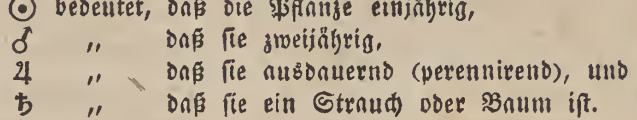




\section{(Etrter Ceneil.}

\section{Felogewänte.}

Sind foldse (sienädble, weldye in Girofen angebaut werden.

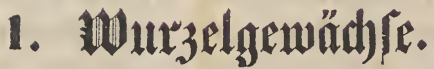

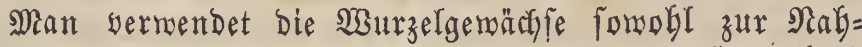
rung bes Menjchen, als auch, und zmax zum gropen Theil,

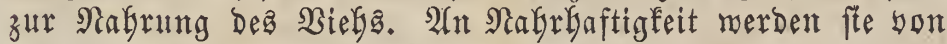
Dem Esetreide und ben Şülfenfrüclyten übertroffen.

\section{Solanum. L.}

Acquartia. Jacq.

Androcera. Nutt.

Bassovia. Aubl.

Ceranthera. Rafin.

Arcythophyta. Neck.

Laridae. Lin.

Oligantherae pentandrae. Roy. Pentandria Monogynia. L.

Relch einblätterig, 5 partig, aufrectst bleibend. Blumen= frome einblätterig, rabförmig, mit 5lappigem, gefaltetent ober tief 5fpaltigen Gaume. Blumenröbre febr furz. SBlu= menrand rüfmärta gebogen. Strubgefäffe an der Baftz der Blunenfrone fthend. Staubfäben 5, furz. Staubbentel läng= (ich, aufrecbt, einander berüfrend, mit boppeltent Iodje auf= fpringent. Frudfffitsten eirund. Griffel walzig. Narbe ftumtf. Beere längliç ober rund, 2fäaberig, bie und ba 4 fäh herig, bielfantig. Samen glatt.

\section{Solanum tuberosum. L.}

Solanum esculentum. Neck. Solanum Parmenterii. Molin.

Rartoffel, Girunbbirne, Erobirne, Eroäpfel, Toffeln,

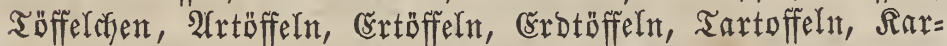
tuffeln, Sirüblitge, Srüblingabaum, Girumbirnen, Snollen,

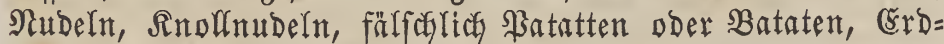
panmerlinge, (अotbwelja), (s.jbarer Nachtjdyatten.

Pommes de terre. (fianz.)

Potatoe. (engr.)

Pomo di terra, Patata, Taratuffoli. (ital.)

\section{Arten, (Shataftex.}

Die :rurzeln find meift zăh, ober aud mebr fraut=

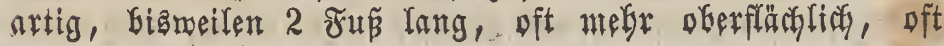

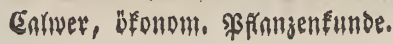

aber tiefer unter der Csrde berlaufend; aus ifnen entroiffeln

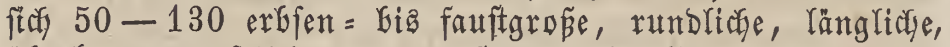
uberfaupt verfdiebenartig geftaltete Inollen, näulidg bie

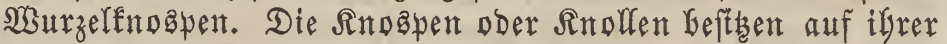
DGerfläche nubr voer wentiger zalglreiche, weitläufige ober gebrangt ftebende, ftarf oder nur febr flach bertiefte (sinub=

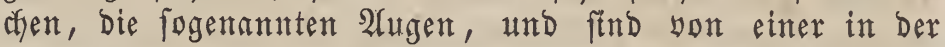

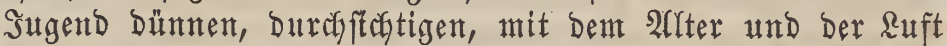
augigejegt, ftch nefr wnd mefr berbiffenden, gelben, rotben, blauen, fanarzen oder marnorirten f̧aut ober Schale unt= geber, welche in ber Reife, befunders bon Den farbigen $\mathfrak{A} x=$ ten, oft eine Meffer = und Saut = färbende Săbärfe bat, und verlebt fich in ober nuper bent Boben erfest, gegen ben

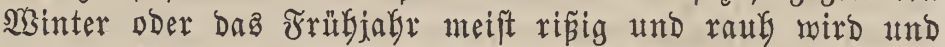
fith in fleinen Bortionen yon Den Rnolfen ablöst. Dą Fleifich ift meift gelblich, ober auth weif́, rotb, blaulich, ge= abert ober geffert. Die Stengel, oft 12-16 an ber 3afir, find zuweilen 4-6 Fuß god, aufreçt oder nieberliegend, oft won Der Diffe eines Daumens ober mebr rutbenförmig, frautartig, meift 3-4effig, geflügelt, ober rund, fnotig, äftig ober einfacy, Gebaart oder glatt, zäbe, grũn oder Graunroth, blaulich angeflogen doer getupfelt. Die SBlätter gefiebergetheilt, langgeftielt, befl = oder bunfelgrün. Blatt= ftiele balbrumb oder chlindrifos, aufiteigend, feinbebart. Die Fieberblättçen eiförmig, etwas runzliç, ganzrandig, glän= zend ober matt, mit weidybgaarten Seiten and wellenför= migen Rändern, Die obern ftnd gröper. Die Afterblättcyen fictyel = ober mondförmig. Blumenftele vft 6 , Boll lang und länger, etwas äftig, feinbebaart, aus Den Blattminfeln ent= fpringend, Blüthen zu $3-15$ in flachen Doldenartigen Trau= Gen ftefend, einblätterig, eingefornitten, fternförmig, in ber Farbe berfateden, belfer doer Dunfler, weí, grau, blau, wiolett, pfitrfich = ober rofenroth mit roisen Spiben. Staub= fäben mit einander bermadjen. Staubbentel länglids, ein= ander berübrend, beimabe berwachen, mit 2 Deffunngen an ber Spite, gelb. Narbe ftumpf. Die Früchte Geerenartig,

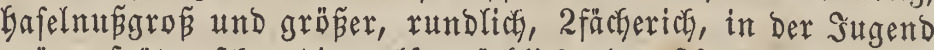

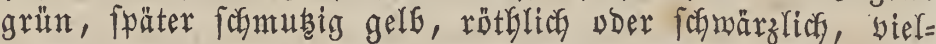
famig. Die Samen liegen oft zu 100 und mefr in Dem falleimig faftigen Fleifale Der Frübte, ftnd nierenfürmig, plattgebrüt und gelfition. 
SIüthe: Beit unt Dauex.

Iuli bis 2luguft. $\odot$

\section{Boxfommen.}

Shr แriprünglictes $\mathfrak{B a t e r l a n d ~ i f t ~ v e r m u t g l i c f ~ S u ̈ b a n t e = ~}$ rifa, Shili, Beru, Gefonders die Năke yon Suito; fe wirb jest alfgenein angebaut.

\section{Sultux.}

Die Rartoffeln werlangen ein etras fendftes, Dunft= reictes und mäp̧ig warmes Slima und gebeiben beffer in Ragen, welche fth melgr gegen Norben, als gegen Süben neigen, indem Der Boben Der gegen Norben gelegenen Fel=

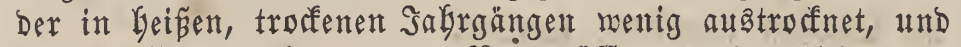
bie Rnollen, weldye burd Regengïffe yon der Ërobe ent= blöpt werben, weniger ftarf Der Sonne, die benfelben eine

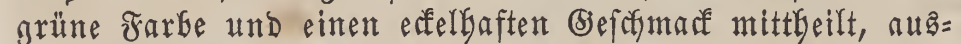
gejest ftnd. Die Sartoffeln fommen igres meift fohnelfen Sanctigthumes wegen auch in fälterent biegenden, wo z. B. Der Seafer noch reift, fort, ftnd jeboch als tropiface Jrüchte ge= gen אälte fehr empfindlict. Sie gerathen faft in jebem $\mathfrak{B D}=$ Den, in nicht zut bindigent ober naffent Thonboden, in troffen gelegtem, nicht zu faurem Moorboden ober Teicfgrunde, ge=

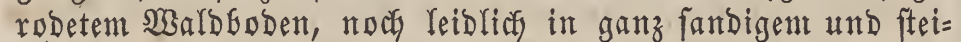
nigtem, wenn nur gebüngtem Boben, befonders gut in fofon im Serbfte zuyor ungebrochenem, nicft zu bindigent lefntig= temt Neubruche, am beften aber in einem fräftigen, Gumus= reichen und fandigen Thonboben. In märmeren bjegenden werfangt bie Rartoffel einen megr Gindigen, in fältern einen

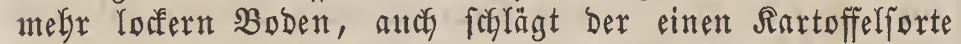
mefr biefer, ciner andern wieber ein anderer $\mathfrak{B} 0$ ben zu.

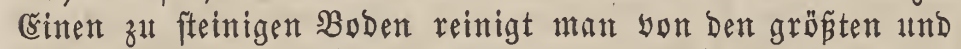
meiften Steinen, einen ftruppigen, mit Difteln und niebri= gem Befträucfe bermachfenen Walbboben brennt ma, und

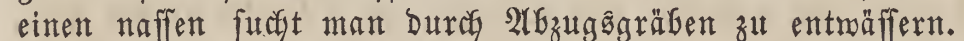
Sft Der $\mathfrak{B}$ oben zu leidgt, fo werbeffert man ifn burch Thon= mergel, ift er zu fajwer, Duref Sandmergel, und einen fau= ren Duraf affeche.

Whenn gleidy bie Rartoffeln auch in einem ungebintng= ten, menn nur noch alte Rraft befthenden Boben gut gera= then, fo findet Doch Dieß ungleich meGr ftatt in einem guten und frifdigebüngten Boben, แnd es bat Das frifiche Düngen nicht alfein Den Sortheif, Dá Der Errtrag Der Rartoffeln ein weit bebentenderer wirb, fondern bá̧ audy bie - auf bie Den Boben ziemlich ftarf, menn audy meniger als betreide, erferyopfenden Rartoffeln folgenden Nachfrüchte Geffer gebei= Gen fönnen; zubent mird auch Durch bie Fütterung Der אar= toffeln Der werbraudgte Dinnger wieber reicflicfer erfetet. Die Rartoffeln ertragen es, ftarf gebüngt zu merbent, Duch ift aud

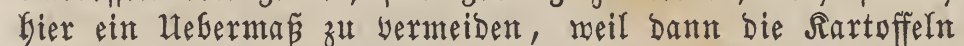
zu ftart in's Sraut treiben, Daffelbe finf lagert, und fich nur wenig Rnolfen aubGilden, und nur bei reichtem und troffenem $\mathfrak{B}$ oben und in troffenen Safrgăngen, und went auf Die Rartoffeln nody weitere Frütchte folgen follen, ift ein

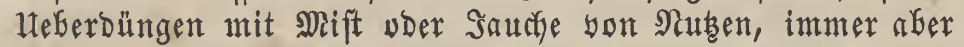
Gebürfen bie Rartoffeln, als Bradgfrüd te gebaut, ba fie mebr Bobenfräfte fonfumiren, auch ntefgr Düngung, als andere in Der Brache gebaute שrüchte. Den Sartoffeln ift faft jebe Sirt yon Dünger genebm, jeboch ift Der Sferbe = und
Nindbiegmift wobl allen andern Dünger= Neaterialien yorzu= ziefyen, Gejonders ber eritere mefr für gefundenen, faltent und feuteften Boben. Dieje beiden Düngungannittel erzengen

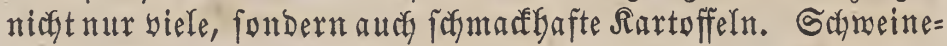
uno Schafmift geben Den ftärfften Ertrag, nur ertheilt Der Yebtere, wie auch Der Nenichenfoth, Den Rartoffeln einen unangenefymen und beisenden Gefogmarf, und felgft bas

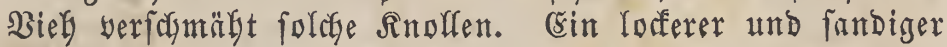
Boden werlangt einen furzen, ein fogwerer unb Gindiger $D a=$ gegen einen langen MRift, Danit er Durch Yehtern lorferer er= Galten werbe. Dả Düngen mit Ralf, (5)pg, Mergel, Sablz= afche, Dem 2lbfalf yon Geifenftedereien maeft. Die Rartoffelt Gefonders wobljcymeffend, ift aber mur in feftent und bindi=

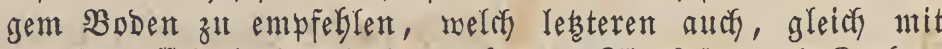
Den Rartoffeln in Den Boben gebracht, Sägefpäte und berber= roke gute Dienfte Yeiften; ebenfu Gefübert das Ëinftrenen

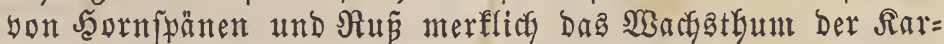
toffeln, und für melyr leichten $\mathfrak{B}$ oben eignen füd bejonderz wolfene, entweder troffene, oder mit Iauche gejättigte, oder aber längere Beit unter Schafen gelegene Rumtpen, wie auts gut zergangener saffentoth, תompoft und Schlamm, melra)

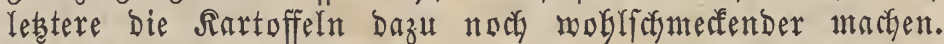
Was bie Beit Des Düntgens anbelangt, fo ift biefe verforte= Den, unb man bat fich bierin bauptfäctictich nach ber $\mathfrak{B}_{e}=$ forfaffenbeit des Bodens zu richten. Sft Derjelbe bindig, falt

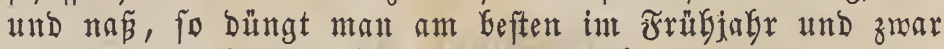
mit frifchem ßfferbemift, indem ein frübes Düngen und ein frifoce Mlift einen fo befdaffenen Boben auflorfern und er= wärmen; bei binbigent und fräftigem Boben fann man audf im Serbft ober zu einer Şälfte yor, zur andern nacif dent Winter büngen. EGGenfalls mürbe gemacht mird Ger bindige Boben auch Durch Das nur flache unterbringen des Miftes. WBa endlich Daz Düngen im 2 Binter Getrifft, fo fann biez bei Gindigem, wie bei leidftem, aber nie zu fegr werunfrau= tetem $\mathfrak{B}$ oben borgenomnen merben, indem ein gefundener Boben baburdy gemürbt, ein leichterer aber burch bie Mift= Deffe verbindert mird, in Frübjagre feine MBinterfeuchtigfeit zu fơfnel auszubünften. Da bie Sartoffeln igre Nabrung nefyr aus Der DGerfläche als Der Tiefe Des fo Darf ber Dung auch nur flach untergefracgt werben. Ěntmeder überftreut man bas ganze Feld mit Dung, Doer

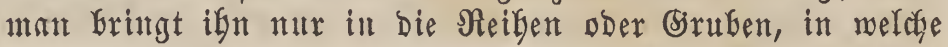
bie Rartoffeln zu Yiegen fommen. Errfteres ift lyautfäcblich Dann zu empfeglen, wenn ber Boben mefy bindig ift, and

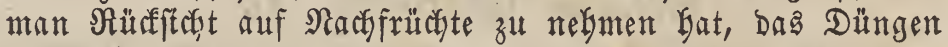
in Reifen ober Gruben aber bat in Den Fällen Den $\mathfrak{B}$ or= zug, wenn man megr auf Den Ertrag Der Sartuffelm jefegt, ber Boben bei noch gröper Thätigfeit ein leidyter ift, unb man nur wenig Dung=\$laterial beftht. W3enn man gleidy beim Rartofferlegen Den Mrift unterfringt, fo eignet fich ein geförig berrobeter meth als ein frifcher, indem bie sinolfen in erfterent weit ficharafyafter werben, noch foll bier bei leidftem trorfenem Boben Der Dung über, Gei fajwerem und leicftem $\mathfrak{B}$ oden aber uriter Die Rartoffeln zu liegen fommen, bamit im erfteren falfe bie Bobenfeudstigfeit meniger ver=

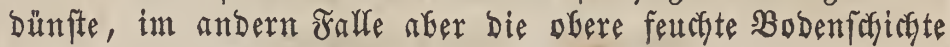
Gälber auştrodfnen fönne.

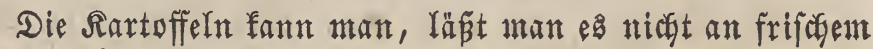
Dünger feblen, faft auf alfe zrübjte folgen Iaffen, nach Denen 
Der Bobert nidyt gerabe in eirem zu' verquecten Suftande

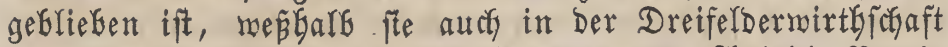

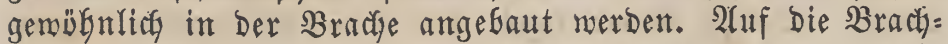

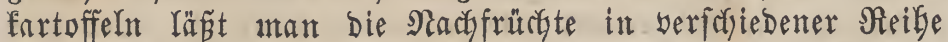
folgen, am beften jeboch, befondera bei gefundenem Boden, eine Sonmerfrucyt, roie Berfte, alfein ober mit Rlee. Die gemögnlidyfte. Fructifolge ift:

Rartoffeln in gebüngter Bracte,

(sierfte und Rlee im Sinterfelde,

Rlee im Sommerfelde,

Rlee in Der Brache, Der einmal gemäht mird, und zulebt (5)esüngter Weizen.

2lndere laffen noch Şafer, Bobnen, Ěrbfen folgen. Diefe

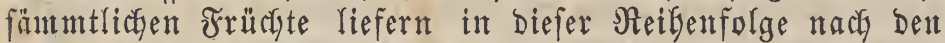
Rartoffeln eimen fitfiern und erwünfdyten (Ertrag. In leicf)= tem SambGoben, bei rarment Rltma entpfieblt ftef nady Rar= toffeln bie SBinterung mefrr. Manche Ranbwirthe Gauen mit Bortheil Die Rartoffeln im Sommerfelde und laffen Den

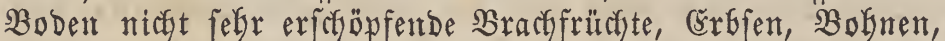
Tabal barauf folgen. (Sut geratben auf bie Rartoffeln fer= uer nod Sommerroggen mit Rlee und Winterweizen.

Die Siartoffeln verlangen igrer jungen zarten Snoffen wegen einen fefre lorfern und reinen Boben; je Ginbiger und

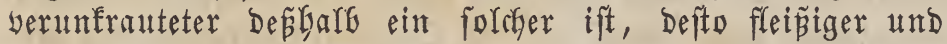
pünftlicher ntü er auth Gearbeitet werdeat. $\mathfrak{B a r}$ Dent $\mathfrak{B}$ Binter yffügt man Den $\mathfrak{B}$ oden melar furchig, fogar bent leichten 3 furofig und intmer fo tief als möglich, auagenontnten einen

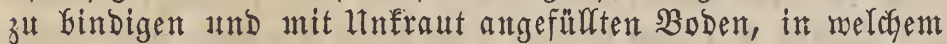

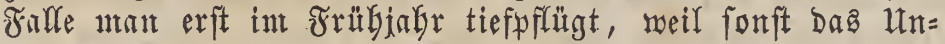

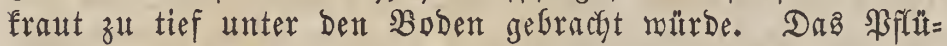
gen erneuert ntan ntit Dem Beginne Des Friłhlings, wo unan bann gleich Den Mifit flach unterbringt. Das unfraut be=

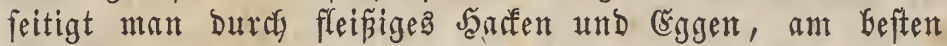
nact) cinent $\Re$ egen.

Die Bermelgrung Der Rartoffelu faun bermöge ifrer ftarfen Reproduftionafraft und ifres ebenjo ftarfen und

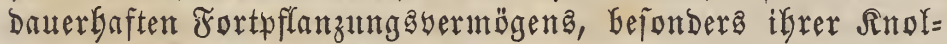

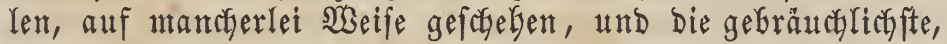

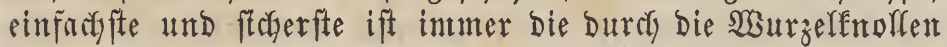

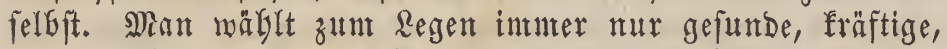
mit confiftentem nicht wäfferigent fleifche verfebene, am bejten mittelgrofe und fogrere אnoffen, welche noch nidgt gefeint voer yout Frofte gelitten Gaben; gröpere Sinollen eignen fted mebr für einen Gindigen $\mathfrak{B} 0$ den, während fleinere und nicgt

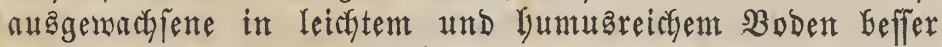
fortfionmen. Utm Das früfe Reinten Der Rartoffeln zat ver= Gindern, Gringt man fte in bünnen $2 a g e n$ ntit eintretendem

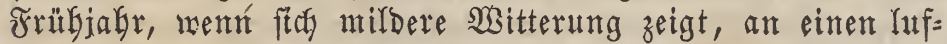
tigen Srt, in eine Sdyeune zc. Inter Den Rartoffelforten

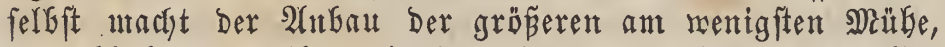
aud) Gleiben yon ignen in Der Ernte nidht fo wiele Snollen in Der Erbe zurihfe, als bei ben fleinern. Mean fefe afer

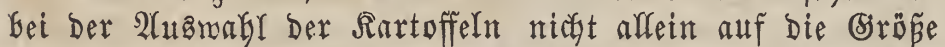

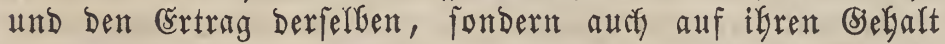

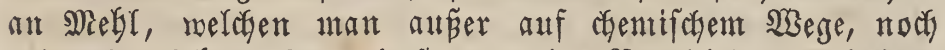
Dadurch erfalgren fant, Dás man eime Vergleichung mit bem

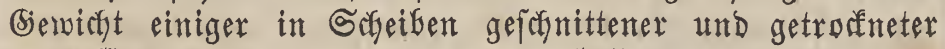

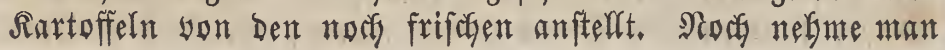

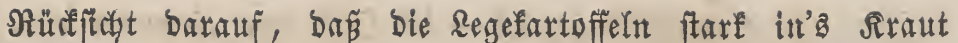
treiben, weil folehes Den Boben megr befdyattet, Daz Utn= fraut weniger auffommen lä́nt, und bie Rartuffeln melgr Nakrungatbeile auts Der Ruft aufnebmen fönten, fomit auch ben Boben weit weniger altsimagern.

Esinige legen bie Rartoffeln ganz, andere zerfantitten, lecteres ift Gejonders bei Rartoffelmangel zu empfeglen, int= Dent Daburch Der Ěrtrag Durchaus nicht geringer ausfälft, Denn aud bei Den ganz gelegten Sartoffeln treiben weit nicht alle, böchitengs 4 Reime, und bie nach unten zul liegen fomurenden entroiffeln fict gar nicht; jeboch arten die zer=

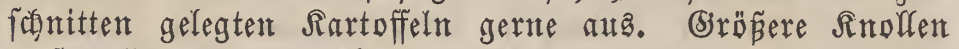
zerfchneidet man gemogfnlicy in 4, bie fleineren aber mur in 2 Stürfe, Deren jedes 3-4 fräftige 2lugen befthen foll; auty

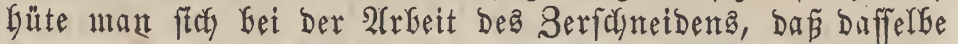
nicht mit einem ftumpfen, fonbern foffarfen Mefier gefochebe, Da gequetfobte Schnittffächen leidgter faulen; ebento beobachte

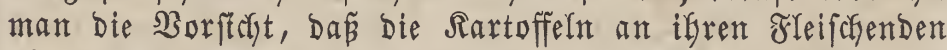
gleichförmig abgefdyitten werben, weil bie 2 (ugen beim \&egen gernde nach oben (und nidjt fohief) zu liegen fommen mulffen. Vor Dem Regen läß̈t ntan Die zeridanittenen Rartoffeln yor= Ger etwas abwelfen. Die Beit Des Rartoffellegenz anbelan= gend, fo foll man Durafan nicht Damit eilen, Da yorber

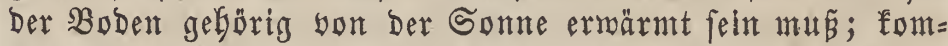
ment fie in falten $\mathfrak{B o b e n}$ zu liegen, fo brauthen fre oft 3

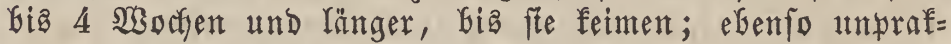
tifoch wäre ez, fie zu fpät zu legen, weil gerade bie in ber

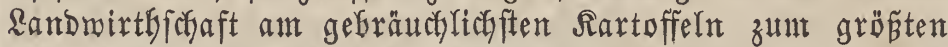
Theile bis zu ifrer bolfommenen 2 Uabiloung einen Beit= raum ban 5 Monaten bebürfen, fite fteth fomit reniger alls= Gildent tönnen, nie fo meglreich und Gäuftg yon Den Fröften überfallen merden. Frnilgreife Siartoffeln find im Alfgentei= nen etwa bärter ala Spätfartoffeln. In märmeren Gegen= Den nimmt man bas Rartoffelftecfen oft fơnon 2 nfangas, in fälteren Mitte ober Ënde 2lprils ober erft int Mai yor. Spăte Rartoffeln legt man früber, frühe fpäter, in warmen salyrgängen oft noch nach andern Früchten im suni, übri= gens ift Der 2infang Mat intuter bie befte Seit zunt Rar= toffellegen. Solfen Die Rartoffeln in bindigen Boben gelegt rerden, fo mús man biefen unmittelbar bor Dem Regent noch eine Furbye geben, auch ift bas regen roontöglich bei troffenem Wetter und yor einent Regen yorzutebnten, $D a=$ mit bie Rartoffeln nicft eingefdymiert werben und zeitiger in's Reimen fommen. Beim Rartoffelbau im Brobénen be= Dient man fitch zum Regen Der Befpanmwerfzenge, Dez \$flu=

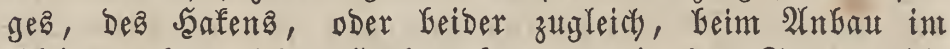
Rleinen aber reidfen אandwerf zeuge, wie Der Spaten, bie Şaue ober Der Bfahl Gin. Bei Der Bearbeitung Des Bodena

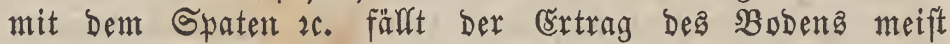

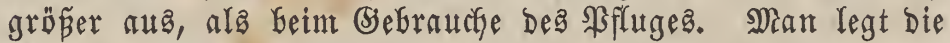
Rartoffeln 4-5 3oll tief, tiefer in locferent und warmem,

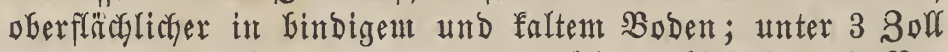
gelegt, werben fte gerne yon ben gröperen $230 ̈ g e l n$, wie $\Re$ a ben 2c. ausigeriffen, troctnen bei trofener Witterung aus und erfrieren bei ซrröften, über 6 Soll tief gelegt, erfticfen Die Reime gerne. Die Rartuffeln legt man inmter fo, Dan

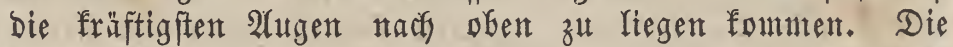
ganzen Rartoffeln Yegt man gemöbrulich in 2 ₹ü won ein= ander gezogene Neitgen in einer Entfermung bon 18 3oll, 
zeriafnittene Rartoffeln in $12-18$ 8oll yon einander ent= fernte $\Re$ eifen und 8-12 3oll yon einander. Siröpere und

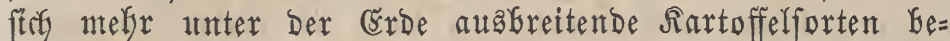

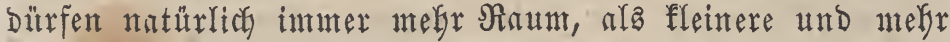
in bie Tiefe gefende; lebtere werben tiefer, erftere flacher gelegt. Im frärtigen, gutgedüngten Boben legt man bie Sintoffeln meitläuftger, in magerem bidyter. (sin bichtę Sartuffelfegen bringt zwar bäufig eine gröpere Menge, aber aud meift um fo fleinere Sintoffeln herbor. Erine meitere

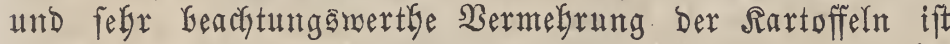

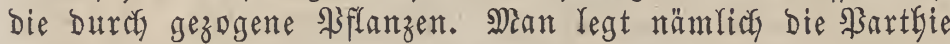

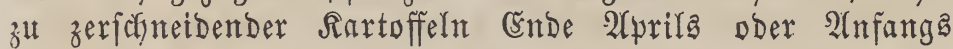
Mat in ein gefp̈rig verarbeitetes Rand. Nach 6-8 Nodyen,

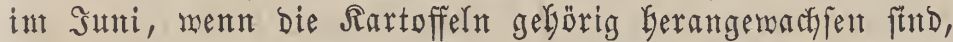
nimmt man yon jebem Sate $2-3$ ber ftärferen Bflanzen aus Der (rrbe und fringt fie mittelft des Rffuges auf ein geförig vorbereitetes und gebüngtes reld. Die Pflanzen werben mun im Duabrate yon 2 శú 6 3oll ganz fohief

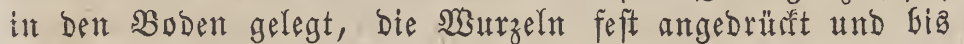
auf 2-3 3oll Des Rrautez mit Ërde beberft. Bei biefer Bebandlunganeife erfyart man nicht nur einen gropen Theil Seb̧firtoffeln, fondern man erbält auts, indent Durch baz Serfeben Der jungen SPflanzen Die SBurzeln roieder mefrere

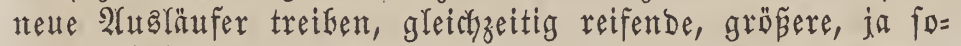
gar nahrbaftere und woblfogmedfendere Sartoffeln, ala bei

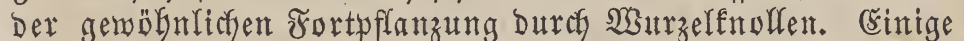
Kartoffelfanten fesen oft 6 Boln goch uber ber Erobe taubenei=

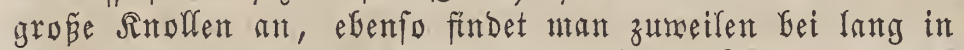
Jaanfen gelegentem Sartoffelfratte, Dá̧ Die Stengel in Der

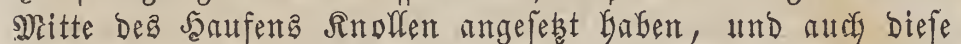

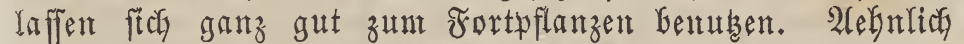
Der $\mathfrak{B e r n t e f r u n g}$ Duref zerfdynittene Rartoffeln ift Die Durch bie Süpre, woruter. man entweber mur mit einem Theil Fleifoy abgefinnttene, mit einigen 2lugen berfekene Rartoffel= ftürfe ober mur ben oberen, bie zaflreicfjten 2 (ugen befthen= Den Theil ber Sartoffeln werftelt. In Sachjen Gejombers

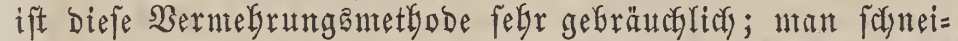

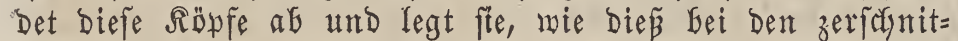
tenen Rartoffeln angegeben murbe, und benüht Das Burürf=

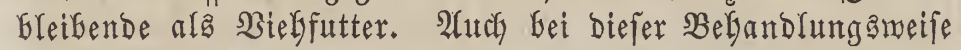
erfpart man Sartoffelin und fant einem ficheren und reich= licyen Errtrage entgegenfelen. Ferner geforiegt bas Fort= bflamzen Der Sartoffefn Durch Das Regen auzgeftorfener 2 ugen. Diefe fticht man etwa pfenniggrof von Den gröpten Rartof: feln mit einem eigens bazu verfertigten foffarfen 2 ober mit Dex Mefferfpise aus und legt fte, Da felten alfe treiben, zu $3-4$ zufammen, $6-8$ 3ulf yon einander ftebend in 20-24 3oll yon einander entfernten Reifen. Man bat

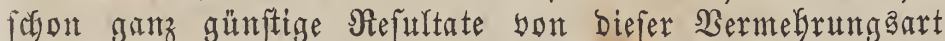
erbalten, nur gefört ein recht lorferer, Gumusareicher Boben und eine mefr feuchte, nidgt aber naffe Şitterung zunt boff= fommtenen Belingen, auth foll an ben 2lugent inturer troch Ginreichend Fleifech gelaffen werben, weil fonft biefelben, zu=

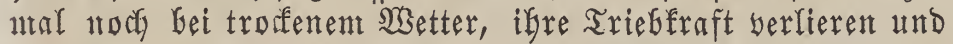

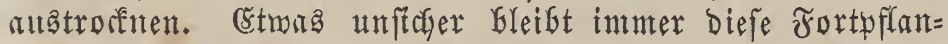
zungasart. Man fant bie Rartoffeln auch burch bie Reime, welche fith in bejumbers warmen Selfern gegen Den Früth=

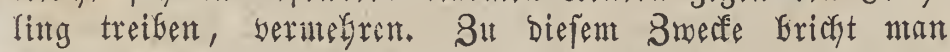
Seinte yon 1 Solf sröpe an ab, zerfegneibet bie grö́peren gefteberten ober fnotigen Triebe in mebrere Stücte und yer= yflamzt fie 6 Boll weit won einander in eimem felgr lodern. Boben. Soldye Reime fann man 4-5mal nach einander abbrecten, da fith immer wieder neue nadjbilden. Der Err= trag ift aber meift gering und beß̧falb bieje Metbode nicht empfeglengmerth, auser in theuren 3eiten, für relche auth allein die Jortpflanzung ber Rartoffeln burdy bie Sdynlen anzurathen ift; man fahneibet nämlich bie Schalen meffer= rürenftarf ab, zertbeilt biefe nody in fleinere, aber inmer mit 2 ugen verjekene Stürfe und legt biefe roie bie ganzen Rartoffeln in's Rand. Bei Gindigent and feuchtent Boben fann man bie Rartoffeln aud Durch abgeichnittene Bueige Der Stengel bernefren, mur gehört Dazu gleidyzeitig ciue feuctyte Writterung voer ein fleip̃iges Begieñen biefer Sterf= linge. Enolich fommen wir noch zat einet wichtigen Fort:

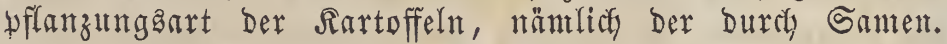
Man yerführt Dabei auf folgende SBeife: Die Sartoffelfrüchte

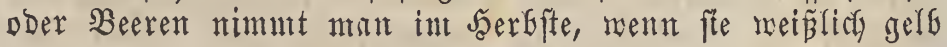
werben und noch nicht yon ber Rälte gelitten baben, yon

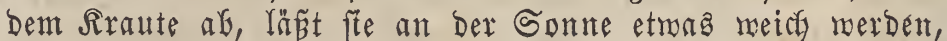
zeriteticht fie unt befreit den Gamen burdh miederboltes und forgfältiges Wafchen son ber ifn umgebenden fleiforig= fohleimigen Sitbitanz, troffnet ifa und bewagrt ifn bis zum

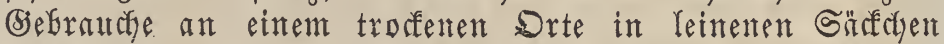
aufgefängt auf. Man legt die Gamen entweder in ein fal= tea Mifftbeet oder in ein Den Serbft zutyor gut gebüngtes, lofferes, troffenes und vout linfraute gefäubertes Rand, unb zmar in einer Entferung yon 2 3olf yon eitander, bringt

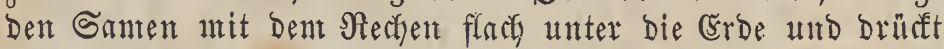
resztere bei trodenent Waetter feft. Die jungen Bfinnzen lei=

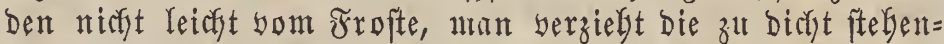

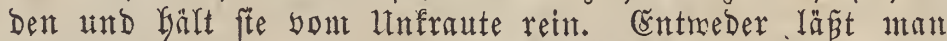
bie Bflanzen an Drt und Steffe ftefgen, ober beffer, man berfetst fete, Gefutfan aus bent Ranbe genonmen, bie int Mriftbeet erzogenen im Mai, bie in freien Rande aufgeward = fenen aber im Juni, 1-2 ซ̧us von cinander entfernt und tiefer, als fie worker geftanden baben, in ein anderes ge=

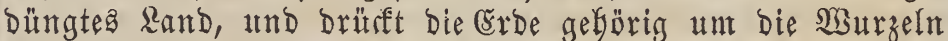
an. Sm Serbfte nimmt man bie ftes gebildet Gabenden Sinolfen aus Dem Rande und bebt fate bis zun Frühjabre an trocfe= nen und froftfrẹien Drten auf. Die Snollen, welige fitis iur erften Sakre angejegt baben, find meift mur flein und,

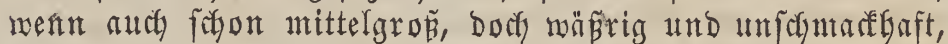
Dephalf noch nicht benubbar, und fe merbent erft int 3tent Jahrgang bolffomment. Dan legt fie mie bie Seghfortuffeln. băufig findet man bein Durcfichneiden Dex Saatfartoffeln in Fleifche Derfelben rotge Ringe: foldye Rartoffeln müffent

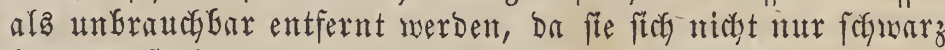
focten, fonbern aud einen änẽerft wibrigen (beruch und (Beffynad beftsen. Da biele Rartoffeln mur felten ober gar

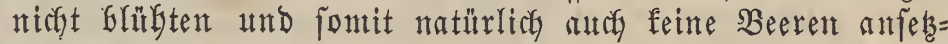

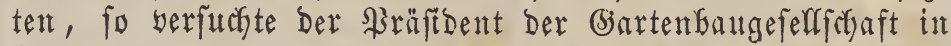
Rondon, und zwar mit (s)lürf, folige Sartoffeln Dennody zum Blüben zu bringen. (Er entblöṕte täntlich im Sommer mieberfolt bie Rartoffelwurzeln yon ber errde und angm

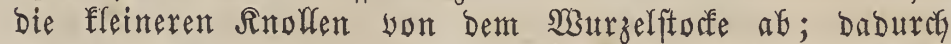

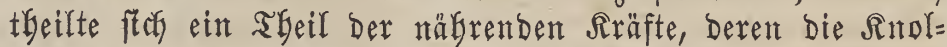
len nicht melgr für fech allein beburften, bent Sraute mit, melches mun in Den Stand gefest murbe, ebenfalls Blintben 
unb Frübte zu tretben. Die Jortpflanzung Dutch Ganen erforbert zwar melgr fleis and längere Seit als bie andern 2roten, allein man erfält, bejonders bei biefer nach gefije= Genter fünftictyer Befrucfutung meift nette, beffern and reich= lickern Crrtrag gebende Sartoffeln; nur unternimmt man Diefe Bermelyrung nicht, wie Biele Der Meeinung ftnd, aus Dent Sirunde, meil bie gleidfen Siartoffeln, längere Beit nach einander angebaut, endich aubarten und an (Siute berfieren; Diep ift Durcfaus nitgt ber Falf. Sobald bie Rartoffeln innter in gletch gutent Boben unter gletedy günftigen $\mathfrak{B e r}=$ Gältniffen und mit gleicher Sorgfalt gefaut werben, fo wirb

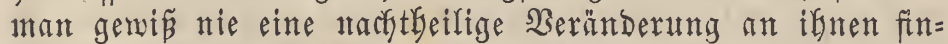
Den; Gat man ja bie nänlichen Sorten forbn 20 sagre lang angebant, ofme ben mindeften ltnterfocied im crrtrage

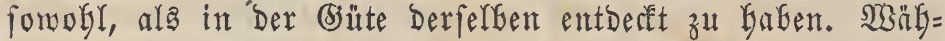
rend Der Begetationsperiode Der Rartoffeln ift es eine

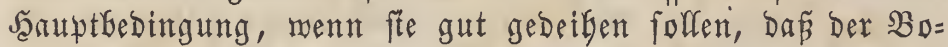
Dent in einem loffern Zuftande und rein yon allem Untraute gebalten werbe.

Die Anşantmenge Der Sartoffeln bängt Gauptäad lic yon Der Gröpe Derfelgen, wb fte zerichnitten wurben ober nicht, und yon Dent engern und weitern $\mathfrak{A f f a n z e n}$ ab, Daber man auf einen Morgen

in Baben . . . . . 20-40 Sefter,

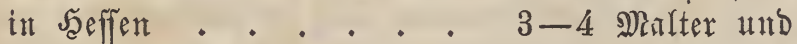

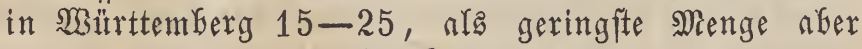
10-12 Simri rectyet.

N3ie. Geint Regen Der Rartoffeln, fo zerfält auth bie weitere Bebandhung Derferken in Die Durdy Scand = und bie Durdy) Sefpanmwerfzenge. Sind Die Rartoffelm mittelft Sand = werfzengen gefterft morben, fo roendet utan auch nur biefe

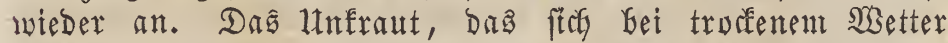
wieber gerne bermegrt, entfernt man burdi Säten, wenn bie Rartoffeln fith noch nicht auperballe des Bobens zeigen; feben biefe aber einmal aus bent Boben Geraus, fo bringt man bas ltnfraut nit ber Sandfade weg. Sind bie Pflan= zen 3-4 3olf goch geworden, fo müffen fie befaufelt wer= Den. Bei troifenem $\mathfrak{S e t t e r}$ und in Yeichtem $\mathfrak{B}$ oben Gebaufelt

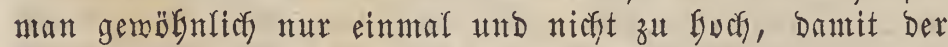
Boben nicht zu fehr austrodfne, in bindigem und feuchtem Boden bingegen und bet Rartoffeln, weldhe futh melgr ober=

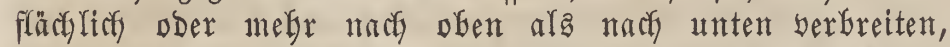
webergole man biés ein = ober eintigemal, went bas Rraut

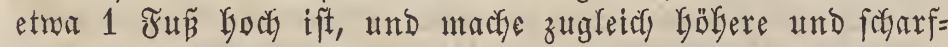
fnotigere Şaufen, Dant folche efer austroffnen fünnen.

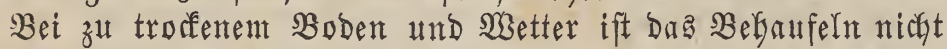
wortheilfaft, weil ber Boben zut febr austrodfnet; in biefent rall befarft unan ben Boben utur frach. Die befte Beit zunt Sanfeln ift bie yor einem $\Re e g e n$. Von nicht unbebenten= Dem Wortheife ift Daz He berwerfen ober Bebecfen Der erft

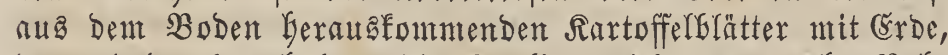

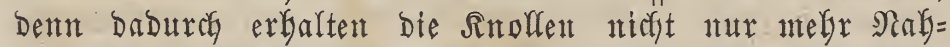
rung, fondern fie fönnen fith aud mit ifren 23 urzeln ftürfer attabreiten, und Das Unteraut mirb Daburch Yeichter unterbrünt, und Der (srtrag ift autf ftets ergiefiger. Bei ber Befand = lung Der אartoffeln mit Jeandwerfzeugen Gat man gewölyn= lict) einte reichlichere ěrnte zu getwarten, als bei ber burch Befpannfyaften, indem Dabei innuer frifdye (Erbe zmiffyen Das Rraut zut liegen fommt. Beim 2inkau. Der Sartoffeln

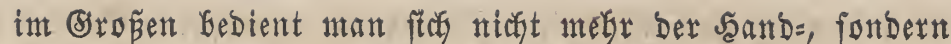
Der befpanmerfzettge. Sft Der Boben fefr leidft und fan=

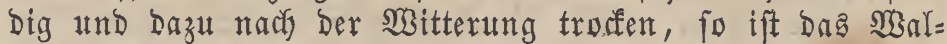
zen unmittelGar nadf Dem Regen ber Rartoffeln unter alfent Umitänden fegr zut empfeglen, Damit Der leichte Boden meGr

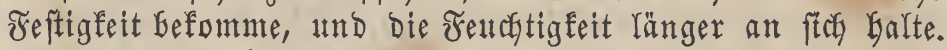
Den Boben erbält man Yurfer, und das unfraut entfernt nan buras sfteres Eggen, aber mit nidyt zu fowmeren eifer= nen Ëggen unb bei Sonnenfchein, entweber erft, renn bie Rartoffeln aus bem Boben heraus, ober wenn foldfe nod

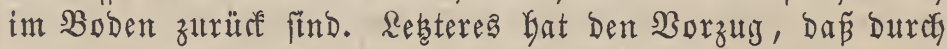
Das Eggen feite Rartoffelpflanzen ab = oder gar augeriffen voer yom $\mathfrak{B i e f}$ zertreten werden. AHch bebient man ftch, um Das Rand ganz vout Itnfraute zu reintigen, nadybent man zugor eimmal geeggt Gat, Des (Extirpators und Durch= eggt, menn Die Bffanzen aus Dem Boben Gerauğfommen, Das ฉand zum zweitenmale. Wenn bie Rartoffeln etwa 4 bis 6 3oll horf gemorden fent, fo werden fe bebaufert; Diefes gefichiegt am Gäuftgiten mit Dem Rartoffelbacken, ober aurfy unit Dent Bfluge. Soll Daz Jaafeln wieberfolt wer= Den, fo ftellt man Den Rartoffelharén das erftemal flady, Das zweitemal aber tief, ober fogleich tief, went man mur einmal gäufelt. Su tief barf Der 5̧arfen nie geftellt mer=

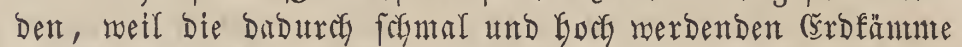

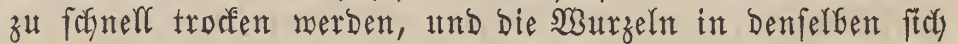
nicht gebörig ausbreiten fönnen, ofne aus der Errbe beraus= zuwachjen.

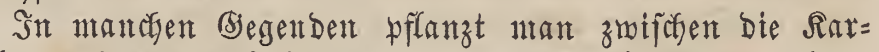

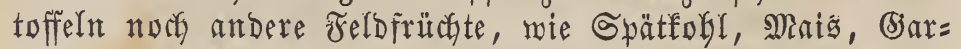

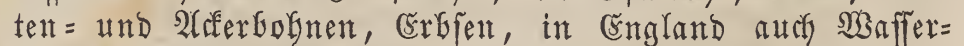
rüben; Giezu gebärt aber ein febr ftarf gebüngter guter

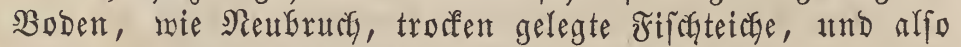
audc) biel Dung; aut wenigften aber wäre Mais afs eine Den Boden fo erfobyfende Pflanze zu empfeglen.

Itm Den Crrtrag Der Rartoffeln zul fteigern, bat man

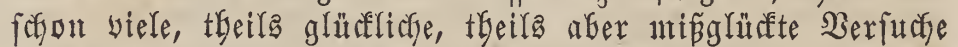

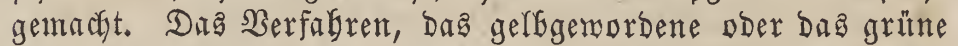
Rraut unzudreben ober afzufdyneiden, um neegr Rartuffeln zut erbalten, ift ganz berwerflich, indent badurch Den Snoffen gerade bie Drgane entzogent werden, weldye ifnen eintent grofenen Theil yon Nafrung zuführen. Das grüne Rraut

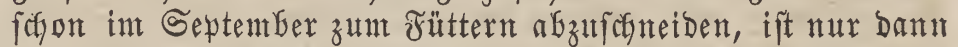
ratbjam, ja faft geboten, menn Daffelbe zu üppig empor= gemachfen ift, und falte, naffe WBitterung einfälat, ba es ben Boden za fefre befchattet, und berfelbe nidyt melgr trodfnet.

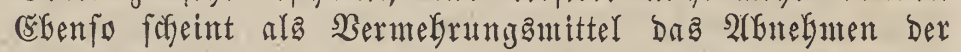
Blüthenfnozoen, wenn aud gerabe feinen Nachtheil, docis wentigftens feinen wejentlicten $\mathfrak{B}_{0}$ rtbeil z" bringen; in

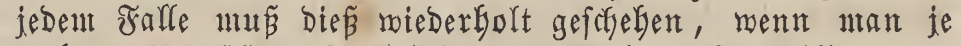
melgr und grö-Bere Siartoffeln Daburch bezwedfen mill.

Die Rurtoffelernte fällt geröbultis in bas ernde Sepl= tembers ober Den 2anfang Dftobers, einige frübe 2rtent reifen oft frton ernde Juli's ober im 2 uguft. In biefer Beit wirb Das Rraut gelb, bie Stengel werben welf, bie

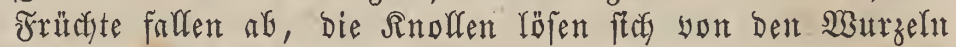
ab vor find wenigitens lodferer unt denfelben berbunden. Man nimmt bie Ernte lieber früber, zunal in gefirgigen

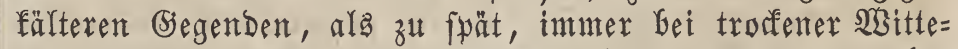
rung yor. Neif fann man bie Sartoffel nennen, wenn ibre 


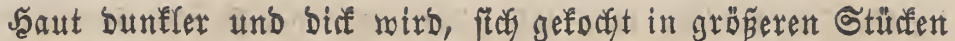

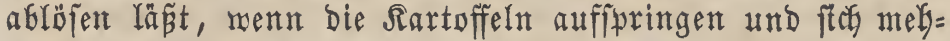
lig fochen. Whan nimmt bie Sartoffeln, nachdem ntan yor= Yyer Das Rraut abgeidyitten Gat, entweber mit Dem Rarit ober Spaten, ober, Gefondera Geim $2(n$ Gat im Sropen, ntit Beppantmerfzeugen aus bem Boben. Die in Rängäreiken gelegten Rartoffeln bringt man Durch tief genug geftellten

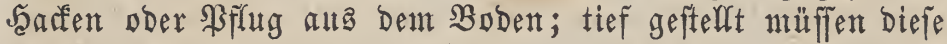
Werfzeitge merben, Damit feine ober fo renig als möglict) Rartoffeltr in ber Ěrbe zurütébleiben. Die fo aufgepflitgten oder aufgefilgrten Rartoffeln Garft ober wühlt man yollends mit Den Saänden aus Der Cordbe Geraus, üferfäGrt Das Feld, jobald bie Rartoffeln aufgelefen find, mit ber Egge, fammelt bie Giedurch auf Die Dberfläcte gebrachten Rartoffeln auf's Neue und yflitgt barauf zum zmeitenmale, um bie noch in

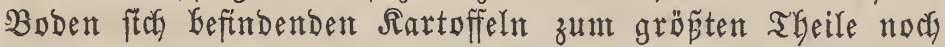
zu Gefonmen. Beim Seeraußnefmen Der Rartoffeln aus nicht

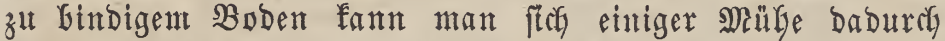
entbeben, Daf man bie Sartufferftörfe zuerft ausziegt, bie Gerabgefallenen $\mathfrak{i n o f f e n}$ yom Boden aufliest, bant die Furchen aufrübrt und bie sarfe und Egge fintendrein gebraucht.

Wag Den Errtrig Der Rartoffeln anbelangt, fo fann

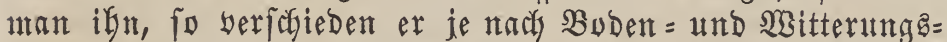
Berbältniffen, nach der אultur und Sorte ift, boch yont Morgen Durchfchnittlich Den 10 fältigen, unter ganz günftigen Untftänden aber Den 30-40fältigen Betrag Dę Rartoffel= fakes antebmen; man resintet auf einent Miorgen

$$
\begin{aligned}
& \text { in Babent . . . 150-600 Sefter, } \\
& \text { in } \mathfrak{x e f f e n ~ . ~ . ~ . ~ 2 0 - 8 0 ~ M i n l t e r , ~} \\
& \text { in SMürttentferg . . 80-320 Simri. }
\end{aligned}
$$

Bor Dem 2lufbewafren ber Rartoffeln mitffen fie you ber ganz won ber ifnen noch anfängenden Errbe gereinigt, Gierauf gut abgetroffret, und bie zerquetichten ober erfrore" nen ausigelefen werben. Die Sartoffeln laffen ftif ülber ben Winter bis zur Regezeit, Die Speifefartoffeln bis gegen Jo= Gannes aufbemabren. Man Gemakrt bie Rartoffeln am bän= figften in trocfenen Rellern auf. So lange fich noch feine Jröfte zeigen, läpt man ifnen gehörig Ruft, bamit fie recht ausbünften fönnen; tritt aber Rälte ein, fo mú man fe

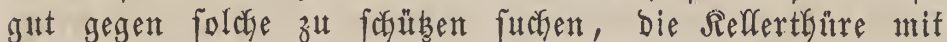
Stroh, Mift oder anderemt Mlaterial beberfen, alle etwa yor= Gandenen Deffnungen verftopfen und bet beftiger Rälte bie Rartoffeln felbit mit Mift belegen. So gerne bie Rartof= feln, wenigftens bie ber obern Sefichte, bei ftarfer אärlte retben, fo nachtheilig fant audy ein zu warmer Refler auf fee einmirfen, indent bie in ber warmen und gefpantenten Relferluft, meift auf gropen baufen liegenden eingefdyloffenen

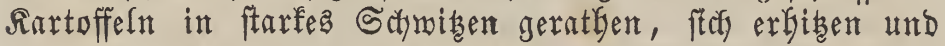
z̆l faulen anfangen. (Eine meitere 2 lufbemalynunganart ift bie in mittelgropen, mit Stroh, Raub z. auşgelegten und mit

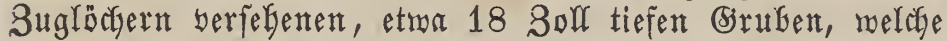
an troffenen Drten gegraben und oben mit 2 Fü Errbe

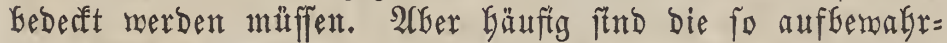
tent Rartoffeln boef Dem Errfrieren, Dent Fraten, Miäujen und

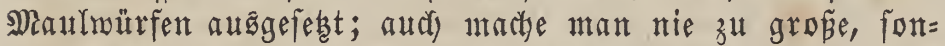
Dern lieber fleinere und megr Gruben, benn went man eimual Rartoffeln aus eitter Grube nefmen will, fo mtäffent fie auth alle Geraugengenumen werben, indem andern zalfs bie zurüafbleibenben bon ber beim Deftnen ber Grube cint=

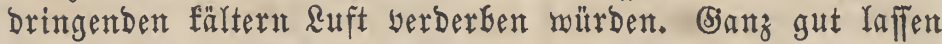
fich Dagegen bie Rnollen in Bruben aufbemagren, Deren Seitenwände mit Barffteinen Doer Ralfeplatten belegt fitnd,

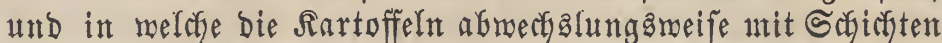
yon Sand zu liegen fommen; aber auds biefe Gruben

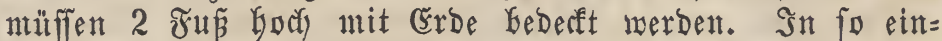
gericyteten Ssruben follen bie Sinrtoffeln 2 Jabre lang feint= fäbig und facharefbaft Gleiben. 2(m beften aber erfalten fitf) Die Rartoffeln in Miteten über Der (rroe und an gefchübs ten troffenen Drten, in Der Näke yon Stalfungen 2c., 3-4 Solf tiefen, 21/2 ËHe breiten und gebörig langen bruten, in meldye bie Rartoffeln bachförmig, 8-10 Fü hoch, fo fpibis als 1möglich aufgefdicftet, mit Stroh beberft werben und

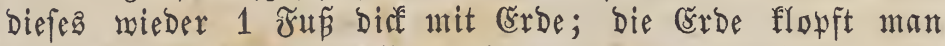
feft an, bamit bie Näffe mentiger butrobringen fann, und auf Dem Frirfte Der Miete bringt man einige Ruftlöcher an, welche man bei eintretender Rälte berftopft. In Biegenden,

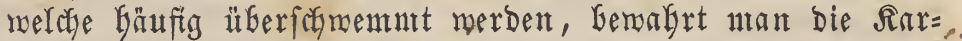
toffeln Gäuftg anf mit Seeu ungeben unt bedecft werben; bet ftarfer Rälte $j e=$

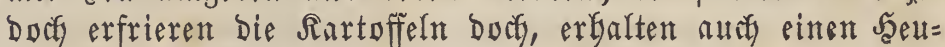

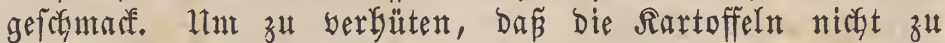
frilt und zu ftarf in's Seimen fonmen, tautft mant fie in einem Sorbe eintige Sefunden lang in ftebendbeipes Wafifer, modurch igr Begetationstrief unterbritaft mird. Itm fte in troffenem Suftande aufzuberwakren, bringt man fie entweber ganz in Den Baffufen, wenn Das Brob beraugegenummen worden iłt, und läpt fte ungefähr 1 Stunde lang Darin,

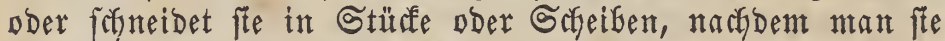

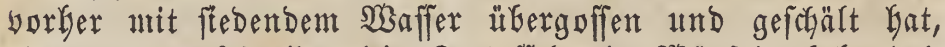

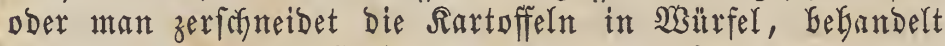
biefe mit Rali und Waffer, um bie freie Săure, Den Exx= traftib = und Farbftoff zu entfernen, und troffnet fie bann bei mäpiger $\mathfrak{B a ̈ r m e . ~ S o ~ b e f a n d e l t ~ f a n n ~ m a n ~ d i e ~ R a r t o f = ~}$ feln einige Jahre lang aufbemafyren und ein gutes Wefhl und guten Sries Daraus geminnen. Esine weitere Methode,

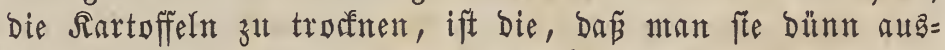
ftreut, Duriffrieren und mieder aufthauen läpt, wodurch fter Das Mebl berfelbent zufammenziegt, Der mäfferige Theil fets

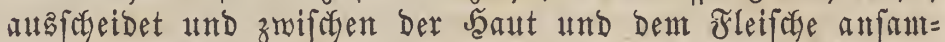
melt; wirb bie Safjale abgenonmen und bas Wanfer ent= fernt, fo troffnet bie Miefliubftanz ofne baullfe yon Feuer in ber freien Ruft yoflends aus. Diefes Berfahren beob= achtet man Gauptiächlidy autb bei folchen Rartoffeln, bie vont Frofte gelitten Gaben.

\section{Sdyäblidbe (Sittintife, Ruanfbeiten zc.}

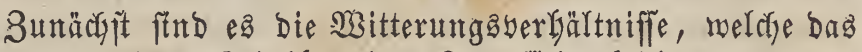
gute ober geringe Sebeiken ber Rartoffelt bebingen. Nact) Dem segen berlangen bie Rartoffeln, wie mir bereits erfahren Gaben, zu ifrem yolffonumenen Beratgen eitte etwas feudyte, aber warne Witterung; zeigt fter einmal bas Rraut über Demt Boben, fo ift ihment eite mekr trodfene und warme,

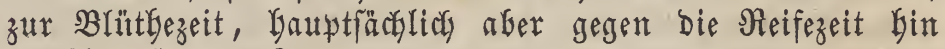
im 2luguft und September mieber eine warme und mäßïig

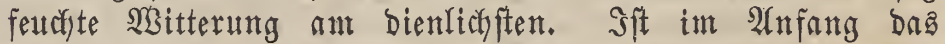
Wetter lange Beit nás, babei aber fefr marm, fo wadjfen die Rartoffeln getl auf und auf Soften ber Inollen burzugä= 
meife nur in's Sraut; fällt aber zur Seit ber şlütbe und Reife faltes und naffes Wetter ein, fo werben die gröperen

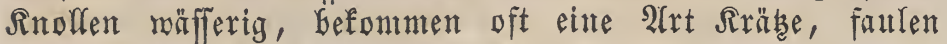
audf zulekt, und bie fleineren Rnoflen bilden fich nicht nebr

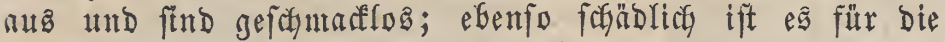
Rartoffeln, fte int Serbfte bei naffeut Wetter zu lange int Boben ztl Iaffen, fte werben ebenfalfs unfamadfbaft, mäffe= rig und zerplasen meift beim Ruchen. A(ndererfeits bei zu trodfenent und marntem Wetter entroiffeln ftify biele Reime gar nicht, ober troffnen wieber aus, dod werden in biefent Falle menigftens die gröperen fnullen gut. W̉erben die Rartoffeln wäGrend Der Blütgejeit bout Sagel getroffen, fo füllt bie Ernte meift ganz gering aus, fowobl in seziefung auf Menge als audh (Sirōêe Der Sartoffeln; in Der Ju= gend yon demielben befidäbigt, geben fite zumeilen doch now einen mittlern Errtrig. Dom Sagel getroffene und baduraf Deß Rrauts Geraubte Rartoffeln magern Den Boben bedelt=

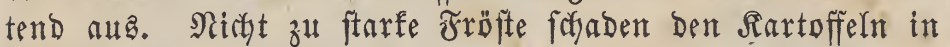
ber Jugeno meniger, alg ronn fte einmal gebörig erftarft find, und es rerben badurify nicht aflein das. Sraut, fon=

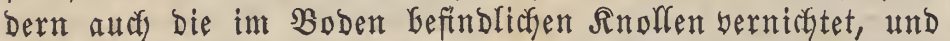
Geide geben Gald darauf in Fäulniś über. (rinen nicht miu= Der Gebeutenden cinffur auf bas biebeifen der Sartoffeln

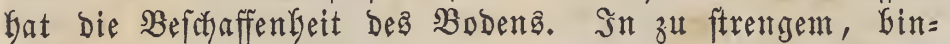
bigem, zu falfyaltigen ober magern Boben ift Der 2nbau Der fartoffeln nie fither und ebenfo wenig einträglich, in naffem oder berfauertem arten fte gerne auz oder faulen. Jañufig Gefommen bie Rnollen, zumal folche Rartoffeln, bie entweder fitch nux flach unter Der Erde aubseiten oder zut flach gelegt morden find, ronn fte aus Dem Boben Geraus=

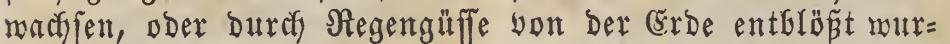
Den, Durch die sinnirfung Des sichts und ber Sonme auf ifrer Dberfläche eine grüne Farbe. Soldye Sartoffeln baben einen erfelfaften (seruch und (sefdymarf und werben nicht aflein mebr won Dem Bief gefreffen, ifr (semús berurjacht Heberfeiten, Erbredyen, Sdymindel, bläht Das Sief auf und marft, Dá̉ trächtige Sdymeine berwerfen; fte Dïrfen nie zur Fortpflanzung berwendet merben, weil fie immer mieber ge= ringe und bäufig aud franflafte Rnollen Gerborbringen. Dft Gaben Die Sfflanzen ein Dürftiges, fallectes 2lusfeben, nux wenige, fleine, fränflicte und früppelgafte inolfen und ftatt ber Reime Gefinden ftch oft tief in Den Rnollen faswarze pfriemenförmige Buben. Diefe 2 Uåartung ift in einer Sifmäche der Broduftionzfraft zu fuchen, und die Hrfache

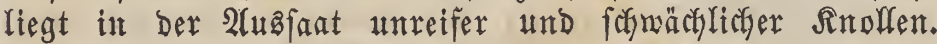
Das Dermunden der Sartoffelpflanzen Gat genöbnlid fleine und unreife Snollen zur Folge; gefdyiebt es in Der Sugend, fo treibt die Bffanze erft. fpäter wieber friface 3weige, ge= fajiebt dies aber, wenn die \$ffanze fayon berangerwadjen tift, fo ftirbt fite nicht felten ganz ab. Soldje berleste Bflanzen

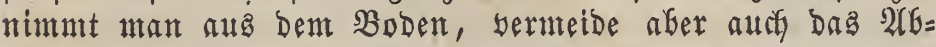
forneiden Des Rrautes yor Der Reife Der Rnollen.

Die Rartoffeln ftnd auser diejen 2(nfällen aurij ver: fabebenen sranfbeiten untermorfen. Sine nicht felten bor= fommende Rranfleit ift Der Noft, Rubigo. Die Rartoffel= Glätter Gefommen Dabei roftbraune Flerfen, welche nady und nach an Uunfang fo zunebuten, Dá̃ Das ganze Blatt mit biefer Roftfarbe überzogen ift. Entweber werben in Folge

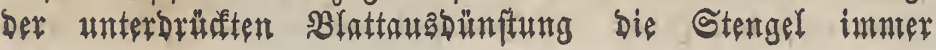

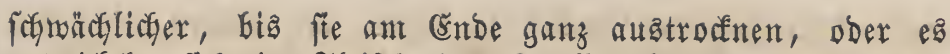
entruiffelt fits int Fleifdye ber Rnoflen Garte, fajerige und frymarze Beulen. Man fennt bis jebt die Urfache diejer Aranffeit nidat, ofgleich einige diefelbe den (sinmirfungen Der Sonne nach einem Regen auf Die noch naffe Affanze

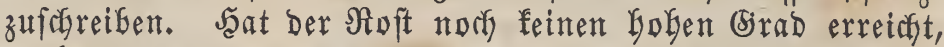
fo Gört er oft nach eineut etroa ftarfen marmen $\Re e g e n$ auf, Gat ex aber bereitz einen gropen Theil Der Sffanze ergriffen, fo ift Das Sathfamite, um noch eine leibliche Ernte zu er= Galten, wenn fich noch feine Blütbenfnuspen angejest haben,

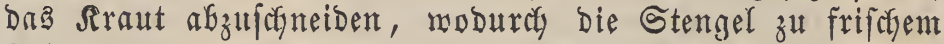
Triebe weranlagt werden. Sine weitere Rranfbeit Der Rar= toffeln ift Die Rräufelfranffeit, Frisole Der Franzofen, ober the Curl der Engländer. Die ganze Affanze erbält ein

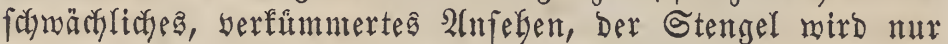
einfach, fest felten 3roeige an, bräunlidggrün ungefledt, oft altify roftflerfig, oft biŝ ins Marf binein, welches eine roft=

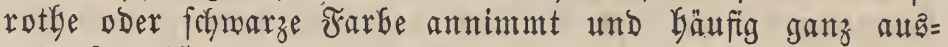
getrodfnet ift. Die nur furzgeftielten Blätter werben rauly, runzligt und farumpfen zufammen, ftnd Geffer doer bunfler und gelbgrün geflefft. Dą ganze Sraut mird mun Gald gelb und ftirbt Dann ab, wenn gerabe gejunde Rnollen ant

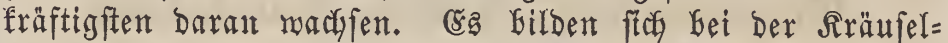
franfleit nur ganz wenige, unreife und gemölynlich auch fochon ausen auffallend gefärbte, edfellaft famedfende, famierige und ber (Siefunbbeit fabaliafe Rnollen. Csinige balten irri= germeife eine Rñferlarbe für Die Itriactye diefer Sranfbeit, Deren Räfer feine čier an bie Rnolfen legen, und welche nun Snollen und Stengel anfreffen und zerftören follen; andere fudjen Den sirund diefer Rrantbeit in Der zufälligen $\mathfrak{B}_{e}=$ fruchtung Diefer Rartoffeln Durdy Den Blüthenftaub Der in Der Näbe derfelben angebauten Howards oder Niebfartofjeln;

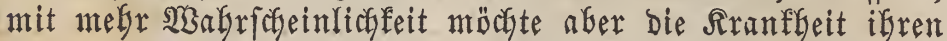
(Brund in einer Berftopfung Der Pffanzenporen Duref Den Janig = ober Diefitya und Dadurch berbeigefübrten Semmung

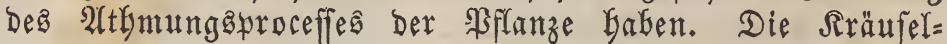
franffeit pflanzt fich fort und bört auch bei ber borfuchtig= ften Sultur erft in Der 4 ten oder 5 ten Bieneration auf. In

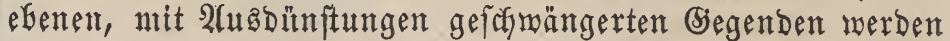
bie Sartoffeln bäufiger bon biefer Rrunfleit befallen, ala in luftreinern (siefirgägegenden, ebenjo find ifr cinige Rartoffel= forten, wie die langen und runben rotben, mebr ausgejegt, als bie weipen. Sur Verbütung Diefer Rranfbeit wermeibe man mo nüglich alles, maş Das (Sleidggemidyt in Der Degetation fignelf aufbeben fönnte, man bearbeite Den Boben tief genus und bertheile ben Dung zwedfüäpig und gleichförmig, ober berforaffe ftat frifage und gefunde Saatfartoffeln ober erziebe foldye aus Samen. Bei einer fernern sranfbet, bent Rodfen, merden die Rnollen fiforfitg, Getommen ein erdigeg

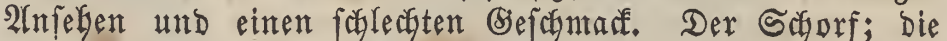
Schale Der Snollen befommt famusig brante Fleafen and fpringt an biejen Stellen auf; bäuftg fundel man unter ibr fleine, 2 Rinien lange und faum fabendife meipe Würmer mit ibren sängen. Sin Scautgrund biefer Srunfbeit focheint ein faurer und zu eifentaltiger $\mathfrak{B}$ oben zu feit. Der Saforf ift zmar meder bejonders berberbend, nod erbliaf, bat aber Doch auf Den Ertrag einigen nawtheiligen Esinflups. Siegen= mittel oder ßräferbative ftnd, die Rartoffeln in feinem $\mathfrak{B D}=$

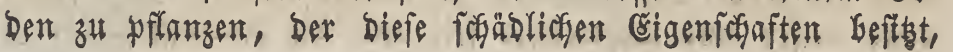


naffe Rartoffelfelder trorfen zu Yegen, Den Boben nicht mit Schaf = pDer Sferbemift, Sauche, rothem \&ehnt = ober Thon= mergel ober eifentaltiger Torfactye, fondern mit Ralfmergel

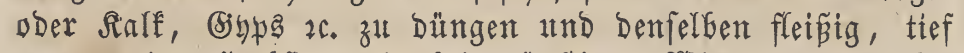
genug, int Serbfte und bei günftiger SBitterung zu be= arbeitert.

Einer eigenthüntichen und feit 3 gahren in fegr bohent (Srabe auftretenden Rranffeit ift hier noch zu erwälnen, nämlich Der Trodfenfüulle, auch Stodffäıle, Şerbftfäule,

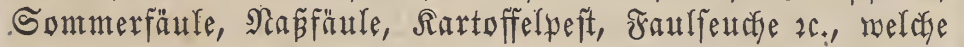
fity burdf ein fodnelfes Fraten und Bufammenfdgrumpfen ber int Seller aufbemagrten Rartoffeln auszeirfinet. Heber biefe. Iranflyeit, welche feit einigen Эagren eine alfgemeine Notg Gerbeifübrte, Gerrichen verfchiebene Meeinungen, und man ift

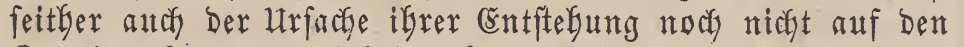
(Grund gefomment, vielfecht fann bies aber in fürzerer oder

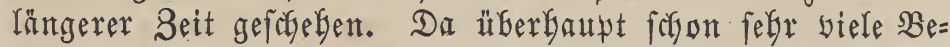
Gauptungen über biefe Rranfleit aufgeftelft morben, und über Diefen Bergenftand figon eine Maffe bon Druffestiften er= fojienen find, fo erlaube ich mir Gierüber fein urtgeil zu fäflen und biefe Saranfleit nidyt länger zu berübren.

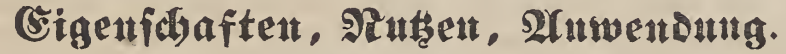
(sing of:

Die vorwaltenden $\mathfrak{B}$ eftandtheile ber Sartoffeln ftend nacty

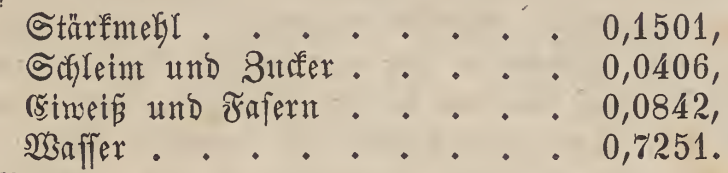

Nacif Burger:

Stärfmefl . . . . . . 0,1643,

Sibleim unb 3urfer. . . . 0,0557,

ઉinei

Sצnffer . . . . . . . 0,7471.

Nady Davg Gefinden fith in 1000 Theilen Rartoffeln:

Näbrende Subftanz. . . 200-260, Darunter

StärfmeGl oder Sçleim . 155-200,

Buffertbeile . . . . . 15-20,

Rleber ober Ěimeiñtoff . . 30-40.

গach $\mathfrak{A}$ bzug Dez $\mathfrak{3 a f f e r s ~ u n d ~ D e r ~ F a f e r n ~ G l e i b e n ~ i n ~}$ 100 Bfund Rartoffeln noch 22 Sfund Stärfe, Budéter, Schleim und Čimei $\tilde{\text {. }}$

2luper biejen Beftandtyeilen entfalten die Rartoffeln

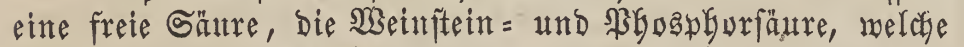
nach $\mathfrak{B f a f f}$ bejonders ftarf in Den innen rotbgeftreiften $\mathfrak{R} a r=$ toffeln fta worftndet, fermer theifneife fotwefelfaures, falz= faures und falpeterfaurez $\mathfrak{K a l i}$, whosphorfaure und falzfaure

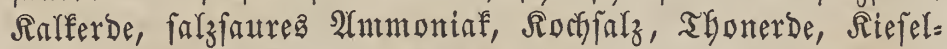

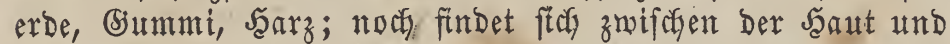
Dem Dberfäatefien Der Rartoffeln ein foharfer Stoff, Der iut frifisen 3utande Der Rartoffeln einen etrage ftarfen Sieruch

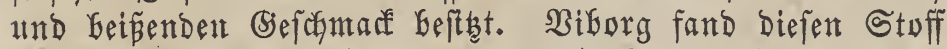
in ben jungen Sirtoffeln wentger ftare entrotifelt, als in Den ber Neife ftat uähernden, fowohl weísen als gelben Rartoffeln, mur nicht in ber Sufferfartoffel. Ěin Raufmann Bergntann in Wald Geim Geurtheilt bie (Süte ber Rartoffeln nach ber Form ber Blätter; ie runber nänliç bieje feien, befto Geffer und meblecicher feie auch bie Rartoffelforte, ie fphisiger bagegen bie Brätter, Defto fohlechter bie Sorte; fo nefme nadf Der Beobachtung an 120 berichiebenen Sorten, in Beziefung auf (b)üte an Meflgelyalt Die Glaunarmorirte Sartoffel Den eriten, Die (sierfartoffel ober Cordiflere Den zmei= ten, Den lebten aber bie Bapfenfartoffel, auch bie Roban=

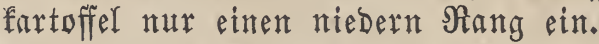

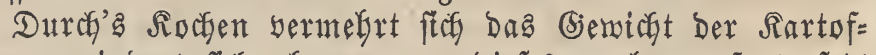
feln, yermindert fith aber, menn biefes zulange fortgefeets miro. Manche Rartoffelm fochen fich Gälder meidy ober nutusig, andere bleiben bart; bei erfteren ift das Stärfmebl, bet lebteren aber Der Ëimein = und ₹ajerftoff präbominirend. Die Rartoffeln gefören unter bie nahrbafteften Jeldgemädffe und werben in biejer Beziefung mutr yon bent Setreibe übertroffen. Binte, comfiftente und meglige אartoffeln ent=

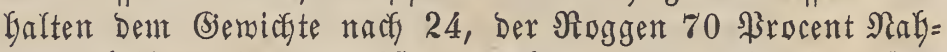
rungstbeile. CËin erwadjfener, arbeitender Menfad Gebarf zu feiner tăglicyen Nabrung yon Rartoffeln 10 şfund, you Brod 22/7 SFfund.

Die Rartoffeln nefmen wobl eine ber woidtigften Stelfen unter allen Feldgerwächfen ein, fte ftnd bie faft unentbegr= richjte Nabruting eines grofenen Theiles ber Menichen, befon= Ders ber ärmeren Rlaffe geworben, Deren faft auşachlief̧lictye Nabrungaquelle fie find. Sie geben denfelben eine nobl=

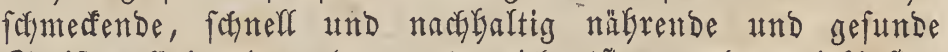
Speife, ftnd eines Der ausgezeichnetften und ergiefigften

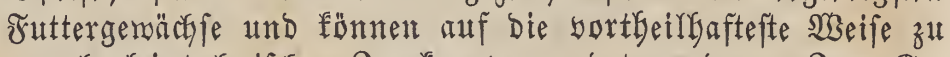
mancherlei technifchen Swerfen verwendet merben. Sum (Sie= muffe Gereitet man bie Rartoffeln auf bie mannigfaltigfte Wheife zu; man pueiast fie gejotten, in der Safale (Gejonders fadmaceflaft in Dämpfen gefocyt) oder gebraten, mit Salz, ober Salz und 3 utter, als Bentüfe in Sdynthe ober Scyei= Gen zerichnitten, als Miú, Suppe, in Form yon Subbing,

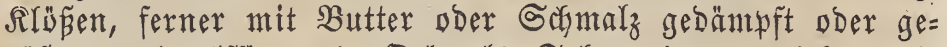
rijftet, mit Esfitg und Del als Salat ober zerrieben als

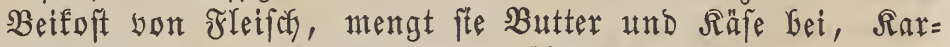

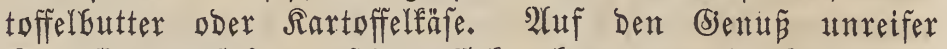
Rartoffeln erfolgten fafon Errfranfungen, mie Schmindel, Blähungen, Diarrgöen, jedoch fünd dieje Fälfe felten und mabridgeinlich Dem fodon genannten fcharfen Stoffe Der Sar= toffeln, ber fith bei jungen, unreifen Snoflen nebyr im $\mathfrak{I n}=$ nern zu befinden fofeint, zuzufdreiben, Solanin? Die Rar= toffeln geben zerrieben und mit Megl berbacfen ein febr nafrbaftes, fojmarffaftes und feuthtes Brod; man Gereitet

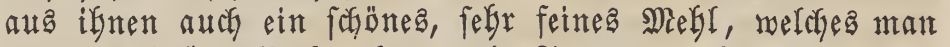
zut Den feinften Baffwerfen, wie Torten 2 . Genulsen fann,

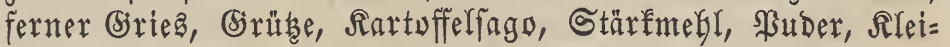
fter, geröftet ein Raffeefurrogat, fect fie Chofolade bei, ge= winnt aus ifnen Buffer, Syrup, Bier, Den Rartuffelmein.

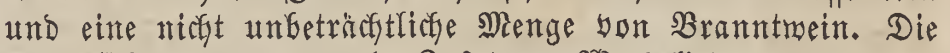

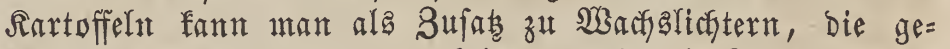
foeften, zu einem Brei werarbeiteten und mit Sauerteig ver =

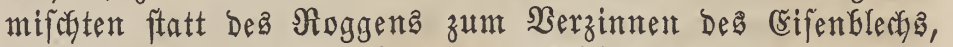
bie wäfferigen Beftandtheile Der meiben Sartoffeln anftatt

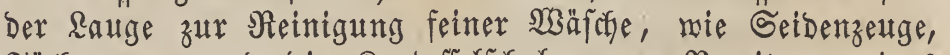
Tüther zc, und Die Rartoffelfichalen zur Bereitung einez geringen ßapiers benuben.

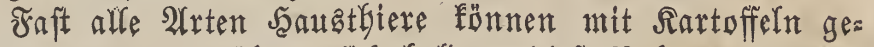
füttert merben, gemobnen fich Gald an bieje Natrung, freffen bann biefelben-gerne und gedeifen babei. Sie find fomolgt 
Taf. I.

2

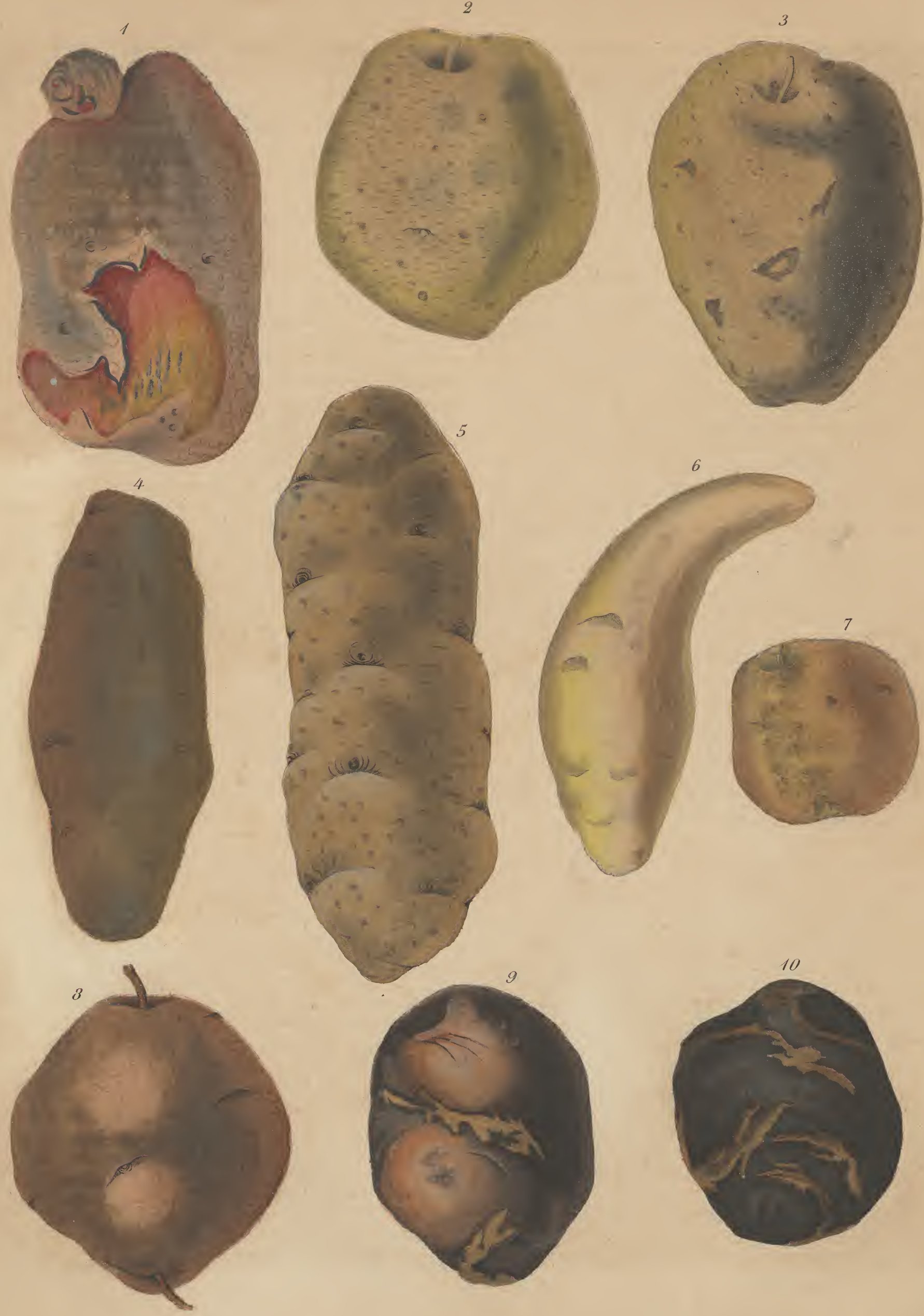





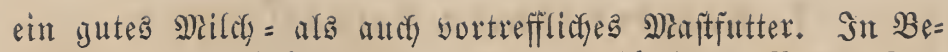
ziefung auf Singrfaftigfeit werben gemöhnlidf 2 ßfund $\mathfrak{R a r}=$

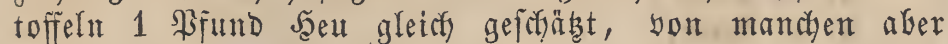
werden bie näfremben Beftandtheife Der Sartoffeln noch Göher

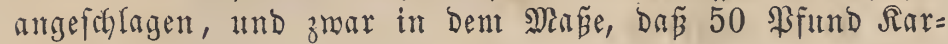

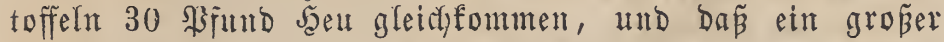

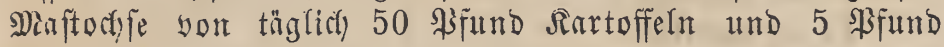
Jaeu fo ftarf anfebe, als yon ciner täglichen Fütterung yon 35 S3jund Selt. Man hat berechnet, Dar ein Berliner

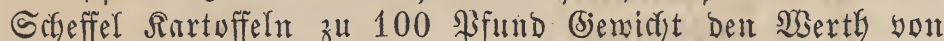

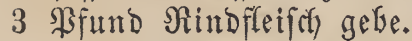

Man füttert bie Rartoffeln roh, gebörrt ober geford, affein vber mit anderem ₹rutter. Bei Der Roffintterung müfjen bie Rartoffeln rein gemajchen fein, Dürfen gejefuitten nie lange, an wenigften in Der $\mathfrak{B a ̈ n}^{2}$ aufGemabrt werden,

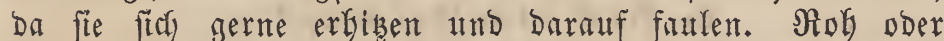
ofue Beintiftyung (bejonderso bie Biegfartoffel, melche auth gerne bläbt,) wirfen bie Rartoffeln anf Das Bieg biuretifoch

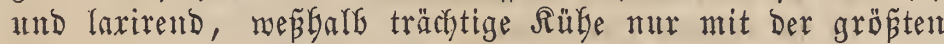
Sorftifyt mit folchen gefüttert merden follen; am beften fiüt= tert man Değhalb bie Rartoffeln mit Jen, Strobgäfjel zc. wermifayt, in meldher Form Das Bieb Die Rartoffeln aud länger gerne frip̈t und fid bie Bäbne meniger abftumpft.

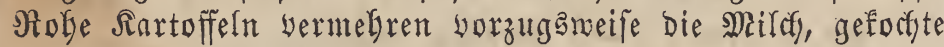
baŝ Fleifch und ซett. SBill man Die Rartoffeln gefocht füt=

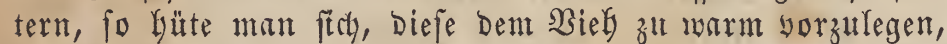
fondern laffe fie zerqueticht 24 Stunden lange liegen, it weldhem Falle fte audh melyr mäten follen. Bjebörrt, ge= fordoten, mit anderem Futter bermifat und etmas gefalzen futid fie Dem 2 Biely befonders bientich, wenn es you grünen

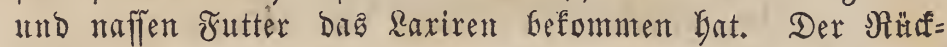
ftand yon ber Branntwein =, Miefl = und Stärfebereitung mit bäffer vermifyt fann ebenfalls als ein fefr gutes and

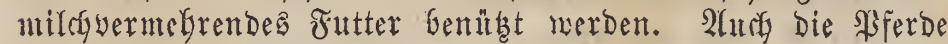
gebeifen fichtlich bei ber Sartuffelfütterung; man vernifdyt

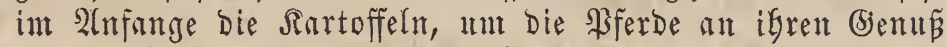

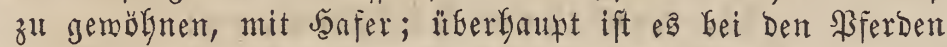
rathfan, zwifhen bie Rartoffefn Ginein yon Seit zul Seit wieber Safafer zu füttern, Da fie yon Der zu lange fortgefebten

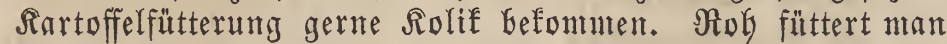
fie Den 3 ferben in Berbindung mit $\mathfrak{R}$ fete; ant liebften freffen fie bie Sartoffeln gebörrt und ift ifgen bies auth am zuträglichften, wenn fïe Dabei fleiß̄ig getränft merben. Den Safafen befagt im 2(nfange die Sartoffelfütterung auch nidyt befonders, fe freffen fie aber fpäter gerne, befonders zerichnitten, mit Salz, Sileie und Jeeu ober Stroh gemifort, merben dabei fett und liefern viel Wrolle. Siegen foll man nicht affein mit roben Rartoffeln füttern, meil fulche die Milley räfferig mathen und berfelben einen unangenebmen

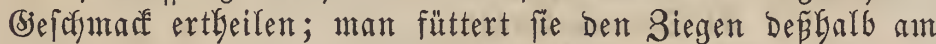
Geften gebört und mit Mähren bermengt. Sefweine mer= Den won Den Rartoffeln Gald fett, Gefonders wenn fie ifnen

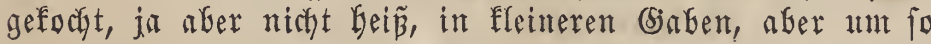
ofter, ober gebörrt oder gefdroten tmb mit einem 8 ufake yon Mübren jefüttert merben. Werben übrigenz bie Sritweine rein mit Rartoffeln gemäftet, fo erbält igr ซett feine ซofeftig= feit; man mäftet fite Depharle in Der lebten Beit bor Dem

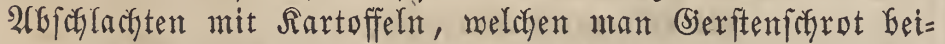
gemifact hat, ober man anterläpt noch befier zulest bie Rirr=

Enfwer, béonom. Pffnnzenfunde.

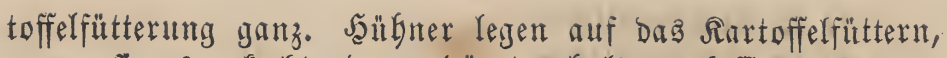
wenn fee es gefocfit ober gebörrt erbalten, beffer und wer=

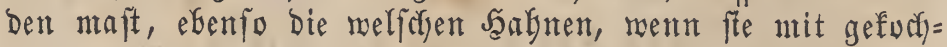
ten zerbrüften und mit Schrot wermengten Rartoffeln ge= füttert merben. Enten, bejonders junge, gebeifen bei bem (jemuffe geforbter Rartoffeln auperorbentlicf) fajnelf. Db= gleidf) (sänfe Die Rartoffeln auch roh gerne freffen, fo ge= lingt bie Maftung Dorf Geffer, memn foldye mit gefordent und mit Safer yermifest worden find, Gefonders wenu fie mit Noggenmegl und Sifrot und in Der Form ban Nubeln geftopft merden. (5ebörrt oder gefocht mit etmas 2 niz be= förbern bie Rartoffeln Das Brüten Der Tauben. 2(uc) für Fifche, mie Schleien, Sectite, befonders aber Sarpfen find bie geforbten Rartoffeln ein fegr gutes und fettntachendes Futter.

Die Rartoffeln Gefithen antifcorbutifoge Sä̈fte und füto Dafer auf Srgiffen ein fegr ermünfdgtes und gefundes Saly= rungsimittel; man mendet tie ferner als fullendes und fogmerzftiffendes Mittel gegen verbrannte beantitellen an.

Das Rartoffelfraut wird in mandyen Biegenden, wie

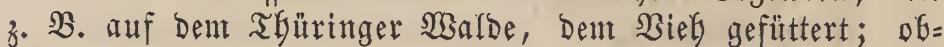

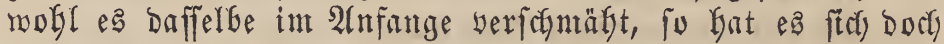
Galb Daran gemöhnt, und es ift folches bei fonitigent ơnter= mangel Durcfaus nicht zu berwerfen; man gift es bem Bieke feiner Gebeutend urintreifenden SBirfung rogen mit anberem שutter vermifont; fegr gerne aber freffen bie Schafe Das gebörrte Sirnut. Seines ftarfen Raligelialta megen be= nübt man Das Rraut auch zur \$otafifenbereitung, in Schme= Den mird Tabaf baraug bereitet, int Hebrigen zur Streu, zur Bermekrung Des Dunges ober alfein zum Dinnjen ber Felber utmo zur Feutung.

Ratban Gereitete aus Den Gtengeln Der Gartoffeln ein

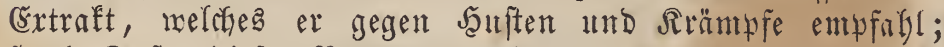
ftarfe Dofen biefes Priparatô inirften mie Dpium.

Die Früchte ober Beeren fönten mit Bortheil Den Schweinen gefüttert und ala eine febr gute Sothlichte in ber Sheberei benutht werden. Die Samenfüner entfalten biel Del. ZuẼer biefen mannigfaltigen $\mathfrak{B}$ ortbeifen, bie man aแ

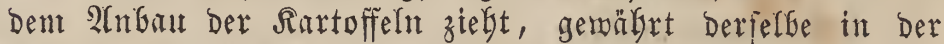
Feldruirthicfaft noch Den bebeutenden Naten, dar ex Den Boden, bejonderś einen fegr binbigen, ftrengen, berunfrau= teten, vernachläpigten, einen Shaideboden, Neubruch zc. yer= Gefiert, indem er Denfelfen auflorfert, mürbe mactit, feine adeferfrume vertieft und zur Aufnabme jeder zolgefrudst empfünglich macht.

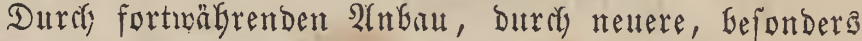
aus SImerifa Gejugene Rartoffeln, Durd) Fortpffanzung burd) Samen ift man nach und nacly in ben Befts einer faft zabl= lufen Mentge yon Barietäten gefommen, bie fitis in Bezie= Gung auf Farbe und Form Der Blütben, Deş Rrauteŝ, Der

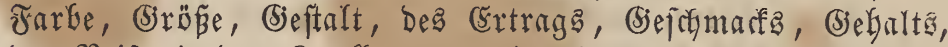
Der Feifezeit Der Fnollen yon einander unterfaciden. Man Gat bieje Sarietäten auf fehr berjobedene $23 e i f e n$ eingetfeilt und bie eben angegebenen bibergirenden Merfunate Der Rar= toffeln als Ëintfeilungągründe Genüht.

\section{Nach Der (beftalt Der ßflanze:}

a) in eimftenglicfte,

b) in vielfitenglichte, 
c) in fleinftenglidete,

d) in gropiftenglichte.

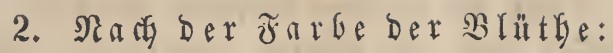
a) in wein Glülyende,
b) in fleifdyfarbig Glitgende,
c) in roth Glübende,
d) in berfGiau Glübende,
e) in Dunfelblau blülyende,
f) in afodgrau Glühende.

3. Nach Der (b) eftalt ber Rnorren:
a) in runbe ober $2(e p$ felfartoffeln,
b) in Greitgebrürofte ober Scymämme,
c) in länglicţe,
d) in lange ober Măupe,
e) in Gornfürmige,
f) in gurfenförmige,
g) in tantenzaหfenförmige,
h) in nierenförmige,
i) in Gübererige,
k) mit najenartigen 2(muน̆tyjen.

4. Nad ber Befdaffenleit ber Sryale:
a) in Dünnfichalige,
b) in biaffictalige,
c) in glattjofalige,
d) in raufctalige.

\section{Nad der Farbe der Gifale:}

a) in einfarbige:
a) iveif́e,
B) gelfe,
ג) rothe,
ס) Slaue,
ع) grüne,
ל) jofmarze:

b) in melgrarbige:
a) rotbgeffecte,
B) Glaugeffecfte,
ג) rothgeftreifte,

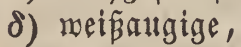

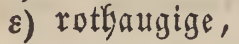
६) purpuraugige.

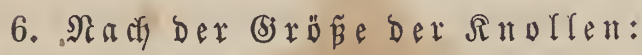

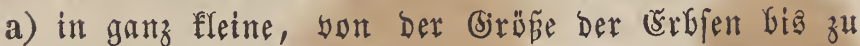

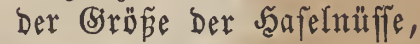

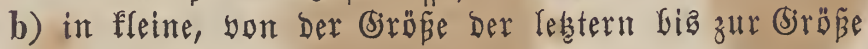
Desิ J̦olzatfelä,

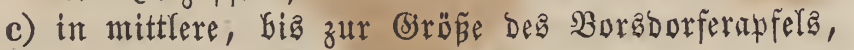

d) in größzere, bis zur Steintettest = (5iröß̈e,

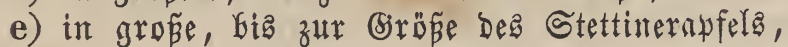

f) in $\mathfrak{g a n z}=$ ober fauftgropere,

g) in enorm groß̧e, yon Der Ränge yon 18 3ad, ber

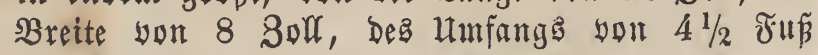

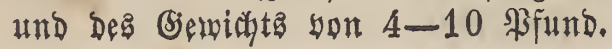

7. Naad ber innexn Beferafienteit:
a) in recicfe,
b) in Garte,
c) in troffene,
d) in mä
e) in ichliffige,
f) in meflige,
g) in meiñffeifchige,
h) in gelbfleiffrige,
i) in rotbfleipchige,
k) in Glaufleif́chige,
l) in reiñfleifogige mit rotgen Fflesten,

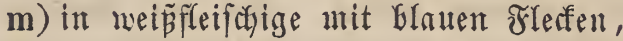

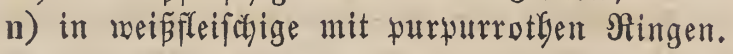

8. Nach de m (5) ef if $m a \mathfrak{a} e$ :
a) in molylichmectende,
b) in nittelmäbig formadfyafte,

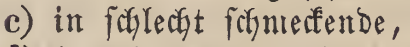
d) in miberwärtig, fü
e) in mildernd finmeffende.

9. Na if ifrer Ergiebigfeit:
a) in arme, 1-5 Sinollent tragende,
b) in beffere, 6-10 Stüt,
c) in ergiefige, 10-20 Stürf,
d) in reiche, $30-50$ Stuif,
e) in fefr reicfye, 50-100 Stünf,
f) in auperorbentlich reiche, 100-200 Stücf.

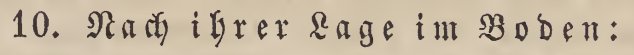
a) in eng liegentide,
b) in weitläufig liegende,
c) in ffact liegentie,
d) in tief liegentoe.

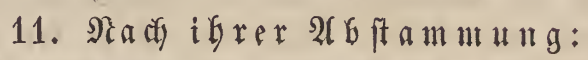
a) in uriprüngliche,
b) in augageartete,
c) in einbeimifache,
d) itt frembe,
e) aแs Seb̧lingen gezogene,
f) aนs Samen gezogene;

voer auch nach ber biegend, alls ber fie bezogen find:

a) in Europäifacte:
a) Ënglifche,

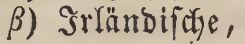
ג) Bseipberger,
ס) Donners̄berger;

b) in $\mathfrak{A}$ merifanijacte:
a) Surinantiface,

в) Beruanifate.

12. Nad ihrex $\mathfrak{B}$ exwendung:

a) in Rüchen $=$ ober Speife $=$ Sartoffern;

bielger gefören:

bie edle gelfe Rartoffel,

bie gelfe Jrübertoffer, 
Surferfartoffer, Sleine Nunfantuffel, Erobeerfartoffel, Sifottländer Rartoffel;

b) in Futterfartoffelu:

Die Jeowards oder Biegfartoffel,

bie englifuche Rartoffel,

Rercyenfartoffel,

Beruaniforye Rartoffeln;

c) 3ut teituitifyen 3meffen:

a) zum Brantweinbrennen,

Beruanifine Sartoffeln,

Bivitterfartoffel,

(5)urfentartoffel,

Englifine Sartoffeln;

ß) zu Mebl = und Stärfebereitung,

Englifche Sartoffeln,

Rerchenfortoffeln,

Seruanifore Rartoffeln.

(ே̌ndict)

13. Nach ber 3 eit igrer Reife:

a) it Frübfartoffeln, แ110

b) in Spătfartoffeln;

weldy) Yegtere Ěintfyeilung wir als bie einfardyfte und fityerfte beibekalten rollen.

\section{A. Ftithéntoffelut.}

Die Friblentoffeln werben Gauptfächlich als Speifefar= toffeln bentilbt; einige von ifuen fönnen in einem Gommer wobl zweintal auf einem 2lder angebaut werben. Sie reifen you 2ufange Sull's bis Ěnde 2 (ugufts.

\section{Nothe snübkartoffel.}

Rothe Şornfartoffer. Corne de vache.

Sitollen langgeftrefft, meift in Der Mitte gefrünmt utid baburch Gornfürmig, oft aucl gerabe und zapfenartig, mit meift folbig verbirften sinfen und finf fpibigen Nabel= ende, mit zaglreidjen, nicyt Gefonders tief liegenden, mit

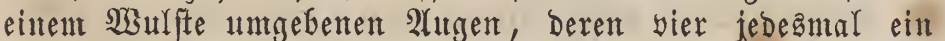
Siererf bilden. Die Sagale ift oft etwas bief und rauly,

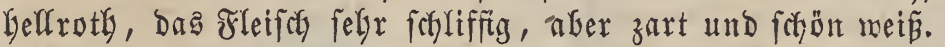
Stengel bünn, eifig, runb, furzfnotig unb befaart, grün unb purpurroth angeflogen, Der Blattftiel fleiner als bie

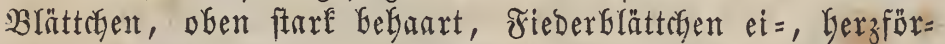
mig, rumzlich, meip̧begart, bben lebbaft grün. Der Blu= menftiel ift zart, bie Blumen find reis.

Diefe אarrtoffel ift bie frübefte Gorte und ift gegen

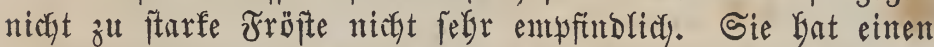
febr angenefuten befdrmadf, ift aber nicht ergiebig.

\section{2. (Gelbe Erübkartoffel.} îpfel.

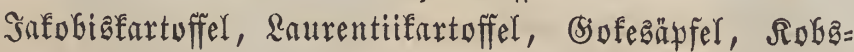

Inollen ntittelgrop, lang, walzenfürmig, oft tannen= zapfenartig, mit entweber wlatt oder vertieft ftbendem Nabel,

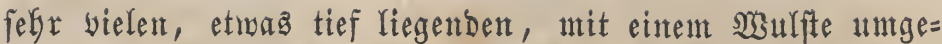

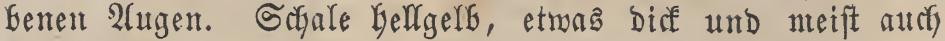

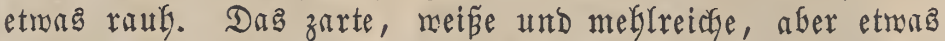
trocfene Fleifch focht fich Gald weich, mirb aber wieber hart, wenn man bie Rartoffeln in ber Schale fitelen läpt. Sten= gel gebogen, äftig, ziemlich glatt, bie Fieberblättusen ei=, herzförmig, eben und langgeftielt, bie oberften mit welfen=

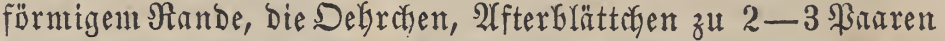
ftebend, Kerzförmig. Blïthenftiel fegr lang; Reldy 5theilig,

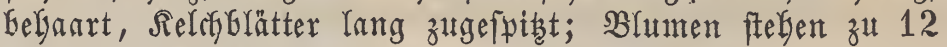

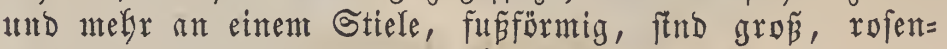
roth mit meínen Spiten und Gaben einen ftarfen fü fen (S)= rud); Staubeutel furz.

Man fann bieje Rartoffel gemöbnlich im Эuli unt Safobi, ober im 2tuguti um Raurentii ernten. Der Ertrag

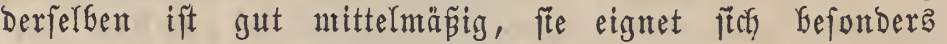
zur Fortpflangung burdy Stengelaffednitte. Sefüeter Samen

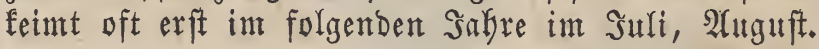

\section{Dlatte weike Srühkartoffel.}

J̧erzfartoffel, Schiffałartoffel. Golden Galleons.

Knolfen ziemlich grof́, meift eifürmig, plattgebrürft, Nafel am fpisen Ënbe nur oberffächlich ober wentig vertieft fithend, 2(ugen mentige und zerftreut ftefend, flact) ober wenig vertieft liegend und mit einent etras erbabenten Ringe unt= geben; Die Schale bünn und gelblich meí̈; Stengel nieber und liegend, zart, melfenförntig geflügelt, röthlich; Blättctien

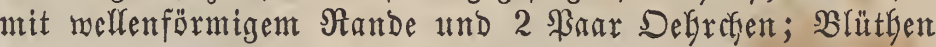
afdggrau, etwas rötglich fótumternd.

Sie giff einen etwas ftärfern Esrtring, ala die gelfe Frübfartoffel. In Der Sajale gefocht, wird biefe Sartoffel mäfferig, gibt aber gefdălt ein moblformerfendes Bentüfe.

\section{Pismut-fantorftel.}

Wurzelfnolfen rund, etrons effig, mit gewöbnlidy felgr wertieftem Nabel, febr wenigen und bauptfäblich aut Nafen= ende liegenden 2lugen; lebstere liegen etwag bertieft, bie ant Nabel poer in ber Mitte ber Rnollen befindlicyen bingegen flact und find mit einem platten Galbumondö̈rmigen Wulfte umgeben. Die Gafale ift gelblich, am $\mathfrak{R a j e n}=$ und $\mathfrak{N a b e l}=$ ende rötglich, welche Frarbe bie ganze Sunolfe an ber suft und bnourch ein negfürntiges 2(nfefen erfält. Stengel fegr Yoch, breifuntig, weffenförmig, frauz uno häutig gerändert; bie Sinoten roth getupfelt; Blattitiele tief und roth gefuregt;

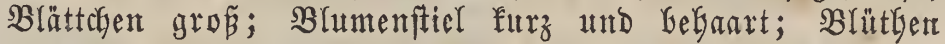
gipfelftändig, pfirfedyblutroth mit weiß̈lidyen Spiken.

Ěrtrag nuttelmä̧ig. Dieje Sartoffel ift febr molgl= fameffend und wirb bauptäarflich zu feinern Sorten Bact= werfs werwentoet.

\section{Gurkenkartoffel.}

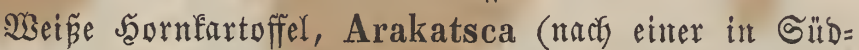

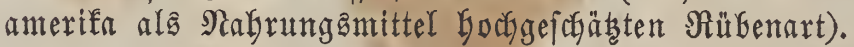

Wurzelfnolfen meift Ianggeftrefft, gegen bas eine Ende

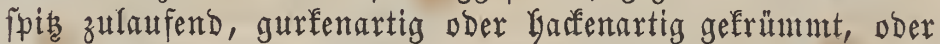
auch gegliebert, eidfelförmig, mit wenigen fefr flach liegen= Den, oft undeutlichen $\mathfrak{A}$ ugen. Die Schale ift zart und blä́二

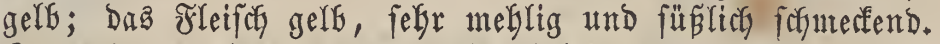
Stengel zart, feffwach, erfig, oben beblättert, grün; Blättchen 
aII Mande wellen = ober Yuffelförntig, bie brei oberften ftud Die größ̈ten, bie unterfter Gilden vft nur Defrechen.

Die Sinoffen liegen unt Den Seatptftengel gebäuft mit Dem fpibigen Ernde an Der 2 Gurzel nady unten in Bobert. Da bie Saornfartoffel mit Dem ftumbfen (Ende ftch gerne aus Dem Boben Gerausanadyt und Daburch bie Rartoffel eine

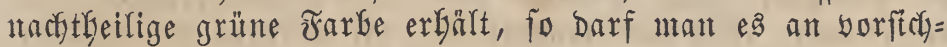
tigem $\mathfrak{B e h a ̈ u f e l n ~ n i e ~ f e g l e n ~ l a f f e n . ~ D i e ~ B u r f e n f a r t o f f e l ~ r e i f t ~}$ 2lnfang 2(ugufte, gibt einen anfefnlichen (Ěrtrag und eignet fitc) vorzugämeife zur Branntweinfabrifation.

\section{Schwarze fantoffel.} (entgl.).

Regerfartoffel, violette Golländiface Rartoffel. Chesnut

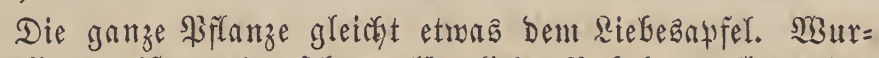
zelfuollen meift rund, feltuer längliç; Nabel nur ffach voer faum etrons vertieft fthend; bie vielen 2 atgen fiben tief und

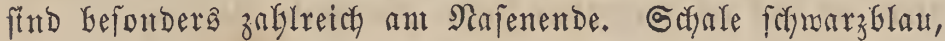

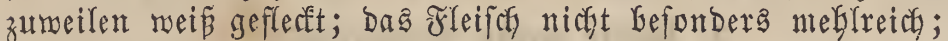
Stengel fotwach nieberliegend, äftig, ecfig, glatt, grau, un= ten Dunfelfraun; Blätter flein, etwas breit, eifürmig, run= zelig, mollig und etwas befanat, mit 2-3 \$anr Defrecyen; Blüthentiel furz, purpurroth; Blütben gipfelftändig, flein, biolett, mit von ben کtaubbenteln eingeichloffenem Siriffel.

Sie vermefrt fich yon felgft Durch Samen, und bie sinollen zeitigen 2 nfangs 2lugufts. Der Ertrag ift gering; ifr. (jefchmarf yerbeffert fict) erft gegen Dftern, indem fie unter fämmtliçen Rartoffelforten an längiten gut Gleibt. Sie mird Gauptächlich zur Biebfütterung benübt.

\section{Rotbblau marmorirte fartoffel.}

SirffGantfartoffel, bellGraume Sartoffel, SPfälzer Grund= Girne, Kirkham Marbles.

SWurzelfnolfen find zientich grof, rundlich und etwas Wlatt gebrürtt mit flach wertieftem Nabel, menigen, meift flady

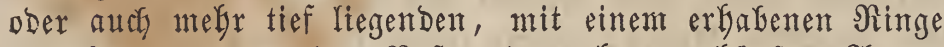
ungebener, gegen baz Nafentende mebr angebäuften $\mathfrak{Z}$ ugen und graurotber Sable, bie in Der Ruft oft bläulich mirb und oft gelblich gebändert ift. Das Fleifach ift meglreich. Stengel Dreifantig und an Den untern Santen fraus und bäutig gef(ügelt und gleidy bünn. B̉attftiel etmens bebaart, Blättâten grof́, eiförmig, flach, Geflgrün, yon ben 2 Banr Defrchen find bie yorbern Gejonders grof. Brä̈tgenftiele GefGart; bie Blüthen afdyfarbig, in's Bläuliche fpielend.

Sie zeitigt (Ende Suli's ober $\mathfrak{A}$ nfangs 2 tugufts und ift jebr ergiebig.

\section{S. Dfälzex frühe bellrotbe fiartoffel.}

\$ommer'fitje Nubel.

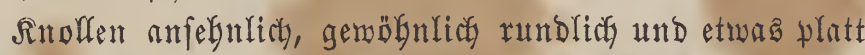
gebrürft, zumeilen mit zikenförntigent Nafenende. Sabel meift platt; bie menigen 2 ugen nicht jonberlich bertieft. Schale

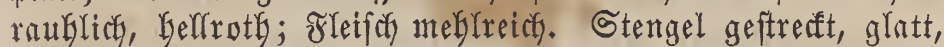
geflügelt und gezalgnt fantig, grün. Blattftiele geftrecft. Blättchen welfenförmig gefaltet = gerändert, matt Dunfelgrün, mit einem $\mathfrak{F a a r}$ gegenüber oder abrectielnd ftelgenden Degr= chen, Deren eines oft feglt.

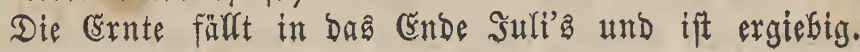

Bleigt biefe Rartoffel zu lange im Boben, und tritt feuctete Witterung ein, fo treift fie neue Sinollent.

\section{Geifisberger fartoffel.}

Nodfáfartuffel am Rbeine, Sidonifdye Rartoffel.

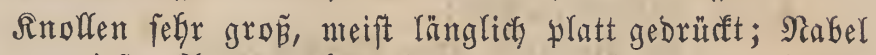

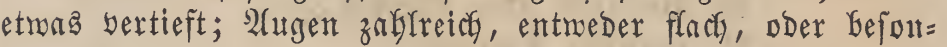
Ders am গafenende etwas verfenft, oder audy ergögt ftefend.

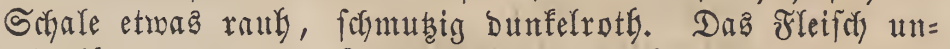
mittelfar unter ber Schale föno Glutroth, ziemlich meblig. Stengel gerade, geflügelt, roth marmorirt. Bhlätter mit un= gleidyer Baf̣ts, meflenfürmigem Pinnd und 1 ober 2 Saar abrechfelnd ftelyenden. 2lfterblättrfen. Blattftiel unten be= banrt.

Der Errtrag ift fegr reichlicf); Der (Sefchutade wirb baupt= fächlich gegen Das Frutbjabr fint gut, wo fie mefilreicher wirb,

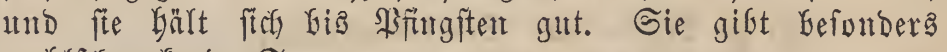
moblichmerfende Suphen.

\section{Rotbe gelbe fartoffel.}

Sammetfartoffel, gute Rartoffel, Rordafartoffel, Secren= firtoffel, edle Sartoffel, gelge Sartoffel, edle gelbe Ratudifel.

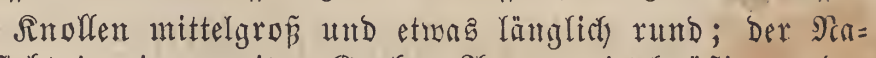
bel fteft in eimer meiten (Srube; Ahgen mittelmäfig an Der Bafl, etwas wertieft ftefend; Schale rauly, gelf. Flejich meblreich. Stengel geftresft, glitt, breifantig, geflügelt, grün, Die Ranten oben welfenforntig befaart. Blattftiel fparfan

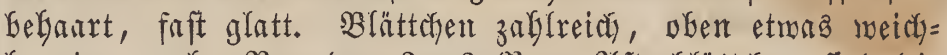

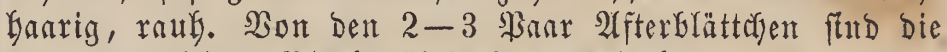

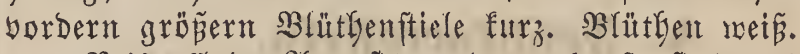

Reift (צnde 2 ugufts und macht fouft Den Hebergang yon Den Früb = zu Den Spätfartoffeln. (Ertrag münfchensิ= werth. Siefchmadf febr angenelgm.

\section{Spätertoffelu.}

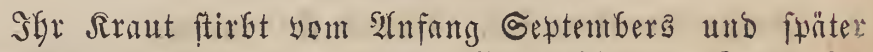
ober audf gar nicht ab. Die Snolfent reifent int Septentber ober Dftober.

\section{1. ferchenkartoffel.}

Waurzelfuoffen groź, etwas wlatt, rund ober lintgrig.

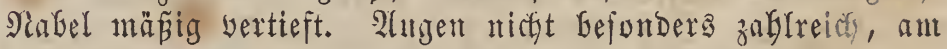
Gäufigften am Nafenende, etmas tief ftebend. Daz siafmende etwas zur Seite gebränt; Schale etmas raub, beffgels.

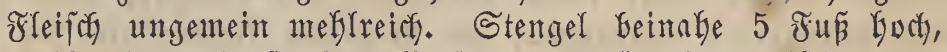
Dreifantig und ftarf melfenfürmig geflügelt, zwifchen ben Flügelanfäben unten rotblyraun gefferft ober gendert. Blätter

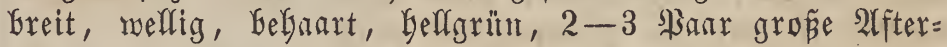

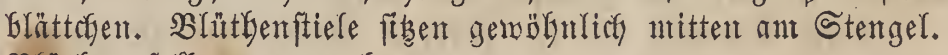
Blüttyen fallen gerne ab.

Die Rerchenfartoffel ift feht ergiebig und wohlfismerfend.

\section{2. Ërobeexliaxtoffel.}

Whurzelfnulfen mittelgró, rund, etwas platt gedrüift. Nabel in eimer flachen (Sirube ftehend. Slugen wenig, etwas tief fthento. Scyale fegr zart, Gellroth. Frleifach gelb, fegr meblreicty. Stengel exft liegend, Dann fith aufrichtend, brei= 


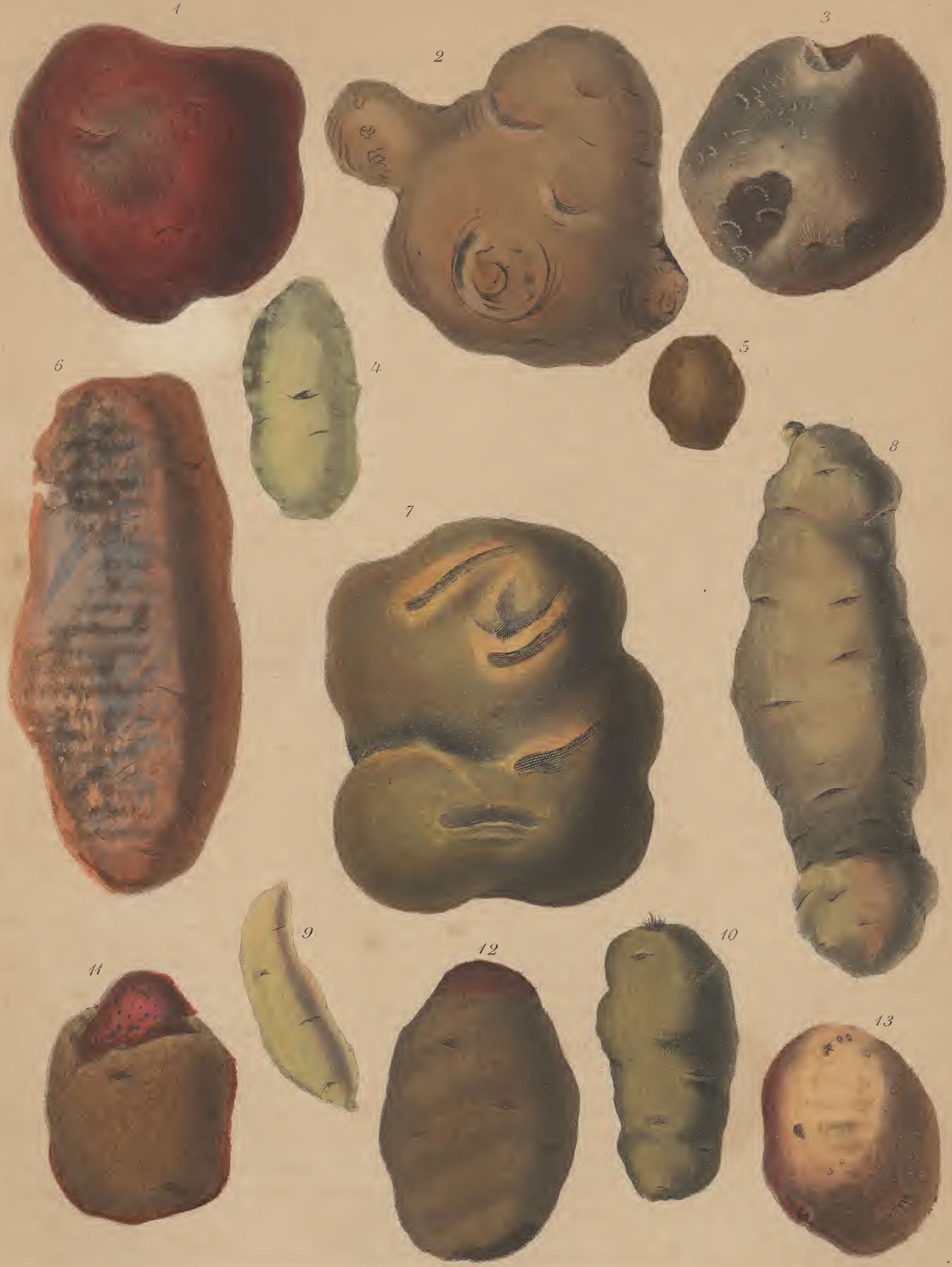





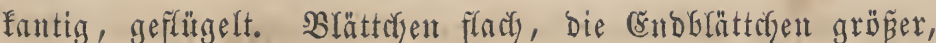
verfegrt = eiförmig, zugefwibt. 2lfterblättchen feglen meift oder find einparig. SBlütbenftiel flein. Blätgen fparfam, yfirfict)blïthfarbig.

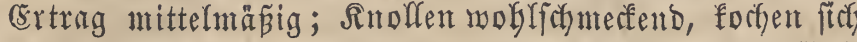

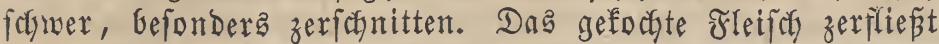
auf Der Sunge. Bute Rächenfartoffeln.

\section{Gute Spei rekartoffel.}

\section{Boเ ติ่orferäpfel = Iartoffel.}

Snolfen vft faum mitfelgroź, Geinahe fugelförmig, bie

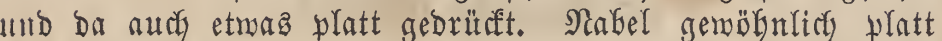
voer nur in einer flacten Esrube fthend. Die menigen $2(u=$ gen befinben ftet in fleinen, tiefen Brnben. Die Schale glutt, tefr fein und fodmutig gelf. Stengel beinabe Drei= fantig; bie Jlügelanfäbe laufen gerabe am Stengel Gerab utid fitto fochunale Blättchen, eiförntig= runblich, yor ber Blüthe ausgefg̈hlt, efenfo bie runblich Gerzförmigen 2 ffter= Glättcuen. Blumentiele verlängert, rund und zwifchen ben oben firfy befindenden zwei Furchen ftarf behanrt; Reley ge= fwalten. SBlütben büfchelweife, of́t zu 24 ftehend, weís.

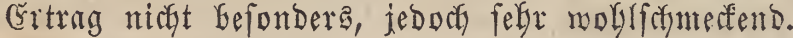

\section{Breis vom follano.}

(Finige balten bieje für eine Spielart ber Burferfartoffel.

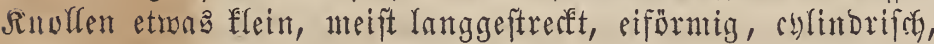
mit plattintsendeut Nabel, zaflreichen, entweder flach ober megr vertieft liegenden and mit flarben 23 ulfte umgebenen 2lugen. Solghe etwas rauly, Glägelb. Stengel folmach, etıoñ niebrig, breifantig, roenig geflügelt, bebaart. B̉ätter weitläufig ftekend, Gellgrün, ein \$aar 2(fterblättchen, bie oft ganz feblen. SBlüthenftiele etwas lang. B̧lütge brau.

Die Rnolfen find fefra molfidymerient.

\section{Dreir vom mefterwalo.}

STurzelfnollen oft flein, rund. Nabel in flacter Girube. 2lugen nicht viele und mäßig vertieft ftebend. Sildale febr raub, wfelroth, und eine weitere unter ifr liegende foün rotbe und wrispunftirte. Stengel aufrect, breifantig, nut Gier und ba etwas befaart, mit etwas aujgetriebenen, Grenn= rotGen Rnoten. BBlattftiele langhanrig. Blättchen eiförmig, runzlis, etras mollig bebart, bie untern etraz fleiner. Die afterblättrfen einparig, abmectfelnd ftefend, Deren gräsere mefr rund find; tiefer ftegt oft noch ein brittea, viel ffeineres. SBlüthenftiel furz. B̧lüthen flein, zu 8-10 fitefent, Gell lifa.

Der Errtrag Diefer Sorte ift gut; fie treibt oft fehr

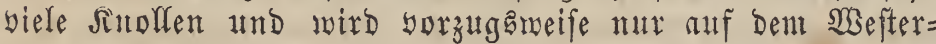
walde angebaut.

\section{Bwiebelkaxtoffel.} de bocuf.

Zniebelfarale, Daffenzunge. Pelure d'oignon, Langue

SGatrzelfnollen meift Girnfürntg, bie jüngern megr rund und cylinbrifoch. Nabel etwas bertieft, und die zablreichen Augen fegr tief fthend and of́t mit beulenartigen Wülften umgeben. Gchale gegen bie Nafe Kin Glau, gegen Den Nabel

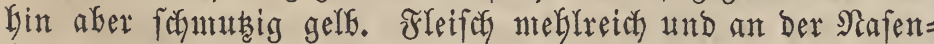

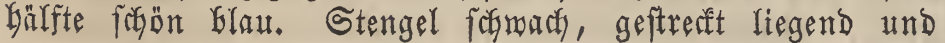

an Den Erfen unumerflidy, aber fdyarf geflügelt, unten fpar= fam beblättert. Blättchen ei=, Gerzförmig, ober runolids, eimander Gerüfrend, Gellgrün. 2rfterblättctsen einpaarig ober fleiner und einzeln ftegend. Blumentitel baarig. Blüthen zu 5, feitwärts ftełend, Dunfelsiolett blau.

Gine edle Sorte.

\section{Meize fartoffel.}

Snoffen oft felsr grof́, rund. Sarbel wlatt oder ver= tieft und eng fithend. Die wenigen 2(ugen fteben mäß̈ig ver=

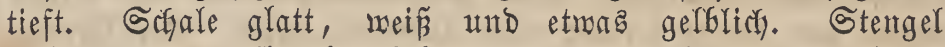
wellenfürntg geflügelt, behaart, an Den zlügeln zerftreut voth getupfelt. Balattfitiele ganz mit 2ifterblättchen befebt. Blättchen eben, an Der Bafta ungleidy Gerzförmig, bebaart.

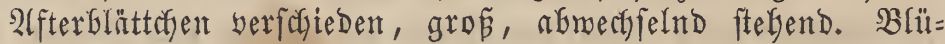

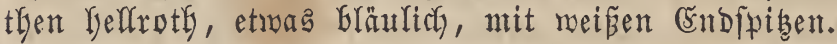

Ěrtrag reichlich, (befichmad jebr anjenefyn.

\section{Kidney Potatoes.}

\section{Anuge rothe Aterenkartoffel.}

Snollen langgeftreift, chlinbrifó, bie fleinern mit ipiki= gen Nabeln und berbiftem Nafenende. Nabel an irgend eimer Errböbung entweder flatt ober mur ffact vertieft fisend. 2qugen zaklreich, in mäpig tiefen (s)rübchen. Fletich fehr

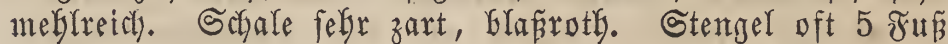
Goch, ausgebreitet, fochach, nieberliegend, unten nafft, ftumbf= fantig. Snoten ftarf aufgetrieben und gefniet. Blättchen

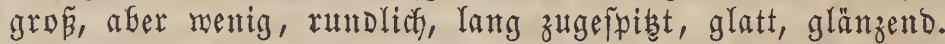
afferblättçen ein $=$, weniger Gäuftg zweipaarig. Brlüthen flein, 10 an ber $3 \mathfrak{a} \mathfrak{d}$, einmärts gefogen, rötglicf.

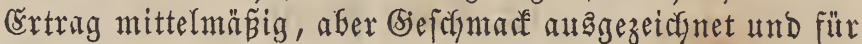
Die Rä̈be und zu feinen $B$ adfwerfen yorzüglicf.

\section{Budiexkaxtoffel.}

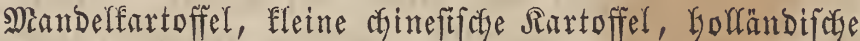
Rartoffel, Sonmerzuderfintoffel, fleine meiß̈e Rartuffel.

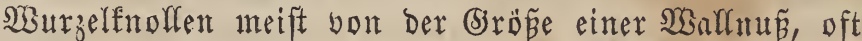

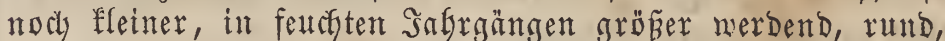
ober länglidy und chlindrifơ, auch fpisig zulaufend, in naffen sahrgängen monftrös mit platt fetsendent $\mathfrak{N a b e r , ~ z a b l r e i c y e n , ~}$ febr bertieften und mit erbobenen $\mathfrak{S B}_{\mathrm{B}}$ ften umgebenen $2 \mathfrak{A}=$

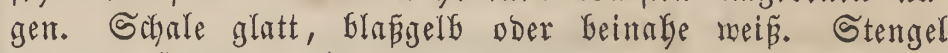
liegend, formadf geflügelt, zrwifdyen Den Fnoten mur furze snterballen. Blättchen etwaz flein, eben, runzliç, an ber Baft马 ungleich, bellgrün. SY ferterblättchen flein, einpaarig, ober auct nur einzeln yorbanden. B̧ütGenftiele zart, etwas gefogen. Reldfeinfdrnitte eif̈rntig, zugefpitst, am Rande Gäutig unb befanart. Blüthen bidyt bufchelförmig, an ben Spiben befarat, fajön blau; Staubbeutel furz Ind fonifas. Sefr ergiebig. (jefdymarf febr angenefm, mandelartig. Sie machen Suppen und Den Robl, anftatt Der Sinfanien beigejegt, fehr moblfagnterfent.

\section{Fileine Sidottlänoex fantoffel.}

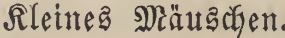

Rnolfen langgeftreift und etwas gefrünmt, viele fefr flein; grö̈ê, uft 3 3oll lang werben fte in fandigem Rehmboben, fleiner in reinent Sanbboben. Nabel auf ber Spibe glatt fthend. Alugen fegr fparjam und fegr flein. 


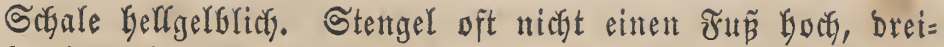
fantig, glatt, Graun gefleceft und getupfelt, oben frauś, unten unmerfliç geflügelt. Blattfitele furz, glatt. Blättchen berz= förmig, eben, etwas fleifcyig, beffgrün, unten etwas bebaart. afferblättchen zweiparig. B̉lüthenftiele geftrefft, yon einan= ber entfernt ftelgend. Blütben einmärta gebogen, gefaltet, Glaubiolett, ntit einmärts geridgteten, weišen und ausen be= baarten Spizen. Strubbeutel getrennt. Eriffel zart.

Die Snollen liegen felgr flact, afer auggebreitet im Boben und erforbern beint Seraumefmen in Der Ërnte megen ber vielen fleinen siel $\mathfrak{A}$ ufmerffamfeit. Der Ertrag ift ausigezeichnet und Der biefchutaf äuêerft angenefm.

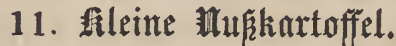

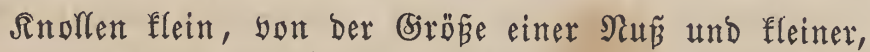
verfochieden geformt, meift rund, ober chlindrifes, ober firn= förmig. Nabel platt fibend. Die wenigen Alugen jteben an größzern Ěxemplaren twenig wertieft, an fleinern oft faum fitstbar. Safjale glatt, fehr zart, Glägelblidymeiz. Stengel fodrach, langgeftreft, glatt, grün, zweifantig, geflügelt, an Den Flügeln oben gezägnelt. Blattftiel Gebaart, ebenio bie Blättçen, und an Nande wellig. Die 2lfterflättchen zwei= warig. Blütbenftiel langgeftredt, befaart. Blüthen gefaltet, etwas ausgeb̆blt, Ganrig, bellblau. Staubbeutel getrennt.

Errtrag reichlich, inbent oft eine ungebeure Menge Sinollen an einem Storfe find. SGr befchma ift fegr an=

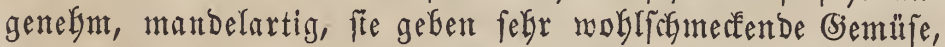
taugen übrigens, wegen ifrer geringen Sröpépe, nicht nofgr zu andern pfonomifgen Broeffert.

\section{Gélbe Matate.}

Murzelfuollen flein, felten etwas groź, rund ober Yäng= licy. Nabel platt oder etwas vertieft fthend. Altgen mittel= mäpitg an ber Babl und etruas tief ftebend. Schale glatt oder etwos rauty, Glapgelf. Stengel aufrect, breifantig, geflügelt, rötglicl). Blätter ei =, Gerfförmig, helfgrün. 2ffter=

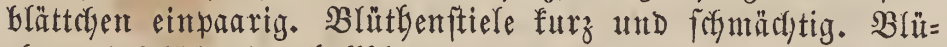
then givfeliftändig, Gellblau.

(je) fchma gat gut.

Beruanifuge Rartoffer.

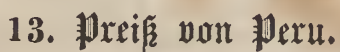

Sinolfen auperorbentlicy gropa, ofit 3 Sifund former, meift mefr rund als länglich, etmas platt gebrüsft, oft Durch Aanüclye momftrös geftaltet. Nabel etwaz sertieft. Alugen zablreidy in ftarfen Sertiefungen liegend, von beulen= artigen Erböbungen umgeben. Schale helfgelb. Stengel glatt, nur felten oben baarig, berfümmert geflügelt, grün.

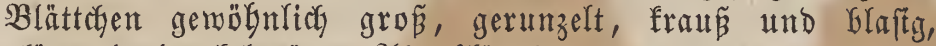
glänzend bunfelgrün. Alfterblättctyen zmeiparrig, ungleicts, abrwechfelnd ftebend. Blatthe weislich.

Itngentein ergiebig. (rigutet ferb ifres ftarfen $\mathfrak{N e b l g e =}$ Galts wegen befonders zur Stärfefabrifation.

\section{Gelbe Bapfenkartoffel.}

Tannenzayfenfartoffel (Brandenburg). 2(nanaŝfartuffel.

Sinolfen lang, vft $6-7$, 0 ll lang und fpiben fich ge= gen bas eine Ende zu, bäufig mehrere zujammengemachfen und ein Iateinifaces $\mathbf{T}$ ober ein Sireuz Gildend. Nabel theils
Wlatt, theils allf einer wargligen Errbabenbeit fthent. Die 2lugen febr zablreich, tief liegend und won einent Fleifich = wulfte untebent. Schale an Siafenende etwas rauly, gegen Den Nabel Yin glatt, Glapgelf, int Boben oft röthlidy ange= flogen. Stengel fafmintflig, fparfam und langbefaart, ge= zăhnt geflügelt, grün. Blattftiel belgarrt, oben ftärfer als

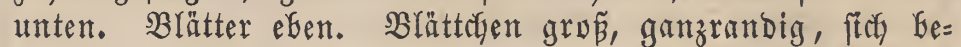

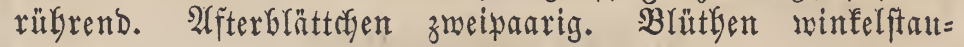
Dig, weiß.

(Ertrag reicslicty.

\section{Spaniridae fantoffel.}

(5ibraltarifache Rartoffel (in Scannoyer). Sleine gelb= liche wlatte Rartoffel.

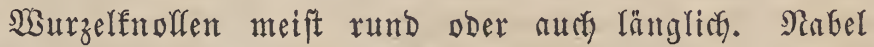
wentg berticft, und bie nicht zalglreichen 2 lugen entrweber ober= flact)lich, ober aber tief und unter eintem Fleipchroulfte fïkent.

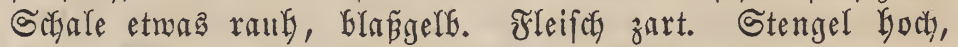
mit 3 frumfen und fyarfan braunrotg punftirten und ge= flerften Ranten. BBlättçyen Greit, länglich, Gelfgrün. Alfter= Glättchen zmeiparag.

Woblfctyntectend.

\section{EErglijche fintoffel.}

The Champion. Saannower'fore Sartoffer.

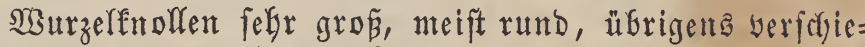
Den geformt, langgeftrecte, berz=, nierenfürnig und ausge = wactfen warzig. Nabel und bie bielen 2lugen tief liegent. Sedyale glatt, bellgelb. Stengel fein bebaart, wellenförmig, fraú geflügelt, grün; Blattfitiele lang, glatt. Die Blättchen yon einanber entfernt ftebend, nach oben an Bsrößze zunefy= mend. Affterblättefen zmeipaarig. Blüthenftiel zant, behaart. Blunten meí̄.

Der Ěrtrag biefer Sartoffelforte ift febr gut, oft cirt $20-30$ fältiger; fte ift auperorbentliç meflreich und eignet

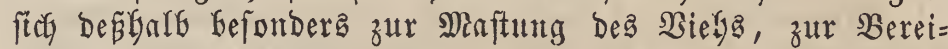
tung yon Stärfe und $\mathfrak{B r a n n t w e i n}$ und zun Brodbaffen. Sie eignet fith mur zunt Rithengebratche, wenn fie in fan= bigem Refunboden gefaut nurbe; in Glos lefmigtem $\mathfrak{B}$ oben wird ifr beftymade unangenelgm.

\section{Wüchefeloex fiaxtoffel.}

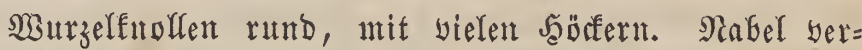
tieft, 2(ugen zaldreich, felgr tief liegend and unter bemt Fleiffywlifte werborgen. Schale etwas raub und riffig aus=

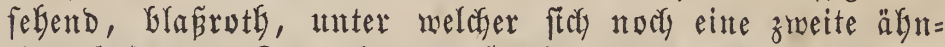

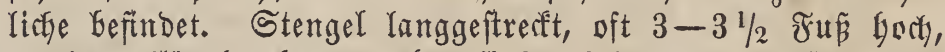
gerabe geflügelt, braunroth gefledt. Blätter ranggeftielt, be=

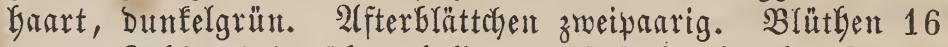

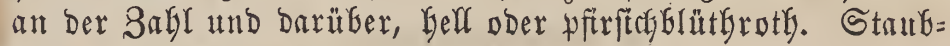
beutel ungleid, malzenförutig.

(Ertrag felgr reichlicty. Sie leidet wentiger ftarf Durdy ชrüblingsfröfte.

\section{Blaue runơ faxtoffel.}

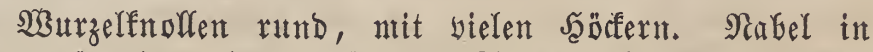
einer geräuntigen birube fitbent. 2lugen febr viele, regel=

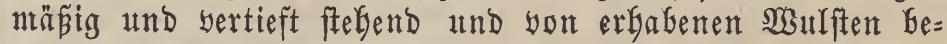
gränzt. Safale etras rauh, in ber (šrbe oft megr röthlidy, 
an ber $\mathfrak{L}_{\text {uft }}$ aber fadmulgig, oft faft fofmarzblau werbend. Sie gleichen bis alf ibre betrüchtlichere (Jröß̈e feGr viel Der Negerfartoffel. Die Rnolfen bängen traubenbeerenartig an Dent foropfigen Sisurzeln und breiten fith weit aus. Stengel langgeftrefft, unten Graunroth voer getupfelt. Sinoten in

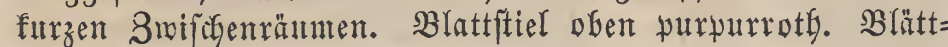
dhen breit, ei-berzförmig, vertieft, oben und unten beharart.

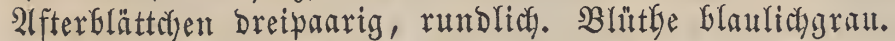

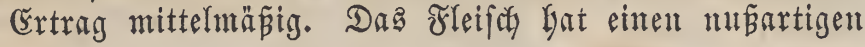
(bicidymakf.

\section{Slaue fornkartoffel.}

Snollen langgeitreeft, ober Gorn = ober gurfenartig ge= frümmt, mit berbicftem গaajen = und abgeftumpft fpiden Nabelende. Nabel gemögnlich platt fikend. Die wenigen 2lugen liegen in flacten, fleinen Bruben. Sdjale ant Najen= ende rauk, famubig Dunfer, beinabe fofmarzblau. Jleifoh

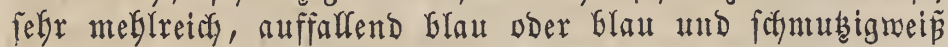
marmorirt, welche Farbe Durch's Sochen an Sntenftä̈t ge= minnt und meift Dunfelviolettblau wird. Stengel nieder, mit vielen foymächtigen 2leften, Graunruth, Gejonders an ber Bafts, gefurcft, gebogen, fraú geflügelt, bebart, gegen bie Hefte bin fich verbiffend. Die Jntervalfe furz; Brätter furz; Blättchen runzlich, befaart, Geflgrün, zumeilen গöffel=

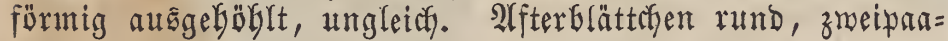
rig, ungleidy. SBlütben mein.

Sie foll aus \$eru abftanmen. (ङrtrag faum mittel= mäвig; meine $\mathfrak{B e r j u c f e ~ m i t ~ b i e j e r ~ א a r t o f f e l , ~ b i e ~ u n t e r ~ v e r = ~}$

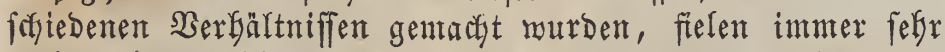
gering aus. Sie arten auch leidyt aus und werlieren in rein fandigent Buben eitten Theil ihres zrarbftoffá. Shr

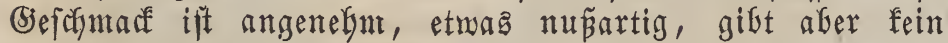
appetitlicfes Sientüfe. Man bat mit Dem biefer Sorte eige= nen Farbjtoffe berfogiedene Beuge gefärbt, alfein bie blaute Farbe bält fich nicht.

\section{Nommex idhe fartoffel.}

Rnolfen febr groß́, gewöhnlidy länger als rund, etron Whatt gedrürft, Göfferig und fich gegen Daz eine (Ende zu= fyikend, bie fleinern megr rund und mit weniger bemerf= Garen Erbähungen. Nabel jebr platt, und bie zahlreichen 2lugen felgr tiefliegend und unter den beulenartigen Fleifad = mulften verborgen. Schale falt glatt, Glapgelb. Stengel Dreifantig, wellig fraú and Gautig geftügelt, unten ver= bieft, mit aufgetriebenen Sinuten. SBlätter groṕ, won ein= ander entfernt ftekend, am Nande weflenförmig. 2ffterblätt=

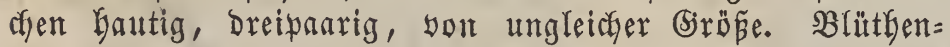
ftiel zart, fommt aus Der Mitte Deg Stengela. Blütben tratbenförntig ftebend, flein, abfällig, blaulidgroth. Staub= beutel verfümmert. lingşföptte.

(5rtrag felgr gut. Sie ift meniger empfindolich gegen Jrüb=

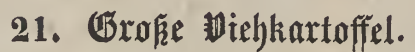

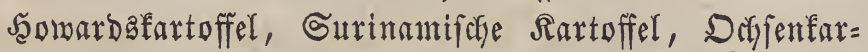
toffel, neuländijdge Rartoffel (yor Aiterä).

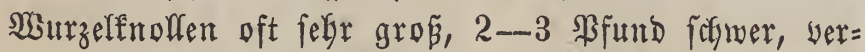
fochiebenartig geftaltet, länglich, rund, folbig berbiaft ober fpibig zulaufend, monftrös. Nabel liegt ftarf vertieft. Die zaflreichen $\mathfrak{2}$ ugen in einer ziemlity tiefen (8)rube, aus weldyer fie neift Glüthenfnoswenartig Gerborragen und Gejonders in

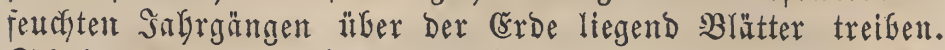
Schale zumeilen raub, fajt rifitg, Glaşgelb und auper bem

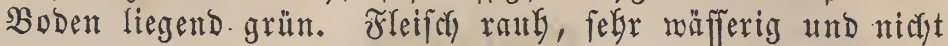
befonders neflig. Stengel einfach, befaart. Blattftiele in

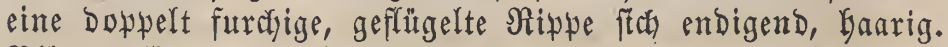

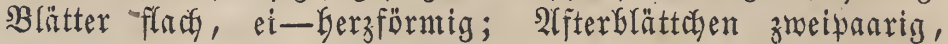
Deren obere gröper fün. SBlüthenftiel fo lang als bie Brät= ter. Die 2 lätter fteben zu 14-15 in einer Doldentraube und find hellroth.

Durch einen Matrofen lamen biefe Rartoffeln 1711 aus Surinam nach Erngland, wo fie zuerft yon einem Defonomen Howard in Badfordshire fultivirt murben.

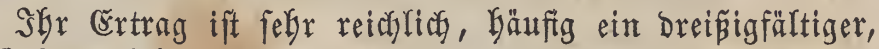

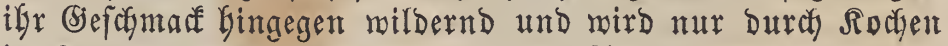
in Däntpfen und Durah 3 uface von 2 faje etmas verbeffert; aud in fandigem $\mathfrak{B}$ oben gebaut werden fie etwas milder. Mau benübt fie Defigalb Gauptfächlich zum Füttern und

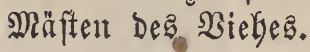

\section{Wilde Eartoffel.}

Bufdelfartoffel. Safyeinfartoffel. Traubenfartoffel. Clustre, Edhoble. Pomme de terre à vache, sauvage ou rustique.

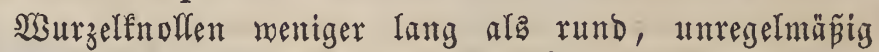

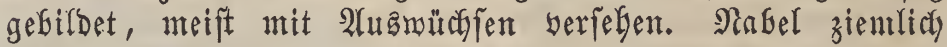
tief, feltener mur flady Yiegend. Schale, frifich aus ber (̌rbe genommen, beinalge feuerrotg, berbleicht aber an ber \&uft und mird gelbroth. 2(nt Nafenende oft nod) am ftärfften roth und raug. S2lut Nabelende glatt. Fleifac fehr mäfferig und mit rotben Ningen. Stengel 4 Fú gorf und Darüber, geflügelt, glatt, grün. Blätter grof́, langgeftielt, faft glatt. afferblättchen zmeipararig, oft ungleidf. Slätbenftiele in ber Mitte Des Stengela, malzenförmig, lang. Reldyeinfdynttte fpitzig - yfriemenförutig. Błhmen einzeln ftefend, belloth. Die Früchte faft fonifd

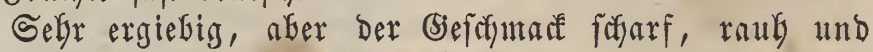
wildernd. Man Genüht fe megr als $\mathfrak{B i e b}$ futter und mit Bortheil zum Brantmeinbrenten.

\section{Bwitterkartoffel.}

Drakes - (5y-gre.

W3arzelfnolfen febr grofi, rund. Nabel flate. Die zabl= reichen 2lugen febr vertieft. Schale faft ganz glatt, nur

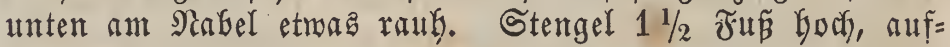
reçt, breifantig, geftügelt, etwas befaart, oben fafwach.

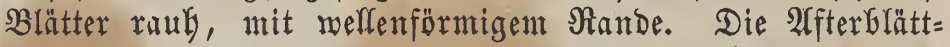
den Dreipanrig, mit grö̈ern vorbern. Blüthen zur Seite Des Stengels, abfälig, bellroth, etwas blau fojimmerno, mit wein̈en Spiken.

Ěrtrag reichlirg. (befdumarif effelfhaft und aud burdy Sieden im Dampfe nur wenig beffer werdend; eignen ftd

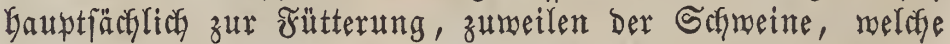
fie gerne freffen, und follen febr biel Branntwein geben.

24. \#oban'/che faxtoffel.

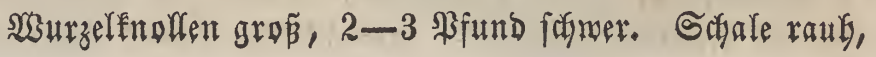




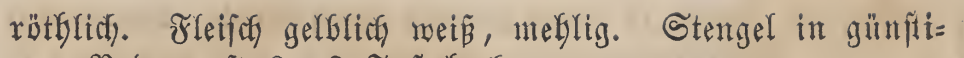
gem $\mathfrak{B}$ oden oft $6-8$ Fun hoif.

Der Ertrag febr gut, ebenjo der bejantarf.

\section{(3)efichte.}

Die Rartoffeln follen, jedoch nach fegr unftifern Nach=

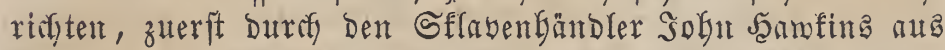

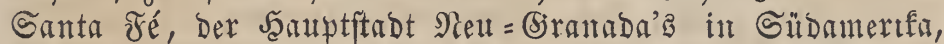
unb zrwar nach (Eirtigen im Jabre 1553 zuerft nach Spa= nien und yon ba nach Stalien, nach 2tmbern aber 1565 mach Srland gefradit, Dort aber Gald mieber vergeffen utio erft Durch 2ldmiral Waltber Naleigh 1584, 1610, 15 voer 23 สus Sirginien gefradgt, auf's Neue befinnt und zuerft in (5iñrten um (5) bughall angebaut worben fein. Der Natur=

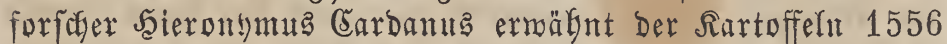
in feintem $B$ utche de rerum varietate, foll fie 1580 in Stalien eingeführt und 1588 fultivirt Gaben. Franz Drafe, ein englifcher 2ldmiral, aber bejonders war es, Dem man Die Serbreitung Der Rartoffeln, igre Rultur un Bentäung ant meiften zu berbanfen Gat. (Ex traf biefelben 1578 in

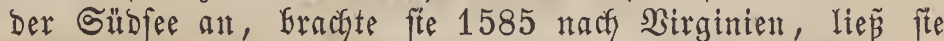
bort anbauen und nagm fite yon ba 1586 nady England mit, wo er Die Berfucfe mit igrer Rultur fortfekte. Der englifuche Botantfer Jobn Gerard, Der yon Drafe einige Rartuffeln erbalten Gatte, theilte yon biejen 1589 Dem Nie=

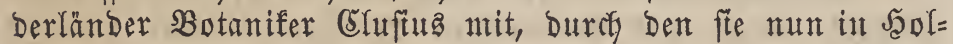
rand und Burgund Gefannt wurben. Shaffpenre erwähnt [1602-40] Der Rartoffeln in jeinen Schaupielen; Cajpar Baubin befurieb fie zuerft 1590 in feinem \$robromus. Zu

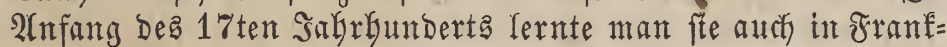

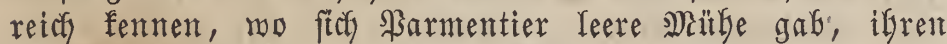

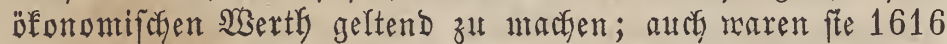
auf ber Röniglicten Tafel zu \$ariz noch cine Delifateffe. Sofann Cofrus redet yon Den Siartoffeln in feinem Sants= Galtungsfuche, SWittemberg 1602; gleichmohl wurben fie in Deutichland erit im Sabre 1640 alfgemein befannt und im 30 jährigen frieg burch eitren nieberländifchen Dff̈̈cier nach BB̈Gmen und in Das Bairentifye eingefüfrt. Durch einen Eandmann Sanz Nogler aus Selb in Boigtlande feien fer= ner bie Rartoffeln 1647, 48 ober 1712 nach Sactjen ge= fommen, wo aber igr $\mathfrak{A}$ nbalt erft in Jabre 1717 affgemein murbe, als fte Jieneral MRiffan aus Dem brabantifchen Rriege mitgebracht hatte. 1648 murben fie zu Biberau int Brop $\tilde{\beta}=$ berzogtfum heeffen fultivirt und verzehendet; Den 1. Dezem= ber 1695 erfefien you Der Rergierung im (5rob̈herzogthum Baben eine Berorbmung über bie Rurtoffelzekenden. Nach Merflenburg famen bie Rartoffeln 1\%08, nach Württemberg 1710 Durch Den Waldenfer Alntoine Seignoret, 1720 Durch bie \$fälzer nach Bremen, 1726 Durch Sonas SUltitrömer nach Schneben, 1737 nard Finnland, 1630 pber 39 in bie Saftreiz, 1740 maren fie faft alfgemein in $\mathfrak{g e f f e n = S a f f e l ~}$ befannt, wurben-1746 in Scjottlano yon Brabam angebaut, und 1762 in Norwegent Durch Den \$robft Jeerzberg zu

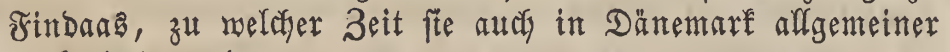
verbreitet rurden.

Bìs zun 7jührigen Siriege Genühte man bie Rartoffeln

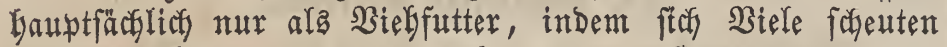

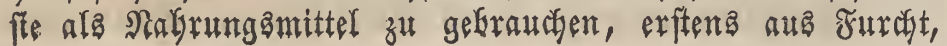

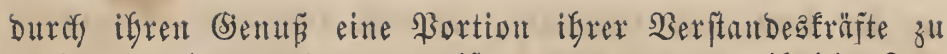
werlieren, oder zweitens vergiftet zu werden, weil bie $\mathfrak{R} a$ toffeln einer Silanzenfantilie, Dem Nereftichatten, Solanum, angebörten, Deren meifte Battungen giftige (sigenfchaften be= ftisen. $2(1 s$ üfrigens im 18ten Jahrbunderte, befonders in Den Sngren $17 \% 0$ - 72 Die grope Theurung eintrat, is

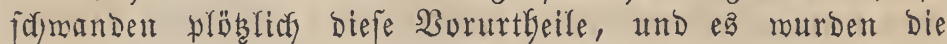

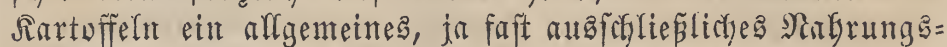
mittel, woburdy ein gruper Theil Der Bebülferung Deutich)= landa youl Şungertode errettet murbe.

\section{Riteratur.}

Soppen, Tob. Comrad: Surger S3ericht von ben Enolligen uno

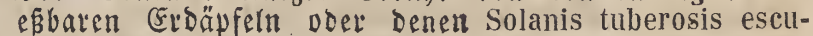
lentis etc. Woblfenbittel, 1747.

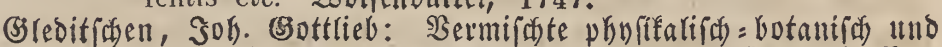

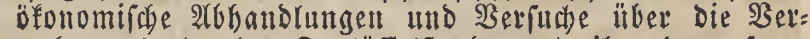
mefrungarten Der Tartöferfaube und ifre Daranf ge: grindete ausinefmende Frudtbarkeit. Salle, 1765.

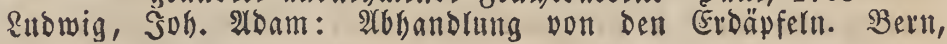
1770.

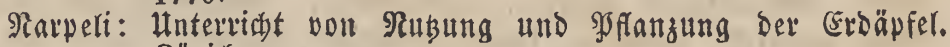
3̈̈rich, 1771 .

\&iiber, গ⿰氵

Die befte Alt Erbäpfel zu bauten. Bern, 1772.

Engel, Sam.: AYnweifung und sadridjt itber bent Froäpferball. 2 Igle. Belll, 1773-74.

Die Sunt Brod aus Erbäpfeln zu backen, ofne Bermifdung mit irgend einem Betreibemebl, zum $\mathfrak{B}$ efut ber Bitrger und

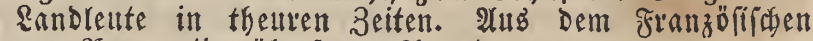
yon Yarmentier überfest. 2Yuggburg 1779.

Sefonomifhe 2ibfandlungen (Evogewäd) Wien, 1781.

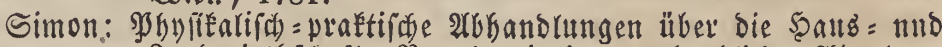
Ranowirtbrhaft. Bon Der jebigen verberblidsen arbartung Der Rartoffeln. 1fter Iheil. Frantéfurt am Dain, 1781.

Befareibung einer febr vortheilfaften Rartoffelmühle, weldhe biebei in einem Supferftiche befindlid ift.

Heber Den vortheilfaften Anbau Der Erbäpfel oder Girunbbirnen

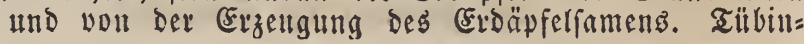
gen, 1793 .

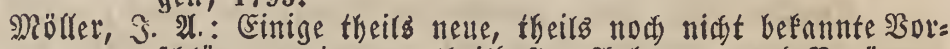

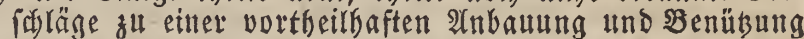
Der Sartoffeln, audb mit Sinficht auf Srantmeinbren= nereí. Dortmund, 1796.

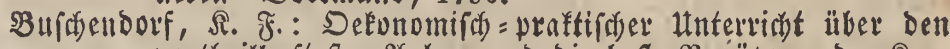
vortbeilbafteften 2 (nbalt und Die befte Senübung Der Sar: toffer. Reipzig, 1795. 1797 und 1806.

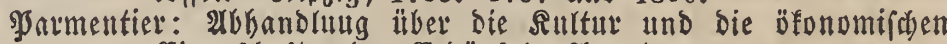

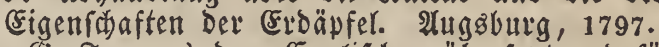

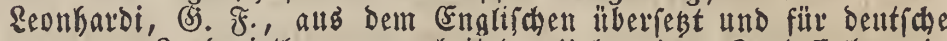
Ranbwirthe umgearbeitet: Heber Den Rartoffelbau in (B)ob́brittanien. Reipzig, 1797.

Interricht über Den 2 nbait und Die Benusung bel Rartoffeln Doer Eidäpfer. SBon einem praktifden DeEnomen. Wien, 1799.

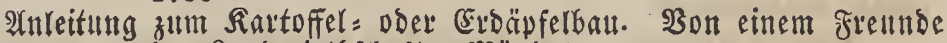
Det Ranbwirthídaft. Mänbeln, 1800.

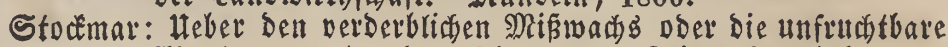
2rbartung unter ben feit langen 3eiten ber befannten Speifekartoffeln, Deren Htrad)en, Эertilgung biefes Hebels $2 c$. Raltich, 1801.

Heber ben Rartofferbau und die beften sitter frudtbaren Samen zu erbalten. Reipzig, 1802.

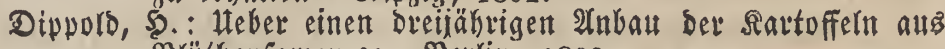
Britthenjamen 2c. Berlin, 1803.

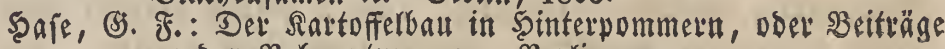
zu Der SBefauptung, 2C. Şerlin, 1803. 


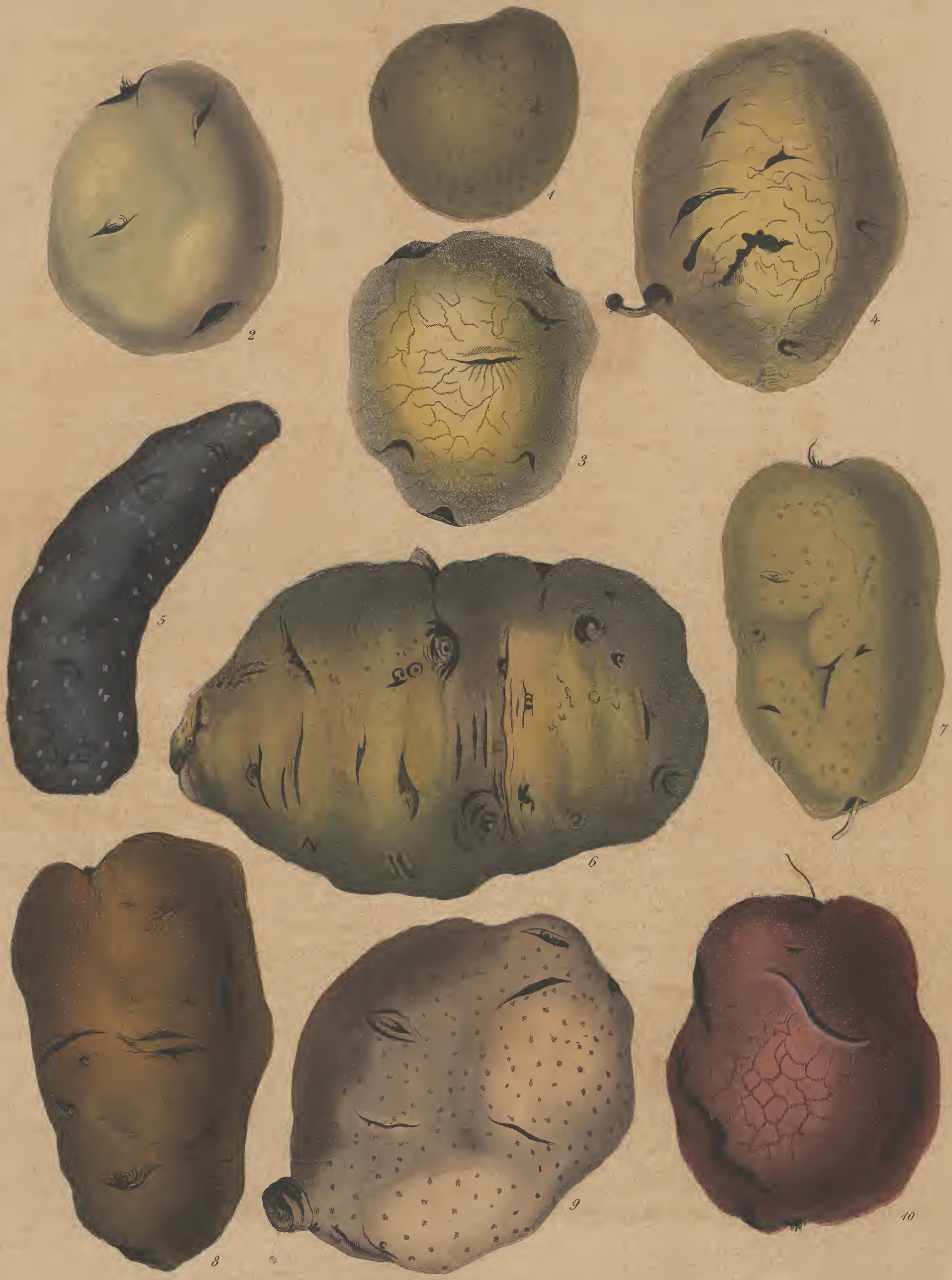





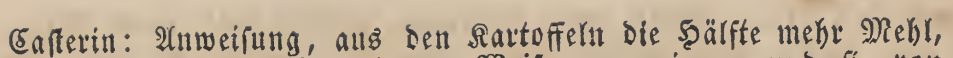
als auf bie bekannte $\mathfrak{W e i f e}$ z" gewinnen und fie von cinet Ernte zur antern aufzubewabtell. Seipzig, 1803 IIIID 1805.

Sfaff, 5. 5.: Heber unreife, frübreife und fpätreife Sartoffeln uno bie verifhiedenen $\mathfrak{B}$ arietäten ber beiden lesteren vorä̈g=

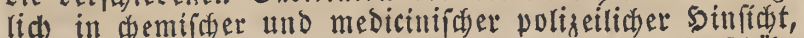
Ino Srofeffor Siborg zu Ropenbagen: von Der Hnidád = lichfeit ser umeifen und Der rothen Rartoffern. Riel, 1807.

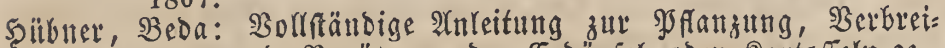
tung utlo Benitgung ber Eroüpfel ober Rartoffeln 2 ., erfter Iheil, welder die landwirthidaftlide Pfanzung enthält. Salzbuta, 1807.

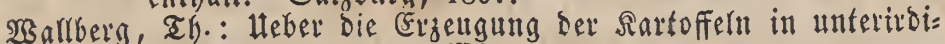
iden $\mathfrak{B e b}$ âltniffen. Wrien, 1811.

Dis Rartofferfucht it Rlidefidt ifres mannigfartigen Rïdenge=

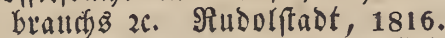

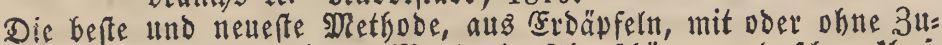

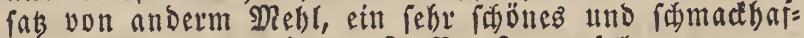
tes $\mathfrak{B r o d}$ zu verfertigen. $\Im$. $\mathfrak{B}$. Stauenfeld 1816.

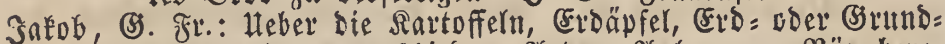
birnen, beren verichiebene Arten, Anbau 2c. Särnberg, 1818.

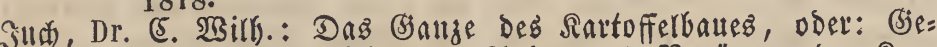
ichide, vortheilfaftefter Ainbau und Benibung Der Rat: toffeln. 1 ttm, 1818.

Büger, Dr. Sof.: SBollftändige Befhandlung über ben 2 (nbaut und die Benübung Dev Sartoffeln. SJefth, 1818.

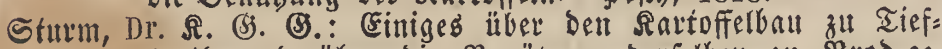

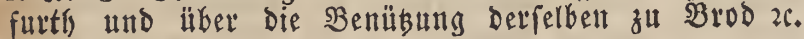
Setla, 1818.

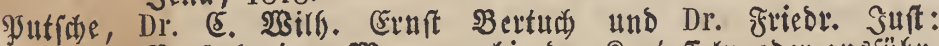

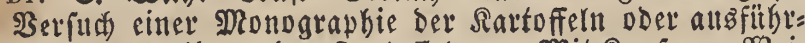
lidue Befduetbung Der Rartoffeln 26. SDit Rupfert. SGei= mat, 1819.

2nreitung zuit zwedmäpigften 2 nbau ber Sartoffern. Saborftast, 1830.

Sreysig: Der Rartoffelbau im (5) rofen. Söniggberg, 1833.

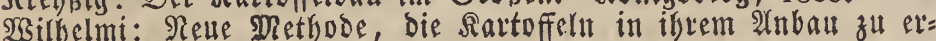
weitern. Berlin, 1835.

Anmeifung zum zwectmäfigften 2lnbau set Rartoffeln. Süterb. 1835.

Heber Sartoffelanbau. Saalferb, 1838.

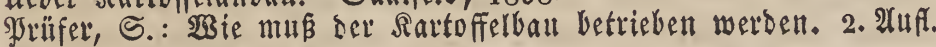
Bauben, 1840 .

Rellex, ED. v.: Sortheile und Feblet bet Dem Rartoffelbau. Son= Dershauren, 1840.

Bohr, F.: Die 100iătrige Feier Des Rartoffeljubiläums. Eeipzig, 1841 .

Robr, :F.: Die Sranffeiten Det Rartoffeln. Reiptig, 1842.

\section{Helianthus. L. \\ Vosacan. Adans}

Siffeme: Actinophyta. Neck.

Compositae amphicenianthae. Reichenb.

Compositae Bidentes. Adans.

Compositae Helianthi. Rül.

Compositae oppositifoliae. L.

Compositae radiatae. Ray. Spr.

Corymbiferae. Juss.

Synantherae Helianthi. Cass.

Syngenesia, Polygamia frustranea. L.

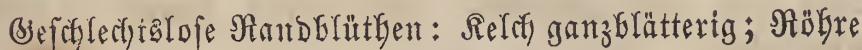
meift breifantig, fabl ober befaart. Saum oberftändig, aub $2-3-4$, zumeilen boritenförmigen, felten gefürbten Sprent= blättchen doer nur einem Sarare furzer Spibchen beftebend

Enrwer, bfonom. spfanzenfunde.
Doer fogar ganz feflend. B̧luntenfrone ganzblätterig, ein=

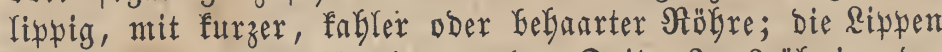
länglich ober lanzettfönmig, an Der Spibe 2-3zälynig Dber zahnlos. Stengel untyolfonmen. Frustefnoten unfruchtbar. Sriffel feblt. - Bmitterige Sctyeibenblüthen: Seldy mie bei

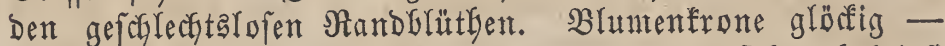
röhrig, fünfzahnig. Rabre ermeitert fich nach Dben baldigft in Den Saum. Staubfaden 5, fabenförmig, frei, ber $\mathfrak{B l u}=$

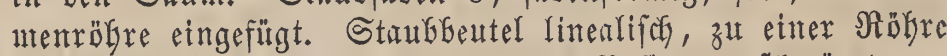
zufanmengeflebt, fornärzlich, an Der $\mathfrak{B a f t a}$ ungefchmärzt, an Der Spibe mit einem 2 (nthängfel gefrönt, zmeifăcherig. Stem= pel einer; Jrutstfnoten einfächerig, unterftändig; (briffel einer, fabenformig, oben zmeifpaltig. Narben pfrientenfabenförmig, auf Dem Rütfen zottig, endigen in einen fteif=

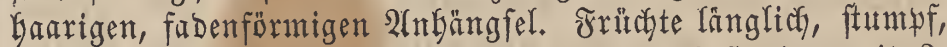
bierecfio, Gebaart ober fabl, einfäç一erig, einfamig, mit 2, felten 4 lanzettfömigen, fwreuartigen und abfäligen Sdjüpp= chen werjeken.

\section{Helianthus tuberosus. L.}

Ěrobinne, fnollige Sonnentume, Erroapfel, Şeruia=

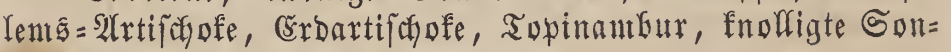
menrofe, Stangenerdapfer. Artichant de Jerusalem. (franz.)

Jerusalem Artichock. (engl.)

\section{Arten, (Shataftex.}

Sizurzel friectend, faferig, mit vielen, oft 50 , Den אar: toffeln ähnlichen, Göcferigen, Graunrötblichen, inten meipen,

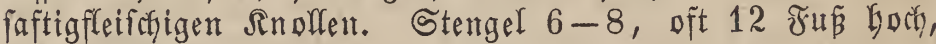
äftig. Blätter furzgeftielt, lăngliogrumb, zugefpidzt, ein mentg gezalynt, fely raub, am blattftiele berablaufend, die untern Gerz-eiförmig, Die obern eiförmig. Selchblättchen gewint= pert. Blütyen grós, gipfelftändig, etwas aufrecht, fobön gelb. Frudytboben fladh.

\section{Słinthe = Beit mto Danev.}

Dftober - Nowember. 4.

\section{จูo1}

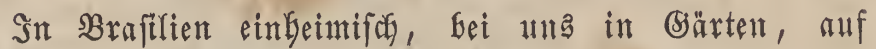
2(ecfern und in Weinbergen fultibirt.

\section{Rultutx.}

Die fnolfigte Sonnenblume gebeigt faft in jebem Rlima, am beften aber in roarmem und måpig feudftem; in faltem fegt fte meniger Sinolfen an und gebeigt faft in jebent $\mathfrak{B}_{0}=$ Den; fie ift in ifrer sugend ganz unempfindlid gegen orrölte und fommt fomofl in feuchtem, als auch, da ibre Blätter biel ซ̌euchtigfeit aus Der Ruft aufnebmen, int trodfenften Boden fort. Sie bedarf in einem nur einigernanen fräfti=

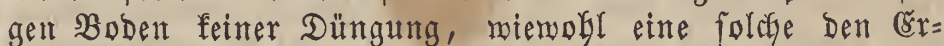
trag, bejondera an grünem Jutter, bebeutend bermegrt und fowohl frifd als ftarf angemendet yon ber Affanze gut er= tragen nirb. SWaß bie Zeit Der Düngung anbelangt, fo ift es gleicfgültig, of fie bor, mit oder nach Der Saat yorge= nommen mirb. Man fann bie Topinambur, ba fe ben $\mathfrak{B}_{0}=$

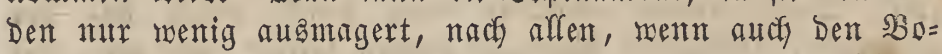

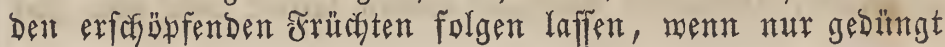


mird. Da aber bie Snollen febr fogmer gänzlidy aus bem Buben. zu bringen fend, bie zurüfógebliebenen über ben $\mathfrak{B}_{\text {inter }}$ Durcty Rälte nicht zu Sirunbe gefgen, immer fortwuchern, und erft im Spätferfif ober zrüljagr aus ber (srde genom= men merben föntnen, fo ift es immer am rätglichiten, zumal Da fie biele Sabre lang fortwadjen, tie auf eigeng fint fie Geftimmte Bläke zu bauen und fo linge Dafelgft zu laffen, als fie now einen gentügenden Errtrag abwerfen, in welchem Falle man aber alle zwei Jabre frifd za büngen bat.

Ěnige Gauen Die Topinambur bei Der Dreifeldermirth = foraft im Somuterfelde. Sierfte und Rlee gedeifen ganz gut auf bie Topinambur, ebenjo Rartoffeln, welde aber, ba fie

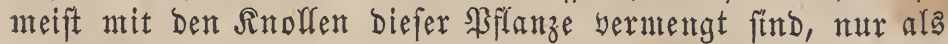
Biebfutter Genutht merden follten. Durof ben Anbau ber Rartoffeln werben bie Gonnentlumenfnollen zum gropen Theil bertilgt, megr aber noch burch ben 2 nbaut yon Wriffen, Die man zum Sweče Der Broünfütterung. und mit Silee an=

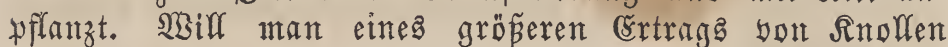

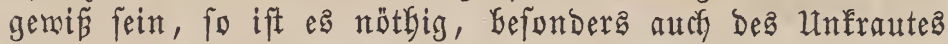

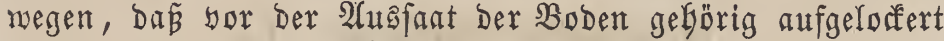
werbe, bamit fith mefr finolfen anfenen. Csinem reichten Boben gibt man 2, einem melyx bindigen $3-4$ Furdhen,

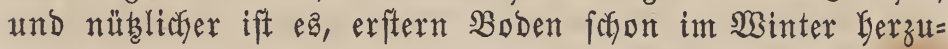
richten und gut einzueggen, lebtern aber, zumal wenn er

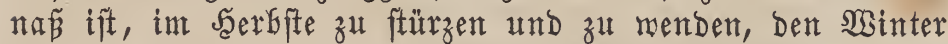
aber in ratger zorthe liegen zu Iaffen und ben Frübling Darauf umzulorfern.

Die Topinamburs werden Durbig Die Rnollen sermefrt, Da Der Same bei una nicht zeitigt, ja Gäufing gar nidgt zut SBlüthe gelangt. Snan nimmt zum Regen bie gröpern ober

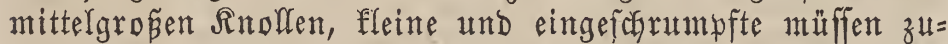
yor breintal 24 Stumben in ein Miftiauche=Faltiges NGaffer gelegt werden. Das Berfectneiben ber Regefnollen, wie dieß Gei ben Sirtoffeln geforiegt, ift wentiger zu entrfeglen; follte

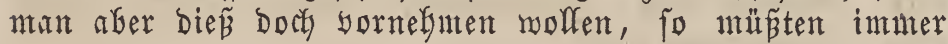

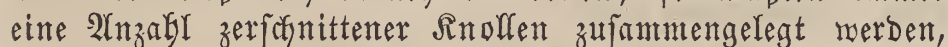
ba immer viele gar nidft in Trief fommen; fomit mürbe man nichts an Samen exfparen. Sn locéerem, trocfenem ober fanbigem $\mathfrak{B}$ oben legt man gewöbnlich bie Rnollen int Serbfte; Der $\mathfrak{B}$ oben hält Dann feine Winterfeuchtigfeit mefra an fich, Itno bie Snoffen treiben in Früblinge, fobald warme Witte= rung eintritt, und bie Sffanzen Geferatten bet trodfener und beifer Sritterung Den Bober. Sit Der Boben Kingegen bin= big ober nấ, fo ift egิ Geffer, Die Rnoffen erft im Jrüblinge zu legen; im erften Falle fann nan bie Sinollen bis Mitte 2lprifs, im zmeiten bout Dftober bis zum Eintritte bes Winters regen.

Das Regen felbft gefdriegt mit bent \$fluge, mit Dem Safen ober reifyenweife in etwas flache Bruber, überfaupt faft wie Gei ben Rartoffeln, in lofferem Boben 3 Soll tief und weiter, etwa $1 \frac{1}{2}$ F̛̃ rem $\mathfrak{B}$ oden fann man fte etwas näher an einander legen. Bei feucfer und warner SBitterung geft bie Topinambur

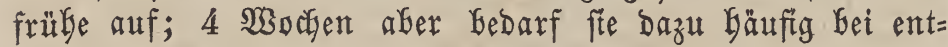

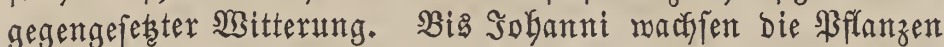

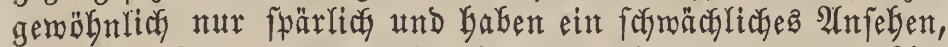
nun aber fommen fie in Trieb, namentlich im Monate $2 \mathfrak{U}=$

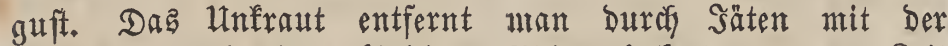
Jeanblafe, und einen bindigen soben loffert man bon Seit zu Seit auf. Wenn man bebaufelt, erbält man mebr Rnol= len, wenn man biejes jeboch unterläpt, megr futter. Bu

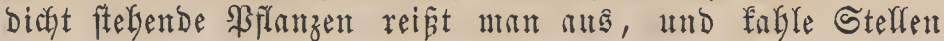
pflanz

Da bie Topinamburs im Buben son der Sälte nicht leiben, fondern fogar nody, wenn fie ben Sinter über im Boben bleifen, nocf reit, oft $1 / 4$ gröber merben, yoratşge=

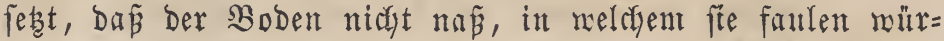
Den, fo bat utan mit ber Ernte nicht zu eilen, und fanti bief̣elbe erft int zröllinge, noch in 2 lpril, (aber nicht fpäter) vornefmen, ober wenigftens int Saerbfte nur fo viele אinollen aus Dent Rande nefunen, als man etra bebarf. Sind bie Snoffen reifenmeife gelegt morben, fo Gebient man fit beint

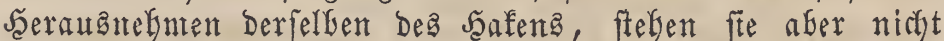
in Neifyen, fo gefraudyt nan Den Spaten, bei beffen 2 n= wendung auch weniger froflen in Der Črbe zurünteleiben. Die Sinolfen nimnt ntan, ba fie feft an ben $\mathfrak{B} u r z e l n$ bän= gen, mit Der Seand af. Baut man bie Topinambur ber Snolfen regen, fo Dürfen zum Befufe Der Fütterung bie Blätter und Stengel ja nicht zu frïhe abgenommen merben,

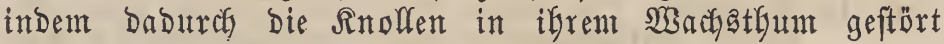
merben und meift $1 / 3$ weniger Errtrag geben, auch verliert

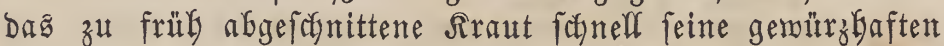

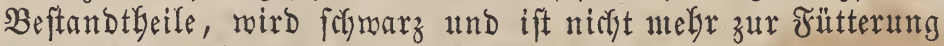
tauglidy. SSill man jeboct bie fnolligte Sonnenblume zu= gleich ala Futter Gemuben, fo ift bie befte Seit zum 2afochnei=

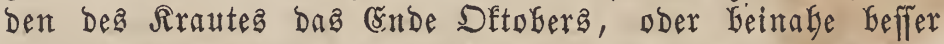
Der Septentber, meil int Dftofer meift foron ungütrftige, feutste W3itterung eintritt, und Stengel und Blätter, wenn man foldhe nicht blos zun Berfüttern wiff, felten mefre ge=

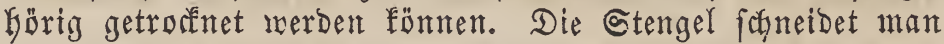
mit einer ftarfen Sichel $1 / 2-1$ Fú über Dem Erbboben

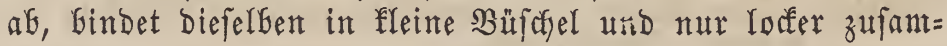
men und ftelft biefe in pyramidenförmigen Sanfen und nicht zu dieft neben einamber auf. Sind die äunern Blätter nun troffen, fo breft man bie einzelnen Etengel fo um, bá bie innern noch grünen $\mathfrak{B}$ lätter nach aupen zul ftefen fontmen, un ebenfalfs austroctien zu fönten, und bortheilbaft ift

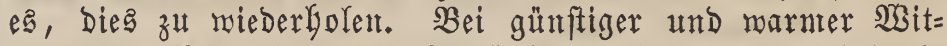

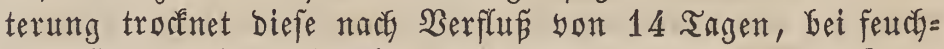
ten Metter aber gefbiegt bies nutr langfam, und bie Sten=

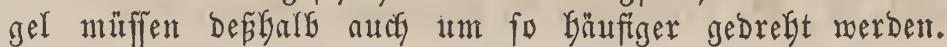

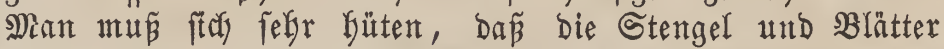
nicht feucht eingefradyt werben, indem fie fonft fohimmelig werben und vermobern; es ift bebhalb fehr zu empfeblen, Dab eingebrachte $\mathfrak{i r a u t}$ yor Dem 2lufbewahren an Yuftigen,

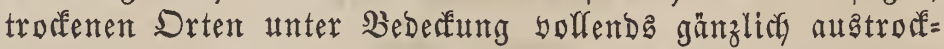
nen zu laffert. Die 2lufberwabrung Der Sinolfen ift einfact. Die int berbfte aus bent Lanbe genommenen Iaffen fites in nticht zu gropen baufen, (Damit fie ftef nieft erfiben und faulen, ) bie man mit (Erbe bebecít unb mit \&uftzügen ver=

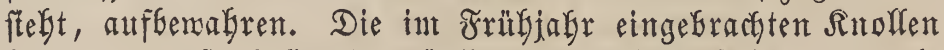
Eringt ntan fo bald als möglicy in trodfene Refler, wo fie lange gut Gleiben. Befrorene Sinolfen fann man, nachbem fie wieber aufgetbaut find, whne 2 nftand berfüttern, nux

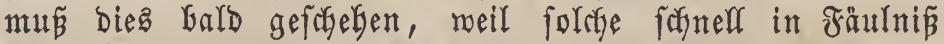
itbergethen.

Mag Den Errtrag Der Topinamburfnollen anbelangt, fo fällt berfelbe meift etwas geringer aus, ala der der Sartoffeln, 
ïberfteigt aber unter befonders günftigen lunfändoen auch bäufig Dentelben.

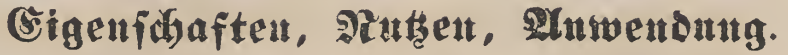

Die Snoffen ber Topinambur beftizen gefocht einen fü $\beta=$

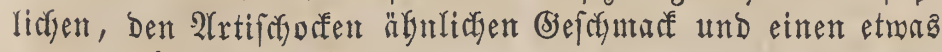

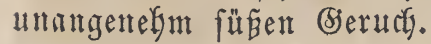

Die yorwaltenden Beftandtheile fitnd nach (singof:

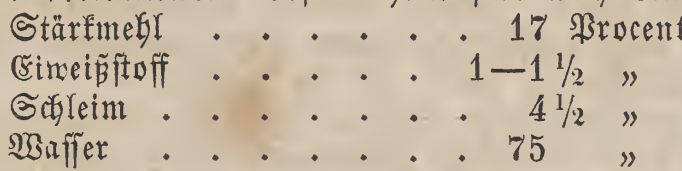

Sach Broconnot:

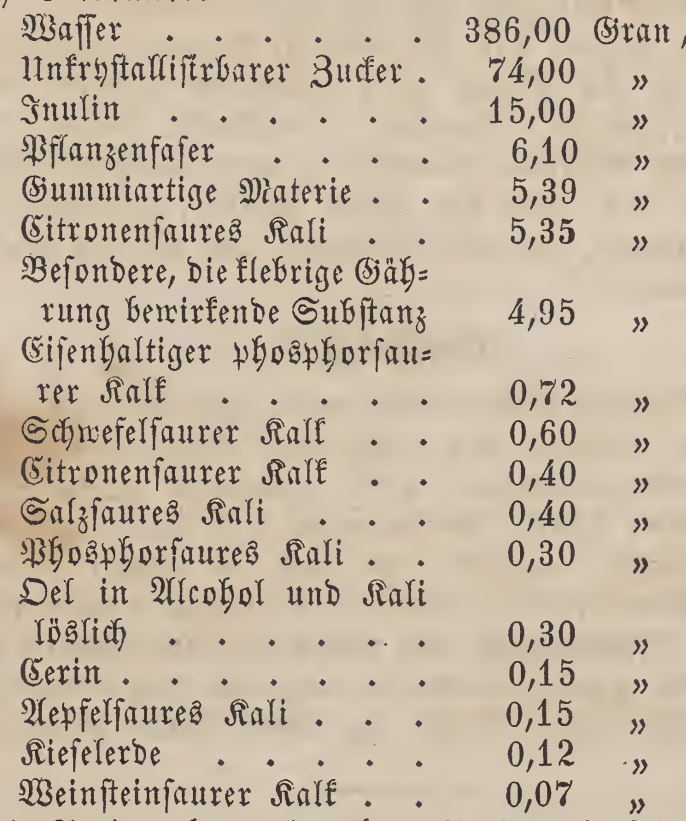

Die Topinambur mird Gauptfächlich als Futtergemächs angebaut, bie Snollen ftefen Den Rartoffeln an nährenden Beftandtheilen weit nach, ftnd mur ein mittelmäßiges Futter und gefen oft nur einen geringen Errtrag; es ift nach bem

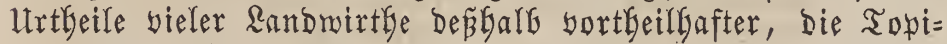
namburz neffr Der Stengel und Der Blätter, als̄ ber Rnoffen

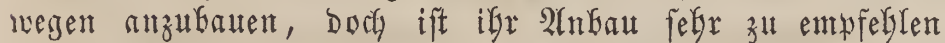
folchen Siegenden, welche troffenen und follechten Boben Gaben, ba fe audf ofhe affe Düngung noch einen Ieiblichen Ěrtrag geben, ferner Siegenden, weldye Mangel an Jablz Yeiden, da

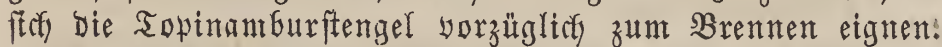

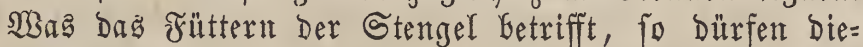
felfen nie ofne Beifutter gefüttert werben, wozu utan ge=

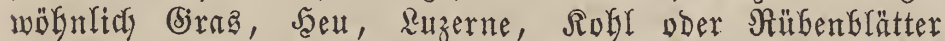
nimmt, weil bas Vief wom Freffen biefer Stengel bald er=

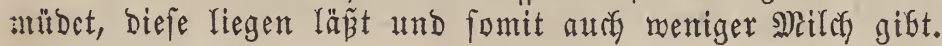
100 Bfund grünex Tupinamburftengel fammen etwa $31 \frac{1}{4}$

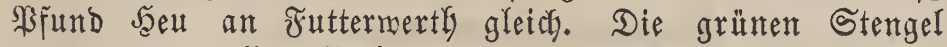
werben bon affem $\mathfrak{B i e f}$ gerne gefreffen, Gaupträblich aber won Bferden, Schafen und Biegen, für meldye fte auth am paffenditen find. CEin befonders gutes Sefjaffutter find bie

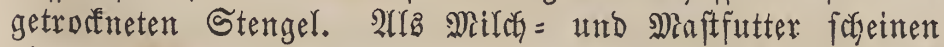

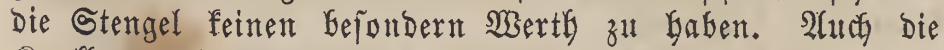
Snoffen merben bon aflem Biebe gefreffen und ftnd efen= falfs yorzugsmeife ein gutes SPferbe = und Schaffutter; in einigen Begenden, wo die Topinamburs int Bropenen angebaut

werben, wie in Sachjen, int Grjä zc., werden fie fitatt ber

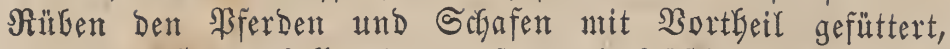
und bie erfteren follen bayon fett und fräftig merben. (̌̌i nige fifäben bieje Rnollen als ein gutes Milchfutter, fte

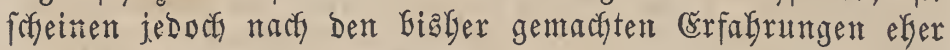
nachtheilig als nủblich alf die Mlildy einzumirfen. In zu grof́en Duantitäten bürfen fie nicht gefüttert merden, weil fie ftarf bläben und beftigen Durdy fall erregen; es ift de $\tilde{\beta}=$ Galb immer vorfichtiger, fie nicht allein, fondern mit ande= rem Futter sernifict bem $3 i e h$ yorzulegen.

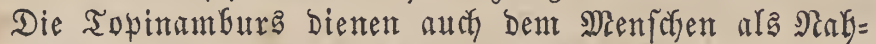
rungsmittel, man verfpeiet fte als (5) müfe, gemöhnlich megen

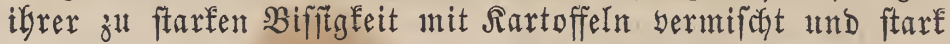
genürzt, weil fe felgr bläben und fowwer berbaulich find. Wie wix oben fefon gefort Gaben, find bie Topinambur= fitengel ein ganz gutes Brennmaterial, bas ftel fogar zum Brobbaffen eignet; fie liefern faft 6 Sirocent 2 fache und eine fegr ftarfe anuge.

\section{Gefodidate.}

Die Topinambur fam vor Yänger als 200 Sahren yon Braftlten nach Ĕurowa, 1617 foll fte zuerft nad Erngland gefumnten und yon ba weiter verbreitet worden fein; Esintige wollen fogar wiffen, Dás Drafe Dieje Bflanze und nicht bie Sartoffeln nach Faland gebracht habe.

Reffen (Topinambur).

\section{Ritetatut.}

\section{Georgina. Willd.}

Dahlia. Cavan. De C. Georgia. Sprengl. Coreopsis. Cass.

Snfteme: Compositae amphicenianthae. Rchbch. Compositae Asteroideae. Less. De C. Compositae Corymbiferae. Mirb. Compositae Helianthi. Loudon.

Corymbiferae. Juss.

Corymbiferae heliantheae. Schultz.

Synantherae Heliantheae. Cass. Syngenesia, Polygamia superfilua. L.

Blütbentoden foreuig. Şülfe dowpelt, äufere vielgätte= rig, intere einflätterig, 8tyeilig. Samenfrone feine.

\section{Georgina variabilis. Willd.}

Georgina superflua: De $\mathbf{C}$. Georgina purpurea. Willd.

Dahlia pinnata. Cav.

,$\quad$ variabilis. Desf.

, purpurea. Poir.

" pusilla. Zucc?

Daflie, verjofiedenfarbige Dablie pber Eseorgine. Ber= änderliche deargie.

\section{Arten, Ghanater.}

Şurzel fnollig, mit vft vielent länglicten, voer auch

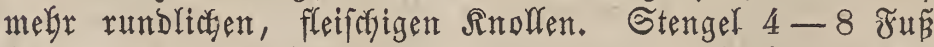
Gocf, aufrecht, aftig, glatt, ober etras raubbelyart, biff, fteif, grün vder bunfelpurpurroth, Gäufig rotgfräunliç ge= ftreift, nit gegenüberftéfenden Zweigen. Blätter grof, 
gegemüberftelend, etwns am Blattiftiele Gerablaufend, un= panrig geffebert, unten faft doppelt gefiedert, 3theilig ober

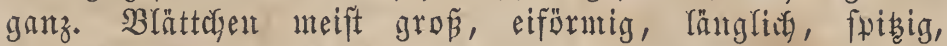
ftumpigezafint, glatt, ober etras rauh, fteif. Blüthenftiele ziemlich lang. Selch Dopwelt oder umbülat, ber äunere 5 brät= terig, rürfwärta gefogen, Der innere 8flätterig. B̧lüthen zablreicy, grof, $3-4$ 3oll breit, am Önde Der Stengel und Sweige ftefend, niffend. Strabl aubigebreitet, werfefie= Denartig, roth, gelb, meí̈, lila gefärbt. Scheife gelf. Fructboben fpreuartig. Saute unkefebert, Yänglich, breit= gebrücte foctuarz.

\section{Błitthe: Beit แnt Danet.}

Suli - November. 4.

\section{Sorfommen.}

Mexifo, wirb bäufig in bänten ala Bierpflanze, in nteuerer Beit aber audy, Doif felten als zrtterpffanze auf zeldern angebaut.

\section{Rultut.}

Die Rultur Der Dablien mird bis jegt nur menig im (jropen betrieben. Sie gebeifen au beften an gejen Rälte und Minde gefchütenten und Der Sonne zugängliçen Drten und faft in jebem Boben, menn fte nidgt gerabe als Bier= yffanze gezogen werben follen. Düngung bebürfen fie feiner, menn ber Boben nicht zu fegr ausigemergelt ift. Wan ver= megrt bie Dahlien Durch Samen, Durch Bertbeilen Der Jnol= Yen ober burify Stedflinge, wozu ntan bie jungen Triebe ober ftarfen 3roeige benübt, jeboch ift biefe lestere Methode bie

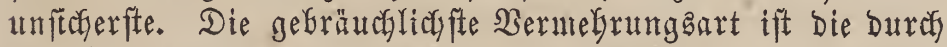
Ias Sertheilen Der ăltern. Snollen, mobei man aber Darauf zu fefen bat, Dấ eine jebe Sinolfe menigitens ein 2luge befthe. Die Jinolfen legt man, fobald feine Jrüblingafröpte melgr zu befüroten find, gemöhnlich 2anfangs ober Mitte

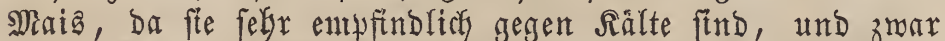
âtere $\mathfrak{R n o f l e n}$ in 15 Sulf tiefe und breite, jüngere in flei= nere Giruben, in melche man zubor SfFäble eingefalagen Gat.

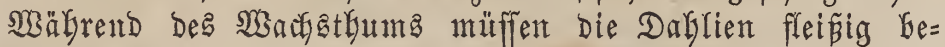
goffen und, ment fie etma 2 Fus boch gemorben find, an

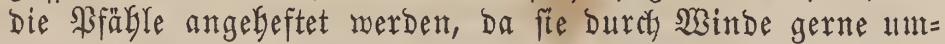
getworfen merden. Die Rnulfen üferwintert man am beften in Selfern, reinigt fee zuyor geförig yon ber ifnen angän= genden Ěrse und läğt fee an fonntgen, luftigen Drten ab= trodfnent. Da fie gerne fohimmelig merben, fo mun man you Deit zu Beit natifeben und bie fesinmeligen Stellen abreiben; bie Snollen aufzubängen ift freilidy bie befte $2 \mathfrak{n}$ f= bemafyrungsart, aber beint 2 thban ber Dablien im (5) ropent mürbe biefę zu viel Mëhye und Beit foften.

Itmftändlider als bier angegeben wurbe, ift bie אultur Der Dablien, als Sierpflanze gezogen, jedoch bat biefe für Den Defonoment feinen siserth, und wir übergeben fe Dep= balk biflig.

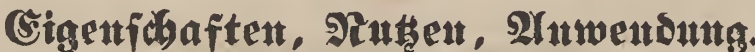

Die vormaltenden Beftandteile Der Beorginen find: Wiffer .... 0,76 , Dablin . . . . 0,10,

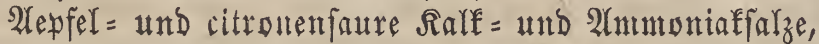

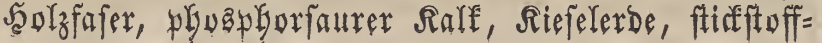

Galtiges Cöimein, ätherifches und fettes Del, bittere, aromatifge Subftanz, folpeterfaures Rali, falzanter Ralf, Gitronenfäure, ftirfftuffGartige, Demt Damazout verwandte Subftanz, fochuefelfaurer Salf and fär= Gende Miaterie.

Die äunere Scaut ber Rnollent enthält mefr fürbende unt mefre aromatifye, ber Bantlle algnlich riechende Subs=

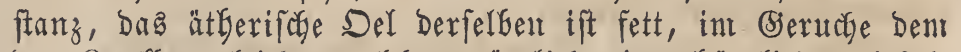
Der Snollen gleich, melcher nämlich eigentgünuliç zniebel= artig ift, aucs entfält bie Şaut mebr Riefelerde, falpeter= und whughborauten Ralf, als bie Snulfen.

Die Daglientudfen fönten ebenfalls serfweist werbell, find aber nicht befonders angenefm, mefr werden fie zur Biegfütterung berwendet wie bie Topinanfura.

Durch Sultur ftnd eine zafllofe Menge Barietäten ent= ftaltben, bie ftch Gäuftg Durch prachtyolle zarben, rofent =, farmoiftut $=$, purpur $=$, fobarlach $=$, ziegelrotg, $\mathfrak{b r a u n}, \mathfrak{f u p f e r}=$ farb, wiolett, fabrefel-orangegelf, weí, bunt, mur bis jebst nicht blau, and Durch fegr foğne gefülfte, zelfenartige oror= men aแşzeichnen, bie aber fämmtliç nur fütr ben Blumiften Wherth baben.

\section{(5ejubidhte.}

Die Dablien famen 1789 zuerft und Madrid, wo fie afer mieber tergeffen und 1804 auf's Reue Durdi) eitte Radis Solfand Gefannt warben, 1814 gelangten fie itach Jrante= reich, wurben bafelgft Mobeflumen und yon da nady (Eng=

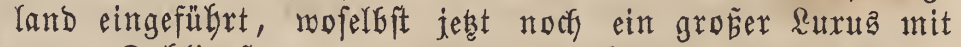
netten Dablienforten getrieben wird; Gäuftg merben für eitue folcte 100 Thaler bezaglt und \$reife zu 1000 Thalern für bie forgonfte und zugleich Galtbarfte alsgejetgt. 1841 murde Durch eine Befelffstgaft eine Daflie um 6000 Thaler ausgefpielt.

\section{Cyperus. L.}

Anosporum. Nees. Papyrus. Pet. Thou.

Arethryon. Raf.

Comostemum. Nees.

Pycreus. Beauv.

Devisia. Raf. Torreya. Raf.

Syfteme:

Calamariae. L.

Cypernaceae. Whlbrg.

Cyperoideae. Juss.

Carices. Ryl.

Chortophyta. Neck.

Gramina Cyperi. Adans. Gramina Nonogyna. Ray. Scirpoideae. Pers.

Triandria, Monogynia. L.

Aebrofen aus bielen zweireifig, ziegeldachartig gefterl= ten, einflüthigen Rlappen zufammengefebt. SUlfe Slappen fructetbar, woer eine doer zrwei der unterften leer. Spelzen feblen. Jruthtfnoten eiruns, feine Borften an Der Baftz. Briffel furz. Narben lang, zmei= ober breitheilig. Santen maret.

\section{Cyperus esculentus. I.}

Cyperus esculentus angustifolius. Scheuchz. ", pallescens. Sieb.

" Hydra. H. B. ?

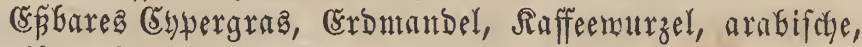
indianifche Gütinuurzel.

Souchet sultan, comestible, ou sucre. (franz.)

Trasi dulcichini. (ital.)

Rush - nut. (engr,) 


\section{Mrtel, Shavafter.}

B33urzel mit bielen, runblichen oder länglict) = eirürmi=

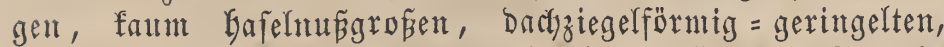
Dünngüutigen und Gräunlichen Sinollen. Şalu nelfenartig

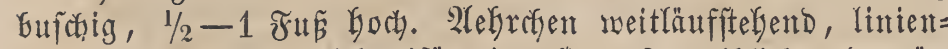
förntig. Bălge lăngliç = eiförmig, ftumyf, gelgfiç und grün geîtreift, glänzend. Allgenteine Jaüfle 4-5Glätterig. Narbe 3theilig.

\section{Sluthe = Beit atto Dater.}

Suli - 2luguft. 24. Reife Der Rnollen int Dftober.

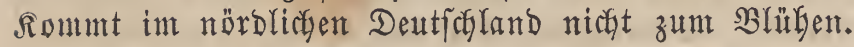

\section{Эorfomment.}

Sn Aegypten und in Drient einfyeimifer, in einigen (jegenden Dę füblidgen (šropas, wie in Deftreict), Baben, Braunfdreig, Gyanien, Jranfreich Gei Miontpellier fultivirt.

\section{Rultux.}

Die Eromandel will zu igrem volffommenen Gebeifyen

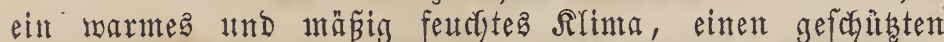
fonnigen Standpunft und einen warmen, etwas feuchten, fetten, gutgebüngten, locfern und bou Unfratt reinen $\mathfrak{B}_{0}=$ Den. Mian Dïngt bie Errontandeln mit berfaultem Mift, Schaf = ober Mrerbenift, Seifenfederaftye, Nulf, Mergel, Siú, Serferlofe. Den Boben ftürzt man im Serbfte und zwar tief, bamit er gehörig aufgeloctert merbe, arbeitet ifn

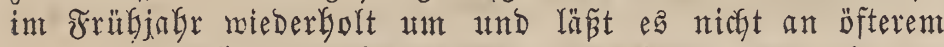
Eggen und $\mathfrak{W a l}_{z e n}$ feglen. Die Sermegrung gejchiegt am bejten und meiften burch bie Sinuflen, wozu ntan bie größs= telt und rumben, yorjährigen, im Nothfalfe auch zweijährige nimmt, welche man yor Dem Legen 24-48 Stunden lang

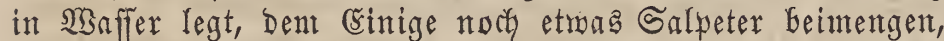
weil fie fonft 4-5 Wooffen lang, obne zu feimten, im $\mathfrak{B} D=$ ben liegen Gleiben. Sn marmen Bjegenden legt man bie

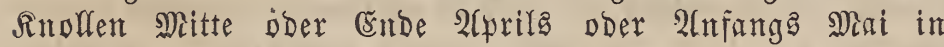
2-3 3oll tief gezogene Furchen 8-10 3oll meit yon ein= ander entrernt und bedecft fie mieber mit (Erde. Sn thiltern (5iegenden Gingegen legt man bie Rnoffen fdyon Mitte Miärz

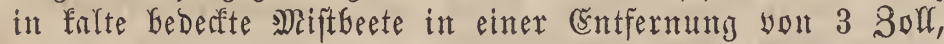

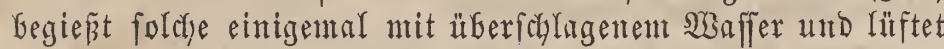

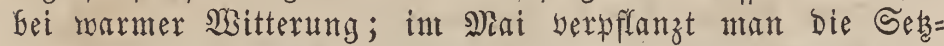
linge ebenfalls 8-10 3oll yon einander. Nian fann bie

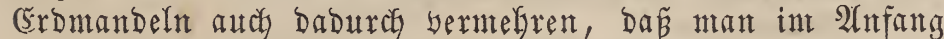
oder Mitte Suli's die Seitenfyroffen yon Der \$flamze ab=

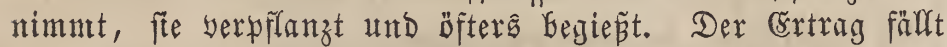
aber bei biejer Fortpffangungand immer gering aus.

Da bie Eromandeln nur ungerne aufgeben, fo ift es

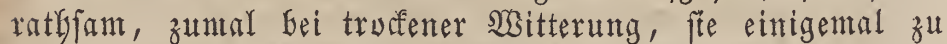

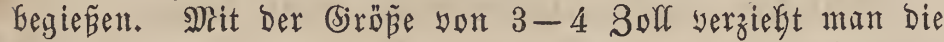
zu bisfit ftebenden Bflanzen und verfest die ausgebobenen in ein anderes geförig zubereitetes Rand. S3ährend bes Wachsthums müffen bie Sffanzen forgfältig yont Unfraut gereinigt, Dfters leidyt befareft und behaufelt merben. Die aus Den falten Mifitbeeten in's Rand berfesten \$flanzen nú man je nach Utmftänden und Gefonders int $\mathfrak{2}$ mfang eiu = bis mefrerental begieß̄en. - Die Ěrdmandeln reifen Ënde, bie im falten Miftbeete auferzogenen fiçon $2(n$ nanga Dftobera,

und utan folf mit Der Ěinerntung berfelben nidgt lange $z^{\circ:=}$ gern, da fie entpfublich gegen Fröfte find. Writte Septem= Gers finn man Săme und B̧ätter Der Eromandeln zut Siehfutter abjchneiden. Man Gringt bie M̧urzelfnolfen bei guter trocfener WBitterung am beften mit Dent Głaten, Den man focräg und tief genug, etroa 4 Boll tief einfticht, ats Dent Boben, foyüttelt bie Errde yon ben אnollen und nintunt rebtere ntit Den Sändent you Den Wrarzelfafern ab. Wan reinigt nun solfends bie Rnolfen yon ber Erbe und Den Wisurzelfajern, mafdyt fie in Sörthen, auggenommen bie zut Sant beftimuten, trodfinet fie an Der Sonte, for üttelt fie an luftigen Drten bünn auf und mendet fie einigemal um, bis fie yollends abgetroffinet find, und berwagrt fie an froftfreien Drten auf.

Der Ěrtrag Der Eromandeln ift oft fefre Gebentend, oft aber aucf febr unfteber. Shre hauptfäblisfiften zeinde fend

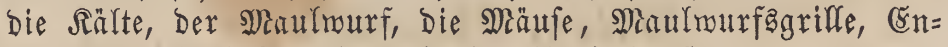

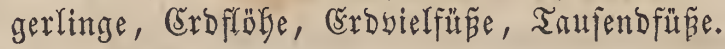

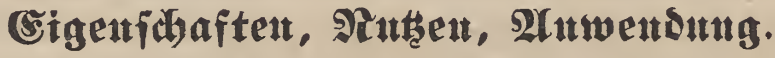

Die Eromandelfnolfen Gejthen eimen mandel = und vin

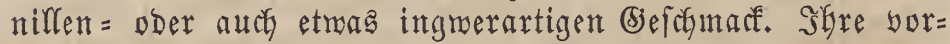
maltenden Beftandtheile find anthluntartiges @abmebl, fettę

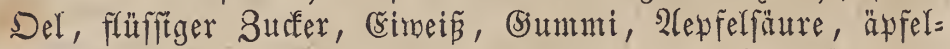
faurer, whoswhorfaurer und fdrofelfaurer Ralf, effitgfatres Rali, thierifch begetabiliface Naterie, Baaluşäure ntit einer Dent Berbftoff ähnlicfen Subftanz, bie nach Dem Serbrennen einige Salze und Sifentorbd liefert.

Die crommandeln geben ein felyr gutes, gemürzhaftes Raffeejurrogat, nur werben fie in netterer Seit wentiger bäuftg

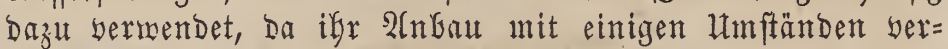

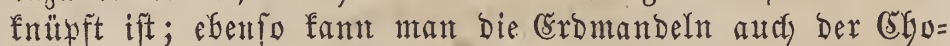
Lolabe beifetsen. Mian ergält aus igr ferner ziemlidy wiel,

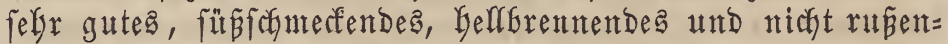

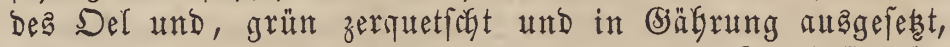
einen fegr feinen und fräftigen Branntmein. Sie laffen fitch wie Mandeln genté̃en, und man bereitet aus ifnen eine febr exfrifcyende Mandelmilcy und ein febr gutes Ronfeft, in

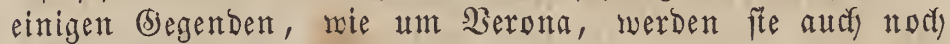
beripeişt; auch) fann man fie zu Mefhl und Brod vermenden. Die Delfuchen Der ausgevrȩ́ten Eromandefn find ein yor=

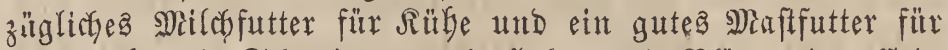

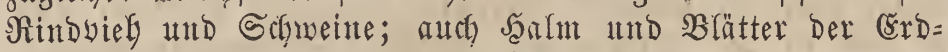
mandeln werden gerne bout $\mathfrak{B i e g}$ gefreffen.

\section{Lathyrus. L.}

Aphaca. Adans. Clymenum. De C. Athyrus. Neck. Eulathyrus. Ser. Brachycerca. Presl.

\section{Syfteme:}

Cyteophyta. Neck. Leguminosae. Juss. Leguminosae regulares. Ray. Papilionaceae Vicieae. Schultz. Spach. Leguminosae Vicieae. De C. Diadelphia, Decandria. L.

Relé ganzblätterig, glodenförntig, 5 zälgnig ober 5 fpal= tig, bie beiben whern Băhne etmą fürzer. Blumenfrone 


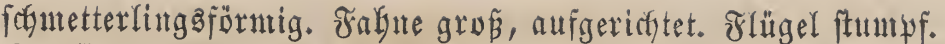

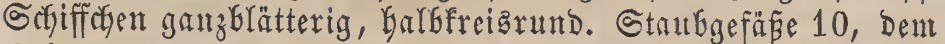
Relctgrunde eingefütgt. Staubfäben yfrienten = fabenfürmig, 9 bermachfeı, 1 frei. Staubbeutel eiförmig, zmeifäctyerig. Stengel 1. Fruchtenoten fisend oder furzgeftielt, zufam= mengebrüutt. Briffel Yinealifă doer afwärta Greiter. Sarfe enbftänbig, Ganrig. Şülỵe zufammengebrürft, einfäcterig, mebrbaarig. Samen fugelig.

\section{Lathyrus tuberosus. I.}

Lathyrus attenuatus. Vivian. Gaubrod.

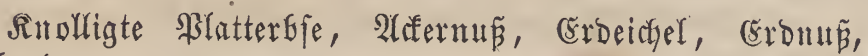

Touberous Lathyrus. (engl.)

\section{Arten, (Sharaftex.}

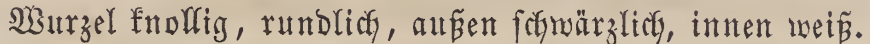

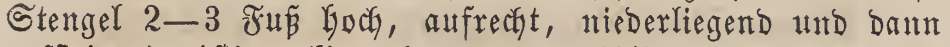
auffigeigend, äftig, erfig, glatt, mit zweiblätterigen, breifpalti=

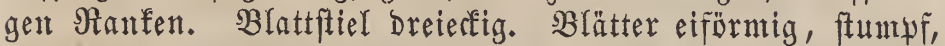
ftachelfpibig, faft ripuenlos, glatt. 2lfterblättchen pfeiflanzett= förnig, ganzrandig. Blumenftiele lang. Blüttgen zientlich grof, meift zu 5-6 ftefend, arljefftändig, furbur = ober rofentoth, wohlriectend. Seülfen zufammengebrürft, glatt. Ganten runblich.

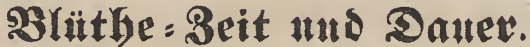

Suni - suli. 4.

\section{Sorfommett.}

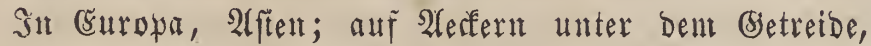
Gefonbers in befirgägegenden, wirb in einigen Begenden,

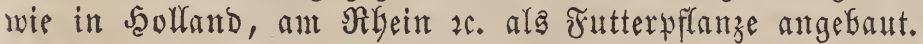

\section{Eigenjdhaften, Nuten, Anwentung.}

Die Snollen baben einen angeneynen, füplity berben,

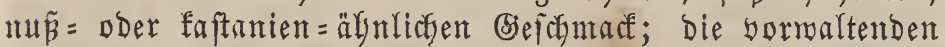
Beftandtyeile futd Burfer und Stärfutebl. Nan veripeiat fie rof oder wie bie Rartoffeln zubereitet, mit Butter und Salz, oder als Gemüre, Gefonders Gäufig in Sadfand, und fie fitnd in Der Tartarei und Sigirien ein mittel. Sie bienen als Saffeefurrogat und liefern eine fobüne weí̧e Stärfe, aud fönnen fte in theuren Seiten zu Brob verbaffen werben. Nean bat es fofon verfucht, Durch ben mit Jannig vermifaten Saft Der Rnollen bie Bienen int SBinter einzufchläfern. Die Rnollen gebraudgte man auch fritber in Den 2 rpothefen unter Dem Namen Glandes terrestres.

Die fnolligte Blatterbje ift ein gutes Frutterfraut für

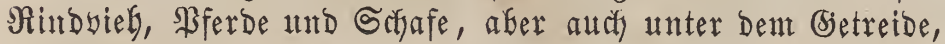
namentlich Der Berfte, ein fehr foğabliches Unnfraut, indem fie fith an bemfelGen Ginauf̣antt. Die Blütben merben bäuftg yon ben Bienen bejucft.

\section{Orobus. I.}

Cyteophyta. Neck.

Leguminosae. Juss.

Fabaceae. Rehbeh.

Leguminosae Vicieae. Adans. De C.

Relch ganzblätterig, röhrig, 5 fpaltig, bie beiben oberen Bixfel fürzer. Blumentrone fichnetterlings̄förmig. Fafhne aufgericftet, an Den Seiten zurüffgefdylagen, größer als bie Flügel. Die 2 Flügel ftumpf, an Der $\mathfrak{B a f t a}$ über Den Sha= gel in eitren boblen 3abn eingebrüntt. Schiffoten ganzblät= terig, ftumpf. Staubgefüpe 10, bent Relefgrumbe cingefügt. Staubfäben priemenförmig = fabenförmig, 9 bermachjen, 1 frei. Staubbentel rumblich, zmeifächerig. Stempel 1. Frucht= fnoten zufanmengebrürt. SSriffel aufíteigend, einmärts ber Ränge nach Gaarig. Narabe föpfig. Şülfe zmeiflappig, ein=

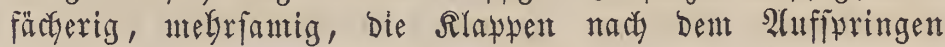
gerutuben. Sament Geinatye fugelig.

\section{Orobus tuberosus. L.}

Astragalus sylvaticus. Thal. Lathyrus attenuatus. Vivian. Lathyrus montanus. Bernh.

$\boldsymbol{\beta}$ Orobus tenuifolius. Roth. 0robus gracilis. Gaud. $\gamma$ Orobus prostratus. Host.

Sinollige W̧alderbje, oder Walderbe, finollige Bergerbje,

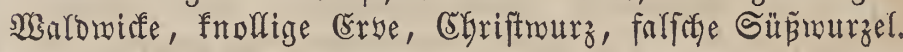
orobe repens tuberosus. (fianz.) Tuberous - Bitter - Vetch. (engl.)

\section{2rtet, Eharaftev.}

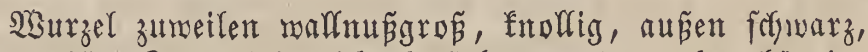

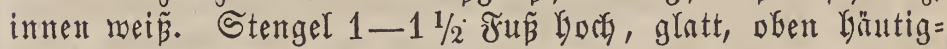
geflügelt. Blattftiel gef́lügelt. Blätter abgebrochen 2-4pan= rig gefiebert, glatt. Blättchen lanzettförmig, ftadyelfpibzig, ganzranbig, unten blau graugrün. 2lfterblättçen Galbyfeil= fürmig, an Der Bafts̃ bie und Da gezäbnelt. Blitthen feiten= ftändig, 2-4 an Der Zafl, violett purpurroth, zumeilen auch wein, mit Dem 2GGGlüfen Glau merdend. Fabute unge= fefrt berzförmig. Siriffel an ber Spibe rund, innen be= Gaart. Saülfe malzenförntig, bünn, lantg, einfüctlerig, fotwarz. Samen flein, rund, Dunfelbraun.

Diefe Br̃anze hat 3 Spielarten:

a) latifolius, bie Greitblätterige.

Bönningh. lec.

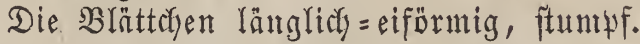

b) linifolius, bie Yinienblätterige.

Bönningh. lec. Schleihtend. b. L 374. var. C. Orobus linifolius. Flor. Wetter. Lathyrus angustifolius. Coes. prus. S. 138. Orobus pannonicus. III. Clus. hist. 2. 231.

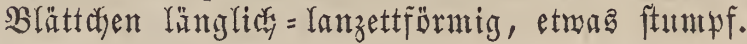

c) tenuifolius, Dünnblätterige.

Bönningh. lec.

$\beta$. Orobus tenuifolius. Roth. II. 170. Hoffm. II. $7 \%$.

Orobus tuberosus. $\beta$. tenuifolius. Wild. sp. III. 2. 1074.

Lathyrus attenualus. Vivian. P. 1714. g.

Blättchen febr fanal, linienpfriemenförmig.

\section{Blütbe = Beit und Dauer.}

Miai - Suni. 4. 


\section{Sระt'ommet.}

In maldigen gefirgigen bjegenden, nuf Sheiben, Șald=

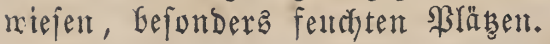

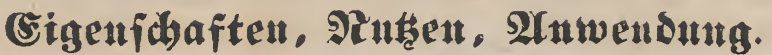

Die SYGurzelfnollen baben einten füß̈en, und gebraten einen faftanienartigen befchmarf, und waren befonbers yor Der Ëntbectung Der Sintoffeln in theuren Zeiten ein gefucf)=

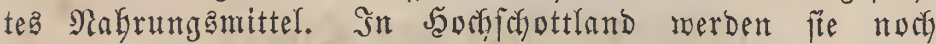
Gäufig genvffen, auch Durch (b)ăbrung ein (b)etränfe Daraus bereitet; fie werben fegr gerne yon ben Gafmeinen gefreffen. Die Sffanze ift ein gutes $\mathfrak{B i e f f u t t e r , ~ d i e ~ B l u ̈ t h e n ~ w e r b e n ~}$ yon ben Bienen alfgejutyt, und bie Santen bienen als (b)= flitgerfutter.

\section{Carum. L.}

Bulbocastanum. Adans. De C. Carvi. De C.

Siftente:

Scadiophyta. Neck.

Umbellatae. L.

Umbelliferae. Juss.

Platyspermae. Rehbnh.

Pentandria, Digynia. L

Sielch ganzblätterig, mit oberftändigem, unbeutliçem Saum, und eirunder, getiefter $\Re$ obre. SBlumentrone 5Glät= terig, abfallend; bie Blätter gleidf, werfefrt = eifürmig, aus= gerandet, mit einent eingefoldagenen Sipfel. Staubgefäpe 5, mit ben $\mathfrak{B}$ lumenblättern eingefügt. Staubfäben fabenförntig. Staubbeutel zmeifächerig, rumblich, einmärta gefelyrt. Steur= wel 1. Fruchtfnoten unterftändig, zmeifächerig, mit einent

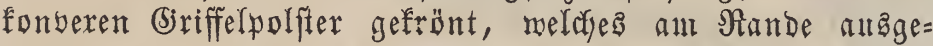
formeift ift. Briffel 2, ausgefwreizt=niebergebogen. Narben flein, beinake fopfig. Spaltfrucht länglich, an ben Seiten zufanmengebrüst. Theilfrübte bicht, 5riefig. Samen unt= gefegrt, eimeiphaltig.

\section{Carum Bulbocastanum. Koch.}

Bunium Bulbocastanum. L. Scandix Bulbocastanum. Moench. minus. Gouan.

Bulbocastanum majus. Bauh.

Sium Bulbocastanum. Spreng.

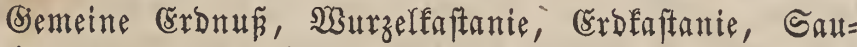
faftanie, gemeiner Erofinten.

Bulbocastanum Earth-nut. (engl.)

\section{Anten, Ghanaftex.}

WBurzelfnollen tief iut $\mathfrak{B}$ oben fterfend, esfig = fugelig, fompaft fleifchis und meglig, ausen braun, itnen meiṕ.

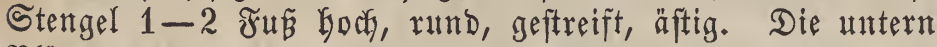
B̧ätter Doppelt zufanturenge eqęt. Blättchen linienförmig, einfach ober faft zweitheilig, feingefpibt, rinnenförmig, bie obern ungeftielt, gefedert. Blütbengüfle gemögnlich 8Glätte=

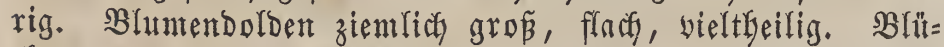
then meí̄. Samen eiförmig.

\section{Słüthe = Beit und Dauev.}

Suni - Suli, 4.

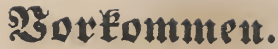

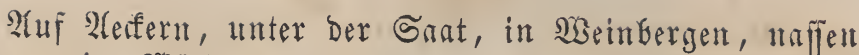
SBeiden, in Mäldern, fteinigen ober fandigen Drten in Deutfaland: Der Bial $I_{3}$, saffau, Shetterau, Gadjen, Baben; Franfreich, Ëngland, und wird bier und da angebaut.

\section{Sultur.}

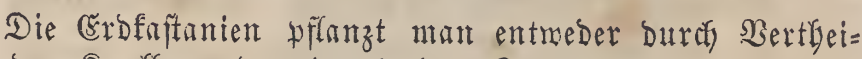
lung ber Fnolfen voer Durch Den Samen. Sn folgenden Sabre Gält man bas Rand geförig rein bom lnfraute und Gebart Den 3 oden einigental. Sm Dftober doer Robember fann man fich feinen Bebari für ben Minter aus bem Rande nefmen. Im zweiten Jafre Glugt die Erofaftanie, febt

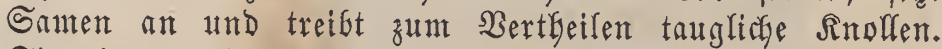
Sie nimmt mit jeben boben und Standpunfte yorlief.

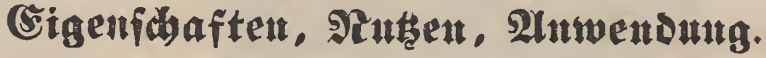

Die Črdnüffe Gaben eimen füpliçyen, faftanienartigen (B)effrmat, find nabrhaft und werben auf verichiedene NBeife zubereitet, in ber 2 fjece gebraten, ober gefotten, mit Butter, Salz und Pfeffer, doer Effitg und Del verfpeist; man fann

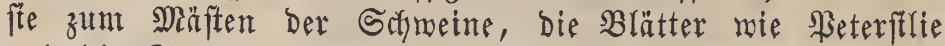
und bie Samen wie Rünmel benuben.

\section{Apios. Moench.}

Bradlea. Adans.

Syfteme: Leguminosae Phaseoli. Adans. De C. Papilionaceae Fabaceae. Rchbch. Papilionaceae Phaseoleae. Spach.

Diadelphia, Decandria. L.

Seldy zweilippig. DGerlippe ausgernnder, Itnterlippe breifyaltig, rumzlict. Falgne berzförmig. Sebiffichen fichel= förmig gebogen und brüft ntit feimer Syibe bie Fagne zu= rücf. Şälfe länglich, felten eiförmig. $1=2=$ and melgrfamig. Samen nierenförmig.

\section{Apios tuberosa. Moench.}

Glycine Apios. L.

Apios americana. Corn.

Astragalus perennis. Moris.

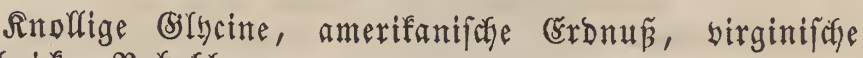
Snolfmide, Bobrblume.

Glycine grimpante à fleurs en forme des boquets. (franz.)

Tuberous rooted Glycine. (engl.)

\section{Anten, Shatäter.}

Wharzel hat melgrere fleine inolfen. Stengel oft 10 $\widetilde{F} \mathfrak{i}$ Goch, mindend, frautartig. SBlätter ungleich, breipaarig gefiedert. B Blättchen ei=lanzettförmig. Das Endblättchen breit

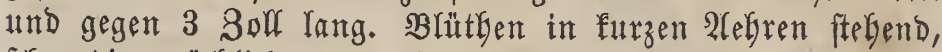
formuthig, röthlich, ober fleiforfarbig.

\section{Şlüthe: 3eit mus Danev.}

2tuguf - September. 4. 


\section{5otrommen.}

In Norbanerifi, Birginien einbeimifor und bei uns in (bï̈rten gezogen.

\section{Rultux.}

Dauern über Den SBinter unbeberft fort.

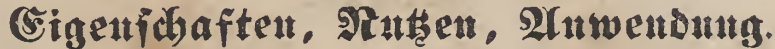

Die Blütgen buben einen beilchemartigen (jeruth), bie Wurzelfnoflen einen angenelymen, artiph ofenartigen Befichnarf und merben in Birginien ftatt Des Brobes veripeist; ald fönnen bie Samen mie Erbfen genoffen merben.

\section{Brassica. L.}

Brassiacastl'um. Link. Eruca. De C. Erucastrum. De C.
Micropodium. De C. Napus. Medic. Spenn. Spach. Rapa. Adans.

Syfteme:

Siliquosae Sisymbria. Rül.

Cruciferae. Juss. Cruciferae trib. Brassiceae. De C. Styridophita. Neck. Cruciferae siliquosae. Spreng. Tetradynamae Siliquosae.

Cruciferae Erucae. Adans. Cruciferae Erucagineae. Vent. Tetradynamia Siliquosa. L.

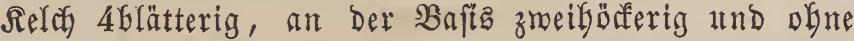
ŞD̈réer; abfallende Relchblätter faft fahn = und lanzettförmig, zugefpizt und nach oflen gebogen. Blumenfrome 4blätterig, freuffürmig, auf Den Blüthenboben ftebend. Bluntenblätter am Rande eben und furznagelförmig, ftumpf. Staubgefäpe 6, 4 mächtig, Dem Blütbenboden eingefebt, frei. Stanb= fäben pfriemförutig, zabnlos. Strubbeutel zweifädyerig, läng= lich, einmärts gefehrt. Stengel 1. Fruchtfnoten linealifs,

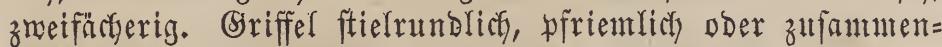

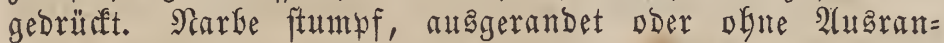
Dung. Schote länglich, ftielrumblich in eimen pfriemenför= migen ober zulammengebrülft = zweifḑneidigen Schnabel endi= gend, zmeiflappig, zweifärtherig. Samen in kebent zanche ein= reib̆g, bängend, fugelig, meift eingejtodyen=punftirt, unge= randet, eimeifłloz.

\section{Brassica Rapa. L.}

Brassica asperifolia. $\gamma$. Lam. tuberosa. Salisb.

Napus Rapa. Spenn.

Rapa oblongata. Nutt.

Sinapis Rapa. Brot.

$\beta$. Brassica Napella. Vill.

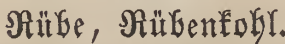

Turnip Cabbage. (engl.)

\section{2utent, Shataftex.}

Die Whıtrzel ift häufig biaf, fpindel = atmb inalzenförmig.

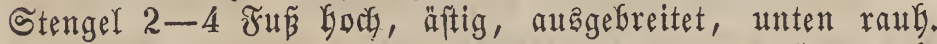
Nourzelblätter geftielt, Jeierförmig, runzlidy, Gorftig raub, Dunfelgrün, bie obern Stengelfiätter herzfürmig, ftengel= umfaffend, ganzrandig, glatt, bie nittlern eingefidnitten, Gochgrün. SBlütben endftändig, in bichten, etroas furzen

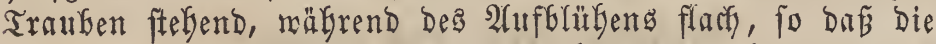
geöffneten $\mathfrak{B l u ̈ t}$ then über bie Blüthenfn̈̈pe Ginataragen. Relch balb fo lang als ber soriffel, 口ffen. Reldeblätter faft fahn = und Inmzettförmig, zugefwitgt und nach vben gefogen. Blume etmas vertieft, goldgelf. Blumenblätter an $\Re a n d e$ eben und furz nagelfürmig. Staubfäben bon gleidyer Stärfe, afitefend, aufftrebend. Stempel länger als bie Staubräben. Narbe balkfugelfümig, gelb. Schote 2 Boll lang, bün, faft aufrecht, mit langen, rundem, difriemenartigem (5riffel an ber Splise. Samten flein, fugelf̈̈rmig, glänzend fojrarz= Grault.

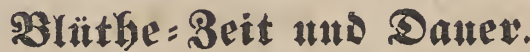

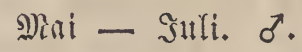

\section{Soxtommett.}

Das eigentliche $\mathfrak{B a t e r l a n d ~ D e r ~ M u ̈ b e ~ i f t ~ u n b e f a n n t , ~ f i e ~}$ foumt aber bie und ba in Ěngland, den Nieberlanden, fel= tener in Deutfaland auf Bracfäafern vermildert vor, und mird faft überalf bäufig fultibirt.

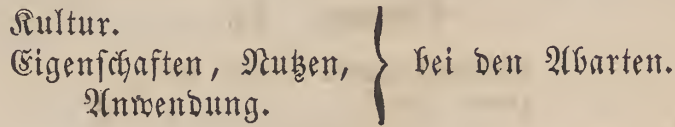

$$
\begin{aligned}
& \text { Interart. }
\end{aligned}
$$

\section{Brassica Rapa rapifera.}

Brassica Rapa. L.

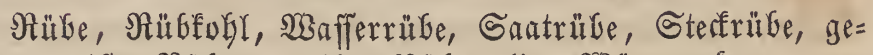

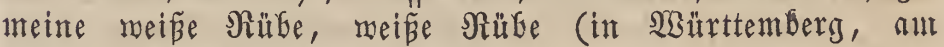
Rabein 2c.), Stoppel=, Stuppelrüben (in Betreibeftopprln gefäete Riüben, in einigen Bsegenden Deutfolands, in Defter=

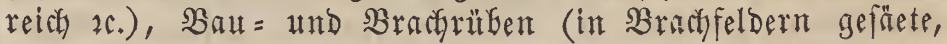
zum Theil in Deutichland).

Repa (in Sflyrien und in Suain).

Rufar (in Sweden).

Ravel (in Franfreid) und bei $\mathfrak{B e n e d i g ) . ~}$

Turnips, Turnip, Turnep (in (England).

W3urzel birf, fpinbelfürnig, mebr lang ober megr rumb, oben meift flach, weis, über ber (srbe mebr ober meniger gefärbt, rofenroth, violett, fechwärzlich, grün ober gelglich, innen meiń, fleifchig = mäfferig, fütrlich fochmerfend.

\section{Rultux.}

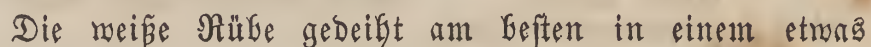
locern, fand = und lefmbaltigen, mefr trodenen Boben, auch toch in trocfen gelegtem Torf = und Mkourboden und in einem feucften Silima. Sït Der Boben nicyt fräftig ge= nug, fo Gilft man mit furzem Dünger, Miftianche voer Durch ben Scyafyferch nach. SMeder ein naffer ober zu bin= biger, noch aber ein zu magerer $\mathfrak{B}$ oben foflägt Der meípen

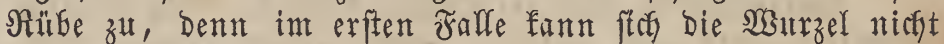
bölig entwiffeln und fault gerne, int andern aber mirb fee mutr flein und bolzig. Su bindigen und naffen Boden fann nrau Durch 2luffülgren son Mergel doer Sinff ver= Gefiern.

Neift baut man bie Rufbe als Bmiffrenfrutgt in Stop= peln, am liefften naid Sintergetreibe, Noggen zc., wozu man yorzugąneife bie Iangen Rüfenvarietäten mäblt. Der Boben mus gleich nach der Ernte amgetffügt und bie Stoppeln gefürig burcheggt merben, melche lebtere man ge=

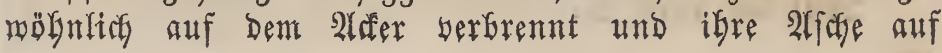


4.
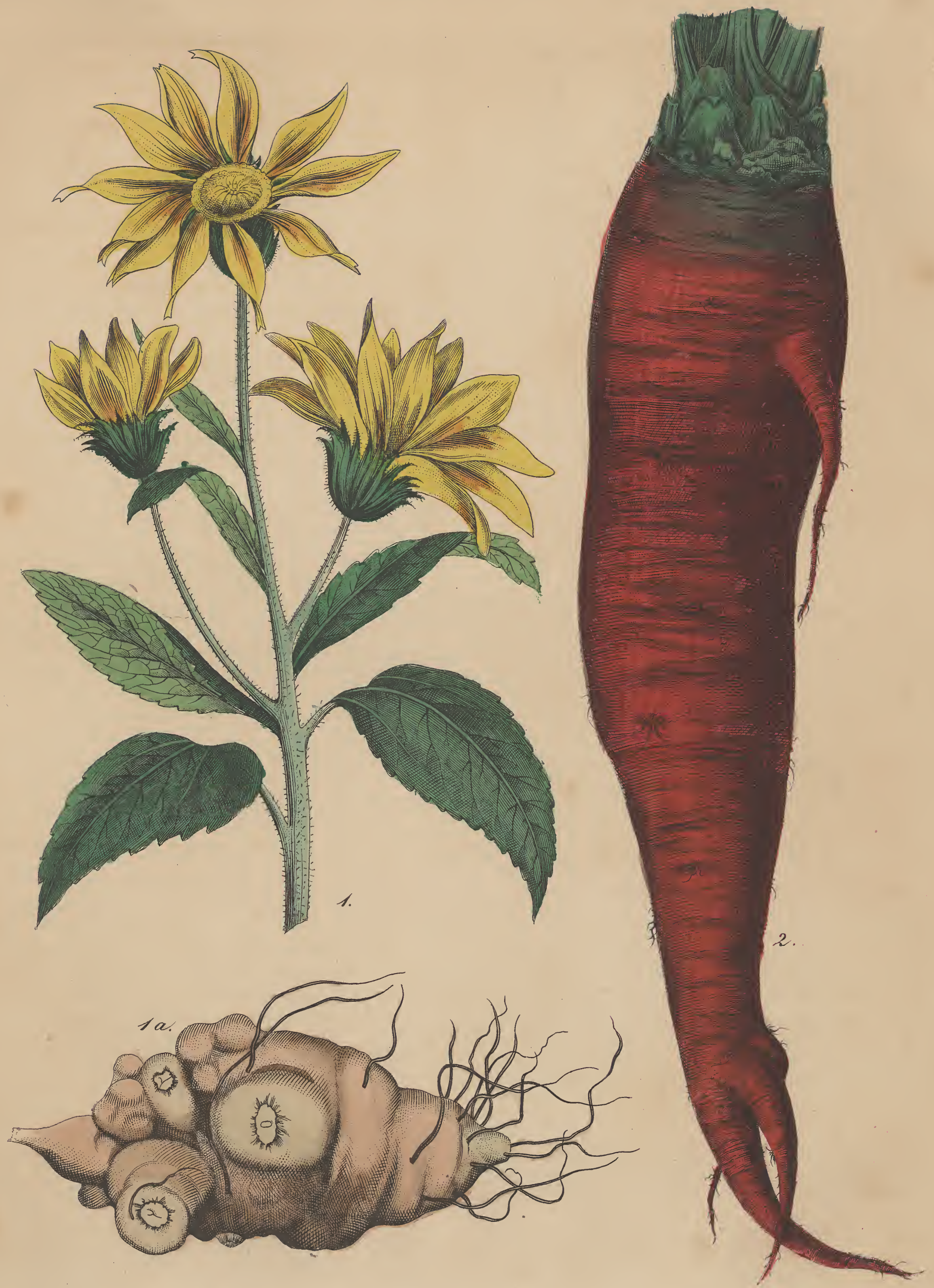

Demelfen unferftreut. Düngung ift felten nötbig, auper menn bie Rübe nach Bierfte ober nach andern, Den Boben ftarf ausntagernden Zrüchten gefraut merben fulfte. Man baut bie Rliben, befonbers bie runben Spielarten, auth in

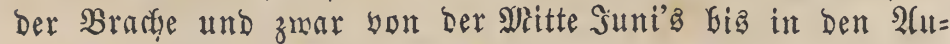
guft, Gei welcher אultur ber Boben gut berarbeitet, gebüngt und bom Unfraut fauber gefalten merben nuß Gindiger fein barf. Der Bracteanbau ift jedoch in Dentich=

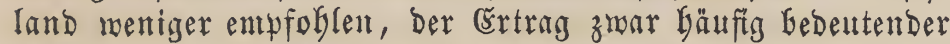
als bei ber Stoppelfultur, oft aber, zumal bei trofener SWitterung, fefr unfitfer, und ez fommt beim 2 fnbau an= Derer Bractefrücfte mefre Geraus, Da ofnebié bie Bracje immer binreidfent gebüngt fein miff.

Dent Sament fäet nan yom März gis Mitte 2 (ugúta, wo möglidy bor einem Regen, in ben frifor und tiefgevffitg= ten $B$ oben, und nicht zu bicht, bamit fech in Der zolge bie

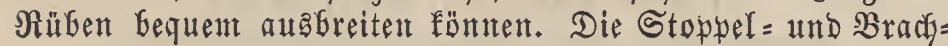

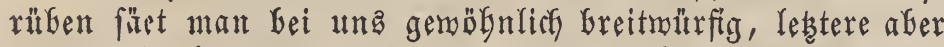

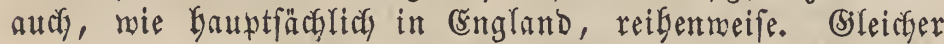
fällt bie Greitmürfige Sant aua, menn man borker ben $\Im_{a}=$ men in 2 gleidge Portionen bertbeilt, Deren eine ber Ränge, bie andere ber Quere nach augigefäet mird. Man eggt ben

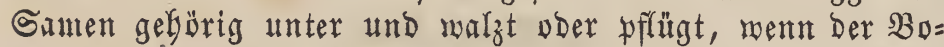
beat fefre leicht fein folfte, flach unter Denfelben, und zran bäuftg mit nieft zu frifchem, furzem Dünger. Rommt gleich nach Der Sat Regen, fo feiment bie Samen fanelf, und es zeigen fted Dann in furzer Beit bie jungen Bffanzen, im

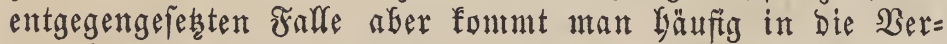
regengeit, bie Saat erneuern zu müffen. Die Sflanzen folfen weber zu bicft, noch aber zu bünne fteben, dent entweber fönnen fit die $\mathfrak{N u r z e l n}$ nicht genügend entwidfeln - welchem jebodf Durch's Berzieken ber Sflangen biz auf $4-8$ 3olf bon einander, je nach ber (5röpe ber Sorten, oft noch ab= gehulfen werben fann - ober geben ifre Blätter zu menig Scfatten, und Das ltnfraut nimntt zu fefr ủberband. Beim Rübenanbait im Rleinen ift bas wiebergolte Bebarfen fegr

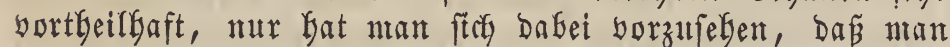

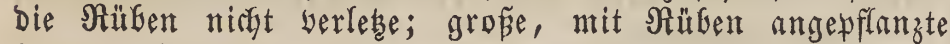
Eläsfen Gingegen werben, jebod oft mit weniger Nuben, fobald fie etwa 6 Brätter angefest baben, 2-3mal burchy= eggt. Diefez $\mathfrak{B} e r f a k r e n$ mirb Gauptfädylicy in ben Nieber=

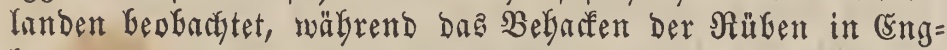
land and in Elfá an ber Tagesordnung ift. Sollte ber Boden zu mager fein, fo fant ifm, went bie siuben ein= mal אraut baben, bermittelft Jauche aufgebolfen werben. Im Serbfte, went bie Rüben beginnen fich zu beftoden, ziegt man bie zu bidft ftefgenden aus und verfüttert fie.

Die Bradgrublen zeitigen yor ben Stopyelrüben, und man famn fie gemöhnlicy im 2lugut ober September benühen; bie Stoppelrüben Dagegen reifen erft im Nobember. Für

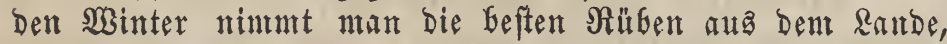
fafneibet bas Rraut ab, verfüttert Daffelfe vber Genübt als Dünger und berwagrt bie Rittben in Rellern ober int Freien Gaufenteife in Bruben, bie man nit Stroh ober Stoppeln und Erde, und bet ftrenger $\mathcal{R}^{a}$ lte mit Strobbung

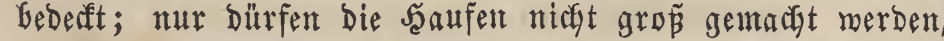
Da bie $\Re$ üben leidgt in sägrung gerntben und faul merben. Sie bauern ben Winter über auch im Jelde ause, wenn bie Temperatur beffelben nidgt befonders medfeelnd ift, und man Enrwer, bfonom. æronnzenfunde.

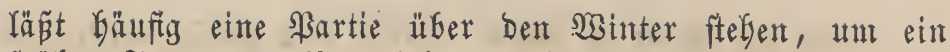

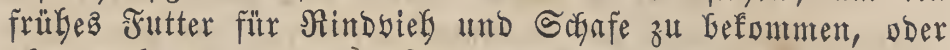
aber audf nur ein paà Stöfe, um int folgenden Sontmer Sament aแs ifuen ziefgen zu fünnen; mur Darf bies nicht zu oft auf einamber gefdefen, ba bie Rilben inmer geringer merben und Gauptfäcalids nur in's Sraut treifen. Die zur Samenzudgt Geftimmten $\Re$ üben nimmt man audf int Serbfte aus Deur Lande, Gringt fie üfer ben WBinter in Den Refler und in Frübjabr in's Santenbeet. 2(uth diefe Metfode barf

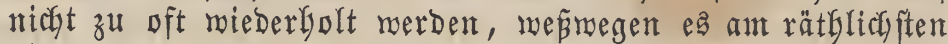
ift, biefe Geiben Befandlungsmeifen abwechjelnd anzumenden. Die Samenpframen febt man im Mărz etra eine (Elle meit yon einander in's beet, befaufelt fee, entfernt etwa yorban= Denes Unfraut; Die Samen reifen meift gegen $\mathfrak{A}$ Hguft, ge= möbnlich aber fefre ungleidf, fallen gerne aub und ftnd eine

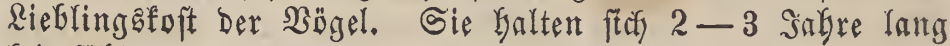
feimfäbig.

Der Ertrag ber Saatrubert ift weniger bebeutend alb Der ber SoGlrüben; man rectynet yom Miagdeburget Morgen an Ertrag 100, im günftigften Falfe 200 Gentner ßüben und Sraut zufaumen. Die Bradjrüben geben etron $1 / 4$ mebr aแb als bie Stoppelrüben, und man rechnet auf eimen Nior= gen Bracfrübenertrag

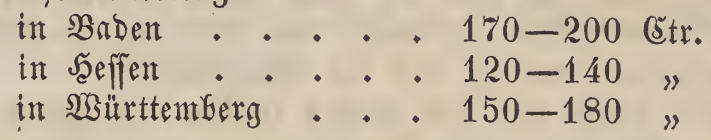

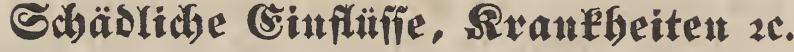

Die Satrübenflätter ftnd, wie bie Der meiften Rohl= arten, Dem Frafe der Erbflohe nusgefect, befonders bie ber früber gefäeten Bractrüben, und nicht mentger fochäblich als biefe fint eine fleine Schneffe und cinige Raupen, mie bie

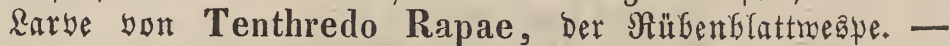

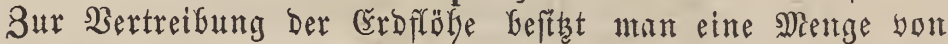
Mitteln, bie aber zum großan Theil ifrem 3meefe nicht yolf= fommen entfprectyen. (šintge vermifyen Den Santen yor ber

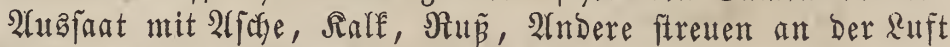
zerfallenen und gut pulveriftrten Rale bünn über bie Siftan= zen, Dber begieß̄en bas Rand ntit einer Mifchung you Seife

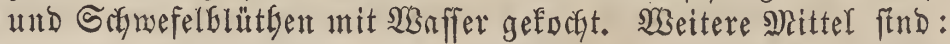
yor ber Saat friftaen und ältern Santen zur Saălfte einige Stunden in $23 a f f e r$ einzuweidfen und bann Den eingerveidfen ntit Dem uneingemeidyten auzzufäen. Durch Das Reiment biefer Samen zul verfogiedenen Beiten ift ntan meift im Stande, mentigfens eine Saat yor Den Eroflöken zut retten.

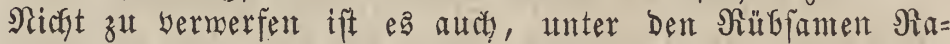
Diess Nettigfraut Galten. Siegen bie ßaupen mentet man fo ziemlicy bie gleichen Mrittel an, und gegen die Grfyerfen

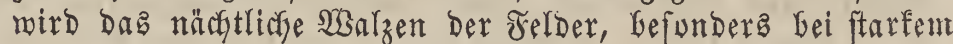
Thau, menn bie ßflanzen nicyt zu fefr erftarft find, an= geratgen.

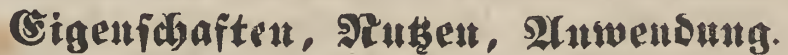

Die vormaltenden 3 eftandtgeile der Saatrüben find nach (singof:

$$
\begin{aligned}
& \text { Buffer . . 0,048, } \\
& \text { (̌̌ineíß . . 0,005, } \\
& \text { Woaffer . . 0,917, } \\
& \text { Fafern . . 0,028, }
\end{aligned}
$$




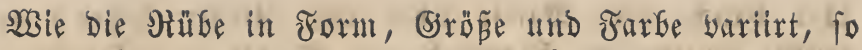

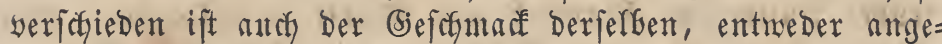
nefu nild und füb, etras freffenartig, wenn fte im berbfte ober Sommer und in Yeidyterent Boben, ober beiṕig tub rauf, ober bitterlich fogarf, wenn fie iul orübjabre und in zu Gindigem oder naffem Boben beftellt wurbe.

Die Santrübe mirb ala Biemüfe ober Galat zubereitet, mit ober reie Sauerfraut eingentadyt, genoffen. Die gröęe= ren Blattripten madyt man in einigen Begenden, wie am Niederrbein, ebenfalfs ein, und bie gelben Blattfeime geben im Winter einen angenehm formerfenden Salat. Worzugs: weife bienen aber die Rüben als Biebfutter. Sie find frnmut Dem Sirate ein gefundes Futter und werben yon alfent $\mathfrak{B i e b e}$ gerne gefreffen, find jedod ifrer mäferigen $\mathfrak{B}_{e}=$ ftanbtheile megen weit neniger nabrbaft arz Robilruben unb

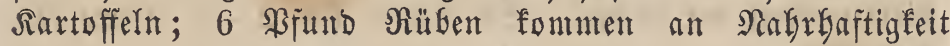

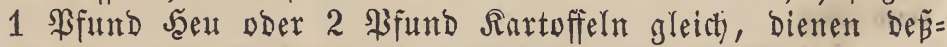
halb meniger zur Miaftung, wermebren zmar bie Milda bei Den süber, macten fte aber, befonders geringere Rüben= forten, wäfferig. Hebrigens Gaten fie immer Den Borzug, daß fte in einer Seit gefüttert werden fönnen, in weldyer anderes grünes శoutter fehlt.

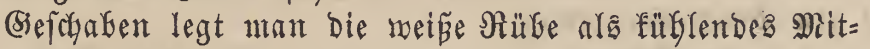
tel auf Brandjchäben, gebraucyt Den Saft und bie Afbfochung aud zumeilen inuerlich und aIs (b) Hrgelmaffer.

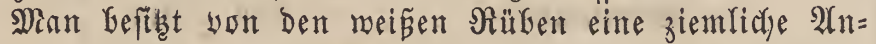

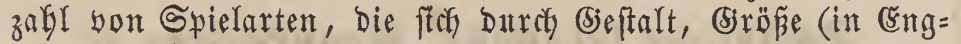

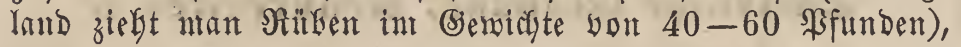
Farbe und befchmar augzeidynen, und wir molfen nun bie befannteften Derfelben ber Neibe uadf aufzäblen:

\section{Lauge ßäbe.}

Brassica Rapa oblonga. De C. Brassica Rapa sativa oblonga. Brassica maxima. Whistl.

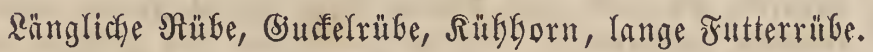
Rave oblongue.

Rübe lang, vber auch länglich und eifürntig, meift weit über ber Erobe ftehend, wein̈, fleifchig.

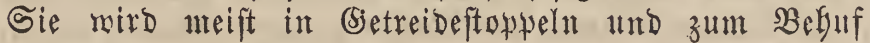
Der Bieffütterung fultivirt.

2luch fe zerfält wieder in melgrere Huterfpielarten:

a) Sigei ze lange $\mathfrak{R}$ übe.

Brassica Rapa sativa oblonga, radice candida.

(5)uffelrübe (int engern Sinne), lange Seerbftrübe, Feld=

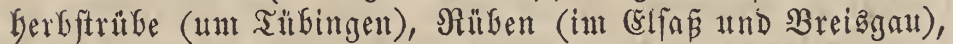
Stoppel = oder Stupfelrübe (in einigen Nateingegenden).

SWurzel in Form vft mie bie Saftinafe, oft auds melgr länglichrund und in ein fleines SBürzelchen aublaufend, oft 5-6 Bfund fobwer, zumeilen mit aufrectitftefenden $B$ lättern.

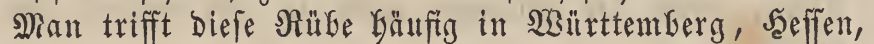

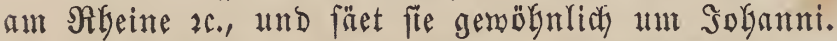

Diefe Rübe ift jung genoffen woblichneeffend, mürbe.

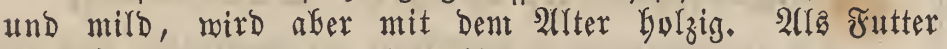
vernelgrt fie Gejonders bie Mitlef.

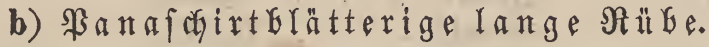

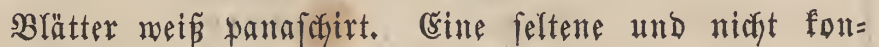
ftante $\mathfrak{B}$ rrietät.

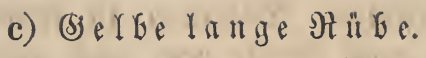

Brassica Rapa sativa oblonga, radice flavescente.

Sublferbftribe, lange gelbe bon Ryon, gelfe Santribe.

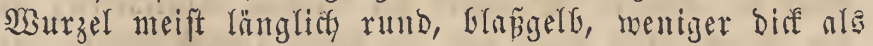
Die weipe SRübe und yon füperem bieftymarf.

d) $\Re$ othe lange $\Re$ übe.

Brassica Rapa sativa oblonga, radice punicea.

Range blaue Seerbitrübe (bei Tübingen), Stowtelrübe

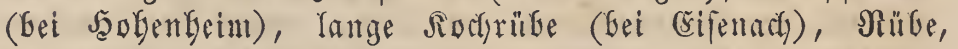

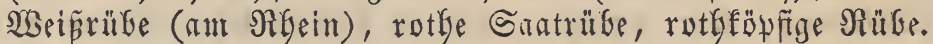

Noburgel aแBen und innen rötglidy, zureifen etwas vio=

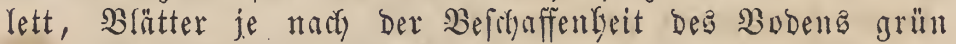
oder fofgun roth. Sie gegt gerne in bie meipe lange säbe. iller.

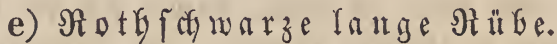

Brassica Rapa sativa oblonga, radice atro-punicea.

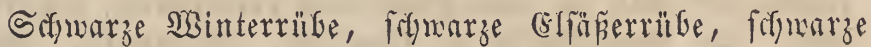

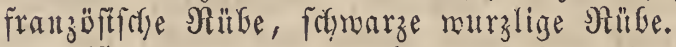
breitet.

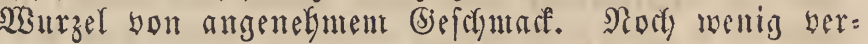

\section{2. kunnoe hübe.}

Brassica Rapa sativa rotunda. Brassica Rapa depressa.

Mairübe, ซrübrübe, Telferrübe, abgedattete Nübe, eng= lifche Turnips.

Rave aplatie.

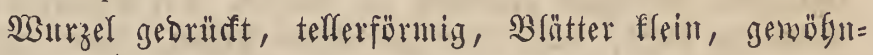
(id) bünngeftielt.

Itnterfpielarten yon ifre find:

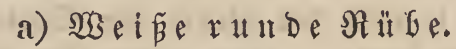

Brassica Rapa sativa rotunda, radice candida.

Jrübrübe, Tefferrübe, Mairube, frübe platte Mairüte

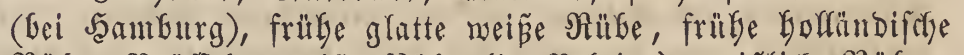

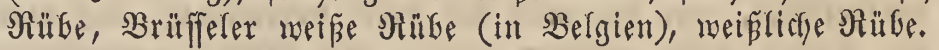

Rave blanchâtre.

Man fäet die Mairübe im Miärz ober Rtril in einen lorfern, etmas fandigen Boben, und bie Samen geben nady

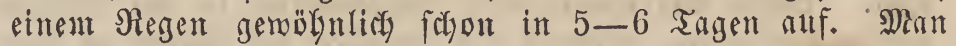

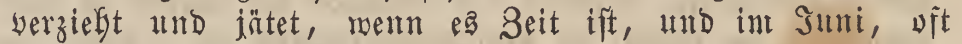

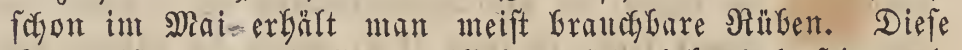

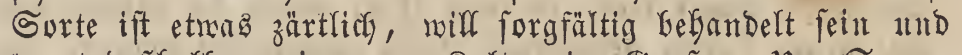
taugt beß̈garg meniger zur Rultur im Bropenen. Itm Samen zu erzieben, ninmt man gegen Safobi eine neue Sat vor, Gringt die Räben in Sftuber und Noventber aus dem

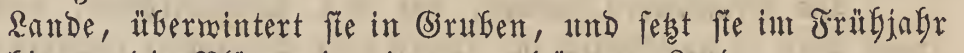
bis an die $B$ lätter in ein gut gebunngtę $\mathfrak{R} a n d$.

Die Nourzel biefer Naübe ift fejt, feldr fün, gift ein

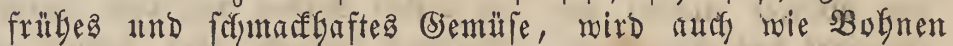
mit Salz und biemürze eingemactit ober it Scheiben ge= fdyitten unb getrofinet bis auf Den Sommer aufberwabrt.

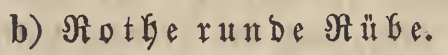

Brassica Rapa sativa rotunda, radice punicea.

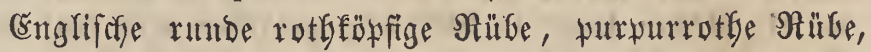

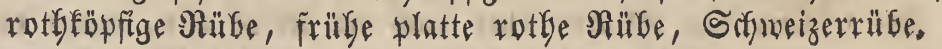
Rave rouge. 
Riibe bisf, oben furfurrotb, unten trüb biolett, yon

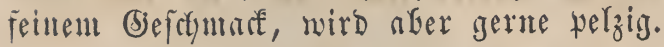

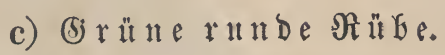

Brassica Rapa sativa rotunda; radice supra tcrram viridi.

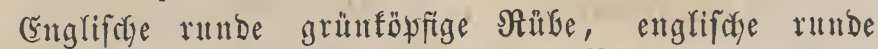

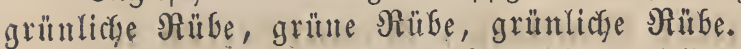

Whie die weine Rübe, aber mit runblicher, über ber

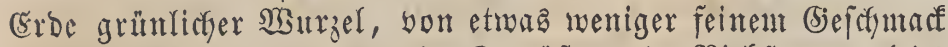
als bie worige, jedoch als bientufe und Bielffutter gleich emtrelglungaswerth.

\section{d) Befbe runde $\mathfrak{R}$ it $\mathfrak{b e}$.}

Brassica Rapa sativa rotunda, radice foris et intus flavescente.

(5elfe 2 seifrübe, runbe gelbe Matrübe (bei Tübingen),

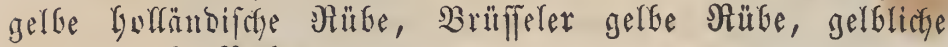
sitbe, gelbe Riutbe.

Rave jaunâtre.

Riibe rundlich, aupen und intren gelblich, yon feinent

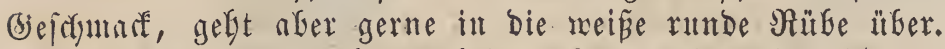

Sie gibt ein felyr moblfchmerfendes Bsemüre, ifte ein gutes Biebfutter und foll ber $\mathfrak{B u t t e r}$ eine gerbe Farfe mit= theilert.

\section{Celtowerrübe.}

Brassica Rapa sativa minima.

Teltiuer Rübe (yon Dem Drte Teltom bet Berlin),

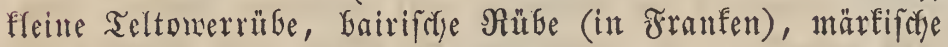

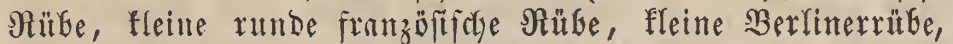

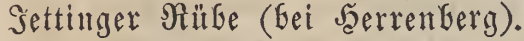

(sine fegr fleitue, oft faum 2 3oll lange und $1 / 2 \quad 30$ ll

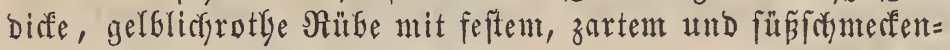
Deur F̂leifche und fleinem Sirrute.

Sie mirb Gauptfäcbliç in Der Marf $\mathfrak{B r a n b e n b u r g , ~ u m ~}$ Teltow und in ber Bergend yon Cáluärde unt dab Dorf Schmarzlofen, im Wüttembergifchen bei Jettingen angebant. Mian fïet fite in (biarten um Jobanni und erntet fie im $D f=$ tober, fie verlangt einen fanbigen und lefurigen $\mathfrak{B}$ oben und, wie es forjeint, wou eigentbitmlictyer Befchaffenbeit, indent fie in jeben andern ausartet. Sie ift of ne Bmeifel bie yor= jüglichfte unter affen Santribenforten und bat eimen äunerit feimen müartigent biefchmarf.

\section{Stechrübe.}

Brassica Rapa sativa, radice brevi.

Gtirfelrïfe.

Rlein, Enollig, mit berfem freifich und ber Teltomer= rübe ägnlictyent befchmarf. Sie und bie vorige werben yon Ěinigen für eine Spielart ber Soblrübe geGaltent.

\section{Ottersbergex lübe.}

Bon rötglidy gelber Farbe und fefr lieblictem Ge=

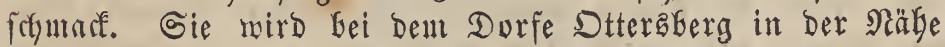
bon Bremen iul Moorbuden gezogen und ift bafelgft, mie bie Teltomerrübe in Brandenfurgifcten, ein bebeutender

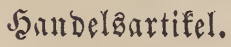

\section{Brassica Napus. L.}

Brassica asperifolia. Lam.

,$\quad$ oleifera. Moench.

" oleracea arvensis. Lam.

, oleracea, S. Spr.

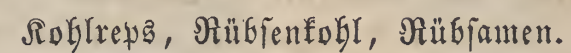

Wild Cabbage or rape (engl.)

\section{Arteit, Shatafter.}

Sarzel fpindelförmig, bei einigen Unterarten ftarf auf= getrieben. Stengel aufredgt, äftig. Untere Blätter fabl, leberförutig. Dbere Blätter find unten etwaz făduäler, un= faffen aber Ga!b mit breiter berzförmiger $\mathfrak{B}$ afis Den Stengel. Bluntentraben locker, focfon bor dent 2 fufblüben verlängert,

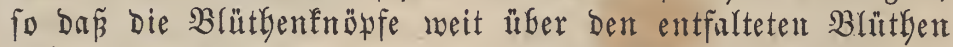
fiteber. Selchblätter gefürbt, etwas abftelgend. Blumenblätter faft feilförmig, goldgelb. Staubgefäßze abjetlend, aufftre= bend. Samen rund, glänzend, bläuliç fónarz.

\section{Słlütbe = Beit und Danev.}

\section{2lpril - suli. $\odot-\sigma^{x}$. \\ \$orfommen.}

SBild in Sicilien und Reapel, werwildert bei unz unter Der Sant an 2lfferrändern.

$$
\begin{aligned}
& \left.\begin{array}{l}
\text { Sultur, } \\
\text { Eigenfofaften, Nuken, } \\
\text { Amwendung }
\end{array}\right\} \text { bei Den 2(Garten. } \\
& \text { Hnterart. } \\
& \text { Brassica Napus rapifera. }
\end{aligned}
$$

\section{Brassica Napus rapifera.}

Brassica oleracea Napobrassica. L.!

Brassica campestris Napobrassica. De C.

Solghübe, Sterfrübe, Sundfentobl unter der Črbe, Unterfohirabi, Bodenfoblrabe (WBürttemberg), Rübenfolgy, Srautrübe (Stejermarf), Rlımurübe, Dorfe voer Doriche,

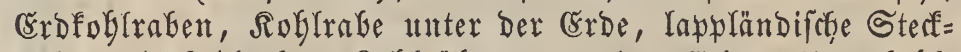

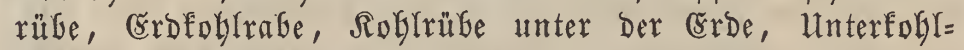
rübe, Rlumperrübe, Solglrabi unter Der (Erbe, Erorübe,

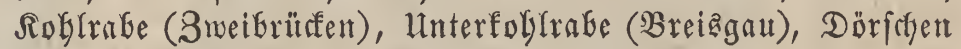
(Baireutf)), Rutabaga.

Cole rape
Chott navet (franz.)

Turnep Cabbage, with the Turnep under Ground. (engl.)

Rute bagger. (

Cavalo navone. (itar.)

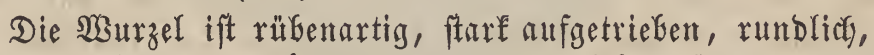
äftig ober einfact, melyr ober weniger tief, oft mur zur

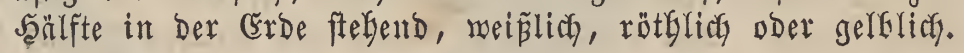

\section{§ultutu.}

Die Soglrübe gebeigt noch in fälteren und böber ge= legenen Drten, ba fre einen ziemlictent Jirnd son Rälte er= tragen fann, fe wird allgemein angebaut, verbient aber nocts wiel werbreiteter als $\mathfrak{b i e h}$ futter gezogen zu werden. Sie berlangt einen lorfern, tiefen $2 e f m b o b e n$, aud ein fdywerer Boben foclägt ifnen zu, wenn er nur gut Gearbeitet und gebungt morben ift; in einem Sandboben bleiben fie meift 
flein. Wian fäet fee int Miärz, 2(pril ober Mai (ber Errb= flöge wegen) auf ein fchattig gelegenes Beet, und verfecet

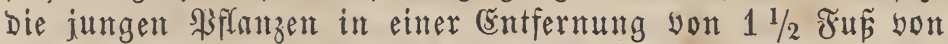

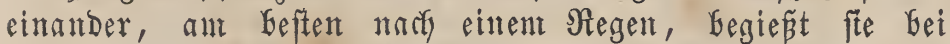
troffenem 3 Setter, GeGart und befaufelt fte eimigental etmas weniger hoch ala das firaut, mas negen Des ltnfrautes und Der grofen Neigung Der Soblrübe, Golzig zu merden, nicht berfäunt werben barf; man Güte fich üGrigens, bei

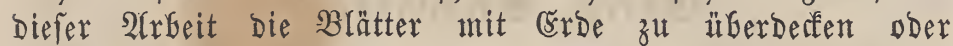
auch) zu boif zu bebaufeln, naffe Solgrgänge ober naffert Boben ausigenommen, ba fite in resteren Fralle zu wenig Bobenfeuchtigfeit erhalten würben. Begieñt man bie Robl= rüben noch yon 3eit zu Seit nit berbiunter sauche, fo swachfer fie nux unt fo fofneller und eräftiger. Sollten bie

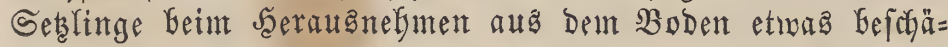
bigt worben fein, fo befchneidet man fie etroas, aber aud

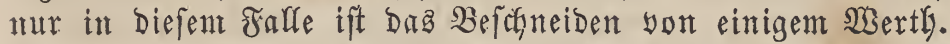

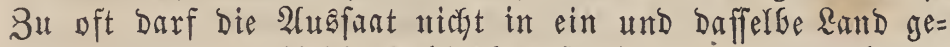

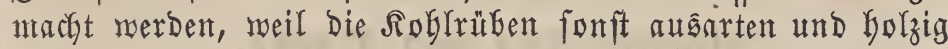
merben. Shitte Septembers fönnen fie ohne allen Schaben afgeblattet werden, nur ift es gut, fie Dann mieber etwas

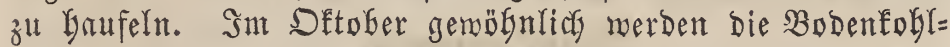
raben ans Dem Rande genommen lind zmar bei troffenem Better und troifenem Boben, ntan entfernt mur bie nod

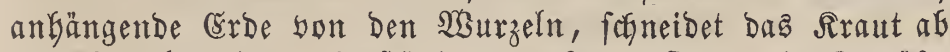
und Geroagrt fte an froftfreien, trodfenen Drten, in (semüfe= felfern, in Bruben (aber bier nicht in zu gropenen seanfen), ober foglägt fie im (barten an yor falten Winben gefobübten Steflen ein und bebeclet fte nur wenig mit Strof ober Erote, oder aber man läpt fie gerabezu ntit ben Blättern im Freien, anchbem man fie vorker gebörig bebaufelt bat. Sie balten ftif genöbnlich gut biz zum zrübling, wenn nicht gerabe ifr SWinterquartier zu warm ober zu feudbt ift. (Etma fau= Yende $\Re$ tüben müffen fogleich entfernt merden. So mentg empfindlich bie Roglrübe gegen Rälte ift, fo wird fie bod Durdy Diefelbe, menn fie zu ftreng und anfaltend ift, pelzig ober faur. Un Samen zu erbalten, nimmt man im Dfto=

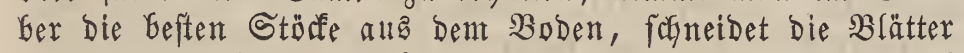

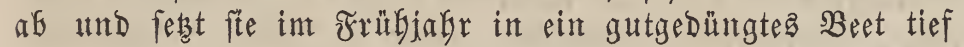
ein; Den beften Samen Gefommt man imner yom beaupt=

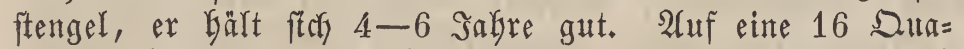

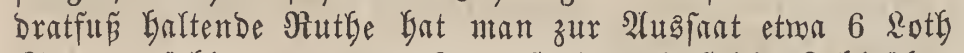
Gamen nötgig. - Man Gat gefunden, dá die RoGlrüben fitd) ganz gut unter Den Ropffohl pflanzen laffen, Da ftaf

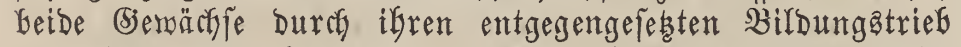
gegenfeitig nicht Ginbern; Der Sopffogl nämlich breitet ftch

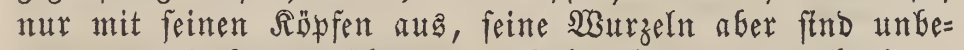
beutend und furz, während die Roblrübe nur unterfalg des

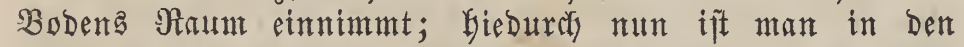
Stand gejest, yon einem Stülf Rnnde ben gleichen Ertrag zu gerwinnen, wozat fonft eine boppelt grope Fräche nöthig gewefen märe. - Sur Samenzudgt nimmt man bie grösten

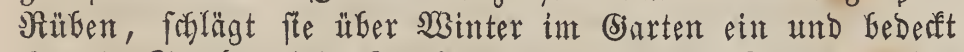
fite mit Strof; Ende Juni's reifen Dann bie Santen, welitye $2-3$ Jabre lang gut bleiber.

Die Bobentublraben geben in einem feuchten Rlina und feutchten $B$ oben einen beträchtlichen Errtrag, allein einen

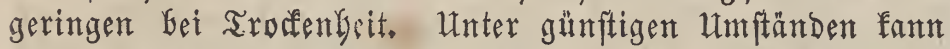

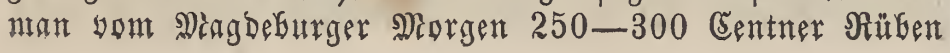

und Blitter erfalten, in anbern Falle aber oft nur 120 Centuer,
in Baben
115-230 อัentmer,
in Şeffen
$85-170$
it $\mathfrak{B}$ itrttemberg
$100-200$
"

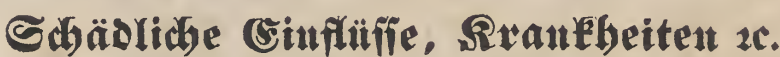

Atud bie Blätter biejer Solglart werben yon ben (Erd = flöben, wie bon Den Raupen, Gefonders auch yon ben Mäu= fen ftarf beimgejucht; um bie Erbflöbe einigermnen abzu=

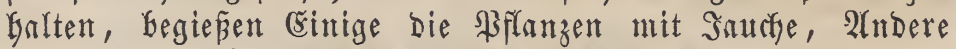
legen igre Roblrübenteete in Der Nälye yon Bjemäffern an.

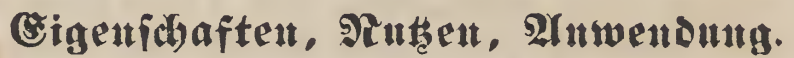

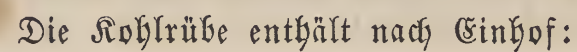

$$
\begin{aligned}
& \text { Buffer . . . . 0,065, } \\
& \text { Ěimeí́ . . . . . 0,005, } \\
& \text { WBäfferige Theile • • 0,875, } \\
& \text { שָaferftoff . . . . 0,055. }
\end{aligned}
$$

Die Rokfrüben gefen zum Theil ein febr gutes, nabr= Gaftez und fochnaffyatez bemüfe, zum Theil aber aud find

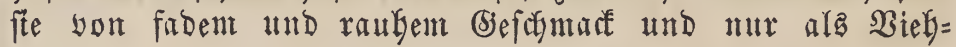
futter bienlidy, als meldaes fête aber autch mit Den Blättern

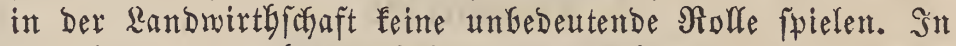
Bezielgung auf ifre Rabrgaftigfeit verbalten fits 4 Bfund

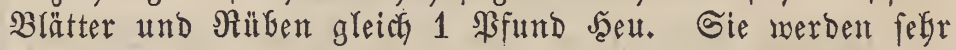
gerne, Gejonders im Eiemenge mit troffentent Futter, yom Biel gefreffen, fie vermebren bie Mildy und taugen zur Miaftung noch mefr als die Royffoblarten, Runfelrüben und Sartoffeln, natürlich bie foglectsten und Golzigen Sorten ab= gerecfinet. Suerft füttert man das firaut und fpäter erfit bie $\Re$ üben.

\section{Schweotild ftoblrübe.}

Brassica oleracea Napobrassica Rutabaga. Brassica lapponica.

Rotfol, Rolrot, Rutabaga, Rotabagi, fchmedifcyer Tur=

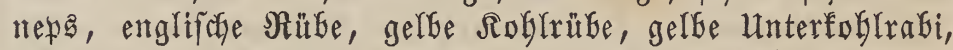

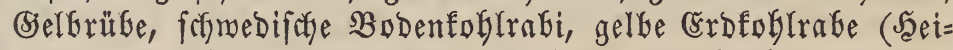

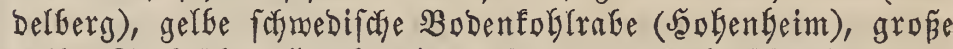
gelbe Steffrübe (Jamburg), gelbe rumbe Roblrübe (Erfurt), gelbe formedifge Roglrübe (Nürnberg).

Swedish turnip.

Sie ift nobl eine ber beften Roflrübenarten. Shre SWurzel wird oft febr grofi, gegen 6-8 \$fund fidwer, ift eiförmig oder mefrr runblich, etwas über ber Erde ftefend, gerb, mit feftem, felgr zartem, beinafe faferlofem und weichem

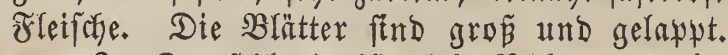

In Deutichland ift Diefe Rübe ungefägr erft 22 sagre Iang befannt und fommt yon England.

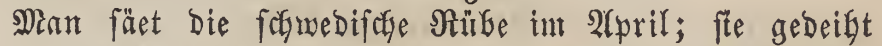

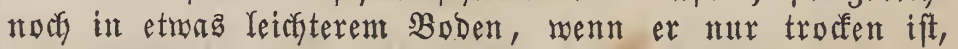
und Dauert int Freien mely als afle andere Sorten über Den Winter aus, wird auch nicht pelzig. Sie liefert ein

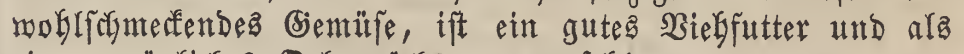

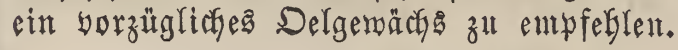

\section{UGelbe fionltübe.}

Belbe fpanifche Roglrübe.

Sie mirb in gutem $\mathfrak{B}$ oben auperorbentlidy grofa, Gat 


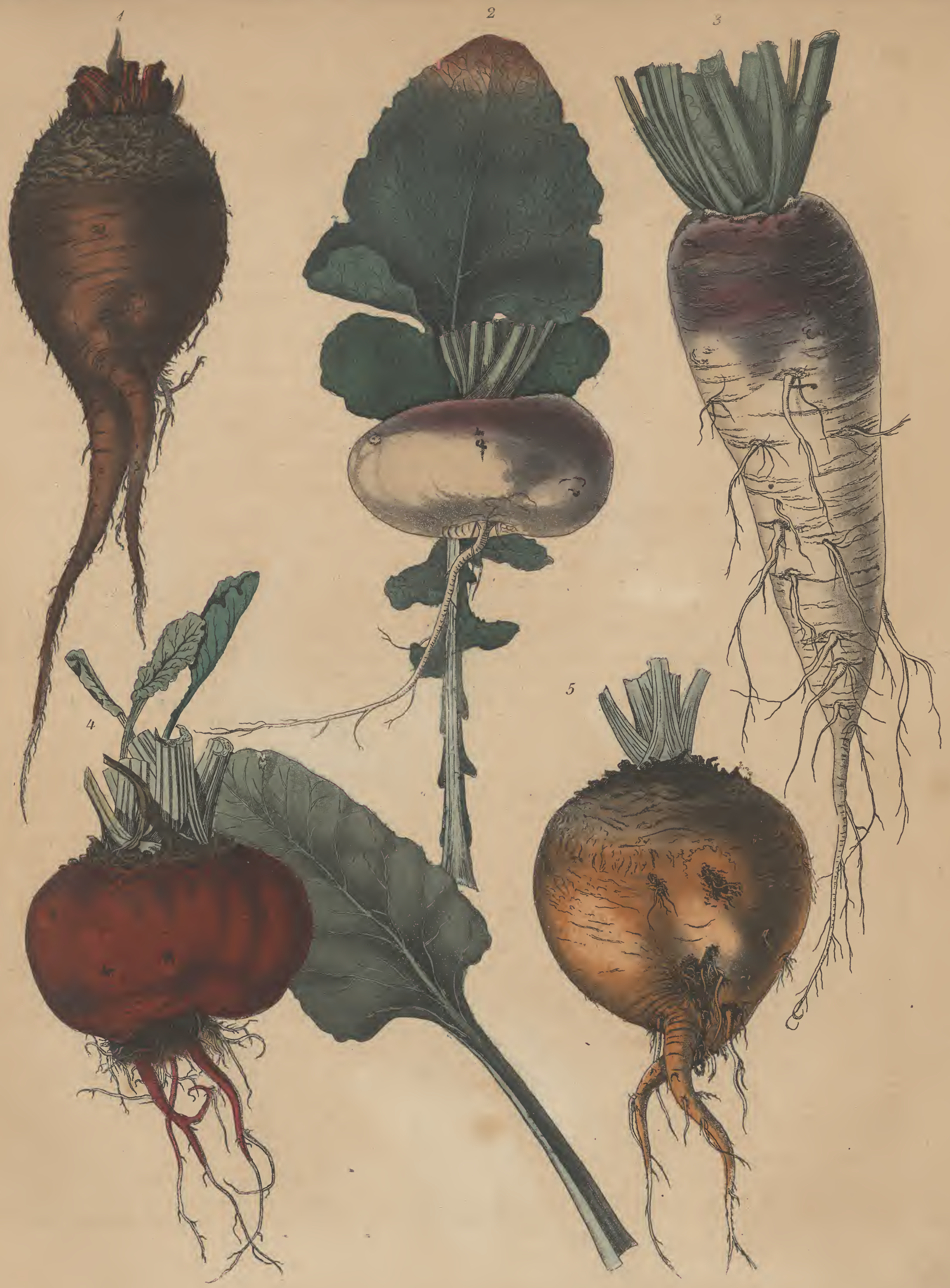



ein fegr zartes, woblfçmerfendes, felten fajeriges, rötflid

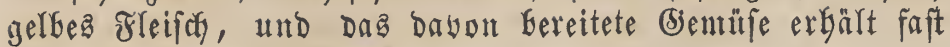
bie Farbe ber gelben Miobre.

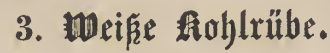

Semeine weise Bobenfohlatabe, eigentlictye Roklrübe,

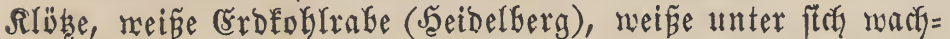
fende Soblrübe (Eifenady), meife Bobentoblrabe (Stuttgart, Tübingett).

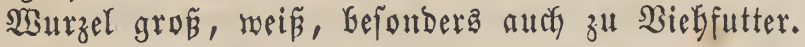

\section{Röthlidbe fionglrübe.}

Rotglaltige Bobenfoblrabi, rotgblätteriger Räbenfogl. SWurzel und Rüben rötblict). - NBird meift mur in (3)årten fultigirt.

\section{Beta, L.}

\section{Syfteme:}

Aizoideae Atripliceae. Reichenb.

Atriplices. Rül. Juss.

Blita. Adans.

Chenopodeae. De C. Spr.

Incompletae. Ray.

Sysellophyta. Neck.

Pentandria, Digynia. L.

Seley 5ipaltig, bleibend. Bluntenfrone feflt. Staub= gefäв̈e 5, Den Relchzipfeln gegenftändig, einem fleifchigen Singe, weldyer Den zrudftboden ungibt, eingefügt. Staub= fäben pfriemenförntig. Staubbeutel eirund. Frustefnoten platt, eirund, mit Dem Rèldye zur bä̋lfte verwadyfen. Briffel fadenförunig. Narben 2-3, lanzettförmig, fpip. Santen in ben sieldy eingefdiloffen.

\section{Beta vulgaris. $\mathbf{L}$.}

Beta rubra. Bauh. $\quad \beta$. Beta crispa. Tratt.

Mangolbrübe, Runffelrüben = Maangold, genteiner Man=

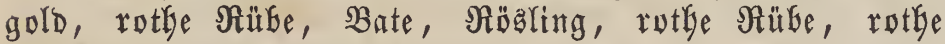

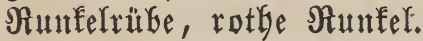

Red Beet. (engl.)

\section{Arten, Eharafter.}

SYGurzel biff, rübenförmig, fpindelförnig, yon verfacie=

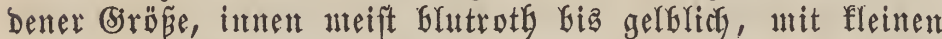

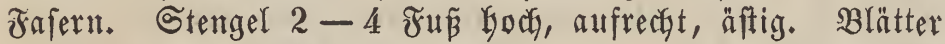
geftielt, gra $\tilde{\beta}$, flach, glatt, glänzend, eiförmig, grůn ober Graunroth. Reld 5Glätterig. Reldyblätter gezälgnt. Blütben gebäuft, grünliç. Same nierenfürmig.

\section{3̧lïthe $=$ Beit ant Damet.}

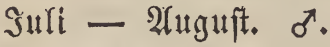

\section{3otemment.}

Sübeurwwa, an ben Rüften Spaniens, Sortugals, Sta= liens 2c., in 2 ffett und 2 frifa.

\section{Nultux.}

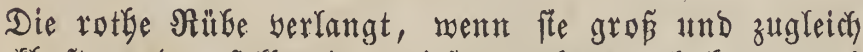
formadfbaft werben joll, eitren tief gegrabenen, locern, noch nabrbaften, aber midyt frifoh gebungten Boben, ber yorber fodon getragen hat; in frifich gebüngtem 2 oben werben fie

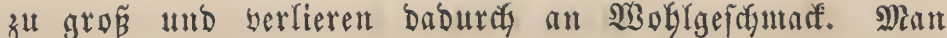
fäet bie Samell, nachbent mant fe gewöhnlich zuyor einge=

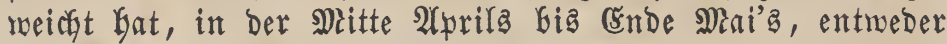

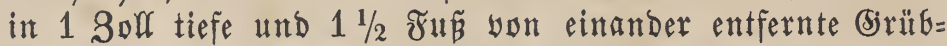
chen unb läpt fie, ofne fie fyäter zu verfeben, an Drt und Stelle; ba bie Samen mit Der Samenfapfel gefäet werben,

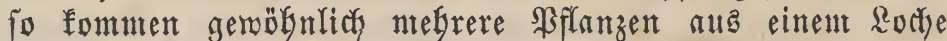
Gervor, biefe entfernt ntan aber bis auf einte; Gei biefer

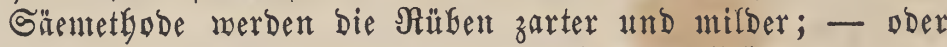

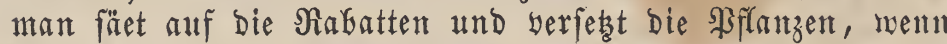
fie $5-6$ Blătter bałen, $1-1 \frac{1}{2}$ Jü you cinander ent= fernt. Später befarfét man fie yor und nach cinem Siegen, reinigt fie yom Unfraute und begiest fie bei trorfenter $\mathfrak{X}$ bit= terung. 2logeblattet folfen biefe Rüben nicht merben, weil

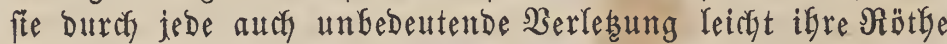
theilweife poer ganz verlieren. Int Anfang Dftobers ober Nobembers nimmt man fie aus bem Ranbe und vermakrt fie, nachbem man yorber bie Blätter abgenommen Gat und Die Siüben gebörig abgetroffuet find, in Gruben ober Selfern

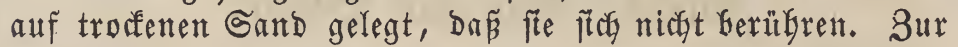
Samenzudgt wählt man bie beften, glatteften und bie fogön= ften Dunfelrothen Bffanzen, Gefreit fie bis auf's Jeerz yon Den $\mathfrak{B l a n t t e r n , ~ u ̈ b e r m i n t e r t ~ f i t e ~ a u f ~ b i e ~ e b e n ~ a n g e g e b e n e ~} 2$ rt, werbflanzt fie im März auf einte fontrig gelegene, yor falten

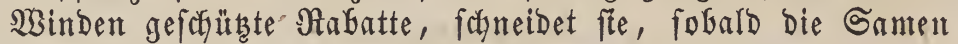
bräunliç werben, ab und bängt fê, um fie volfends reif und troveen werben zu Iaffen, an lufttigen Drten nuf.

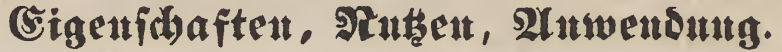

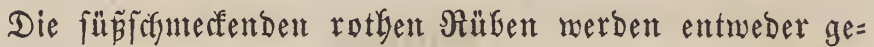

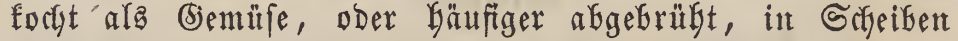

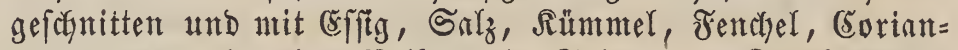
Der, Meerrettig ober Nelfen als Galat und Zugehör wer= fpeist. Sm Dantyfe gefocht, Gleiben fie foubuter roth utro werbent milder. Die zarten Blätter bienen als (bemüfe, bie

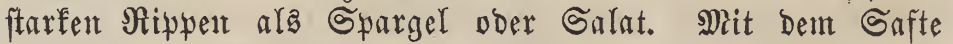
Der rotben Rüben färbt man Gie unb Da rotbe Weinte.

Man bat folgende Barietäten:

\section{Wentine rothe läbe.}

2. (Éroge rotbe Rübe.

Beta vulgaris rubra major.

33irb am Gäuftoften angebaut; meift länglictye, intuen und auneat Glutrotbe $\mathfrak{B}$ Burzel.

\section{Aleine rotbe hübe.}

Sleiner als bie sorige, aber yon gleicher Farbe, fü $\bar{B}=$ fognterfend, ift viel früber unb fann oft fordon im 2luguft Genüht merbent.

\section{Runde rothe läbe.}

Runb und elen fo frül.

\section{UGelbe rothe Rübe.}

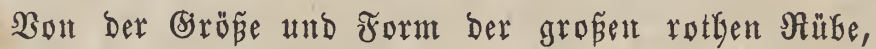
afer you füperem Befrsmat.

\section{Meicke rotbe läbe.}

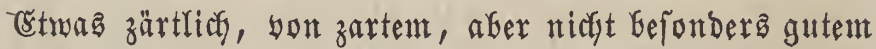
Befictmanf. 


\section{Beta Cicla. I.}

Beta hortensis. Miller.

sativa. Bernh.

", vulgaris. L. var. L. Sprengl.

, altissima. Beckmann.

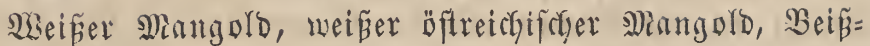
folgl, Beifrübe, Burferritbe, Burgunderrube, Bangers,

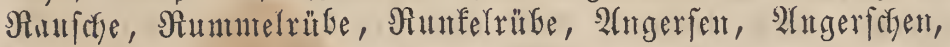
Sinutrübe, Diff́rübe.

White Beet. (engl.)

\section{artew, Eranafter.}

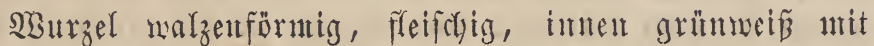

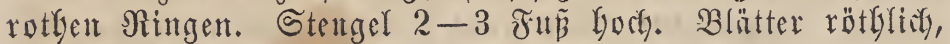
breit, weffenförnig, mit weisent Nerben und Stielen. Sten=

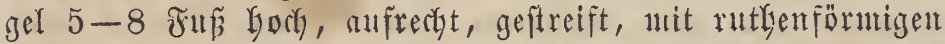
alefter. B̉ütben fteben zu 3 . Jielchblättchen glatt, an ber Baftz ungezăbint.

\section{3lütbe = Beit "nto Danev. \\ Suli $-\mathfrak{A}$ uguft. $\delta^{x}$.}

\section{Sorfoument.}

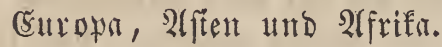

It $\operatorname{terart.}$

Beta Cicla altissima.

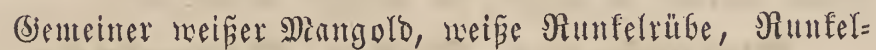
rübe, ßunfer, Diffrübe.

\section{Nultux.}

Die Siunfelrüben wolfen eiuen Yorfern, wiederbolt und tief untgeyflitgten, etwn $30-40$ srocent thongartigen, magr=

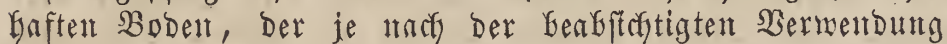
Der Piulfeln utegr doer meniger gedungt werden mús. Bum Düngen gebraucht man gut zergangentr, berfaulten, aber nie frifchen Rinds =, Sferbe = voer slenfichendung, welchent

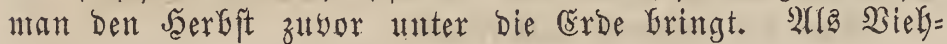
futter angebaut, müffen bie Nutrfelrüben notgmendig gebüngt werben, während die zur Bufferfabrifation Geftimmten burch frifches Düngen forwammig und arm nu Bufferftoff werben

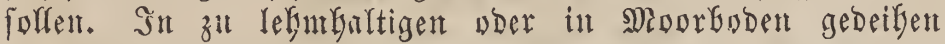
Die Runfeln nicht, fondern faulen meifteng. Die Futter= runfeln wolfen alfo einen fetten, wenn audy utegr bindigen,

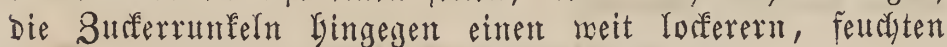
Boben, am beften utit ntergeligen Untergrund. Šin etmas feuthtes, aber warmes Slima foblägt ferner Dem 2 mbau biejer

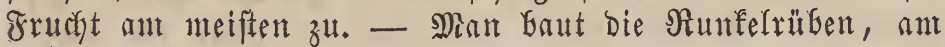
Geften bie zun Futter Geftimuten in Der Brache, bie zur Surferbereitung aber häufig int Sonmerfelde an. Mian fann fe beinake trach jeber Frutht Gauen, und fee magern ben Boben mentiger aus, als bie Rartoffeln und Roblarten, yor=

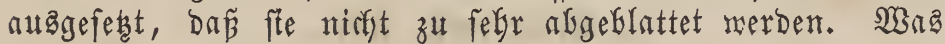

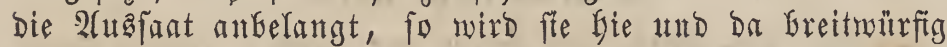
gemactyt, jeboid felten, was inbrigens wenig zu empreflen ift; bie Sant füldt zu ungleich aus, bie zu bicht ftelyendent

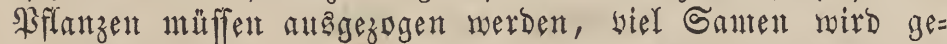
wöhnling verfohlendert, und die zarten feimenden Bjfanzen frnuchen zu lange Seit, bie meift Garte Eroftrufte zu burds= brectgen, und viele berfelfen geben zu Grunde, wenn mau

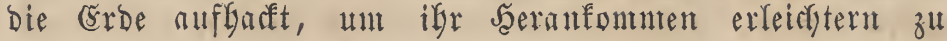
mollen. Noch mebr anzurathen ift bie Metbode, bie Santent gleich an Srt und Stelle, wo bie SBflanzent jethen bleiben folfen, reifenmeife zu ftecfen, wozu aber ein gut verarbei= teter, locferer, gänzlich you lunfrant gereinigter, marnter

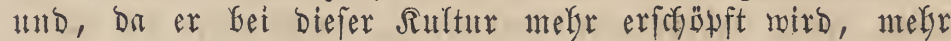
nabrbafter SBoden und ein ntildes Rlinta und ein günftiges

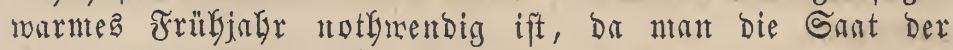
Rälte wegen nicht früfyeitig bornefmen fann. Man werfäbrt

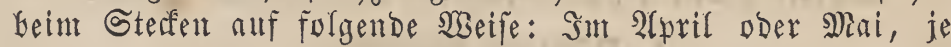
nadi) Der SBitterung, ftedft man $1-2$, nacf andernt $3-5$

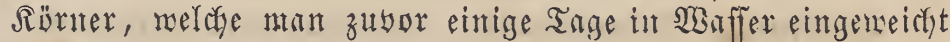

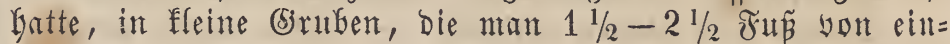

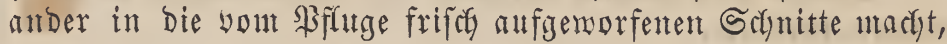
und zmar fo, bas je in ben zrweiten ober britten Sclynitt Samen gelegt mird, alfo bie Samenreifen etra in eine Entfernung yon 2 Fus you eimander zu fteten fomntent. Die Samen bebect man nur eimen 3 oll boch mit Ěrbe, voer brücft fie bei zu bindigem ober zu feuchtent Boben mur etmas in bie (Erbe ein and malzt bierauf bas Feld. (bie=

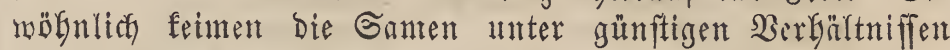
innerbalb 10-12 Tagen. WGadjen aus einemt Roche mefr

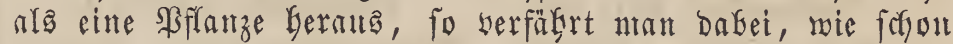

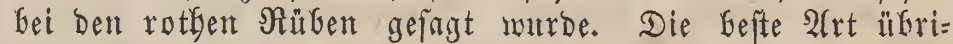

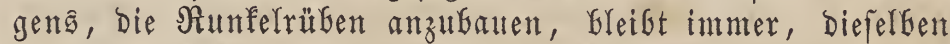
in Ifframzenbeten zeitig aufzuzieben und fte nabbler zu ver= fesent Daburch erbält man zum Berpflanzen tauglidye (bie= wädje zu einer Zeit, in welcher ntan genöbulich erft bie Gamen fterfen funn, und bie Runfelrüben fömten fich yolf= fonmener augbilden. Man fäet bie Sanen in ntit nodh

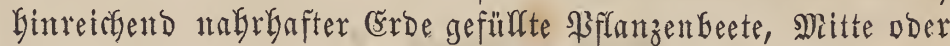
Ende März, ober, aber mit meniger Sidferkeit, focyon im

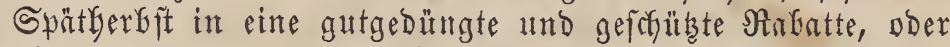

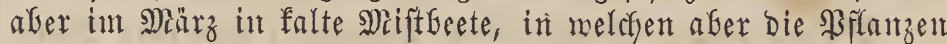
meift serzärtelt und wentiger tauglich zum 2 erpffanzen in's Feld werben. Die in ben Samenbeten gezogenen, gebörig erfarfaten, etwa 6 Blätter und follanfe einfircle 23 urgeln

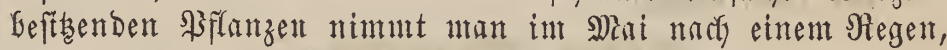
vber nachbent man fte zubor begoffen hat, mit ber Jando

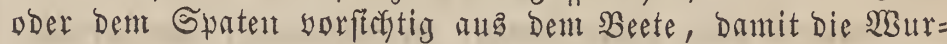
zeln nicht befcyäbigt merben, ftubt bie Blätter etwab ein und werfect fie wo möglich wor einemt Begen auf bas Feld, ent= weber gleicy Ginter bem \$3fluge in bie Jurchen ober Geffer

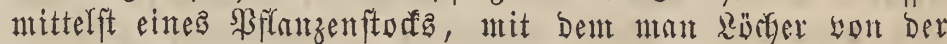

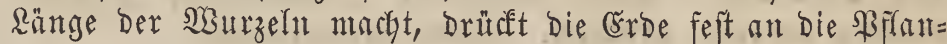
zen an, Güte fitch aber, bamit bie beerzblätter zu überdeden,

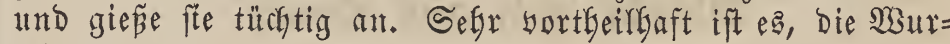
zeln nit einem ans leitgtem Thonmergel und Sande gentach=

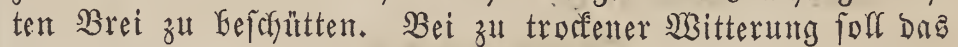
Verpflanzen mut Abends oder frith Miorgenz vorgenommen und ber Boben zuyor mit berbünnter Sauche üfergoffen werden. Das 2abftusen Der Wurzeln yor Dem Beryffauzen ift nicfyt ratbjam, da fee baburdy in ifrer Ëntwidflung ge= ftört merben, jebenfalfs aber mus biefez mit einem fogarfen Meffer gefdefenen, bamit der Sagnitt bälder verfarrfefe. -

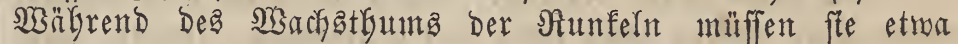
breimal befacft, bon unfraut forgfältig gereinigt unb bei troctener Mitterung begoffen werden. Erinige ratben noch 
cin Mnตี

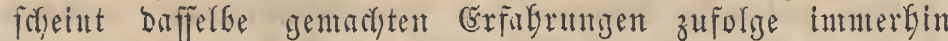

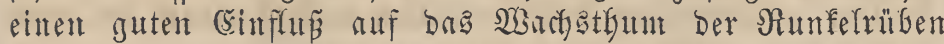

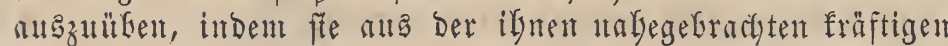
Erde wieber frifdye Nabrung ziefren fönnen. - Egfe Die S3urzeln ifre volfommene 2(usbildung erreicht baben, foll nicht abgeblattet werben, am menigften in troffenen Sont mern, weil bie $3 \mathfrak{B}$ rzeln baun immer flein Gleiben, wäfferig ober Golzig rerden; zunal ba bie zu Gald afgendumenen Blätter nicht cinmal gerne wom $\mathfrak{B}$ ief gefreffen merden und reber etras für Maftung, noch NRifchwermegrung Geitragen. Die zur 3urferfabrifation beftintmen $\Re$ unfeln butren in feinent zalfe abgeblattet werben, weil fie fonit ungentein biel 3urferftoff berlierent mürben. - Die Estnte füft in bas (Ende Septembers ober Den Anfang Dftobers; Die Rutben länger int Felde fteben zu laffen, ift ber möglicherweife eintre= tendent Fröfte regent nidgt anzuratten. Bon zrofte angegrif=

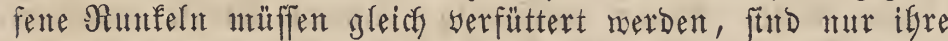

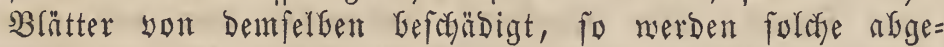
fojnitten, fonft faulen fite fodnelf; zur Bubferbereitung taugen folche gar niçt metgr. Wentiger find Dent Frufte bie meiß̄ent

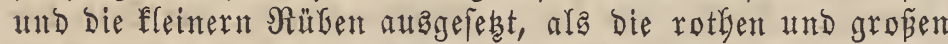
und foldge, bie fith gerne aus der Erde Geraustreiber. Sind bie Nunfeln zeitig, fo ninunt man fee bei trocfenter 2Sitterutrg, je nadj Der Bindigfeit Deas Bobeñ mit Der Sand ober Dent Grabjcheit aus Dent Rande, entfernt yon Denfelgen bie nodf anyängenden (Erotgeife und forneibet ben Sopf ntit den Brättern und bie STHrzelfafern ab.

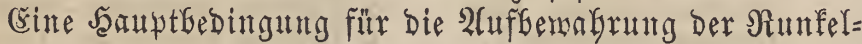
rüben ift, bieferben trodfen einzubeimfen, bannit fte ftef, ein=

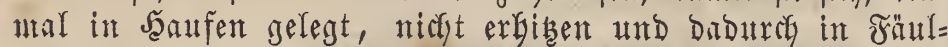
níz übergeben. Sisill man fie Gald werfüttern, fo bringt ntan fte in eine Scheune ober in eimen andern froftfreien und trodfenen Drt, auf eine etma 3 Fú Gobe Stroblage, und beberft foldge bei eintretenden fröften mit Dem gleichen

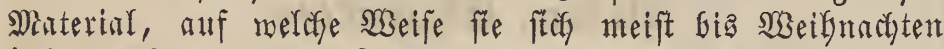
balten. Für längere Seit Gerwaknt man fie am beften in

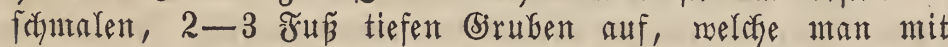
Stroly und Errbe beberft, ober auch in Sellern, melise meder zu frilt, nody zu warm ober feurgt fento; Dody gey ören Reller mit biefen ssigenfogaften zu Den fertenern und es futnd Dés=

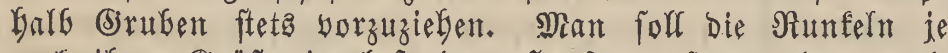

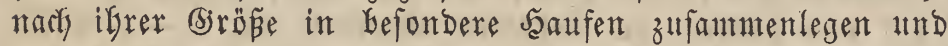

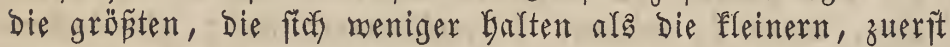
Genthen. Die zur Bufferbereitung beftimmten Nunfelrüben

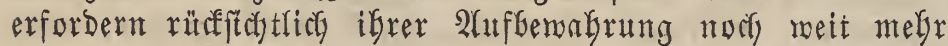
Sorgfalt, als die đutterrüben. Die Des Ropfa, Der Blätter

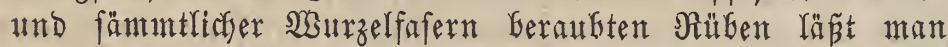
an Deberften Drten fo lange liegen, Giz Die Schnittflutefent Derfelben abgetrodfnet ftnd, Gringt fte Dann in trodene, ge=

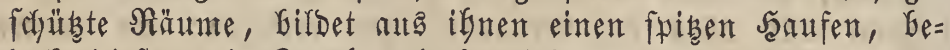
Deset biefen nit Stroh und fo biel Erbe, daf oben mur ein

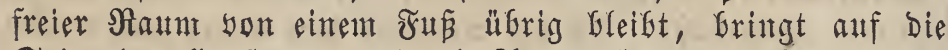

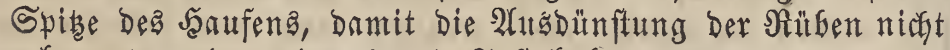
gefentmt werde, eine 4-5 Fus bohe, aus Brettern oder

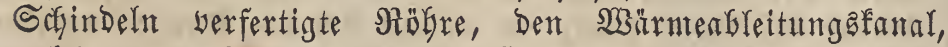
welefe utan bei ungünftiger SBgitterung beberft und ibre Definung Gei eintretender Rälte mit Stroh verfoblieśt. Snt Jefrunr und Miärz Gei gelinder SSitterung Greitet man mun

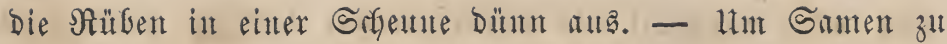
ziegen, ninunt man bie beften, glatteften, aber niçt gernde die gröp̃ten Punfelu iut Sergfte aus dent Rande und ver= metgrt fe bia zun fommenden Frügling, wie bereits ange= fïlyrt nurbe, und febt fie, fobald es warm mirb, in einer Ěntẽermung von $2 \widetilde{\mho} แ \tilde{\beta}$ yon einander in ein yor falten

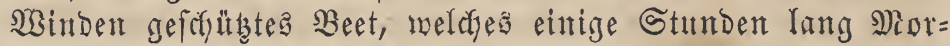

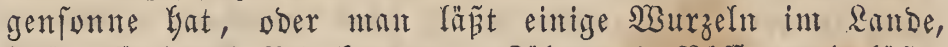

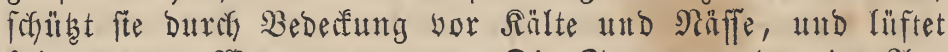

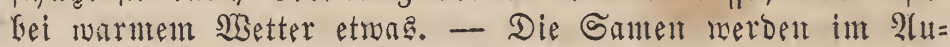
guft oder September reif, aber meift ungleich, und man formeibet die reife Samen Galtenden Stengel ab und läpt fie an einem trodfenen, luftigen Drte aufgebängt troffen mer= Den. Sie falten 4-5 Gabre und länger gut. - 5-6 SFuto Sörnerbebarf redyet man gemöhnlidy auf den Morgen.

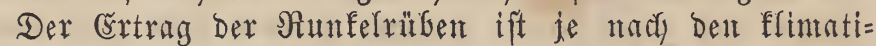
foren und Boden = Bergältniffen und Der Befteffung verforie= Den, beträgt jeboch Durdyfdrittlicfy yom Morgen

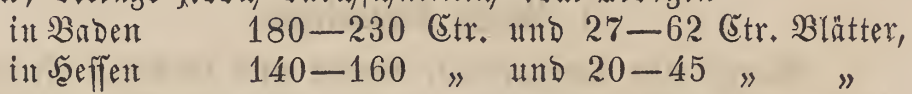
in $\mathfrak{B}$ intttemberg $160-200 "$ "utb $23-58$ " "

\section{Sabäblibe Cinflüfie, Rrantheiten 2 c.}

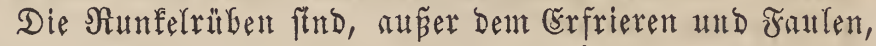

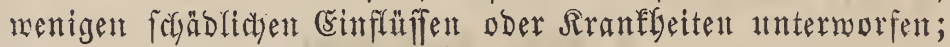

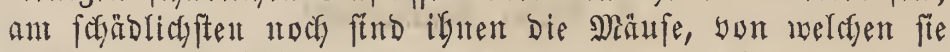
dft gant ausgeföblt werden, ferner bie Engerlinge und bie grauen Erobrauper.

\section{Eigenfdhaften, Nutzen, Atwendun.}

Die Nunfelrübe entyält uach Ëinfof:

$$
\begin{aligned}
& \text { Sucferftoff .... } 10 \% \text {, } \\
& \text { Éimeís . . . . . } 31 / 8 \text {, } \\
& \text { Fafern . . . . . } 31 / 8 \text {, } \\
& \text { Wäfferige Theile . . . } 86 \% 3 \text {. }
\end{aligned}
$$

Sbmogl bie Nunfelrüben zumeilen audy als Salat ge=

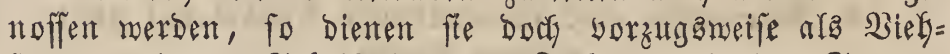
futter und zur Fabrifation Dez Surfers und Des Syrups. Sie fitnd ein füpes und mie aud bie yolffommen auşgebil= Deten $\mathfrak{B}$ lätter ein dem $\mathfrak{B i e h}$ willfommenes und gefundes Futter, jedody fein ausigezeidyutes Milchfutter; fie follen

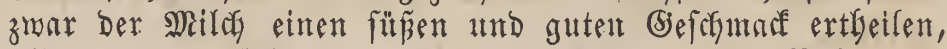

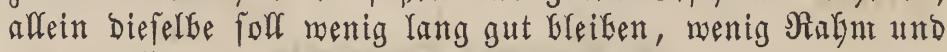
pine wäfferige, nidst Galtbare Buttter geben; Die Sirfunts

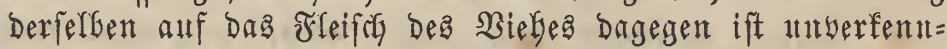
Gar. Aan Nabrgaftigfeit ftelen fte Den Rartoffeln, Mïgren

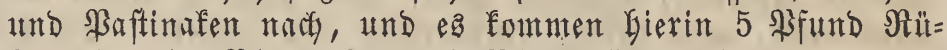
Gen ober 10 Pfund Srrut 1 Pfund beu gleid\%.

Heber Den Januar ober Februar Ginaus foll man bie

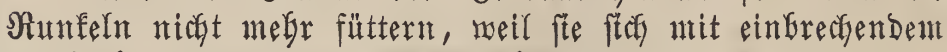
Frübjabr zerjegent und nicft mebr zur Jütterung Grauchbar ftnd. - Mian Genübt die Siunfelrüben, mie mir efen be= nterft Gaben, it meuterer Seit bauptfächlich zur Fabrifation Des 3ưfers, bejonders Gäufig in Franfreidf, Deftreidy und

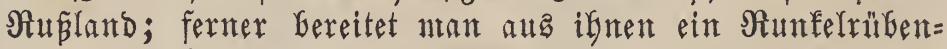
bier, wie bäuftg in Ëngland, meldfes woblfobmesfend und

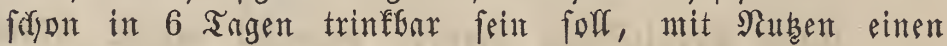
Sunfelrübenbranntwein und aแz Dent Geim Branntroeinbren=

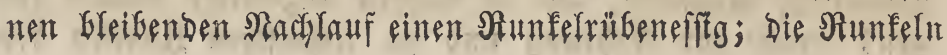


find beim Ranbyolf als Raffeefurrogat beliebt, geben auds,

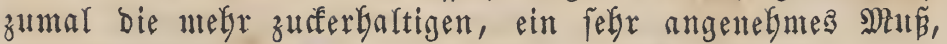
und bie Blätter merben bei ber Tabafafabrifation verwendet, inbem man fie orbinärem Tabaf Geinifogt.

Die AnnfelrüGen unterfaciden ftef in ntannigfaltiger Beziefung wou einander: (sinige find ber Form nadi faft rund oder eifürmig, andere mefre länglich, eintige ftefgen ganz in ber Erdoe, andere zu $2 / 3$ über Derfelben, wieber an=

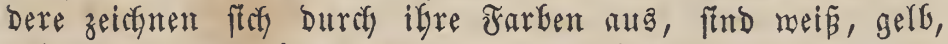
gelblidgrün, megr voer meniger roth ober geflest. Die meí̧en, gelfen und bie aupen rotben, inuen aber meisen, und bie grünlicfen gebraucht man megr zur Sudfer = und Surupbereitung, fte find neift fleiner, baben ein fefteres, wenig mäfferigę Fleifoch und leiden meniger bon ber Rälte, bie blaprotben aber, relche größ̈er, faftiger, an Bufferftoff ärmer und gegen sröfte weniger baltbar fitro, ziegt man als Jutterruben yor.

\section{Meife liunkelrübe.}

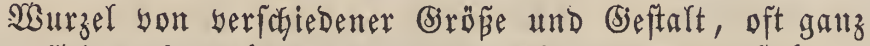
in Der Errbe, oft nefgr ober weniger itber ber (srbe ftehend.

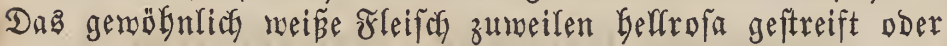
gereift. Blätter glänzend belfgrün, ftarf und weip geftielt, gerippt ober gendert.

\section{2. Üelbe Runkelrübe.}

Wurzel yon mittlerer biröß̈e, runblich, oft megr Girn=

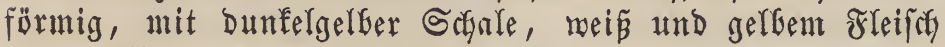
und gelben Rern. B̉ätter grüı, grüngelb geftielt und gerippt.

\section{Rolenrotbe odex incarnatrotbe Runkel.}

SBurzel mit rufenjarbiger Sifale, mebr ober meniger weif́n, mit incarnatrotben ßingen und Rerne beriebenem Fleifade. Blătter Glaugrün, braunrötgliç) geftreift.

\section{Rofenrotbe odex incarnatrotbe Runkel mit ganz

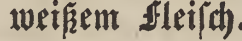

Wurzel groṕ, mit megr ober minder meí̈ent und an Der Sagale etwaz incarnatrotbent, zartent, fefr faftigent

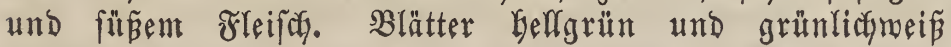
gerippt.

\section{5. fjodbrothe Runkelrübe.}

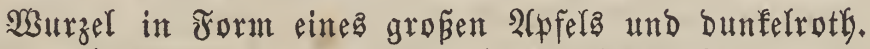
Blätter zablreich, gefaltet, glatt, ftarf geftielt, Graun ober Dunferroth, ober grün, rotbgerippt und geabert. Sie bat mieber einige Spielarten.

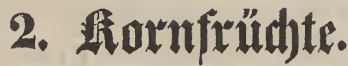

Unter Rornfrüchten verftegt man int engern Siune

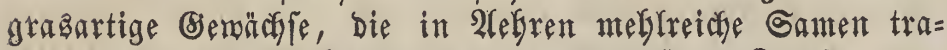
gen, welche zur sabrung und zu technifden Smerfen ver: mendet werben. Stärfutehl, Rleber, Šimeisftoff und zurfer

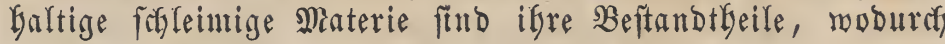

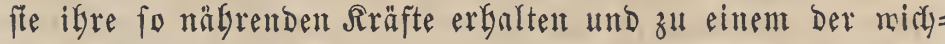
tigften Erzengniffe unferer Erbe werden.

\section{'Triticum. L.}

Achyrophyta. Neck. Gramina. L.

Siffeme: Gramina digyna composita. Ray. Gramina hordeacea. Spr. Kunth. Gramina Tritica. Adans.

Gramineae. Juss.

Triandria Digynia. L.

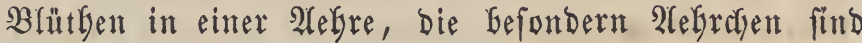
mit ber ffachen Seite an eine gemeinfunatlidye Spindel ge= ftellt. Relch zreizeilig, zmeiflappig, brei= und melgrblüthig,

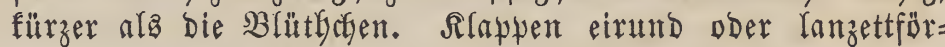

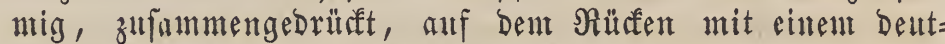
lisgen Riele. Sirone zmeifpelzig; untere Spelze zutgefpibt, ober ftumpf, oder abgeftudgt, unberwegrt ober mit einer (B)rante berfełen; Dbere länglidy, zmeifielig, auf Den Rielen

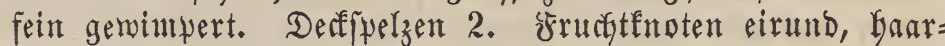
fchopfig. Bsriffel febr furz. Narben federig, zur Seite Ker= bortretend. Frudgt frei ober bon einer haut = ober horn= artigen Sagale eingefdloffen.

\section{Triticum vulgare. Cillars.}

Triticum aristatum. Gisek. Triticum compactum. Host. Triticum cereale. Schrank. Triticun erinaceum. Hort.

Triticum sativum. Lam. $\quad$ g Triticum velutinum. Schübl.

Triticum aestivum. L. $\delta$ Triticum Hosteanum. Clem.

$\beta$ Triticum hibernum. L.

Weizen, Waizen, gemeiner SEeizen.

Froment, Bled. (franz.)

Wheat. (engl.)

Grano, Fromento. (ital.)

\section{2lvten, (Sbatafter.}

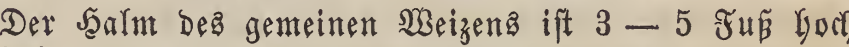
und Gokl, bei einigen Spielarten etwaz nartig, bie und ba gegen bie alebre bin etwas. Fuiralförmig gerounden. Die Blätter find $1 / 2-1 \frac{1}{3}$ ₹uß lang und $1 / 2-1$ 3oll breit. Die 2 ebrafen vierfeitig und bie 2 Flädyen, an Denen bie 2(elyrden fich fpreizen, breiter, gebrängt, ziegeldadjförmig,

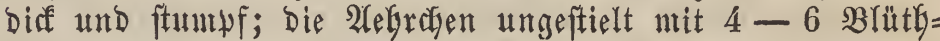
chen, Deren 2, feltener 3 verfünntert find; bie äup̃eren Relche, Bälge, Rlappen doer Relchjpelzen find bautbig auf= getrieben, eiförmig, abgefüubt, meift focyarf gezahut, unter=

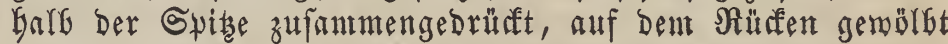
und mit etwas Gerborragenden Ripyen verfeben; Die äuperen Bälgdyen, Blumen= oder Rronenfpelzen find entweber ge= grannt, wie beim Bartmeizen, ober bloß nit einem längern Safn und oben nit Grannenfpisen verfeben; bie innern Sronenfpelzen Dagegen zartbäutig, auf beiben Seiten nacken= förmig auşgeboglt. Sit Der Somnter fehr warm und trodfent, fo merben bie Spelze auch meniger lang und beberfen bas Sorn nur menig, und werben in fruchtbaren Safren bie Rörner befondera grofa, fo treiben fith bie Spelzen aubein= ander, und bie Brannen Der bemefrten SBeizenarten fteben Dann faft magrecht von ber Spindel ab; restere ift meift zälge, entweber lang gegliebert, wie bei Dem Rolbenmeizen, 



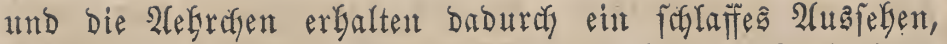
Dber fee ift fefr furz gegliebert, wie bei den Jgelmeizen= Zrten. Staubfüden febr dün, meís. Staubbeutel blaźgelb,

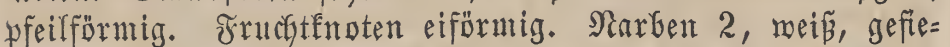
bert. Die Samen meift Yänglich= dual, oft anf beiben Sei= ten abgeftumpft, rundlisy, goldgelb, weiplich ober roth= bräunlidy; Der Rern meift ganz meblig, boer auth Gorn= Dber glabartig.

\section{Błätbe = Beit แtto Dauer.}

Sonmer. $\odot \cdot \sigma^{\pi}$.

\section{รัotfommett.}

Der Saeizen murbe fochon in ben früfeften Beiten in Sübetroya als bie Gauptfächlicfite Rornfrudgt angebaut. Sein Baterland ift, wie Dab Der Cerealien überbaupt, nicht befannt. (Sriechifate und römiface Schriftfteller Gieltent Si=

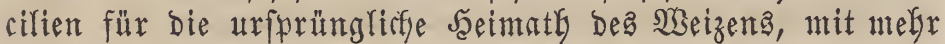
NGangricheinlinffeit bürften wir aber affen als biefelbe an= feben, und audf Strabon fübrt als joldye bie llfer Des Indus

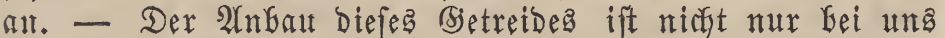
fefre verbreitet, jondern auth in andern begenden und SWelt= theilen. Man findet es in Scfottland bis in bie Näke yon Jnvernés unter Dem 58. Birnbe, in Norwegen bis Dront= Geim unter dem $64 .{ }^{\circ}$, in Shyeden bis zum \$arallel yon 620 Breite, int weftlichen $\Re$ uffand bis in bie Bjegend yon @t. Peterşurg, $601 / 40$ SBreite; Miosftut, unt melctes nach

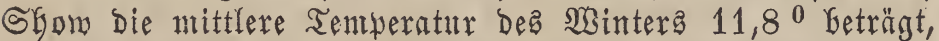

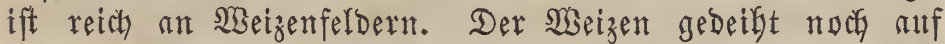

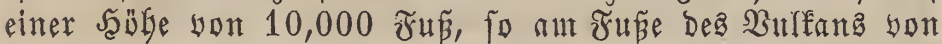
2lrequipa; gebaut wird er noch bis zu einer bëble yon 12,\%00 テun, wie ant See yon Titicaca, reift aber bier nicht melyr, weil bie Sommermonate fogn zu falt ftnd. Nach

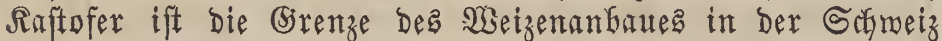

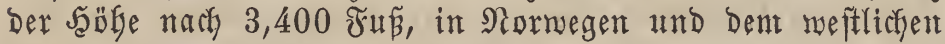
Rappland Dex Breite nach $64^{\circ}$. Da wo das Rlinta Durch bie Seefuft gemäpigt mird, gebeigt ber Weizen nuch in ber nörblicyen Breite yon 55 Srraben, und feime Rultur fann moch, wie überhanpt aud bie ber Eerealien, Gei einer mittleren Sabreastemperatur bon $22^{0}$ bis $25^{0}$ ftattfunden.

\section{Sultux.}

Der gemeine Sreizen geräth num beftedt in mittelforme=

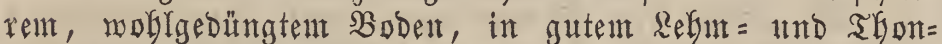

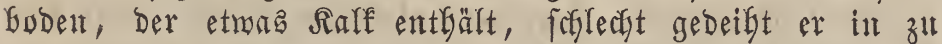

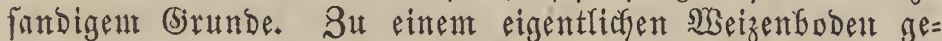
Gören etwa 56-80 Jaunderttyeife Refm, 2-12 5aundert= theile Şumus, und ars die meiteru Beftandtheile Sand and

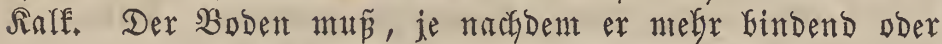
leidyt ift, eimual ober zmeimal gepflügt merbent und foll fer=

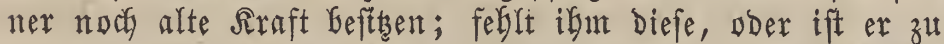
thonbaltig, fo mus frifo gebungt und Ralf unb Sandmer= gel aufgefulbrt werben. Seier fommt es ganz barauf an, was ber Boben yorber getragen bat, of er yorker fefon ge= Görig gebungt wurbe oder nidyt. Bismeilen ruft auch zu friface Düngen Den Brand doer Das Ragern Kerbor. Der

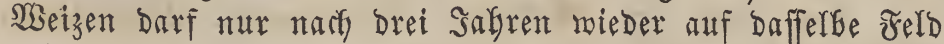
gefäet merben. 2(nt beften gebeift er nacf reiner Bracte,

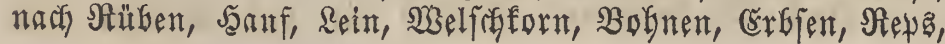

Entwer, beonom. ஒrfanzentunde.
Tabaf, Jater, Jierfte, Rlee, audy nach Rartoffeln. - Die Saatzeit wälrt je nadf Der Rage und Dem Rlima yom $\mathfrak{A} \mathfrak{n}=$ fang Septentbers bis Nobember. Sit Der Boben faber, fo wirb Der Same mit Der Ëgge, ift er leidft, mit Dent Sfflutge

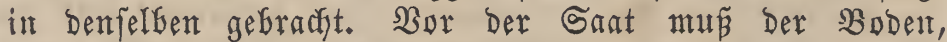

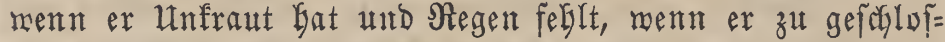
Fen ift, Gei troffemer 23 itterung Durcheggt werben. Der

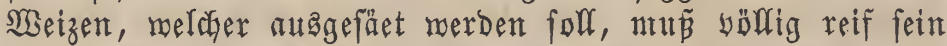

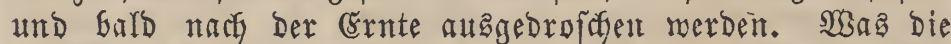

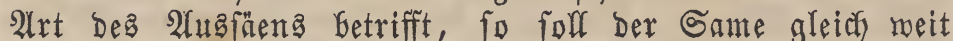
auggeftrent neerben; wird zu biel Samen ausgemorfen, io

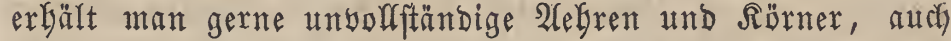
ein furzes Strof; nimmt man Dagegen zu wentig, fo fautu

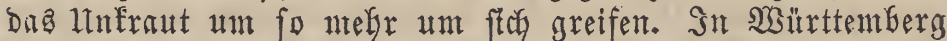
fäet man alf Den Morgen 2-4 Simri, in Banden 4-6

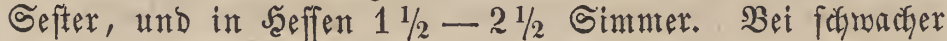
Weizenfaat mirb Den WBinter über burd Düngung nachge= Golfen, bei zit üppiger Saat fadrüpft mant im Nonate Nai.

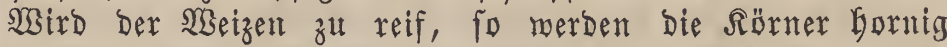
und liefern Daun ein etwas formarzes Miegl; autch ift berfelbe

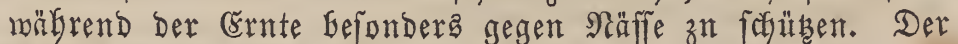
NGeizen mird mit ber Sidfel gefifnitten.

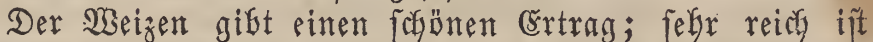

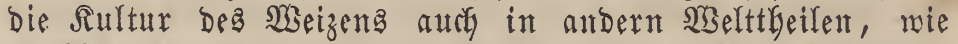
in 2lmerifa, z. $\mathfrak{B}$. in Éfili, Den vereinigten Stanten Deß

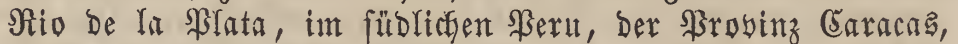
Infel Cuba; auch sndien, Gefondera bie nörblichen unb weft=

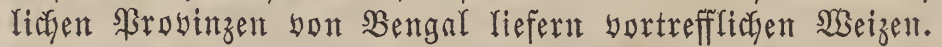

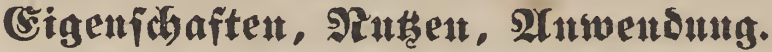

Die Sheizenförner, follen fie igre Bolfommenteit er= reicht Gaben, müffen fogwer, glatt und runblicy fein, eine bünne Schale, einen flachen Spalt und einen feimen, weipen Rern Gaben. Der weizen liefert gorzugameife ein febr rei=

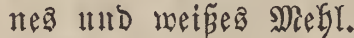

Die bormaltenden Beftandtyeile diefes Mefris find nach Bogel:

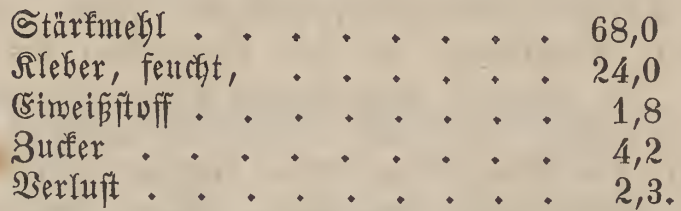

Nach Srouft entyält es noch 1 \$rocent gelbes Saarz.

Der norbifche SWeizen ift nach Davg reiffer an Stärfe tull ärmer an Rleber, als Def wärmerer \&änder, bas Nebl Des erfteren baber meniger gelblicy, als das des lebtern. Jermer fand Davy in Dent im Serbfte gefäeten reifen $13 e i=$ zen in 100 Theilen 77 Theile Stärfmebl und nur 19 Theile

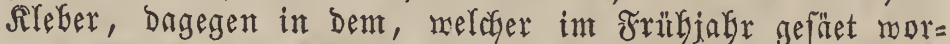
Den war, gegen 70 Theile Stärfmehl und 24 Theile אileber.

Dex Miseizen Yiefert Dem Menfefen eiutes ber widytigften

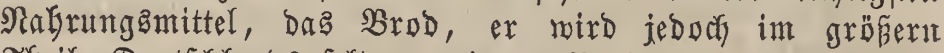
Theile Deutfalands feltmer rein zu Brob berbaden, fondern

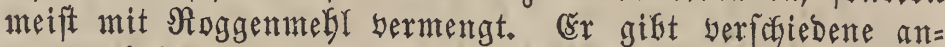
Dere nabrbafte Speijen, mie Sirenpen, Siries, feltner Srübe,

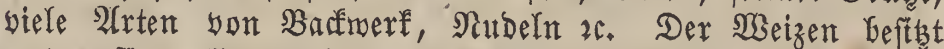
anter fämntliçen Betreidearten ben gröpten Bebalt yout Stärfmebl, und wird beß̋halb bäufig zu Stärfe, DGlaten, PHber und Sileifter verwendet. Man benübt ifn ferner zu 


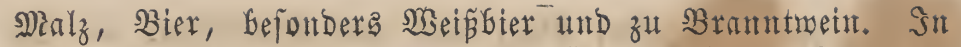
Der Seilfunde. wendet ntan Das STSeizentegl trodén ober

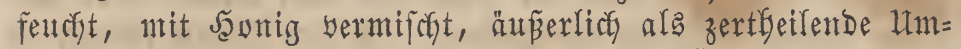

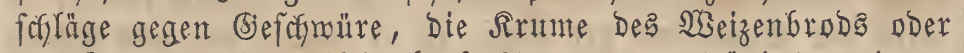
bie Semmeln in Mildy abgefodyt, gegen entzundete umb er= bärtete Brüfte, gegen Reiffdymerzen 2c., Die SBeizenfleie und

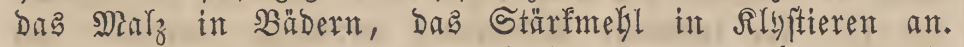
Dioscorides (Rit. 2. Canp. 10\%) fafreift Dem roben (Semtffe

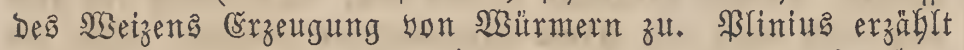
(Rib. 22. J̧ift. nat. Cał. 25.) yon einem fpanifgen Jürften, Sextus Somponita, er Gabe ftaf Dadurty Das. A3odagra ber=

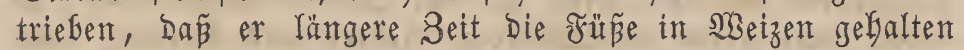
Gabe. Die Rleie bient als Futter für Bieh, junges Eeffü= gel, wie (Enten, (bänfe. Die Tartaren Gereiten fith aủ Dent Mizeizen Den Mieth, Die Japanefen Den Sachi, und Daz Stroh

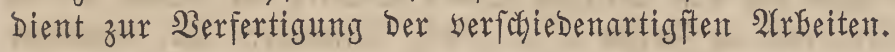

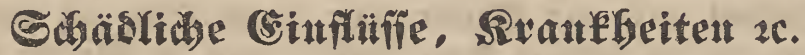

Der Errtrag Des Şeizens mirb Gäuftg fefr berringert Durch verfoctedente Rranflyeiten, Denen Derfelbe untermorfen ift, ober Durch forgäbliche Injeften.

SYm meiften ift Der Weizen Dent fogenannten Brande ausgefest. Dieje Siranffeit entfegt Durch eine Berfebung

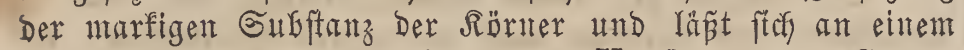
fofmarzen \$ulver, eimem Staubyilz, Urodinea ober Coriomycus, welder ben 2 (efren anfängt, erfennent. Die thr=

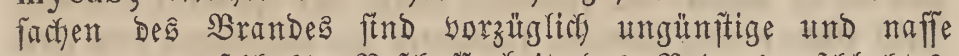

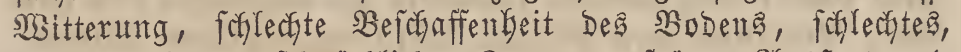

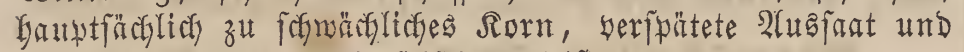
zut ftarfe Dïngung mit frifchem Mifte.

Die Zorfeugungantittel gergen Diefe Sranfleiten geben fitl) atts biefem eben biejagten gröptentbeirs fijon son felbjt,

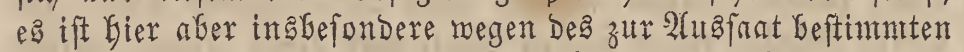
Sornes noch eines Untftandes zu ermabnen, Der wohl alfgenteitre

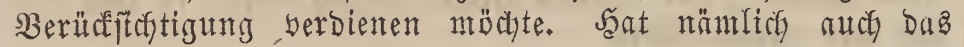

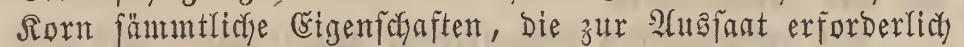
find, fo feflt Demrelben boch hänftg bie Siraft, ifnt ähnliche gefunde Rörner wieber herborzubringen, zunal renn noch

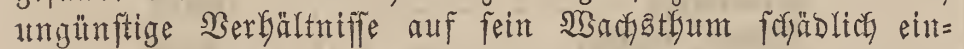
wirfen. Itm nut Dent ausaträenden Sorne etra mangelnde

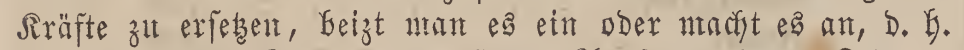
ntan legt Den Samen yof fetuer 2lusfant einige Beit in

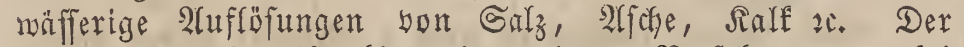
ßjarrer Siraue gift bier ein weiteres Verfatgen an, bet Deffen 2lnmendung er nie Den Srand unter Dem Siseizen entfteben gejeben baben will; er begieñt näunlich die fogon gefäeten $\mathfrak{R}$ öner einigemal mit biülle, und zwar bei trodfener,

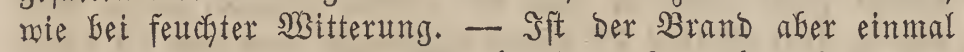
fidon im betreide, fo mird bäuftis, aber olyne bejondern (Exfolg, Das Bejprengen mit in sisaffer aufgelöstent farf, Esifentitriol, Galz voer Jautche empjoblen.

Man unterfacidet 3 Arten yon Brand, nämlich Den Faulgrand, Den Nấ = und Den Rappenbrand.

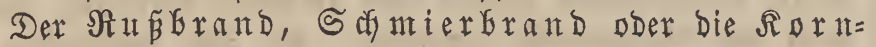
fäule, Ustilago sitophila, ift ein fleiner Staubilz, und Das bryon befalfene Rorn ftegt 2 (nfangz fajmärzlich= grït, Dann fogwarzbräunlich aus, Die franfen Rörner und afebren fadeinen reif, wäbrend die gefunden noch grün find.

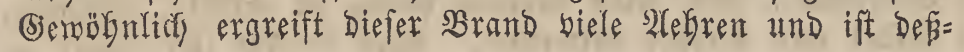

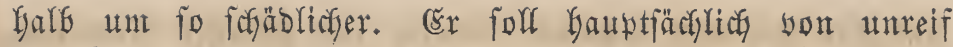
eingebracftem oder feudgtgemordenent Gatforn Gerrügren. Das 3 Bandmegl verderbt und verumreinigt Das gute Miegl

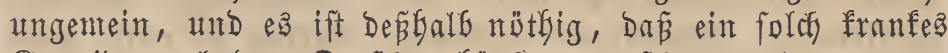
(b)etretide nady Dem Dreịchen bäufts gemajoyen merde.

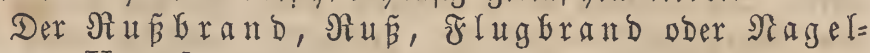
brand, Ustilago segetum, ift ebenfalfs ein $\mathfrak{B i f}_{3}$

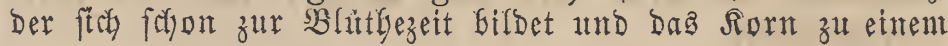

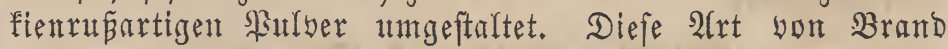
berunretnigt Das Mefl mentger ftare, Da Das fofwarze \$ul= wer bor Der Ěrnte meift bollig verffiegt. (Er entftegt in naffen Sabrgängen, bauptfächlich auf magern und trodfenten Felibern.

Éndlich Der Rapłenbrand, Ustilago glumarum. (Er zeigt fitch erft nach Der Bhütfezeit DDer wie beim Safmierbrand nach Der Entroiffung Der Sïnner. Der Hoct)=

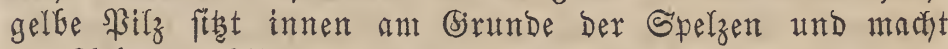
Die 2lefrafen bräulichgrün, Dann roftfarbig getupfelt. Das Sorn yerfirumpft und vertroffnet, and Das Mebl, Das

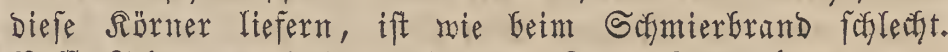
Naffe Felder yorzinglich rufent Den Rappentaratid herbor.

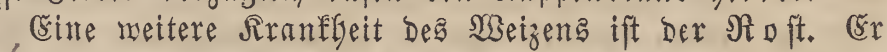

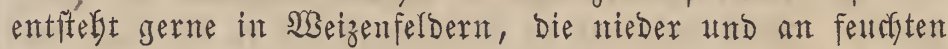
Steflen gelegen find, bejonders menn noch biele Rebel auf= fteigen; aber auch in trocfenen Salgrgängen fundet man Den Roft, wenn Die 2\{usfant zu fpät gemadyt murde. Noftähn= lieffe Flerfen an Dem Struh Des Getreides bezeidfnen biefe Rranffeit. Bräfervatimuttel gegen Den Roft find baupt= fächlich Das gute und zeitige B̉eftelfen Der Felder, tiereres

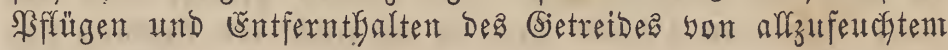
Boben.

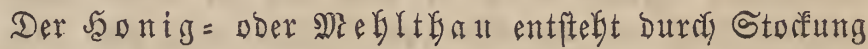
Der \$flanzenfäfte, in Folge zu fonteller Tentperaturmechfel, Gejonders in Den Getretbefeldern, melche in Thälern, in Der গRălye yon (Bemäffern Yiegen. Der Gäuftge Befuch ber Bie= nen, welche Der jünen, flefrigen Jeuchtigfeit, bie Gei Dent

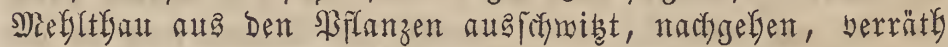
oft fogleicf) Diefe Siranfleit. Mnittel gegen biefes SPflanzen= leiden bat ntan bis jegt noch nicist entberft.

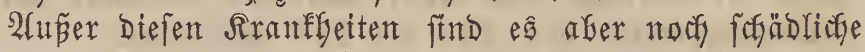
Snfelten, welche auf Den 23 seizent zerftörend einmirfen, und wir wolfen mun bie gemöbnlichften und foyäblichften bier aufzzäblen.

Die Rarye Des Saatforingers pder Santfornelffäfera, Draftrourm genannt, Agriotes striatus, Esch, oder Ela-

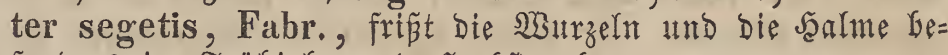
fonders im ซrrügafr und Jerbfte af.

Der fignarze Sornmurm, Die Rarbe Des Sorntüffel= Făfers ober Rornbolgrers, Calandra granaria, Fabr, ift auf Dem Sornboben auBerordentlicty nachtheilig.

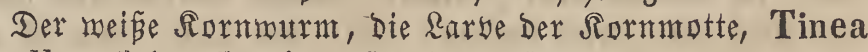

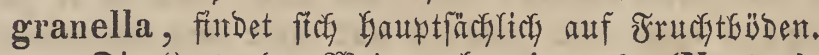

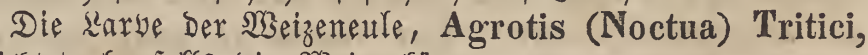
wernichtet ebenfalls die Szeizenföner.

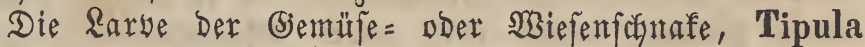
oleracea, Genagt Die Nisurzeln und Jalme Deß Setreides.

Die Rarbe Der fichäblichen Schlufmeane, Ichneumon culpatorius, zerftört bie Rörner.

Noch ala befonders fochäblich für das bietreide wäre 


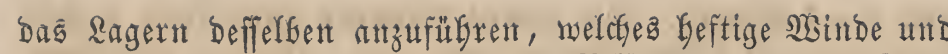
Regen berurfaçen. Durch tiefes Bffügen bor Der Saat, Schröpfen Derielben, ehe fte zu fochiepen beginnt, bet trodfe=

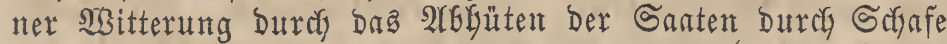

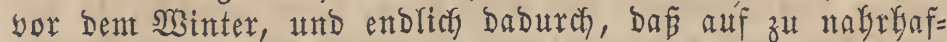
tem $\mathfrak{B}$ oben fein betreide angebaut reerde, mirb bäufig bent Rageru borgebeugt.

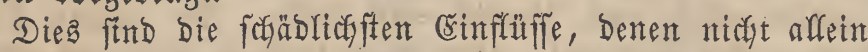

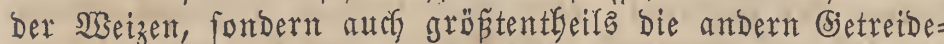

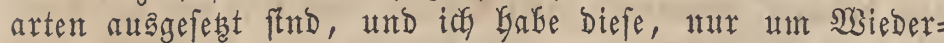
Golungen zu vermeiden, Gier zumal abgefandelt.

\section{Riteratuts.}

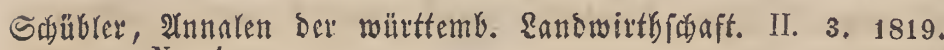
Nr. 1.

Seringe, Monographie des Cereales de la Suisse. Berne, 1818.

Mebger, europäiftse Gereatien. Seibelberg, 1824.

Shaer, Stundäse Der rationellen Randwirtbrhaft. Berlin, 1812

Loudon, Encyclopädie of Agriculture. London, 1824.

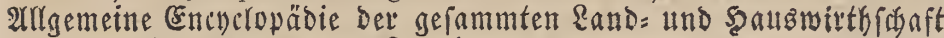
Dev Deutficn. Reivzig, 1837.

British farmer's magazine (Nov. 1832).

Bayle Barelle, Monografia agronomica, dei Cereali. Milano, 1809.

Giovanni, Mazzucato Sopra alcune Specie di Fromenti. Padora, $180 \%$.

Şoft und Rernet, 2tbbiloung aller D̈conomifden, SPfanzen. Tübin= gen, $1786-96$.

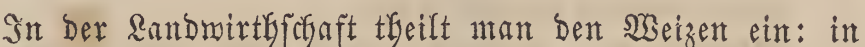

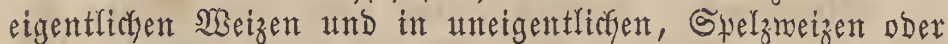
Spelz; zu bent erfteren gebüren ber gemeine, ber englifore, Der Bartweizen im engern Sinne (Triticum durum) und Der polnifuse Weizen; zu Dent lebteren Yingegen Der Spelz= weizen mit feinen Barietäten. Der eigentlicsye Siseizen zer= fält wieber in gegrannten ober Bartweizen, und in ange= granten ober Rolbentweizen.

Früfer theilte man, wie audy bie andern betreibearten, Die SBeizen in Sommer = und Winterfrüctyte eir. Rinné Fil $=$ Dete aus benfelben fogar 2 Fantilien, Den Triticum hibernum und aestivum, itbrigens find bie botaniforen Fentl=

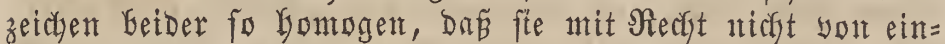
anber getrennt werbent fönten, zuntal ba ja auch befanter = manen eintge $\mathfrak{2}$ (rten Sommer = unb WBinterfrüchte zugleich fint.

\section{A. 3artweizent}

Biegranter Weizen.

Der Bartweizen Yiefert ein ftärferes Stroh, ift meniger Dent Brand and Roft augefest, und wird audy nicht fo febr won ben $\mathfrak{B o ̈ g e l n ~ G e i m g e f u r f t . ~}$

\section{Weifex gemeinex Baxtweizen.}

Triticum vulgare aristatum album glabrum.

W̧einer gemeiner Brannentueizen, genteiter WBeizen mit grünem $\mathfrak{\text { Ierne. }}$

Froment d'automne à épi blanc. Froment commun barbu blanc et glabre. Blé grison.

White common bearded wheat.

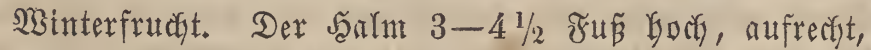
hofl, ant untern zweiten finoten etras fnieformig gefogen,

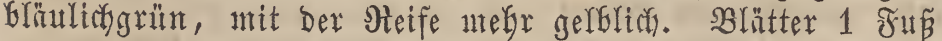
lang and länger und $1 / 2$ Soll Greit, Gläulidggrün, fărben fitef aber it fettent Boben Dunffer. 2(ebren 4-5 3oll lang,

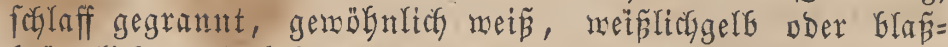
Gräutlich, und befommen manchmal, aber wakrjcheinlich unr in Folge yon franfleit, ein etwaz fammtartiges 2lusfeben. Die 2lebrchen fteben zu 18-22 Geifammen, Gaben 3 Jirnt= nten, eine weitere Branne bat oft ben meift berfümmerten

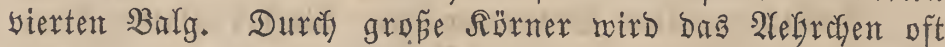
weit aus einander gefpreizt und fächerig, es entfält 3 , felt= ner 4 förner, und bas Enbägregen oft nur 2. Die Bsrant= nen find 4 8ull lang, bie untern fürzer, gelb vber weif. Die Reldafyelzen etmas Ereit, glatt, weíp ober gelb, feltner etwas bräunlich, neift lang und grannenförmig gezäbnt. Die äıtern Sironfpelzen gegrannt, weís ober gelblich, Die innern Durchftchtig, Gäutig, glänzent, auf beiben Seiten nachenförntig und bohl. Gpindel weitläufig gegliebert, weišs= Iref. Die Samten mei

Diefer Saeizen wird Gäufig in Deatfegland, aber auch in Jranfreich, England, Stalien und Spanien angebaut. Et werlangt im 2(Kfgenteinen eitren ntebr gebundenen, Fraftigen,

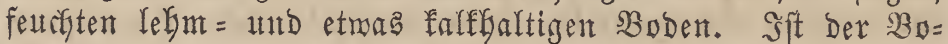
Den zu locfer, fo fento bie Sisurzeln als nicht gebürig ge=

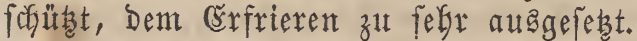

Der Errtrag an Sorn und Strof ift gut.

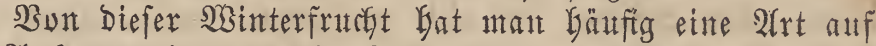
Den Zlerfert, bie auch als Sommerfatcht benübt wirb, boch yerbirbt fte gerne über Den 3 inter, wemn fie nicht intmer

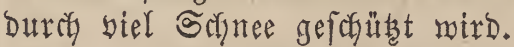

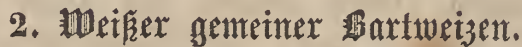 \\ Triticum aestivum.}

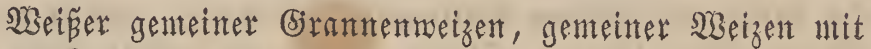
grünem Serne.

Blé remois. Touzelle blanche barbue.

White spring wheat. Summer wheat.

Sommerfrudyt. (ar Gat gleiche Cogaraftere und gleidfe Iultur mit Der Winterforudy und ift eine vorzüglicte Weizenart. Die 2ebren ftnd melgr blä̧brännlich, oft gelb= risjgrün.

\section{Weifer fammtaxtigex gemeitut faxtweizen.}

Triticum vulgare aristatum album velutinum.

ख̉eiper fammtartiger gemeiner birannemmeizen.

Froment commun barbu blanc et velouté.

White common bearded velvet wheat.

Winter = und Sommerfrucht. Die IeGrent find yollet und gröper als bei Dett yorigen Arten, Die Relchipelzent Gaben nicht ben langen, fondern nur einen furgen, fobarfen

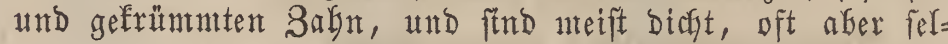
ten, faft gar niaft bebart. Die äunere Sironenfpelzen find ebenfalls baarig. Die Spindel ift etwas breiter, und die Samen ftnd rötblidy, oft Gräuntiç und meiftens Gurnig.

Diefe 2int mirb biel feltenter angebnut, fee mifl als Sonmerfucht nicht recht gedeifjen, und ntan foll fie zu bie=

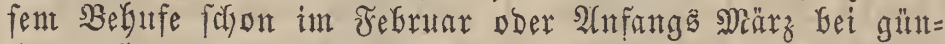
ftiger 2 itterung ausfäen, afer auch in biefem Falfe roird

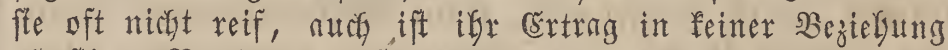

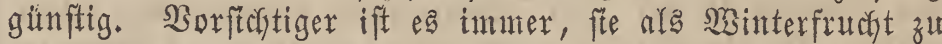
Gauen, Der Nothen ift etras geringer ars ber bes gementut 
Grautten Bartweizens, Gält aber nidat leidjt einen ftrengen Winter aus.

\section{Rothex genteinex fantweizer.}

Triticum vulgare aristatum rubrum.

Triticum vulgare opica laxa aristata rufa glabra. weizen.

Notber genteiner Cirannenweizen. Notger glatter Bart=

Froment commun barbu, roux et glabre. Touzelle rouge barbue. Saisette de Tarascon. Blé rouge.

Red common bearded wheat.

Minterfrutçt. Santnt 3 Fup lang und lïnger, aufrect, Gohl. Blätter 1 Fun lang und länget und $1 \frac{1}{2}$ Bolf Greit.

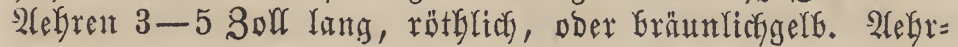
djen nidgt weit yon einander ftekend, 16-22 an ber $3 a b l$, 3-4grantig, mit 3-4 Samen. Die Brannen 4 Solf lang, Defren fith nach oben immer weiter aus und find belfgelfs= Yich Graun und unten etrwas Dunfler gefärst. Die Reldé fpelzent lang und fpiţig gezalgnt, jung gelblich und grün

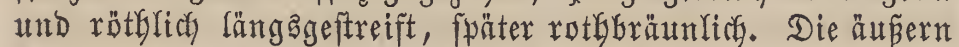
Sronfpelzen gegrant, außen bräunliç und an Der Bafts weiślich. Die innern seronfpelzen bünthäutig, glänzend,

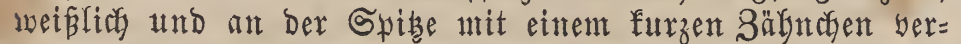
fehent. Die Spindel ift reit gegliebert, breit, glatt und theilmeife etruas grau. Die Samen belfrobthliogbraut, obent und unten weiplich, gefurdft, furg, überfaupt etwas fleiner tuld meift Gornig.

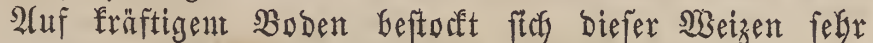
ftare und gift reichlich aus; ars ऽommerfrudyt angebaut reift er fpät und gift eitren fohlechten rertrag. Man baut ifa bäufig mit andern 3 seizenartent vermengt, und ex liefert, ofgleich feine Sïnner rötglich und meift Lornig find, ein

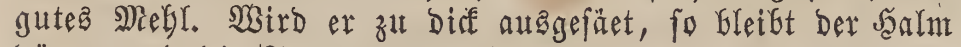
Dïnne und bie Frucht lagert ftes gernte.

Eine Barietät Dez rothen genceinen Bartweizens ift:

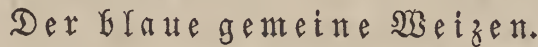

Triticum vulgare spica laxa aristata coerulescente glabra.

La varieté bleue. Froment commun barbu, bleuâtre glabre.

Winter = und Sontmerfrucit. Mebger und 2(ndore ftelfen ifn als befondere $\mathfrak{A}$ rt auf, Siraufe nber bielt ifn nur für eine Barietät deg rothen genteinen Bartweizens.

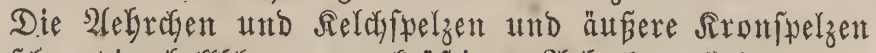

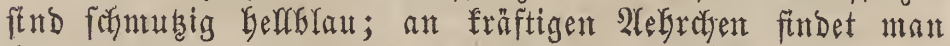
his und ba audf 4 (biramen.

\section{Rotbex fammtartigex gemetnte Battweizen.}

Triticum vulgare rufum velutinum.

Triticum vulgare laxa rufa velutina.

ßotber fammtartiger srannenmeizen.

Fromeñt commun barbu roux et velouté.

Red common bearded velvet wheat:

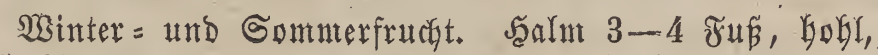
zuerft blïulichgrün, gegen bie SReife Gin ftrobgelfe Blätter, 12-14 3oll lang, gegen 1 30ll breit unb bläulichgrün. Zebren 4-5 3oll lang, fạtaff, auf beiden Seiten flach:

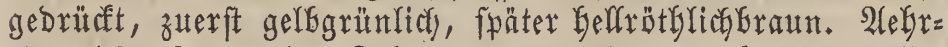
cten 16-20 an ber Babl, fächerfürmig ausgebreitet, Iaffen

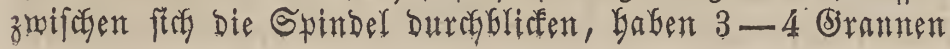

unt 3-4 Samen. Die oberen Siranten zunt Theil 5 Sull lang und auf beiben Seiten reit bon einander abjtebend, nach unten rerben bie Brannen fürzer und rentger gefpreizt,

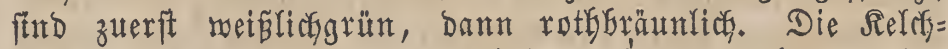
fpelzen find abgeflacht und meift lang, fidarf gezalgnt, in bet Blüthezeit mit befaartent und theilmeife gefranztem ßande, gelblicfgrün, gegen Den $3 a$ hn Gin länga grün geftreift, fpöter rotbgräunlich, auch blaulich und flectig. Die äupern Siron= fpelzen find gegrannt, wben Gerborftebend bräunlidanthlich

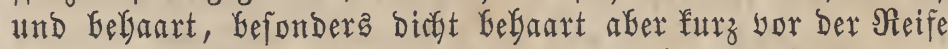

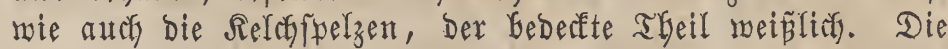
innern Blumenfpelzen Gäntig nit Gelforäunlichen Gpiben. Spindel weiṕlich gegliebert und fparjam befaart an ben

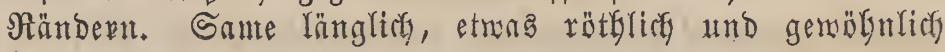
yornig.

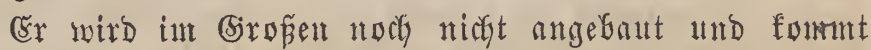
in Beziebung nuf feine (Eigenfdyaften fu ziemlich mit Dem meiz̈en fanmtartigen genteinen $\mathfrak{B a r t w e i z e n ~ u ̈ b e r e i n . ~}$

\section{6. מraumex gemeinex mentweizen.}

Triticum vulgare aristatum fuscum glabrum.

Triticum vulgare spica laxa aristata fusca glabra.

Brauter Srantentueizen, Fudshroeizen.

Froment commun barbu roussâtre glabre.

Brown common bearded wheat.

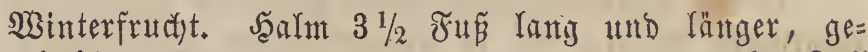

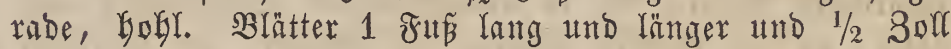
breit. 2lebren 5-7 3ulf lang, reif bellgräunlich bis braun=

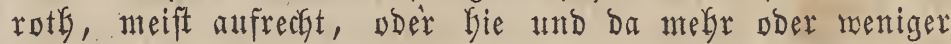
niffent. Aefrefgen 20-26 an Der 8afl, mit 3-4 Sran= nen, Deren mittlere fürzer ift, und $3-4$ Samen. Selch yerfünmert, zumeilen mit einent fleinen Sorne. Sbei fräf= tigen 2 (elgren ftnd bie 2 fefrchen, oft weit affelyend und man

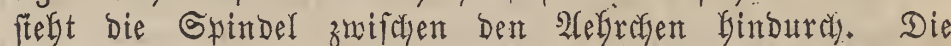
(5)annen fint 3-4 Soll lang, rauf, gelbfräunlich poex rothbraun, gegen bie Spitge bin weiter abftebend. Die Relde= fpelzen glatt, lang, vft grannenförntig gezahnt, oft bunfel= gelb, Dunfelfrum und gelfgeffeft; "äupere Rronenfpelzen Gegrannt, da wo fie frei ftefen, Keffer oder. Dumfler bram, mo fte bederft ftnd, weís und glänzent ; die intern Rron= fpelzen fend Durchftertig, Güutig und zu beiben Seiten nacten= fürmig. Spindel bei größeren Exxemplaren lang and breit gegliebert. Die Samen find yon den ättfern Srompelzen

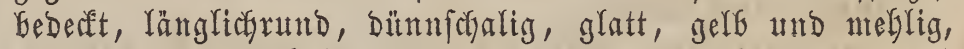

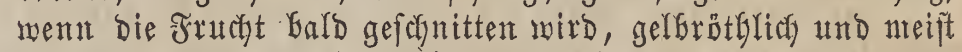
Gornig, went das segentheil geforieft.

Der braune gemeine Bartweizen wirb in manctyen (bie= genden båufty angebaut, er nimmt auth mit einem minber guten, oft fefr bindigen soden yorlieb and reidet nicht Durey ftrenge Winter. Wean baut ifn alfein ober mit an= Dern SGeizenarten vermifyt. Sm Spätherbfte bei günftiger Witterung gefäet, gedeifyt er ant beften. Waas bas Scynei= Den Diefes SYGizens anbelangt, ' fo richte mant fich fo mentig ober nod meniger als bei andern Weizen Darnady, of bas Strofy noch grîn doer fereits gelf fei, Denn ift Der Boben

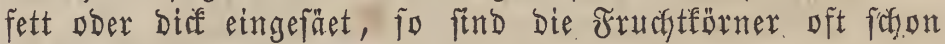

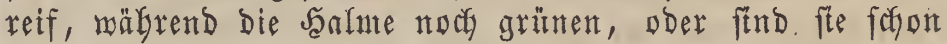
gelb und die Särner noch unteif; fondern ntan febe Gaupt= 


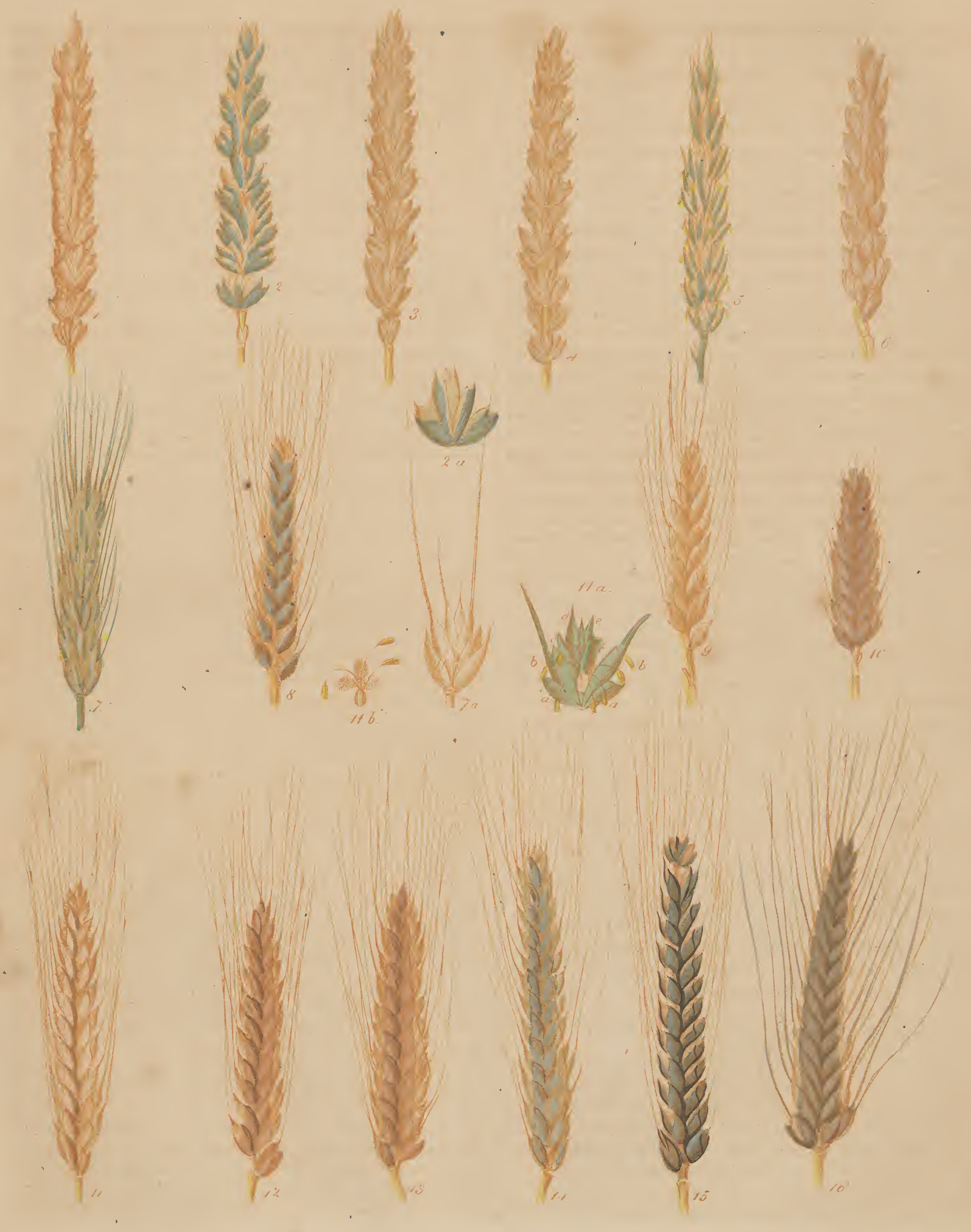


. 


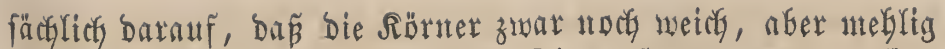
und nicht mefy milchig feien. Die gejunben

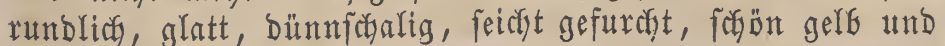
meflreicy, und liefern ein fogönes, aber etrong gelblicheas,

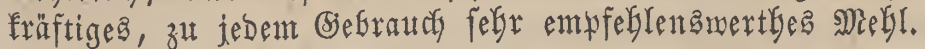

\section{\%. Sidjuntzer gemeinet fantweizen.}

Triticum vulgare aristatum nigrum (velutinum). Triticum vulgare spica compacta aristata nigra.

Froment commun barbu noir.

Black common bearded wheat.

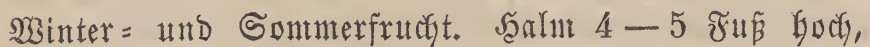
glatt, etwas marfig, unb unreif Gläulichgrün. Blätter 1 ₹ü lang and länger und ftart $1 \frac{1}{2}$ Solf breit, bläulichgrün. 2lefren $3^{1 / 2}-4$ 3olf lang, GeOfgrün, werben aber in trocte=

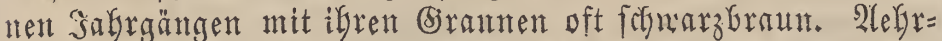
chen 18-22, bicht gebrängt, 3-4 famig, und mit ber Reife fefr augigebreitet. Grannen $6-7$ 8oll lang, zuerft bicht

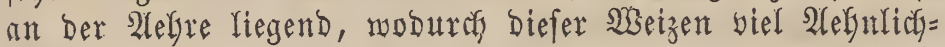
feit mit Dent englifdyen befommt, mit Der meiteren Entwié: lung. aber megr abfebend und faft Gorizontal ftelgend. Die

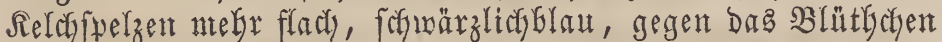
meişlidygrün und unter Dem furzen Bafgne bunfelgrün ge=

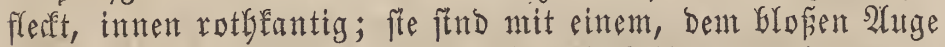
nicht leicht bemerffiçen, fulzigen bienebe befleidet. Die äunern Sironfperzen ftnd gegrant, tief nachenförntig, bas Gedecte

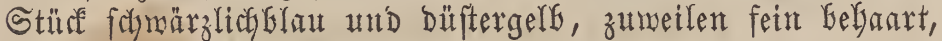
yor ber Blütlye gelflicfweis, wälrend und nach berfelben

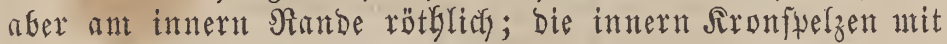

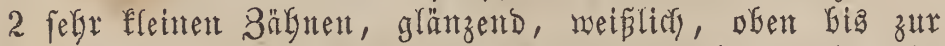

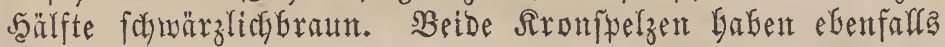
Den filzigen Hetrerzug Der Relebfuelzen. Spindel zientich furz gegliebert, bas Regeldyen ift fparjant befyart unb, wo e马

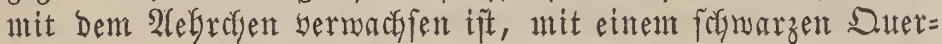
ftrich verfeben; Der Same ift am Seftübelchen fpisig, am Nagelfferfe aber bick, Gat eitren etwag gerutzelten siürfen und eine nulfitig geränberte, tiefe eñngafurche; er ift furz, gelf you zarbe und meflig.

Der formarze gemeine Bartmeizen ift bis jebt int (5) ofent nicyt angebaut worden. (5r taugt nach biaker gemadytent Erfalyrungen yorzugameife nur zur Minterfant; will ntan ibn Gingegen als Sommerfruct anbaten, fo ift es am ratb)=

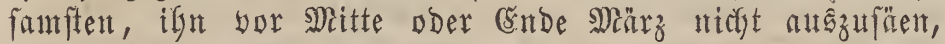

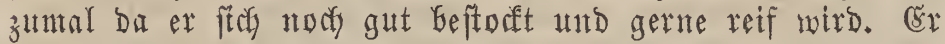
gibt ftarfe 2 (ehren, fräftige, gelbe und mehtreiche Sïntuet und ein Langes, aber etwas ntarfiges and fteifes Strof,

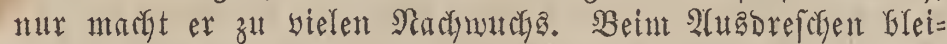
ton bie Shelzen gerne an Den Rörnern fthen, auth folfen die $\mathfrak{B}$ g̈gl biefen 2 beizen vorzugatweife lieben.

\section{Rolbentucizent}

Unbegranter 3 eizen.

Die Afefren ftnd eintigermagent gefornt wie die Samen= folfen Des Safilfea, bafer die Benennung. Der Rulten= meizen ift bünnfultftger als der Bartweizen und gibt eint feineres Miegr.

\section{Weifzex folbenweizen mit weislichem Samen.}

Triticum vulgare album glabrum, seminibus albidis.

Weip̈meizen.

Froment commun blanc sans barbes, à graines blanches. White common beardless wheat, its grains white.

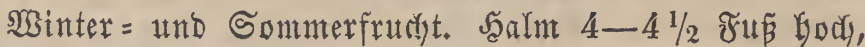

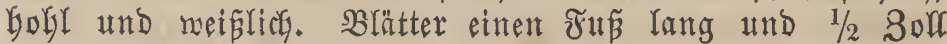
Greit, Gläulichgrün. 2lefren 4-5 3oll lang, etwas Greit, oft runblicf, gelblicfigrün. 2lebreffen $16-20$, mefyr ge= Drängt ober entfernt ftefend, 3-4jamig. Die Feldgfpelzent etwas breit, furz and rötglich gezahnt, gelb and mit grït= nen Rängsftreifen verfeben zur Zeit Der Brüthe, mit ber

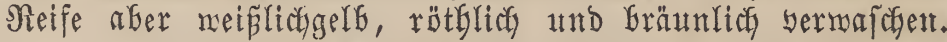
2lat Der Spibe Der Sronfpelzen bie und ba werfümmerte (Siannen, fogenannte Stummelgrannen, und gewöhnlich gramenartige Bähue. Die äuéern Rronfpelzen an bem be= Defften Theile wein, an Dem unbeberften ebeño rwie bie Selchfpelze gefärbt. Die innern Felchfpelzen fünd Durdffutedtig Gäutig, glänzend. Die Spindel hie und da am Yande fpar= fant bebaart, glänzend und weín. Die Samen etraz furz rutndicf, weißglichgelf und meflig.

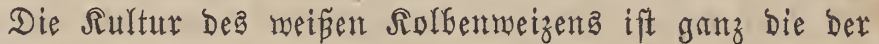
andern gemeinen Weizen. Šr ift mentigftens für unfer Rlinta

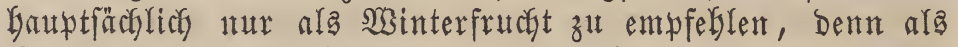
Somnterfrucft gebeift er nur unb volffummeat in bärmern (5egenden. Mian füet ifn unvermengt ober mit anbern SWeizenarten atta, wie in Franfreich mit Dem weipen gemei= nen Bartweizen 1 nter Dent Nanen Tonzelle blanche.

Ere beftocit fich gemögulich ftarf and gibt einen witt=

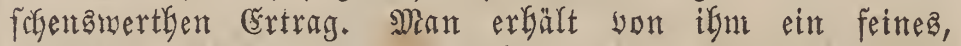

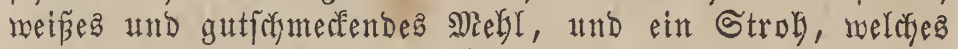

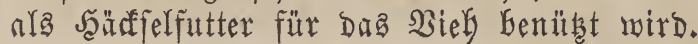

Der weiß̧e Solbenmeizen bariitt Gefonders in Beziefung auf bie Farbe feines Stengels and murbe son Csinigen ars eine befondere 2 trt bes gemeinen Rolbentweizens aufgeftellt.

a) Weifer Solbentweizen mit weífrichem

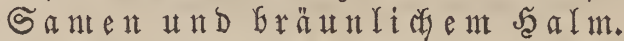

Triticum vulgare album glabrum, seminibus albidis et culmo subfusco.

La váriété jaunâtre.

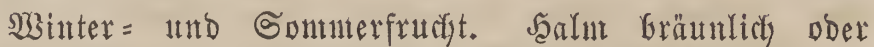
rötglist), wie mandhmal audy Die Spelze, und bie übrigen

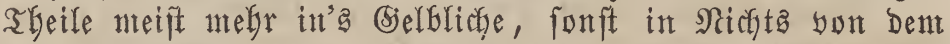

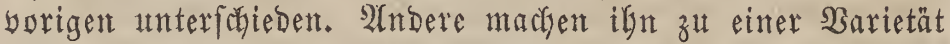

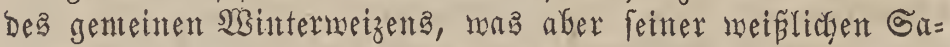

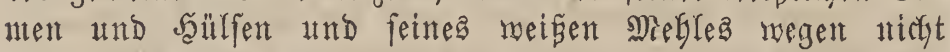
richtig ift.

\section{Weirer folbenweizen mit gelbem Samen.}

Triticum vulgare muticum album glabrum, seminibus aureis. Triticum vulgare autumnale.

Triticum vulgare hibernum.

Talaberameizen.

Froment commun blanc sans barbes, à graines jaunes. White common beardless wheat, its grains yellow.

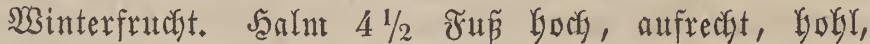

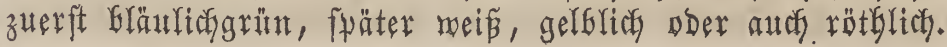




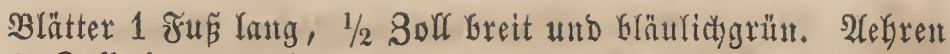

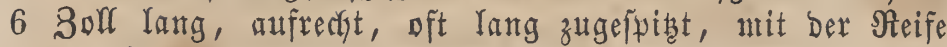

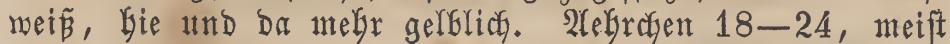
fehr gefpreizt ftebend, 3-4famig. Alu Der Spibe Der 2legren Stummelgrannen und unten felgr furze fpitige 9äbne. Die

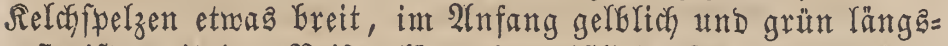

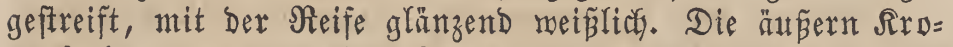
nenfpelzen grannenartig, fürzer ober länger gezalgnt, und won Der gleidgen Farbe wie bie Reldyfuelzen. Die intuern

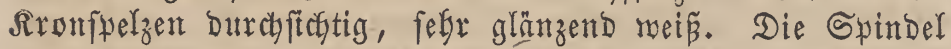
lang gegliebert, weî́ und an Dem Der Sonne auggeferten Theile gelblich. Die Rörner grof́, fockner, längliçrumb, fogon goldgelb, in ungünftigent Boben rötglicf werbend und meflylig.

Der Talavera = Weizent ift eine augigezeichnete Frudyt. Diejer Sinolfenweizen fommt aus Der Begend yon Talatera

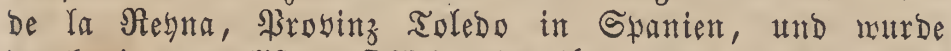
burch einen englifdyen Dffizier, Der ifan natb England bractste, zuerft befannt.

Err word bei uns nicht wobl iut Bropent angefaut, eber nody in einigen Begenden Baierns, bent er artet in unferem $\mathfrak{B}$ oben und bei anfera flimatifchen Bergältniffen febr Gald aus. Mian fäet ifan geröbnlicf in Februar. Die (Ernte ift reichlich. Ein gentiffer Barbenter zu Wefton bei Bath erfielt bon Einem Sorn 7445 weitere Rörner; er

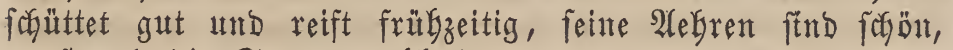
grós und bie Samen meflreidy.

(Er wariirt unter Dem Namen:

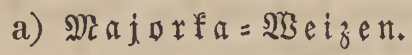

$$
\begin{aligned}
& \text { Triticum majorcanum, }
\end{aligned}
$$

weldyer in einent Theile Stalienz befonders bäufig angebaut

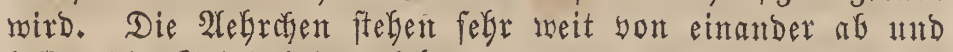
raffen bie Spindel Durctfeken.

\section{Weifer fammtaxtiger falbenweizen.}

Triticum vulgare muticum album velutinum. Triticum muticum glumis villosis cinereis. meizen.

Weiper Saatweizen, Göhnį̣ater Saatweizen, Mous=

Froment commun sans barbes blanc et veloutć. Blé de Bohême. Froment grisâtre, épi velouté, graines d'orées.

White common beardless velvet wheat, its grains yellow.

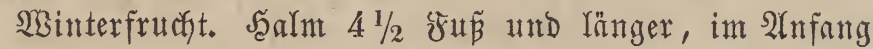

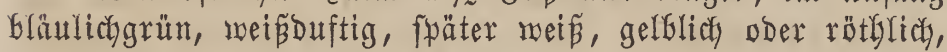
befonders am obern Theile. Shlätter 1 Fús lang und län= ger, gegen 1 Boll breit und yon Der Farbe Des Saalms. Die 2lebren aufrecht, etwas flachgebritut, 5 oft 7 Boll lang, fanmtartig und fein bebaart, exft gelblicfgrinn, mit der

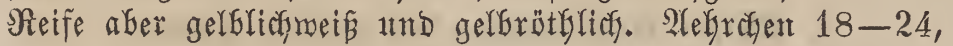
find fefr gefpreizt, und man ftebt die Syindel. 2ln ber Spibe Der Alefren fteht man bie mb da febr furze Stran= nen, febr felten einen soll lang. Reldyfpelzen meift furz und fogmal, ftarf befarrt, mit gemimperten $\Re$ ändern, jung gelblich mit grünen Rängŝftreifen, fpäter neiß̧lich, gelblich,

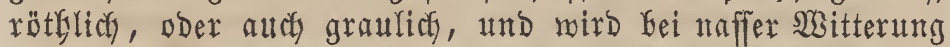
gerne fledig. Die Rronfyelzen futd grannenartig gezabnt,

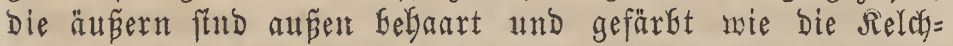
jpelze, die intern Bluntenfpelze ftnd bäutig, glänzend und flach nachenförmig wertiert. Die Spindel ift glänzend, glatt, unb an iyrem Rande mur mentig Gebaart. Die Samten gelb=

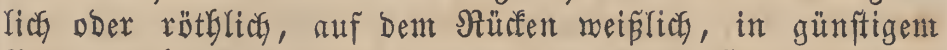
Boben melylig, in folledgtem, ober menn ber $\mathfrak{B}_{e} i_{\text {zen }}$ zulang geftanden, Gornig rerbend.

Diefer Weizen foll aus $\mathfrak{B}$ öbmen ftammen. Bei uns

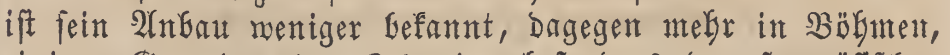
einigen Biegenden Der Schmeiz, befondera Der franzöjiffonen Schreiz, in Der Nornumbie und in Staltent.

Er taugt bei unz nur zut Winterfaat und leidet nicfyt

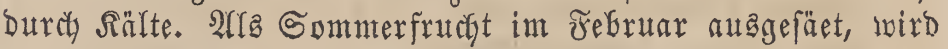
er gemöbntich richt reif ober bolffonmen. Soll er fict gut beftorfen und einen fwönen Ertrag geben, fo verlangt er

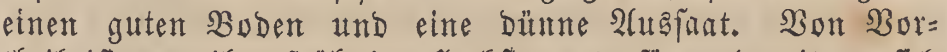

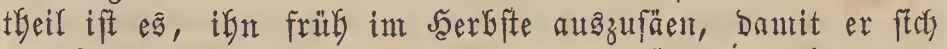

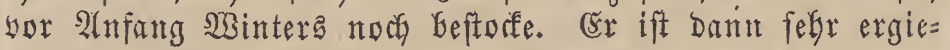
big, eine bolfontmene 2 fegre liefert $65-75$ Sïrner. -

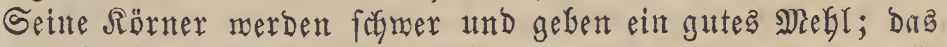

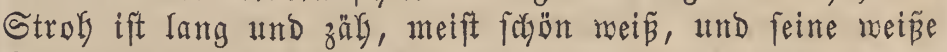
Spreu Dient als Biebfutter.

Eine Spielart Diefes Weizens ift:

\section{a) Der Modsueizen.}

Triticum vulgare muticum album velutinum glumis cinereis.

Tessier.

Die 2lebre graugelb, oft etwas rötylich; er ift fouft nicht you bent ofigen veridicbert.

\section{Rothex glattex fiolbenweizen.}

Triticum muticum rubrum glabrum.

Triticum hibernum. L.

Triticum muticum hibernum. Schübl.

(S)meiner 33 interweizen.

Touzelle rouge (rougeâtre) sans barbes.

Brown common beardless wheat.

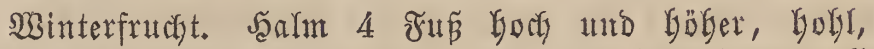
meióliçgelf. Blätter 12 3oll lang und $1 / 28$ ofl breit, Gefl ober bunfler grün. Alegren $3-5$ Boll lang, etwas freit, ungegrannt und unbebanrt, gelbliçweif und rötblichgelb. 2lefrefen 18-22, Gautsig, melgr voer weniger gebrängt, Dodf) meift etwas entfernt über einnuder liegend, Gefonders bei gropen Rörnern, wit 4 Blüthen, Deren eines unfrudtht= bar ift, und mit 3 , feltner 4 Samen. 1 Boll Iange Stum= melgrannen findet man zuweilen an ber Spiege ber Aefren. Die Selchfuelzen fend fodmal, ftumtpf gezafint, rötglich oder röthlichgelb. Die äunern Sironfpelzen meift etwas lünger gezahnt, ifr äuperer Theil yon Der Farbe Der Jeldafpelzen,

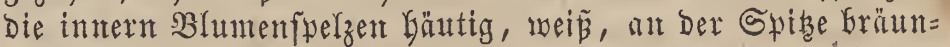
lidy. Die Gpindel furz gegliebert, glatt und an belt Sufer=

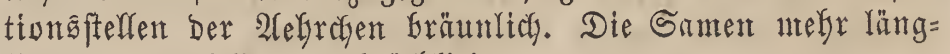
rici) ober runblich, gelbrötylicy.

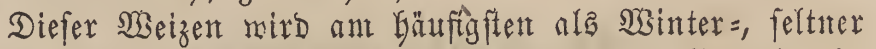
als Sommerfrudyt angefant, und nicht mur affgemein in unfert, fondern auch ebenfo in andern, wie bauptförslich in Den Rheingegenden, in Gadyjen $z$.

(5x verlangt yorzugämeife einen thommergel = oder lehnt= Galtigen Boden, bejonders it wärntern Gegenden, wälyrend er in mittelmä̧igem ober faltent Rlima einen farfmergel= Gartigen yorziegt. Die Rärner Dez $\mathfrak{B}$ intermeizenz find melgl= 


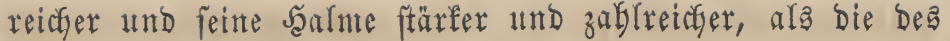
Sommerweizens.

(Sine volffommene 2 (ebre enthält gegen 65 Rörner, und

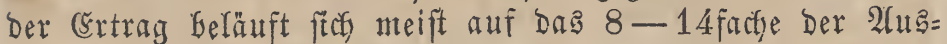
faat, fo Dá man alfo in 2 ürttemberg bon einem Morgen $21 / 2-6$ Scheffel Rorn und $12-35$ Eentner Stroh, in Baben 3-9 Nialter Sorn und 14-40 Eentmer Strob, und in Jeffen $2 \frac{1}{2}-6$ Mialter Rarn und $10-28$ Eentner Struh erbalten fann. zu fein:

Nur eine Barietät son Dem rotben Rolbenweizen forfeint

a) Der brane $\mathfrak{x}$ olbentueizen.

Triticum muticum rufum glabrum.

Triticum vulgare spica laxa mutica rufa glabra.

Deffauer = Weizen.

Froment commun sans barbes, raux et glabre. Froment sans barbes à épi d'oré et à graines jaunes. Blé Lámas.

Brown common beardless wheat.

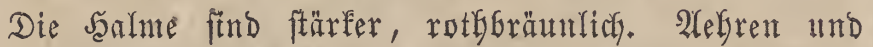
Relihipelzen oft Dunfelbraun. Die Samen goldgels oder rötflidggelb; hat int Hefrigen alles mit Dem glatten rothen iolbenmeizen gemein.

\section{5. \#nthex fammtaxtigex falbenweizen.}

Triticum muticum rufum velutinum.

Triticum vulgare spica laxa mutica rufa velutina.

Sother Sammtweizen.

Froment commun sans barbes, roux et velouté.

Red common beardless velvet wheat.

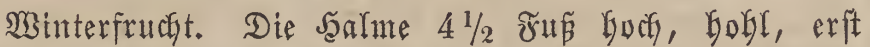

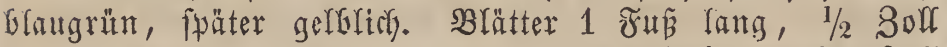

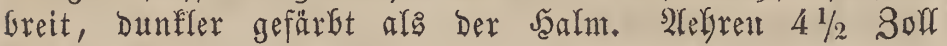
lang, jung grüngelglich, mit Der Neife nelgr oder mentger rötflich ober gelflict. A(ebraten 18-22, Gäufig febr weit yon einamber abftefyend und gefpreizt, mit 3 Rüntern. Seldy= fpelzen furz gezahnt, ftarf Gefaart, mäbrend der Blütbe

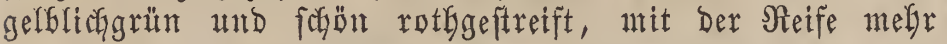
oder wentger rötgliç, bräunliç, gelblich oder grauliç. Die äuperen Sromenfpelzen felten grannenartig gezalnt, aupen befant und yon Der Farbe Der Relchfpelzen, bie innern Durreffichtig Gäutig und boppelt nacfenfürmig bertieft. Die Spindel glatt, an ben Siegelfuppdyen fpariam befanrt, meifs. Die Gamen l"̈nglichrumb, doer Gauchig, zumal Die gröpern,

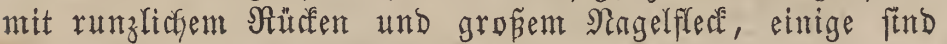
gelf und meblig, andere afer mefre röthlich und glafts.

Der 2 (nbaut biejer șeizenart ift wenig verbreitet und

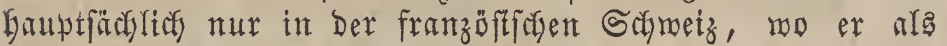

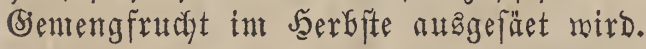

Der (sratrag ift ermünfGt, und bie Söner werben in günftigem Boben gelb und melylreich.

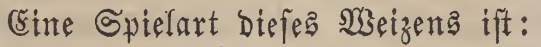

a) Der bla La varieté bleue.

Ste ift mely pber ntimber graubläulich und zeidgnet

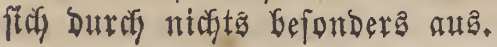

\section{Sgelweizen.}

Triticum compactum.

Die 2fegren Dez Jgelweizens fint biel bichter und fürzer als Gei ben vorigen $\mathfrak{W e i z e n a r t e n . ~}$

\section{Wintex - \$gelweizen.}

Triticum vulgare erinaceum hibernum.

Triticum autumnale compactum aristatum.

Triticum vulgare autumnale spica compacta aristata alba glabra, seminibus albidis.

Sgelmeizen mit weiß̨lidyem Samen.

Froment commun d'automne à épi barbu et compacte.

White compact bearded winter wheat.

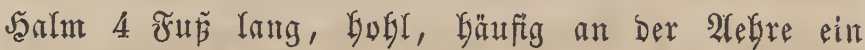
mentg fpiralförmig gebregt, gelblich ober meislicf. SBlätter

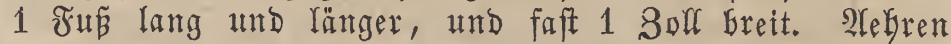
2 Solf lang, fegr bicht und oft phramidenartig ftebend, faft

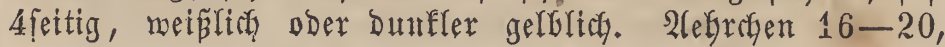
bicgt fablend, 4grannig, meift ftnd 2 sirannen fürzer, $4=$, feltner 3 jamig. Die Erannen 4 Solf lang, unten für $=$ zer, ftefen bidgt, Gei üppigen Sörnern Gäuftg fefre gefwreizt, jung grünlich und fömärzlich berwajchen, ntit ber Neife

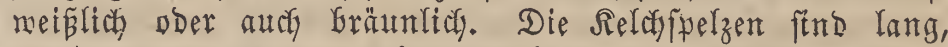

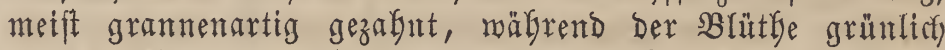
und Dunfler längågeftreift, fpäter gelb, bie und ba rötblich= bräunliç. Die äunern Sironfpelzen find gegraunt, mit

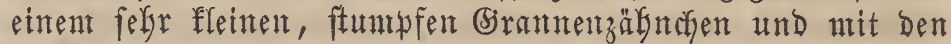
Relchfpelzen gletchfarbig; Die innern Srompelzen felgr bünn, glänzend und bopwelt flact bertieft. Die Spindel hat enge

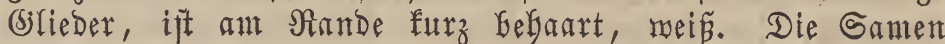
furr, bise, breitgefurdyt, yon Farbe rötblidy und gegen die Spize zu meiflich, felten etwas meblig, fondern meift glaftg.

Die Sonmerbeftelfung eignet ftef für biefen nicat, wohl aber bie Minterfant. (Ér ift febr ergiebig, menn ber Bobent aucf nut einigermafen günftig, und Gălt ben Winter ganz gut aus.

\section{Sommex - \$gelueizen.}

Triticum vulgare erinaceum aestivum.

Triticum vulgare spica compacta alba glabra, seminibus aureis. Igelmeizen mit gelfem Samen, Binfelrweizen, 3merg= meizen.

Froment commun de printems à épi barbu et compacte.

White compact bearded spring - summer - wheat.

Salm $31 / 2-41 / 2$ Juß boch, aufrect, fteif, bobl, gelb=

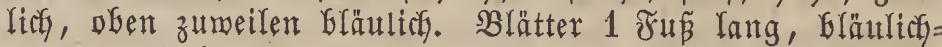
grün, auf ifrer untern Seite meiflich. 2(efren $21 / 2-3$ Soln lang, aufrecht, bicht, und zur Blütbezeit blaugrünlich und

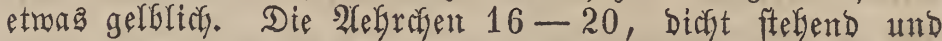
meift ftarf gepreizt, mit $3-4$ Samen und eben fo vielent

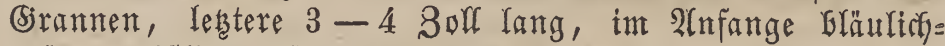
grün, weiblicf geflecft und punftirt, fpäter roiblich und bis

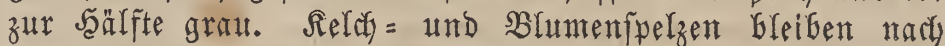
Dem Ausfallen des Samens an der Spindel ftzen. Reldy= fpelzen lang, bäıfig grannenartig und gefrümmt gezalint, gelblich, grau ober Glauliç. Aleupere Blumenfpelzen ge= zăbnt und wie die Relchpelzen Dünnfäutig, flach vertieft. Spindel mit furzen Siliedern und glattem, feltner etmas

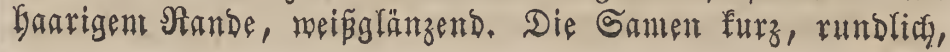


mit gegen ben Nagelflecf Gin furzen Rürfen unb Greiter Furche, rötglich und meift glaftg, Dber gelgrich and bann fefr meflig.

(Ein bei uns menig angebauter Weizen, Der trok feiner furzen 2lebren siele und fobjue Rörner und ein Dem Der (berfte ähnliches Mefl, unter günftigen Utmftänden aber ein

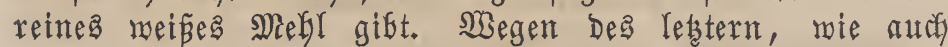
wegen Der furzen Vegetationaperiode yon nur 4 Monaten,

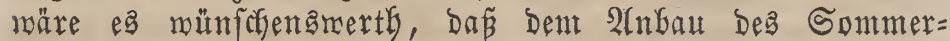

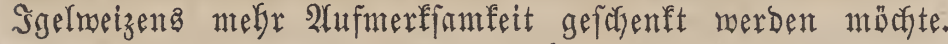

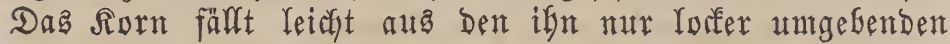

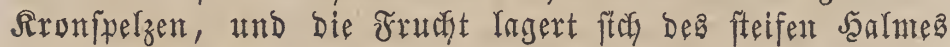
wegent felten.

\section{Weizex fammtaxtinex 3gelweizen.}

Triticum vulgare erinaceum velutinum.

Triticum vulgare spica compacta aristata alba velutina.

Froment commun de printems à épi barbu compacte et velouté. White compact bearded velvet wheat.

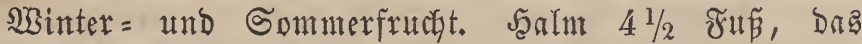

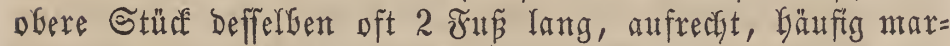

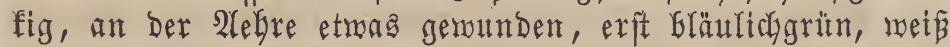
angeflogen, fpäter gelbliç. Die Blătter 1 sun Iang, Dunfler Gläufichgrìn, auf ifrer Utnterfeite und an Den Sifjetbent meiplich. 2legren gegen 4 80ll lang und ant längften unter

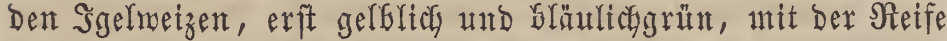
meiplitygelb und Durdy naffe 23 itterung flectig werdend.

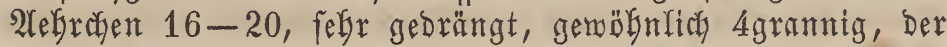
vierte Reldy furz gegrannt und meift berfümmert, 3 famig. (Erannen gegen 5 80ll lang, auf igrer breiten Seite etwas

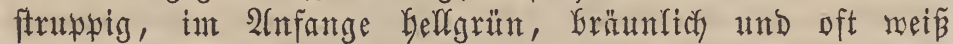
wunftirt oder geflecft, mit Der Sieife weiplich, oft in's Bselbe übergebend. Relchjpelzen fobarfrürtig, lang, Gäuftg granten= artig und frummzabnig, juntg grün geftriçelt oder gefferft, ftarf Gebaart, ant intern Rande genvintwert, in Dex Reife fammtartig und gelblicf. Die äusern Sronfpelzen find an Dex Spike gegrannt und oft noch gezühnt, und auren wie bie Seldhfpelzen befaart und gefärbt. Die innern Siton= fpelzen Greit, Durdffichtig=bäutig mit boppelt nachenförmtiger

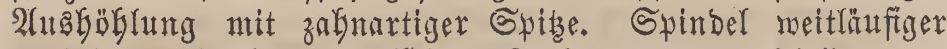
gegliebert ars bet Dent WBinter=Sgelmeizen und feitlich nur renig Gefgart. Die Samen find grof, lang, faft 3ertig,

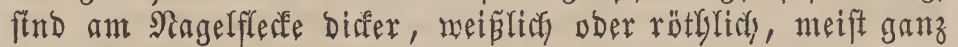
Gornig.

Aluch Diefer Ggelmeizen ift nur wenig befannt, ex be=

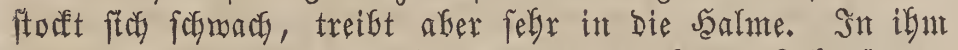
zufagendent Boben und in warmen trodfenen Jabrgängen geräth er gut in Şezug auf feinte 2(ebren und Rörner, wie feines Strokes. Sn naffen Sabrgängen, ober wenn man ifn zu bicht aus gefäet bat, wirb ex gerne taub ober bringt mur fohlechte sörner herbor.

\section{Binkelweizen.}

Triticum compactum muticum.

Triticum vulgare spica compacta mutica rufa glabra.

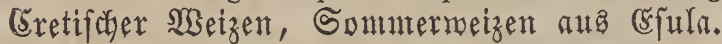

Froment compacte à épis courts roux et sans barbes. Blé de Crête, Froment d'Alsace à epis courts, Froment de Phalsbourg, Blé mottu.

Red compact beardless wheat.

WBinter = und Sommerfrudt, aufrecht, Gobl, oft an ber 2 (ehre etwas gebrebt, oben erft

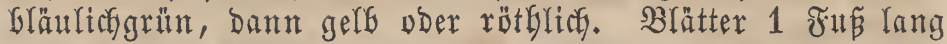

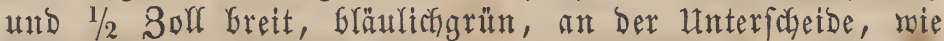

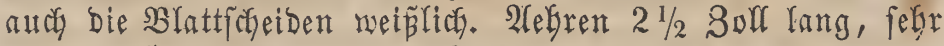
Diclyt, faft 4ecfig, an ber Spike vft furz gegrannt, jung

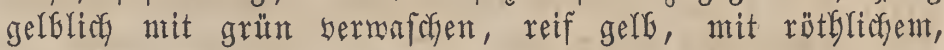

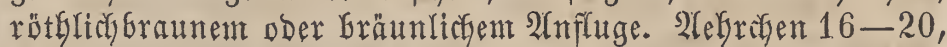
fefr contuact, Der 4te Relch neift verfüntmert, $3=$ feltner 4 famig. Die (jorannen feglen oft ganz, dft ftnd fie nur

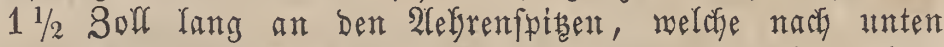
fürzer merden. Seldfipelzen furz, Gauchig aufgetrieben, glatt, ftuntpf gezähnt, exft gelblicfgrün und grün längågeftreift DDer grün verwafdyen, mit brĭunlichem Nande, reif gelbs und rötglich. 2leusere Jironfpelzen mely ober meniger lang, vft grannenartig gezähnt, gefürbt wie Die Relofipelzen und weit aus Den Yedertert Gerbortretend; Die intuen Rronfpelzen zart, Durchferestig = Gäutig und boppelt nacfenfürmig bertieft, an Der Spindel fthen Greifend. Spindel fegr furz, meís= glänzend, Gie und da etnaz bläulich, gegliebert und am Nande feltent befanrt. Die Sament furz, fajt 3erfig, am Nagefflecte biffer, mit tiefen, Greiten zurchen, röthlich, oben und unten meiplict und genöbnlich Gornig.

(Ěx mird namentlich in einigen Begenden Der franzöft=

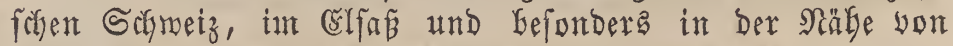

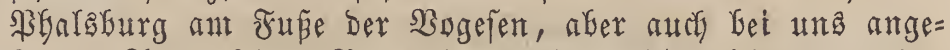
baut. 2urch feine Begetationaperiode ift gleich Der dez Sommer=รgelweizens furz; ntan fäet ign gemöhntich Mitte Mañz ober auch noch Mitte 2lprifa, und Ende Suli's oder

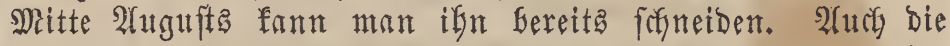
Sönner gleichen Denen Des Somnter=Sgelmeizens ungentein, tund ex Ingert fitch, wegen der fteifen sberchaffentyeit feiner Salme, efen fo wentig als biefer. Die Sïrner find zwar

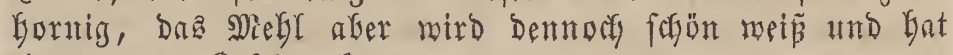
eimen guten Biefcrmadf.

\section{Triticum turgidum, L.}

Triticum aristatum $\delta$. Hall.

Triticum compositum. L.

Triticum Linnaeanum. Lagask.

Triticum polonicum $\gamma$. Pers.

Triticum sativum turgidum. Delil.

Triticum vulgare $\gamma$ turgidum. Spr.

$\beta$ Triticum quadratum. Mill.?

Englifder Weizen, Bartmeizen, raufanatger Waeizen. Froment renflé. (frant.)

Turgid Wheat. (engl.)

\section{Stren, Shavafter.}

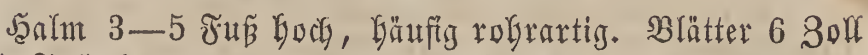

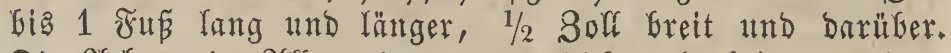

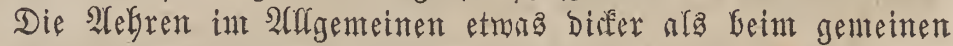
Bartweizen, ziegeldachförmig, 4 feitig, mit 2 ummerflich fchmälern Seiten. Die 2leferchent gedrängt and fobuppig über eimander ftehend, zmeigramig, meit auseinander gefpreizt mit 4 Blüthchen, wabon eines doer zmei verfïntutert find. Die Spelzen eiförmig, ftumpf und zufammengebrüḉt. Die Rlappen furz und ftumpfzalgnig. Die Grannent Der ăupern Sirnipelzen meift jegr lange und raub, meniger augigebreitet und nidgt fparrig; meift haben bie oronenfpelzen noch eine 
Dritte, aber Stunmelgranne. (šin 2(efrechen entbălt $2-3$ rundliche, meift Gauchig aufgetriebene, gelblicte Rörner, meldye in gutem Boben meblreich), in forfedjtem aber und bei ungünftiger Witterung Gornig und länglich werben.

\section{Blütbe = Beit und Danet.}

Mai - Juli. $\odot$.

\section{Batromment.}

Wirb theilmeife bäuftg Gei unz fultibirt.

\section{Rultux.}

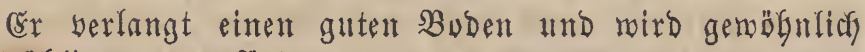
im ชrüblinge auถgefäet.

\section{A. Bierfeitiger englifuer Meizen.}

Triticum turgidum spica tetragona.

\section{Weiser glattex engli jachex Weizen.}

Triticum turgidum album glabrum.

Triticum turgidum spica aristata alba glabra. pellier.

Froment enf lé blanc à épi doux. Froment blanc de Mont-

White turgid wheat.

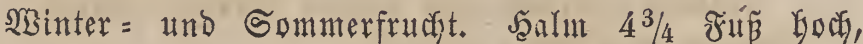

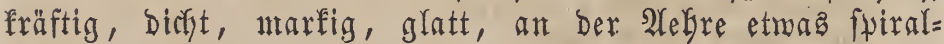
förntig getwunden, erft belfgrün, Dann weiślich. SBlätter 10-11 3oll lang, $1 / 2$ 20ll breit und blänlifggrün. 2(ebre 4 Bolf lang unb länger, 4jeitig, aufrectst, fpis, phramiden= fürmig zulaufend und meif. 2legrefen (befonders unter günftigen Umftänden) oft gegen 26, meift bicht und bachziegelfürmig, 2grannig und genöbnlich 3fantg. Die (3ranten vft gegen 6 solf lang, feingefpist, zäke, in trofece

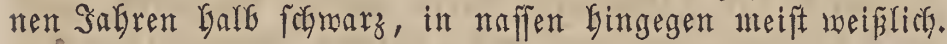
Die jungen Spelzen ftrtb nicht inmer ganz glatt, fondern oft, befonders in naffen Jahrgängen mehr ober weniger ftarf fammtartig. Die Relchipelzen auf Dent Riucen gerippt, etroas mulftig gerändert, furz und făarf gezähnt, feinbelgart 4nd weín, wäkrend ber Blüthe Gellgelb, an ber Spise und am Nande grün geftridgelt. Die äunern Sironfpelzen lang gegrannt mit erbabenem gefielten Riufen und tief nachens fürmig auagebält und am Sande fein befanrt, wälarend ber

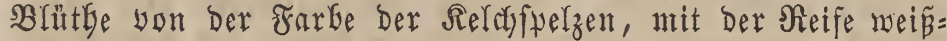
lichgels; bie innern Sronftelzen ffach, fein, Durchfitstig= Güutig, ben Samen lodfer umgebend. Spindel furz geglie=

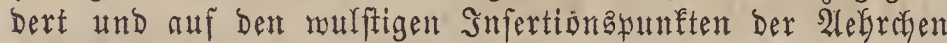
fein Gürtenartig begant. Der Sane länglicinumb, bauchig

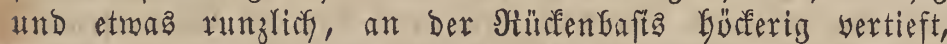
bie Rängsfurche mulftig gerändert, won Farbe gelblich und etwaz in's Röthlidje berlaufend, meflig.

Diefer SWeizen wird in (šngland, Franfreich und Stalien faron longft angebrut; er ift menig emtpfindlicf gegen ftrengen und ungünftigen Wainter und eignet fath fowobl für bie Sisinter = als auch Sonimerbeftelfung, ebenfo aud zur (bie= mengfant, Gefonders mit bem $\mathfrak{B}$ underweizen, indent er fith feiner fteifen Salme megen nicht rogl lagert und baburch Das Falfen Der compacteren 2 Trten einigermazen werbinbert. Säet man ben Gauren etra Mitte Dftobers Dünn aus, fo

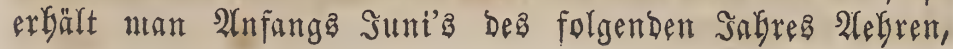

Enfwet, bfonom. ærfanzenfunde.

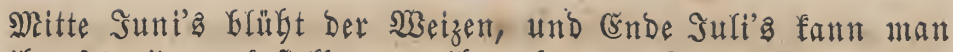
ifn forneiden; beftellt man ign aber als Sommerfrudt und zmar 2lnfangs aprila, fo blügt er Ende Juni's und reift

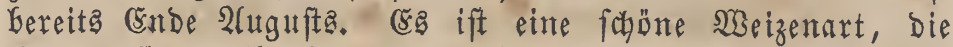

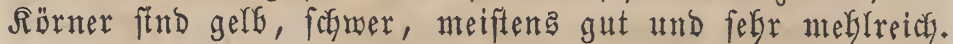

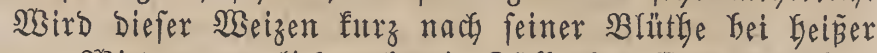
troffener $23 i t$ terung etlicfemal mit bjüfle begoffen, fo erbält

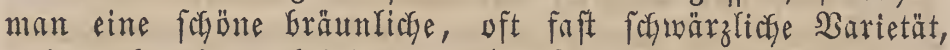
melche aber fodyon bet der näriften 2lusfant mieber eine belfe Farbe anninmt.

\section{Weichex faumtaxtigex englijhex Weizen.}

Triticum turgidum album velutinum.

Triticum turgidum spica aristata velutina.

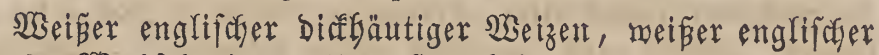

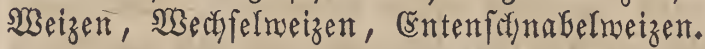

Froment enflé blanc à épi velupetianelle blanche et velouté.

White turgid velvet wheat.

WBinter = und Sommerfrucht. Diefer Weizen fogeint Feine für feth Geftefyende 2 (bart, fondern melgr eine Spielart

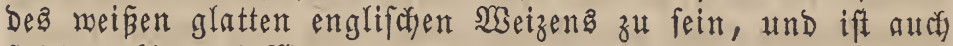

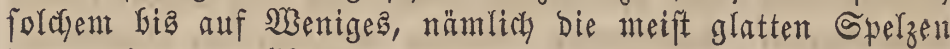
Des yorigen, yollfonmen gleirf.

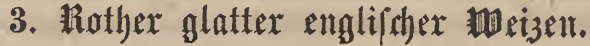

Triticum turgidum rufum glabrum.

Triticum turgidum spica aristata rufa glabra.

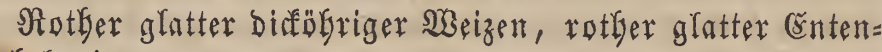
fdynabelmeizell.

Froment enflé roux à épi doux, Gros blé à épi roux et glabre, Froment rouge de Montpellier.

Red turgid wheat.

WBinter = und Sommerfrucft. Şalnt $4 \frac{1}{1} 2$ Fú lang, marfig, yor Der Neife Yelfgrün, auch rötglich ober röthlich geftreift, fpäter meiz. SBlätter $\%-9$ Soll lang und $1 / 2$ Soll breit, belfgrün. 2lebre 3 Solf lang, aufreçt, nach ber Spibe hin purantidenförmig, ofdymäler verlaufend. 2lefgrchent 20-24, fegr gebrängt, mit 2 sirannen und 3 Samen. (Brannen 5-7 3oll lang, rötbliç = bräunlich. Sieldyfpelzen aufgeforwolfen, furz-und figarf gezahnt, weífgrauliof, etwas

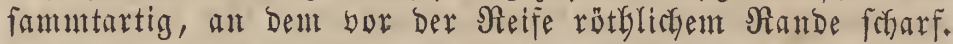
Die äupern Rronfpelzen find bejonders gegen die Brrmmen Gin glänzend und rotgloäunlich mit rötglichem Nande; bie innern Sironfpelzen find dünnfäntig. Die Spindel Gat furze

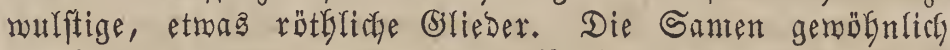
länglich ober auch rumblich, Der Rüufen baudsig, oft rumz=

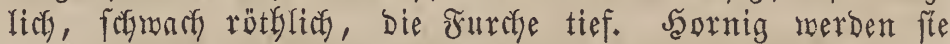
meift nur in forlechtent Boden, ober wenn man fte zu reif werben läpt.

Dieje Art baut man in Bropenen, bauptfächlitit im füb= richen (̌uropa, in Franfreich unt Montpelfier, in Ërgland und Spanien. Die Winterbeftelfung ift ify am zutrïglidy= ften, und fie bauert Den Winter ganz gut aus; fäet man fee Ende Dftubers, fo fann man oft foldon in ben erften Tagen

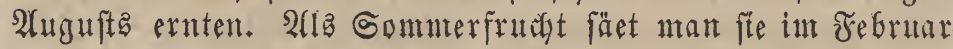

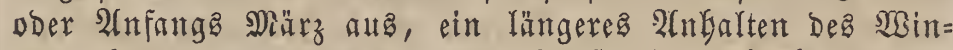
ters aber und mieber eintretende Fröfte find fegr Gäufig bem Gebeifen der Sommeriant Gimberlicf.

Der rotfe englifase weizen, gibt eimen reidylidyen Ertrga an Sörnern und Stroh, welch' Yetsteres aber mentiger ftart 
ift. Die Brannen fallen ifrer Sprobigkeit regen, zumal in trofenen Jafrgängen und bei heftigen Swinden, gerne ab.

\section{Rotber fammtartiger englifher Weizen.}

Triticum turgidum rufum velutinum.

Triticum turgidum sqica aristata rufa velutina.

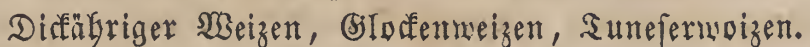

Froment enflé roux à épi velu, Froment roux de Montpellier, Gros blé, Blé de Sicile, Froment renflé, petianelle rousse.

Red turgid velvet wheat, Clock - wheat.

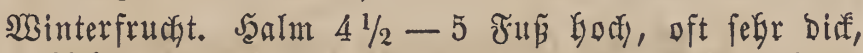
an Der 2 lebre fpiralförmig gerounden, glatt, marfig, Gläu= liçgrün, oben meí̄liç. Blätter 13 Soll lang uno länger, $1 / 2$ Solf breit und Greiter, blaugrün. SAebre 4 Soll lang und länger, 4 feitig und an jeber Seite beinabe $1 / 2$ Soll breit, naw oben fdytäler berlaufend, Gängend und mit ber Reife roth. Alebrefen 20-30, didyt ftebend, 2grannig und ge= wöbnlich $3=$, feltner 4 famig. Grannen meift 3 , in fettent Boben auch 4 , die äupern find $5-5 \frac{1}{2}$ Soll lang, die mittlere ift furz, fie find fefr raub, fein und forarf gezabnt,

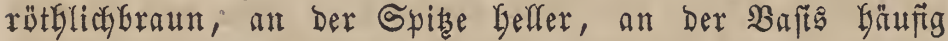
bläulidgrau. Relchpelzen bauchig aufgetrieben, frummge= zabnt, weiplich Gebart und ibr innerer Band meiblich ge= sointpert. Die äupern sronfpelzen ftarf bertieft, meift mit

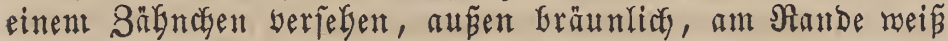
gewimpert und innen weiglich; Die innern Rronjpelzen Dủnn= Gäutig, feitlid bertieft, am Rande und an ber Spite bräun= lich. Die Spindel furz gegliebert, weí und an Dem rulftis

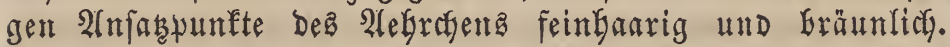
Gamen grof́, längliofy, mit ftarf conbexem, gerunzeltem Sürfen und marziger, nagelförmiger (5rube am biffern Ende unb breiter Ränggfurdye, meift rötblich und graulidymeib̈ ober gelb, meglreict mur, wenn. fie gelb an Farte gerntet mer= ben, im andern Falle aber Gornig.

Crine bei uns befannte $\mathfrak{A} r t$, welche im guten Boben eine reicfliche crante gibt, fich ftarf beftorft und fobuttet. Seiner gropen und formeren alebren regen ift er Gejonders

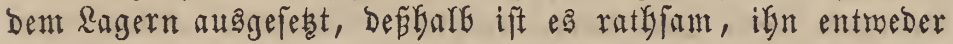
nur bünn augujäen, reil ftch Dann feine Salme biel mefr entricfeln, ober ifn int Semenge mit einer ifm bermanden 21rt, wie etwa mit bem weipen englifdyen $23 e i z e n$ z $b e=$ Gauen, melde Denfelben ifrer fteifen Salme wegen aufredst erbalten würbe.

Unt ein gutę Mebl zu Gefommen, nü man diefen Weizen faft nody bor ber Gelbreife eitzubringen fuctsen.

\section{Bläulidggrauex fammtaxtiger englijder weizen.}

Triticum turgidum subglaucum velutinum.

Triticum turgidum spica aristata subglauca velutina.

Froment enflé gris de souris. Froment noir, velouté et lache. Grayish - blue turgid wheat.

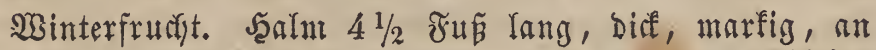
feinem untern Theile nidjt gefniet, feltner an ber 2lebre etras fpiralförmig gerounden, grüngelb. Slätter $6-8$ 3oll lang und $1 / 2$ 3oll breit. 2lefren oft 5 3olf lang, gemöbn= rich aufrectit, gegen die Sleife Gin grünlidy und gelgricumeíp. 2lebrofen 20-26, fallaff, feltner nefr ober weniger bidyt, mit 2 Srannen and brei Santen. Sirannen 6 Soll Iang, nach oben ficty etmas ipreizend, exft bellgrün, Dann bläuliç =
Gräunlidy, an Der Spibe Gelfer, an Der Baftz Dagegen fichärzlicy. Reldafpelzen etwas ffach, furz gezabnt, diçt meib̄bebaart, grünlid und Glăulidggrau geftreift, mit ber Reife nimmt Die lebtere Farbe mefr äberband. Die äubern Sronfpelzen länger alg bie Reldypelzen, tief augheb̆blt,

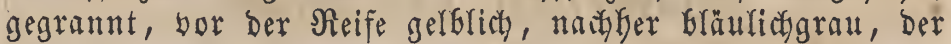

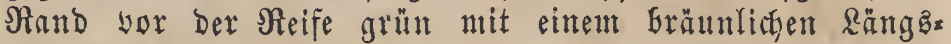
ftreifen und wie ber furze 3afn meibbarig, an Der Reldy= fpelge glatt, röthliç ober gelfliçbraun. Die oritte mittlere Srompelze ift oft mefr oder weniger granmenfpibig, frtymubigs gelb ober Gläulictbräunlich; die innern Blumenfpelzen feit= lich wertieft, glänzend, Durchfechtig=bäutig, ant Rande ge= färbt. Spindel meift furz und begant, gegliebert, unit einem Gläulichen Duerftridse unter Dem Wulfte am Regeldyen.

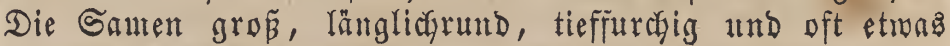
gerunzelt, gelbrötgliob und meblreich.

(5x bält Den Winter gut aแb, unb wenn man ifn etwa

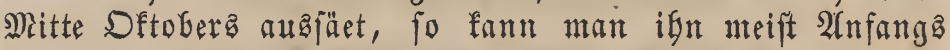
2uguftz einernten. Maan baut ifn autf iu Siemenge an, er ift ergiefig, fofuttet gut unb gibt febr viel Strob.

\section{Rla}

Triticum turgidum violaceum velutinum.

Triticum turgidum spica aristata violacea velutina.

Froment enflé bleu à épi velu.

Blue turgid velvet wheat.

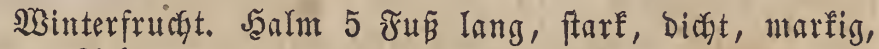
an Der 2Uefre etmas fpiralförmig gebrebt, mäbrend der Blütbe bläuliçgrün. Blätter $9-10$ Solf lang und $1 / 2$ Soll Greit und etwas dunfler gefärbt alo die Salute. 2rebren $4-5$ 3oll lang, fich oben zuppibend und bäufig niafend, bläulia

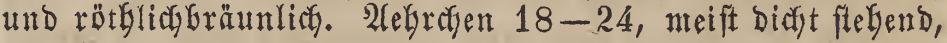
gemöhnlia mit 3 (Sirannen, Deren mittlere fürzer ift, oder nur 1 Stummelgranne und mit 3 Samen. Siramen $6-61 / 2$ Boll lang, rotboräunlidy, oben Geller, an Der şafts aber etras farmärzlidy gefärbt. Releffyelzen ffach convex, fdyarf= gezagnt, weibgebart, ant Spindelwulfte feftükend und bläu= Iich. Die äurern Rrompelzen furzgezalont und ftarf nachen= förmig augeboglt, weib̈begant und bläulich, gegen die Reldyfuelze bin ofit bräunlidyoth; Die innern Rronfpelzen

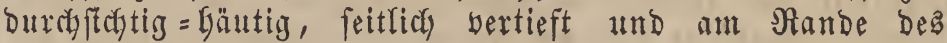
Rüufens etras Gläulicy. Spindel furzgegliebert unb rang= befant, namentlich an Den roulftigen Enden des Regeldyent. sörner febr grofi, länglia, ftarf conbex, tief gefurdyt und zeitig eingebraidt, fegr meblreich.

Arud diefer Weizen gebeift meift, trob bes ftreitgften

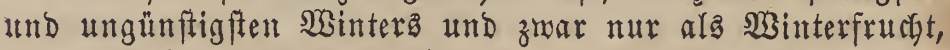
Denn als Sommerfucht beftellt, reift er, aud nody fo frube auşgejäet, febr ungerne.

(̌rr ift felr ergiebig, fomobl in Rörnern als in Strob, und lagert fith), tros feiner fidweren Aebren, feines robr= artigen Strobes regen mur felten. Seine föner geben biel und ein fĕpones, fräftiges Mebl, fein ftarfes und mar= figez Strof erzeugt einen guten Dung und Dient befonders zu Stroboädyern. In naffen Jabrgängen berliert diefer Weizen gerne feine blaue Farbe, was Beranlaffung gegeben Gat, ign für çine art mit ben bläuliograuen fammtartigen Weizen zu galten. 


\section{Schwarzex fanmmtartiget englifider Weizer.}

Triticum turgidum nigricans velutinum.

Triticum turgidum spica aristata nigricante velutina.

Froment enflé noir à épi velu. Gros blé à épi noir et compacte. Gros blé noir, velouté et serré. Froment noir de Montpellier.

Black turgid velvet wheat.

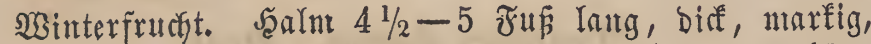
feltuter an ber 2lebre etwas fdraubenartig gebreft, oft hăn= gent. Blătter 12-18 30ll lang, oft Dunfelgrün, fefon=

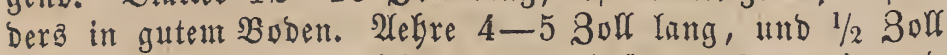
Ereit. 2lekrdyen $20-24$, etwas gebrängt, 3 granuig und

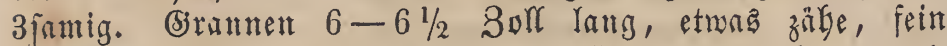

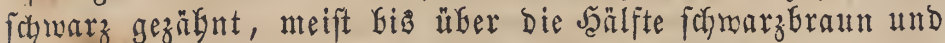
gelbrötglich fojimmernd, an ber Spize etwas Kelfer. Reld $=$ fpelzen aufgetrieben, fpibgezahnt, meiglicy bebarat, ant innern

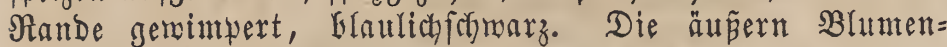
fwelzen farf nactenfürmig, wertieft, befaart und am Rande

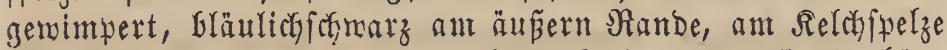
fodmutiggelblidy; bie innern Brumentpelzen burdffichtig = bäu= tig, auf beiben Seiten vertieft, nit ftumpeem Bübnchen und Gläulichfdymarzem Ranbe. Die Sronfyelzen madfen fith wont Sorne log, fobald man eine Siranne abreist. Spindel furz= gegliebert und an bem 2 tnfabunfte bes 2(efrefens gefranzt.

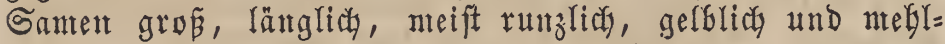
reich; in zu bindigen reie in reinem Thonboben werben fie Gäuftg graulich ober graurobthlich und glaftg.

Eine Weizenart, bie wie bie erft Gejefriebene nur als Winterfrucht zu empfeblen ift und fich eben fo bart gegen ungünftige $\mathfrak{B}_{3}$ tterungagverbăltniffe zeigt. Sie foll ebenfalls, wie bie beiben borigen 2(rten, bünn ausgefäet werben, zus utal ba er nody ftärfer beftorét als biefe. Silet man biefen

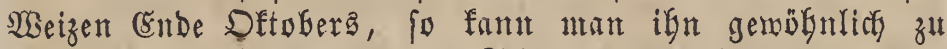

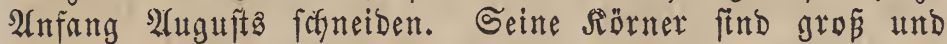
meglreich, und fein Strol ftarf und lang. Seine fteifen

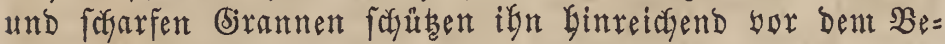
furtye Der $\mathfrak{B} \dot{g} g$ l.

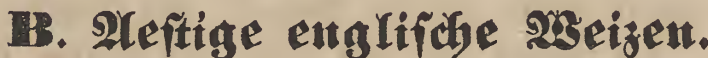

Triticum turgidum compositum.

Triticum turgidum spica multiplici seu ramosa.

Wunbermeizen, Wrechjelweizen, vielf̈rniger. Wreizen, äguptijuer Weizen, vieläbriger Weizen, Jofephazeizen, Spreitmeizen, arabiftyer Weizen.

Unter ungünftigen Umftänben berftünmelt bie und ba ber Wunberweizen und näbert fidy wieber megr beut ein= factien englifaten.

\section{Weifer glatter munderweizen.}

Triticum compositum album glabrum.

Triticum turgidum spica aristata alba glabra ramosa.

3eifer äftiger Sonmmerneizent.

Blé de miracle blanc à épi doux, Blé de miracle à épi blanc et grabre, Froment blanc à épi rameux.

White smooth egyptian wheat.

Sonmerfruçt. Şalm $4 \frac{1}{2}-5$ Fús Inng, biff, an ber Aefre etwas gemundou und an unterften Rnoten etwas ge= fniet. Blätter 12 Soll Iang und $1 / 2$ Soll breit, jung bläuliçgrün. 2lebre 4 Soll lang, neiftens bis zunt Yebten Drittel ibrer Ränge ftarf und $10-12 \ddot{a} f t i g$, einige oft faft

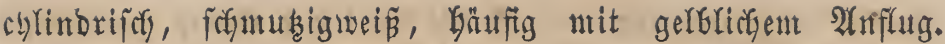

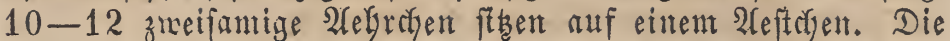

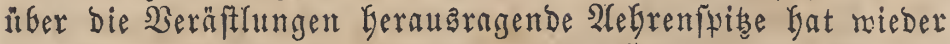

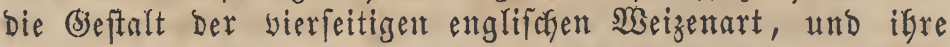
2lebrafen baben faft un die Sălfte längere (etroa 5 3oll

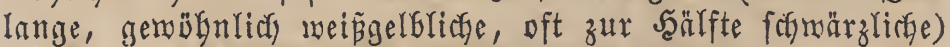
(5)rnnen, als bie ber 2lefte ftnd, 2grannig and 2 famig. Die Relisfipelzen find fdutal, glatt, furzgezalgnt und roeizlidy;

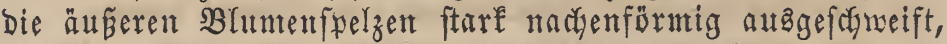

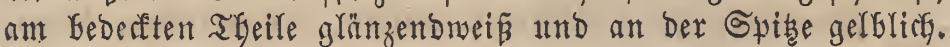
Die innern Sronfpelzen an Geiben Seiten concay, Durdfitcy=

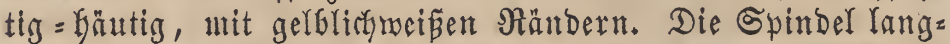
gegliebert, bie wulftigen 2InGeftungâpunfte lang Gürftenförmig

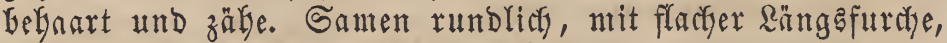
Glapgelb von Farbe und fefr uteblig.

Went man biejen Sonmex= Bunberweizen im 2infange Thrils auşäet, fo fant bie Esrnte meift fochon gegen bent 20. 2fuguft Git gemaigt merben, er Gat aljo eine furze Begetationsperiobe; fäet mant nocf fruber, fo ift er meift frgon csnde Sult's forneibefäbig.

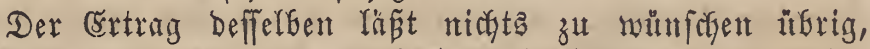
die Rörner fountten gut und liefern ein feines, weifes aber furzes Mebr. In naffen Sabrgängen leibet übrigena biefer

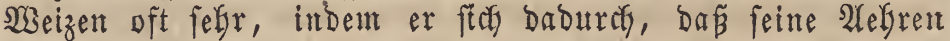
fith mit Waffer anfüllen, gerne Ingert; in Jolge anbaltender Näffe föntent nutn die 2 efgren nifft reifen, fte werben grau und faulen zuletst. Die Sirannen bresgen gerne ab und futd nidyt fo feft utit Den Blumenfpelzen verbunben, als bie bei= Den borigen 2 inten.

\section{Rothex glattex Mundexwetzen.}

Triticum turgidum compositum rufum glabrum.

Triticum turgidum spica aristata rufa glabra ramosa.

Rotber glatter bielägriger Wunberweizen, rotber glatter äftiger Natizen.

Blé de miracle roux à épi doux. Blé de miracle à épi roux et glabre.

Red smooth egyptian wheat.

Sontmerfrutft. Scalnt über $4 \frac{1}{2}$ J̛ü lang, birf, ant

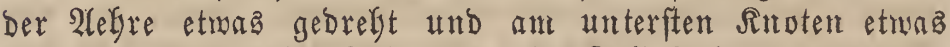
gefniet. Blätter 12 Bolf lang, $1 / 2$, Solf Greit, in ber Ju= gend bläuliçgrün. Die Afebren wie die bei bem borigent geftaltet, find aber robthlidyer und bei mandsen erftredfen fids Die Beräftelungen bis zu ifrer Spibe. Sämmtlidye Aebren find 2grannig und 2fanig. Die Grannen 5 soll lang, an Der Spibe reiflidy und an Der Bafte rotffräunlich ober

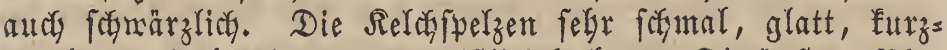
gezahnt und bäufig etroas weibliç=betbaut. Die ăuß̄ern Blu= menfpelzen ftrd ganz nabe an Der Sranne gezabut, am äupern Theile rötbliç, ant bebedften aber weiplich. Die innern Ironfpelzen an beiben Seiten bertieft, burdyfititig= Gäutig, an Rande an Der Spibe rötflicy. Spindel furz=

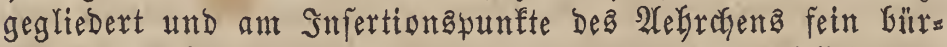
ftenartig bebaart. Die Samen fart conbex, runblicy and tief längaggefurçt, gelblich, ant biffern (snde rötgliç mit eiförmiger, böferiger und bräunlicker sirube.

In Spanten, befonders in Catalonien und 2rragonien, foll biefer Weizen Gänftg int Sropen angebaut merden. Wurde die Gaat in ber erften ober zmeiten Wodje bes 


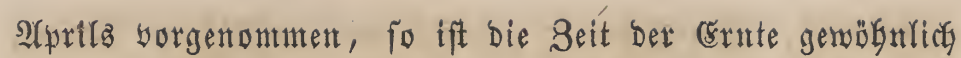

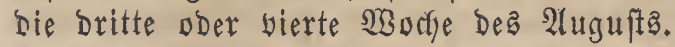

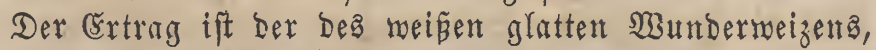

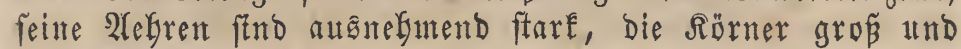
yoll, und bas Megl fitün und gut.

\section{Rother Fammtartigex}

Triticum compositum rufum velutinum.

Triticum turgidum spica aristata rufa relutina ramosa. Matizen.

Sammtartiger bieläbriget SBeizen, fammtartiger äftiger

Blé de miracle roux à épi velu. Gros de blé à épi rameux et velouté.

Red egyptian velvet wheat.

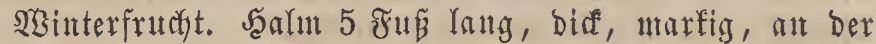
2lebre etiwas fuiralförmig bin und ber geboger. Bätter 10 3oll lang und länger und $1 / 2$ 3ulf breit. 2Hegre 4 Soll

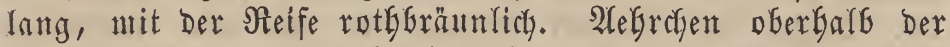
Verïftelungen etmas gefwreizt, 2grannig und 3 famig. Die 2leftcten find 10-14zäblig, Gaben 8-10 2grannige und 2 famige 2 fegrefen. Die Jirannen 3-4 3oll lang, bie Der 2lefte fürzer, meift rotgbräunlich, bäufig bon Der $\mathfrak{B a j t a}$ an

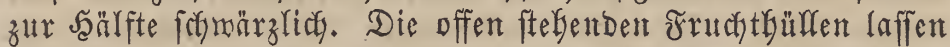
die Sament zunt gropent ageile fehen. Die Relchfuelzen find

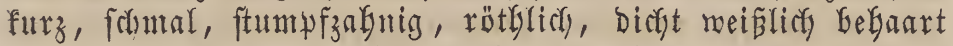
und nu Rande fdyărzlich gemimpert. Die äuBern $\mathfrak{B l u m e n =}$

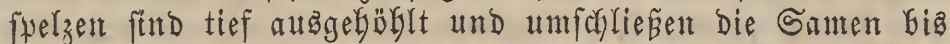
itber die Sălfte, find Galb yout Selchipelze bedecft, befyant und röthlichgelf, ifre Ränder find grau und weíflich, ge= mimpert. Die innern Rronfpelzen ftnd Durchfectig= bäutig,

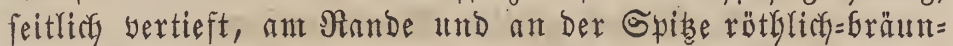
ricy. Spindel bat furze Belenfe, 2 befararte Geitenränder,

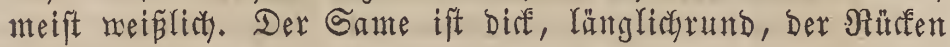

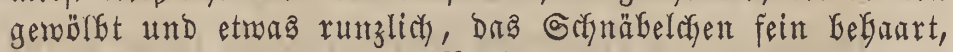
an feiner Bafts gegen ben SRürfen zu nit einer eifürntigen,

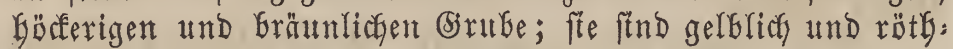
lich, und menn fie mit ber Geffreife geffynitten merben, fefr meblreich.

2rß Somnterfrutcht gezogen taugt biefer MBeizen meift nichts, bie 2lefren merben unvolfommen, Gaben oft nur 2lnbeutungen won 2leftefen, und ber Same wirb flein und Gornig. Ěr mirb im Ganzen wenig mefr angefaut, Da bie

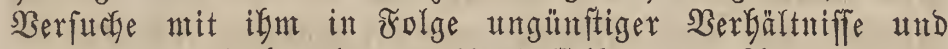
unbefannter Befandlungarweife Deffelben im 2 (nfang mi langen und Daburaf berfelbe jedoch mit wollem unrecht in Berruf fant, wie es überbaupt fo mandyen Betreidearten ergangen tft, indem man, fobald ber erfte Berfucf nicht jo=

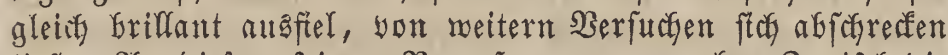

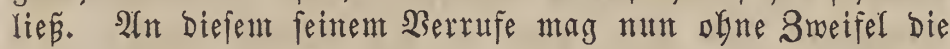
grope Neigung Diefę Weizens, ftef zu Iagern, Die Schurd getragen baben, roodurch ein groper Theil des Betreides wernichtet murbe. Wie biefem sagern aber nuf meift leicfte atrt worzubengen jei, ift fogon etfichentale bei foldhen aus= gefebten 2(rten angegeben worben, nämlich burch bie (Bse= mengfant mit fteifgalmigen Weizen, und Giezu würbe ber weise glatte und ber fammtartige engliftye Wreizen an mei= ften zu entwfeblen fein. Diefe Sorte beftorft ftch ganz gut, nur barf er efenfalfs nicht zu birfe ausigefäet merben, was mogl bei ben erften mit ifn gemadgten Rulturberfuden ber
Fall getwejen feint mag. 2(nfang Nowembers gefäet, reift er unter günftigen Unffänden Mitte 2lugufts unb liefert eiu

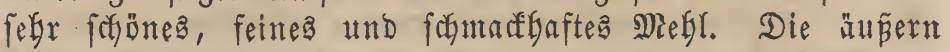
Sronemfyelzen löfen fich leicht mit ben Brammen ab.

\section{Triticum durum. Desf.}

Triticum Bauhini. Lagasc.

Triticum brachystachium. Lagasc.

Triticum cochleare. Lagasc.

Triticum fastuosum. Lagasc.

Triticum hordeiforme. Host.

Triticum platystachium. Lagasc.

Triticum sativum $\beta$. Pers.

Triticum tomentosum. Bayle.

Triticum villosum. Host.

Triticum vulgare palmare. Delil.

Triticum vulgare var. turgida. Spr.

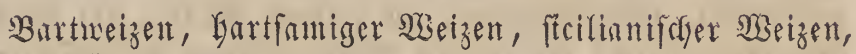
arabiftyer Binterweizen.

\section{2uten, Ebataftev.}

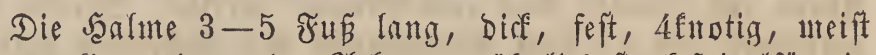
gauz marfig unb an ber 2 fefre getwölntich ftarf fpiralförmig gewounden. Die Blätter 1230 fl fang und länger, $1 / 2$ Bolf

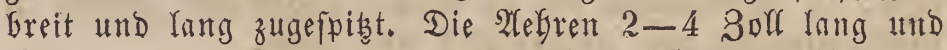
igrer gropen sörner megen fparrig, faft cylindrifs und nicht regelntäßig 4 feitig, Gie und Da gegen dos obere Ernde zu fpibig verlaufend mie bie Rolfenmeizen, feltner pyrant= Denförmig und in gutem 3 DDen bfter überbängend. Refte

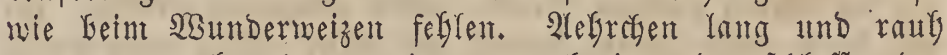
gegrannt, melyr ober meniger ausefgreitet ober folaff, ober bicht ziegeldachfürmig, ftekend und fegr gefpreizt, 46lütfig, 3-4jamig. Rlappen länglich zufammengebrüreft, weniger bauchig, etwas breit nit eimer ftarfen Rängshippe, die in einen breiten, gefrünmten $3 a$ bn ausläuft. Die Sironfwelzen ftnd ebenfalls meniger convex und gegrannt. Die Brannen

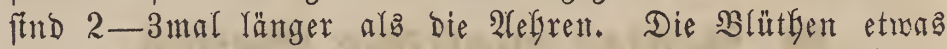

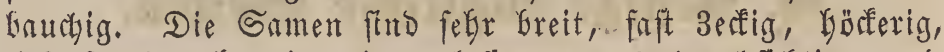
tiefgefurcht, Gornig ober glaftg, etwas burdsfectig, und

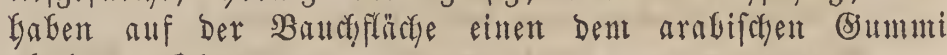
âlulidyen sinnz.

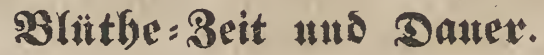

ริแni. $\odot$.

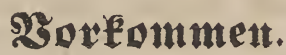

Der Bartweizen mird int ganzen nörolictyen affrifa bäuftg fultigirt und ift bafelgft auperorentrich ergiebig; er gibt jägrlict) eine 2-3ntalige (5rnte. In 2(egypten fobeint er fojon in ben frübeften Beiten angebaut worben und yon ba nach Gpantent und Sicilient gefommen z" feit, wo er aud jest noch fegr beliegt ift; er mord übergaupt in einem

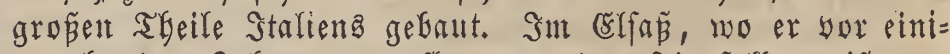
gen Gundert Jafiren angeyflanzt worden fein foll, wein man jest wenig melyr yon ifm. In Raufafen, zunal in Bieor= gien, wird die Rultur Des Bartweizens ftarf getrieben und ging yon ba aus bermutblid an bie Rititen Des fdywarzen und afomfchen Mieerez über. 


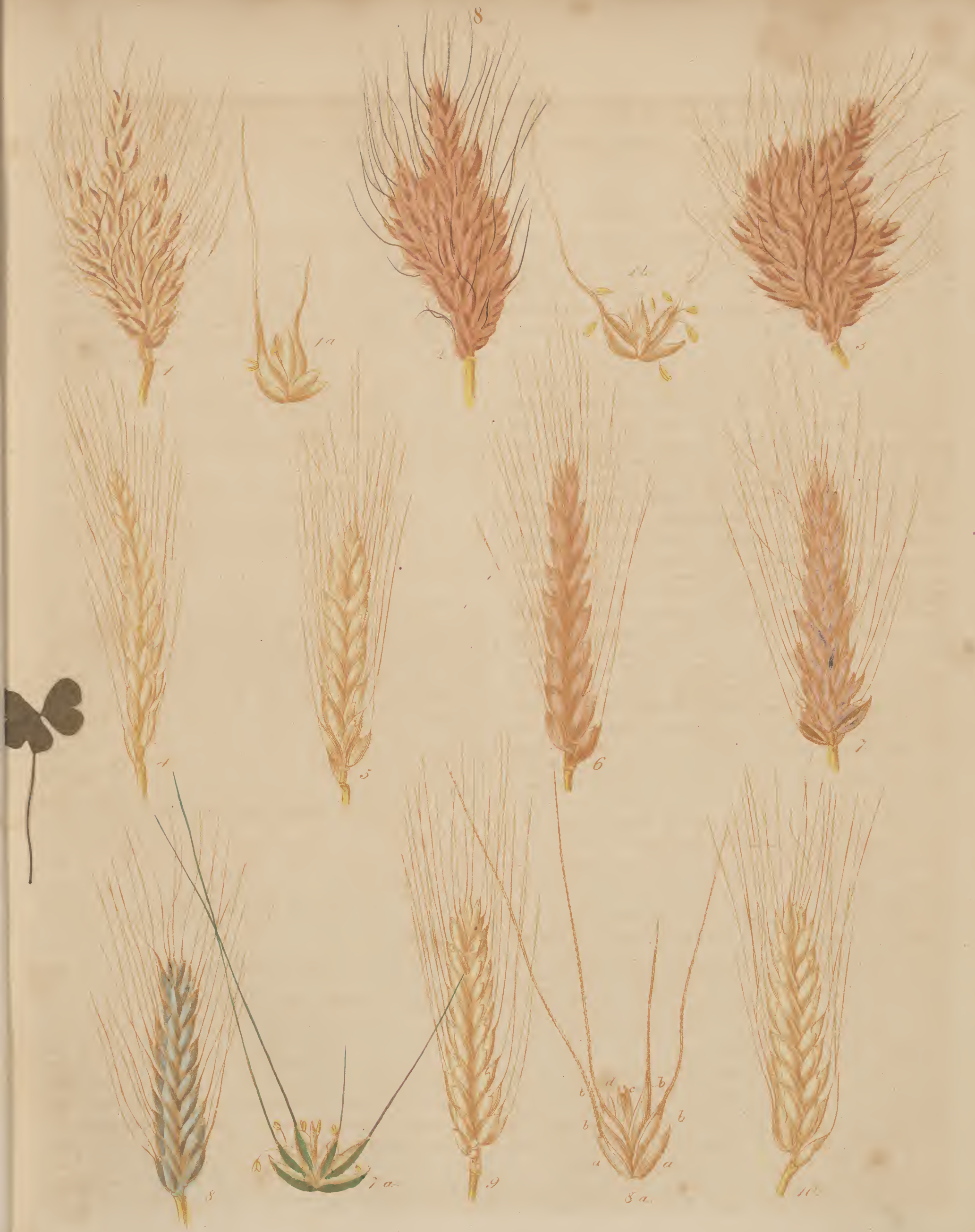





\section{Rultur.}

Der Bartweizen liebt yorzugąneife troffene Safrgänge, gut beftelften und gedunngten (etrag bindigen Thon $\Rightarrow$ Boben

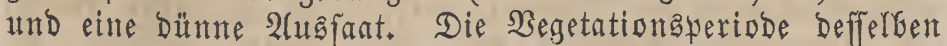
ift felgr furz, oft faum 3 shonate lang. Man bat aut Verfuche mit ifn als 2 Binterfrucht gentacht, bie zum Theil ziemlief gelungen ftud, jeboch füberer bleibt inmer bie $B e=$ ftellung bes Bartweizens als Sommerfrudyt. - Vögel und WBild find dem Bartweizen nicft gefälyrlict), da fie ficts an Den langen und forgarfen Brannen leicht berwumben; fein

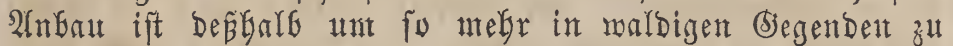

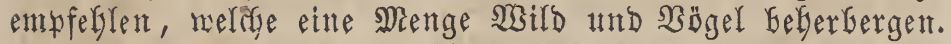
2luf Den Stpenninen, in 2 (pulten, yor metreren Gunbert

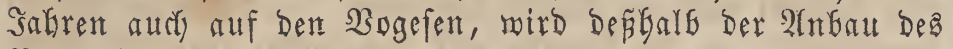
Bartweizens yorgezugen.

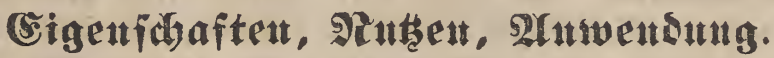

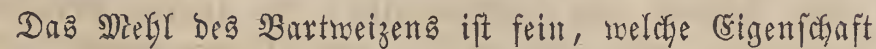
es befonders empfeglt, fekr trocfen und auserorbentlich nabshaft.

Seine Beftandtyeile ftnd:

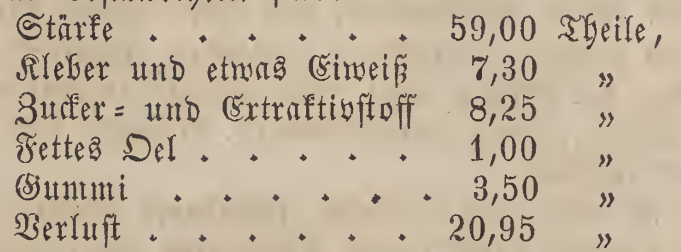

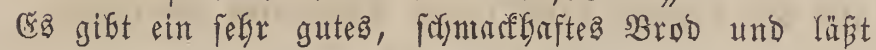

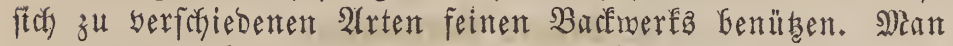

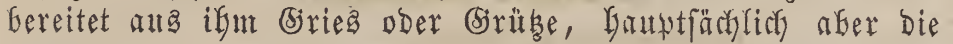
in Stalien fo affgemein und auperorbentliç gejuchten Maca=

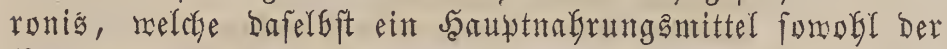

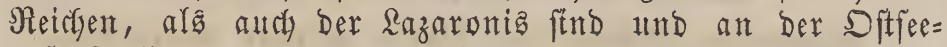

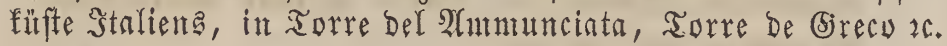
Gejonders gut zubereitet werben follen. Das meift lange und bicke Strof bient nur zur Biefftreute, nls శ̛utter für Das 2 ief ift es zu bart und troifen, und zu Strobbachern werarbeitet, fault $e \bar{s}$, ment $e \mathfrak{g}$ oft $\mathfrak{n a} \tilde{\beta}$ mird, feitter marfigent Beftandtheile wegen fegr Gald.

\section{Riteratuts.}

Desfontaines: Flora atlantica. 2. Sceft. Seite 1. Paris 1798.

Delite: Histoire des plantes cultivées en Egypte.

Maria Lagasca: Genera et Species plantarum, quae aut novae sunt, aut nondum recte cognoscuntur. Madrid 1816.

\section{A. Eigentliber słatweizen.}

Triticum durum spica laxa.

\section{Meifex glattex מaxtweizen.}

Triticum durum album glabrum.

Triticum durum spica laxa alba glabra.

Weifer gerftenartiger Bartweizen, welfçer $\mathfrak{B e i z e t . ~}$

Blé cornć blanc glabre.

White hard - wheat.

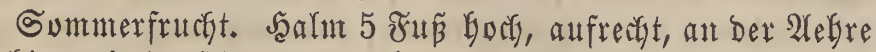
nur bie und da fofwady gebrebt, zur Blüthezeit bläulitfgrün,

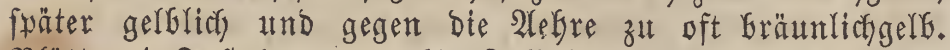

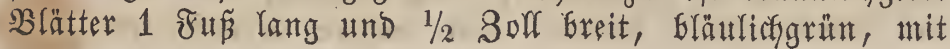

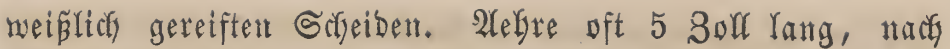
vben ftch zufpizzend, bei fleineren (sxemplaren faft regelutăpig 4 feitig, bei solffommtnern bingegen mefr afgerundet und

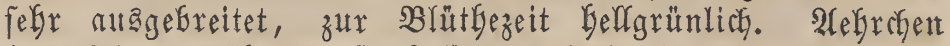
18-24, gemöbnlich ftarf fids auslreitend, 3grannig, bie mittlere Siranne fleiner, 3-4 famig. Brannen 8-9 3oll

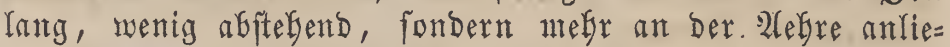
gend, un bie Blütbezeit Gelfgrün, fpäter weíplicfgelf, feltner

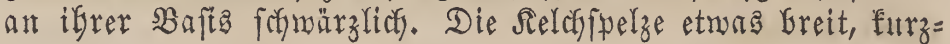
gezahnt und aufen ant $\Re a n d e$ zumeilen fein bebart and auf

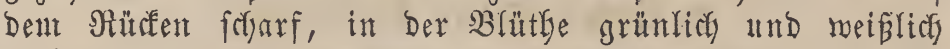

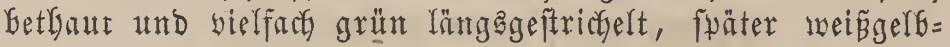
Yicf. Die äunern Blumenfyelzen lang, ftarf nachenförmig ausgegbylt und gegrannt, Der freie Theil zur $B$ lüthezeit gelglich mit grünen Streifen. Die innere Blumenfpelze zartbäutig und an beiben Seiten grübig. Spindel glatt,

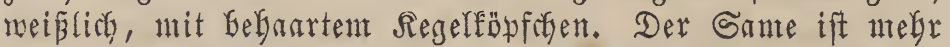

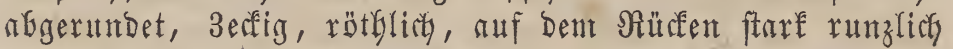
und weişliç, Gornig und undurdyfictstig.

Der $2 \mathfrak{l}$ ba in Dentfigland verfucht morben, in stalien bagegen focheint nan mit Demjelfen wertrauter zu fein. (Er gebeift auch it minber gutem Boben und fein Errtrag ift gut. In $B$ ezie= Gung anf feine Vegetationsperiobe und feine Sultur gilt Das yom Bartmeizen int Affgemeinen Bejagte.

\section{Meiser laumtartiger}

Triticum durum albidum velutinum.

Triticum villosum.

Triticum Trevesium.

Triticum fustuosum.

3̧eiper zottiger Bartweizen.

Blé corné blanchâtre velouté. Froment dur de Barbarie.

White velvet hard-wheat.

Grano dure, grano del mare nero.

Sommterfrutgt. Şaln 5 ซ̌s lang und längex, meift an ber Aegre ftarf fodralbenförmig gebregt, aufrecgt, mar= fig, yor und in ber Bläthe Gläulitigrün, fpäter gegent die Aebre zu etwas Dunfelftrufgelb. 2legre $3-4$ 3oll lang, beinalye regefmiäpig 4 feitig, nach oben fpib berlaufend, um bie Blütbezeit anf Der Greiten Seite grüngelglich, nuf ber fobmalen aber gritnlich, ntit ber Sieife gelblicymeiś, und in naffen Sabrgängen bäufig grauliç. 2Gehrchen 18-22, meb̆r ober weniger bicft ftefend, meift aber megr follaff, etruns gefpreizt, 3gramig and bie und ba noch mit einer Stum= melgranne mit 3-4 Samen. Srrannent 9 3oll lang, wäb= rend und nach Der Blüthe Geffgrün und anliegend, ntit ber Seife gelblich und gelbgräunlich, Gäufig yon Der Bafts an etwas formärylicybraun, weldye ซarbe in fegr trodfenen Som= mern oft bie Sällfte Der Birannen einninmt. Selchfpelzen länglich, mit forfarfent 3ahne und rärfen, befaart, ant

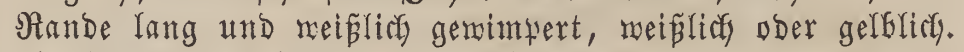
Zeupere Blunemfuelzen Yang, ftarf vertieft, Kegrannt, mit

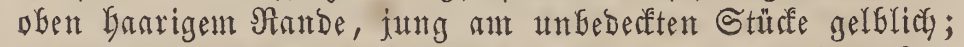
Die innern Blunenfpelzen Dünn burchftectig, an beiben Sei= ten concas. Spindel etwas Greit gegliedert und am Regel=

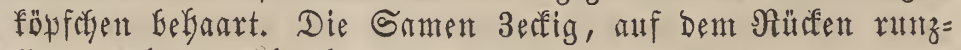

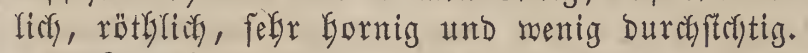

Sobiel yon Der $\mathfrak{B e r b r e i t u n g ~ u n d ~ D e r ~ F u l t u r ~ b i e f e s ~}$ Weizens Eefannt ift, wird ex befonders in Stalien, sloulien, 
aud in ber Srovençe und vermutblicf such in eittem Theife Spaniens angefaut; in ben Bogejen und um Straṕburg, unt Trier folf er, bejonders zur Reformationzzeit, Gåuftg fultisirt worben fein. N3ird biefer $23 e i z e n$ im 2 twril aug $=$ gefäet, fo reift er meift 2 tufangs 2 (ugufta und noif früber. 2lud bie WBinterjaat glütefte fơnon nach günftigen, bejonders fontreereishen $\mathfrak{\text { Bintern. }}$

Dieje Art mirb bauptäăblica zur Bereitung ber Miacca= ronis benübt.

\section{Rothex glattex Bartweizen.}

Triticum durum rufum glabrum.

Triticum durum spica laxa rufa glabra.

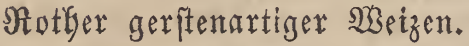

Blé corné roussâtre glabre.

Red hard - wheat.

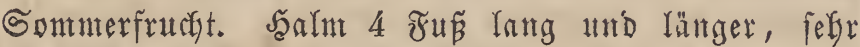

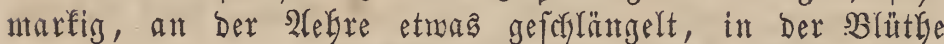
bläulicf)grün tud obent melyr ober neniger gelf. Die Blätter 1 Fuf lang und lătger, an ibrer Scheibe $1 / 2$ Soll breit, lang zugefpitst und Dunfelbläulichgrün. 2Helren $4-4 \frac{1}{2}$ Solf lang, aufrecift, gebrängt ober aucli etroas foclaff, bei= nake regelmäpig 4feitig, jung gelblichgrün, mit Der ミeife rötglictbräunlicy und in Gefonders troffenen und beisen

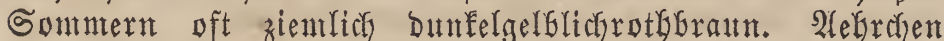
20-24, mekr doer mentiger fálaff utto ber bisfen Gamen wegen meit abftelyend, 3-4granntg, bie eine ober bie zwei mittleren brannen meift etwas fürzer, mit 3 volfommenten tuld eittent 4ten berfümmerten Samen. Siramen 9 3oll lang, zur Blüthezeit gelbliçgrün, an ber 2lebre anliegend,

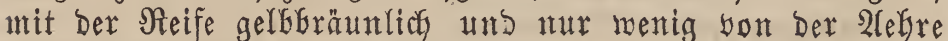
abftebend. Reldafwelze Gaben einen fogarfen Rüléen und cinen

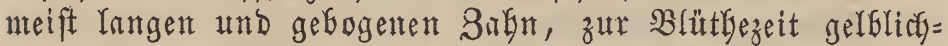

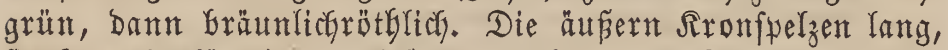
ftart nachenförmig bertieft, umgeben Den Gamen gänzlich und find gegrannt, in ber Blätthe Gelfgrün, Der unbebecte Theil bellbraumätylidy; bie intern Sronjpelzen auf beiben Seiten vertieft und meífglänzend. Die Samen lang, 3effig, mit einer tiefen und Greiten Rängsfurche und tiefem Nagel= flerf, fte funb weiprötglich, Gornig, wit unbedeutendem Megl= punfte and ziemficy burchfocheinend.

Sn gutem $\mathfrak{B}$ oben und unter günftigen $\mathfrak{B}$ erbälturiffen beftorft fich biefer WBeizen gut und fringt reichliche und

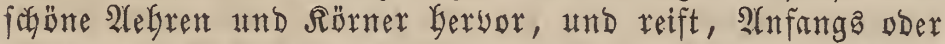
Ende 2lprifa gefäet, 2lufangs ober in der zmeiten 230 che DeG 2uguta.

\section{4. litothex /ammtartiger fartweiser.}

Triticum durum rufum velutinum. Triticum durum spica rufa velutina.

ßotber zottiger Bartweizen.

Blé corné roussâtre velouté.

Red velvet hard - wheat.

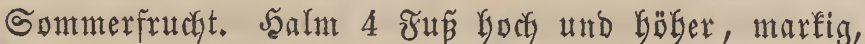
obent mentg fuiralförmig gemutnden, in Der Blätbe Gläulich=

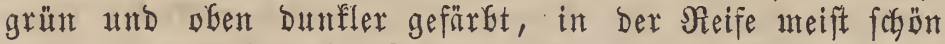
gelb. Blätter 14-15 3oll lang, an Den Scheiden beinabe 1 8ull breit; lang zugefpist und Dunfelgläufichgrün. Rebre 4 3oll rang, unten baubsig, gegen oben aber an Untang abmegmend, neift 4jeitig, oft aber aud bei gröperent Exent= plaren faft etwas chlinbrifat, Gie und ba überfängend, in

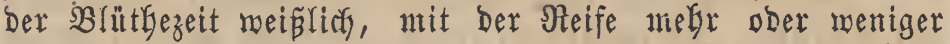

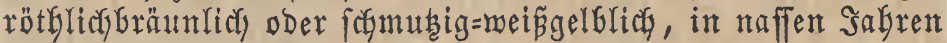

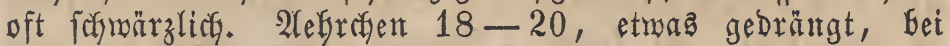
itppigen $\mathfrak{A} e G$ ren bagegen meit gẹpreizt, mit 3 Sorannẹt, einer mittlern fleinern und oft noch einer 4ten Stumnels grante und 3-4 Sament. Die Grannen find 8-81/2 30ll Iang, zut Blütyezeit anliegend, Gelfgrün, Gäufig foldon in's Schmärzliche verfaufend, fpäter foymarzbrinut und an ber Spibe Gräunlisygelb. Die Spelze röthlich und in Folge

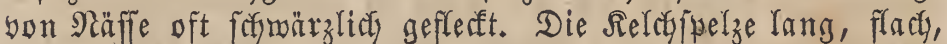

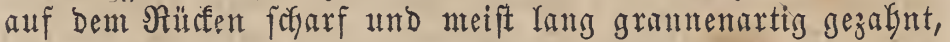

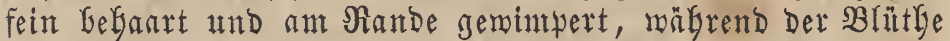
fchrnefelgelb, an Der Srrante und Dem Sahme grủnlidy, fpäter

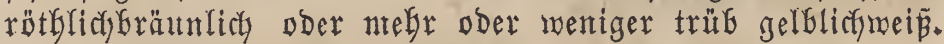
Die "̃usern Rrominelzen meisgrau befaart, an freien Theile

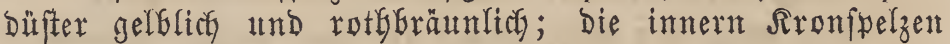
Durdfftchtig, binn und Dowpelt nachenfürmig wertieft. Spin= bel ift eng gegliebert, an Den Regeldyen und ant Seitenrande ftarf lyanrig und ftrobgels. Same länglich, mitten biff, an ben Enden etroas abgeftuntyft, mit einer breiten \&ängsfurche und einem grofen, vertieften, runzliçen sagelfeef verjeben

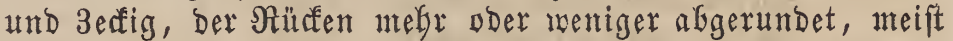
fofarf, Gornig, wenig burdffdeinent, blägelb unb nur un= Gebeutend rötblices.

(5sz ift biejer ein ebenfalls fruchtbarer \$eizen, ber fitch yon Den yorigen Durdy nichto Befonderes auszed

\section{Blauex antweizen.}

Triticum durum bicolor.

Triticum durum versicolor.

Triticum durum spica violacea glabra.

Blaumein̈er Bartweizen, Glauer welffter Bartweizen.

Blé corné â deux couleurs.

Blue hard - wheat.

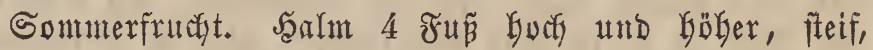
unarfig, an ber $\mathfrak{A}$ egre bie und ba etwas fpiralförmig ge= Dregt, ifre in Der Jugent grüne Farbe ift, zumal an Dent $\mathfrak{B l a t t f d y e i d e n , ~ m e i \tilde { \beta } ~ G e b u f t e t , ~ n i t ~ b e r ~ \Re e i f e ~ m e g r ~ o b e r ~ w e n i = ~}$

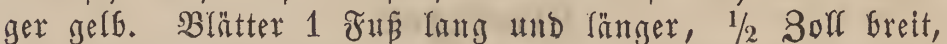
Dunfelgrün, utt fterben bei trudfener $23 i t t e r u n g$ dft fchon

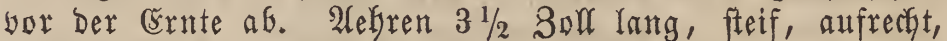
ziemlich 4 feitig, mach obent fpitzig auslaufend, mur felten

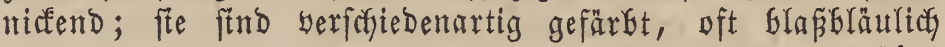
Dber fogmarzblau, ober aud mieder trüb odfergels, gemögn=

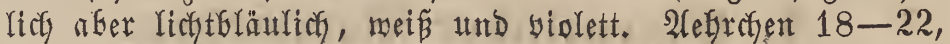
gebrängt brabziegelförmig, mit 3 (5rannen unb oft nody einer Stummelgrante an eintem 4 ten $\mathfrak{B a l g e ,}$ und mit 4 , feltner 5 Samen. Sranmen $7-9$ 3oll lang, nicht Gejonders abs

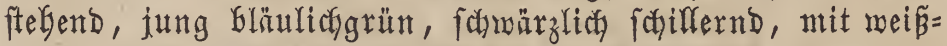
Yicher Spise, naç Der Blüthe blaugrün mit fodwarzem Schimmer int Grauner Spike. Die Reldypulzen lang, flach,

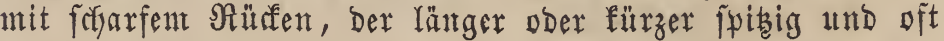
gefrümmt gezalgnt ift, aud ifgre zarbe müançirt, wie bie

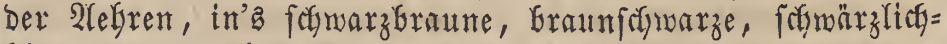
Glaue, ober megr ober wentiger offergelbe, und ift nact' ber Blüthe Kelfgrün marmorirt, weip bethaut, and die Spibe Des Rürfenzalgnes braun. Die äüern Rronjpelzen oben 
runblid, aufgetrieben, tief nachenfürmig und foflię̆en bas Sorn bulfeummen eitt; ber unbederfte Theil gelflich, wein Gethaut unb gegen bie biranne Gin grünlich längägeftricfelt, int ltebrigen gefärbt mie bie Reldyfpelzen. Die innern Rront= fpelzen zart, Durchfirgtig= Gäutig, feitlich bertieft und băufig in eine Spize fich endigend. Die 2(njatefegeldyen ber Spin= bel find ftarf behaart. Der Same auf Dem Rücfen conber, unten megr breit mit tiefer Rängaffurct)e und ftarf bertieftem

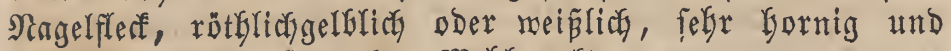
felten mit einent fockmadten Mieflyunfte.

Diefe Gorte ift im Ganzen fegr wentig befannt, fie bat pbenfalla eine furze Begetationaperiobe, ift aud fordun als Sainterfrucht befandelt fo ziemlich gebieken, boch feflt ez überbaupt an reiteren Erfagrungen über bie Rultur Derfelgen.

\section{B. Rolbenbattweizen.}

Triticum durum compactum.

Triticum durum spica compacta.

\section{Weiser falbenbartweizen mit weizen Grannen.}

Triticum durum compactum albidum glabrum, aristis albidis. Triticum Siculum.

Sounterneizen aus Sicilien und Neauel.

Blé corné à épi compacte glabre et à arêtes blanches.

White compact glabre hard-wheat, its awns (beard) white.

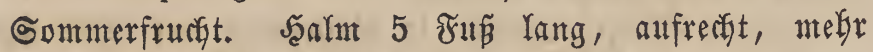
ober meniger narfig, Gäuftg ftarf friralförmig gemundent,

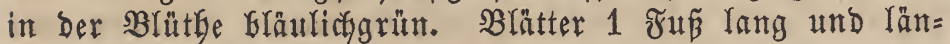

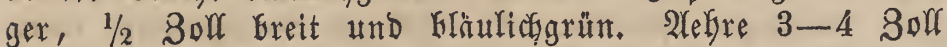
lang, oft febr biaf und walzenförmig, mit 2 oft fefr breiten Seiten, in Der Brütge gelblic ober fdyrärzlidgrün, in ber

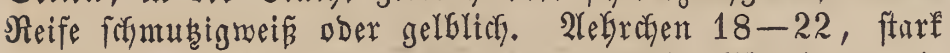
aus eimander gebreitet und gebrängt Dadaziegelförmig, zwei= grannig, mit einer mittleren fürzern Siranne und meift 4 Samen. Grammen 9-11 Solf lang, febr raub, in ber Blüthezeit bidst Geifammen riegend, meift fanmubigmeiñ und Gelloräunlida. Seldyfpelge etmas breit, mit einem fofarfen, rangen, frummen und fdarf gezabnten Sätifen; auf Der breiten Flñdye ftegt oft bie Nippe ftarf Gersor and ift ftumpf gezabnt; räbrend Der Blüthe gelblicf, gegen den barlm bin etras weiplich, grün geftreift und weif́ betbaut, der innere Sand ift bautig und weif́. Die immern Rronjpelzen auf Geiben Seiten yertieft, zart bureffedtig und an ibren Enden zugefpitht. Samen furz, röthlicf; Der Nangelffecf grof und

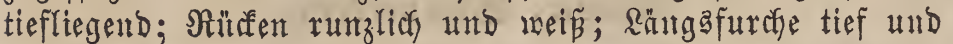

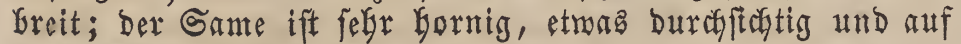
feiner B̧ruchflärge glaftg.

Der meipe Rolbenweizen wird bis jebt nur in Sicilien und Neapel, nach (Einigen auds in S̈ldpanien, Sranaba 2C., im Sirofien aflein ober als Sientengfructit fultivirt. Sn $\mathfrak{B e}_{e}=$ ziebung auf ifre (süte fontmen die Rörter Dem roif̈en fammtartigen Bartmeizen gleidy.

Wan Gat bon diefem Weizen eine Spielart, nämlicty ben

a) S্Eি Triticum durum compactum albidum glabrum, aristis nigris.

Blé corné à épi compacte glabre et à arêtes noires.

White compact glabre hard-wheat, its awns black.

Diefe Spielart unterfacidet fith son bex surigen mur
Duraf bie Farbe ifrer (Srannen, weldye pft bis an bie Spibe Gin fogmarz, zur Blüthezeit aber fonmärzlichgrün ift.

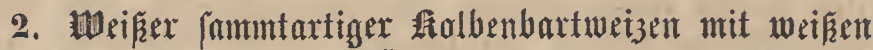 Granner.}

Triticum durum compactum albidum velutinum, aristis albidis. Triticum cochleare, Lagasc.

NSei

Blé corné à épi compacte blanchâtre velouté et à arêtes blanches.

White compact velvet hard-wheat, its awns white.

Sommerfrucht, Sădm $5-5 \frac{1}{2}$ Fus lang, marfig, be= fonders ant obern Theile, jung bläuliefgrŭn. Blätter 12 3olf lang und länger, bläuliçgrün, mit meiß̄ betbauten

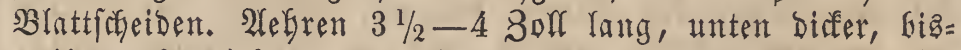
meilen aufgetrieben, nach ofen fpitiger werbend, zur Blätge=

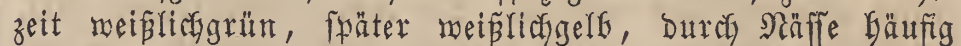

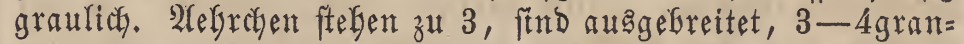
ntig und 4fantig. Branten $9-1080$ ll rang, unter ber

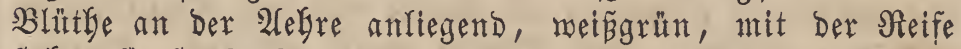

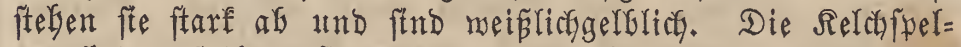
zen find auf ifrer DGerfäabe dicht befaart und am Rande

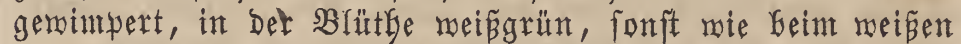
Rolbenfartmeizen. Die äuEern Rromjuelzen begrannt, Der

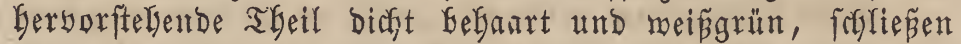
bas Rorn gänzlid ein. Die innern fronfperzen febr zart burchifchtig, auf Der innern Seite meniger ftarf nadjenför= mig wertieft als auf ber anbern. Spinbel eng gegliebert, mit Gebaarten Seitenrändern und Regelfüpfaden. Samen etwas gröper als bet ber borigen 2 trt, Gäuftg ftarf runzlict, webr ober meniger röthlich, hornig unb auf ber Bruchfläche gumuniglänzend.

Sacty Ragasica Gaut man biefe 2lrt im fübliclyen Spa= nien, wie Branada 2. , int Bropanen an, aud in Stalien, alfeit und int Bsentenge.

2(uc) yon Dem meipen fammtartigen Rolbenbartweizen fennt man eine Spielart, mie fie beim glatten meisen Rolben= Gartmeizen vorfommt, und bie fich roie bie bes lebteren nur Durdy ifre fonmarzen (Sirannen unterfocidet.

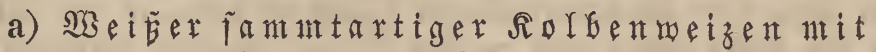

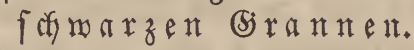

Triticum durum compactum album velutinum, aristis nigris.

Triticum Gaertnerianum. (?) Lagasca.

Blé corné à épi compacte blanchâtre velouté et à alêtes noires.

White compact velvet hard-wheat, its awns black.

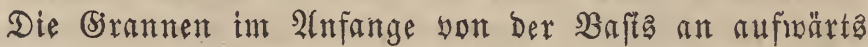
fănärzlichgrün, fpäter fărarz, befonders in trodfenen, beifent šabrgängen.

\section{Weikex dichährigex falbenbaxtweizen.}

Triticum durum compactum pyramidatum albidum glabrum.

Blé corné blanchâtre à épi pyramidal compacte et glabre.

White compact pyramidal hard-wheat.

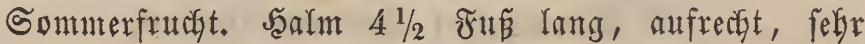
marfig, meift an Der aefre ftarf faraubenförntg gebreft. Brätter 9 3oll lang und länger, beinabe $3 / 4$ Boll breit, oben ant Salme meift aufrecht ftebend und an bemfelben

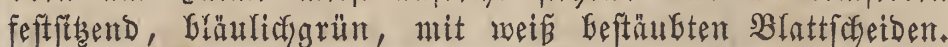
Yefren 3 solf lang, mit 2 fomälern Seiten, gemöbnlid 
ygramidenförmig, wäbrend bex Şlüthe gelggrünlidy und meiflich angeflogen, mit ber seife meinggelblich, auf Dent Greiten Geiten etruas rötflich. 2(efrechen 16-22, febr bicht bachziegelförmig ftebend, ronig gefureizt, 2-3grannig, oft mit einer 4ten Stummelgranne, $3-4$ jamig und eitrer 5ten

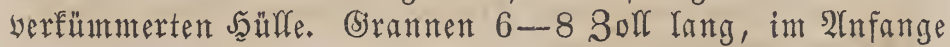
biedt anliegend, blangrün, mit Der Neife meílich, etwas ftrobgelb und etroas fpreizend. Die flachen Selchfpelzen Gaben einen conberen, fibarfen uth furz gegranten Rürfen and

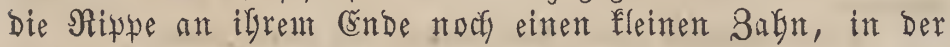

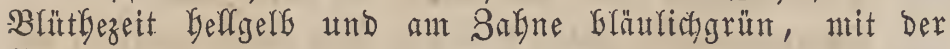
Sieife meif̧lich oder gelblidy. Die äunern Fromfpelzen be=

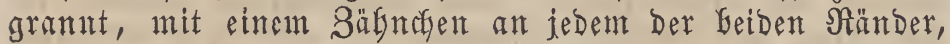
tief ausigebüglt, Den Samen bergend, während ber Blüthe Der unbederfte sheil gelblich und an ber (Branne grün, fö̈ter glänzend und weiplich. Die innern Fronfpelzen zart, Durcejętegtig = bäutig, feitlich vertieft, lang zugefpibt, an ben

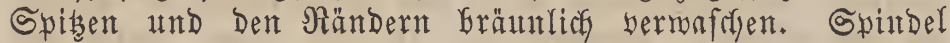
eng gegliedert, glänzend, am Rande und Deur Regelfüpfoctent Gefaart, weiß̧liç. Der Gamen meipt weiǵlich, Gornig, Durchfteftig; Nagelffect meift grón; Schnäbeldyen fpibzig;

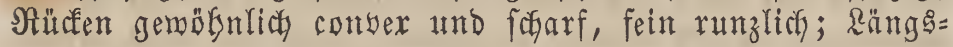
furche tief, nit meit yon einamber ftegenden Rändern.

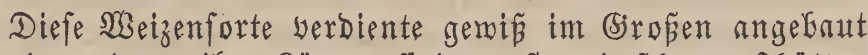

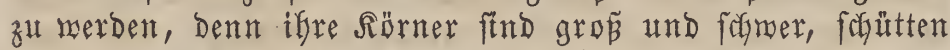
gut, und bas sagern fommt ber fteifen balme megen fel= ten yor.

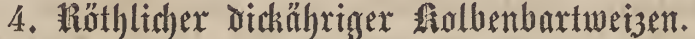

Triticum durum compactum pyramidatum subrufum glabrum. Rötglicher bicfälgriger Bartweizent.

Blé cornć roussâtre à épi pyramidal compacte et glabre. Red compacte pyramidal hard-wheat.

Sommerfrucht. Die Aetgren wäbrend der shlätge gelfo= grünlich und ziemlich ftarf weís betfaut, fpäter auf ifrer Greiten Seite rotgbrăunliç, oft Gräuliçwei an angeflogen. Die Brannen röthlich, oft rutbibraun. Die Relchfuelzen mährend Der Blüthe Dunflex grün gefärbt ala bet ber wori=

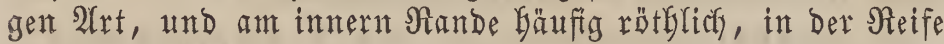
an ber Safts Gelfer und an ben Bälnen Dunffer rothbräun=

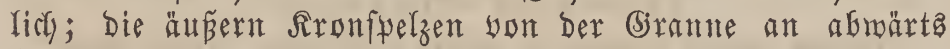
bräunlich. Die Gamen rötglich und Gräunlich, Gornig und menig Durchitctitig.

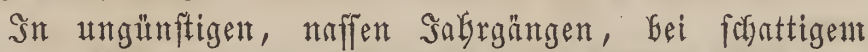
Standpunfte and wemit fte zat didft gefäet worben find, Iaffen ftery Diefe zwet lestern atrten faum you einander unter= fajeiden, indem unter ben oben angegebenen lamftänden bei bem rötglidyen Bartweizen die ifn Gezeidyende Farbe oft ganz feglt and man lebtern befigalb für identifos mit dem erftern Galten fönnte, wenn bie rötgliçe Farbe in Geisen und troffenen Sommern ftil nifft iumer als fonftante er= meifen mürde.

\section{5. อี \\ Triticum durum spica gracili.}

Blé corné à épi mince.

Thin eared hard - wheat,

Sonmerfrucht. Saaln 4 Juß Goch, aufredyt, martig,

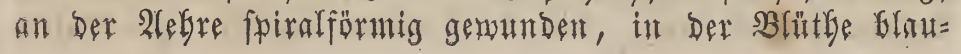

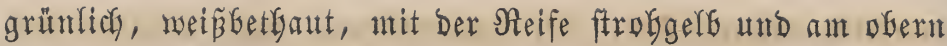
Эuternobium Gäuftg röthliç. Blätter 10-12 30ll fang und $1 / 2$ Bolf Ereit, Glaugrintich. Alefren 3 3oll Iang, faft 4jeitig, vitt megr breit, ober mebr rumblich, nach oben ftery

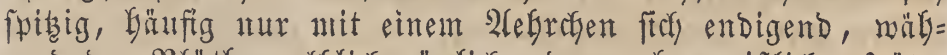

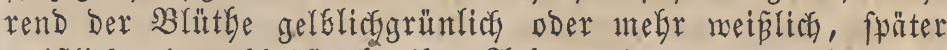

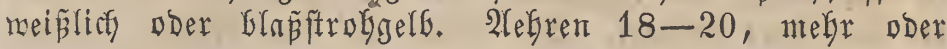
wentiger gebrängt, Dachziegelförmig, 2grannig und an bet mittleren $B$ Lumenlülle mit eitter 3ten Stumnelgranne und 3 famig. Sorannen 6 3olf fang, oft noch fürzer, in ber

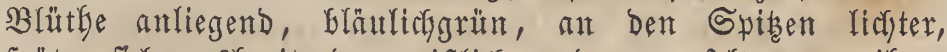
fpäter fich ausoreitend, reeíslich und nur felten an ibrer Bafte folymärzlicf. Selchfpelzen etwas freit, mit fognrfent,

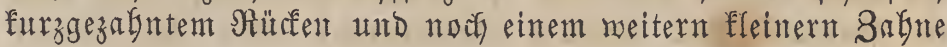

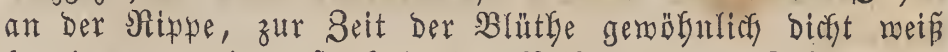

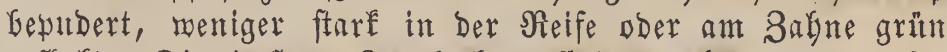
gefferft. Die 'aufern Sronfwelzen ftnd gezahnt, ant unbe= Dedften Stüfe rälarend Der Blüthe reeiślichgrün, fpäter

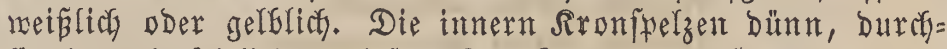
fitytig und feitlich bertieft. Die Spindel meift furz geglie= Dert, ant Rande und Dem Regelfüpfoyen etwas befarart, meişlich. Santen aufgetrieben, weislich und rötglich, faft 6erfig, mit tiefer und breiter Rängṣfurche, Gokem, gerun= zeltent, Geffgrauem Rücten, gropeent, etwas flacfem Nagel= flecif; fite ftud freinalge Durchjtistig, glaftg, mit einem felgr geriugen Mieblftreifen verfeben.

Diefer șeizen gleidft in Beziefung auf feine 2lebren

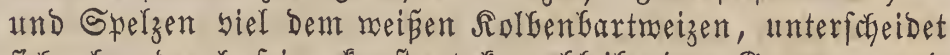
fich aber Durch feine fouftant furz Gleibenden Grannen und feine baurfigten Röner. (Ěr verlangt yorzugsmeife einen guten Boben, Geftodft ftef aber nicht ftarf und bas Strob Gleift etrong furz.

\section{Triticum polonicum. I.}

Triticum Cevallos. Lagasc.

Triticum laevissimum. Hall.

Triticum glaucum. Moench.

SBolnifdyer Weizen, Rothringer WEeizen, Ruggenartiger

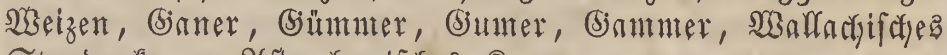

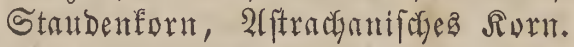

Froment de Pologne. (franz.)

Polish Wheat. (engl.)

\section{Heten, Shawafter.}

Die ganze Bffrnze mefr doer wentger grau. Salm

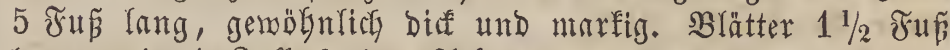
lang und 1 Solf freit. Aefren $4-7$ 8oll lang, meift

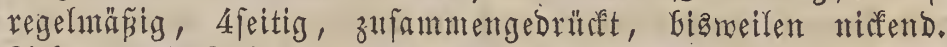
Zlebrchen 1 3olf lang und länger, meift fohlaff, 4blütbig, movon $2-3$ fruchtbar ftud. Selchfpelzen 1 Sulf rang, etwas baudjig und etras breit, auf Dem $\Re$ ücfen ftarf gefielt, mit

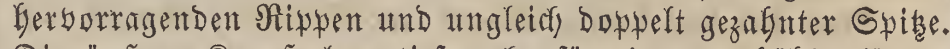
Die äuß̌ern Rronfpelzen tief nachenförmig ausgeğblt; länger voer fürzer gegrannt. Die innern Sronfpelzen nisft länger als ber Sante; lebterex felyr lang, ant feimem untern Ende zugefpibt, ant obern serbieft und oft forbufig, Durchfichtig und glaftg. 


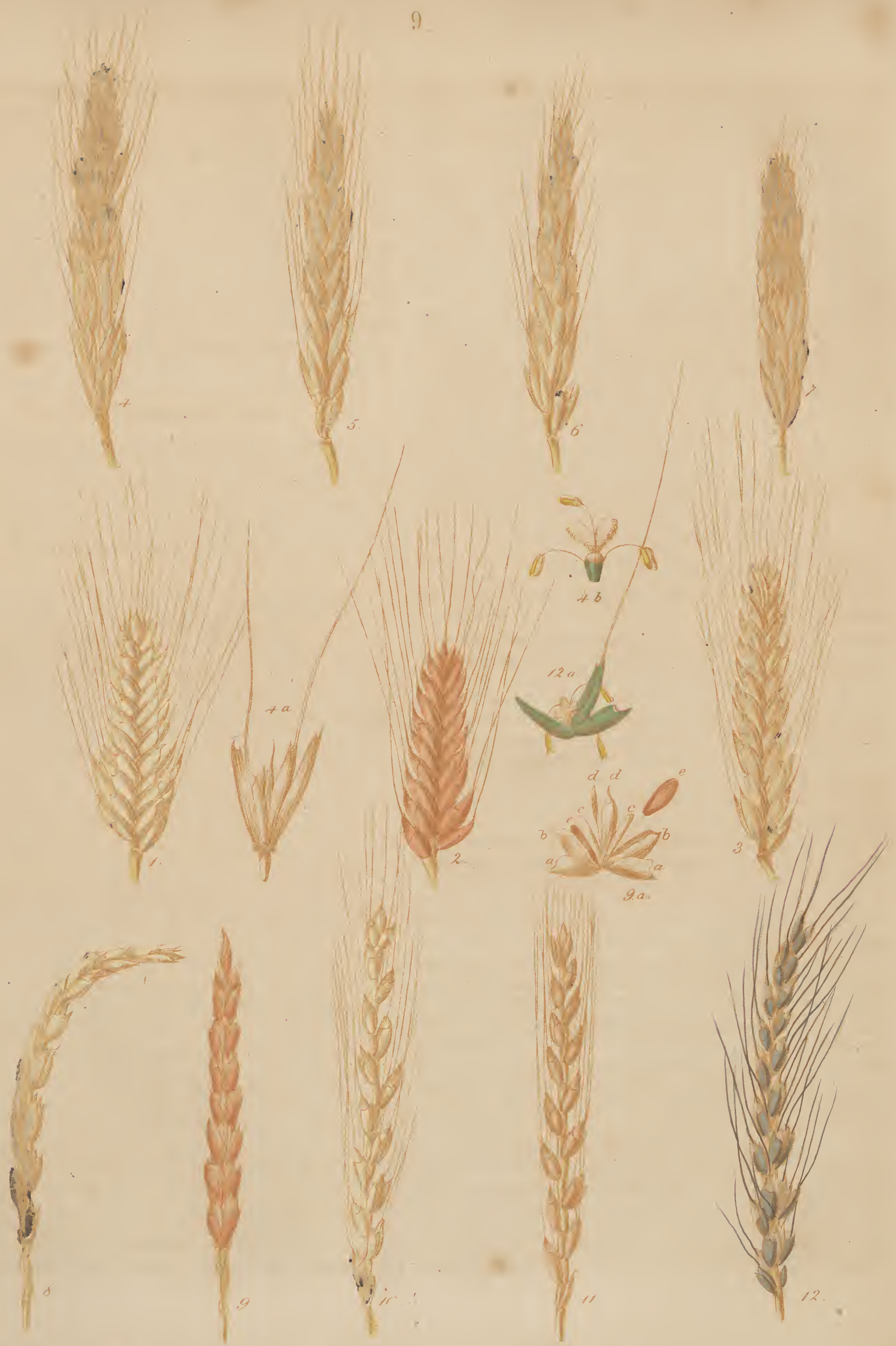




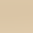




\section{F)lüthe = 3eit แtto Daute.}

รuni. $\odot$.

\section{Yoxpmmett.}

Das Baterland bes polnifchen Weizenz ift fo menig ermittelt als bas ber andern 5anlmfrüchte. Črinige glauben fte einft in Beorgien, anbere in 2(rmenien unb Mebien ein=

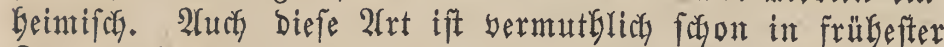

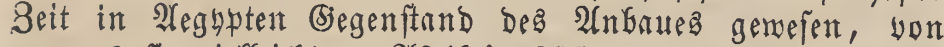

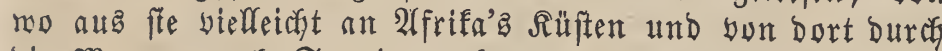
die Mauren nadg Spanien gebradst tourde. In Rotfringen

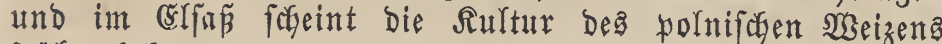
frilber befannt gemefen zu fein, und nach, aber mur unfthern, Nachricten mird er noch in Spanien, Jranfreich, Ëngland und Bolen angebaut, feltner fedoch in Deutichland.

\section{Sultux.}

Der folnifuse Meizen will einen guten, gebüngten $\mathfrak{B}=$ ben und einen marmen, troffenen Sommer. Die fämmt= liçen 2 (rten Deffelben find Sommerfrüchte und Dauern felten ben Winter aus; fie bürfen nicht zu bicht gefäet werben, ba die Salme gerne vergeilen und Dep̧yalg fich ragern, was überbaupt in naffen Jabrgängen bäuftg bei Diefer Battung borfommt.

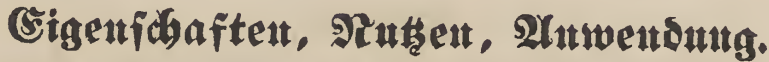

100 Theile ber reifen Rärner entbalten:

Jeines Mefl . . . . . 82,6

Rlete . . . . . 8,2

Feuchtigfeit . . . . . $\quad 9,2$

Die vorwaltenden Beftandtheile Deg Mefla (yon melcher Spielart ift nidgt angegeben) find nach 2(pothefer Greif:

\begin{tabular}{|c|c|c|c|c|c|c|c|c|}
\hline Extraftioft & $f f$ & • & • & & • & & 61 & (5) \\
\hline freber. & - & . & - & & . & & 91 & " \\
\hline (simei & . & . & . & . & . & & 14 & \\
\hline $\mathfrak{A} \mathfrak{m} \mathfrak{x})(\mathfrak{l})$ & • & • & $\bullet$ & • & • & & 290 & \\
\hline Schleim. & - & & - & • & - & & 11 & \\
\hline rluft . & . & & & . & & & 33 & \\
\hline
\end{tabular}

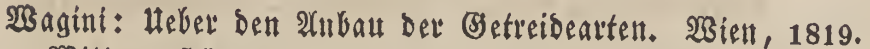

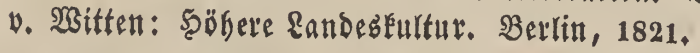

1. Gemeinex polnilicher Weizen.

Triticum polonicum vulgare.

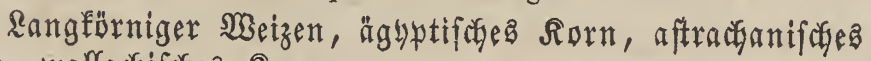
Rorn, wallachiffites Siorn.

Blé de Pologne à épi glabre et barbu. Blé d'Egypte.

Poland wheat. Polish wheat.

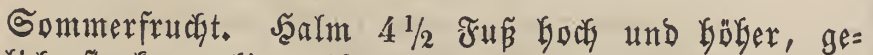
wölnilich ftarf marfig, 4fnotig, nur felten an ber sefebre etwas fpiraffürmig gemunden. Blätter 14 3oll lang, gegen

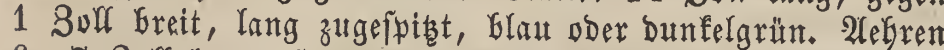
6-7 Soll lang, fwlaff, 4 feitig, ober audy mebr rumblich,

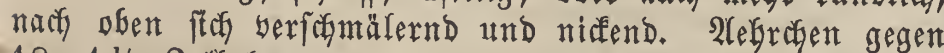
$18,1 \frac{1}{2}$ Soll lang, weit yon einander abjtebend, fo baj bie Spindel gefefen merben fann, 2grannig und 3jamig. (brannen 5-7 3olf lang, feglen oft, indem fie zumal bet trocfener WBitterung gerne abfallett. Relchfpelzen 1 Soll lang und länger, fchmal, mit vielen \&ängarippen, einem fleimern und einem gröpern $3 \mathfrak{a} \mathfrak{h}$, int 2 nfange grün, am bintern

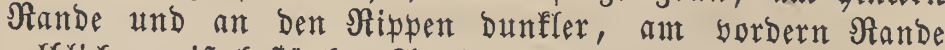

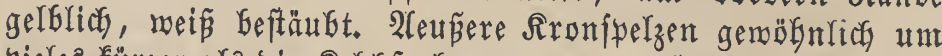
bieles fürzer alz bie Reldefpelze, gegrannt, ftarf nachenförmig

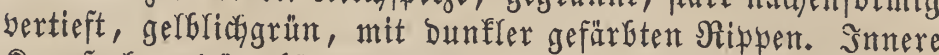
Sronfpelzen bünngăutig, feitlicf aubgefüglt und gleich lang mit bem Samen. Die Spindel lang gegliebert, an Dent Infertionapunften ber Aelyrafen Gaarig, glänzendmeiñ. Die Samen beinabe $1 / 2$ Boll lang, unten zugefpibt, when ver=

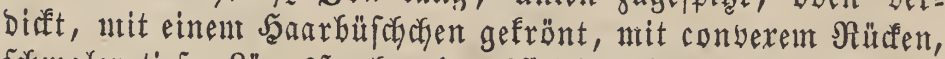
fodmaler tiefer Răngafurche; Durchfedtig glaftg und mit faunt erfennbaren Miebrftreifen.

Ein trodfenter, warmer sahrgang und ein fräftiger und Gejonders zur Jeerfftzeit gebüngter Boben tragen bas Meifte

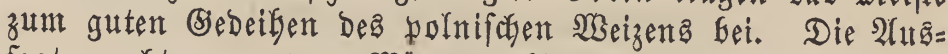
faat madyt man yom März an bis Mitte 2 dorila, und in 4, Göbftens 5 Monaten bet günftiger WBitterung ift er fănetbereif. 2ars \$Binterfruclat erfriert bie Saat bei ftärfer eintretendem Froft, und Der günftigen Refultate yon ber Winterbeftellung mögen es wobl nur wenige fein.

\section{Sammataxtiger polniicher $\mathfrak{w}_{\mathfrak{r}}$ izen. Tríticum polonicum velutinum.}

Blé de Pologne à épi barbu velu.

Wooly - eared Poland wheat.

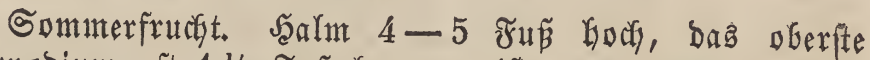
Snternobium oft $11 / 2$ ₹ur lang, meift ganz maxfig, an ber

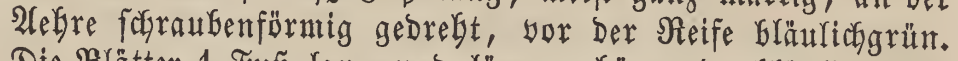

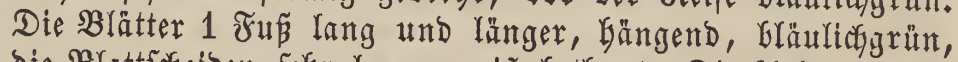

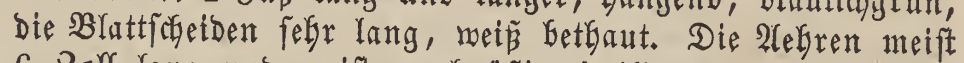
6 3oll lang und meift regelmäpig 4zeilig, nach oben zuge=

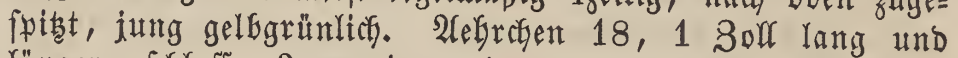
länger, faglaff, 2grannig, mit noch einer 3ten Stummel= grante; bie obern 2 lebrchen $2=$, bie untern 3famig. Srannen 6 3oll lang und 3 3oll länger als bie Alefre, vft an ber Bafta gebregt und jung gelblichgrün, falfen nicyt leicfst ab. Relchfpelze 1 3olf lang, etwas Greit, mit 2 3ñhnen, Deren einer fleiner, ber anbere gröper ift, ntit bielen Rängåripyen, bie auf Dem $\Re$ üffen ftärfer Gerbortreten, und fein gemint= pertem 2urenrande; jung find fie etwas molfig befaart, grün und mitten gelbliç. Die äusern Iironfperzen meift fürzer als bie Reldefpelzen, gegrannt, ftarf augegeloblt, aut Nande gemimpert, jung oben fanmtartig. Snnere fron= fpelzen fo lang als Der Same, felyr zart und auf beiden Seiten vertieft. Die Spindel meitläuftg gegliedert, an ben

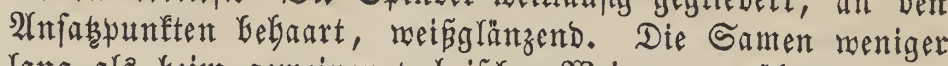
lang alz beim gemeinen polnifchen SBeizen, gemöbnlich breit

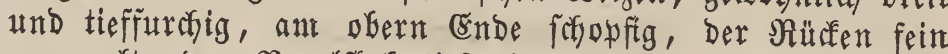
gerunzelt, ber Nagelflef tief eingebrücft, balb bureffecftig und glaftg.

Diefer Weizen beftofft ftity bortreffich und gibt Den

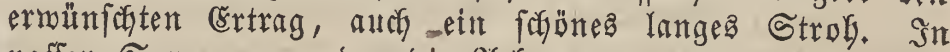
naffen Sommern merben bie $2(e f y r e n$ yon bem $\mathfrak{W a f f e r}$, das fith in ben Gpelzen fängt und in Denrferben bảngen freibt, afdhgrau und gerne zu Boden gebrütft. Die Sïnrner gleichen biz auf ifye geringere Ränge ganz Denen Des gemeinen pols niffyen $\mathfrak{B s e i z e n}$. 


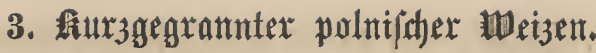

Triticum polonicum aristis brevibus.

Blé de Pologne à barbes courtes.

Shord-awned Poland wheat.

Sonmerfrudst. Die Salme find fürzer ala bei ber

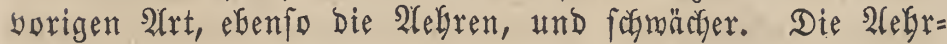
dyen fteben gebrängter. Die Sirannen oft nur Stummel= gramen und brecten febr gerne ab. Die Relch $=$ und Rron= fwelzen meder befaart, noch gemimpert; die Samen etwas länger, aber famäler.

Diefer Weizen Geftorft fich meift reniger gut als ber borige, und gebeibt mur felten, benn aud in gutem soben und anter fonft günftigen Umftänden erbält man gegenüber Deut borigen mur $1 / 3$ Ertrag, fowolgl an Rörtern als an Strob, und in naffen Sommern geft er oft ganz Darauf.

\section{4. \#olbenaxtigex polnilsex meizen. \\ Triticum polonicum compactum. \\ Triticum polonicum striclum. \\ Triticum Cevallos. ? Lagasc.}

Blé de Pologne à épi compacte.

Compact Poland wheat.

Sommeriruct. Salm $4 \frac{1}{2}$ Jun lang (Gefonders lang Dasิ wbere Snternobium), ntit Marf angefüllt, jung Gelfgrün,

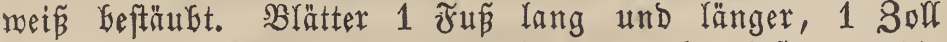
Greit und Gängend; Die Brattfacident umgeben faft ganz die Snternobien und bie oberfte überragt noch Die Alebre, blau= grün. Die Aebren 3-4 Soll lang, an Der Spibe meift tumus, bie breite Seite ift in ber Mitte gefurcht, indem ftch Die Relchpelzen ftarf nady ber fogmälern Seite ber Webre

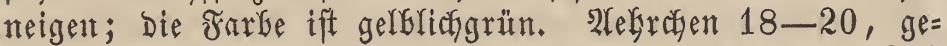
Drängt, 2grannig, 2-3famig. Sirannen bäufig nur 1 soll lang, anliegend und feblen an Der Bafte ber Aebre oft ganz. Relchpelzen 1 Soll lang, wertieft, ftarf längşgerippt, 2zaly= nig, oft ofne Den fleinern 3abn, jung grünmeíz betbaut.

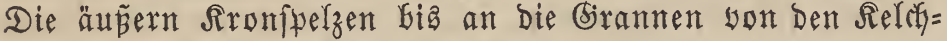
fpelzen ungeben, ftarf nafhenförmig bertieft, furz begrannt,

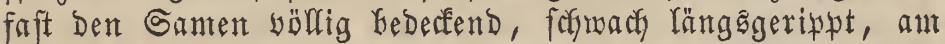
berbortebenden Stürfe gelblich, an Der Spike grün. Die innern Rrompelzen bäutig, mit 2 nadyenförnigen 2 ertiefun= gen. Die Spindel eng gegliedert, weipgränzend; die Regeldyen ein menig borftig. Die Samen länglich, unten etras fpibig, oben wollig befaart, mit formacher Furdye, gerunzeltem

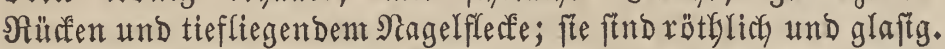

Diejer Weizen foll in Spanien im Srobent angebaut merben und auch er gebeigt nur gut in geförig gedungtem Buben und fällt in geringem mur falleçt aus. 2luch ala 2Binterfrud angebaut, lieferte ex fifon ganz ermünfide Stejurtute.

\section{Triticum Spelta. L.}

Triticum Arias. Lagasc.

Triticum rufescens. Hort.

Triticum Zea. Host.

Spelz, Weizenpelt, Wefen, Gommerppelt, Dinfer, Dinfelweizen, gemeiner zweiföniger Dinfelweizen, Rrull= weizen, Suälforn, Sraftmeblipelt.

Epeautre blanc. (franz.)

Spelt wheat. (entgl.)

Spelta. (ital.)

\section{Arten = Sharafter.}

Şalm glatt, Gobl. 2Hefre 4feitig ober runblia, faralfel zufammengebrücft, nicfend, meift glatt, felten faumtartig. 2lebrchen 2reigig, reitläuf ziegelbachförmig, mit 4 Blütben, bon Denen gewöhnlich nur $1-2$ fructstbar ftmd. Relctifpelzen wben abgeftutet, Greit=eiförmig, Gefonderz Greit auf bent längegerippten ßücfen. Der Spelzfiel ift furzgezahnt. Die Sronfpelzen find gegrannt wder nur gezaknt. Cpindel zerbrectilicy. Die Samen find obal ober etmas 3ecfig, $a b=$ geftudit, gelblich ober rötblich, weniger uteblig als glaftg, and ftnd yon Den fironipelzen zum gröbten Theile einge=

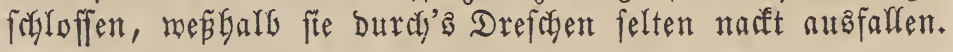

\section{Şlüthe = 3eit ttto Danev.}

รักi. $\odot-\sigma^{x}$.

\section{ลิorfommet.}

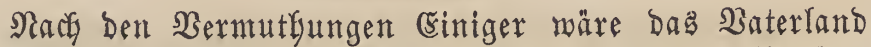

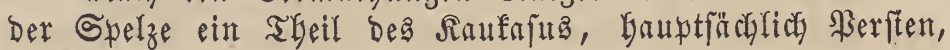

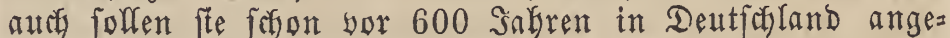
Gaut morden fein. Viefleidyt famen fee nit andern Setreide= arten aub Stalien zu uns. Sn Sübdeutfohland, rie am Rlbein, in Jranfen, Shmaben, Der Sefmeiz merben bie Spelze häufig fultivirt.

\section{Sultut.}

Der Spelz ift in Beziefung auf Den Boben noch meni= ger empfindich ars ber gemeine Weizen, und es barf berferbe meber zu frifo, noch zu ftarf gebüngt merden. Das Unter= pflügen ift zumal bei leichtem Boben bei biefer Bsetreideart wobl anzurathen, Da bie in Den Spelzen eingeforloffenen Samen mefr Feurdigfeit verlangen, um gefürig feimen zu fünnen. Die Winterjant fann geröbnlich in 2 (uguft ge=

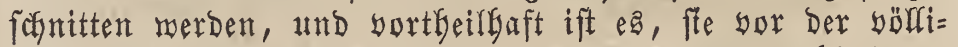
gen Reife abzumäben, meil Der Spelz Dann meblreictere Röner liefert und bie fpröben Spindeln nidgt fo leidft $a b=$ brecten. Nach Dent Drefden merben bie Samen auf foge= nannten Berbmüblen gegerbt, D. W. igrer Spelzen berabt, und Dann erft merben bie Serne gemaglen.

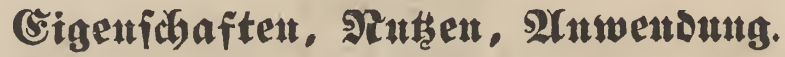

Die Spelze liefern ein fehr feines Mebl, das foge=

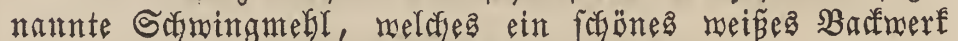
gibt; man bereitet aus dent Rernen aud Siriea, Gefonders in Der Sifmeiz. Der Ertrag bon Stroh ift meniger ftarf

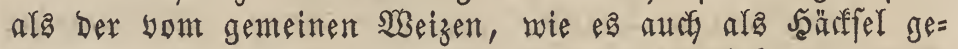
füttert, lebterem an Nabrbaftigfeit roeit nachftegt.

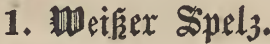

Triticum Spelta, spica mutica alba glabra. Triticum Spelta alba. Schübl.

Wseiper Dinfel, Dinfelmeizen, Vejen, Sommendinfel, Winterdinfer.

Epeautre sans barbes, blanc et glabre.

White glabre Spelt wheat.

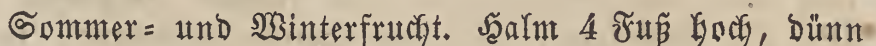
und Gobl, bas obere Snternobium zumeilen 2 ซus lang, in Der Sugend melgr ober meniger beff = Dber Gläulicfigrün. Blätter 6-10 3olf lang, fajmal. Alebren 6-7 3olf fang, 
bünt, fäbelförntig gebogen. 2lebrefen 16-20, meift zwei= famig, meitläuf ftekend, fo bas man feitlich bie Spindel

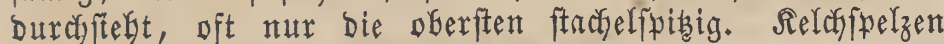
etwas breit, oben ftumpf, fein längarippig, ber Riel mit einem breiten, zarten, einmärts gebogenen, an bent $\mathfrak{B}$ łumen=

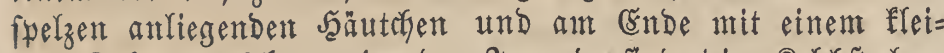
nen Sabue werfeken; in ber Jugend find bie Relchfpelzen gelglich und gran längågerippt, fwäter aber mit ber Neife weis. Die ăuBern Sironfpelzen ftnd etras länger ala bie borigen, unnterflich gegrannt bis auf bie, weldfe an ber Spibe ber 2lekre ftenen, erft gelblich, oben grün zartgeftreift. Die intern Fronfpelzen find zarthäntig. Die Spindel ift felgr zerGreatlich, meiplich, und das betreffende Spindelglied bleibt beim 2lbreinen an ben 2Hebraben Gängen. Der Same ift auf Dem Nincen contex, gelbfich, oft rötglich angeflogen,

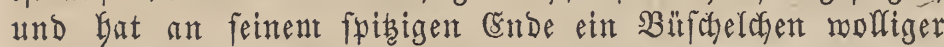
Saare; er ift meflig, mirb aber mit feiner yolfommenen Neife glnfig.

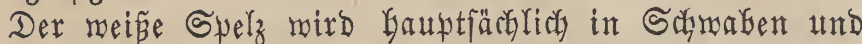
Der Sedneiz, bejonders int Santon $\mathfrak{B}$ ern fultivirt. Ër ber= langt einen guten, iräftigen Boben und wird als Sommer= und als Sinterfrucht angebaut; Doch ift bie lebtere Sultur alfein zu empfeglen, ba bie Somnterfant, mentgitens bei umfern flimatifochen Berbältniffen, nicht Yeicht einen nur leid= lichen Ertrag liefern wirb.

Diefe Spelzart gift wie aud bie folgende wogl bas feinfte und foünfte Schningmebl, und bejonbers beliebt find bie grünen Rerne biejer beiden Sorten zu Supwent. Itm biefe grünen Rerne zu erfarten, fdueidet man bie grünen

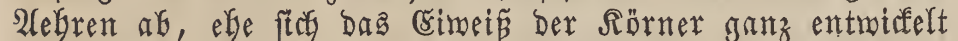
lyat, wenn fie etwas bart gemorden find ; Gerauf dörrt man fie, brifat fie aus und läpt fie bann gerfen. Der Saandel mit biefen grünen Särnern ift felgr einträglicf.

\section{Kiothex Spely.}

Triticum Spella, spica mutica rufa glabra. Triticum Spelta rufa. Schübl.

Rother Dinfel.

Epeautre sans barbes, roux et glabre.

Red, glabre Spell wheat.

Whinterfrucht. Die Relcypelzen fend jung gelblids, ntit Der Reife Gräunliçrötblich, wie aud̆ bie änÉern Rromplet= zen. Spindel bräunliç.

(rr wird wie ber vorige an ben gleichen Drten bäuftg gepflanzt und foll noch ein feineres Mebl geben als ber

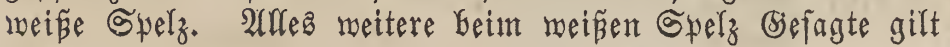
audy yon biefert.

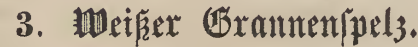

Triticum Spelta, spica aristata alba.

SBeiper gegranter $\mathfrak{B}$ eizen.

Epeautre barbu, à épi blanc.

White awned Spelt wheat.

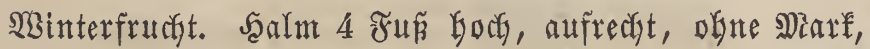

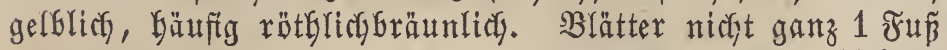

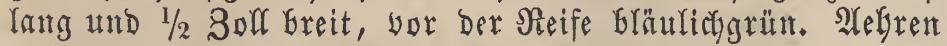

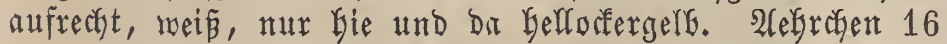
bis 20, neifít mit 2 Simen und oft noch mit einem 3ten fleinern. Grannen meislich, anliegent. Seldgfpelzen und äup̃ete Sironfpelzen weiślich. Die innern Sronfpelzen fegr

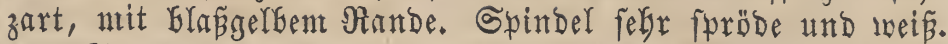
Die Samen auf ber breiten Seite etras breit, röthlich, auf Dent Ränfen conbex und weiślicf, fallen beim Drefisen felten nadet $\mathfrak{a} \mathfrak{i}$.

Der weine Grannentpelz mird in Deutfohland, Der Sefrueiz, in England, Jranfretch, Spanien und StaYien angebaut und befonders in roaldigen, gebirgigen biegenden,

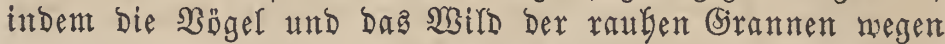
fith nicht an biefes (S)etreide machen.

Diefer Shelz ift felgr ergiefig, zumal in gutem Bober, forobl an Sïrnern als an Stroh, geräth aber atter nock in geringem Boben. Der meipe Brannenfuelz Gefommt Den Brand nicht leidft und lagert ftef aud nidyt, auser er mürbe zat bicht gefäret.

Mezger fütgrt eine 2 Gänberung an, nämlich

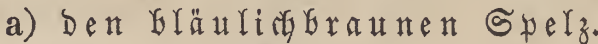

Triticum Duhamelianum. Mazzucato.

Triticum Spelta, var. spica mutica coerulescente glabra. Sering. Get weldyer bie Gpindel rötbliç und Der Scalm bräunlich, bie 2lebre Graunbläulich angeflogen ift.

Sie foll in Stalien angebaut werden, aber einen ge= ringen Meblertrag geben, fobeint aber nach gentachten $\mathfrak{B e r}=$ fuchen eine niçf fomftante Sarietăt zu fein.

\section{Rothex (bramentpel3.}

Triticum Spelta, spica aristata rufa.

Epeautre barbu, à épi rougeâtre.

Red, awned Spelt wheat.

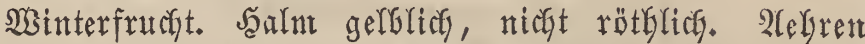
gefrümnt, röthlichbraun, Dber, Gefonders in naffen Safy $=$ gängen, of́t mur rötglich angeflogen. (Srannen rötglichgelb, etwas fparrig. Relch und andere Rronfpelzen rötglibbräutn= lich. Spindel zerbreçliç, jelblich mit röthliçent Schimmer.

Der rotge Brannenfpelz erforbert eine längere Begeta= tionaperiobe als ber weí̈e und taugt nocf biel weniger als Diefer zur Gommerfant. Der mit ungegrannten Spelzen angebaute rothe Grantenfpelz foll an (süte und Ěrgiebigfeit verlieren. Sonft ift biefe 2art mit ber worigen in anfent

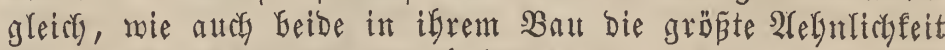
mit Der folgenden Warietät Gaben.

\section{Bläulithex (15xammenjpel3.}

Triticum Spelta, spica aristata coerulescente glabra.

Epeautre barbu, à épi bleuâtre glabre.

Bluish, awned Spelt wheat.

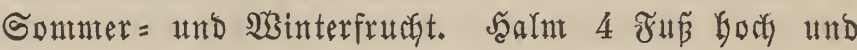
Göber, marflos, erft Gell und bunfelgrün, bann melyr ober

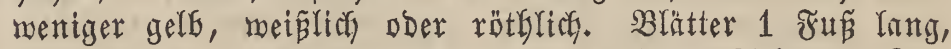

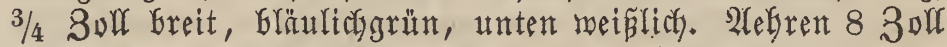
lang und länger, bäuftg gebogen, fchlaff, oben zugefpibt, zแ⿰: $\mathfrak{B}$ lüthezeit bläuliçgrün, mit Der Reife blau, bis in'z

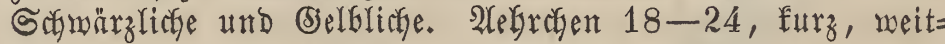
läuf, mit 3 Srannen und einer 4ten Stunmelgranne, unten 3 , oben 2 Samen. (5irannen 2-4 80 ll lang, im 2 (ñfang Gläuliçgrün, fpäter gelbliçmeís, ober grau, 1mten manch = mal faft fofwarz. Relebfuelzen etwas Greit, oben ftumpf, nacfenfürmig, bie Rängärppe berläuft in einen mit einent Săntergen verfebenen (brantenftummel; in ber Jugend matt= 


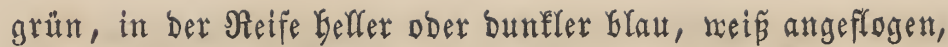
ober afdygrau, auch fétwärzlich. Die äufern Sironfpelzen find länger als bie Sieldyfpelzen, gegrannt, bertieft nachen= förntig, Dent Santen zur Şälfte untgebend und wie bie Reles= fwelzen gefärbt. Die innern Rronfpelzen febr zarthäutig. Spindel lang gegliebert, fehr fpröbe, bläulictgrau und trüb= gelb; reist mant ein 2Oegreben ab, fo Gleift ein Stüt bon Der Spindel Daran bängen. Der Same ift grós, 3ectig, tieffurchig, am ofern Ende rollig befgart, rötglich bon Zrarbe, etrag Durchfictitig und glaftg.

Der 2 (nbau biefez Spelzes ift bia jest noch menig be= fannt. Rach gemadbten Erfabrungen geräth er als Sonmer= frucht am beften. Der Errtrag an হärnern und Stroh ift wünfuchenserth). (Er lagert ftey gerne, befonders in naffen Jabrgängen ober in zut maftem Boben, voer aber, wenn bie

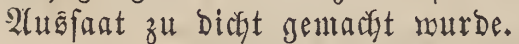

Mian bat you biefan Spelz eine 2(bünderung mit melgr Dober wentiger grauer 2(elge,

a) Triticum Spelta nigrescens. Schübl.,

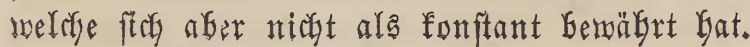

\section{'Triticum amyleum. Seringe. \\ Triticum dicoccum. Schrank. Schübl. \\ Triticum atratum. Host. \\ Triticum Cienfuegos. Lagasc. \\ Triticum Forskahlei. Lagasc. \\ Triticum Gaertnerianum. Lagasc. \\ Triticum monococcum majus. Dumeril. \\ Triticum Spelta. Host. \\ $\beta$ Triticum tricoccum. Schübl. \\ Zea amylea. Moris.}

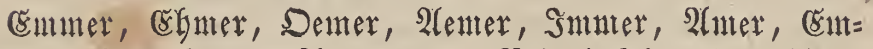

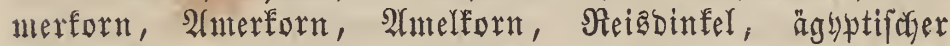

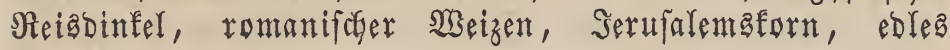
Bmeiforn.

\section{Arten = (Shatakter.}

Scalm 3 Jึı ober meniger marfig, geftreift. Blätter 5 3oll bis 1 Juß fang und Darüber, $1 / 2-1$ Solf Greit und foğn Glaugrün. 2) recht, lang gegrannt, dber faft ungegrannt, uneift etwas âtig, und in biefent Falfe unten etrus aufgetrieben, rund = lich ober faft 4 feitig und ofen mefre breit. 2lebrcten ge= brängt, eifürmig, zugefpibt, nit 3 , Gie und ba auch 4-5 Staubgefäpen und 2, feltuter 3 Samen. Sieldyipelzen flach, nit 1-2 Gervortretenden Streifen an Den Seiten, fodarfent,

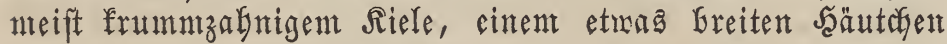

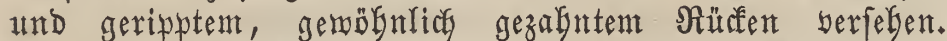

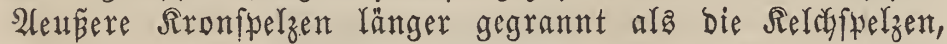
woer nur lang zugefpibt, faft 3 erfig. Spindel eng geglie= Dert, meift fehr fpröbe. Die Samen beinake ganz won Dent äuBern Srompelzen umgeben, fend gemöbnlich breit, läng= lich, vben und unten fpibig, ntit bertiefter Rängafurche und

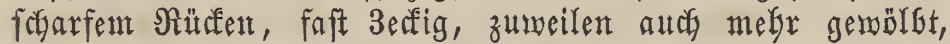
gerunzelt woer böferig, mit grofent Nagelfledfe, won Frarbe

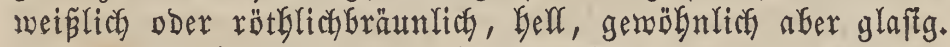
Bei Den meiften Sorten merden Die Rörner Durcts's Drefden nicht enthüllt.

\section{Sluthe : Beit und Danet.}

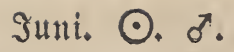

\section{פัorfommen.}

Nach Rinf mären bie faufafff̣en Rănder bas uriprüng=

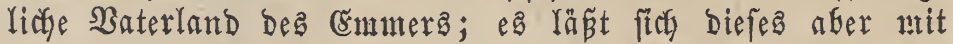
fo menig Beftimmtheit als bet Delt inbrigen 2 Seizenarten be=

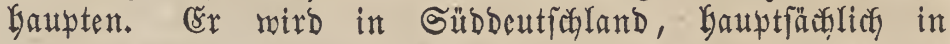
Wourttemberg, wo feine Rultur fochon feit 300 Jabren be= fant ift, in ber Schweiz, in Jranfreidy und Stalien ange= Gaut, in Norbdentfaland facint er nidyt zu gedeifen.

\section{Bultur.}

Der (Ëmmer geräth bauptfächlich in trocfenen, warmen Sahrgängen und zwar nody in magerent, troffenem, doch aber am beften in geförig umgearbeitetem und befonders

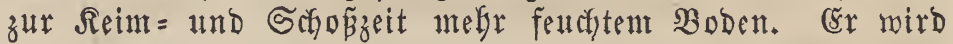
yorzugatneife als Sontuerfrutht angebaut. Die 2aşant ge=

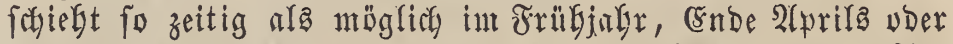

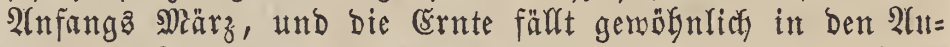
guft und September. Man baut ben \&mmer entweber allein, DDer, zumal ba er fpät reif nirb und fter nicht lagert, mit Seafer und Errbfen, ober auch mit MBiffen, bie grün gefüttert werben follen. Dieje Betreideart foll mo möglich bei tronfe=

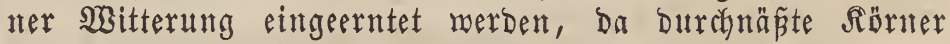
ein bitteres und bein Barfen zerfliésendes miebl geben.

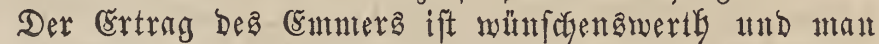
ninmt wom mürttembergifchen Morgen 8 Scheffel poet 39 biz 45 heftoliter som Şeftar Rörner Errtrag an; eVenfo ergiefig ift ber (Ëmmer audh an Stroh. In ber Defondmie ziegt mat ign ber bierftefuttur yor, wie Gauptfächlidy in Deftreich.

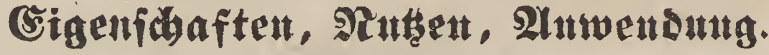

Das Mefrl fommt Dem bes Crinforns an (b)üte gleidy,

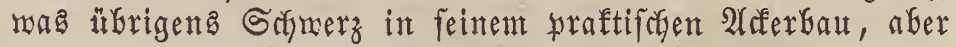
mit linrecht, beftreitet, riefert aber ein fpröbes 2 Brod, weE=

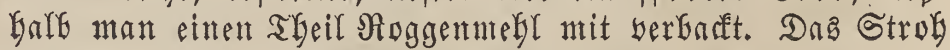
eignet fich feiner Steife wegen nicht zur şütterung, auper Der Enmer wäre in foblecftent Boben aufgenachfen, um fo mely aber zum Dachbecfen und zur Stalfitreu, aucis als Brenmmaterial, and erbält man yon ifm biel Dünger.

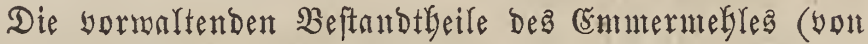

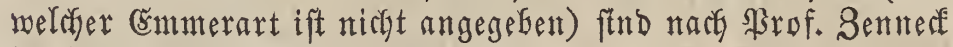
in 100 Theilen :

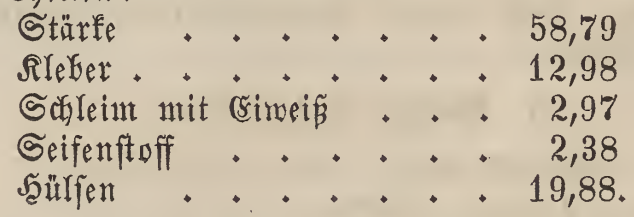

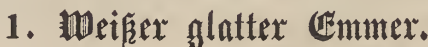

Triticum amyleum album glabrum

Triticum amyleum spica aristata alba glabra.

Triticum farreum.

Triticum Zea.

Triticum amyleum, var. A. Sering.

Triticum dicoccum album. Schübl.

Triticum Cienfuegos. Lagasc.

Zea Württembergicum. 


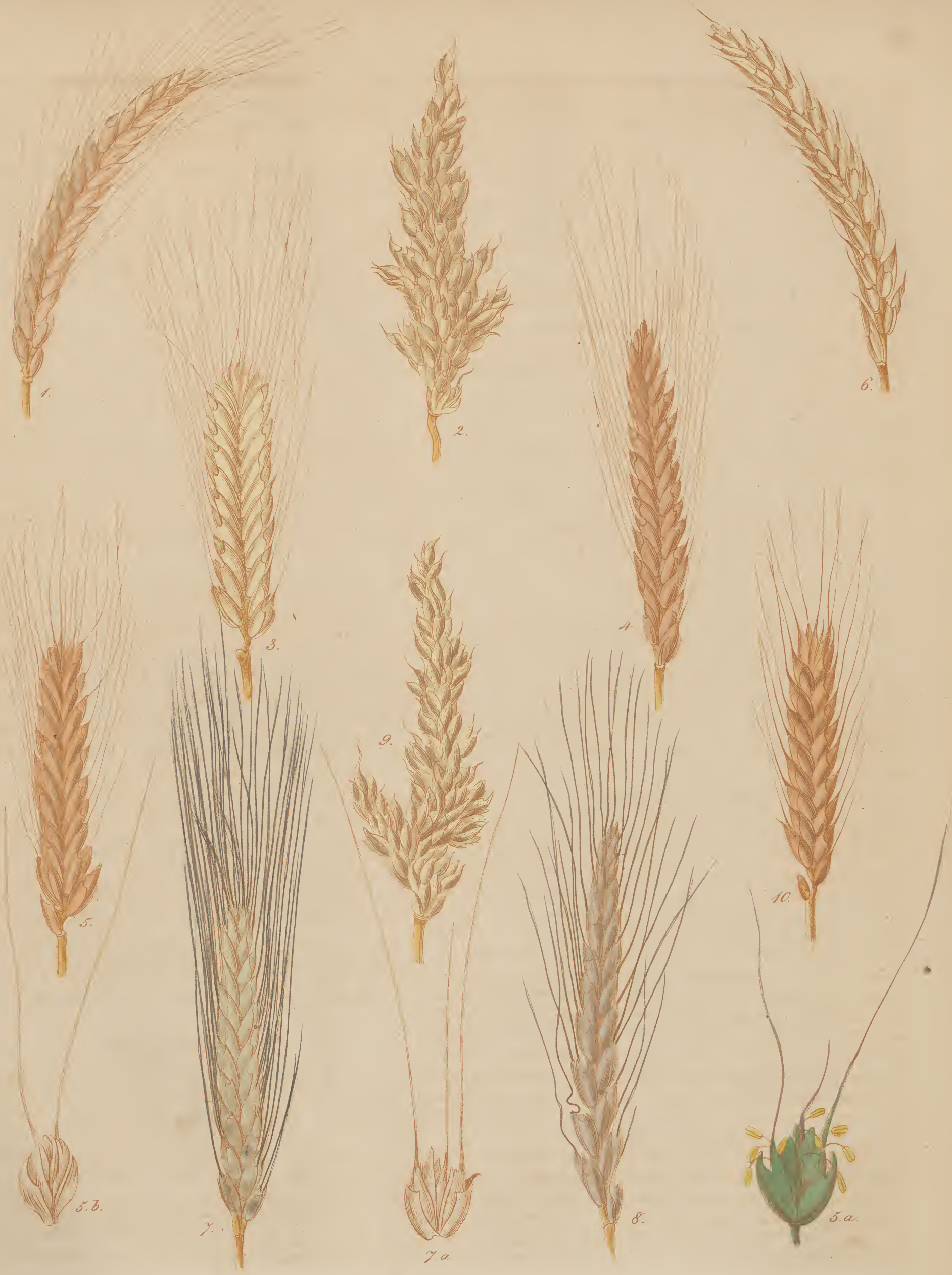




\begin{abstract}
Weiper Emmer, Reisoinfel, romanifder :zeizen, Ieru= falemätorn, 2lmelforn, 2(mblon (iut Elfá̧).

Blé de Jerusalem, Blé amidonier, Blé amidonier blanc glabre, grande épautre.

White Amel - corn.
\end{abstract}

Sontmerfrucht. Salm 5 Fü God, aufrect, rofrartig, etruas marfig, glatt, 4-5fnotig, in ber sugend bläulich=

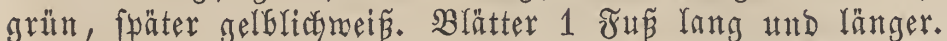
$3 / 4$ Soll breit, bie an ber Spibe bes balnts aufrect, blät= richgrün. Die Blattfociden berlaufen in einen etmas bäuti= gen, rötblich geränberten Rragen und find blaugrün. Die Aelren find $4-5$ sull lang, erit gelblicfgrün, fpäter weiglidy, und fteben in 2 Neifen. Die 2(efrchen $20-30$ an ber Sabl, eiförntig, ftumpf, gebrängt ftegend, 4blütbig, 2grannig, mit befaarter Narbe, und $2=$, felten 3 jamig. (Sirannen 4 3oll lang, raub, zientlicf anliegend, in ber

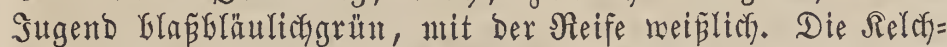
ipelzen ftarf glänzend mit fararfen, gefrümmtem, furz und fruman gezahntent Riele, gelbblĭulichgrän, am Babne Dunflet

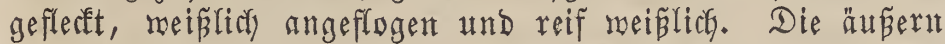
Blumenfpelzen viel Yänger ala bie Relchfpelzen, gegrannt, won ber gleidjen Farbe wie bie lebtern, jung ant freien Theile etmas gelblicf. Die innern Blumenfpelzen lang zu= gefpist. Spindel zufanmengebritft, glatt, an Den Sinteen aber zart befanart, erit bellgrün, ntit Dunflerent Snfertions=

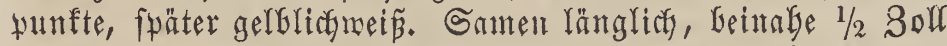
lang, oben und antent zugefpibt, mit breiten, aber fleinent Rängsfurdjen, convexent, fobarfent Rürét, graulidymeiś, Durdyfdecuend und glaftg.

Man Gaut Den meipen Emmer bäuftg in Ş3̈rttemberg, it Der Sabreiz, Gefonbers in Ranton Aargau, in Franf: reids, Stalien, zuntal in ben 2 (penninen, bäuftig an, wabr $=$

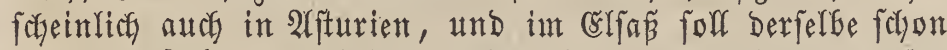
bor 300 Jabren fultibirt worben fein; nat) Einigen wäre

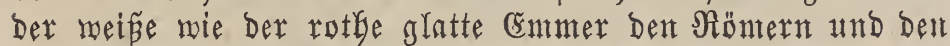
2leghptien (2. Buch Mof. 2, 32.) Gefannt gervejen.

Der meipe Esmuter gibt frgon in eiment mittelguten, zumal etmas tyonigen $\mathfrak{B}$ oben eiuen reichlichen Ertrag, der ftech aber in gutgedingtent Buben wobl auf das 200 fältige ber 2uŝfant fteigert. Mian baut ifn au bäufigften ala Somnterfrucht, befonders int Sientenge, in Witrttemberg bäufig mit bent rotben glatten Crmuter und ant liebften mady

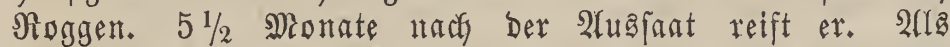

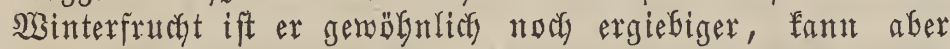
als foldye nut in milderem Slima gebaut werden. Dem Brande ift biefer crmmer wenig ausgejezt.

(ât liefert eiut feittes, weipes Mebl und Stärfmebl, aucy bereitet man aus belt viel Graleiut entbaltenden Rör= nern gute Siraupen and Gries. Das won diefem Megle Gereitete Brod foll Gald auBtrornen, wešruegen man Dent= felben eitten Theil Roggenmebl beintengt. Der Strobertrag läfit midyts zu münfigen übrig und man fann das Gtrob, menn es nidgt zu maft aufgeroadfen ift, tod als Sẳffel= futter benïben.

\section{Wothex glattex (Exmmex.}

Triticum amyleum rufum glabrum.

Triticum amyleum spica aristata rufa glabra.

Triticum dicoccum rufum. Schübl.

Rotber Ėmmer.
Blé amidonier rougeâtre glabre.

Red Amel - corn.

Sommerfruct. (Er Gat in Beziefung feiner Gotanifdent Gharaftere, feiner Sultur und feines Errtrags, das speifte int bem borig Befdriebenen gemeit. Seine alebren ftnd Gäuftg länger, rothbräunliç, die (siannen rötbliç, die Reldyfolzen Gräunlicf.

Der rotge Enmer gedeigt nocf eber ars Sinterfrudit, ift noch ergiebiger als der weipe und bie meiften andern (smmerarten, und foll nach Schwerz nocf $1 / 4$ nebr cratrag geben als ber genteine Sommermeizen; übrigens ift fein Mefl weniger fein und weís ars das bes borigen.

\section{Wei}

Triticum amyleum spica alba glabra ramosa.

Blé amydonier blanc, glabre, rameux.

White smoolh many - eared Amel - corn.

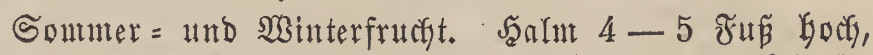
unten befonders bick, wenig narfig, erft etras Dunfelgrün

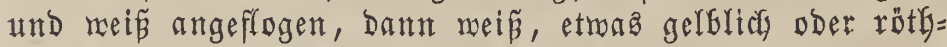

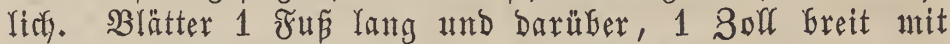
bielen Rängaripyen und einer befonders berbortretenden weiber Mittelriple; int Uebrigen fund fte blaugrän, unter weib̆licy. Alefren 5 Soll lang, unten breit, nach oben zit ftif berfduntälernd, welbr ober weniger affig, oft wie bie Wunderweizen, oft aber auch faft einfach, mit Der Seife roeí. 2lefrefyen 20-30 und mefr, ciförmig, in Der Mritte fitf ausbreitend, furz gegrannt, $2 \Rightarrow$ feltner 3 fantig. Die (Sirannen weip oder fămärzlich. Relchfyelzent etwas breit, ofsen ftumpf, mit einem fictarfen, ftumpfanguigen Riel, mel= dyer an Crnbe feinter Mittelridpe noch einen berfümmerten Safn bat; int Anfange ift bie Frarbe gelblidagrün, gegen

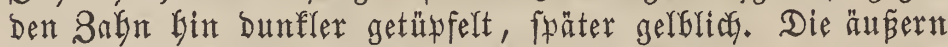
Blumenfpelzen ftarf nachenförmig, mit fdyarfen, conbexem

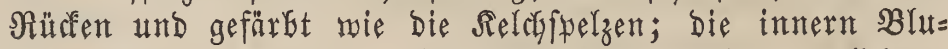
menfpelzen dünnbäutig. Spindel glänzend, furz gegliebert, zäbe, jung an Dent belenfen grün angeflogen, fuñter roeí̄. Santen furz, eiförntig, aut Sanäbeldsen mollig begaart, gelb, meflreidy, und faffen beim Dreforen zunt grofien Theile aus.

Diefe Sorte berlangt ben gleidyen Boben mie ber meipe glatte (smmer; fte gibt einen reidylicten Ertrag und beftodf fich gut. Die Winterfant exfriert meiftens, wenn fite nicht Den ganzen Winter uber wom Sanee Gebeft bleibt. SGre Rörner ftnd fobon und meblig.

\section{Weich kuxz gegranntex 迎mex.}

Triticum amyleam, spica submutica alba glabra. Triticum amyleum var. B. Sering.

Triticum tricoccum. Schübl.

2eguptifaer Gyelz, äguptifdyer Winterweizen, weiper SBinteremmer.

Blé amydonier à courtes barbes.

White Short - awned Amel - corn.

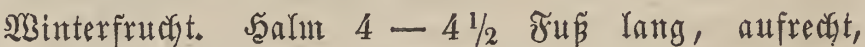
rund, an Der Aebre bie und ba etwas gebrebt, unten ge= fniet, Gobl, geftreift, in bet sugend Glä̧bläulichgrün, bas oberfte Snternodium Dunfler gefärbt, nit ber Neife gelblids=

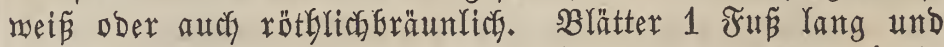
$3 / 4$ Soll freit und nur bas oferfte Blatt aufrecht ftebend, 
Dunfelgrŭn. 2íegre 4-6 Soll Iang, gewögnlich aufrecht,

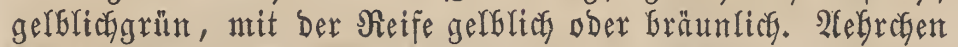
20-26, it ber Mitte erweitert, aufgetrieben, eiförnig, gebrängt ftebend, $2=$, feltner und bann bie untern 3 fantg. Die Srannen find Stummelgrannen, welche felten und böch= ftens nur 3 soll ling, in Der Sugend gelflich und grün geflectt ftrnd. Die Relchfpelzen oben ftumpf, an Der Seite erfaben geftreift, mit fcharfent, ftumpfgezäfntem Riele, Deffen Mittelrippe ftes in ein weiteres 8älnchen endigt; in Der Sugend gelblich, grün geftreift, gegen Den 3 abn bin bunfler,

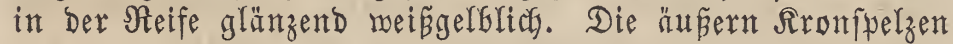
ragen meit unfer bie Seldafpelzen Ginatus, ftnd furz gegrannt voer nur fpibgezagnt, jung gelbfich, ntit grünent 3ahne. Die innern Srompelzen find gleich lang, Gäutig, Doppelt

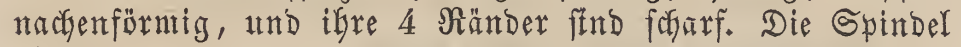
ift furrz gegliebert und glänzend gelblidfweis, ferge foröbe und an ben Gelenfen beGart. Die Samen länglich, conber, in

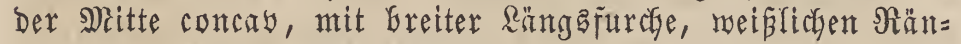
Dern, etwas wolfig befantent Scynäbelchen, etroas runzlichem

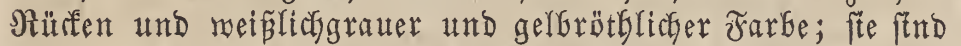
fehr meblig, wenn man fee nicht erft in ber Bollreife eint= beinst, fonft aber und in naffer Jabrgängen Gornig.

Die Sultur biefer Betreideart ift Gei unz bis jebt mut felgr wentig befannt, in Stalien wirb fie bie und ba ange baut. SBlos als Sommerfrudlyt liefert fte in trodfenen, war=

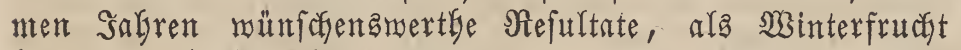
bingegen ift fite feltent ausbauernd, went fie nisgt gerabe Durch sine Gleibende Schneeberfe gegen Fröfte geichüht ift. Sie reift Gald, beftorft fith gut, liefert gute Rörner und verbiente DebGalb einer weitern Beachtung.

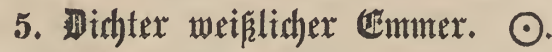

Triticum amyleum compactum albidum.

Blé amidonier compacte blanchâtre.

White compact Amel-corn.

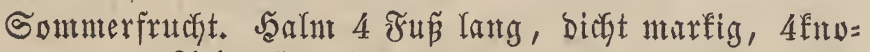

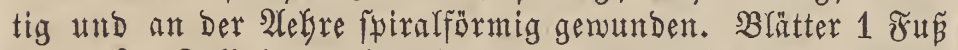
lang, 3/4 8olf Greit, Gläulidgrän, oben geftreift, mit einer

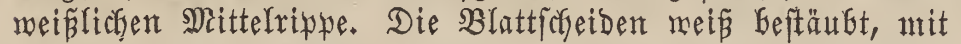

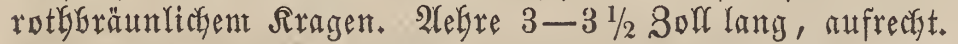
oben meift ftumpf, feltner zugefpitzt. 2(elgrchen $18-24$, eiförntig, Dieft ftekend, 2grannig, $2=$, felten 3 famig. Bran= nen 8-10 3oll lang, jung Gräulichgrün, reif rotbgräun=

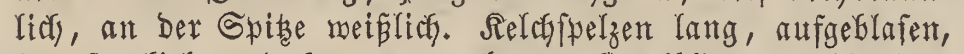
fcharf gefielt und frumm gezaGnt, erft gelGlidy ober Gläuliç= grütn, ntit Dunfel gefärbtent Dahne und Rängğftreifen, Daun

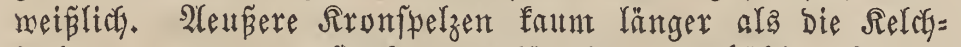
fwelzen, gegrant, ftare nachenfürmig auggefablt. Snnere Rronfpelzen Doppelt nachenförnig vertieft. Spindel furz= gegliebert, fétet biameilen Durch, an Dent Siliebern ein wentig

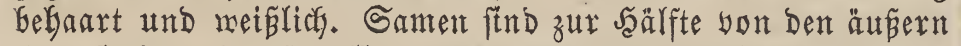
Srompelzen eingefchloffen, 3erfig, mit nollig bebarter Spise,

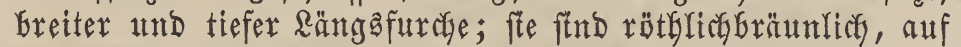

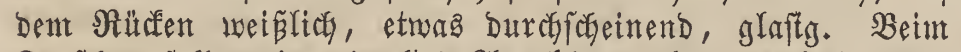

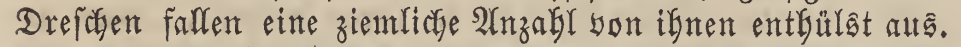

Berfuche int Bropen find mit biefent (snumer noch nicht angefteflt worben, and bie, melefe man int Rleinen gentacht

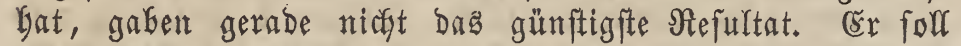

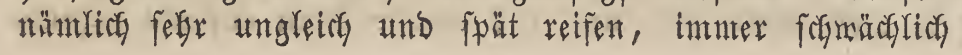

bleiben und als SBinterfrutgt meiftens erfrieren; jeboch follen feime Sörner grof́s und yolfomnen werden. Der Extrag an Stroh foll fely gering ausfallen.

\section{Rother glatter äftiger (⿺𠃊mmer.}

Triticum amyleum spica rufa glabra ramosa.

Blé amidonier rameux, roux et glabre.

Red many - eared Amel - corn.

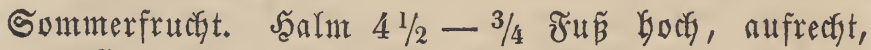

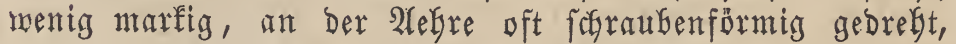

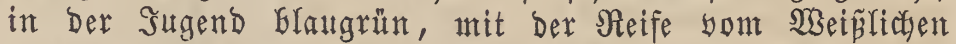

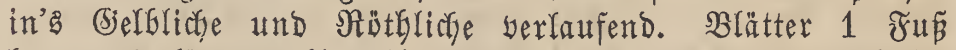
lang und länger, Gismeilen 1 3oll breit, oben mit erbabe= nen Rängaripwen und eben folder weiser Mittelrippe und

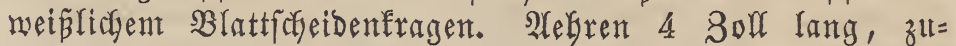
meifen etwas gefrünmt, Glaggrün und fpäter ntelgr voer reniger rötglicbrautn. 2(ebraben 20-24, und je nach ber geringern Doer ftärfern Beräftlung Der 2(ebre weit ftärfer an $3 \mathfrak{a b l}, 2=$, unten oft 3jamig. Sorannen bei mebr åfti= gen 2 eferen meift unt Stunntel, länger jeborh bei mefrr einfacten, felten ubber 3 8oll lang, rotgbrătunliç. Die Spelzen mebr oder mentiger rothbraun, bie und da, zumal in troffenen Sommern, weiß̧lich angeflogen. Seldypelzen ftumpf, gegen bie Spibe hin etwas fpisiger, glntt, gezalynt, mit gezälyter Rängartipye. Die äufern Rrompelzen länger als bie Reldyfpelzen, an Der Spise Der 2HeGre wie bei bent lebtern gegrannt und zumeilen nod gezalnt. Die inmern

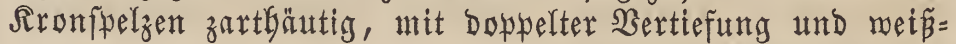
gränzend. Samen furz, mit mekr ftumpfen Rändern utto

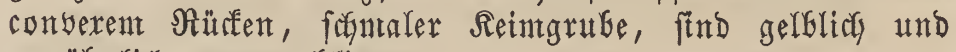
getwöhnlich ganz meflig.

Diefer (rmmer fofeint Gefonders nur als Sommerfrudit recat zu gedeiben und Den gemünfobten Ertrag zu liefern. Seine Begetationaperiobe ift etwa 5 Monate, feine Sörner

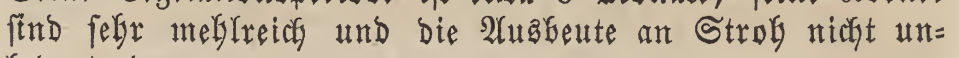
bebeutent.

\section{\%. 匇idhtex xőthlidhex (êmmex.}

Triticum anyleum compactum rufum.

Blé amidonier compacte rougeâtre.

Red compact Amel - corn.

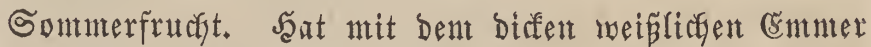

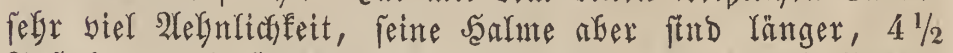

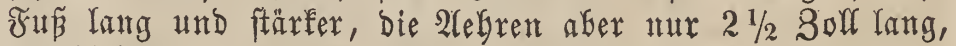
bie 2lelgrchen Gäufig breifamig; bie Brannen 5 3ull lang, Gie und ba gebrebt und gelblich; Die Reldefpelzen länger ge= zalunt, gelflichbräunliç ober megr rötglicy und weís ange= flogen; Spindel zäGer.

Er wirb als Sommerfrueft angebaut, in öfonomifocher

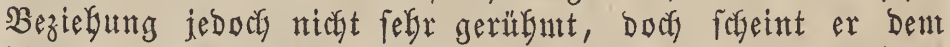
bichten weifen (Entmer noch yorzuzieken zu fein; er beftort

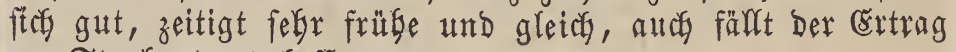
an Strob etwas beffer aub.

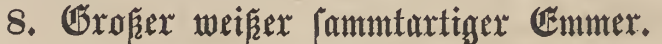

Triticum amyleum majus, album velutinum (aristis longissimis).

(Sroper meiner Ënnter.

Grand blé amidonier blanc et velouté.

Great white velvet Amel-corn.

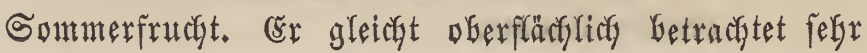




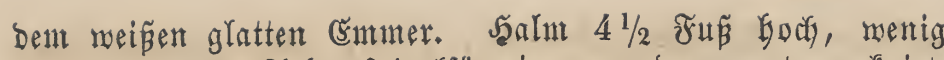
marfig, an ber 2 fegre fpiralförmig gerwunden, unten gefniet, in Der Jugend Gläulithgrün. Blätter $14-15$ Soll lang, 3/4 8ulf breit, mit aufrecht ftebendent oberftem Blatte, wei $\tilde{\beta}=$ gerippt, Gläulicfgrün, unten meís angeflogen, Der Siragen ntit rötglicyent Rande. AYebren 6-8 Solf lang, son zmei Seiten zufammengebrüt, fpichig verlaufend, bismeilen ge=

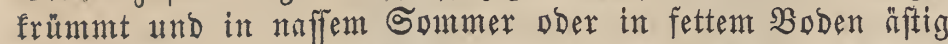
werbend, Gellbläuliçgrün und gelbliç. 2(ebreben 24-40, an ben formalen Seiten foblaffer ftelgend, 2grannig und 2jamig. Brannen 8-10 $80 \mathfrak{l l}$ lang, meift etıas anliegend,

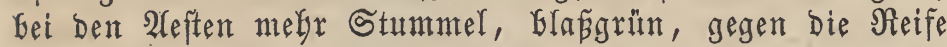

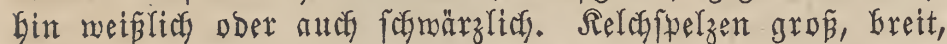
längarippig, etmaz bebart, mit fagarfem, gezabntent Riele und gezähnelter Mittelrippe, Gell Glaugrünlich und gelblich, mit Dunfler gefärbtem 3nkne, mit ber ßneife gelblich. Die äüern Sronfwelzen gegrannt und yon Der Farbe Der Sieldy= fwelzen. Die innern Rromfpelzen bäufig Doppelt nachenförmig und etwas gefaltet, mein. Spindel breit gegliebert, mit baarigen Sintften und fubon unreif fpröbe. Samen läng= lich, an Geiben Ěnden zugefpibt, mit breiter, gefalteter and wertiefter Seimgrube, wolfig befarartem Sefnäbeldyen und

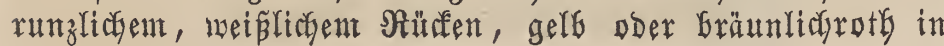
Der Selbreife.

In gutem Booben ijt Der Ertrag biefeg Emmers ein ganz erroünchter, und in foldyem und zugleich in naffen Jahrgängen aufgemachfen, wirb er faft immer äftig; er wird etra 8 Tage jpäter reif als Der meí̉e glatte Emmer.

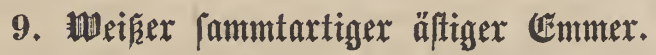

Triticum amyleum spica alba velutina ramosa.

Triticum Spelta. Host.

Triticum amyleum. Var. C. Sering.

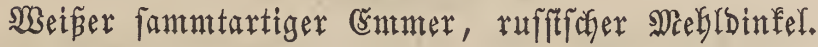
velouté.

Blé amidonier blanc, velouté, rameux. Blé amidon, à épi

White velvet many - eared Amel - corn.

Whinter = und Sommerfuctht. Diefer (Emmer gleicht bis auf Das Sammtartige Dem meí̄en glatten äftigen Ernmer. Die Aebrefen 20-28 an Der 3ahr, gebrängt ftebend, ftnd etmaz fürzer gegrannt, $2=$, felten 3famig. Die Reldyfpelzen

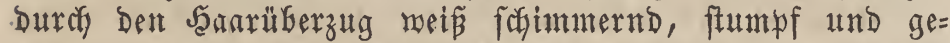
zahnt. Die äunere frunfpelze etwas bauchig, Diffrandig and Gerworragend. Srannen fo lang als bie 2Aebre, raug,

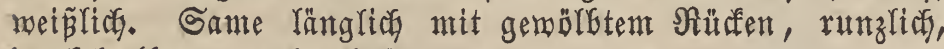
Dunfelgelbgrau und glaftg.

Diefer (rmmer ift wobl einer Der ergiebigften, went ex in gutem 3 oben aufmächast; er beftorft fith auserorbentlich gut und eignet fict befonders zum Sommeranbau; Denn nach biater angeftelten Derfuchen erfriert er febr gerne itber ben sinter, Gleift er nicht fortwäbrend yom Ganee be=

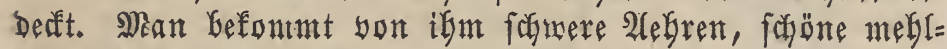
reitge Ränner und ein langes Strof.

\section{0.}

Triticum amyleum semicanum villosum.

Blé amidonier grisâtre velu.

Gray - white velvet Amel-corn.

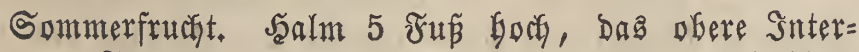
nobium 2 Fัuß lang and länger, bagl, gefniet, erfit blau=

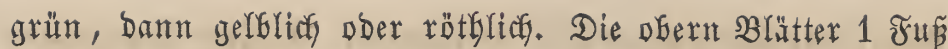
lang unb Darüber, 1 3oll breit, längaggeriwnt, aufrecbt, Glaugrïn, Jiragen rötglich, Blatticheiden etwas gewumben.

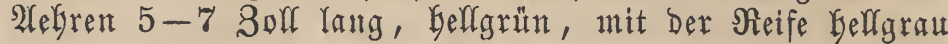

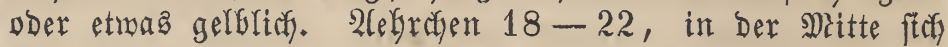
ermeiternd, etmaz fălaff, 2grannig, 2fanig. (s)rannen 4-7

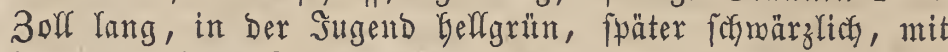

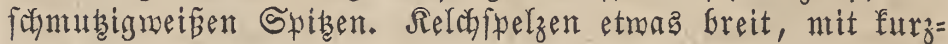

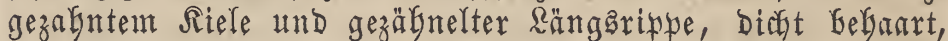

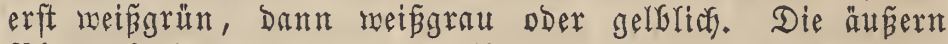
Bfunenfpelzen gegrannt, ant Nande genimpert, gefärft mie bie Relchipelzen, an Der Giranne aber etwas grünlid . Die innern $\mathfrak{B l u m e n f p e l z e n ~ b u ̈ n n g a ̈ u t i g , ~ f p i s i g , ~ f e i t l i c h ~ v e r t i e f t . ~}$ Die Spindel langglieberig, feitlich and am 2 Buffe befaart, glänzendmeín, fpröbe. Samen faft 8ectig, mit breiter, tiefer Rängşfurche, grofem Nargelfferf, wolltg behaartent Sihnäbel= chen, bei ber Volfreife rötflich und Durcfaus glafts.

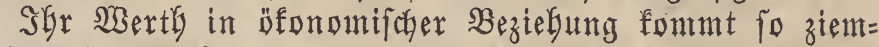
Yich) Dem Des rothen und meízen glatten Ënnmers gleich. (Er wurbe bis jebt nur als Sommerfrucht angebaut, gibt grope

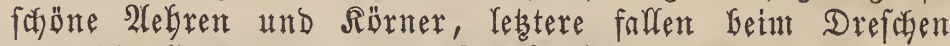
über bie Sălffte ausิ. Dą Stroh ift lang und ftarf.

\section{1. liather fammtaxtigex (Emmex.}

Triticum amyleum rufum velutinum.

Blé amidonier rougeâtre velouté.

Red velvet Amel - corn.

Sommerfruteft. (Ex gleidgt in Bielem bem glatten äfti=

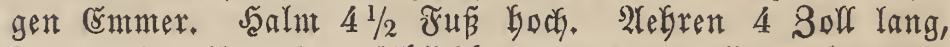
fetDenartig glänzend, rötglidgbraun und grauliç. Siranmen 4 Soll lang, oft halb fobmärzlich, zumeilen nur Stummel.

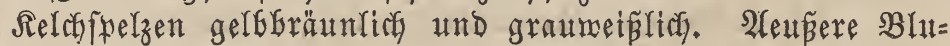
menfpelzen aupen ftarf bef̧art, gelbbräunlich. Der Same fomie affes Hebrige gleich mit bem rotben glatten äftigen (smmer.

\section{Schwanzex fummtaxtigex (Emmex.}

Triticum amyleum atratum velutinum.

Triticum amyleum spica aristata atrata velutina.

Triticum atratum. Schübl.

Triticum amyleum, var. D. Sering. 2)frifa.

Sdjmarzer Sinteremmer, fchmarzer Winteripelz auß

Blé amidonier noirâtre velouté.

Black velvet Amel-corn.

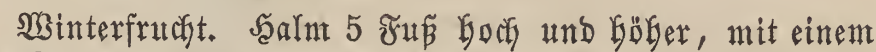
oft 2 Fus boben obern Snternobium, unten Gefonders farf, aufrecht, an Der 2lebre etwas fpiralförmig gerounden, mentig oder gar nidgt marfig, weiślicf. Slătter 15-16 Boll lang, $3 / 4$ Soll breit, Glaugrün mit rötglidem Rragen. SAlebren 3-4 3olf lang und barüber, aufrecht, nach oben ftch zu= fpibend, 2reifig, in gutem Boben etwas fablaffer werdend. 2Aefren 18-22, Dicht ftehend, eiförmig, 2grannig und 2jamig. Girannen 4-5 3oll lang, fararf, etwas unregel= mäpig ftebend, jung Glafsgrün, reif, oben fămusigmeiplich Dber Dunfelbräunlidg, gegen unten faft fogmarz. Seldafpelzen biat an Den Sronfpelzen anliegend, ftare behart, auf Dem Sücfen erbaben gerippt, mit ftarfem, fáarfem, furz und fararf gezabntem Riele, erft Glaugrün, metp̧bebaart, mit grïn geftreiftem Babne und rotbbräunlicfen Süfen, fpäter 


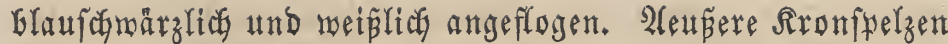
gegrannt, weit länger ala Die Relchlpelzen, an Der Granne

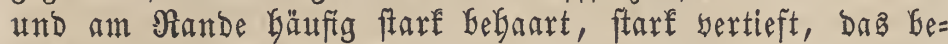
becfte Stủa gelfbräunliç. Die innern Rronfpelzen länger als bie yorigen, reniger feingäutig, an Den Geiten und ant Rande Glaufdamärzlich. Spindel furz gegliebert, focmal,

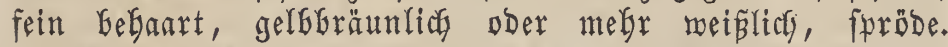
Same faft 3 ecfig, freit aber nicht tief gefurifgt, oben und

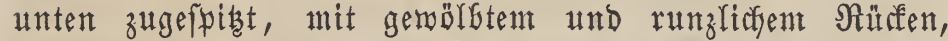
länglichem Nagelflect, graurötglich bis in's Dumfelgraue, in ber Belfreife theilmeife meblig, Gei ber Bolltreife übrigens Durctanas glaftg.

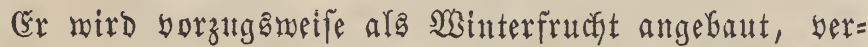
langt aber in fältern Begenden zu feinem Schube ben SWinter über eine Schneederfe. Etwa Mitte Dftobers aus= gefäet, fann man ifan unter günftigen umftãnden Nitte ober Ěnde Juli's einernten. Man Gat ifn auth figon als Sommerfrucht angebaut, fäete ifn in trodfenen, warmen Jabrgängen Mitte März und fonnte ifn 2 nfanga Geptember fduneiden.

Der Errtrag an Rönnern ift zmar münfdengamerth, aber Das Megl Derfelben ift nicht fein und meís; Das Stroh ift fteif und taugt bauptfächlich nur als Stalfftreu, auch ift biefer (rmmer Dem Mebltbau am meiften ausigefetst. Wit Bortheil fönnte er übrigens fur Maftung Des Biekes und

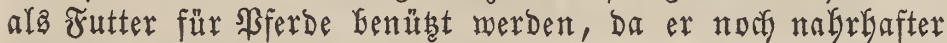
ift als ber Saafer. Die Saithner follen Dem formarzen Emmer nicht nachgefent und es fönnte foldyer ganz in Der Näbe son Wobnungen angebaut merden.

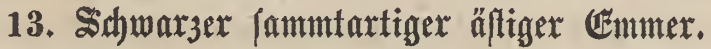

Triticum amyleum atratum velutinum ramosum.

Blé amidonier noirâtre velouté rameux.

Black velvet many - eared Amel - corn.

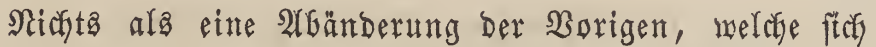

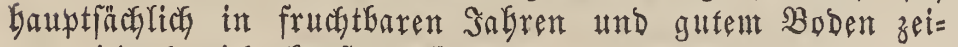
gen, feboch nicht fonftant fint.

\section{I'riticum monococcum. L.}

Triticum Hornemanni. Clem.

Triticum pubescens. Bbrst.

Briza monococcos. Lobel.

Einföniger Weizen, Einforn, rothes Einforn, Sant= Beteraforn, ßeteraforn, ömmerforn, Dinfel, welfcher Din=

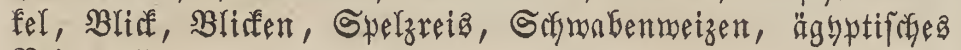

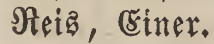

Froment monocoque. Froment uniloculaire. Blé locular. Petit ćpeautre. Froment monosperme. (firanz:)

one grained wheat. (engl.)

\section{Irten = Shataftex.}

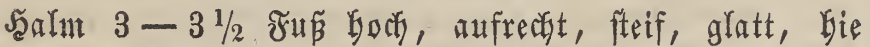
unb ba marfig, 5 fnotig und an ber Alefre etwas gebreft. Bătter 8 Soll lang, fefmal, in Der Jugend belfgrün. 2fegren 3 Soll lang, aufrectst, flachgedrüdeft, 2reigig, ge= grannt, in ber Sugend gelfgrünlich, mit ber Neife röthlicts= grünliç. 2(ebregen $22-40$, feltner 50 , gebrängt Dady = ziegelförntig ftebend, fabnat, fpitigig, 2-36lütgig, $1=$, nur felten 2 famig, ba yon ben 3 Relegen gemöbnlich 2 berfüm= mert ftnd, meift 1grannig. Sirannen oben 4 3olf lang, an

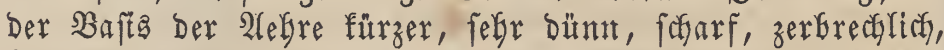
bäuftg - Gejombers die ofern - gebrebt, erfit grünliff,

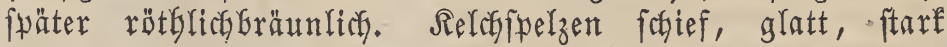
bertieft, mit gezabntent Riele und gezähnelter Răngăripbe, in Der Jugend gelblich, fein grüngeftreift, in Der ßeife Gräun= lich. S(leupere Sronjpelzen ebenfalfs ftarf nadyenförmig ber= tieft, mit einer langen und einer Stummel= Siranne, erft grünlich, fpäter Gräunlich, Giąmeilen fein bebaart. Innere B̉lumenfpelzen formal, feGr feingäutig, nachenförmig ver= tieft. Spindel furz gegliebert, glänzend röthlich oder metr weí̄lich, furöbe. Samen faft ganz yon ben sironfpelzen eingefchloffen, etraa flachgebrüd, oben und unten fuge=

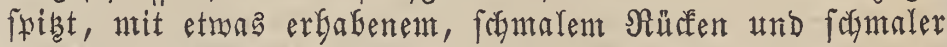

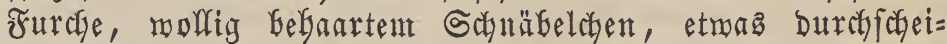
nend, meís, etnas rötblich angeflogen, in ber Bjelbreife meGlig, in ber $\mathfrak{B}_{0}$ flreife Gingegen megr glaftg; fie Gleifent Geim Drefiben in Den Spelzen.

\section{Błätbe: Beit mnd Danev.}

\section{รัuni. $\odot$.}

\section{}

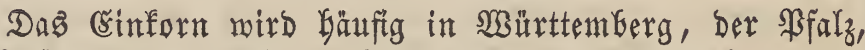
im Naffauiforen angebaut, befonders in malbigen Begenden,

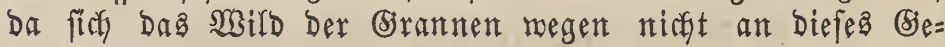

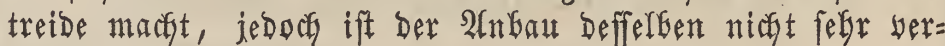
Greitet.

\section{ฌultux.}

Das Činforn mird feiner langen Segetationaperiobe, Die oft 13 Monate Dauert, und feiner geringeren (smpftnd =

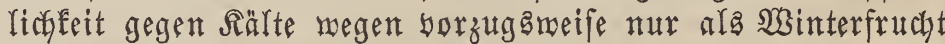
angebaut. (ङ̌s gebeifyt in einem magern, fteinigen, raub Gearbeiteten Boben, Der für ben Dinfel nicgt megr tauglicf tif, um fo beffer aber natürlich in einem gebörig bearbeite= ten und nagrfaften Boben, zunal renn Derfelbe noch über= büngt mird; auch roill bas sinforn ein melyr feuchteo slima. Da naan Das Csinforn im December und zumeilen noch $2(\mathfrak{n}=$

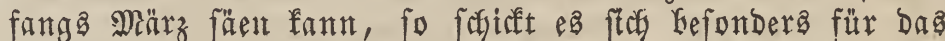
Sommerfeld. Sian fäet eas gewöbnlich unt Gofanni, ent= meber alfein oder mit Dinfel vermifcht, und um bie Jeälfte Dünnet als Den Dinfel, gemp̈hnlich 4-5 Simri Samen auf Den mürttembergifchent Morgen. Die Ernte DeB Crinforng tritt fpäter ein, als bie DeB Dinfela, . und fällt meift in ben September ober Dfober. Man farneibet es nicyt yor ber

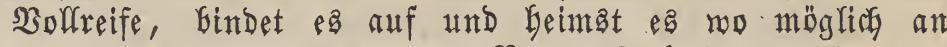
einem Tage ein, Da es Durch Regen Noth reibet und gerne

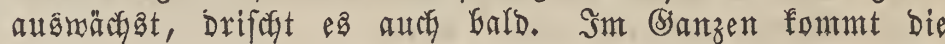
Sultur Des Çinforns mit ber Des Dinfels überein. Das

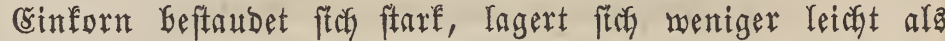
Der Spelz und ift überbaupt meniger nadytgeiligen Esinflüffen ausgefett.

Der Crrtrag bez in fräftigem $\mathfrak{B}_{0}$ ben aufgemadfienen

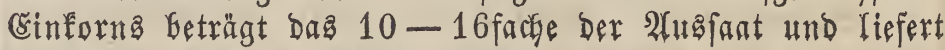
nuef mely Särner als der Spelz. 


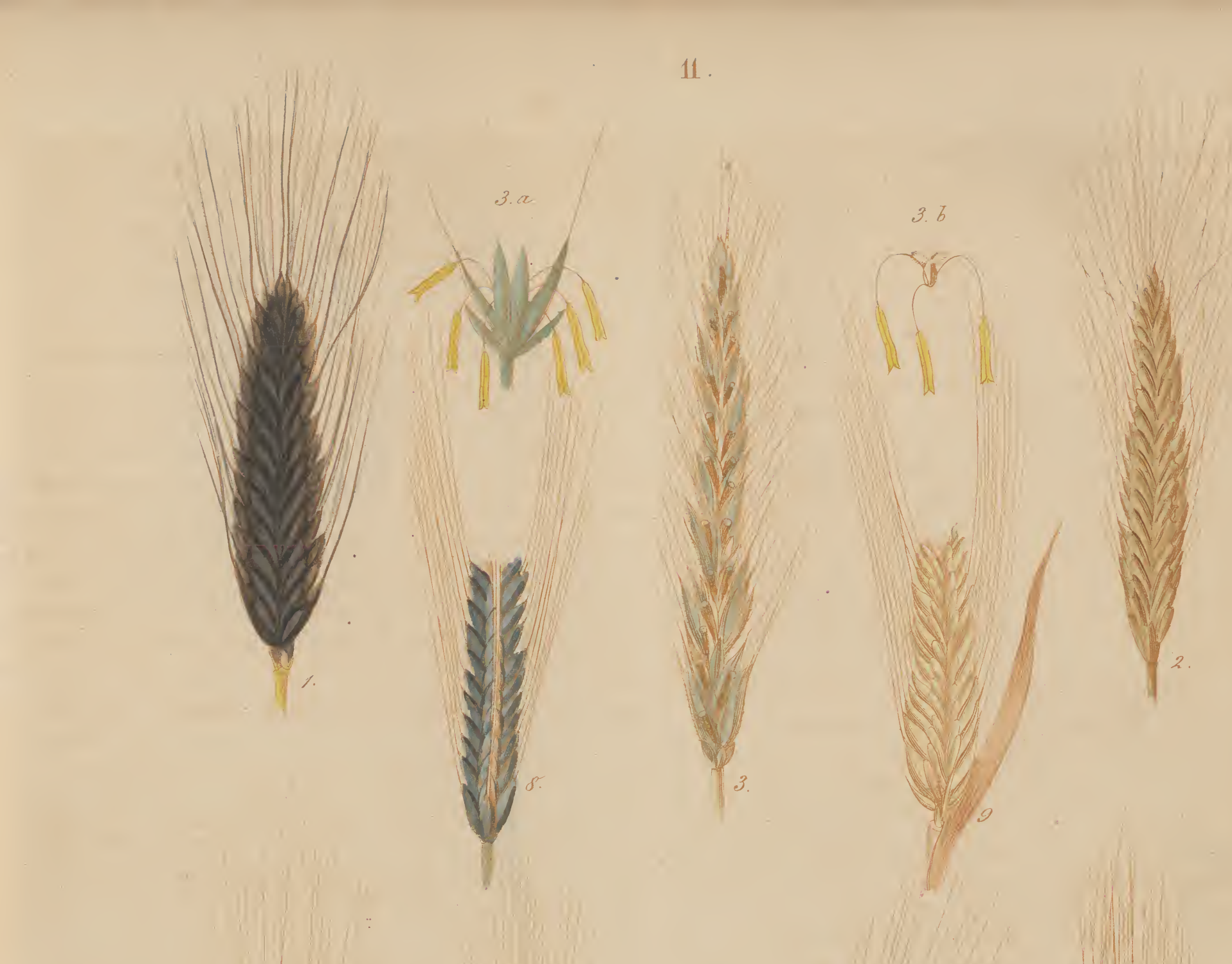





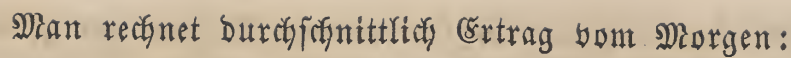
in Württemberg . 4-10 Scheffer Rörner und 12-30 Centrer Stroh, in Broben. . . 5-15 झalter Rörner und $12-33$ Sentuer Strof,

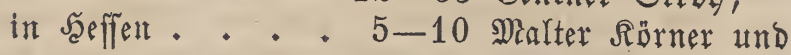
8-22 Gentrer Stro\%.

\section{હigenjabaften, Ruten, 2 tuwendutg.}

Die chemifchen Beftandtheile Des ungebeutelten Mebla yom Einforme find nady Bented in 100 Theilen:

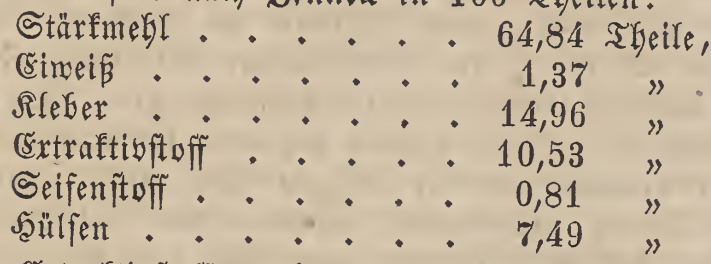

Die Extruftiuftoffe entfarten noch meiter:

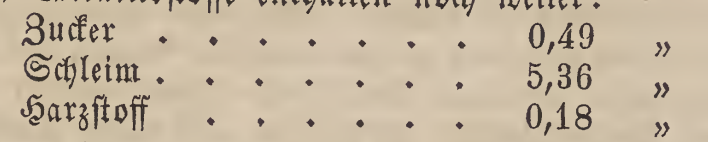

Man erfält yon bent Crinforn ein fojönes, aber etwas gelbeb, oft audy ein bräunliches Megl und ein Corfereş, aber fidroarzes und riffitges $B$ rod, 广edoch yon angenefmem, füßs=

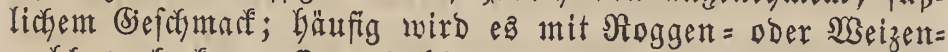
mefl werbacfen. Das PRegl eignet ftch in Der Rủche zum Siplten oder Schmelzen der Speifen noch mefr alo das (Berftenntegl. Mian benübt bie Rörner bäuftg zu Giraupen, Branntwein, Bier und Esfitg, und füttert fie gefchroten Dem Bief und rob dem Gieflitgel. Das. Dünne, fichwere und feite

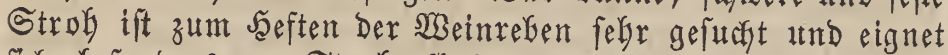
fich befonders zu Strobgeffectiten, Rörben 20. , zun Dach= Deffen, gibt yiel Dung, taugt aber, wenn aud gefdonitten, nicht zur Biegfütterung.

\section{(Gejaidite.}

Daz Činforn war fogon yor 300 Jabren am Rbeine, in ber Giegend yon Wormb Gefannt, wo eB ala Mintfutter angemendet murbe.

\section{Secale. L. Spr. \\ Syfteme: Achyrophyta. Neck. \\ Gramina. L. \\ Gramina digyna. Roy. \\ Gramina Hordeacea. Kunth. \\ Gramina Tritica. Adans. \\ Gramineae. Juss. \\ Triandria, Digynia. L.}

Reldy 2flapwig, 2Glüthig, mit bem geftielten $2(n$ nake zu einem 3ten Blütbchen. Rlappen gleidh lang, pfriemenför=

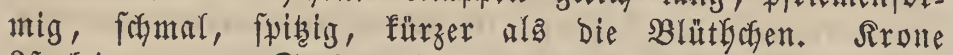
2fpelzig, untere Spelze mit fodarfgemintertem Rande, wben in eine Yange, flache, raube Granne auşgebend, obere Spelze linealifor, ftumpf, 2fielig, auf Den Rielen fobärflich, fo lang als bie untere. Decffpelzen 2, oben ftumpf, zerriffen. Frudftenoten eirund, Gaarichopftg. Briffel fegr furz. Narben feberig, zur Seite berbortretend. Samen frei.

Carwer, Bfonom. $\mathfrak{x}$ frnmenfunde.

\section{Secale cereale. L.}

Secale barbatum. Moench. Secale creticum. Sieb.

Secale triflorum. Beauv. $\quad{ }^{\text {. Secale compositum. Koel. }}$ Ranbroggenfurn, Roggenforn.

Seigle, Seigle de Ceres. (ftant.)

Manured Rye. (engr.)

\section{Strten = Shanaftex.}

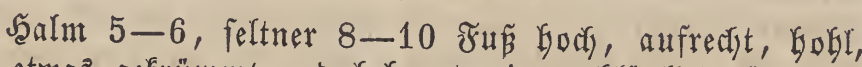
Dben etwas gefrümmt und befaart, jung Gläulichgrün und gelbliçgrün, weís angeflogen, in ber Reife gelblich ober auch röthliçbräıulich. Blätter $7-8$ 80H, bie untern oft 12 3olf lang, $1 / 4$ Solf Greit, mit ftarfer Mrittelrippe, gelfb= lichgrủn, weí⿱㇒㠯 angeflogen. Der Blattfragen flein und ge= faltet. 2lefren 3-6 $\frac{1}{2}$ Soll lang und britber, in ber Sut gend zufamntengebrüaft, grünlidyrötblich ober wei

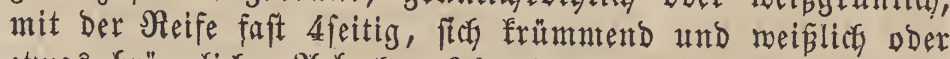
etwas bräunlich. Hebrchen 24-36, ungeftielt, 2reigig und fislaff ftefend, mit 2 Reldien und oft mit eitem britten berfümmerten, $2-3$ Blütben, 2 (sirannen und 2 Samen. (Srannen 1-3 3olf lang, aufrecht, fegr fpitis, raub, it ber Sugend grünröthlich, fpäter weifílich. Relchipelzen fchmal pfriemenförmig, 2flappig, ntit erbabenem Siuffen und einer

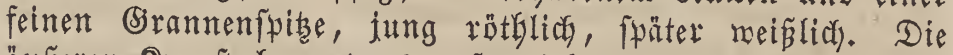
ăuneren Sromfpelzen etwas aufgetrieben, am Sande fein und focharf gezalgnt, gemimpert, ntit fägenrtigem Rürfen und ge= granntem Riele, auf beiben Seiten 2 Rängaripwen, jung rötglich. Die innern Sirompelzen fürzer als borige, bunn= Gäutig, ungegrannt, nachenförntig vertieft, mit f(achent

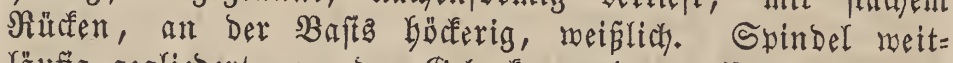
läuftg gegliebert, an Den (sielenfen und an Rande fein $b_{e}=$ baart, jung Gelfgrünliç, ant Infertionşunfte Gläulich, fpäter meiplicy. Samen zur Jälfte yon Den Rronfpelzen einge= fobloffen, ränglich, fwmal, oben ftumtr, unten zugefpist,

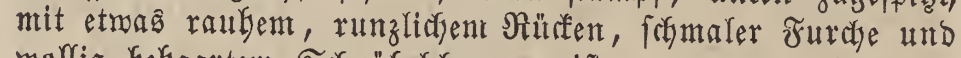
mollig befaartent Scfnäbelcyen, meift grau, yon afch = biz bunfelgrau; rötglich, bräunlich ober gelblichgrünlich, meblig, oft auch glaftg.

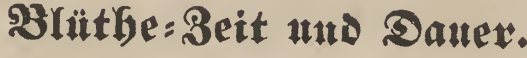

\section{$\mathfrak{M a i}-\mathfrak{s u n i .} \odot-\delta^{7}$. \\ Sortemmett.}

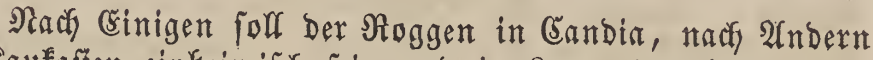
in Raufaften einbeimifas fein und in Rangueboc băuftg wild

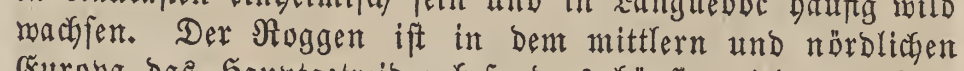
Europa das Sauptgetreide; befondera bäuftg wirb er gebaut

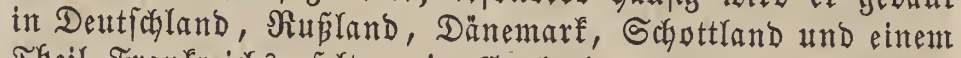
Theil Jranfreids, feltuer in England; ferner in 2legypten, 2trabien, Norbindien, Berberei, Nubien, Den canarifden Infeln. Err findet fith nady Raftyofer in ber Schmeiz nody in Der Saghe yon 4600 Jun, ferner in Normegen, ber Weftfeite Gdjwebens, Meftlappland bis Rat. 670 n., auf Der Otfeite Sagmedenz bis \&at. $621 / 20$.

\section{Rultut.}

Der 2 (nbau des Roggenz ift wobl unter allen Sanlm= frubleten in Deutichland ber verbreitetfe. (Er gebeigt noch 
in geringem und magerem Buben, in gebörig umgearbeite= tent Neubrudie, troden gelegtent Moor = und Sceidoboden, in hocfigelegenen, falten und troffenen biegenden, wo Wei= zen nicht mebr angebaut merben fann, an beften aber in einem leichten, mürben, aufgelorferten, fanbigen, falfmergel= und relgmbaltigen, Gumuareicfen und mehr troffenen Buben, aurfy noch in eimem vorberrichend fandigen ober nicft zu Gindigen Thonboben; ift lebterer aber zu feft unb dazu noch

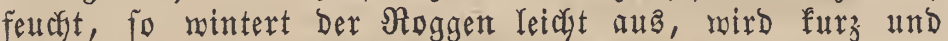
Gefommt nut bünne Sealne. Im Sandboden merben bie Rörner feinfülfiger, fchmerer, meblreicher, ber Strobertrag -aber ift meift unbedeutender, mäbrend in Thonboben bie

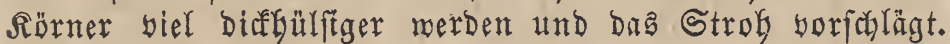
Das Dïngen bes Noggens ift zmar nicht unbebingt nötbig, wermebrt aber, wie wobl DenfGar, Den Ertrag Deffelben; jeboch ift zu bemerfen, Dás ez immer beffer ift, Den $\Re$ og = gen niegt auf einmal zu ftarf zu büngen, fundern lieber ¿jfer und mäßiger, auch nie zu frifchen ober gar bibigen Mift anzumenden. Reichten und wärmern $\mathfrak{B}$ oben büngt man fămächer, Gindigern und fältern färrfer. 2(m yortheilgafte=

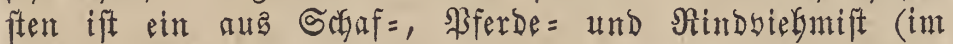

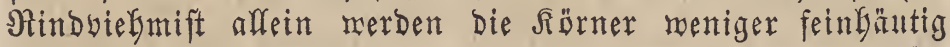
und meflreich) beftefyender Dung; Der Schafpferch eignet fith yorzüglich für fpät angeftelle Nioggenfanten; meiter yon $\mathfrak{B}_{e}=$ rang ift bie Düngung mit 2 fiche, Ralf und Mergel, efenjo für den fyätern 2(nfou bes Sioggens, ferner bie Compoft= (Gejonbers Safianmbüngung) und begetabilifoche Dïngung,

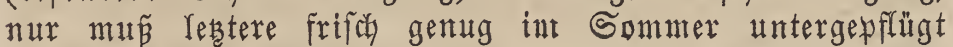
werben, Damit fte fid yor ber (sinfaat noch geförig zerfesent fann. Bei mekr magerem, faltent und bindigem SBoben fann geförig zergangener und berfaulter Mifít ofne Schaben gleich yor Der Saat untergefracht merden. SBei Dem Stop= werroggen foll man zeitig nach ber Ernte Der Borfrüchte Düngen, Gei Der Roggenfaat in bie Bracte aber Den Dung gleicy unterpflügen. - Ěin mäpig feuthtes und marmes Rlinta fohlägt ferner bem Noggen am meiften zu, benn, wenn gleidy Derfelfe aud bet marmer und troctener 3 Bitte= rung noch geräth, fo ift doch fein ơratrig mentg ftarf; er werträgt übrigena bie ftärffte Rĭlte, fo lange ex nicft in 2lebren gefdyoǵt ift.

In Der Dreifelderwirtbjchaft baut man Den $\Re$ oggen ent= meder nach Sracke, wo er ant beften geräth, ferner nach (biraland, wenn es gefrannt wurbe, voer nach Bractefrüch=

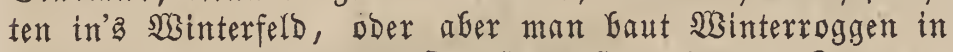
Roggen =, NBeizen = ober Delpffanzenftoppeln Dez Sommer= feldes. Dex Noggen nuß Gauptfächlich nach folchen Frücdten angefaut werben, melche Den $B$ oben in einem noch Ginreichend fräftigen und locfern 8 uftande zurüffaffen; man baut ifn

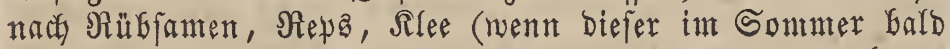
umgebrochen wirb), Tabaf, Jaülfenfrüchten, wie Bofnen, Erbfen, Wisfen (aber nur menn fe zeitig eingeerntet mer= Den tönnen und igre Stoppeln gleidy umgefrocken merben),

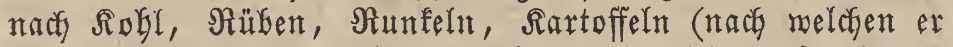
gemölynlich am foslechteften gedeift), nach zeitig unbrochenem Spergel, Budfmeizen, taach bietretbe und nady igm felgft, aber nur bei fandigem und felyr fräftigem 30 ben, in reldem Falle er einige Salyre lang auf Das gleidye Jeld gebaut wer= Den $\mathfrak{f a n n}_{\text {, }}$ da er meniger als bie andern Betreidearten ben Boben exfdyppt. Diefe fämmtliç genannten Borfrüchte müffen aber, foll ber auf fie folgende ßuggen gut gebeiken, in einem locfern und fräftigen $\mathfrak{B}$ oben aufgewachfen fein. -

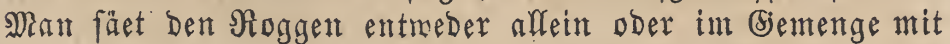
Dinfer (etma $2 / 3$ ), in ber Schmeiz bäufig mit Siseizen, be= jonders Gei fegr lefnigent Boben; in Rithauen Gat man

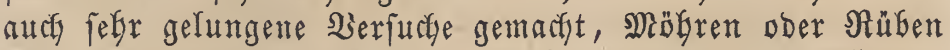
unter Den Noggen zu fäen; bie Mïbren läß̨t man ben Winter

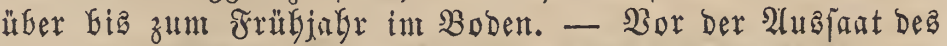

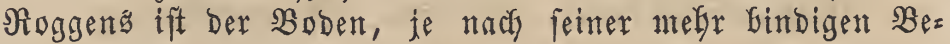

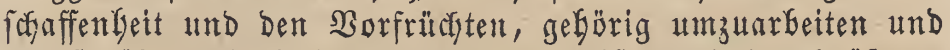
unt fo ofter, je foglechter Der Boben ift, und Durey offeres (ङggen und Saafen bom Hufraute zu fäubern. In einent fojweren Boben ifte eine 3-4 jurchige Beftellung nöthig, in einem leidytern reidyt eine 1-2furdfige bitr. 3ur 2luşant fulf man nur frifdyen Samen nebmen, ba man von älterem

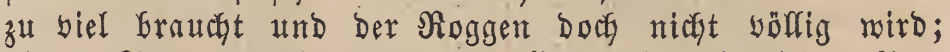

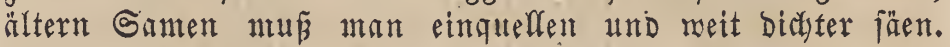

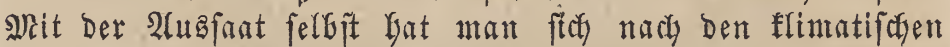

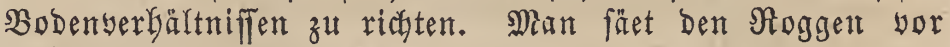
Sobannt bis December, ja oft noch bis 2lnfang des Miärzes. Se bälder man übrigenz fäet, Defto Geffer Geftodeft fitds ber

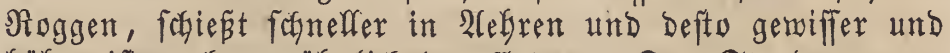
Göber ift audf geröbntich Der Ertrag. Den Staubenroggen fäet man 8-14 Tage Gälder alz den gemöfnlitben, ebenjo fäet mtan in geringen $B$ oben früber als in frăftigent ull gutgedungtem, in Mloor = und Torfboden, wie in Boben, melthen man tief wftügen fann, macht man bie 2(ub̂aat fpäter. In gełirgigen, fältern und raubern begenden fäet

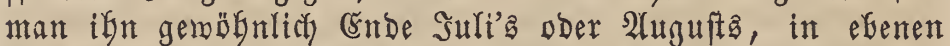
und rärntern Gingegen Mitte Septentbers ober int Dftober, gemöfulidy aber 14 Tage yor ober nady Mictaeliz. Bor ber

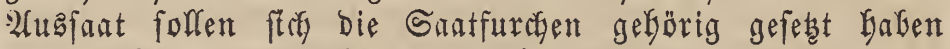
und Defigalb 2 - 3 SWochen yorker gezogen werden, bamit bie Saat fith gleicher bertyeilen laffe, gleidyförmiger aufgefe und Der Boben weniger austroffne. Crin magerer Bobent erbeifat eine bichtere, ein nabrbafter eine bünnere Sanat, Torf = und Moorboben aber bie bichtefte Saat, meil in ifm

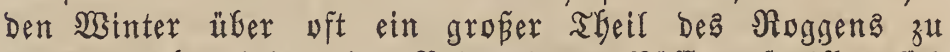

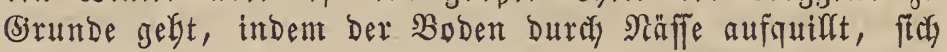
in bie Shofe bebt und Riffe befomnt. Die Auşaat foll wo möglich nur bei troffener S:Sitterung, nicht bei Stebel und bei troffenem (Erbreid yorgenommen und ber Same nur flach mittelft melgr ober minder fogmeren Eggen, je nach Der Bobenart mit Erde bebefft werben; je fanbiger ber Buben, befto tiefer, je Gindiger. Derferbe aber ift, befto flacher ift Der Sante anterzubringent. Reidyten $\mathfrak{B}$ oben eggt man mur einntal in bie Ränge, Gindigen aber $2-3 \mathfrak{m a l}$ freuz und

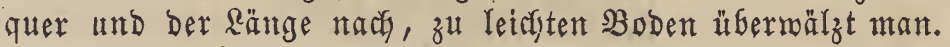
Sn $\mathfrak{B}$ eziefung auf bie Siltur unteridgeidet man Soumer=

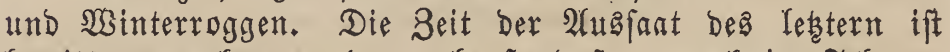
bereits angegeben worden, ebenio dás er noch im Februar und März augigefäet werden fönne, aber ber Errtrag Dez WBinterruggens an Röntern ift in leterterem Falfe felten ber, melchen man burch bie Serbftausafat genoint. Nact) Dem Winter, went Der Roggen geförig eingemurzelt, ift Das

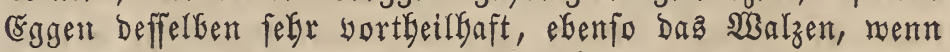
Derfelbe Duref ftrenge Rălte emporgeboben murde. Das Utrs fraut entfernt man Durch Säten. Der Sommerroggen geräth am beften in einem locfern, fand = und lebmbaltigen $\mathfrak{B}$ oben 
mit feuchtem Untergrund unb bei füglem, feurgtem Frübling; er eignet fitd beg̈halb ganz gut für Torf = und Mluorbobent

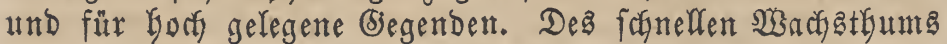
wegen werlangt ber Sommerroggen eiuen fräftigern und ftärfer gebüngten $\mathfrak{B}$ oden als ber Sisinterroggen, und felbr zuträglifn ift ifm bas Dïngen mit Mergel ober Salf, $\mathfrak{b}_{e}=$ fonders in Gebirgägegenden, ebenio daz Heberbüngen mit Mift gleidy nach ber Saat, zunal wenn ber Boben fegr trocén ift. - Sorgfăltiger noch ala beim Winterroggent nนu bas Sonmerroggenfeld Gearbeitet werben, ba es einen lofern und bon alfem Unfraut gefäuberten Boben berlangt,

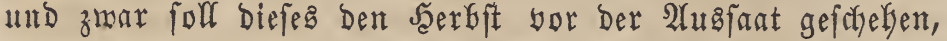

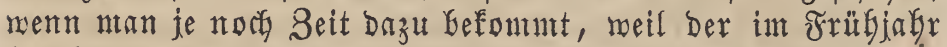
bearbeitete Boden gerne zu fehr auĝtrodfnet. Bet mefr bin= bigem $\mathfrak{B}$ oben madft uran bie Saatfurche im Fribjakr, bei fanbigem fow on int ferbfte. Den Sounterroggen fann man

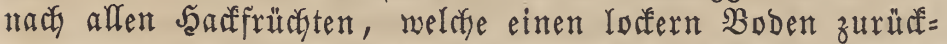
laffen, anbauten, am beften aber nach Sartoffeln, auch nach Winterweizen, nod Geffer aber nach SBinterroggen, wenn Der Boben zeitig verarbeitet worben ift. Die Sett ber Saat anbelangend, fo bängt fte elonfalla yon bent Boben unb ben Witterungşerbältniffen ab. Man macht fie im zrübjabr (längftens biz Mitte 2(prila) fo zeitig ala möglich unb, ba fer Sommerroggen nidgt fehr empftublich gegen אälte, fubald ber Boben gebürig trocfen ift; je Gälder fee angeftellt mirb,

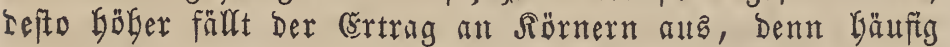
miß̈räth Der Sonumerroggen ganz, menn feine erite 2 (4ấbil= bung in trodfelte und Geiß̧e Monate fällt. Die Saat mird gemöGnlich Greitwürftg gemacht, und nur bei binbigem, feuts= tem Boben, nach Rartoffeln, fann man bas Driffen an= wenden. Nach Der Saat ift bem Sommerroggen zur Ret= mung eine feltedte Witterung angenteffen, Damit bie Saat gletch und bidyt aufgebe, eime füble Witterung aber, ment ex einntal Blätter befoumt, bamit er menizer fogleâe, fon=

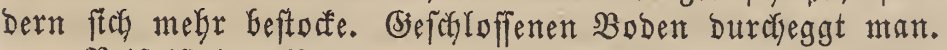

Neif ift Der Noggen, wenn Die Rörner Gart find und freim Gchütteln ausfallen unb bie Sealme eine gelblichmeipe Farbe befommen. Der Winterroggen reift gemöhnlidy (rnbe Juli' und Der Sommerroggen $2-3$ SWocjen fpäter alz ber

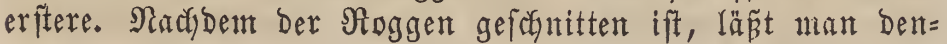
felben entweber auf Dem Zrelde in Schmaben yollig aftrodf= nen, vber man bindet und mandelt ifn, bejonders wenn er feutfit gemorden ift und nidyt zu biel unfraut hat, auf. 3ur fünftigen 2luz̧aat wable man bie reifften, böligften unb bon aflen Samen möglichit gereinigten R̈ornter. Unter

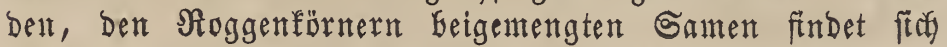
bäufig ber fo fegmer ausaufcheidende Treapenfamen, ba er Eeim Berfen Der Rörner immer aut mit in Den $\mathfrak{B o r b e r}=$ murf fommt.

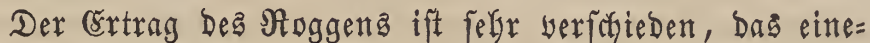
mal ift ber ber Särner felgr goch und Der Des Strobes ge= ring, bas anderemal ift es ungefehrt; bocil rectuet mant Durdefechnittlite tom Miorgen:

$$
\begin{aligned}
& \text { in Württemberg . . 2-7 Gibeffel Rörner unb } \\
& \text { 9-38 Centuer Strof, } \\
& \text { it Baben . . . } 3-8 \text { Mialter R̈̈rner unb } \\
& \text { 10-40 Centuex Stroh, } \\
& \text { in } \mathfrak{x e f f e t t . ~ . ~ . ~ . ~ 3 - 7 ~ M i a l t e r ~ א i ̈ r n e r ~ u n d ~} \\
& 7-30 \text { Eentmer Stroly. }
\end{aligned}
$$

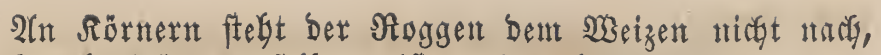
und Strob liefert berjelbe meift noch mebr.

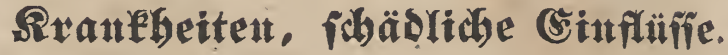

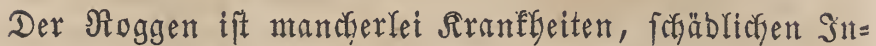
feften, überbaupt einer ziemlich grofen 2 lnzahl fochäbliçer Ěinmirfungen außgefegt. Befonders empfindlich gegen Rälte

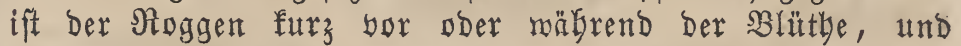

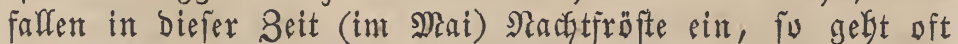

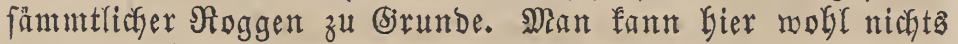
Befferes thun, als ben Roggen gerabezu abzumähen, Da

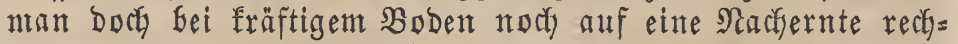

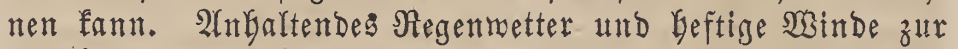

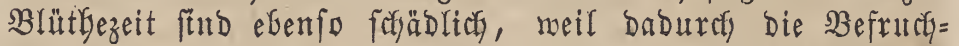

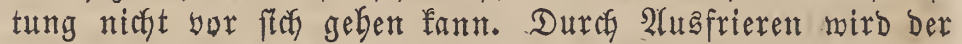

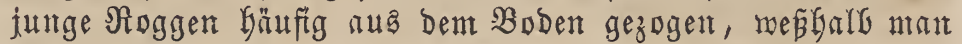

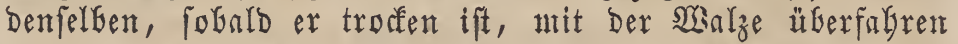

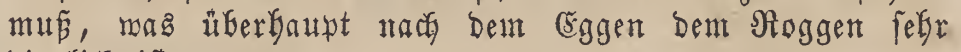
bienlich ift.

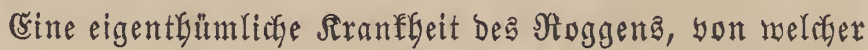
ex befonders in naffen Sabrgängen und tach zu ftarfer Düngung Des Feldes Gefaflen mird, ift Das Mutterforn, Secale cornutum, Balding, seu Sclerotium Clavus, DeC., ein walzenförmiger, bornartig gefrümmter, längşgefurdyter, oft 1 Soll langer und 2-3 3oll birfer, auren fochmarzuioletter

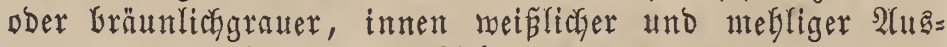
wuthe in bent Spelzen Der 2legrent, bon Denen wir weiter แnten bas Meitere anfübreat mollen.

Die Dem Noggen fuablichen Infeften find Gejonbers bie Engerlinge, bie Werre voer Minulmurfagrifle, Die Şeu=

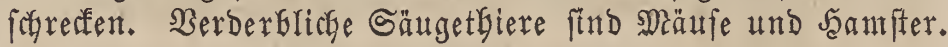

Noch fttro als Dem Roggen febr nachtheilig bie Un= fräuter zut ermäbnen, worunter als bie berbreitetften und

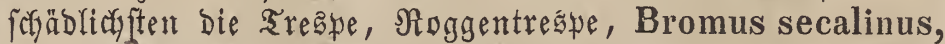
L., bie Quecfe, Triticum repens, L., und bie Diffeln

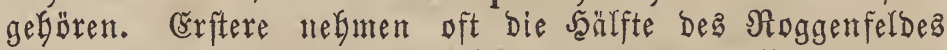
ein, Gefonders in naffen Sakrgängen und naffem Boben; man mirb ibrer felten ganz los, renn man moch fo reinen

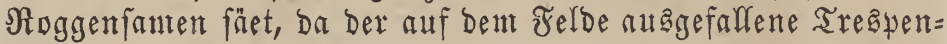
famen ftch lange Seit feimfähig int $\mathfrak{B}$ oben erbält. (sintige Rnmbleute verwerfen bie Treape in ifren Roggenfeldern

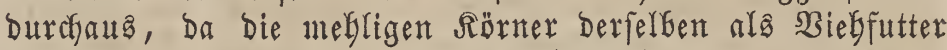
und Dą Strof gleich Dent Roggenftroh benübt merben fant. Dns Trespenmebl ertbeilt übrigens dem Megl einen bittern Bsefdimate.

Eine eigene Errofyeinung zeigt fith beim $\Re$ oggen, in Deffen $\mathfrak{N a ̈ h e ~ D e r ~ B e r b e r i z e n f t r n u c h ~ o b e r ~ S a t e r b o r n , ~ B e r b e r i s ~}$ vulgaris, $\mathbf{L}$, wächs̄t, indent berfelfe, etwa bis auf 20 Scfritte bon Yesterent entfernt, fed mit einer Graunen, biffen und

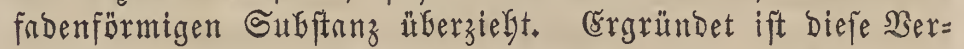

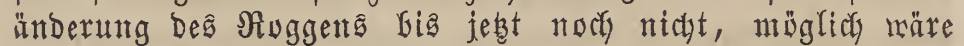

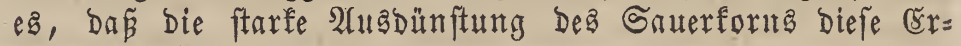
foyeinung berborbräçte.

Das 2(bGüten bes Noggens burch Schafe ift Demfelben nachtbeilig.

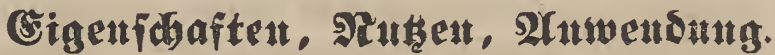

Die Beftandtheile Des Roggennefla find it 100 Theilent 
macy (sinfor:

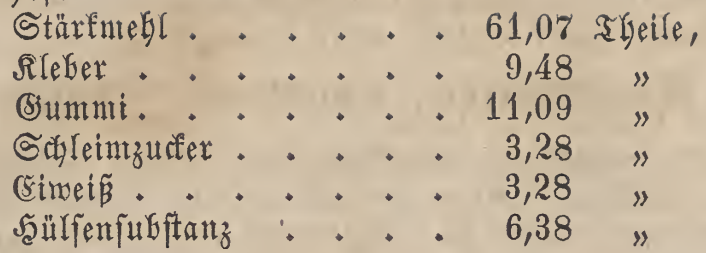

nach Braf:

\begin{tabular}{|c|c|c|c|c|c|c|c|c|}
\hline Stärfuebl & & & • & & & & 58,8 & 3 Igeile \\
\hline Rleber & & & & & & & 12,8 & $"$ \\
\hline Yeim & & • & & * & & * & 7,2 & 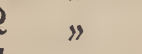 \\
\hline tifer & & . & 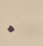 & . & & . & 10,4 & " \\
\hline$i \tilde{B}$. & & . & . & 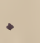 & • & . & 3,0 & " \\
\hline latjt & & . & & . & & • & 7,8 & 3 \\
\hline
\end{tabular}

nach Breif:

Extraftibftuff .... 47 Bran,

fileber...... 47 "

(simeí̈. . . . . . 16 "

2(mblum . . . . . 304 "

Styleiın . . . . . 54 "

Serluft . . . . . $32 "$

Das troffente Roggenftroly entbält in 100 Theilen nach Sprengel:

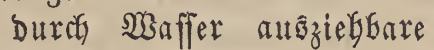

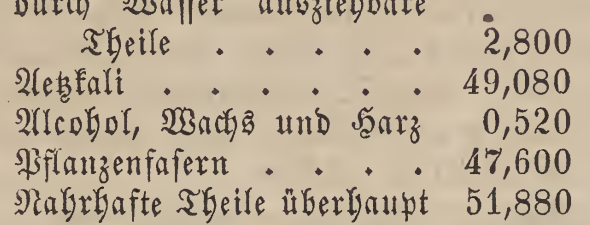

2(13 100 Theilen 2 foche biefes Stroba befrum Sprengel:

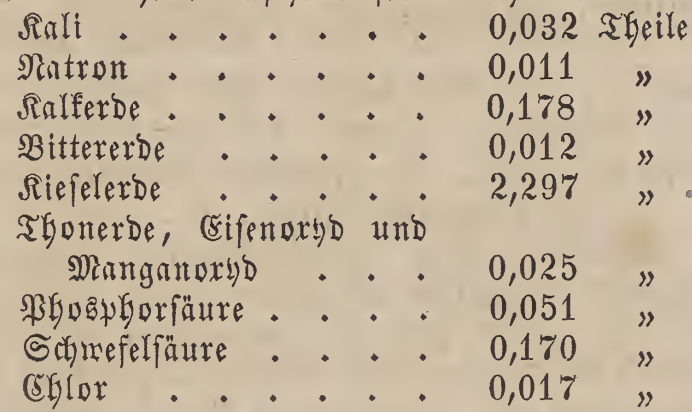

Der sioggen ift gewie eine ber milslidffiten und aff= gemein verbreitetften (5)etreibcarten, er gibt zwar ein weniger

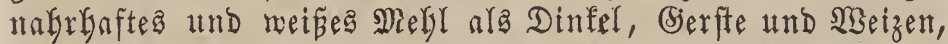
aber nefr Megl und ein Galtbarerez, gefundez, fräftigez und frhmarthaftę Brod, Gefonders went Dinfel=, SBeizen= vber Rartoffelmegl, audy Rleie Darunter genticgt werben.

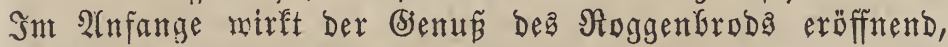
Da $e^{3}$ int Magen Säure erregt. Şäufig Gereitet man aแß Dem Roggen SBrantwein und Den fogenanten Stoggenfaffee, aud wirb Das Rorn als Bieffutter Genübt. Celfug focheibt

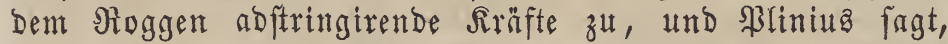
aber mit gropent Unrecht, menn anders nicft eine andere Barietät Dez Roggens, wie Secale nigrum, gemeint war,

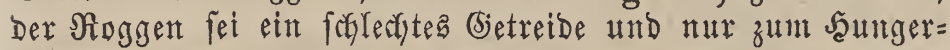
ftiffen nüblich. Der ßoggen gift unter aflen Betreibearten Das ftärffite und längfte Strob, ift ziemlich nafraraft und wirb als Jăăferling, bejonders bas weidjere Sonnterroggen=

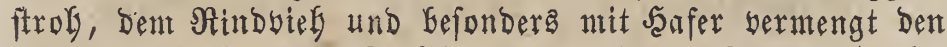
Bferben gefüttert, zur Stalftreu, zum Dachbeifen, zu Garbe=

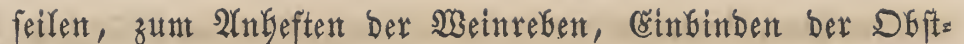
Gäunte, zu Füsteppichen, Strofymatten auf Miftbeete, Strobz: Güten, Brobmulden, Taubenneftern 2 . Genübt und gibt einen fehr fräftigen Dung. Die Noggenfleie mird bäufig yout

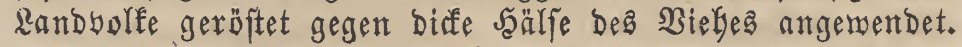
Das Mutterforn, ofwobl es in geringer Menge bent Megle beigemifact nicht fadablich ift, erregt boch in gröperer Mrenge genoffen bie fogenannte Sriebelfrantheit, Raphanie, Betäubung, Mattigfeit, periobiface Conbulftonen, oft epilep=

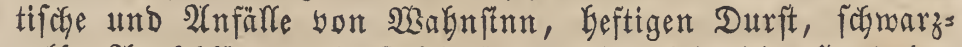

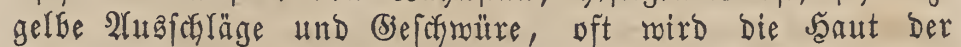
Sefen und Finger troifen, Gart und fojmarz. Diefe Rrant= beit Gat einen $\mathfrak{B e r l a u f}$ yon 10 Tagen bia zu 2-4 Miona= teit und endigt nicht felten mit Dem Tobe. Siegenmittel find

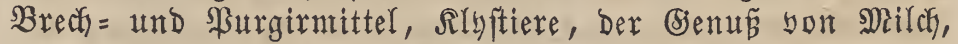
bei beftigerent Srabe Der Sranffeit, wenn Conbulftonen vor= banden futnd, innerlidy noch Reizmittel, wie Eampler, 2lms moniaf, âtetber und äunerlicy auf bie Saaut angebrachte

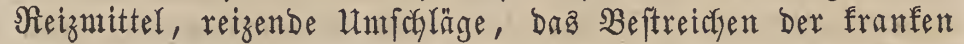
Saat mit Terpentinöl 26 . - Das Miuterforn mirft ferner ftimulirend, trägt zul Contraftionen Der Bebärmutter und fomit zur Befaleunigung Der befurt bei und wirb bäufig gegen paffțe Bebärmutterblutflüffe angemendet.

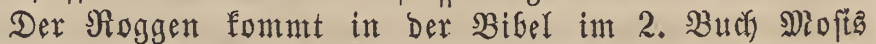
9, 32. vor und foll zur Seit 2Uttila's int 13. Sabrfundert burct) bie Miongolen in Dentfaland Gefannt genorden fein.

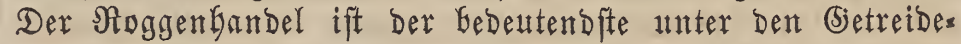
arten. 2(miterbau, unb ramentlich Dann Bremen, J̧am= burg, Rübece, Stettin, Danzig, હ̌lfing, Sönigaberg, Dientel,

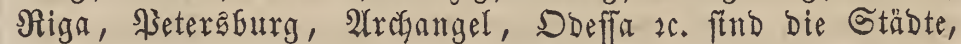
in weleyen biefer Saandel aut ftärffenten getrieben wird. Man unterfacteibet bafelbit gerwögnlid 5 Sorten, nämlidy ben

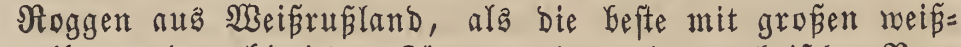
gelben und meblreiden Rörnern, Dann Den polnifchen $\Re$ ogs gen, mit ebenfalfs grofen, reinen, trofenen, aber nidyt fo fchönen $\Re$ örnern, als Dritte Sorte einen grobförnigen, nirht

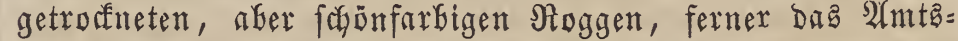
und Bauergut, Der befonders nach Schweben und Norwegen aubgefüfrt wird, und endlich bie fünfte und fohlechtefte Sorte, bie Gauptfädylich mur in Der Branntmeinbrenteret Genüht wirb.

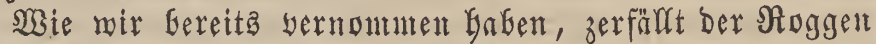
in Sonmer = unb Sinterroggen, Secale cereale aestivum seu vernum et hibernum seu autumnale, welche ftidy aber in botanifcher Seinftedt nicht wefentlich yon einan= Der untericheiden.

Der Sommerroggen mirb im Frübjabr gejäet, Gejtodet

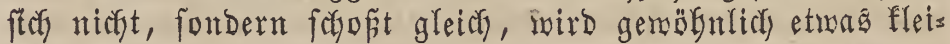
ner, feinfülffger, gibt mefligere, gemöbnlich roniger uno fleinere Rärner, aber gleidguiel Stroh, Glïbt und zeitigt fpäter unb gebeigt reniger fither als ber Şinterroggen,

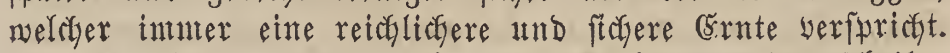

Der Winterroggen entbält nach (singof: in 100 Theilen

$$
\begin{aligned}
& \text { Stärfintel } \ldots . \cdots 0,548
\end{aligned}
$$

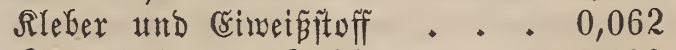

$$
\begin{aligned}
& \text { Süpe forleinige Subftanz • • 0,090 }
\end{aligned}
$$

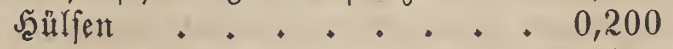

$$
\begin{aligned}
& \text { Feuchtigfeit . . . . . 0,100. }
\end{aligned}
$$

Die Durch flimatiface Serbăltuiffe, weränderten Boben 


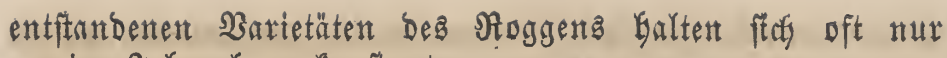
wenige Jagre lang fonftant.

\section{Staubentoggen.}

Secale cereale multicaule.

Staudenfort.

\section{Sommextfaudentoggen.}

Ěr berlangt einen mely feucften, bindigen und frifti= gen $\mathfrak{B}$ Doden; er Geftaudet in fräftigem Boben ftärfer ala ber gemöhnliche Sommerroggen und gibt mebr হänner und mehr längeres, ftärferes Stroh. (ङ̌r reift etmas fpät, lagert fitch felten, wirb aber in magerem soben wieder gemöhn= licter Roggent.

\section{Winterftaudentoggen.}

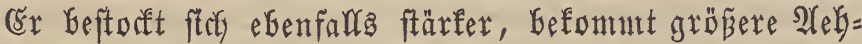

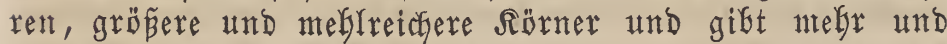
ein längeres und ftärferes Stroly als ber genteine Swinter= roggen, Dois artet er wie ber Somnterftaubenroggen in magerent $\mathfrak{B}_{\text {Ddent }}$ Dber went er zul Yang in bent gleictyen $\mathfrak{B}=$ Den gebaut rurbe, audi bei piner fpäten Saat aus. SMan fäet biefe Barietät fidon 2 nfangs Septembers, in fältern

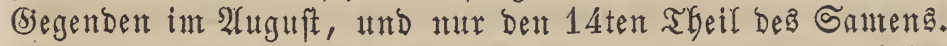
(rr gelangt fpäter zur Reife ala Der Winterroggen, Yeibet wber noch meniger burch Ralte, Yagert fted nicht leicht atno fant ofne Sdyaden im Seerffte zu J̆utter abgemäht ober ab= gefütet werden. - Man fann Den Staubenroggen autry

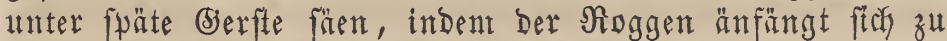
Geftauden, went bie Gierfte geerntet wirb.

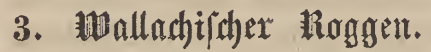

Secale cereale wallachicum.

Waffrecifides Staudenforn, Staudeforn, Modeforn.

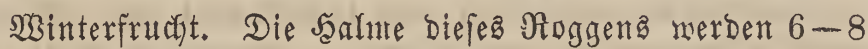

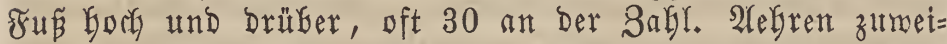
len 6-8 3ull lang, fchmer. Sörner groß̈, Dünnfülftg, Gräunliç, mit bielent reisem Meegl.

(Er wifl befonders einen fegr nagrbaften Boden und eine güntige Witterıng zu feinem volffommenen Bebeifen. Man macht bie 2 Hâaat frübe und zwar noch bünter als beint gemögnlicten Staubenroggen, weil or fids fogon int berbfte ftarf Geftort, Gefonders aber im Jrübjabr. 2atet unter ben fodon angegebenen Uumtänden ebenfalfs leicht aus.

Der Črtrag bes waflachifden Noggens ift oft 42fältig.

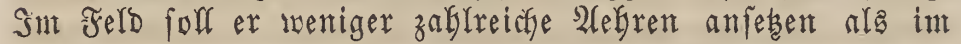
(biarten, wo man fofjon $30-50$ an Činer słflanze gefun= ben bat.

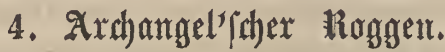

Secale cereale archangelieum.

2urfangelifactes Staubeforn.

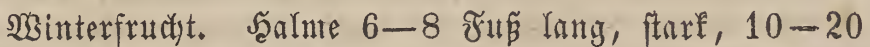
an Der 3nbl, Rörner aber flein.

Der Errtrag zumeilen 25fältig, eine 2(ebre Gite und ba 60-70 Samten. Diejer Roggen foreint fo ziemlich gleich mit bent walfarfifichen zu fein.

\section{Hotwegi/hes Staudekorn.}

2(ebren länger als bei ber vorigen Spielart unb bie Samen braumer, falfen nifft aus ben Spelzen.

Der Ěrtrag ift $32 f a ̈ l t i g$, auf einem Stode find oft 20 2lebren und 1000 Rörner. Das Stroh foll zur Fütterung zu bart jein.

\section{STebetorn.}

\section{6. faleberoggen.}

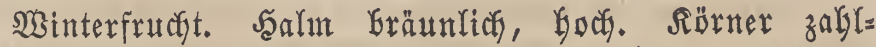
und meftreich. Stroh lang, beftaudet fich ftart.

Mant fäet ifn nicht zur Frübzeit und ant bünnften mady (sinigen in fräftigen, nact) 2(ndern aber in minder fräftigen Boben. SBälgrend ber Blüthe ifł ifm ungüuftige sisterung bejonders nachtyeilig, jebody foll er gleidzeitis reifen und nirgt fo gerne anzartent als bie übrigen Stauben= ruggenarten.

Jofannizkorn.

\section{Iobannimxoggen.}

Winterfrucht. Man fäet ifn fơdgn Mitte Juni’s um

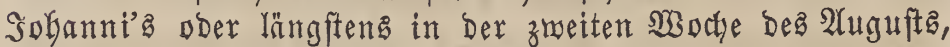

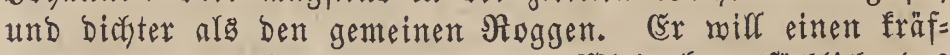
tigen und gutgebüngten Boben. Wird bauptfäctlich DeB Jutters megen angebaut; man fann ifu noch cinnal fobn im Spätberbite fochneiden und ein paarnal im fünftigen Erübjakr. Der Jofanniaraggen gibt ein fefr gutes und

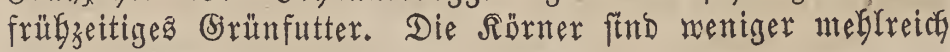

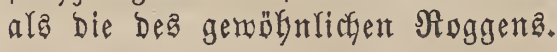

\section{Rỏhmi/dhex Staudenroggen.}

Sommerfunt. Soll nidgt Gefombers bortheilfaft fein.

\section{Aegyptildhex \#oggen.}

Secale cereale aegyptiacum.

Sommerroggen aนล 2 Yeghpten, Serufalemąfuru, tumeft=

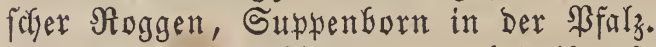

(ङ̌ foll in 2(egypten eingeimifor) fein, bäufig in ber Pfalz und in Salleften fultibint werben und fted felgr ftarf beftauben. (Ex gebeigt beffer in einem melgr feuchten, bin= bigen und felgr fräftigen $B$ oden; man fäet ifn ziemlich bủnn, früber ober fwäter, und er fommt audf noch in raubern Sisegenden fort, folf unter ben Sommergetreidearten Den Göct)=

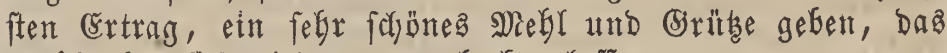
Mebl aber fitch ntcht gut berbarfent laffen.

\section{Dielälyrigex $\Re$ oggen.}

Secale cereale compositum. De C.

Secale cereale spica ramosa. Seringe.

Secale spicis ramosis. Tenzel.

Sit Glos eine Spielart Des genteinen Roggens, welcher nut in befonders fruchtbaren Jabrgängen äftige 2lefren be: fonme, fie fpäter aber wieber verliert.

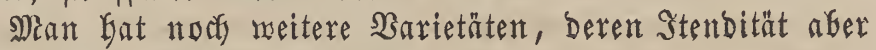
noch ziemlich in Sweifel geftellt ift:

\section{Anextiknilider Staudentoggen.}

2(nterifanifater Staubenroggen.
12. Sibirifhex lioggen.
13. Cauripher Rogger. 


\section{Hordeum, L. Spr.}

Zeocriton. Beauv.

Si)fteme: Achrophyla. Neck.

Gramina. L.

Gramina Hordeacea. Kunth.

Gramina Tritica. Adans.

Gramineae. Juss.

Triandria, Digynia. L.

Aefrifen itt einer 2lefre zul 3 geftellt, baz nittlere znitterig, bie zux Seite männlich ober gejalechtąos, bei Den fultibirten 2irten find bie lebteren aud zroitterig. Reld 2flappig, 16lütbig, mit einem borftenförmigen 2lnfage zu einent zreiten obern Blütboffen. Slappen fonttal=lanzett= förmig ober bfriemenförmig, neben eimanber bor bas slüth= chen geftellt. Srone 2fpelzig, untere Spelze lauft in eine Sranne aus, obere 2fielig und auf Dent Rielen birft und zart gewimpert. Narben gefiedert, feitwätb Gerbortretend. Gamen bon ber erbärteten אrome umgeben.

\section{Hordeum vulgare. L.}

Hordeum hexastichon. Forsk. Hordeum plumosum. Gilib.

$\beta$. Hordeum coeleste. Vibory.

$\gamma$. Hordeum nigrum. Willd. Hordeum sanguineum. Hortor. Hordeum sativum. Pers.

Hordeum polystichum. Hall. Hordeum multicaule. Hort.

Berfte, gemeine Berfte, Rerngerfte, gemeine 4zeilige Bierfte, Früblingągerfte.

Orge. (franz.)

Barley. (engr.)

0rzo. (ital.)

\section{2uten = (5)arafter.}

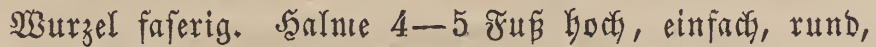
Gold, mit $4-5$ glatten Sinoten. Blattfocheiden geftreift, glatt, bie obere ift etwaz erweitert. Blätter lang zugefpitat, oben und unten und am Rande find fe rürfrärts raug an= zufüblen. 2lebren unregelmäß̈ig 6zeilig oder faft 4erfig, in=

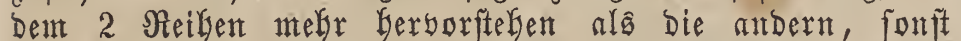
langgeftrefft und fodlaff, gelblich. Telegrefen $12-15$ in einer

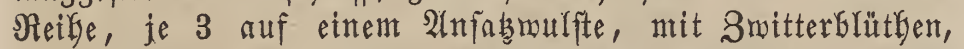
1 Branne und 1 Santen, meip̈gelglich. Reldyfpelze an ben Santen angebrürft und bie Rronfpelzen feft mit bemfelfen verbunden, bie äufere ift lanzettförmig, fielförmig gewölbt, glatt, 5nersig, bie innere ift abgeftust, auf Dem Rüfent flach, 2nerbig. Brannen abfekend, rauf, gelblich. Spindel weiślicd. Samen länglidy, Gauctsig aufgetrieben, glatt und nteflreidy.

\section{Blütbe = Beit and Datter.}

Sontmer. $\odot . \sigma^{7}$.

\section{มูor'ommett.}

Sack Mofes yon Chorene, einem armenif cyent Saiftorifer

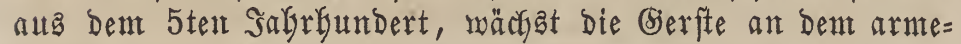
nifacen Fluffe Sur wild, und jegt nody findet man fie Dort wilb, wie audi in Beorgien, im nördlicfen Indien und Sicilien, unb nady Berofos bejonders in Babylonien zwi= foren bem suphrat und atgris; fie fodeint übrigens in megr fübliden Rändern einbeimifad getwefen zu fein, da fie als

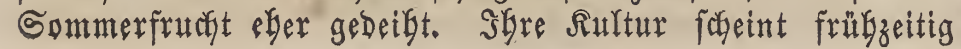

befannt gervejen zu feitr, inamentlidy in Deutichland, wo fte jest übernll berbreitet ift; Befonders bäufig ifit ber $2(n$ bau Der Serfte auts in England, Scfittland und Jrtand. Man baut fite in Norwegen, wo fte nod unter $67020^{\prime}$ nöros licher Breite ganz gut gebeifgt, an, ferner in Schmeden, ferbft noch auf ben Fraber = Snfeln und an Den Süften yon $\mathfrak{L} a b r a=$ bor $57^{0} 8^{\prime}$ nörblicyer Breite, mo fte aber nut ärmlicy ges beigt und Dures Dfenbihe yolfends reifen nutu.

\section{Multut.}

Ěin fanbiger (50-60 \$rocent Sand) und yorberrfatend

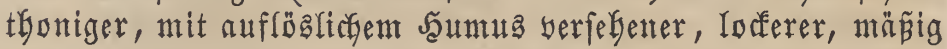
felldyter, nahrbaftex, yom ltnfraut gänzlidy gereinigter $\mathfrak{B} \mathfrak{D}=$ Den, ein jogenannter bierftentoden, foglägt Der Sierfte ant meiften zu; in zat binbigem vder thonigem Boden geräth fie niegt, Da Der Reim ber Serfite bie errbe fonft nicht Durch= brecten fann; ebenfomenig aber eignet fatf, altgenonmen fältere und feuchte begenden, ein zu locferer $\mathfrak{B}$ oben, meil biejer zu foynell austroffnet, DDer Saeide =, Torf = und Moor=

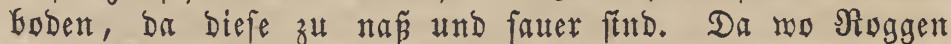
gut gebeigt, geräth auch meift bie Berfte. Crin ntit Den obigen guten Eigenfochaften begabter Boben foll yor ber

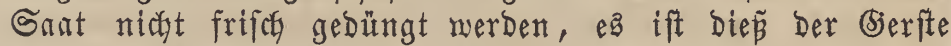
ibres rafchen Wachathumb megen febr nachtheilig, fte mächat

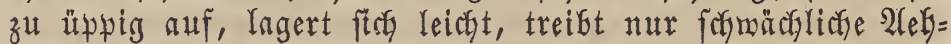
ren; ein leichter und lofferer trocfnet Durch zu frifoches Düngen

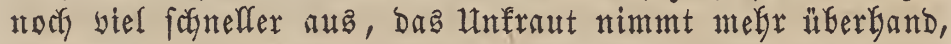
Der Errtrag an Rärnern fälrt geringer aus und bie Jierfte feint beim Mialzen nur Ianglant. Ěin Boben Gingegen, Der wenig Rräfte beftst, zu thongaltig, feudst und falt ift, ein folcher berträgt nicht mur ofne Nachtheil eine frifde Dün= gung, fondern fite ift fogar noch zuträglich. Sft ber Boben uticyt fräftig gentug, man aber boch Sierfte bauen mill, fo Düngt man Dert $\mathfrak{W}$ inter yor ber Saat und Hflügt Den Mift

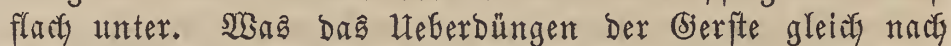
Der Saat anbelangt, fo ift biés Gauptfächlich bei melgr lorfez rem $\mathfrak{B}$ oben und feuchtent Rlinta zu empfeglen. Şiezu taugt wohl am beften bie Saudfe, nadi ifr, wenn Der Boben nidft zu trorfen ift, Ralf, Mergel, âfaje, S5yps; mit Bortheil fäet man in einigen segenden, wie in ber $\mathfrak{B F a l}_{z}$, Serfte in Boben, welchen man zum Bebufe ber Düngung mit $\mathfrak{B i r f e n}$ angepffanzt und biefe yor bent $\mathfrak{B i n t e r}$ untergepflügt hat, jeDocf jofeint bieje Düngermethode nur für fräftige und farfe Galtige Boben entufeflengmerth zut fein.

Die Berfte fann man, ift Der Boben nahrbaft genug und bom llnfraute gefäubert, faft auf affe orrüchte folgen

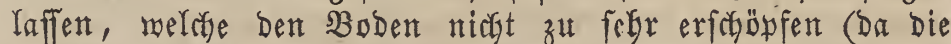

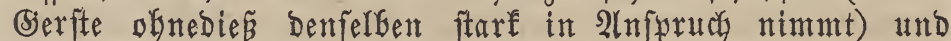
melifye ign in einent loffern and reinen Zuftande zurủd = laffen. - Man fann Berfte auf Berfte folgen laffen, aber nutr bet felgr fräftigent Boben und menn bie Sierfte in Dung gefäet wird, unt man thut bier ant beften, zuerft bie grope 2zeilige und nach ify bie fleine 4zeilige Bserfte zu bauen, Da Yestere einen weniger fräftigen Boben Gedarf; bie Sierite

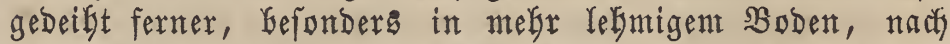
gebüngtem Bracteroggen und Spelz, meniger nach $B r a d y=$ meizen, Gefonbers gut aber, wenn ber Boben nicht zu bindig und yom Unfraut ganz rein ift, zumal ntit Rlee ober Rinfen gemengt, naç Sartoffeln, Runfelrüben, Iraut zc. - Der 
2(nbau yon Stoppelruben als Swifchenfrudyt ift Der Bserfte

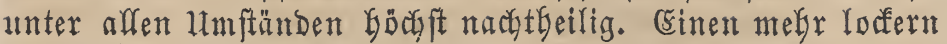
und nidyt zut feuthten Boben, nach Saaffühten, Rartoffelt,

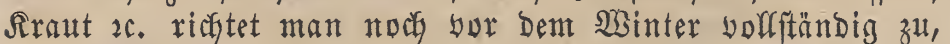
einen megr binbigen und feuchten bingegen mur man meift in Frübjabr yor Der Saat noch einmal auflodfern, indem man igm 1-2 Furchen gibt; Diefes unterläpt 'man übri=

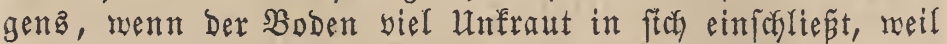
foldes Durch ein im Frïbjabr erneuertes Itnarbeiten Des Bobenz unt fo ftärfer ftés entwiffelt. Sit Der Boben zu Gindig, thonig ober nás, fo Gilft Das Serarbeiten beffelben

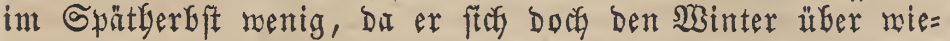
Der zufanmenbafl und feft wirb. Folgt bie Sierite auf Bintergetreibe, fo mun ber Boben aud forgfältiger benr= beitet und bie Stoppeln nach Der Ernte Gald ungebrocten

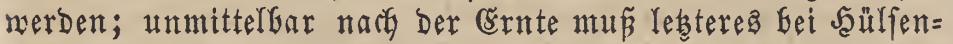
früchtenftoppeln gefdefsen. Sn einem gefoürig aufgelocferten und fräftigen Boben reichen oft 2 flache zrurchen Gin, ge= wöfnlidy afer fäet man bie berfte in $3-4$, aber nie zu tiefé Furchen, Da bie Bjerfte ifre Pabrung bauptfäblid aus ber obern Bobenfachidste erbält, - bie man, wie eben an= gegefen nurbe, ie nach ber Befarffenteit Deß Bobens, ent= meder yor Dem 23 inter pder erft im Jrübjagr mit Dem Pfluge voer ber Saafe madyt. SWo Der Boben feine Winter= feuchtigfeit Gald berliert, pflügt man bie berite audf flach unter und eggt barauf.

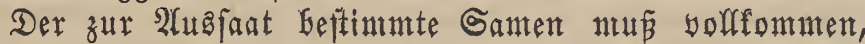

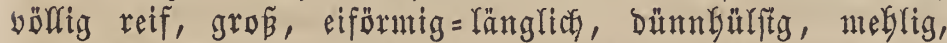
yon beller Farbe und neu fein, damit er gleichförntig auf= gebe, bie Gaat feine reeren Stellen zwiichen fith befomme,

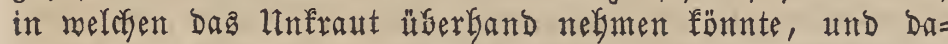
mit bie Rörner bei ber Ernte bollétumen und meblreich

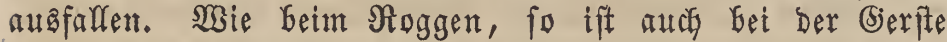

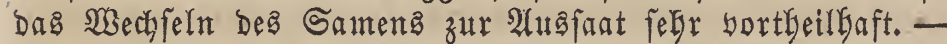

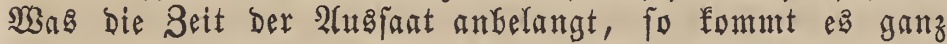
Darauf an, of man Frűh = ober Suätgerfte alszafüen bat, D. G. eine Berfte, melche an eine früfere oder fpätere Sant gemöhnt ift; erjtere barf megen zu ftarfer Sonnenwärme nicht zu fpăt, restere ber Fröfte megen nicht zu bald aub= gefäet werben. Die Frülgerfte gibt meift ein fob̈neres Rorn und einen böGeren Errtrag als Die Spätgerfte. Weiter ftnd

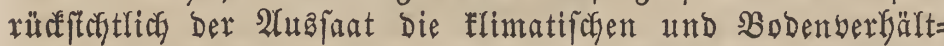
niffe, wie aud bie Seit in Betracht zu zieflen, in meldher Der Boben werarbeitet morben ift. Bei locferem, yon $\mathfrak{H} n=$ frat reinem und troffenem Boben und troffener Sitterung wirb bie Berftenjat früker angeftellt als bei mefr bindigem, berunfrautetem und feuchtem Boben. Săet man Silee unter

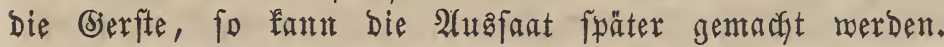
Restere foll man wo möglidy an einem troffenen Tage yor= nefmen, Da Durch Nebel und Regen ber Boden beim Ěggen fchmerig ift. In ebenen, rärmern begenden, bet locferem, troffenent Soben fäet man bie Sserfte Ënde Februars ober ian März, in böber gelegenen, rauberen und fältern, an Seefüften, großßen శlupgebieten, bei mefr bindigem und feudstent Boben erfit im 2lpril ober Miai. Die Saat felfift foll im 2iffgemeinen weber zu bünn noch zu bicht gemacht werben. Man bat fich Gier Gefonder nach Der Befdaffenbeit Des SBobeng, Samens und Der Berftenart zu richten. In

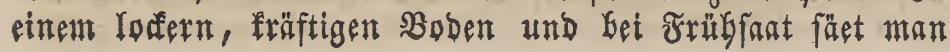

ftets bümer, als in einem magern ober rauben Boben und bei Spätjant; ebeño bebarf man natürlich wentger zur

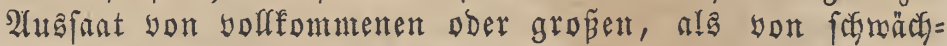
licten ober fleinen Samen.

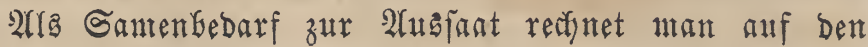
Mergen

$$
\begin{aligned}
& \text { in Baben . . . 5-71/2 Sefter, } \\
& \text { in } \mathfrak{t e f f e n ~ . ~ . ~ . ~ . ~} 1 \frac{1 / 2}{2}-2 \frac{1}{2} \text { Simmet und } \\
& \text { in } 2 \text { ürttemberg . . 3-4 Sintri. }
\end{aligned}
$$

Sft ber Boben locter, leidft, ober auch bindig, nur aber gut verarbeitet, troffen und berunfrautet, bder bie Saat fpät angeftefft worden, fo unterpflügt man bie Samen 3-4 3oll tief, je nadyent ber Boben melyr ober meniger

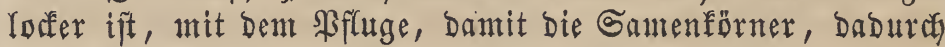
bá fie tiefer in ben Boben fommen, fich feuchter balten und bälder und gleichförmiger feimen fönnen; Gierauf folgt Das (sineggen, bei feudyter $\mathfrak{B}$ itterung und bindigem $B$ oben fpäter, Gei letuderent Boben und troffener MBitterung gleich nach Dent Unterpflügen des Samens, ober nuch beffer, nan walzt in lesterem Falfe zuerft ben Boben und eggt erfit

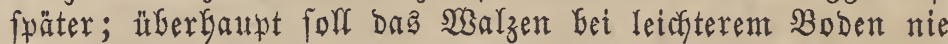
übergangen merben. Bei fơnerem Boben, nach Sareffrüd = ten, wenn er fadon frübzeitig und gebörig zur berftenfaat vorbereitet morben ift und er blos noch gebörig aluzutrodf= nen bat, empfteglt unan mefy das ffache Hnterbringen bes Samins mit Dem Exptirpator, ebenfo bei einem foymeren und feuchten Boben Das 3-4malige čneggen der Berfte, Der Rănge, Dutere und Sçräge Des 2lifers nach mit einer

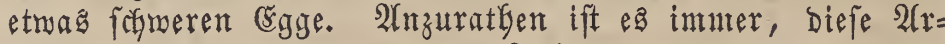
beit bei einem mäßig feuchten 3uftande Des Bobeng yorzu= nelgmen, ba fech bie Samen bet böllig troffenem Boben nicht leidgt eineggen laffen; follte aber gerabe das (segentheil ftattfinden und Derjelbe zu feudyt fein, fo mus man ify zubor bis zu einem gendiffen Srade abtrocfnen laffen. Nods erwäkne icf des fegr yortbeifgaften Berfafrens, bei trocener Witterung Die Berfte 2 (Gends wäbrend eines Thaues (nidyt aber Nebela) zu fäen und Den anbern Tag in Der frübe

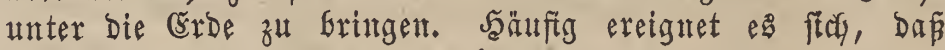
ein zu Ginbiger $\mathfrak{B}$ oben nach heftigem ober lange andauern= bem $\Re e g e n$ und nady Darauf folgender Somnentike eine Garte Rrufte befommt, Die Der feimenden Berfte Das Durchbringen oft unmöglich macht; in biefen Faffe Durchs eggt ntan entweder Den Boben miedergolt, ober Geffer, man überfäbrt ifn mit einer Stachelmalze. Selgr nötgig ift eq auch, Gejonders in naffen Jahrgängen, in ber Năh ber

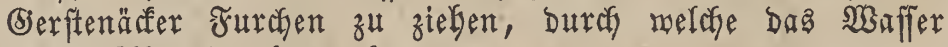
feinen 2 GGlauf nefmen fann.

Die Berfte fann man unter günftigen Utmitändoen fódon in $\mathfrak{J u l t}$ ernten; Da fte felten gleichförmig reift, fo fodneibet man fle, fobald bie meiften 2 elgren reif fend, mit ber Sickel,

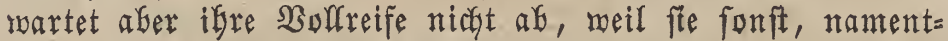
licf bei zut trodfener $\mathfrak{B}$ itterung, leicft abfalfen, fondern mant fochneidet fie, wenn fie und baz Stroly eine weipliche Farbe befomnen und bie 2 efren. noch meich, aber nicht megr mildyig ftnd. Bei fegr trofener Witterung fofneibet mant Die Gerfte megen Der Spröbigfeit Der Alefren Dez Mlorgens mâtrend eines Thaue ab und läpt fte zum Nachreifen einige Tage lang in Schmaden liegen. Borübersetyender Negen

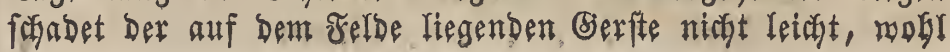


aber, wenn er angaltend wirb, ba bie Rörner gerne aubs=

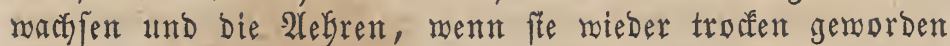

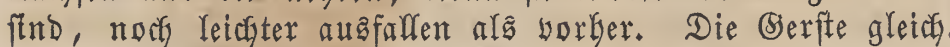
nach Dent Schnitt Dber üferbaupt feucht in bie Scheune zut bringen, ift gänzlith zu berwerfen, weil bie noch meichen Sïrner Des in Der Gelfreife eingebrachten Gietreides fich germe erbiten, baburch leicht verberben, bas Strof buntpig

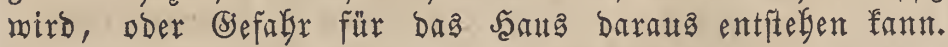
Die Scheunen, in meldyen menn auch bollig trocfene berfte aufbemagrt merden foll, müffen ber \&uft geförig zugänglicf genadut werben, ba, wie gejagt, bie Berftenförner und bas Stroh ftarf audountenten.

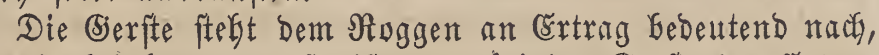
und wie bet lesterent, fo ift audy bei ber Gerfte ber Ërrtrag fowohl an Rörnern als an Stroh fehr berfobieden, bei war=

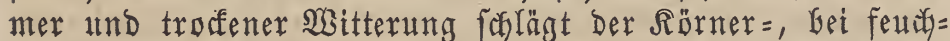
ter ber Strokertrag yor. Der Geritenantau mi gaglüaft noch Gäufiger als Der Des Noggens, gibt Den boben Ertrag nicht

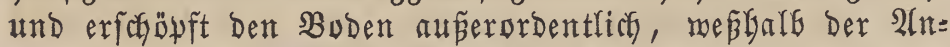
bau Der Serfte im Sroben nur folchen anzurathen ift, bie uberflüfitgen Dung Gefthen und ifgre berfte in Nienge und zu guten \$reifen an Bierbrauereien berịgliesent fönnen.

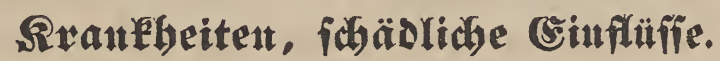

Die Berfte ift bauptfätich Dem Flug = ober Stauts=

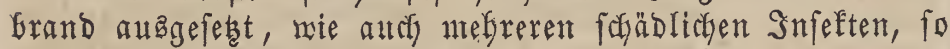
ber Saateule, Agrotis segetum, Herr. Sch., und Der Irautfonnarfe, Tipula oleracea, welche Den Sălm an= freffer.

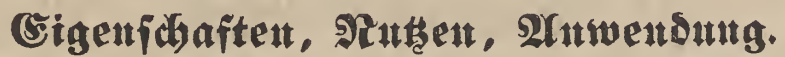
Senneif:

Die Gerftenförner entbalten in 100 Theilen naris

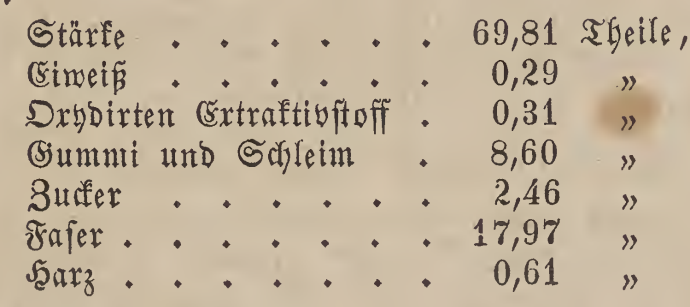

Das Mefl nach (Einlyof:

\begin{tabular}{|c|c|c|c|c|c|}
\hline Stärfe & . . & . & - & & 67,18 \\
\hline Sileber & . . & . . & . & . & 3,52 \\
\hline Schleim & . & . & . & . & 4,62 \\
\hline (Eimei & . & . & . & . & 1,15 \\
\hline Suffer & . . & . . & . & 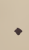 & 5,21 \\
\hline 10 (2) & srjaure & er Salf & f. & - & 0,24 \\
\hline afer. & . . & . . & . & 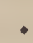 & 7,19 \\
\hline
\end{tabular}

Die 2 fidfe ton 2 Pfund main Safrader: Riefelerde ....66,7 Bran, Rohlenfaure Ralferde . . 24,8 " Rohlenfaure Bittererde : 25,3 " Thonerbe . . . 4 4,2 " rifenoxibs . . . 3,8 " Manganoxyd . . . 6,7"

Das Stroh nach Sprengel in 100 Theilen: Durd Waffer ausziebbare Theife $, \cdot .+11,330$
$\mathfrak{A}$ eţfaltit . . . . . 38,237

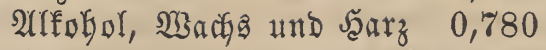

Brfanzenfajern . . . 49,653

Nährende Theile überbaupt 49,567

100 Theile 2 fidge bes trodenen Strolyes nady Sprengel:

Rali...... 0,180 Theile,

Natron . . . . 0,048 ”

Inlferde . . . . 0,554 "

Bittererde . . . 0,076 "

Riefelerde . . . 3,856 "

Thonerbe . . . 0,146"

Eifenoxbd . . . 0,014"

Manganoxbd . . . 0,020"

\$yogłhorfätre . . 0 0,160"

Schroefelfüre . . . 0,118 \#

EfGlor . . . . 0,072"

Das Berftennegl mird felten affein zH Bierftenbrod,

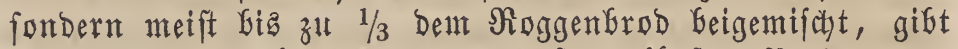

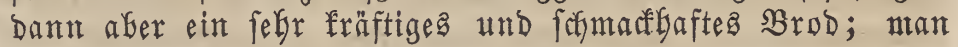
Gebient ftef bes weipern und feinern Mielies yom 1 ten und 2 ten

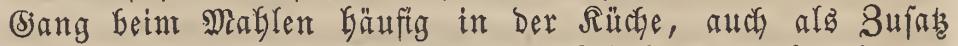
za Semmeln, Das figmärzere zurürtbleibende Mebl aber zu gröbern Speijen, zu אilüpen, Brei 2c. Man berfertigt ferner

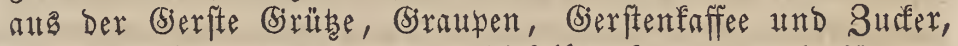
am Gäufiglten vermendet man biefelbe aber zu Malz für bas Bierbrauen, wie auth zur Esfftgfabrifation, feltner zun Branntweinbrennen. Die sereftenförner füttert man gequeft

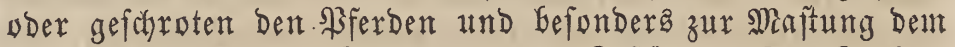
Rindsieg, Sefjafen, Schweinten und bieflügel. Die Spelzent

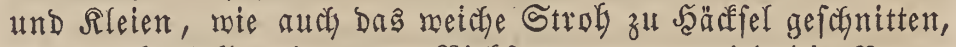
bienen efenfalfs als gutes Bieffutter, mur mirb Die $\mathfrak{B}$ utter yon Rüben, welche viel ntit Serftenftroh gefüttert merben, etwaz bitter won (biefdymaf. Das Strub eignet ftad bejon= Dera in Strohjärfe und zut Beffechten auf Seffel. AlGgefochte

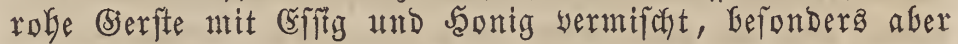
Die Bjerften = und Serlgraupe in şaffer aufgelöst ober mit Roftnen, Feigen 26 , abgefocyt, ftnd ein fegr gutes und an= genefmes Getränfe für Fieberfante, ebenfo gebraud man Malztränfe bei Brufteranfleiten.

\section{Gefididite.}

Die Berfte fam zuerft aub Stalien nach Deutfaland; 2Aeghptier und Jeberäer Gauten biefelbe fohon affgemein und

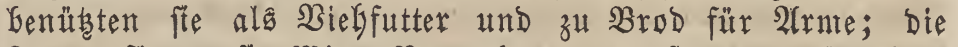
Iuben fäeten fite Mitte Nobembers und founitten fie (sinde

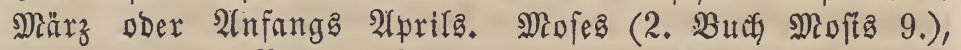

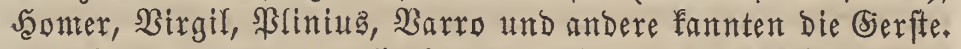

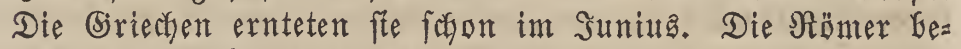
reiteten aus ifr, indem fte fte in Saffer einmeidyten, röftes ten und zerrieben, ifre Solenda und aus biejer mit Mild, Waffer, Sonnig ober SBein ein Brod, Maza genannt, ebenfo bie şlifana, abgefochte Berfte, auch liepen fie ifre Soldaten zur Strafe Gerftenbrod effen. Scyon in Germanien, San= nonien, Gallien und Saifpanien, war bie Bereitung Dez Bieres aub Gerfte Gefannt. Mian gebrauchte bie Dberkefen ftatt des Sauterteigs łum Brobbarfen, und das meibliche

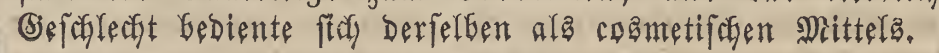




\section{Gemeine Soummergerfte.}

Hordeum vulgare, spica flavescente.

Hordeum polystichum vernum. Morison.

Sommergerfite, 4zeilige Sommergerfte, Sandgerfte, Spätgerfte, Beilengerfte, gemeine Berfte, vielzeilige Bserfte, gelfliche genteine Bserfite, fleine Serite, fleine 4zeifige (5)erfte.

Orge commune, épi jaunâtre. Orge commune d'été.

Common four - rowed yellowish barley. Spring barley.

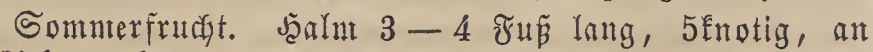
Der 2lefgre fegr butun und gebogen. Blatticheiden gelflich= grün und Gühlen bie Snternobien beinake ganz ein; Iragen meisliç. Blätter 9 3oll lang, unten 1 3oll breit, Iantg= zugefpibt, Gäufig über die Aefre binausreichend, gelggrün. Aebren 4 Bolf lang, ungleicy 6zeilig, gemöhnlich niffend,

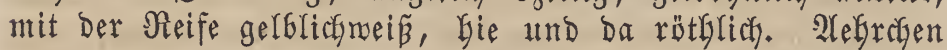

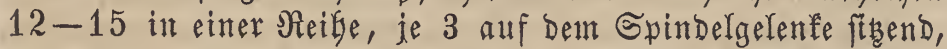
gegrantt. Branmen 9 Boll lang, forarf, glänzend, anlie= gend, bei der nirfenden Aebre oben etwas abjekend, erit grün, Dann weipgelblicy. Seldhfpelzen yfriemenförmig, mit eimer 1 Boll langen, freien Spibe werfeben. Aenpere Sron= fpelzen gegrannt, erft gelblichgrüu, Dann meißslich ober röth= lich und wie bie innern Srompelzen Den Gamen feft ein= fos)ließend. Spindel furzgegliebert, glatt, mit ftarfen Gelenfen, gerblichmeip. Samen oben und unten zugefpibt, etwas run= zelig, unter ber Rronfpelze grauliç, mit convexem Rücfen und einem Mieglpunfte.

In 2infange werlangt bie Sonmergerfte eine mebr füble und etwas feuchte Witterung, bamit fie gleidfförniger auf= gebe und meniger vergeile, zur $B$ lüthezeit der Yeidytern $\mathfrak{B} e=$ frudgtung wegen eine utelgr trodfene und gegen bie Reife hin eine abwedffelnd feudte und marme Nitterung. (sin leich= ter, etras fandiger (bis 75 \$rocent Sand, wenn bie Jabr= gänge nicft trodfen find), warmer und milder $\mathfrak{B}$ bden foblägt ilgr ferner am beften zat.

Man fäet bie Sommergerfte, fobald feine Rachtfröpte

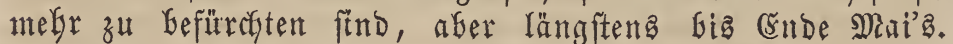
Der Sante foll mur flach untergebracht merben, was ant Geften mit Dem Extirpator gefdyiegt. Wenn bie (jerfte $1 \frac{1}{2}$ Gis 2 3oll horly geworben ift (fpäter nicft mefr), fo eigt man bei binbigem $\mathfrak{B}$ oben ant Geften nach eitrem SRegen und

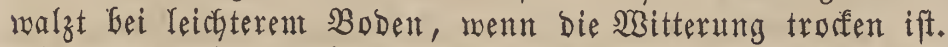
Die Errnte ift gemöGnlidy Mitte slugufta. So leidgt und

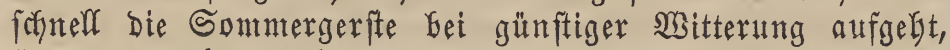
fiv. Iange mährt es bet trofenter Witterung, und fommt fie auch in's Reimen, fo gefoleht bié, Doch ungleidy, indem bie tiefer nekgr in feuchter (Erde liegenden Gamen bälder feimen als bie oberfäallide ftody befindenden; ebenfo nachtyeilig ift Der Sommergerfte, nachdem fie aufgegangen ift, zul lange andauerndes naffes Sisetter, fie vergeilt und erfolt ftef felten mieber. Esine nicht zu ftarfe Rälte beim 2 (ufgeben ber Sant bringt felten Gleibenden Nadytheil. Saat Der Boben gleich nad) Der Ëinfaat in Folge vorangegangenen Siegentwetters eime harte Rinde Gefommen, fo Darf Das Ëggen deffelben nicht übergangen werben.

Befonders fechäblich find biefer Bierfte ber Seeberich ober milde Nettig, Raphanus Raphanistrum, L., Hnd Der Şafnenfanm Dber Das Rlapperfraut, Rhinantus Crista Entwer, benom. ஒrfanzenfunde.

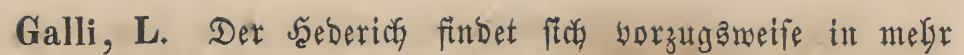

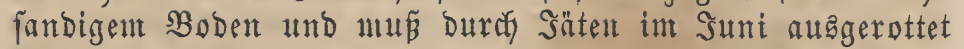
werben; Der Seabnenfanum rö̈bst melyr in binbigem und

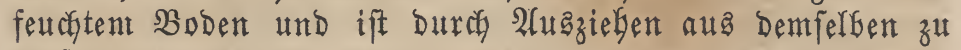
entfernen.

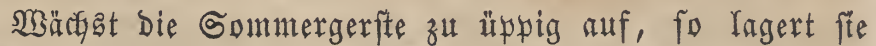

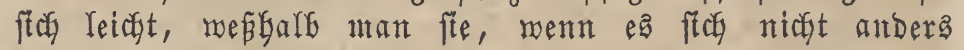
machen läs̆t, fagröwfen muñ. Die Bierfte ift ferner Dem Flug= ober Staubrand ausegefest, wie auch mefreren foüblictent Infeften, wie ber Chrysomela polygonum und Der Rraut= fochnadé, Tipula oleracea, Deren Rarben ftef in Mienge itt Den $\mathfrak{B l a t t f}$ dyeiden aufgalten und den Saalm anfreffen. Cernde

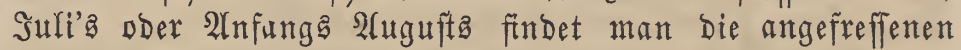
Jaalne gebleidgt, marzig, umgebogen ober gelagert; hiegegent bifft nichtas, als bie Besfite grün abzubringen.

\section{Grmetre Minterger te.}

Hordeum vulgare hibernum.

Rerngerfte, Bärengerfte, Rett' Den Mann, Nettungş= nann, Mintergerfte.

orge commune d'hiver.

Winter barley.

WBinterfrucht. 2Yebren 5 Soll lantg, fonft gleidy mit Der Somntergerfte.

Man Gaut bie Wisintergerfte meniger bäuftg arô bie Sommergerite, Defto mefr aber in theuren Beiten megen igrer Jrübreife, am bäufigften noch in füblichen Deutfós= land. Sie gebeifit noch in geringen Boben, am beften aber in einent mebr bindigen, etwas feuchten, aber fegr fräftigen Boben und in feuchtem Rilima, fobledgt aber in magerem, zu locferem und trodfenent Boben; fie verträgt feime leftige Rälte und am wenigften unter allen betreidearten săffe. Sie eignet ftch ganz für Marichboden, Geftocft fich ziemlich gut, lagert fich aber, Doch ofne befondern Nachtbeil, in zut fettent Boben gerne. Die Wrintergerfte mill ftarf gebnngt und Der Boben ebenfo bearbeitet fein, rie beim Şeizen, und fergr gut ift es, Den Mift mit ber Saat unterzupftügen, banit lebtere fo nake als möglich an exfteren zu liegen fomme.

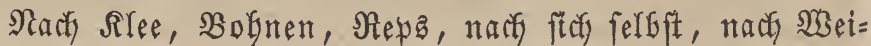
zen Dber Sager, aber mur in fegr nabrbaftent Boben. (Se $=$ möbnlich fäet man fte 2infangs Septembers oder Dftobera, nach) gemachten Erfafrungen gebeibt fie audy, nachdem man fie in Der Mitte Februarz augefäet Gatte. Das Befarfen Darf bei ber Wintergerfte nicyt verfäumt werben, lieber eggt man meniger, Da biefeg nicft fo tief nötgig ift. 2luf bie 2Bintergerjte fann man 5̧afer, WBinterroggen, $\mathfrak{B}_{\text {eizen }}$ und Roggen, News und Tabaf fulgen Iaffen. Da bie Ninter= gerfte von affem betreibe am bäldeften zeitigt, fo wirb fie befonders bon ben $\mathfrak{B}$ geln beimgefucht, mintert aud Gäuftg ganz aแs.

Die Wintergerfte hat meift geringere und Ieidgtere $\mathfrak{R} 0$ nex als bie Sommergerfte, fie gibt ein raules und formar= zes Brod und eignet fiff meniger zum Bierbrauen.

\section{3. fange bläulidbe gameine Gerfte.}

Hordeum vulgare spica longa coerulescente.

(Brope gemeine Bierfte, Grăulicfe SBintergerfte.

Orge commune bleuâtre à épi long.

Long four-rowed violet-blue barley. Long eared barley. 


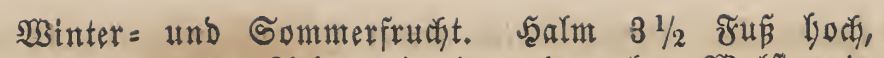
4-5fnotig, an Der 2lefre mit einem Doppelten $\mathfrak{B}$ ulfite, in

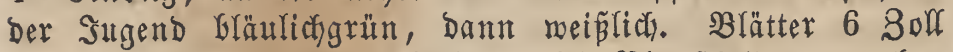
lang, $1 / 2$ 30ll breit und Greiter. Die Blattidyeiben umgeben

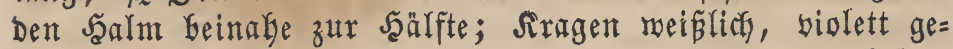

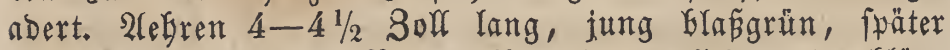

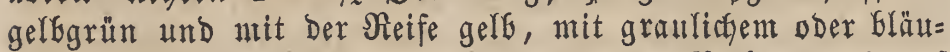

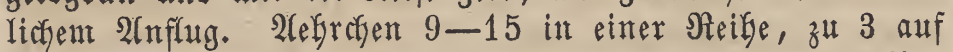
Dem Spindelwulfte ftebend, Gläuliçnei un und unten bunfler. Brannen 9 Boll lang, freit, geftreift, raub, deben an ber

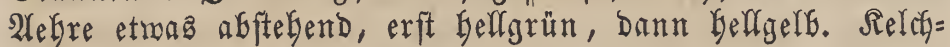
fpelzen pfrientenförmig, furz und fein gegrante, reip̧lict. Die äušern Rronfpelzen bie Samen feft einfchließ̄end, jung

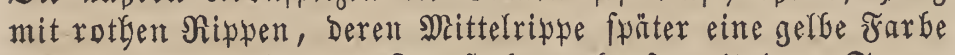
Gefommt. Die inmern fironipelzen ebenfo mit dem Samen verwachfen mie bie äufern. Spindel furz gegliedert, etmaz Greit, ausgerandet, Gläulicfweiñ Dber gelblicf. Samen an Geiben Enben zugefpibt, aufgetrieben, mentig bläulich be= thaut, mit erbabenem Rücen, fohmaler Seimgrube und faft ganz melglig.

Der Anbau Der Glăulicfen Gerfte eignet jtch bejonders für Nieberungen. Nach Noggen und bei ซrübfaat 2 nfanga März als Sommerfruct gebaut, ift ify Errtrag an Rörnern und Strof oft fefr ftarÉ und meift fityerer, Denu als Winter= frucht; fie beftaubet fich zmar als folche, 2infangs Dftobers gefäet, ftarf und ift Gäufig ebenfo ergiebig, gebeibt aber Gauptjächlich nur in mefr jüblich gelegenen siegenden und bei nicht zut ftrengem Winter.

Die Rörner merden grof, aber meift nur zum Sagro= ten und zur Biefmaftung angemendet. Das Strof mird

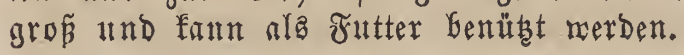

\section{4. futurze bläulidhe gemente}

Hordeum vulgare spica brevi coerulescente.

Orge commune, à épi court et violet.

Short four-rowed violet-blue barley.

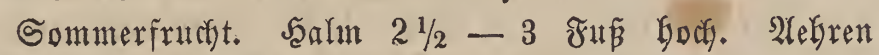
3 Soll lang. AeGrchen $8-10$, Glauet won Farbe als bei Der yorigen Barietät. Sirannen 6 3ull lang. 2leupere Sron= fpelzen ftärfer blau, ebenio auch bie Samen, meldbe nur

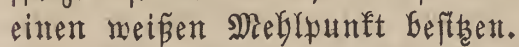

Gie zeitigt gewühnlict) etras bälder als bie lange bläu= fiche Berfte, aber fite gewälyrt einen immer etwas geringern Ertrag an Rỉnern und Stroh, eignet ficf auch mur zur Sommerfruedt.

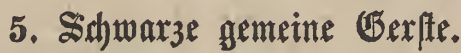

Hordeum vulgare nigrum.

Hordeum vulgare seminibus nigris.

Hordeum vulgare var. b. seminibus vestitis. Sering.

Hordeum nigrum. Schübler.

Sdymarze (jerfte, fofmarzährige Sierfite, fodmarze Winter=

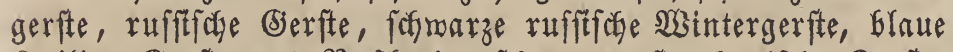

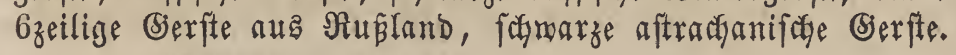

Orge commune à épi noir.

Four-rowed black barley. Common black barley.

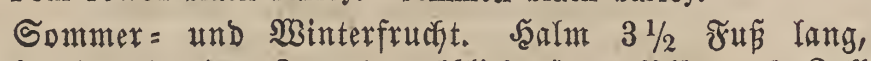
4-5fnotig, in Dex Iugend gelblidgrün. Blätter 980 H lang, $1 / 4-1$ 3olf breit, aufrecht, zugeipibt, meiplich $\mathfrak{b}_{e}=$ thaut. Der నiragen im Ánfange beflgrün, fpäter rötblich und biolett geabert. 2Tebren $3 \frac{1}{2}$ 3oll lang, ungleid 6reibig, mit 2 Freitern und 2 fdumälern Seiten, erft gelfgrünz

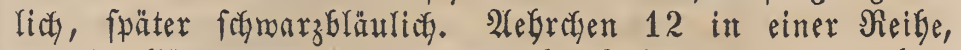
bachziegelförmig. Erannen 6-6 $1 / 2$ 3oll lang, feingezalgnt, oben braungelb bis dunfelbraun, gegen die Bafts bin grau Gis founärzlicf, in ber sugend gelblichgrün und an der Spibe Keller. Die Relchipelzen zart, pfrientenförmig, furz= gegramnt. Die äußern Rronfpelzen 5rippig, gegrannt, jung

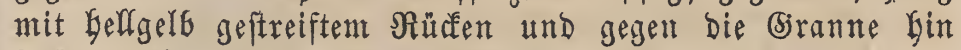
fcyon gelb, fyäter formärzlich und blau angeflogen, um=

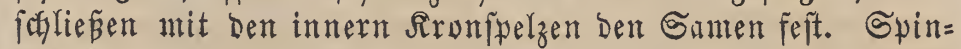
Del furz gegliebert, glänzend, auf ber einen Seite mehr rund, auf Der andern mefr breit, gelblich. Samen oben und unten zugefpist, mit ziemlich flachem siürfen und reís= lich, dft Glaulich gerandetem Mieblforn.

Sie wirb yorzugaweife ala Şinterfrucht angebaut und zeitigt oft foryon im 2(nfang Suli’s, nenn ber 2 Sinter nicht zu ungünftig war. In fräftigent Boben, aber auds nur in foldyem, Geftorft fich biefe Berfte recht orbentlich, Gefommt

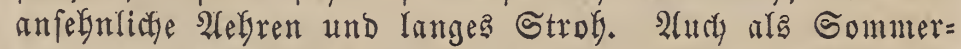
frudyt gebeigt fre băufig nach $\mathfrak{B e r f u d j e n , ~ u n d ~ i n t ~} 2$ (prif ge= fäet fann man fie in günftigen Sabrgängen oft im suli ernten.

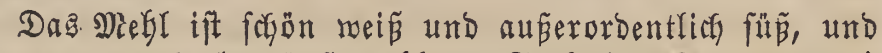
gibt, wenn auch (Der äupern blauen Farbe bes sornz megen)

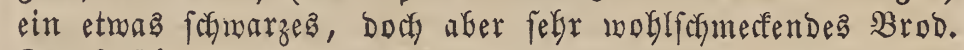
Der Frübreife und Der Süpigfeit Der Rärner Galber ift biefe Frucht Dem $\mathfrak{B}$ ogelfrape bedeutend augెgefert.

\section{Machte gemeine $\mathbb{W} \mathfrak{d} x$ fte.}

Hordeum vulgare var. coeleste. L.

Hordeum coeleste. Schübl.

Hordeum vulgare, seminibus nudis.

Saimalabagerfte, Şimmelăgerfte, Şimmelâtorn, äghpti= fajez תorn, Weizengerfte, Fleine narfte Berfte, fleine Itaffe 6zeilige Serfte, Jerufalemşorn, Jerufalemsgerfte, Davids=

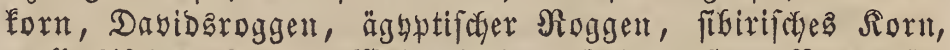
wallachifches Sorn, WBeizenfpelz, Sirieg̈gerjte, Reisgerfte, Thurgerfte (Schmeden und Norwegen).

Orge commune à graines nues. Orge de Jerusalem. Orge rue.

Four rowed naked barley. Naked barley. Nepaul barley. Nepaul wheat.

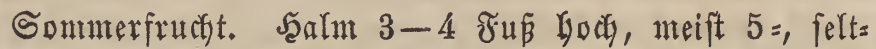
ner 6fnotig. Blatticheiden gelfgrünlich, Die Snternubien ganz ungebend. Băäter $9-10$ 3oll laug, unten 1 Boll Greit, oben lang zugefpint und oft bie 2febre üferragend, gelbgrüt. Siragen violett. 2iefren $4-5$ Solf lang, etmas runolich. Brannen 8 80 ll lang, unten breit anliegend, fajt regelmäß̈ig 6zeilig, in Der Jugent geloliefgrün, mit ber Reife fprobe und leidyt abfallend, mit ftarf Gerbortretender Mittelrippe und foharf gezähnelt. 2(ebrethen of̣t 15 in einer Reife. Reldafpelzen pfriemenförmig, lang und febr fein zugefpint. Die äupern §ironfpelzen 5rippig, gegramnt, und find nicht wie bie ber andern gemeinen (Serften mit Dent Santenform bermachfen, fondern urr lorfer verbunden. Innere Sirompelzen zart und etwaz länger ala bie äunern. Spindel furz gegliedert, glänzend, weißflich. Samen fleiner wie bei Der gemeinen 4zeiligen Serfte, aber oft 70 in einer 2 (e) oben und unten zugefpidst, in ber shitte aufgetrieben, glatt, 


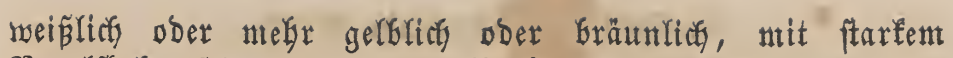

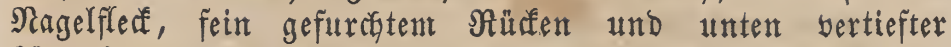
Rängafurcte, in ber belbreife nteglreid, in ber Bollreife

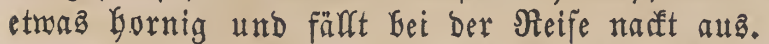

Ěinige, mie Wragini, meinen, bie Şimmelägerfte feie nichts $\mathfrak{2}$ (nDberes, als eine 2 Gart Der gemeinen 4 żeiligen berfte, aber fie unterfcheidet fir boch wefentlich you ber=

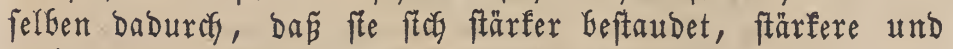
mebr Salme treibt, längere und förnerreicfere 2lelgren, ifre sïrner anders befchaffen und nicht mit Den Sirompelzen vernachfen find, baber leicht ausfallen und ibre Branten gerne berlieren.

Man baut bie Sinmelsggerfte bie und ba in Deutfaland, z. B. in Baiern 2c., Gejonbers afer in raukern und fältern (5iegenden, wo ber SWeizen nidft megr rogl geräth, in Seffreben, Normergen, auch einem Theile Dea aftatiforyen

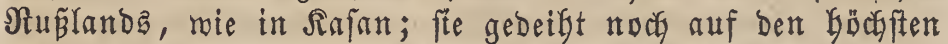
Bebirgen, wie auf Dem 15,000 bis 26,000 Fuß̃ Goben Şinalabagebirge und auf ben Goken Gebirgen zwicken Steiermarf und Särntben.

Dieje Berfte bauert, wie wir oben gejeben baten, eine żemlich ftrenge Rälte aus und reift frübe, meift 8-10 Tage früfer nod) als bie genteine 2zeilige bierfte, fite werlangt aber cinen fraftuoflen und noris beffer werarbeiteten Boben als Die genteine 4zeilige Berfte; in fohlechtem $B$ boen befonmt fie oft mur zzeilige 2(efren. Sie mirb, ba fie Durat Fräh= fröfte felten leibet, im zrübjalyr felsr zeitig und ber ftarfent Beftucfung unb zahlreicyen Slätter megen etwaz bünn aubz= gefäet. Trodfene ober naffe 2 sitterung fothabet igr weniger als ber genteinen 4 zeiligen berfte. - Nach Jadeffrürbten be=

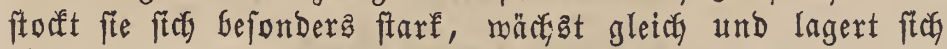
iGrer fiteifen und ftarfen Scalme regen felten. Sur Seit Der Ernte falfen bie sïrner gerne aus und merben bäufig bon

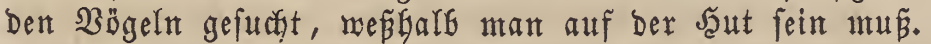

Der Errtrag biefer Serfte ift Durdfichnittlich ein 9 facher, surbe aber in bäarten fchon biz auf ben 21-32fältigen gebracbt. Err fonm Dem Der 2zeiligen gemeinen Berfte bei= nabe gleicy, an Strob aber meift etwas fodmächer, überfteigt jedoch ben ber gemeinen 4 zeiligen Berefte.

Die Şintalayagerfte entbălt naty Činfof:

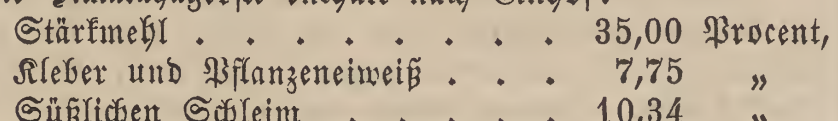
Süplichen Sigleint . . . . 10,34 " Soraue Subftanz (Galb Stärfmegl, balb thierifide (safferte) - 19,66 " Wäfferige Theile . . . . . 10,00" Ђ̆ülfen . . . . . . . 17,25 "

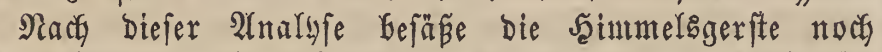
megr nährende Beftandtheile als bie gemeine 4zeilige Serfte.

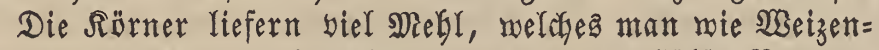

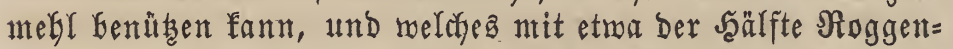

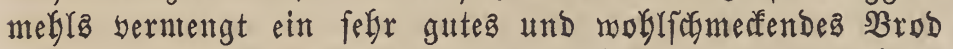
gift; man füttert fie ferner Dem $\mathfrak{B i e h}$, Gereitet aus ifnen

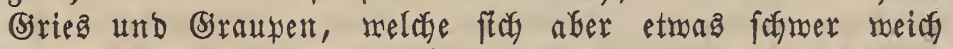
fod)en Iaffen, nicht angenelgm bon biefdrmad fênd und Blä= Gungen verurfactyen. Man Graut, wie Gauptfächlidy in Schwe= ben und Normergen, ein guteg und farfeg Bier aub ifnen,

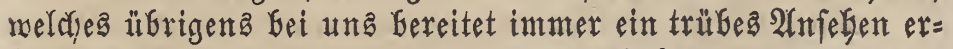
Gielt; ebenfo werden fe zum $\mathfrak{B r a n n t w e i n b r e n t e n ~ g e b r a u c h t ; ~}$ zut Bereitung yon Stärfe eignet fich biefe (serfte niaft wobl, Da igr (sebalt an Stärfmegl zut gering und das sorn fohwer zu entbülfert ift. Die naffte Gerfte liefert viel und ein bem

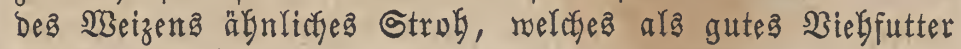
zit fiffäben ifit.

Die Şimmelşgerfte murbe fón längft int füblichen Deutidylamb gebaut, yon wo aus fie nach Norbeutropa, Ěngland und Sifmeden fan.

\section{Hordeum hexastichon. L.}

Hordeum heterostichum. Beauv.

Hordeum vulgare. $\beta$. Lam.

Sectazeilige Sierfte, sielzeilige Berfte, 6zeilige Wsinter=

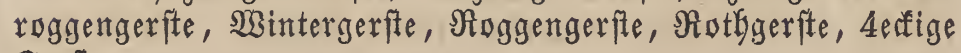
Berfte.

Orge à six côtes. Orge d'automne. Escourgeon. (frantz.)

Winter barley. Square barley. (engl.)

Orzuolo. Orzolo. (ital.)

\section{2utent = Şarafter.}

Blätter breiter als bei ber gemeinen Bserfe, auf ber

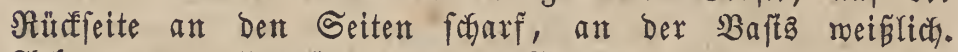
Qebren yhrantidenförmig ober elfiptifs, runb, regelmäpig 6zeilig, mit 3 fructstbaren $B$ lüthen, fürzer und biffer als bei Der gemeinen Berfte und melgr aufrecft. 2lehrcten zu 3 auf einem Spindelgelenfe und gebrängter ftefend; 2 pfrie= menförntige Sielchfpelzen utto 2 ăuß̈ere Sironfpelzen, welche nactenförntig bertieft, 5rippig, gegrannt, mefgr eiförmig und mit bem Gamen vermachen find. Die Spindel fürzer ge=

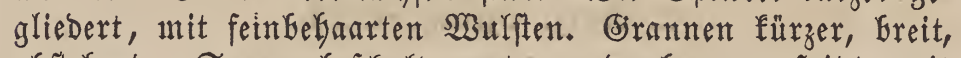
abfebend. Sauten befchalt, unten und obent zugefpist, mit

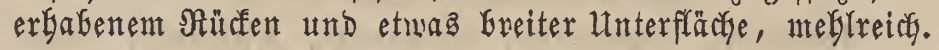

\section{Ş゙̈̈the = Beit แuto Dauter.}

Sonnter. $\odot{ }^{\pi}$.

\section{Por Eommet.}

Sie wird mefr int füblicfen Deutfolland angefaut.

\section{Ruttut.}

Die $\mathfrak{B e g e t a t i o n a p e r i o b e ~ b e r ~ 6 z e i r i g e n ~ B e r f t e ~ i f t ~} 3$ Mo= nate, fte werlangt einen febr fräftigen, megr feuchten und waruten Boben, in trodfenem $\mathfrak{B}$ oben und Rlima fällt fịe inmer gering aus. Man baut fie bejonders gerne in Nie= Derungen als Sommer $=$ Dder 2 Sinterfrud erftere foron int rebruar, aud noch int 2tpril, went bie Witterung es nidft anbera zuläpt. $2(13$ WBinterfrudyt baut man fie entrober nady reiner Sommerbracte, doer nacis

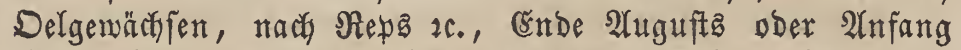
Septembers; fie Yeibet aber gerne Durch Rälte. Die Ernte

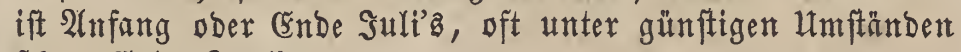

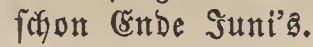

Der Ertrag an Rönern in oben angegebenem Boben aufgewachjenter 6zeiliger berfte fommt Dem ber 2 zeiligen Bierfte gleich. Der Errtrag an Strol ift noch ftärfer, jeboch ift lebteres bäufig fürzer.

Die 6zeilige Berfte ift ben $\mathfrak{B}$ ögeln und Miäufen fefr ausige 


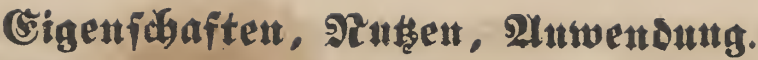

Die Rörner find fpeciffich leichter als bie ber 2 zeiligen (Serfte. Man gefraucht fie zu Bringe, Berlgraupen, unb bereitet aus ifnen ein febr gutes Mekr, Genübt fe zur Maftung Des Biekes, zur Fabrifation son ङffifg und Brannt= wein, wentget zun Bierbrauen. Das Stroh ift ein guteg Biebfutter.

\section{Lange 6zeilige CHexfte.}

Hordeum hexastichon, spica longa.

Orge à six rangs, épi long.

Long six-rowed barley.

f̧alme $3 \frac{1}{2}$ శ̛u tig, oft fo biaf mie ein (3änfefiel, an Der 2 efyre oft fpiral= förmig gebregt, jung bellgrüı, fpäter meí̧lich, gelGlich oder rötblicty. Die obern $\mathfrak{B l a ̈ t t e r} 8-10$ Soll rang, bie untern fürzer, gegen 1 3oll breit und lanj zugefpide, blandich= grün und unten weí́ angeflogen, mit ftarfer Mittelripye, Glaß̧bläulictgrünen Blattfcheiden, Gäutigem, meiölichem und Gell siolett, geadertem Rragen. Aefren aufrectyt, chlinbrifach, ftumpf, 3 Soll lang, in Der stgend bläultchgrün, fpäter

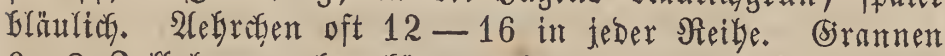
6-8 3 ofl lang, oben fürzer, breit, in Der Jugeno gelb=

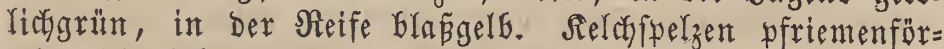
mig, fein behaart uno fehr fein zugefpist, meiß̧lich. 2(eũere Rronfpelgen 5rippig, gegrannt, Gläulicf; Die innern Rrun= ipelzen 2rippig und wie bie äupern feft mit ben Gamen berwathfent. Spindel eng gegliebert, aufgetrieben, an beiben Ěnden fith zufpitend, bläulich und meglreich.

\section{2. ffurze 63eilige CGerfte.}

Hordeum hexastichon, spica brevi.

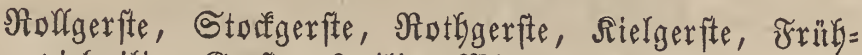
gerfte, vielzeilige Serfte, Gzeilige siontergerfte, Jaerbftgerfte.

Orge à six rangs, épi court. Orge à six cotés.

Short six-rowed barley.

Sanlme wentger bif als bei ber borigen Barietät. 2(e Gren 28 oll lang, fürzer, bichter ftebend, phrantbenförmig, in ber Jugend gelbrötblich angeflogen, fpäter gelbrich. Brannen

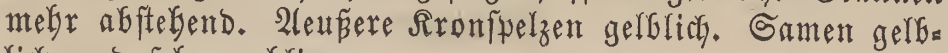
rich und fefra meglig.

Die אultur, Der Errtrag und Der Nuken biejer Geiden Spielarten ift bereits bei Der 6zeiligen Berfte im 2lOfgemei= nen angegefen worden. - Die furze 6zeilige Berfte foll noch ergiebiger fein als bie erftere. Nach Esinigen foll fie ben SSinter gut ausbaueru, nach 2 troern aber und mit mefr

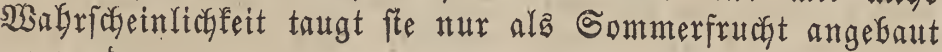
zu werden.

Schufarth fübrt nody 3 weitere 6zeilige $\mathfrak{B a r i e t a ̈ t e n ~ a n : ~}$

\section{Sidwarze 6zeilige genteine Sommexgextte.}

Aebren yon fobmarzer Farbe. Sïnner zuterereider als bie ber meiken Berfte.

Von Mezger für identija mit ber Glauen gemeinen (Sierfte segalten.

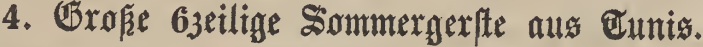

Beftaubet ftch ftarf, reibet burch Spätfröfte nicht und foll eimen 20fältigen Ertrag geben. Samen graugelb.

\section{63eilige norwegi/dige Gerfte.}

Berfte aus Norwegen.

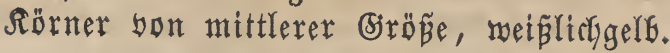

\section{Hordeum distichon. I.}

Hordeum aestivum. var. Hall.

Zeocriton distichum. Beauv.

$\alpha$. Hordeum distichon erectum. Schübl.

$\beta$. Hordeum distichon nutans. Schübl.

$\gamma$. Hordeum imberbe. De C. Schübl.

Smeizeilige (5erfte, 2zeilige Sommergerfte, fleime (B)erfte, Ditfeegerfte, Futtergerfte.

\section{Átelt = $\mathbb{G h a t a f t e r .}$}

Zelgre unbollfonnten 6zeilig, platt, auf jebem Spindel=

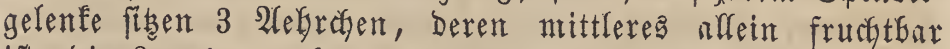
ift, bie 2 andern aber männlici und unfructbar und ntegr

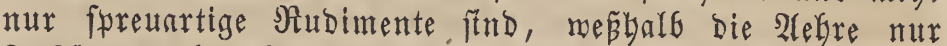
2 sörnerreifen beftht.

\section{BłïtGe: 3eit tnd Danex.}

รuni. $\odot$.

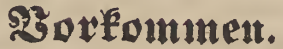

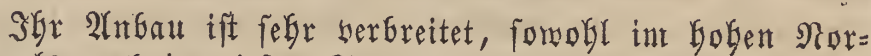
ben, als audf im tiefen Süben.

\section{Rultux. હigenfduaften, Nuten, Anwendutg. Sieke bei ben Barietäten.}

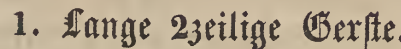

Hordeum distichon, spica elongata.

(Brof̧e 2zeilige Bierfte, Blattgerfte, grop̧e Sommergerfte, ซrübgerfte, 2 zeilige Sommergerfte, grop̧e Berfte, ซutter= gerfte, Ziegelgerfte.

Orge à deux rangs, ćpi alongé. Orge distique. Pamelle, Pacumoule, Baillard.

Long eared (two-rowed) barley.

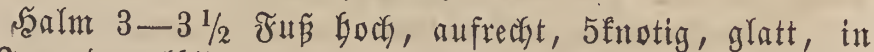
Dex Sugend gelblichgrün, in Der Reife gelg bia röthlich. Blätter 9-10 3oll lang, gegen 1 Solf breit, gelflich ober Gläulichgrün. Siragen violett und Dunfler geabert. 2(elgren

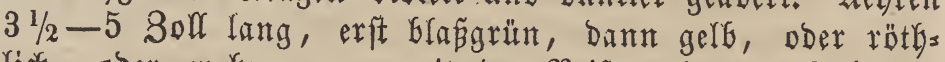
lich, pder mefr grau, mit Der Reife gebogen. Aebraten $14-17$ in einer $\Re e i b e, 1$ fantig, 1 grannig, reif gelblicty= meí́. Sirannen 8-9 $80 \mathfrak{l l}$ lang, raub, jung anliegend,

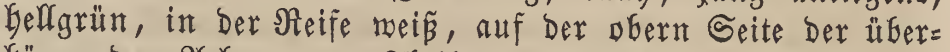
Gängenden 2lebre zum Theil meit abftebend. Relchfpelzen $1 / 2$ Soll lang, fein pfriemenförmig, meiß̧lich, gegrannt.

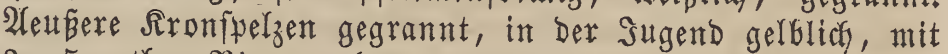

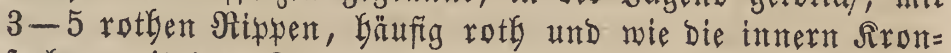
fpelzen mit Den Samen fejt termachjen. Spindel lang ge= gliebert, glänzend, gelblichmeiñ. Samen in Der frorm ver= fobleben, zum Theil megr gemölbt, zum Sheil aber mieber melyr flach, meift aber aufgetrieben, oben und unten zuge= fpidet, glatt, meflig, bei $\mathfrak{B}$ olltreife aber băufig glafts.

Diefe Berfte ift fegr meit berbreitet und nicht affein in Europa, fondern aud in andern Beittbeifen. Man findet 
12.
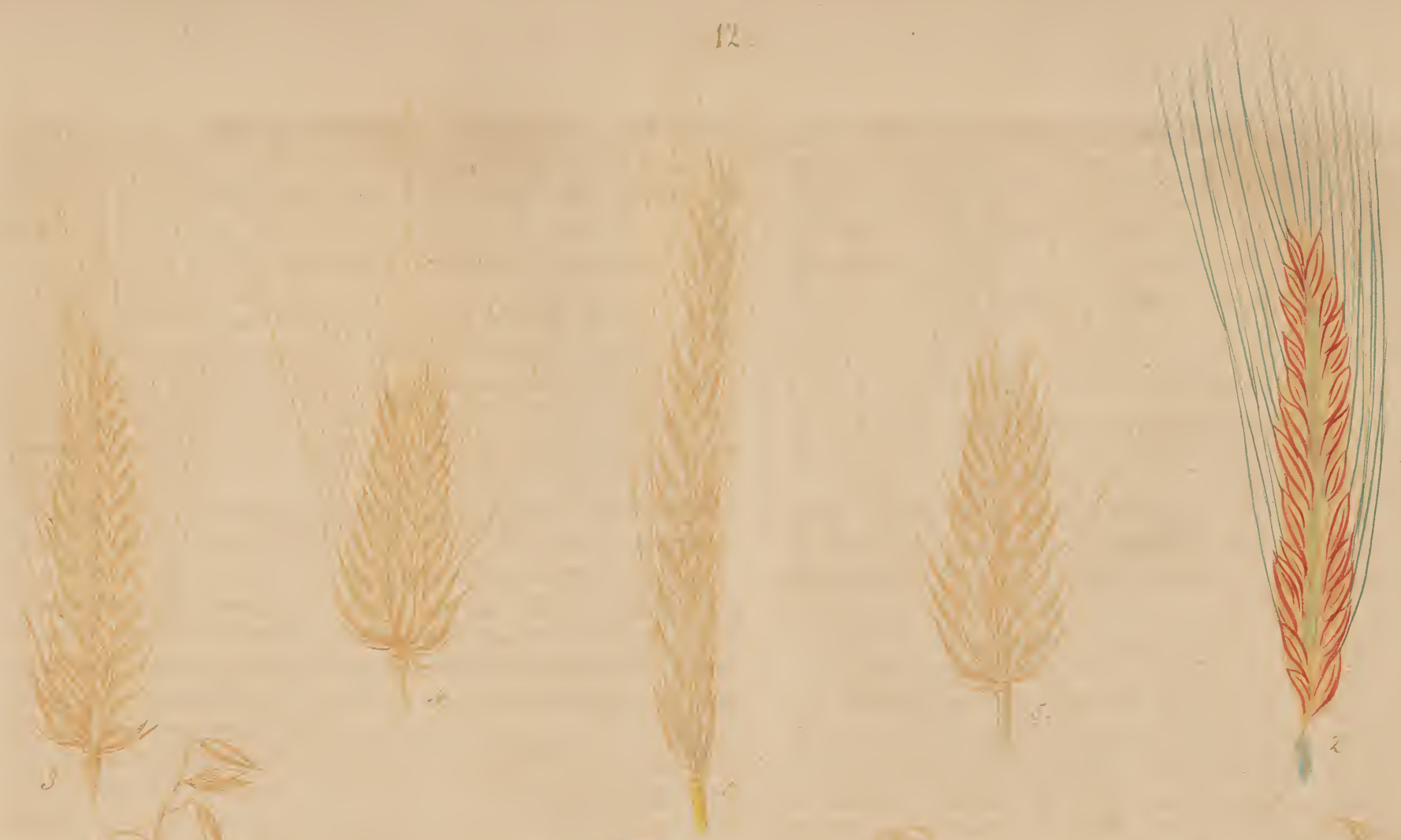

की

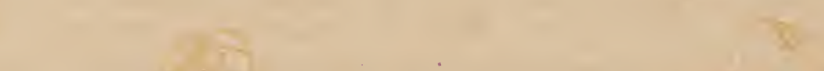

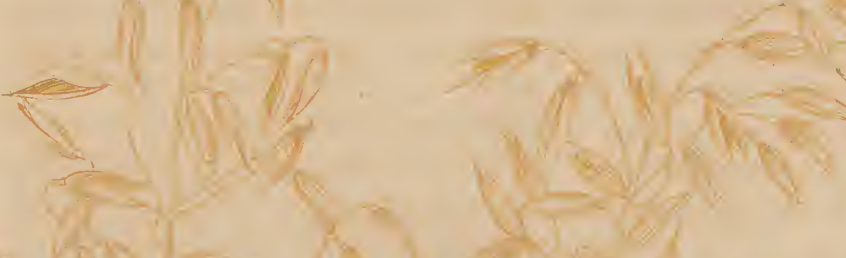

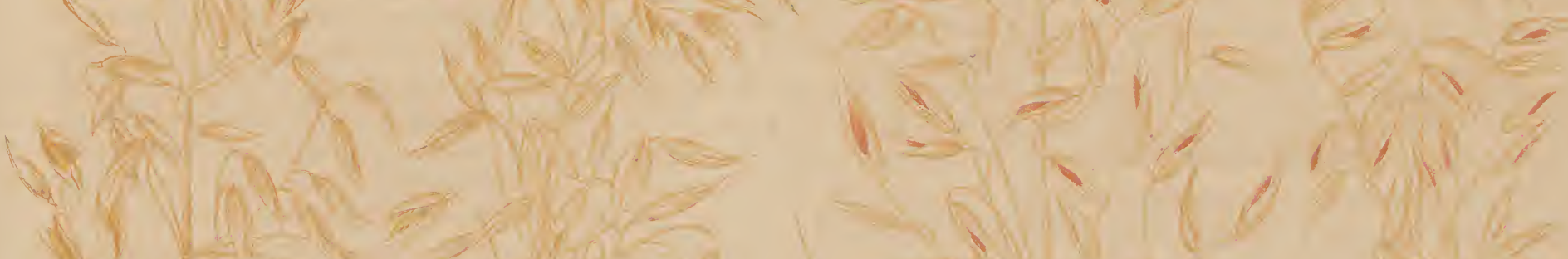

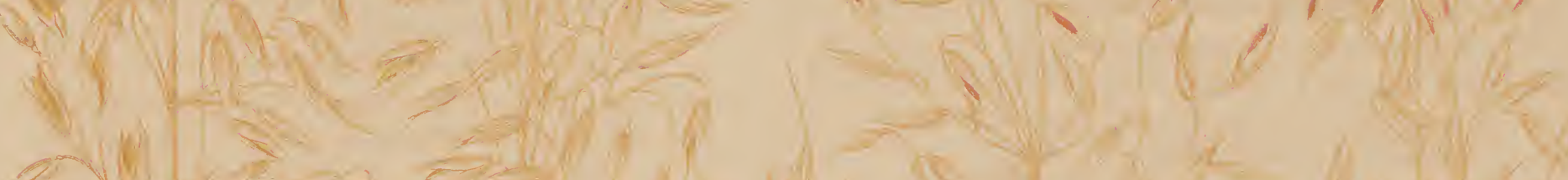

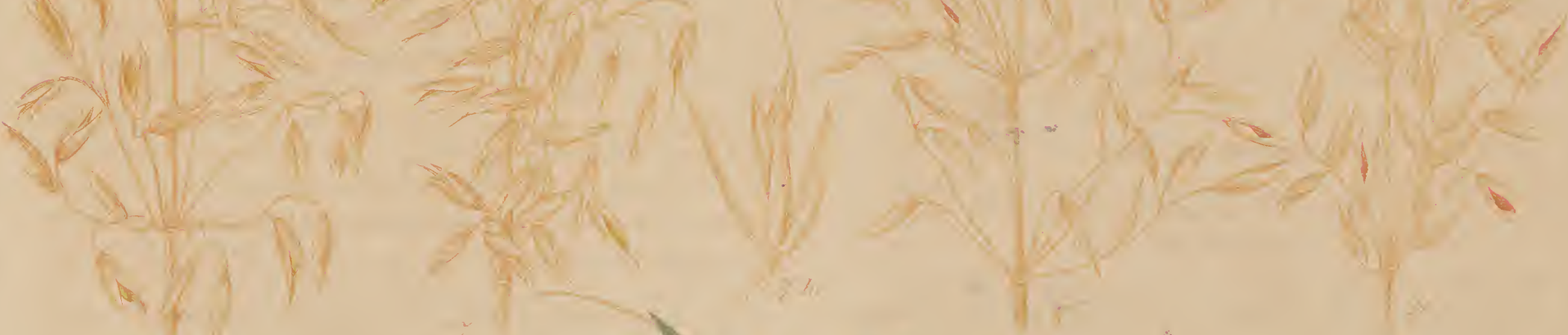

at की

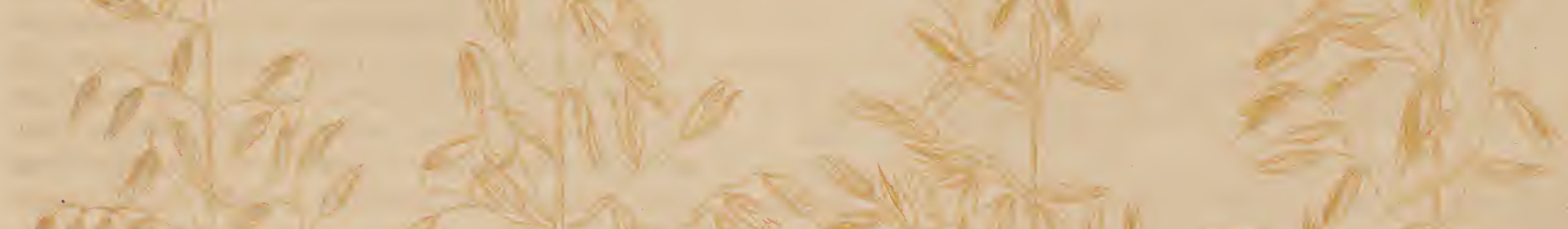

Mins

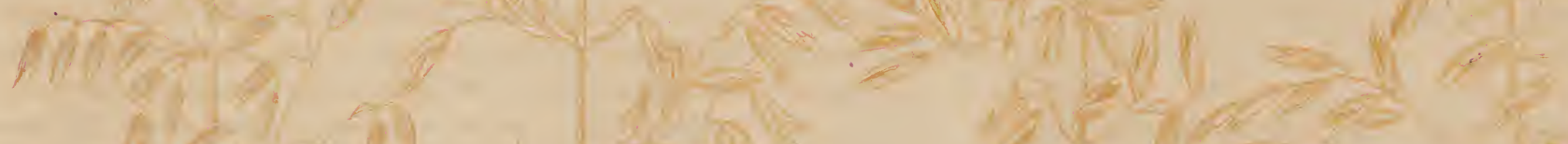
Find की

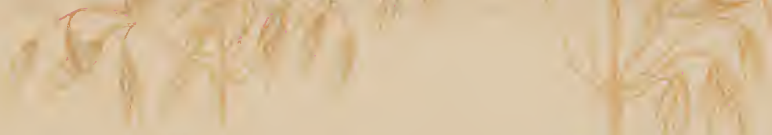

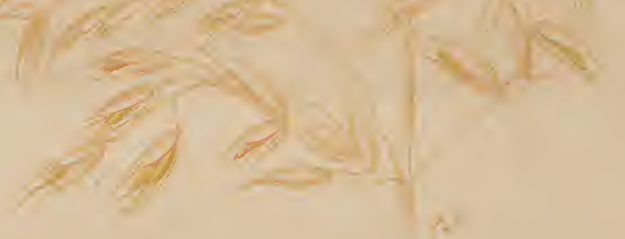



fie noch int Goben Norben angebaut, wie in Sifneben, Norwegen, Dänemarf und ben angrenzenden Injeln, fogar in Rulea Raypmarf, wo fte freilich und $\mathfrak{m}$ ur unter ganz

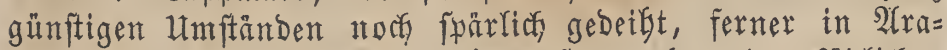
bien und 2legypten, ant bäufigften aber int füblichen Deuticyland.

Sie mirb gemblfnlich nur als Sommerfruct angebaut, ifre Begetationaperiobe Geträgt nicyt yolfe 4 Monate. 2(n=

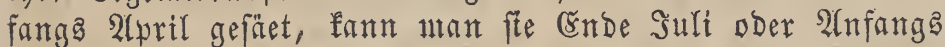
2luguft einernten. (šin fräftiger Boden, Der gleiche Theile

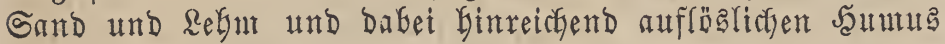

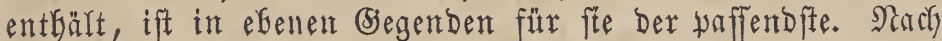
Noggen gefaut, geräth fte gut. Frifches Düngen ift biefer Frudyt ifres fohneflen Machsthums regen nicht vortheilfaft, wobl aber eine Düngung bon gutem zergangenem Mifte. Sn fräftigem 3 oben fäet man unter bie (serfte audf-Silec, welchen man 1-2 Jabre lang benüben fann. Heber Winter gebaut, werlangt bie Sierfte ein mildes filina, da fie eine ftrenge Rialte nicft augbautert.

Der Errtrag ift meift reichlicher ars ber ber gemeinen 4 zeiligen Bierfte.

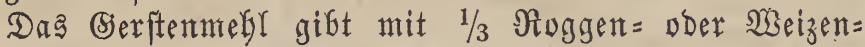
mefl ein gutes und nafrfaftes 20 rod, und man. Genüht es auff zu anderem Barfwert und verfchiedenen Speifen, Gefon= Ders bäuffg aber zum Bierbrauen, ferner zur Bereitung

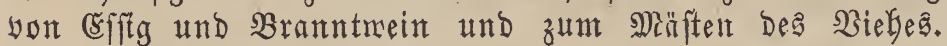
Das reiche Stroh Dient, Gejondera mit Runfeln, Rautben, Sartoffeln zerfactitten, als fefr gutes Siebfutter.

Dieje Serfte foll fison bor 300 safren in ben obern Rheingegenden fultivirt worben fein.

Man bat yon ber grofent $2 z e i l i g e n$ (bierfte noch 3 Spiel= arten, bie aber nicht fomitant fitnd:

a) 2 ange rothe 2 zeilige (s)erfte.

Hordeum distichon, spica elongata rubicunda.

Aefren rötblicf, Gald grau merdend. Die Jirannen oft bis zut Sălf

b) 2leftige zzeilige (bierfte.

Hordeum distichon, spica elongata ramosa.

c) Saflaffährige 2 zeilige (b) exfte.

Hordeum distichon, spica elongata laxa inbricata,

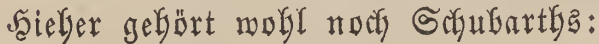

2 zeilige forbarze (b)erfte,

als 2lGart ber langen 2 zeiligen Serfte, bie aber Gloṕ Durdy bie formarzen Brannen verichieden ift, als Sommerfructit gebaut wirb und an Burferftoff reicher als bie meipe Berfte fein foll.

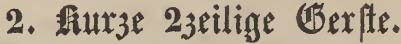

Hordeum distichon spica erecta seu rigida.

Hordeum distichon erectum. Schübl.

Hordeum distichon multicaule. Wagini.

Hordeum ramosum seu frutescens. Viborg. (3)erfte.

Spiegelgerfte, Staudengerfte; Blattgerite, ફ̧ainfelder

Orge distique à épillets rapprochés. Orge distique à épi roide et court, épillets densement imbriqués.

Two - rowed erect barley.

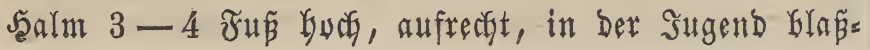

gelblicfgrür. Blätter 9 3oll lants, $1 / 2$. 30 ll breit, bie untern fürzer und fómäler, lang zugefpibgt, Dunfelgrün, mit ftarf Gervortretender Nittelripye und biolettem, roth= geabertem fragen. 2(efren $3-4$ 80hl lang, zujammen= gebrucft, quramidenförmig, aufrecht, it Der Jugend bla $=$

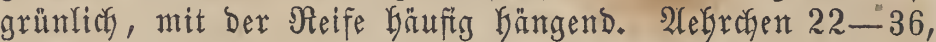
bicht und bactziegelförmig ftekend, 1 fantig, gegrant, gelb=

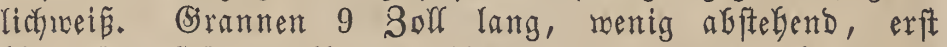
Glägrün, fuäter gelb, zumeilent an ber Baftz röthlich und an ber Spitze grünliç. Sielchfpelzen fomal yfrientenfürntig, fein und furz gegrannt. 2(eupere Blumenfpelzen gegrannt,

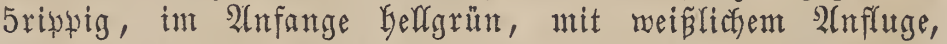

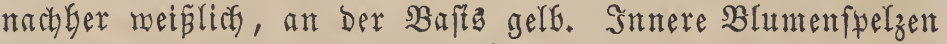
ungegrannt, beide mit Dem Samen bermadjen. Spindel eng gegliebert, glänzend, weig̈gelb. Samen aufgetrieben, oben unb unten zugefpibt, mit erfabenem $\Re$ üfen, wägrend Der Blütge Gelfgrünlich und rötglich, in Der Reife ziemlich weif und meflreict.

Sie mird bejonders bäufig in shüringet, แm \$Nopas= feld 2c. angebaut. In Nieberungen, bet feuchtent, fonwerent Boden und bet Dünmaat gebeigt biefe Berftenjorte am beften, fie beftocft fich febr gut und treift oft 10 und bobe Salnte; in nargerem und troffenem $\mathfrak{B}$ oben artet fie reidyt at?. Sie wirb nur als Sommerfrucht angebaut, und zur Slusfant braucht man Den 4ten Theil meniger als bon einer andern Bierfite. Sie wächst auBerorbentyich fohnefl, man fann fie noch bis estnoe Suni's fäen, und doch mirb fte mit andern bierftenarten, bie figon im 2tpril gefaut wurben,

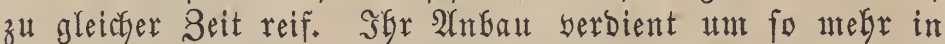
foldyen Gegenden einer weitern Bearbeitung, in "welefen eine andere bierfte bes fonweren und naffen Bobens wergen ntidft meGr gebeigt. Die אärner ftnd Gäuftig fleiner als bie ber genteinen 2zeiligen Bierfte, fommen ibr aber oft an Brößje ganz gleich.

Der Errtrag ift ftüfer als bei ber gemeinen 4 zeiligen

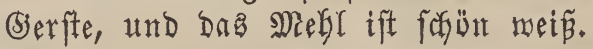

\section{Hachte $23 \mathfrak{e}$ ilige $\mathfrak{G e x}$ fte.}

Hordeum distichon nudum.

Hordeum distichon var. nudum. L.

Hordeum nudum. Schübl.

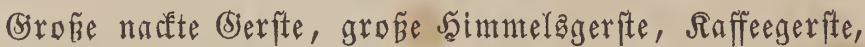

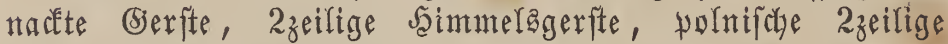
Sommergerite, W3eizgerfte, ruffifctye Berfte, äguptifch Rorn,

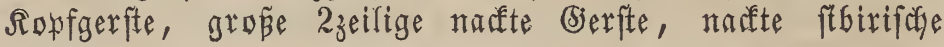
(5)erfte.

Orge à deux rangs nue. Orge à graines nues enflées. Orge à Café. Orge de Perou.

Sibirian barley. Holiday barley.

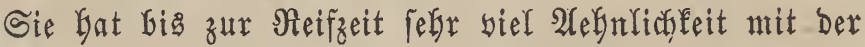
langen 2zeiligen Gierfte, aber bie Salme werdent gröber, ebenfo audf bie Blätter. 2leGrent gleith lang, aber biffer;

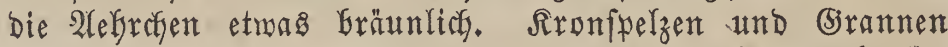
oft auch rötglich. Sörner aufgetrieben, febr feingülfig,

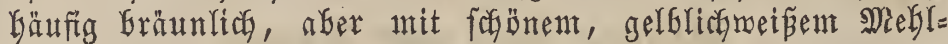
forn. Der Sante fält beim Drefchen nact, aber fefr fohrwer aus.

Sie werlangt einen loffern, bom 1 tnfraut gereinigten, fegr fräftigen 3 oben und darf, ba fte fith in folchent felgr 
ftarf beftaubet, tur bün ausgejäet merben, auch fann bie Saat frübzeitig geforelen, Da fte wom Frofte felten leibet. Sie bebarf biz zul ibrer Reife nicht ganz 4 Mlonate und zeitigt noch 8 Tage bärber als bie nacte 4 zeilige (serfte.

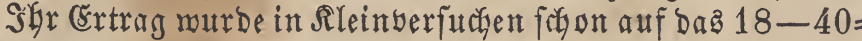
färtige gebracht und ift wobl unter fämmtlicken Berjtenarten und günftigen 2 sitterung = und Bodenverbältniffen ber bebeu= tendfte, fowohl an Söntern als an Strolj; erftere übertreffen Gäufig bie andern Berftenförner an Bröpe und follen aud am meiften nägrende Beftandtheife Gefthen. Das Setreide foll trocfen eingebradgt wub entweber gleich oder bei ftrenger Sälte gebrofden merben. - Die Rörner geben ein gutez

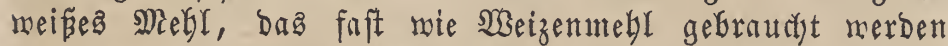

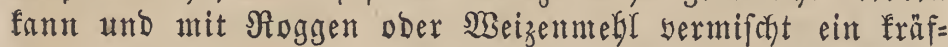
tigez und nabrbaftea, nicht leicyt rifftg rerbendes Brod giøt. Wian bereitet aแs igr ein guteg und fräftiges Bier, und 10 Mesen ifres Malzes thun bie gleichen Diente wie 16 Mesen Dez Malzes won ber gemeinen 4zeiligen Bierfte. Ferner benübt man fie noch zur (Efftg= und Branntweint= fabrifation (fite foll einen felgr guten und melyr Branntwein geben als Der Roggen, ) und als Geliebtes Raffeefurrogat. Das weicfie Stroh ift ein fehr gutes $\mathfrak{B}$ ieffutter.

\section{Hordeum zeocriton. L.}

Hordeum distichum. $\beta$. Lam.

Zeocriton commune. Beauv.

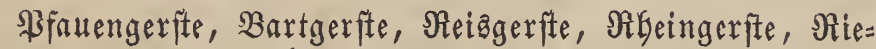

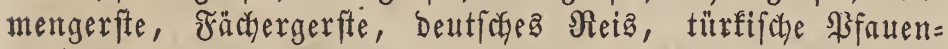

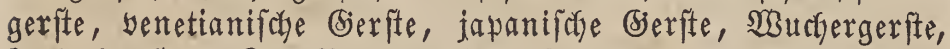

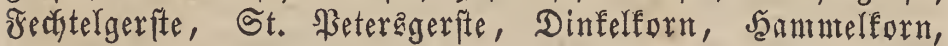
türfifche Eerfte, Weizengerfte.

Orge en éventail. Orge pyramidal. Orge faux-rix.

Sprat-barley. Blatt ledore barley.

\section{Arten $=$ (Shavaftex.}

J̧alme 3 Sull lang, aufrecht, 5fnotig, geftreift ober

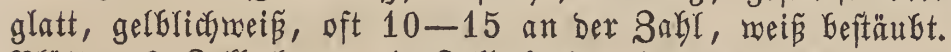
Blätter 9 3oll lang, 1 Boll breit, lang zugefpidet, erft Gläulich, fpäter gelfgrän, mit gerippten $B$ latticheiden und meiß̧lichen, Gerfviolett geabertem und häutigent sragen. 2lefre 2 3oll lang und länger, an ber Baftz gegen 1 3oll Greit, 2zeilig, aufrecht, Ianzett = phramidenförmig, wlatt= gebrürft, glatt, gelbgrünlich. 2Aebreffen 20-30, gegrannt, beren fruchtbare abtefyend, beren unfrudtbare aber anliegend ftrto. Sirannen 6 Soll lang und länger, fächerförmig oder yfautenfeberartig auzgefpreizt unb freit, in ber Sugend jeboch anliegender, Gelfgrün, mit rötglichen Spiken. Relchfpelzent fein, furz, mit felgr feiner 1 Soll langer Sranne. 2leupere Sirnipelzen gegrannt, mit 5 in ber Jugend rötflicten $\Re$ ip= pen und rie auth Die innern Sironfpelzen mit Den Samen verwachfen. Spindel eng gegliebert, glänzend, gelblichmeín. Samen gegen $1 / 2$ 3oll lang, aufgetrieben, oben und unten zugefpist, oben convex, meblreich.

รuni. $\odot$.

\section{Słlüthe = 3eit atto Danex.}

\section{Sorfommet.}

Diefe Serfte foll in Baläftina einfeimifor fein.

\section{Sultut.}

Man Gaut bie \$fauengerite Gauptfand lich in Den Niebers lamben, in England, Jranfreich, Spanien, Stalien, auch in 2legypten, meniger bäuftis melyr in Deutfdyland, und zwar nur als Sommerfrucht. Sie beftofeft fich in einem guten, mefr binbigen und feucteten Boben, und bünn (etron $1 / 3$

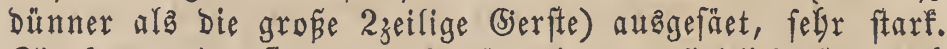
Sie fann, Da fie gegen Fröfte niefst empfindlicf ift, früb aughgeäet und in fâltern Begenden angebaut werden. SGre Begetationzperiobe ift unter günftigen llmftänden 3 Mronate, und fte reift oft zu gleidger Seit mit ber genteinen 2zeiligen berfte, oft aber auch 8 Tage fuâter als folche. Sie bat fpeciffich fodmerere, aber meift fleinere Sïrner ala lebstere. \$hres furzen und biffen Strobes twegen lagert fie fith alith bei ftarfent Winde und Regent nicyt leicht, auth faflen ifre

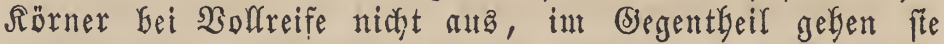
forfwer auz ben 2 (eljren.

Shr (Grtrag im Gropent ift ein 22 fältiger, im fileinen Dber in bärrten aufgewachjen oft ein 50 făltiger, ber bes Strofez aber geringer als bei ben andern Betreidearten; fie ftegt jeboch Der grofenen zmeizeiligen Bierfte in Beziefung iGres (Ertrages nach.

Der 2(nbau biefer Gerfte pap̧t bauptfächlich für (jegent= Den, beren Boben gut, beren flintaticthe Berbältniffe afer nicht gerade bie günftigften fint.

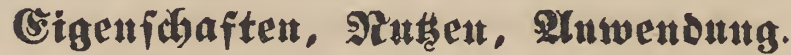

Die ßfauengerfte liefert ein febr fänen Megl, gute

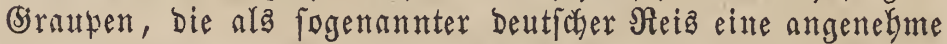
Speife geben, eignet fith borzüglich für Bierbrauereien und wirb befonders in Ëngland uns Frantreich zu Weip̈bier, fonft audf zur Bereitung von Branntwein und Efitg benübt. In Den Nieberlanden bienen bie Rörner als Sdyweine=, in Spanien als ßferbe = und in Stalien und 2Aeghnten ala Bjeflitgelfutter. Daz Stroh ift ala $\mathfrak{B i e g f u t t e r ~ z u ~ b a r t ~ u n d ~}$ zit grob.

Vor megreren Gabrhumberten war ber 2anbau ber Bfauengerfte in Deutfaland fegr verbreitet und rourbe als Deutficter Reis zu mancherlei Speifen werwendet.

Bon ben $\mathfrak{B}$ g̈geln bleibt fite ifrer ausgebreiteten brannen wegen verfignt.

\section{Avena. L. Spr.}

Trisetum. Pers. Beauv.

Snftente: Achyrophyta. Neck. Gramina. L.

Gramina Avenae. Adans Spr.

Gramina bromea, avenacea. Kunth.

Gramineae. Juss.

Triandria Digynia. L.

Sieldy 2flappig, 2- bielblütfig. Slapwen Gauchig, zu= fammengebrïaft, ungleich; untere Slappe fürzer. BBlüthchen zwitterig, an ber Bafts und auf Der ZUupenfeite Gebart. Srone 2fpelzig, Intere Spelze an Der Spibe gefpalten ober gezăhnt, mit einer gefnieten Sirante, weldye unter bent Rnte gebrefgt ift; obere Spelze 2 fielig, auf Den Rielen zart und

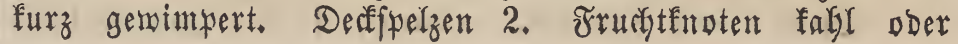


Gaarfdopfig. Briffel furg. Narben federig, feitwärtz Gerbor= tretend. Samen frei doer an bie arrome angeroachfen.

\section{Avena sativa. L.}

Avena anglica. Autor. Avena cinerea. Autor. Avena disperma. Mill. Avena diantha. Hall. Avena flava. Hort. Avena fusca. Ard.

Avena Georgiana. Zuce. Avena Georgica. Hort.

Saafer, Saaber, Niäpentafer, gemeiner Saafer, zabner

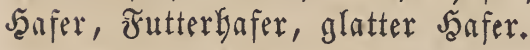

Avoine cultivée. (firantz.)

Cultivated oat. (engl.)

\section{$\mathfrak{A r t e n t}=$ (Shavafter.}

WBurzel faferig, mit Gaarförmigen Bafern bidyt befeci=

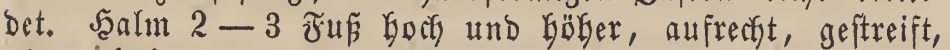
glatt, Gobl, mit 5-6 snternobien. Blätter int Berbăltnís Greit, lang zugefpibt, glatt, am Rande und auf beiden

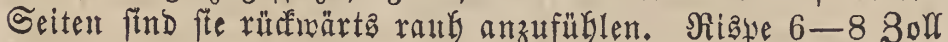
lang, ausgebreitet, ibre 2lefte find am sirunde verbiaft und abmechfelnd nach einer Seite geriogtet, $5-6$ meift äftige Blïtbenftiele entfpringen an Dem untern Rnoten Der Spin= Del, fie find won werfobiedenter Ränge, gegen bie Spise bin merben fie fürzer, einblütbig, und fteben zu $2-3$ beifan= nen, ant Brunde find bie Gefondern Blüthentiele ftarf ser= biff. 2(ebrethen 2blüthig, mit einem felgr fleinen geftielten

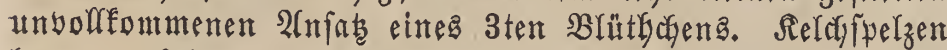
lang zugefpięt, am Sande und Der Spibe băutig, glatt,

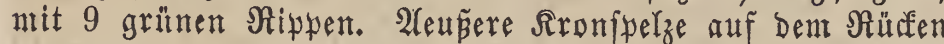

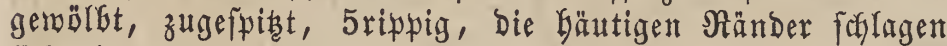
fith ein und umgeben bie innere Sironfpelze, meldye burcf)= ftchtig atnd an ben grünen Seitenrippen fein gervimpert ift. Staubfäben Dünt. Staubbeutel gros, gelb, pfeilförnig.

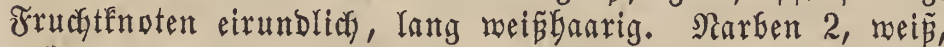
gefiebert. Samen oben und unten ftumpf, fein bebart. meiplicty, fallen Geint Drefchen nicyt aus.

3uli. $\odot$.

\section{Sliththe = Beit und Dautex.}

\section{Sorfommett.}

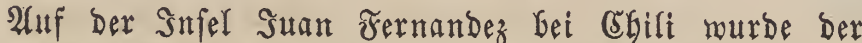
Safer wilbrachjend gefunden, und ex folf nach ber Bernutu= thung Criniger im nörblichen 2 fïen einkeimifa ober eine

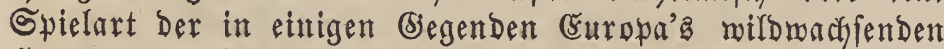
Jaferarter, Avena orientalis ober Avena nuda, fein.

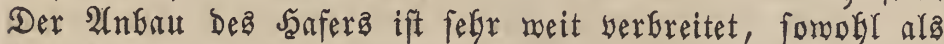
Brobfrudyt, mie Normegen, Schmeden, Schottland, ala audf als Pferbefutter, mie in andern Rändern, bauptfädylich in Deutfacland, bejonders aber in folden begenden, beren Bobenberbăltniffe es nicht mobl geftatten, eine andere (bje= treibeart, mie berfte ze. anzubauen.

\section{Ruttut.}

Der Saafer ift in Bezielung auf Rlima unb Boben burdyaus nidft heifel, er geDeigt fowobl in faltem als rats= mem, feucftem und troffenem Rlima, obrobl er cin etrab feuchtes und nicfyt zu warmes am meiften liebt; er geräth fermer in fandigem und lefmigtem und magerem, reie in trucfenem, naffem, faltem unb faurem Boben; man baut ifn befbalb geroogntidy in raubem 3 seizenboden, in naffent ober aud fegr trocfenem Boden, in Neubrud, Meorboben, in Teichen, weline abgelafien worben find, überkaupt in einem Boden, in welchem andere Betreidearten, Gejonders die Eierfte, nicht mefyr gebeifyen mollen. Sft Der Boben nidyt zu erfoüpft, fo bebarf Der Săfer nidjt notbmendig einer

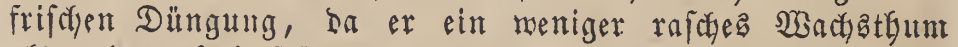
als andere Salnifrübyte ullo vermöge feiner ftärfern Drgane auch reniger leidft auflöende und nährende, bielmefr audy gröbere Stoffe in fict allfunebmen im Stande ift. Dod gebeigt der Sagfer um fo Geffer, wenn er frifos gebüngt wird, zumal ba er eine frifaje Dängung felgr gut werträgt, und ez ift bas Düngen Gauptfächlidy foldyen Randowirtben

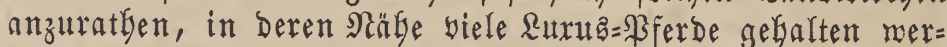
ben, ober für foldye, bie übrig Nift aber menig Stroh be= fthen, Da Durch frifthes Düngen Der Seafer auserorbentlich

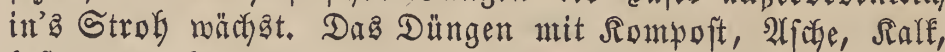
Gefunders aber mit Mergel, ift bent

In Der Dreifelderwirtbfafaft baut man ben Seafer meift in's Sommerfeld, zuweilen aber audy in's Winterfeld, menn

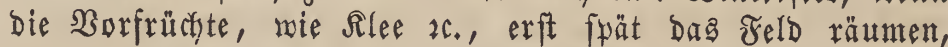
oder man baut ign auty in ber SBractye, nadydem ntan in Derielben zubor Rartoffeln und auf biefe Berfte und Rlee gepflanzt bat. Man fann Den Seafer faft auf alle Jrüchte folgen laffen, aud nach foldyen, die ben Boben fehr in Anfpruch nefmen, wie berfte, Rein zc., und ifn in gut= gebüngtem Boben eine Reife yon Salren nach fich felbit bauen, da er daz Feld zwar in einem bermilderten, aber nur wenig erfobupten Buftande binterläpt. 2(m beften ge= beigt mogl ber Jafer nach foldyen Borfrüdyen, welche nuch viele vegetafilifdye Nabrungaftoffe im Boben zurüaflaffen, fo nach) Dreificte nary Rlee, \&uzerne, Esaparjette, ferner nach

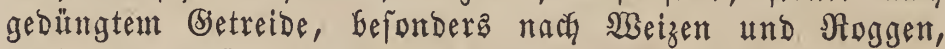

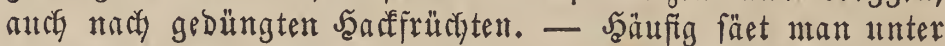
Den Jeafer Rlee doer auch Erbfen. - Der Jaafer yerlangt im Sanzen eine meniger forgfältige Beitellung Dez $B$ odenz als bie übrigen Getreidearten, und fie ift entweber eine ein= furchige ober aber eine mebrfuratyige Beftellung; erftere eignet fitch bejonders für einen leidhten, troffenen und ftart ver= unfrauteten voer einen Durch Borfrüchte aufgeloderten Boben, für Neubruch, und mird entroeder yor ober nach dem Minter gemacht. Wur bem Winter mirb Der Arfer Gauptjächlich einfurchig beftellt, wenn ber Boben felgr locfer ober falfe= Galtig ift und feine Winterfeudftigfeit in Jrithiakre zu bald

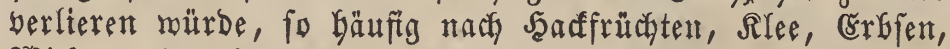
MYicfen, ober Gei Neubruch, Dantit Derfelbe Den SWinter über geförig Durchfriere and fomit loderer werde; nud bem WBinter aber, menn ber Boben mebr bindig, ná und falt, Dber man verbindert ift, eine mefrfurchige Befterfung sur= zunehmen, ebenfo nach Borfrübten, bie ben Boben febr erfoüpren, wie Serfte, Rein 2 . , Deren Stoppeln man über

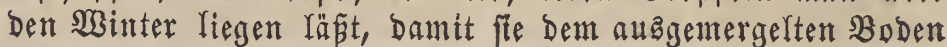

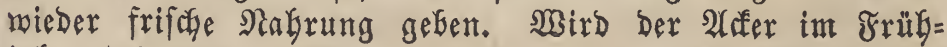
jahr einfurchig beftellt, fo folf biés fo früh als möglich gefobeben, tief genug (aber auch nicht zu tief) gepfügt und 
Das umgepflügte Frel' noch lüngere 3eit Yiegen gelnffen mer=

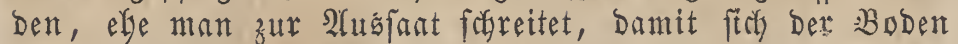
noch geförig feben famu, auch foll ber Boben zulest noch

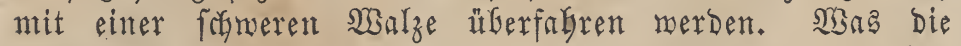
melgrfurchige Beftellung anbelangt, fo ift biefe vorzuzieben bei zu bindigent, naffem, faltem und fegr verquerftem $\mathfrak{B} \mathfrak{D}=$ Den, ober went Silee unter ben Seafer gefäet merben foll, und gemögnlich reichen 2 Furchen Gin, Deren eine bie Stürz= furche vor bem winter und nur flach, bie andere bie Saat= furche im Frifliafle und tief genug gezogen wirb; Durch bie Stürzfurche werden oft biele Unfrautmurzeln auf bie DGer= fläche gebracht, melche ben wisinter über zum größ̈ten Theile erfrieren. Bei fegr ungünftigen Bubentergältniffen iłt übri= gens oft eine $3=\mathfrak{u n b}$ melyrfurdyige Beftellung nötbig.

Sur 2łusfaat nefme ntan nux yolfoumenen, reifen und bom Unfraute gefäuberten Santen, ant beften yom vor=

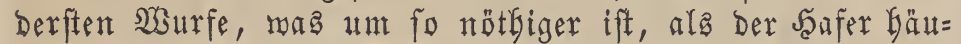
figer Demt bie übrigen Setreibearten nur in geringent Boben gefäet rird und gerne in Barthafer auanatet; es ift Deb̧alb auch fegr zu entpfehlen, Den Samen bout Beit zu Beit zu mechfeltr. (sinjäbriger Gamen ift intmer beffer als älterer, Da lesterer immer bicfter gefüet werden nú und überfaupt ber Şafer Ianger Seit bedarf, bis er in's Seimen geräth. Sur Spätaat Darf man nur eine frühe Saaferforte wäblen. Mian fäet Den Saafer, zumal bet leidstem Boden und trocte= nem אlima, zeitig int zrühjakr, wenn nicht gerabe andere Umftände eitue fwätere 2lusfaat bebingen, Da er zun Reimen nothmendig ber Minterfeudigtigfeit Gebarf, wie fornon gejagt faymer feimt und yon der Rälte meniger als berfte und Sommermeizen leibet; fpät gefäet geft Der Saafer ungleidyer und focherer auf, befonnt meift weniger solffonmene und meglige Rörner und mird boypelmühgftger. Bei bindigem, naffem $\mathfrak{B}$ oben und feuchtem Silima fam man bie Saaferfant in bergigten Giegenden noch bis (rnde Mai's, in ebenen bis

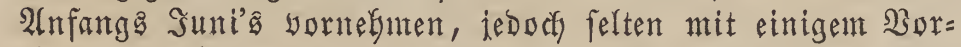

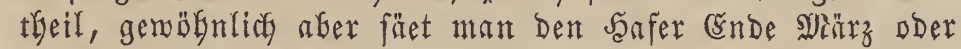

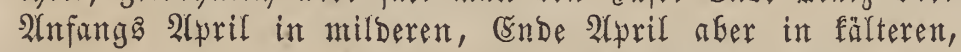
früber in böber, fpäter in nieber gelegenen bjegenden. In binbigent Boben foll man bie 24ugaant nicht elyer machen, als bis er gebörig abgetrodfuet ift, ein lecthter, trodfener und fandiger Boben Dagegen barf zur 3eit Der 2luşanat feucht fein, Damit ber Seafer in biefen beiden Fällen nut

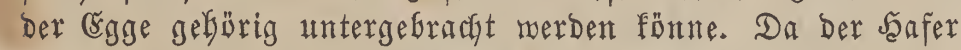

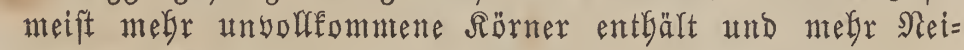
gung zum Dopyelmudhie lgat ala bie andern Betreidearten, fo imur er audy biffer gefüet merben als biefe.

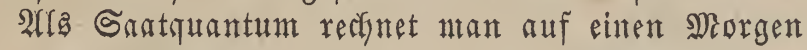

$$
\begin{aligned}
& \text { in Baben . . . . 6-12 Sefter, } \\
& \text { in Seffen. . . . . } 2-31 / 2 \text { Simuter utb }
\end{aligned}
$$

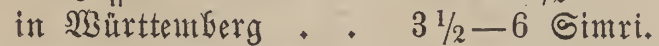

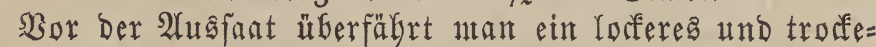
nea zeld mit Der $\mathfrak{B a l}_{\mathrm{z}}$, einen findigen ober feuchten $\mathfrak{B}_{\mathbb{D}}=$ Den mit ber Ëgge, Damit Die Saat gleidgförmiger auşänt, und mun bringt man den Samen fo unter bie Errbe, Dấ er geförig bon berfelben bederft wird, widrigenfalfs or ent= meder gar nicht feimen ober boch nur fahmächliche SBfianzen Gerborbringen mürde. Sft der ßoden felyr leicht, trodét und berunfrautet, Dber auch mebr bindig, menn nux gut Gearbeitet, Dofr iff man mit feiner Saat fpät Daran, fo ift

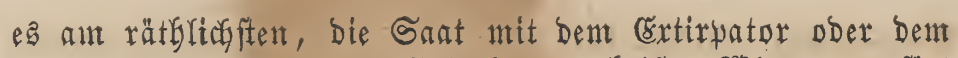

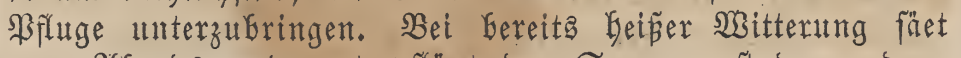
man Abends und unterpflügt den Santen erf́t den andern Tag, Damit er bie Nacht infer bum Thau befenchter merde. Dag Unterpflügen Des Samenz gefdyege aber immter mur bei gefjörig abgetroffuetent Boben, Denn bas fogenannte čnin= fichmeren Des Safers ift berwerflich, indem der Same, nacts=

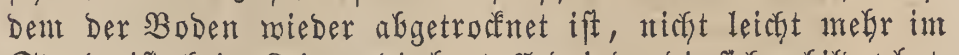
Stande ift, Geim Reimen bie Garte Erobrinbe, bie fich gefildet hat, zu Durchbrecten. 2luf Das Unterpflügen folgt Daš Čineggen, entmeder gleich nach ber Saat doer auch fpäter. Eine mei= tere 2 rt, Den Samen unter bie Errbe zut Gringen, ift bie vermittelf́t der Ěgge, und diefe gebraud man yorzugs̆meife Gei ber einfurchigen Beftellung bei bindigem, fotwerem und raubem $B$ oben und bei feuchter SSitterung; man mentet ant beften fajmere Ëggen an, Damit Der Sante tief genutg unter= gebracht merbe. 2luf Das Esineggen ober Unterpflingen Des

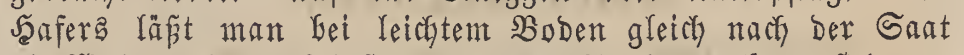
Die $\mathfrak{S a l}_{3}$ folgen, bei fafmerem und bindigem aber erft dann, menn Boben und Witterung trofen ftnd. - Naci Der Saat

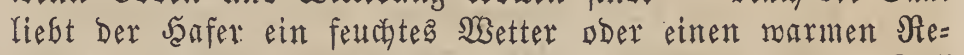

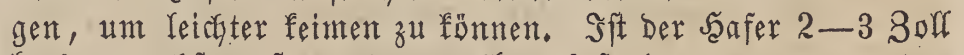
Goch geraactifen, fo eggt man ifn, befonders renn er unter= gepflugt morben ift, und walzt ifgn Darauf mit 3 ortbeil bet

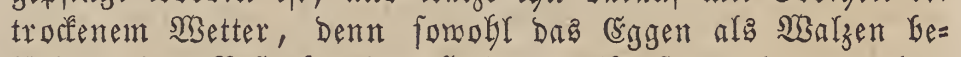
förbern Das Beftorfen des Seafers. Esbeño rendet man das ¿̌ggen und Walzen nach einem beftigen $\Re$ egen an, Der bent Boben werfalemmt hat, fobald er mieber troffen geworben ift.

Der Jafer reift fpăter als die übrigen Getreidearten, in füblicfen Gegenden im 24ugut, in nörblicfen ttmb bei fpảter 2(uâaat oft erft im September und Sftober; er mirb in Der Sanalbreife und meift in Schmaden geidntitten, doer bei befonberer Sable Der Salme abgerafft. Nach Dent ๔chnitt

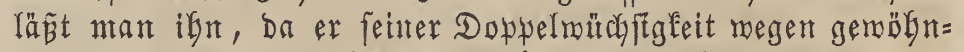
lich nod viele unreife sörner bat, nod fo lautge liegen, bis ex troffen ift und feine Rörner reifer gemorben find, Dann fäume man aber nicht mebr, ifn aufubinden, bamit

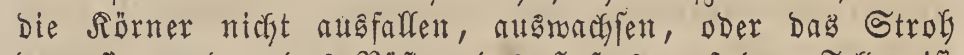

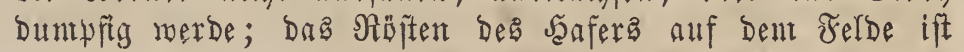
Dépharg Durchaus zu werwerfen.

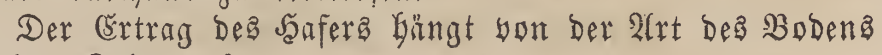
HID Der Rultur ab.

Man recynt Den Extrag bon einem Miorgen

$$
\begin{aligned}
& \text { in Baben . . . . 3-12 Malter und } \\
& \text { 10-27 Etr. Stroh, } \\
& \text { in Seffen . . . , } 3-6 \text { Malter und } \\
& 6-20 \text { Satr. Strof, } \\
& \text { in } \mathfrak{3 u ̈ r t t e m b e r g ~ . ~ . ~ . ~ 3 - 9 ~ S i b e f f e l ~ u n d ~} \\
& \text { 8-22 Cetr. Strulg. }
\end{aligned}
$$

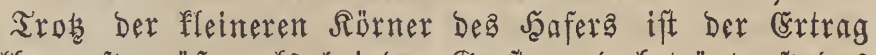
berfelben oft größer als bei Der Gerite und beträgt oft bas

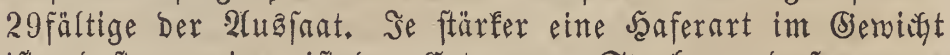
ift, Defto weniger ift ber Ertrag an Strof, und fo umge= fehrt, imner aber bedeutender als bei ber Gerfte. Der Berg= Gafer wird Gejonders gefuct.t. Da ber Jaafer Den Boben weit weniger erfoüpft als die Bierfte, fo fann man faft alle Früchte auf ifn folgen laffen, borausgefegt, Dap Der Boben nidyt zu nager, fondern zubor gebüngt worben fei; bejon= Dera gut gebeift nady ifu der Ruggen. 
in.

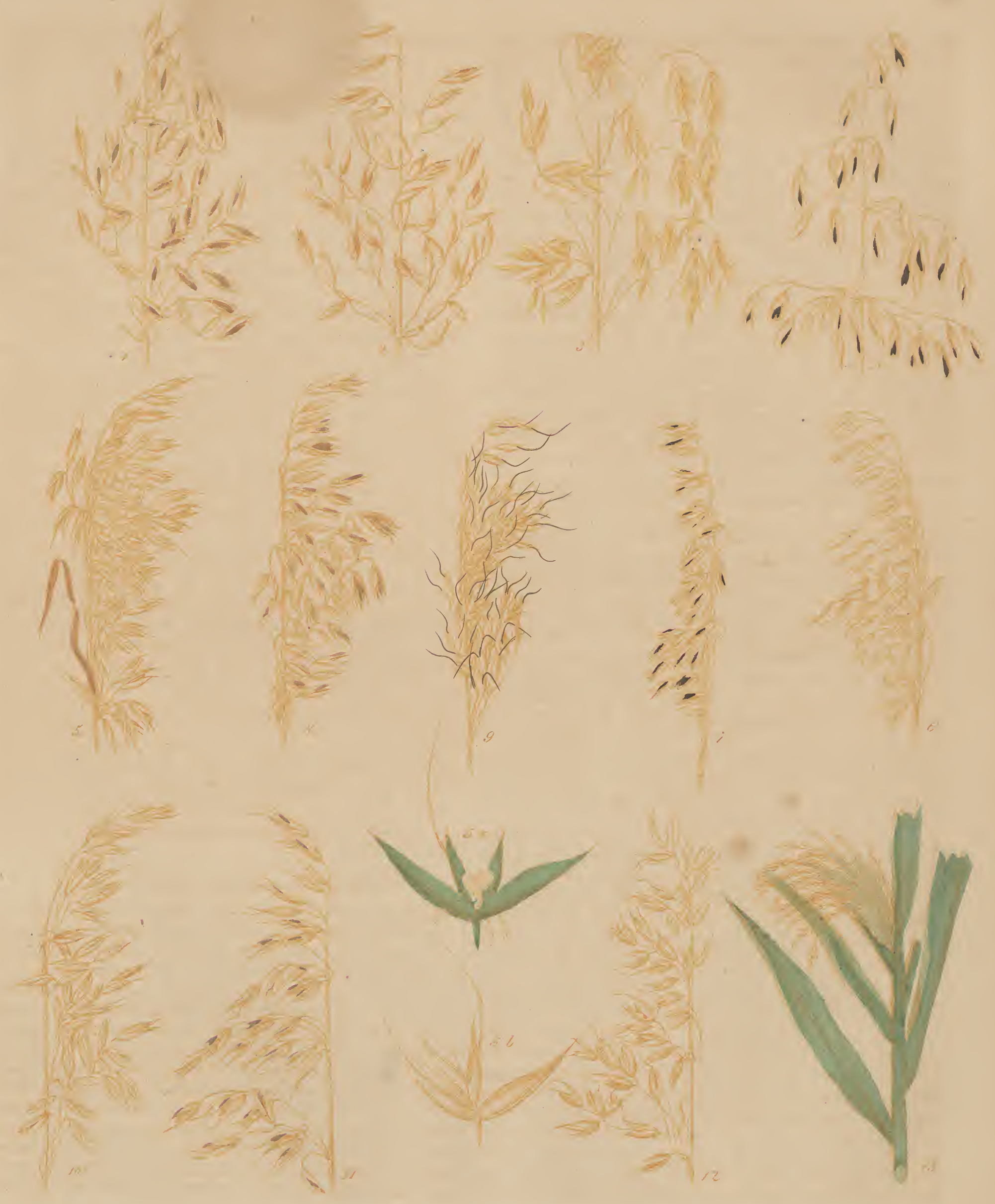





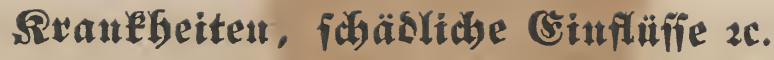

Der Safer wird unter Den Unfräutern am meiften yom Seberich Geimgefuct, und biefer fonn nur noif ganz jutg Durch die Eggge ausgerottet werden, ebenjo yom Flughafer, Avena fatua, L., und Der $\mathfrak{B}$ ucherblume. Am beften beugt man bem Heberbanonebnen dez Infrautez bor, wenn man Das Jaferfeld noch bor Winter beftellt.

Da Der Safer fith felten lagert, fo ift man aud meift Deg Schröpfents überboben.

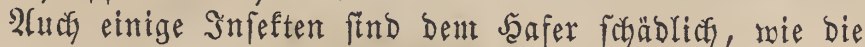
Rarye DeB Ichneumon culpatorius, nelcfe feine Rörner vernicftet, und die Musca avenae, bie feine Salme benagt, woburch die Rispen eine weipe Farbe erbalten und abrelfen.

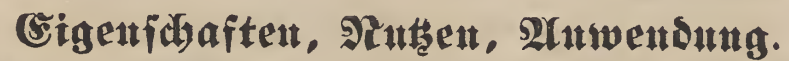

Der Sanfer entbält in 100 Theilen nabrbafte Beftand= theile nach Sprengel:

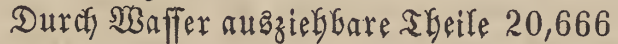

2lebfalf . . . . . 31,623

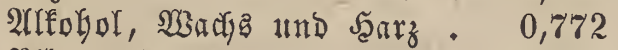

Pflanzenfajern . . . . 46,939

Nabrbafte Theile überbaupt . 52,289

Die Frübte entbalten nach Noger:

Stärfutegl . . . .

Dent geronnenen Gimeiš äbn=

licbe Materie . . . . 4,30

Buder und Extraftioftoff . . 8,25

Jettes Del . . . . . 2

(Summi . . . . . 2, 2,50

Sagrader fand in Der Afdye yon 2 \$ٓund Rörnern und 2 SFund Strof :

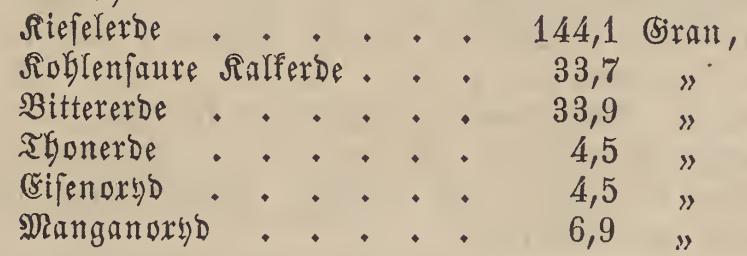

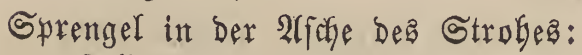

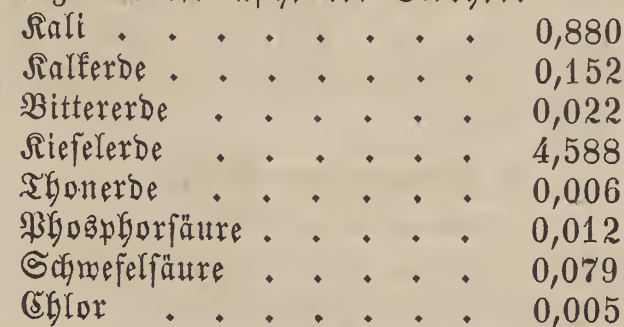

Der $\mathfrak{c a f e r}$ beftist weniger näbrende Beftandtheile als die (bierfte. Ant bäufigften dient er als ein febr gefundes und friftiges Futter für ßferde, Da er faft gar feine Rleber, bingegen biele Extraftibftoffe entbält, felten in (säbrung fontmt und fitf int Nagen in furzer Beit zu einem Srei umgeftnltet; man füttert ifn Gäufig mit Sä̊fiel, nur büte man fith, ifg zu jung, dompfig, formmelig ober ftrubig Den Siferden abzureicyen. (Er Dient aber auch anderem 2 ief zux Nabrung, wie den Şügnern, welche auf ben Senúp Deffelben fleipiger legen, man gebraudut ifn zum Mäften ber Schweine und (bänfe und gibt ibn abgefucht trädytigen und fäugenden sïben und Rälbern.

Enfwer, bfonom. Pfinasenfunde.
Der Şafer wird aud, Gefonders it fälteren (5iegenden, wie in Sayottland, im Norben won Sigmeden und Norme= ger, und it theuren Beiten zu Brod berbacfen, welchea zmar to famarfyaft wie das Berftenbrud, aber febr trofen, farwerberbaulidy ift und gerne Säure in Nagen erzengt. Wan bereitet aus bem Scafermebl mit $\mathfrak{W a f f e r}_{\text {gefocht }}$ ein angenebmes bielée, in Sabottland, bem nörolidyen Theile bon England, in Sameden und Norwegen und in Drient, Glop mit Waffer zu eittent Teig angerübrt und gebafen, die Safermeflfurben, Bannoifs, ferner die Sanfergrübe, Avena excorticata, welcfe bäuftg bet Diarrbỏen, Der Subr, anbaltendem Satarrh, Bruftentzündungen angerventet und bei Csntzündungen und frampfgaften Umftänden nit Mility zu einem Brei gefocht als zertheilendes und rinderndes Mittel aufgelegt mird. (5inen befonders guten (biries and Mebl bereitet man auz Dem gebörrten Safer in eittem Theile Der Sarmeiz, bon wo aus eit ftarfer Sandel bamit nach Deutich= land und Jranfreich getrieben wird. Man werfertigt aus Diefem (Soriefe febr fräftige Suppen und einen fodmadfyaftent Brei, und füttert mit Den yulberigen 2lbfall, Den man bein Durchfieben erbält, Rälber ober mäftet Bieb Damit. Beliebt in Fiebern als fublendes Mittel ift die Sanfertifane, mit Şaffer abgefodgte Grübe, weldyer Sudfer beigemifibt wird. Die Saferförner follen mit Serftenmalz vermifdgt ein gutes Weifbier geben.

Das Scaberftrob ift ein febr gutes Biebfutter, zunat weinn in Folge Des Doppelmuchfes noch zientich Rörner in

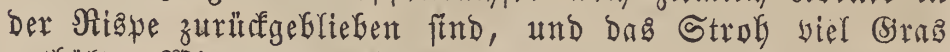
entbät. Wie Das Sierftenftrog, fo ertbeilt audy das Sarfer= ftrob ber Milch einen bittern (Sefchmad, aber nur went es bent Bieb ausfallieflict zur Nafrung angerwiefen wirb.

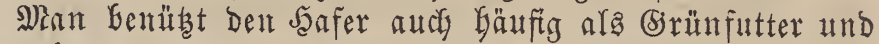
fann ifn zu diefent şefufe unter günftigen lumftundent 2-3nal dea Sabra fifneident.

\section{(Šefididate.}

Die alten (Siriedjen, Röner und 2(egsyter fonnten ben Safer nicht, ftatt feiner fütterten fie Den Bferden (Serfte,

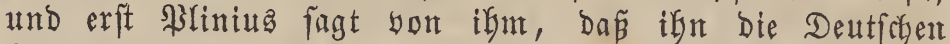
Gauten; Diefe benübten ben Safer ars Saryrungsmittel zu

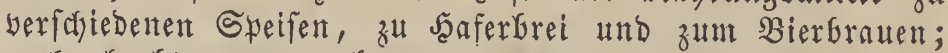

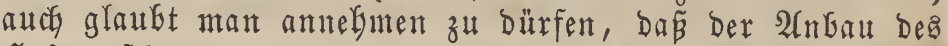

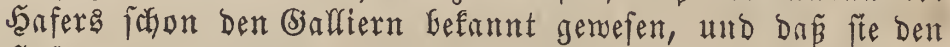

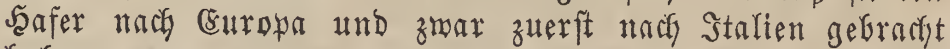
Gaben.

\section{Meifex gegranntex litapenbafex.} Avena sativa alba aristata.

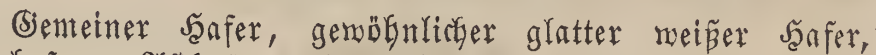

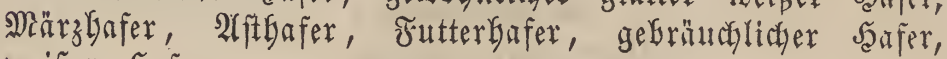
meiper Saafer.

Avoine ordinaire blanche et barbue. Avoine cultivée.

White common awned oat.

Salm 4 Fus goch und orüber, aufrecty, rund, Gobl, in Der Jugend bläulicfgrün, in der Steife Gellgelf. SBlätter $1 \frac{1}{2}$ Fú lang, 1 Soll breit, geftreift, mit ftark berwor= tretender Mittelrippe, die obern Blätter aufrecht, mit ge= bogener Spibe, blüulidgrün, bie ofiern Blattfleiden bon Derferben Farbe, die untern aber nebr gelblidgrün. Riape 10 
8-10 3oll lang, meî́t etwas einfeitig. Błhmenftiele 4-8, abwechielnd ftekend, an ifrem Snfertionspunfte wulftig, an Der Spitse Gaarförmig, nach oben an Zabl und \&änge afb= nefyend und zulebt blós noch zu $1-2$ ftebend, in der Jugend Gläulichgrün. 2lebrchen bängend, die obern häuftg $3=$, bie untern 2 jamig, bas gröpere Rorn gegrannt. Relch =

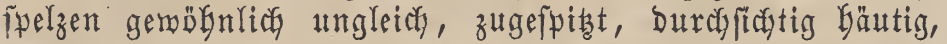
8-11rippig, an ber $\mathfrak{B a f t a}$ etwas aufgetriefren, reiflich doer gelblich, in Der Sugend mit blangruñliden Ripten. Die אronftelzen fürzer ala bie Relchipelzen, erft Glaugrünlidy

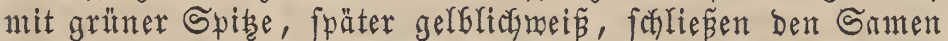
bicft ein. Samen buredfcheinend, feinbebart, mit zartem

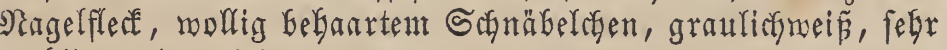
meblig und meich.

Diefer Safer ift am meiften werbreitet und wirb bäufig

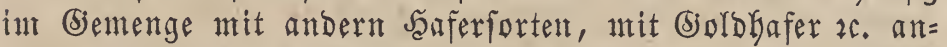

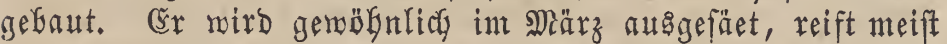
int $2 \mathfrak{A}$ fang Septembers, ift in gutem Boben fefr ergiefig und liefert ein gutes und fogpnes Stroh. Sm Hebrigen gilt Dra im 2 Afrgemeinen yom F̧afer bejagte auch yon biejent.

\section{Wei}

Avena sativa praegravis.

Avena sativa glumella alba mutica.

Avena anglica.

Sifmerer englifcher Saafer, fpanifacer reicher Saafer,

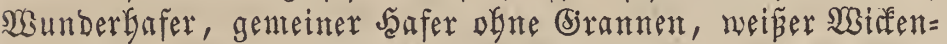

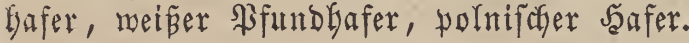

Avoine ordinaire blanche, sans barbes,

White common great grained oat.

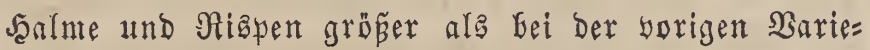
tät. Blätter breiter. Błhnenftiele abmechfelnd unten zu 8

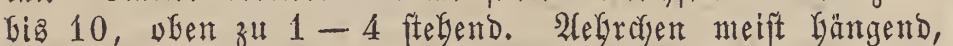
2-3fantig, aufgetrieben und ftumpf. Brannen feblen. Sa=

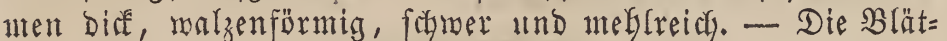
ter merben bei naffer 2 Bitterung und bei zu biefter Sant gern rupig und bie Niispen Grandig.

(̌r ift weit meniger werbreitet als ber weipe gegrannte

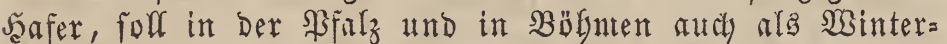
frucht angebaut merben, und man folf ifa nur bünn aus=

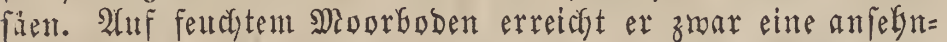
liche (Srröße, wird aber nicht fo fogwer, fondern mur grob= Gultiftg. (Er beftaudet fitch ftarf.

(̌r ift eine Der beften Jaaferjorten, und fein Ěrtrag ein $30=$ und unter befonders günftigen ltmftänden ein 40 fălti= ger, bebeutend ift auch fein Strobertrag. - Err miro in England zum Bierbrauen Genübt. - Nur die Jeălfte von ifut als PFerbefutter Dient zur Sättigung.

\section{Exübbafex.}

Avena sativa praecox.

Arena georgiana alba.

Avena podolica.

Avena benghalensis. v. Witt.

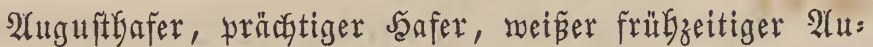
guftbafer, Frubbafer aus Georgien, Jrübbafer aus Podolien, Jrüblyafer ato 2 (nterifá

Avoine hâtive ou précoce.

Premature oat. August oat.

2(ebraten etwas weniger ftarf arz bei ber sorigen Barietăt und aufgetrieben und ftumpf, felten gegrant, in Uebrigen wie bei Der yorigen $\mathfrak{B a r i e t a ̆ t . ~}$

Safeint eine 2lGart Des borigen zu fein; er zeichnet fiery

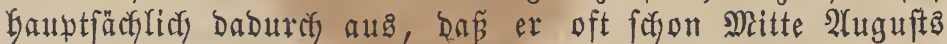
reift; er gebeift fifon im Mittelfoden und eignet fich yors zugämeife für gefirgigte begenden, in weldyen andere $\mathfrak{3 a f e r =}$ forten oft fegr fpät ober gar nicht melgr zeitigen. Seine säner find fefre meblreich, falfen aber bei Heberreife gerte aus.

\section{4. fiartoffelyafex.}

Avena sativa turgida.

Avoine de pomme de terre des Anglois.

Potatoe oat.

Salme in gutem Boben bäufig Göher als bei ben bor

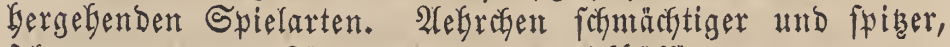
felten gegrannt. Rürner grof́ und biffétuftg.

Das Strob Iang. Err murbe in Ëngland, in Gumber= land auf einem Rartoffelacfer entbecft, wo er früber gropese 2(uffégen gemucht bat und sielfeitig angebaut rutrbe; in Deutichland und in andern Begenden wirb ef nicht iut (5roßsen fultivirt.

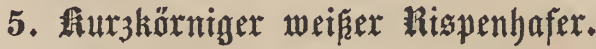

Avena sativa alba mutica, seminibus brevibus.

Weip̈er ungarifcher Jaafer.

Avoine ordinaire blanche, à courtes graines.

White common short-grained oat.

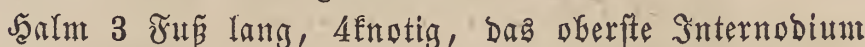
fegr lang; Slätter 148 oll lang, $1 / 2$ 8ofl Greit und barï= ber, geftreift, bunfelgrůn; Blattfcheiben gewunben, geftreift;

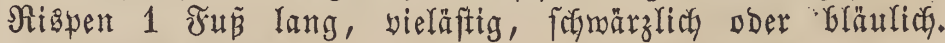
Blumenftiele abmechfelnd ftehend. STefrchen zahlreich, etmaz flein. Sirannen fellen meift. Selchfpelzen meifyt gleidy Iang, feinrippig, fürzer aber aufgeblafener ala beim meinen unge=

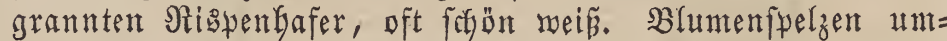

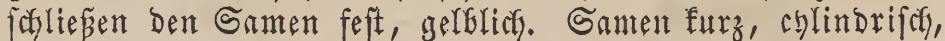
weiplict) und melglreiry.

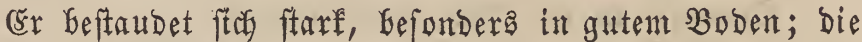
Rörter fitt' zwat flein, aber zahlreid, fofwer, bünnfülftg und jefr meblig. Der Strobertrag ift unbedeutend, ba bie Sanlme nicht Gody merben.

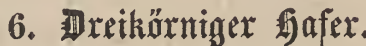 \\ Avena sativa trisperma.}

Slumplyafer, boppelter Şafer, (5äbeleß̆afer.

Avoine ordinaire blanche, à trois graines.

Common three - grained oat.

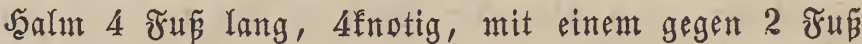
langen obern Internobium, Glaugrün in Der Jugend. SBlät= ter 15 3oll lang, 3/4 3olf breit, geftreift, in ber Jugend

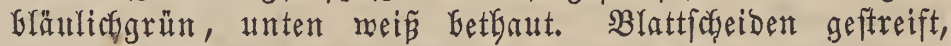

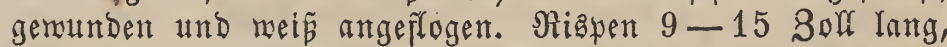
oft auf 2 Seiten focmăler, jung Glăulichgrün. Blumenftele äfig. 2lebren ftarf bauthig aufgetrieben, an ber Spibe offenftebend laffen fie meift 3 fïrner feben, won Denen 2 gemöbnlich mit (Sirannen berfegen find. Selchpelzen ftarf auf= geblafen, mit bäutigem und etwos fadarfem Nande, 11-13=

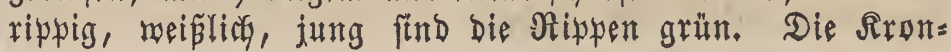




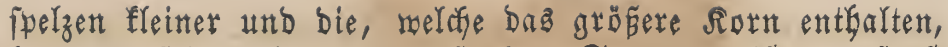
lang zugefpidst. Grannen aufredst. Samen meift 3 , fonft ruie beint gemeinen fagfer.

SBird in einigen Begenden SBüttentergs fultibirt. Die

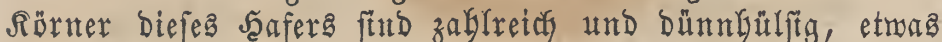
flein und weniger meflreich. 2Ut Strobertrag Gingegen fonmt er bemt genteinen Sagfer gleidf.

\section{Gelbex ungegrantertatopenbafex.}

Avena sativa flava seu aurea, glumellis muticis.

Brolbyajer.

Avoine ordinaire jaunâtre sans barbes.

Common yellow awnless oat.

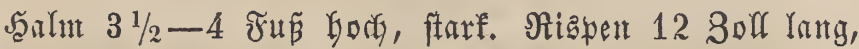
gelf. Alebrefen oft meit geoffinet, $2=$, oft 3 fantig. Relds)= fpelzen meizlitggelb, mit 11 Ripwen, bie in Der Jugent bläulidygrün find. Samen gelb, oft fădön goldogelb. - Die

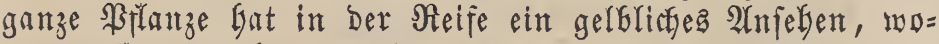

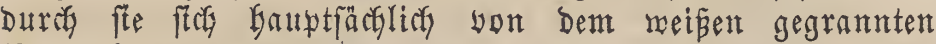
Rispenbafer auszeichnet.

rrgiebig, aber noib menig befannt.

\section{8. $\mathbb{E} \mathfrak{e l b e r} \mathfrak{g e g}$ rannter}

Avena sativa flava glumellis aristatis.

Begrannter Bolbhajer.

Avoine ordinaire jaunâtre barbue.

Common yellow awned oat.

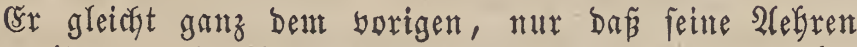
noch weiter auseinander gefpreizt und in feuchten Gafr= gängen gegrannt find. Die Rörner find meflrelif und bünn= Güliftg.

Sein (rrtrag an Rärnern und Strof ift ganz mün= forjensimerth.

\section{9. 你rauter gegrannter Riguenhafer.}

Avena sativa aristata, semine fusco. Römer et Schult.

(sictyelfafer, brauner Scafer, bunter Şafer.

Avoine ordinaire brune, barbue.

Brown and awned common oat.

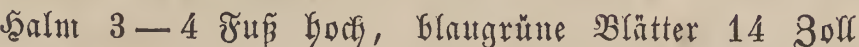

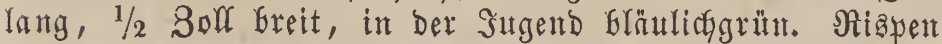
1 ซ̛ur Iang, aubigefreitet. Blumenftiele lang, aufrectft, in

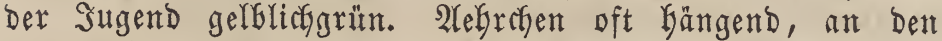
untern Stielen oft 16-18. Relefipelzen lang, aufgetrieben,

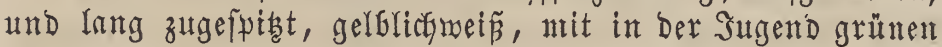

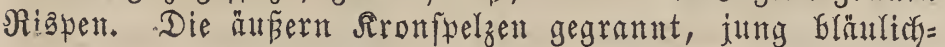
grün, bann rötglich, netgr pder meniger gelb, Gellbraun biz focharzbraun. Srannen lang, meift gefniet, fognarzbraun,

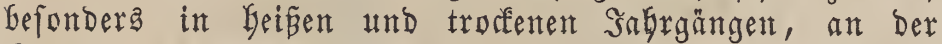

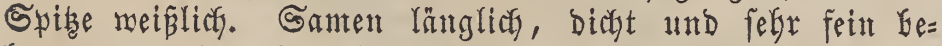

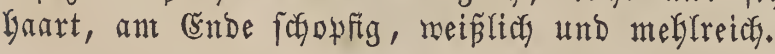

In gebirgigen und waldigten Begenden wird er băuftg gefaut, er reift bor voer mit Dent gemeinen beafer, artet aber in zu leichtem ober audy zu formerent Boben gerne

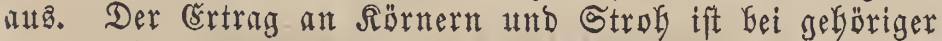
Sultur Gedeutend. Die Rärner fetto grof́, meglreidy, aber

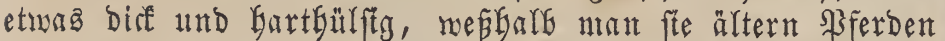
nicht füttern foll. Das Strof ift füg̈n, grof́ und meich,

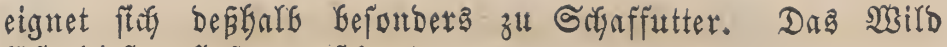

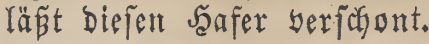

\section{Mothex gegramntex kitspenhafer.}

Avena sativa aristata, seminibus rubidis.

Rother Esictelgafer, rother Scafer.

Avoine ordinaire rougeâtre, barbue.

Red and awned common oat.

Sit nur eine Barietät Des vorigen Eichelfafers und

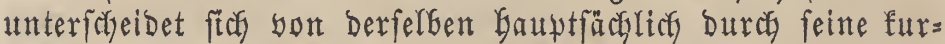
zen Şalme, burch igre fürzeren, etwas Gängenden Blumen=

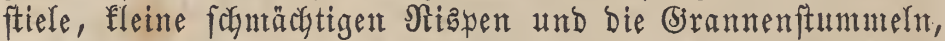
bie aber bäuftig ganz mangeln, and baburch, baź bie Siron=

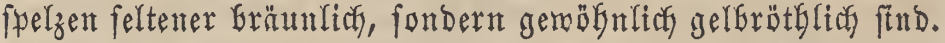

\section{Schwarzex gegranntex hizisenbafex.}

Avena sativa nigra. L.

Avena sativa glumella nigra, aristata. Séring.

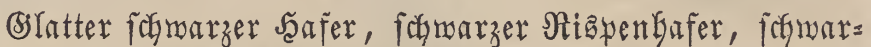
zer Seafer, Gefirgabafer, Mmaldyafer.

Avoine ordinaire noire, barbue.

Common black awned oat.

Şaln febr niebrig, oft faum 2 Fus boch, fteif, auf=

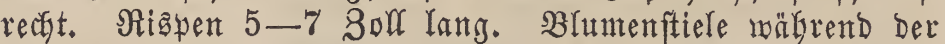

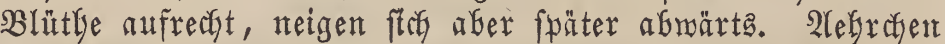

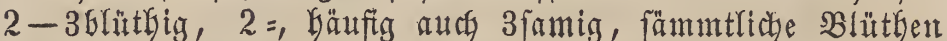
frucgtbar. Sielchfpelzen genöbntiog bauchig, ftarf gerippt, weip̈lich voer gelblicf. Die äufern Sironfpelzen mit Dent Rörnertt vermachfen, wentig gegrannt ober mur ftummels

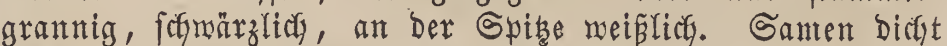

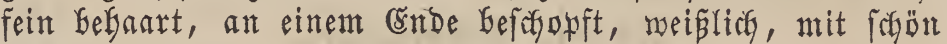
reipent פeblyunfte.

Diejer Safer reift fegr frübe, oft fochon Ërbe Juli'a,

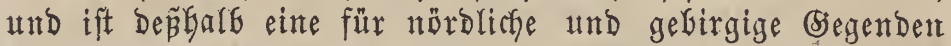

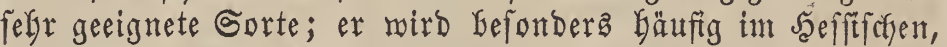

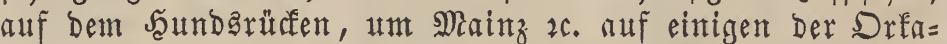
Dent angebaut. In Bezielyung auf feinen Rörnerertrag fant

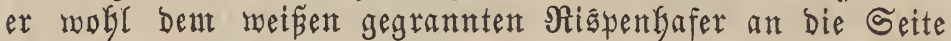
geftellt werben, unt fo geringer aber ift fein Errtrag an Stroh.

\section{Sidwarzex ungegranntex \#ispenbafer.}

Avena sativa glumella nigra mutica. Sering.

Avoine ordinaire noire mutique.

Common black awnless oat.

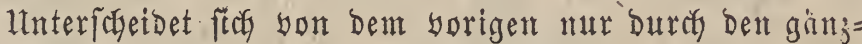
lichen Mangel an Brannen 1 tnd möchte, wie altch bie zmei folgenden, faft eine und biefelbe Gorte mit bemfelben fein. 2hfes Hefrige wie bei bem yorigen.

\section{Sibwarzex Augutthafer.}

Reift frübe, taugt dep̧halb ebenfalls Fefonders für ber: gigte biegenden, gebeigt in mittlerem $B$ oben und ift ergiebig.

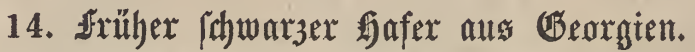

2rfes wie beim sorigen, folf zu oft angebaut wieber it ben fobrarzen gegrantent ober ungegrannten Saafer auss arten. 


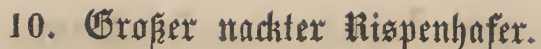

Avena sativa, seminibus grandiusculis nudis.

Arena sativa nuda.

Avena sativa chinensis.

(şineftfcher J̧afer.

Avoine ordinaire à grosses graineș nues.

Common naked oat.

Salm 4 Fúp lang und länger, unten oft felyr ftarf, in Der Jugend Gläultich ober gelglicf)grün. Blätter 16-17 8 oll lang, $1 / 2$ 3oll Greit, Geffgrün. Siâpen oft 1 Fú rang, nusgebreitet. Die untern Blumenftiele befonders lang. 2lefr= then zum Theil gegrannt. Reldypelze pitt 1 Soll lang, am Rande bäutig, 11-13fach fadyady gerippt, und bie grözere Rörner entfaltenden weit geöffuet. Die äupern Sironfpelzen

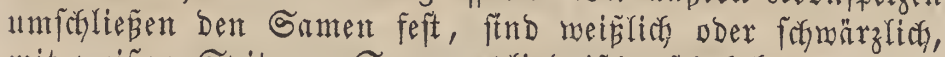

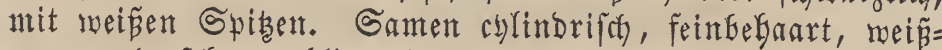
grau und fefr meglig, faflen in ber Solfreife und beint Drefchen gerte aนs.

\section{Avena orientalis. Schreber.}

\author{
Avena heteromalla. Mönch. \\ Avena racemosa. Thuil. \\ Avena sativa. $\beta$. Trin. \\ Avena tartarica. Ard. \\ $\beta$. Avena unilateralis. Sering.
}

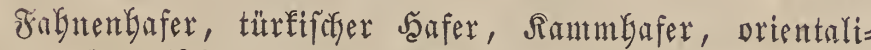

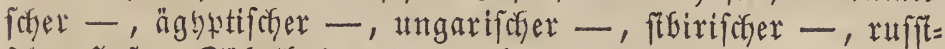
fober beafer, Säbelgafer, Tamtentafer, 3obdelfafer, Trauben= Gafer, Beilenbafer, melficher Şafer.

Avoine de la Turquie.

\section{Mrtent = Shatafter.}

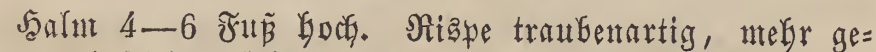
brängt, einfeitig, fafmenartig, meift mit niffender Spibe. 2lebrchen nach eitter Eeite Gängend, 2-3Glütbig, $2=$, felten 3 famig. Sielchipelzen etwas bauchig, längliç zugefpibt, 7-8rippig. Rronfpelzen fürzer, mit Dem Samen verwarly=

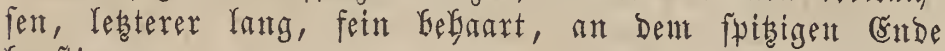
borftig.

\section{SIIthe = Beit und $\mathfrak{D a n e x}$}

গuli - 2luguft. $\odot$.

\section{0x}

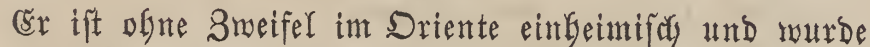
yon ben Türfen bei ifren Einfälfen in bie Donaugegenden, Ungarn 2c., bielfeidgt aud burdy bie אreuzfabrer aug affen voer 2Aegypten nach (suropa gebracht. Die Sultur ift fegr werbreitet und wird befunders Gäuftis in Itngarn betrieben, wo fe forjon in früben Beiten befunt war.

\section{Rultut.}

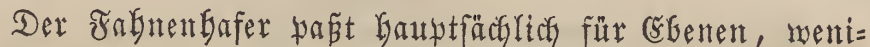
ger für Gjebirgşgegenden. Die 2luşarat beffelGen foll zeitig gentacht werden, ba er fofwer feimt und fpäter reift, gegen

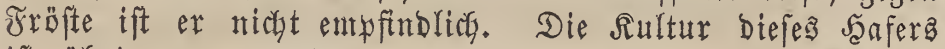

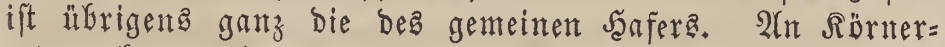

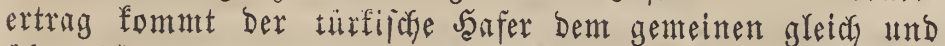
itbertrifft benjelben fogar oft bei gutem $\mathfrak{B}$ oben und bei guter
Sultur, aucf Stroly gift er gemöhnlicf mebr. Die Rärner ftnd etwas birffülftg, aber fegr meglig und ein gutes Pferbes futter, falfen aber beim Drefchen ungerne auz.

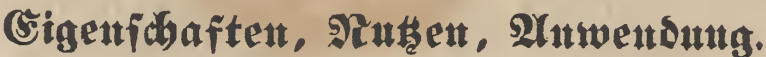

Das Struh wirb yom Biefe Dent Dea gemeinen Fafers yorgezogen, Da inmer Rörner in Den Rigpen zurürfbleiGen,

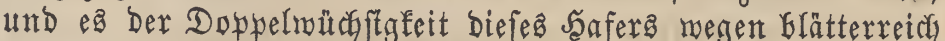
ift; audy ertheilt biejes Stroh Der Mild einen weniger bittern (S)effynta af ntit.

\section{Meiker gegrannter \$abmenbafer. \\ Avena orientalis alba aristata. Avena tartarica.}

Taubentafer, welfoser Saffer, podolifcher f̧afer, Mlor= gentafer, Bartmifdyafer.

Avoine d'0rient blanche et barbue. Avoine unilaterale.

White tartarian awned oat.

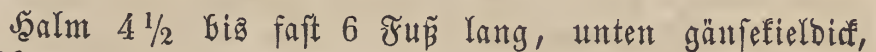
5-6fnotig, geftreift, gelb. Blätter 18 3oll lang, $1 / 3-1 / 2$ Soll breit, Geffer oder bunfelgrün. Blattfdeiden geftreift.

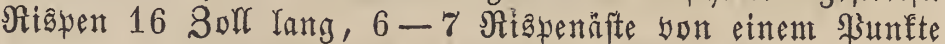
oben ausgebend. Blumenftiele abmechjelnd, vft 6 Boll lang und fegr äftig. 2lefyctyen ntefr ober weniger nach einer Seite bängend, 2 famig, felten 3 \{antig. Orannen fund faft imner vorfanden, mur feltener, wenn bie Siflanzen in fettent Boben und zu bicht ftelgen. Fielchfpelzen lang zugefpist, geftreift, reislich ober gelblich, in Der Jugend mit fattgrü= nen Rippen. Sromitelzen gemöhnlid) bidf, mit bent Santen

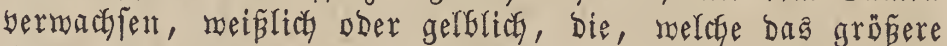

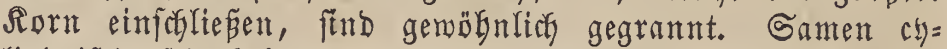
linbrifch, fein bebaart, graumeis, oben und unfen zugefpibt, Ditmbülfftg, meblig, mit zarter Reimgrube unb zartent Nagel= flest und am obern (snde falowfig Gebaart.

Diefe 2(rt mirb hauptfäcblich bäuftg in Der Rebante und

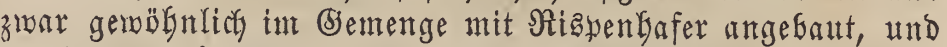
verbiente wobl auch bei uns eine größere seachtung. Da er yon Spätfröften nicht leibet, fo fant ex früb ausgefüet werben, und es ift biép jognr faft nöthig, da feine $\mathfrak{B}$ egeta= tiongperiobe 4 Mionate ift. In gutem Boben Geftorft ftef biefer Janfer borzüglich uttb gibt auberorbentlich fofwere Nispen, wirb aber befonders gerne boppelmütiftg. Die Rör= ner geben, nachdem man fe mur furze Seit Der Thauröfte unterworfen, Gein Dreforen gerne aแs Den Spelzen.

Sie find ein gutes \$fFerdefutter und fönuen aud zu Brod, Jeafergrübe, Jaafernebl und zun Bierbrauen benübt

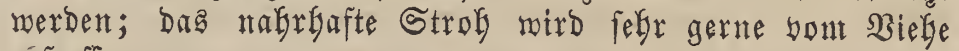
géfreffent.

\section{Weifer Avena orientalis alba mutica.}

Avoine d'0rient blanche sans barbes.

White tartarian awnless oat.

Dem sorigen faft in SHent gleidf; die Rizpen aber meift fleiner, weniger Aebrafen and inmer ofme Grannen.

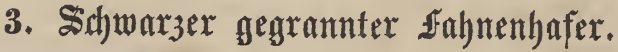

Avena orientalis nigra.

Sabmarzer Fabnenbafer. 

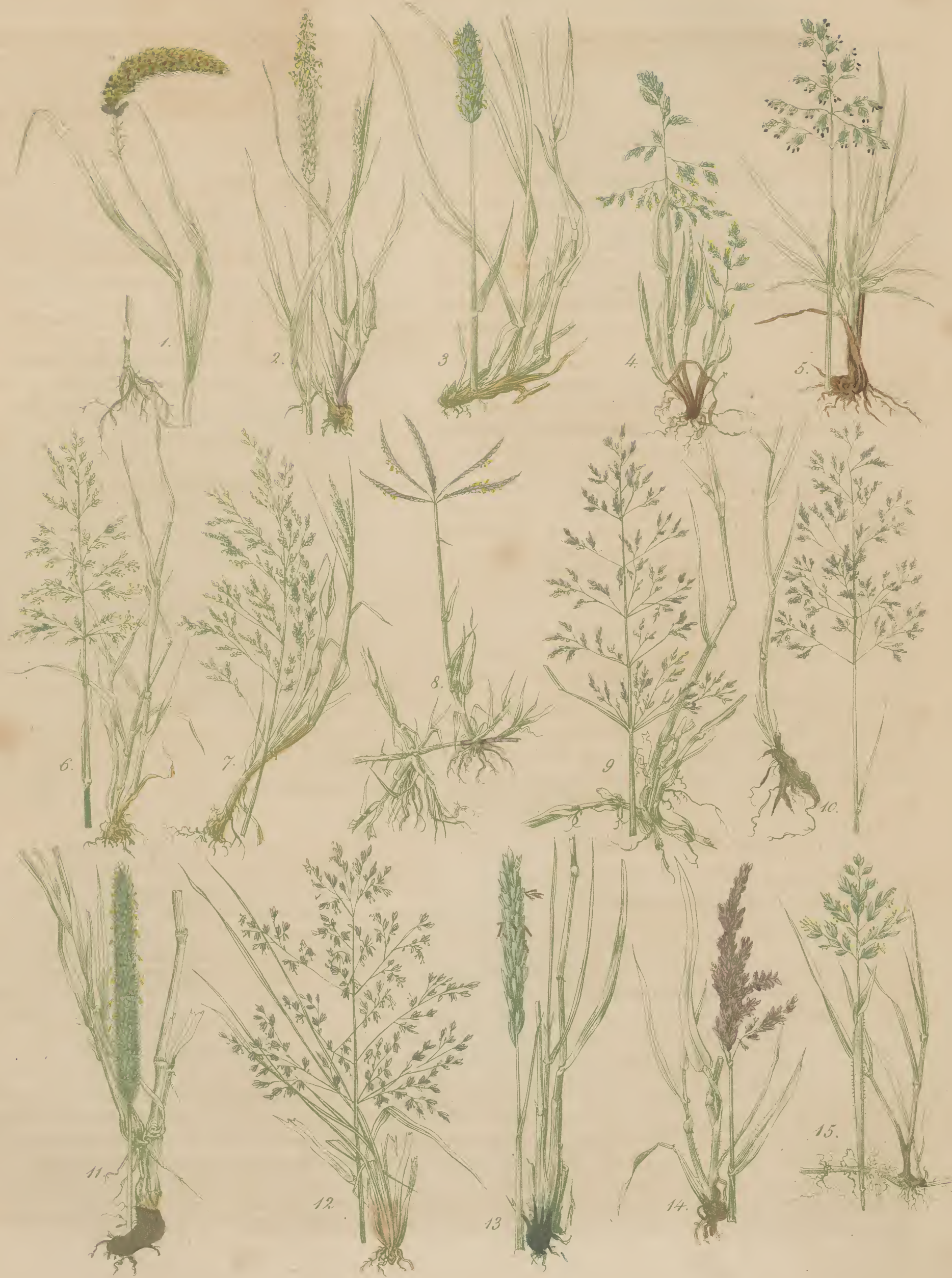
Avoine d'0rient noire.

Black tartarian oat.

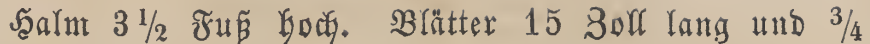
3oll Ereit. Rispen 10-12 3oll lang, jung Dunfelgrün. Blumenftiele bünn. Sebrefen meift nach einer Seite bün= gend, 2-3 fanig. Sirannen feblen bäufig. Seldafpelzen weï̈lich, unten gelb. Sronfpelzen ntefr ober weniger braun

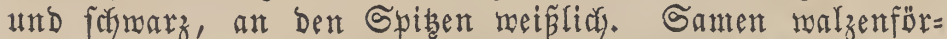
mig, bidst und zart bebaart, ant fpiben ernde forpyfig,

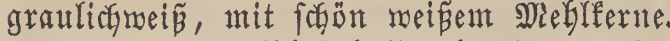

(Ex foll in Rbeinbeffen bäuft's angebant werben, er be= ftaubet fict fefr gut, er bat nur eite Begetationsperiobe bon $3 \frac{1}{2}$ Mionaten 1 nd wird faft mit Dent firwarzen Safer reif. - Nan Gat aud fobon gelungene Berfucbe gemaift, ifn als Winterfrudgt anzubauen. - Er ift einer Der ergie=

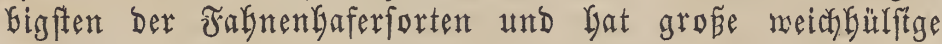
Söner. Der Strobertrag Dagegen ift gering, eignet fich übrigenb feiner Steifbeit wegen nisft zur Biebfütterung.

4. Grofer nacht/amigex Jabnenbafex.

Avena orientalis nuda, seminibus grandiusculis.

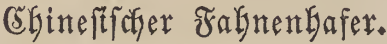

Avoine d'0rient à grosses graines nues.

Great grained naked tartarian oat.

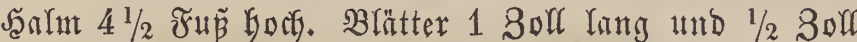

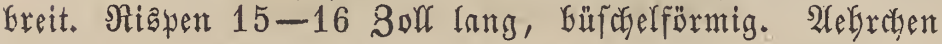
$3-4$ fantig. Sieldfipelzen aufgetrieben, lang zugefpibt und bäuftg meit flaffend, mit 9 Gerborragenden ßrippen. Iron= fyelzen meift formarzbraun, an Den Spiben gelblich. Samen yon Der Giröpe Der Noggenförner, walzenförmig, fein, an ber Spike fdopfig bebant, Gräunlidyeín, mit etwas breiter Reimgrube und ganz weiß̈en Mchlferne.

An Ertrag fommt er faft Dent weipen gegrannten Fabnenbafer gleich, und bas Strob ift buch.

(5) Gleiben uns jebt noch foldye Sanferarten zu befarei= ben ifbrig, beren sörner ztwar nod benübt werben fönmen, relefe aber feltener diefer, fondern mebr Der Benübung als (S) runfutter megen angebaut merben.

\section{Avena strigosa. Schreb.}

Avena nervosa. Lam.

Danthonia strigosa. Beauv.

$\beta$ Avena alba. Cav.

Avena agraria. Brot.

Avena arduensis, Lejeun.

Avena Cavanillesii. Hort.

Avena Freyta. Orteg.

Avena hispanica. Hort.
Sandbafer, Saubgafer, Siraubafer, Burbafer, geftreif= ter: Safer, Rarthafer, Sietreidebafer.

Avoine strigeuse. Avoine nerveuse. (franz.)

Meagre oat. (engl.)

\section{2liten = Chatafter.}

Scalm oft 5 ซ̛น

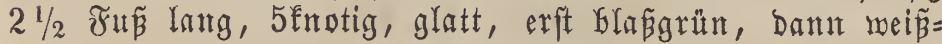
licf). Blätter 12-13 3oll lang, 3/4 80ll breit, beffgrïn. Blattjcheiden erbaben geftreift. Riâpen 14 Sull lang, nach einer Seite gericytet roie Der Fagnenfafer, Daker bon csini= gen auch zu ifm gezăglt. Blunenftiele fegr bünn, bie untern länger. Alebraten zart, 2famig, 1grannig. Brannen ftarf,

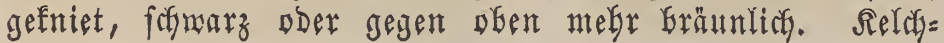

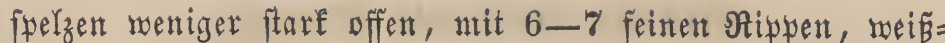
lich. Rronfpelzen rötglichbraun ober figmärzlich, und bie Das grösere Rorn einfdhließenden gegrannt. Samen flein,

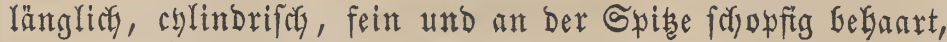
etwas rauh, leicht, birffülftg, graulich, mit Greiter aängas=

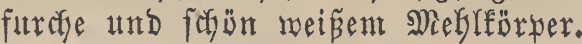

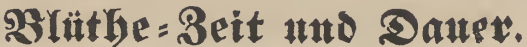

รuli - 2lugut. $\odot$.

\section{פYorkmmen.}

(Ex wächąt wilo in Deutfoland und Franfreid unter an= Derent Betreide, an Wegen, $\mathfrak{A}$ ferrändern, Băunen, und

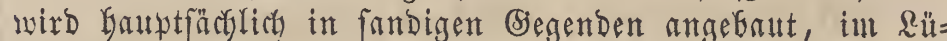
meburgifutyen, Eellifichen 26.

\section{Nultut.}

Der Sandhafer wirb yorzugameife in eittem reichten, fanbigen ober fteinigten Boben angebaut, wo feine andere Frudyt, ja nicht ciumal melyr andere Seaferjorten fortfommen fönter. Wian fann ifn, ba er eine furze Begetationaperiobe Gat und Sälte ifm nicht leidyt fodabet, früh ober fpät aus=

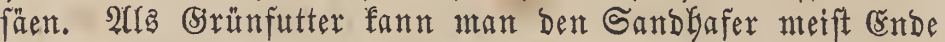
Mai’ zum erftenmale mäben, fpäter zum 2ten, und it gutem 2 oben und bei günftiger 2 Sitterung oft zum 3 tennale.

\section{Eigenibaften, Nutset, 2 tuwendutg.}

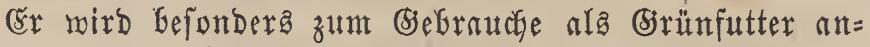
gebaut; Denn obgleich bei guter Siultur unb bei gutem $\mathfrak{B}$ oben feine fonft fleine Ganen etwas gröber, bünnbülftger und meljlreidser werben and einen guten Ertrag geben, zu Biebfutter, auty zur menfollichen Nakrung, zur Bereitung

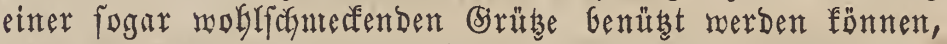
fo rirb bod ein Ranbmirth zu Diefem 3werfe nicht wogl einen guten Boben mit eitter Ssetreiseart anbauen, bie faft alfen andern an Nubbarfeit nawhteft. Der Ganblafer ift unter anderem betreide feiner ftarfen Beftrubung wegen ein forjäblictes Unfraut.

\section{Avena brevis. Roth.}

Avena nuda. Thuil.

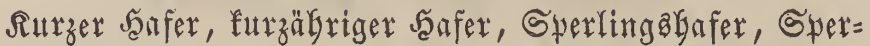
lingşcthabel.

Avoine courte. (fratt.)

Short-stalked oat. (engr.)

\section{Siten = Ghanater.}

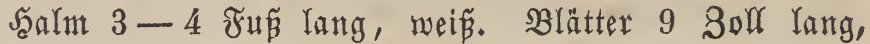

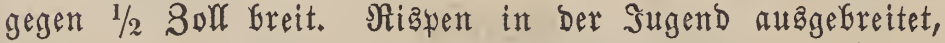
zielyen fech aber bald zufammen, etrag eimfeitig. 2abreffen fint nach einer Seite geriaftet, 2jamig und 2grannig. (Brannen gefulet, won ber Bafts an gemunden und farmärz= lich, Dann mefr ober weniger bräunlicf. Srunfpelzen mit Dent Gament vermachfen, fodmärzlich ober Gräunlich, an bent Spisen belfer. Samen flein, cylindrifd, oben und unten fpisig, mekr ober meniger ftarf grau ober meíflich, bicht und fein befanat, am obern Ende fisopfig, mit gelblictent Nagelflecte, Greiter Reimgrube und ganz weipem Meflelpunfte. 


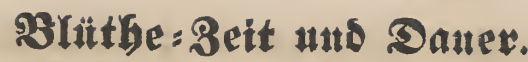

Iuli - 2uguft. $\odot$.

\$orfommen.

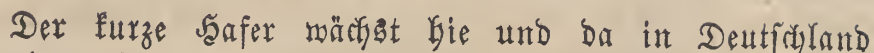
unter Dent Betreibe rwild, wie in Defterreich, Brenten zc., Gei Spa unter bem Pamen Sperlingsfonabel gefaut.

\section{Sultur.}

In etwas frifftigem und feuchtem Boben beftaubet er fict) ftarf, lagert fitid aber bei Dicfiant febr reicht und zeitigt in einem Beitraume yon $31 / 2$ Monaten.

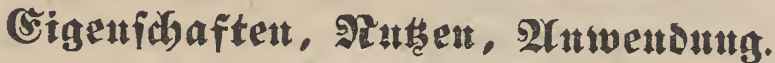

Die Rörner Geftben wenig Nebl, überbaupt wenig năh=

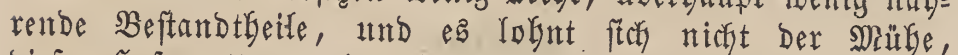

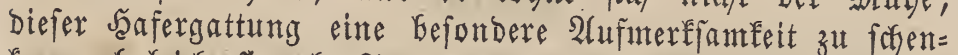
fen, vbgleicf fite als Jutterpflanze Der weiçen und blätter=

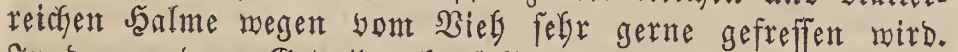
Sn bem andern Eetreide ebenfalls ein nachtyeiliges Itnfraut.

\section{Avena argentea. Willd.}

Avena sesquitertia. Willd.

Avena distichophylla. Schrad.

Avena disticha. Lam.

Trisetum argenteum. R. S.

Trisetum distichophyllum. $\beta$. Trin.

Silberbafer, brittbalbblüthiger baafer.

Avoine argentine. Avoine deux et demiflore. (franz.)

Silver - coloured oat. (engl.)

\section{Arten = EGarafter.}

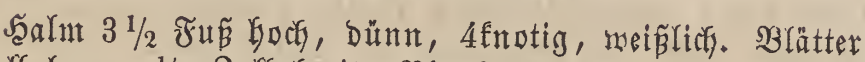

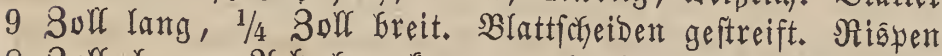
8 Solf lang. 2lebrchen furz, nach einer Seite bängend, 2-3famig, 2grannig. Brannen gemöbnlid gebogen, unten

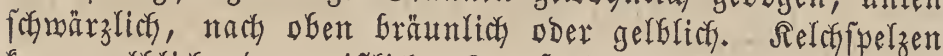
furz, gelblich ober weißßlich. Sironfpelzen gelblich, mefr doer wentger Gräunlich. Samen furz, längliç, graumeiø̋liç, mit weífent Mieglfern.

\section{Błäthe = Beit แtto Daner.}

\section{ริเni - 2tuguft. 4.}

\section{S2orfommet.}

In Deutichland, Deftreich, Sableften, Sachlen, : im

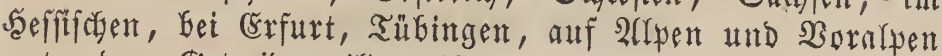
unter bem Setreide mildwachfend.

\section{Nultux.}

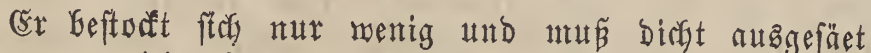

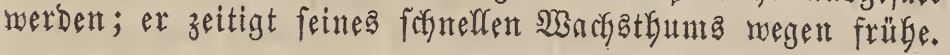

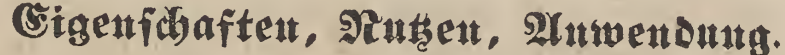

(Er mirb fo menig als bie beiden borigen feiner fäbr= nex wegen, fonbern nur bie und ba zur Benubung als

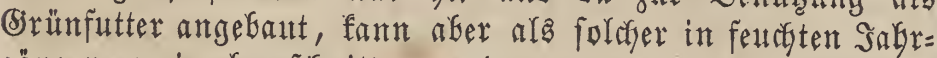
gängen zmeimal gefofnitten merben.

Avena nuda. L.

Avena nuda, seminibus exiguis.

Avena nuda microsperma.

Nadfter Saafer, fleinfamiger nadter Şafer, fleiner nadte fantiger Jalyentafer, Spinnbafer, Spinnenfafer, tartari= fojer Srübbafer, Sagogafer, Sanbjafer, Grübbafer, tarta= rifoder saafer.

Avoine à petites graines nues. (fræatz.)

Naked small - grained oat. Pillcorn. Pilure. Pillis in Cornwallis. (engr.)

\section{Arten = EGarafter.}

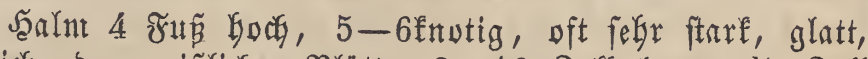

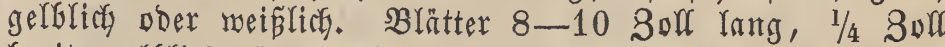

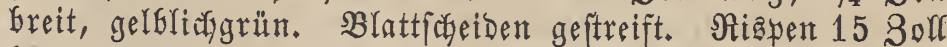
lang, einfeitig und mefgr traubenartig, meipgelblicy. $\mathcal{A}$ ehr $=$ chen meift nach einer Seite gerichtet und oft biele ofine Sament. Brammen feit, ftarf gefogen, gelblich, gegen bie Bafts Gin dft bräunlich DDer graulicf. Sironfpelzen Der 2 untern $\mathfrak{R}$ örner gegrannt. Relchplpelzen fürzer als gorige, lang zugefpikzt, weit geoffnet, bünnhäutig, glatt, 9rippig, weipliç. Samen flein, platt, oben und unten fpis, am

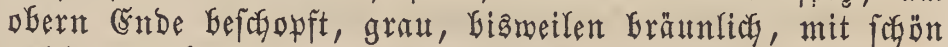
meí̄en Diegrerne.

\section{SIlüthe: Beit atto Daut.}

Suni - গuli. $\odot$.

\section{Yorfommen.}

Ex swird zuweilen in Deutfalant wildrachfend gefun= ben, autch bie und ba bafelgft wie in Deftreich, fermer in Ëngland, Grfottland und Spanien fultivirt.

\section{Sultux.}

Der nadete Safer werfangt feinen Gejonders guten $\mathfrak{B}_{0}=$ Den und Darf, weil ex fich ftart beftorft, mur bünn augige= fäet werben. Seine Vegetationsperiode ift furz; erft int Mai

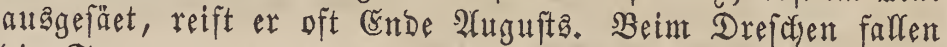
bie Samen ungerme ats, um fo leidyter aber bei Heberreife auf Dent Jelde.

\section{Eigenfidaften, Nutzen, Atwendutg.}

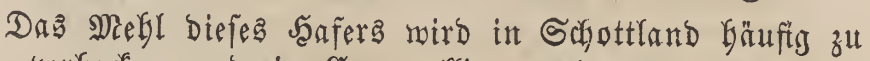
Brud berbacten utrd in Connwalfis macht man aus feinen

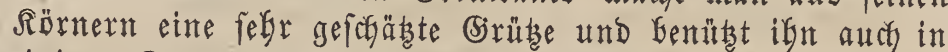
einigen Biegenden zunt Bierbraten. Das furze und reictse

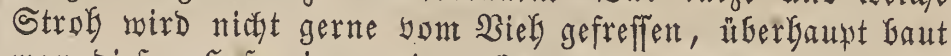
man biefen Jaafer in menigen Segenden an, Da ber Ërtrag an Sörnern fomol als an Strof zu unbebeutend ift.

\section{Panicum. L. Spr.}

Bambusella. Rchbch. Brachiaria. Trin. Cabrera. Lagasc. Digitaria. Hall. Dileucadea. Rafin. Echinochloa. Beauv. Flexularia. Rafin.
Glanduliloba. Rafin. Harpostachys. Trin. Ichnanthus. Beauv. Isachne. R. Br. Ischnanthus. Roem. Schult. Miliaria. Trin.

Oplismenus. Beauv. 
Orthopogon. R. Br. Paractaenum. Beauv.

Tricholaena. Schrad. Urochloa. Beauv.

Phanopyrum. Rafin. Virgaria. Trin.

Setaria. Beauv.

Sifteme: Achyrophyta. Neck.

Gramina. L.

Gramina digyna simplicia: Roy.

Gramina Panica. Adans.

Gramineae. Juss.

Triandria Digynia. L.

Reld 3flappig, 2 Rlappen gleith grof́, bie 3te biel

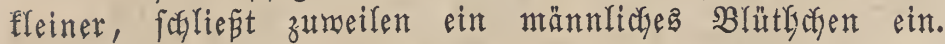
Srone 2fpelzig, bie untere getwölbte Spelze untgibt bie obere

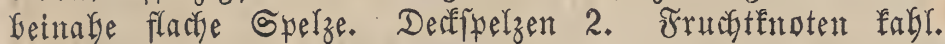
Briffel lang. Narben fprengredelig, treten unter ber Spibe bes Blüthchenz berbor. Snumen eirund, glänzend, mird yon Den erbärteten Spelzen umgeben.

\section{Panicum miliaceum. L. \\ Panicum asperrimum. Lagasc. \\ Panicum Milium. Pers. \\ Milium esculentum. Moench. \\ Milium panicum. Mill. \\ $\beta$. Milium attenuatum. Moench.}

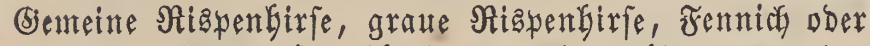
Bfennich, Baniforn, Duaftbirje, gemeiner Kirjentmagender

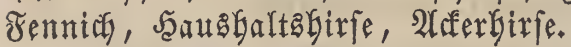

Milet des 0iseaux. (franz.)

Millet. (entgr.)

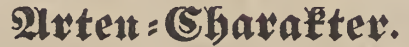

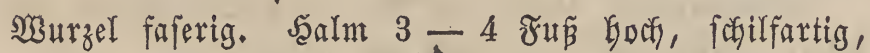
enotig, unten etwas mulfig behatart, yon ben Blatticheiden umgeben und äftig. Blätter breit - Ianzettfürntig und mie

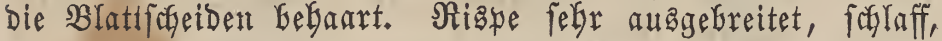
überbängend, nach einer Seite geridytet. 2Yebrefen einfantig, ungegrannt. Releffpelzen ftachelfpitig, geftreift, grau. Blit= then roth. Spelgen felgr glatt und glänzend. Sante flein, eifürmig, meis̄, gelb bis fogmarz, glünzend, bünn und bartichalig.

\section{Slütbe = Beit and $\mathfrak{D a n e x}$.}

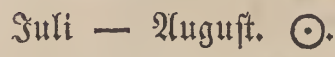

\section{Soxtomment.}

Då̉ urforünglicye Baterland Der J̧irfe ift Dftindien, und fate mird Gäuftg in Deutfaland, befonders in Deftreich, Schleften, in Brandenburg, Jeeffen, Baiern und șürttem= berg fultivirt.

\section{Nultut.}

Die Jairje gebeibt am beften in einem warnten, trodfes nen אlima, in lorferem, leichtem, gut berarbeitetem, yon affem $\mathfrak{u n f r a t t e}$ gereinigtem, fandigem, ober foblammigem, noch fräftigem und warmem Bober, in auggetrodfneten Teichen, Miourgrund und it Neufruch. Sat ber Boben zu ntager, fo fann obne Nadytgeil frifon gebungt werben. Man baut fie am nteiften nach Saaffrubcten, bie Den Boben in einem lofern Suftande zurüffaffen, ober nach Slee; nady reterem Dofr nach gedungter Winterung in's Sommerfers gebaut, mú Der Boben 3furchig befteflt werben, auch foll bie Bearbeitung Deffelten mit Egge und $\mathfrak{W a l}_{z e}$ noch yor

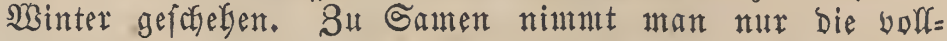

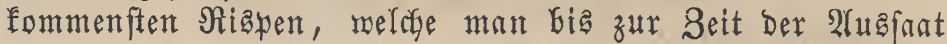
an einem Der Ruft zugänglidyen Drte aufberabrt und Dann erf́t außjamt. - Man fäet bie Rispenfirfe int Mai, fomie marme Witterung eintritt, bringt Den Samen nur flad

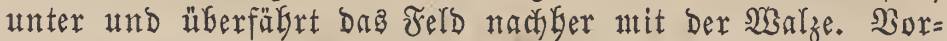
theilgaft ift $e$ B, bie Sairje, menn fre anfängt aufangeben, zu eggent und, menn fite etra $1 / 2$ Solf goch ift, zu jäten. Die Segetationaperiode Der RianenEirfe ift 3 Monate und bie Ernte gemöhnlich int 2quguft. Sie reift febr ungleich und

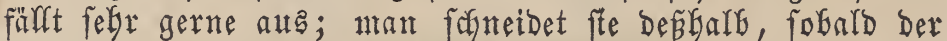
gröste oberfte Their ber אänner zeitig ift, Da man fonft zu

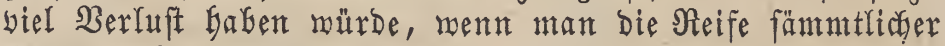
Rörner abmarten wollte. Unt bet ber Errnte fo wenig als mögliç einzufünen, fajneibet man bie Şirje fegr vorffechtig mit Der Sidfel, findet fie gleich auf, utberberft ben $23 \mathfrak{s} g e n$, auf bent fle Geimgefüfrt mird, mit eirem Tuche und brüct

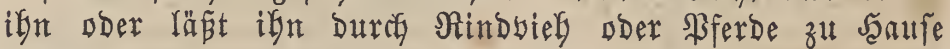

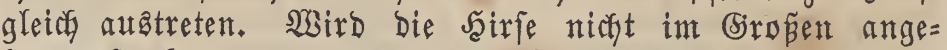

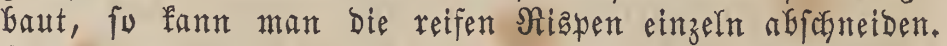
Die auşgebrofichenen Samen breitet man bün auf Dem $\mathfrak{B} D=$

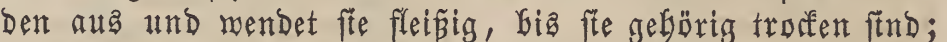
unreif und feudat aufbewabrte Samen erbiben fuch und be= fommen einen bittern (befdymarf; ebenfo mú nan aud bas Stroh auf Dem Boben auBgefreitet und auBtrofinen laffen. Sum (Sebraudse müffen die Scirfenförner in Stampfmüblen voer Sandbirfemulflen entfülst werden.

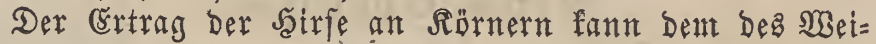

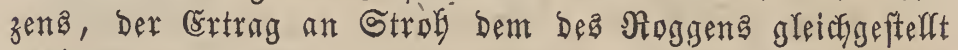
werben.

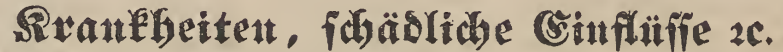

Die Şirfe erfogpuft ben Boben mentg, ift empftnolich

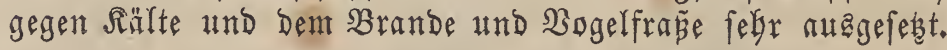

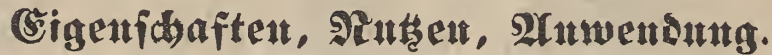

Die Şirfe gibt ein fräftiges, nabrbaftez, aber fobmer verbauliches Mefl, aus welchem man mit Mildy verfocht ben auf Dem Rande fo Geliebten und ftopfenden Şirfenbrei Gereitet, auth Brod Daraus barfen fann, wie Gäuftg in 2Aeghpten, nur mird biefes riffig und feft und ift blos frifoc jumadffaft. Sn ben Nieberlanden unb in Benebig verfer= tigt man aus Dem Meble Torten und Ruchen. Ferner Dient bie Şirje zum Füttern yon Bögelı, jungem (Seffügel, Tau= ben 2c. Der albfall bei ber Meflbereitung und Das in ber

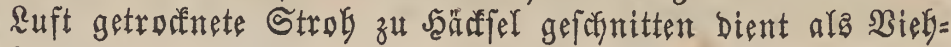
futter.

Spielarten Der Riapenfirje find:

\section{Uelbe filumphix/e.}

Panicum miliaceum semine luteo, seu flavo, seu stramineo.

Bjelbe Saitre, gemeine Sairfe mit gelben Samen.

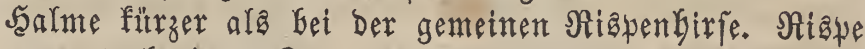
meniget ałaggebreitet. Samen gelf.

Sie mird bäuffg in Deutfoland und der Sefreeiz an= gebaut und unterfsheidet fich int Lebrigen in NRidsta yon ber sorigen 2 rrt. 
Aurd bariirt je wieder in 2 Spielarten:

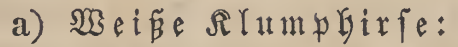

Panicum miliaceum semine albo.

Wei

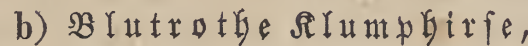

Panicum miliaceum glaucis seu valvulis purpurascentibus.

\section{Sdhwarze hiapenbir/e.}

Panicum miliaceum seminibus nigrescentibus, nigris et badiis.

Schtoraze J̦irfe.

Weniger häuffig angebaut als bie yorigent.

\section{Panicum italicum. L.}

Panicum asiaticum. Hort.

Panicum attenuatum. Hort.

Setaria maritima. R. S.

Panicum erythrospermum. Hornem. Setaria germanica. Beauv.

Panicum glomeratum. Moench. Setaria rubicunda. Dumort ?

Panicum indicum. Hort.

Panicum melfrugum. Hort.

Panicum setarium. Hort.

Panicum setosum. Hort.

Echinolaena erythrosperma. R. S. Panicum serotinum. Hort.

Pennisetum italicum. R. Br.

Setaria italica. Beauv.

Setaria Melinis. Link.

$\beta$. Panicum maritimum. Poir.

Panicum sibiricum. Hort.

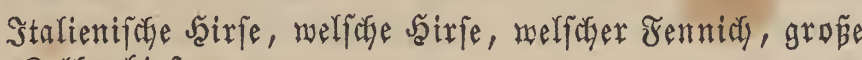
gelbe Rolbentirfe.

\section{Arten $=$ (Shaxafter.}

Scalm 4 ช̌up Goch, Geinalye ganz yon Den Blatticheiden umgeber, ftrofgelb. Blätter rauf. Niąue ährenförmig, boptelt zufanmengefest, überfängend, gelappt, boll langer Burften. Spindel und Blumentiele rauh Gegnart. 2Hefrchen fnäuelförmig zufammengebäuft. Reldhipelzen 3 , Deren 2 obere aufgetrieben, eifürmig, geabert find, beren untere aber flei= ner und zugefpist ift. Die Rronfpelzen gels, nit bem Sa= men verwachfen, lektere rund, glatt, ftrolggelb und meglig und fleiner ala bie der Riöpenfirfe.

\section{SYüthe = Beit mito Dauer.}

$$
\text { suli - 2uguft. } \odot \text {. }
$$

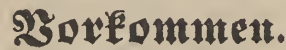

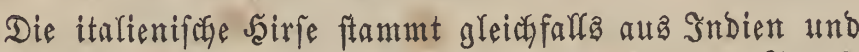
wirb Gäuftg in Sübeuropa, Stalien, Dem füblicten Frant" =

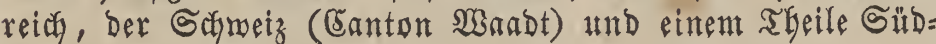
Deutfajlands angefiaut.

\section{Rultux.}

Die Rolbenbirje berlangt einen etwas jefwerern Boben

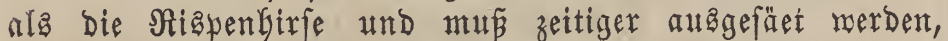
menn eas bie Wsitterung zuläpt, Ende 2fprifa, ba fee bis zut igrer Neife einen Beitraum yon 5 Monaten bebarf. Sie fann gemplynlich erft im September eingecrutet merden, bie Samen reifen aber gleicher und falfen meniger aus. Die Rolbenbirfe ift gegen Rälte noch weit emtpfindlidjer ala bie gemteine Sairfe.

Der Errtrag an Sïrnern und Stroh ift ftärfer.

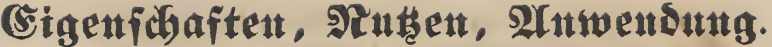

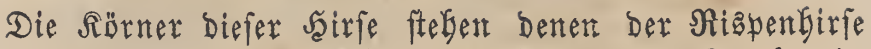
nach, Dagegen ift das mebr zuderftoffgaltige Stroh ein Gefferes $\mathfrak{B i e h f u t t e r . ~ - ~ D i e ~ B e n u ̈ b u n g ~ i f t ~ b i e ~ g l e i d f e , ~ m i e ~}$ bei ber gemeinen Şirfe.

\section{Gílbe kleine ferdbenbirle.}

Setaria italica spica minore. R. S.

SWird an ben gleidyen Drten gebant mie bie vorige

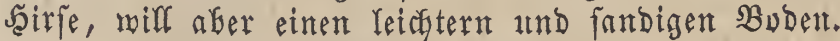

Jn Ungarn baut man Dieje Seirfe unter Dent Namen Moliar, meift unt fte als (5rünfutter ober Seeu \$̧erben und Rinbvieh zu füttern. Die Samen beftben einen angenebnten (befdymaf, merben aber bauptfächlich nur zut Fütterung yon Febervieg benitst.

Mian bat einige 2lbarten yon biejer Sirje:

a) Drangengelbe Stite.

Panicum italicum var. seminibus aurantiacis. Sering.

Der Same ift leichter alz bet ber borigen Sirfe.

b) Siolette Rolbentirie.

Gamen rötgliçbraun, mirb Gauptfächliç in Rärntben furttivirt.

\section{Ungegrannte falbenbix \\ Panicum germanicum. Host. \\ Setaria germanica. R. S.}

Deutfore Sairfe, Deutfige Rolbengirfe, Deuticher Sairfen=

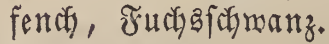

Blumenftiele fürzer ala bei ber gelfen fleinen Rolben= Girfe. Alefre melgr eiförmig und bicfer.

Sourde früber in Deutfecland Gäufig angebaut und jest noch in Ungarn und Rithauen. In gutem Soben foll ibr Ërtrag bebeutend jein.

\section{Sorghum. Moench. Pers.}

Andropogon. L.

Syfteme: Achyrophyta. Neck.

Gramina. L.

Gramina Sacharoidea. Spr.

Gramineae. Juss.

Triandria, Digynia. L

Sielch 2flappig, 2blütthig, länger alz bie sBlüthchen. Rlappen Iederartig. Rronte 2fpelzig, untere Spelze gefpalten mit einer gebrebten Branne. Samen beberft.

\section{Sorghum vulgare. Pers.}

Sorghum (Holcus) album. Hort. Sorghum medium. Hort.

Sorghum (Holcus) pylramidale. Hort.

Andropogon Sorghum. Roth. Roxb. Holcus Dona. Micg.

Holcus Curra. Forsk.

Holcus lubens. Gaertn.

Holcus Sorghum. L.

Siemeine Moorbirife, indifdes Rorn, Sirf,

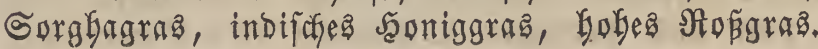

$\beta$. Solghum bicolor. Willd. Andropogon bicolol. Roxb.

Holcus bicolor. L. $\gamma$. Sorghum nigrum. R. S.

Sorghum nigricans. Hort. Andropogon niger. Kunth. Holcus niger. Gmel.

Holcus nigerrimus. And. Sorg, 
15.




\section{Arten = Şaratex.}

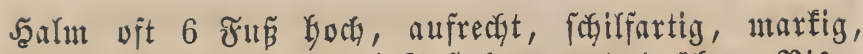

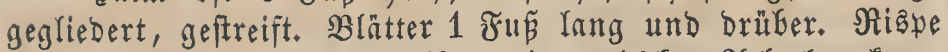
bicht und an ber Spibe folbenartig verbifit. 2lehrchen furz= geftielt, 2blüthig, 1grannig. Sieldyfpelzen 2flappig, zähe, feinbehara, fohwarz und ben Samen feft eimfdylieñend. Siron= fpelzen 2flappig, fegr fein, beren eine mit einer gefnieten

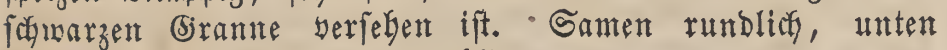
fpibig, fafmarzbraun und melglig.

\section{3litbe= Beit und Daner.}

รuni. $\odot$.

\section{Sorfommen.}

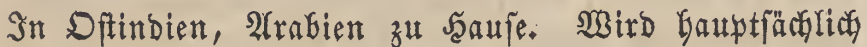

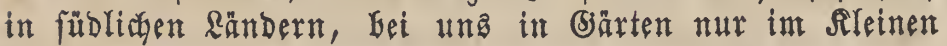
angebaut.

\section{\$ultut.}

Wird, wie to eben gejagt, ftatt ber gemeinen Sairje nur in füblicfen Begenden, wie im Drient, Stalien, Siau= faften und Gei ben nogaijăen Tartaren angebaut. Bei gủn= ftigem ₹rübjalyr und warnem Sommer, in paffendent Boben reift fie übrigens audy in Deutfoland im September.

Der Errtrag Der Mloorbirje ift uft ein 200 fältiger.

\section{Eigenidhaften, Rutsen, Stuwendung.}

Das Methl Der Noorbirje ift gering, whte befondern Befidmanf und gift ein jogmarzes Brob.

\section{Gefoldidyte.}

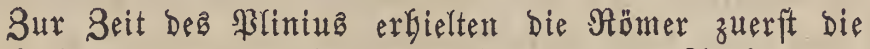
Moorfirfe; aus Morgenland fam fte burch bie 2araber und nady (ruropa Durch Die Portugiefen.

\section{Sorghum saccharatum. Moench. Pers,}

Andropogon sacckaratus. Roxb.

Holcus Dochna. Forsk.

Holcus saccharatus. L.

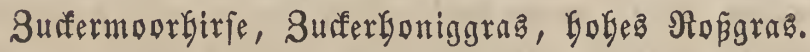

\section{Arten = Gharafter.}

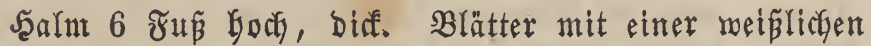

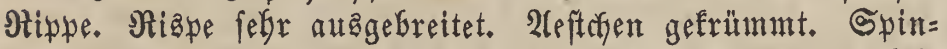
Del glatt und nicht fatjarf. Spelzen zottig. Samen an bei= Den Enden zugefpist, Goctgelb.

\section{Błätbe: Beit แnd Dauet.}

Эufi. ๑.

\section{S2orfomment.}

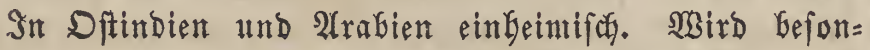
Ders in Ungaru, Der Buctharei und Aftrachan fultivirt, und

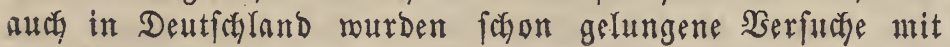
Der Sillur biefer şirie angeftellt.

\section{ßultux.}

Will man bie Sutermoorbirje in Deutfaland bauen, fo gebort Dazu ein guter Boben unb eine fefre furgfältige Carmer, bfonom. Pfinnzenfunde.
Pflege. Man fäet Den Samen it Răften, weldfe gegen Sålte gefdüht fein müffen, und berfegt Die Bflanzen, wenn

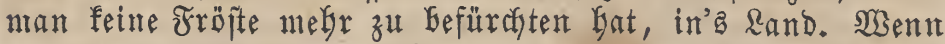

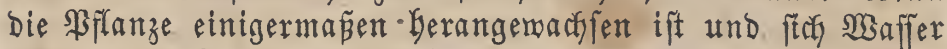
in ben Blattfaciden fammeln follte, fo mú biefes jebesmal entfernt merben.

\section{CEigenfidaften, Nuthen, Arwenoung.}

Die 3uderntoorfirie ift befondera in ber Bucfarei feft gefdăgt, Da fte aus ifr allein ifr Brob Gereiten und bie Stengel zum ซ̌euern benủken. Sur Grünfütterıng fant man bie Stengel bei una oft zneimal bea Jahleses abjohnei=

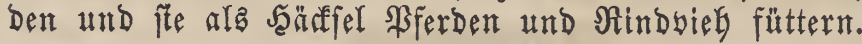

\section{Zea. L. Spr.}

Mais. Mirb. Adans.

Syfteme: Achyrophyta. Neck. Gramina olyrea. Kunth. Carices. Rül. Gramina oryzea. Spr. Gramina. L. Gramineae. Juss. Gramina diclina. Roy. Monoecia Triandria. L. Gramina Mais. Adans.

Befrudtungsomerfzenge auf berfelben Pflanze getrennt.

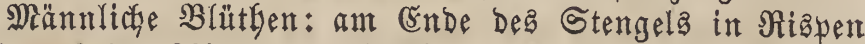
fithent. Sieldy 2flappig, 2flüthig. Rlappen länglidarumb, fpikig, bauthig, unbemehrt. Blume 2fpelzig. Spelzen un= Gemegrt, ftumpf. Das obere Blüthden ift fleiner.

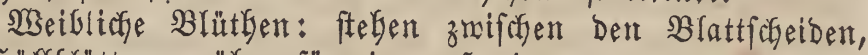
in Saülfblättern, ährenförmig auf einem gemeinfdyaftlichen Jruchtboden eingefügt, zahlreidy. Relch Gleibend, 2flappig, 1 blüthig. Blume 4pelzig, ungleids, bleifend, bäutig, burch= fichtig. Zruchtfnoten fugelförnig. Siriffel fegr lang, faben= förmig, überfängend. Sarbe furz, gefpalten. Samen runb= lidy, auf bem ralzenförmigen, biffen, folfigen Frudtboben bicht in geraben, oft gemundenen Reifen ober ganz unregel= mäp̃ig fthend.

\section{Zea Mays. L.}

Zea alba. Mill. Zea vulgaris. Mill.

Zea altissima. Gmel. Mays americana. Baumg.

Zea americana. Mill. Mays vulgare. Seringe.

Zea minor. Gmel. Mays Zea. Gaertn.

Zea praecox. Pers.

Maiz, gemeiner Mais, türfficter Meizen, Melfofforn, gemeiner groperer Mais, türfifches Sorn, Jlorentiner Rorn, Canabenfer Mais, fpanifchez Rorn.

Kukuruz. (flavij

Mais cultivé. (franz.)

Maize, Indian corn. (engl.)

\section{Arten = Shatafter.}

Der Stengel 3-12 Fun boch und 1 Soll biuf, runb, glatt, gegliebert, fteif, marfig. Blätter $1-2$ ₹ur lang, 2-3 3oll breit, abmechfelnd, ftengelumfaffend, abftehend, linienförmig = zugefpitet, ganzrandig, Gäufig mellenförmig, glatt, fattgrün. Die Riąpe mit Den männliçen Blumen an

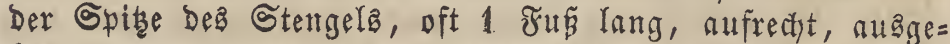
Greitet; Die männlichen Blüthen weislich, Die Sriffel Der weiblichen şlüthe felgr lang, bủnn, in vielen feibenartigen 
Făben büfdyelmeife und fohlaff Gerabgängend. 2Aekren ober Samentolben 1-3, feltener 4 an einer \$flanze, 3-12 3oll

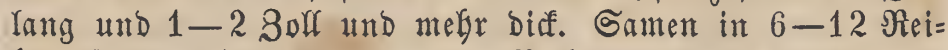
ben fthent, $12-30$ in einer Reife, oft 100, 200 und

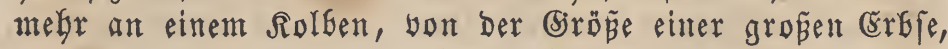
runblich, feltener flach, auf Dem $\Re$ Rüfen meift etmas concay, nard unten ftch zufpibend, glatt, Gart, mekr poer meniger gelb, rotg, Gräunlichbiolett ober Glaugrün und untent immer

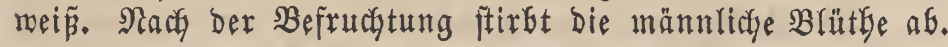

\section{Blüthe= 3eit und Danex.}

\section{Juni - Iuli. $\odot$. \\ פoxfommet.}

In Norbamerifa und $\mathfrak{B e f t i n b i e n ~ e i n k e i m i f a ~ u n d ~ m i r d ~}$ in affen wärmeren Rändern angebaut, wie in ber Türfei, in Eriechenland, Spanien, Portugal, Sübfrantreidy, Sta= lien, Utngarn, in Sĭd = und einem $\mathfrak{I}$ beil - aber meift mur in (Bärten - von Norbdentfalland, in DGerjolleften; man nimnt an, bás, mo bie Beintraube im Freten noch fü $\tilde{\beta} e$ wirb ober ber Buchmeizen als 2te שrucht nody zeitigt, aud Der Maiz noch gedeigt.

\section{Rultux.}

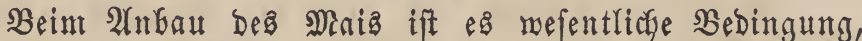
Daß̉ Derfelbe burch günftige, marme flimatifche Berbältniffe und burch einen fräftigen warmen $\mathfrak{B}_{0}$ ben gebörig in feinem Wachsthume unterftüht merbe, benn je mebr cin foldjer be= fördert mird, je megr fich ber Mais bei warmer Witterung ausbilden fanu, beito bolffommenter wirb er auch in allen feinen Theilen. Bu feinem völigen bebeifen verlangt Der Wais marme, mä̈̈ig feudbte Safrgänge, einen funnig gele= genen und windftiflen Standpunft und einen thätigen, war= men, wom Unfraute gefäuberten, tiefen und locfern Boben, ber in märmeren (Siegenden binbiger, in nörblidy gelegenen leidgter fein mü; er geräth ant beften in einem lebmbalti= gen, mit Salf und Mergel ober Saylanm untermifaten $\mathfrak{B}_{\mathbb{D}=}$ Den, in gegörig berarbeitetem Neubruche, in trocfen gelegten Teichen zc. Der Mais verträgt nicht nur eine fekr ftarfe frifche Düngung, fondern er Gedarf berfelben fogar, wenn

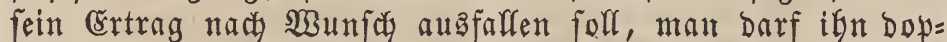
pelt fo ftark Düngen als andere Sagaffrüctete, zแmal menn man auf ifgn noch meitere Früchte folgen laffen will, ba er ben Boben febr ausmagert, oder in nörblicyen Bjegenden unb in zu bindigent $\mathfrak{B}$ oben. - 2 He Arten yon Dünger ftnb Dem Maiz wiffenmuen, am liebften aber Gat er Mienjeţen= foth; Gei leichtem und trocfenen Boben mente man aber nur geförig zergangenen Mlift an. Die befte Beit zum Düngen ift das Frübjabr, unmittelbar yor Der Saat. Die= jenigen, weldye mit ifrem Dung frarjam zu SBerfe gehen müffen, fünnen ben gleichen Smeaf Daburdh erreidfen, baß

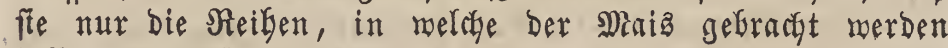
folf, mit Mift belegen.

Der Mais mirb gemögnlic im Sommerfelde und nur bei fefr warnem filma und günjtigem frübjabr, wo ex Gald gefäet unt geerntet werben faun, in ber Brache ange=

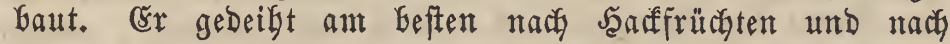
Slee, und auf ifn läpt man am liebften $\mathfrak{B}$ ognen, Tabaf, und wenn er Das Feld Gald räumt, auch Weizen folgen.
WBirb Der Maiz nach Früchten angefaut, bie Den Boben in feinent loffern und reinen 3uftande Ginterlaffen, wie nady (jietreide 2c., fo erforbert bas Feld auch eime forgfältigere Bearfeitung; man gift ifm bie erfte und gleich tiefe ซorurdse

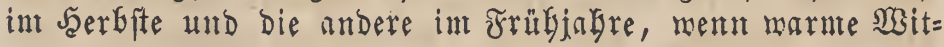
terung eingetreten ift.

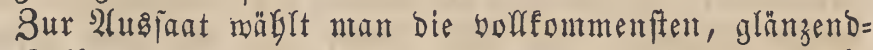
ften Rolben, Deren אärner nidjt zu flach, fondern mebr conbex ftnd, und bängt biefelfen, nachbem man bie noch unreifen Rürner entfernt bat, bis zur Saatzeit an luftigen

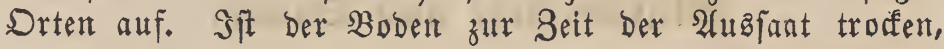
fo meidft man bie Rörner vorber 24 Stunden lang in Maffer ein. - Der Mais ift gegen Rälte fegre empfindlid und man Güte foch Değhalb, Denfelben zu frülye auszufäen; ebenfo trage man aber auch Sorge, Daßj bie 2(uşanat nicyt zu fuăt ge=

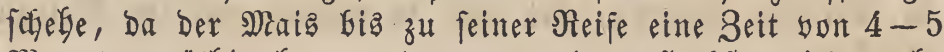
Pionaten nöthig bat, und er yor bem Jeerbite nicht melgr reifen und yon ben fpäter eintretenden Jröften vernichtet ruürbe. Die befte Seit zur Saat ift in fältern begenden Der Mai, in wärmern Die Mitte $\mathfrak{Y}$ (prils. Die Gaat barf nur bei trodfener und warmer Witterung und bei niçt zu naffem Boben vorgenommen werben. Mian fäet den Miais

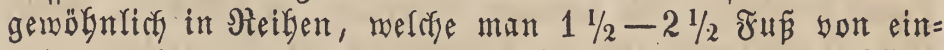
ander entfernt nacht, je nachbem Der Boben ober Das Rrima

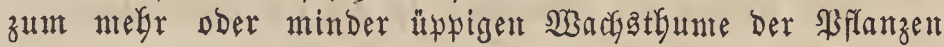
Geitragen, und fäet ifn bünn, da vei Diaffant bie şflanzen mur boch, aber bünnfengelig werben und fich lagern, und gift bent Samen, Damit er fofneller aufgebe, mux eine

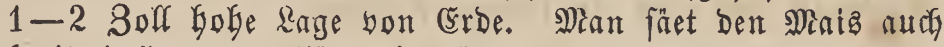
Greitmürffg und fffủgt ifg flach unter, mas aber meniger zu entyefflen ift, meil man das Feld mit ber Saand befacfen

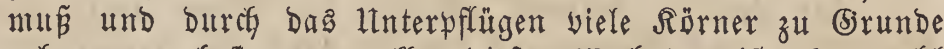
geben; am beften won allen biefen wiethodent ijt aber wobl bie, Den Gamen mitteift eines Brlanzftodz in eine vorber

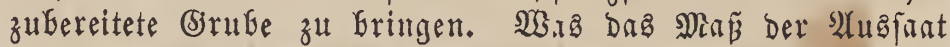
anbelangt, fo Gat man fich ganz nach Der (Jiöpe ber Mais= förner zu ridhten. Bei günftiger warmer Witterung, bei feuchtem $\mathfrak{B}$ oben geft Der Miais geroünlich in 10-12 Tagen auf. Sit derfelbe etwa $4-6$ Soll hod gemadjen, fo lodert man ben Boden burchy Jaafen doer Ëggen auf, entfernt yor= Gandenes Unfraut und füllt etra ftebende Rüffen mit $\mathfrak{A} f$ tan= zen alls, bie worker zu bicht geftanden find. Nad 12-14 Tagen, wenn bie Pflanzen bie Săble von $9-10$ Sulf erreidyt baben, wieberfolt nan das 2 (uflorfern, aber etwas tiefer, und befäufelt fie, wenn fie 1 Fैup goch gemorben fitid, Gei

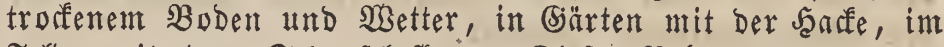
Felde mit bem Schaufelpfluge. Diefes Bef̆äufeln barf nie

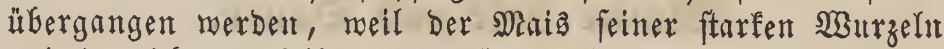
und Der itber Derfelben am erften Belenfe fith neiter befind = liçen $\mathfrak{V}_{3} u$ rzeln wegen gebörig mit Ěrbe umgeben fein mus, Damit fich bie ftärfere, Glätterreictye Sffanze im Boben mefra

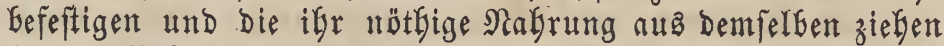
fann. Bebäufelte Maizßpflanzen werfen immer einen ftärfe=

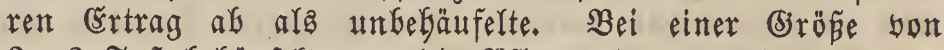

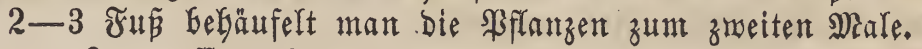

$\mathfrak{I n} \mathfrak{n a f f e m}$ Buben treigt ber Mais Gäufig fodmadse

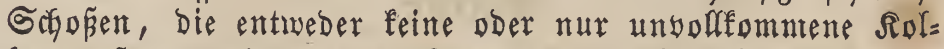
ben anfegen und nur Der Sflanze einen Theil ifrer Nagrung

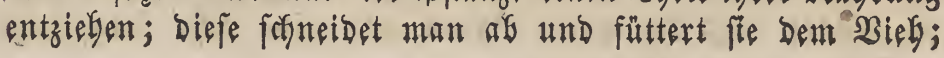


ebenfo entfernt man tada erfolgter Befrudutung, aber erit wenn bie Rörner fich volfemmen entwiffelt, b. h. ifre boll= fommente Reife erlangt Gaben, die Risuen Der männliçen Blütben aul Ernde Der Stengel, fummt Den obern Blättern, mtan entfahnt fre, auch bie berfümmerten ober überflüfïgen

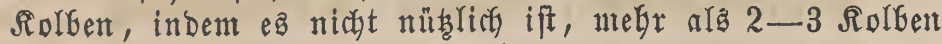
an einer Bflanze fteben zu Iaffen. Durch biefez Entfernen Der zum Sebeiben der Samenfolben nidgt nöthigen Theile

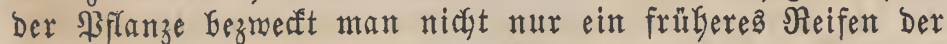

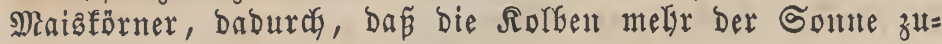
gänglid gentacht merben, fondern man erłält auch baburch

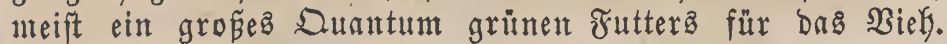
Bffanzen, bie feine Solben anfeben, forneibet man ebenfallz ab und benüht fie zu gleicfiem Smeefe.

Smifothen ben Mais fann man auch andere Früthte Gauen, und zwar ohne Rachtbeil fleine Buhnenjorten ober

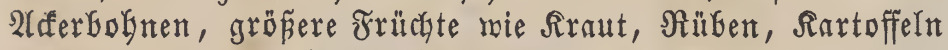
taugen nicht, Da fie bie Begetation dez Mais leidgt unter= brünén.

Der Maiz reift int füblidyen Deutidyland meift int Sep= tember, oft foron im 2(uguit, im Norben Deutfalandos aber erft Ende Septembers ober in Der erften 23 oche Dez Dfto= Gerg, in ftarf gebüngtem $\mathfrak{B}$ oben zeitigt er oft 14 Tage fpäter alz in ungebüngtem. Reif ifł er, wenn bie Blätter, meldye

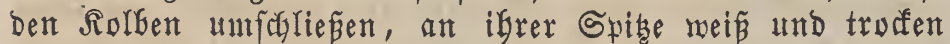
- Ind bie Rörner Gart und glänzend werden. Der Mais zei= tigt nicht gleichförmig, man nimmt Dȩ̧́alb entmeder bie Rolben, wie fle reif merben, nach und nach ab, ober läßjt

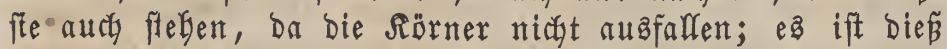
lebstere fogar vorzuziefen, ba bie Solbent an Der Ruft bei warmer SBitterung fơnon zunt Theil auŝtroffnen fönnen; bei eintretender Rălte übrigens Darf man mit Dem 2 Gbringen Des Maiz nidyt mefhr zögern. Die mach F̧aufe gebrachten Siolfen foll man längftens nach Berflú yon 24 Stundent

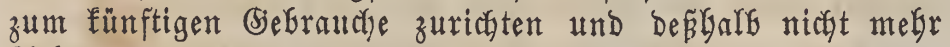

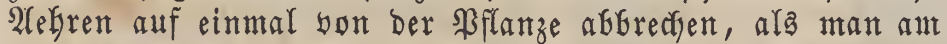
gleidgen ober Dem folgenden Tage bejorgen fann. Nactbem bie Rolben eingeheimst find, iđneibet man bie Mraiŝftengel $\mathfrak{a b}$ und Gindet fie büforgelmeife zufamment. Bum Bebufe ber

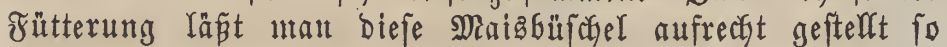
lange int rreien fteflen, bis fie bolffommen truafen find; will mant fie aber nur zur Stallftreu vermenden, fo fann

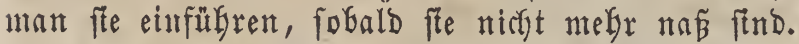

Die Maißfolfen merben auf werichiebene Meije getrod:= net. WYenn man bie Solben zum Trodênen aufgängen wifl, fo entfernt man bon benfelben zuerit bie äunern DecfGrätter, man febert bie Silben ab und läpt nur Die innerften $3-4$ Blätter am Solbenftiele, mit weldyen maı melrere Solben, 4-6 zufammenfüuft und fie in freier $\Omega_{u f t}$, Dod bor $\Re_{e}=$ gen gefountht, unter Dem Darde, in Der Scheune auf Stangen ober Seilen, aber nidyt zu nabe an einanber aufgängt. Das

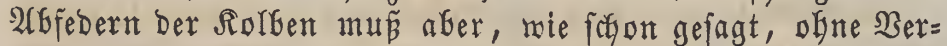
zhtg yorgenommen merben, fobald man fre tad Janufe ge= bradgt Kat, da fie fith fonft erbiben, ifre Blătter faulen und bie Sörner einent fojlectenten Sefchmad befommen; ober aber man Gringt zum Bebufe bes Trofnenz die Rolben, nabjom ntan bie Decfblätter abgenonmen bat, an einen luftigen, troofenelt und gegen Măuje geichühten Drt, legt

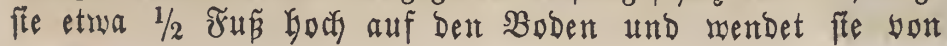

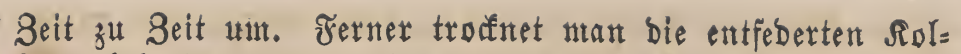
ben, befonderz went fie noch unreife Rörner baben, in Badföfen, welche etwas ftärfer alz zum Brobbaten gefeuert werben, und in melsgen man fie 24 Stunden Iang liegen läpt, in meldyer Beit man fie eintigemal im Dfen ummenbet. Das Megl erbält zmar bei biefer Befandlungămeife einent

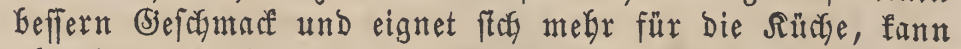
aber bann weniger gut zum $\mathfrak{B r o b b a f e n ~ b e n u ̈ b t ~ m e r d e n . ~ I n ~}$

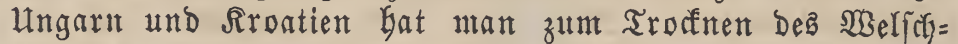
fornes eigens bazu eingerichtete Troffenbäufer, bie Rof in benen oft 500 Wiener Meken Rolben auf einmal getrof́= thet merben fönnen. Sind bie Rolben nun ganz trofen, fo nimmt ntan bas (šntförnern, Atbmachen berfelben yor, relches im Rleinen mit Der Fand gefdeffen fann, int Grozen aber

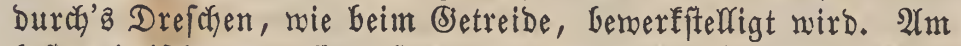
beften brifdyt nan fe erft fommentoes Frübjabr. Mian fann ez zmar fohon im Winter thun, aber bie Rolben entbal= ten Dann bois meift noch zu biel Feudftigleit, und wartet Deg̈galb lieber mit biefer 2 rrbeit bis zum Jrüfling, wenn

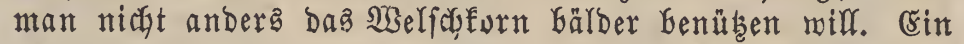

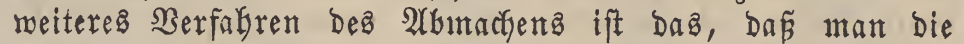
Solben über fognaffantige Inftruntente, abgenubte Senfen, Brerdeftriegel 2c. abreibt, bet melder Manipulation bie Sïrs=

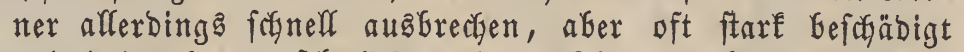
und baburef unanfehnlich werben. Die aus̃gebrochenen sär= ner folcher Solben, bie aufgefängt ober auf Troffenböben gelegen waren, müffent bis zur bolf fonmenen Troffenkeit in Iagen von $1 / 2$ ₹̛̃ auf Yuftige ulb troffene $\mathfrak{B}$ öben gebradgt und fleip̧ig umgenuendet werben, bantit fie nicht bumpfig merben, und es ift oft ein Beitraum won $8-10$ SWochen

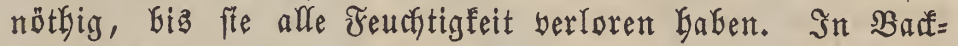
öfen getroffteten Mais fam man Dagegen pogleich aufbe= rohyren. - Der Miais fann auf bie eben angegebene Woeife lange aufGetwahrt merben, man wermabrt ifa mit Bortbeil

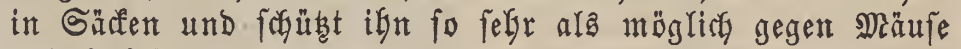
und Infeften.

Der Ertrag wechfelt fehr unb beträgt auf 1 Morgen:

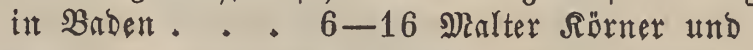
30-50 Etr. Stengel, Blätter 2 . in Şeffen . . 4-8 Malter Rörner und 20-36 Cotr. Stengel, Blätter 2c. in Bürttemberg 4-12 Scheffel Rörner und 25-45 (5tr. Stengel, Blätter 2 .

In nörolichem filima erreicht Der Miaiz meift nur eine

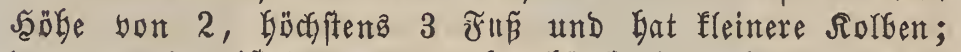
Demungendetet ift Der Ertrag aber häuftg Der gleidfe mit Dent füblicter Ränder, ba bie fleimeren Sflanzen wentiger Raum alt Dent Felde einnebmen und alfo unt fo mefre auf einer

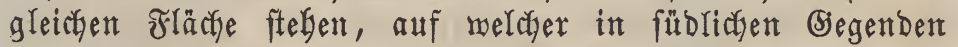
zwar gröpere, aber weniger \$flanzen fich befinden; zubent werben in $\mathfrak{R o r b e n}$ felten alle Rörner an Rolben reif.

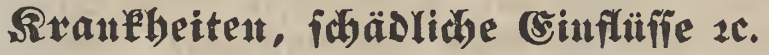

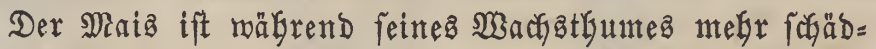
lichen Crinmirfungen auşgefest, als bie übrigen Bsetreibe= arten. WBir Gaben weiter oben foron erfafren, Dá̧ ber Maiz in feiner Sugend Gefouberz empfinblich gegent Rälte

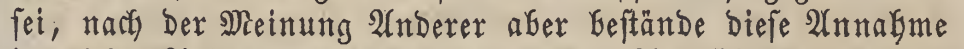
in nichta 2 (ndoerent, als in übertriefener 2 Lengftlichfeit, inbem 


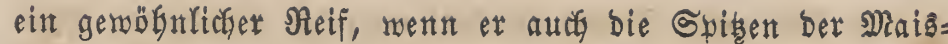
blätter angreife, boch bie \$flanze niçt zerftöre, ba eine nicht

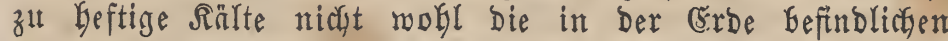
Reimblätter und die ŞGurzeln ergreifen fönne; übrigenz ftnd

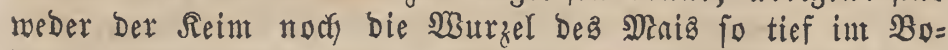
Den, Dá̧ bei einfalfenbem Reife nicht zumeilen bie ganze junge \$flanze zu Srunde geken fönnte, und eฮ Gleibt immer eine gemagte Sache, auf biefe $\mathfrak{A n}_{\text {ngabe }}$ bauend feime Saat zu frübe borzunekmen. Man fann wobl annefmen, bá̃ ein reichter Neif bei gefdühtem Standpunfte Der Maisuffanze

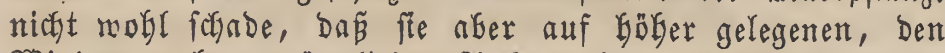

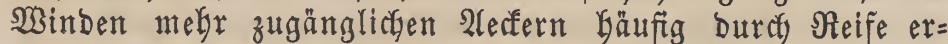
frieren fönnen, wie es mir felgft einnal mit meiner fleinen

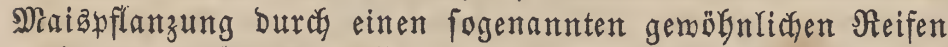
erging. - Giegen $\mathfrak{R a ̈ f f e}$ und Dürre ift Der Miai rentiger Geifel, Dagegen find ifgm zur Blüthezeit Winde und Keftige

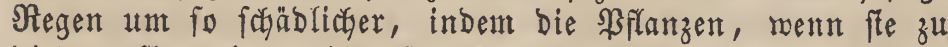
bicht gefäet oder nidat forgfältig bebäufelt ruvben roaren, leicht umgemorfen, abgefnicft ober abgeriffen werben. - Sagben fich Die Sflanzen gelagert, fo läp̈t man fte, int Falle fie

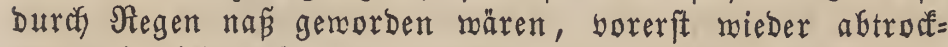
nen und richtet fie Dann vorftedtig auf und brüft bie (srbe rwieber feft un bie $W_{3} u r z e l n$ an, nefme fted aber babei in Acht, bá man bie Briffel ber weiblicten Blüthe an ben jungen Rolben nicht Getafte und Durch Das Jeineintreten in Daz Maiŝfelo nicht noch mehr Unbeil anribhte unb bie noch ftekenden Sflanzen beim 2lufridgten der gefalfenen nicht yollends zu Boben werfe.

Der Mais miro Gauptfäcblict) nut yon 2 Siranfbeiten

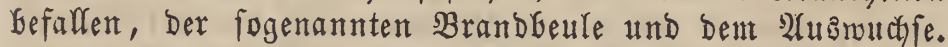
Die erftere gift fich burch Berbiffung irgend eines rafeiles Der Bflanze, meift aber Dez Rolbens, ausen burdy eine

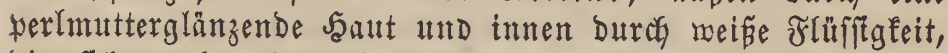
bie ftedy nach und nady zu einem foymarzen Bulver verbifft, zu erfennen. Die Branbbeule ift Dent Miais nidft Gejonders fafäblich, ba fie nicht leicht werbreitet yorfommt. Nach nei= ner Beobarftung befält bie Brandbeule die Maisôflanzen yorzugğmeife in beip̌en und Dabei feuchten Jahrgängen und Gei zu maftem Boben. - Der 2luanutus bejefyt in einer formlofen, Granbigen, Graunen, Grätterförmigen Ërbubenkeit an bent Maiśtolben, an weldyent Derfelbe zu (srunde gebt.

Dem Mais ftelfen befondera Miñfe und Jögel nach, welche oft einen gropen Theil Sörner gleich naid Der Saat

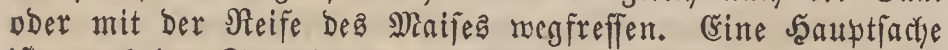
ift, nach ber Saat jebes noch auf bem Boben liegende. Saat=

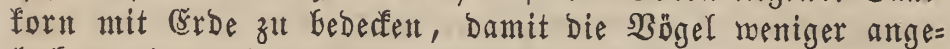

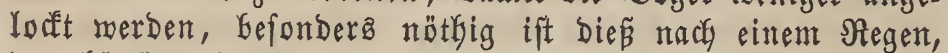
ber Gäuftg bie Ẽrbe über Den Rörnern regipült und bié Siörner Globlegt; babei wergeffe man daz zeitweife $\mathfrak{B} e r=$

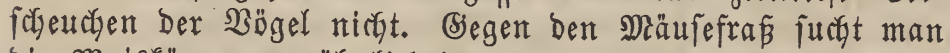

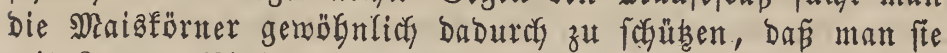
mit Rauge, Nięrourzel =, Coloquintben = 2(bfochung 2c. beizt und fte nadjher mit (5)pas, Schwefelblunten beftreut; aber meift Gilft biés nicht viel.

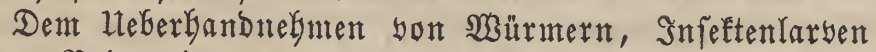
in bem Boben Der Maisfelber zu begegnen, Gleigt immer

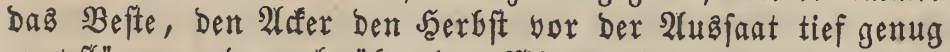
zu łflügen und raug über Den $\mathfrak{B i n t e r}$ Yiegen zu Yaffen, wo bie meiften Rarben und Eier ber Jnfeften auf Die Dberfläche

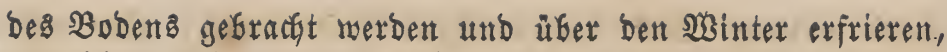
unb bie, welche nicft zu Sirunde gegangen find, bernichtet gemögnlich volfends bas im zrübjagre anzuftellente wieber= Golte \$flügen und Ěggen.

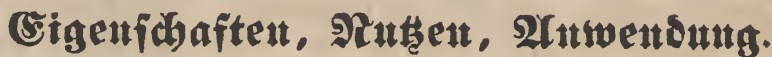

Die Maisłärner Gaben einen jüß̈en, mebligen unb etwas

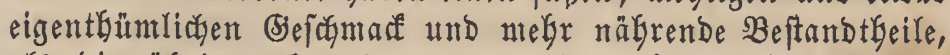
als bie übrigen Betreidearten, แnd entbalten bauptfädblid Stärfmehl, Zెưfer und Rileber.

Borwartende Beftandtheile find mact Breif:

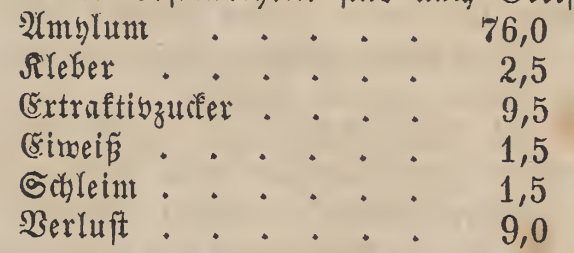

Der Nuben Des MRais ift yon Der manchfaltigften 2 (rt:

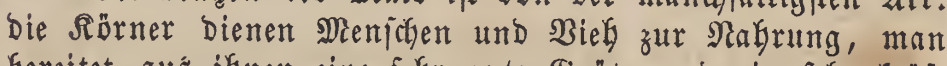

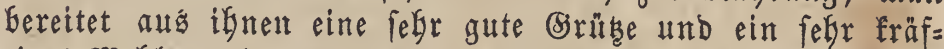
tiges Mebl, und vou biefem numberlei Meblfpeifen, Suppen, Brei, $\mathfrak{B}$ boing, Bolenta (in Stalien) und in Berbinbung

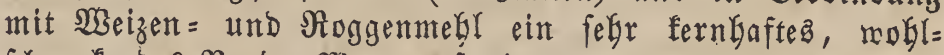

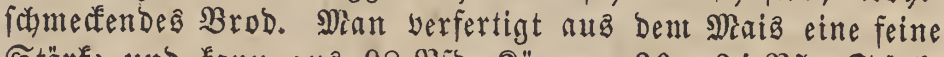

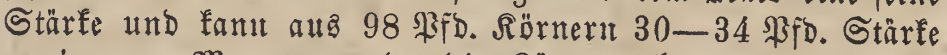
geminnen. Man berwendet bie אiörner, hart ober gequell,

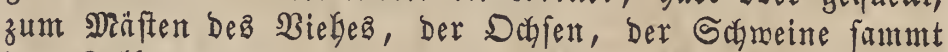
Den Rolben, Des Geflügels, gefdroten als ein yortreffliches テutter für angeftrengte \$ferbe, zum Bierbrauen und $\mathfrak{B r a n n t =}$ meinbrennen. Die ganz jungen Maişolben benübst man mit

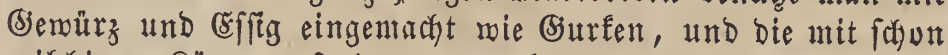
milchigen Rörnern fpeist man gebraten, ntit ben gefehlibeten

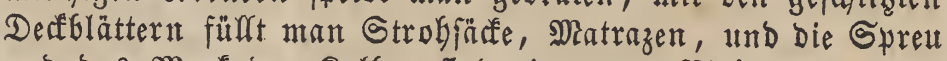
und Das Marf Der Rolben find ein gutez Biebjutter.

Der obere Theil Des Stengela mit Der Riape entyält befonders viel Burferftoffe, und man gefraucht ifn zur Bucfer= und Syrupbereitung, fogar mit mehr Bortbeil ala bie Run= feln, unb zur Brantmeinbrennerei.

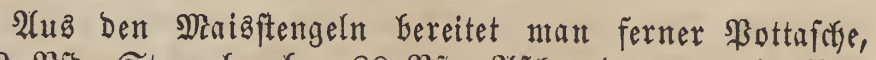

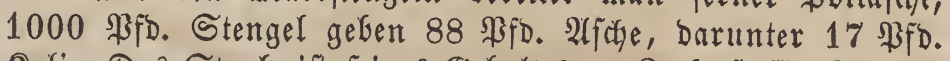
Rali. Das Strub ift jeines (Bebaltez an Sucferftoff, Schlein und Stärfntell wegent ein ausgezei funtetes Biebfutter und ein Gefondera gutes Mitlchfutter ftnd bie grünen Maisftengel.

Da fich bas Maisftroh nur fohmer fchneiden läst, fo

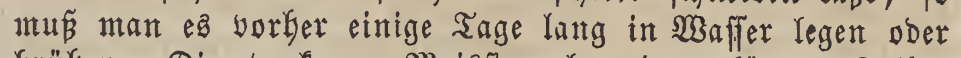
brüben. Die troffenen Miaisftengel und entförnte Rolben werben bäufig als Brenmuaterial verwendet.

\section{Gefidichte.}

Der ঐais fant nady Der Entberfung yon 2(merifa zuerft nach Spanien, yon two nus ex in bie übrigen Theile (Ët= ropa's eingefüfyrt wurbe; tad Stalien fam ex aus Dex $\mathbb{R}_{e}=$

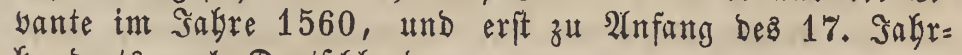
Gunberta nach Deutfaland.

Der Mais bat verfabiebene Spielarten, bie fach yor=

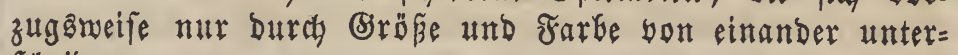
fodeiden. 
16.







\section{Amerikanifhex mais. Zea americana.}

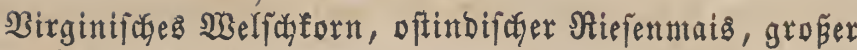
Mrais, Riejentweljaţorn.

Stengel in Carolina oft 16-18 ซúp lang, 1-2 8oll

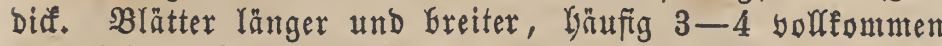

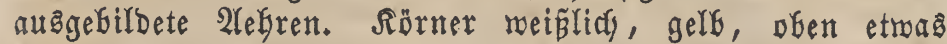
concab und fladg. Eer ift in affen feinen Theilen gröper als ber folgende.

(区x mirb in Dem größten Tyeile 2(merifa's und in bies Ien füblichen Rändern Europa's, in Stalien 26. , auch in neuterer Seit in Dentfogland angebaut. In fältern Biegenden

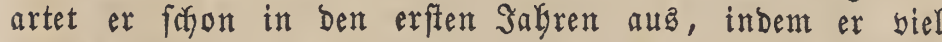
fleiner wirb; er bebarf fiz za feiner Reife felbjt int mär=

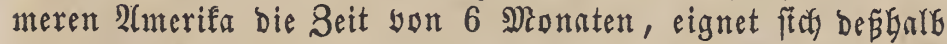
für nörbliche (siegenden nicht, Da er in foldyen nur felten zeitigt.

Nady 3obn (Sorbam in Norbamerifa enthalten 100 Theile getrofneter amerifanifcher Maiğtäner:

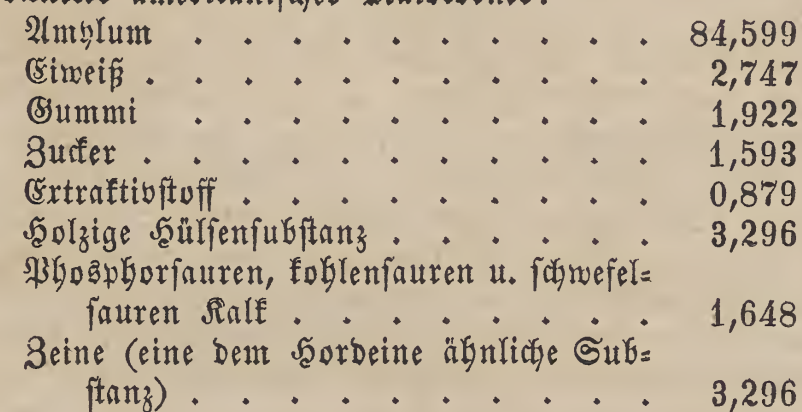

2. Biblber kleinex Ants.

Zea Mais praecox.

Zea Mais minor.

Zea Mais spica exili.

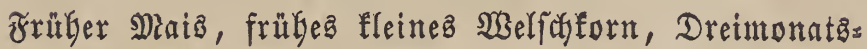
mais; $\mathfrak{N o b a n f a f t o r n ~ ( i n ~} 2(\mathfrak{m} e r i f \mathfrak{a})$.

Stengel nur 4 ช̛น oft nur bon ber Grö̈pe einer fleinen Erbfe.

(ङ̌r werlangt ein etwas meniger rarmes Rlima als ber Riejenmais und gelangt fojon innerbalf 3 Monaten zur ßReife.

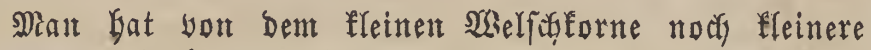

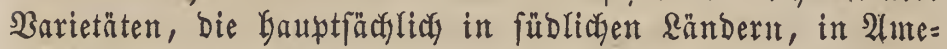
rifa, in Stalien (Gier unter Dent Namen Quarantino, Cins= quantina 2 c., $40=$ und 50 tägigea $)$, und int Sleinen auch it Deutidaland angebaut merben und oft nur eine Seit yout 40-60 Tagen zu ifrer Neife bebürfen.

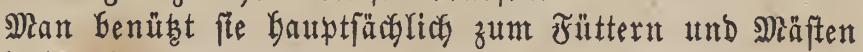
Degి B)eflủgels.

Dieje Mais = Barietäten zerfalfen je nada ifrer Farbe wieber in weitere:
a) $\mathfrak{B} \in \mathfrak{i} \tilde{B} e r$ genteitter $\mathfrak{M a} \mathfrak{i}$.

Zea Mais granis albis et albicantibus.

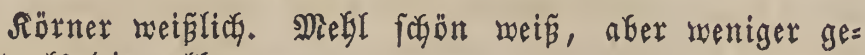

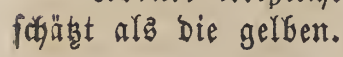

b) Nother gemeiner Mia

Zea Mais granis rubris et purpureis.

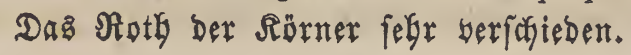

c) BIa Zea Mais granis violaceis.

Siörner blau, bäufig mit gelben vermengt.

d) $B \mathfrak{B} \mathfrak{n} \pm \mathfrak{f} \mathfrak{a} \mathfrak{b} \mathfrak{i g e r} \mathfrak{M} \mathfrak{a} \mathfrak{i}$.

Zea Mais granis variegatis.

Noch weniger fonftant als bie 2origen.

e) Meais utit äfiger $\mathfrak{A}$ efre.

Zea Mais spica ramosa, granis aureis.

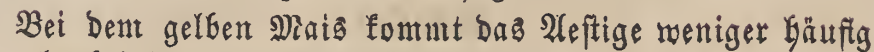
yor, als Gei bem anders gefärbten.

\section{Polygonum. L. Spr.}

Acnogonum. Meissn.

Amblygonum. Meissn.

Asicaria. Neck.

Avicularia. Meissn.

Bistorta. Adans. $L$.

Fagopyrum. Moench. Gärtn.

Fagotriticum. L.

Helxine. L.

Persicaria. L. Adans.

Tiniaria. Meissn.

Tovara. Adans.

\author{
Syftemte: Holeraceae. L. \\ Incompletae. Roy. \\ Persicariae. Adans. \\ Polygona. Rül. Juss. \\ Sysellophyta. Neck. \\ Vaginales. L. \\ 0ctandria Trigynia. L.
}

Selch 1 blätterig, an ber $\mathfrak{B a f t z}$ freifelförmig, tief 5 ipals tig, zufammengebrücft ober ftumpf, 3fnotig, feine Sipfel ungleich, bleibend. Staubgefäße 5, 6,7 und 8,5 reedy= feln immer mit ben Sielchzipfeln ab. Fruthtfnoten oberftän= big, 3 feitig und 3 Narben, Dber zufantmengebrü fot, bann nur 2 Narben. Sriffel $2=$ voer melgrpaltig. Narben föpfig. Samen bon Dem Gleibenden Seldge untchloffen, 3ecfig ober zufammengebrürft.

\section{Polygonum Fagopyrum. L.}

Fagopyrum esculentum. Moench.

Fagopyrum saracenicum. Dumort.

Buchmeizen, genteiner Buchweizen, Fetbeforn, gemeinez

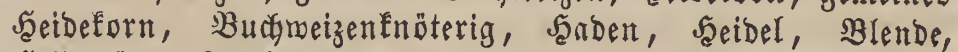
ફeibgrüze, Jiricfer.

Sarasin. Bled noir. Seigle Vellar. Rougherbe. (frottz.)

Buck - wheat. (engl.)

Saraceno. (ital.)

\section{2raten $=$ (5)arafter.}

WBurzel faferig. Stengel 2 Fú boch und böker, faft ganz aufrecht, frautartig, Gobl, rund, oben etras bebaart, röthlicy. Bañtter Gerz - pfeilförmig, geftielt, ganzranbig, abruetfielnd ftefend. Blumen in Trauben und am Enbe bes Stengels ftehend, weís, fpäter rötglich. Blütbenfticlìjen ftnd am Sorunde nit eiförmigen, randGäutigen Deffblättern verfeken. Staubgefäpe fürzer als ber Griffel, bie 5 äußern abftefend, bie 3 innern entipringen aus einem Drülenfranze. Oriffel lang, fadenförmig. Narben 3. Samen 3fantig, zu= gefpiç, faftanien = ober fobmärzlichbraun, meglreich, bem Bucbeforn ährlid. 


\section{Słlutbe:3eit utt Dater.}

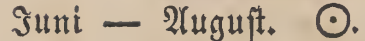

\section{SYorfommett.}

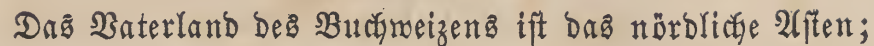
er wirb in Deutidjland und andern \&ändern bäuftg fulti= virt, Gejonbers in gebirgigen, fanbigen ફ̧eibegegenden, it welden anderes betreide nidft megr gut geräth, auch in nörblicfen wegen feiner futren Begetationaperiobe.

\section{Rultut.}

Daz Seibeforn gebeift noch in einem fandigen, und

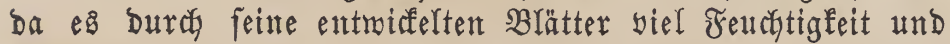
Nabrung auz ber Ruft ziegt, megr troffenen und magern Boben, wenn berfelbe nur locfer und nicht zu binbig ift; uแn fo üppiger wächat er übrigenz in einem fräftigen, feucid=

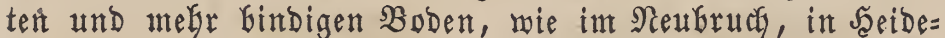
und Moorboden, Gejonders wenn lebterer gefrant ift, ba

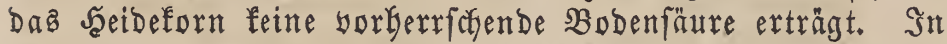
mebr magerem Boben merben feine sörner beffer, in fräf=

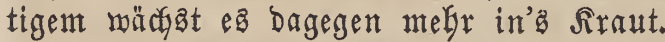

Was Das Rlima betrifft, fo fallägt ifm eit warmes und măpig feuchtes ant beften zu, bei zu trocfenen ober bei

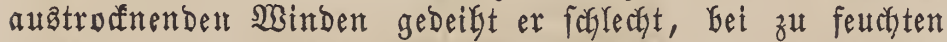
wächst es hauptfächlich nur in's Siraut. Sitt Der Bobent nidgt zu mager, fo ift Dängung überflüfftg, Da bie \$flanze

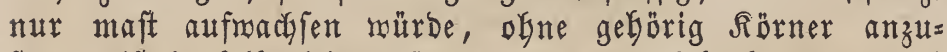
feken; ift berfelfe jedoch feurft, falt und fehr bindig, fo ift ifm auch eine Düngung fehr bienlich. Solde barf aber

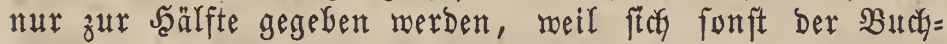

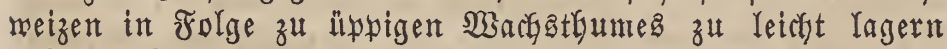
mürde. Frifcher Dünger feGlt für bent Buctyeizen mentger, als gut zergangener pDer fihon im Seerbfte untergebrachter und geförig mit bem $\mathfrak{B}$ oben yermengter Dung. Rindvief = mift, bejonders Compoit, berfaulte Siajen, Schlamm eignen fich am beften für ify, und wenn ber $\mathfrak{B}$ oben etwas feuctit ift, mit Salf, (5)pas und Mergel.

Der Budfueizen mirb gemblanlich in ber Brache ober in warmen Begenden und Jahrgängen und bei fräftigem Boben als 3rifchenfrubt in anderes Betreibe ober in Rüb= famen angebaut. (Er magert Den Boben anter fänmtliduen (B)etreibearten am menigften aub, und mas er yon Nalurunģ= theilen confumirt, erjest er gemögntich dent Boben burds feine zurüableibenden Stoppeln; und bat ber Buchmeizen bicht geftanden, ben Boben gut brichattet, ifn aljo renig erfey opft und in einem lodfern 3 uftande Ginterlaffen, fo fam man wobl fämmtliche Früchte auf ifn folgen Iaffer, mur mun man Das Feld zeitig nach ber Ernte umpflügen, Damit Das Unfraut nicht überkand nefmen fann. Rlee roirb Gäufig unter ben Buctweizen gejäet, zumal rwenn Der Boben für Den 2Uleintau bes Slee's zu trorfen ift, und zur Benübung alB Grünfutter wirb Der $\mathfrak{B}_{4}$ fyweizen oft in $\mathfrak{B i f f e n , ~ R i n f e n ~}$

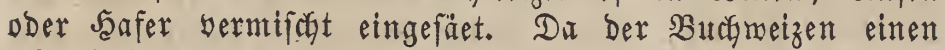
felgr lofern Boben werlangt, fo bat er eine $3-4$ furdigige Beftellung nöthig; Gei feuchten und bindigem $\mathfrak{B}$ oben gibt

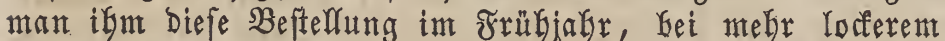
und troffenem Boben eine tiefe Furche noch im Jerbft und bie 2 voer 3 andern in Früfling. Das Unfrant entfernt

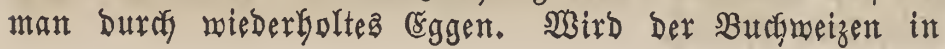

Wintergetreibeftoppeln als Smifdjenfrutyt gebaut, fo mun man bieje gleich nach Der Ërnte umbreçen, und man gibt in biejem ซalle, rie auch bet gut bearbeitetem Neubrudde, nur 1 ซurcte.

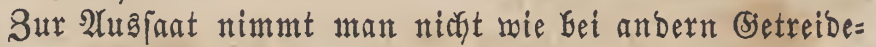
arten nur ben yolfommenften, fondern im sergentheil ben leichten und weniger meblreicfen, immer aber vom Unfraut bölig gefäuberten Samen, Der gemöbulid beim Werfent

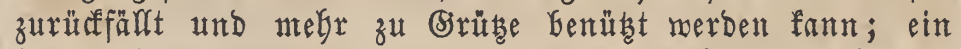
folder bringt bermöge feiner ftarfen Reimfäbigfeit megr und mehlreichere Samen alz ber bollfommene, Der meift nur üppige und Glätterreiche Giemächfe Gerborbringt. Die 2(us=

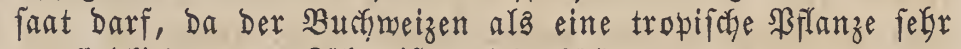
empfindlich gegen $\mathfrak{R a ̆ l t e}$ ift, nidgt bälder yorgenomment mer= Den, als bis feine Fröfte melgr zu befürchten fend, in făls tern Biegenden nicht yor (Ende Mai's ober Geffer Mitte Suni’a,

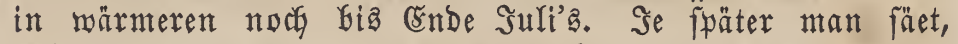
Defto größern (Ertrag an Rörnern erbält man, je früber aber

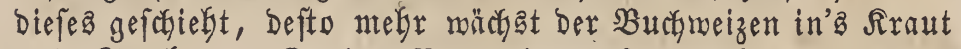
und Strof. - Da ber $\mathfrak{B} u$ fumeizen oft aus bis jebt uner= flärliçen Grünton nicht gedeifyen will und ofne alfen 3mei= fel nod unenträtgfelte Utmftände zur 3eit Der Saat Gier yon gropem Einflus ftnd, fo ift es ratbjam, Den Buchweizen zu verfdyiebenen Setten auszufäen. Der Budfweizen barf meber zu bicht, noch aber zat bünn ausigefäet merben; im erftern

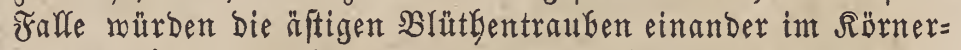
anjeten Ginderlidy fein, int zmeiten Falfe aber ber Budyei= zen Dem Boden niçt Kinlänglich Schatten geben und Dadurch Das Emporfommen Des Unfrautes begünftigen. 2im 'beften fäet Mtan furz bor einem গiegen und ber Ränge unb ber Breite nach, bant bie Saat gleichförmiger werbe. - 2 (1)

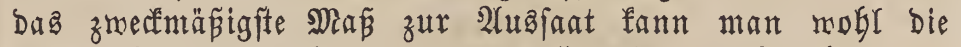
Sealfte Samen, weldyen man zur Şaferfant nötbig bat, an=

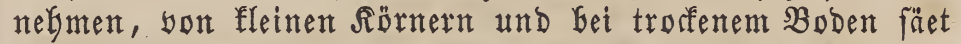
man mefry, weniger bon yolfommenem Samen und bei feutedem Boben. Da ber Buchweizenjamen nur flach und lorfer mit leidyten Egggen unter bie Errbe gebracfit merben Darf, fo iłt meder bas Unterpflügen baffelfen noch bas $\mathfrak{Y B a}=$ zen yor ber Saat zu entpfeblen. - Zu feinent erften bie= Deiben Gebarf Der $\mathfrak{B}$ udweizen notgmenbigerweife eine warme und zugleich mäp̃ig feudyte NBitterung, Denn burch faltes ober naffes- Wetter wirb er in feinem Noadjatfume unterbrüct, und fein Ertrag forobl an אörnern als an Stroh fält mut gering aus. - Der Bucfmeizen verlangt yon ber Beit an, wo er fein brittes Blatt befommen Gat, bis über bie 14 Tage lang mährende Blüthezeit einen abrecthfelnd warmen Negent und Sonnenfdein; andauernbe গegen und Trofenbeit aber,

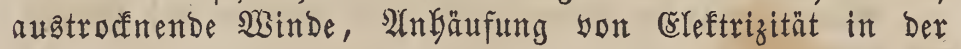

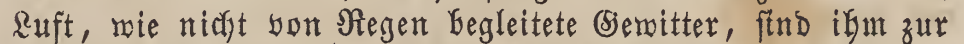

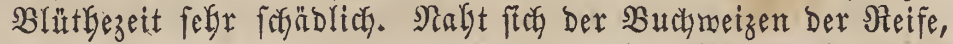

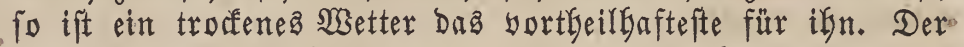
Butcheizen reift febr ungleich, man bringt ifan aber ab, $f_{0=}$

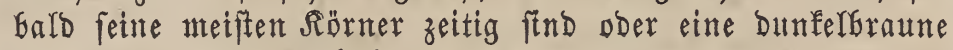
Farbe angentommen Gaben; bie noch unreifen Rörner läpt man auf bem Schwaben bollendz reif werben. Jrüly gefäeten.

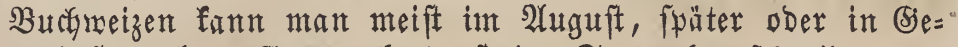
treibeftowpeln gefäeten aber erft in September fogneiben. Nachbem er burch bie Senfe abgebracht ift, läp̃t man ifn zum Albtroffnen noch einige Tage in Safmaden auf bem 
Felde liegen, bie man yon Seit zu Seit umwendet, bindet

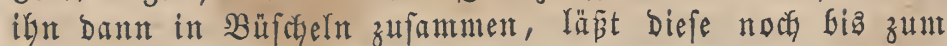
bölligen 2lftrortnen auf Dem zeloe fteblen, worauf man fie in ruftige Scheunen bringt und ben Buchueizen wie andere (j)etreibearten brifact.

Der Errtrag Des $\mathfrak{B}$ ufweizens an Rörnern ift oft aufer= orbentlich ftarf, bagegen in manchen Jalgren wieber fegr gering; man nimmt an, bá er als erfte Jrucht gebaut afle 3 Iabre, in Stoppeln gebaut aber nur alfe 7 Sabre

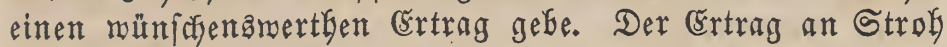

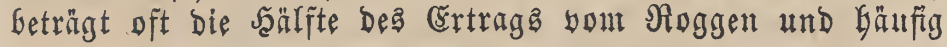
auch mefr.

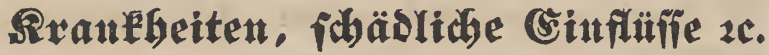

Der Buchweizen mird bauthtä

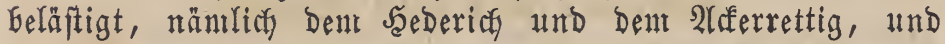
man fann Dem umfitfgreifen Derferben nur Durch zeitiges

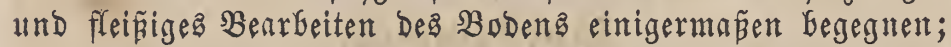
bafen fte aber einmal, zumal ber beberich, zu fefr über= Gand senommen, fo Gleibt nidyta anderes übrig, als ben

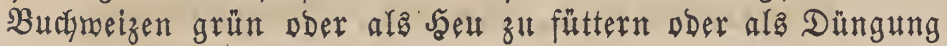
unterzupflügen.

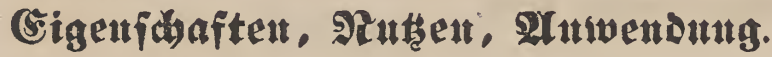

Die yormaltenden Beftandtaleile Des Bucfweizens ftnd man Söflnet in 1000 Theilen:

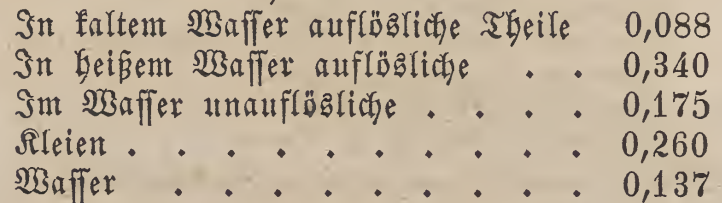

Der sucfweizen ift bejonders in getreibearmen begen= Den eine felgr gefdyalde Frudyt. Man bereitet auz feinen Sörmern, nachdem fie worber in Barföfen gebörrt ullo in

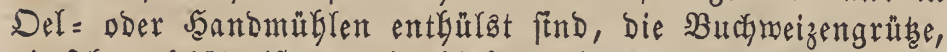

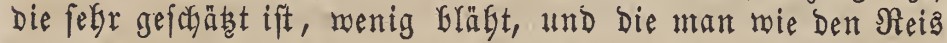
zu mandierlei Speifen benüben fann. 24u einem Scheffel

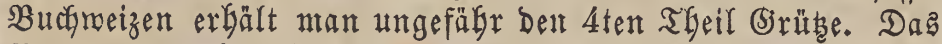
Burbweizenmegl ift auperorbentlicy nabrbaft und gibt mit

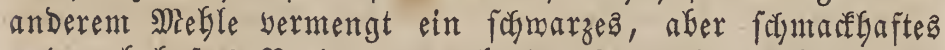
und nabrhaftę Brod, nur gelgt Der Teig nicht gebörig auf. Man bereitet ferner aus Den Sörnern Der, mit Miogren

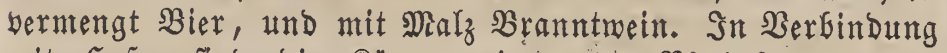
ntit Safer ftub bie Rörner eit gutes Bferdefutter, nur fchmiten die bamit gefütterten \$iferde ftarf; Die geringern

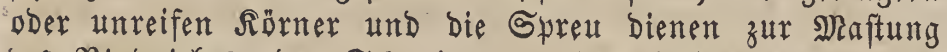

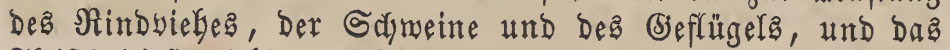
Fleifd biefer Thiere erfält baburd einen febr angenefmen

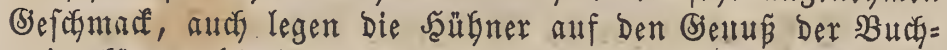
meizenförner Gäufiger. Hebrigets behauptet man, Dá̧ das mit $\mathfrak{B} u$ chmeizenförnern und grünen $B$ ud weizen gefütterte Biel, Gefondera das meiffarbige, wenn ea in bie Sonne fomme, elge biefes Futter berdaut fei, frampfgafte Sufülfe und Taumel befomme, welde aber mur fo lange anthalten,

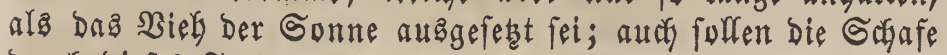
Durch biefez Jutter bisffopfig merben.

Das Rraut gift, fomohl grủn als getrodnet, feines Blätterreichthums regen ein gutę und febr nahrbaftea Bieh=

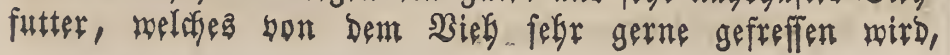

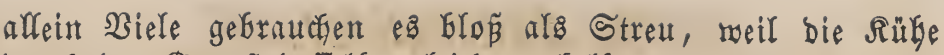
Durd Den (s)enus Deffelben leidgt werfalben, weit weniger und

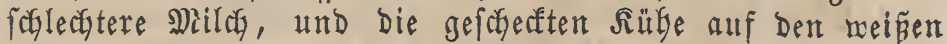

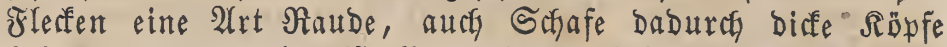

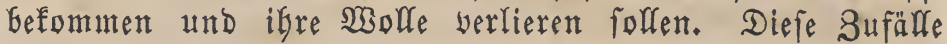
fcheinen aber yon bem Genuffe berborbenen und Dumpfigen

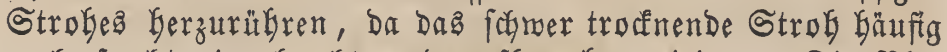
noch feucht eingebradyt und aufbemafht mird. - Die $\mathfrak{B l u}=$ men Des Buchmeizens merbent bäuffig bon Bienen bejucht und geben Denferfen biel Jonig. - Das Rraut funn man in

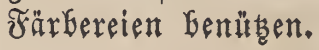

\section{(Beiditate.}

Der $\mathfrak{B u c h m e i z e n ~ f a n t ~ D u r a ~ b i e ~ R r e u z f a b r e r ~ i m ~} \mathfrak{A}$ nfange Des 15. Jahrhunderts aus Der Türfei nach Deutidiland.

Polygonum tataricum. L.

Polygonum sinarum. Dev.

Fagopyrum tataricum. Gärtn.

Fagopyrum tataricum. Gärtn.

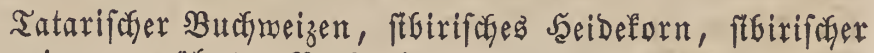
Bucfweizen, gezälnter Bucfweizen, tatarifcher. Inöterig.

Tatarian Polygonum. (engl.)

\section{2lrten = SGatafter.}

Stengel 2 ₹ur boch und brüber, 2theilig, aufrectst, glatt, ofent etwas beldaart, Gubl, geftreift, faftig. Blätter abmechjelnd Gerz - pfeilförmig, bie ofern fürzer geittelt alz bie untern. Blïthen flein, grünlich, Güfchelig, end = und achjelftändig. Staubgefäpe fo lang als die Erriffel. Samten 3erfig, an ben ङ̛⿱中⿰㇀丶㇀ ungleid gezahnt, rauh, grau, meblig.

\section{Blüthe= Beit and Dauex.}

$$
\mathfrak{s u l i}-\mathfrak{2} \mathfrak{u g u \mathfrak { f t }} \text {. } \odot \text {. }
$$

\section{SYox Éonmen.}

In Sibirien und Der Tataret einbeimifa und mird bort mie auch in Schmeden, bei unz aber meniger băufig fulti= wirt, wie im Doenwalde 26 .

\section{Bultut.}

Da biefer Bud̆beizen meniger empfindlith gegen Siălte

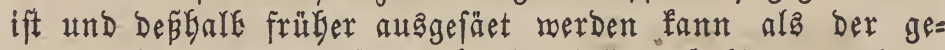
meine, fo eignet ex fted melyr für făltere Bebirgägegenden; er erträgt auch Durcfminterung int Freien. Die weitere Rultur Gat er mit Dent gemeinen ŞBeizen gemein. Er foll fofwerer und Geffer geratgen als Der gemeine Buchweizen. Diefe Pflanze ift in alfen Theilen ftärfer und blätterreider als bie yorige und als sirünfutter nodf melyr zu fojätzen; ifre אörner afer fend fleiner, biffüulftger und meniger mebl= reid, ber Ertrag bingegen fo ziemlida gleidy mit bem Dez genteinen Bucfmeizens.

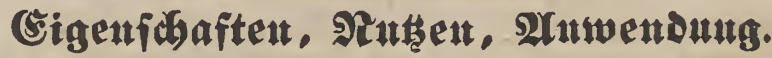

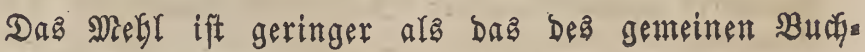
meizens; bie Benübung aber bie gleiche. 


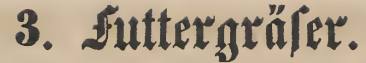

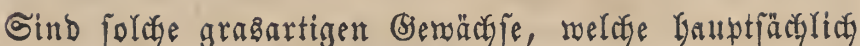
auf unjern WBiefen wadjen und nur zur Nabrung dez Biefg bermendet werben.

\section{Alopecurus, L.}

Syfteme: Achyrophyta. Neck.

Gramina. L.

Gramina agrostidea. Spr. Kunth.

Gramina digyna simplicia. Roy.

Gramineae. Juss.

Triandria, Digynia. L.

Selch 2flappig, 1Glütbig. Slappen beinake gleidylang,

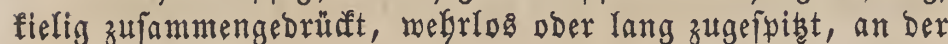
Baftis mit einander vermadjen. Blüthdyen 1 fpelzig, zufam= mengebrünt, foblauchförmig, auf einer Seite gefpalten, mit

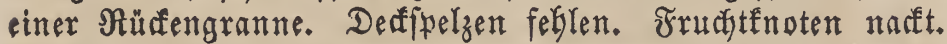

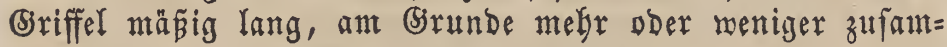
mengewadjen. Narben lang, zottig, treten aus ber Spibe ber Blume herbor. Same frei, wirb yon ber bertrofneten Blume Gebert.

Alopecurus agrestis. L.

Alopecurus myosuroides. Huds. Curt. Phleum flavum. Scop.

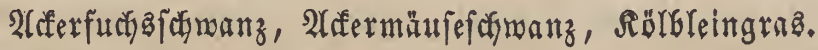
Field fox-tail Grass. (engl.)

\section{2rten: Ehatafter.}

Ş3rzel zajerig, etwas friectyend. Şalm aufredyt, oben

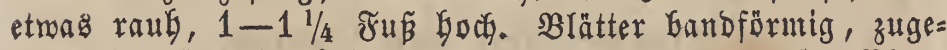
jpig̨t, fcharfrandig, Gelfgrủn, mit lăngliç̧em, ftumpfem Blatt=

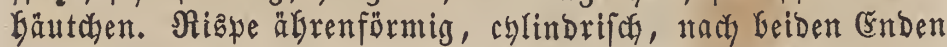
zugefpibt, ntit furzen 1-2brintbigen 2 feften. Slappen an ber untern Saălfte vermadyfen, fpisig, an Dem ofern Theile Des Siels fehr furz gemintpert, weip̧lich, aud violett, mit grünen Nerven. Spelze längliç - Ianzettfürmig, fpis, meiñ, mit vivletter ober grüner Spike und einer Rürfengranme. Staubbeutel gelb.

\section{Blitthe:Beit mo Danet.}

Эuni - Эult. $\odot$.

\section{Sorfommen.}

Aluf fotbigen ßläk̨en, auf Aecfern unter bem Getreibe, an SBegrändern.

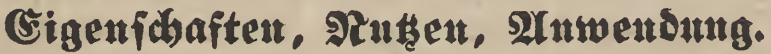
Biehfutter.

(sin Infraut unter bem Gietreide, fonti aber ein gute:

Alopecurus pratensis. I.

Alopecurus scaber. 0piz.

Alopecurus villosus. Gilib.

Alopecurus sericeus. Gärt.? $\quad \beta$. Alopecurus alpestris. Whlbg.

Alopecurus trivialis. Seidl. $\gamma$. Alopecurus candicans. Salzm.

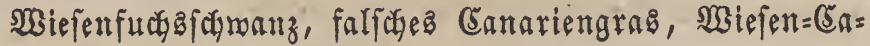
nariengraø̃, Taubengerfte, Rolbengraz.

Meadow fox-tail Grass, (enthl.)

\section{2lrten = Ebarafter.}

Barzel zaferig. J̧alur aufrect, glatt, zumeilen etronz

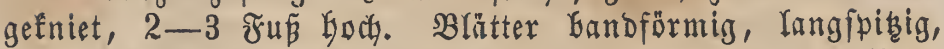
fcharfrandig, 2-6 3oll lang und 2 Rinien breit, mit läng=

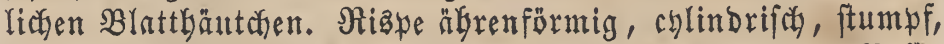
mit 3-66lüt tyigen Aeften. Ritappen fpitzig, an ber Bajtz verwadhfen, weíflich, grün geftreift, grannenlos, mit zottig gemimpertem Riel. Spelze fojlaurbförmig, meí̄, grïn ge= ftreift, auf bem Rüfen mit einer langen Sranne. Staubs Geutel violett=rötglids.

Mertens und Rioch unterfaciben eine Barietät:

$$
\beta \text {. spicis digitatis. }
$$

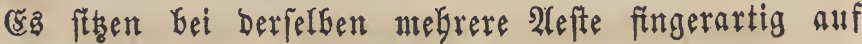
Dem ફ̧alme.

\section{SIIitbe = 3eit แno Dauex.}

Mai - September. 4.

\section{Soxfommen.}

2uf $\mathfrak{B i e j e n . ~}$

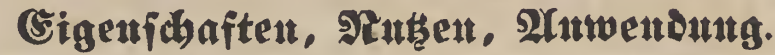

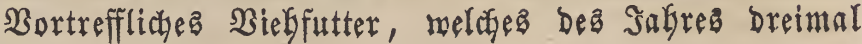
sejadnitten werben $\mathfrak{n}$ ann.

\section{Alopecurus fulvus. Smith.}

\author{
Alopecurus aristulatus. Michx. \\ Alopecurus geniculatus. Host. L. var. Spr. Trin. \\ Alopecurus paludosus. Beauv. \\ Alopecurus Konradii. Opitz. \\ Alopecurus subaristatus. Pursh.

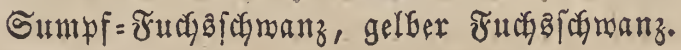

\section{2ivten = Shaxafter.}

Jaalm auffiteigend, glatt und mie bie Blattjifyeibe grau=

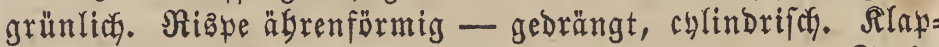
pen an Der Baftz werwadjen, ftumpf, genimpert. Spelze mandfyal etrą länger und breiter als bie Rilappen. Die (jranne mächą aus ber Mitte Der Spelze Geraus und ift fo lang, oft noch etroas länger alz bie Spelze. Staubbeutel linienförmig, viel fürzer als bei ber vorkergebenden 2 rtt, gelblichneiñ, zulest eiförmig - länglich, fafrangelb.

\section{Şüthe=3eit mo Dauer.}

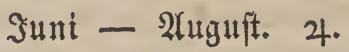

\section{S马otfommett.}

2uf feucten Wriefen und SEeiben, in Gräben, ftebens

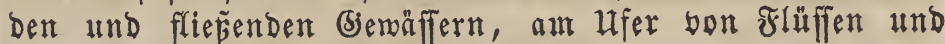
Bärhen yon Ěrarapa und Norbamerifa.

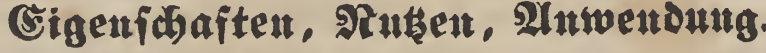

Futterfraut.

\section{Alopecurus geniculatus. I. \\ Alopecurus aequalis. Soboles. Alopecurus paniceus. Fl. dan. \\ $\beta$. Phleum villosum. Willd.}

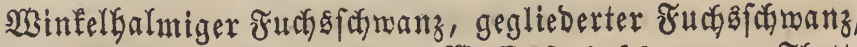
friechender indenfuchafchranz, Naafferfuchafchnanz, Flutt= gras.

Flote fox-tail Grass. (engl.) 


\section{2ivten = Ehataftex.}

\$3urzel zajerig, treift mebrere balme. Saalm gewöhn=

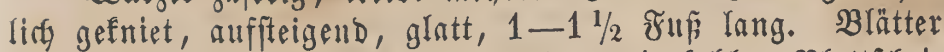
2-6 3ofl lang, flad), faharfrandig, mit fahlen $B$ lattfdyei=

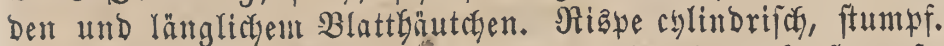
2lehrcten eiförmig - längliç. Rlappen längliơ, a ageftumpft,

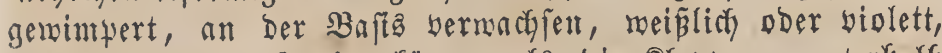
grün geftreift. Spelze fürzer ala bie Rlappen, unterbalb Der Mitte gegrannt. Staubbeutel gelblicfueís, nact) bem

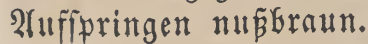

\section{Brïthe = 3eit und Damex.}

รuni - 2uguft. 4 .

\section{SYotFommen.}

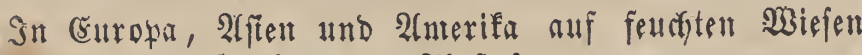
und Weibet, in Bräben, an Flup̧ufern.

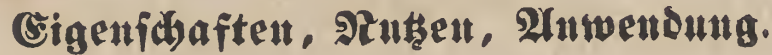

(rin gutea Biefengras.

\section{Panicum. I.}

\section{S. Seite 78}

\section{Panicum Crus-galli. L.}

Panicum Crus-corvi. L. ? Panicum digitatum. Gilib. Digitaria hispidula. Willd. Echinochloa Crus-corvi. Beauv. Echinochloa Crus-gálli. Beauv. Milium Crus-galli. Mönch. Oplismenus Crus-galli. Kunth. Orthopogon Crus-galli. Spr. $\beta$. Panicum orizinum. Gmel. Panicum Burmanni. Bbrst.? Panicum Hostii. Bbrst. Panicum oryzoides. Arduin. Panicum stagninum. Host. Echinochloa commutata. Schult $\gamma$. Panicum hispidum. Rhbrg. Panicum hirtellum. Walt. Panicum muricatum. Mchx. Panicum Walteri. Pursh. Oplismenus muricatus. Kunth. Orthopogon hispidus. Spr.

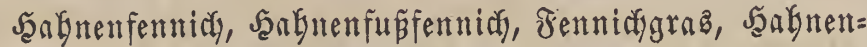
pornfennicy, Sirfegras, Rammbirfe, Sorggras, (šntengras, ริülynerfenticty.

\section{Arten = (Shatafter.}

Whurzel znjerig, treift megrere Salme, biefe find $11 / 2$ bis 2 Fü Goch, aufreçt ober aufíteigend, unten äfig, runblidy. Blätter fountal - lanzettförmig, flacl), fpibigig, fidarfrandig, mit zufammengebrüaften fafilen Sifjeiden und

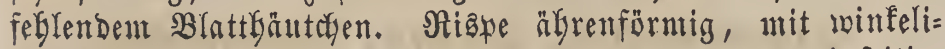
ger, hariger Spindel. 2lelgrajen eifürmig, grïn, einjeitig, 2reifig. Rlappen eirund, Gorftig, geftreift, grün oder fđunuzig siolett, mit einer E̋ndgrante. Staubfentel unb Narten purpurroty. Gamen eirumb, glänzend, dben zwei= ipizig.

Enrwer, ffonom, Pfongentunde.

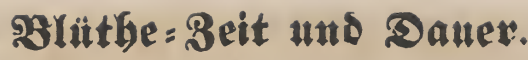

Эuli - 2lugutit. $\odot$.

\section{SOH Fommen.}

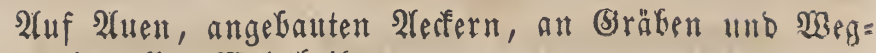
rändern in allen Selttbeilen.

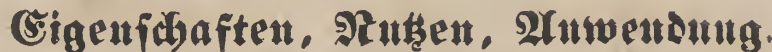

zuttergraz.

\section{Cynodon. Rich.}

\author{
Syfteme: Achyrophyta. Neck. \\ Gramina. L. \\ Gramineae. Juss. \\ Gramineae Chlorideae. Kunth. \\ Triandria, Digynia. L.
}

Relă 2flappig, einblütgig, fürzer ala bie Rrone. Rlap: wen abjebend, ungleith, unberwegrt, rederartig, gefielt -

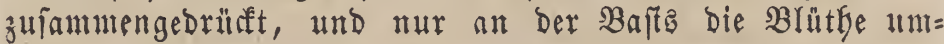
faffend. B̉huthdyen 2fpelzig, Yederartig, fthend; die obere Spelze fagmäler, won ber untern eingejchloffen. Derffpelzen 2. zrudiffnuten fagl. Briffel lang. Starben fprengmedelig, treten an ber Seite bes 2Aefredens Gerbor. Samen yon ber werbärteten Sirone amgeben.

\section{Cynodon Dactylon, Rich.}

Cynodon linearis. Willd.

Cynodon maritimus. H. B. Cynodon occidentalis. Willd. Cynodon portoricensis. Willd. Agrostis bermudiana. Tuss.

Agrostis linearis. Retz.

Chloris Cynodon. Trin.

Chloris maritima. Trin.

Dactylon officinale. Vill.

Digitaria Dactylon. Scop. Ell.

Digitaria linearis. Pers. Spr.

Digitaria stolonifera. Schrad.
Fibichia umbellata. Koel. Milium Dactylon. Mönch. Panicum Dactylon. L.

Panicum lineare. Burm. Paspalum Dactylon. Lam. Paspalum praecox. Walt. Paspalum umbellatum. Lam. Vilfa linearis. Beauv.

$\beta$. Cynodon stellatus. Willd. Agrostis stellata. Willd.

Vilfa stellata. Beauv.

$\gamma$. Cynodon tenuis. Trin.
Fingerhundzzakn, auslaufendez Fingergraz, rwurzel=

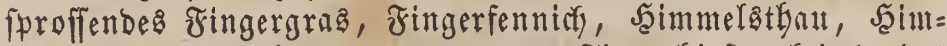
melafdjmaden, zagmes Mannagraz, Jingerbirfe, frientendes 2ิafergrą.

\section{2uten = (SGaraftex.}

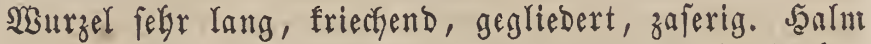

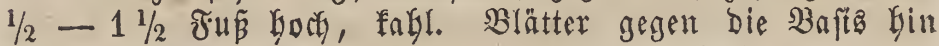
Gaarig, fafmal, lanzettförmig, fpibig, 4 3oll lamg, uno 1-2 Rimien breit, mit fallen ober nach wefen etwas befaars ten Blattideiden und aus einer langen Reifye won Saaren beftebendeu BIattbäutchen. 2fefren $4-7$, fingerförmig, 1-1 $\frac{1}{2}$ 3oll lang, fefre fajmal, einjeitig, burch bie abftes

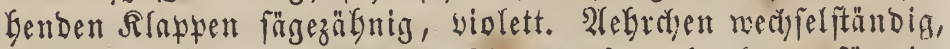

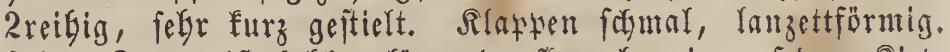
Drere Spelze ift fabl, glönzend, flaumbaarig auf Dem Siele

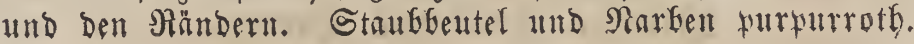

\section{SIlitbe = Beit uto Dauev.}

Suli - September. 4.

\section{Soxtommen.}

2uf trodfenen Sุügeln, Sanbplähę, an fanbigen Mfern, 12 
Wegen, in füblicfen Deutidjland, Bobmen, Schlefien, Deft= reich, Baiern, $\mathfrak{B F a l}_{z}, \mathfrak{B e t t e r a u , ~ M a i n z , ~ D a r m i t a d t , ~ W e r t h = ~}$ Geim, Dorften, Duiaburg, audf in Weftinbien, Norbamerifa und Dftindien.

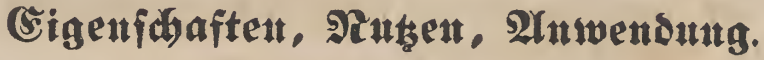

¿̌s ift ein gutez Futtergrab, aus dem Samen bereitet

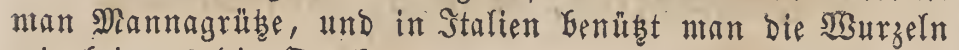
mie bei unz bie Suerfen.

\section{Phalaris. L.}

Syfteme: Achyrophyta. Neck.

Gramina. L.

Gramina agrostidea. Kunth. Spr.

Gramina Phalarides. Adans.

Gramineae. Juss.

Triandria, Digynia. L.

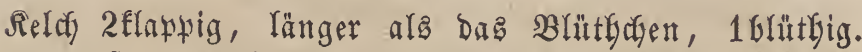
Slappen zufamnengebrüct, gefielt, fpib, Gäutig, Geinabe gleich. Blütfichen 2fpelzig, leberartig, unberwebrt; pbere Spelze zufammengefaltet, mit einen Riele. Dedfpelzen 2, länglich, fpidgig. Fruchtfnoten nafft. Eriffel febre lang. Narben zottig, faft fprengmedelig, treten aus Der Spibe bes Blütbrgens Gerbor. Samen eben, glänzend, yon ben ber= Gärteten Spelzen umidyloffen.

\section{Phalaris arundinacea. L. \\ Phalaris colorata. Beauv. \\ Phalaris picta. Hort. \\ Arundo colorata. Ait. \\ Baldingera arundinacea. Dumort. \\ Baldingera colorata. Fl. Wett. \\ Calamagrostis colorata. Sibth. \\ Calamagrostis variegata. With. \\ Digraphis arundinacea. Trin. \\ Typhoides arundinacea. Moench.}

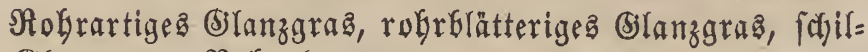
fige (3) (anzgras, Nobrglanzgras.

\section{Artent = Gharafter.}

Würzel friectend, Golzig, gegliebert, treift mefrere

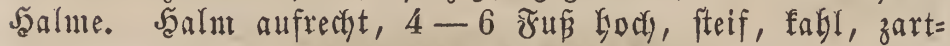
geftreift. Blätter bandförmig, fpibig, beflgrün, mit einem gropen Blattgäutchen. SRiąpe abftebend, fnäuelförmig, auf=

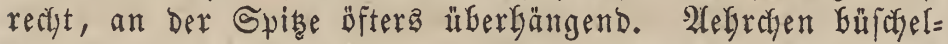

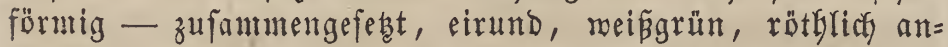
geflogen. Rlappen fpibig, fabl, zufammengebrïrft, 3nerbig. Blütydjen fürzer alŝ bie Rlapwen, glänzent, am (s)runde

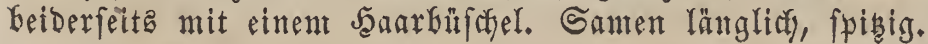

Barietäten Gat man:

B. foliis variegatis,

mit Gunten Blättern.

\%. flosculis viviparis.

\section{Slutbe= Beit und Daner.}

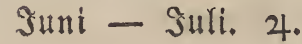

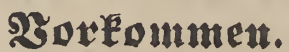

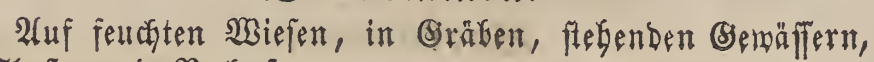
an $\mathfrak{F l u \beta}=$ unD $\mathfrak{B} a \mathfrak{d} u$ fern.

\section{(Eigenidhaften, Nuthen, Anwenoung.}

ซnttergras.

Phleum. L.

Stelephuros. Adans.

Syfteme: Achyrophyta. Neck.

Gramina. L.

Gramina Agrostidea. Kunth. Spr.

Gramina digyna simplicia. Roy.

Gramina Phalarides. Adans.

Gramineae. Juss.

Triandria, Digynia. L.

Selch 2flappig, 1blüthig. Slappen fielig, zujammen= gebrürft, meiftens an Riele gemimpert, ant Ernbe abgeftucht, ftachelfpibig. Blüthatjen 2ipelzig, untere Spelze unbewelgrt, Dber mit einer ßücfengrante, obere Spelze meift 2fielig. Deffiperzen 2. Jrudgtfnoten fagl. Briffel mäpig rang. Narben Yang, zottig, an Der Spike Des 2(ehrchens herbor= tretende Sament frei, mird bon ber getroifneten $\mathfrak{B l u m e} u \mathfrak{m}=$ geben.

\section{Phleum pratense, $\mathbf{L}$.}

\section{Phleum arvense. Pourr.}

Phleum ciliatum. Gilib.

$\beta$. Phleum nodosum. L.

Phleum bulbosum. Host.

Phleum tuberosum. Panz.

$\gamma$. Phleum stoloniferum. Host.

$\delta$. Phleum Bertolonii. DeC.

$\varepsilon$. Phleum villosum. 0piz.

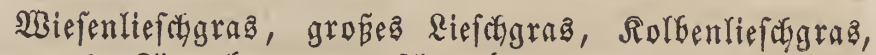
Sairtengras, Timotheusgras, Timothygras.

Timothy-Grass. Meadow Cat's tail Grass. (engl.)

\section{Arten = (Shaxafter.}

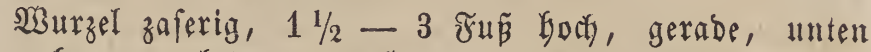
niebergebugen, glatt, zartgeftreift. Blätter lang, Ganbför= mig, fpisig, fcharfranbig, mit länglichen, abgeftukten Blatt= bäutchen. Sabeinähre walzig, fteinig, $1-6$ 3oll lang. 2legrcten furz geftielt, gebrungen. Rlappen meï̈lich ober

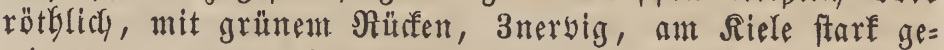
mimpert, gerabe, oben in einen Stadel, weldyer nach ausen gebogen ift, aualaufend. Blüthcyen bebeutend fürzer als ber Relch, bünnfäutig, zartnervig. Spelzen oben ftumpf.

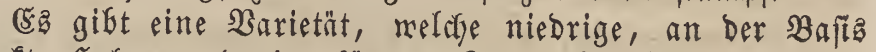
werbiafte Jalme und eine fürzere Sdjeinăbre bat.

\section{Błtüthe = Beit แub Dauer.}

Nai - 2uguft. 4.

\section{જgotrommen.}

2ruf feurbten Wiefen, an $\mathfrak{B}$ egen, bie enotige Barietit

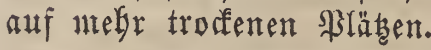

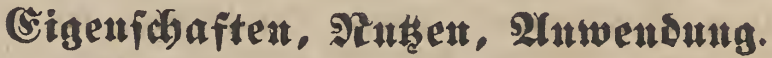

(Yin gutes Șiejengras, weldyes yorzugameife von ben Bferben gefucht wirb, meniger vom Rindsieh, Die Schafe freffen befonders die Wurzeln gerne. 


\section{Poa, L. \\ Honialopea. Dumont. \\ Spizopoa. Dumort. \\ Stenopoa. Dumort. \\ Syfteme: Achyrophyta. Neck. \\ Gramina. L. \\ Gramina bromea. Kunth. \\ Gramina composita. Roy. \\ Gramina festucacea. Spr. \\ Gramina Poae. Adans. \\ Gramineae. Juss. \\ Triandria, Digynia. L.}

Sield) 2flappig, 3-4blütbig, fürzer alz bie Blütgdent. Slatyen zufammengebrürft, Gäutig, ober frautig, gerabe. Blume 2fwelzig, bie untere Shelge zufanmengebrüct, ge= fielt, häutig germbet, unberwefrt, bie obere 2fielig. Derf= fipelzen 2. ซruchtfnoten narft. Sriffel furz. Narben feberig, tretent an Der Seite Der Blüthdyen berbor. Samen frei, bebefft.

\section{Poa annua. L.}

Poa triangularis. Gilib.

$\beta$. Poa humilis. Lejeun.

Poa annua varia. Gaud.

Poa variegata. Hall.

$\delta$ Aira pumila. Pursh.

$\gamma$. Poa supina. Schrad

Catabrosa pumila. R. S.

Poa alpina. $\gamma$. Willd.

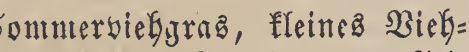

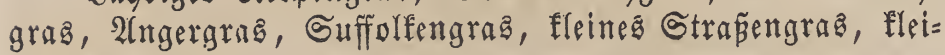

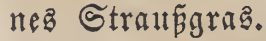

Annual Meadow-Grass. (engl.)

\section{2rten = Sharafter.}

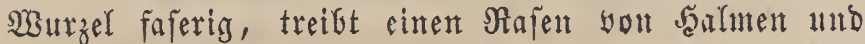

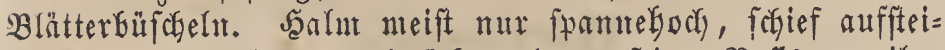

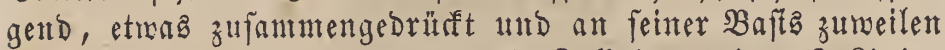
wurzelno. Blätter weid), $2-5$ 3oll lang, $1-2$ sinien Greit, bandförmig, fpibig, fryarfrandig. Riĝpe einfeitig, ausggebreitet, meift etras bunt gefärbt. 2lefte zu $1-2$

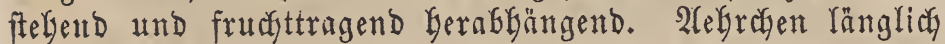
- eiförmig, 3- Fblüthig. Rlappen ungleich lang, fpibig, Die untere fürzer, 1 nervig, bie vbere 3 nervig. Hntere Spelze länglid - eirund, fpibig, 5nervig, bie obere fpibig, weis. Staubbentel blä́gelb.

\section{Barietäten:}

$\beta$. villos a, bie zottigbefanate.

Die Blütychen, ber Riel und Der Nand zottig bebaat. $\gamma$ varieg a ta, bie Gunte.

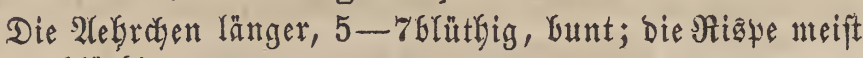
wettiger Glütbig.

\section{Blitthe $=$ Beit und Danex.}

Faft Das ganze Jahr Gindurth, Gia faft in ben Winter. $\odot-\sigma^{7}$.

\section{รัorfommen.}

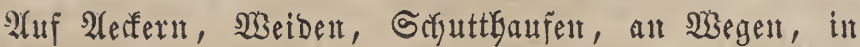
wentig gangbaren Strafen, SWälbern. Die Barietät $\gamma_{\text {. nuf }}$ feudsten 2llpen, Sarzburg 26 .

\section{Eigenidaften, Puten,}

Diejes Gras wirb woun Biel gerne gefreffen utro gibt,

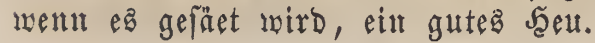

\section{Poa nemoralis. L.}

Poa nutans. Gilib.

Poa nemoralis vulgaris. Gaud.

Poa angustifolia. $\beta$. Huds.

$\beta$. Poa nemoralis firmula.

Poa angustifolia. $\alpha$. Huds.

Poa caespitosa. Poir.

Poa coarctata. DeC.

Poa dubia. Suter.

Poa firma. Wormsk.

Poa Gmelini. Koel.

Poa gracilescens. Schrad.

Poa pratensis var.? With.

Poa recta. Willd.

Poa rhenana. Lejeun.

Poa salebrosa. Panz.

Poa Scheuchzeri. Suter.

Poa trivialis. Leers.

$\gamma$. Poa nemoralis rigidula. Kuntb.

Poa palustris. DeC.

Poa polymorpha. Wibel.

Poa pratensis. Leers.

Poa scabra. Kit.

Poa serotina. Schrad.

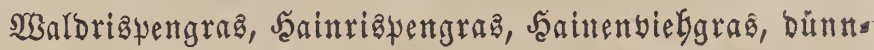

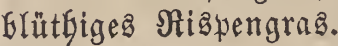

Wood Meadow-Grass. (engl.)

\section{Slxteu = Sharaftex.}

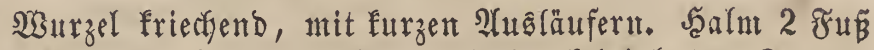
Gocis, fichady, glatt, runblich, mit Dunfelvioletten Sinoten. Blätter flach, 5-10 3oll lang, 1-2 1/2 Rinien freit, oben und am $\Re a n d e$ fidarf, mit glatten, geftreiften Scheiden und felgr furzem, abgeftudem, oft ganz fehlendem Blatthäutchen.

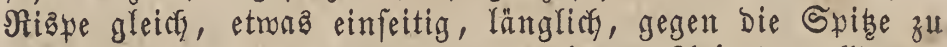

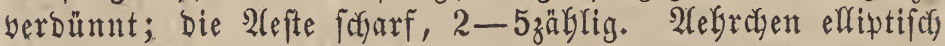
- Ianzettförmtig, 2-5blätbig, grün, violett fchattirt, meiß̈ gerandet. Itutere Spelze bat auf Dem Riele und ant Rande einen Saarrtreifen, ber beinalye bis zur Mitte gebt, yor ber

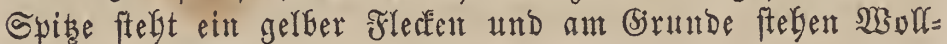
baare, melche biameilen feglen.

(ङ3 gibt you bent Waldriapengras mefrere Spielartent:

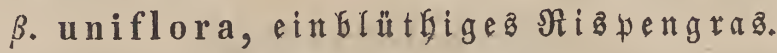

Die 2 efren mit einem einzigen, solffommen ausgebil= beten Blüthdyen verfeken, bie 2 geftielten Rutbimente it Röpfdyen befeftigt.

\section{$\gamma$. firmula, ftraffez Rizpentigra.}

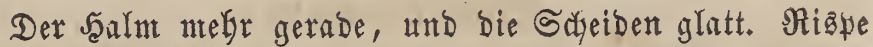
bielblütbig, augebreitet, etwas geneigt. 2(ebrdaen $3-5=$ Glütbig.

\section{ס. rigidula, fte ifes Rišuengras.}

J̧alm etwas fteif, pben wie aud bie Sryeiben etwas fcharf. Ftispe bielblüthig, auşgebreitet, abftekent, ftraff,

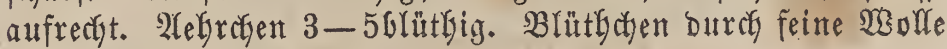
mit einander yerbunden.

E. coarctata, bidtrippige ßiapengras.

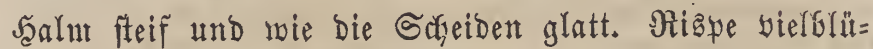
thig, gebrängt, aufredft ober nirfent. Aefgrdyen 3-5Glü= thig. Blütben burch feine şolle zufammentängend. 


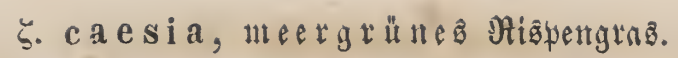

fralm fteirer und oben wie bie Sheiben gewögnlich

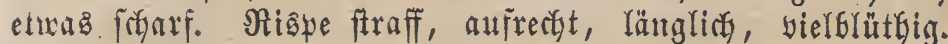
Zlefte etras ftarf, vielblütbig. 2lebrchen 3-5blütgig. Blü= then mit feiner Sigolle verbutton. Siffanze meergrü.

\section{Şlüthe = Beit uts Dauex.}

รัuli - 2luguft. 4.

\section{5ot fommett.}

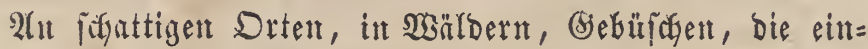
blütbige Barietät an Den gleidyen Drten, in Rleingau, bie

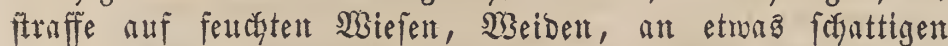
maldigen Drten, bie fteife auf Wriejen, Weiden und Warb= rändern, bie biçte Spielart auf Mauern, Felfen, an troffe=

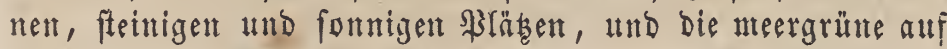
Ulerfern itr \&üttich.

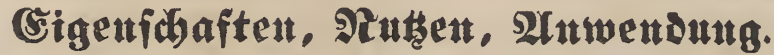

(̌in befonders ben Safafen fehr bienlidyez Jutter.

Poa bulbosa. L.

Poa alpina. Pall $\quad \beta$. Poa crispa. Thuil.

Poa trivialis. Koel.? Poa prolifera. Schmidt.

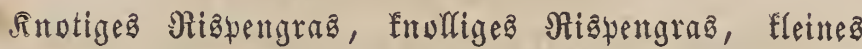

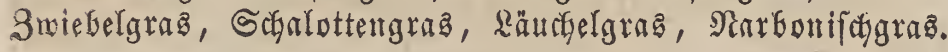
Bulbous Meadow - Grass. (ettgr.)

\section{Arten = ÇGarater.}

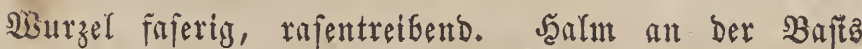
finstig, glatt, aufredyt, unten gefogen, $6-12$ Soll bocf. Blätter lamzettförntig, fwibig, $1-3$ 3oll lang, 1 Rinte breit, nactyenfürmig, fagarfandig, mit weí̄em Blattgäutchen. Stiape gleicf, eiförmig, abfebend, bie 2 2lefte etwas juarf. Alebr= (b)en eifürmig, grün und biolett, 4-7blüthig. Die obere Relchflappe ift 3 nervig, bie untere 1 nerbig. Dbere Spelze efeñalls 1 nervig.

Barietät :

\section{$\beta$. vivipara.}

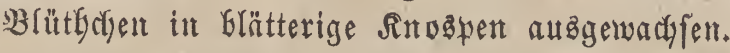

\section{Błintbe = Beit and Dauex.}

Drai - Suni. 4.

\section{Borfomment.}

IIt trodèen, fandigen Drten, auf fornigen Şügeln, at $\mathfrak{B e g e n , ~ ש e l b r a ̈ n d e r n . ~}$

\section{(Eigenfd)aften, Nutuen, 2tuwentung.}

(6)uteg Sdjaffutter.

\section{Poa pratensis. $\mathbf{L}$.}

Poa trivialis. Leyss.

Poa viridis. Gilib.

. Poa pratensis latifolia. Weihe. Poa glabra. DeC

Poa depressa. Presl.

Poa humilis. Ehrh.

Poa subcoerulea. Sinith. $\gamma$. Poa pratensis anceps. Gaud. Poa cinerea. Vill.

Poa sudetica. Schleich.

d. Poa glabra. Ehrh.

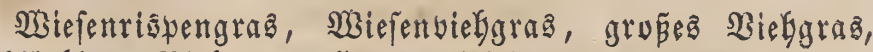

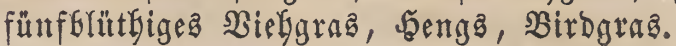

Great Meadow-Grass. (engl.)

\section{Arten = Şaraftex.}

Wurzel friectend, fproffentreibend. Şalm $1-3$ Fü

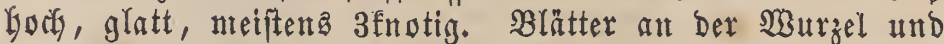
an ben ItIfruchtbaren Şalmen lang; Şalmblätter fürzer, mit

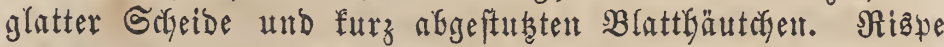
gleich, ausgebreitet, mit meiftens 5 fitarfen $\mathfrak{A}$ eften. Alebr= c)en eiförmig, zufantmengebrüfét, 3-56lütbig, gelbgrün nit biolett gemifot. Spelzen unten mollig. Strubbeutel gelb ober Gellroth.

Man fennt einige Barietäten:

\section{$\beta$. latifolia.}

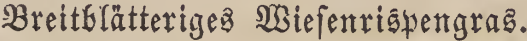

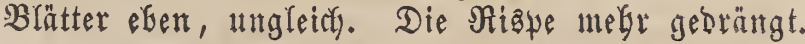

\section{$\gamma$. anceps.}

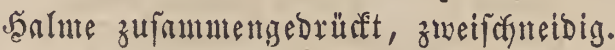

8. angustifolia.

Sctunalblätterigez SBiefenriànengraz.

Watrzelglätter furz, Gorftenfürmig.

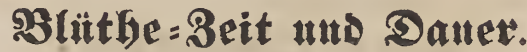

$\mathfrak{3} u n i-\mathfrak{s} \mathfrak{H}$. 4.

\section{Sorfommen.}

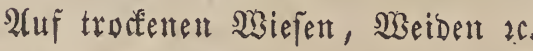

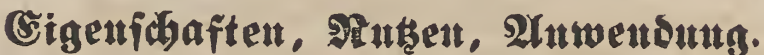

Ěine Der gemeinften und beften BBiejengräfer.

\section{Poa trivialis. L.}

\author{
Poa cilianensis. All. \\ Poa dubia. Leers. \\ Poa Kitaibelii. Schult. \\ Poa pratensis. Poll. Roth. \\ Poa scabra. Ehrh. \\ Poa setacea. Huds.
}

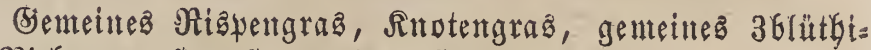
ges Biefgras, ftrauntragendes Wiefengras.

Paturin. (franz.)

Common Meadow-Grass. (engl.)

\section{2rten = Shatafter.}

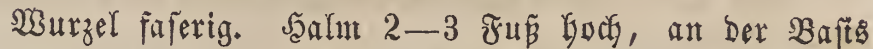
oft nieberliegend und bajelbft zufammengebrücft, meift 5 fno= tig und mie bie Safeide fafarf. Blätter bandfömig, fpisig,

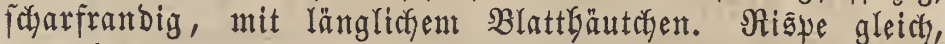

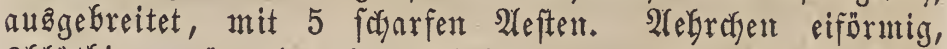
3 blüthig, grün ober braunvivlett, mit weiß̄er Spize. Rlap= pen lanzettförming, zujammentgebrürot, mit fharfem Riele; bie untere Spelze iift bon Derfelben Bildung, 5merbig, am Riele when fobarflich. 
BYutbe $=$ Beit utto Daute

รแกi - 2uguft. 4 .

\section{Botfommett.}

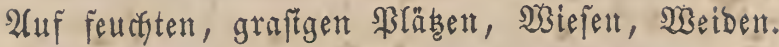

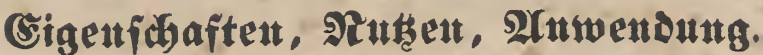

Gebr gutes ruttergras, aber tutr fo lang es noch jung

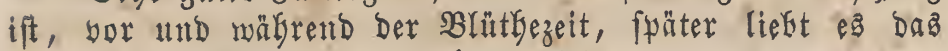
Bieh nidạt megre, da es zu bart mirb.

\section{Poa fertilis. Host.}

Poa angustifolia. S. Poa effusa. Kit.

Poa palustris. Roth.

Poa riparia. Wulff?

Poa serotina. Gaud.

Poa trivialis. L.

$\beta$. Poa botryoides. Trin.

Turtsch.

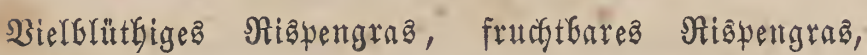
llferrispengras.

\section{2rtent = Chatafter.}

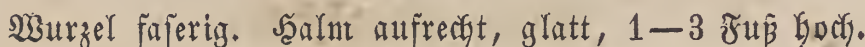
Blätter an Der $\mathfrak{B a f t a ~ g e f a l t e t ; ~ D a z ~ o b e r e ~ ł a l u b l a t t ~ l a ̈ n g e t , ~}$ Das Blattbäutchen Der obern Scyeiden berlängert und fpibig. Rizpe gleirf, ausgebreitet, nit 5 forarfen Aeften. Zebrcten ei - Innzettförmig, 2-5blütyig. Untere Sperze ftumpf, fdrwadynervig, mit eiment odfergelben Fledfen bor Der Spibe, aul Eitunde gewöhnlity rollig.

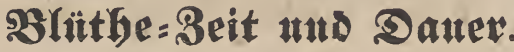

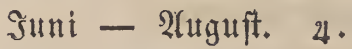

\section{5otemmet.}

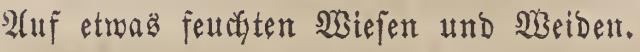

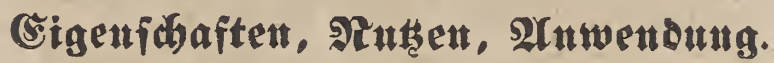

(5)utes Futtergraz.

\section{Poa compressa, L.}

Poa muralis. Wibel.

Poa planiculmis. Weber.

$\boldsymbol{\beta}$. Poa anceps. Presl.

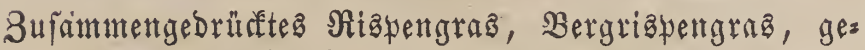

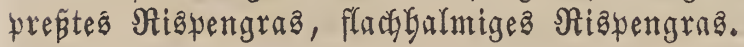

Creeping Meadow-Grass. (entgl.)

\section{Wrten = Shavafter.}

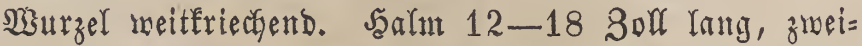

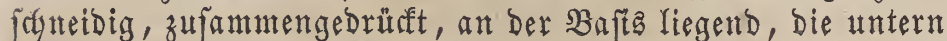
Inoten beffelbent futeförmig, oft mutzzelnd, glatt. Blätter 2-3 8oll lang, etwaz Greit, bas obere fo lang ala bie Scheide. Blattgäutchen furz abgeftukt. Rispe faft einfeitig, aufredyt, gebrängt, mit $2-5$ fubarfen Aeften. 2(ebrafent eiförmig - länglich, 5-9blütbig. Spelzen am Sorunde molfig. Staubbeutel gelf.

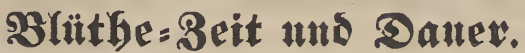

গuni - গuli, 4 .

\section{SHotrommet.}

2Uf trodenen Wrejen, in SBeinbergwegen, auf Mauern, Felfen und Däcyern.

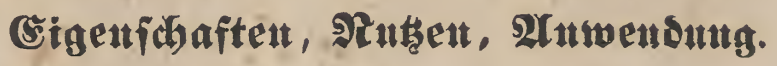

(5)tę శuttergrą.

\section{Glyceria, Beauv.}

Syftellte: Achyrophyta. Neck.

Gramina. L.

Gramina festucaceae. Kunth.

Gramineae. Juss.

Triandria, Digynia. L.

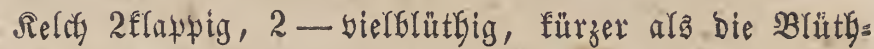
rigen. Rlappen Gaucfig, Die untere ift fürzer. Błlunte 2jpelzig, untere Spelze länglich, ftumpf, voer abgeftud, ganzrandig,

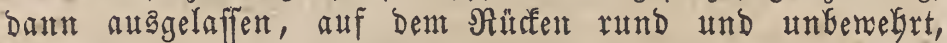
obere 2fielig, etwas fithelfürntig und gefaltet. Decffpelzen 2, furz, meifi abgeftutht, bismeilen zufammengerwadyen. Fructst= fnoten fagl. Griffel furz, felten mañ äftig - gefiebert, feitwärtz Gerbortretend. Santen frei, Geberft.

\section{Glyceria fluitans, R, Br.}

\author{
Devauxia fluitans. Beauv. \\ Festuca fluitans. L. \\ Festucaria Heisteri. Fabric. \\ Hydrochloa fluitans. Hartm. \\ Poa fluitans. Scop.
}

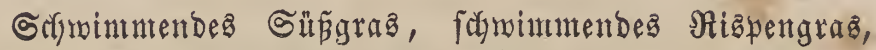
Zluthjü

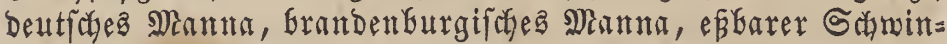
gel, fdyimmenter Scfimingel, frlottgras, Ěntengras, Schwa= Dengraz, Sdymaden, Jranffurter Sdjmaben, J̧immeläthau,

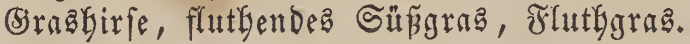

Manna de Pologne, Grain de Pologne, Fétuque flottante, Herb à la Manne. (frantz.)

Fescue-Grass, Flate, Manna-Grass. (entgr.)

\section{Arten = SGataftex.}

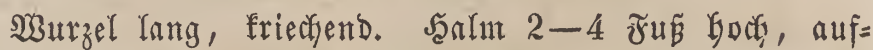
fteigend, geftreift, rund, fagl. SBlătter fochmimmen, fegr lang, machenförmig, fcharfrandig. Siäpe oft 2 Fus lang, augegreitet, einfeitig. 2lefte bor ber Blüthe an bie Spin=

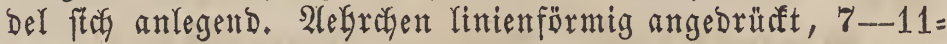
Glütfig. Silapyen lanzettfürmig. Untere Spelze geftreift,

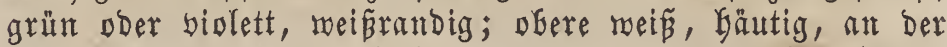
Spibe mit 2 furzen 8ähnen. Strubbeutel rotg. Sriffel lang. Narben fprengmedelig. Derffyelzen 2, beinabe 4erfig, zufantmengemachfen.

\section{Şlüthe: Beit und Dauex.}

Suni - September. 4 .

\section{\$ot}

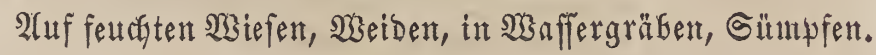
Rultux.

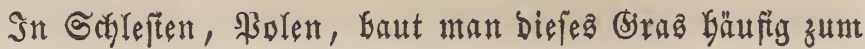


Befufe ber Brübebereitung an; Der 2 (nbau beffelben taugt befonders auf Miefen, bie man nicht wobl austroffent fann.

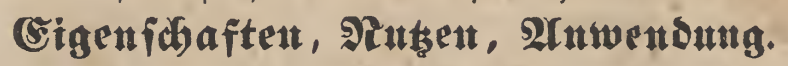

Der Mannafchmingel ift ein ganz gutes, fünes, wahr=

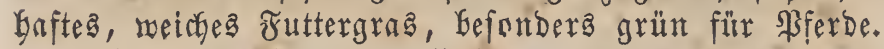

UHą Dem Samen Deffelfen Gereitet-man die Nanna=

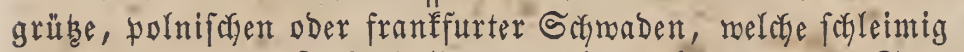
füß fómerft, biel Bucferftoff und Mebl entgält und zu Sup=

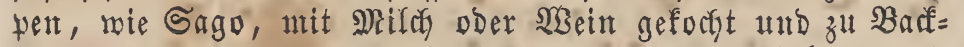

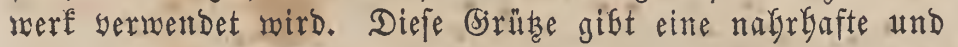
leicyt werbaulicye Rojt. Die Samen werben am Geften Mior=

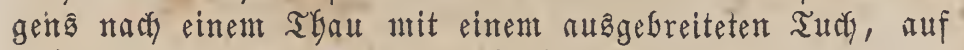
weldyem man bie Niisyen vorüberfitreift, gefanmelt.

Waffervögel, wie Ënten zc., Yieben feGr biefent Samen, ebenfo bie Jifche, wie Forellen.

Glyceria spectabilis. M. et $\mathbf{K}$.

Glyceria aquatica. Whlbrg.

Hydrochloa aquatica. Hartm.

Melica aquatica. Weber.

Poa altissima. Moench.

Poa aquatica. L.

$\beta$. Melica altissima. Sobolesk.

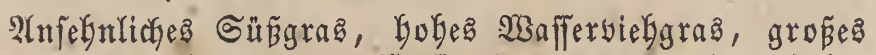
Biebgras, Riedftraupgraa, NBafferriebgria, gropez $R$ okr=

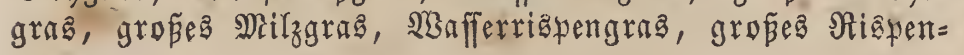
grąa.

Water Meadow-Grass. (entgl.)

\section{Wrten = Sharafter.}

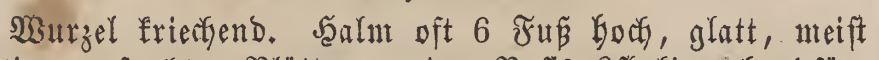
9fnotig, aufredyt. Blätter an Der Bafis 2fleftig, Gandför= mig, fpibig, fognrfrandig, feingeftreift, $1-1 \frac{1}{2}$ ₹̛n fang und 4-5 Rinien breit, mit futrzem, ftumpren Blattbäutchen.

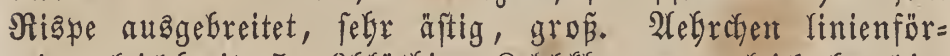
mig, gleichfreit, 5-96lütgig. Relchflappen ungleich, baudbig, eirund - Ianzettförmig, Graun, weiß̈randig, 1 nervig. Untere Spelze baudgig, 7nervig, fpibig; obere gleidflang, oben 2zähnig. Staubbeutel roth. Narken weiṕ. Deffipelzen furz, 4 erfig, geftukt.

\section{B̧lüthe=3eit ntts Danet.}

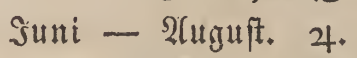

\section{S5orfomment.} upern.

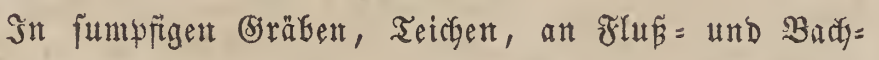

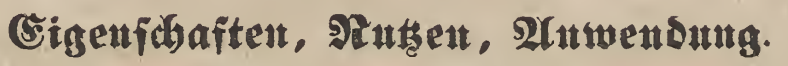

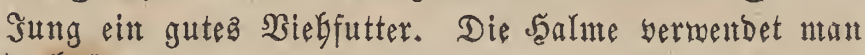
子孔 Strobbädfert.

\author{
Milium. L. \\ Syftente: Achyrophyta. Neck. \\ Gramina. L. \\ Gramina Agrostidea. Spr. \\ Gramina digyna simplicia. Roy. \\ Gramina Panicea. Kunth. \\ Gramina. Poae. Adans. \\ Gramineae. Juss. \\ Triandria Digynia. L.
}

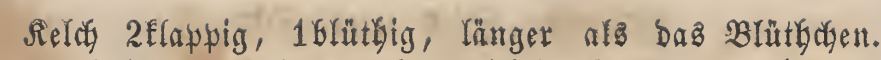
slappen faft gleich ober auch ungleid, frautrrtig, bäutig, concay, bie untere länger. Blütbethen 2ipelzig, anfthend oder furz geftielt, rederartig; bas untere elliptifo, unbe= wefgrt ober an ber Spike gegrannt, bie Giranne an Der Baftz etrą zufamutengezogen, abfällig; baz obere fannäler, contex, etwas gefielt. Dedffpelzen 2. Frudtefnoten fabl. (Briffel furz. Narben lang gefiedert, feitwärtz Gerboriom= mend. Samen mird yon ber erbärteten B̧นume als Scfale untgeber.

\section{Milium effusum. L.}

Agrostis effusa. Poir.

Miliarium effusum. Moench.

$\beta$. Milium confertum. Mill.

Milium scabrum. Merlet.

Milium vernale. Van. Hall.

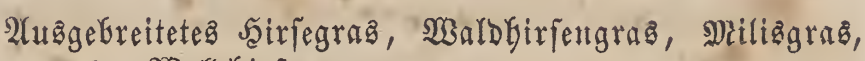
Fladbergrą, SBaldbirje.

Common Millet-Gråss. (entgr.)

\section{Arten = Shaxafter.}

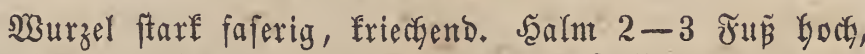
aufrecht, zartgeftreift, glatt. Blätter 6 Soll lang, $4-5$ Rinien breit, banbförnig, fpikig, flach, forarfranbig, mit

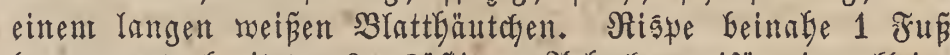
lang, auşgefreitet, 6-8äftig. Hefhrcten eiförmig, fleit, glatt, Gaudjig, gelfgrün, unberwebrt. Staubbeutel gelf. Narben weif́. Samen eifömig, fpisig, glatt gelblich.

\section{Blittbe=3eit แnd Daner.}

mai - Suni. 4.

\section{SHorfommen.}

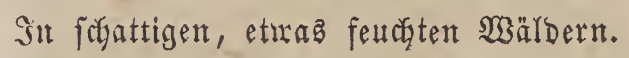

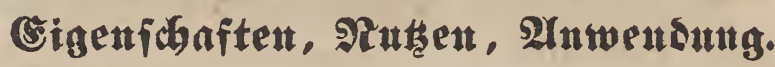

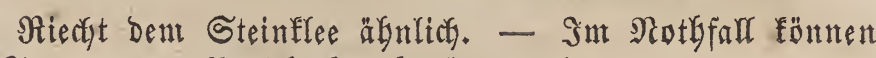
bie Samen zum Brobbarfen benüht werben.

\section{Agrostis. L.}

Agraulus. Beauv.

Anemagrostis. Trin.

Anemochloa. DeC.

Syfteme: Achyrophyta. Neck.

Gramina. L.

Gramina Agrostidea. Kunth. Spr.

Gramina Avenae. Adans.

Gramina digyna simplicia. Roy.

Gramina Phalarides. Adans.

Gramineae. Juss.

Triandria, Digynia. L.

Relch 2flappig, 1Glüthig, länger ars bie Blütthchen. Rlappen conbex - zufamnengebrücat, Janzettförmig ober ei=

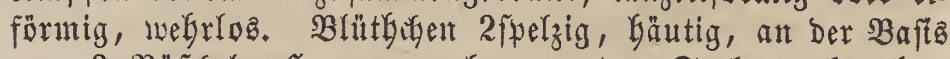
yon 2 Büfifeln Saare untgeber; untere Spelze unbenebrt, oder mit einer Dünten Stücfengranne; vbere fleiner, an Der Spike 2fpaltig, ober feglend. Deaffpelzen 2. Frudutfnoten 
fabl. Griffel febr furz. Narben feberig, feitwärtz berwor= tretend. Samen frei, beberft.

\section{Agrostis Spica venti. L.}

Anemagrostis Spica venti. Trin.

Anemochloa Spica venti. DeC.

Apera Spica venti. Beauv.

$\beta$. Agrostis interrupta. Autor.

$\gamma$. Agrostis longearistata. Aut.

$\delta$. Agrostis purpurea. Gaud.

Apera purpurea. Beauv. Rchbch.

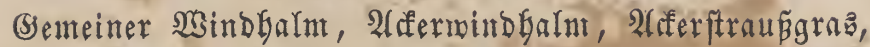
(3)etreideftrausgras, grop̃e 2lferjomiele, Thaugras, gropes

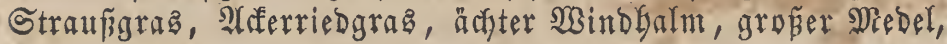
fleine Duedfe.

Silky Bent-Grass. (engl.)

\section{Arten = ÇGarakter.}

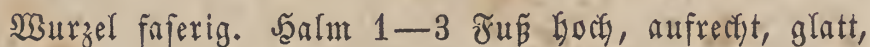
zartgeftreift, 3-5fnotig. Blätter Gandförmig, flach, lang= fpibig, fcharfrandig, ntit langem $B$ latthäutchen. Niąpe aub= gebreitet, vielGlüthig, grün ober Graunrotb. Slappen lan=

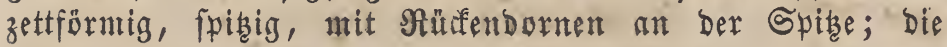

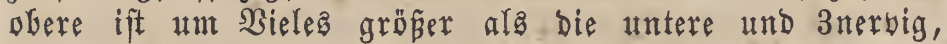
Tebtere nur 1 nervig. Blütfhen fürzer ala bie untere Rlapye; untere Spelze lanzettröprnig, fpibig, mit einer $3-4 \mathfrak{m a l}$

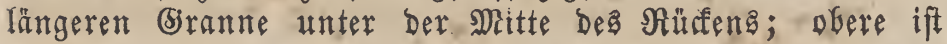
fromüler, fürzer und an ber Spite 2zähnig.

\section{Blüthe $=3$ eit und Dauex.}

$$
\text { รuni - suli. } \odot \text {. }
$$

\section{0rtommen.}

Unter Dent Getreide, an Wegrändern.

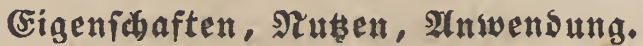

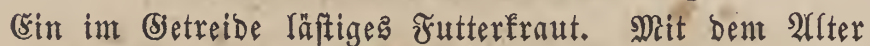

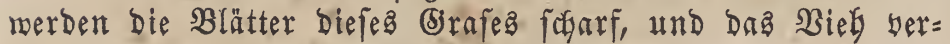
mundet fich beim zreffen Derfelben gerne.

Mian berfertigt aus bem Stroh verfogiedene (Beffectste,

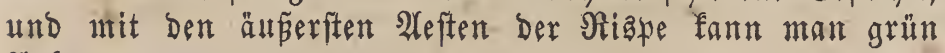
färben.

\section{Agrostis vulgaris, With.}

Agrostis alba. Balb. Loise. Agrostis alpina. Savi. Agrostis atropurpurea. Hort. Hafn.

Agrostis canina. With. Agrostis capillaris. Schkr. Agrostis decumbens. Host. Agrostis divaricata. Hoffm. Agrostis dubia. DeC. Agrostis hispida. Willd. Agrostis intermedia. Balb. Agrostis lithuanica. Bess. Agrostis nigra. With.? Agrostis polymorpha. Huds. Agrostis pumila. L. Agrostis rubra. Whlbrg.

Genteiner Windbaln, gemeinea Straubgras, mudhern= feinriapiger Windbalut.

Creeping Bent-Grass. (engl.)

Vilfa sylvatica. Beauv.

Vilfa vulgaris. Beauv.

$\beta$. Agrostis rubra. L.

Trichodium rubrum. R. S.

Agrostis sylvatica. Koel. Pol

A grostis tenuis. Sibth.

Agrostis violacea. Thuil.

Vilfa pumila. Beauv.

Vilfa hispida. Beauv.

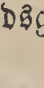

Arten = Eharakter.

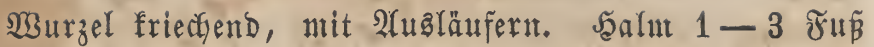
Gock, fabl, auffteigend, an den unterfiten selenfen rour= zelnd. Blätter bandförutig, langfpisig, fdarfrandig, ntit jebr

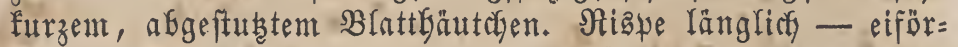
mig und Gefonders wäbrend Der Blütbe ausgebreitet, meift rötblich gefärbt, mit augigebreiteten, meift fdarfen QYeften. Rlappen Geinabe gleich, bie untere Gat oben Rüctenftacteln. Spelzen bünbäntig, zart, weiplidy, untere unbenefgrt, mit gezäbnelter Spibe, beinabe fo lang als die Slappen, obere Spelze bebeutend fürzer, oben gezăbnt.

Man hat folgende Barietüten:

\section{B.Agrostis stolonifera. Leers.}

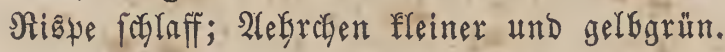

$\gamma$. Agrostis sylvatica. Poll.

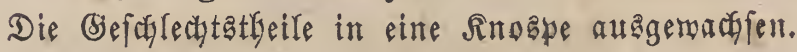

\section{Agrostis rubra. L.}

2ebraben mit fnieförmigen Brammen verfeken, weldge länget alo der Relch fitto.

\section{Shlüthe $=3$ eit und Damer.}

$$
\mathfrak{s u l i}-\mathfrak{2} \mathfrak{u g u f t} \text { 4. }
$$

\section{3:orommen.}

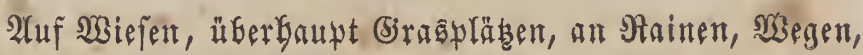
in Wälbern.

Bigenidaften, গtüen, Anwendung. (S)utę శuttergrą.

\section{Agrostis alba. Schrad.}

Agrostis alpina. Roth. Agrostis ambigua. R. S. Agrostis argentea. Schleich. Agrostis aristata. Sincl. Agrostis capillaris. Pollich. Agrostis coarctata. Ehrh. Hoffm. Agrostis compressa. Willd. Agrostis conferta. Willd. Agrostis cremenica. Bess. Agrostis decumbens. Gaud. Agrostis diffusa. Host. Agrostis disticha. Schweig.? Agrostis dulcis. Poir. Agrostis flava. Fl. Dan.? Agrostis gigantea. Roth. Agrostis gracilis. Kit. Schult. Agrostis Kitaibelii. Schult. Agrostis mutabilis. Knapp. Agrostis neglecta. Schult. Agrostis obliqua. Autor. Agrostis palustris. Sincl. Agrostis pallida. With.? Agrostis patula. Gaud. Agrostis pauciflora. Srhrad.

Meiper Windbalm, weip̈ę Straub̧grns, Sumpfrind: Galnt, Fioringras.

White Marsh Bent-Grass. (engl.)

\section{Arten = (5) Garater.}

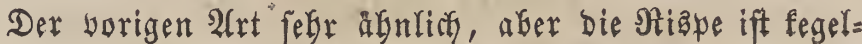

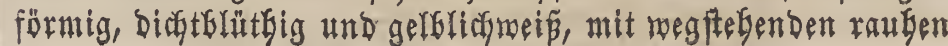
grostis procumbens. R. grostis rivularis. Brot. Agrostis stolonizans. Bess. Agrostis straminea. Hartm. Agrostis sylvatica. Host. L. Agrostis sylvestris. Fl. Dan. Agrostis stricta. Vitm. Gmel. Agrostis trichotoma. Autor. Agrostis varia. Host. Agrostis vernalis. Hort. Dorp. Agrostis vinealis. Schreb. Agrostis vivipara. Bivon. Phalaris semiverticillata. Forsk. Vilfa alba. Beauv.

coarctata. Beaur. Vilfa glaucescens. Pres Vilfa neglecta. Beauv. Vilfa patula. Beauv. Vilfa stolonifera. Beauv. Vilfa sylvatica. Beauv.
Agrostis polymorpha. Huds. 
Zleften. Die linienfürmigen Blätter baben länglidue Blatt= Gäutchen. Rlawen gleichlang, oben auf Dem SRüfen etmaz ftachelig. Hntere Spelze ift fo lang als bie Rlappen, wbere nutr balb fo lang und 2fpitigig.

Bartetäten bat man:

$\beta$. Agrostis alba var. $\beta$. Schrad.

Riąpe theila lănger, theifa fürzer, nur gebrängter, idjlaffer, wiolettpurpurroth gefärbt.

$\gamma$. Agrostis gigantea. Gaud.

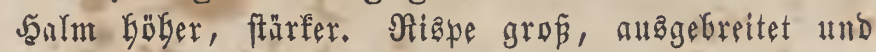
Ereit. 2(egrefen grünlicty.

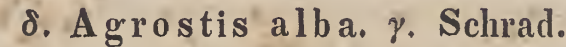

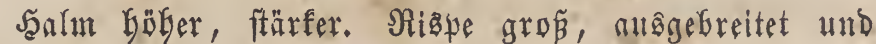
breit. 2lefredsen meiftens gegrannt.

\section{Blüthe = Beit und Dauer.}

\section{$\mathfrak{s u l i}-2 \mathfrak{2}$ guft. 2 .}

\section{Sorkommen.}

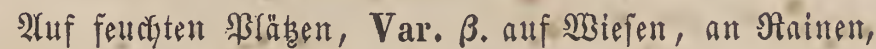

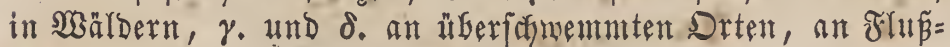
unb Bactufern.

\section{Sultur.}

Wrird zientlier Gäuftg in Ěngland angebaut. Berlangt einen fegr fandbaltigen und Dennocif, Gumuarreichen Boben, und bie Feudigtigfeit Darf weber Der Ruft, noch Dem (ErD= reiche mangeln. In einem fandigen, aber troffenen $\mathfrak{B o b}_{\text {en }}$ Gleift die Gragnarbe zu Iorfer und bie Saalme werben zu feft, in eimem bindenden Boden gebeigt ea fpärlich.

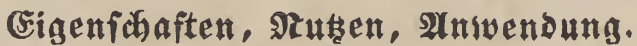

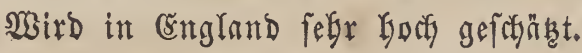

\author{
Arundo, L. \\ Calamagrostis. Adans. Roth. \\ Degeuxia. Clarion. \\ Syfteme: Achyrophyta. Neck. \\ Arundines. Rül. \\ Gramina. L. \\ Gramina avenacea. Spr. \\ Gramina arundinacea. Kunth. \\ Gramina digyna composita. Roy. \\ Gramina Poae. Adans. \\ Gramineae. Juss. \\ Triandria, Digynia. L.
}

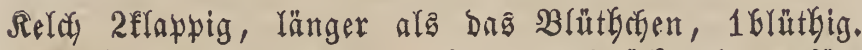

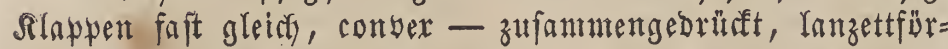

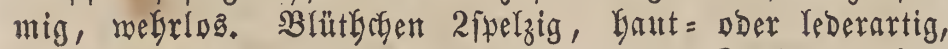
an ber $\mathfrak{B a f t}$ yon şanren ungeben; untere Spelze gezahnt,

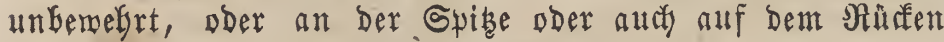
mit einer zarten Branme, bie obere ift an Der Spike 2thei= lig. Derfipelzen 2. Fruchtfnoten fabl, Briffel furz. Narben feberig, feitwärta Gerbortretend. Samen frei, bebert.

\section{Arundo Epigeios, I.}

Agrostis Calamagrostis. Poll. Arundo Calamagrostis. Light. Huds, Suter.
Arundo canascens. Wigg.

Arundo intermedia. Gmel.

Arundo stricta. Gilib.

Calamagrostis canescens. Beauv.

Calamagrostis Epiglios. Roth.

Calamagrostis lanceolata. With. DeC.

$\beta$. Calamagrostis Hubneriana. Rchbch.

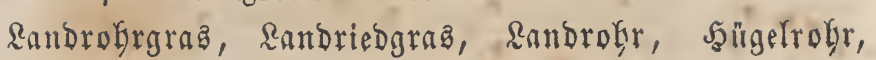
Bergiffilf.

Small Reed-Grass. (engl.)

\section{Arten $=$ charalter.}

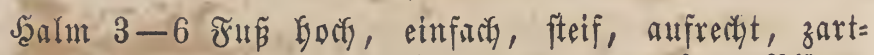
geftreift, am SBarzelfopfe yon 2(usläufern umgeben. SBlätter 8-12 3olf lang, meergrün, Gandförmig, langpitigig, zart= geftrcift, mit einem lănglichen Blattbäutchen. Riape fteif, aufrectgt, abftehend, Jappig - gefnäult, lanzettfürmig, an Der Spibe zufammengedrüft, pfriemenfömig. Silappen fefr idymal, fpibig. Stebraten Kalb fo lang als bie Rlapwen; bie 2 Spelzen find oben tief gefpalten, bie untere noch eimmal

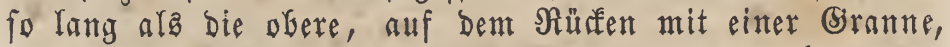
melche bie Ränge ber Spelze bat, an Der Bafts befaart.

Blutbe = Beit und Dauer.

$\mathfrak{s u l i}-2 \mathfrak{A}$ guft. $\%$.

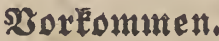

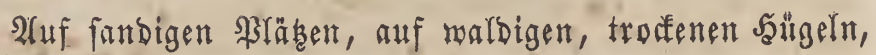
an $\mathfrak{B a c h u f e r t .}$

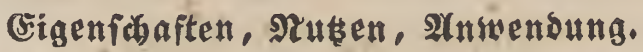

(5)eringes Futtergras, mirb yon ben Geyafen niryt gerne gefreffen.

\section{Arrhenatherum. Beauv.}

Syfteme: Achyrophyta. Neck.

Gramina. L.

Gramina bromea avenacea. Kunth.

Gramina avenacea. Kunth.

Gramineae. Juss.

Triandria, Digynia. L.

Selch 2flappig, 2Glütbig, oberes B̧lütfchen zwitterig, unteres mănnlich, Geibe an Der Baftis mit furzen Jaanren umgeben. Silappen conbex - zufammengebrüft, bäutig, un= gleich, bie antere fürzer. Blüthchen 2fpelzig, Ianzettförmig, untere Spelze an Der Spibe gezăhnelt, bei ber männliçen Blüthe mit einer langen gefnieten, gebregten ßücfengranne,

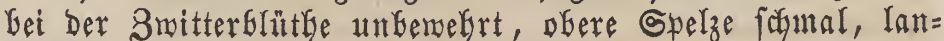
zettförmig. Deeffyelzen 2, Tanzettförmig, groṕ. Staubgefäß̈e 3.

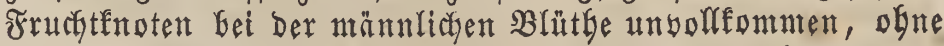
Narben, Gei Der Zwitterblüthe baarig, mit fefr furzem

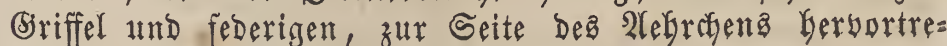
tenden Narben. Samen angemadfen.

\section{Arrhenatherum avenaceum. Beauv.}

Arrhenatherum elatius. Presl.

Arrhenatherum biaristatum. Petterm.

Avena elatior. L. .

Avena nodosa. Cullum.

Holcus avenaceus. Scop. Sm.

Hordeum avenaceum. Wigg.

$\beta$. Arrhenatherum bulbosum. Presl. 
Arrhenatherum avenaceum. $\beta$. R. S.

Arrhenatherum precatorium. Beauv.

Avena bulbosa. Willd.

Avena precatoria. Thuil.

Holcus bulbosus. Schrad.

Şuker Glattyafer, Gober Jaafer, Bratthafer, snolfen= hafer, Şiefenhafer, Gaferartiges Roğgraz, Jaafergraz, Gilatt=

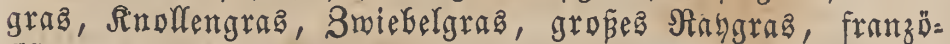
fiffches Siagrag.

Avoine fromentale margal. (framz.)

Tall 0at-Grass. (engl.)

\section{Arten = Charafter.}

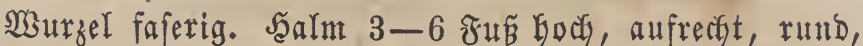
glät, geftreift, Geffgrün. Blătter 6 3olf lang, $1-3$ Rinien Ereit, Ganbfürmig, lang zugefpitst, fahl, bängend, mit glat=

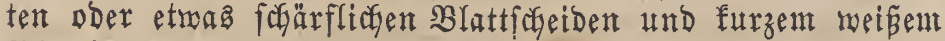

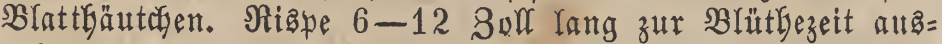
gebreitet, nachber zufammengezøgen, überfängend, 5-8äjtig.

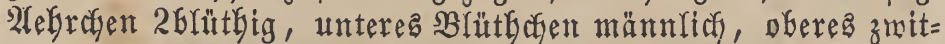
terig. Rlappen lanzettförntig, Gauchig, glatt, geftreift, obere noch einmal fo lang als bie untere. Die 2 Spelzen an Der Bafts furzhanig, fo lang als bie obere Rlapye. Itntere Spelze bes männlicfen Blüthchens geftreift, mit einer lan= gen, gefnieten, gebrebten Rürfengranne, welche unter son brauner und oben won meiplicher Farbe ift. Frudgtfnoten unbolfommen, ofne Narken. Itntere Spelze Des Britter= blütbchenz nur an Der Spike geftreift. Jruchtfnoten baar= fohopfig. Sriffel febr furz. Narben federig.

Barietät :

\section{$\beta$. bulbosum.} bebaart.

Murzel fnotig, aufgetrieben, und bie Salmfnoten zottig

\section{Frübling, Sommer. 2 . \\ Blütbe $=$ 3eit und $\mathfrak{D a u e r}$.}

\section{Bortommen.}

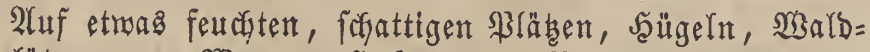

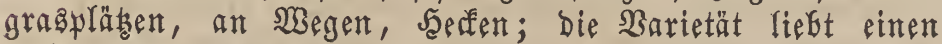
melgr troffenen Stanbpunft.

\section{Eigenfraften, গtuken, Anwendung.}

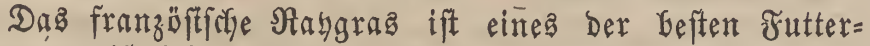
gräfer, es ift fehr bauerbaft, wäusat auperorbentlich fochnelf und fann 2-3mal bes Sahres abgemäht werben. (E̋ eigutet fith bejombers aud zur 2lnlegung fünftlidyer Sisefen und (Sragepluke.

\section{Holcus. L.}

Syfteme: Achyrophyta. Neck.

Gramina. L.

Gramina avenacea. Spr.

Gramina diclyna. Roy.

Gramina bromea avenacea. Kunth. Mas.

Gramina Sorga. Adans.

Gramineae. Juss.

Gramineae Phalarideae. Kunth. Gran.

Triandria, Digynia.

Reldy 2flappig, 2Glüthig, dą untere Blüthchen zmit= terig, bas obere männlich, beide geftielt. Rlappen zujanmmen= Enfruer, Bénom. Pframzenfunde. gebrüaft, fraut - bautartig, an Der Spike fachelfpibig,

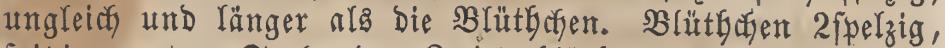

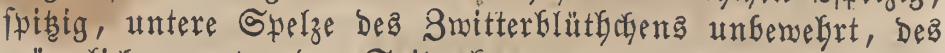
männlichen unter Der Spibe furz gegrannt. Deffipelzen 2.

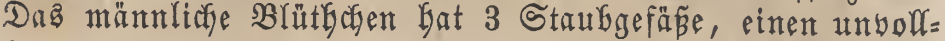
fommenen Jrudgtfnoten und feine Narben, das 3witter= blütbchen 3 Staubgefäße, fablen Fruchtfnoten, febr furzen (Sriffel und federige, feitwärţ berbortretende Narben. Samen frei, bederft.

\section{Holcus lanatus. L.}

Avena lanata. Koel.

Wolliges Jenniggras, gemeines Jeoniggrą, Darrgrą,

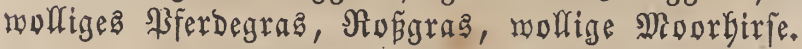

Woolly Holcus. (entgr.)

\section{Arten = Cranater.}

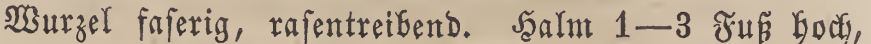
aufrecht, geftreift, Gelfgrün, meichbaarig. B̧ätter fanzettfür= mig, langipidig, geftreift, weichloarig, mit geftreiftent weich= Gaarigen Blatticheiben und fleinem, meífem, länglichem Blattfäutchen. Siałe gleirg, auggefperrt, mit feinbefaarten 2leften. Rlappen lanzettförmig, Glaprötblich, am Riele ge= mimpert, zufammengebrüft, bie untere ift fürzer und 1 ner= wig', bie ofbere 3nersig. SBlütbchen geftielt, fahl, glănzend, 2fpelzig, fürzer alz bie Silappen, Daŝ untere ift zmitterig, Das obere männlich, meldfę unter Der Spise eine furze, in ber Mitte berbicfte, hacfig zurürfofefogene Branne beftht. Die Derffpelzen Des 3witterblütrychens find lanzettförmig.

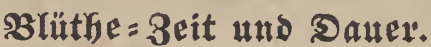

Suni - September. 4 .

\section{3oxemmen.}

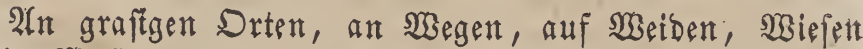
und in $\mathfrak{M a ̈ l d}$ ern.

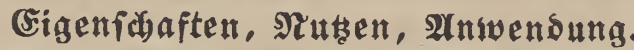

ઉ̌in fü yon allem $\mathfrak{B i e f}$ gefucht mirb.

\section{Holcus mollis. I.}

Aira Holcus mollis. Vill.

Aira mollis. Schreb.

Avena mollis. Koel.

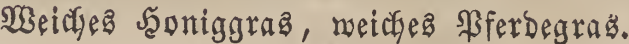

\section{Arten = Sharaktex.}

Wirzel friectend. Şalm an ben Snoten behaart. Brät= ter etrwas fafarf, mit glatten Safeiben. Niaßue gleidy, aus= gefperrt. Aefrecten grö̈er als bei Der borigen 2(rt. Rlappen lanzetfförmig, zufanmengebrüatt, fpikig, an ben Nerven mit furzen, etwas fteifen Saaren befegt, bie untere ift fleiner, 1 nervig, bie obere 3 nervig, die Nerven einander mefr ge= nähert. Das obere männliche Blütbchen ift an ber Baftz bon einem Bündel Saare umgeben; Die Grante ift länger und fommt über ber Mitte Kervor, fite ift zuerft aufredyt, Dann gefniet, unbemegrt und reicht über bie Rlappen Ginaus. Derffpelzen gröfer, länger, fpitiger, zumeilen ftchelf̈̈rnig, mit einen langen Seitenzafn. Die Spindel ift glatt. 
Blithe $=$ 3eit und Dauer.

Suli - Septemtber. 4 .

\section{Borémmen.}

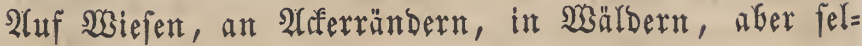
tenter als̆ bie yorige $\mathfrak{A}$ rt.

(igenjuaften, গ⿰u中en, Atnwenoung.

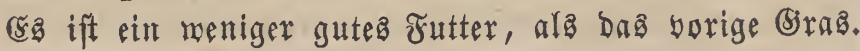

\section{Aira. L.}

Avenella. Koch.

Corynephorus. Beauv.

Deschampsia. Beauv.

Poa. Adans.

Syfteme: Achyrophyta. Neck.

Gramina. L.

Gramina avenacea. Spr.

Gramina bromea avenacea. Kunth.

Gramina digyna composita. Roy.

Gramina Poac. Adans.

Gramineae. Juss.

Triandria, Digynia. L.

Sielch 2flappig, 2Glütthig, ober 2Glüthig mit einem $\mathfrak{A} \mathfrak{n}=$

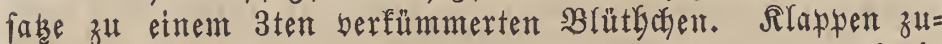

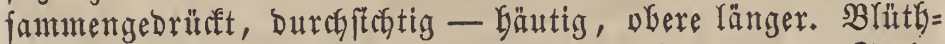
afen zmitterig, an Der Baftz befaart, 2fpelzig, untere Spelze mit einer geraben Rübfengranne, obere 2fielig, auf Den Sielen zartgemimpert. Deeffpelzen 2. Fruthtfnoten fabl. (S)iffel febr furz. Narben feberig, feitmärto Gerbortretend. Samen frei, bederft.

\section{Aira caespitosa. L.}

Aira alpina. Roth.

Aira altissima. Moench.

Aira breviaristata. Gilib.

Aira glauca. Hartm.

Aira parviflora. Thuil.

Aira paludosa. Wibel.

Calamagrostis Arundo. Roth.

Calamagrostis Leersii. Koel.

Campella caespitosa. Link.

Beauv. $\varepsilon$ ? Deschampsia grandis. Bess.

Deschampsia parviflora. Beauv. $\zeta$. Aira bottnica. Link.

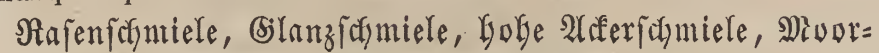

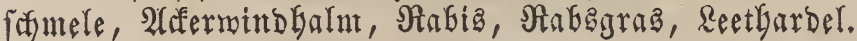

Turfy Hair - Grass. (engl.)

\section{Arten $=$ (Sharakter.}

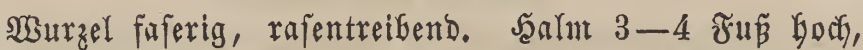
aufrecht, fabl, glatt, oben zartgeftreift. Blätter fochmal, flach, gefurcht, mit geftreiften Scheiben und langem, meišem

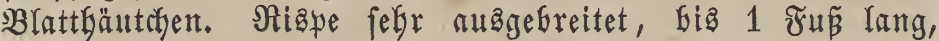
fehr äftig. 2lefrecten llein, glänzend. Rlappen lanzettförmig,

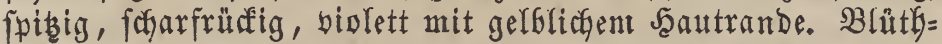
chen io lang als bie Rlappen, an Der Baftz beljart, Dą untere ungeftielt, bas obere furzgeftielt. Untere Spelze wein,

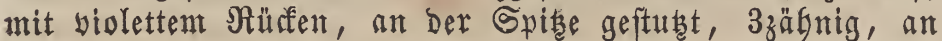

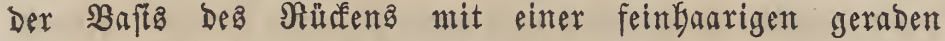
(oranne. Dbere Spelze foumäler, meís, 2zäbnig. Staubbeutel

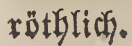

Barietäten :

$\beta$. Aira parviflora. Thuil.

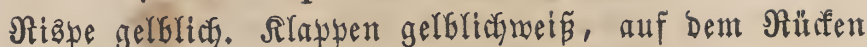
grün. Blütgchen grünlifiggelb, an Der breiten Spite meip̈liç.

$\gamma$. Aira paludosa. Wib.

Mit nod einmal fo gropen 2 felgrefen und breiteren Blăttern.

\section{d. Aira vivipara.}

Lebendig gebärend.

\section{Blüthe $=$ Beit und Dauev.}

$\mathfrak{s u l t}-\mathfrak{A} \mathfrak{u g u f t} .4$.

\section{Sorkmmen.}

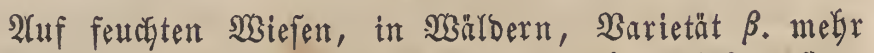
in fofattigen, feuchten Șaldungen, $\gamma$. Mebr auf funtpfigen Misient.

(sigenicbaften, গtüen, Atwenoung.

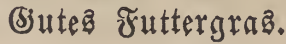

\section{Aira canescens. I.}

Avena canescens. Web.

Aira clavata. Gilib.

Corynephorus canescens. Beauv.

Weingärtneria canescens. Bernh.

(siraue Sogmiele, graugrüne Sigmiele, Silbergraz, grauer Bod

Gray Hair-Grass. (entgl.)

\section{2urten = Charakter.}

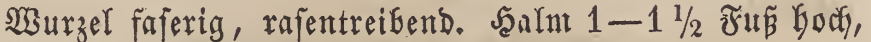
foglanf, glatt, oben zartgeftreift, aufrecht ober auffteigend. Blätter Gorftig, eingeroldt, fteif, graugrün, mit geftreiften

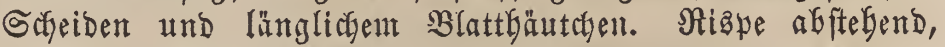
gebrängt, äftig. 2lebreben $1-1 \frac{1}{2}$ Rinien lang. Rlappen

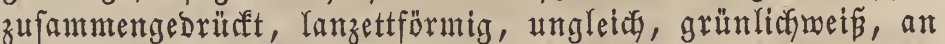
Der Spise purpurroth. Blütken fleiner als ber Relch, Das obere Gaurig geftielt, Das untere ftiellos. Itntere Spelze

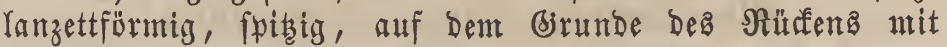
einer Sranne, welefe Gis zur Mitte fabenfürmig gebregt und Graun ift, in ber Mitte einen Rreis bon furzen Şaaren trägt und über ber Mitte meís und nach oben feulenfïrmig mird. Staubbentel Dunfelviolett, felten gelb.

şlüthe = 3eit und Dauer.

รักi - 2(uguț. 4 .

\section{2orEmmen.}

$\mathfrak{Z} \mathfrak{n}$ fanbigen Drten, an Wegrändern.

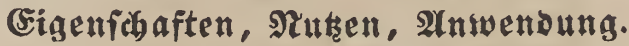

3war ein geringez Juttergras, welctez aber yor ber Blüttge wou den Schafen gerne gefreffen wird.

Avena. L.

Sielge Seite 70. 


\section{Avena flavescens. L.}

Trisetum flavescens. Beauv.

Trisetum pratense. Pers. Nutt.

Trisetum splendens. Presl.

(bolbbafer, gelblicher Saafer, Saabergras.

Yellow 0at - Grass. (entgh.)

\section{Arten = (Sharafter.}

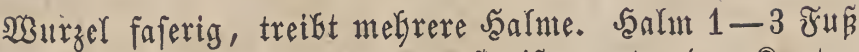
God, aufrecht, rund, glatt, zartgeftreift, unter Den Rnoten Gie und ba banrig. Blätter fandförntig, zugefpist, facharf= randig, etwas zottig, mit geftreiften Sdyeiden und furzem, meipem Blattbäutçen. Rispe abftebend, 4-6 Soll lang, bielblütbig, åtig. Alebrchen zujammengebrüct, gelbgrün, glänzend, 2-3blütgig. Slappen febr ungleid, lanzettför = mig, untere 1nerbig, biel fleiner als bie 3nervige obere Siappe. Intere Spelze Innzettfömig, gelblichgrủn ober bell= violett, meífrandig, mit blab̧bräunliçer, 2fpaltiger Spike und einer langen Raffengranne. Dhere Spelze an Der Spibe autigerandet. Gamen gelb.

Man fennt 5 Spielarten:

\section{$\alpha$. fl avescens.}

Die Aegrafen bon gelblicter Farbe.

$$
\beta \text {. major. }
$$

Die Alebrçen ftnd Gier un Das Doppelte größer.

$$
\gamma \text {. } \mathrm{minor} \text {. }
$$

Die Alefratyen fleiner.

\section{o. variegata.}

Die Aebrifen Gunt gefarbt.

$$
\text { ع. villos a. }
$$

Die ganze Sfflanze zottig Gebaart.

\section{Blüthe = 3eit tud Dauex.}

$\Im \mathfrak{u l i}$ - September. 4.

\section{פorfommen.}

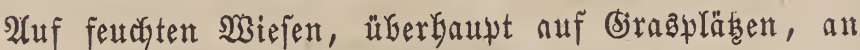

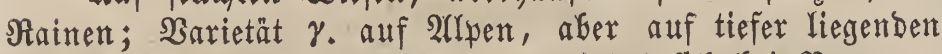
Drten; Barietät $\varepsilon$. ift feltener und findet fitch bei Bonn.

Sigenfd aften, গtutsen, Anuenoung.

Sebr gutes Futtergras, weldues, wenn es fith bäufig borfindet, bie sïte dea Seues Gebeutend bermebrt.

\section{Avena pubescens, L.}

Avena pratensis. Gort. Gouan.

Avena sesquitertia. L.

Trisetum pubescens. R. S.

Trisetum sesquitertium. Beauv.

$\beta$. Avena montana. Vill. Gmel.

Surzbariger Scafer, weithaariger Şafer, feinbaariger

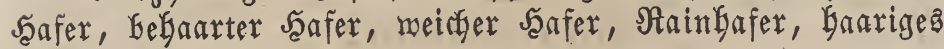
Safergraz.

Soft 0at-Grass. (engr.)

\section{Arten $=$ (Sharakter.}

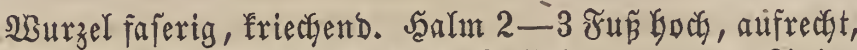
rund, zartgeftreift. Blätter $3-6$ 3olf lang, $2-3$ Rinien
Greit, Ganbförmig, flach, fpithig, weidhàarig. Blattioleiben

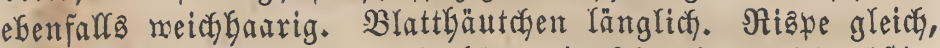
etraz traubenartig, wben überbängend, fodmal, ungleidy äftig.

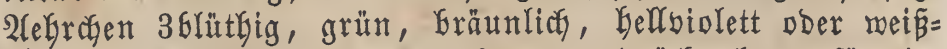
fìjecfig. Rinwpen conver - zujammengebrüdt, Ianzettförmig, fuibig, ungleich. Untere Spelze oben ftumpf, meif̨ 4zäbnig, länger alz bie Rlappen, mit einer langen, gefnieten und gebrebten Rücfengrante. Dbere Spelze fürzer. Spindel nit

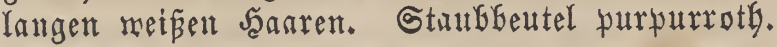

\section{Blüthe $=$ 3eit und Sauer.}

Mai - Suni. 4.

\section{Bortommen.}

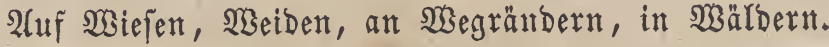

Eigenfdbaften, গtuten, Anwendung.

Mohlfarmecfendes und zartea Futtergras; nur fogade, Dáp Der Scalut yor bem Srignitte melf mirb.

\section{Avena pratensis. L.}

Avena bromoides. L.

Avena montana. Fl. Wett.

Avena spicata. Gilib.

Avena splendens. Aut. Gall.

Wiefenthafer, Feld hafer, Berghafer, Triftyafer, ähriger

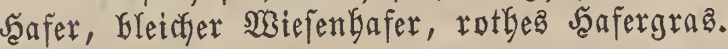

Meadow 0at-Grass. (entgl.)

\section{Atrten $=$ (Shauater}

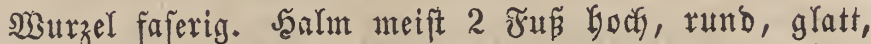
aufrecht, fteif. BYătter und Scheiben glatt und etroas fteif,

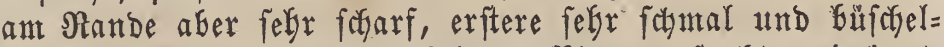
artig, bie $\mathfrak{B}_{3}$ rzelflätter gefaltet. Siaßpe aufredft, gebrängt, traubenartig, mit fogarfen 2eften und Stielchen. Rebrefjen $4-5$ blüthig, etwag bunfler violett gefürbt als bie vorige

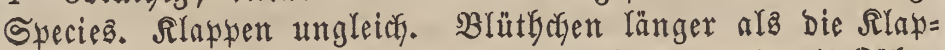
ben, an ber Spibe mit biel längeren Saaren und mit Bähn= chen verfeben, yon Denen bas eine über bas andere berbor= ragt. Spindel baarig.

Man bat yon biefer 2 (rt eine etmas größere Barie= tät, bie

$\beta$. A vena bromoides. L.

\section{Blüthe $=$ Beit und $\mathfrak{D a u e r}$.}

Stnt - Suli. 4 .

\section{3oxtommen.}

2łuf trockenen, bodyliegenden Bräben, megr geringen Wiejen, Warlowiejen, graftren Sähgeln.

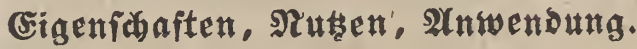

Buteg Futter.

\section{Avena fatua. I.}

Avena lanuginosa. Gilib.

Wilder $\mathfrak{T a f e r , ~ F l u g h a f e r , ~ W i n d b a f e r , ~ B a r t b a f e r , ~ \Re \Re a u l y = ~}$ Gafer, গ⿰氵 Gafer, Bruchbafer, Disyentafer, Stymanghafer, Niffen,

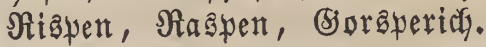

Wild 0at-Grass. (entgl.) 


\section{Arten = Eharater.}

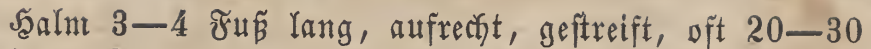
auf einem Stoffe, 4 fnotig. SBrätter 18 3oll lang, 1 3oll breit, lang zugejpikt, Dunfelglaugrün, und mie auch bie

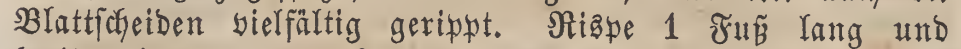
breit, ringsum auşgebreitet, in Der Jugend aber nefr ge= brängt. 2(efrafen 2-3jamig und 2-3grannig, wäGrend Der Blüthe aufrecht ftebend, fpäter bängend, auseinander= gefpreizt. Brannen lang, zumeilen an Der Bafts genumben, in ber Jugend aufrecht, unten fogmärzlich, ofen grün, mit Der Reife ftaré gefniet und oben Gräunliç. Slappen $7-9=$ nerbig, oben zufanntengebrủdet, fobarf gefielt, in Der Jugent Gellgrün, fpäter weiß̨licy. Syelzen an ber Bafte furz und bräunlichgelb, fonft aber lang und borftig bebanrt, braun, oft faft fodmarz, mit beflern Spiten. Samen lang, unten ffach, bicht und fein befaart, an ber Spibe brännlich be=

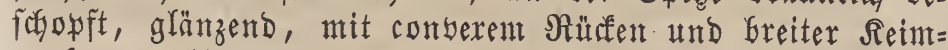

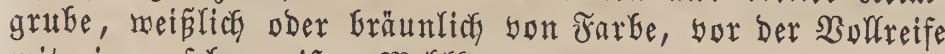
mit einem febr weinen Meblferne.

Blüthe = Beit und Datuer.

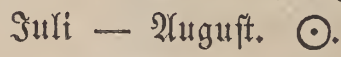

\section{Borkommen.}

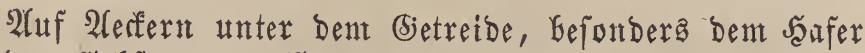
und ben (Erbjen, an $\mathfrak{B} e$ gen vermildert, foll in Gefjueben angebaut werbent. Nach Ëinigen wäre Stalien, naç 2Hobern

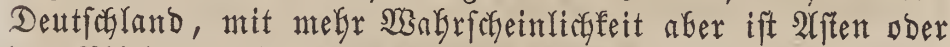

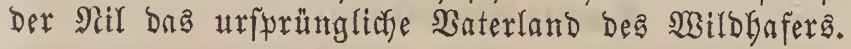

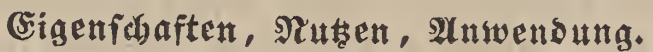

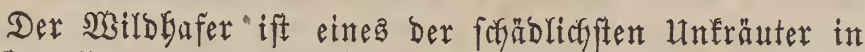

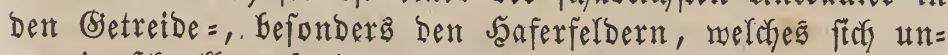
gemein fodnefl berbreitet, fohnelf wächst und reift, oft Jakre

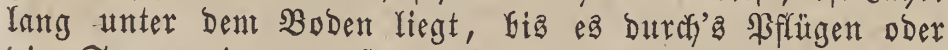
Die Somnenmànme auf bie Dberffäctye Deffelben und in's Reimen fommt, no es bann in furzer Zeit Den ganzen Arefer berunfrautet. - Sat biejer Saafer einmal überband genommen, fo benfe man nicht an ein 2lusirotten Deffelben, und es Gleift meift nichts üfrig, als ein folches zeld mit

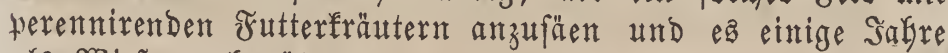
nIs Wieje zu Genüker.

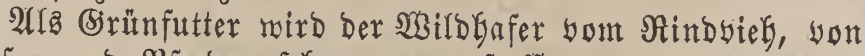

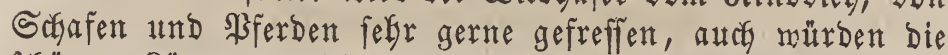

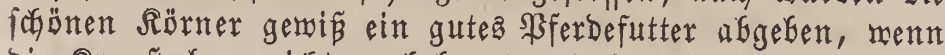
bie Sirompelzen nicht zu befyart tind fofarf mären. In Da= lefarlien in Schweben foll man fie zum Brobbaden ver= wenden.

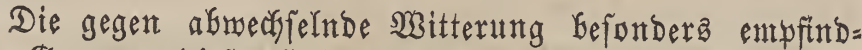

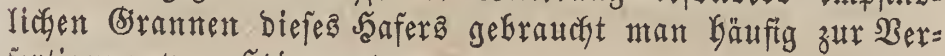
fertigung yon

\section{Melica, L.}

Dalucum. Adans.

Syfteme: Achyrophyta. Neck. Gramina. L.

Gramina digyna simplicia. Roy.

Gramina bromeae. Kunth.
Gramina festucaceae. Spr. Kunth.

Gramina Poae. Adans.

Gramineae. Juss.

Triandria, Digynia. L.

Sild 2flappig, 1-2blüthig, bas 3te Blüntchen un= yolfowmen, berfümert. Sirqpen eirund, Gautfig, etwaz ungleich, bie untere fürzer. BYüthchen fo lang als ber Relch, 2 fpelzig, fnorpelig, unberwelgrt, untere Spelze über. Dem Rühfen gemölbt, obere 2fielig. Decfjpelzen in eine zujamment=

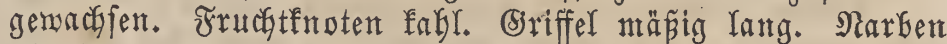
feberig, feitwärtb Gerbortretend. Daz unentwiffelte, geftielte,

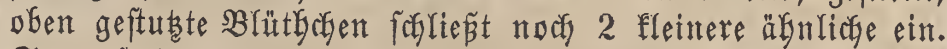
Sante frei.

\section{Melica ciliata. L.}

\author{
Melica amethistina. Pourr. \\ Melica cristata. Trin. \\ Lascagrostis variegata. Meyer. \\ $\beta$. Melica provincialis. Clar.
}

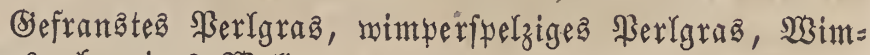
pergraz, haarigea \$aldgrab.

\section{Arten = Erfarakter.}

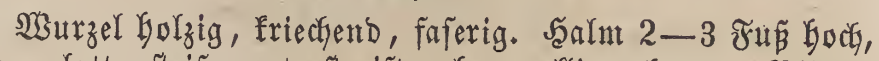
rutid, glatt, fteif, zartgeftreift, oben wellig gebogen. Blätter

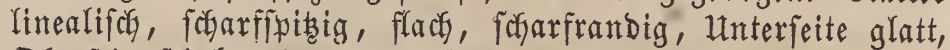
Dherfeite feinfaarig, 6-9 3oll lang und 1-2 Rinien Greit, mit geftreiften Scheiben und gefpaltenen Blatthäutchen. SRizpe

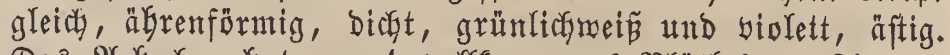

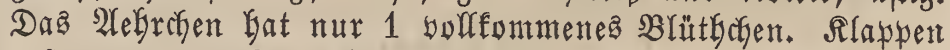
zufammengebrürft, geftreift, fpibig. Utntere Spelze grünlicf,

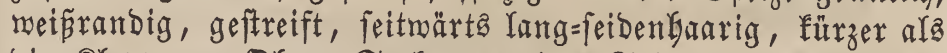
bie Rlappen. Dbere Spelze an ber Spite mit 2 3äGnen. Decffpelzen felyr furz, Greit, ftumpf, zufammengerachjen. DaB zweite $\mathfrak{B l u ̈ t}$ chen if́t berfümmert, fabl, and entfült noch 2 fleitrere. Staubbeutel mein.

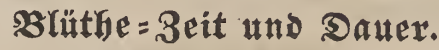

Mai - Suni. 2 .

\section{3ortommen.} rändern.

Atuf ซ̌lfen,

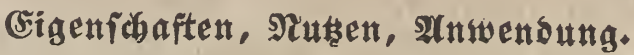

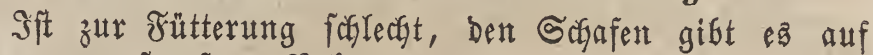
Weiben nur fparfame Nabrung.

\section{Melica nutans, L.}

Melica montana. Huds.

Aira nutans. Wigg.

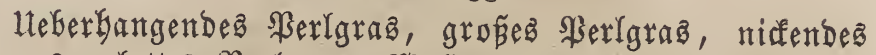

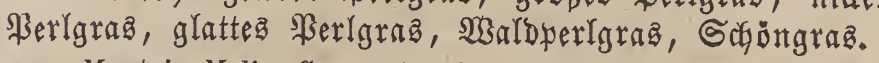

Moutain Melic - Grass. (ettgl.)

\section{Arten = (Sharafter.}

Wurzel friecfend, rajentreibend. Saalm $1 \frac{1}{2}-2$ Fú Goch, gebogen, zartgeftreift, 4 erfig. Blätter $6-9$ 3old lang und 2 Rinien breit, Ganbförmig, fpitig, forarfranbig, mit Geller" Mittelripbe, zweifchneibigen Scheiben und furzem, faum bemerflichen $\mathfrak{B l a t t b a ̈ u t c j e n . ~ \Re i a ̨ p e ~ n i c f e n d , ~ t r a u b i g , ~}$ 
einfeitig, mit gepaartent ober einzelnen 2Yeften. 2(ebrefent mit

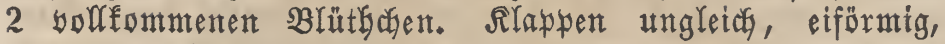
bauchig, geftreift, 5-7nersig, biolett, reinrandig, funtzer als bie Blüthaten. Spelzen bauchig, untere geftreift, fituntpf, grün, oben braunviolett, obere an ber Spibe mit 2 3äbnen und etraas fürzer. Daz britte Blüthchen ift geftielt, $\mathfrak{u n}=$ volftommen, eB berbirgt noct 2 andere fleinere. Staub= beutel gelt.

\section{Blüthe $=$ Beit und Dauter.}

\section{Mai - Juni. 4 .}

\section{3ortommen.}

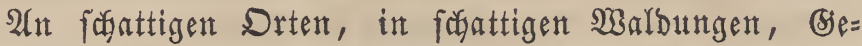
büfden, gebirgigen Esegenden in ganz Europa, son Jtalien Giz nach Rappland, in Norbafien.

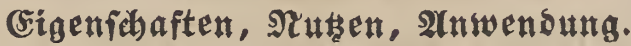

Giutez Futtergras.

\section{Melica uniflora. Retz.}

Melica Lobelii. Vill. Melica nutans. Lam.

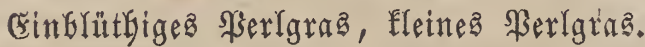

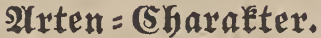

Die ganze Sflanze hat mit Der yorigen 2 rat viel 2 (e) richfert, ift aber in affen Theilen zarter. Das Blattbäutedyen ift länglidy, rautartig und Dent Blatte gegenfändig. Niąpe äftig, einfeitig. Die Alefte wieber beråftelt, einfeitig, baar=

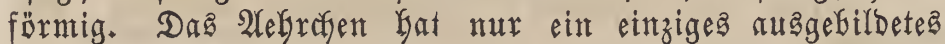

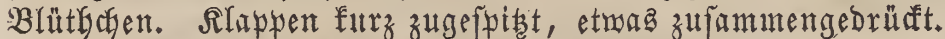
Spelzen io lang als die Rlappen und oben aubigerandet. Siriffel lang. sarben fiprengruebelig. Die unvolffommenen Blüthdyen fetto wie bei Der yorigen 2 (rt.

\section{Blüthe $=$ Beit und $\mathfrak{D a u e x}$.}

Mai - J゙แni. 4 .

\section{3orÉmmen.}

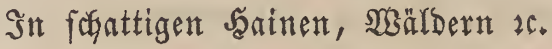
Ëigenfabaften, গ⿴uten, Anwenoung.

శruttergrab.

Koeleria, Pers.

Syfteme: Achyrophyta. Neck.

Gramina. L.

Gramina bromea. Kunth.

Gramina festucacea. Spr.

Gramineae. Juss.

Triandria Digynia, L.

Selda 2flappig, 2-5blüthig, fo lang ober etwağ länget ala bie Blüt förmig zugefpibt, untere אlappe fürzer. Blüthdyen 2fpelzig, trocenenbăutig; untere Spelze fielig zufammengebrübt, lanzett= förmig, fwibig, untemelgrt, ober unter ber Spibe mit eitner geraben Branne; obere Spelze feldr jobmal, 2fielig, auf ben Rielen zart genimpert. Derfipelzen 2. Jrudgtfnoten Eakf. Erriffel furz. Narben feberig, feitroärta berbortretend. Sament frei, bebert.

\section{Koleria cristata, Pers.}

Aira cristata. L.

Airochloa cristata. Link.

Dactylis caudata. Brot.

Dactylis cristata. Bbrst.

Festuca cristata. Vill.

Festuca dactyloides. Roth.

Poa cristata. With. Willd.

B. Poa nyramidata. Lam.

$\gamma$. Koeleria gracilis. Pers.
Aira gracilis. Trin.

Airochloa gracilis. Link.

Poa aristata. Leers.

Poa nitida. Lam.

$\delta$. Koeleria grandíflora. Bertol.

Poa grandiflora. Rich.

$\varepsilon$. Koeleria mollis. Mann.

Melica Gmelini. Roth.

Melica hirsuta. Koel.

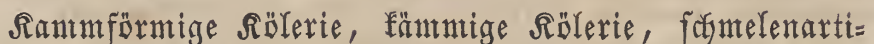

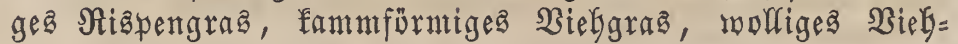
graż, Rammichmiele.

Crested Meadow - Grass. (entgl.)

\section{Arten = (Eharakter.}

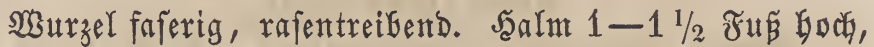
aufreç, geftreift, oben flaumbararg. Shlätter Gandfürmig, fpisig, fogarfranbig, eben, zottig gemimpert, mit geftreiften,

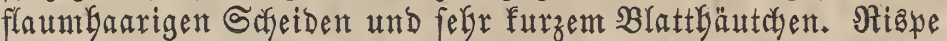
etwaz ährenformig, an Der $\mathfrak{B a f t s}$ unterbrocten, mit furzen wetchlyarigen Aeften. Alebrefen 2-3Glütthig. STappen lan= zettförmig, zugefpist, auf Dent Riele fubärflich, röthlidy ober weiß̈lich, bie wbere etrog länger und 3nervig, bie untere 1 nersig. Itntere Spelze Tanzettförnitg, -fpib, obere fürzer und an Der Spibe 2zäbnig. Staubbeutel purpurroth. Spin= bel feittaarig.

(ङ3 gibt einige Warietätent :

\section{$\beta$. gracilis.}

Blätter febr fámul. Niape gebrängt, unten unter= broctgen. 2lefgrçen 2blüthig.

\section{$\gamma$. pyramidata.}

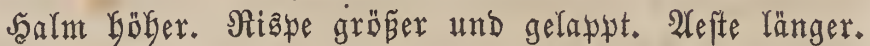
2regrchen gröper, 3-4 Glütgig, bie untern Spelgent etwas größet utb am Riele fobarf utb etwas gemimpert.

\section{3lüthe = Beit und sauex.}

Suni - Suli. 4 .

\section{3ortommen.}

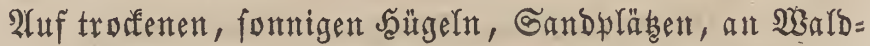
ränbern; Varietät $\beta$. auf fteintgten, trocfenen Sängeln in

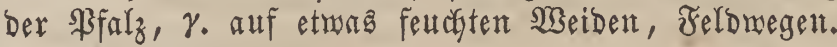

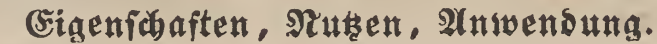

(5)utes Futtergrą.

\section{Molinia Koeler。}

Snftemé: Achyrophyta. Neck.

Gramina. L.

Gramina bromea. Kunth.

Gramina festucacea. Spr.

Gramineae. Juss.

Triandria, Digynia. L.

Silch 2flappig, 2-4blütgig. Slappen bäutig, fürzer

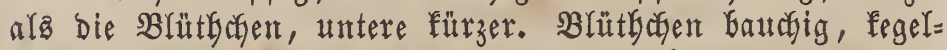
förnig, fpikig, 2jpelzig. Spelgen beinafe reberartig, bie untere an ber Spise ganztandig, unbewegrt ober ftachel= fpikig, bie obere etmagి gefaltet. Briffel mäpig lang. Narben 
feberig, feitwärta berbortretend. Samen frei, breit gefurcht, mit 2 ftectenden Spisen.

\section{Molinia coerulea. Moench.}

Molinia varia. Schrank. Molinia variabilis. Wibel. Aira caerulea. L. Enodium caeruleum. Gaud. Festuca caerulea. DeC. Hydrochloa caerulea. Hartm. Melica caerulea. L. B. Molinia altissima. Link.

Blaue Miolinie, Glaues Berlgras, Bergreitggras, ge= meines Pfeifengras, Binfenbalm, SBaldrubr; blaue Samiele.

\section{Arten = (5)arafter.}

V̧urzel ftarfzajerig, rajentreibend. Şalm $3-5 \widetilde{\mho u}$ boch, fteif, runb, glatt, zartftreiftg und nur gegen die Wurzel bin mit einem Snoten berfeben und fajt blätterlos.

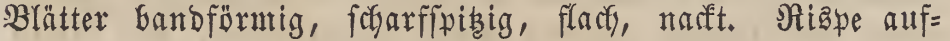
recht, zuanmengezogen ober etmas abfteliend, mit fajarfan, äftigen, febr ungleidyen, geraben ober gefdlängelten aleften. 2lebrcfen 2-4blütbig, fegelförmig, bunfelblau mit sin̈n

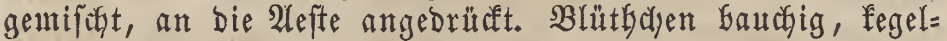
förmig, oben etwas zujammengebrünt, zur Blütbezeit etras entfernt, geftielt, bas oberfte bleibt unentroifelt. Silapen eirund, fpibig, bäutig, biolett, mit grünem Sitcfenftreifen, Gei bent Berblüben bräunlids, bie obere noch einmal folang als die untere. Spelzen bellbläulicfgrün, bie obere bäutig, nur wenig fürzer. Dedfpelzen breit, ftumpf. Strubbeutel bunfelviolett. Giriffel mäpig lang. Narben gefebert, Dunfel= biolett.

Man Gat eine größere Barietät:

\section{ß. major.}

\section{Slüthe = Beit uns Sauer.}

Iuli - 2uguft. 4 .

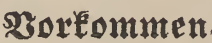

2uf feutgten, walbigen ßläben, Torfwiefen.

(5igenfídaften, গtutsen, 2(nswenoung.

Wird nur in ber Sugend wont Biebe gefreffen.

Man gebraudyt die Salme zum Reinigent Der Tabafis= preifenrobren.

\section{Briza. L.}

Calotheca. Beauv.

Chascolytrum. Desv.

Poa. Adans.

Syfteme: Achyrophyta. Neck.

Gramina. L.

Gramina digyna composita. Roy.

Gramina festucacea. Kunth. Spr.

Gramina Poae. Adans.

Gramineae. Juss.

Triandria, Digynia. L.

Selch 2flappig, 3- bielblüthig. Rlappen Gäutig, eiför= mig, bauthig, gleichlang. SBlütbchen länger alą ber Relch, unberolgrt, ziegelDachförmig, 2reihig, 2fpelzig; untere Spelze bauchig, ftumbf, where 2fielig, auf ben Sielen furz gemin= pert, Deeffpelzen 2. Fruchtefnoter fagl. Eriffel furz. Nar= ben Iang, feberig, zur Seite bes Blïtbchens Gervortretend. Samen frei, beberft.

Briza media. L.

Briza tremula. Lam. Koel. B. Briza viridis. Pall. Briza virens. Bbrst.

(5)meines Bittergras, mittlerea Dittergras, Whiejenzitter=

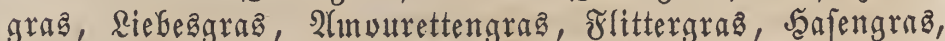

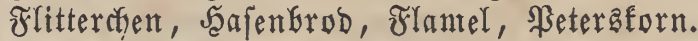

Middle Quaring-Grass. (engl.)

\section{Arten (E)arater.}

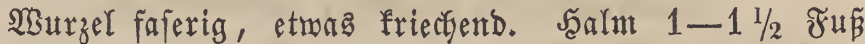
Goch, rund, glatt, zartgeftreift, mit $2-3$ rotbGrautmen $\mathfrak{R n D}=$ ten. SBlätter Ganbförmig, furzfpiţig; flach, geftreift, făarf= ranbig, $2-4$ 3oll lang und 2 Rinien breit, mit weip̈er Mittelripye, glatten geftreiften Scheiden und furzem, ftumpfem Blattgüutchen. Rispe aufrecht, aubgebreitet, abftebend, fein= äftig. 2(ebrofen runblich - eifürmig, etwas zufammengebrü ưt, 5-96lüthig. Silappen eiförnig, convex - zufammengebrücft, violett, weinrandig, obere zut beiben Seiten an Der $\mathfrak{B a f t}$ auzererandet. Hntere Spelze breit - eirund, contbex, ftumpf, Gerzfömig, 7nervig. Shere Spelze an ber Spibe ausige= randet.

Bariirt mit grünen, weínrandigen Rlappen und Blütflyctr.

\section{Blüthe = 3eit $\mathfrak{t n d}$ Sauer.}

Mni - Suni. 4 .

\section{Zørtoment}

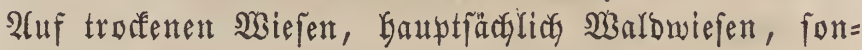
nigen 2 Beiden.

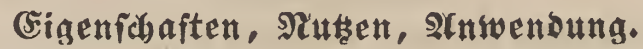

(5)tę Futtergraz.

\section{Bromus, L.}

Snftente: Achyrophyta. Neck.

Gramina L.

Gramineae bromeae genuinae. Kunth.

Gramina festucacea. Spr. Kunth.

Gramina Poae. Adans.

Gramineae. Juss.

Triandria, Digynia. L.

Seldy 2flappig, 3- vielglüthig. Silappen conbex obet zufammengebrücft, fpisig, untere fürzer. Błhüthcten länger als Der Sielch, 2fpelzig; untere Spelze elfiptifdy, Ianzettför = mig ober pfriemenförmig, an ber Spise augagerandet ober 2 ppikig und unter berfelben gegrannt; obere Spelze bäutig, länglich, 2fielig, auf ben Rielen ftarr gemimpert. Dedffpelzen

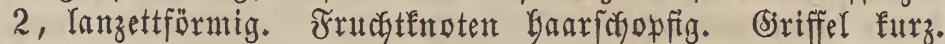
Narben gefiedert, feitwärts Gerbortretend. Santen ange= wachjen. 


\section{Bromus secalinus. L.}

Bromus arvensis. Weigel.

Bromus Ehrharti. Roem.

Bromus hordeaceus. Gort.

Bromus maximus. Gilib.

Bromus polymorphus $\gamma$. secalinus. Huds.

Bromus squarrosus. Lam.

Bromus vitiosus. Weigel.

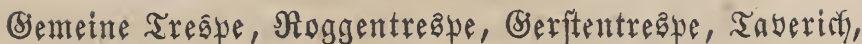
Töberich, Dort, Spibling.

Seigle bâtard. 'Draue. (franz.)

Cockles. Cockle-weed. Field Brome-grass. (engr.)

\section{Arten $=\mathbb{( 5 G a x a l t e r}$.}

SWurzel fajerig. Şalm 2-3 ऊuß boch, aufrect, fteif, glatt, mit etwas Gaarigen Rnoten. Blätter Gandförmig, zugefpibt, frfarfrandig, nit gefuraten, Ganrigen şattfaci= Den und furzem Blattbäutchen. Sispe abftebend, reif unt Der Spibe nifend, mit bin und ber gebogenen Aleften. AGe br= chen grof́, eirund - längliç, 6-12blütbig, erft roalzig, bann flach, Gelfgrün. Rlappen elliptifi, ftumpf, obere 5-7nervig, untere 3-5nervig, zumeilen furz ftachelfpitgig.

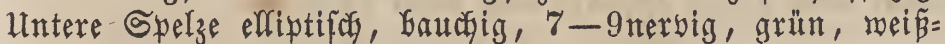
randig, unter ber Spibe nit einer mellig gebogenen Siranne. Dbere Spelze beinabe von gleisher Rănge.

\section{Blüthe $=$ Beit und $\mathfrak{D a u e r}$.}

$$
\text { รันni - 2ługutt. } \odot \text {. }
$$

\section{3ortommen.}

Säนfitg unter Dent Betreide.

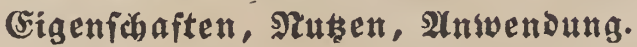

Die gemeine Treảye ift ein läftigę Unfraut unter bem (Setreibe, Gejonders Dem Soggen und Weizen; Der Same, wenn ex mitgemablen nird, madyt bas Mebl bitter und theilt Dem Brode betäubende Sraft mit, audy madyt der Same die Şüfner taumeln.

Die jungen Blätter merben Gefonders yon ben Gafafen aufgefucht.

\section{Bromus grossus. Desf.}

Bromus multiflorus. Gmel.

Bromus secalinus $\beta$. L.

Bromus nitidus. Dumort.

Bromus velutinus. Schrad.

$\beta$. Bromus hordeaceus. Gmel.

Feinbarige Treĝpe, diffe Trespe, bielblüthige Trespe.

\section{Arten = Charaktex.}

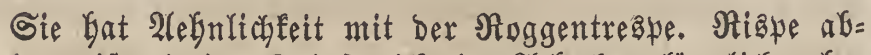

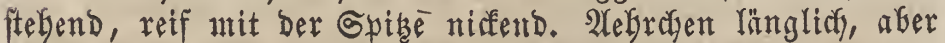

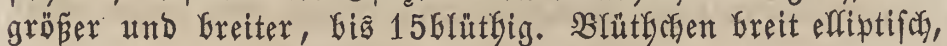
unteridieben, entfernt son einander ftebend, rund und auf

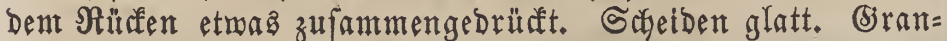

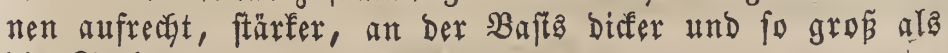
bie Spelze.

Man fennt 3 Spielarten:

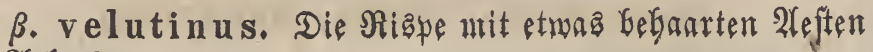
und 2)

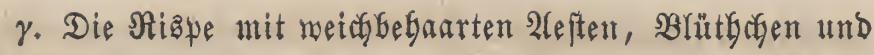
(s)rannen.

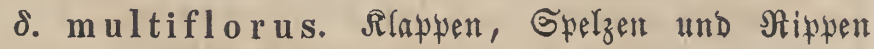
etwas fodarf. Branmen fitjarf.

Blütbe $=$ Beit und $\mathfrak{D a u e x}$.

รuni - 24ugut. $\odot$.

\section{3ortommen.}

Bfalz, Unterrbein, Schwaben, unter Dem Setreide.

Eigenidaften; Nutuen, Anwenoung.

SWird jung gern yon ben Sifafen gefreffen.

\section{Bromus racemosus. L.}

Bromus agrarius. Hornung.

Bromus commutatus. Schleich.

Bromus Gaudini. R. S.

Bromus hordeaceus. L. Whlbrg.

Bromus multiflorus. Roth.

Bromus polymorphus. $\beta$. $\delta$. Huds.

Bromus pratensis. Ehrh.

Bromus simplex. Gaud.

Bromus Ventolanae. Hort.

$\beta$. Bromus elongatus. Gaud. treape.

Traubenthlutgige Treàe, traubenartige Treảpe, Ssiefen=

\section{2roten = (5)arater.}

ŞaIm nach unten nacét pber fparjam weich befaart. Blät= ter und Scheiben mebr ober weniger meidjharig, Yeterere

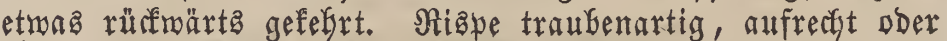

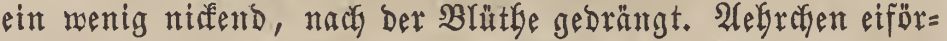
mig - läuglicf, fcharf. Rlappen bäutig gerändert, fodarf, bie untere 3 zäglig, Die ofere 5-7nervig. Untere Spelze 7nersig, fajarf, bie mittlere Nerve unterhalb der Spibe ganzandig und in eine aufred te, fofarfe Sranne auglau= fend, melche fürzer ober auch fo lang als bie Spelze ift.

Blüthe $=$ 3eit $\mathfrak{u n d}$ Dauex .

Mai - Suni. $\odot-o^{x}$.

Borkommen.

2uf Wiejen, Aerefern, an Wegen.

Ėigenfabaften, Nutzen, 2nwendung.

(5) The Futtergrag.

\section{Bromus mollis. L.}

Bromus polymorphus. $\alpha$. Huds

Bromus secalinus. $\gamma$. Lam.

Bromus hordaceus. L.

$\beta$. Bromus nanus. Weigel.

$\gamma$. Bromus compactus. Hort

Bromus multiflorus. Hort.

$\delta$. Bromus arenarius. Th. Desmas.

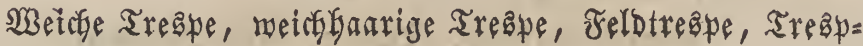
grias, Feldourt.

Soft Brome Grass. (engl.)

\section{Srten = (S) barater.}

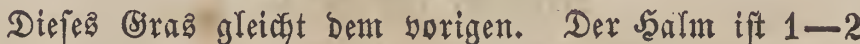

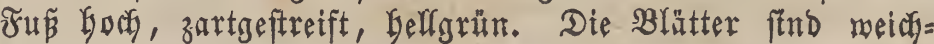
baarig, Gandpömig, fpikig, mit meidbebarten, faum 
merfliçen Blattbäutchen. Die Blattidyeiben bidjt mit meidfen, rüffwärta gebogenen, wolligen und meip̈grauen Şaaren be= fest. Niape aufrecft, nach Der Blütlye gebrängt. Die Alefte

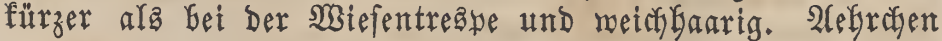

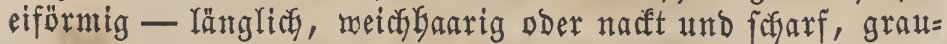
grün. Spindel weichbefaart. Hntere Spelze mit ftumpf=

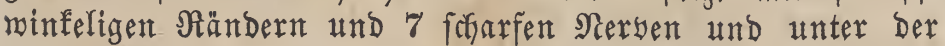
Spibe meniger ftarf, 2fpaltig, in eine aufrechte, fodarfe Granne verlaufent, melche faft fo grof als ber Balg ift; obere Spelze 2fpikig. Blantforen breit-elliptifac, bei ber Reife ziegeldadyförmig.

\section{Man Gat 3 Barietäten:}

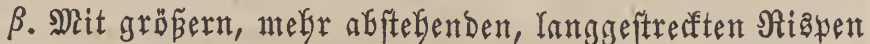
und länger und yon einander entfernter ftebenden 2 reften.

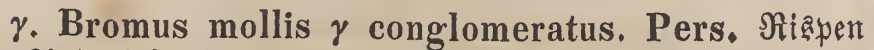
furz. Alefte felfr furz und bicht gebrängt.

$\delta$. Bromus mollis $\beta$. leptostachys. Pers. 2 ef madft, etmas ficharf.

\section{Slüthe $=$ Zeit uns $\mathfrak{D a w e x}$.}

Mai - Iuni. $\sigma^{7}$.

\section{3ortommen.}

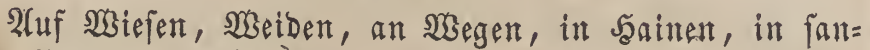
bigem Boben, auf Felien.

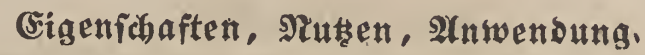

(5)uteß Futtergras, bejombers füt Gchafe.

\section{Bromus squarrosus, L.}

Sparrige Treape.

$\beta$. Bromus villosus. Gmel.

Corn Brome Grass. (engl.)

\section{Atrten = Ehatakter.}

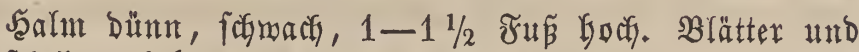

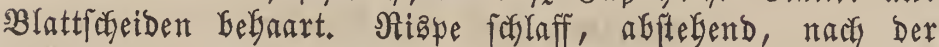
Blütthe mit nicfender Spise, meift einfach. Alefrachen groß, länglich - lanzettfürmig, 12-20Glütbig. Untere Rlappe $5=$, obere 9nerbig. Itntere Spelze bäutig gerandet, in Der Mitte

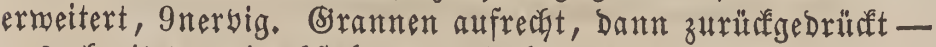
auggebreitet, weit abftebenb! SBlütGchen breit - elliptifdy, am Rande ftumpfroinfelig, biaft ziegeldachförmig.

Baritit

\section{$\beta$. mit flaumbanrigen 2(ebrafen.}

Blüthe = 3eit uns Dauer.

รuni. $\odot$.

\section{3orkommen.}

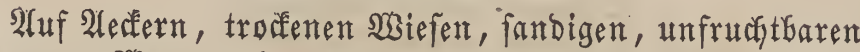
Drten, an Wisegen. Franfreidy, Schweiz, Deftreich, Baiern, Sribaben, Sibirien.

\section{Futtergrab.}

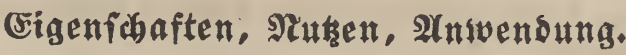

\section{Bromus arvensis. L.}

Bromus altissimus. Gilib.

Bromus erectus $\beta$. arvensis. Huds.

Bromus longissimus. Spr.
Bromus multiflorus. Weigel.

Bromus polymorphus. Hort.

Bromus secalinus. Savi.

Bromus Ventolana. Schleich.

Bromus versicolor. Koel. Pollich.

Af f́ertreâue.

Corn Brome Grass. (entrl.)

\section{Arten = (5Garafter.}

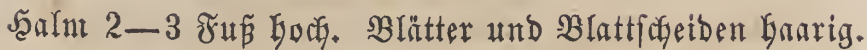

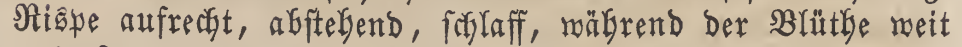

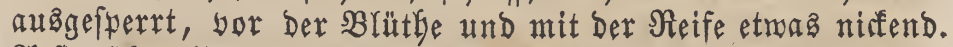
2lefte überall abftefend, bie unterften balb fo lang ala bie Niape und 12Glütbig. 2lebrchen linten = - lanzettförmig, rund und etwas zufammengebrǚft, 6-7glüthig, grün und

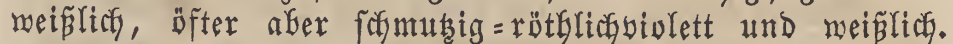
Untere Rlappe mit 3 , bie obere mit 5 Nerven. Hntere Spelze 7nerbig, bäutig gerandet, an ber Spibe gefpalten und unter berfelfen mit einer rothen geraben branne, welche fo lang als bie Spelze ift. Obere Spelze ein mentg fürzer, ober fo lang als die untere. Blütychen fodmal, elliptifor - lan= zettfönnig, am sande ftumpf-minfelig, ziegeldachförmig, nact ober etwa befarart und oben facharf.

\section{Slüthe $=$ Beit und $\mathfrak{D a u e x}$.}

$\mathfrak{J u l t}-$ 2luguft. $\odot$.

\section{Boremuten.}

शuf 2eefern, unter bem 'Betreide.

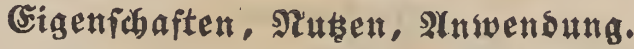
Unfraut.

(rin gutes Futtergras, aber unter bem Bsptreide ein

\section{Bromus sterilis, L.}

Bromus distichus. Moench. Bromus grandiflorus. Weig.

Taube Treâpe, bünteönige Treåpe, unfruchtbare Treappe, Taubhafer, Dwelf.

Barren Brome Grass. (entgl.)

\section{Arten $=$ Charaktex.}

Wurzel faferig. Şalm glatt, geftreift, aufredyt ober

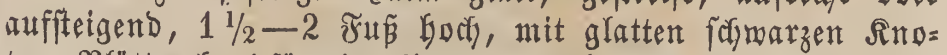
ten. Blätter Gandförmig, flach, etmas haarig, 6-8 30ll fang, mit geftreiften Sefeiben und geftudem meinen, fegr fleinen

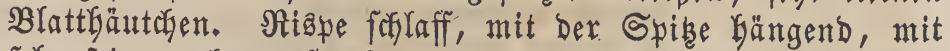
fehr feinen, langgeftredften, an Der Spibe bängenden 2 feften. 2lefrchen länglicf), oben breiter, 5-9blütbig. Rlappen fofmal, lanzettfürmig, foharfipibig, ungleicf, untere fürzer mit 1, where mit 3 Nerven. Utntere Spelze lanzettförmig, grün ober biolett, 7nervig, an Der Spike gefpalten und langgegrannt; obere Spelze fürzer, ftumpf Dber augigerandet.

\section{Blüthe $=$ Beit und Dauer.}

Suni - September. $\odot$.

\section{3oróntomten.}

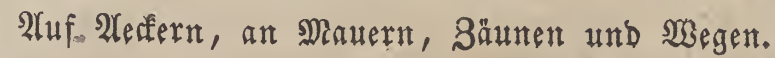

(sigenichaften, Nutsen, Answendung.

(5)utes Schaffutter. 
Bromus tectorum. L.

Bromus ciliatus. Fisch.

Bromus grandiflorus. $\beta$. Weigel.

Bromus sterilis. $\beta$. Lam.

Dachtreâpe, Sandtreape, Mauertreappe, rauke Treappe.

Nodding planice'd Brome Grass. (entgl.)

\section{Arten = Sharakter.}

Sałan fleiner als bei ber yorbergebenden 2 rat, $1 / 2-1$

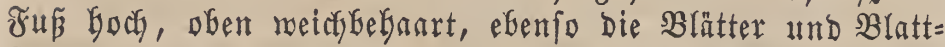

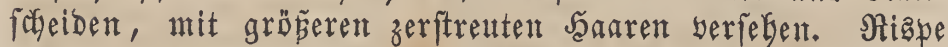
fleiner, vielmelyr zufantmengezogen, faft eimfeitig, ftare über=

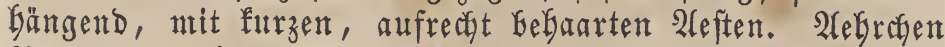

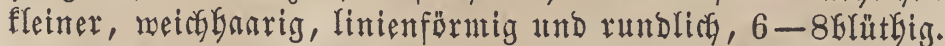
Rlappen ungleitg, grün, aut Rande ftlberglänzend; ofere an ber Spike oft 2fpaltig. Untere Spelze feinfaarig, grün, weiß̈gerandet, bie Brannen fo lang als biefe; obere an ben Rielen gemimpert. Blütbchen lanzett-linienförmig.

Man bat eine Warietăt:

$\beta$. mit naffen fadarfen 2 lefyraten.

\section{Blüthe $=$ 3eit uns $\mathfrak{D a u e r}$.}

Mai - Iuni. $\odot$.

\section{3orónmen.}

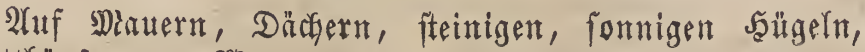

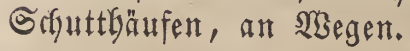

Bigenichaften, গtüen, anwensung,

Sat ebenfalla ein gutes Schaffutter.

\section{Cynosurus. I.}

Snftemte: Achyrophyta. Neck.

Gramina. L.

Gramina chloridea. Spr.

Gramina digyna composita. Roy.

Gramina Poae. Adans.

Gramineae. Juss.

Gramineae Festucaceae. Kunth.

Triandria, Digynia. L.

Rełd) 2flappig, 3-5brütgig, fürzer ala bie Blüthen. Rlappen zujammengebrïft, lang zugefpist, Gäutig, untere fürzer. Srome 2fpelzig, untere Spelze lanzettförmig, etwaz chlindrifa, laug zugeipiest, ftachelfpisig Dber furz gegranut; bie obere gefaltet und an Den Rielen etwas gemimpert. Derf= fpelzen 2, unten berwadjen. Fruedffinoten eirund, glatt. Briffel furz. Narbsa lang, gefiedert, zur Seite Des sBlüth=

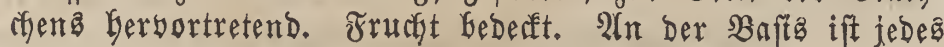
2lebrajen mit einem 2zeiligen gefederten Dectiblatte geftubt.

\section{Cynosurus cristatus, I.}

Phleum cristatum. Scop.

(5) emeimes Rammgrna, geftedertes Rammigras, fteifea

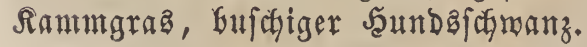

Crested Dog's-tail-Grass. (engl.)

\section{Arten = Sharaltex}

- Burzel fajerig. Jaalm aufredyt pder am Girunde ge=

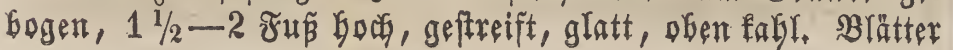
Cormer, Bffnom. ærofanzenfunde.
Ganbförnig, fpibig, fabl, mit nacften, ftraff angelegtent Scheiden und furzem, geftutem Blattbäutçen. Siaze auf= reefft, gebrängt, ährenartig, linienförmig und einfeitig, mit

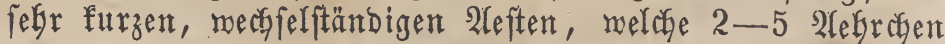
tragen, bie am Sirunde ein gefiedertes, eirundes Dectolatt Gaben. 2Aebraten 3-5Glütbig. Rlapwen fuibig, etwaz un= gleich. Utntere Spelze mit einer furzen Sranne Dber einer Stachelfpibe; obere bäutig, furz, 2ppibig. Staubbentel rufenroth.

รuni - รuli. 4 .

\section{Blitthe $=$ Beit und Dauer.}

\section{3orkmmen.}

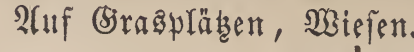

Eigenfdaften, stuten, stuwenoung. gefreffen.

Diefez Gras mirb Gefombers yon den Safafen gerne

\section{Dactylis. I.}

Amaxytis. Adans.

Sufteme: Achyrophyta. Neck.

Gramina. L.

Gramina Bromea. Kunth.

Gramina digyna simplicia. Roy.

Gramina festucacea. Spr.

Gramineae. Juss.

Triandria, Digynia. L.

Seldy 2flappig, 2-7Glütbig. Silappen zufammengebrủlett, bäutig, fpibig, auf ber einen Seite conber und breiter, auf

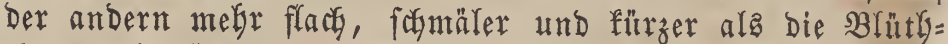
dyen, mit ftacheligent Riele; untere Rlapte etmas fürzer. Sirone 2fpelzig; untere Spelze Ianzettförnig, zufaumenge= brüct, ftachelig gefielt, mit einent ranken Endftachel; obere Spelze Gäutig, fürzer, etraas gefaltet. Jruchtfnoten länglicy. (Eriffel ziemlich lang. Sarben geftedert, zur Seite bes Blüth)= dien Gerbortretend. Jrudst angemady fen.

\section{Dactylis glomerata. L.}

Dactylis scabra. Mann.

Bromus glomeratus. Scop.

Festuca glomerata. All.

Poa Dactylis. Trin.

$\beta$. Dactylis glaucescens. Willd.

$\gamma$. Dactylis abbreviata. Bernh.

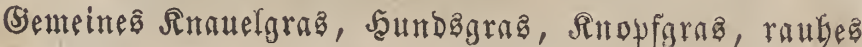

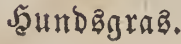

Dactile. (frantz.)

Common cock's foot grass. (engr.)

\section{Arten = (5)arakter.}

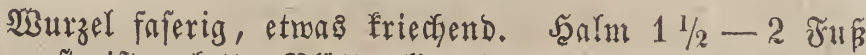
hod, geftreift, glatt. Blätter linealifó, lang, langzugefpist, joharfrandig, mit ftarf vorftefender Mittelrippe, zufammen= gebrüaften, fodarfen Scheiden und zerriffenem $B$ lattbäutçen.

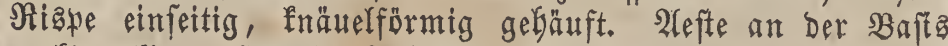

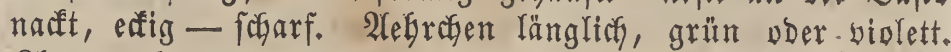
Rlappen lanzettförmig, fpitzig, zufammengebrücte, auf Dem Siele borftig gemimpert; untere 1 nervig; obere größex, 3 mervig, 14 
auf einer Seite conbex, auf Der andern concab und flach, mit forjief geftumter Spize. Itntere Spelze 5nerbig; obere fürzer und 2zäknig. Staubbeutel belfroth.

\section{Blütfye = Beit und $\mathfrak{D a u e x}$.}

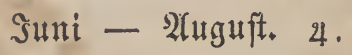

\section{Borkommen.}

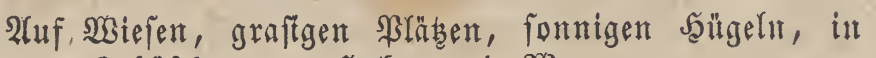

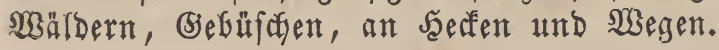

ङigenfdyaften, গtuten, Anwenoung.

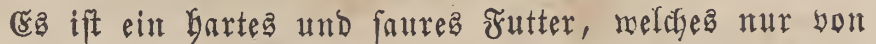

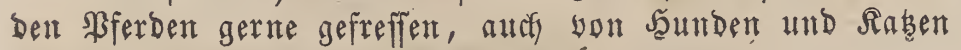
genofien mirb, worauf fie fich erfrectien.

\section{Festuca. L.}

Vulpia. Gmel.

Syfteme: Achyrophyta. Neck.

Gramina. L.

Gramina bromea. Kunth.

Gramina digyna composita. Roy.

Gramina Poae. Adans.

Gramineae. Juss.

Triandria, Digynia. L.

Seldy 2flappig, 2-bielblütbig, ungleidg. Silappen con= yex ober zufamulengedrüa t, lang zugefpist und fürzer als Die B̉lütgchen; untere Rlappe fürzer. Sirone 2fpelzig; untere Spelze auf Dem Rürfen rund, etmaz malzenfürmig, lang, fein = ober ftumpf zugefpikt, ganzrandig ober gezäbnelt, ober auch 2ipaltig, gegrannt ober ungegrannt; obere etwas ge= faltet, an bent Rielen etwas gemimpert. Decfipelzen 2. Frutht= fnoten glatt ober jogpfig Gebart. Ssriffel furz. Narben feberig, feitwärtz Gerbortretend.- Samen frei ober ange= mactifen.

\section{Festuca ovina. L.}

Festuca duriuscula. Pollich. Festuca nigra. Gilib.

Festuca tenuifolia. Schrad. Bromus ovinus. Scop.

$\beta$. Festuca capillata. Lam.

Festuca amethystina. Schleich.

Festnca debilis. Schleich.

Festuca pauciflora. Schleich.

Schafichningel, Schafgrab, Jaartgras, fleiner Barfa bart, Safafämaldy, fadenblätteriges Berggrą.

Fétique ovine. (fialtz.)

Sheeps fescue - Grass. (engl.)

\section{Arten = Sharakter.}

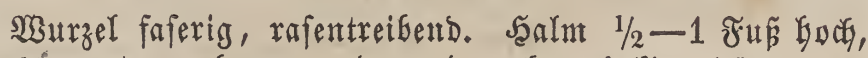
aufrectit, unten gefogen und rund, oben 4ecfig, bünn, ge= ftreift, feingarig. SBlätter felgr fagmal, eingerollt. SBurzel= blätter länger alz bie mit einem febr fleimen 2ärigen Blatt= Găutçen verfebenen Jă länglidy, beinabe einfeitig, mit einzeln ftekenben 2leften.

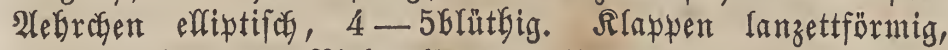

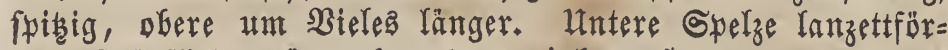
mig, fchärflich, grän, oben etma biolett, ftachelfuibig; obere

Spelze an ber Spibe 2zăhnig, Geinake yon gleidger Ränge. Staubbeutel belfgelb.

(5.s gibt mefrere Barietäten:

$\beta$. tenuifolia.

Blätter nod̆ feiner, länger und fad laffer.

$$
\gamma \text {. villos a. }
$$
Gefect.

Blütgdyen mefr ober meniger mit furzen Särdben

\section{8. vivipara.}

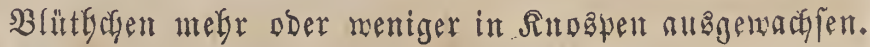

\section{Blithe $=$ 3eit tno sauer.}

Mini - Suni. 4.

\section{3orkommen.}

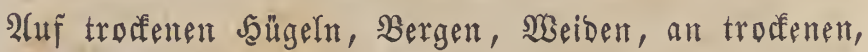
janbigen Drten.

\section{Eigenichaften, Nutuen, 2 (nwendung.}

(5ines Der beften Schaffutter.

\section{Festuca glauca. Schrad. Lam.}

Festuca calcarea. Tausch.

Festuca duriuscula. $\beta$. Whibrg.

Festuca involuta. Moench. Schleich.

Festuca laevigata. Clairv.

Festuca longifolia. Thuil.

Festuca ovina. L. var. Trin.

Festuca pallens. Host.

Festuca pungens. Daval. Schult.

Festuca strictifolia. 0piz.

Schedonorus glaucus. Beauv.

Seegrüner Scymingel, Glaugrüner Scymingel.

\section{Arten = Sharater.}

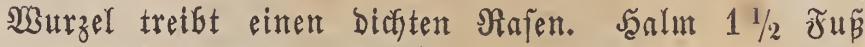
Goch, graugrün. Blätter borftig, fteif, glatt, graugrün,

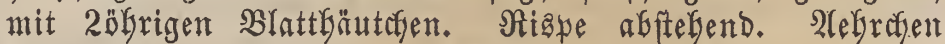
lanzettförmig, zufammengebrüct, gegrannt, 5blütfig. Untere Reldaflappe $1=$, obere 3nervig.

Alendert ab mit fablen und furzharigen 2 (ebrefen unb mit mebr ober mentger langen Sramnen.

$$
\begin{aligned}
& \text { shlüthe= Beit und Dauer. } \\
& \text { Dai - Iuli. } 4 \text {. }
\end{aligned}
$$

23orexommen. 2llpen.

2(uf Wiejen, Triften, Şügeln, felf̈̈gen Bergen und

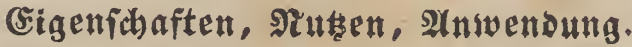 \\ ซuttergras.}

\section{Festuca duriuscula, L.}

Festuca dura. Host. Festuca glauca. Bbrst. Festuca intermedia. R. S. Festuca ovina. Schrad. Festuca stricta. Host. Gaud. $\beta$. Festuca ovina villosa. Schrad. Festuca hirsuta. Host. $\gamma$. Festuca curvula. Gaud. Festuca caesia. Smith.
Festuca dumetorum. L. $\delta$. Festuca multiflora. Schleich. Fetuca curtana. Autor. Festuca Eskia. Lejeun. Festuca heterophylla. Spr. Festuca laevigata. Schleich. Festuca Lemanii. Lejeun. Festuca longifolia. Vivian. Festuca nemorum. Leyss. 
Festuca oraria. Dumort.

Eestuca curtana. Lejeun.

Festuca siracusana. Jan.

Festuca pallens. Host.

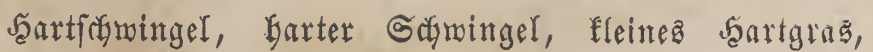
bärtlider Schmingel, Borftidyingel.

Fétique durete. (firattz.)

Hard Fescue-Grass. (engl.)

\section{Alrten = Sharakter.}

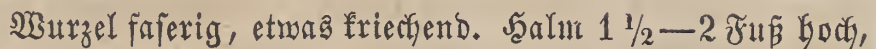
aufrecht, glatt, geftreift, oben nicht focharf 4 erfig. sBlätter

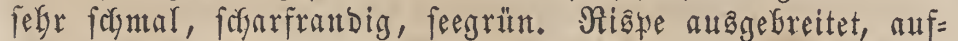
reatst, mit gepanaten 2(eften. 2(eGrchen meift 5-6blütbig, Geffgrïn. Rlapwen Innzettförmig, fpibzig; obere noch einntal fo lang als bie untere. Itutere Spelze lanzettförmig, fpibig, wit einer Enogranne.

2fendert $\mathfrak{a b}$ :

\section{$\beta$. subvillos a.}

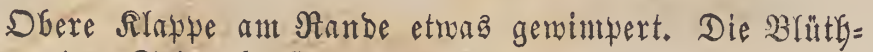
dyen an ber Gyibe burftig.

\section{$\gamma$. villosia.}

Drere Rlappe an Nande etmas gewintpert. Die Blüth= ryent überall Gorftig.

$\delta$. nemoralis.

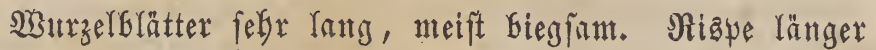
und fochlaffer, gerö̈gnlich etrag niffend.

$\varepsilon$, curvula.

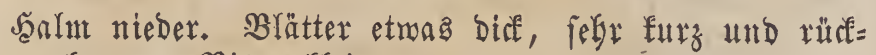

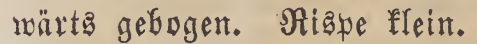

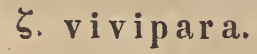

Blütben in Sinoàpen augagemadyfen.

Shlüthe $=$ Beit uno $\mathfrak{D a u t x}$.

$\mathfrak{M a \mathfrak { i }}$ - $\mathfrak{J} \mathfrak{u l}$. 4.

\section{Bortommen.}

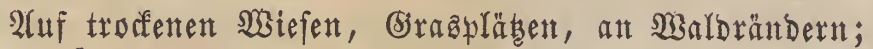
Barietät $\delta$, in fodattigen Waaldungen, Barietät 2. an feuch)= teren Drtert.

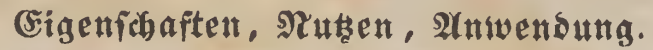

Futtergrą.

Festuca rubra. L.

Festuca duriuscula. Weihe.

Festuca heterophylla. Weihe.

Festuca stricta. Schleich.

Festuca dumetorum. Rafn. Festuca rubra arenaria. Fries. Festuca villosa. Baer.

$\beta$. Festuca rubra villosa et subvillosa. M. K.

Festuca barbata. Schrank.

Festuca dumetorum. L.

Festuca duriuscula var. dumetorum. Gaud.

Festuca montis celtici. Delarb. Schedonorus dumetorum. Beauv. $\gamma$. Festuca rubra lanuginosa.

Festuca arenaria. 0sb.

Festuca baltica. Hornm.

M. K. $\zeta$. Festuca cambrica. Huds.

Festuca glabra. Lightf.

Festuca repens. Knapp.

Bromus glaucus. Spr.
Rotber Sdyingel, rother Boffatbart, purpurfarbiges (Briffelgrab.

Fétique rougeâtre. (franz.)

Purple Fescue - Grass. (entgl.)

\section{Sreten = Sharater.}

Waurzel friectyend und fproffend, rajentildend. Jgalm

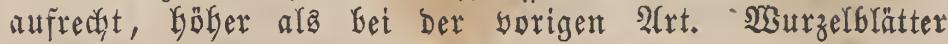
Gorftig. Salmblätter ffach ober zufanmengerollt und meift Greiter. Die Scheiden melyr pder meniger meidjefyaart. Daz

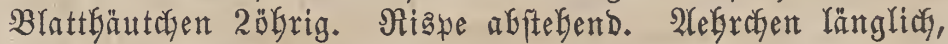
begrannt, 5-7blüthig, meift rötglich, öfters wollig befaart. Blüthdyen lanzettförmig und lang zugefpibt.

Aluch Diefer Schmingel befitht einige Warietäten:

$$
\beta \text {, villos a. }
$$

Die obere Rlappe am Rande gemimpert. Die Blütychen überall borftig.

\section{$\gamma$. lanuginos a.}

Die Blätter genteiniglich einmärta gerolft. Die Aebrehen größer, etwas feimwolfig und 4 -7blüthig.

Mit Greiteren $\mathfrak{B}$ Yättern.

$$
\delta \text {. latifolia. }
$$

\section{$\varepsilon$. vivipara.}

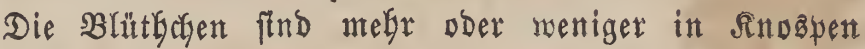
aแรggetwachfen.

\section{Błüthe = 3 eit uns Dauex.}

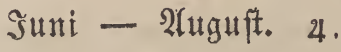

\section{Bortentent.}

$\mathfrak{A}_{\mathfrak{n}}$ Dürren, graftgen Drten, auf Wiefen, Weiben, itt

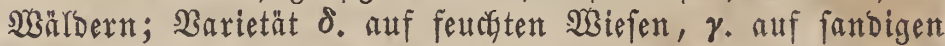
Mlägen, an Den Ufern Dez Galtijojen Mieerea.

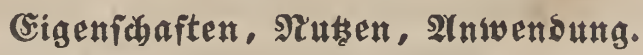

శ్suttergras.

\section{Festuca heterophylla. Haenk.}

Festuca duriuscula. L.

Festuca nemorum. Leyss.

Festuca nemorosa. Latour.

Festuca viridis. Panzer.

Beridyiebenblätteriger Schningel.

Arten = Charater.

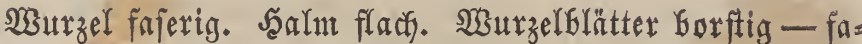
benförmig, fegr lang. Salmblätter flach, lintenförmig, febr

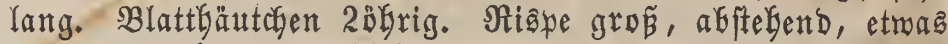

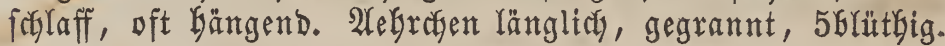
Blüttyçen făntäler, lanzettförmig und an ber Spike pfrie= menfürmig, gegrannt. Die Branne fo lang ober etwaz fürzer als bie Spelze.

$$
\begin{aligned}
& \text { SBlüthe }=\text { 3eit uno } \text { Dauer. } \\
& \text { sult }- \text { Auguft. } 4 \text {. }
\end{aligned}
$$

\section{3ortontmen.}

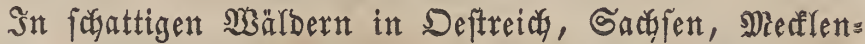

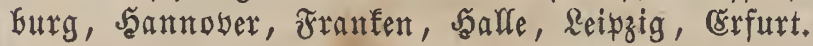

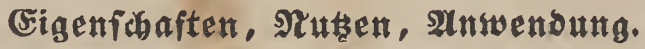
శuttergras. 
Festuca pratensis. Huds. Schrad.

Festuca elatior. L.

Festuca fluitans $\gamma$ pratensis. Festuca loliaceata. Autor Huds. Festuca Phoenix. Vill.

Bromus elatior. Koel. Poa curvata. Koel.

Bromus pratensis. Spr. Schedonorus curvatus. R. S.

Schedonorus pratensis. R. S. $\gamma$. Festuca intermedia. Koel.

ISiefenfifroingel.

\section{Arten = ÇGaraktex.}

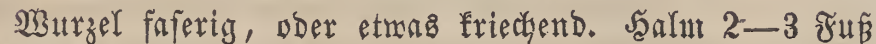
Goca, aufrecht, runb, fabl. Blätter bandförmig, langfpibig, flach, die untern glatt, die obern fararfrandig. Blattbäut= dyen felgr furz. Rispe einfeitig, abftebend, aufrectst, mit

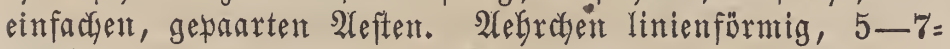
blütgig, grün und violett. Slapyen Ianzettförntig, fpikig, ungleidy. Untere Spelze eirund - Ianzettförntig, baudjig, fpibig, tnberwebrt; obere Spelze an Der Spibe 2ppaltig.

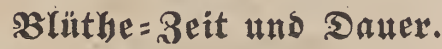

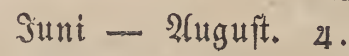

\section{3orkommen.}

Iuf feuditen Graß̧plähen, NSiejen.

(sigenfhaften, গ⿰ułen, Atruenoung.

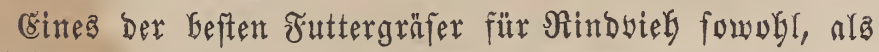
für झ̈Ferde.

\section{Festuca arundinacea. Schreb.}

Festuca elatior. L.

Festuca Phoenix. Vill.

Festuca spadicea. Moench.

Bromus arundinaceus. Roth.

Bromus elatior. Spr.

Bromus littoreus. Weigel.

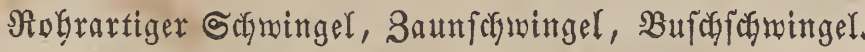

\section{arten = Sharater.}

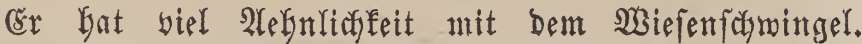
Wurzel fpropend und etmas friectiend. Falnte meift böber, ftärfer und fteif. Die Blätter flach, Ianzettförnig, breiter, fteifer und tiefer geftreift. Blattbäutchen febr furz. Riape augigebreitet, etwå geneigt, gröfrer und gleiô. Die Aefte unten gepaart, weräftelt. 2lefrchen ei-lanzettförmig, $4-5=$ blütbig, zujammengebrind, fleiner und fürzer. Untere Rlappe 5nerbig, an Den Nerben und Dent Riele fararf, meifi furz und fodarf begrannt, feltener unberwebrt. Blütbdien webrloz boer unter ber Spibe fractuelpipigig.

\section{Blübe = Beit und Dauer.}

Suni - Suli. 4 .

\section{3orémmen.}

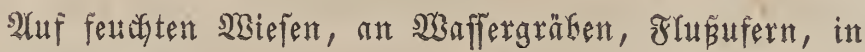
Noribengebüchen.

\section{Futtergrag. \\ (sigenfigaften, গtuten, 2(nwendung.}

Festuca loliacea. L.

Festuca adscendens. Retz.

Festuca elongata. Ehrh.
Festuca fluitans. Leers. Festuca Phoenix. Thuil.

Brachypodium loliaceum. Link.

Poa loliacea. Koel.

ฉolitartiger Sifuningel.

Schedonorus Ioliaceus. R. S. Triticum patens. Brotz.

\section{arten = (5)arater.}

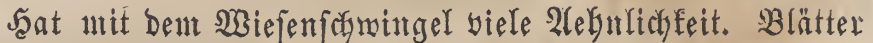

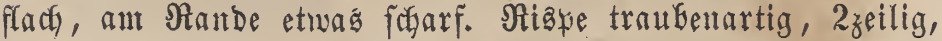
etwas nicfend. 2abrajen linienförmig - länglid, abrwedy felnd unb entfernt ftebend, die obern ftielrog, die untern geftielt. Untere Slappe 1=, obere 4-5nerbig. Itntere Spelze an ber Spitge 5nertig.

\section{Blüthe $=$ Beit ans Sauer.}

Mai - รัuni 4.

\section{Rortemtmen.}

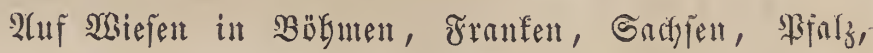
fannover, Saffau, Srameiz, Jranfreid), (England.

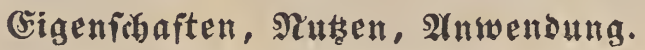

ชuttergrag.

\section{Festuca sylvatica. Vill.}

Festuca altissima. All.?

Festuca calamaria. Smith.

Festuca latifolia. Host. Willd.

Bromus patentissimus. Weigel.

Bromus triflorus. Ehrh.

Poa atrata. Pers.

Poa binervata. Ehrh.

Poa quadriflora. Moench.

Poa sabauda. Vill. Schmidt. ?

Waldidninger.

\section{Arten = (5)arater.}

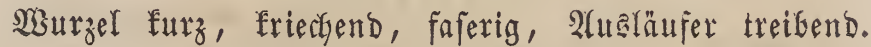

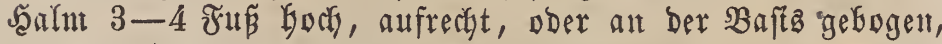
glatt, geftreift. Blătter 1-1 1/2 ₹ü lang, robrartig, flact, lanzett - linienförmig, mit fdyärflidyen Scheiben unb fefrr

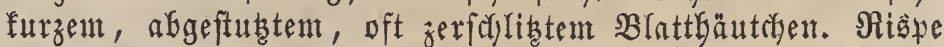
aufrertyt, augigebreitet, febr äftig, bieläbrig. Alebrafen lant= zettförmig, 3-46lütyig. Slappen lanzettförmig, zugefpibt, untere 1 , obere 3 nerbig. Intere Spelze lanzettfömig, febr fpibig, unbervebrt, 3nervig, grün ober violett, nit weiper Spibe. Dbere Spelze füzer, 2zihnig. Frudtfnoten bari: fif opfig.

\section{Blïthe = Beit und Dauer. \\ Эuni - Suli. 2 . \\ 3oremmen. \\ In gebirgigen, fwattigen $\mathfrak{B a l d u n g e n .}$

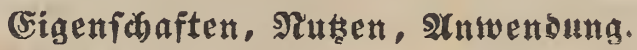 Futtergrab.}

\section{Festuca gigantea. Vill. Sm.}

Festuca triflora. Smith. Bromus aquaticus. Cmel. Bromus giganteus. L. Bromus triflorus. Fl. dan. Bromus strigosus. Lam. Schedonorus giganteus. Gaud.

Riefenfigmingel, Futterfobmingel, Futtertregue, groper Sabminger, Bachmeizen. 


\section{2)rten = Charater.}

Burzel fajerig oder etwas friectgend, rajentreifend. Saatur

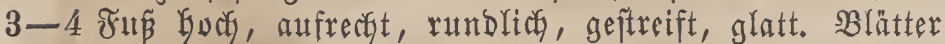

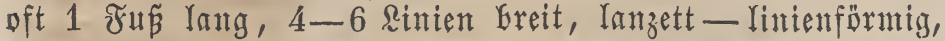
langfinizig, foharfrandig, an ber Bafts beiberfeits mit einem

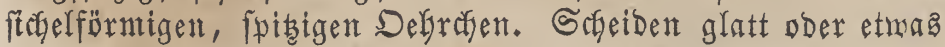

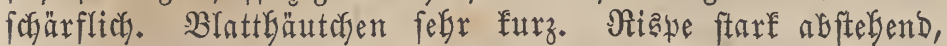

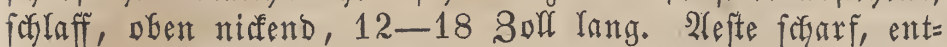
fernt, unten zu zweien, zur ફ̧älfte nacte, bum getheilt, wellig und üferbängend. 2(ebrefen lanzettförmig, 5-8blü= thig, gegrant. Rlappen lanzettfömig, fpitzig, untere 1=, obere 3nervig. Itntere Spelze 5nervig, glatt, fwitgig, oben etwas fcharf, grün, mit breitent, weî́ent Nande, unter Der Spibe mit einer langen, fein gefoulängelten Branne. DGere Spelze an ber Spite ganz ober $2 z$ älanig, unb eben fo lang. zrudetfenoten fagl.

\section{Blüthe = Beit tnd Dater.}

\section{รuni - 2ługut. 4 .}

\section{3otentuten.}

$\mathfrak{A}_{\text {it }}$ etwas feutdeten, warbigen und fodjattigen Drten, in (S) büfchen, an Griäben.

\section{Eigenfabaften, sutuen, 2tnwendung.}

(Eiit wortreffliches Bieffutter. Die faftigen Scalute "tnd großen Blätter bleiben bis in Spätberbft binteit grün แnto

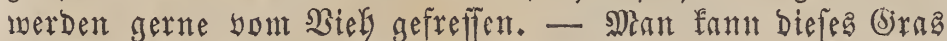
3 -4mal des Jahrea funneiden.

\section{Festuca aspera, M. et $\mathbf{K}$.}

Bromus altissimus. Weber.

Bromus asper. L.

Bromus dumetorum. Lam.

Bromus giganteus. Vill.

Bromus montanus, Scop. Pollich. Gmel.
Bromus hirsutus. Curt. Sibth.

Bromus nemoralis. Huds. Bromus nemorosus. Vill. Bromus ramosus. Murr. Bromus sylvaticus. Vogler. Bromus versicolor. Pollich. Schedonorus asper. Gaud. $\beta$. Bromus hirsutissimus. Cyrill.

Nauber Sifwingel, ranbe Trespe.

\section{Arten = Sharafter.}

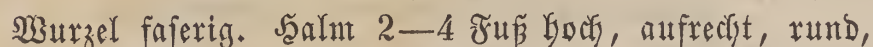
feinbaarig. B̉ätter lanzett-linienfürntig, fuitigig, flact), behaart, ant brunde beiderfeita geöhrt, mit glatten voer

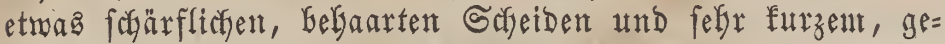

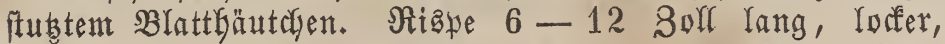
nicfend, mit Iangen, Dünnes, făbarfen, zur J̧älfte fablen, unten zu 2-3 ftebenden 2 eften. SleGrchen lanzettförmig, 7-9blütbig, gegramnt. Silappent ungleich, Ianzetfö̈rntig, untere $1=$, obere 3nervig. Untere Spelze 5nerbig, zottig, mit ganzer ober etwas geftuteter Spibe und unter biefer nit einer bünten, gerabent Soranne, weldye aber fintzer als bie Spelze ift. Drere Spelze mit ganzer Sphibe, nuf Den Rielen fein und fegr furzmintperig. Fructefnoten barachopfig.

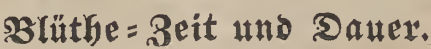

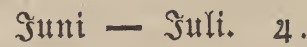

\section{Sortommen.}

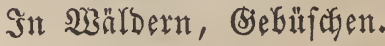

ङigenfaften, Nutuen, Anwenoung.

Futtergras.

\section{Festuca montana. Savi.}

Festuca erecta. Wolbr.

Festuca hirta. Seen.

Bromus agrestis. All. Host.

Bromus angustifolius. Schrank. Bbrst.

Bromus arvensis. Lam. Pollich.

Bromus asper. Poll.

Bromus erectus. Huds.

Bergformingel, Bergtreape, aufrechter Schmingel, auf= rechte Treape.

\section{Arten = Charater.}

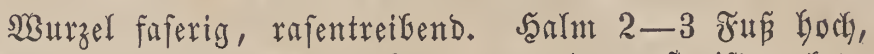
aufrecht, unten oft nebergebogen, rund, geftreift, glatt. Mourzelblätter febr lang, fommal, meift fielig gefultet, be= Gaart, mit fdyarfent, gemintpertem Rande. Saalmblätter Greis ter, flacy, Gandförmig, faun bebaart, mit geftreiftent Schei= Den und furzent, geftulgtent Blattgäutcjent. Ris̄pe aufrecht, etwas abftehend, mit foharfen 2leften. 2(ehrafen lanzett-li= nienförmig, zuerft malzig, fpäter flacher, 5-106hiotbig. Alapyen lauzettförnig, fpibig, untere $1=$, obere 3nerbig. Intere Spelze ranzetfföntig, fabl, nit 3 ftarfen serven und eitrigen forronden, unter ber ftumpfen Spibe nit eitter geraben oder gefolgängelten Soranne, welche faum halb fo lang als bie Spelze ift. Sbere Spelze unt $1 / 4$ fürzer, ftumpf

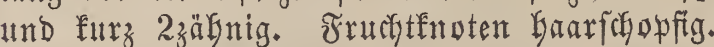

Eine Sarietat:

$$
\text { B. villosa, }
$$

bei weldfer die untere Spelze fürzet voer länger be= Gaart ift.

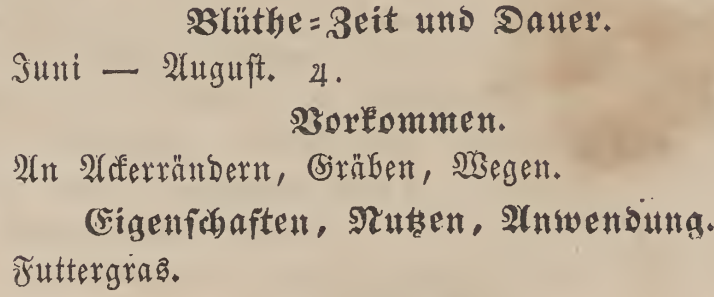

\section{Festuca inermis. DeC.}

Festuca Leysseri. Moench. Festuca poaeformis. Pers. Festuca poaeoides. Thuil. Festuca speciosa. Schreb. Bromus inermis. L.

Schedonorus inermis. R. S.

Schedonorus longifolius. Trin.

ふurzgranniger Schmingel, granmenlofer Schmingel, glat= ter Gifiningel.

\section{Arten = Sharatex.}

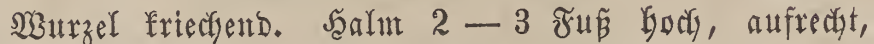
glatt, rức, geftreift. Blätter lintenfürmig, ffady, glatt, noch einnal fo Greit aber fürzer als bei bem Bergfdymingel.

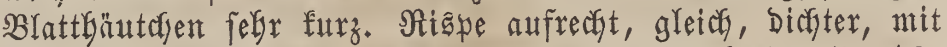
4-6 2leften. 2(ebraben lanzettförmig, gleichbreit, 5-10= Glütbig. Rlapwen lanzettfürntig, fpibig. Itntere Spelze 3ner= wig, unferwelgrt ober mit eimer faum über bie Spibe binaus= reichenden Eranne. Dbere Spelze fürzer, 2zähnig. Staub= Geutel gelb. 
Eine Rarietät:

mit Gebarten shebromen.

$$
\beta, v i l l o s a,
$$

Blüthe $=$ Beit uno Dauer.

Suti - $\mathfrak{A} u g u t$. 4 .

\$orEmomen.

2) Wִ ufern.

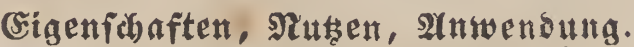

Juttergras.

\section{Festuca Myurus. L.}

Festuca bromoides. L. var. Spr.

Festuca hybrida. Brot.?

Festuca linearis. Gilib.

Festuca monandra. Ell.

Bromus bohemicus. Schmidt.

Mygalurus caudatus. Link.

Vulpia Myurus. Gmel.

$\beta$. Festuca pseudomyurus. Willem.

Vulpia pseudomyurus. Rchbch.

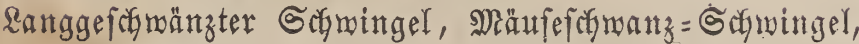
fleiner Sobroinget.

Fétique queue - detrat. (ftanz.)

Wall Fescue - grass. Capon's - Tail grass. (engl.)

\section{Alten = Sharałter.}

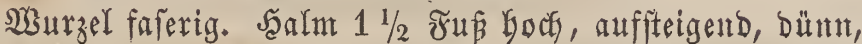

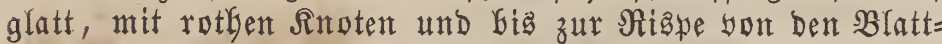
ficheiden ungeben. Sispe einfeitig, äbrenförmig, gebrängt,

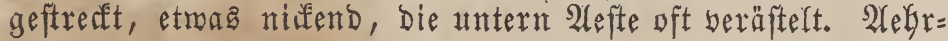
don 5-7blütrig. Dbere Slappe Doppelt fo lang als bie untere. Untere Spelze gegrannt, bie obere an Dex Spibe

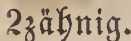

\section{Blüthe = 3eit und Datter.}

Mai - Suni. ๑. $\sigma^{\pi}$.

\section{3or Eommen.}

Zn fanbigen, trodfenen, graftgen Drten, Wegen, פrard = rändern, auf Mauern.

(̌igenfibaften, গutsen, 2(nuenoung.

Fruttergras.

\section{Brachypodium. Beauv.}

Sifteme: Achyrophyta. Neck.

Gramina. L.

Gramina digyna composita. Roy.

Gramina hordeacea. Kunth. Spr.

Gramina Tritica. Adans.

Gramineae. Juss.

Triandria, Digynia. L.

Relá 2flappig, vielblütbig. Rlappen ranzettförmig, lang zugefpibt, ungleich. BBlütbchen 2fpelzig, länger als bie Slappen, untere Spelze lanzettförmig, ftumpf, nit 5 un= Deutliben Nerben und in Der Mitte mit einer aufrechten, gefnieten Giranne. Dbere Spelze afgeftubt, ant Siande mit rürwärta gebogenen Saaren gewimpert. Dedfpelzen 2.

Sriffel febr furz, Narben gefedert, feitwärto berbortretend. Frueft Gornig.

\section{Brachypodium pinnatum. R. S.}

Brachypodium caespitosum. R. S. Bromus tigurinus. Suter. Brachypodium rupestre. R. S. Avena laeta. Salisb.

Bromus caespitosus. Host.

Bromus corniculatus. Lam.

Bromus fragilis. Lam.

Bromus gracilis. Leyss.

Bromus pinnatus. L.

Bromus rupestris. Host.

Festuca pinnata. Moench. Koel. Schrad.

Festuca ramosa. Gass.

Triticum bromoides. Web. Wibel. Triticum gracile. DeC. Triticum pinnatum. Moench. $\beta$. Brachypodium contractum. Presl.

Geffederte Swenfe, gefiederte Trespe, gefiederter Sabin= ger, gepinte Smenfe, Sittertreape.

Spick 'd Brome-grass. (engl.)

\section{arten = (5)arater.}

Wurzel friectend. Salm $2-4$ ซuB god, aufrecht, fteif, geftreift, oben faharf. Blätter linienförmig ober lan= zett-linienförmig, fpibig; fararf, flad, vft etwas baarig, fteif, mit einer zottigen Stelle auf Der Utnterfeite an Der Bafta, fdjarfen, geftreifter Blattforeiden und abgeftubtem

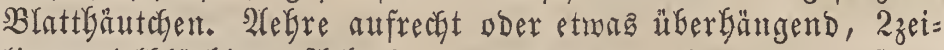
rig, bielblüthig. Zuefrchen etwas won einatider entfernt ftebend, fpäter abftebend. Slappen lanzettörmig, fpibig, gefurcht, mimperig - gerandet, untere un bie fälfte fleiner. Untere Spelze Innzettförmig, gefurd, mimperig-geranbet, mit einer meift $2-3$ Rinien langen Siranne. Sbere Spelze bäutig, geftubt.

Barietäten gibt ea:

$$
\begin{aligned}
& \beta \text {. mit naditen 2lebrogen, แnd }
\end{aligned}
$$

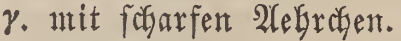

\section{Blithe = Beit uns sauer.}

Şuni - ști. 4

\section{DorEommen.}

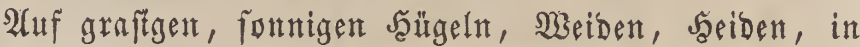
5ainett.

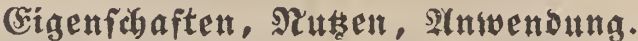 \\ Futtergras.}

Triticum. L.

Siefye S. 32.

\section{'I'riticum repens. $L$.}

Agropyrum repens. Beauv.

$\alpha$. Triticum arvense. Schreb.

Bromus glaber. Scop.

$\beta$. Triticum subulatum. Schreb. $\gamma$. Triticum dumetorum. Schreb. Bromus villosus. Scop.

$\delta$. Triticum Vaillantianum. Schreb.

$\varepsilon$. Triticum Leersianum. Wulf. Schreb. $\eta$. Triticum imbricatum. Lam.

Duecte, geneine Suedfe, Suedengras, Duerfentweizen,

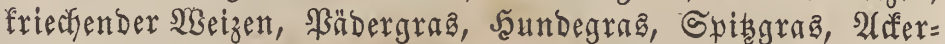

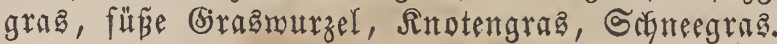

Froment chiendent. (franz.)

Couch - Grass. (engl.)

Thiticum sepium. Thuil. Agropyrum sepium. Beauv. Elymus caninus $\beta$. Roth. Leer's. Elymus dumetorum. Hoffm. Agropyrum collinum. 0piz. $\zeta$. Triticum firmum. Presl. 


\section{Alten $=\mathbb{S} \mathfrak{S}$ arafter .}

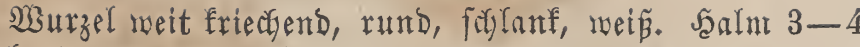

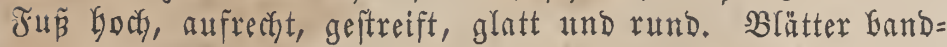
fürmig, lang, fpibig, flach ober zufammengerollt, fabl, oben und ant Sande focharf. SBlattbäutchen furz. 2(elgre 2zeilig, $3-4$ 3oll lang, ntit rauber Sfindel. 2aferchen 4-5blüt= thig, zแfamnengeorürt. Rlappen fpithig, 5mervig. Itntere Spelze zugefpibt, bismeilen furzgrannig; Die obere 2zäbnig. Barietäten find:

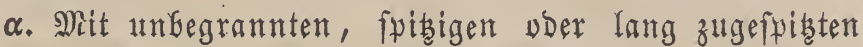
B(ütheden.

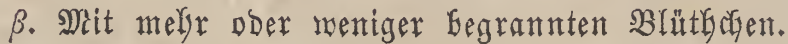

$\gamma$. Die untern Blüthaden gegrannt, zu zwei DDer brei ftebent.

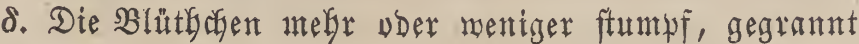
ober wefrlog.

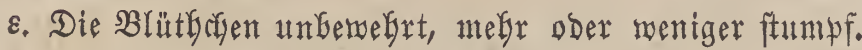
Die Blätter einnärto gerollt.

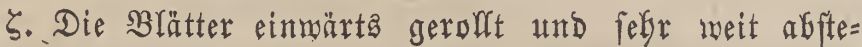
Kend. Die ganze Aflanze graugrüt.

\section{Slüthe = Beit und $\mathfrak{D a u e r}$.}

Juni - গult. 4.

\section{タัorénmen.} Plăb̧ent.

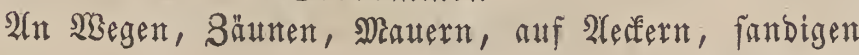

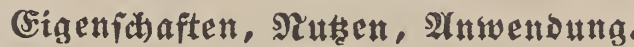

Die Suedfe ift ein - ifrer wuchernden Naurzeln wegen febr läftiges Itnfraut. Die 23 urzel ift officinell und befibt befänftigende und biuretifche Siräfte, man fann aub ify ein Megf bereiten und biejes in theuren Seiten nit anderem Miefl zu Brod verbaden. In fandigen begenden bienen fie zur Befeftiguni Des Ffugiandea, Der Dännte zc.

\section{Triticum caninum, Schreb.}

Triticum sepium. Lam.

Agropyrum caninum. R. S.

Elymus caninus. L.

Festuca nutans. Moench.

$\beta$. Triticum caninum Gmelini. Ledeb.

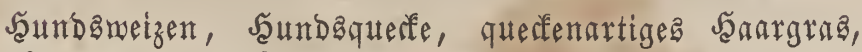
rotfes Duerfe, Jૃundaghargras.

\section{Alrten = ÇGaratex.}

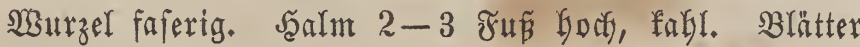
beffgrün, flacty, auf beiden Seiten focharf. alegre nach ber B̧hüthe überbångend, 2zeilig. 2lebrchen 5Glütbig, gelbgrün. אlappen gleich, Ianzettförnig, furz gegrannt, meift 3nervig, id)arf. Hntere Spelze nach oben 5mersig, mit einer boppelt längern, geforblängelten Brante. Dbere an Der Spibe zmei= fpaltig.

\section{Blüthe $=$ Beit und Dauer.}

Iuni - Iult. 4 .

\section{3orfommen.}

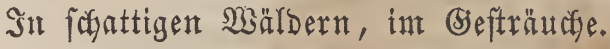

Eigenidaften, stuen, Anwendung. Futtergrą.

\section{Lolium. I.}

Syfteme: Achyrophyta. Neck.

Gramina. L.

Gramina digyna composila. Roy.

Gramina hordeacea. Kunth.

Gramina Tritica. Adans.

Gramineae. Juss.

Triandria, Digynia. L.

Zebre aufgeblajen, 2zeilig. 2lebrchen ftiellog, abrect) felnd ftebend, megr ober meniger zuammengebruaft und mit ber fogmäiern Seite an bie Spindel angebrütfft. Sielch $3=$ bis bielblütbig, an Den Seitenäbrefen 1 flappig, Der Spindel gegenuberftebend, lanzett= ober linienförnig, convex, felten ift eite 2te, aber biel fleitnere, an ber Spindel liegende

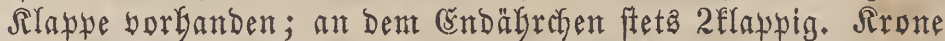
2fjelzig. Utntere Spelze länglich, welgrlos and unter ber Spelze bemelgrt; obere. Spelze foumal, 2 fielig und an ben Rielen fein gemimpert. Decfipelzen 2. Jrudeftenten abgl. Briffel furz. Narben geffedert, zur Seite berbartretend. zrudeft angemathfen.

\section{Lolium perenne. L.}

\author{
Lolium agreste. Hort. \\ Lolium Halleri. Gmel. \\ Lolium tenue. L. \\ Lolium vulgare. Host. \\ $\beta$. Brachypodium tenue. Beauv. \\ Triticum tenue. Autor. \\ $\gamma$. Lolium compositum. Thuil. \\ Lolium cristatum. Hort. Pers. \\ Lolium latum. Roth. \\ Loliun ramosum. Hort.
}

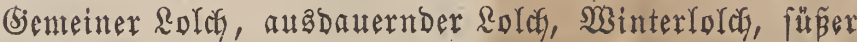

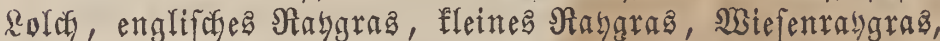
Taubenforn, Dinfelweizen, Dinfelpelzen, Jürftbafer, Roth= hafer, Swilbhafer, Mäufefafer, Dort, (Braslauch, Taufd, Röthe, wintertreäpe.

Fausse Juraye. (frattz.)

Red Darnell. Perennial Rye-grass. (ettgl.)

\section{Arten = (5)araftex.}

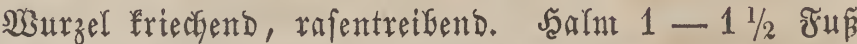
Gody, fajief aufiteigend, glatt, geftreift, rund. SBlätter limer = lifch, zugefpitst, ffach, ficharf auf Der DGerfeite und am Siande, mit zufammengebrulften, geftreiften, glatten Scheiben und furzem Blattbäutchen. Aegre aufrecht, gerabe ober etwa gefogen, 2zeilig, flady, 4-10 3oll lang, mit melfig gebo=

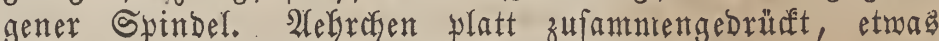

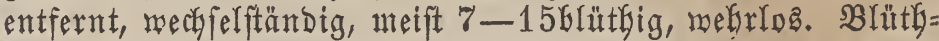
chen liegen anfanga bidyt auf einander, fpäter fend fte etroas

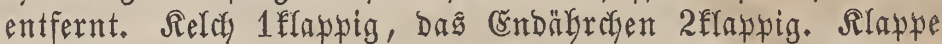
lanzettförmig, fpis, 7nerbig, mit einem meip̈lichen J̧ant= rande. Intere Spelze Ianzettfömig, 5nervig, megrlos, fel= ten unter der Spibe mit eitter febr furzen (branne. Sbere Spelze Geinabe yon gleicher \&änge. Staubbeutel gelf.

Man fennt melsere Spielarten:

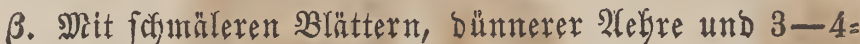
blütffigen 2lebroben, melche länger ala Der Relch find.

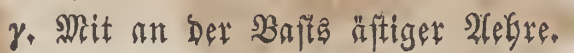


8. Mit beinabe 10 3oll langer 2lebre, melefe 20 und mefar 2lebregen entGält.

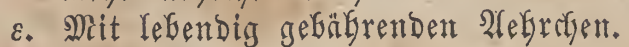

Blüthe = 3eit and Dauet.

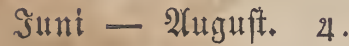

\section{3ortommen.} rändern.

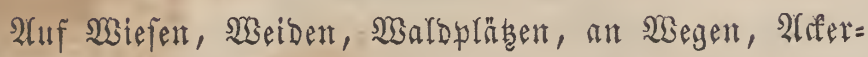

\section{Bigenfábter, stutset, Anwensung.}

Jung ift e⿱乛龰 ein ganz gutez Futtergras und bient zut

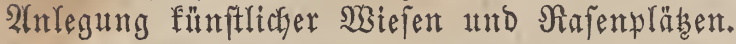

Sn Der Ranbwirthfdgaft fultimint man werfogiebente Spiel= arten Diejez Raggrafes.

Lolium perenne italicum.

\section{Italienilides $\mathfrak{R}$ oggras.}

\section{Heinftes la a femroggras.}

Lolium perenne tenue.

Sit bie oben angegebene Warietät $\beta$.

3. Withworths engli/des liaygras.

Lolium perenne Withworthii.

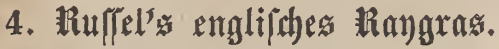

Lolium perenne Russelianum.

\section{Stidkney ${ }^{y}$ engli}

Lolium perenne Stickneyi.

\section{Lolium arvense. With.}

Lolium annuum. Bernh.

Lolium asperum. Roth.

Lolium multiflorum. Koel.

Lolium remotum. Hoffm. Schrank.

Lolium temulentum. Huds.

Lolium tenue. Bbrst.

2afferlolds.

\section{Arten = Sharater.}

Der 2 deferlolds ift mit bem vorigen zienlich serwand.

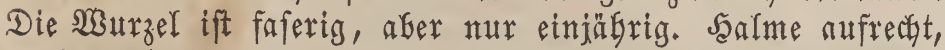
rund, geftreift, glatt, aber ofhne B̧ätterbufiger. Saalmblätter

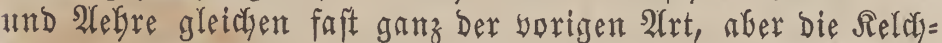
flappe ift länger, fo lang ala bas 2lefrachen, ober faum etwas fürzer. Utntere Spelze eiförmtg, zugefpitst, gegen bie Spibe Git fictarf gefielt, endigt ftu auf Der mittleren Nerbe

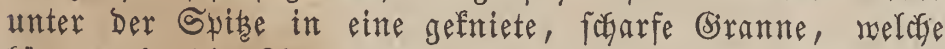
fürzer als bie Rlappe ober gerabe fo lang ift. BlütGchen lanzettförntig, melgr ober weniger gegrannt und gröper ala Die Rlappe.

\section{Slithe $=3$ eit und oatter.}

รuni - suli. $\odot$.

\section{Sortommen.}

Tuf 2lerfern, zumal auf Jlachgfeldern.

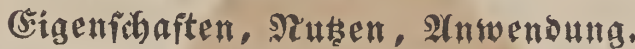
Futtergraa.

Hordeum, L. Spr, Stebe S. 62 .

\section{Hordeum murinum. L.}

Zeocriton murinum. Beauv.

$\beta$. Hordeum murinum chilense. Brongn.

$\gamma$. Hordeum leporinum. Link.

Mauergerfte, Mäufegerfite, Mäufefchronzgerfte, trube (Serfe, Baftardogerfte.

\section{arten = Sharater.}

33urzel fajerig, rajentreibend. Saalm 1-1 1/2 Fuß bory, aufrecht oder auffteigend, geftreift, fabl. SBlätter banbfür= mig, fpibig, ant Ranbe ffuar, etwas befaart, an Der Bafts Geiberfeits geblgrt, mit faglen Sigetben und furzem Blatt= bäutchen. 2rebre zuerft aufreçt, bann nideend, etras zufan= utengebrinft und undeutlich 6zeilig, $2-3$ soll lang. Spit= bel fabl, rathrandig, zerbrecflich. - Mittleres Sebrafen fibend, zwitterig, ntit gervimperten fobnalen Rlappen, meldse in eine lange raube (Sirnne endigen. Hutere Spelze famal, lanzettförmig, mit einer nod längeren rauben Sranne. Dbere Spelze fürzer, Ianzettförntig, ftumpf. Staubbeutel und Stanbfäben mie bei den männlichen 2refratsen. Fructst= fnoten Gaarig. - Die männlichen Aefraben Gaben famale, unten berwadyene Rlappen, yon Denten die innere Geiberfeitz genimpert, die äunere aber ungervimpert, jedocy feinbarig ift. Spelzen geftielt und gleich gebaut no bie Spelzen dez Srotteräbranens. Staubbeutel furz. Staubfäben lang, faben= förmig. Frudgtfnoten unbulfommen. Narben feine.

$\mathfrak{s u l i}-\mathfrak{2} \mathfrak{i} \mathfrak{u g u t}$. $\odot$.

\section{Blüthe = Beit und Datter.}

\section{3orénumen.}

2(n unbebauten Drten, an NGegen, Mauert.

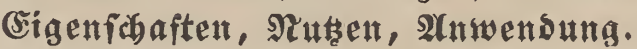

(jutes Pferde =, Sagaf = ınd Biegenfutter.

\section{Hordeum pratense, Huds.}

Hordeum maritimum. Fl. d. Roth.

Hordeum maximum. Vill.

Hordeum murinum. $\beta$. L.

Hordeum secalinum. Schreb.

Hordeum nodosum. L.

Zeocriton nodosum. Beauv.

Zeocriton secalinum. Beauv.

$\beta$. Hordeum sibiricum. Link.

Rnotige Getfe, Wiefengerfte, roggenartige Mäufegerfte. 2rten = Sharater.

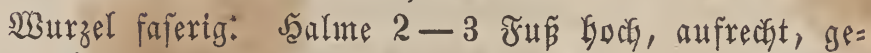
ftreift, glatt, rund und oben nafft. Blätter Gandförmig, fuibig, foraf, etmas Gebaart, $3-5$ soll lang, mit geftreif= ten, Gaarigen Sabeiden und furzen, geftubtem Blattbäutben. Aebre 3-4 3olf lang, zufammengebrüf, falanf, rötblich

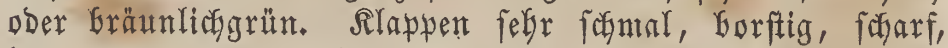
lang gegrannt und nidyt gemimpert. Die feitlidsen a ebrafen ein rontig länger geftielt, aber fürzer gegrannt.

2lendert ab: $\beta$. Wit meidgaarigen Seitenäbraben. slintbe = 3eit uns Dauex.

Sัuni - suli 4 .

Bortommen.

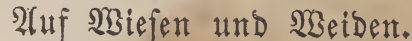

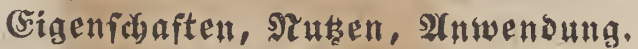
Futtergras. 


\section{Elymus. L.}

Sitospelos. Adans.

Syfteme: Achyrophyta. Neck.

Gramina. L.

Gramina Hordeacea. Kunth.

Gramina Tritica. Adans.

Gramineae. Juss.

Triandria, Digynia. L.

Alebrefien meift zu 3 , feltener mefr ober wentger, an die Spindel geftellt. Relch 2flappig, $2=$ ober mefrblüthig. Rlappen gleich, fwmal, lanzettförmig, fpisig, wor bas 2lebr= chen geftellt. Rrone 2fpelzig. Untere Spelze lanzettförmig, lang zugefpist; obere fürzer, linienförnig, etrag gefaltet, an Den Rielen gemimpert. Deffielzen 2. Fruchtenoten baar= ficopfig. Siriffel furz. Narben feberig, zur Seite berbor= tretend. Frudit angemaiffen.

\section{Elymus arenarius. L.}

\section{Elymus europaeus. Willd.}

Hordeum villosum. Moench.

Sandbaargraz, Ffugfandgras, Strandgras̄, Glauts Sandgras, Sanbmeizen, milber Weizen, milber Roggen, Stranblafer.

Elyme de sables. (franz.)

\section{Arten = (5)arater.}

Wurzel biaf, ftarf, meitfriestend. Salm $2-4$ ซuв boch, aufrecht, glatt, geftreift, rundlich. Blätter fofntal, 7ibig, fteif, einmärts gerollt, mit tiefgefurchten Scfeiden und einem langen Blatthäutchen. 2lelare aufrecbt, $6-12$ Boll lang, bidyt. Spindel zottig. Slebrchen lanzettförmig, vben und unten zu 2 , mitten zu 3 ftebend, neift 3 blütyig. Rlappen fornal-lanzetförmig, zuammengebrürft, ftarf ge= fielt, won Der sänge Der 2lefraben. Untere Spelze lanzett= förmig, zufammengebrüft, fpibig, feinbanrig, 5nervig; obere auf Den Rielen fein geroimpert.

\section{Blüthe $=3$ eit $\mathfrak{u n d}$ Dauer.}

$\mathfrak{s u l t}-2 \mathfrak{H} \mathfrak{u} \mathfrak{t}$. 4 .

\section{פorEommen.}

भn Den HFern Der Ditfee, an Flü̈ufern, fanbigen Drten.

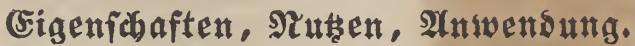

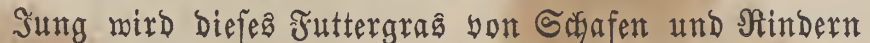
gerne gefreffen.

Wegen feiner weitfriechenden Wurzelranfen wird ęิ auf ben Gandbünen Dex Nord = und Ditfee bäufig angepflanzt.

\section{Anthoxanthum. L.}

Syftente: Achyrophyta. Neck. Gramina. L. Gramina digyna. Roy. Gramina Avenae. Adans. Gramina Bromea. Kunth. Gramineae. Juss.

Triandria, Digynia. L.

Reldy 2flappig, 16lütGig, slappen ungleidy zujammen= Calwer, bétnom. \$franzentunde. gebrünt, frautig - Gäutig; Die untere furz, 1nervig; Die obere länger und 3nervig. Blume 2fpelzig, fürzer als ber Relay. Spelzen gleich lang; untere Spelze unter der Spibe, bbere an Der Baftz gegrannt. Staubgefäpe 2, utit baar= förmigen Staubfäben und aufliegenden Staubbeuteln. Dedt= ipelzen 0. Frudbtfnoten fabl, länglida. Siriffel rang. Narben fabenförmig, Gaarig, aus ber Spibe Des Alebraneng berbor: tretend.

\section{Anthoxanthum odoratum. L.}

$\beta$. Anthoxanthum villosum. Loisl. Anthoxanthum paniculatum. Hort. $\gamma$. Anthoxanthum asperum. Mann.

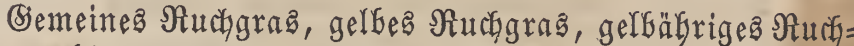

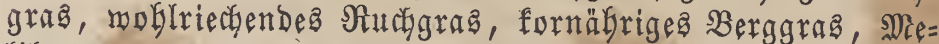
lilottengraas.

Sweet scented Spring-Grass. (engl.)

\section{Alrten $=$ Sharakter.}

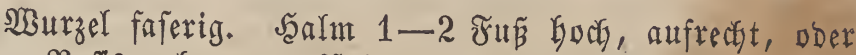
an Der Baftz gebogen auffteigend, glatt, geftreift. Blätter lanzett-linienfüntig, zugefpibt, faharf, Dünnbarig, meich, mit meichlfarrigen Scheiden. Niaßpe ährenförmig, eiförmig - länglich, 1-3 3oll lang. 2Aelorchen turzgeftielt, fegel= förmig. Rlappen ungleich. SBlume fleiner als bie Rlappen, 2fpelzig, Bon Den Spelzen ift Die eime mit einer eben fo langen, bie andere aber mit einer 3 mal längern, an ber

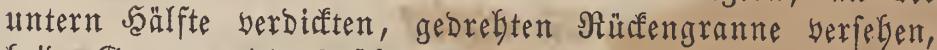
Geibe Brannen jedoch überragen Den Sielch nicht.

Aendert $\mathfrak{a b}$

$\beta$. Mit einer Dopwelten und aftigen $\Re i s p e$, und

$\gamma$. Mit meidgaarigen Rlappen.

\section{Blütbe $=$ Beit uno Dauer.}

Mai - Suni, und zum zmeitenmal im Sommer, 4.

\section{0rEmmen.}

2Uff Wiefen, Weiben, fandigen J̧ügeln und Bergen,

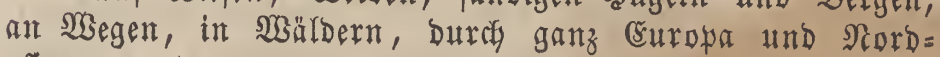
apten.

\section{Cigenfibaften, গuţen, Anwenoung.}

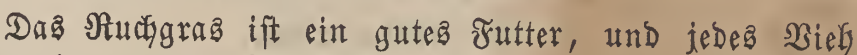
ziegt es ben andern Juttergriffern yor, und fand bes Jah)= res 2-3mal gemähet werden, gibt ein fefr gutes, an= genefmez und fteinfleeartiges SeH, Gefonders went Schafweiden wächat.

2(uB Der ftarf riectenden 2 surzel bereitet man mit nocf andern Sirüutern bermengt, eimen Gefnupftabaf, Radica genannt.

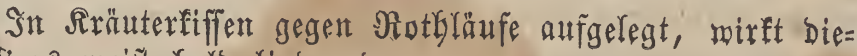
fes bras meipt Gald lindernd. 


\section{Suttexkrảuter.}

Darunter berftegt man foldạe frautartige benärafe, welche nur zur thierifdyen Nabrung bienen; fie werben ent= weber im Srropenen angefaut, oder man findet fie mit ben

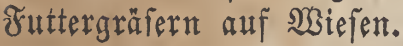

\section{Achillea. L.}

Millefolium. Adans.

Syftente: Actinophyta. Neck.

Compositae. Juss.

Compositae Achilleae. Rül.

Compositae amphigynanthae. Rchbch.

Compositae Calthae. Adans.

Compositae radiatae. Roy. Spr.

Compositae Senecionideae. Less.

Corymbiferae. Vent.

Synantherae Anthemideae. Cass.

Syngenesia, Polygamia superflua. L.

Blüthendecte eirund ober glorfig - Galbefugelig, mit ziegeldachartigen, angebrücten Schuppen. Weibliche গtand= Glüthen 5-10, geftubt, ftraglig. Scheibenblütgen trichter= förmig, 5 zähnig, zmitterig. Fruchtboben fohmal, ffach, fpreu= artig. Samen elfiptifoh, zufammengebrünt, ungefrönt.

\section{Achillea Millefolium. L.}

Achillea subhirsuta. Gilib.

$\beta$. Achillea collina. Becker.

$\gamma$. Achillea Millefolium crustata, Rochel.

Achillea crassifolia. Hort.

Achillea scabra. Host.

$\delta$. Achillea polyphylla. Schleich.

$\varepsilon$. Achillea dentifera. Rchbch.

Achillea Haenkiana. Tausch.

Achillea magna. Haenk.

Achillea Seidlii. Presl.

Achillea sudetica. 0piz.

Achillea sylvatica. Becker.

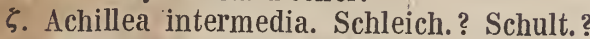

$\eta$. Achillea occidentalis. Rafin.

$\vartheta$. Achillea gracilis. Rafin.

Sifafgarbe, gemeine Schafgarbe, gemeines Garbenfraut,

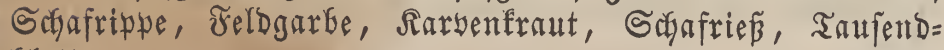
Glatt.

Common white or purple Milfoil. (engl.)

\section{Arten $=$ ÇGarater.}

NSGurzel Ditnn, walzen = und fpindelförmig, faferig,

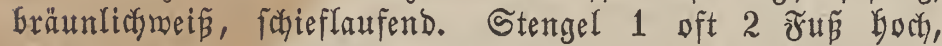
aufrecht, ftetf, bäufig oben äftig, rund, etwas bäutig, bie und ba beinabe glatt, Gäuftg an ben Aleften 5 Enotig und gefurcht, öfter aber zottig. Wurzelblätter 6-12 30 ll lang und $1 / 2-1 \frac{1}{2}$ Solf breit, freisförntig; bie fleineren Sten= gelblätter find theila boch =, theils graugrün, oben glatt, unten zartbebaart ober auch überall beinake glatt, fte fthen feft und afwechfelnd, umfaffen Den Gtengel zur bälfte, find ränglich - lanzettförmig, etwas fteif und beinabe biz zur Blattrippe Doppelt geftedert; Die einzelnen Fiebern ftnd läng= lick und baben balb ober ganz gefteberte, fuibig gezäbnte,

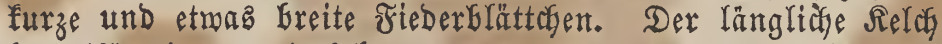

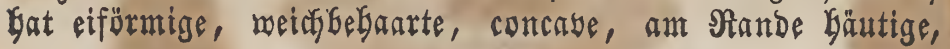

meišlichgrủne und gegen Die Spise zu Eraungemimperte Blättchen, weldye ziegeldadyfürmig über einander Yiegen. Die Blüthen ftehen meGr ober wentger gebrängt doldenförntig, gleich Goch und find flein, weíp ober je nach bem Stand= wunfte ber Siflanze auken rofen = ober purpurrotg, runblich, abgeftuntwft, mit 3 ähnigen Bändden; Die menigen Schei= benblüthen find graumei $\tilde{\beta}$. Niandblüthen feinrunzelig und meift 5 an ber $3 \mathfrak{a b l}$.

\section{Blütbe = 3eit uns Sauev.}

Juni - Septentber. 4 .

\section{3oreontmen.}

Die Sifafgarbe liebt hauptfächlich trocfene Drte, wäbat übrigenz beinabe überall an $\mathfrak{S e g e n , ~ \Re a i n e n , ~ a u f ~} 2$ (erfern, Weiden, Wiefen und in Wräldern.

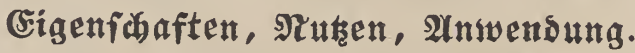

Die Blumen Der Schafgarben beftsen einen ftarfen,

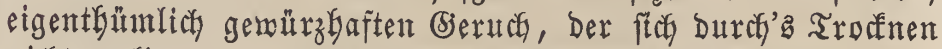
nicht verltert, und eitten etras bittern, Gerben, beifend aro=

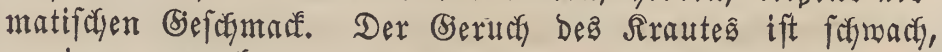
meniger angenefm, und fofmerft bitterlich falzig und fraut= artig.

Bormaltende Beftandtheife Der Schafgarbe find: ätheri= ictes Del, Gitterer Ertraftivftoil und eifengrünender Gerbe= fitoff.

Sie ift ein gute Biegfutter, zunal für bie Gahafe. Dås Raraut mird in manchen biegenden als (S)emüle, bie Blumen aber bäuftg als Thee, als Mlagen = und Rrampf= ftiffendes Mittel werbraudyt.

\section{Centaurea. L.}

Acrocentron. Cassin.

Acrolophus. Cass.

Aetheopappus. Cass.

Alophium. Cass.

Antaurea. Neck.

Callicephalus. Meyer.

Centaurium Cass.

Chartolepis. Cass.

Cheirolophus. Cass.

Choretropsis. DeC.

Crocodilium. Vent.

Cyanus. Gärt.

Heterolophus. Cass.

Hyalaea. DeC.

Hymenocentron. Cass.

Hypophaestum. Gray.

Jacea. Juss. Vent.

Lepteranthus. Neck.

Leucantha. Gray.

Lopholoma. Cass.

Lupsia. Neck.

Melanoloma. Cass.
Calcitrapa. Juss. Gärt.
Mesocentron. Cass. Microlophus. Cass. Odontolophus. Cass. Pectinastrum. Cass. Phalolepis. Cass. Philostizus. Cass. Phrygia. Pers.

Piptoceras. Cass. Platylophus. Cass. Plectocephalus. Don. Podia. Neck.

Polyacantha. Gray. Psephellus. Cass.

Pterolophus. Cass. Seridioides. DeC. Seridia. Juss. Spilacron. Cass. Stenolophus. Cass. Stizolophus. Cass. Stoebe. Pers.

Triplocentron. Cass. Verutina. Cass. Verutum. Pers.
Syfteme: Cynarocephalae. Juss. Compositae amphicenianthae, Rchbch. Compositae capitatae. L. Compositae Cardui. Rül. Compositae Cynareae. Less. Compositae Xeranthema. Adans. Synantherae Centauriae. Cass. Syngenesia, Polygamia frustranea. L. 
Blüthenberfe eiförmig, ziegelbactartig, bauchig, ntit waffenlofen ober bornigen, fproben und gewimperten Sdfup= pert. Ranbblüthen trichterförnig, ftrablig, an ber Deffnung

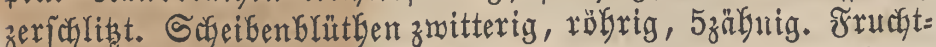
Gobent boritig. Samen eirund, glatt, reberartig, mit einem Gorftig= Gaarigen Jeberchen gefront.

\section{Centaurea Jacea. L.}

Cyanus Jacea. Fl. Wett. Baumg.

Jacea pratensis. Cass.

Rhaponticum Jacea. Moench.

$\beta$. Centaurea pratensis. Thuil.

Centaurea Jacea grandiflora. Gaud.

Centaurea nigra. Lam.

$\gamma$. Centaurea decumbens. Thuil.

Centaurea simplex. Murr.

Cyanus humilis. Fl. Wett.

$\delta$. Centaurea mollis. Schleich.

$\varepsilon$. Centaurea decipiens. Thuil. Pers.

Biemeine Floffenblume, gemeine fohmarze Florfenblume, wilber Soflor, gemeiner Sazen.

Common Centaury. (ettgl.)

\section{Arten = Charater.}

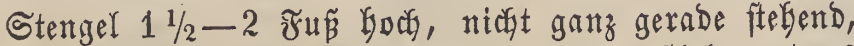

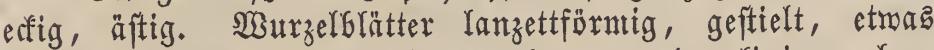

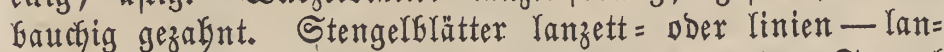
zettförmig, ganzrandig, anftsend, zur beälfte ben Stengel

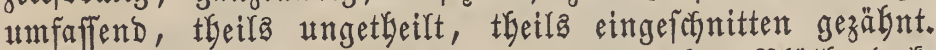

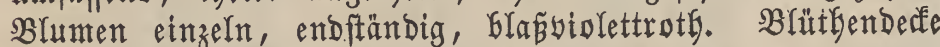
ntit grünen, eifürmigen, trodfenen, raufdenden, an ber Spise zerriffenten ober gefdyliken Schuppen, yon benen bie

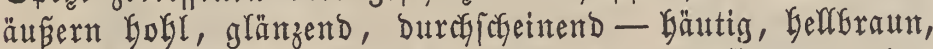

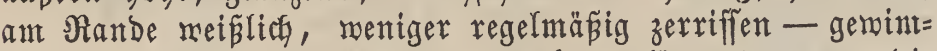
pert und gefranzt, bie innern melgr berlängert, gegen bie

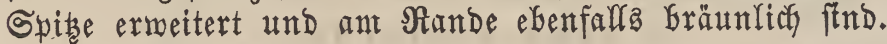

Diefe Florfenblume bariirt feldr in ifrer ganzen beftalt, in ber Bertheilung und Form ber Blätter, wie in ber Ser= theilung und Dem Wutafe Der Stengel, maz einigen Bota= nifern Beranlafjung gegeben bat, einige nettere Speciez att diefer ßflanze zu bitben; Doch untericheidet man baupträchlich nur eine Sarietät und zwar bie

\section{$\beta$, decumbens.}

Der Stengel ift hier nieberliegend, wentg zertyeilt, ge=

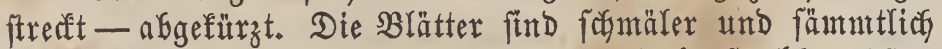

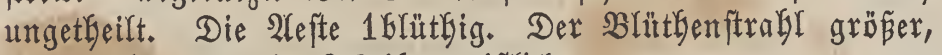
rojentoth, und bie Styeibe meifflidy.

\section{3lüthe = 3eit $\mathfrak{u n d}$ Sautr.}

Suni - September. 4.

\section{3ortomen.}

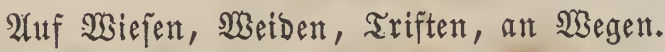

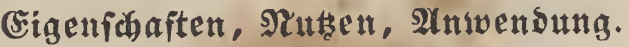

Die Sisurzel bat einen bittern, fefyr forarf Geínenden, Rraut und Blument einen meniger fobarfen, aber bitter fal=

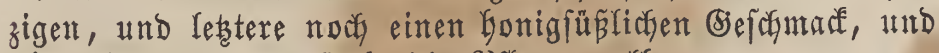
ohme (serudis; aud farbt die \$ffanze gelb.

\section{Centaurea Scabiosa. L.}

Centaurea sylvatica. Pourr. Cyanus Scabiosa. Moench.

Jacea Scabiosa. Lam.

$\beta$. Centaurea italica. Lam.

$\gamma$. Centaurea tenuifolia. Schleich.

$\delta$. Centaurea coriacea. W. K.

$\varepsilon$. Centaurea badensis. Tratt.

$\zeta$. Centaurea affinis. Frivald.

Scabiofenfloctenblume, falfoçe Sabiofe, Eifenturzel, Trommelferlägel.

Scabious Centaury. (engr.)

\section{Arten = Eharalter.}

Wurzel lang, ziemlich biaf́, malyen - fpindelförntig, vielfäpftg, fajerig, braun und fofiefgebend. Stengel $2-3$ Fü God, aufreçt, wenig äftig, etwą raulg ober auch glatt, gefurcht - geftreift. Blătter Galggefiebert, bie untern wft beinahe boppelt gefiedert - getheilt, etras rauh anzu= füflen, mit Ianzettförmigen, fwiben, an ber Bafte gefie= bert - getheilten Raypen. Blütben grof́, ftart biolett - pur= purroth, feltener wein, fthen aufreedt und bereirzelt auf langen, gefurchten Stielen. Blüthedecfe fugelig, mit grünen, eiförmigen, meitblyarigen, an ber Spibe 3ectigen, zugefpits= ten, weís gemimpert-gezăhnten, faft ftacheligen und bunfel= Graun=Gäutigen Schuppen. Die RandGlütben find bebeutend lünger als die ber Scheiben, mit 4-5theiligem Rande.

\section{Blüthe $=$ 3eit und Dauer.}

\section{Suli - September. 4}

\section{Bortommen.}

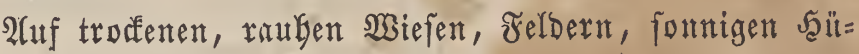
geln, an $\mathfrak{B}$ egen und bürren Bergen.

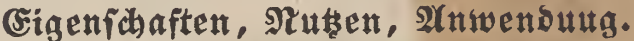

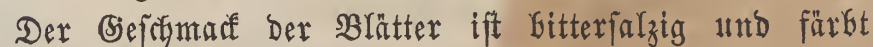
gut gelb und olivenbraun.

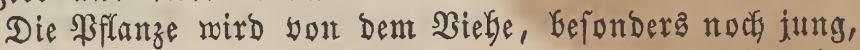
gerne gefreffen, aud geben bie Samen eit Fotter für ein= zelne $\mathfrak{A}$ rten yun Singyögeln.

\section{Anthriscus. Pers.}

Snfteme: Pentandria, Digynia. L. Scadiophyta. Neck.

Umbellatae. L.

Umbelliferae. Juss.

Relch ganzblätterig. Saum oberitändig, undeutlicy.

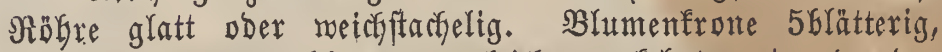
affallend. Blumenblätter ungleity, werfegrt-eirund ober feilförmig, abgeftugt ober fodmach ausgerandet, mit eintent eingejeflagenen, fegr furzen Bipfel ober mit ober obne einem Spitschert. Staubgefäpe 5, mit ben $\mathfrak{B}$ (untenblättern einge= fügt. Staubfäben furz, fabenförntig. Strubbentel runblich, 2 fächerig, eimwärta gef́ebrt. Stempel 1. Fruchtfnuten unter= ftänbig, mit einem gemölbten Briffelpolfter gefrönt, 2 fäctserig. (Eriffel 2, zuerít fegr furz, fpäter länger. Narfen ftumpf. Spaltfruct lünglich Dber eirutnd, feitlich zufanmengezogen, glatt, Gefornelt ober ftachelig. Theilfrüchte bicht, beinalge 
ftielrund, nut am Nabel 5rieftg. Samen umgefegrt, eimeíp= baltig.

\section{Anthriscus sylvestris. Hoffm. \\ Anthriscus procera. Bess. \\ Cerefolium sylvestre. Riv. \\ Chaerophyllum sylvestre. L. \\ $\beta$. Chaerophyllum alpinum. Vill. \\ $\gamma$. Chaerophyllum magellense. Tenor. \\ Myrrhis sylvestris. Tour.}

SiStlder Rörbel, Rürfel, Tolfferbel, genteiner Rälber=

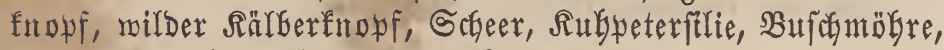
nilder Marrbenferbel, wilder Fenchel.

Wild chervil or cow weed. (entgr.)

\section{Arten = $\mathfrak{G h a r a k t e r}$.}

W3arzel lang, gleich bić, meís, glatt, gefurcht, äftig,

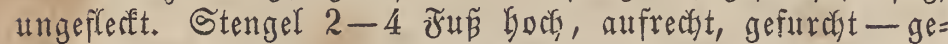
ftreift, anten zottig, oben glatt, bick, bogl, ungeffecft, mit etwas aufgetriebenen und rötglich angelaufenen Sinoten, Błätter oft 2 Fuß lang, 3theilig, Doppelt zufammengefest,

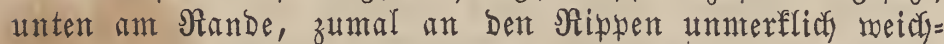
Gehaart, Deren eimzelne Blättchen eiförmig, geftedert - getheilt ftnd und bäufig fleine, längliche, etras abgeftubte (sinfchnitte Gaben. NWurzelblätter langgeftielt. Dolden gipfelftändig, flach und 12 ftrablig. Blumenftiele glatt. Das Blüthenbüllfigen lot 5-10 furze, lanzettförmige, abmärts gebogene und

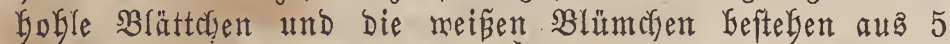
berzfürmigen, eingebogenen Blättchen. Staubfäben einfach. שrucht länglich - eirund, zugefpitat und glatt. Samen 4 Sinien lang, länglich, glatt, flach erbaben, glänzendbraun.

Slüthe $=3$ eit uns Sauer.

\section{Mai - 2Uuguft. $\%$. \\ 3orkommen.}

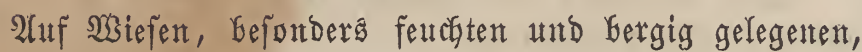
oft in groper Menge in Der Näke ber Mogkmungen, an

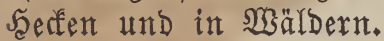

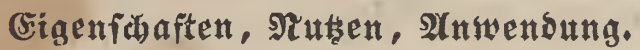

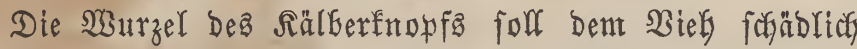

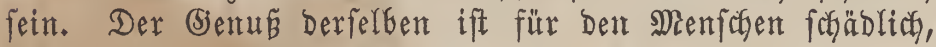
erregt Sajlaf, Mäbigfeit, Bangigfeit und Beraufdung.

Die Siflanze mirb won allem $\mathfrak{B i e h}$ fegr gerne gefreffen. Sn Ramtichatfa Dient Der Rälberfnopf ala Speije, aud fann

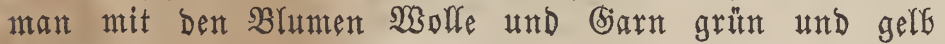
färben.

\section{Plantago. L.}

Arnoglossum. Endl.

Psyllium. Neck.

Syfteme: Darinyphyta. Neck.

Holeraceae. Whlbrg.

Jasmina. Adans.

Oligantherae tetandrae. Roy.

Plantagines. Rül. Juss.

Primulaceae. Rchbch.

Tetrandria, Monogynia. L.
Coronopus. Endl.

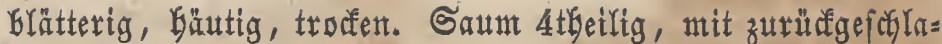

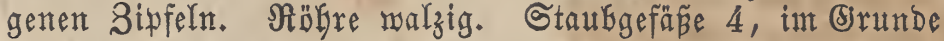
Der Blumenröbre eingefügt, länger als̈ Die Bllumenfrone. Staubfäben fabenförmig. Staubbeutel länglidy, aufliegend.

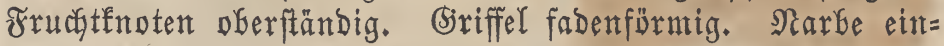
faç. Sapfel runbum auffpringend, eirund, $-2-4$ fächerig. Samen einzeln voer melyere in einem Fache.

\section{Plantago lanceolata, L.}

$\beta$. Plantago hungarica. Willd. Plantago decumbens. Rchbch.

Plantago humifusa. Bernh.

y. Plantago lanata. Host.

Plantago lanuginosa. Bast.

$\delta$. Plantago nigricans. Link.

$\varepsilon$. Plantago lanceolata sylvatica. Pers.

Spibuegerich, fabmaler S3egetritt, Ianzettblätteriger

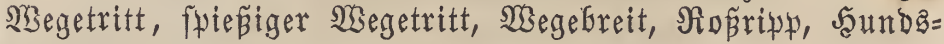

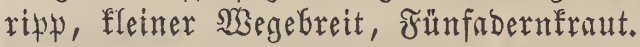

Ribwort Plantain. (entgl.)

\section{Arten = Sharater.}

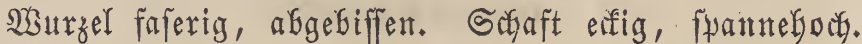
Blätter 6 Soll lang, furzftielig, lanzettförmig, fpibig, etwaz zafinig, mit $3-5$, auch 7 glatten ober auch raulyen Ritp=

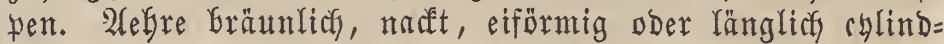
rifa, gebrängt, 1 Solf lang. Deḉflättchen eiförmig, Iang=

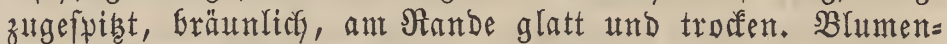
fitele erfig. Selch 2lappig, bie Rappen oft mit einamber

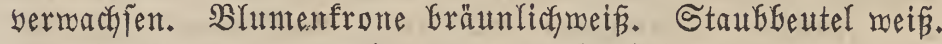
Stauffäben etwa $3 \mathfrak{m a l}$, und der Briffel $2 \mathrm{mal}$ länger als bie Blumentrone. Fruchtfapfel länglich - obal, offnet fith unter igrer Mitte und enţält 2 Samen.

Man unterfacheibet megrere $\mathfrak{B a r i e t a ̈ t e n : ~}$

\section{$\beta$. sphaerostachya.}

Dieje Spielart ift fleiner, mit einer fugeligen 2 efere und fofmalen 3rippigen Blättern.

\section{$\gamma$, sylvatica.}

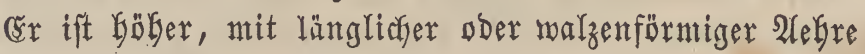
und längern aufreçten $\mathfrak{B l a ̈ t t e r n . ~}$

\section{ס. polystachya.}

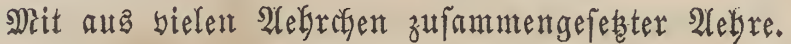

\section{ع. la nuginos a.}

Sn Beftalt Der erfteren Sarietät gleidf, aber mit son weichen, yon einander afftebenden Saaren bebecten Brättern.

Blüthe = Beit und Dauer.

2lpril - Dftober. 4.

\section{Bortommen.}

Şăufig auf Wiefen, Wreiben, an $\mathfrak{B} e g=$ und $\mathfrak{W a l b}=$ rämbern, unbefauten Drten zc. yon Earopa, 2ffen und 2(merifán.

\section{Eigenfihaften, Nutuen, 2tuswendung.}

Der Spismegerid ift ein fefr gutę $\mathfrak{B i e f f u t t e r}$ und

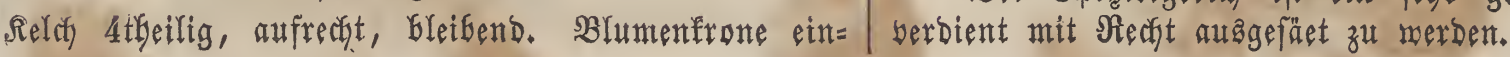


17.
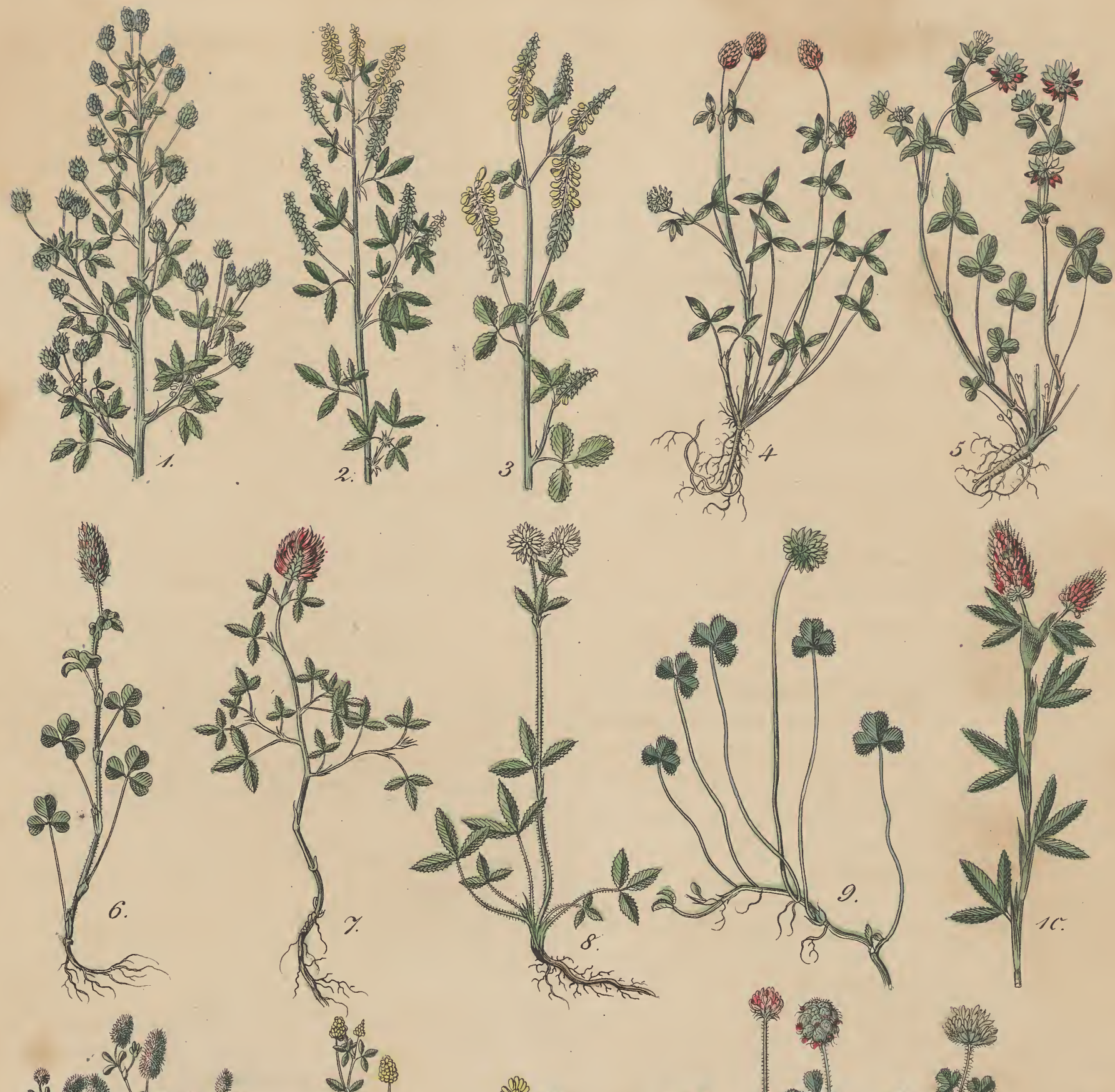

invel

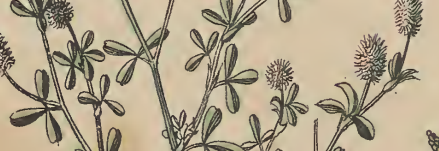

* - 1525
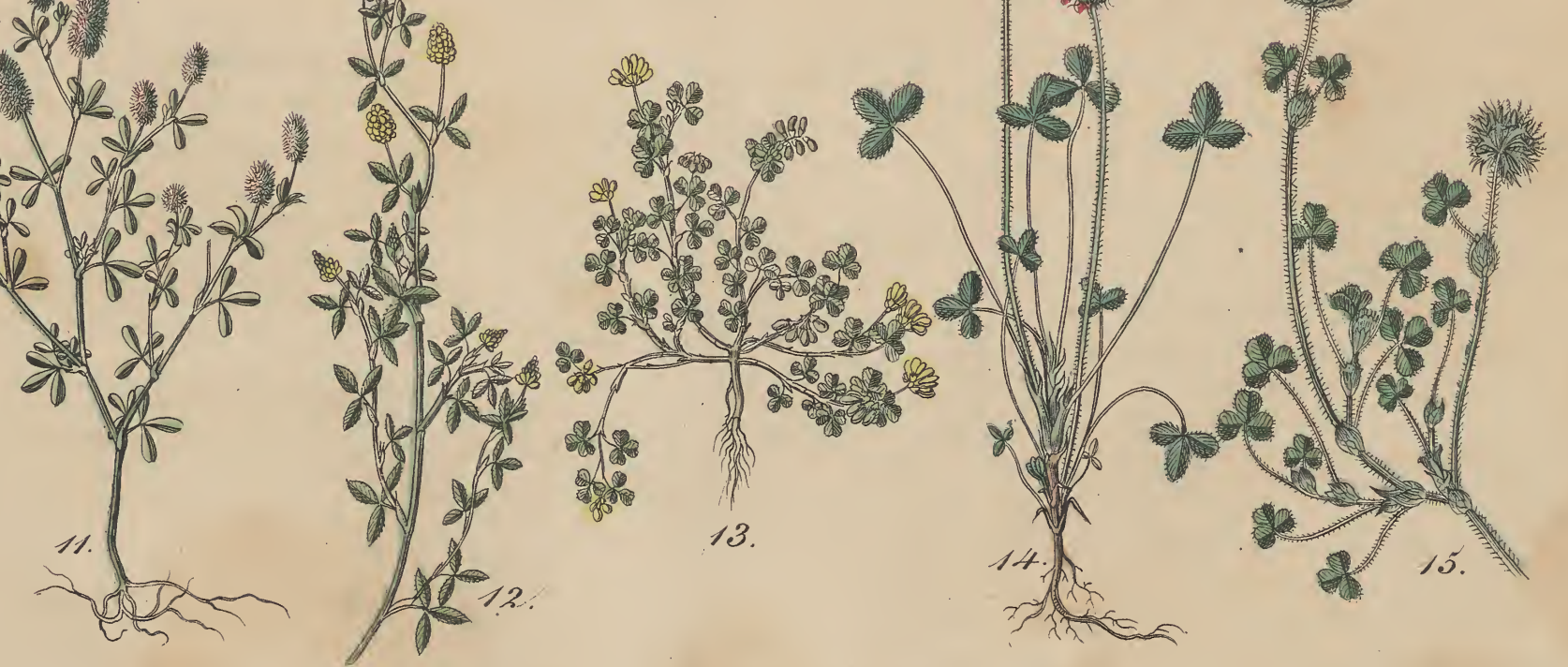



\section{Plantago major. L.}

Plantago bracteata. Moench.

Plantago intermedia. Gilib.

Plantago limosa. Kit.

Plantago minima. DeC.

Plantago nana. Tratt.

Plantago subsinuata. Hornm.

Plantago Tabernaemontani. Baumg.

Plantago uliginosa. Schnidt.

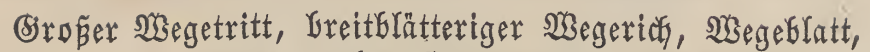
Wegebreit, Rartentiatt, rotber $\mathfrak{W e g e r i c h}$, Bergeblatt, Baflen= fraut, Schafzunge.

Creat Plantain. (engl.)

\section{Arten = (5harakter.}

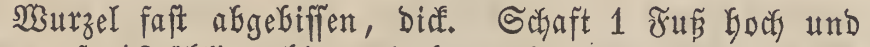
böber, oft 12 zällig, Gin und ber gefogen, rund. Blätter 48 oll lang und 2 3oll breit, geftielt, etwas aufrect, bei= wabe glatt, eiförmig, 5-9rippig. Aefre linienförmig - ch)=

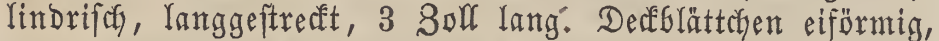

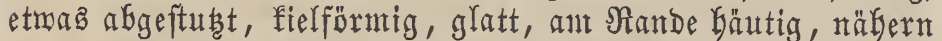

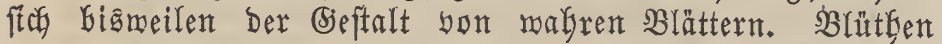
grünlich, ziegeldactförnig liegend. Staubfäben zweimal fo lang alş bie $\mathfrak{B}$ lüthe. Staubbeutel braun ober bläuliçrotly. Fruchtfapfel ftumpf, mit 8 Samen.

2Uach biefer Begerich Gat melgrere Barietäten:

\section{$\beta$. leptostachya.}

(Es find alfe $\mathfrak{B l u ̈ t}$ then in einer langen formalen 2 felyte entfernt und wechfelftändig geftelft.

\section{$\gamma$. brachyst a chya.}

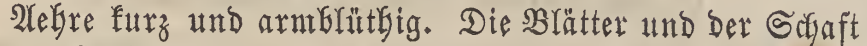
ftelyen aufredft.

mit fleinen $\mathfrak{A}$ ebren.

$$
\text { ס. microstachya. }
$$

\section{E. phyllostachya.} Aefre.

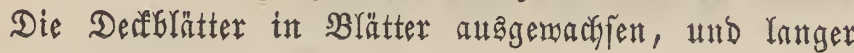

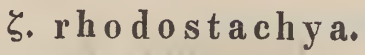

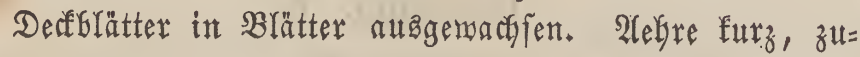
fammengezogent.

$\eta$. polys tach ya.

Die 2(ehre in mebrere getheilt.

Blüthe = 3eit und Dauer.

รult - Dftober. 4.

\section{Borkommen.}

Zuf Wheiben, an WBegen und Waldrändern, aแf wal=

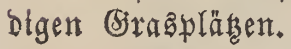

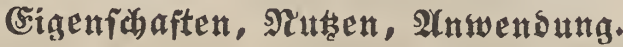

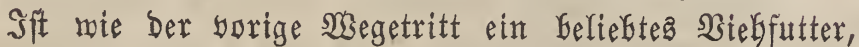
auch wird ber fohleimige Samen felgr gerne bon $20 \ddot{g e l n} g e=$ freffen und bient als şinterfutter für biefelben, Gefonders für Sanarienyögel; auch yon Den Bienen merden bie Blü= then zablreich befucht und in manchen Begenden, wie aud won ber vorbergekenden und folgenden 2 trt, bie jungen Blätter als Gemüfe, wote Spinat, gefodut und gegen eiternde (B)efduatre frifo aufgelegt.

\section{Plantago media. L.}

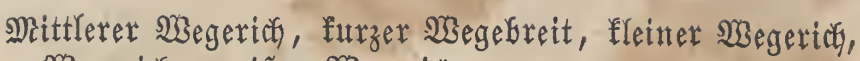
rauber Wegerian, weíner Wegerid.

Hoary Planlain. (entgr.)

\section{Arten = Sharater.}

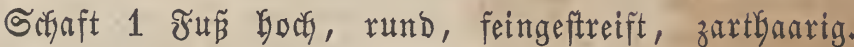
Blätter 3 3oll lang und 2 3ull breit, elfiptifd, futrzefttelt, etwas gezäbnt, auf beiben Seiten borftig, 7-9rippig, aus= gebreitet. 2lebre $1 \frac{1}{2}$ 3oll lang, länglich - ralzenförmig, etrons biffer und fürzer als bei Der borigen $2 \mathfrak{T}$ t. Deff́lătter eiförmig, etwas afogeftumpft, glatt, am アande membranartig.

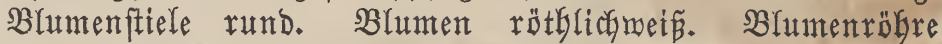

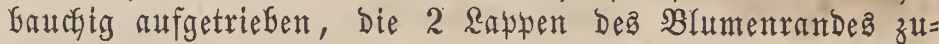
rürfégogen. Staubfäben 4 mal länger als bie Blumenröbre. Staubbeutel bivlett. Frudtetfapjel 2-4jamig. Die Samen fenb an ibrem Nabel concay.

\section{Blüthe $=$ Beit uns $\mathfrak{D a u e r}$.}

Mai - গuni. 4 .

\section{SorÉontent.}

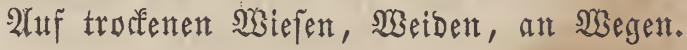

\section{(sigenfaften, Nutaen, Anwendung.}

Die Blumen Gaben einen angenebmen, bantllenartigen

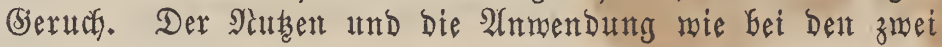
-ben beforiebenen Arten.

\section{Trichera. Schrad.}

Lychnoides. DeC.

Knautia. DeC.

Tricheroides. DeC.

Syftente: Aggregatae- L.

Caprifoliaceae, Dipsaceae. Rchbch.

Dipsaceae. Juss.

Psydomorphyta. Neck.

Scabiosa. DeC. Adans. Rül.

Tetrandria, Monogynia. L.

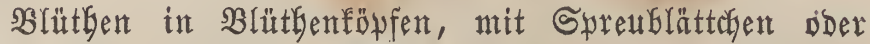
Borften auf Dem Bhlütheboden untermifdst und einer 6- viel= blätterigen, fternförmig auḡgebreiteten ober aufreçten $\mathfrak{B l u}=$ menderfe. Nebenfelç furzgeftielt, ganzblätterig, zufammen= gebrürât, ungefureft, in 4 ober mekrere 3ähte endigend. Relch gantblütterig. Saum oberftändig, in 8-22 pfriemt=

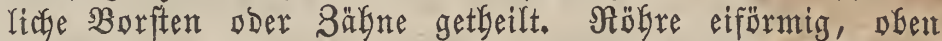
berbünnert. Bluntenfrone ganzblätterig, 4-5 fwaltig, röb)= rig - trichterförmig. Nöhre oben erweitert. Die Sipfel Des

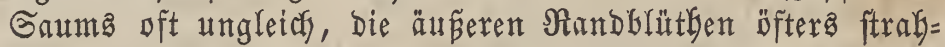
rent. Staubgefäbe 4, in Der Mitte Der Blumenröhre ein= gefügt. Staubfäben fabenförmig. Staubbeutel eiförmig-läng= lich, 2fächerig, einmärtz gefelgrt. Stempel 1. Fruchtfnoten unterftändig, 1 făcherig. Esriffel 1, fabenfürmig. Narbe etwas triçterförmig, mebr voer meniger 3-2lappig. Frucht you bem 4 feitig - zufammengedrürften, ungefurchten Nebenfeldye bicht umfalloffen, 1 fäduerig, 1 fantig und yon bem $8-22=$ zahnigen Seldafaune gefrönt. Santen ungefelart, eimeip $=$ baltig. 


\section{Trichera arvensis. Schrad.}

Trichera hirsuta. Schulth.

Knautia arvensis. Coult.

Scabiosa agrestis. Schmidt.

Scabiosa arvensis. L.

Scabiosa bohemica. Schmidt.

Scabiosa canescens. Hort. taur.

Scabiosa collina. Schmidt. Reg.

Scabiosa dubia. Moench.

Scabiosa hirsuta. Lapeyr.

Scabiosa hybrida. Bouch.

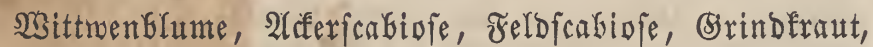
Schnörfraut, Nonnenflepuel, (S)lieberlänge.

Field Scabious. (entgr.)

\section{Arten $=$ (5harakter.}

Wurzel ftarf, lang, meiñlidy. Stengel $1-3$ Fü goch, gabelförmig, furz= und fteifbehaart. Wurzelblätter tbeils ungetbeilt, theils eingefanitten ober geffedert - getheilt. Sten= gelblätter gefiebert - getbeilt, bie untern geftielt, bie oberu bagegen anfthend, mit länglidyen, fpiben, ungetbeilten oder etroas gefägten, berablaufenden, bebarten sinfidnitten yer= feben. Blumenföpfe flacy. Blumen 4fpaltig, ftrablenförmig,

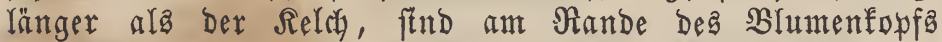

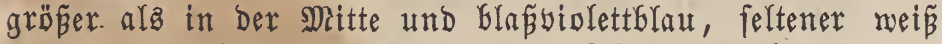
ober fleifafarbig. Sarbe 2lippig. Samen Ianglaarig.

(5.) gibt eine Spielart

$\beta$. Hei welcher fänuntlicfe Blätter ungetbeilt ftnd.

Blütfie = Beit und Dauer.

Mai - Dftober. 4.

\section{BorEontmen.}

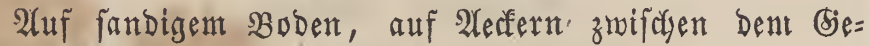
treibe, troffenen Wiejen, ફügeln, an Wegen.

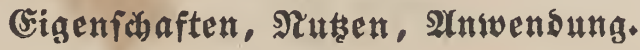

Fruttertraut.

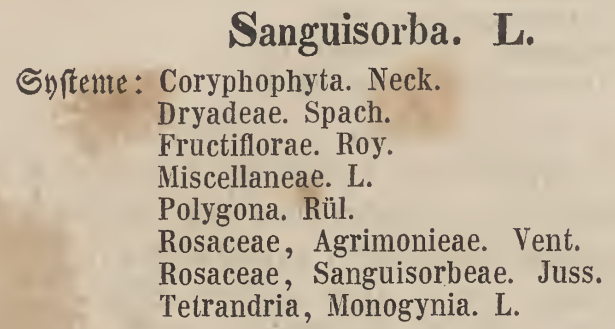

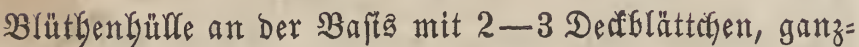
Glätterig, 4fpaltig, Gleibend. Sobre 4fintig. Sipfel eirund, ftuntpf. Staubgefäpe dem Sdylunde eingejebt, 4, 6- 15 . Staubfäben fäblich, nach oben breiter. Staubbeutel runblich, 2fächerig. Stempel 1. Frudytfnoten frei, elliptifd, zujan= mengebrünt, 1 fäcterig. Giriffel endftänoig, fabenförmig. Rarbe beinabe fopfig, etwas 2lappig, Gaarig. Rapfel woin ber şüthenbülröbre eingefdloffen, 1 famig. Samen umge= fegrt, eimeí̋loz, am untern Ĕnoe abgejtubt.

Sanguisorba officinalis. L.

Pimpinella officinalis. Gaert.

$\beta$. Sanguisorba altissima. Mill.
Sanguisorba auriculata. All. Ścop.

Sanguisorba cordifolia. Opiz.

Sanguisorba präcox. Bess.

$\gamma$. Sanguisorba sabauda. Mill.

$\delta$. Sanguisorba hispanica. Mill.

$\varepsilon$. ? Sanguisorba neglecta. G. Don.

Bemeiner WBiefenfopf, officineller M̧iejenfnopf, gemöhn=

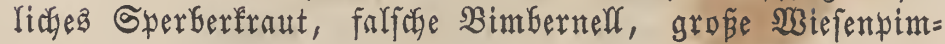

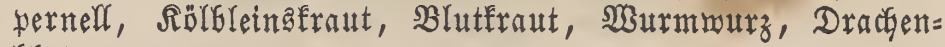
Glut.

\section{Sanguisorbe, Pimpinelle commune. (franz.)}

Burnet, Great Burnet. (engl.)

\section{Arten = Çarater.}

Warzel fingersbiaf, auken Dunfelbraun, innen gelblich. Stengel gegen $2-3 \widetilde{F u}$ boch, fabl, geftreift, oben aftig. Blätter glatt und geftebert; $\mathfrak{B u r z e l b l a ̈ t t e r ~ g e f t i e l t , ~ b e i n a l y e ~}$ fwannelang, mit 11-15 Blättchen; bie obern Stengelblätter etwas fleiner ala bie übrigen; Blăttraen Gerzfürmig, eifür=

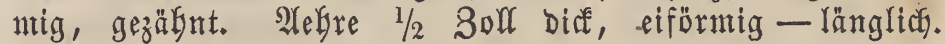
Blütfen Dunfelfraunrotg. Decfblătter eirund, fpibig, etnaz

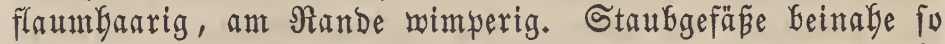

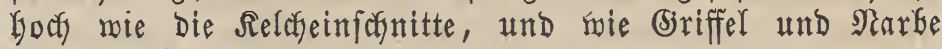
putpurroth. Staubeutel formarz.

\section{Blüthe $=3$ eit und Dauer.}

$\mathfrak{s u n i}-\mathfrak{2} \mathfrak{u g u f t} .4$.

\section{3ortommen.}

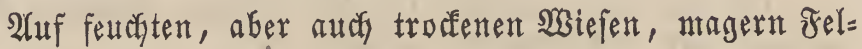
Dern, SYGeiden, an Bäctjen 26 .

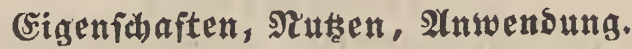

Das Dieh, befonbera aber bie Schafe freffen bieję an fich barte Bieffutter fefr gerne, aud fönnen bie jungen zarten Blätter als Salat gentoffen werben.

Die Wourzel fahmerft zujammenziełend, und man ge=

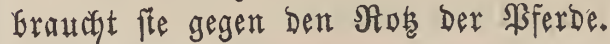

\section{Poterium. L.}

Leipoterium. DeC.

Pimpinella. Adans.

Rutidopoterium. DeC.

Syfteme: Dryadeae. Spach.

Fructiflorae. Roy.

Miscellaneae. L.

Menoecia, Polyandria. L.

Polygona. Rül.

Rosaceae, Agrimonieae. Vent.

Rosaceae, Sanguisorbeae. Juss.

Sanguisorbeae. Loisl.

Sarcodiphyta. Neck.

Blüthen vielehig, männlidae, weifficte und Switterblu= men. Blütbenfüfle an ber Bafts mit $2-3$ Deifblättchen, ganzblätterig, 4fpaltig, Gleifend. Näbre 4ertig, mit bereng= tem Soglunde. Sipfel eirund. Staubgejäpe 20-30, dent Schlunde eingefügt. Staubfäden fabenfürmig, Gerabjängend. Staubbeutel runblict, 2 fächerig. Stempel 2-3. Fruchtfno= ten innerbalb ber Blüthenbülfrögre, Yănglichrund, 1 fächerig. siriffel endfändis, fabenförmig. Narben fprengmedelig. 
Seflieñfrud $2-3$, in Der Geerenartigen Blüthenröbre ein= gefoloffen, 1jamig. Santen ungefehrt, eimeí̄loz.

Poterium Sanguisorba. L.

Pimpinella minor. Lam.

Pimpinella sanguisorba. Gaert.

Sanguisorba minor. Scop.

ß. Poterium glaucescens. Rchbch.

Poterium guestphalicum. Boengh.

Poterium polygamum. Lejeun.

Bieneine Becherblume, fleine Bibernelf, welfche Biber=

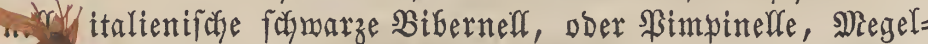
fral. Sagelfraut, Benußnabel, 2rfterblutfraut, raubez Blut= fraut, Shangelfraut, Sperberfraut.

Pimpinelle d'Italie. (franz.)

Burret, Stone parsley. (engl.)

\section{Arten = (5)arater.}

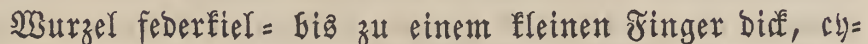
linbrifa, fpindelförmig - vielföpfig, aupen braun, etrąs gelb ober röthlich, pervendifulär gerunzelt, innen etwas hol=

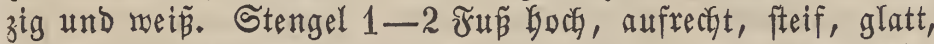
Dber meidyanarig, etwas ectig. Stengelblätter ungleich gefte= Dert, anithend, afwedy felnd ftelyend, an Stengel oben etwas länglich. Nơrzelblätter um 4 3oll länger, langgeftielt, runbliç, oft beinake nierenförmig, weitläuftg gejägt, meift zottig befaart, unpaarig geftedert, und aus 7-13 Blättchen beftehend. Fiederblättcten eiförmig - zirfelrumb und gezähnt.

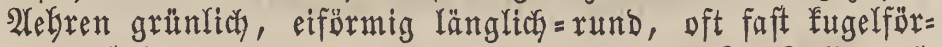
mig, ftefen bicgt und eingeln und fitt $1 / 2-3 / 4$ Soll grofs. Die Blüthen ftelen am Ernde Der Stengel und Bweige, ftnd purpurfarben und aus ben obern weibliçen Brlütben ragen bie feberigen doer pinfelförmigen, rothen Narben Gerbor. (Sriffel fabenfürnig. Staubfäben felgr lang, mit gelben Staub= beuteln. Die grünliche శrudotfapfel ift höberig, 4feitig und geflügelt.

\section{8lüthe = Beit und Dauex.}

Mai - suli. 4 .

\section{2rortommen.}

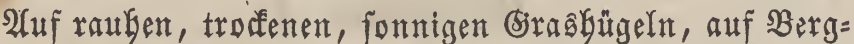
wiejen, W̧eiben, an Wregen und Rainen; wirb audi alz Sierpflanze in હäarten gefaut.

\section{Bigenichaften, গtuten, A(nwendung.}

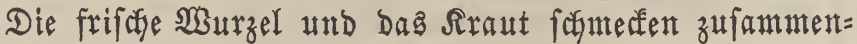
ziebend, gemürzbaft und riechen angenebm aromatifo.

Bormaltende Beftandtheile find: Bitterer Extraftinftoff, eifenbläuender Berbeftoff, ätherifches Del und Săleim.

Die gemeine Becherblume ift ein guteg, bie Mild ser=

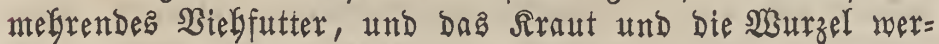
den ala Galat ober in Guppen gentffen.

\section{Polygonum. L. Spr.}

Siebe Seite 85.

\section{Polygonum Bistorta. L.}

Polygonum bistortoides. Pursh. Polygonum ellipticum. Willd.
Siemeiner Rnöterig, Dtterwurz, Nattermurz, Sajlangen= wurz, Natterfnöterig, MSiejenfnöterig, Schlippenwurz, Nrebaz= murz, હ゙änfeampher, Drachenmurz.

Bistorte à épi feul. (fronz.)

Great bistort. (engl.)

\section{Arten $=$ (5harater.}

Nourzel faflangenförmig gemunden, lang, fungersobif́, Golzig, ausen fónarzbraut, innen rötblidy. Stengel $1-4$

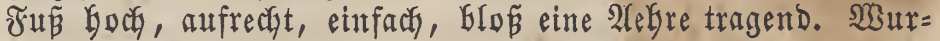
zelflätter 6 Soll lang und 3 3oll breit, in ben sBlattftiel Gerablaufend, eiförmig. Stengelblätter ei= und wellenförmig, bie obern ben Stengel herzfürmig umfaffend. 2lebre 3 , 0 M lang, aufredt, bicht, walgenförmig. Blütfen rofenroth. (siriffel 3 fnotig.

\section{Slüthe $=$ 3eit $\mathfrak{u n d}$ Dauet.}

Mai - $\mathfrak{s}$ lit. 4.

\section{YZorÉommen.}

2łuf Bergmiejen, Bergueiben, an fumpfigen Drten Deutfalanda, Baierna, Deftreidys, Shynabemb, Salzburga, Schleftens, Der Schmeiz und Franfreidy.

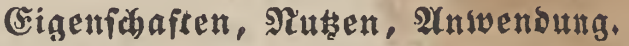

Die Şurzel bat eiten febr zuammenziefenden ferben

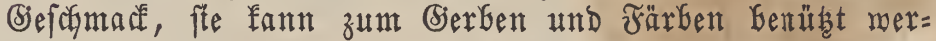
Den, auch gefraudft man fie gegen bie Nufyr und in Bäbern:

Die wohlriechenden Blütfen werben fegr bon ben Bie= nen Geintgefucht.

\section{Polygonum Convolvulus. L.}

Polygonum convolvulaceum. Lam. Bilderdykia convolvulus. Dumort.

Fagopyrum carinatum. Moench.

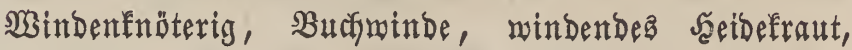
Scymarzminide.

\section{Black Polygonum. (engl.)}

\section{Axten = (S)arafter.}

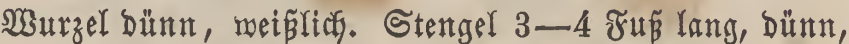
eaftig, windend. Blätter geftielt, berz-yfeilförmig, lang

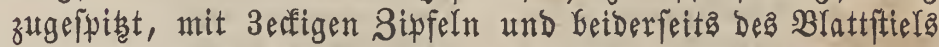
mit einer abgerundeten Bucht; bie obern framäler. Blüthen 3-6 in ben Blattminfeln, überbängend, gloftig, 3fantig, grün, meís eingefápt, inten grün. Griffel 3effig. Staub= beutel biolett.

\section{Brütbe = Beit und $\mathfrak{D a u e x}$.}

รuni - 2uguft. $\odot$.

\section{YorÉmmen.} Şedfen.

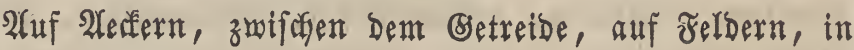

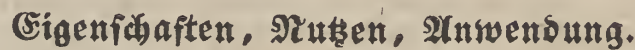

Die Butfwinde ift ein gutes Schaffutter. 2Yuf 2 (ectern mirft fte fonablidy auf bas Getreibe ein, indent fte fich an Demielsen Ginaufranft und eas niederdrücft. Die Samen fön= nen in theuern Beiten wie Srühe Genübt werben. 


\section{Polygonum aviculare. L.}

Polygonum centinodum. Lam.

Polygonum humifusum. Sievers.

$\beta$. Polygonum erectum. L.

Polygonum monspeliense. Pers.?

$\gamma$. Polygonum neglectum. Bess.

Polygonum oxyspermum. Ledeb. Bung.

$\delta$. Polygonum aviculare polycnemum. Rchbch.

Polygonum virgatum. Loisl.?

Bogelfnöterig, Wegetritt, Taufendenoten, Bhlutfraut,

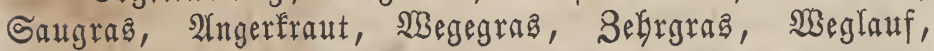
Blutgarbe, rentegrop.

Common Knot-grass. (engl.)

\section{Strten = charakter.}

ŞMrzel lang, bünn, fpindelig, äftig, faperig. Stengel 1 Juß lang, frautartig, äftig, nieberliegend, fabenfürmig, zartgeftreift, fabl. Blätter 130 ll lang, furzgeftielt, ellip= tifá-lanzetffürmig, am Nande rauh. Die Tuten 6rippig,

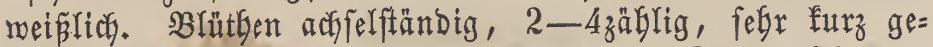
flielt, reis poer röthlich. Siriffel 3ecfig. Samen feinrun= zelig, 3fantig.

Baritirt :

\section{$\beta$. littoralis.}

Diefe Gpielart fommt an ben Mfern Des Galtifyen Meeres yor. Die Blätter find eifürmig, dié, faftig. Der Stengel roentger åftig.

Slüthe $=$ 3eit und Dauex.

Suni - Geptember. $\odot$.

\section{3oxfommen.}

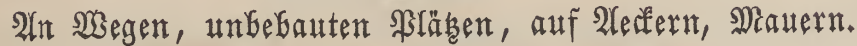

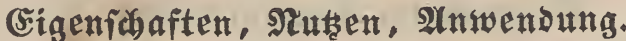

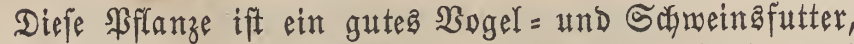
bagegen merben bie Safafe bayon verftopft und faul, aud

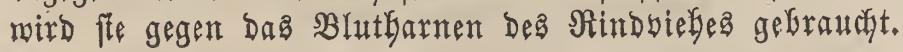

\section{Salvia. L.}

Aethiopis. Benth.

Gymnosphace. Benth.

Hemisphace. Benth.

Heterosphace. Benth.

Horminum. Benth.
Hymenosphace. Benth.

Notiosphace. Benth.

Plethiosphace. Benth.

Pycnosphace. Benth.
Microsphace. Benth.

Syfteme: Corytophyta. Neck.

Diandria, Monogynia. L.

Labiatae. Adans. Juss.

Labiatae Monardeae. Benth.

Ringentes gymnospermae. Roy.

Verticillatae. L.

Relch 1 blätterig, etwas glocfenförmig, geftreift, 2lippig, $5=$, felten 3zäGnig, Gleibend, mit nacter Maünoung. SBCh= menfrone 1 blätterig, unregefmǟ̈ig, nachenförmig, 2lippig.

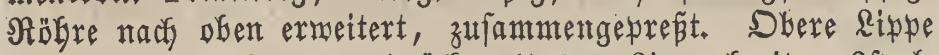
Gelmförmig, zufammengebrünte. Untere Rippe Greiter, 3fpal= tig. Staubgefäape 4, find Der Duere nach yaarmeife an ein Stielefen gebeftet. Das obere Saar fruchtbar, mit einem Iangen, aufliegenden Staubbeutel; das untere unfruchtbar und ofne Staubleutel. Griffel fadenfümig, fang. Narbe gefpalten, ungleicis. Samen 4 , naát.

\section{Salvia pratensis. $\mathbf{L}$.}

\section{Salvia rubicunda. Wender.}

Horminum pratense. Riv.

Sclaraea pratensis. Mill.

$\beta$. Salvia agrestis. L.

$\gamma$. Salvia rostrata. Schmidt.

Salvia dumetorum. Andrz.

Wiefenilarbey, milde Galbey, Marbjalbey, türfifade Sal= Gey, wilde Sajarleh, Scharlegfraut, Scharlachlaut, mildę Marafatellerfraut.

Meadow-sage, Meadow-clary. (engr.)

\section{Arten = SGarater.}

23urzel aftig, yolzig, braun. Stengel 1-2 Fun boch, aufrecht, 4 erfig, befaart, oben flebrig. Blätter längliah - berz= förmig, eingeichnitten, Doppelt geferbt, runzelig und unten meichbeganart. " 2 burzelblätter $4-5$ 3oll lang, langgeftielt. Stengelblätter furzgeftelt, Die obern ftellos.. B̉lumen quirl= fürmig, in 6-10 3oll langen 2lehren, am Ende bea Sten= gelś und ber Alefte. Deff́lüttchen fleiner als Der Relch, je= Doch Gäuftg gleich groṕ in Den untern Duirlen, berz-eifürmig, lang zugefuibt, concay. Blumenfrone groṕ, fäb̆ blau, fel= tener weís uber Glaproth. Der Corolfentelm ftchelförntig, flefrig; bie untere Rippe länger ala bie obere. Staubgefäpe in Dem Salme eingefoflofien. Die Staubfäben freiten fta in eine farbige \$latte ałڤ. Briffel fabenförmig, ränger als Die Staubfäden.

\section{Slüthe $=3$ eit uns Dauer.}

Mai - Suli. 4.

\section{\$or Emmen.}

Aluf Wiejen, b̧ügeln, SWeiden.

\section{Bigenfabaften, গtuten, Stnwenoung.}

Die Blätter baben einen ziemlich farfen, aber unanges

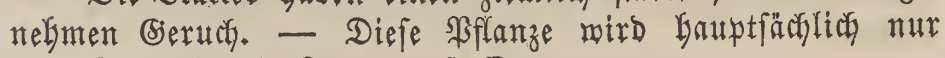
yon Sifafen und Siegen gefreffen.

\section{Heracleum, L.}

Carmelia. DeC.

Euheracleum. DeC.

Tetrataenium. DeC

Sphondylium. Adans. Scop. Hffm. Wendia. Hffm.

Syfteme: Pentandria, Digynia. L.

Scadiophyta. Neck.

Umbellatae. L.

Umbelliferac. Juss.

Umbelliferae, Peucedaneae. DeC.

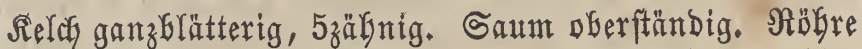
behaart ober nafft. Blumenfrone 5blätterig, abfallend. Blu= menblätter werfebrt-eirund, auŝgerandet, mit einem einge= fadlagenen Sipfel, bie äunern oft ftrahlend, 2fpaltig. Staub= gefüßе 5, mit Den $\mathfrak{B l u m e n b l a ̈ t t e r n ~ e i n g e f u ̈ g t . ~ S t a u b f a ̈ b e n ~}$ fabenförmig. Staubbeutel runblich, 2füdjerig, einmärta ge= felyrt. Stempel 1. Frudbtfnoten unterftänbig, 2fächerig, mit einem gemölbten Briffelpolfter gefrönt. Siriffel 2, faben= förmig. Narben ftumpf. Spaltfucht eiförmig, verfebrt-ei=

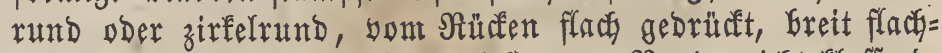
randig. Theilfruchte bicft, 5riefts, am Nande nicht Ilaffend. Samen umgefelat, eimeiphaltig. 
Heracleum Sphondylium. L.

Heracleum branca ursina. All.

Heracleum proteiforme. Crantz.

Sphondylium branca. Scop.

$\beta$. Heracleum elegans. Jacq.

\%. Heracleum laciniatum. Desf.

Unächte Bärenflaue, gemeines Seilfraut, Bartia, ge= meine Bärenflaue, Borft, wilder Paftinaf.

Brancursin, Fausse. (franz.)

Common hairy, Cow parsnip. (engl.)

\section{Arten = (Sharakter.}

Wurzel didf, fpindelförmig, ăftig, aupent gelb, innen

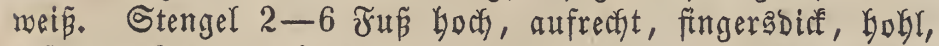
gefurcht, fnotig, oben äftig unb raubbaarig. sBlätter groß́, einfach = geftedert, 5lappig, 2paarig, rauh-langhaarig, ge= zäfnt. Wurzelblätter fefrr grob, breit, wellenförmig, lang und fodjeibenartig geftielt. Blättchen feitlich, länglich, buch= tig, Deren äuperftes 3lappig, Gandförmig und etmas fpibig ift. Dolden grof́, flact, weitfrablig, winfel= und gipfel= ftändig, mit 24 Strablen und Gorftenförmigen Şüllblättchen. SBlumen meí̄, bis̄meilen rötblify, ftrablig. Sandoblütben größ̈er. Frücbte beinabe glatt, gelb. Santen eiförmig, zu= fammengebrüct.

Dan Gat eine Barietät, nảmliç:

\section{$\beta$. lasi oc a r p u m,}

bei weldyer, fämmtliçe ßflanzentbeile, jelbft bie Jrüchte, mit furzen, fteifen Saaren bededft ftnd. Sie findet fich an ben

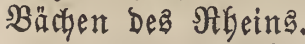

\section{Slüthe = Beit und $\mathfrak{D a u e x}$.}

Эuni - September. $\sigma^{7}$.

\section{Э2or'Emmen.}

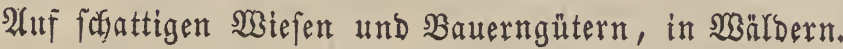

(Eigenfidaften, গtüen, Anvendung.

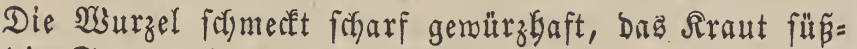
rich, bie Samen riechen unangenehm.

(̌in lăftigez Unfraut. Neben Dem, Dá̉ ber unăchte Bärenflau alo Siebfutter Dient, fönnen auch bie jungen Blätter und Stengel als Bemüfe genvfien merben; in Berften und Samtichatfa bereitet man aus Der füßen mels= ligen Subftanz, Die fach aus Den zroar gefwälten und ge= trodineten Stengeln abjondert, eine $2(r t$ Suffer und $\mathfrak{X}$ Gein,

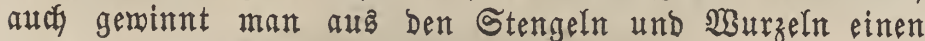
ftarfen, angenely ichmectenden Branntwein.

Die ganze Pflanze bient zu ermeidyenden Humichlägen.

\section{Spergula, L.}

Arenaria. Adans.

Buda. Adans.

Spergella. Rchbch.

Snfteme: Alsines. Adans. Rül. Spach.

Caryophylleae. L. Juss.

Catotaphyta. Neck.

Decandria, Pentagynia. L.

Diplosantherae. Roy.

Relch 5Glätterig, Gleibend. B̉umenfrone 5blätterig, Gald verfămindend. Blumenblätter eirund, ungetbeilt. Staub= Confmer, benom. ærofanzenfunde. gefäße 10, hie und da nur 5. Staubfäben mechfelmelfe an Der Bafts auf einer Drüfe ftekend. Staubbeutel aufrectst, eirund. Frudtfnoten eirund. Siriffel 5. Narben laufen an Der innern Seite Der Siriffel Gerab. Sapfel eiförmig, 1 fäeberig, 5flappig und bielfamig. Samen niebergebrǚft-fu= gelförmig, mit einem ausigeränderten Rande umgeben.

\section{Spergula arvensis, L.}

Spergula geniculata. Pers. Spergula maxima. Boenningh Spergula refracta. Dethard. Spergula sativa. Boenningh. Spergula viscosa. Dethard.

Spergula vulgaris. Boenningh. Alsine arvensis. Crantz. Arenaria arvensis. Wallr. Spergularia arvensis. Cambess. Stellaria arvensis. Scop.

Alferfparf, 2luferfpörfel, beutfouer Spergel, weiper Sper= gel, wilder Spergel, Sandipergel, Spurre, Sperf, Spur: gel, langer Rnebel, Nettetamm.

Espargoutte des champs. (franz.)

Corn spurry. (engl.)

\section{Alrten = SGaraeter.}

Sämmtliche Theile Der SPlanze find furz Gebart. Wur= zel Dünn, fpindelig ober äftig. Stengel etra $8-10$ 3oll lang, aufrecht, 4 fnotig, einfach ober äftig. Blätter quirl= und fchntal pfriemenförmig, etmaz fleifwig, ftumpf, bie lunter= feite mit einer Furche. Affterblättchen abgerundet. Blütben

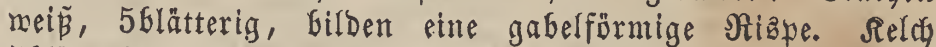
5 blätterig. אapfel fpringt in 5 Rlappen auf. Samen fchmarz, fugelrund, etras böfferig, fumal gerändert, an Nande fpis und auf Keiden Seiten Der Sedjeibe mit weiplicben, etwas geftielten Rärnchen befest.

\section{Slüthe = 3eit und Dauer.}

Mai $-\mathfrak{A} \mathfrak{u g u f t} . \odot$.

\section{3ortommen.}

2tuf fanbigen-2lecfern, ફ̧ügeln.

\section{§ultur.}

Der Spörgel wird im nöblicfen Deutfaland und in Den Nieberlanden angebaut und verlangt einen reinen, gut gelorferten, lebmigten Sandboden. Man fäet ifn Nitte Mai;

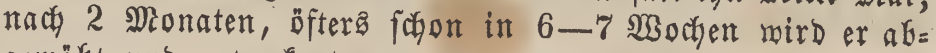
gemäht und getrodfnet.

Cigenidaften, গtuten, Anwendung.

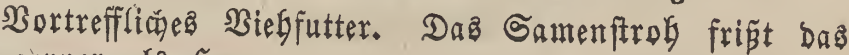
Bieh gerner aIs ફૅน.

\section{Anthyllis. L.}

Aspalathoides. DeC. Dorycnoides. DeC.

Barba jovis. Adans. Erinacea. Adans.

Cornicina. DeC. Vulneraria. Adans.

Snfteme: Cassiae Genisteae. Rchbch.

Cyteophyta. Neck.

Diadelphia, Decandria. L.

Leguminosae Genistae et Phaseoli. Adans.

Leguminosae irregulares. Roy.

Papilionaceae. L.

Papilionaceae Loteae. Spach.

Relch eifonrnig-länglich, in ber Mitte aufgeblafen, mit einer ungleiçen, furz 5zälgnigen Münoung, Gleibett. BCumen= 
frome fđmetterlingåartig. Frahne an ber Geite zurütofgebogen,

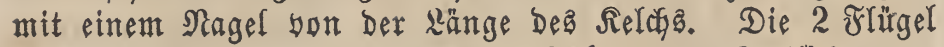

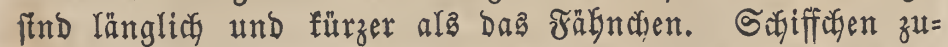
fammengedrủ̆ft, yon der Ränge und Beftalt der Flüger. Staubgefäß̨e 10, Dem Reldhgrunde eingefügt. Staubfäben erweitert. Staubbeutel eiförmig - runbliç, 2fäeferig. Stem= pel 1. Frudiftenoten länglidy, geftielt. Briffel fabenfürmig, aufiteigend. Narbe endftändig, fopfig. Saülfe im Seldche ein= gefchloffen, flein, runblid, 1-2jamig. Samen eifürmig, glatt.

\section{Anthyllis Vulneraria. L.}

Anthyllis affinis. Britting. Anthyllis alpestris. W. K. Rchb.

Anthyllis Dillenii. Schulth.

Anthyllis maritima. Schweig.

Anthyllis polyphylla. W. K.

Anthyllis rubicunda. Wender.

Anthyllis rustica. Mill.

Anthyllis Tournefortii. Schult.

Vulneraria Anthyllis. Scop.

Vulneraria heterophylla. Moench.

Vulneraria rustica. Lam.

$\beta$. Anthyllis macrocephala. Wender.

Anthyllis rusticana. Wender.

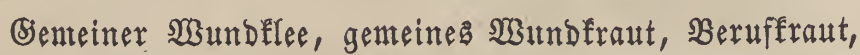
Sakzenflee, J̧endelwei gelber $\mathfrak{B u n d f l e e , ~ B r u f f f r a u t . ~}$

Vulneraire des paisans. (franz.)

Kidney-Vetch, Ladies-Finger, Common yellow Anthyllis. (entgl.)

\section{Arten = Charatex.}

Ņurzel äftig, fajerig, wielfäpftg. Stengel oft faft 1 Jü You, rund, aufiteigend, theils wein befaart, theils faft glatt. Blätter meiftens bichte Najen bildend, geftielt, läng= lich-lanzettförmig, ganzranbig, meidsbelyaart, hautptfächlich unten, ober beinabe glatt und yon Farbe graugrün. Wur= zelblätter lang geftielt, einfach und längliá, die Stengel= blätter Gingegen ungleich geftebert, 4 paarig. Die Endofieder=

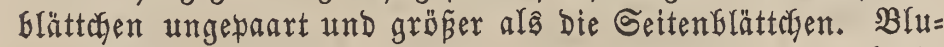
mentöpfóten anfelynlich, flach, gipfelftändig, meift zu 2 ftehend, yon gefingerten 3-7fpaltigen Nebenblättchen umgeben. Relch) weiélich, zottig und furz 5zălnig. B̧lumen gelb, an ber Spite purpurroth. Blumenfrone etwas lünger als ber Seldd. Staubfäben nur in 1 Bündel berwachjen, Greiten fted an Der Spike aıts. Şülfe flach, furz, oft faum liniengrof́,

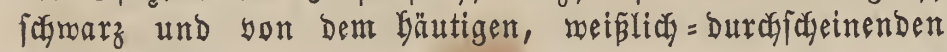
seld bebect.

\section{Blütbe $=$ 及eit und Dauter .}

Эuni - รuli. 4 .

\section{3ortommen.}

\{uf trof̌enen $\mathfrak{B}$ eiden, Bergen, fonnigen Bergmiefen, an sisen, am gernften auf Ralfboben.

(rigenid)aften, stusen, Anwenoung.

Die \$flanze fámecft fade frautartig. Daz Sraut färbt gelb und bie Blumen blau.

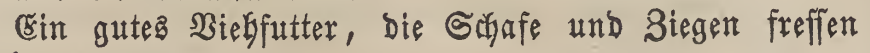
es fehr gerne.

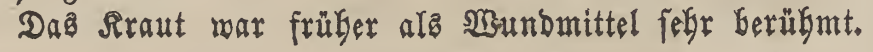

\section{Astragalus. L。}

Aragalus. Neck.

Sufteme: Cyteophyta. Neck. Diadelphia, Decandria. L.
Leguminosae Astragali. Adans.

Leguminosae irregulares. Roy.

Leguminoseae Loteae Astragaleae. DeC.

Papilionaceae. L.

Papilionaceae Astragaleae. Rchbch.

Reldy ganzblätterig, röbrig ober glorfig, 5zälynig. B̉u= menfrone fafmetterlingäpörmig. Frahne ftumpr, aufrecht, feit= lich zurürfofefogen, lünger als bie Fllügel. Die 2 Flitgel ftumpf, ganz, felten 2fpaltig ober tief ausgerandet. Safiff:= chen abgeftumpft, augigerandet. Staubgefäpe 10, Dem Sielch= grunde eingefügt. Staubfäden fabenförmig. Staubbeutel rundlish, 2fädserig. Stempel 1. Fructitfnoten geftielt ober fthend. (Sriffel pfriemenförmig, auffiteigend. Narbe endftån= big, ftumpr. Şülfe böferig, fogeint Durdy bie untere ein= märta gebogene গaght 2 făcherig, biel = ober wenigjamig. Gamen nierenförmig, zufammengebrünt, glatt.

\section{Astragalus glycyphyllos. L.}

Hamosa glyciphylla. Medic.

$\beta$. ? Astragalus rotundifolius. Presl.

Süner Tragant, fleeartiger Tragant, milbes Süpholz,

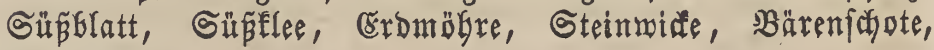
Wolfäfd ote.

Milk-Vetch, Licorice-Vetch, Milk-wort. (engr.)

\section{Arten = Efarater.}

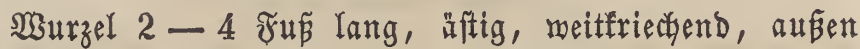

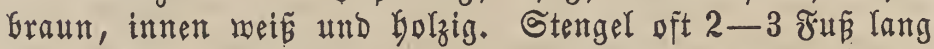
und länger, nieberliegend, gegliebert, rund, zientlich biaf und,

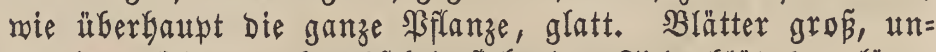
paarig = gefiebert, abrechfelnd ftehend. Fieberblättchen läng= licf-eiförmig, ftumpf, an ber Spthe ftachelig, wben bunfel=,

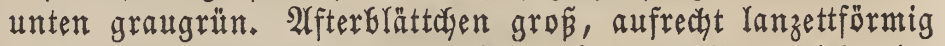
und zugefpitht. Die 3 untern Selchzăhne zlemtich gleicfartig, fo Goch als bie Bhlumenrögre, bie übrigen bagegen um baz Doppelte fleiner. Blüthen furzgeftielt, yon einem ziemlich lang und fabenförmig geftielten Deff́lättchen unterftükbt, ftelgen einzeln und in Dichten eifürmigen, ährenartigen Trauben, und ftnd bla fthend, etwas gebogen, untent gefurdat, diaf, glatt und zmei= fächerig. Samen nierenförmig, $6-7$ in jebem శache.

Man unterjafeibet alß $\mathfrak{B a r i e t a ̈ t ~ b i e ~}$

$$
\beta \text {. pubescens, }
$$

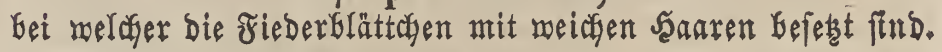

$$
\text { Blüthe }=3 \text { eit } \mathfrak{u n d} \text { Dauex. }
$$

$$
\text { Эuni - Iuli. } 4 \text {. }
$$

\section{Dorfommen.}

2łuf Aecfern, Weiben, maldigen Şügeln, in Wäldern,

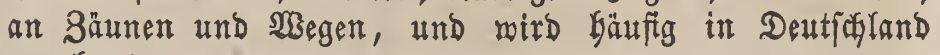
angebaut.

\section{Cigenfobaften, গtuten, Anwendung.}

Die ßffanze bat in aflen ifren Theilen einen Dem Süßs Golz ăhnelnben, fü

Ein beliebte und gutę Biegfutter.

\section{Astragalus Cicer, L.}

Astragalus vesicarius. Lam. Astragaloides Cicera. Moench. 
ß. Astragalus Pseudocicer. Opiz.

Astragalus microphyllus. Schübl. v. Mart.

Astragalus minor. DeC. fraut.

sidjerntragant, wilbe Ridger, Ridgerfraut, Mirbel=

Bladder'd Milk Vetch. (entgl.)

\section{Sarten $=$ Çarater.}

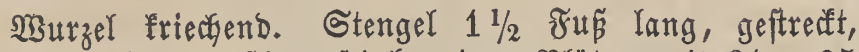
gefuraft, röbrig, äftig, feirbarig. Blätter mit $21-35$ länglich-lanzettförmigen, faft elliptifact, Garigen Fieber= blättchen. Nebenblätter an Stengel fthend und nidat ver= nadjen. Blumentraube actielfänbig, eirund. Blütben gelb. Blüthenftiele länger als Dấ Blatt. Sriffel an Der Spibe fanft auffteigend. Fruchtfnoten zottig, Geinabe fthend. Sälfen etwas fugelig-aufgetrieben, an ber Spibe ftectend, grau, bicft fanmarz = und meiphaarig, mit $2-3$ Dunfelgelben Gamen.

Man Gat eine Barietät, die

$\beta . \mathrm{min}$ or.

Der Stengel ift niebergeftredt, aber wieber auffeigend. Die Fieberblăttaen $20-30$ an ber $3 a \mathfrak{l}$ l, ftnd etwas menig bebart. Die pfriemenförmigen 2 fterblättchen fteben einzeln, einander entgegengefebt. Die 2lebren find geftielt, und län= ger als das Blatt. Die Sălfe runblich-baudig und zuttig.

Blüthe $=$ Beit uns Dauex.

Эuni - Iuli. 4 .

\section{0rentment.}

Auf Sanbboben, Wiejen, Sirab̧ügeln, in becfen, an Säunen, Weinbergen; Die Darietät in gebirgigen Wälbern, im Schmarzmalb, im shüringifdyen, bei Närnberg, in Deft= reich, Schmeiz, Stalien.

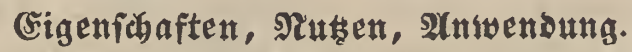

Writb als vortreffliches Futterfraut empfollen.

\section{Coronilla, L.}

Emerus. Neck. Mill. Adans.

Snfteme: Cyteophyta. Neck.

Diadelphia, Decandria. L.

Leguminosae Coronillae. Adans.

Leguminosae Hedysareae. DeC.

Leguminosae irregulares. Roy.

Papilionaceae. L.

Papilionaceae Hedysareae. Rchbch.

Reldy ganzblätterig, furz, glodenförmig, mit 5 Sä́ $=$ nen, Deren untere fleiner find, bie 2 obern aber ganz nabe betiamnten fteben. Blumenfrone foumetterlingartig; Die Blumenblätter befthen einen langen Nagel. Fabne berzför mig, überall zurüafgebogen uno faum etmas länger als bie Flügel; Yetere find ftumpf-eiförmig, und nach der Spibe bin gegen einander gebogen. Schifficn zufantntengebundt, lang zugefpitht, auffteigend und bäufig fürzer als bie Flügel. Staubgefäßre 10, Dem Relchgrunde eingefügt. Staubfäben abrochfelnd berbreitert ober gleich did, 9 ftnd in eine siogre zufammengemadgfen und ber 10 te ift frei. Staubbeutel rund $=$ liaf-eiförmig, 2fädserig. Stempel 1. Jruchtfnoten linea= rifa. Siriffel gefniet, fabenförmig, nadet. Narbe ftumpf,

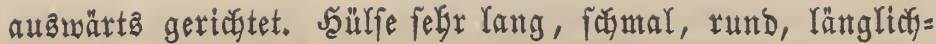
gegliebert ober zwifdyen ben einzelnen Sament berengt, viel= f̣äberig, nicht auffifeigend. Samen lintealifah ober eifürmig, beinake walzig ober zufanmengebrüreft, glatt.

\section{Coronilla varia. L.}

Astragalus glaucoides. Gmel.

Hedysarum purpureum. Tabern.

Bunte Sromwiffe, Gunte Beltiffe, gemeine Rronmiffe, Gunte Nagelmife,e, Sdjaflinje.

\section{Arten = Sharater.}

Wirurzel friectend, äftig, runzelig, auñen bellbraun,

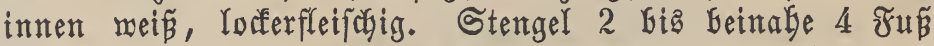
lang, niebergeftreift und mieber auffeigend, weit fich auts= Greitend, effig gefurdst, glatt oder zeritreut furz= und raub= Gaarig. Blätter $2-3$ Boll lang, abroedjelnd, geftedert, mit fegr bielen, fleinen, ganzandigen, ftechenden, glatten und verfegrt ei-fpatel = ober lanzettförmigen Fieberblättedyen. Dolden vielGlüthig. SBlumenftiele lang, ecfig gefurdst und

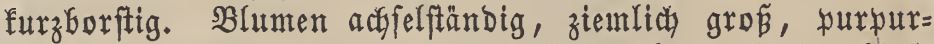

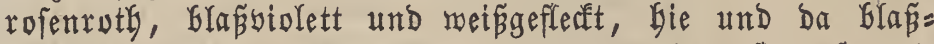
meiflich. Jaülfen gegliedert, glatt, gerabe, ftumpf und walzenföntig, mit einer langen, einmärts gefrümmten Spibe werfegen.

\section{Blïthe $=$ 及eit แno $\mathfrak{D a u e r}$.}

รunt - 2uguft. 4 .

\section{\$orEmmen.}

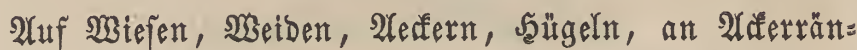

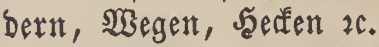

\section{Eigenfabaften, গtusen, Anwenoung.}

Das Siraut ift geruchlos und Gat einen bittern, reizen= ben und falzigen, bie 2 sturzel einen bittern und reizenden

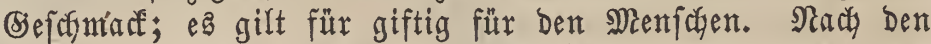

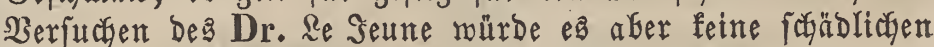

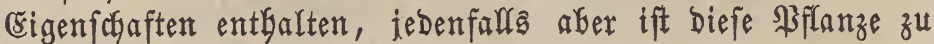
Den verbächtigen zu reănen.

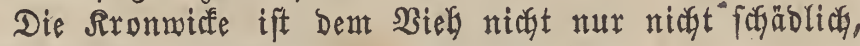
fondern wird yon demfelben gerne gefreffen.

\section{Galega. L.}

Syfteme: Cyteophyta. Neck.

Diadelphia, Decandria. L.

Leguminosae Genistae. Adans.

Leguminosae irregulares. Roy.

Leguminosae Loteae. DeC.

Papilionaceae. L.

Papilionaceae Loteae. Rchbch. Spach.

Selch ganzblätterig, glocfenförmig, unterftändig, $5 z a ̈ \mathfrak{h}=$ nig. SäGne pfriemenförmig und zientich gleich. Blumen= frome fametterlingåartig. Fafgne verfegrt-eiförmig, etmas länger alş bie F̧lügel. Die 2 Frlügel ftumpf, an ber $\mathfrak{B a f t s}$ über Dem Nagel in einen Goblen Bahn eingebrücft. Schiff= b)en ganzblätterig, ftumpf, an ber Spibe etwas aufgebugen. Staufgefấe 10, bent Reldygrumbe eingefügt. Staubfäben

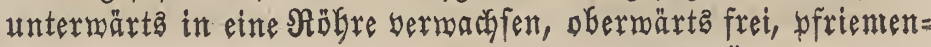


färmig. Staubbeutel eifürmig, 2fäbugrig. Stemuel 1. Zrucht= fnoten fisend, fohmal. Srriffel aufifeigend, fabenförmig, naift. Narbe endftändig, fẹr flein. Şülje länglich, aufrecht, zu=

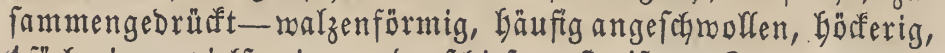
1 fächerig, bielfamig und fobief geftreift. Samen glatt, malzig.

\section{Galega officinalis. L.}

Galega vulgaris. Lam.

$\beta$. Galega africana. Mill.

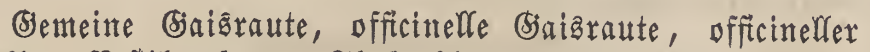

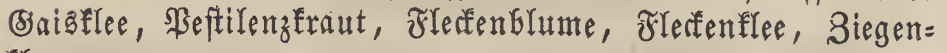
flee.

officinalis blue Galega. (engl.)

\section{Arten = CGaraeter.}

Wurzel ftarf, weín, äftig, fajerig. Stengel $3-5 \widetilde{z} u \tilde{B}$ Goch, fteif, äftig, glatt. Blätter 6-9.80ll lang, unpaarig= geftebert, glatt; Die Stengelblätter fteben abmecthjelnd, bie WurzelGlättę freiaförmig; bie Fieberblättchen $1-2$ 3oll lang und $1-3$ Rinien breit, 13-17zählig, ganzrandig, ftachelfpibig, Ianzettförmig, fohief paralfel geabert, glatt und Gochgrïn. 2lf́terblättct)en bfeil-lanzettförmig. Blumenftiele lang, fteif und glatt. Bhlumen zablreich, fabön violettblau, oft weiplich, $1 / 2$ 3oll und barüber lang, fteken achielftändig tnd aufrecht in Trauber. Seullfe $1 \frac{1}{2}-2$ Soll lang, gerabe, aufrecht, walzenförmig, Dünn, etwas Göcferig, fchief geftreift und glatt. Samen gegen 2 linien lang, länglich-nieren= fürmig, glatt und gelblich.

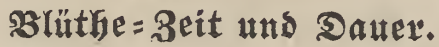

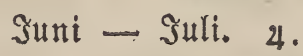

\section{\$orťommen.}

In Sübeuropa an feuchten und überfchmemmten Drten, Ůferrainen, Bäunen, in Spanien, Stalien, Der Schmeiz, Deft= reich, Sableften, Miextlenburg, Baiern zc.

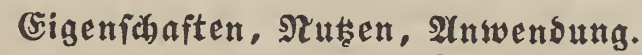

Das an fich gemürzlofe siraut riechi beim Serreiben unangenefm, fdymefft widerlich bitter und berb, und Der Speichel mirb Durch's Sauen Deffelben ftarf gelogrün ge= färctot.

Der Gaißflee ift ein febr gutes Jutterfraut unb miro Gie und ba angebaut. Man fann ign Des 3abres oft 3 mal fónneiden. - In Эtalien werben bie Blätter als Salat ge= geffen.

\section{Onobrychis. Gaert.}

Dendrobrychis. DeC.

Eubrychis. DeC.

Echinobrychis. DeC.

Hymenobrychis. DeC.

Onobruchus. Medic.

Syfteme: Cyteophyta. Neck.

Diadelphia, Decandria. L.

Leguminosae Hedysareae. DeC.

Papilionaceae. L.

Papilionaceae Hedysareae Onobrycheae. Rchbch.

Sielch ganzblätterig, 5fpaltig, mit pfriemenförmigen

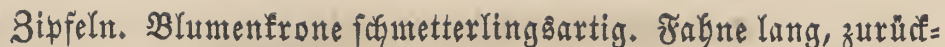

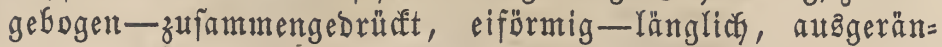
Dert. Die Flügel felgr furz. Schiffchen quer abgeftumpft, fatnabellos. Staubgefäze 10, Dem Relchgrunde eingefügt.

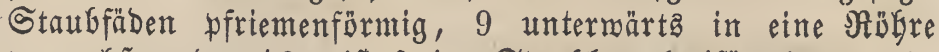
bermadffen, Der 10 te ift frei. Staubbeutel eiförmig-rund= lich, 2fächerig. Stempel 1. Zruchtfnoten eiförmig, zufam= mengebrüct. Siriffel felgr lang, pfrientlich-fadenförmig, in ber Mitte gefniet, macft. Tarbe endfändig, ftumpf, beinalye fopfig. Saullfe furz, zufammengebrufuft, an Der obern Nałt geebnet, abgeftust, fammförmig, mit Erübchen berjeben und nicht auffuringend. Santen glatt, nierenförmig, zujammen= gebrittet.

\section{Unobrychis sativa. L.}

\author{
Onobrychis spicata. Moench. \\ Onobrychis viciaefolia. Scop. \\ 0nobrychis vulgaris. Jaum. \\ Hedysarum Onobrychis. L. \\ $\beta$. Onobrychis sativa subvillosa. DeC. \\ Onobrychis sativa tatarica. Fisch. \\ 0nobrychis tanaitica. Fisch.
}

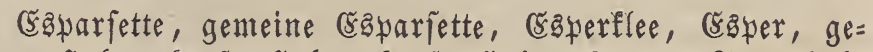

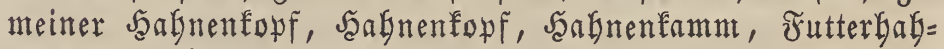

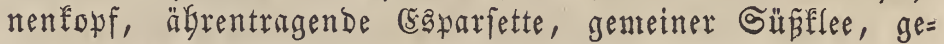
meine Jutttęrquefte, Jaeiligheu, Stachelähre, Schett, Jaafenfopf, türfifther Silee, Schildflee.

Bourgogne, Esparcette. (ㅍำtz.)

Cock's head, Medick-vetching, Saintfoin, Esparcet. (entgl.)

\section{Arten = (5)arater.}

Wurzel lang, äftig, welche oft über eine E̋lle tief in Den $\mathfrak{B}$ oben fith einfchlägt. Stengel $2-3 \widetilde{\gamma} u \tilde{B}$ boch, auf= fteigend aufred,t, äftig, geftreift, glatt. Blätter abmedyjelnd ftelend, unpaarig - geftebert, feilfürmig, glatt. Fieberflätt= d)en 9-13, graugrün, ganzrandig, ftechent, länglich-linient= förmig, unten etwas weicfbefanart. Blumentitele febr lang ınd glatt. 2lebren grof́, lang, walzenförmig-eifürmig. Selcf) 10 partig. Blüthen rofenroth und purpurfarbig ge= adert. Flïgel Der Blumenfrone felgr furz, bie Fabne zurüt= gefogen-zufammengebrürt, aug̈gerandet, Gcjiffchen fürzer

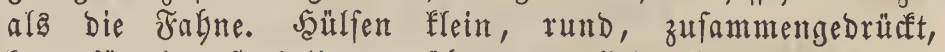
fanmförmig - ftachelig-gezägnt, runzfich, glatt und 1 famig. Samen glatt, nierenfürmig, grau, mit einem fobnärzlichen Nabel berfeben.

\section{Mai - 2uguft. 2 . \\ Blütfe = Beit und Dauer.}

\section{BorEmmen.}

2uf Dürrem, unfructbarem, føwer zu befteffendem,

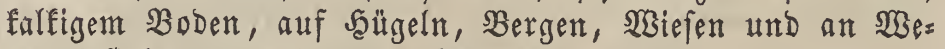
gen faft in ganz Ěuropa, Sibirien.

\section{Nultur.}

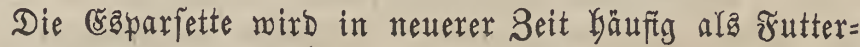
fraut angebaut; fee gebeifgt auf unfrudbtbarem, fteinigtem und bürrem Boben, am meiften aber auf fandigem Ralf= Goben mit Mergełuntergrund, auf lesterem Boden fann fee 10-15 Safre lang bleiben; naffen voer zu lefmigten Boben

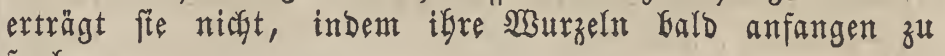
faulen. 







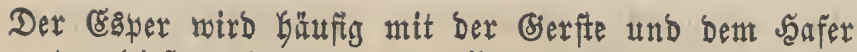

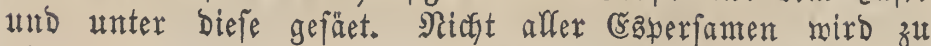

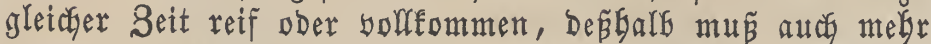
auf einen $2 \mathfrak{l} \mathfrak{d f e r}^{2}$ gefäet werben, als fonjt nöthig wäre. Der zut fäende Samen Darf nidft fodwarz und eingejdyrumpft, fondern foll wolffommen, glänzend und won gelbröthlicher

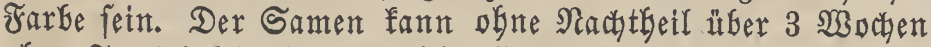
ofne Feudftigfeit in ber (Erbe liegen, nach ber Saat aber feimt er nach einem Siegen in 12-14 Iagen. Man fäet Den Samen meiftenz nit ber ફ̧ülfe und recfnet auf ben Mergen in $\mathfrak{B a b e n} 12-18$ Sefter, in $\mathfrak{g e f f e n ~} 1-1 \frac{1}{4}$ Mal= ter und in $\mathfrak{S u ̈ r t t e m b e r g ~} 3 / 4-1 \frac{1}{2}$ Scheffel zur 2 Lâfaat. (befäet fann im zrübjabre, Somnter und im Seerbfte mer= Den; ift Der zrübling gelinde, fo fäet mant frühe, am beften

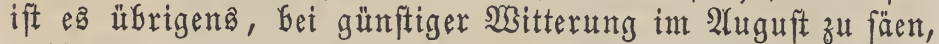

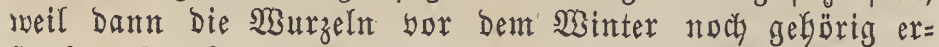
ftarfen. Der ๔anten Darf in mittlerem FelDe nur etwa $1 / 2$ Soll tief, in einem Yeichtern etrag tiefer in Den Boben fommen.

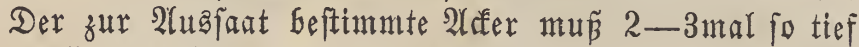
als möglich gepflügt unt aufgelocfert werben, bamit bie NWurzeln Der jungen SFfanzen bard tief gemug einfaglagen fönnert.

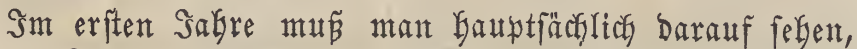

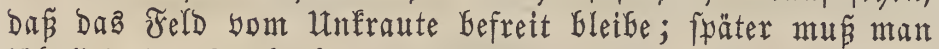

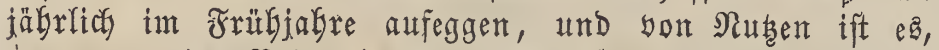

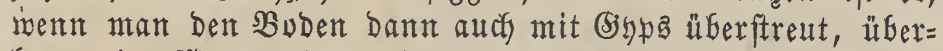
Gaupt im Sisinter Demfelben etwas furzen Dung gibt. Jn

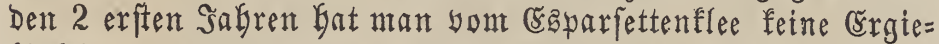

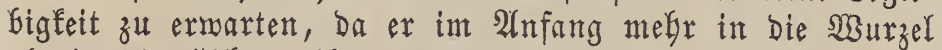

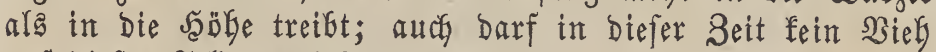
auf biefes Feld getrieben merden.

Die (ङ.Bparfette gift meift nur 1-2, feltener 3 Safnitte,

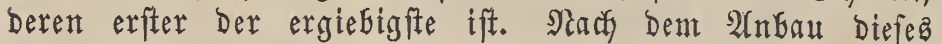

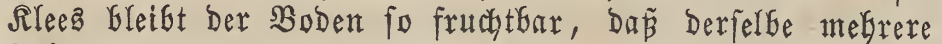
Jahre nach einander noch reiche Ernten liefert. $3 o r$ Dent. 3ten Doer 4ten Jagre foll man won Diefer Rleeart feinen Samen ernten. Man ftreift entweder Den reifen Samen mit Der f̧and ober fodnetbet bie fpigigen Stengel mit ber Sidyel af und trodfnet fe bollends auf einen Tuche; Den ausge= flopften und gereinigten Samen breitet ntan auf Dem

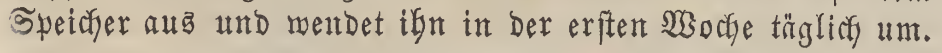

\section{Ëigenfabaften, Nuten, anwenoung.}

Der Eşper ift eine Der yorzitglichiten Jutterpflanzen

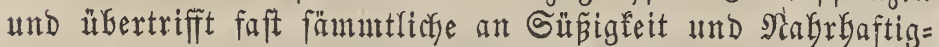
feit, fowohl grün, als auch Dürr gefüttert; ex yerträgt bie "sí̧eften Sommer, wälrend er anderntheils aucis son ftren= yำ Wintern nichts zu Gefürchten hat.

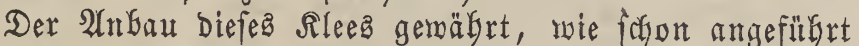
rourbe, nicht geringe Bortbeile; er fann auch Den Prerben, infoferne fie nicht zut barte Dienfte zu leiften baben, anftatt Des Seafers mit Naten gegeben werDen; nach Dem Sannitte geroährt bas Feld noch eine gute Schafwetde, auch find bie Samen ein gutes faübnerfutter.

\section{Lotus. L.}

Eulotus. Sering.

Krockeria. Moench.

Lotea. Medic.

Syfteme: Cyteophyta. Neck.

Diadelphia, Decandria, L.

Leguminosae irregulares. Roy.

Leguminosae Loteae. DeC.

Leguminosae Phaseoli. Adans.

Papilionaceae. L.

Papilionaceae Loteae. Rchbch. Spach.

Relde ganzlätterig, röhrenförmig, Gleibend, ntit faft 5 gleicfen, aufrechten und fpisen B̈̈Gnen. Blumenfrone jobmet= terlingsförmig. Fange runblich, rütfwärtz gebogen, mit einem länglich concaven Nagel berjeben. Die Flügel rund = lich, fürzer, Greit, nach oben ftch berübrend. Schiffdyen furz, lang zugefpidzt, aufíteigend, unten böferig vertieft. Staubgefüfe 10, Dem Relchgrunbe eingefügt. Staubfäben faden= förmig, 9 verfunden, 1 fret. Staubbeutel eiförmig-rund=

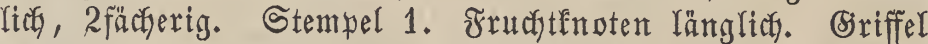
gefniet, yfriemlich-fäblich, nateft. Narbe ftumpf, fopfig. Şůlfe aufrecht, fchmal, rund ober zufammengebrü fat, meift walzenförmig, - Yänger als ber Relch, 2flappig, sielfamig. Samen malzenfürmig, glatt.

\section{Lotus corniculatus. L.}

$\beta$. Lotus arvensis. Schkr. Lotus tauricus. Hort.

$\%$. Lotus ciliatus. Tenor. $\delta$. Lotus villosus. Thuil.

$\varepsilon$. Lotus alpinus. Schleich.

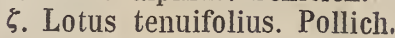

Lotus decumbens. Forst.

(Befgönter Schotenflee, genteiner Scyotenflee, Jeornflee, Jonigflee, Walzenfraut, gelber Ropfílee.

Common Birdsfoot - Trefoil. (engl.)

\section{Arten = charafter.}

Warzel lang, bünn, äftig, faferig. Stengel hand $=$ bis

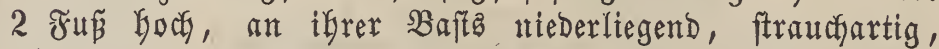
äftig, glatt ober zottig. Blätter flein, furzgeftielt, abrwech= felnd und zu 2-3 ftefend. Fiederblättchen 6 Rinten grof́, 3 sinten breit, zart, werfefrt-eiförmig, ganzrandig, glatt Doer zottig befaart. 2afterblättchen rund, am Blattftiele. Blüttenföpfe 5-12blütbig, Doldenartig, niebergebrünt. Blumenftiele lang, nadet. Reldy 2lippig, 5 zähnig, bie und Da braunroth geflecft. Blumen achferftändig. Blumenfrone gegen $1 \frac{1}{2}$ Solf lang und länger, Goubelb und, ebe fte fith

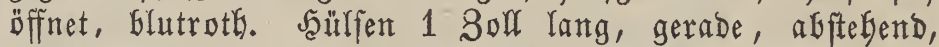
malzenförmig, rund, glatt, einfächerig, meift 8jamig. Samen malzenförmig-nierenförmig, braunroth geflect.

Die Bffanze yaritrt nach ifrem Standort in jeber $\mathfrak{B}_{\mathfrak{C}}=$ ziefung.

\section{$\alpha$, c a m p e stris. Wallr.}

Blätter und 2 fterblättçen ftnd fótef eiförmitg, am Nande gerrimpert.

Die campestris zerfälnt in 3 weitere Spielarten: in a) glaber, (arvensis) Schkr.

Die Blättchen auf Geiden Seiten und Der Relch ganz glatt.

b) hirsutus. (villosus. Thuil.)

Der. Selch und bie Blättchen auf beiben Seiten mit wulligen, bichten baaaren befletbet, und

c) crassifolius. Pers,

Mit Dicferen Blättçen. 
$\beta$. u li g in os u s. Wallr. (riparius. Pers.)

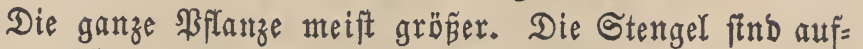
recft, gröper, rund, febr glatt und hokl. Die faft berz= förmigen Afferblättchen beinalye fo grof́ ala bie Fieber= blättchen.

\section{$\gamma$. tenuif olius. Wallr.}

Die Stengel ftnd Dünn, langgeftreât und auşgebreitet. Die Blăttchen länglid -lanzettförmig, lang zugefpibt.

\section{Blüthe $=$ Beit $\mathfrak{u n d}$ Dauer. \\ Miai - Suli. 4 .}

\section{3ortommen.}

Die erfte Barietät (campestris) ftndet fidf auf Feldern, Wiejen und an 2laferrainen, bie zroeite (uliginosus) auf

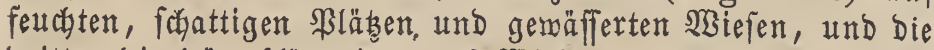

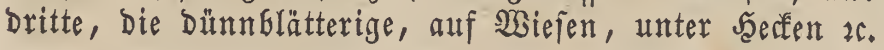

\section{Cigenfabaften, গtuten, Stuwenoung.}

Dả Sraut befteft feinen Beruch, aber einen fraut= artigen, bitterlich berben und etmas falzigen (5efchmaax. Der Beruch Der frifochen Blumen ift angenefum honigartig, Der Befchmad berb füb̈bitterlich.

Diefer Rlee ift eine felyr gute Futterpflanze.

\section{Medicago L.}

Diploprion. Vivian.

Hymenocarpus. Savi. Sering.

Lupularia. Sering.

Medica. Mill. Adans. Lam.

Spirocarpus. Sering.

Syfteme: Cyteophyta. Neck.

Diadelphia, Decandria. L.

Leguminosae irregulares. Roy.

Leguminosae Loteae Genisteae. DeC.

Leguminosae Phaseoli. Adans.

Papilionaceae. L.

Papilionaceae Loteae. Rchbch. Spach.

Relă ganzblätterig, glocfenförmig-çlindrifor, 5 fpal= tig, lang zugefpist und gleichförmig. Blumentrone fchmet= terlingsartig. Fahne ganzranbig, eiformig, zurürtgebogen, am Nanthe aber eingebogen. Die 2 Flügel länglich-eifür= mig, burch einen 2 (ngängfel an Das Schiffchen befeîtigt und an Der Seite fich vereinigend. Schiffdyen länglidh, abftehend, 2fpaltig, ftumpf, som Stempel abftebend und yon ber ₹ahne etwaş entfernt, flaffend. Staubgefäße 10, Dent aielchgrunde eingefügt. Staubfäben, 9 berwachfen, 1 frei. Staubbentel rumblich, 2fädserig. Stempel 1. Fruchtfnoten nach Der $\mathfrak{B}_{e}=$ frudutung in einen $\mathfrak{B}$ ogen aufwärta gefrümmt und an bie Fahne angelefnt. (5iriffel fabenförmig, gefniet, fabl. Narbe endftändig, ftuntpf. Şülfe Der Form nach verfedieben, zat= fammengebrücft, immer aber fthelförmig ober fpiralförntig gemunben, 1 fächerig, 1-vielfamig. Samen nierenförntig, eiförmig, länglich, Đerfefrt= cirund oder beinatge 3ecfig, glatt Doer quer gerunzelt.

\section{Medicago sativa. L.}

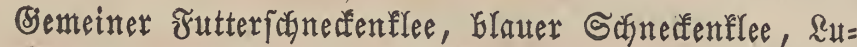
zernerflee, \&uzerne, Glauer emiger Rlee, emiger Rlee, Spargel= flee, Şöntrerflee; Monatåflee, Stengelflee, welfader STlee, Burgunderflee, ftciliantipuer Silee.

Luzerne, Lucerne. (franz.)

Manured-Medick, Lucern-Medicago, Cultivated Medick. (entgl.) Arten = Ebarater.

Wurzel'ftarf, åftig-fajerig, fchmutigmeins, gebt oft 4 Fur lang in ben $\mathfrak{B}$ oden Ginein. Stengel $1-21 / 2$ ₹rus Goch, auffeigend, aufrecht, äftig, etraas fteif, glatt ober meiçbebaart. Blätter geftielt, 3zäblig, abwedhelnd ftebend.

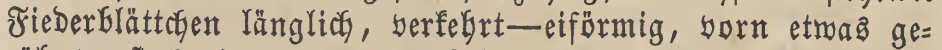
zäbnt, ftechend, unten zartbebaart, graugrün, oben glatt und Dunfelgrün. 2ffterblättchen ganzrandig, Ianzett-pfrie= আñenförmig. Bluntenftiele äftig. Blumen in fleinen, bich= ten, länglichen Trauten ftefend, fobön violettblan, gelfliç,

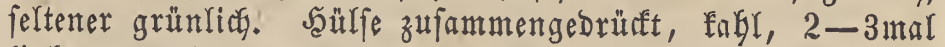
linf́g genumben.

\section{Slüthe $=$ Zeit $\mathfrak{u n d}$ Dauex. \\ গัuni - 2luguft. थ.}

\section{3ortommen.}

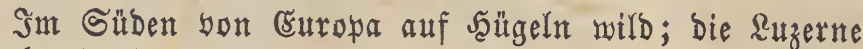
wirb bäuftg bet unz angebaut, findet flet aber bäuftg auf troffenen Biejen, Weiben, in Wreinbergen bermildert.

\section{§ultux.}

Die Ruzerne will einen mürben, trockenen, nur feinen feuchten, weber zul locern, noch aber zu bindenden, etwas thonigten Boben, ber wegen ber tief einfwlagenden $\mathfrak{B}$ urzeln 3-4 Fú tief gleichartig fein und eituen wafferlofen $11 n t e r=$ grumb haben folf; auf foldyem Boben bauert bie \&uzerne, gut geffegt, $10-15$ Saldre, jedoch ift es rathjam, nach Dem 7-8ten Sabre, in weldyer Beit fted gerne Rüten zei= gen, ben 2ldé umzureižnen.

Das Feld, meldes bie Saat aufnebren foll, mú zu= yor geförig zubereitet, noch einmal raul geeggt, yom $\mathfrak{u} n=$ fraut kefreit werben und büngerfräftig fein; man făet; ge= mögnlich Mitte Mai's, Den Samen mit 3 Fingern, Damit er nicht zu bünne und gleich ausgefftreut merbe; man eggt mun Den Samen mit einer Jeichten Eggge ein und äberfährt ifn noch mit ber umgerwandten und befdyerten Ëgge. Man fäet ben emigen Silee am beften ofgne Mrifchfrucht, ober aud olne Sierfte und Safer; yor Der Saat Erbfent unterzupflü= gen, Gält theilmeife das Unfraut ab und fobüt die jungen Sffanzen; Glïben bie Erbfen, fo werben fte afgefohnitten.Son erften Sommer ift ber 2 ffer etlichemal zu jäten und fo fehr als möglich yom lunfraut rein zu Galten. In Den erften zwei Sabren foll man biefen Rlee oft abmäken, bamit feine Stöble melyx erftarfen; im britten Sabre, wo er anfängt and meiften Ěrtrag zut geben, bünge man ben 2 defer mit

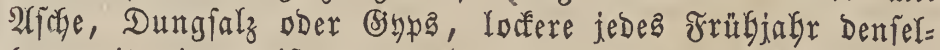
ben mit einer eifernen Ëgge auf und uberftreue ibn in Shinter nit gutent und furzem Mrift. Sefjr gefteigert mirb

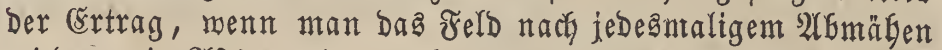

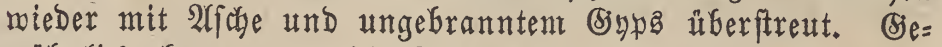
wöbnlich fann ntan bie Ruzerne 4-5mal und öfter bez

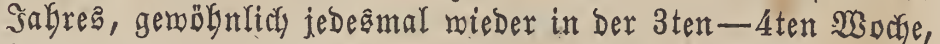

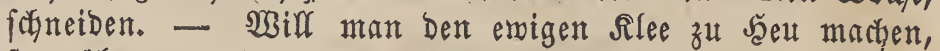
fo mähet man benfelben wie Dent rothen Rlee, wenn fich feine Blüthe noch nicht yolffomment geöffnet Kat, und jafneidet bie 
Bflanzen fo eben ala möglidy ab, bantit bie folgenden Sifope früber und häufiger nachnachfen; wegen ber faftigen Stengeln

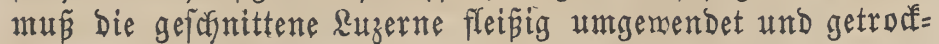
net merben, indem man biejelbe dünn verbreitet und $\mathfrak{M o r}=$

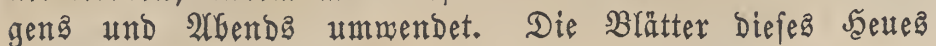
ftosen fich beim 2 Hufladen nicht fo leidht ab, als beim rotben Silee, aber boch ift ez yortbeirkafter, Das Jeat erft 2lbendas ober Morgens auf Den $\mathfrak{W a g e n}$ zut Eringen, Da um bieje Beit Der Tyau Daffelbe etwaz gefdymeidiger macht.

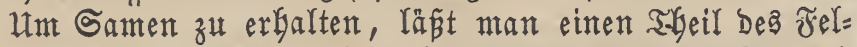
Des yom zmeiten Rleetrieb ftehen, finneibet Die Stengel, wenn ber Same gereift ift, mit. Der Sichel ab, und fetht fite 8 Tage lang Der Sonne ober Dent Negen aub, ftellt $\mathfrak{n u}$ bie Stengel auf, bis bie Samen yolftommen troffen und zeitig find, und Gebandelt fie weiter mie bie bes rothen Rleez. Der auf Dem Speidjer liegende Samen mú 14 Tage lang offers ungemendet merden, meil er fich gerne erbight und Daburch zur 24us]aat untauglich mirb.

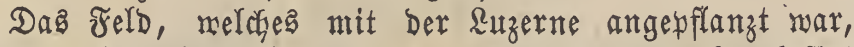
foll unter 10-12 Jahren nicht nober mit bemfelben befäet werben; es trägt bingegen, nachbent ez umgeriffen ift, auch ofne gebungt zu werben, mefrere Betreibearten, Rartoffeln 3 .

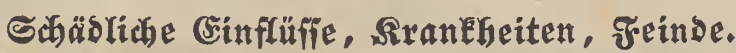

Die Felder, melche mit Dem Glauen Rlee angebaut find, werben febr gerne yom Untraut beimgefucht, befonders yon Der Dueffe; um Das 2 uffommen Derjelben zu verbindern, ift es ant räthlichften, vor Der Einfaat Der \&uzerne bas Feld im Jeerbfte zu bủngen und ben Dung tief genug unterzu= afern, im ซrribjabre darauf zu eggen und nach einigen Wodchen wieber zul pflügen; auch fann man ein Jabr vor

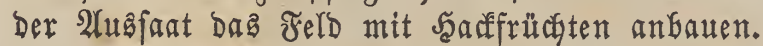

\section{Cigenfibaften, গtutsen, Atnwenoung.}

Dab Sirat hat einen etmas berben und miderlich falzig bittern Bejchmadf. Die Ruzerne ifit ein fefr gutez Futter und werbient aud Déblalb und Gefonders neben bem Sopf= flee alfgentein angefaut zu werben, meil fëe ein Keiß̈es, trodfenes Rlima berträgt, in meldyem Der Ropfflee berborren mürbe; menn gleich weniger nahrbaft, als ber Ropfflee, ift fte boch eines ber frübeften, aber auch fä̈teften ơrünfutter, fie fängt mit bem $\mathfrak{M a n} r z$ an zat machfen und bautert bis bie Serbftröfte fich einfenden. Das Dayon gefütterte $\mathfrak{B i e l}$ mird weniger aufgebläht, als yom rotben Rlee, und liefert eine

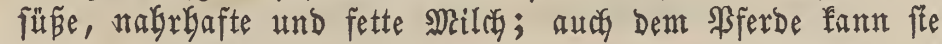

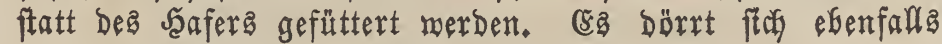
reichter als Der rothe Rlee.

\section{Medicago falcata. L.}

$\beta$. Medicago annularis. Bess.

$\gamma$. Medicago media. Pers.

Medicago falcata. Lam.

Medicago sativa var. flor. pallide coeruleis. Willd.

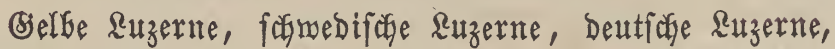

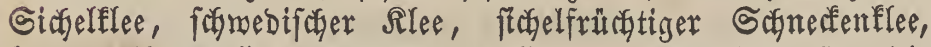

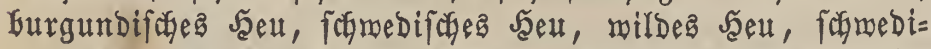
foher Jaeufame, wilbes beiliges Șeu, gelbe Bergluzerne, großßer gelber Schneffenflee, gelber Steinflee.

Lucerne de Suède. (finanz.)

Yellow Moon Trefoil. (engr.)

\section{Arten = Charafter.}

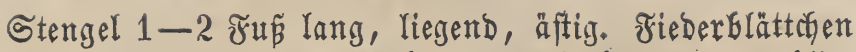
länglió, an ber Spibe gezälynelt, meichlyarig, 3zäblig.

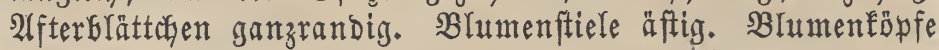

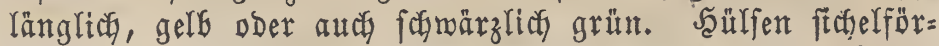
mig ober nuondförmig gefrümmt, gefdnäbelt, Gebaart, $5-8$ famig.

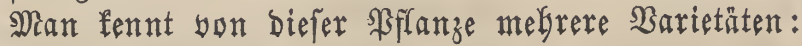

$$
\alpha \text {. riparia. }
$$

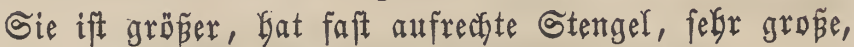
längliche, an ber Spibe gezăbnelte und faum abgeftuste Blättcten, langgeftreçte und vielblumige Trauben und etwas größ̄ere gelfe Blumen.

\section{$\beta$. montana.}

Der Stengel ift Dünn, fabenförutig, nieberliegend. Die Blättatben flein, linienförmig-länglich, abgeftubst und faft gezalynt. Die Trauben fopfförmig, tragen wentg Blüthen; Die letsteren find gelf und beinake um bas Doppelte fleiner als bie ber borigen $\mathfrak{B a r i e t a ̈ t . ~}$

\section{$\gamma$. pratensis.}

Stengel auşgebreitet; bie Blättdyen linienförmig-leil= förmig, fchmal, an ber Spite fodarf gezahnt, abgeftubt; bis Trauben abgefürzt.

\section{8. versicolor.}

Blumen blä̧blau, fpäter gelbliç.

Błüthe = 3eit und Dauex.

$$
\text { รuni }-\mathfrak{A} \text { uguft. } 4 \text {. }
$$

\section{3orkommen.}

2uf unfuchtbaren Bläßen, trof́enen Şiefen, Bergen,

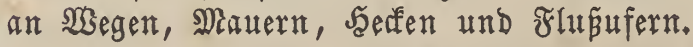

\section{§ultur.}

SBirb in Sçmeden Gäufig angebaut. Man mähet ben

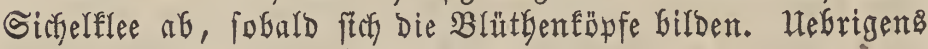
ift bie Befandlung gleich Der Der \&uzerne.

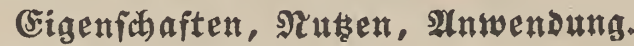

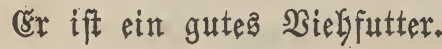

\section{Medicago lupulina, L.}

Medicago Willdenowii. Merat.

Trifolium lupulinum. Savi.

B. Medicago corymbifera. W. L. E. Schmidt.

$\gamma$. Medicago lupulina unguiculata. Sering.

Medicago mniocarpa. Wallr.

Trigonella mniocarpa. Wallr.

$\delta$. Medicago lupulina corymbosa. Sering.

Şopfenflee, Gopfenartiger Sdynedfentlee, Jొopfenluzerne,

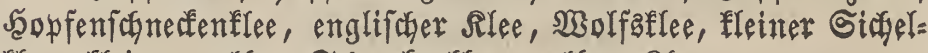
flee, fleiner gelber Sdynerfenflee, gelber Alee.

\section{Arten = Éarafter.}

Stengel nieberliegend, Dünn, extig, äftig auŝgebreitet, 6 Soll bis 1 Fur lang. FieberGlättchen amgefegrt-eiför= mig, meiftenz rundlich, felten gegen bie Spike bin augege= breitet, 3zäblig, vorn gezahnt. 2afterblättchen eirund, ge= zühnt, zugefpibt. Die gelGen Blüthen in bichten, ffeinen,

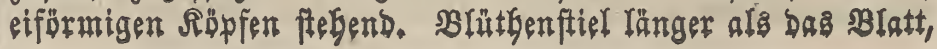




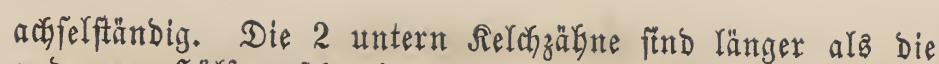

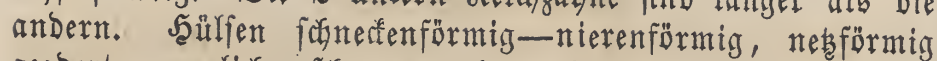
geabert, runzlich, fodwarz, glatt ober farram mit zarten und angebrüaf́ten Särraten beberft und 1 famig.

\section{Blüthe = Beit und Dauer.}

Suni - September. $\odot$. $\sigma^{\top}$.

\section{3orkommen.}

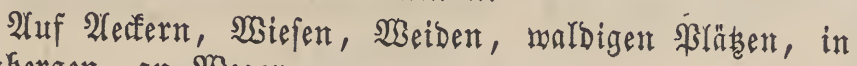
NSeinbergen, an $\mathfrak{B}$ egen.

ङigenidbaften, stułen, stuwenoung.

Der אopfentlee ift als ein yortreffliches zutter für bas Biel) z" empfeblen.

\section{Melilotus. Adans, Lam.}

Campylorutis. Sering.

Coelorutis. Sering.

Grammocarpus. Koch.

Plagiorutis. Sering.

Syfteme: Cyteophyta. Neck.

Diadelphia, Decandria. L.

Leguminosae. Juss.

Leguminosae Phaseolae. DeC.

Papilionaceae. L.

Papilionaceae Loteae. Rchbch. Spach.

Sielch ganzblätterig, röbrenfürmig, 5zälnig, bleibend.

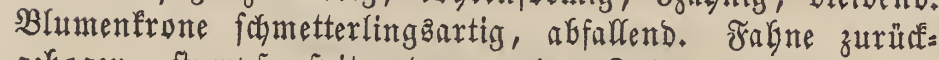
gebogen, ftumpf, fpis ober an ber Spise gezăbnelt. Die zmei Flügel gleichförmig conbex. Schiffchen ganzblätterig,

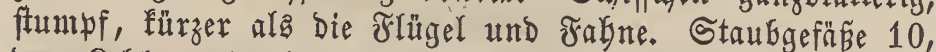
bem Sieldygrunde eingefügt. Staubfäben: 9 verfunden, 1 frei. Staubbeutel rundlich, 2 fächerig. Stempel 1. Jruchtenoten geftielt, rundlich ober eirund. Siriffel auffeigend, fabenför= mig, nact. Narbe ftumpf, flein. Scullfe beinake fugelig, ober eirund, länger als ber Jielch, 2flappig, oben auffiprin= gend, abfällig, 1 fächerig, แnd $1-3$ famig. Samen glatt, eirumb.

\section{Melilotus officinalis, Lam. Pers.}

Melilotus citrina. Duval.

Trifolium Melilotus officinalis. L.

Trifolium officinale. Willd.

Gemeiner Steinflee, officineller Steinflee, äd bter Stein= flee, gelber Steinflee, Mielotenflee, Melilote, Tonfofraut,

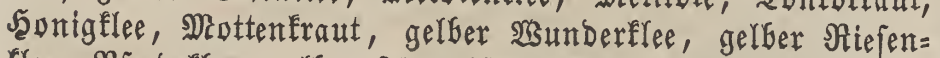

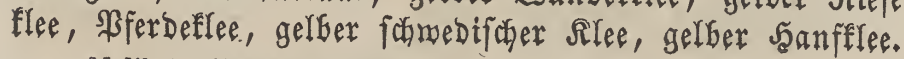

Melilot officinal. (franz.)

Common Melilot Trefoil. (entgr.)

\section{Arten = Charater.}

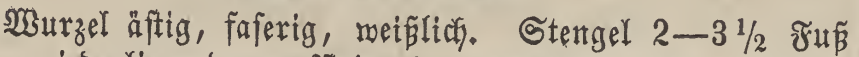
lang, nieberliegend, auffeigend, aufrect, fteif, abmects felnd äftig, oben etwas eefig, unten mebr abgerundet, glatt. Blätter geftielt, 3zäblig, abmechfelnd ftebend. Fieber= blättçen 4-8 Rinien lang und 2-4 Rinien Greit, etwa meitläufig aber Doch focharf gefägt, glatt unb gochgrün, bie wberen linien-lanzettförmig, beinake abgefubt, bie untern aber Iamzettförmig - ftumpf. 2ffterblättoden Elein, pfriemen= förmig. Blumentrauben 2-4 3oll lang, aufrecht, beinabe einjeitig, und etwas fwlaff. Blumen flein, faft Doppelt fo lang aIs ber Jelch, actfelftãndig, Godigelb ober auch mei lich; Die Falyne fraungeftreift, und Die Flügel find fo grop

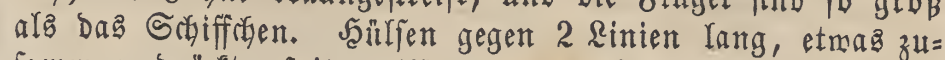
fammentebrücft, fpis, eiförmig, trauben= und netgërmig, runzelig, befaart, 2 föcerig, geabert, 2famig, feltener $1=$ ober 3 famig, und nit ber Zeit fogwarz merbend. Samen zu= fammengebrủnt, rundlidy-eiförmig, ungleich böferig und glatt.

(E⿱ g) gift eine Barietät:

\section{$\beta$. al t is s im a. Gmel.}

Der Stengel ift bier febr bod, ftraff, und bie fălfe madft und 1 famig.

\section{Blüthe $=3$ eit $\mathfrak{u n d}$ Dater.}

sunt - suli, $\sigma^{T}$.

\section{\$ortomuten.}

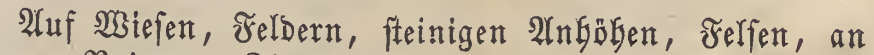

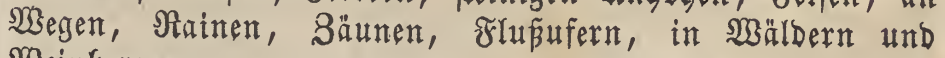
Weinbergen.

\section{ßultur.}

(̌r wirb bauptfäçlich in England angebaut; man baut ifn Dort auf einem tiefgrundigen $B$ oben, ber fonnig und troćen liegt. Nan fanneidet ifn, fobald er Blüthen getrie= ben bat, Denn nach Der Blüthe erbält man zwar Göbere, aber biffere und Golzigere Stengel. Nar zur Samenzud

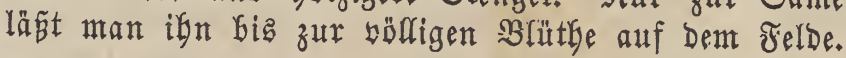

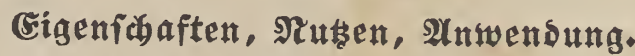

Diefe Futterpflanze, Gefonders die Blüthen Gaben einen ftarfen, eigentfümlichen, Gonigartigen (Seruch, Der Durch's Trodfen noch an 2 romta geminnt, und einen fobleimig bit= terlichen, etras fcharfen, gemürzhaften und falzigen sefdymadf.

Nach $\mathfrak{B o g}$ el find die yorwaltenden Beftandtyeile Des gemeinen Steinflees ätherifhes Del, bitterer Extraftioftoff und $\mathfrak{B} e n z$ oëfäure.

Diefer Rlee ift ein Beftandtheil des STräuterfáfez; er wird ferner unter Den Schnupftabak gemengt und zur $\mathfrak{V e r}=$

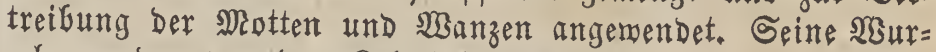
zeln merben yon Den Ralmütefen gefpeișt.

\section{Melilotus alba. Desr.}

Melilotus altissima. Schult. Thuil.

Melilotus leucantha. Koch.

Melilotus officinalis. $\beta$. Willd.

- Melilotus vulgaris. Willd.

Trifolium altissimum. Loisl.

Trifolium germanicum. Smith.

Trifolium Melilotus vulgaris. Heyne.

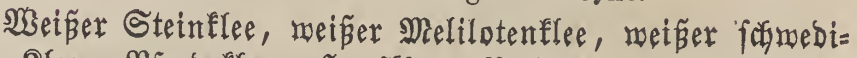

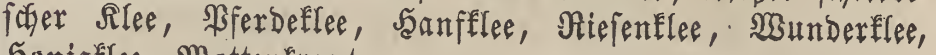
Şonigflee, Nittenfraut.

\section{Arten = Crarakter.}

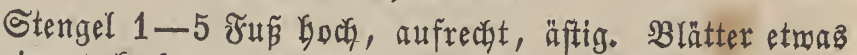
eiförmig, geferbt. Blättchen abgeftuht, gefägt, bie obern lanzetfförmig, bie untern fajt rautenförmig. Arfterblättchen Gorftenfürmig. "Blumen in langen Irauben. Blumentrone 
Geinake bowpelt fo lang als ber Reld und meí̈; bie obern fthenden Blumen find ftets unfruchtgar: Das Schiffchen ift

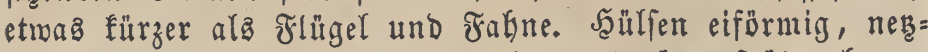
förmig, runzelig, naft, fđ̆musig grasgrån, fpäter Graun merbend, 1 famig.

$$
\begin{aligned}
& \text { Blüthe = } 3 \text { it und } \text { Dauer. }
\end{aligned}
$$

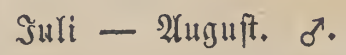$$
\text { Sorkommen. }
$$

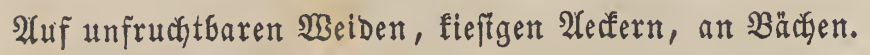

(sigenidbaften, গtüen, Anwenoung. (5)utea $\mathfrak{B i e b j u t t e r . ~ S r a ̊ f t e ~ u n d ~ ( B ) e r u c h ~ m i t ~ M e l i l o t u s ~}$

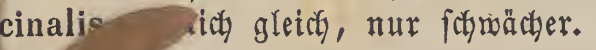

\section{Melilotus dentata. Willd.}

Melilotus procumbens. Hort.

Trifolium dentatum. W. K.

Biezwhiter Rlee, ungarifuer Steinflee, Salzfteinflee, fpiber Steinflee.

Melilot denté d'Hongrie. (franz.)

Arten = (5harakter. .

Stengel yon feiner $\mathfrak{B a f i z}$ an aufiteigend, aufrecht, rund, geftreift, 2 శuß hoch; bon jedem Blatte lauft eine erfabene linie am Stengel berab. Blätter länglich, făarf und fein gejägt, und biefe fägeförmigen (sinfohnitte ftegen bicht an einander und find beinabe ftachelfpibig. Blättchen länglich, jobarf fein fägeförmig. Afterblättchen an ifyrer $\mathfrak{B} a$ fiz getbeilt. Blumen gelb, woblriechend, in langen srauben. Die Flügel

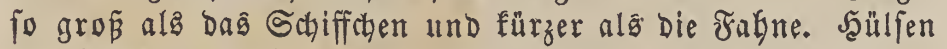
traubenförmig, Geinabe fugelig, fpitig, runzelig, an ber rarn Nabt zujammengebrücft, glatt, 2 jamig, fđmarz wer= send. Samen nicht punftirt.

Wallroth fülgrt eine $\mathfrak{B a r i e t a ̈ t ~} \mathfrak{a n}$, bie

$\beta$. angustifolia.

Unterfachet fith Durch linienfo̊rmige Brätter.

Blïthe=3eit und $\boldsymbol{D a u e x}$.

Juli - September. ठ7.

\section{3orkmmen.}

2Uf Miefen, an Megen, in Sachjen und Ungarn.

(E: genfabten, গturen, Anwenoung. Jutterpflanze.

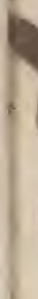

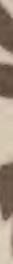

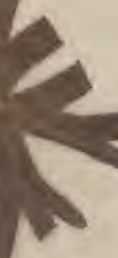

\section{Melilotus coerulea. Lam.}

Trifoliastrum coeruleum. Moench.

Trifolium coeruleum. Willd.

Trifolium Melilotus coerulea. L.

Trigonella coerulea. Sering.

$\beta$. Melilotus connata. Bernh.

Blauer Steinflee, Glauer Melilotenflee, Scgafziegerflee,

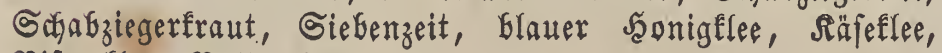
Bifamflee, Baljamflee.

Melilot bleu de Bohême, Trefle odorant, Trefle musqué des jardins. (franz.)

Blue Melilot. (engl.)

Entwer, BEonom. PronzenEunde.

\section{Arten = (5harafter.}

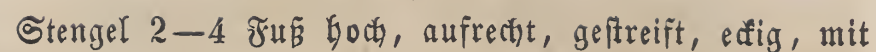

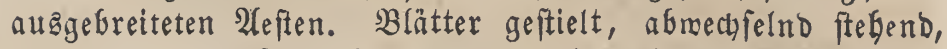
3 zäblig, glatt. FiederGlättchen längliç-lanzettförntig, fein= geferbt. S2lfterblättchen lanzettförmig, faft 3ecfig, bäutig. Bblütgentrauben dibt, äGrenförmig, eiförmig urb langgeftielt, Geinabe fopiförnig und aufrecht. Blumen meiślich und blau geadert. Sẳlfen weich|tachelfpibig, bauchig-aufgeflafen, run= zelig, Galbnaft, 2 famig. Samen naft.

\section{Blütfe $=$ 3eit und Dauer. \\ suni - গuli. $\odot$.}

\section{3orfommen.}

Sein uriprủngliches Baterland ift Norbafrifa, findet fith aber verwildert im mittleren und füblichen ङuropa wie

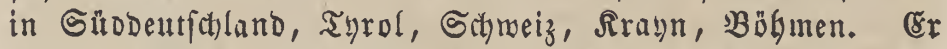
mirb befonders in Der Schweiz und in Böbmen angebaut.

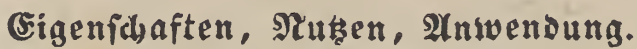

Daz Sraut, hauptiäcllich Daz getrofinete, hat einen eigenthümlițen, fart balfamif = aromatifiten Beruch, und eg wird in Der Shweiz yorzugrweife zur Bereitung des ip= genannten Schabziegerfäfę, grünen Schmeizer= oder Rräแter= fáfę benüht.

\section{Melilotus Petitpierreana. Willd.}

Melilotus arvensis. Wallr.

Melilotus diffusa. Koch.

Melilotus expansa. Hort.

Melilotus officina.is. Lam. var. Spr.

Melilolus pallida. Bess.

Trifolium Petitpierreanum. Hayne.

Betitpierrifder Steinflee, Afferfteinflee.

\section{Arten $=$ Sharakter.}

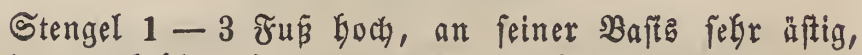
auffeigend, fahl, oben etwas åftig. Friederbiättithen ber= felgrt-eiförmig, unregelmäß̈ig gezäbnt. Nebenblatter boritig, zafnlog. Blüthentrauben achielitändig, langgeftielt. Blumen

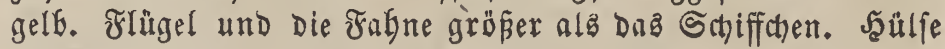
traubenartig, eiförmig, fpikgig, querrunzelig, naft, in ber

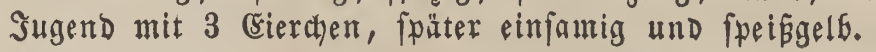

\section{Slüthe = Beit und Dauex.}

suni - suli. $\delta$.

\section{3orkommen.}

Unter Dem Getreide, auf Sautt, Naucrn und Feljen, an Wegrändern.

\section{(sigenidhaften, গtüen, Anwenoung.}

(8)

\section{Trifolium. L.}

Amarenus. Presl.

Amoria. Presl.

Calymorphum. Presl.

Chronosenium. Sering.

Dactiphyllum. Rafin.

Eutriphyllum. Sering.
Fragifera. Koch. Galearia. Presl.

Lagopus. Sering. Lupinaster. Moench. Micrantheum. Presl. Mystyllus. Presl. 
Paramesus. Presl.

Perisaema. Fisch. Mey.

Phleastrum. Sering.

Trifoliastrum. Sering.

Triphylloides. Moench.

Versicastrum. Sering.

Syfteme: Cyteophyta. Neck.

Diadelphia, Decandria. L.

Leguminosae Genistae. Adans.

Leguminosae irregulares. Roy.

Leguminosae Loteae. DeC.

Papilionaceae. L.

Papilionaceae Loteae. Rchbch. Spach.

Sielch ganzblätterig, rökrenförmig, 5zähnig ober 5 fpal= tig, Gleibend. Blumenfrone fogmetterlingäfürmig, Gletbend. Jahne aufíteigend, länglich, eiförmig, verfefrt-herzförmig, glatt ober jefurcht, an ber Spike gezähnelt, ausgerandet

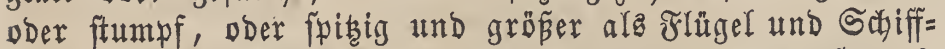
chen. Die 2 Flügel ftumpf pder fpib. Schiffctien ftumpf. Staubgefäв̄e 10. Staubfäben: 9 verwactjen, 1 fret. Staub= beutel rundlich, 2 fächerig. Stempel 1. Frudftenden fîsend ober geftielt, eirund ober länglich, biz zum siriffel gerade. Briffel lang ober furz, fabenförmig, auffeigend, nacet, an Der Spise gerabe doer Gafig. Narbe endftändig, ftumpf, fopfig. Şülfe eirund ober länglich, fitsend ober geftielt, im Selche eingefálofien und yon Der Blumenfrone untgeben; 1 fächerig, 1-5famig. Samen eirund, eiförmig ober fugelig, glatt.

\section{Trifolium pratense. L.}

Trifolium sativum. Mill. Rchbch.

Triphylloides pratense. Moench.

(Bemeiner Silee, SWiejenflee, rother Wriefenflee, Futter= flee, Dreiblätteriger rotber Slee, Ropfflee, fpanticher Rlee,

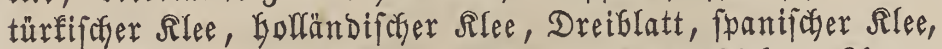
grop̈er Rlee, welfcher Rlee, brabanter Rlee, Rleber, Rleber.

Trefle des prés. (frñ ‡.)

Red clover, Common purple Neadow Trefoil, Field Honey suckles. (entgl.)

\section{Strten $=$ (5)arater.}

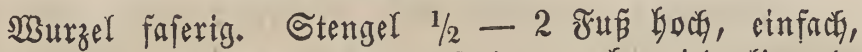
fparfan äftig, bei bem mildmadyenden mebr nieberliegend, auffeigend, oben geftreift, glatt. Blätter geftielt, abmechfelnd ftebend, $3=$, felten $4=$ und melyrzălig. SBlättchen eiförmig, faft ganzrambig oder etwas geferbt und etwas zottig gewimpert, zart, Dunfelgrủn, Gäufig weís und braun gefferft. Iffter=

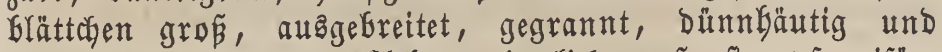
burchfocheinend aberig. 2(ebren ziemlich groṕ, ftumpf-eiför= mig, bicht, einzeln ober zu zwei ftehend und yon $\mathfrak{B}$ lättern umgeben. Blumenftele in Den Blattwinfeln entipringend und länger als bie Blätter. Selctzăhne ungleich, Der untere nänlich fürzer, pfriemenförmig, gefranzt und fürzer als bie Blumenfrone. Blumen ziegeldachförmig geftellt, feb̆̈n purpur = und rofenrotg, fleifchfarben ober meis. Fagne nie=

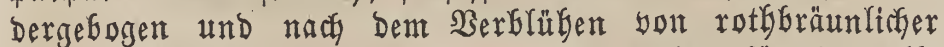

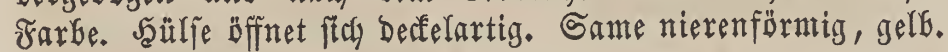
Die 2lbart:

\section{$\beta$. sativum,}

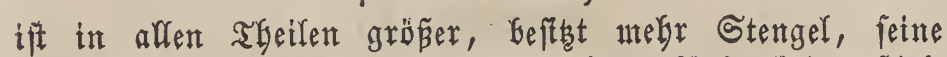
Blättchen ftnd länglida und bie slumentäpfe find geftielt und faft gepart.

Slüthe $=$ Beit und Dauex.

Suni - September. 4.

\section{Borénmen.}

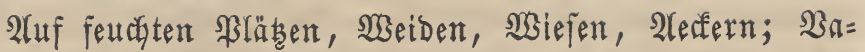
rietät $\beta$, wird bäuftg angebaut.

\section{Sultux.}

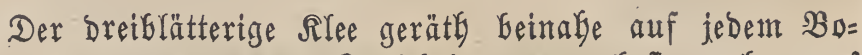
Den, augigenommen Den Sandboben, am beften aber auf einem gebundenen, Gumofen, tiefgelodferten, auch etwas, nur nicht' zu febr falfyaltigen ober etwas lefmigten Boben mit feutgtem, mafferangaltendem Untergrunde, auf einem gut

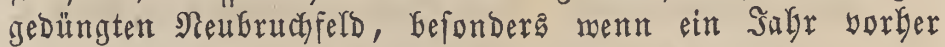

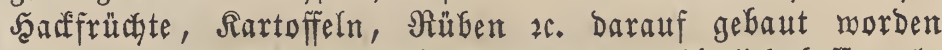
waren. In sebenen gedeift der Rlee gemögntich beffer als auf $2 \mathfrak{A}$ boben, und fann auch, weil ex mentiger tief wurzelt als die andern Rleearten und Daburch Den $\mathfrak{B a ̆ u m e n ~ m e n i g ~}$

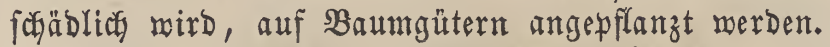

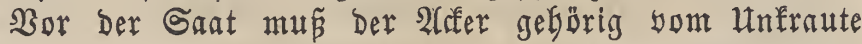
gereinigt und gut gebüngt werden, bejonders wenn ber $B_{D}=$ ben fandig ift. Esin zu thonigter $\mathfrak{B}$ oben mirb befondera aufgeloffert Durcy fleipiges Düngen mit \$ferbe= oder Schafas= mift. - Der אlee mird im Jrübtakre, im Notbjafle aud Gei ganz günftiger $\mathfrak{B}_{\text {itterung }} \mathfrak{i m}$ Serbfte gefäet, und zwar meiftens unter bie Sommerfructs ober auch unter Rein, Buthweizen ober "Wicten. Will man Den אllee unter Daß

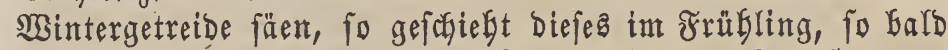
als möglich und fobald daz reld bolfig trocfen ift, und

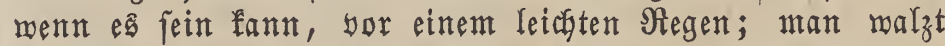
Den Samen, ober mas noch beffer und zugleich für bie bese= tretbefrucht yon Bortbeil ift, man eggt ign ein. Wraz bie Saat unter Das Gommergetreide, wie unter Safer und Serfte, anbelangt, fo wird Der 2 lafer, wenn das Setreide als grüne Futter benübt werben foll, entweber gleich ge= walzt, Der Game mit 3 Fingern gefäet und leidut geeggt,

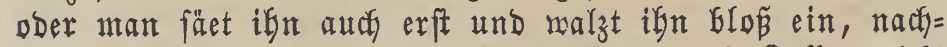
Dem bie Sommerfrucht foyn bie bäbe yon 2 Soll erreicyt

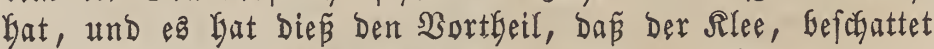
yon bem aufgegangenen Sietreibe, gleicher aufgeht und ment= ger bergeilt. - Goll bie mit Rlee eingefäete Frucht einge= erntet werben, fo $\mathfrak{m u} \tilde{\beta}$ fte $\mathfrak{n}$ t $1 / 3$ Dünner augefäet werben, weil fte fonft Den aufgebenden Silee zh felgr verdämmt. -

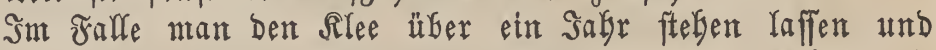
Dann als NGeide Genühen mill, fäet man benfelben mit meisem und gelbem Rleefanten und berichiedenen andern

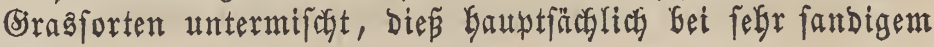
Boben.

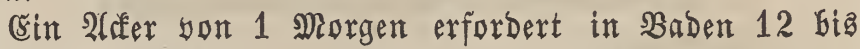

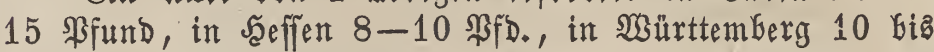
12 Pfd,, dDer 1 Bierling, dDer $3-4$ Man Samen zur 2H

Der zur $\mathfrak{A}$ uşaat beftimmte Gamen foll eine grünlich gelbe ober rötyliche, ja aber feine fobmärzliche Farbe befthen, foll nidgt über 2 Jabre alt und yermöge feiner Sabmere im Waffer unterfinfen.

Der Rilee Darf nur alfe 9, hobftenz alle 6 Jahre auf Das gleidfe Feld gebaut merden. Im Jrübjofre büngt man

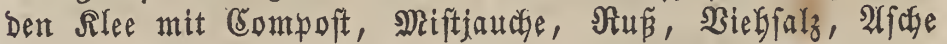
und ungebranntem (s)pas; biefer letere befonders ift für Den Rilee ăuperft yortheilfaft, wenn auf jeine $2(n$ mendung

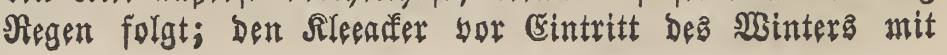


Dift zu Geftreuten, ift ber Mäuje wegen, bie ftu gerne unter bemielben auffalten, nicht anzurathen; ebenfo fayablich ift, ben jungen Rlee afweiben zu laffen. - Sind in Dem Rlee, Durce's (Érfrieren 2c., Rürent entftanden, io müffen biefelben int Früblinge mit Sommerroggen ober mit Jaafer aubgefüet merben.

Der Silee fann 3-4nal, unter bejondera günftigen Utmftänden, Gei guter Dïngung 2c. fogar 5 mal gejdutten werben. - Nean füttert Den אilee entweder grün ober ala

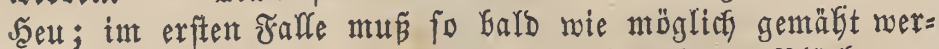
ben, weil ber Rlee, fummt er bas erftemal zur Blüthe, zu biel an Sräften werliert, (bei Dem zmeiten aber und Den folgenden Gantten barf ex nicht bald wieber afgemäht wer= Den, ba fein șusts fouft zu oft unterbrocten mirb, ) und zwar fo lange fort, als er nody wom Bieb gerne gefreffen wirb. Wsill man aber Rleebeu machen, fo mäbet man ben

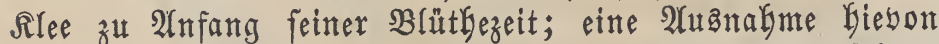
maedt man jeboch, Das Keiśt, man wartet bie Entmidfelung ber Blüthen niegt af, went man bie 2lGftift lyat, in ben Sleearfer $\Re e p s$ zu fäen, indem man fonft nicht molgl 2 mal fochneiben fönnte.

Bein Trodfnen Des Rlees und Einheimfen Des Rlee= Heues ftnd folgende Borftchtamagregeln zu beobachten: erjtens,

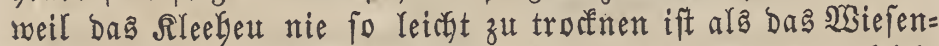

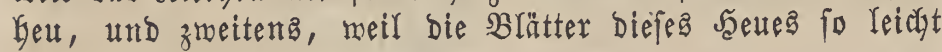
yon ben Gtielen fallen.

WGas Das Trodf́nen Des Rlees nun Getrifft, fo serfäbrt man babei auf folgende 2 seife: Sitt ber Rlee abgentäbt, fo läpt man ifn einen Tag in Schrodoen liegen, wendet bes andern Tages, Morgens ober 2 bends, wenn er bethaut ift, Denfelfen um und legt jebesmal 2 Schroden fo gegen ein= anber, bás fête oben einen Samm bilben. So gelagert läpat man fie trodfnen, und ift biefes gröptentheits gefchehen, dann bilbet man aus ifnen fleine, locfere Saaufen, bie man fo Iange mieber untwendet, biż bie Stiele Geim Hntbiegen feine Zeuchtigfeit mekr wahrnekmen laffen. - Man bebient fich zum Trocfnen Dez RTees veridiedener Vorridytungen, unter benten bie gemöhnlichte Der Rleereiter, Rleefefieber, Rlee= phramide ober Rleeluntte, welches ein 3feitiges, yon Ratten berfertigtes und innen Gobles Berüfte ift; auf biefe nun wird Der abgerwelfte Rlee Get troffenem Sisetter lodfer, ja

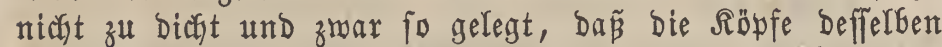
eimwärta feGen und Der Rlee Den Boben nicht berührt. Bei biefer Befandlungabweife verbirgt ber Rlee and bei anbal= tenbem Negenmetter nicht leidgt. SWie fodon oben angefübrt murbe, trodfnet ber Rlee ziemlich ungerne, mephalb auch bie Scheunen, it meldye Das Rleeleut gebradst merben foll, mit bielen Ruftlöchern werfeben fetn müffen und das Seu fo

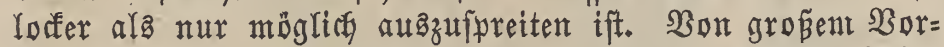
theil ift ein in ber Scheune angebrachter, 1 rup boher

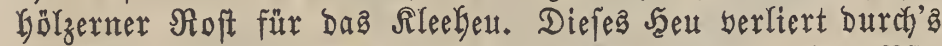

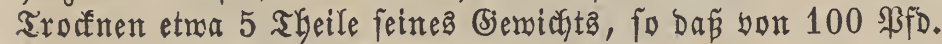

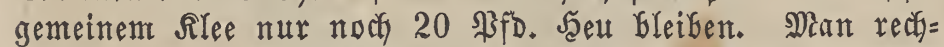
net bon einem Nagbeburger Morgen in 2 Schnitten 60 bis 70 Sentner Seeuertrag. Sn Baben redfnet man yon einem Morgen 24-70, in Seeffen 16-50, und in 2 Gürttentberg 20-60 Centner ફ口eu.

Um Samen zu erzielen, läpt man einzelne, magere (geil aufmadjender Rlee gift menig Samen) Steflent yom zweiten ober aud erfiten Seynitt ftehen, (Gier ift zu bemer=

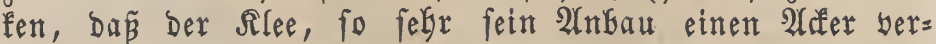
beffert, wenn er geförig abgemähet wirb, bas zeld auBers orbentlich ausentergelt, fobald er zur Samenzudyt fteben Gleibt; ez ift baher fehr zu beaden, nicht zu biel Samen zieken zu wollen, wenn man nidat anders einen Sandel mit Rleefamen zu treiben beabjtedtigt, in melef' Iebterent Falle Durch Doppelt fleisigen Bau und vermegrtes Düngen Dem

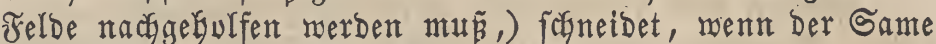
gelblica, bie Blumenföpfe Dunfelbraun und Die Blätter fahwarz

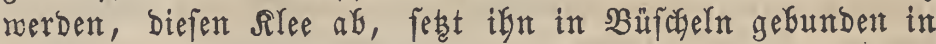
Jaaufen, vber nodj beffer, man bängt ibn auf Rleereiter. Sit ber Samen trocfen, fo Drifoht man ify entroeber gleich,

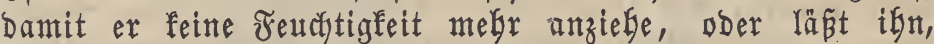
wenn man ifn nidht ganz aubbreforen fonte ober er feucht eingefleimst wurbe, now einige 3eit in ber Scheune an einem luftigen Drte liegen und Drifcht iGn bei ftarfer Rälte

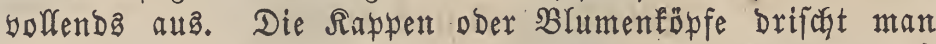
entreber in ber Scheune los ober bringt die Samen zù biefem Berufe in bie Stampfnühle. S3enn bie gedroldyenen Rappen noch Ganten bebalten baben, fo läpt man fte in warmen Stuben nod mebr ausitrodfnen und brifost fie in

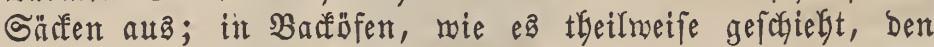
Sieefamen zu trucfnen, ift nicht ratbjam, ba er gar zu leidft in Dempelben gänzlich bertrof́tnet. Den Samen reintigt man yolfends auf einer mit feinen Sieben verjebenen regenmüble

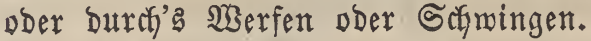

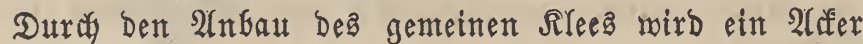
beträchtliç verbeffert, indem feine abfalfenden Blätter und feine ftarfen faftigen SSarzeln Den Boben fofon reichlidy büngen, und ungebüngt, nach nur eitmaligem Hamadern, übertrifft ein folcher an süte oft einen Brachader, voraus= gefekt, Dás Der אleeafer im zmeiten Jabre fodon umgeriffen wurbe.

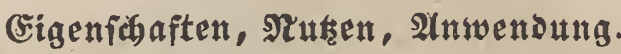

Der Rlee ift geruchloz und Gat einen Gitterlichen, etraa

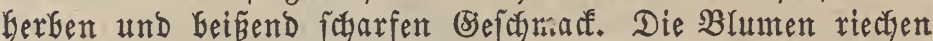

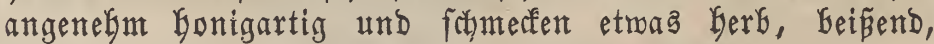
auch Der Samen beftist einen fodarfen Befchntarf.

Der Dreiblätterige Rlee ift, wolgl bie midytigfte Futter=

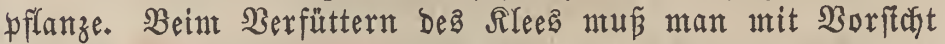
zu Werfe geben, Da er bauptfächlich int 2 nnfange ber žntte=

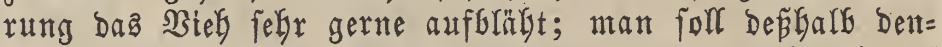
felben, bejonders wenn er noch jung ift, mit Stroh auf

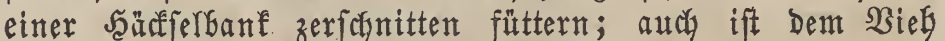

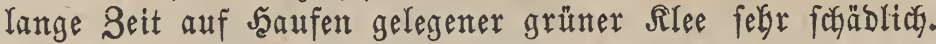
Das Rieeftroh fann auch Den ßferben als Rurzfutter gege= ben werben.

Den Ganten gebraudedt man als Breiumidlägen und gegen $\mathfrak{g} u$ ften. In Irland und Schottland bereitet man aus ben getrodfteten Blumen bas jogenannte Stantufbrod, Cham-

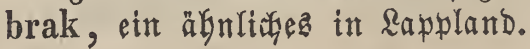

\section{Biteratux.}

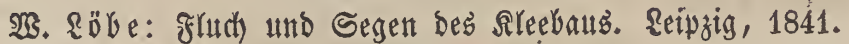

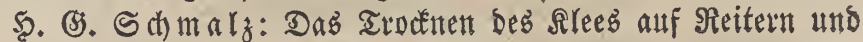
Siltten. \&eipzig, 1839. 
Trifolium incarnatum. L.

Trifolium rubens. Aubry.

$\beta$, Trifolium Molinerii. Balb.

Incarnatflee, Saafentee, fleifdurotber Slee, Blutflee.

Treffle de Roussillon. (fintz.)

Flesh-colgured clover. (engl.)

Arten = (Sharalter.

Stengel über 1 Fuв lang, aufredt, weichbebaart, wentg= äftig. Blattfitele lang, rinnenförnig, behaart. Blättcyen rundich-umgefebrt-berzförmig, eiförmig, geferbt und zottig behaart. Nebenblättchen ftum»f, gezăbnt, weiś, oben grủn, geabert. 2lefren länglid, ftumpf, Glatrlos, zottig behaart. Selch Gaarig, mit 10 Streifen; Der untere Sahn nur menig länger. Blumenfrone fchỏn Dunfelroth, felten meí́. Fabne fefr lang, mit Den andern Sironblättern nur an Der Bafta berbunben. Sểlfe flein, 1 famig:

\section{Blüthe $=3$ eit und Dauer.}

Suni - September. $\odot$.

\section{0remmen.}

UUf etras feuchten $\mathfrak{B i e f e n ~ u n d ~}$ Iecfern, Stahn, am Stgein 2c.

\section{ßultur.}

Diefer slee berlangt einen fräftigen fandigen Refun= Goben und eine warme gefchübte Rage. Man erbält nur

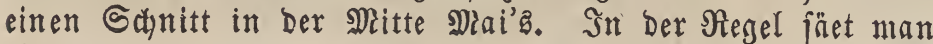

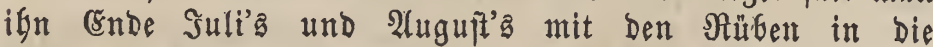
Stoppeln.

Bigenicbaften, Nuten, 2xnenoung. (S) ites Biebfutter.

\section{Trifolium repens. $\mathbf{L}_{*}$}

Trifolium album. $\alpha$. $\beta$. Lam.

Amoria repens. Presl.

$\beta$. Trifolium luxurians. Hort. Par.

Sriechender Slee, meifer Slee, fleiner Silee, Rämnter: flee, Felbflee, Bienenflee, Schafflee, meiber Steinflee, Gol: läubifther Rlee.

Trefle rampant. (finatz.)

Creeping white Irefoil, Dutch clover. (entgl.)

\section{arten = Eharater.}

Stengel 1 Fú lang, friectend, wurzelno, einfach ober sermorren åftig und glatt. Blätter langgeftielt, 3zäblig, glatt. Blättchen berfehrt eiförmig-länglich, ober werfehrtberzförmig, ftumpf, auagerandet, geftreift, am Nande fein und fharf gefigt, bie und ba meis geflecft ober fraunrotb= licb. Afterblättchen breit, faft bäutig, nit fegr furzer, gipfelftänbiger Sranne. Blumentöyfe runblid, beinabe Dol= benartig ausgebreitet, im 2lnfange aufredut, wenn fich bie Früchte anfegen aber bängend, braun merbend und fteben bleibend. Blumentiele fely lang, geftreift und glatt, ent= fpringen aus Den slattminfeln. Selth glatt, ungleicy ge= zabnt. Blumen flein, aufrecht, etmas doldenartig-fopf= förnig, meiblict und fpảter blaffleifafarb. Şülfen bom Selde bebert, fpringen ringsunt auf und find $3-4$ famig.

\section{Brätbe = 3eit und sauex.}

Iัuni - September. 4 .

\section{Bortommen.}

Heberall auf Wiejen, Weiben, 2Ueçern, an Wegen.

Cigenfibaften, Nuten, anwenoung.

Die Blüthen Kaben einen Gonigartigen Geruch und

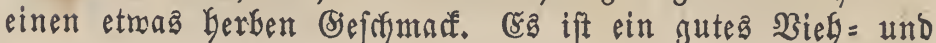
Schaffutter.

Trifolium hybridum. L.

Trifolium album. $\gamma$, Lam.

Trifolium bicolor. Moench.

Trifolium intermedium. Lapeyr.

Trifolium polyanthemum. Tenor.

Amoria hybrida. Presl.

Baftarbflee, Sannigflee, Baftardjogotenflee.

Trefle hybride. (frinz.)

Bastard Trefoil. (entrl.)

\section{Arter = ÇGarater.}

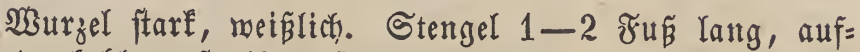
fteigend, fahl, geftreift, äftig. Blätter langgeftielt. Blätt= chen eiförmig-länģlich, nuşgerandet, feingefägt und glatt. Alfterblättchen breit-lanzettförmig, fabl, mit einer Branne, an Der' Baftz meíflict). Blumenftiele aus Den obern Blatt= winfeln fommend, abmedyfelnd ftefend, einzeln, und gefurcht, ftnd Iänger ala bie Blätter. SBlumenföpfe Doldenartig. Relch)= zäbne faft gleich. Sielity und Bluntenfrone größer und lebs= tere rofenroth, oder meís, Gefonders die mittelftelyenden. J̧ülfe 3-4 jamig.

Blüthe $=$ 3eit uns Dauer.

รuni - 2quguft. थ.

\section{Borkommen.}

2Uuf feuchten $\mathfrak{W i e j e n}$ und Weiden.

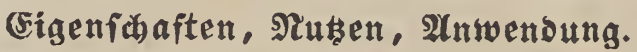

Bortreffliches Biegfutter, bas angebaut zu werben yers bient.

\section{Trifolium rubens. $\mathbf{L}$.}

Triphylloides rubens. Moench.

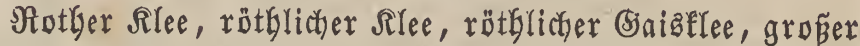

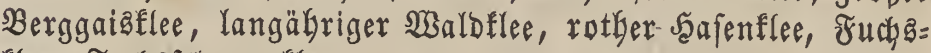

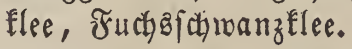

Trefle rouge. (franz.)

Long spiked Trefoil. (engl.).

\section{Shten = (Sharaeter.}

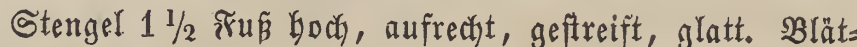
ter furzffielig. Fieberblättchen lanzettrörnig, fumnp, rippig

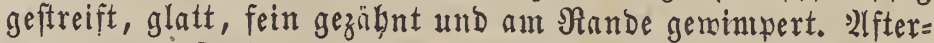
Glättchen 3 Boll lang und länger, fdymertförmig, fcheiben= artig und aufgeblafen. Aegren aujrecht, eiförmig, chlinbrifch, länglich, gipfelftändig, bicht, biaf. Seldbä̆ne zottig beyaart, ber unterfte fo lang als bie Blumenfrone, lestere ungleich einblätterig, furpurroth. Seủlfe rundlich, etraas zแfammen= gebrüct, yom Relche bebecft, glatt und 1 famig.

\section{Blütbe $=$ Beit und Dauer.}

Эuni - ฐuli. 4 . 
19.

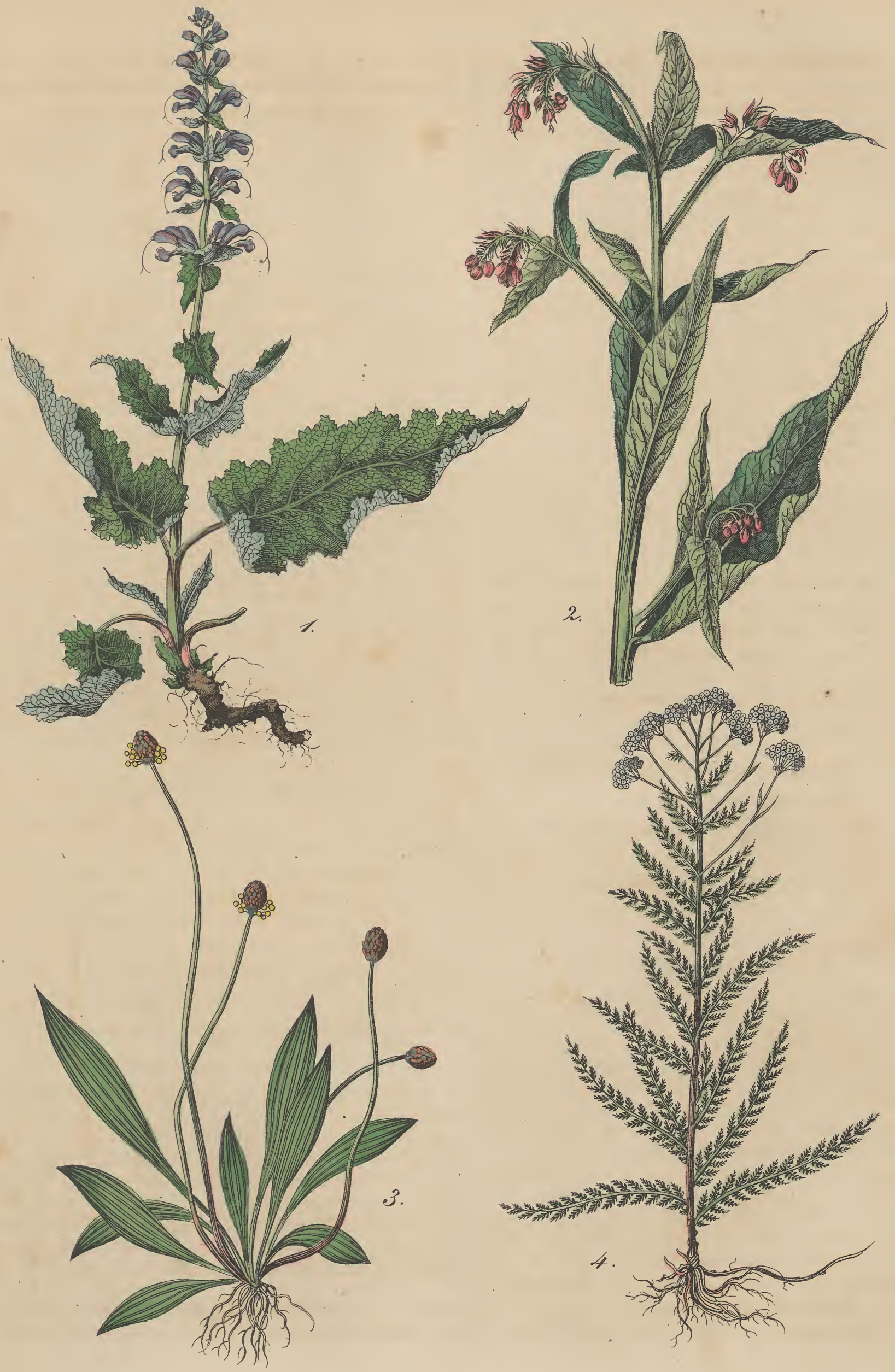





\section{3ortommen.}

In neyr füblichen Begenden Deutfalalanda, in gebirgi=

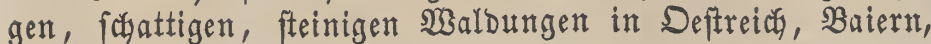
Sableften, Gachfen, Der \$falz, Schwaben, Jranfen, 5aan= nover, Thüringen, ber Swmeiz, Stalien, Jrantreich.

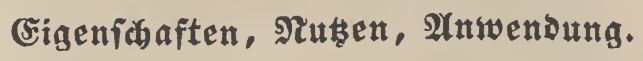

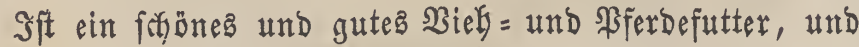
yerbiente häuftger angebaut zu werben.

\section{Trifolium medium. L.}

Trifolium affine. Lejeun.

Trifolium alpestre. Crantz. Autor.

Trifolium flexuosum. Jacq.

Trifolium patulum. Tausch.

Trifolium pratense. $\beta$. Gorter.

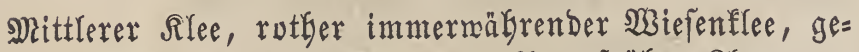
bogener Şafenflee, grüner Rlee, Trogflee, früher Rlee.

Trefle tortueux. (frantz.)

\section{2lrten $=$ (Sharakter.}

Diejer Silee Gat ziemlich 2 (ebnlichfeit mit Dem breiblät= terigen, unterfacheidet fith jedoch in mandher Beziefung yon bemielben; feine Stengel find böber, äftig und fnienrtig gefogen, bie Fieberblättchen fchmäler, an ifyrer Saftz ver= bünnter, äuzerft fein gefägt, oben glatt, bie untern eiför= mig, bie obern elliptifa; Die Affterblättchen yfriemenförmig und febr lang zugefpitst; bie 2lebren find gröber, herab= Gängend, fuft fugelig und einzeln ftefend; Der Selch ift um Daz Doppelte fürzer als die sblumenfrone, und ber unterfte Relchzakn etwas länger als bie ůbrigen und etwa fo lang als bie Blumenröhre. Blumentrone faft gleichartig, purpur= roth. Şülfe 1 famig.

\section{Blüthe $=$ Zeit und Dauter.}

sunt - Suli. 4.

\section{3orḱommen.}

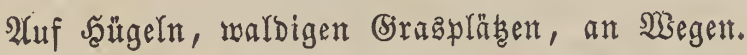

(sigenicbaften, গ⿰ułen, $\mathfrak{A}$ wwendung.

Selgr gute శutterpflamze.

\section{Trifolium montanum. L.}

Trifolium album. Crantz. ภlee.

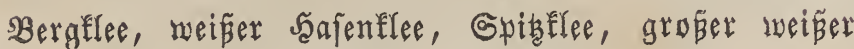

Trefle de montagne. (frantz.)

Mountain Trefoil. (engl.)

\section{Strten $=$ Sharater.}

Stengel 1 Fú hoch, aufrecht, haarig, grauliad, oben getheilt. Blätter furzgeftielt. Blätteben eirund-länglidy, fein und fpisig gefägt, zart geftreift, fein behaart. 2lfter=

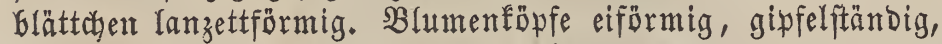
zottig geftielt, gemöbnlich zu 3 ftefyend. Seldy faft glatt ober fein befaart, bejonders an feinem Sande. Relchzähne un= gleich und fo lang als bie Blumenröbre. SBlüthen meif.

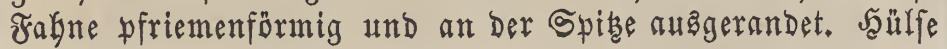
flein, eirund, nacht, 1 jamig.
Mai - รuni. 4 .

\section{Slithe $=$ 3eit und Dauex}

\section{3orÉomen.}

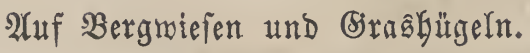

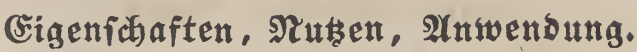

Der Bergflee ift ein vorzüglictes $\mathfrak{B}$ iegfutter und wirb auch roie Der breiblätterige Rlee fleisig yon Den Bienen bejucht."

\section{'Irifolium arvense. L.}

Trifolium Lagopus. Neck.

Trifolium pectinatum. Willd.

$\beta$. Trifolium gracile. Thuil.

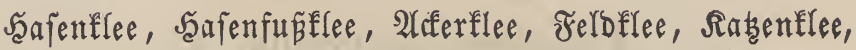

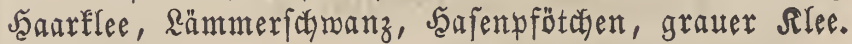

Patte de lievre, Trefle des moissons. (franz.)

Hare's - foot Trefoil. (entrgl.)

\section{$\mathfrak{A} \mathfrak{t}$ ten $=$ (5)arafter.}

Stengel $1 / 2-1$ Fun hoch, aufredyt, einfad ober, fehr äftig, weich bebaart und bäuftg foủoun roth gefärbt. Blätter furzgeftielt, abmectfelnd ftekend, 3zählig. Blättchen ganz=

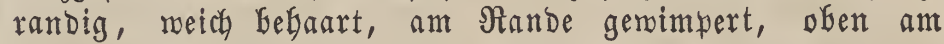
Stengel fotmal, verfebrt eifürmig-linienförmig, unten feil= förmig, ftumpf auşgerandet. Afferblättchen bäutig, vernad)= fen, zottig, pfriemenförmig zugefpitst. 2(ehren flein, bicht, geftielt, blätterlos, länglich-eifürmig, faft ralžnförmig, felgr bicht und zottig behaart, fpäter melyr langgeftrecft mer= Dend. Relchzăhne faft gleid, lang zottig behaart, Gedeutend länger als bie B̧lumentrone, welche flein, reiplich ober fleif̧çarbig ift. Seülfe flein, rundlidy-eifürmig, glatt und $1-2$ jamig.

Wallroth Gefdreibt eine Barietät biefer $\mathfrak{P f l a n z e : ~}$

$$
\beta \text {. sylvaticum. }
$$

Der Gtengel gegen 2 Fuß Goch, felyr äftig. Blättchen linien-lanzetfförmig; bie 2 elgren länglich und langgeftielt.

Bläthe = Beit und Dauter.

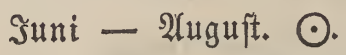

\section{Borkmmen.}

2uf $\mathfrak{A}$ erfern und Triften, unter ber Saat; Die $\mathfrak{B a r i e =}$ tät in W̧äldern, in Sadjfen 26 .

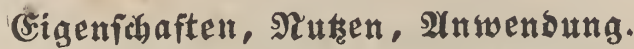

Die ßfflanze hat einen Dem breiblätterigen Rlee ähn= lichen, angenekmen, Gonigartigen, nur noch ftärferen (Se= ruch und einen frautartigen, füßlichen, etwab berben Befchmad?.

Man bat Den Saafenflee zum Berben empfoblen.

\section{Trifolium stellatum. L.}

Sternförmiger Rlee.

Trefle étoile. (franz.)

Star Trefoil. (engl.)

\section{2lrten = Çharaéter.}

Stengel 8-9 8oll lang, zottig, augagebreitet. Blätter mit langen, haarigen Blattfitielen. Slättchen berfegrt-berz=

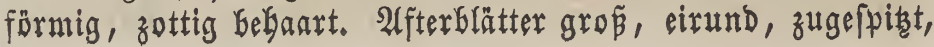


geabert, zottig. 2(ekren eiförmig, behaart. Selch you ber Blumentrone abfebend, ftarf zottig bebaart, und feine Säbne gleidy, fajmal und fo lang als bie Corolle. Blumen meí

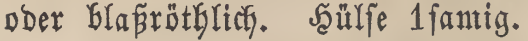

Blüthe $=$ Seit und Dauer.

รuni $=2 \mathfrak{H g u f t}$. $\odot$.

\section{3orEmmen.}

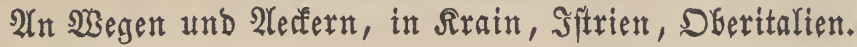
Dalmatien.

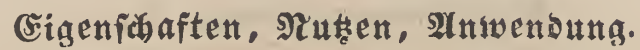
benulut.

গুsird in Franfreich als Futterfraut angebaut und

\section{Trifolium fragiferum, L.}

Galearia fragifera. Presl.

$\beta$. Trifolium fragiferum proliferum. Bernh.

Erobeerflee, Blafenflee, rotger friectyender Rlec.

Trefle fraise. (franz.)

Strawberry Trefoil. (entgl.)

\section{Arten = Sharakter.}

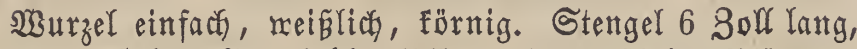
friectend, ätig, effig, fagl. Blätter langgeftielt. Blättçen werfehrt-eiförmig, ftumpf ober augagerandet, glatt, fein gezähnt. 2lftérblättçen lanzettförmig, fpitig, grün geabert. Blumentitele Yang. Blumenföyfe runblich, werben mit ber Jructreife gröper und erbalten burdy bie ftet aufblafendent Selche eime Den Erbbeeren äGnliche bieftalt. Relch bäutig, weidbaarig, ftefen bleifend. Sieldazange boritig und zwei bavon rủffwärts gefogen. Blumen flein, rofenroth. Şülfe eirund, zufammengedrü cft, $2=$ ober 1 famig. Samen nieren= fürmig, glänzend.

Bliithe $=$ 3eit und Sauer.

รuni - $\mathfrak{4}$ gut. 4 .

\section{3ortommen.}

2Uuf feuctyten $2 \mathfrak{s i e f e n ~ u n d ~ F e i d e n . ~}$

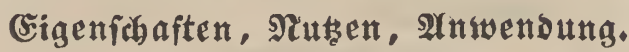

๔̌in fehr gutes Bieffutter, weldyes băufig mit bem Scopfentlee bermifcht angebaut wirb.

\section{I'rifolium agrarium. L.}

Trifolium aureum. Pollich. Vill.

Trifolium campestre. Gmel.

Trifolium strepens. Crantz.

Amarenus agrarius. Presl.

Belber Silee, goldfarfiger Rlee, gemteiner Jaoffentlee, gelber Fapfenflee, raufdender Rlee, grober (5) old flee.

Trefle des champs. (frant?.)

Yellow Hop Trefoil. (entgr.)

\section{SHten = Sharater.}

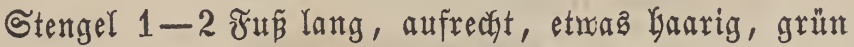
vber röthlidy, aftig. Blätter zahlreid, furzgeftielt. Frieder= blättchen lanzettförmig-feilförmig, fein gefägt. 2afterblätt= dyen aufrecht, lanzettförmig, glatt. Blüthenftiele ach fel = und endftändig. Aebre eifürmig, ziegeldaryfärmig. Relchzägne। glatt, ungleich und pfriemenförmig. Blütben fäb̈n golbgelb,

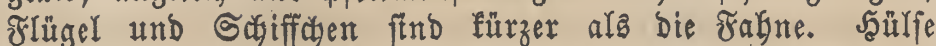
flein, yon ber bertroctneten Blüthe ungeben, geftielt, eiför= ntig, zujammengebrüaft, 1 jamig. Samen eiförmig, gelbliç, glatt.

\section{Blüthe $=3$ eit und Dauer.}

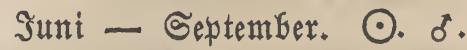

\section{YorEommen.}

Aư 2 ecefern, Brachärfern, und unter ber Saat, auf

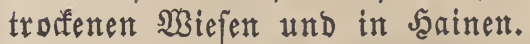

Bigenfáb aften, Nuten, צnwendung.

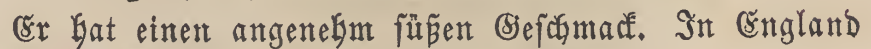
wird Diefer Rlee unter daz Getreide gejäet.

\section{Trifolium filiforme. L.}

Trifolium luteum. $\beta$. Lam.

Trifolium minus. Sm.

Trifolium procumbens. Pollich.

Amarenus filiformis. Presl.

$\beta$. Trifolium filiforme multiflorum. DeC.

Trifolium dubium. Abbot.

Trifolium procumbens. Huds. Curt.

$\gamma$. Trifolium filiforme microphyllum. Sering.

Trifolium controversum. Jan.

Jabenfürmiger Rlee, Fabenflee, Hleiner Goldflee, Hlet= ner gelber Şopfenflee, feinftengeliger ßilee.

Small Trefoil. (entgl.)

\section{Arten = Sharater.}

Stengel 3-12 3oll lang, nieberliegend, felten etwas aufrectit, Gaarig, yon unten an mit berlängerten Aleften. Blattftiele befaart, Die obern fürzer. B̧lättefen berfebrt-berz= förmig, fahl, geftreift, unten ganzrandig, oben gezäbnelt, geftielt. 2ffterblättchen eiförmig, fpis, gemimpert. 2(ebren fopfförmig, Galbfugelig, wenig blütbig, etwäb hängend. Blu= menftiele fadenförmig, faft doppelt länger als das $B$ latt. Jielch glatt, bie untern 3 Sähne fend länger. Blütben gold = gelb, zulebt Graun. Falyne etwas büngend, geftelt unb bleis bend. Şülje länglia, 1 jamig.

\section{Slüthe = Beit und Dauer.}

$\mathfrak{s u n i}-\mathfrak{s u l i} \odot$.

23ortommen.

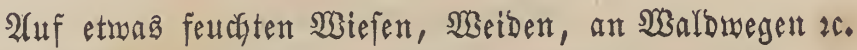

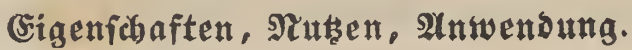

(ङ)นtę̧ Futterfraut.

Lathyrus. I.

Sieke S. 21.

Lathyrus Aphaca. L.

Lathyrus segetum. Lam.

Aphaca vulgaris. Presl.

Pisum Aphaca. Brot.

Vicia exstipulata. Gawl.

Rinjenblatterbje, Glattloje \$latterbje, gelbe \$latterbje. Yellow Lathyrus. (engr.) 


\section{Arten = Sharakter.}

Stengel 6-12 30ll hod, fdjwath, liegend, 4eefig, nacft, blattloz. Sifterblätter fehr grus, pfeil= unb Gerzför= mig, einander gegenüber fefend, feftftsend, gerippt, grau=

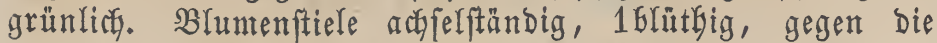
Spibe Gin etwas berfblätterartig und etwas befaart. B̉̆ men flein, fonmefelgelf. Sielefzälgne fpikig, etros fürzer

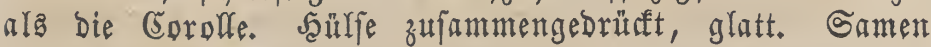
glẳzend.

\section{Blüthe $=$ Beit $\mathfrak{u} \mathfrak{s} \mathfrak{D a u e x}$.}

গuni - suli. $\odot$.

\section{3ortentumen.}

2Huf Aerfern, unter Dem Setreide.

\section{Eigenfdaften, গ⿰ułen, Amwendung.}

Wird yom $\mathfrak{B i e h}$ fefr gerne gefreffen, ift aber, weil bie Pflanze blätterlos ift, ein fegr unbedeutendes Jutter.

\section{Lathyrus pratensis. L.}

$\beta$. Lathyrus Hallersteinii. Baumg.

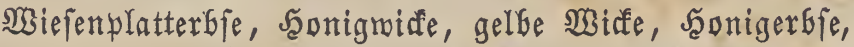
gelbe 2ogelnidfe, Zaunmiffe; gemeine Bogelniffe, SBiejen= ficher, șiefenerbje.

Gesse de prés. (firanz.)

Meadow Lathyrus. (entgl.)

\section{2lrten = (5)arałter.}

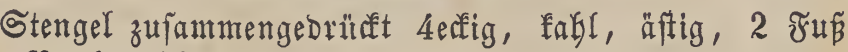

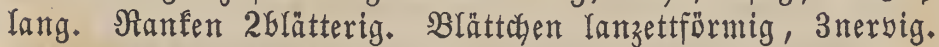
2ffterblättchen yfeilförmig, und fo grof́ ala bie Blättchen. Blütbenftiel lang, gefurcht. Traube einfeitig. Blütben gelb.

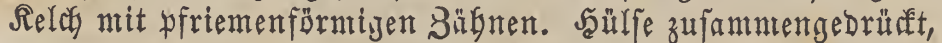
glatt und farwarz. Samen rothbraun. Blättern.

Die SPfanze wariirt mit glatten and biel Ereitern

\section{Blüthe $=$ Beit und Dautr.}

Mni - $\mathfrak{H}$ II. 4 .

\section{Borḱmmen.}

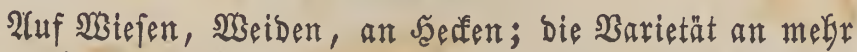
feucisten Drten.

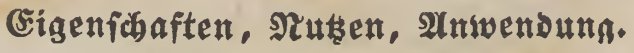

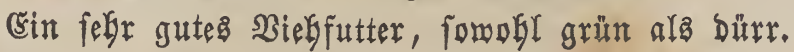

\section{Vicia. L.}

Faba. Adans. Juss.

Syfteme: Cyteophyta. Neck.

Diadelphia, Decandria. L.

Leguminosae regulares. Roy.

Leguminosae Vicieae. Adans. DeC.

Papilionaceae. L.

Papilionaceae Fabaceae. Rchbch.

Papilionaceae Vicieae. Spach.

Reld ganzblätterig, röhrenförmig, 5 fwaltig, zugefpibt, mit 2 obern fürzern, einander fith näkernden Rappen. Blu= menfrome fofmetterlings̃förmig. Frabne eiförmig, an ben Seiten zurürffgefogen, mit einem breiten, länglichen Nagel, an Der Spibe auşgerandet unb mit einer Rängalinie berjeben.
Die 2 Flügel Yänglich, aufrecht, Galbherzföntmig und fürzer

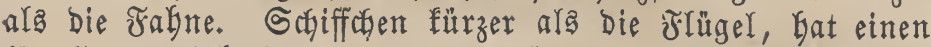

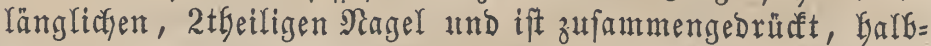
zirfelfürmig baudbig. Staubgefäpe 10, Dem Reldtgrumbe ein= gefủgt. Staubfäben fabenförmig, 9 vermachien, 1 frei. Staubbutel rumblich, doer eiförntig, 2 fücherig. Stempel 1. Frudgtfnoten fthend DDer furzgeftielt, längliç, zufammen= gebrürtt. Beriffel gefniet, plattgebrücft oder fabenförmig, oben unter Der Narbe ntit einem Barte. Narbe endfändig, ftumpf, lopftg. Shülfe länglich, zufantmengebrüưt, leberartig, fith in eine Spize endigend, 1 fächerig, vielfamig. Samen etmas fugelig, จber etwas zufammengebrủaft-eiförmig.

\section{Vicia Cracca. I.}

Vicia multiflora. $\propto$. Lam.

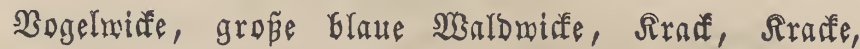
Bogelfeu.

Tufted Vetch. (engl.)

\section{2rrten = Eharater.}

Wurzel friedjend. Stengel 2-4 Fur Goch, erfétg, ge= furcht, weidhbarig. BSlätter abmechlelnd, mit $16-20$ lan= zett-linienförmigen, ftumpfen, etwaz beftäubten Blättchen. alfterblättchen mit 2 fchmärzlichen Flecfen verfeben, ganzran= big, Galbpfeilförmig, linien-pfriemenförmig. Blüthenftiele länger alä bie Blütter, achfelftündig, gefurcht. Blüthen violettblau, in bichten, ziegeldachförmigen, Güngenden, lan= gen Trauben ftehend. Die 3 untern Relchzägne Gaben einen fabmärzlichen Fleden. Şủlfe hångend, geabert, vielfamig. Samen fugelig, fchmarzbraun.

\section{Slüthe = Beit uns Sauer.}

รuni - suli. 4 .

\section{Sorkommen.}

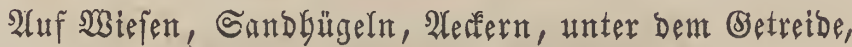
an $8 \ddot{a} \mathfrak{n}$ en.

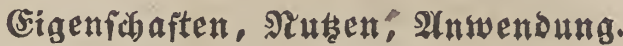

(5)utes Futterfraut.

Vicia sepium. L.

Vicioides sepium. Moench.

Wiggersia sepium. Fl. Wett.

$\beta$. Vicia ochroleuca. Bast.

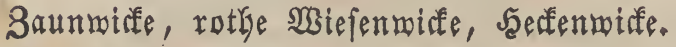

Vesce des haies. (finmz.)

Bush Vetch. (engl.)

\section{Arten = (5) Garater.}

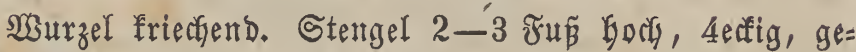
furcht, nacft. Blättchen 12-14, ganzranbig, eiförmig, mit

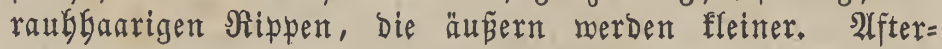
blättchen gezälnt, mit einem braunen Flecfent. Blütbentraube zu 4-6 ftefjend, achjelftäbig, einfeitig. B̧hmenfrome an= feb̆liḑ, Gla bebaart, roth. Jaủlfen etwas geftielt, etraas zufammenge= brǚt, rumb, glatt, bängend, reif aber aufrecht. Samen glatt, braun und fomarzflectig. 
Blüthe $=$ Beit und Dauer.

Mai - Suni 4.

\section{Borkomuten.} Şäldern.

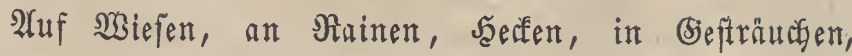

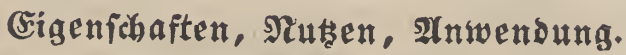

(3)

Trigonella, L.

Buceras. Moench.

Falcatula. Brot.

Foenugraecum. Adans.

Grammocarpus. Sering.

Kentia. Adans.

Snfteme: Cyteophyta. Neck.

Diadelphia, Decandria. L.

Leguminosae Genistae. Adans.

Leguminosae irregulares. Roy.

Leguminosae Loteae. DeC.,

Papilionaceae. L.

Papilionaceae Loteae. Rchbch. Spach.

Relch ganzblïtterig, glocfenförmig, Geinabe 5fpartig ober 5 zälgnig. Blumenfrone fchmetterlingaförunig, abfaflend, beinabe 3blätterig. Fahne aufgerichtet, eirund. Die zmei Flitgel abfebend, conver. Gchiffchen ganzblätterig, ftumpf, flein. Staubgefääe 10, Dem Sielchgrunde eingefügt. Staub= fäben: 9 serwachfen, 1 frei. Staubbeutel runblich, 2 fäche= rig. Stempel 1. Fruchtenoten bis zum Jiriffel gerabe. Siriffel auffteigend, fabenförmig, narft. Narbe endftündig, ftumpf, beinabe fopfig. Sä̆lje länglich, fchmal, geftielt ober

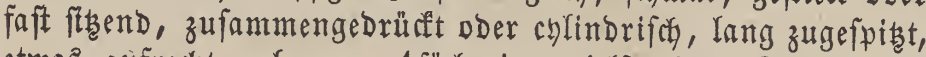
etras aufrecht gebogen, 1 fädherig, bielfamig. Samen bei= nale 4effig woer eifürmig, runzelig ober Geförnt.

\section{Trigonella Foenum graecum. L.}

Trigonella gladiata. Hortul.

Buceras Foenum graecum. All.

Foenum graecum officinale. Moench.

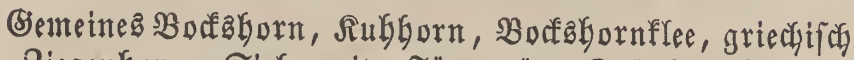

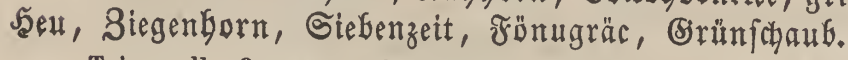

Trigonelle fenugrec, Sennegrain. (franz.)

Common Fenugreek. (engl.)

\section{Arten $=$ (5)araltex.}

Wurzel einfach, Dünn, befafert. Stengel $1-2 \widetilde{\mho u}$ boch, aufrecht, einfach Doer äftig, runb, geftreift, glatt und fteif. BBlätter 3zäblig, theilmeife langgeftielt, abrecbjelnd ftebend, glatt. Blättchen $1 / 2-3 / 430 \mathfrak{l l}$ lang, feilfürmig, verfebrt-eifürmig, ftumpf ober ausegerändert, yorren feit gezälght, glatt, unten gegen die Bafta Gin theilmeife bebaart. Blattfiele ebenfalls fowmach barig. Blumen flein, einzeln ober zu 2 ftefjend, achfelftändig, fikend und bla

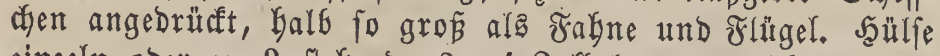
einzeln oder zu 2 ftelgend, $3-4$ Soll lang und $1 \frac{1}{2}-2$ Ri= nien Greit, ungeftielt, linienförmig, zufammengebrüft, lang zugefpibt, fictelfërmig gefrümmt, neţartig geabert, böcferig, glatt, iteif, vielfamig und graugelslich. Samen $1-2$ Rinien lang, 1 Rinie breit, rundlich, zujammengedrünt, an ben
Ënben frgief afrgeftutht, ecfig, auf simer Seite flach, auf ber andern conber, zur Jäalfte fohief gefurcht, matt braun ober rothgelf und innen gelf.

\section{Blüthe = Beit und Dauer. \\ Suni - suli. $\odot$.}

\section{3orkommen.}

In Sübeuropa, bem füblichen. Jrankreid, auf 2(ecfern, in 2leggpten und in Deutfhland (Thüringen, Bamberg 2c.), Stalien, Solen angebaut.

\section{§ultur.}

Der Boofabornflee serlangt einen guten, mürben und rein yout Unfraute gefaltenen Boden, Der gut aufgelocfert

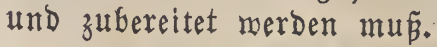

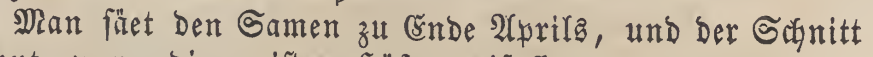
beginnt, nenn bie meiften ફ̧üfen reif find.

\section{Cigenfibaften, গtüen, 2(nwenoung.}

Der Samen entmicfelt zerftop̈en einen ftarfen, wiber= richen, Dem Steinflee einigernaken ähnlichen (jeruch und Gat einen mebligen, unangenebm gemürghaft füßlid_-bittern \&e= (c) mate.

Bormaltende Beftandtheile Deffelben find: AYetherifdyes und fettes Del, bitterer (Extraftioftoff und Silleim.

Wie oben angegeben, Gaut man bas griectifdye Sent noch in verichiedenen Segenden an, jeboch als Jutterpflanze

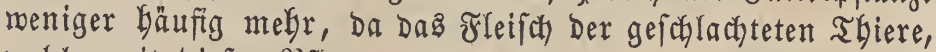
welche mit biefer \$flanze gefüttert merben, Den Beruch Der= felfen beigebält.

Man gebraudft bie Samen zu ermeidenden Umidhlägen, yorzuganeife in ber Thierkeilfunde; Das Sulver foll Die Sopfläufe vertreiben. Früber gebraudte man Das Rraut als Siemüle; in 2legypten mirb aus bem Samen mit Milcts ein Brei Gereitet, Deffen Gäufigem Benuf bie Weiber ifre Moblbeleibtheit zu werdanfen Gaben folfen.

\section{Ervum. L.}

Ervilia. Link.

Lens. Sering.

Syfteme: Cyteophyta. Neck.

Diadelphia, Decandria. L.

Leguminosae. Juss.

Leguminosae irregulares. Roy.

Leguminosae Vicieae. Adans. DeC.

Papilionaceae. L.

Papilionaceae Fabaceae. Rchbch.

Papilionaceae Vicieae. Schultz. Spach.

Relch ganzblätterig, glocfenförmig, 5fpaltig ober 5 zăgy= nig, mit fchmalen Bipfeln. Blumenfrone fchmetterlingaför= mig. Fahne aufgerichtet, länger als bie శ̧lägel und bą Schiffdyen. Die 2 Flügel ftumpf, an Der Baftz ủber bem Nagel in einen boblen Babn eingebrücft. Schiffden ftumpf, zugefpibt, ganzblätterig. Staubgefäße 10. Staubfäden pfrie= men-fabenförmig, 9 verwachfen, 1 frei. Staubbeutel rund= lich, 2fächerig. Stempel 1. Jrubthnoten fizend ober furz= geftielt, läıtgliç. Srriffel auffeigend, frobenförmilg. Narbe enditünbig, ftumpf, beinabe fopfig. Saülje zufammengebrüuft, 1 fächerig, 2flappig, 1 = - mebrjamig. Samen zufammen= gebrüctit, fugelig Dber faft 3 ecfig, glatt. 
Ervum tetraspermum. L.

Vicia gemella. Crantz.

Vicia pusilla. Mhlbrg.

Vicia tetrasperma. Schreb.

$\beta$. Ervum gracile. DeC.

Ervum longifolium. Tenor.

Ervum tenuifolium. Lagasc.

Ervum tenuissimum. Bbrst.

Vicia gracilis. Loisl.

Vicia laxiflora. Brot.

Bierfamige Errffe, vierfamige Rinje, vierfantige Rinfen= miafe, vierjamige milde Rinfe, fleine glatte Feldmiffe.

Ers tetrasperme. (frallz.)

Smooth tare, Little smooth tare. (engl.)

\section{2lrten = 5 harakter.}

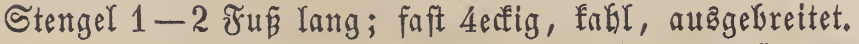
Blättchen länglich, lanzett-linienförmig, afgeftubt und ftactel= fpitzig. 'Utferblättchen halb pfeilförmig. SBlumenftiele $1=$, fel= tener $2 \mathfrak{b l u ̈ t h i g , ~ a c h j e l f t a ̈ n d i g , ~ e t w a g ~ u ̈ b e r h a ̈ n g e n d . ~ B l u ̈ t h e n ~}$ flein, violettpurpurroth. Şŭlle glatt, rundlia, 4 famig. Samen fugelfürmig, Gräunlich, fchmarz getủpfelt, reif fochmarz.

Blüthe = 3eit und Dauer.

Iuni - Inli. $\odot$.

\section{צyorammen.}

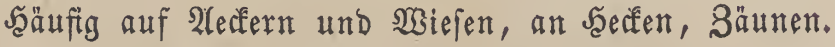

(sigenfabaften, Nuten, Alnwendung.

Die vierjamige sinfe ift ein gute zutterfraut.

Ervum hirsutum. L.

Ervum filiforme, Roxb.

Vicia hirsuta. K.

Vicia Mitchelii. Ráin

Sweifamige Rinfe, Gefaarte 'infe, fleine Bogelmidfe, behaarte Erbe, zottige Rinje, rauke Rinfenwitfe.

Ers velu. (franz.)

Hairy tare. (engl.)

\section{Alrten = Sharater.}

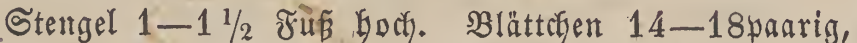
linien-lanzettförmig, abgefubt, an Der Spibe gegrannt. 2lfterblättchen 2theilig. SBlüthenftiele fo lang alä Das Blatt, 4-8flumig. SBlumen flein, meiflich violett. Şülfe furz, raul befaart, 2 famig. Samen kugelig, vrivenfarbig, braun marmorirt.

Blüthe $=$ Beit $\mathfrak{u n d}$ Danex.

รuni $-\mathfrak{A}$ uguft. $\odot$.

\section{0rtommen.}

Aนu 2Tecfern, unter Der Saat.

Eigenfuaften, গuten, Anwenoung.

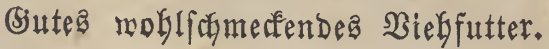

\section{Ervum Ervilia. L.}

Ervum plicatum. Moench.

Ervilia sativa. Link.

Vicia Ervilia. Willd.

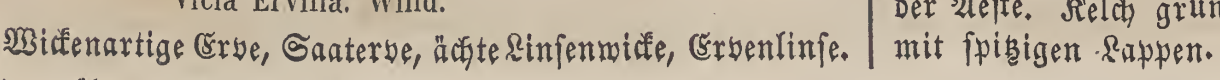

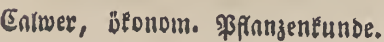

\section{Arten = Charater.}

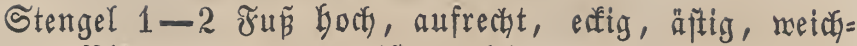
behaart. Blätter geftielt, meift ungleich gepaart. Blăttchen berfefrt-lanzettförmig, an ber Spike eingebrünt, furz ge=

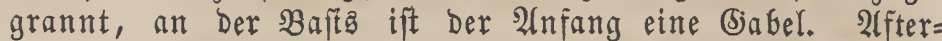
blättchen eirund-lanzettförnig, mit einem Sakne beider= feitö. Blumenftiele furz, adyelftändig, $1=$, felten 26 lütfig. Selch Gelfgrün, glatt, 5 fpaltig; bie 3ipfel gleichförntig. Blü= then meís. Fahne violett geftreift. Das Sdhiffchen bat eine Glaue Spibe. Şülfe glatt, bauchig, fnotig, 4jamig. Samen fugelförmig, ftumpfectig, afchgrau.

\section{Blüthe = Beit und $\mathfrak{D a u e x}$.}

Iแni - 2ugut. $\odot$.

\section{BorEmmen.}

Auf Aecfern, unter Dem Setreibe.

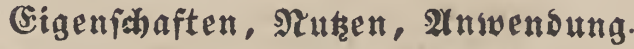

(3ute $\mathfrak{B}$ iehfutter. Wirb in Franfreidy und Der Schmeiz angebaut.

\section{Scleranthus. L.}

Knavel. Adans.

Syfteme: Blita. Adans.

Chenopodeae. R. Brown.

Decandria, Digynia. L.

Incompletae. Roy.

Paronychieae. DeC.

Polygona. Rül.

Portulacaceae. Juss.

Sysselophyta. Neck.

Sclerantheae. Bartl.

Seldh 1blätterig, röbrig, am Saalje verengt, $5=$, felte= ner 4 fpaltig, Gleibend. Blumentrone feglt. Staubgefä́a 10 , yor Dem Sdylundringe eingefügt. Staubfäben pfriemenför= mig, febr flein. Staubbentel rundlich-2fnotig, 2fächerig, einnärtz gefehrt. Stempel 1. Fruchtfnoten oberitändig, in Der Seldyrögre eingefchloffen, 1 fächerig. Esriffel 2, fabenför= mig. Narfen endftändig, fleinfopfig. Schließ̈̈rucht eiförmig, febr zart, yon Dem Reldye umgeben, 1 fächerig, 1 famig. Samen melar oder meniger conbex oder flach, glatt.

\section{Scleranthus annuus. L.}

Knavel annuum. Scop

Loefflingia hispanica. Hort.

$\beta$. Scleranthus collinus. Hornung.

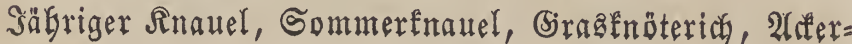
Enöterich.

Annual Knawel. (engr.)

\section{2urten = Coharafter.}

SWurzel bünn, weí̃, gerade, fpindelig. Stengel faum fingeralang, abftefend, aufrectst, an Der Bafta äftig und nieberliegend, auf einer Seite flaumbaarig, auf Der andern nacft. Blätter gegenftänbig, borftenförmig, fuibig, Dber= feite flach, Unterfeite conbex, am verbreiterten ranbGă Grunde zufammengemachfen und gemimpert. Blüthen ftgend, in Niäpen ober in Doldentrauben, oder angebäuft am ङ゙nde

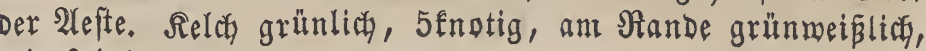




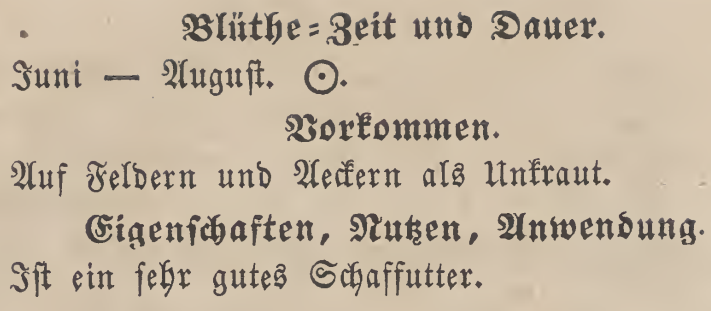

\section{Alchemilla, L.}

Syfteme: Dryadeae. Spach.

Potentillae. Rül.

Rosaceae. Adans. Juss.

Rosaceae Agrimoniaceae. Vent.

Rosaceae Dryadeae. DeC.

Rosaceae Sanguisorbeae. Spr.

Sanguisorbeae. Schultz.

Sysselophyta. Neck.

Tetrandria, Monogynia. L.

אelch 1blätterig, 4fpaltig, frugförmig, bleibend, mit chlinbrifcher Röhre und 8jpaltigem Saume; bie Rappen af= wedjelnd fleiner. Blumenfrone feblt. Staubgefäze 1-4, Dem Drüfenringe Dę̧ Gchlundes eingefügt. Staubfäben pfriemlich - fäblich. Staubbeutel runblich, 1 fächerig. Stem= pel 1 - 4. Frudstfnoten frei, länglich-rumb, 1 fïcherig. Griffel fadenfürmig, an Der $\mathfrak{B} a$ fts Des Jrudytfnotens einge=

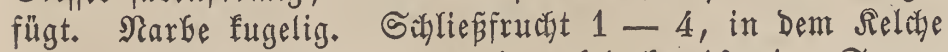
eingefchloffen, yon einer feinen baut beberft, 1 famig. Samen

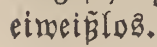

\section{Alchemilla vulgaris. L. \\ Alchemilla glaberrima. Schmidt. \\ Alchemilla glabrata. Tausch. \\ Alchemilla multicaulis. Tausch. \\ Alchemilla palmata. Gilib. \\ Alchemilla pratensis. Schmidt. \\ Alchemilla sylvestris. Schmidt. \\ Alchemilla truncata. Tausch.}

Selber Sinat, Erauenmantel, Sonnenthau, sreyemi= ftenfraut, \$lutterfraut, Tappe, gemeiner Römenfú, Bären=

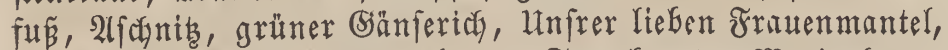
Zrauenbís, Siefenfommerthau, Sternfraut, Marienfraut,

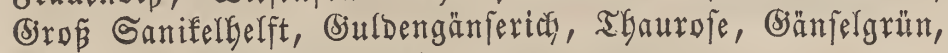
Römentappe, Marienmantel.

Common Ladies Mantle. (entgh.)

\section{Slrten $=$ Ebarater.}

2Surzel biaf, Gorizontal, fabmarzbraun, faferig. Stengel fpannelang, gabelförmig, meift behaart. Blätter $2-3$ 8oll lang und Greit, nierenförmig, mantelartig gefaltet, $7-10=$ lappig, bie Rapyen rundlich, fpibig - gezähnt; untere $\mathfrak{B l a ̈ t}=$ ter auf langen haarigen Stielen, bie oberen alfmällig finrzer

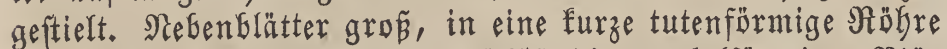
verwadjfen. Doldentraube gipfelftändig, gafelförmig. Blü= then flein, gelflich.

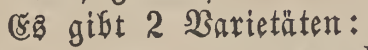

$$
\beta \text {. gl a bra. }
$$

Die Blătter am Siande und unten an Den Rippen etwag baarig, im Hefrigen glatt.

Sebart.

\section{Blüthe = $\mathfrak{Z}$ it $\mathfrak{u n d}$ Dauer. \\ Mai - Suli. 4 .}

\section{3ortommer.}

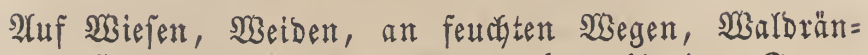

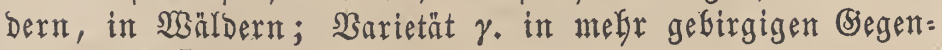
Den, Varietät $\beta$, in Schleften.

\section{(Eigenichaften, গtuten, Anwendung.}

Wurzel und Sraut baben einen zujammenziebenden (5es= fifmáa

Die Allchymiften fammelten yon Den Blättern diéfer Pflanze Den Thau.

\section{Meum. L.}

Pentandria, Digynia. L. Scadiophyta. Neck.

Umbellatae. L.

Umbelliferae. Juss.

Umbelliferae Seselineae. DeC.

Relch ganz̧lätterig, mit oberftändigem, 5zăbnigem Saume und fabler, geriefter $\Re$ b̆hre. Blumenfrone 5blätterig, ab= fallend. Blumenflätter gleid, verfebrt - eirund, etwaz auas= gerandet, mit eingefalagenem breitem Sipfel. Staubgefäpe 5, mit Den Blumenblättern eingefügt. Staubfäden faden= förmig. Staubbeutel eiförmig - rundlich, 2fächerig. Stem= pel 1. Frudutfnoten unterftändig, 2fächerig, mit einem ge=. mölsten Sriffelpolfter gefrönt. Giriffel 2, fabenförmig. Narben ftumpf, fopfig. Spaltfrudgt eiförmig, zujanmengebrücft. Theilfrüchte Dicht, 5 ftriemig. Samen umgefebrt, eimeiß̧altig.

\section{Meum athamanticum. Jacq.}

Neum anethifolium. Fl. Wett.

Aethusa Meum. L.

Athamanta Meum. L.

Ligusticum capillaceum. Lam.

Ligusticum Meum. Crantz. DeC.

Seseli Meum. Scop.

(Senteiner Bärmurz, officineflet Bărmurz, Bärfend del= wurz, Nuttermurz.

Common Spignel, Baudmoney. (entgl.)

\section{Arrten = Ełarakter.}

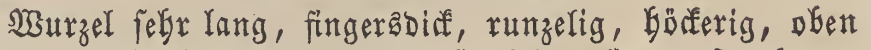
yon Den abgeftorbenen Blattftielen ftarf foy opftg, ausen braun

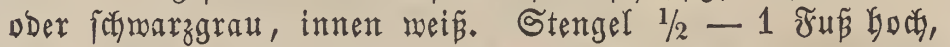
faft einfach, gerillt, fabl. Blătter vielfach zufammengefect, Gorftig. Warzelblätter langgeftelt, Geinabe baarförmig ge=

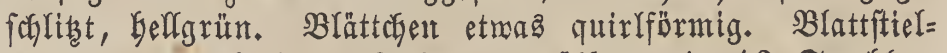
fcheiden aubigebreitet. Dolden gemölbt, mit 12 Strablen, eiper faft 1 Glätterigen Sälfe tmb $3-6$ blătterigen, faft nur

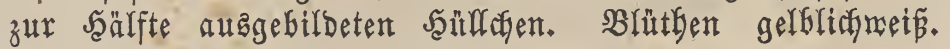
Frucht 3 Rinien lang und braun.

\section{słüthe = 3eit und sauer.}

รuni - 2uguft. 4 .

3ortommen.

2uf Gohen Bergmeiden, in Swmaben, Jranfen, im 
Schwarzwald, in Thüringen, Der Dberlauth, Safleften, Deftreich, Galzburg.

\section{Eigenídaften, Nutzen, Strwendung.}

Die ganze Bflanze, Gauptfächlich aber $\mathfrak{i s u r z e l ~ u n d ~ S a = ~}$

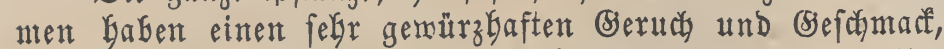
ift ein fegr gutes und gejundes Biefjutter, Mitldy und Butter befommen burch ite einen angenehm aromatifoct Bieruch

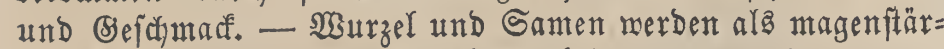
fendes Mittel und gegen Biehfrantheiten angemendet.

\section{Aegopodium. L.}

\section{Syftente: Pentandria, Digynia. L.}

Scadiophyta. Neck.

Umbellatae. L.

Umbelliferae. Juss.

Umbelliferae Ammieae. DeC.

Selch ganzblätterig, mit oberftänbigem, unbeutficyem Saume und eiförmiger, nacfter Röhre. Blumentrone 5Glät= terig, abfalfent. SBlumenblätter etmas ungleid, berfehrt - ei= runb, augegerandet, mit einem eingefolagenen 3ipfel. Staub= gefä 5 , mit Den Gorollenblättern eingefürt. Staubbeutel rundlich, 2 fädjerig, einmärts gefebrt. Stempel 1. Frucht= fnoten unteritäubig, 2 fächerig, mit einem conberen, ant

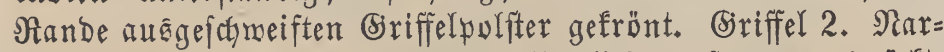
ben einfach, fupfig. Spaltfrucht länglich, zufanmengebrürft. Theilfrüctte bicht, 5 ftriemig. Samen umgefegrt, eimeižlos, ber zruchtiofale angefängt.

\section{Aegopodiúm Podagraria. L. \\ Aegopodium ternatum. Gilib. \\ Ligusticum Podagraria. Crantz. \\ Pimpinella angelicaefolia. Lam.? \\ Podagraria Aegopodium. Moench. \\ Seseli Aegopodium. Scop. \\ Sison Podagraria. Spr. \\ Sium vulgare. Bernl. \\ Tragoselinum Angelica. Lam.}

Benteitner Strengel, gemeiner (bierf reinfraut, Sierardąraut, Jeffel.

Common goud Weed. (engl.)

\section{Arten = Sharater.}

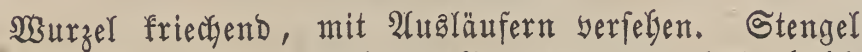

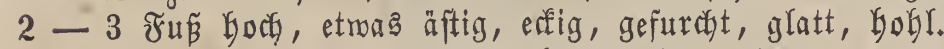
Blätter Doppelt ober 3fach, 3zählig. Siarzelflätter lang= geftielt, 2-3fach gefiebert, mit aufgetriebenen Scheiben.

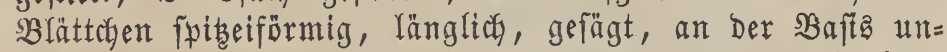
gleich, unten nur zu 2 ftebend. Dolden flad, 18 ftrablig.

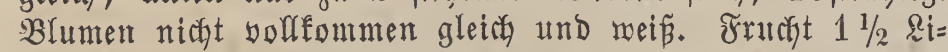
nien lang, eirund - länglich, bunfelbraun.

\section{Blüthe = Beit und Dauer.}

Mai - Suni. 4.

\section{Zorkommen.} গูGälbern.

$\mathfrak{M}$ feuchten Drten, in Graşgärten, an Şeffen, in

\section{(sigenfaften, গtuten, Anwendung.}

Das Sraut ift etwa gemürzlyaft. Der sierfich ift ein

gutes Schmeinefutter, wirb auth von Siegen und Sedafen gerne gefreffen, ift aber in Bärrten ein läftiges und ber

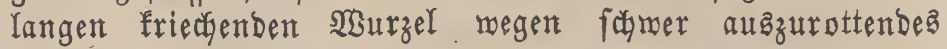
unfraut.

\section{Pimpinella. L.}

Anisum. Adans.

Ledebouria. Link.

Tragium. Spr.

Tragoselinum. Moench.

Syfteme: Pentandria, Digynia. L. Scadiophyta. Nęck.

Umbellatae. L.

Umbellatae Carea. Adans.

Umbelliferae. Juss.

Umbelliferae Ammieae. DeC.

Relcy ganzblätterig, mit oberftänbigem, unbeutliçem

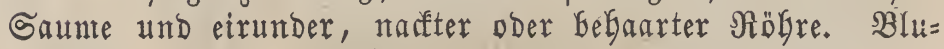
menfrone 5blätterig, abfallend. Blumenblätter gleich, ver= felgrt-eiförmig, augegerandet, mit einent eingefhlagenen, gezähnelten ober ganzrandigen, nacften ober befaarten Sipfel. Staubgefäß̨e 5, mit Den $\mathfrak{B}$ lumentiüttern eingefügt. Staub= füben fabenförmig. Staubbeutel eiförmig - runblich, 2 fäcţe= rig, einmärts gefegrt. Stempel 1. Frutchténoten unterftän= Dig, 2 f̧ächerig, mit einem legelfürmigen Bsiffelpolfter gefrönt. (Sriffel 2, lang, fabenfürmig, am Ënde zurürfigebogen. Nar= ben fopfig. Spartfrucht eirund, feitlicf zufammengezogen, narft ober bebaart. Theiffrüchte bicht, 5 ftriemig. Samen untgefefrt, eimeiphartig.

\section{Pimpinella magna. L.}

Pimpinella major. Gouan. Mill.

Pimpinella Saxifraga. Scop.

Tragoselinum magnum. Moench.

Tragoselinum majus. Lam.

$\beta$. Pimpinella rubra. Hort.

$\gamma$. Pimpinella orientalis. Gouan.

Pimpinella austriaca. Mill.

Pimpinella media. Hoffm.

\section{Grofée Bibernelle.}

Great Burnet Saxifraga. (engl.)

\section{Arten $=$ (5harakter.}

Barzel fpannelang und fungersెbick, fpindelförmig, zu=

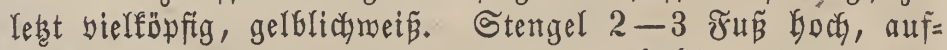
recht, ecfig gefurdst, oben gabelförmig, Gobl. Blätter gefie= Dert, die untern geftielt. Blättchen fpis, gefägt, etmaz gelappt und glänzend. Dolden $9-15$ ftraflig. Scüllen und

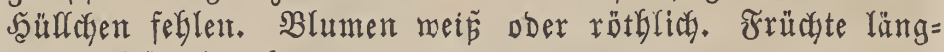
lich-eiförmig, braun.

Mian fennt yon biefer Pffanze einige Varietïten:

Mit rothen Blüthen.

$$
\beta \text {. floribus rubris. }
$$
ipitigig.

$$
\gamma \text {. orientalis. }
$$

Blättçen geffedert-gefpalten; Die Rappen lanzettförmig,

\section{$\delta$. dis s e cta.}

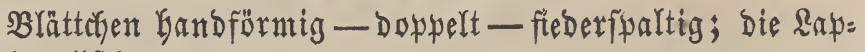
pen Yinenlifich. 


\section{B(iithe $=3$ eit und Dauer. \\ Suni - ฐuli. 4 .}

\section{Borénmen.}

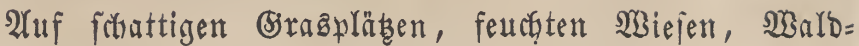

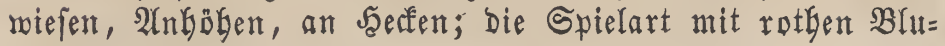
men auf 2rTpen.

\section{Cigeniaden, stuten, Anvenoung.}

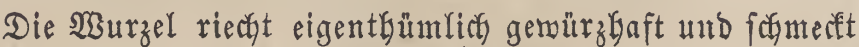

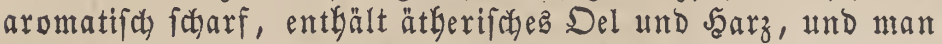
bereitet aus' ifr daz fogenannte BIaumaffer.

Die SPllanze ift ein gute $\mathfrak{B i e f f u t t e r}$ und wird zur Berbefferung faurer Biefen vermendet.

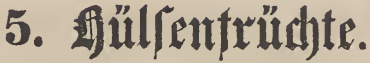

2lefergemäcţie, beren Samen in 2flappigen Sdjoten ober

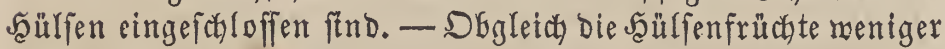
Mebl als die Setreidearten entbalten, fo find fie doch megen

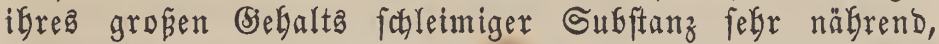
aber mebr ftopfend und Gläbend, Deß̧̧alb ibr senus eine

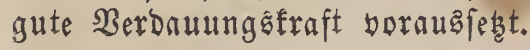

\section{Phaseolus. L.}

Drepanospron. Benth. Euphaseolus. DeC. Lasiospron. Benth. Leptospron. Benth.
Macroptilium. Benth.

Microchloe. Benth.

Phasellus. Moench.

Strophostyles. Ell.
Syfteme: Cyteophyta. Neck.

Diadelphia Decandria. L.

Leguminosae. Juss.

Leguminosae Phaseoleae. Adans. DeC.

Papilionaceae. L.

Papilionaceae Fabaceae, Rchbch.

Papilionaceae Phaseoleae. Spach.

Reld ganzblätterig, glodfenförmig, 2lippiog ober faft 5fpaltig, an Der Baftz mit 2 Derfblättchen verfehen; obere Rippe ganzrandig ober 2 zăgnig, die untere 3 zägnig. Blu= menfrome fametterlingsförmig. Frafne runblich, aufgeridhtet DDer zurủiffebogen, DDer etwaz gedreht, an Der Baftz ge= Dfrt. Die 2 Flüget ftumpf, rundlid, werfegrt-eirund voer länglich, fo lang ober länger alš die Frafne. Schiffchen gejdnäbelt uno oben foneffenförmig zufammengedreht. Staub= gefäße 10, Dem Reldggrunde eingerügt. Stauffäben pfriemen= förmig - fadenförmig, 9 vermadfen, 1 fret. Staubleutel eijörmig, 2fächerig. Stempel 1. Fruchtfnoten beinate finend, an Der Bafīs yon einer furzen Saneibe umgeben. Biriffel pfriemenförmig - fadenförmig, unter Der Sarbe behaart. Narbe länglich. Scülfe berlängert, zufammengebrüct oDer walzig, gerade uber fichelförmig, 2flappig, mehrfamig. Sa= men längliđ, eiförmig ober rundlich.

\section{Phaseolus vulgaris. L.}

Phaseolus lieac. Zucc.

Phaseolus nigerrimus. Zucc.

Bokne, gemeine Bohne, Samintbogne, Saneibefohne,
Stangenbohne, Stengelbohne, Shymertbohne, Sartenbohne,

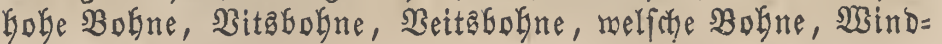
bofne, Steigbofne, Fajeole.

Faséole Haricot. (Frantz.)

Kidney - Bean. (emgl.)

\section{Arten = (5harater.}

Der Stengel ift 6-15 ซup Goch unb Göker, einfach,

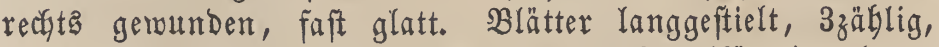
abmechfelnd, bie einzelnen $\mathfrak{B l a ̈ t t c h e n ~ g r o ß ́ , ~ e i f o ̈ r m i g , ~ l a n g = ~}$

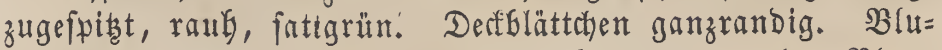
ntentrauben fürzer als bie Blätter, fommen aus Den Blatt= minfeln, flein, locfer, einzelnftebent , $4=$, meift 56lütbig. Blumenftiele 2blüthig. Affterblättchen etwas fürzer, aber Greiter ala Der Reldh, zu 2 und abftehend. Blumenfrone fleit, gemöhnlid) meí̄, ober gelflichroth, purpurroth, Gla $=$ biolett, meift roth geftreift oder gefleceft. Şülie grof́, bån= gend, meiftens fanderdfförmig, megr ober meniger höferig und wulftig, glatt, gegen bie Sieife hin wirb fie weif́lich = gelb, bünner, zăber, lederartio, innen mit perganentartigen ซ̌ächen. Samen länglich - eiförmig ober nierenförmig;

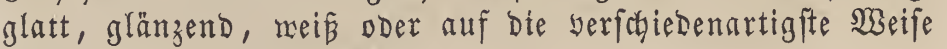
bunt gefärbst oder geflerft.

\section{Bälühe = Beit uns Dauer.}

Mai - รuni. $\odot$.

\section{Borénmen.}

Utrprönglict in Dftindien und wabricheinlich auch am

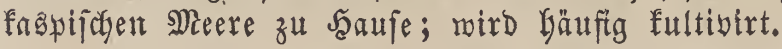

\section{Niultur.}

Die Bofnen verlangen einen locfern, nidyt zu fetten, gut gebüngten, trorfenen und nicht zu naffen Boben; einen

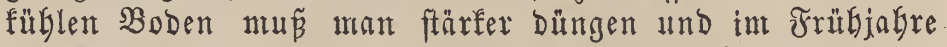
bie Serne fpäter fterfen. Da bie Bohnen fefr empfindlict gegen Den שroft und ifre Varietäten nach Slinia und Boben fehr veränderlich ftnd, fo Gat man fich mit Dent Stecten nach Dem Sabrgange und ber Dertlichfeit zu richten. SBifl man Die Bobnen grün effen, fo ftecft man fie von 2 bril bis Ënde 3̈ul's, wilf man biejelben aber bürr rerben laffen, yom 2lpril bią Ende Mai’ß. Man ftefft bie Stangenbohnen

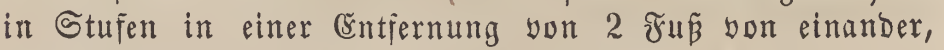
und zwar 4- 7 Serme in eine Stufe, und Defit fie mit

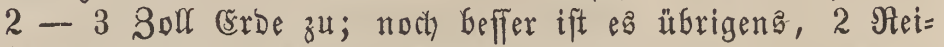
ben gall nake neben einander zu pfianzen, einen ßaum yon

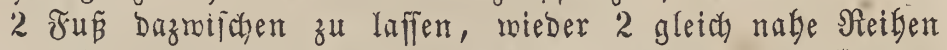

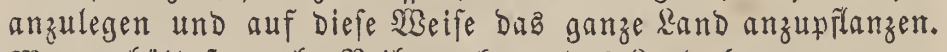
Man erbält fo mebr Sieifen, fann das Rand bequemer yom Unfraute reinigen und die Räpfe abftuten, bie Bobnen be= fommen mefr \&uft, weldye ifnen bejunders zur Blüthezeit Durchaus unentbebrlia ift, und ber Ertrag ift wohl Der 3 factle. - Wenn bis $\mathfrak{B}$ ohnen $6-8$ Soll hoch gewachen

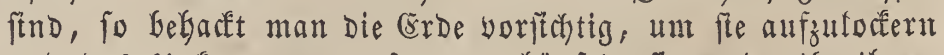
und Das unfraut zu entfernen, yäufelt fie und gif́t ifnen

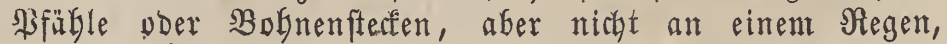

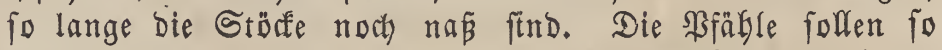

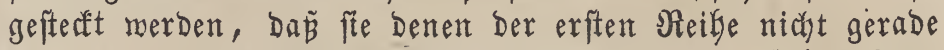
entgegen, jondern afmechfelnd mit benfelben zu ftelyen font= men. Mian fann bie SHfäble audy gleich bei ber Saat ein= fwlagen. 2Hocre ftecfen bie Boknen $2-3$ an ber $3 a$ hl 


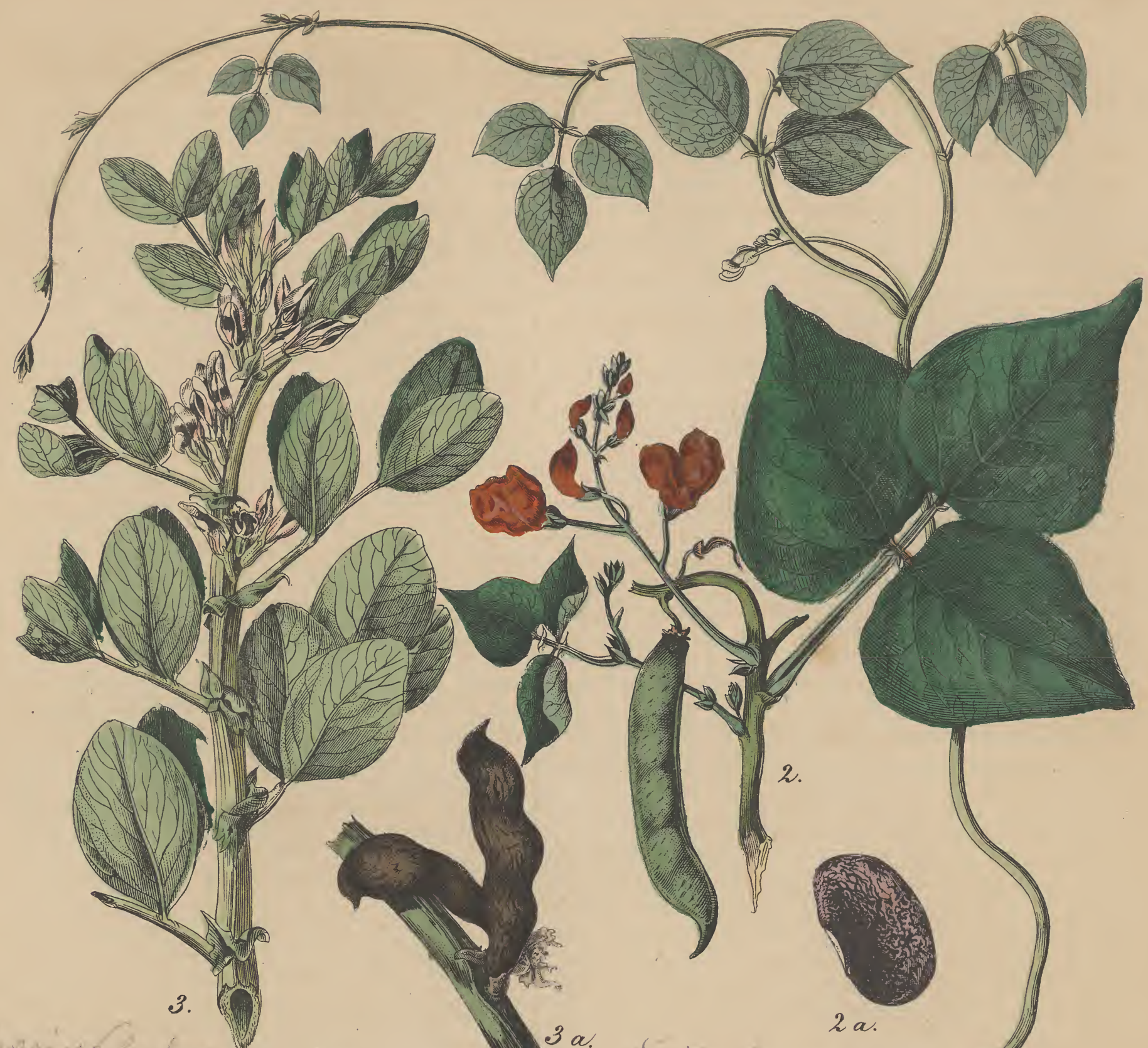


nur in einer Entfernung yon $2-3$ Soll yon einanber,

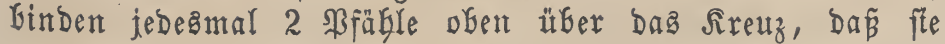
ungefägr 1 ชuñ lange (sabeln bilden, und befeftigen in biefe querüber einen meitern $\mathfrak{B f a h l}$, unt bie Stangen gegen Den Sturm zu fchügen. - $\mathfrak{U m}$ guten Samen zu zieken,

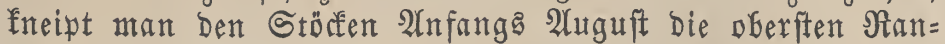

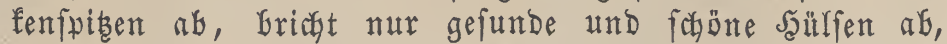
twenn fe zeitig find, und bemahrt Den Gamen in benfelben auf; Dbgleich bie Bobnen 4 Safre and länger feimfäbig find, fo follen zur 2 Ua 2 faat bod nur ein Gabr alte gemählt werben, ba letstere faft $2 \mathrm{mal}$ melgr tragen als altere. - lunt früber junge $\mathfrak{B}$ ofnen zu befommen, befolgt man bäufig bie Metfode, Dás man auf Dem anzupflanzenden Beete etra $12,2-3$ Sulf aus einander ftebende sinien zielgt und folche

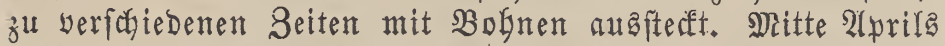
beginnt man unb belegt nun 3 Rinien mit $\mathfrak{B}$ ohnen, wartet 8 Tage weiter, belegt mieber 3 Rinien und fofort. Fänt nun bei biefer Bebandlunganeife ein Froft ein, fo befinden

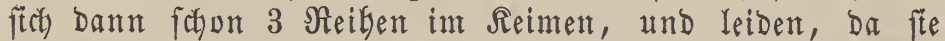
nody in ber Erde find, nidht bon bemfelben, baben fomit einen Borfwrung bor ben bereits aufgegangenen aber erfro= renen, meldye erft wieber burch erneuerte Gaat erfest werben müffert. Tritt nun aber gar fein Froft ein, fo gefdielgt es oft, Daf die Bognen fämutlicher Rinien unbejobäbigt bleiben,

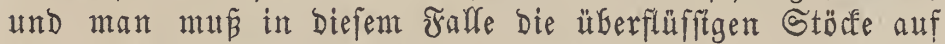
ein. anderes Beet verpflanzen. Bei anbaltenden beipen Sisetter werben bie Bognen gewöbnlich fohon in 14 Tagen zum Giefrauche als grünez Giemủie zu Gart, man pflanzt fie DeÉGalb yon Der Mitte Mia's an bis in Suli affe 14 Tage

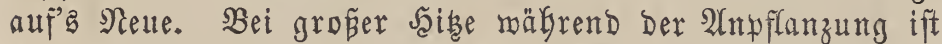

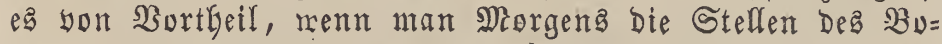
Dens, in melche Bobnen zu liegen fommen follen, mit 2 saffer

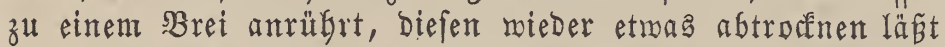
und Dann erft bie Bofnen legt; lestere erficheinen Dann ftatt erfit an 7 ten, fchon am 4ten Tage.

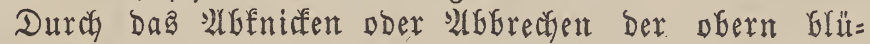
Genden Ranfen wird ber Saft nach Den Tragzmeigen gelei=

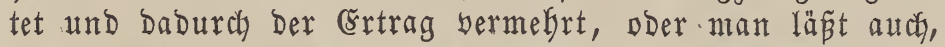
unt lebterea zu erzielen, die Bobnen fo range ftelfen, bis bie oberften sBlumen beinabe alle in Der Blüthe find, und Gridyt ignen bann oben ben $\Re$ opf, aber nicht zut tief, ab. Bei ganz günftiger WBitterung fesen bie Bolgnen, fo behan= Delt, affe ant.

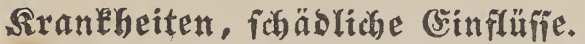

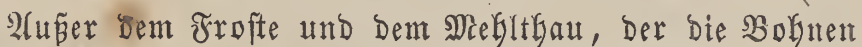
fo gerne überfäldt, gift ez aber noch andere Feinde, welche

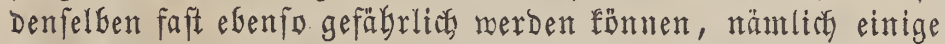
Infeltenarten, welche fie, wie auch andere beülfenf̣rüthte, mie Erbfen, Rinfen.zc., benagen. Sie finden fiff beforbers im Frübjafy in Menge und pflanzen fich nur in weichen und noch grünen büulfenfrüchten, nicht aber in troffenen, fort. Die gefäbrlichften fênd: Der bălfenfamenftecher (A pion Craccae, L.), Der (Erbfenfantenfäfer (Bruchus Pisi, Fabr.), Der J̧ülfent= famenfäfer (Bruchus granarius, Fabr.).

Samen, relche folche Snfeften enthalten ober yon ifnen berborben roorden find, follen nie auggefäet werben.

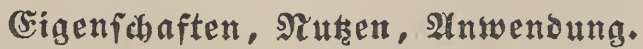

Die $\mathfrak{B}$ ofnen find gerublos und bafen roh eimen faden, erbigen und ntefligen Befchmarf; bie vorwaltenben $\mathfrak{B} e$ ftand theile Derfelben find nath sraconnot:

$$
\begin{aligned}
& \text { Stärfmebl . . . . . . . 42,34 } \\
& \text { Regumin . . . . . . . . . 18,20 } \\
& \text { (5)allertãume mit noch etwa Regumin } \\
& \text { und Stärfmeld . . . . . 1,50 } \\
& \text { Sihleimzunfer . . . . . . . . } 0,20
\end{aligned}
$$

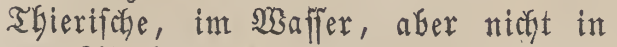

$$
\begin{aligned}
& \text { 2llcobol löblicte Subftanz. . . 5,36 } \\
& \text { Eettige Subftanz . . . . . . . 0,70 } \\
& \text { Bhošthorfuter Ralf und Rali, orga= }
\end{aligned}
$$

ơine gute Bofnenforte foll nicht zäke werben, feine ftarfe Fafern faben und fomoly grün als bürr gut focten.

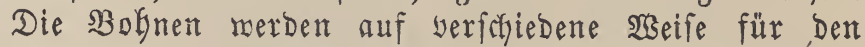
(5)enú zubereitet, entweder werden bie reifen Sanmen nact Art ber (Ërbfen gefocht, wozu man gemölgnlich Bufgnenarten

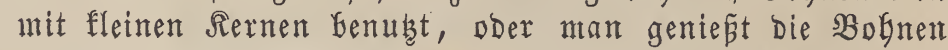

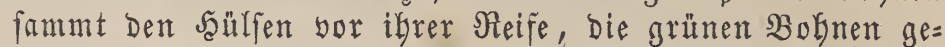
fodyt ober als Salat, meldye auch weit werdaulicher find.

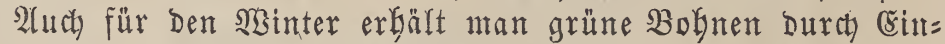
falzen. Das Bofnenmefl berbart man mit anderent Megl

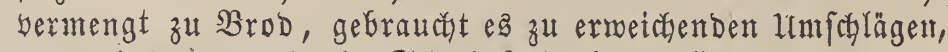

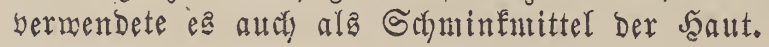

\section{(sefabichte.}

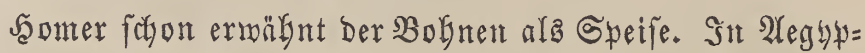
ten murden fie meder gebaut, noch gefpeist; ifr (semus mar Gauptjärdich Den Srieftern unterjagt, aber auch bie nach

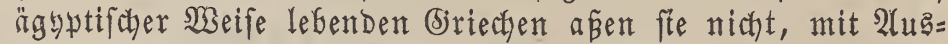

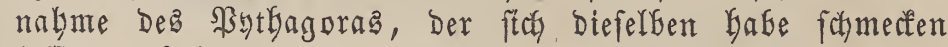
Iaffen, ofgleich er Den Benué feinen Schüfern verfotent batte. Die Bobgnen galten nämlich als eine unreine žrudgt, unb zwar nach (Ëintigen, weil fie Syntbole Der Riebe raren, Deren ftch bie Sriefter fli entralten Gatten, nach 2 ndoern aber, und ragricheinlider, weil man fee yon ben beiftern $\mathfrak{B e r}=$ ftorfiener Geroghnt glaubte, oder Durch bie Blägungen, bie ify Benur berurfachte, die geiftigen Fähgfeiten follten ge= formintht werben und ben Schlaf unrubig madyen. Bei Den

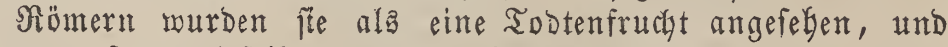
man feste Diejelben an Den Remuralien Den Gethatten Der Berftorbenen zur Speife bor; am Matronalienfeft jedods wurben fere affgemein genoffen. Die römifchen ßriefter, bie Flamines Gingegen Durften Die Bobnen meder berühren, noch iffer erwägnen. Die Briechent yotirtent bei Beridgt ntit $\mathfrak{B}$ ofnen, Die fawwarzen serurtheilten, bie meinen binge= gen furachen frei.

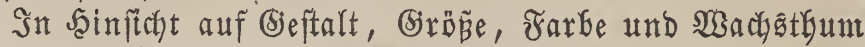
Der $\mathfrak{B}$ ohnen hat man Durch Sultur auererdentlich viele $\mathfrak{B} \mathfrak{a}=$ rietäten erfalten, und wir moflen baber megrere Dent Sament nach aufzăblen:

1) Dunfertotge Stangenbohne.

2) Eifömige Stangenbogne.

3) (5) lbe fraungefteifte Stangenbogne. 
4) Belbe Stangenbohne.

5) (belbe farmarzgefledte Stangenbolne.

6) (s) ra getigerte Stangenbohne.

7) (3)

8) Rleine malachitgrủe Stangenbohne.

9) Jaelrothe Stangenbolne.

10) Rleine weíne Stangenbolne.

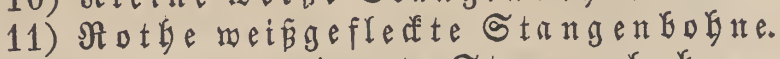

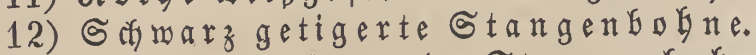

13) ธăbarz glänzende Stangentohne.

14) Strobgerbe Stangenbohne.

15) $\mathfrak{B}$ eild enblaue $\widetilde{a}$ tangenbohne.

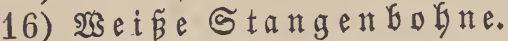

17) $\mathfrak{3} e \mathfrak{i} \tilde{\beta} \mathfrak{g} \mathfrak{a} \mathfrak{u}$ Stangenbolne.

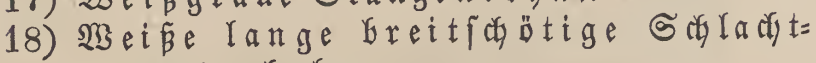
fid werdtagolne.

19) (3)

20) Rleine wei

21) $\mathfrak{b} \mathfrak{u} t \mathrm{e}$ Speistohne.

22) (rnglijale Syargelbolne.

23) Durdfidtige $\Re$ e isbolne.

24) $\mathfrak{J} \mathfrak{n} \mathfrak{g} f \in \mathfrak{r} \mathfrak{b} \circ \mathfrak{l} \mathfrak{n}$.

25) Rletie Berlbohne ohne Samen.

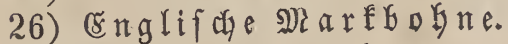

27) $\mathfrak{R} \mathfrak{a t b} \mathfrak{a} \mathfrak{u}$ ferbol $\mathfrak{n}$.

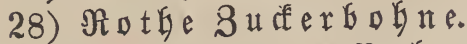

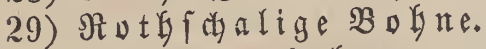

30) $\mathfrak{x}$ orcelfanbohne.

31) (b)

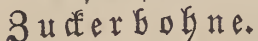

32) S

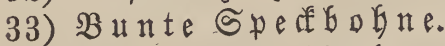

34) Weine Spextholne.

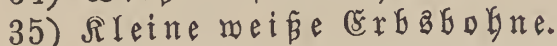

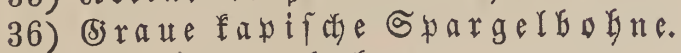

37) $\mathfrak{B} \mathfrak{n}$ te (sierbolne.

38) $\mathfrak{R} \mathfrak{i}\{$ 出 $\mathfrak{b}, \mathfrak{h} \mathfrak{n}$.

\section{Phaseolus nanus, L.}

Swergbohne, Bufchbohne, Stodfbohne, Sintuboline, Franzolgne, Rriechbohne, niebrige Bobne, italienifache Bobne, welfue $B$ ofne, Brectbohne.

Dwarf Kidney-Bean, Trench-Bean. (ettgl.)

\section{Arten = Ebarater.}

Der Stengel ift nur $1-1 \frac{1}{2}$, Göchftens 2 Fun hoch, indem ex fech bald unten seräftelt, etwas hin und her gebo= gen, aber nicht mindend, glatt. SBlätter fpikgig - eif̄örmig.

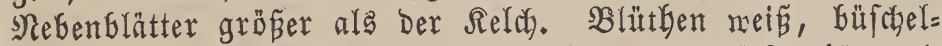
färmig und endfändig. Schoten zufammengebrüuft, bängend und runzlids. Sm Hebrigen ift biefe Gpecies Der yorigen ganz ähnlich.

\section{Slüthe = Beit und Dauer.}

Miai - Iuni. $\odot$.

\section{Borfommen.}

Sie ftammt ebenfalls aus Dftindien und mirb wie bie yorkergefgende alfgemein angebaut.

\section{Sultux.}

Sum Stedfen find nut 1-2jäłrige Samen amzuratben,

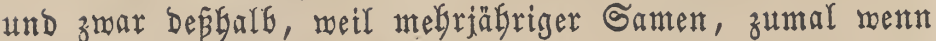
ex moch in maften, feuchten Boben fommt, SFfanzen treift, bie geil aufwachjen, rooburdy meift bie untern überwachfen= Den Bobnen werfaulen. Whan lege bie 3mergbohnen im Freien entweder auch $2-3$ 3oll tief und $1 \frac{1}{2}$ Fur yon ein= ander entfernt in (Srübcten, nur etras näber zujammen als Die Stangenfolynen, ober aber, und gemöbnlicter, in $1 \frac{1}{2}$

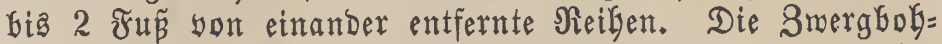
nen eignen fted insbejondere zur Treiberei; Dieje aber bat ihre Schwierigfeiten, bejonders mas die Beftelfung Der zrïh)= beete anbelangt. Dá man bie $\mathfrak{B}$ oknen meifteng bią Ěnde März Gaben mill, fo mun man gegen Ěnde Samuars bas Beet anlegen; bringt man mun gefrorene Dber naffe errbe auf Den frifch eingetretenen Dünger, fo geft bie erfte 2 (us = faat zu Crrunde, Da fte während Dess 2qufthauens ben obern Düngerlagen bie WGärme entzieben, und Daburch bie in ber

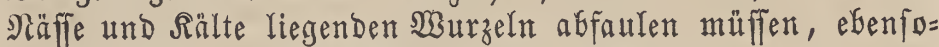
wenig Darf man bie Saibe, bie fter aut bem Dünger im Mifftbeete entwiffelt, zut fehr überband nefmen laffen, indem Dadurch bie gelegten Rerne auBerordentlich fohnelf feimen und oft bie jungen zarten $\mathfrak{B}$ urzeln eigentlich berbrennent. (ङz ijt alfo eine Der Scauptauggaben bei Der Bohnentreiberei,

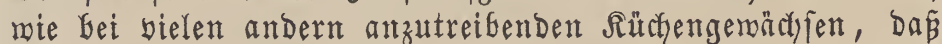
immer bas richtige Má unb hiezu ift eine Temperatur bon 18-200 ^eaumur nötyig. (sine fermere Beachtung verbient, zumal mährend ber Blütbes zeit, Dả oftere Rüften Der Beete, fofald ez nur bie Witte= rungaverbăltniffe erlauben, Denn Dumpfe Ruft, forwie aud Das 2lbtropfen Der Beetfenfter fochabet Der Bofnenzudyt unge=

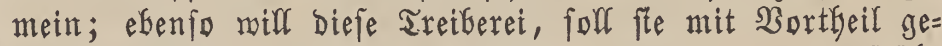
trieben werden, gưnftige und belle şsitterung. - 1 tm frübe Bobnen zu befommen, Gat man verfochiedene Methoden, fie zu Yflanzen; man fteeft entmeder 2(nfang $\mathfrak{z a n u a r z}$ etwa

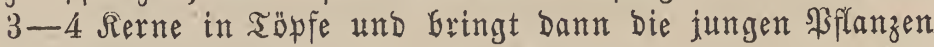
mit Dem Erbballen in ein warmes f̧aus, oder weit beffer, man fterft je 3 Boofnen 1 Fu

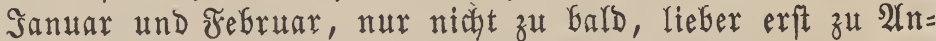
fang Dez März in ein marmes Miftbeet, welches man fo oft

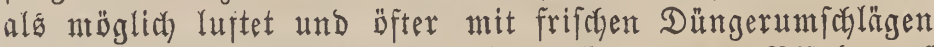
werfteht, poer auch, man yerpflangt fte yor ber Blüthe auf

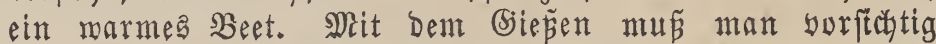
fein, es Darf nicht zu bäufig, am mentigften aber bei naffer Noitterung gefthebent.

\section{Sitantheiten, fabablidbe Einflüfie.}

Sourbe bereits Gei ber Stangenbolne angegeben.

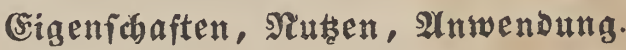

So reichlith als bie Stangenfobnen tragen bie 3werg= bogmen nicht, fend jebody leichter zu fultiviren, Glüben frü= Ger und fterben nach ber Neife ab; alfeg Hebrige Gaben fte mit Der yorigen $2 \mathfrak{c}$ rt gemein.

Die Bwergbolgnen Gaben nod megr Spielarten, bie befonders in Der Jarbe ifrer Samen fely baritren; Die Gauptfäcblichften ftnd:

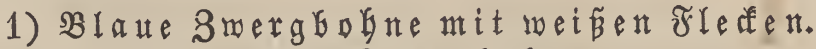

2) $\mathfrak{B} \mathfrak{x a f i f i a n i f b e ~} 3$ mergbolne. 


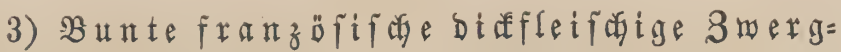
bohne.

4) Erbfenartige 8 wergbohne.

5) ซrühe gelbe 8 rergbolne.

6) Jrukge meífe 3 wergbogne.

7) (5elbe fdyarzgefledte 3 wergbolne.

8) (5elbe 3 mergbolene.

9) $\mathfrak{s} \circ \mathfrak{a n n i z b o h n e . ~}$

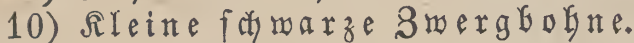

11) Rleine meize 8 rorgbogne.

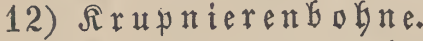

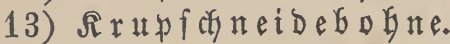

14) Niebere Galatbogne.

15) ßerlbrech bogne.

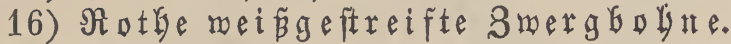

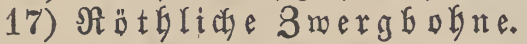

-18) Stroggelfe 3rotgbogne.

19) Stroggetbe 8 mergbolne mit branen $\mathfrak{A} \mathfrak{u} \mathfrak{e n}$.

20) Stroggerbe 2 mergbohne mit gefben $\mathfrak{A} \mathfrak{u} \in \mathfrak{n}$.

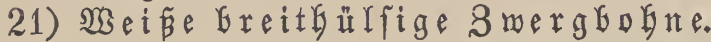

22) Weį́e walzenförmige 8 mergbolne.

23) Jrühe fatmarze Neger.

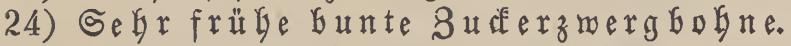

25) ซrủbe gelbe 3 uferzergholne.

26) Fräbe gelbe, fehr bolftragende 3 merg= bohne.

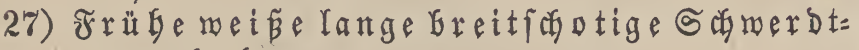
zroergbogne.

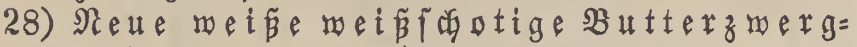
bohne.

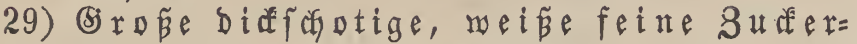
D Der $\mathfrak{B}$ utterzaergbohne.

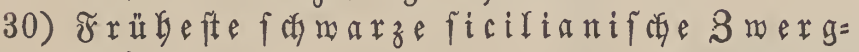
bohne.

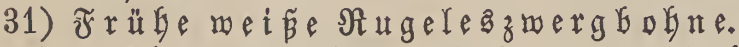

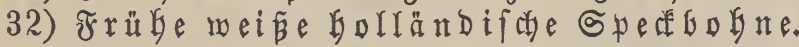

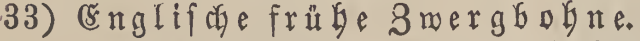

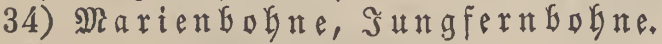

35) Wei Be Drefab ol $\mathfrak{n}$ e.

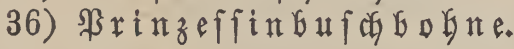

\section{Phaseolus multiflorus. Lam.}

Phaseolus vulgaris. Schk.

Phaseolus vulgaris $\beta$. coccineus. L.

Phaseolus coccineus. Kniph.

B. Phaseolus multiflorus albiflorus. Lam.

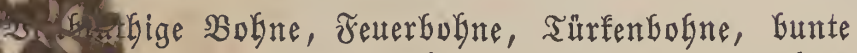

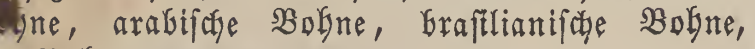
barladyrothe sokne.

Haricot d'Espagne. (framz.)

Scarlet-Bean, Scarlet Kidney-Bean. (engl.)

\section{Arten $=$ Sharakter.}

Stengel mindend, grün, geftreift. Blätter $3 z$ äblig. 3lat Fiele etwas zufammengebrüfft, oben rinnenförmig, 4 bis 3oth lang. SBlättchen eiförmig, langgefpist. Seitenblätt= (ben art Der ăufern Seite breiter, geftelt, bie Stielden marzig, fein behaart, an Der $\mathfrak{B a f t z}$ mit fleinen, Ianzettfärmigen
Ifterblättajen werfeken, woyon bie aur Stiele bea mittleren Blättchens beinake pfriemenförmig ftnd. B̉ätthentraube ein=

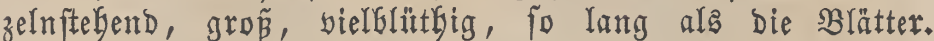
Blumenftiele zu 2 ftehend. Derfblättchen angedrủ aft, fleiner als ber Relch. Schoten bängend mit biel gröpern, oft über L Soll langen, fladjen, blaufdywarzen und bejonders am Rande rötglich und fogmarz biolett gefprengten und geflamm= ten Samen.

\section{Błintfe = 3eit und Dauex.}

Mai - Juni. $\odot$.

\section{SorÉontunen.}

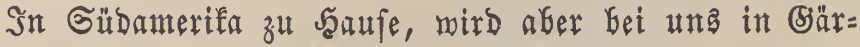
ten gezpgen.

\section{§ultur.}

Die Rultur ift bie gleiche mie bet Der Stangentobne.

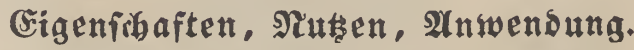

Die Türfentolne roird mie bie gemeine $\mathfrak{B}$ ofne benütht, bient aber meift zur Sierbe in Giärten.

Man unterfajeibet 3 Barietäten:

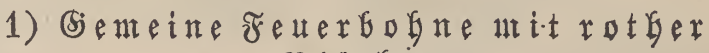
$\mathfrak{B}$ I นึ乚

Blïthe fün fäarlachroth.

2) (5e meine reuerbogne mitrother

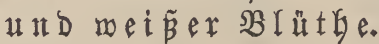

Die Samen ftnd wie bet Der borigen Barietät.

3) (5) meine Feuerbolne mit weiser Blutthe.

Naseise türtifche $\mathfrak{B o b n e . ~}$

Blüthen und Gamen fend meí̄.

Pisum. L.

Syfteme: Cyleophyta. Neck. Diadelphia Decandria L

Legúminosae. Juss.

Leguminosae regulares. Roy.

Leguminosae Vicieae. Adans. DeC.

Papilionaceae. L.

Papilionaceae Fabaceae. Rchbch.

Relch ganzblätterig, glocfenförntig, 5fpaltig. Blumen= frone fonmetterfingäartig. Fabne aufgerichtet, zurủffgefdlagen, breit, an Der Baft 2jotymielig. Die 2 Frlügel ftumpf und länger als bas Schiffchen. Scyiffchen ganzblätterig, ftumpf gefłnäbelt, am untern Mande geftelt. Staubgefäpe 10, Dent Relchgrumbe eingefügt. Staubfäben: 9 vermachfen, 1 frei, pfrienenförmig - fabenförmig. Staubbeutel eif̣̈rmig - rund: lich, 2fächerig. Stempel 1. Frudjtfnoten fizend, zufammen= gebrü fitt. Griffel gefniet, zufammengebrủfft, oben behaart. Narbe jtumpf. Şülje entweder zufanumengebrủft ober auf= getrieben, nauft ober flatmig, 1 fächerig, $2 \mathfrak{f l a p p i g , ~ v i e l j a m i g . ~}$ Samen fugelig, platt.

\section{Pisum sativum. L.}

Pisum baclium. Hort. Pisum chlorospermum. Hort. Pisum borussicum. Hort.
Pisum caerulescens. Hort. 
Pisum excorticatum. Desf.

Pisum fertile. Hort.

Pisum humile. Mill.

Pisum macrocarpum. Hort.

Pisum macrospermum. Hort.

Pisum praecox. Hort.

Pisum prolificum. Hort.

Pisum quadratum. Mill.

Pisum roseum. Hort.

Ërbje, gemeine črbje, Sifrotenerbje, Jelberbfe, zabme

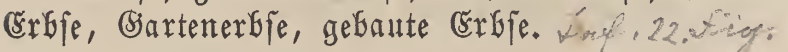

Pois des Jardins. (fiantz.)

Pea, Common garden pea. (engr.)

\section{A)ten = 5 harater.}

Stengel 1-4 Fun hoch, fanady, äftig, gletternd, glatt. Blätter abmechfelnd, 2-3paarig geftedert, glatt. Blättchen eiförmig, lang zugefpist, am Rande welfenförmig, glatt, bie runblichen Blattftiele in 3 fpaltige, gabelförmige $\Re$ anten aus =

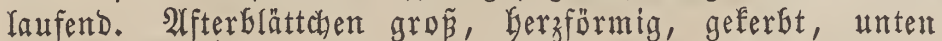
abgerunbet. b3lumenftiele achfelftändig; $2=$ bis vielblütbig.

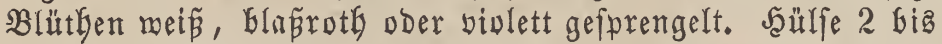
3 Soll lang, gerabe, chlindrifh, leberartig, bängend, 1 fädhe=

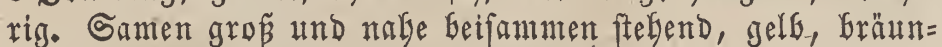
liç, bläuliç.

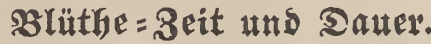

Mai - รuni. $\odot$.

\section{BorÉntmen.}

Das Baterfand Der Erbje ift unbefannt; hie und da findet man fte, zumal im füblichen Ëuropa, verwildert, bäufig aber mird fte itberall angebaut.

\section{Sinltux.}

Man baut bie Ěrbfen entmeder auf Dem Felde alą ซ́ld = erbien Dber im Garten als Gartenerbien. Bum Baue Der Felberbfen foll Der Boben lodfer und nicht zu frifh gebüngt fein, benn im leteteren Falfe merden fie zu maft, wachjen zu febr in's Strof und legen ftch gerne. Esin fefter Boben

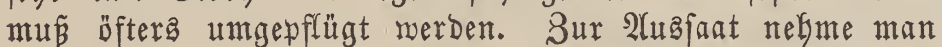
nur bollommenen, reifen Gamen; zmeijälgriger foll meniger auzarten, melchen man entmeder in ₹rühjalyr im März, bei günftiger Witterung fodon im Jebruar, fogar bet offenem Boben int December, Dantit bie Blütlye nicht in Suni und Sult fommt, wegen Der Meblthaue, oder bor Dem Winter bicht einfüet, und bringe ifn, um ifn yor ben Tauben zu berwabren, mit Dem şflug ober Exftirpator fo meit unter bie Errde, Dá̃ er etma 4-5 Soll von Derjelben bederft mird. Wenn bie Erbfen einmal 1 Zolf über Der Errbe ftnd, fo ift ęs yon Bortheil, biefelben zu malzen, Gefonderz went fie bon Den Erbflofen Keimgefucht werden, ebenjo fie zu eggen, wenn fie bie Säbe yon 2 3oll erreicht Gaben.

Die Bartenerbjen verlangen einen mittelmäp̈igen, lodfern und, wie Die Felderbfen, nicht frifh gebüngten BBoben und eine fonnige, luftige $\mathfrak{L} a g e$. Sie werden fefyr frühe gepflanzt, fdyon im Miärz, wenn Der Boben ftch peffnet, Da fte ziemlich

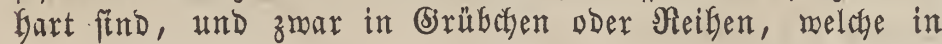
einer (sntfernumg von 1-2 3oll von einander gemacht mer= Den. Rommen bie Ěrbjen aus Dem Boben Gerbor, fo befäu= felt man fte, fuson auch Des zroftes megen, und ftnd fee

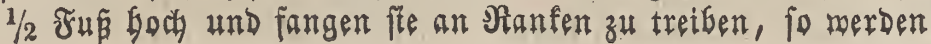

abwechjelnd an ber itnern und äunern Seite Neifer zmifchen

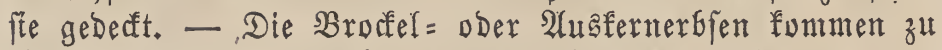
ifrem Gebrauche geroofynlich Ende Suni's in Errtrag, und

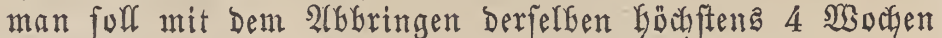
lang zumarten, weil fie fpäter hart und nidyt melgr ala grü= nes Siemüle genoffen werben fönnen.

Unt frübe (srbfen zu ziefen, fat man berichiedene Mes tyoden, und wir molfen einige Derfelben bier anfübren. Jaiezu taugen aber nur bie Smergerbjen. S4 21nfang Februars

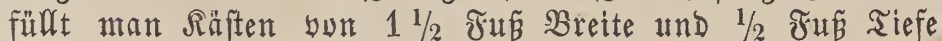
mit guter, fetter, etwas jandiger Miftbeterbe 5 3oll goch an und bringt fte an bie Fenfter eines fitblich gelegenen und tentperirten Simmers; man fäet bie Samen fo Dicht, da

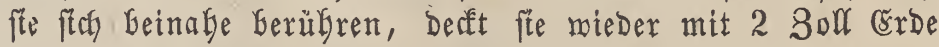
孔t und gibt ifynen etwas 3 raufe. Errfcheinen Die jungen Pffanzen, was meift innerfalb 14 Tagen gefchieft, fo bifnet man an fonnigen Tagen einige Mal Dez Tagez Die Jenfter, Damit biefelben frifche Ruft befommen. In. Den erften Tagen

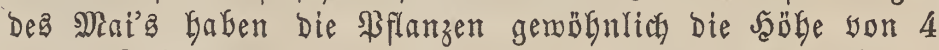

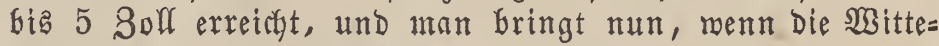
rung günftig ift, Den Saften in's Freie auf eine geichühte Rage, Gălt aber Matten, Bretter Dder Fenfter in Bereitichaft, um gegen allenfalls eintretende Fröpte, falte $\mathfrak{B i n d e}$ ober Schneegeftöber die Räften beberfen zu fönnen. Nachdem die Raften etma 14 Tage im Freien geftanden Gaben, bebt man bie \$flamzen mit Der Bartenfelfe aus, fohneidet porfichtig bie langen $\mathfrak{B f a h l m u r z e l n}$ ab und febt te 3 Pflanzen in eine ber borber geförig zubereiteten, weit und tief genugen (s)uben, Güte fich aber, Die an Der Wurzel angängende (srbe zu ent= fernen ober bie. Erode beim Seken der Bflämzct)en zu feft ein= zubrücfen, Damit biefelben nicht abgefnifft werben. Das

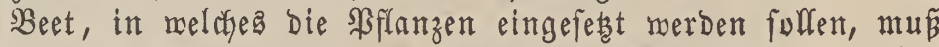
tief umgefcharrt und mit verrottetem Sugbünger verfeben werben. Nach 6-8 Tagen bebautt man die Pffanzen, rel= nigt ben $\mathfrak{B}$ voen von Unfraut und begieñt geförig. - $\mathfrak{u m}$ noch frübere (šrbfen zu befommten, berfäbrt man auf fol= gende 2art: Mian bereitet fith, fowie es bie Mitterung er= laubt, Mitte Februarz ober 2 nffanga März ein Miftbeet, wie etma für (B) urfen, zu, bringt, fobald ftch Der Dung er= bist, 6 solf goch gute, locfere, nafrbafte und borber burdy= geftefte Erobe barauf, brüct fie recht feft an, bringt auf biefe Rage noch 1 Zjoll hoch reinen Flup̧and und fäet in biefen

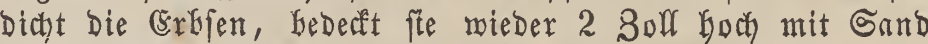

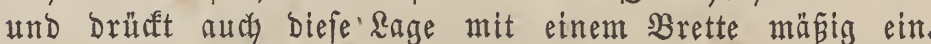
$\mathfrak{A} m$ beften gedeiben bei diefer $\mathfrak{B} e$ handlungsmeife die frühe 3wergzudfererbfe und bie frühe franzoftfche. - Daz eigent= liche Treiben ber Erbfen anbelangend, fo gejchiegt biefer entmeder in (b) lazhäufern und Miftbeeten oder aber theilmeife - bine Diefe Sorrichtungen; 2lnfanga ober Nitte November fäet man in 7-8 3oll Gobe und 10-12 3oll weite, mit

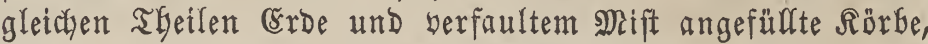
je $20-25$ Errbjen in einen Rorb, und bederft Diefelben 1 Soll God mit zertbeiltem Nopoung. Die אiorbe bleiben int Freien, in eimer warmen 2 age, entweder frei fteben, in melchem zolfe fte bäuftg begoffen merben müffen, oder beffer, fie merben in Die Erde eingegraben. Bei 1 Brab Rălte fün=

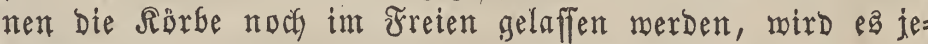

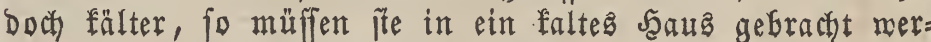

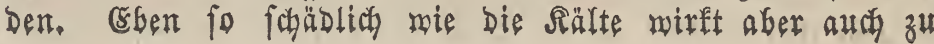







. 


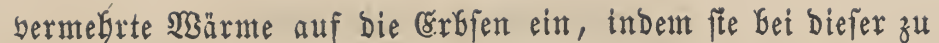
jefr in Trieb fommen und vergeilen. Bei $12-15^{0}$ Reaumux feben bie Erbfen fchon gat an. Sm rebruar gräbt man bie Rörbe etma 6. 3oll bon einander entfernt in Das Miitbeet, Deffen Düngererde Der Wöntme regen mit etrons \&obe ver= mengt worben ift. Sobald bie Errbjen Glüfen, fneipt man fie, um mefr Früchte zu erzielen, immer bei ber 2ten ober 3ten 3 linthe ab. Uluf biefe Wreife befandelt, tragen bie

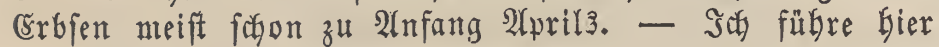

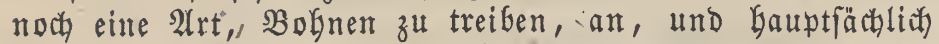

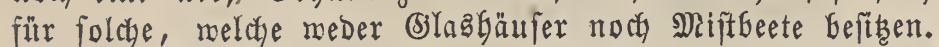
In Ermanglung Diefer meidyt nan im Fefruar früte Bmerg=

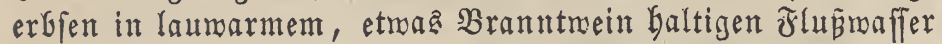
24 Stunden lang ein, legt fie, in ein nuffenes ruch ein= gegüllt, auf einen mäßig ernürnten Dfen und feuchtet fite bie und ba mit lauem $\mathfrak{B a f f e r}$ an. Mit ber Ěntwifflung bez Reims fteift man bie Erbjen in mit geftebter guter and locferer Bartenerbe angefüllte Räfthen, Deren Buden mit

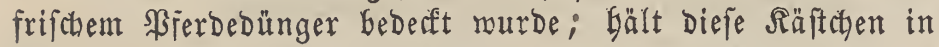
Der marmen Stube und begiept fte Bfter mit überfahlagenem

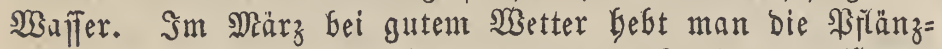
chen aus und verpflanzt fite in ein gegen fröfte und sisinde gefdhủbte Beet in's Jreie.

Bifl man Erbfen noch im Spätherbfte haben, fo fäet man fie Ënde 2 (uguftz oder 2 (nfanga Septemberz in Rörbe und begient fie bei troffener Bitterung afle ander Tage, gibt ifnen, wenn fie 5-6 Schuh hoch gemorben find, Stecfen

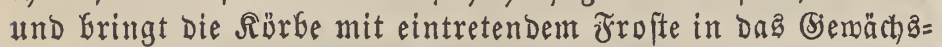
Kaus, aus biefem aber, fo oft bie Temperatur mild ift, immer nieder in'z Freie. Nit Dem Anfange Novembers fangen bie Errbfen an zu tragen und. machen fort bis Ënde Decembers. SĐber man fäet im Nlobember die Ërbfen gleich

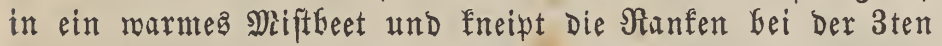
Doer 4ten $\mathfrak{B l u h t}$ the af. 2 Huch noch im December und Sanuar fann man nody Erofjen jäen; man fäet fie in diejem Frafle ebenfalls bicht in ein warmes Miftteet in $6-7$ 3oll meit yon einander entfernten Rinien, in einer Nabe yon 4 3oll je zu 2, und fringt bie 3-4 3olf hoch genordenen $\mathfrak{B f l a n =}$ zen in ein frifdez, mäpis marmes Mifteet. SWie bei Der Bofnentreiberei, fo ift ez aud bei ben Erbjen yon Belang, fo oft als möglich Ruft zuzulaffen, und diés Darf mit meni= ger Borfatht gefcheben, Da Die Erbfen meit bärter fend als bie $\mathfrak{B}$ ohnen. - $\mathfrak{H} m$ einen reichen Ertrag an Erbjen zu ge= winnen, Gringt man bermoberte $\mathfrak{B a f f e r l i n j e n , ~ ' w e l c h e ~ e t m a ~}$ $1 / 2$ Safr lang yorker 'gelegen Gaben, 1-2 3olf bod in bie Neiben, legt die Erbfen Darauf und bebecft folde mit Ërbe, bie Erbjen fommen auch um 8 Tage bălder.

Die Ernte nimmt man bor, menn Der gröpere Theil Der Errbfen unten am Storfe gelbreif ift, Da nuan die Nieife fämmtlicher Stöfe nicht mobl abmarten fann, funeibet fie

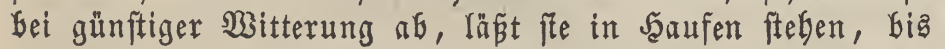
Die Samen volffomnen Gart find, und macht fie entweder

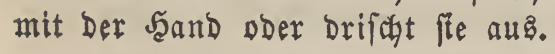

\section{ßrankbeiten, fảäblidbe Einflüfie ze.}

Jaßhner, Tauben und Sperlinge find gefäbrliche Feinde

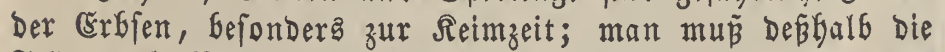

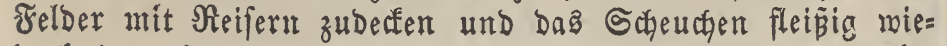
Dergolen; ferner find ben aufgehenden Erbjen die Erbfloge,

Entwer, bénom. Pfinnzenfunde.
Den fajon reifen aber bie ङrbfenfäfer, Bruchus Pisi, Fabr.,

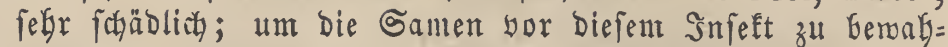
ren, Gefprinzt man biefelben einige Tage yor ber 2 uşant mit' in $\mathfrak{B a f f e r}$ aufgelöstem $\mathfrak{B i t r i o l , ~ S a l z ~ o b e r ~ R a l f ; ~ e f e n f o ~}$ ift Der fogenannte \$leglthau, bejonderz zur Blüthezeit, Den Errbjen Göchit nadytbeilig.

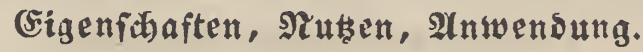

Die Errbjen Gaben fo ziemlidy bie gleichen Beftanotheile wie die Bognen, gehören zut Den meblreidyften Früchten und Gleiben 1-6 Jahre feimfähig. Sie merden affgemein angebaut und binterlaffen Den Boden in einem fegr lurfern und guten 3 uftande, ftnd aber etwas unftchere srüchte, me $\bar{\beta}=$ regen igr $2(n b a u$ im Bropen nur da anzurathen ift, wo biele Schafe gebalten werden, da das Erbfenftroh bejonders für trächtige Schafe und Rĭhe ein felgr gutes Jutter ift.

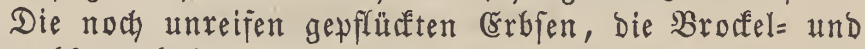
Sucfererbfen, Gaben einen angenebmen, füplichen (biefduadf und werden bäuftg allein oder mit gelben Mögren gefodyt

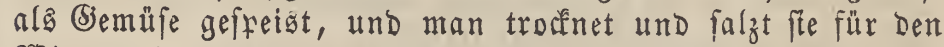
Winter ein, worin bie ruffitchen Erbfen ben Borzug ver= bienen. Die reifen Erbjen werben als MRú, Suppe, ent= Gülat ober mit ben Sañuten genoffen, verlangen aber gute

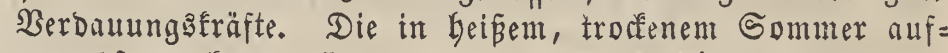
gemachfenen fochen fith ungerne meich, überbaupt werben bie

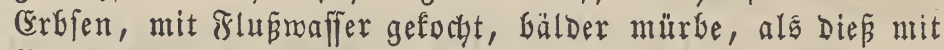
Brunnenmaffer gefchiegt.

Das Erbfenmegl, mit Noggen yermengt, liefert ein formarffaftes, Dauerthaftes, aber etras hartes Brod; man gebrautht es auch zum Shafben, unt die Saaut rein und fein zu fonferviren. Man legt fie ferner in Fontanelle, unt foldte offen zh erbalten, und jprengt Schäbel, bie man zers legen wiff, mit ifnen, indem man Diefe mit Errbien anfüftt

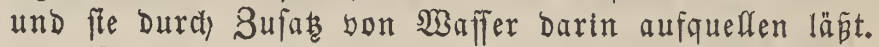

Sie bienen als Futter, befonders für Schmeine, ent= weder gequellt oder troffen mit SBaffer, ober mit srobirmen gefocht; Dureh fie mirb Der Sperf fefter, Das Fleifh aber nirht fo rooklfchmedend, als Durch Jjerftefütterung. Jür Pferde, Gefonders angeftrengte, und Schafe find bie Errbfen

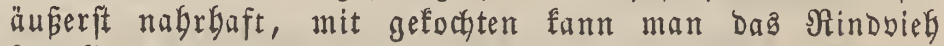
fdyell fett machen, auch für (5änje und Tauben fend fie zuträglich, nur mird yon igrem (S)enuffe Das Fleif̧ Der lebteren meniger rohlfchmeatend.

Das (Erbfenftroh fann nicht nur Den Schafen und bem

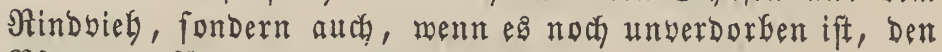
Pferden gefüttert merden.

\section{A. 3udferenten.}

Pisum sativum sine cortice duriore.

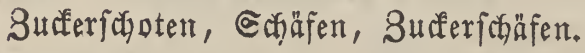

Pois sans parchemin. Pois gourmands. (franz.)

Sugar pea. (engl.)

Die Schoten find fleifalg und efjear, fie merben mie Die Der Bobnen geidhnitten und mit Der Frucht als Bjemúfe benübt. Die Samen merben mit Der Reife runzlid.

Sie verlangen, namentlich bie fpät gefäeten, einen beffern Boden ale die Brodfelerbjen. 


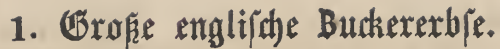

(S)

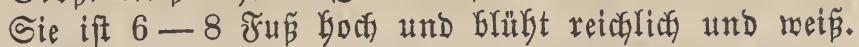
Sidoten gerabe, fpringent nicht leicht auf und baben $6-8$ felderbjengrobe, glatte, Gelfgelbe, Geinahe rreif́e Santen.

Schoten und Samen baben einen füpen

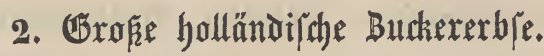

Pisum quadratum majus.

Biereffige Erthe.

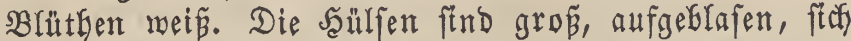
frümmend, Dixf, und baben menig Samen. Samen groṕ, wertieft und trocfen runzlich, faịt 4 erfig, Gelfgelbgrünlich. Bei Regenmetter fyringen Die Gigoten auf, moburch bie

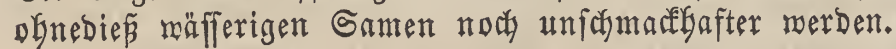

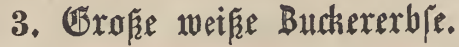

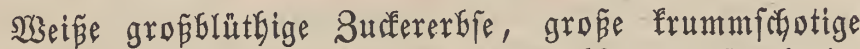
Bucfererbfe, groß̧e fäbelförmige Zurfererbje, großje breite ธăbelzuffererbfe, Schmerbtzudererbfe.

Blüthe purpurroth. Sie mirb $5-7$ Fü bod, bie Sẳlfe 4 Bofl lang, fehr breit, nach Ginten etmaŝ gebogen, fels fleifaig, mit $6-8$ yon einander entfernt ftekenden, bertieften, grünlicblauen und rotggelben, dicht Dunfelblau punftirten Samen.

Diefe Sorte mirb auch grün ausigebürät gerne gebraucht, man Darf aber mit Der Benuthung Derfelben nicht zu lange warten, ba bie Schoten gern zălye werben.

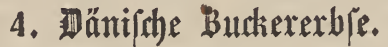

Schottiftye graue 3ucfererbje.

Sie blügt blau und Gat fleine, fahmale; Dunfelgrüne, aber bidyt wolfe Saltrfen mit Derbem Jleifor. Samen erfig, gelb ober graubraun.

Sie ift febrergiefig, fodyt nicht fo zufanmen, wie biele andere Ěrbjenjorten.

\section{Sibwarze Shotenzutherexble.}

Sdyrarze Silyote.

Sie mird 5-6 Fun Goch, blügt bunt unb bat einen Gefonder fü

\section{Jrübe Bwexgundiexichote.}

Pisum praecox anglicanum.

Frübe englifche Smergzuctererbje, frübe Maizuterererbfe,

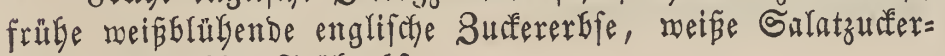
erbje, Miaierbje, Jrüberbje.

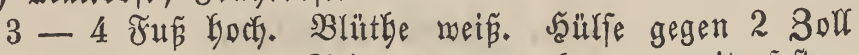
lang, fdymal, an Der Spibe etras gebogent, mit feftem

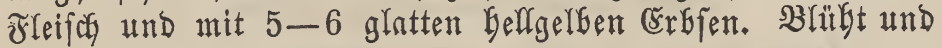
reift yon unten berauf.

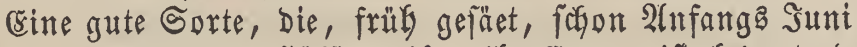
zum (5ebrauche ferfige Sälfen giff; ifr Errtrag ift bebeutend and fte ift zum Treiben mie zur fpäten 2luşanat gleich gut geeignet.

\section{\%, faleine bolländi|che Buckexerble.}

Sie mird gegen 1 Jup boch und bat Geinabe gernde $4-5$ famige Şülfer.

\section{Braunkörnige Butkererb/e.}

Bropé blau und roth Glübende Surfererbje, groṕe

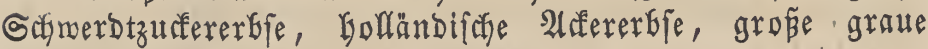
Säbelerbje, Sichelerbje.

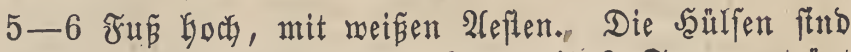
3 8oll lang, zăke, aber jung ep̃bar, mit 6 Samen, trăgt reichlich und fann auch fpät angepflanzt werden.

\section{9. ßie/enzudkexerble.}

Sdjoten fegr grof und fleiforig.

\section{Sidhelexble.}

(Srap̃e graue Gäbelerbfe.

Sifuten fithelförmig gefogen.

\section{B. Stocterewbit.}

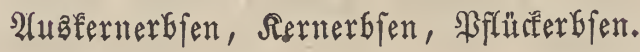

Sie find zun 2 (4aิmachen beftimmt und bienen fowobl noch unreif als reif zur Nagrung und tragen im geringften Boben oft am reichlichften.

(E⿱ 口) gibt Früh = und Späterbjen; Die erfteren haben ben Borgug yor Den Yeseteren, weil biefe, obgleidy fie fräftiger und mefr in's Stroly wachjen, febr fpät fend und in falten und naffen Jabrgängen oft gar nicht reifen und Dem Mefhl= und Jannigthau febr auâgefegt find.

\section{Belbe frühreife Rrockelexble.}

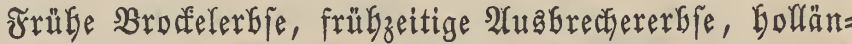
bifche Michauxerbje, yolltragende gelbe englifule Marerbje.

Sie ift gegen 4 Schul Goch, wein und yon unten an

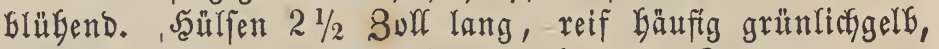
mit 5-7 Der gemeinen Felderbfe ägnlichen Samen.

Sie reift gemöhnlich 4 STBdyen bälder ala bie andern sorocfelerbjen; menn man fie im žbruar fäet, fo befommt

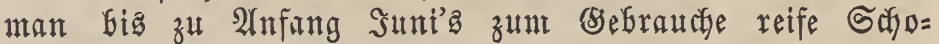
ten; ziegt man fie in Töpfen, Räften ober Mitftbeeten, fo reifen fte fison Mitte Mai's; fee fann auch zmeimal in einem Sommer auf Dem Felde gezpgen merden. Diefe Sorte ift

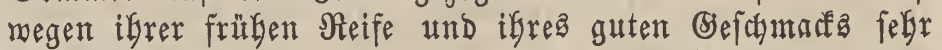
berfreitet und wird in manchen seegenden bäuftg als zeld = fructst angebaut.

\section{Weifre Bxockelexble.}

(b)enetine Felderbje, Saaterbje.

(s)egen 2 Fú hoch, åftig auffiteigend. Şülfe flein, mit $3-5$ helfgelben Samen. Wird Gäufig im Jelde gebaut.

\section{3. fontanellerbie.}

Pisum sativum hortense. tenerbje.

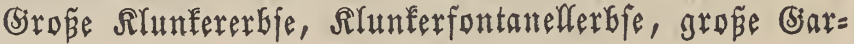

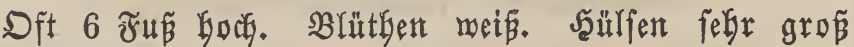
und fleifryig. Samen wentg, aber grof́, etwas platt, glatt, gelf, woblfanteffend, boch nicht befonders ergiebig; fte haben grün ober teif genoffen einen guten Befchmate und fönten eingemadyt werben. 


\section{Gohe grüne Prockelerble.}

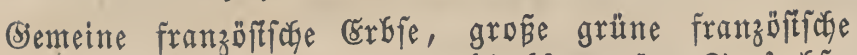
(bartenerbje, grünbleibende Sruppablerbfe, grủne Topferbfe, furze Sapererbje, Glaue preupifiche Erbje, grope grüne Orar= tererbje.

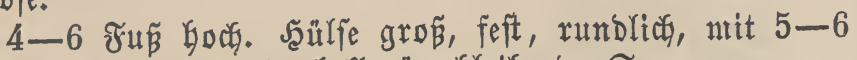
auch int reifen Zuftande beflgrün Gleibende Samen.

Sie ift fekr tragbar, reift 14 Tage fpäter als bie ge= wöbntiche Maierbje. SYGenn man fte in 3mifdenräumen yon 14 Tagen etrags tief legt und fie bei trodfener Witterung Gäuftg gieșt, fo ift fie befonbers ergiefig; fte tangt auch

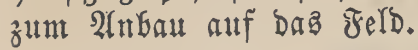

\section{Bisthopg Bwexgerble.}

Biăgops allerfrübefte Maierbje, frühe 3mergerbfe, yolf= tragende Sruppablerbje, Franzerbje.

ซ̛ine ausgezeiffnete Treiberbfe; fie wird faum 2 ซus Goch und hat furze rundliche faulfen mit $4-6$ Samen. Sie trägt yon unten auf, frübzeitig und reichlicts.

Da biefe Sorte leidft zugebert merben fann, fo taugt fie auch noch zur fpätern 2 (nqflanzung und auf Daŝ Feld auf tiefliegenden $\mathfrak{B o b e n .}$

\section{Doldenerble.}

Büfcyelerbje, Rojenerbje, Traubenerbje, türfticte Ĕrbje, Sromerbfe.

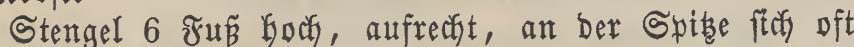
Gandartig auabreitend. Die Blütben fteben büfchelförmig an ben obern Zmeigen in Dolden. Die Saülfen ftnd flein, furz, gerabe, nicht fleifchig, ftelgen ebenfalfs in Büfcheln unb haben $4-6$ Gamen.

SBill man biefe 2irt fpăt anpflanzen, fo ift fte eber zu entpfeGlen; im Hebrigen wächat fte zu fegr in's Siraut und gibt menig Errtrag.

\section{\%. Enights groface Alaxkexb/e.}

Ënglifade Wiarferbfé.

Sie wirs 6-7 Sdyuly hoch, hat 3 Soll lange, bunfel= grüne Schoten und Samen yon fehr füp̌em und, wenn auds

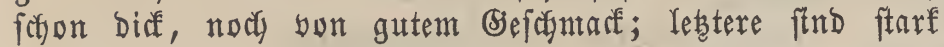
runzlidid.

Sie ift ergiefig und fann früh ober fpät angepflanzt werben. Will man fâe erfit fpät gebraucten, fo mú man fte tief in nicht zu magere (Erbe einbringen, woburd auch

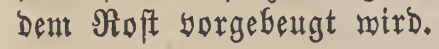

\section{S. fintights kleint Alaxketb/e.}

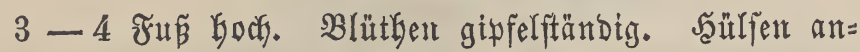
felunlich, lang, und $5-6$ Samen yon ausgezeichnetem Boblgefidmaá entyaltend.

Das Mreitere mie bet ber yorigen.

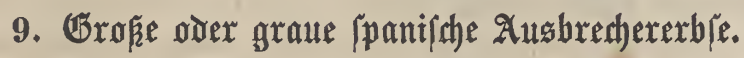

Spantiche Marotte, 2ifterbje, Michautrerbfe.

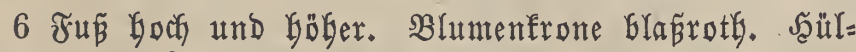
fent $2-2 \frac{1}{2} 30$ ll lang, mit $4-6$ gropen, biefen, etwaz zufammengebrürften, vertieften, meift brantelben Gamen mit figrwarzem Sieimflerf.
Wirb hie und ba auf bem Felde, feltener in siantent angebaut. Sie hat einen berben Befchmar..

\section{Paxifex Golderbje.}

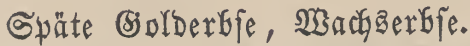

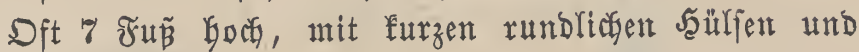
$4-5$ fugeligen, citrongelben Gamen.

Gie trägt mefy an Den obern 2 eften, nicht biel und

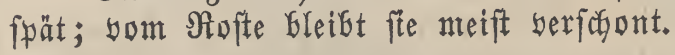

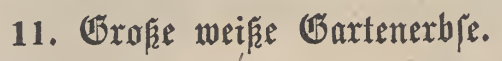

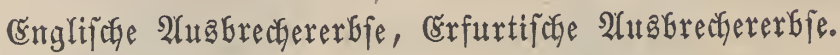

Sebr hocf. SBlütlye meí̄. Schoten grop. Santen fuge= lig, glatt.

Sie ift eine fpäte, aber bortrefficife Gorte, bie aud Gänftg im Jelde angefaut mird.

\section{Pisum arvense. I.}

Pisum sativum. $\varepsilon$. arvense. Poir.

Pisum uniflorum. Moench.

Lathyrus oleraceus. $\beta$. Lam.

Stoferbje, milde ærbje, Schäferftorferbje, Juttererbje, Felderbje, Taubenerbje.

\section{2lrten $=\mathbb{C b a r a k t e x}$.}

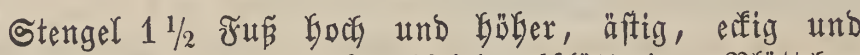
glatt. Blätter gefiedert, afmedffelnd, 4 flätterig. Blättcifen furz umb rundgeftielt, runblich - eiförmig, gezähnelt. ' 2 ffter= Glättchen meift größer als bie Fiederblättchen, ofen afgerun= Det, in Der Mitte geferbt. Blüthenftiele 1 Glütbig. J Juhne meís, purpurroth geadert. Friugel Dunfelpurjurfarbig und

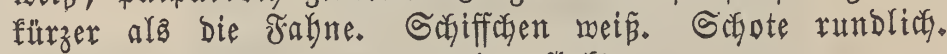
Gamen flein, rumb, grau und geflecft.

\section{Blüthe = Beit uns Datter.}

รuni - 2luguft. $\odot$.

\section{Borkommen.}

Unter bent Sommergetreide, Gie und ba audi gebaut.

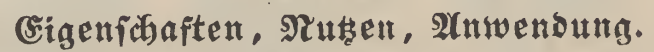

Sie Dienen meniger als গalfrung, megr zum fanttern yon Beflủgel, bejonders yon Tauben.

\section{Cicer. I.}

Syftente: Cyteophyta. Neck. Diadelphia, Decandria, L.

Leguminosae irregulares. Roy.

Leguminosae Vicieae. Adans. DeC.

Papilionaceae. L.

Papilionaceae Vicieae. Rchbch. Spach.

Relch gamblätterig, tief 5 fpaltig, an ber Bafts böferig, bie 4 ofern \&appen liegen auf ber Fahne. Blumenfrome

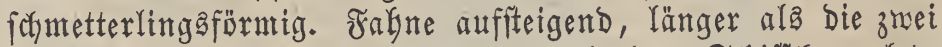

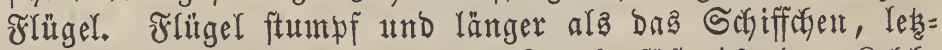
teres ganzblätterig und ftumpf. Staubgefäpe 10, Dem Reld $=$ grumbe eingefügt. Staubfäben: 9 verwachfen, 1 frei. Strub= beutel rumblich, 2fächerig. Stemtel 1. Fruchtfnoten febend, eirund ober eiförmig. Sstiffel pfriemenförnig - fabenförmig, 


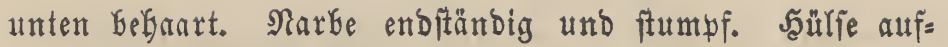
getriçen, Gäutig, rautenförmig ober eiförmig, 1 fächerig, 2famig. Gamen berfebrt-eirund, fantig, runzelig, an bex Bafts gefchnābelt.

\section{Cicer arietinum. L.}

$\beta$. Cicer physodes. Rchbch.

$\gamma$. Cicer sativum. Schkr.

Eemeine Richex, Richererbje, Sifererbje, Sifererbfe, Saffeerbie, Sicherling, Deutiche Saffeebokne, franzöfifche Saffeebokne.

Pois chiches, Chiches de Belier. (ftrttz.)

Chick - pea. (engl.)

\section{Arten = (5haralter.}

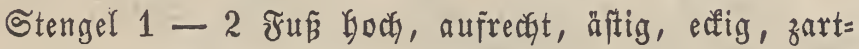
behaart. Blätter abrechfelnd, unpaarig - geffedert, brüfen= Gaarig, blaugrūn. Blăttchen $1 / 2$ 80ll lang und ungefälyr bie Scălfte breit, 15-17zăglig, eiförmig, feinbehaart, gefägt. Blumentiel 1 Soll lang, zurügebogen. Seldy 5fpaltig. Blunten flein, einzelnftebend, winfelftändig, bängend, biolett= rötglich ober weiślicy. Flügel und Schiffchen fürzer als bie

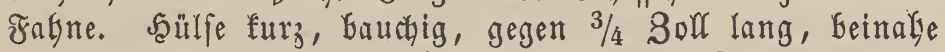
rautenförmig, brüftg graubaarig, 2jamig. Samen erbjen= groź, rundlid, braunrotg ober weíslid, Gaben eine furze, zufammengebrürfte, etraas gefogene Spite und unter berfel= ben eine fleine Grube, und merben Dephalb mit bem Japfe eine Wibtors werglichen.

\section{Bliithe = 3eit utts Dauter.}

รินni - รuli. $\odot$.

\section{Sorkommen.}

Die Richererbje findet fich in Drient, füblichen Europa, Spanien, auch Deutfchland, Deftreich, Steiermart, Rärn=

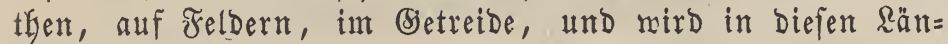
Dern zum Theil bäufig angebrut, bet uns wirb fie in (bärten und bie und ba auch in Feldern fultibirt.

\section{§ultur.}

Sie verlangt ein warmes und fräftiges Sanbland und gebeift ba, wo regen ber angaltenden Saite und Dürre Rinfen, Ěrbjen und Bobnen bertroffnen; Dep̧regen eignet fie fich für ben Süber.

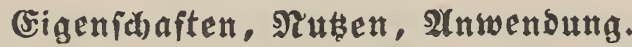

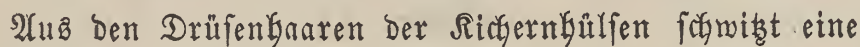

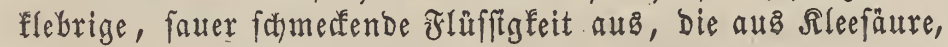
2lyfel = und Esfitgfäure befteht.

Die Samen Gaben eine bủne Saljale, einen barten, meisgelben, mebligen Sern und einen idwach bittern und

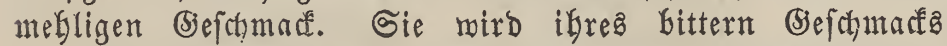

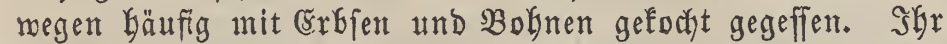

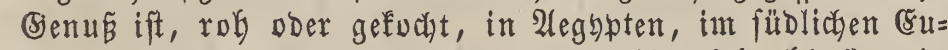
roka, in Gpanten zc. mie ber Der Erefen felyr bäuftg, in Stalien find bie-noch grünen Samen eine fehr beliebte Speife, gerpiftet merben fie hie und ba als Raffeefurrogat gebraucht und in Spanien Den Suppen zugefegt. Die Richern find jebort) fchwer zu berbauen. Daz Richernmegl fann mit (berftenmegl zc. zu $\mathfrak{B r o b}$ und Sudhen berbacfen merben, wie

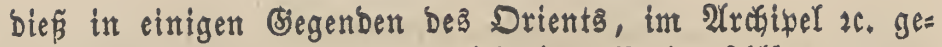

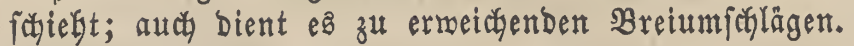

Man bat eine Spielart:

$$
\text { Sabme } \mathfrak{A} \text { ider. }
$$

Cicer sativum.

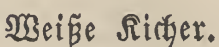

Blütben und Samen fitnd weís und baben megr ben

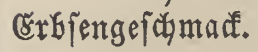

\section{Eirum. L. \\ Silbe Seite 136.}

\section{Ervum Lens, L.}

Lens esculenta. Moench.

Lens sativa. Hall.

Lens vulgaris. Bauh.

Lathyrus Lens. Peterm.

Cicer Lens. Willd.

$\beta$. Cicer nigrum. Hort.

Sinfe, gemeine sinfe, Rinfenfidyer.

Lenticelle cultivée des jardins, Lentille, Lentillon. (frantz.)

Lentil, Common Lentil. (engl.)

Lenticcia. (ital.)

\section{Arten $=$ (5)arafter.}

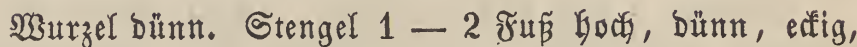
glatt, ober zottig, nieberliegend, äftig auß̈gebreitet. Blätter abrechfelnd gefiedert, glatt, unten zottig. Blättchen $1 / 2$ biż $3 / 4$ 20ll lang, 8-12paarig, ftachelfpił̧ig, eiförmig-läng= lich, ganzranbig, glatt. Alfterblättchen lanzetfförmig, ganz= ranbig. Blattfitele ranfig. Reldjeinfahnitte oft länger als bie Blunenfrone, lanzettförmig, zottig bebaart. Blumen= ftiele zart, faft fo lang als bie Blätter, winfelftāndig und 2-3blütyig und ebenfaffa zottig. Blunten flein, achfelftän=

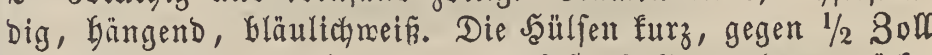
lang und 2 rinien breit, oual, faft 4ecfig, plattgedrünt, glatt, gelbbraun, 2-4famig. Samen flady conber, freis= förmig, megr ober meniger braun.

\section{Blüthe = Beit und Dauer.}

รuni - รuli. $\odot$.

\section{\$orkommen.}

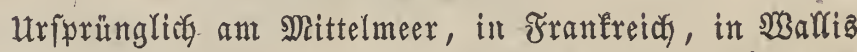
unter bem Setreide, in Saläftina in $\mathfrak{B}$ einbergen, hie und ba bermildert, bet uns aber bäuftg fultivirt.

\section{§ultux.}

Die Rinfen werben felten ausigebefnt angefaut, fite lie= ben einen mefr fanbigen, aber boch etwaz gebundenen, fräf= tigen und nicht frifd gebungten $\mathfrak{B}$ Dden und eine warme,

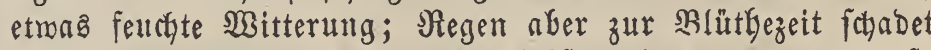
ifnen. Da die Rinfen bie Nadffrofte nicht auBduern, fo

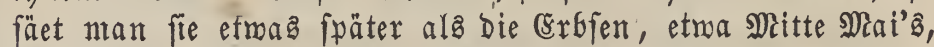
aber audy. foron im Märy. Den Boben, Der bie Rinfen auf=

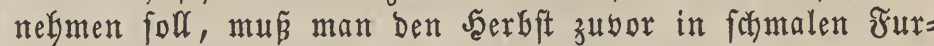
chen pflïgen umb geförig eggen. Mlan fäet reinen Samen, am beften nach Sartoffeln und nicht zut tief, entweder allein 


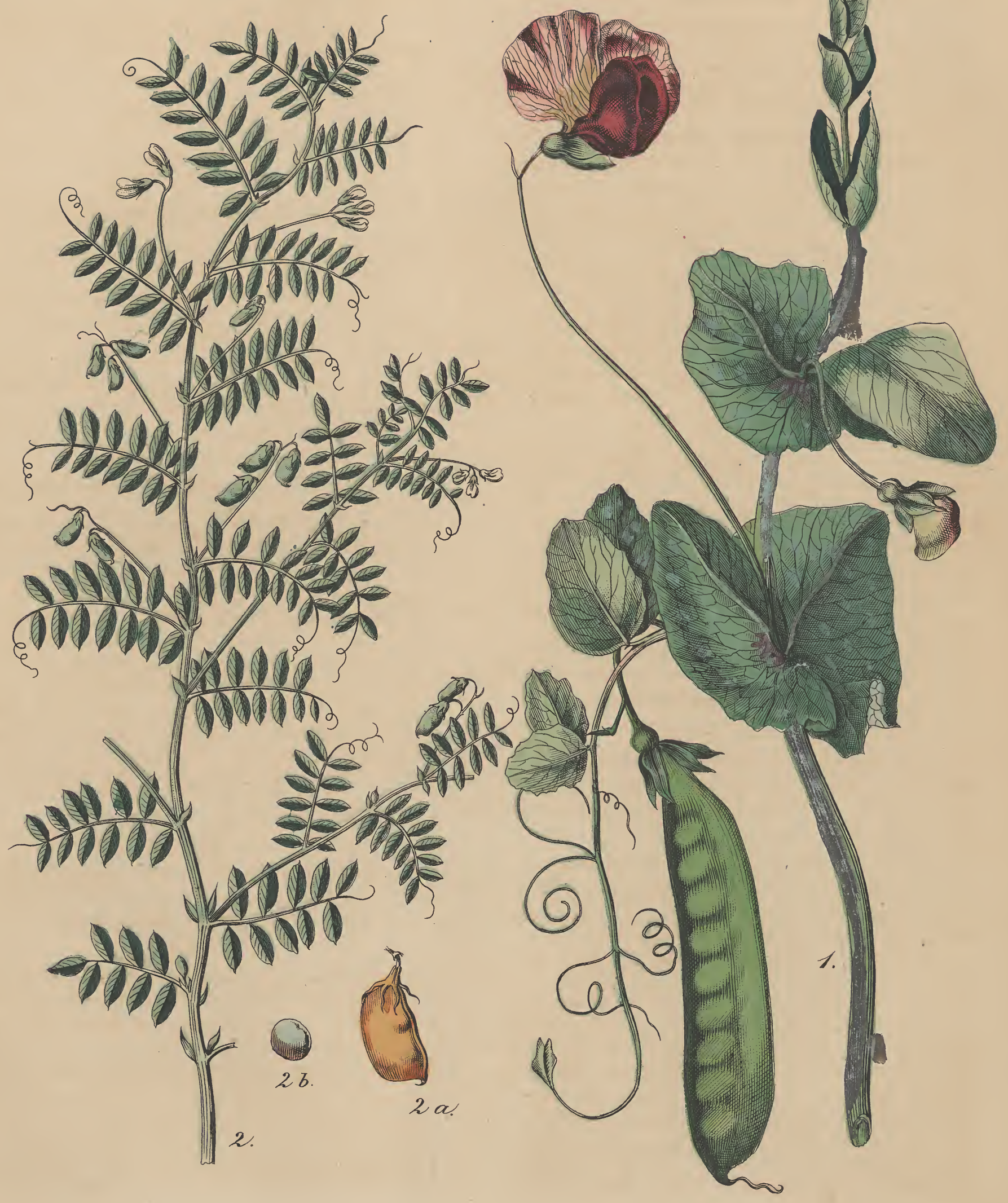



Dbet unter Gerfte und Sommerroggen. Sommen bie jungen Pflanzen aus bent Boben bervor, fo eggt man fte leicht auf, beharft fite gut und reinigt fie yout IInfraute. Die Ernte

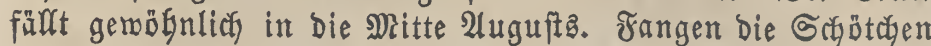
an Graun zut werben, wenn audy gleidy bas Sraut noch grủn ift, to find bie Rinfen zum AGneGmen Ginreidend reif; Denn läp̆t man fie zul lange fteflen, fo fpringen die Săllen gar

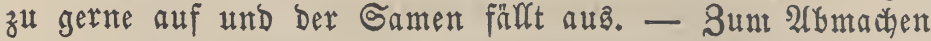
Der linfen wählt man einen warmen, trodtenen $\mathfrak{T} a g$, fin=

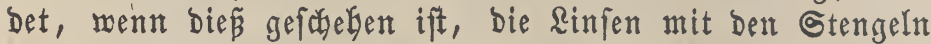

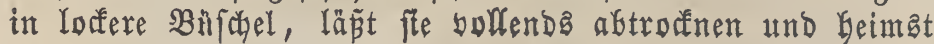
fite bann ein.

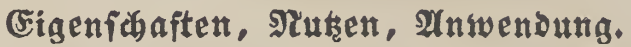

Die Rinjen find meblig, fromerfen formach bitterlich und

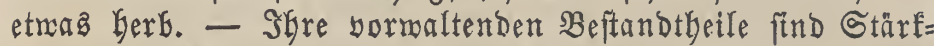
mehl und Gerbftoff; nach Ering of enthalten fte in șundert:

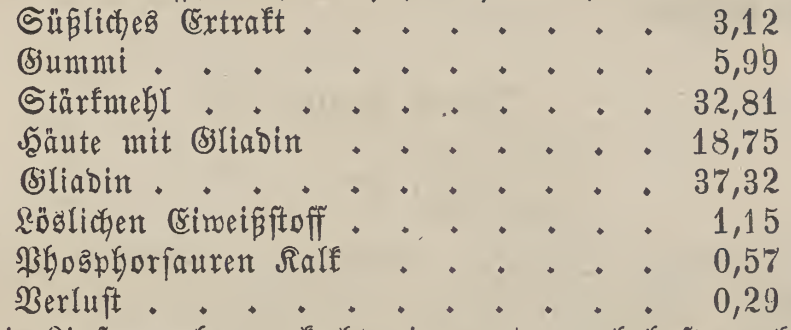

Die Rinfen geben gefocit eine gute, nabrhafte, aber ebenfalls jefwer werbauliche Speife; man genient fie als (5es=

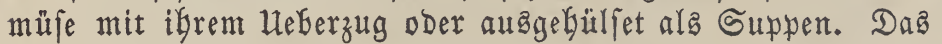
Rinfenmegl fann auch Dem Brod beigemengt werben. Bsequelft ober gejchroten find fe ein gutes Biebfutter, befonders für Gchweine, fte bermebren bei Den Rüfen Die Milch und brin=

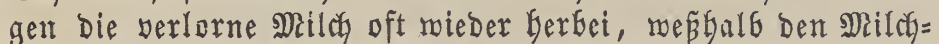
füben nicht zu viel babon gereicft merben barf. 2(ud bảs

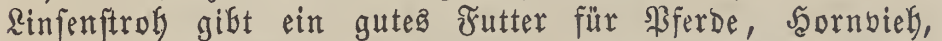
Schafe und Biegen, Gauptfäçłich für Sälber und Rämmer,

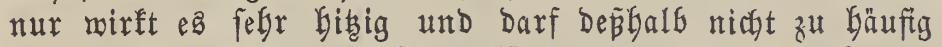
und nur in fleinen (s)abent gefüttert roerdent. Das Schrot benäbt man ferner zum $\mathfrak{B r a n n t w e i n b r e n n e n . ~ - ~ M a n ~ g e = ~}$

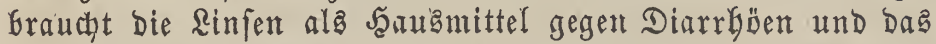
Rinfenmegl als umfdylag gegen Bsefdyüre und berbärtete Drüfen, Gejonders, mit Bier zu einem Brei gemijeyt und zmar bäuftg mit Erfolg, gegen Inodyengefdmüre.

\section{1. $\mathfrak{G} \mathfrak{e m e i n e ~} \mathfrak{A} \mathfrak{i n} / \mathfrak{e}$.}

Sileine beutiche Feldinfe.

SWird am meiften angebaut.

\section{UTroke Gartenlinie.}

Brenniglinie, F̧ellerlinje.

Sie find bejonderŝ grof́, meflreidjer, baben eine bellere Farbe als bie fleinen ober zelolinfen, afer feinęn fo feinen (5)efdymad.

Sie müffen fleigiger befandelt und gejătet merden; zum 2Haşāen diefer Surte foll man 2jügrigen Samen nebmen, bamit fie wentiger auzarte.

\section{3. 跕ovençet finle.}

Sie fummt aud gut in leiditent Boben fort und gibt

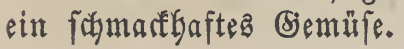

\section{Gir $/$ h hlin/e.}

SBird feltenter angebaut und bann meift mit Somnter= roggent.

\section{Lathyrus. L. \\ Siebe Geite 21.}

\section{Lathyrus sativus. L.}

Cicercula atrata. Moench.

$\beta$. Lathyrus semimaculatus. Hort.

$\gamma$. Lathyrus semipunctatus. Hort.

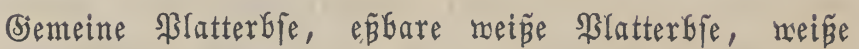
Deutfache Ricter, Saatplatterbje, Erbiz, punifdye Ridher, fpa=

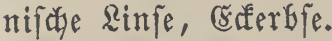

Gesse commune, Nentie de Suisse. (fiang.)

Common Lathyrus, Annual chichling - Vetch. (entgl.)

\section{Arten = 5 Garafter.}

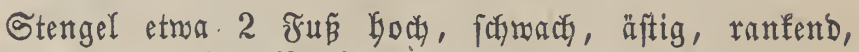

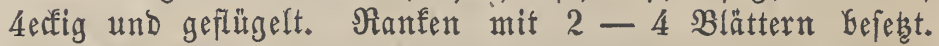
Blättchen fohmal lanzettförmig, fpis, 1 paarig. Afterblättchen fo breit als bie Blätter und Galb frieśförmig. Silumenftiele gegen 2 8oll lang, actjelftändig, 1blüthig, unter ber Blume gegliebert. Sielity lang und fpibig gezähnt. Blumen anjegn=

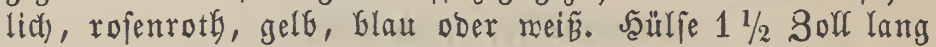
und $1 / 2$ Boll breit, eiförmig, zufanmengebrülft, neţïrmig geabert, auf Dem Rủcfen länggigefurdst, mit 2 erbabenen

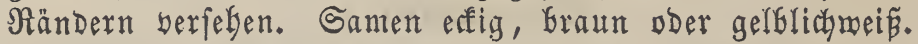

\section{Bliithe $=3$ eit und $\mathfrak{D a u e x}$.}

รutni - รuli. $\odot$.

\section{3oremmen.}

Snt füblidłen (ङ̌ropa, Spanien, Stalien, Eranfreidy, Trieft, Rrain, auf $\mathfrak{2}$ uen und fultivirten Aerfern, und mird bie und da gefaut, Gefonders in Stalien.

\section{Nultux.}

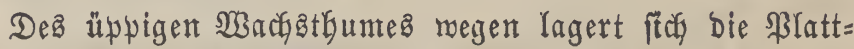

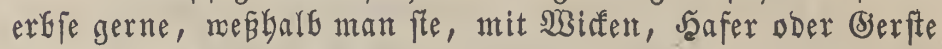
wermifict, anbaut.

\section{(sigenidaften, Nutuen, $2(n \mathfrak{w e n o u n g}$.}

Die \$latterbje ift meglreich, wirb wie bie đrajen als (Semůfe Genüht, Doch ift Der Benuz derfelben nicht gefund; man bermendet fie gefdroten, bauptfächlich zur Mlaftung Dez Siebes und Der Schmeine und bie \$flanze als Errủnfutter.

\section{Vicia. L.}

Siebe Seite 135.

\section{Vicia sativa, L.}

$\alpha$. Vicia sativa obovata. Sering. $\gamma$. Vicia leucosperma. Moench. Vicia helvetica. Hortor. Vicia alba. Moench.

Vicia sativa nemoralis. Pers. $\delta$. Vicia glabra. Schl.

$\beta$. Vicia segetalis. Thuil.

Vicia luganensis. Schl. $\varepsilon$. Vicia sativa pygmaea. Sering. Vicia lathyroides. Thomas. 


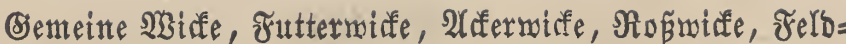

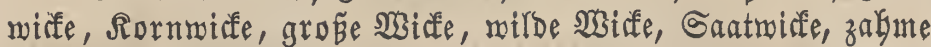
Sita, , Taubenmiffe.

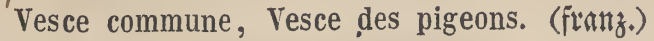

Vetch. (engl.)

\section{Arten $=$ Charaktex.}

Die ganze ßffarze ift mekr ober meniger meicjbebart.

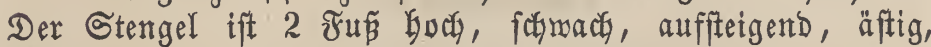
exfig gefurcht, glatt ober etmas furzbefaart, raug. Blätter 3-8paarig, ranfentragend, abgebrochen - geftebert, und ab= wechfelnd ftebend, aus 6-16, 1/2-1 3olf langen, 2-2 $1 / 2$ Sinien breiten, berfegrt-eiförmiḡen, abgeftumpften, aus= gerandeten, zartbefaarten, ftactelfpitzigen und Gocbgrünen Blättern zulammengejeģt und von fleinen, gezähnten, balb wfeilförmigen und fămärz̧lich geflefften 2 ffterblättchen unter=

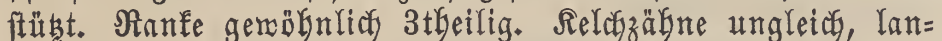
zettförmig, borftig, und faft fo boch als bie shlumenröbre.

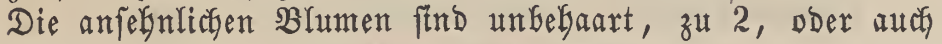
einzeln ftebend, adjelftändig, fehr furz geftielt und violett

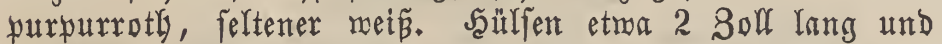
2 Rinien breit, anfikend, aufrecht ftelyend, faft gezweit, Görferig, etwas ylattgebrülft, figwerbtförmig, furz und meid filzig Gelgart, reif Gellbraun, bielfamig. Samen runblich, zufammengebrücft, ftumpferfig, glatt, Graun ober meişlich und fictwarz geflecift.

\section{Blüthe = 3eit und $\mathfrak{D a u e r}$. \\ sunt - 2luguft. $\odot . ~ \delta$.}

\section{3oréntumen.}

\{łuf 2 ecfern, ein Unfraut unter ber Saat, Heịonders

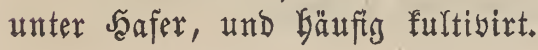

\section{§ultur.}

Sie mirb auf Bracfäcern mit Bortbeil als Jutter an= gebaut und trägt felbft zur Düngung Derfelben bei, erbält Den Boben lorfer und läpt Itnfraut weniger auffommen, gebeift auf jebem $B$ oben und berträgt fogar einen fohweren, fichon etwas feuchten, felbjt auf einem fteinigten, mageren Boden fomnt fite fort.

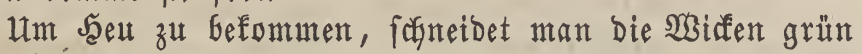
$\mathfrak{a b}$, fobars bie Gamen anfangen gelb zu merben.

Nidgt alfein wegen ibrez Futters, fondern aud wegen

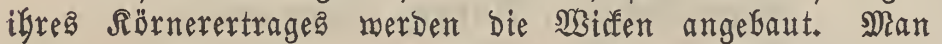

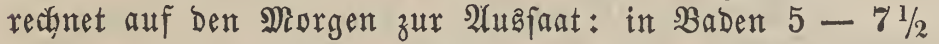
Sefter, in Seffen $1 \frac{1}{2}-2$ Simner, und in 2 surttemberg $2^{1 / 2}-3$ Simri. SGr Ânbau ift ganz Dem Der Erbfen

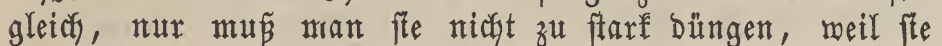
fonft melgr in's Stroh treiben, aber weniger Sörner an= fesent.

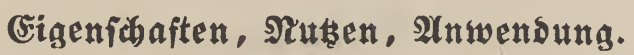

Die Samen find melylreich und etwas bitterlicy; die yormaltenden Beftandtbeile find nach bireif:

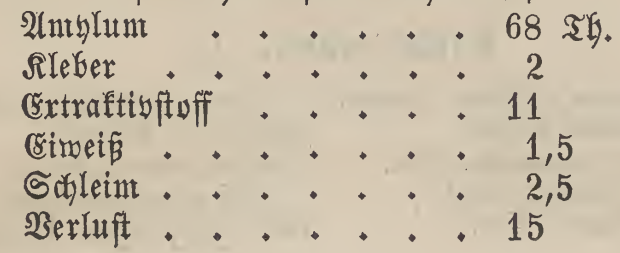

Die 2 (afermiffe ift ein febr gutes Biebjutter und ibre Samen merben bem Geflügel und befondera ben Tauben gefüt= tert, aud fant bas Nebl zu Breiumfarlägen benüht werben, nur in theuren Beiten yerbact man Das Sidfenmegl unter BroD.

Man bat yon Der Frutterwite verforjiebene Spielarten:

1. Gewönnlidhe sutterwidke.

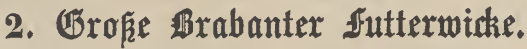

3. $\mathbb{G r o} \mathfrak{z} \mathfrak{e}$ englitche 5 utterwicke.

4. Weize Hutterwidke.

5. Bweijährige widke.

Vicia sativa biennis.

WBinterniafe.

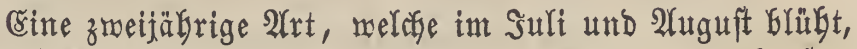
treibt ftarf in Schp̈plinge und ift einez ber frudbtbarften Jutterfräıter.

\section{Vicia Faba. L.}

Faba vulgaris. Mill.

Faba major. Desf.

Faba sativa. Autor.

Bemeine Saubohne, 2laferbohne, Buffbohne, Brerbe=

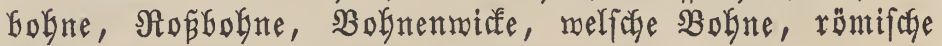

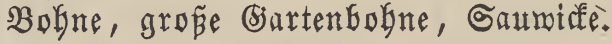

Féve de Marais commune. (franz.)

Broard Bean, Common Garden Bean. (entgr.)

\section{Arten = ÇGaralter.}

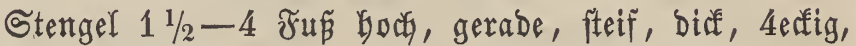

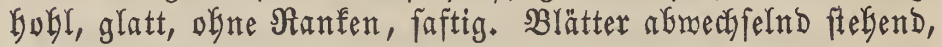
$2-3=\mathfrak{u n d} \mathfrak{n t e \mathfrak { r }}=$ paarig, ganzranbig, eifürmig, lang zuge= fpibt unb abgebroct)en geffebert. Blättchen 2 3oll lang und 1 3olf breit. Nebenblättchen 3erfig, gezähnt, eiförmig und glatt. Blattfitel fich in eine Spitse endigend. Blumen ziem= lich grof́, $2-3=$ und $m e \mathfrak{b r}=$ zăblig, einjeitig, bicht und in Den SBlattroinfeln ftefend, rein weís und in ber Mitte ber Flïgel ein fammtartig fatwarzer flect. Shülfen $2-3$, 0 oll lang und $1 / 2$ 3oll biff, furzgeftielt, zu $2-3$ ftelyend, leber= artig, etwas rolzenförmig aufgefdmolfen, böfferig, mit febr furzen fammtartigen und filzigen Jeaarent befegst, an einent Stengel oft 20-70, 2-5famig, mit Der Reife fandwar merbend. Samen grof, $1-1 \frac{1}{2}$ Soll lang, eiförmig - nie renförmig, zufammengebrủcft, mit an Dent biffern Ende fthendem Rabel, weísviolett ober Graungefürbt.

Man hat eine Barietät:

\section{$\beta$. e qu in a.}

Vicia Faba. $\beta$. equina. Pers.

Faba minor equina. Bauh.

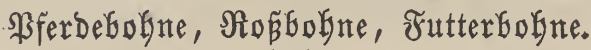

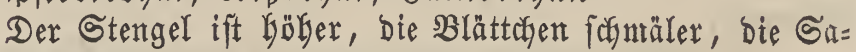
men viel fleiner und unmerflich zufammengebrüreft.

Słüthe = 3 eit und $\mathfrak{D a u e r}$.

รuni - 2lugut. $\odot$.

\section{3orEontmen.}

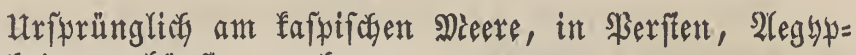
ten, bei unz bäufị angebaut. 


\section{§ultur.}

Sie mirb als Brachfrudyt ober int Frudytmedffel gebaut, DDer als (3rünfutter in Der Gtoppel.

Die Saubohne berlangt einen fräftigen, fofweren Thon= Goden, Den jogenannten SBeizenboden; ein trodfener, loderer Boden ift ifr zuroider, Dagegen fommt fie auf einem Marjady= Goben und gutem Refmboben gut fort.

Unter allen baủlfenfrüchten bertragen fie ben meiften

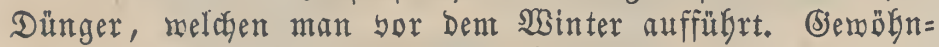
lich wird der für bie \$ferdebofnen Geftimmte 2 (cfer im Jerbfte zmeimal gełflügt, nach Dem zmeiten Pflügen bleibt er über ben Winter rauly liegen. Sobald Der Boben im Frübjagre abgetrodfnet ift, wird Der Dünger flach unterge= pflügt und ber Boben wird Dann geeggt.

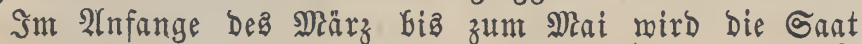
borgenommen; man mäblt gemölndich bie breitmürfige Saat,

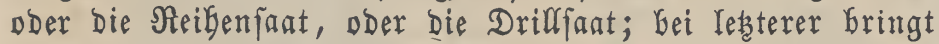
man bie Bofnen mit Der pogenannten Driflmafdine ober mit Der Şand in die zmeite Furche.

2(uf Den Mergen rewhet man bet ber Greitwürfigen Saat: in Baben 6-9 Sefter, in Seffen 3 Simmer, und

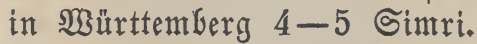

Benn bie Bofnen $2-3$ 3oll lang fend, fo werben bie Greitmürftg gefäeten übereggt, und bie, melche gebriflt worben ftnd, Gearbeitet man mit Der \$ferdeface und mer= Den fpäter mit Dem baäufelpftug behäufelt. Die auf erftere 2rat untergebrachten $\mathfrak{B}$ ofnen werden mit Der Saafe zmeimal gefelgt, und die, weldye zu dicht ftehen, můffen verzogen

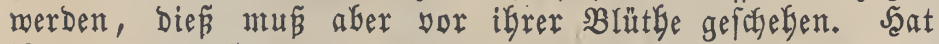
ifnen ein Froft gefdhabet, fo ift es am räthlichften, fie $\mathfrak{a b}=$ zumähen, zu ftreuen und unterzupflügen. $\mathfrak{B e n n}$ fite feine Schoten anjeten follten, fo merben fte mit ber Sidyel ge= gipfelt.

Sm September und Dftober, wenn bie Sayoten fanăr lich fend, werden bie Bobnen geerntet; man zieft fie ent= weber aus ober fohneidet fie mit ber Sichel ab, und um fie abtroffnen und nadgreifen zat laffen, werden fte fegelförmig gegen einander aufgeftellt.

Man rechnet auf einen Morgen Ertrag

in Baben 4-9 Malter und 15-24 Centner Strof, in Seffen $2-5$ Mialter und $10-18$ " " in $\mathfrak{B u r t t e m b e r g ~} 3-6$ Scheffel und 12-20" "

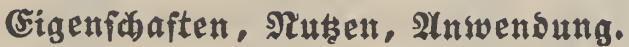

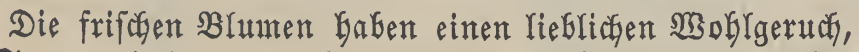
bie Gamen riechen nicht befonders angenegm und fohmerfen meflig. Die Blütthe entgält befonders ätherifoges Del und bie Samen nach Eing of in 100 sheilen:

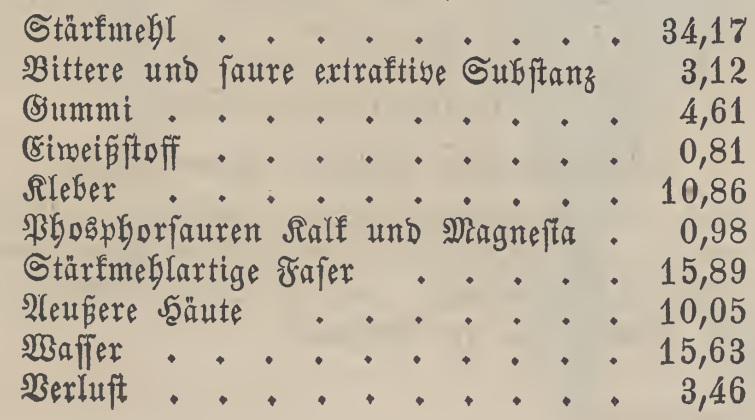

\section{Nady (Breif:}

Stärfmefl . . . . . . . 68

Rleber . . . . . . . 2

Extraftib= 3 uffer..... .10

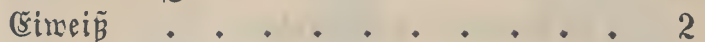

Schleim . . . . . . . . . 3

Verlujt . . . . . . . 15 Aficte.

Die Stengel geben Durch Berbrennen eine faligaltige

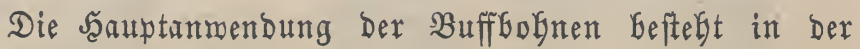
Maftung, bejonders gefdroten, und ift als Srhrot auch ein gutes Sferde =, Rindvief = und Schmeinefutter, auch merben fie jung, entweder allein, Doer mit Den Şülfen als (5emüfe, ober auch beinabe fajon reif, gefajălt, mit Belbrüben, mie im Thüringifchen, gefpeizt. Ferner bient daz Gamenmefl zu Breiumfchlägen und roird audy hie und Da unter $D a b$ Brod verbafen. Das deftillirte $\mathfrak{W a f f e r}$ Der Blüthen gilt alz Schönkeitamittel. Die $B$ lüthen werben Gäufig von ben $\mathfrak{B} i e=$ nen aufgejudt. Daz Stroh, menn ez nicht zu reif ift, ift ein felgr gutes Futter füt ßferbe, Rühe und Schafe. Goten.

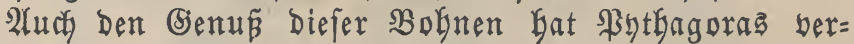

Durch Rultur Gat man megrere Spielarten erbalten:

1. Blaue dicke Ackerbobne.

2. Blaue engliphe Adterbohne.

3. (15rözte Adkerbohne.

Bfennigbolyne, $\mathfrak{B}$ indjorbogne.

Windsor Bean. (engl.)

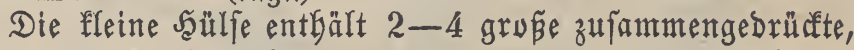
runbliche, Gräunliche Samen, bie einen nicht unangenebmen,

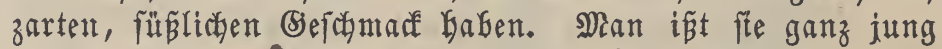
mit Den J̧ŭlfen, "reif aber nur bie Bobnen. Syr Meol fann man auch zu Brod verbacten, Brei und Suppen Daraus be= reiten. Sie wird bejonders in Rondon büufig gegeffen. Der

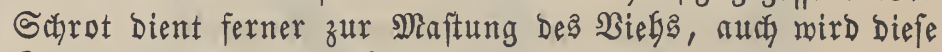
Sorte als Brünfutter benübst.

\section{Urofare Ackerbobne.}

Siemeine Buffookne.

Stengel ftare, Samen grof und flachgebrüct.

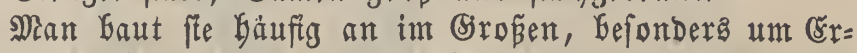
furt, mofelbft fie auperordentlicy beliebt fint. Man berfpeist fie grün, mit ober ofne faủlfen.
5. Rothblühende Ackerbohne
6. Rotbjamige Arkerbohne.
7. Schwar3 3 amige Ackerbobne.
8. Weipgraute Ackerbohne.
9. Weik witke Ackexbobne.
10. Wei enge englifhe Ackerbobne.
11.
12. Sdjwarze Winterackerbohne.
13. faleine Aikexbobne.

Rleine Sferbebohne.

Petit Feveralle. (franz.)

Horse Bean. (engl.)

Der Same fleituer alz bet ber Bufferohne und megr rund,

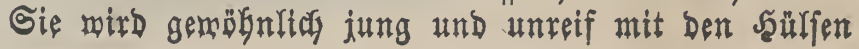


beripeist, ober aud nur bie reifen $\mathfrak{B}$ obnen, ift aber etwas

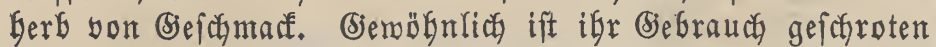

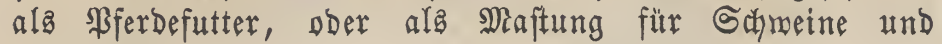
Rindbief.

\section{4. filsinfte Arkerbobne.}

Sanz tleine Raffeebohne.

Wird wie die borige angerendet.

\section{Magazanbobne.}

Riffaboner Bobne, portugieftfobe Bobne, Mazaganbohne.

cine fleine, febr frübe $\mathfrak{B}$ obne von angenefmem (5)e= famad, fann oft fajon iun Mai benübt merben.

16. Brüne mailändiĺdbe nuffbobne.

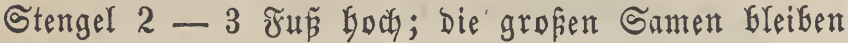
aucf trocfen grün.

Sie ift fefr früb und ergiefig und foll bem (bieformact nach allen anbern borzuzieben fein. Man iśt fie mie bie (Erbjen, reif als Mup ober Suppen, ober grün, allein ober mit gelben ßüben.

17. faleine fpani/che rabne.

Früb und bon angenefmem sefichmaf.

Man fann mit biefer Sorte auch Gartenbeete einfaffen.

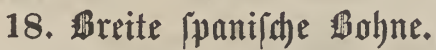
ficheden.

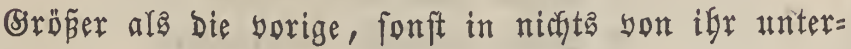

19. Corkerbohne.

(Etmaś grö́cer ala die Magazanbulgne, ift febr ergiebig, aber weniger moblichmedfend.

\section{Sandwidhsbohne.}

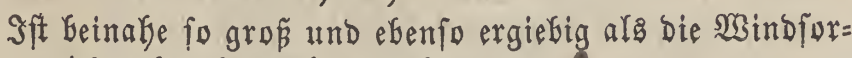
bolyne, nicht aber fo moblidymectend.

\section{Tetragonolobus. Scop. Moench.} Scandalida. Adans. Medic. Neck.

Snfteme: Cyteophyta. Neck. Diadelphia, Decandria. L.

Leguminosae Loteae. DeC.

Papilionaceae Loteae. Rchbch. Spach.

Relch ganzblätterig, röbrig-glơfenförmig, 5ppaltig oder 5zăbnig. Blumenfrone fametterlingarartig. Fabne auf= gerichtet, ränger als bie Flügel. Die 2 Flügel ftumpf, an ber Spibe nicht zufammenbängend, mit Dem obern Ranbe zufammengeneigt. Schiffchen ganzblätterig, auffteigend, ge= fănäbelt. Staubgefåpe 10, Dem Reldagrunbe eingefügt. Staub= fäben: 9 berbunden, 1 frei, an Der Spize berdicft. Staub= beutel eiförmig - runblich, 2fächerig. Stempel 1. Frucht= fnoten linealifa, 4fantig. Siriffel glatt, gefniet, oben berbiaft, an Der Spize einmärta gebogen. Narbe rinnig ober 2lippig, Gobl. Sulfe 4jeitig abgerunbet, mit 4 blatt = ober flügel= artigen 2 nfäben berfeben, welche längs ber bällje verlaufen, 2flappig, vielfamig. Samen fugelig, glatt.

\section{Tetragonolobus siliquosus. Roth.}

Tetragonolobus prostratus. Moench. Tetragonolobus Scandalida. Scop.
Lotus pratensis. Mill.

Lotus siliquosus. L.

Scandalida siliquosa. Scop.

$\beta$. Tetragonolobus maritimus. Roth.

Lotus maritimus. L.

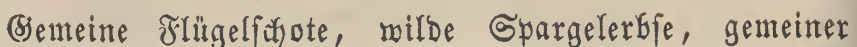
Schotenflee, gelber Schotenflee, Flügelerbje, 4erfiger Scho= tentlee.

Square-podded Birdsfoot Trefoil. (engl.)

\section{Strten = Sharafter.}

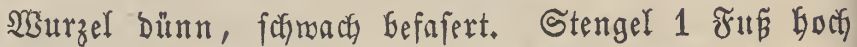
und Güber, aufrecht, feltener liegent, frautartio, meich zottig

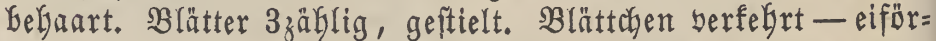
mig, zugefpist, Unterfeite feibenfaarig, das mittelfte etmaz gezäGnt. 2afterblättchen et - lanzettförmig, ftumpf. $\mathfrak{B l u m e n =}$ fitiele lang, achfelftändig, 16lunig. Reldh $5 z a ̈ h n i g$, bie 2 an Der Fafhe fed befindenden 3ähne find länger. Die Relch= zälgne faft fo lang als die Blumenfrone und länger als bas Schiffchen. Blumen fochön fodmefelgelb, cultipirt auch purpur=

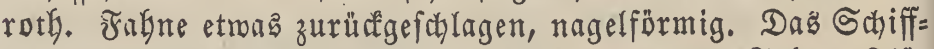
chen fürzer als die đ̛lügel und biefe fürzer als bie శaghne. Flü= gel großs. Schifficten etraz aufgeblajen, vben und unten an ber Nabt gefielt, Gäutig. Scủlfe 3 Soll lang und länger, einzeln= ftegend, höcferig, abgerundet 4effig, gerabe, mattgrün, mit

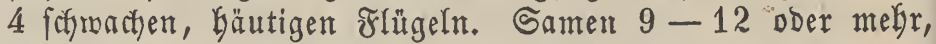

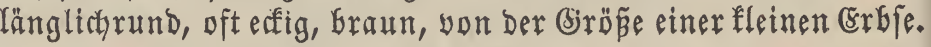

Man unterfacibet 2 2Harten:

$\alpha$, g l a b e r (maritimus).

Stengel aufrecht und die Blätter glatt.

$$
\beta \text {. pubescens. }
$$

Stengel liegend, Blätter unten meidbarig.

Blütbe = 3 eit $\mathfrak{u n d}$ Dauer.

Iuni - ฐuli. 4 .

\section{3ortommen.}

In Stalien, Sicilien, int füblicfen Franfreicf), auf ફ̧ü= geln. Die Barietät $\alpha$, an falzigen Seefüften, in Sachfen 26. ;

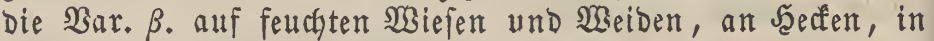
Schmaben, Baiern, Der $\mathfrak{B f a l}$, Jranfen, Wetterau, Thürin= gen, Deftreich, Saljburg, Jirain, wirb bie und ba in (Sär=

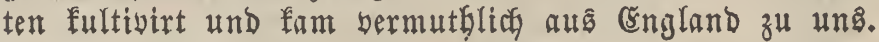

\section{Sultur.}

Man fạet bie Samen im Frübjabr, wenn bie Fröfte yorüber ftnd, in Furchen und ziemlich nake an einander,

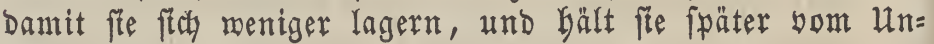
fraut rein.

Der $\mathfrak{A}$ nbau Der Spargelerbfe serbiente megr atrerfen= nung, ba berjelbe mit feinen lumftänden verfnüpft ift und Die Sfflanze biz in ben September fortwährend in bie Scho= ten treift. Säet man fie zu verfobledenen Seiten aus, fo bat man immer ein mohlfomerfendez Bjemüfe.

\section{(sigenfabaten, stuten, Anwendung.}

Man ist bie jungen Schoten entblättert rie Spargel,

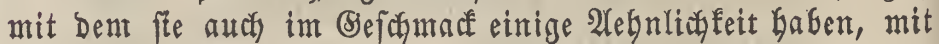
einer SRabmjauce zubereitet oder als Salat, efenjo bie Sa= men afs Eemüpe mie bie $\mathfrak{B}$ obnen. 
14

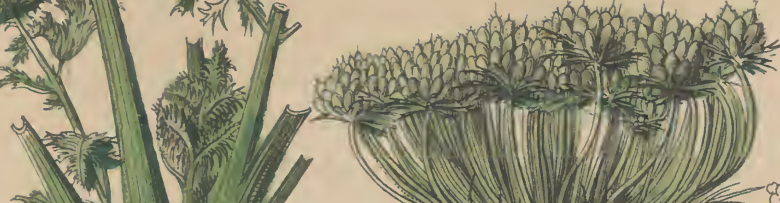

त)
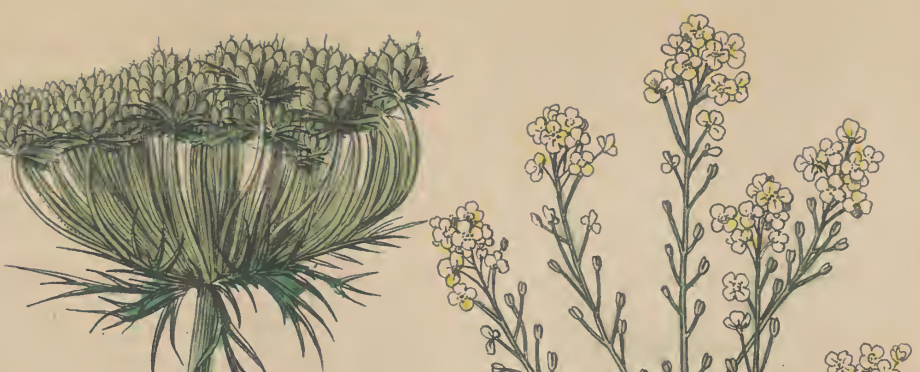

wey (2)

s

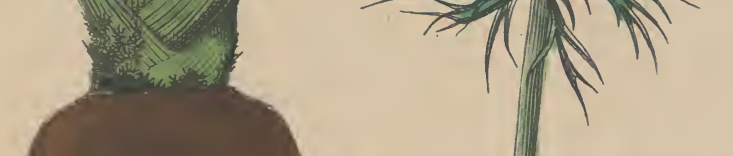
$10 \sqrt{0}$
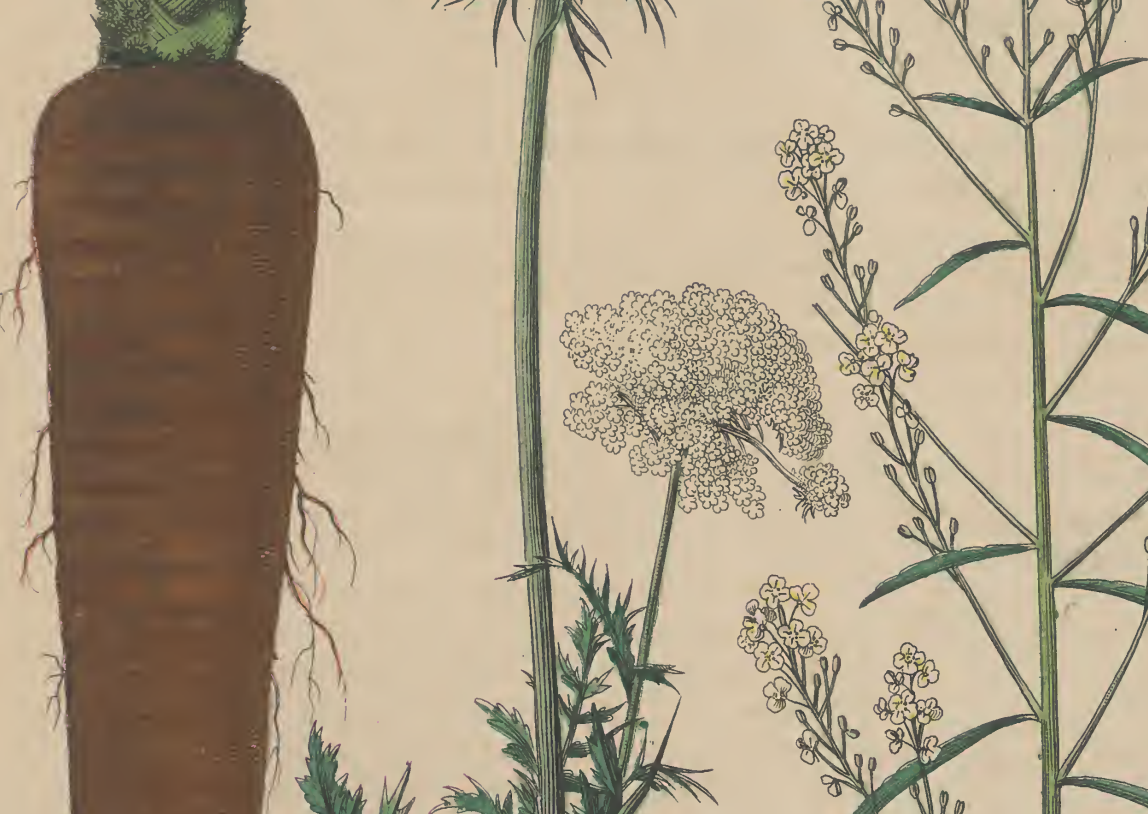

㩆

,

$+2$

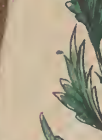

$\sqrt{2}$
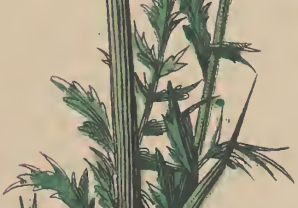
.
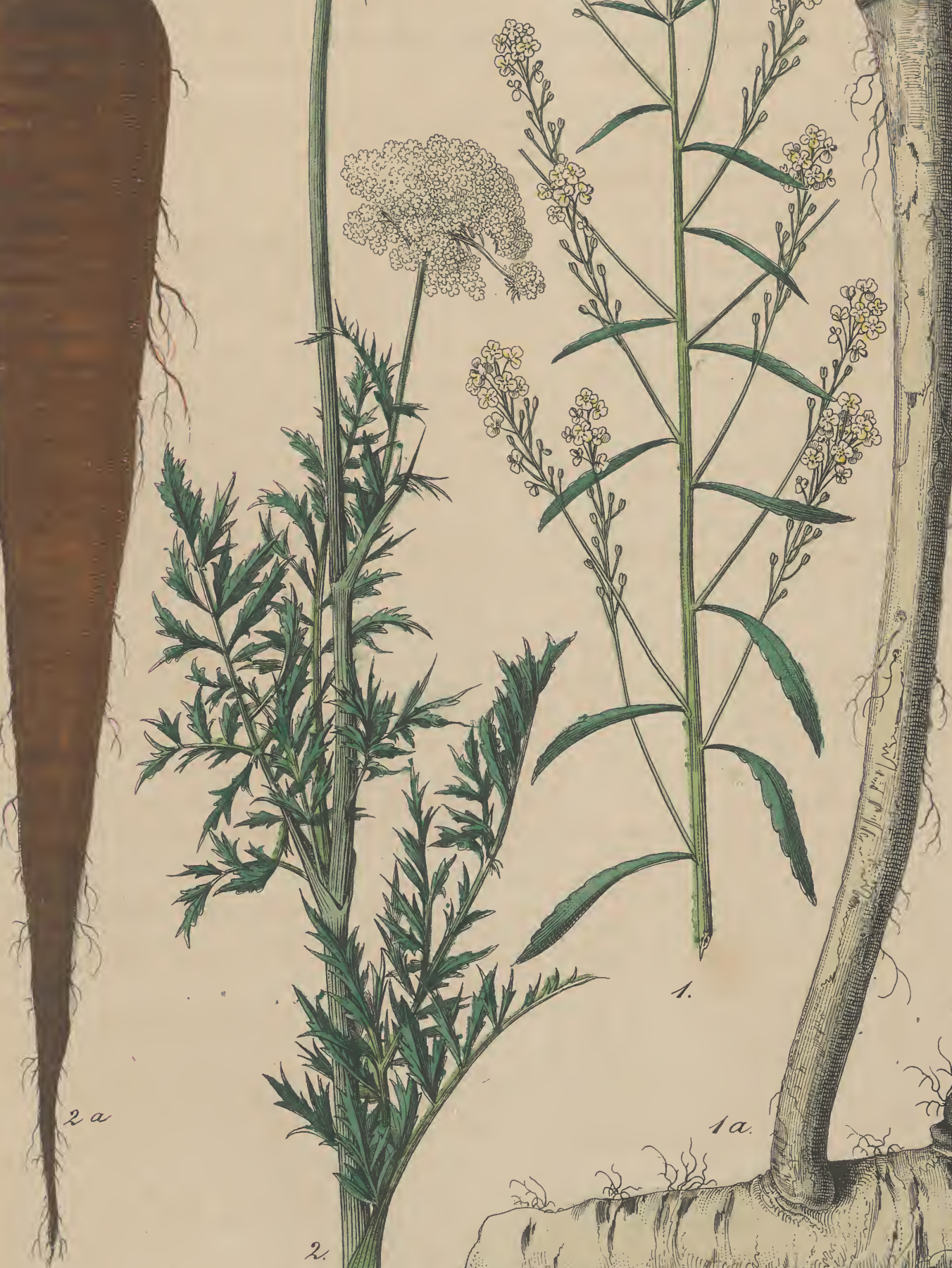

WW 



\section{Bweiter Cebil.}

\section{Gartengewädy}

Sind folche Gienäbjle, weldye bei uns im Sleinen angebaut werben.

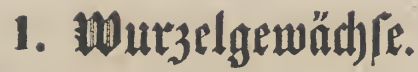

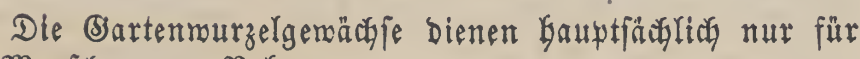
Den Menjofn zur Nabrung.

\section{Daucus. L.}

Anisactis. DeC,

Carota. DeC.

Platyspermum. Hoffm.

Snfteme: Scadiophyta. Neck.

Umbellatae. L.

Umbelliferae. Juss.

Dauci. Adans. DeC.

Pentandria, Digynia. L.

Selch ganzblätterig, 5zäłnig, ber Saum oberitändig, bie $\Re$ öbre ftachelig. Blumenfrone 5Glätterig, abfallend. Blumenblätter berfefgrt - eiförntig, aug̈gerandet, mit einem eingefwlagenen Bipfel, oft ungleich. Staubgefäpe 5, mit Den $\mathfrak{B l u m e n b l a ̈ t t e r n ~ e i n g e f u ̈ g t . ~ S t a u b f a ̈ d e n ~ f r o d e n f o ̈ r m i g . ~}$ Staubbeutel rundlich, 2fächerig, einmärts̈ gefebrt. Stempel 1. Fruchtfnoten unterftändig, mit einem ziemlich platten Griffel= Holfter gefrönt, 2fächerig. Sriffel 2, fabenfürmig. Narben ftumpf. Spaltfrudst eiförmig ober länglich, yom Rüfen ber etmaz zufaumengebrücft, ftachelig. Theilfrủchte bicht, mit 5 Jaapt = und 4 Rebenriefen. Samen umgefegrt, eimei $\tilde{\beta}=$ baltig.

\section{Daucus Carota. L.}

Daucus sylvestris. Mill.

Daucus vulgaris. Neck.

Caucalis Carota. Roth.

$\beta$. Daucus Carota sativa. L.

Daucus sativus. Hort.

$\gamma$. Daucus exiguus. Pers.

Pastinaca sativa. Lobel.

(E)meine ober gelbe Mäbre, gelbe Mübe, Mobrrübe, Moorrübe, gelbe Siarzel, Carotte, Sogelneft, Miaure.

Carote. (finnz.)

Carrot; Birds nest. (engl.)

Carota. (ital.)

Entwer, benom. æronnzentunde.

\section{Arten $=$ Sharater.}

Die ganze SPlanze if von furzen, fteifen Saarent mekr ober meniger raub ober auch faft glatt bedefft. Die $\mathfrak{B}$ urzel Der wilden Miogre ift flein, weißlich, lederartig, trorten, bie ber berebelten grof́, blakgelb oder orangefarbig und faftig. Stengel 3-5 ₹up Goch, aufred,t, 2theilig, geftreift, mit borftigen 2leften. Blätter 3 fach gefiebert, ftarf einge= fdnitten, begaart, Geffer oder Dunfler grün, iłr Stiel unten gerippt, ifre Einfonnitte lanzettförmig, fein zugefpist, bie Dolben Doppelt zufammengefest, oft 40 ftrahlig, röthlichmeís, yor Der Blüthe mit abjtebenden 2leften, nach berjelben aber zufammengezogen und Dadurch in Der Mitte eine F̧öblung Gildend. Relch 5fpaltig, faft fo lang als bie Dolbe. Die Blüthen meiplict oder fegr blapgelblich, in Der Mritte Dez Strabla befindet ftch ein verfümmertez purpurrothez Blüth= chen. Die Scheibenblütben find unfruchtbar. Staubfäben 5, Gaarfürmig. Staubbeutel einfacy. (5riffel 2, furz, unge= bogen, mit ftumpfen Narben. Die Frrüchte rundich, an Der Spibe mit bafenförmigen, ftacheligen Borften verfefen.

\section{Blütbe = Beit und $\mathfrak{D a u e r}$.}

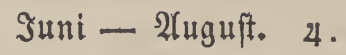

\section{Borkommen.}

2luf Feldern, 2lecfern, troffenen Wiefen, SBeiden, an

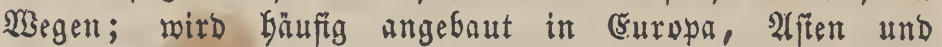
Amerifa.

\section{Sultur.}

Der Mäkrenbau wirb in neuerer Seit nicft megr fo

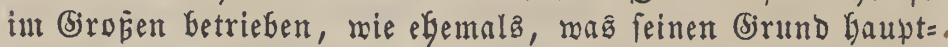

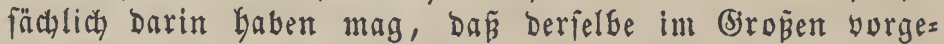
nonmen, bod mit ziemlich viel Mhbe verbunden ift, mobin

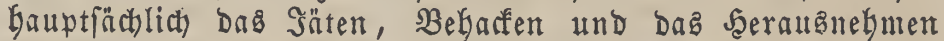
Derfelben ahs bem Boben gefören; übrigens folfte man fich biefe Arbeiten meniger beroriȩ́en laffen, renn man bie Bortbeile Der Möbrenfultur näber in's 2luge fä̈t, yon welden wir an bem paffenden Orte fprecten merben.

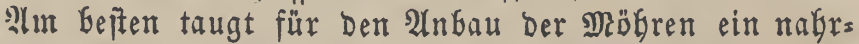
Gafter, lebmbaltiger, von Steinen und Unfraut Gefreiter, tief umgegrabener Boben. Das ltmpftügen, am beften mit 
einem Doppelpfluge, foll Den Serbft yor der Saat und we=

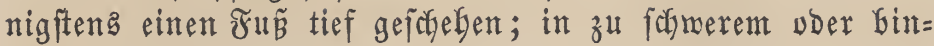

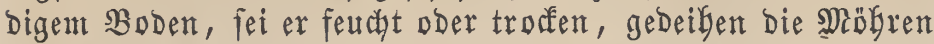
nicht; ba fie ftch entweber nicht yolftändig entwicfeln ober in Fäulniés übergefen. Sullte ber Boben zu mager fein, fo büngt man ifn mit geförig verfaultem Mift, und zmar am

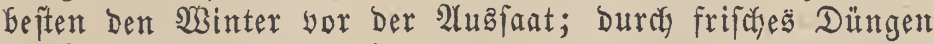
nimint bas unfraut ntegr überband, bie Möbren treiben zu fefre in's sraut und befonmen einen meniger angenefmen Siefchmadx. Şat man int Seerbfte auth ben Boben umge= pflügt, fo ift es boch son mefentlidfem Bortheil, Denfelben im ₹rübjafr yor ber 2luzajat zu eggen uno noch einmal

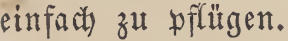

Die Mïbren lieben ein feutidea, aber marmes Slima, Gei trodfenem gerathen fie weit weniger gut, fate bleiben flein und befommen gewöhnlich einen unangenefmen, etwas fidyar=

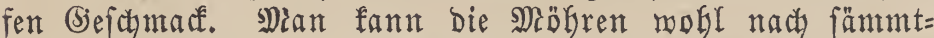

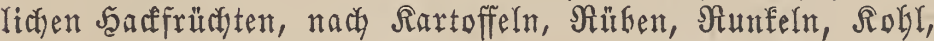
auch nach Rein, welche gebüngt roorben find und ben Boben in einem locferen 3uftande zurürffafinen, anbauen. Itm fte als 3mifchenfrucht nach Getreibe zu bauen, ift es am yor= theilkafteften, fie nach gebüngter sointerung zu beftellen, ba zu Diefer Seit Der Boben beffer zubereitet und yout Itnfraute reiner ift. Jghre Rultur zwifchen andern orrücten ift nut Dann za empfeglen, wenn Der Boben fegr fräftig ift und feime

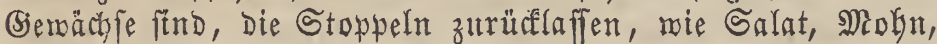

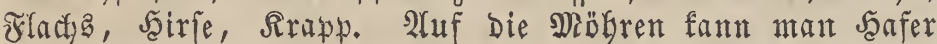
und Rifee folgen laffen, zumal da bie \$lobgren unter allen

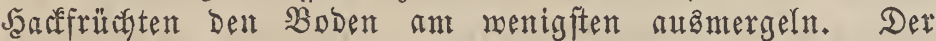
Samen, welcher gefäet merben foll, mus bölig trocfen, fo

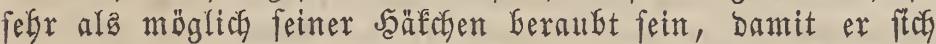

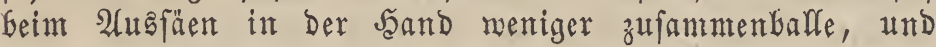
beffer ifte brauchen und Denfelben, regen feiner Neigung fich zufammen=

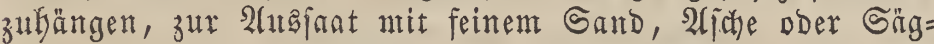

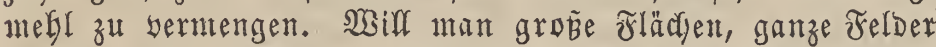
anfäen, fo theilt man Den Samen in zmei gleiche Sarthien und jäet bie eine in bie Ränge, bie andere aber in bie Duere und nicht zu biaf aus, Gringt ifn nur oberflächlich

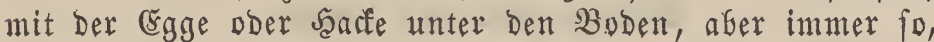

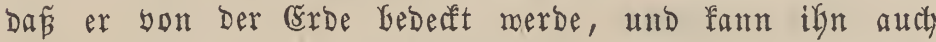
überwalzen. 2atm beften fäet man aber bie Mähren in Net= Gen, meldye man $2 \widetilde{z} u \tilde{\beta}$ yon einander entfernt madat, und eg Kat Diefe Methode Den $\mathfrak{B}$ orzug, Dan die Mibfren Gei ber

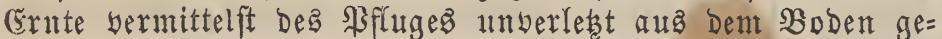

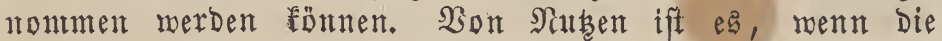

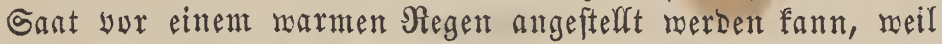

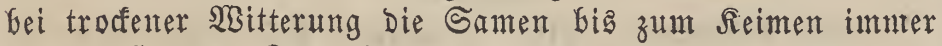

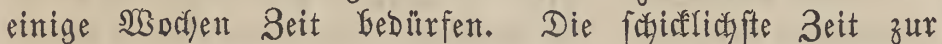

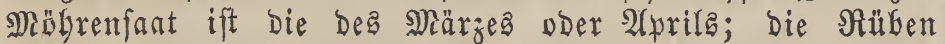
fohon, wie es häufig gejohieft, im Februar oft bei noch lie= gendem Schttee za fäen, ift immer geraggt, indem bie Sa= men zul lange Beit zun Reimen nötbig Gaben, mäbrend weldher das Itnfraut um fo megr um fteh greifen fann,

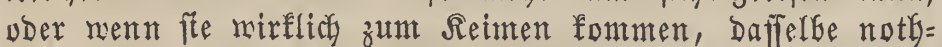
wenbigermeife burch leidgt eintretende $\mathfrak{R}_{a}$ Ite unterfrochen merben mus. (şGe die Samen berborfeimen, jätet man bie Erbe yorfichtig, Damit die zarten Bfränzchen bom unfraute nicht zurüffiegalten werben; find biefe etwa 2 Soll hod gemorben, fo befad man fie und vergiebt biejentigen, weldye

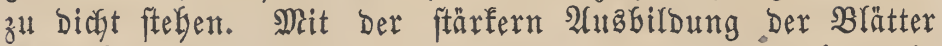
wieberfolt man bas Befacfen, mie auch baz Serzieken, fo Dafi bie ßrflanzen in einer Erntfernung yon 9-10 3oll yon einander zu ftehen fommen. Das jorgfältige Bebarfen bei Der Mabrenfultur fann nie genug entpfoblen merben, indem Diefes einen bebeutenden (sinfluf auf ben zufünftigen Errtrag

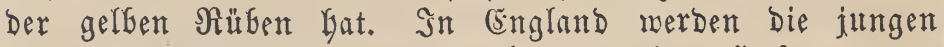

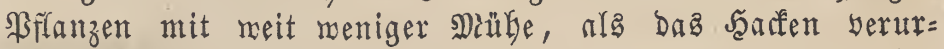

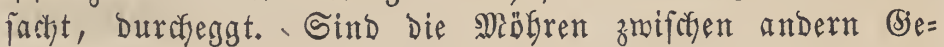
mächfen angebaut, fo eggt man fie, fobald biefe auz bem Ranbe entfernt worben find. W3urbent fie alfein angebaut, fo werben jie gemogntich um Michaelis benutbar, gefdyah bie Gaat aber zmifchen andere Frunchte, fo reifen fee erft Mitte ober Ende Oftoferz. Sind bie Mighren in Folge

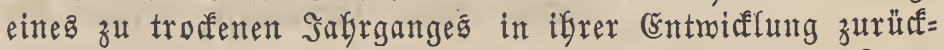
geblieben, fo beeile man fich nicht, menn etra das Rraut anfangen follte abzumelfen, biejelben aus bent relde zu nehs=

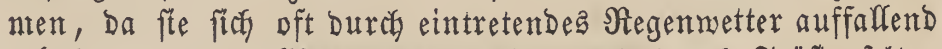
erfolen, nody yolfommener werben und burch fröfte felten leiden; jeboch ift Gier zu Gemerfen, daz zröfte nur den MibGren felten fdyaben, bie yon Samen im Felde angebauter gezogen wurben, das aber bie von (Onatenmöbrenjament ber= rübrenden, an fich viel zărter und mäfferiger, gar leicht bem Frofte unterliegen und oft foyon int relbe za faulen foegin=

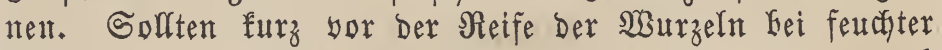
Witterung Die Blătter zu üppig genadhjen fein unb badurch Den $B$ oben zu febr beforatten, fo fohneidet man fie ab, unt

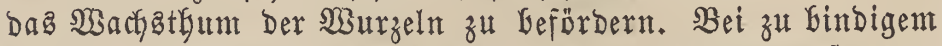

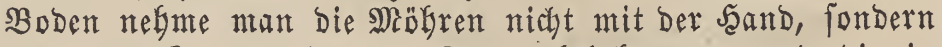
mit bem Spaten Dber Der Dunggabel heraus, und bie in

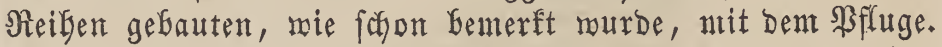
Dis aus Dem Rande genommenen $W_{3}$ urzeln merben yon ber

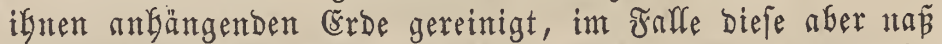
und anflebend wäre, zum 2lbtroffuen fo in Saafen geftellt,

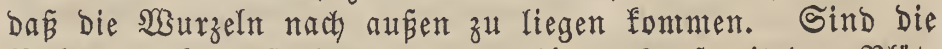
Rüben troffen, fo fohneibet man ibren Sopf mit ben Blät= term ab und läpt fie bernady fo lange nody in einem bebeef= ten Rofale bünn ausgebreitet liegen, bis bie Schnittmunde wernarbt und bie Rübe etwas melf geworden ift.

Die Mëbren werlangen, wenn fe ftch gut balten fulfen, bauptfächlich einen troffenen 2(ufberablangaort, fonft wer= ben fe leidft fobinmelig und faulig; man lege fte Dep̧balb, mag man fee in Simmern, Siruben oder in Rellern über= wintern rolfen, intmer auf Stroh, trorfenen Sand ober auch trodfene (Erbe, auch verfäume man nie, ben אapf und

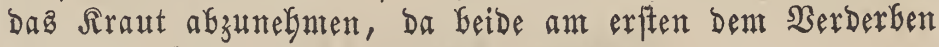
augęgefert find.

8ur Samenzudft nimmt man im Saerbjte bie volffom= menften und nur rein fpindelförmig gefildeten grope und

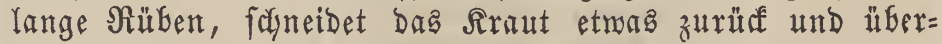
mintert fie auf bie angegebene 2 rrt. 23 eniger gut ift $e$,

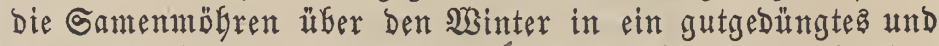
geforuthtez sortenbeet zu bringen und fie bei ftarfen Fröften zu beberfen, meil fie baburch immer berzărtelt umb häufig yon Den Mäufen aufgezegrt werden. Im Früfjahr, Mitte 2lprils, wenn es bie $\mathfrak{B}$ itterung erlaubt, verfetst man bie Samenpflanzen etwa 1 Fur meit yon einander in'z Freie. Der Samen zeitigt gemöbnlich in 2(uguft, aber ungleidt; man 
nimmt beskalb iumer ben, ber zulest reif mirb, unb bängt ifn, um ifn tollenos augzutrodfnen und reif werben zu Iaffen, mit Dem Gamentengel an einem trofenen Drte aur. Weiter bat man bei Der 2lufberabrung Deś Samens darauf

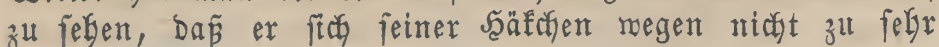

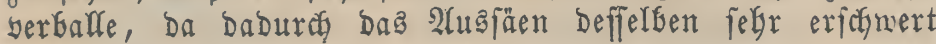
würbe. Unt biefem zu begegnen, läpt man am beftent die Samen gerabezu bis zur Giebrauchzzeit an Den Stengeln,

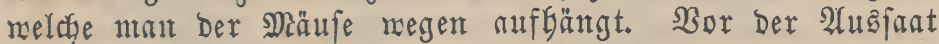

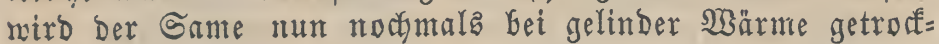
net, won ben Stengeln abgeftreift und forgfültig mit Den Sănben berrieben. Der Samen bleibt, borfictig aufberabrt, $3-4$ Jafre lang gut, und man bedarf bon ifut etwa 3 bis 3 1/2 Bfund auf Dag Jelb ober $3-4$ Roth auf ein Siar= tenbeet.

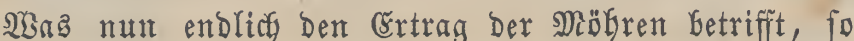
ift er, wie mogl benfbar, ant Göctifen, wenn biefelben allein angefäet roorben find, Da bie ŞGrzeln, unter andern Früch= ten aufgemadien, nur jelten zu ibrer sollfommenen 2 Gabil= bung gelangen; im erftern Falfe erbält man yom salagde= burger Miorgen Durchfofnittlich 200 Centner 23 urzeln and 50 Eentner Rraut. In Ěngland rechnet man yom 2lcré 395 Eentner Ertrag.

\section{Grbäbliche (sinflüfie, §rantheiten.}

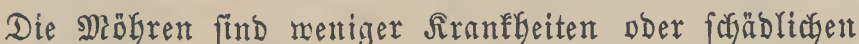

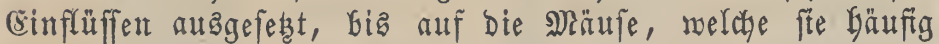
beinturfyen.

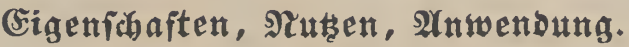

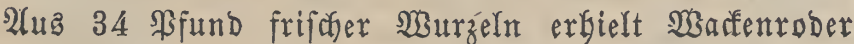
$1 / 2$ Dracfme farblojes ätherijictes Del bon wibrigem (se= fidmate und Durdidringendem (5ierudje. - 100 Theile Ex= traft enthalten aub Dent frifonen Gafte:

Saleintzưfer, mit etros Stântmegl und 2hfelfăure . . . . . . 93,71

Eimeís. . . . . . . . 4 4,35 fettes Del, nod ätberifacs entralteno - 1,00 rotbe, frbftallifrbare, Garzartige Subfanz (Carotill) . . . . . . .

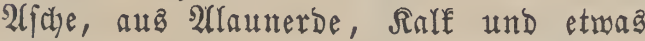
Eifen Geftebend....... . 0,60

Die fultibirte Möbre Geftht einen angenebmen, füpen, bie wilbe Gingegen einen faben und melor fararfen Siefantarf. Aus ben Miögren Gereitet man ein Gefanntes, gefundes̆, tahrbaftes und Bielen angenefmes Gemūle, frefonders yon Den jüngern Miobren, meldye man bäufig mit grünen (šbjen werfocht. Sie geben ein yon allen Saustbieren, zumal den Schafen und bent Rindbieh febr gefuchtes und ein Denjelben fefr gefundes Futter. In England, zum Theil auch in Deutichland, füttert man nit Nuben ftreng arbeitende SFerde anftatt Des Safers mit Mobren, und Gefonders beilfan ift ifr Genur erbibten Bferden. Dbwobl zur Maftung reniger borzüglich, Schroeine und (s)̈nfe etma auagenommen, ftro

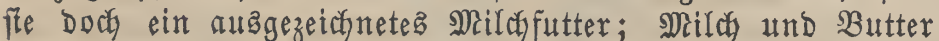
erfalten bon ifunen eine gelblicfe Farbe und lebtere audf ibren sefamad, ebenfo wird auch das Fett des Damit ge= mäfteten Biebes gelblicf. Wan vermendet fie ferner zur Branntweinbrennerei, bereitet aus ifnen eine 2 rt $\mathfrak{B}_{\text {bein, }}$ Den zur Syrup = Confftenz eingedictent MäGrenfaft, Roob
Dauci, welcten man ftatt bes Sucfers unb als auflöfendes Mittel gegen Salften oder aud gegen N3ümer gefraudit, und benübt fie zerjonitten und geröftet als Raffeefurrogat ober als Sulab des Raffee's. Die jungen Blätter fann man

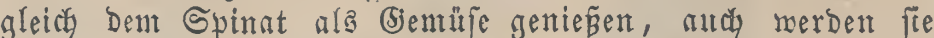
grun ober gebört yom Biebe gerne gefreffen, fobald fie gefanitten und bent Säctifel beigemengt gefüttert merden, int andern Falle meniger, weil bie Blattrippen und Gtiele Dem Biebe gerne zrwiffen den Bäbnen fterfen bleiben. 2us ben Samenftengeln Der wilden Wöbre verarbeitet man ben Stiel= quarf, cine 2(rt Duarffäje bon genoürzbaftem (Siefduarf. In Beziebung auf Nabrbaftigfeit fommen $2^{2} / 3$ Sfund Möbren ober 10 \$funo Rraut 1 jĩund Seut gleidy. MRit. andern Ingredienzien zerrieben geben die gelben Rüben ein gefun= Des und beliebtes Futter fitr biele Stubengügel. Frifw ge= fuabene Migren leiften oft gute Dienfte bei SBrandjuäben, Rrebs und andern Gefogmüren. Die Blütlyen werben bäufig yon Den Bienen befucht.

Die M̈bren wariten ebenfalls in Beziebung ifrer Form und Farben, fie find entweder lang und fpitgig fith endigend, voer biaf faft chlinbrifa, unten mefr ftumpf, wie die eigentlicfen Carotten, neipliçgelb bis̄ in's röthliçgelbe.

\section{C5emeine gelbe flöhre.}

Daucus Carota radice lutea.

23urzel gelb, meift furz, didf, mit ftuntper SYurzel= fafer. Sine gemöhnliche Sorte, bie fich blof für's Feld eignet.

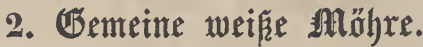

Daucus Carota radice alba. Tournef.

sine Spielart ber borigen, aber wobl bie geringfte aller M̈öhrenforten; Doch Gat man bon ibr nody eine $\mathfrak{B a}=$ rietät, die gut und fegr zucterreich ift.

\section{Gologelbe odex orangegelbe fnöhre.}

Daucus Carota aurantii coloris. Tournef.

Sat eimen febr angenebmen (5iefamadf und ifre Farbe färbt Durch's Rochent die Brübe nicht.

\section{Srühmőhre, bolländi/che oòer engli/che frühcatotte, - kuxze rotbgelbe bolländi/dhe Exilhearotte, balländilabe Goloriube. \\ Daucus Carota nobilis.}

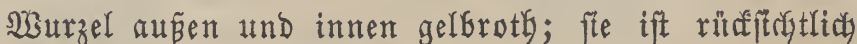

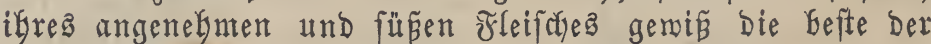
Mbkren. Diefe, wie alle feineren Gorten, die man in ber (5ïrtnerei in engern Sinne unter Dem Namen Carotten begreift, follten eigentlich nur im füthengarten fultivirt mer = Den. Da bie über ben $\mathfrak{B i n t e r}$ eingefalagenen Carotten bei

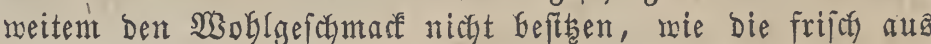
Dem Ranbe genommenen, fo follte man fie Gefonbers int 2uguft Doer September anbauen; die Seete bebedt man bei eintretenden Fröften nit Strof ober $2 a u b$, und bat auj

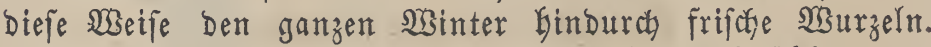
Sie eignet fich befonders auch zum Treiben in Frübeeten.

\section{Natbe Alöhre.}

Daucus Carota radice atrorubente. C. Bauh.

23urzel grof́ und lang, niçt befonders fün und färbt die Brïbe. 
6. Exube rothe möhre ơer Carotte.

Man benübet fie Gauptfäd)lid zun Treiben und erbålt fite früfjectig.

\section{Pastinaca. L. \\ Malabaila. Hoffm. \\ Syfteme: Scadiophyta. Neck. \\ Umbellatae. L. \\ Umbelliferae. Juss. \\ Peucedaneae. Rchbch. \\ Pentandria, Digynia. L.}

Seld gangblätterig, ntit oberftanndigem, unbeutlidłem

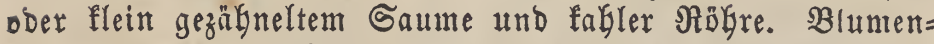
frone 5blätterig, abfallend. Bluntenblätter gleid, runblid, unausgerandet, eingerollt, mit beinake 4ecfiger, eingebrüfter Spibe. Staubgefẩe 5, mit ben Blumenblättern eingefïgt. Staubfäben fabenförmig. Staubbeutel 2fächerig, rundich, cinnärtz gefegrt. Stempel 1. Fruchtfnoten unterfänoig, 2 fächerig, gefrönt mit einem etroas genölbten, am Fanbe Wlatten und geferbten Briffelpolfter. Griffel 2. Narben ftumpf. Spaltirucht eiförmig ober runblich, yom $\Re$ tudfen Ger platt zurammengebrüfft, mit einem breiten, flachen Sande

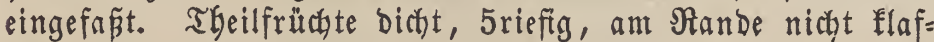
fello. Samen umgefétert, eimeísloz.

Pastinaca sativa, L.

Pastinaca arvensis. Pers.

- germanica. Moris.

- opaca. Bernh.

- pratensis. Fl. dan.

- $\quad$ sylvestris. Mill. Huds.

taraxacifolia. Hort.

Anethum Pastinaca. Wibel.

Selinum Pastinaca. Crantz.

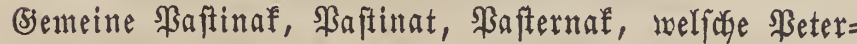
ftlie, Seftnachen, Şirfdübre.

Panais. (fratlz.)

Garden Parsnep. (engl.)

\section{Arten = (5haraeter.}

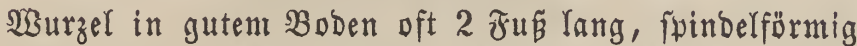
ober mehr birf, meí, Golzig, bei ben berebelten faftig.

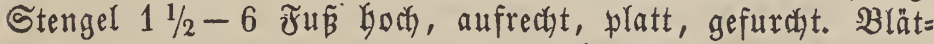
ter gefiebert, glänzend, unten meichbefaart, bei ben fultivir= ten wtelgr glatt, blä́ ober gelblichgrün. Fiederblättchen eiför= mig, geferbt gezahnt, an ber Baftz eingeichnitten, mit 3 lappigen Ěnoblättchen. Dolden bielftrablig. Bluntenblätter einnärta gebogen, gelb. Samen länglich, flach, nicht bücfé $=$ rig ober mit Säłf(t)en verfeber.

$\beta$. var. arvensis. Pers.

Heberall bidat meiß̈bebaart.

Blithe $=$ Beit und Dauer.

গัuli $-\mathfrak{A}$ uguft. $\delta$.

\section{Bor fommen.}

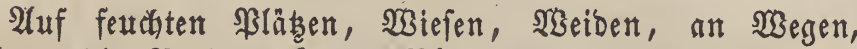
Bräben; bie Sarietät $\beta$. am Nhein; wird aber bäufig ful= tivirt. (ङuropa und Afien. @ultur.

Man Gaut bie Baftinafe bet uns yorzuggeneife nur in (5ärten, fie berbiente aber wobl im Grofien mefr angebaut

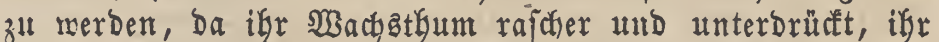
Errtrag nod) fiärfer als Der ber Mäbren ift, fie Durçaus nictit yon zropften leibet und ein gutes $\mathfrak{B i e f f u t t e r}$ abgibt. Shre Sultur gleidyt fo ziemlich Der ber Mobgren. Wie bie DibGre, io verlangt aud) Die \$aftinafe einen Iocfern, Den Serbft zuvor tiefgepflügten und gedüngten $B$ oben und ein

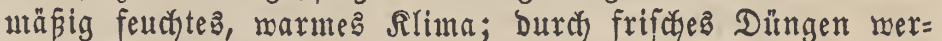
ben bie SBurzeln leidht flectig. Mian fäet fie entmeber audl) zrwifchen andere Jrüchte ober beffer aflein, im $\mathfrak{N a ̈ r z}$ ober, wenn man fie febr früly baben will, im Dftober, und ge= wögnlich in 8 3oll yon einander gemachte Reifen, und be= befft fie etras ftärfer mit Errbe als die M̈ofhren. Die zu bicht ftebenden Pflanjen verzieft man und berfegt fé; Daunit fie aber ifre gebörige Groópe erreichen fönnen, bürfen fie nicht unter $6-8$ Soll yon einander zu ftefen fommen. DGgleich bie Baftinaffamen Gäloer feimen als̄ bie Möhren= fanten, fo Darf Docf Säten und Befacfen nie übergangen werben. Das 2lgblatten finabet ben פ⿹urzeln. Meit Dem Einbeimfen ber ßaftinafen fann man länger zuwarten, als

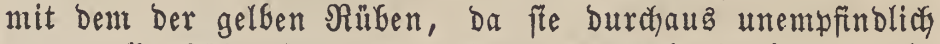

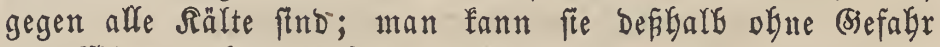
Den Winter über im Rande laffen, nur mú man fie fom= mendez Jrübjagr früfzeitig aus Demfelben bringen, weil fie

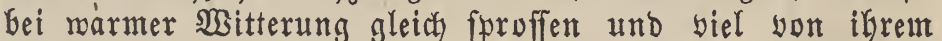
Woblgejdmaf verlieren. (Semöhnlid nimmt man fie aber zur Heberwinterung aus bem \&anbe, vermatyrt fie in trodfe= nen Giruben uno Sellern ober fotlägt fê in Bartenbeeten ein. Sind bie Baftinafen im Jrübjabr auşgefäet worben, fo befommt man meift foun im 2luguft benubbare $\mathfrak{B u r}=$ zeln, nimmt zuerft bie gröperen, io viel man beren gerabe

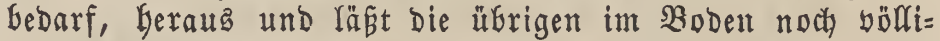
ger werben. Bur Samenzucht nimmt man am Geften bie

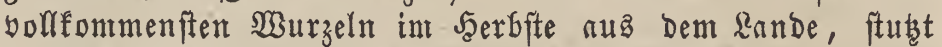
Die Blätter etmaa, regt fie in einen trocfenen Reller in Gand uno berpflamzt fite im Frülyling in's Gamenbeet, ober man

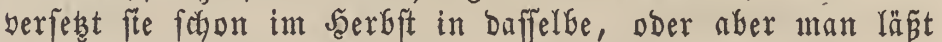
fie gleich über ben $\mathfrak{S i n t e r}$ int Rande. Der Samen reift im Geptember, aber audy ungleich, und bălt ficth nut 2 Gabre lang gut.

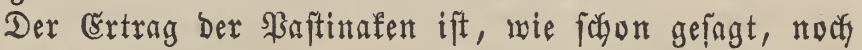
Gäber als ber ber Mogren.

\section{Bigenfichaften, Nuten, 2tnwenoung.}

Die ßaftinafe entfält nach (Cromes:

Stärfmebl...... 1,76

Eimeí̂́ftoff........ 2,09

Scbleimzudeter . . . . . . . 5,47

Gchleim und Extraftioftoff . . . . 6,11

Sfflanzenfafern . . . . . 5,12

şäfferige Theile ...... 79,45

Die milde saftinafe foll verbädytige Erigenfchaften bes

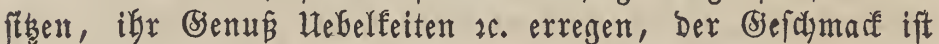
etwaŝ fuarf; Der lestere ift üErigenz bet ben fultivirten

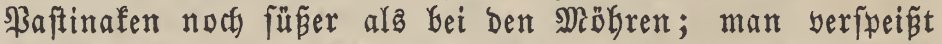

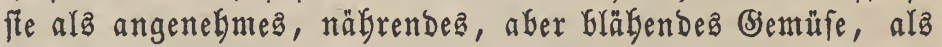
fak yon Suppen 3c., und fê find ein febr guteǵ und 







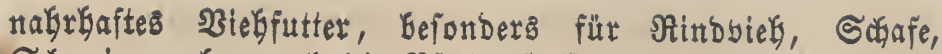
Sdymeine, aber auch bie \$ferde freffen biefelben fest gerne, fite vermegren bie Mlild, machen fee fett und geben eine gute Butter; in einigen Oegenden, wie in England, Gejonders auf Der Jnfel Guernfeh, werben bie \$aftitufrumzeln ala

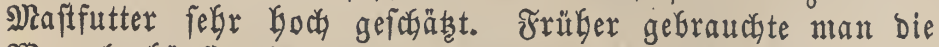
Worzeln bäufig als urintreibendes, auflöjendez Mittel, gegen Schwindjuchten, Den Stein. In Irland bereitet man aus ifnen eine $\mathfrak{A}$ rt $\mathfrak{B i e r}$ und in andern Giegendent einte 2 (r)t Wein. Die Blätter ber zalymen \$ajtinafe find ebenfalfs ein gutes Milchfutter, nur merben bie ber milden nicht Geion= Ders bom 2 ieh gefucht. Sie färben auch gelb und rotb= braun.

Man bat yon Der Saftinale einige Barietäten:

\section{Iange Daftinnke.}

Wurzel lang, bief, oft auperorbentlich grón, fpindel=

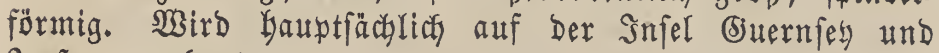
Serieg angegaut.

\section{Fileme Paftinake, Buckerpaftinake.}

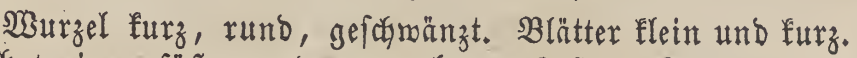

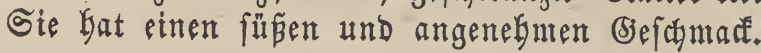

\section{Scorzonera. L.}

Euscorzonera. DeC.

Galasia. Less.

Gelasia. Cass. DeC

Lasiospermum. Fisch.

Lasiospora. Cass. DeC.

Pentachlamys. DeC.

Polyclada. DeC.

Snfteme: Cichoraceae. Juss.

Compositae Cichoraceae. Spr.

Compositae Hieracia. Rül.

Compositae Lactucae. Adans.

Compositae semiflosculosae. L.

Glossariphyta. Neck.

Synantherae Lactucaceae. Cass.

Syngenesia, Polygamia aequalis. L.

Reld lang, faft malzenförmig, ziegelbachförmig gefauppt. Die Relafduupen etwas breit, anliegend, am Rande bäutig. Frudytboden nadft. Samen länglid, chlinbrifa, geftreift und anftiend. Feberchen anjtgend, oder beinabe geftielt, feber= artig.

\section{Scorzonera hispanica. L.}

\author{
Scorzonera denticulata. Lam. \\ sativa. Gater \\ rumicifolia. Schleich.
}

ß. Scorzonera montana. Mutel.

Spaniface Safermurzel, fpanifuse Scorzonere, Scorzo= nere, Schwarzmurzel, Bartenbafermurzel, Gartenbafernurz, gebaute Scorzonere, Shlangengrnz, Salangentumzel, ipa= nifule Bipermmurzel.

Scorsonere. (fianz.)

Spanish Scorzonera, Viper's Grass, Garden-Scorzonera. (engr.) Scorzanera. (ital.)

\section{Arten = çharakter.}

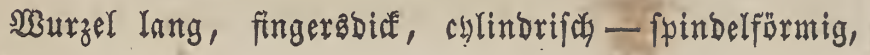

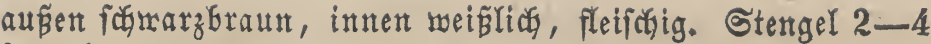
Jus Goch, aufrecht, geftreift, oben äftig, glatt ober fein fpinnenwebenartig firzig, vielblütbig. Blätter lanzett= ober Yinienlanzettförmig, lang zugefpitst, fafarfranbig, ober fefr feit ober an ber Baftz reitlüuftg gezähnt. WWurzelblätter lang geftielt, gezähnelt, glatt, länglia- -lanzettförmig. Die obern Stengelblätter an ber $\mathfrak{B a f t z}$ feGr breit anfthend, ften= gelumfaffend, bie untern gegen bie Bafts Gin fich veridhnä= lernd und in eiment geftügelten Stiel fich endigend. Blumen= ftiele lang, rutbenförmig. Fruchtboben nacet, marzig. Blü= then enditändig, aufrecht, grofis, geftielt, gelf. Blumenfrone augigebreitet. Selch cylindrifd, nach Der Blüthe fitch auftrei= bend, glatt ober wie ber Stengel filzig; Reldyichupyen un= gleidy lang, breit, ziegeldachfürnig, bie äuñern eifürmig-lan= zettfürmig, bie innern länger und Greiter. Staubfäben febr furz, baarförmig. Staubbeutel malzenförmig, rögrig. Frudat= Enoten länglich. Erriffel fabenförmig, fo lang als bie Staub= fäben, mit zurücf́gebogenen Narben verjeben. Santen ziem= lich lang, bünn, länglidy, geftreift, nady oben fitch berichmä= Iernd, weiglich. Feberchen fitsend, feberartig, fteif.

Man fennt 1 Barietät:

$\beta$. dentata, gezabnte Scorzonere.

Blätter linien-lanzettförmig, gezalnt, Die BäGne ent= fernt ftehend, Ianggeftreft und bivergirend.

\section{Slüthe $=$ 3eit uns Dauex.}

Эuni $-2 \mathfrak{A g u f t} .4$.

\section{গ̧orkmnten.}

Sn Spanien, ßalätina, Nordafen (in Sibirien) cin= Geimify, wächat hie und ba wild in Deutfohland, in Deft= reich, Sachfen, Der Wetterau, Itngarn in gebirgigen Eje= genden.

\section{Siultux.}

Die Scorzonere berlangt eine warme, fonnige Rage und einen nodh thätigen, Das Sagr zuyor gedüngten, lorfern und tief gegrabenen Boben. Mitte März findet gemöhnlid die Saat ftatt, man fäet ben Samen entweber breitrürrfig ober reifenmeife und bünne; man fann auch im Saerbft fäen,

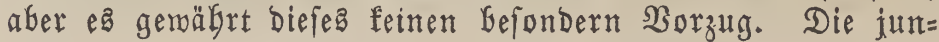
gen, einigermaken Gerangenadufenen $\mathfrak{A f l a n z e n ~ v e r z i e g t ~ m a n ~}$ yon Beit zu Beit, wenn fie zut bicht fteben, bis auf $4-6$

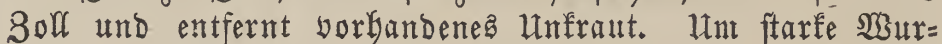
zeln, zll Gefonmen, Düngt man im SpätberGfte Das̆ Rand

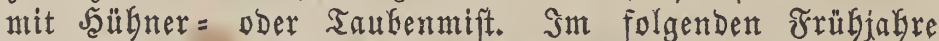
treibt die Sflanze Stengel und Blüthe. Slan fann zwar bie

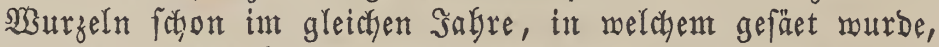
aub Dem Rande Keraus̄nebmen, aber beffer ift $e \bar{s}$, nidyt Da=

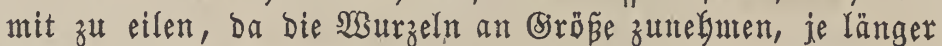
fie im Boben Gleiben, Durch bie Rïlte nicht leiben und gut bleiben, fo lange fe beim $\mathfrak{B}$ erwunben noch mildbigen Saft yon fich geben. Nathjam ift es übrigens, fith feimen $\mathfrak{W i n t e r =}$ bebarf im Spätherbjte aus bem Rande zu nebmen und in einer Sirube oder im Refler im Gand aufzuberahren. Der Samen reift ungleich und fann Dep̧Galb nur nach und nacts abgenommen merden; man trofinet ifn bollends, indem man ign in leinenen Sinufchen an luftigen Drten aufgängt; er Gleibt faum 3 Salgre lang feimfähig.

Der Scazonere find bie Jafen fegr gefäbrlich und fie 


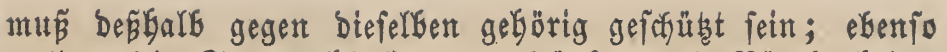
werben bie Samen bäufig yon Măufen und Vögeln beim= gejucht.

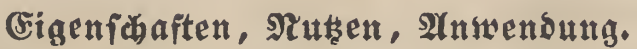

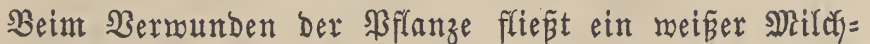
faft aus. Die $\mathfrak{B u r z e l ~ b a t ~ e i n e n t ~ f u ̈ ̈ e n , ~ e t m a s ~ b i t t e r l i c h e n , ~}$

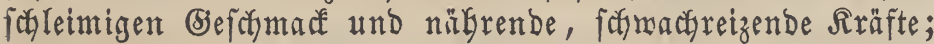
iGre vormaltenden Beftandtheile ftnd Buder und Schleim. Sie gibt cin fegr angenefymes, nublichmerfendes und leicft

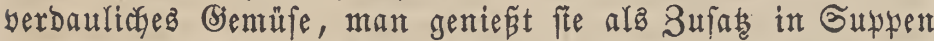
und als Salat, und verorbnet fie Gauptiächlich Siranfen und Refonvalefcenten als ein fegr gejundez diätetifches Mittel und gebraudyt fie in einigen Begenden geröftet als $\mathfrak{R} a f f e e=$ furrogat.

Die Scorzonere wurbe auch als Seibentaupenfutter empfoblen. Die Blütben merben yäuftg von Bienen bejucht.

\section{Scorzonera glastifolia. Willd.}

Scorzonera bohemica. Schmidt. edulis. Moench.

- hispanica. $\beta$. Wallr. Koch.

- graminifolia. Roth. Hoffm.

$\beta$. Scorzonera angustifolia. Wohlb. Schrad.

Grofblätterige Scorzonere, grogblätterige Samarzmur= zel, weibenblätterige Saberwurz, maibblätteriger łafermurz.

Willow-leav'd Viper's Grass. (entgl.)

\section{Arten = (E)arater.}

Stengel äftig, aufrectht, oft 1blumig. Bmeige aufftei= gend. Blätter lanzettförmig, lang zugeipizt, glatt, gerippt, eben, ftengelumfaffend. Blüthen gelb. Relct) nadft, glatt. Die Blüthenfüpfchen find enger und nur balb fo groṕ als an boriger und ganz $\mathfrak{f a b l}$.

\section{Błüthe = Beit tno $\mathfrak{D a u e r}$.}

Mai - $\mathfrak{s}$ uli. 4 .

\section{Boremmen.}

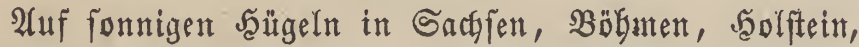
bei toöttingen, Saalle, Reipzig, und wirb bäufig fultivirt.

\section{$\left.\begin{array}{l}\text { Rultur, } \\ \text { (Sigenfdaften 2c. }\end{array}\right\}$ wie bei ber yorigen $2 \mathfrak{r t}$.}

\section{Tragopogon. L.}

Adopogon. Neck.

Snfteme: Cichoraceae. Juss.

Compositae Cichoraceae. Spr.

Compositae Hieracia. Rül.

Compositae homoianthae. Rchbch.

Compositae Lactucae. Adans.

Compositae semiflosculosae. L.

Glossariphyta. Neck.

Syngenesia, Polygamia aequalis. L.

Sield phramidenförmig, einfact. Sieldjoduppen 8-9, an ber Sabl gleidy, Ianzettfürmig, vermachfen. Fruchtboben tract, flach und rauly. Blüthen faft fo lang alz Der Relch, zungenförmig, abgeftubst, an ber Spize 5zähnig. Starben zurüfógebogen. Samen Yänglich, auf beiden Seiten fith ber= fămälernb unb längågeftreift. Freberchen büntugeftielt, feber: artig.

\section{Tragopogon porrifolius. L.}

Tragopogon sativus. Gater.

Tragopogon porrifolium. Pers.

Tragopogon purpure0-coeruleum. Moris.

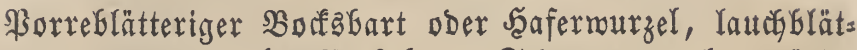
teriger ober purpurrotber Borfabart, Schnarzrourzel, unäddte Scorzonere.

Cercifix â feuille de poireau, Sersifi des pauvres. (franz.)

Purple Goat's-Beard, Salsifi, Salsafy. (engl.)

\section{$\mathfrak{A r t e n}=\mathbb{C b} \mathfrak{a r a t e r}$.}

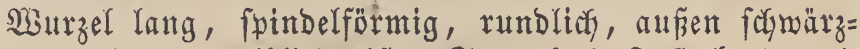

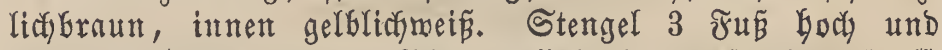
Drüber, ftraff, glatt. B̧lätter linienlanzettf̣̈rmig, ftraff, ftengelumfaffend. Blumenftiele oben verbicft. Relchblätter 8-13 an Der 3ahl, find länger als bie Blüthe, Yegetere ganz flach), biolettroth.

\section{Blüthe = Beit und Dauer}

รuni - 2ugut. $\delta$.

\section{BorÉommen.}

W3ächät mild in Deutfaland, Der Sayweiz, in Sachjen, ซranfen, Schwaben, Deftreich, Breupen, Breftphalen, Ěng= lanb, Thracien, Stalien auf etroas feuthten $\mathfrak{W}$ iefen, Săt= geln, in maldigen seegenden, und wirb bie und ba in bjăr= ten fultivirt.

\section{Rultur.}

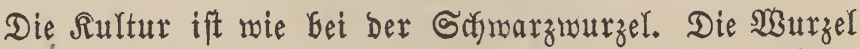

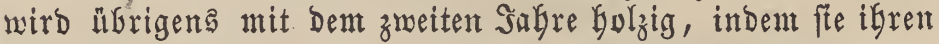
Milchjaft verliert. Der Sament reift im September.

\section{Eigenidhaften, গtutsen, Antwensung.}

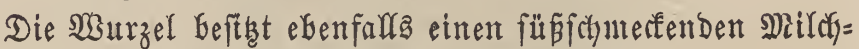
faft, hat ganz bie Ëigenfidaften Der Scorzonere, und mird auch wie biefe vermentet. AlGgefodyt und mit Citronenfaft verfebt, gift ftè ein für Fiteberfranfe füblendeŝ und ange= nelymeŝ Betränf.

\section{Tragopogon pratensis. L.}

\section{$\beta$. Tragopogon sinuatus. Lallem. $\gamma$. Tragopogon undulatus. Thuil. Tragopogon pratense. Pers.}

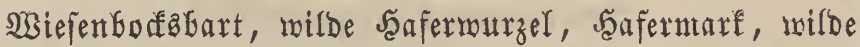
gelbe Seafermurzel, miefenliefende Safermurz, Jofephblunte, milde Gcorzonere, Morgenftern.

Cerficix des près, Sersifi, Barbe de bouc. (frattz.)

Common yellow Goat's-Beard. (entgl.)

\section{Arten $三$ (Sharakter.}

SMurzel einfact, fpindelförmig, aupen braun, innen

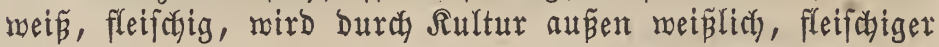
und faftiger. Stengel 1-3 Fuß hoch, gerabe, oben etwas äftig, fteif, glatt, faftig und marfig. Blătter lanzettförmig, abwechfelnd, ftengelumfaffend, an ber Baftz rinnenförmig, lang zugefpibt, ganzrandig, glatt. Blumenftele oben ver= Dicft, runb, glatt. Die 8 Relchblätter gleidy, an Der Baftz 
etmas vermadjien, beitake fo lang als bie ftumpfen 5 jabni= gen Straflenblumen. SBlütben gipfelftändig, eingelt und aufredst ftebend, groB, Godggelb, bie einzelnen slüthen zungen= förmig. Bei fuönem Wetter öfnen fith bie Blumen Mor=

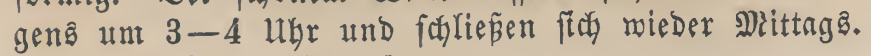

Nan Gat 2 Barietäten:

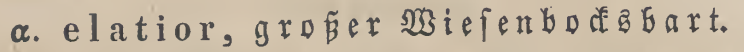

Stengel $1 / 2-3$ Jun bod, mebr oder meniger äftig. 23urzelflatter welf. Bluthen Glabgelb.

B. humilis, niederer $\mathfrak{B}$ of a bart.

Stengel beinabe einfary, 1 Fuz bod, oft faum fo foch ober nur menig Göber als die Wurzelblätter. Blütben tief gelf.

\section{Blütbe $=3$ eit แnd sauer.}

Mai - כuli. $\delta$.

\section{3orfommen.}

Xuf fetten gebirgigen Wiefen, Weiben, in Ěuropa und Dent Drient. NBird felten fultivirt.

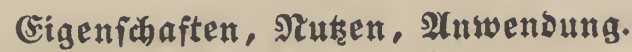

Sufer und Saleim ftud die bormaltenden Beftandtheile. Wan fann bie Wurzel nidyt nur, mie bie vorigen, fondern audy bie jungen Sproffen und Die ein fefr fübes Mark ent= baltenden und faftigen Stengel als Bemüpe gebraudjen. Die

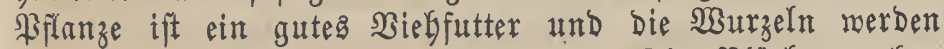
begierig yon Den Safweinen gefurbt. Die Blüthen geben Den Bienen biel Sonig.

\section{Sium. L.}

Berula. Koch. DeC.

Eusium. Koch.

Mauchartia. Neck.

Sisarum. DeC.

Syfteme: Scadiophyta, Neck.

Umbellatae. L.

Umbellatae Chaerophylla. Adans.

Umbelliferae. Juss.

Umbelliferae Ammieae. DeC.

Pentandria, Digynia. L.

Relă ganzblãtteriog, 5zäbnig, mit oberfändigem Saume und eiförmiger, geriefter siöbre. Blumenfrone 5blätterig, abfaffend. - Blumenblätter gleich, werfebrt-eiförmig, aubs= geranbet, mit eingeidlagenem Sipfel. Staubgefäpe 5, mit Den Blumenblättern eingefügt. Staubfäben fabenförmig. Staubbeutel 2fächerig, eiförmig - rundich, einwärtg gefefrt. Stempel 1. Frufftenoten unterftändig, 2 fächerig, mit einem fiffenförmigen, am Rande niebergebrücten und gererbten (Sriffelpolfter gefrönt. (siriffel 2, fabenförmig, zurürgebo= gen. Narben ftumpf, fleinfopfig. Spaltfrucht eiformig, an Den Seiten zufammengebrüt, beinabe 2fnotig. Theilfrüdte didyt, 5riefig. Samen umgefebrt, eiweibgaltig.

\section{Sium Sisarum. L.}

Sium brevifolium. Hort.

- podolicum. Hort.

- montanum. Kaempf.

$\beta$. Sium Ninsi. Burm. Thunb.

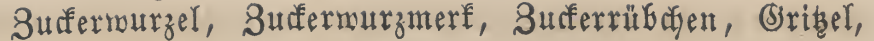
(5irlein, Ninftiraut.

Chervi, Racine sucrée. (franz.)

Skirret. (engl.)

Sisaro. (ital.)

\section{Arten $=$ sharalter.}

Whurzel beftegt aus $7-9,6-10$ 3oll langen und

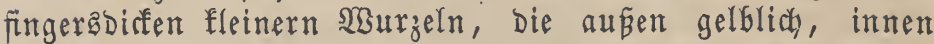

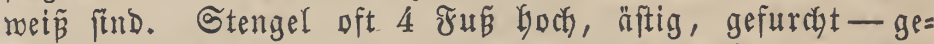
ftreift. Blätter geffedert, Das oberfte blo 3 z $3 \ddot{a}$ hlig, Die ein= zelnen $\mathfrak{B l a ̈ t t c h e n ~ l a ̈ n g l i c h ~ - ~ l a n z e t t f o ̈ r m i g , ~ f e i n g e z a h n t , ~ g l a t t . ~}$

\section{Blütfre $=$ Beit $\mathfrak{u n d}$ Dauex.}

\section{suli - 2ługut. 4}

\section{Sortommen.}

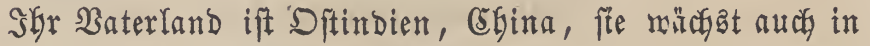
einigen (begenden Deftreicha mild und mird in Bärten ful= tivirt.

\section{Sultux.}

Die Zưfermurzel fann nicht mur in (Särten, fondern auch auf Dem Felde, wenn man Den $\mathfrak{B}$ oben Doppelt rajolt, angebaut merben, und gebeifgt am beften in einem Iurfern, Guntuareichen Boben, Der aber nicht frifh gebüngt merben Darf, meil bie 2 Surzeln fonft formarzflectig und bolzig mer=

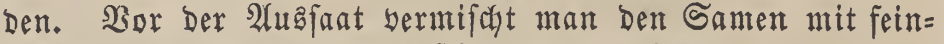
geftebter, etwas feuchter mistbeeterbe, melche man bis zum

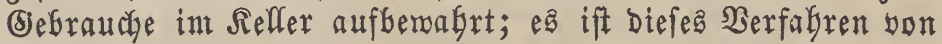
Werth, Da ber Same Der Sulfermurzel jumer feimt. Wan fäet biefen Samen nun entmeder int Maảrz in ein mäpig

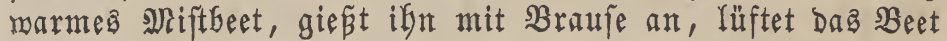
fleişig und fäubert ę yom Unfraute, ober beffer, man madjt bie 2 (uşfant fohon im Spätherbft in's Freie, nur faulen ba in feuchten $\mathfrak{B}_{\text {intern }}$ die Samen gerne, doer in ein faltes Miftbeet, und untgift Diefes in Frähjagr mit warmen $\mathfrak{H} m=$

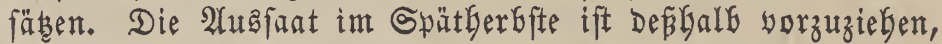
meil Die im Jrübjahre gefäeten Bflanzen gerne Samen an=

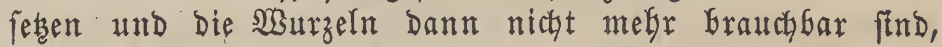

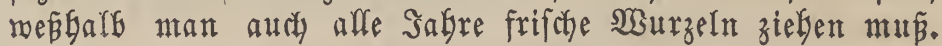

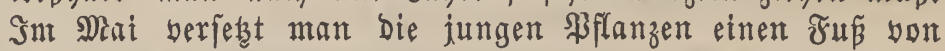
einander entfernt in's freie Rand; DDer verzieft bie gleich in lesteres gefäeten bis zu diefer Entfernung yon einander,

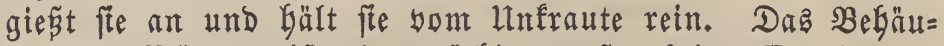
feln Der Sflanzen ift nicht nöthig, aufer bei naffem Soben. Sm Spätfommer oder Spätherbjte, je nachbem man bie

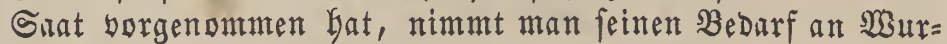
zeln für Den Winter aus dent Rande und fablägt fie im Freien oder im Relfer in Erde dDer Sand ein. Su Samen

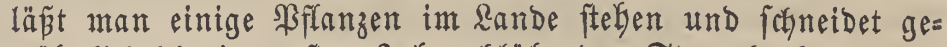
wöhnlich bie im erften Jahre Glühenden Stengel ab, um im zweiten Sagre megr und yolfommere Samen zu erzielen; Diefer bălt fith faum 2 Jahre lang gut. Die Zuffermurzel

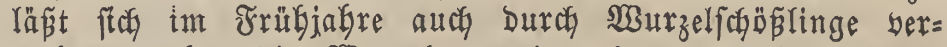
mefren, aber bie SWurzeln werden bann neniger wobl= folmerfend.

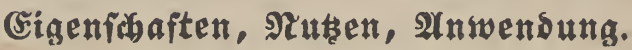

Die Suffermurzeln Gaben einen angenegmen, füpen, jaftigen und etmas aromatifyen befdumad, und werben in 


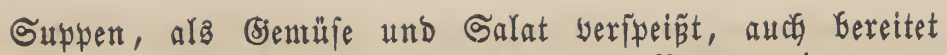
man aus ifnen Syrup und einen guten Branntwein.

\section{(Se)idbidate.}

Diefe Surzel foll yon China aus zuerit nach Borber= aften und yon Da nach (5uropa gelangt feir. Nach ßliniuz

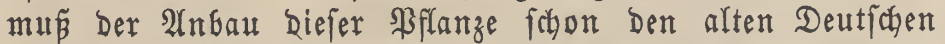

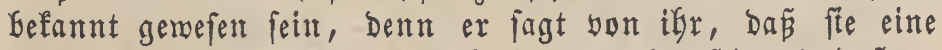

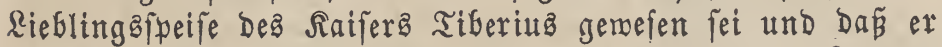
fie alle Jafre yon ber Rayeingegend bezogen habe. In ben (3)ärten Der Mannaflöfter mar Der 2lnbau Der Zucfermurzel, ber yermeintlicten ftimulirenden SBirfung wejen, unterjagt,

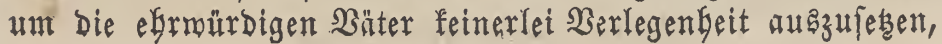

\section{Chaerophyllum. L.}

Brachystylis. DeC.

Euchaerophyllum. DeC.

Myrrhis. Sprengl.

Physocaulis. DeC.

Rhynchostylis, Tausch.

Syfteme: Scadiophyta. Neck.

Umbellatae. L.

Umbellatae Chaerophylla. Adans.

Umbelliferae. Juss.

Umbelliferae Scandicineae. Spr. DeC.

Pentandria, Digynia. L.

Selch ganzblätterig, mit oberftändigem, undeutliç, m

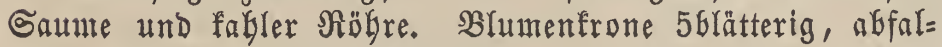
lend. Blumenblätter gleich ober ungleich, werfegrt - Kerz= förmig, tief augerandet ober 2fpaltig, mit einem einge= fablagenen Bipfel, fahl oder beljaart. Staubgefäße 5, mit Den Błumenflättern eingefügt. Staubfäben fabenförmig. Staubbeutel 2 fächerig, einmärtz gef́lght, rundich. Stempel 1. Fruchtfnoten unterftändig, 2 fäcterig, mit einem jlattgebrǚf́= ten ober fegelförmigen Biriffelpolfter gefrönt. Briffel 2, faben= förmig, Gerabgebogen ober aufrecht. Narben flein, fopffg ftumpf. Spaltfrucht länglich, fohnabelloz, fagl, an Den Geiten zufammengebrünt. Theilfrüchte bicht, 5riefig. Samen umgefelyrt, eimeísgaltig.

\section{Chaerophyllum bulbosum. L.}

Andriscus elatior. Bess.?

Chaerophyllum verticillatum. Pers.?

Cicutaria bulbosa. Bauh.

Myrrhis bulbosa. Sprengl.

- foetens. Riv.

Scandix bulbosa. Roth. Moench.

Rnolfigter Rălberfropf, Rörbelrübe, Golliger Rălber= fropf, Rübenförbel, Errofaftanie, Beperlein.

Bulbous rooted Chaerophyllum. (engl.)

\section{Arten = Sharatex.}

Şurzel birf, fnollig, rủbenartig, bäufig eiförmig zu= gejpist, weí̈, fleifchig, bei der mildwachjenden Sflanze oft

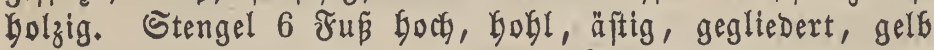
ober braunroth gefleft, Die obern Internodien glatt und aufgeichmolfen, unten bis zum zmeiten Snoten aufmärts borftig bebaart. Blätter linienförmig, $3=$ und mebrjpaltig, oben glatt, unten bebaart, Dunfelgrủn, bie slattftiele und
Blattfiele zerftreut, lang unb weiß̧̧ebaart, ber bejonbere Sielch glatt, fein gefpibt. B̉luntenblätter meí̄. Samen lang, glatt, Gräunlich, bielfältig gelblich gefurucht.

$$
\text { গuni }- \text { suli } \delta \text {. }
$$

\section{Brütbe $=$ Beit $\mathfrak{u n D} \mathfrak{D a \mathfrak { e r }}$.}

\section{3orEmmen.}

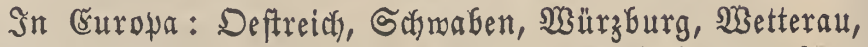

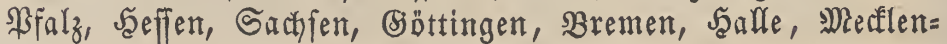
burg, Erlangen und in Norbaften an Zäumen, Jeeten, $\mathfrak{N}_{\mathfrak{S}}=$ gen, ufern, und nirb bie und ba in Särten angebaut.

\section{গultur.}

Die Rärbelrübe geräth faft in jedent Boden. Man fäet ben Gamen yom September biz Nobember 1 3oll meit yon einanber unb wirb 1 3olf tief mit ber Jaafe unter bie Erbe gebracht. Heber Den Winter bedarf Das Beet feiner Bebeffung.

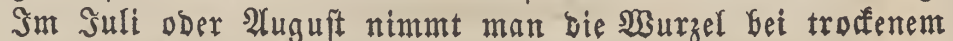
Wetter aus bem Rande und trodfnet und bemahrt fie an luf= tigen Drten auf.

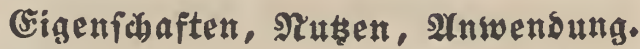

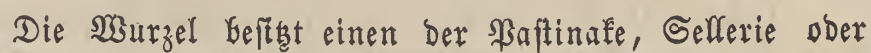
Den Raftanien ägulichen Bjefchmarf, und man geniept fie mie

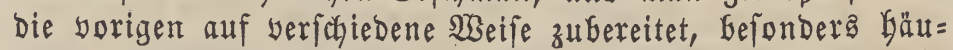
fig in Deftreich und in Hngarn (unter Dem Namen Magyorósaláta, Bubolyitska, Michály-Kamonya, Baraboly) ala Salat. Diefe Wrurzel foll yor Prichaelia nicht benutedt werben, weil fie fonft zu meglig ift, nur 10 Mrinuten lang gefocht uttd bann gleich veripeiat merben.

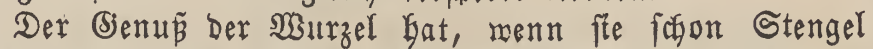
getrieben bat, wie auch Der Deb Samena, Ropfichnerzen und Schmindel verurjacht.

\section{Myrrhis Adans.}

Syfteme: Scadiophyta. Neck.

Umbellatae. L.

Umbelliferae. Juss.

Umbelliferae Scandicineae. DeC.

Pentandria, Digynia. L.

Sield ganzblätterionefor flein 5 zähnig, mit vber ftändi=

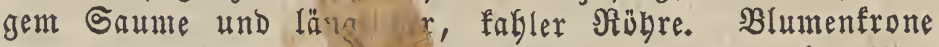
5 blätterig, abfallend. mig, tief augigerandet, mit einem eingejwlagenen Sipfel. Staubgefäfe 5, mit Den Blumenblättern eingefügt. Staub= fäben fadenförmig. Staubbeutel 2 făcherig, rundlid, einmärtb= gefegrt. Stempel 1, in ben männlichen $\mathfrak{B}$ lüttgen ganz ver= fủnmert. Fruchtfnoten unterftändig, 2 fächerig, gefrönt mit eineut fegelförmigen Griffelpolfter. Siriffel 2, verlängert, fabenförmig, ausgefperrt. Narben ftumpf. Spaltfrucht groź, länglich, von Der Seite zufanmengedrü aft, an Der Spike in

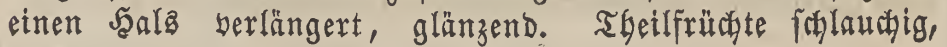
5riefig. Gamen umgefelgrt, eimeishaltig.

\section{Myrrhis odorata. Scop.}

Chaerophyllum odoratum. Lam. Scandix odorata. L. 
Woblriectyender Rörbel, Magrbenferbel, emiger Rerbel,

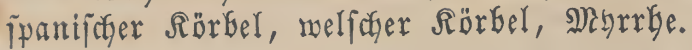

Cerfeuil musqué (finız.)

Sweet-scented Myrrh (engl.).

\section{Arten = Elyarakter.}

SWurzel ziemlich biff, fleifochig, Geinnhe fpindelförmig, zumeilen etwas äftig. Die ganze Hifanze faft zottig bebaart.

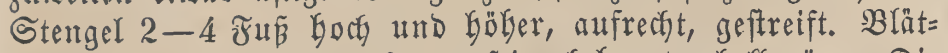
ter vielfad zufammengejebt, fein befaart, Gellgrün. Die Blättchen ei-Ianzettförntig, gefiebert getheilt, bie \&appen ge= fägt und gefiebert getheilt.. Der Gefondere Selds lanzettför= mig, gemintpert. Die mittlern Blüthen männlicy. Samen grof́, gefdynabelt, gejurdyt, 8ectig, braun.

\section{Blüthe $=$ Zeit and Dauer.}

Mai - $\mathfrak{s}$ li 4 .

\section{3orémuten.}

In Sübeurowa, Schleften, Deftreid, Salzburg, Baiern,

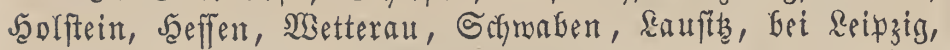
in ber Schweiz, in Spanien, auf Boralpen, in Mittelnften, und mird zumeilen in bsärten cultibirt.

\section{Sultux.}

Der Meyrabenferbel geräth beinabe überall, am beften aber an fesattigen Drten. Man füet Den Samen gleidf, nachbem er reif ift; er Gleigt nicht länger als ein Jaht feimfäbig. Man pffanzt ifn auch burch Sarzeltbeile fort;

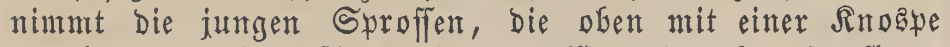

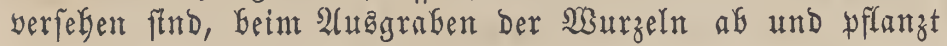
fie 2 ชुus meit yon einander entfernt in einen tiefgegrabenen, fräftigen $\mathfrak{B}$ oden.

\section{Eigenfichaften, stuten, smwendung.}

Die ganze Pffanze bat einen angenefymen, fün̈lichen und anizartigen (Seruch. Die Wurzel gibt fefr gute Suppen und fann auch auf andere SWeife bereitet genoffen merben.

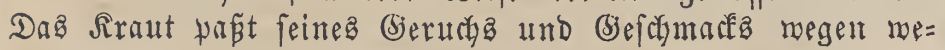
niger als Suppenfraut, Denn Der gemeine Bartenförbel.

Man gebraucht bie Bflanze gegen Drüfenanformellungen,

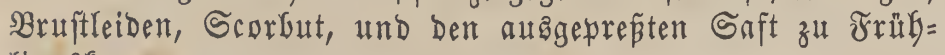
lingafuren.

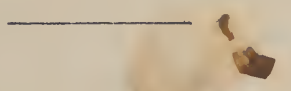

\section{Petroselinum, Hoffm.}

Apium L.

Syfteme: Umbellatae. L.

Umbelliferae. Juss.

Umbelliferae Ammieae. DeC.

Pentandria, Digynia. L.

Seld glanzblätterig, mit oberitändigem, unbeutlichem Saume und geriefter Rähre. Blumenfrone 5blätterig, ab= faflend. Blumenblätter gleidy, rundlich eingefrümmt, ganz,

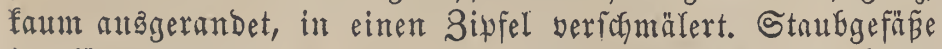
5, länger ars bie B̧lumenblätter. Staubfäden abftekend, fabenförntig. Staubbeutel 2 fächerig, runblich, einwärtäge fehrt. Stempel 1. Frueftenoten unterftändig, mit einem gemölbten, furz fegelfürmigen (sriffelpolfter gefrönt, 2 fäche= rig. Briffel 2, furz. Narben ftumpf, einfart. Spaltfructst Cnrwer, bfonom. Pffnnzenfunde. eiförntig, an ben Seiten zufammengezogen, etwas 2fantig. Theilfrüchte bicft, 5riefig. Samen umgefehrt, cimeibfaltig.

\section{Petroselinum sativum. Hoffm.}

Petroselinum hortense. Hoffm.

- romanum. Sweet?

Apium Petroselinum. L.

- vulgare. Lam.

$\beta$. Apium crispum. Mill.

$\gamma$. - latifolium. Mill.

$\delta$. - tuberosum. Bernh. Desf.

c. - romanum. Zucc.

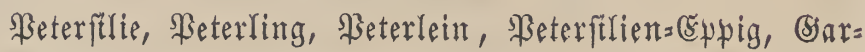
tempeterftlie, gemeine Beterftlie.

Persie. (franz.)

Parsley. (entgl.)

Petroselino. (ital.)

\section{Arten $=$ Sharakter .}

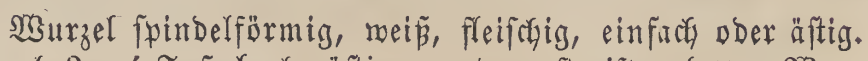

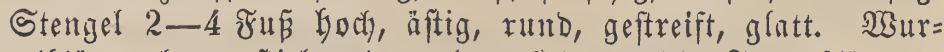
zelblätter langgeftielt, Doppelt geftedert, bie Jieberblättchen 3 zäblig, geffebert zerichnitten und gezahnt, glänzend grün und Gaben an ben Spizen Der Bähne meíse Bunfte. Sten= gelblätter focheibig, die untern $\mathfrak{B}$ lättchen eiförntig - feifför= unig, 3fpaltig gezalgnt, Die obern lanzettërmig, faft ganz= ranbig. SBlütlyen mein, alt Den Epizen Der 2 lefte in

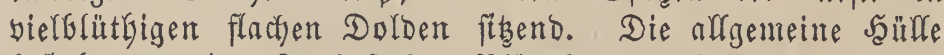
bejtegt aus 1-2 einfachen $\mathfrak{B}$ lättchen, melche jedoch audy, aber felten, gefiebert-zertheilt find. Befondere Şülfe aus

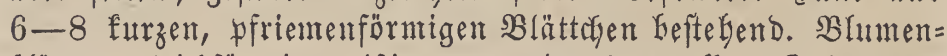
blätter gleichförmig, eiförmig, mit eingerollter Sqibe und grünlicfgelb. Staubfäden länger als bie Bhlumenblätter. Strubbentel gelf. Fruchtfinoten eifürntig, glatt, feitlich zu= fanmengebrunfft, 3ripbig. Briffel aufrecht. Narbe meif, verdicft. Frucft eiförmig, an Den Seiten zufammengebrücft. Theilfritchte auf Dent gemölbten $\mathfrak{R}_{\text {ücten }}$ 5rippig.

\section{Blüthe $=$ 3eit und Dauer.}

รuni - 2luguft $\delta$.

\section{3ortemuter.}

In Sübentropa, Sarbinien einbeimifd, bie und ba auch in Deftreich auf fetten Miefen mildomadyfend; mirb bäufig in (5)ärten fultibirt.

Wir wolfen bier nur die Spielart anfübren, meldfe

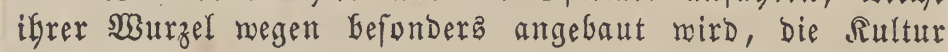
und meitere Benukung Der Schnittpeterfftie ift Gei Den Rüchen= Fräutern angegebèn.

\section{Buckerpeterfitienwurzel.}

Apium Petroselinum rapaceum.

- hortense Petroselinum maximum. C. Bauh.

SBanzelpeterfilie, Zưferatenmurzel.

Die Saurzel ift biel gröper ala bei ber gemeinen Beter: ftlie, ift fleifchig, zart und hat eimen angenefmen, füben,

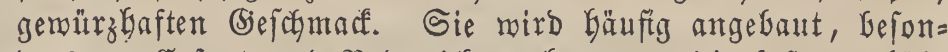
Ders unt Erfurt und babeniaf, woher nan bie bejten erbält.

\section{§ultux.}

Sie gebeigt am beften in einem tiefgegrabenen, gut 21 
werarbeiteten, etwaz fandigen $\mathfrak{B}$ oben und in einer melgr forattigen als fonnigen Rage; man fäet fte bom Frebruar bis

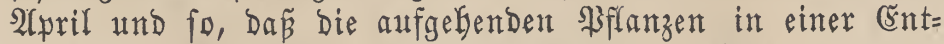
fermung yon etwa 4 3olf yon einander zu fteken fommen.

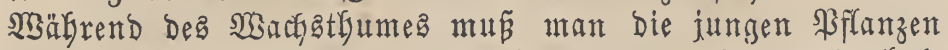
mebrmals yezzieken und den Boben yom Utnfraut rein bal= ten. Şaben bie \$eterfitlienmurzeln bie Diffe einer Schreits= feber erreicht, fo fann man fte figon aub Dent Boben nef $=$ men und in ber Rüche Genüben. Seat man nach und nach

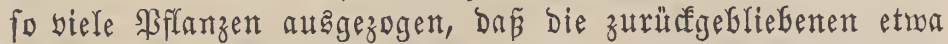
einen $\widetilde{J} u \tilde{B}$ bon einander entrernt fteken, fo merbent fie be= Gadft, und yon Bielen, um fie yon ber Stärfe Der Miögren

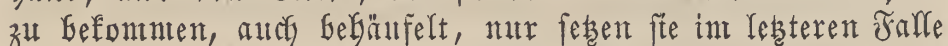
viele Nebenwurzeln an. In einen lofferen, gut verarbeiteten

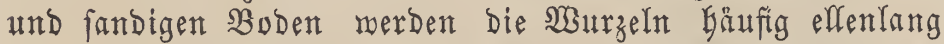
und fönnen iut 2luguft berfpeist werden. Sm Serbfte nimmt

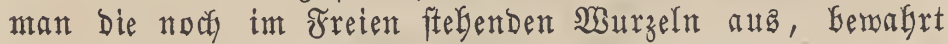
fie im Reller in trodfenem Sande auf and gebrautift fie mie Die Baftinafen.

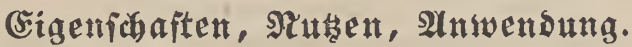

Die Seteritlie bat fefr viel 2 defnlicyleit mit bem in (8)ärten ebenfalls nicht jelten borfommenden giftigen Schier= ring ober f̧undapeterfitlie, Aethusa Cynapium L., Yeşterer Gat aber gröbere, biffere, Dunfelgrüte, auf Der untern Seite glänzende Blätter, einen geffeḉten Stengel und an ben $\mathfrak{B} l \mathfrak{u}=$ menbolden 3 lange, fhmale und fpikige Blättchen, und einten midrigen, ftutenden (sieruct.

Die yorwaltenden Beftandtheile find: ätherifches Del und Beterftlientampher, bei Der Wurzel und Rraut auth Sagleiut und Solleintzureer.

\section{Apium. I. \\ Celeri. Adans. \\ Selinon. Adans. \\ Snfteme: Scadiophyta. Neck. \\ Umbellatae. L. \\ Umbellatae Foenicula. Adans. \\ Umbellatae Pimpinelleae. Spr. \\ Umbelliferae. Juss. \\ Umbelliferae Ammieae. DeC. \\ Pentandria, Digynia. L.}

Relch ganzblätterig, mit oberiłändigen, unbeutlichent Saume und geriefter $\Re$ ägre. Blumenfrone 5blätterig, abs= fallend. Die Bhlumenblätter find gleich, flach, rundlich, nicht ausgerandet, an Den Spiben eingerollt, Staubgefä́pe 5, frei. Staubfäben fabenförmig. Staubbeutel 2 fücherig, rumblich, einmärts gefefrt. Stempel 1. Jructitfnoten unterftändig

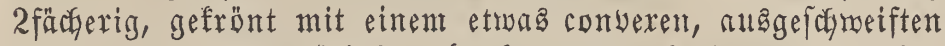
(5riffelpolfter. Soriffel 2, fefr furz, zurüdfebogen. Narben einfach, ftumpf. Spaltfrudst runblich, an ben Seiten zu= fanntengezogen, 2fantig. Theilfrüchte Dicht, Geinake Galbfu= gelig, 5riefig. Samen untgefefrat, eimeiphaltig.

\section{Apium graveolens. L.}

Apium Celeri. Gärtn.

Seseli graveolens. Scop.

Sium Apium. Roth.
Sium graveolens. Vest.

$\beta$. Apium dulce. Mill.

$\gamma$. Apium rapaceum. Mill.

$\delta$. Apium lusitanicum. Mill.

Selferie, Belferie, Seflerie=(Eppicfy, ftartriedyender Peter=

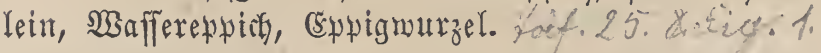

Smallage Parsley, Celery, Celery root. (entgl.)

Sedano, Radice di sodano. (itar.)

\section{Arten = ÇGarakter.}

B̧urzel biaffnollig, äftig, fajerig. Stengel gefurdht, febr äftig. SBlätter geftedert, die 23urzelblätter glatt, gläuzend, mit 3 lappigen, eingefdynitten gezähnten, eiförmigen Blätt= chen, bie ebenfalfs 3lappigen Stengelblätter mit eingefdnit= tenen feilförmigen: Blättchen. Dolden flach, bielftrablig. Blütfyen, flein, weí̃. Santen flein, rundlich, etroas aufge trieben geftreift.

\section{Blüthe $=$ Beit $\mathfrak{u n d} \mathfrak{D a u e r}$.

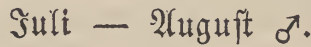

\section{Borénmen.}

Wächat mild in Deutichland, in SBejtphalen, bei Diffen, in füblichen Jranfreich, in fumpfigen, überfdymemmten und

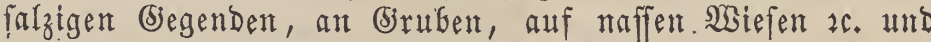
mird überalf in Gärten Eultivirt.

SWir wollen ala bieber geförig Gloô den Gelferie an= fübren, Der um feiner 2 sutrzel miffen angebaut wird, und bie übrigen, mie Den Rrüuter = und Staudenfefferie; bei Dent Salat voer Den Rüchenfräutern befogreifen.

\section{1. 位nollentellexir.}

Selferiaf.

Apium graveolens rapaceum.

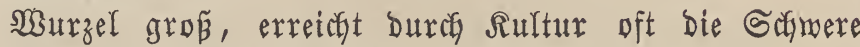

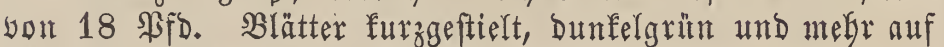
Dem $B$ oben liegend.

\section{Sultux.}

Der Sellerie gebeigt ant beften in einent füblen, feuch ten, gutgebüngten, iut Serbft zubor tief umgegrabenen, ober

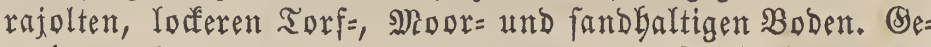
möhnlich fäet man Den Sefferie zeitig im Jrihbjabr in ein Frübeet, tritt locfer Den Boben etwas zufammen, fäet ben Samen bünn aแs und bringt ifn, Damit er feimen fann mit ber Jaarfe nutr oferffächlich unter bie Errde. Da Der Seflerie zu feimem Beratben immer einen gegörigen (Brad yon Feuchtigfeit berlangt, fo überftreut man bas Rand mit PFerdebünger, modurch zugletch auch bie Regenmürmer ab=

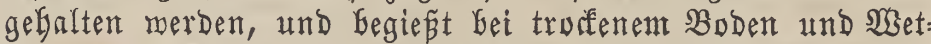
ter fleipig. Die faft feberfieldiffigenurdenen Aflanzen berietst

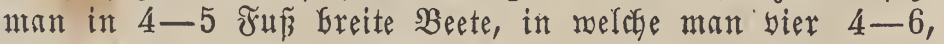

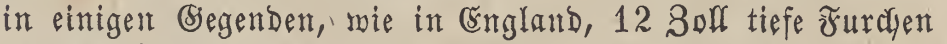
gezpgen bat, in eimer Entfermung yon 12-16 30lf yon

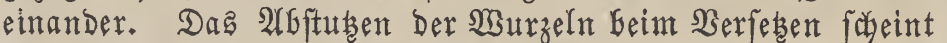
feinen bejonderen $\mathfrak{B}$ ortheil, aber auch, wie 2lndere glauben, feinen Nachtheil zu Gringen; gut ift e⿱一彑 Beren Blätter Der Siflanze abzufchneiden. Nach dem $\mathfrak{V e r}=$

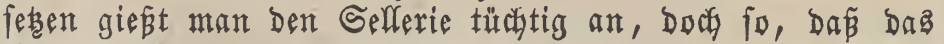

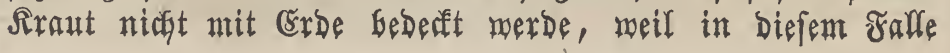




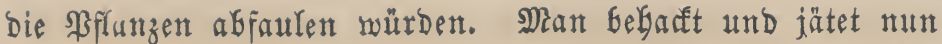
die Bflanzen fleipig, reinigt fie yom Umfraute und Gegiest fie Gäufig. Esinige berieben die Gelleriepflanzen gar nicht, fonbern verzieben fie bis auf $1-1 \frac{1}{2}$ Fur yon einamber, Gefarfen und beGäufeln fte oft, und erbalten bei biejer $\mathfrak{B}_{e}=$

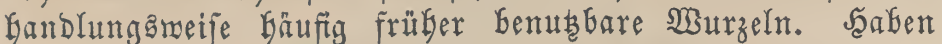

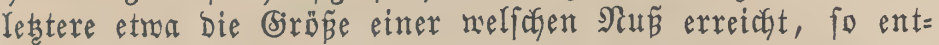
Glöpt man fte oben bon ber Errbe, fanneibet bie $23 u r z e l f a f e r n$

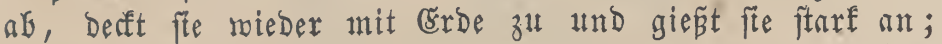
erneuert man bieje Pantipulation im Spätfonmer, fo erfält man nur um fo ftärfere $\mathfrak{B u r z e l n . ~ M a n ~ f a n n ~ D e n ~ S e l f e r i e ~}$

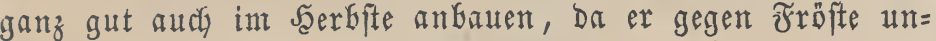
empfindlich ift, audf pffanzt man zmifcten ifm Salat und andere fleinere (Jenäethle. Jür Den Wointer nimmt man bei

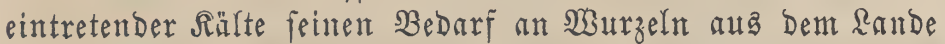

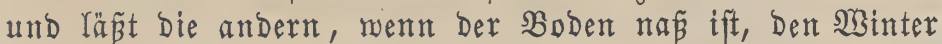
über in ซreien. Man Gemafrt bie Wurzeln, nachbent man Das Sirat abgeftubt Gat, in Feller im Samb ober in trodfe= men Bruben auf. Sur Samenzucht bebt man einige ber

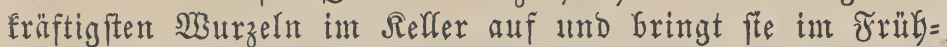

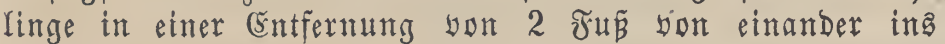

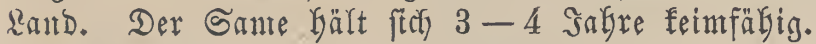

\section{Sd̆äblidbe Einflüfie.} Sellerie.

Schnerfen und Würmer fund bie gröpten Feinde Des

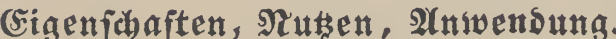

Der wilbmactjende Gelferie Gat in affen feinen aheilen einen unangenefmen (B)eruch und fdyarfen bittern Befdymad, und foll oft wirfliche Bergiftungązufälle, Schmindel, Baetäu= bung 2c. erregen, wirft auch giftig anf bas Febervieh ein, Durd) Rultur aber verliert er alle biefe berbächtigen und be= bält nur feine excitirenden und biuretijchen Esigenjodaften bei, und wirb als nahrbafte, gemürzhafte Gpeije băufig als Salat, als Zujabs zu Siemüjen, Suppen und Fleifor ge= nofien.

Die zerfocynittene, getrocfnete und Graungeröftete SGurzel foll, einem Drittel Raffeebognen beigejebt, Dem Raffee einen angenteknen Biefoymate geben.

Spielarten Des Snolfenfellerie ftnd:

a) $\mathfrak{x}$ obltabenfelferie.

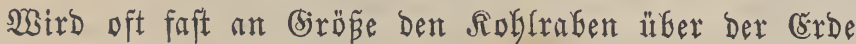

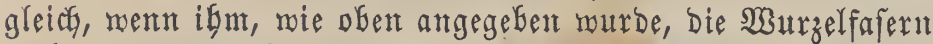
wäbrend feines Wachatbums afgentomment merben.

b) Weíze Rnollenfellerie.

c) Rothgeaderte Rnolfenferrerie.

Weniger gut als yorige.

\section{(Gefabidate.}

Der Selferie wurbe erft int 17. Sabrbuntoert in Deutfich = land befant und in $\mathfrak{s} a \mathfrak{l} r 1690$ yon einem gerwiffen $\mathfrak{S}$ e $\tilde{B}$ als eine nete Gartenpfanze bejchrieben.

\section{Oenothera. L.}

Agassizia. Spaeh.

Anogra. Spach.
Baumannia. Spach. Boisduvalia. Spach.
Calylophis. Spach. Chamaenerion. Adans. Cratericarpium. Spach. Godetia. Spach.

Hartmannia. Spach.

Holostigma. Spach.

Kneiffia. Spach.

Lavauxia. Spach.

Syfteme: Calycanthemae. L.

Coryphophyta. Neck.

Epilobia. Rül.

Fructiflorae. Roy.

0nagrae. Adans.

Onagrariae Onagreae. DeC.

0enothereae. Rchbch.

0ctandria, Monogynia. L.

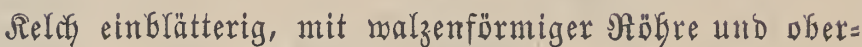

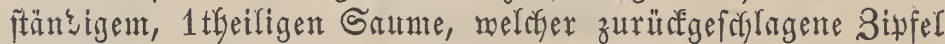
Gat. Blumenfrone 4blätterig, abfalfend. B̧lumenblätter wechjeln mit Den Reldzzipfeln af, find furz genagelt, werfelyrt - Kerzförmig. Staubgefä̃e 8, ntit Den $\mathfrak{B l u n t e n b l a ̈ t t e r n ~ e i n = ~}$ gefügt. Staubfäben fribenförmig, gernde ober aufitetgent. Strubbentel 2fäcyerig, länglich, einmärtägefefrt. Fruchtfno= ten unterftändig, 4 fäcterig. Soriffel 1, fadenförmig, an ber Spise theift berbicft. Narbe 4fpaltig, rüctwärtägefogen. Jructeffapfel rederartig, walzig, feulenförmig, mit 4 in igrer Mitte mit einer Scfeidemand verfefenen Rirappen, vielfamig. Gamen unbefaart, eimeíploz.

\section{Oenothera biennis. L. \\ Onagra biennis. Moench. \\ - europaea. Spach. \\ - vulgaris. Spach.}

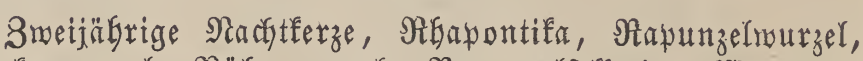

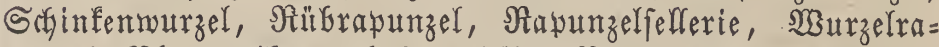

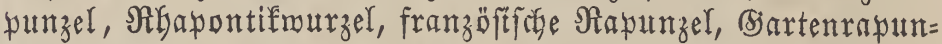

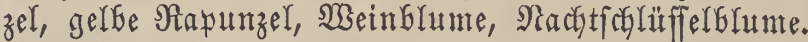

onagre, Herbe aux anes, Onagre Jambon des Jardiniers. (fr'attz.)

Broad-leav'd 0enother'a, Tree Primose, Night Primose. (engl.)

\section{Arten $=$ Shaxafter.}

2Burzel meift fpindelförmig, aupen braun, innen beim Duerburdyfdyitt gefottenem Schinfen ähnlith, fleifchig. Stengel 6 Fur God), 3erfig, äftig, weidfitachelig und zottig befaart. Blätter, ei - Ianzettförmis, SWarzelflätter geftielt, bie obern

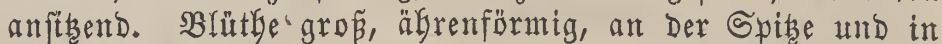

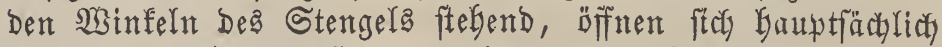
mur bei buffterem Wetter, ober nach Sontenuntergang. Staubfäden fürzer als bie Blumenfrome. Samen effig und unbelaart.

\section{Slüthe = Beit und Datex. \\ צuni - 2lugutt. $\sigma^{\pi}$.}

\section{3orEmmen.}

In Norbamerifa einfeintifd, bäufig bei uns serwildert,

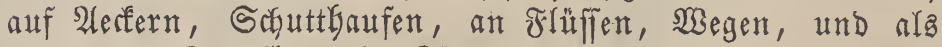
Nath= und Sierpflanze in Esärten angebaut.

\section{Sittur.}

Die Napunzel berlangt einen gebüngten, loćeren und

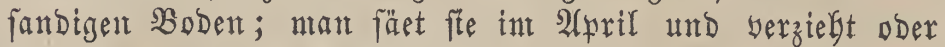
werfest fie fpäter 6 Bolf reit von einander. Heber ben 
Whinter berwart man fie entweber im Seller in Sand ober lä̧̨t fee im Rande ftelen.

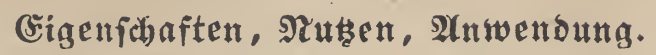

Die Blütge Der Nachtferze bat einen angenelunen ftar=

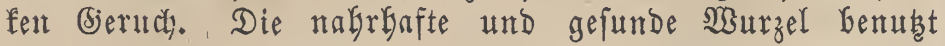
nan mie Sellerie zu Salat, Dem fogenanten Schinfenfalat, 子ł Giemũfen und Sแppen.

\section{(3)efrichte.}

Die Siapunzel fam 1614 aus Sirginien nach (̌uropa

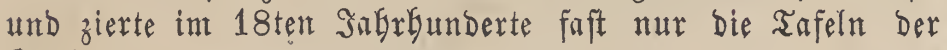
Gropent.

\section{Raphanus. L.}

Dondisia. Neck. Ormycarpus. Neck. Raphanis. DeC. Raphanistrum. DeC.

Sy)fteme: Cruciferae. Neck.

Cruciferae Raphani. Adans.

Cruciferae Eurucagineae. Vent.

Siliquosae. L.

Siliquosae Sisymbria. Rül.

Tetradynamae Lomentaceae. Rchbch.

Tetradynamia, Siliquosa. L.

Selch 4blätterig, an Der Bafta 2höcferig, abfallend. Seldhblätter aufredgt, Yängliç. Blumentrone 4blätterig, freuz= förmig, abfallend. Bluntenblätter genagelt, berfegrt - eiför mig, ganz, ftumpf ober leicht ausigerandet. Staubgefäßze 6, $4 m a ̈ c b t i g$, Dem $\mathfrak{B}$ lütbenboden eingefügt. Staubfäben yfrie= menfürmig. Staubbeutel länglich, 2fücherig, einnärtägefehrt. Stempel 1. Jrrudftfrnsten 2fächerig, länglich. Siriffel pfrie= menförmig. Narbe ftumpf ober fopfförmig. Sdjote rund, nit Dent contifben Griffel an ber Spitse, vielglieberig, fnotig, olgne Rlappen, reber= ober forfartig, 2fächerig ober Duref bie oft feblende hautartige Scheidemand 1 fäetherig, theilas gleich)= weit, theils aber verengert. Samen fugelfürmig, bängend, eimeí̄los.

\section{Raphanus sativus. L.}

Raphanus radicula. Pers.

- rotundus. Mill.

- oleifer. Hort.

- Landra. Hort.

$\beta$. Raphanus chinensis. Mill.

$\gamma$. Raphanus niger. Mill.

$\delta$. Raphanus orbicularis. Mill.

$\varepsilon$. Raphanus Gayanus. Sweet.

Raphanistrum Gayanum. Fisch. et Meyer.

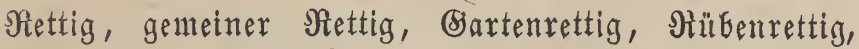
zafmer Siettig, gefauter Rettig.

Raifort. (fianz.)

Radish. (entr.)

Rafana, Ravano. (ital.)

\section{2rten = (5harater.}

NSurjel bidf, mefr doer weniger rund ober längliá, rüben= und fpindelförmig, fleifchig, faftig. Stengel $1-2$

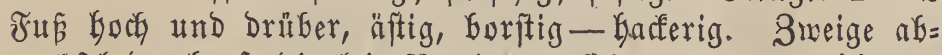
wechjelnd, efenjo bie leierförmig - geféderten und raubgari=

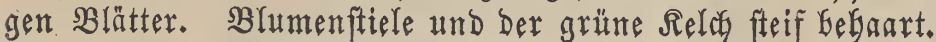

Blüthen in furzen Trauben ftebend, weín, Gefrviolett ober purpurröthlich. Sdyote $1-2$ 3oll lang, faum etras Yünger als Der-Stiel, länglià, walzenförmig, aufgetrieben, zugefpig̨t, etrags gefrünımt, fachammigfnotig, glatt, mit $2-3$ runblicfen, ftumpfeffigen, etwa pfefferforngropenen, hellbrautnen Samen.

Blütbe = 3eit und Dauer.

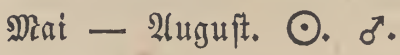

\section{3orÉommen.}

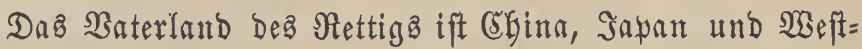
aften und wird ủberall Gäufig in Bänten angebaut.

\section{Sultux.}

Der Rettig werlangt einen etwas fahattigen Standuunft und feurgten, füGlen, lorfern Boben, 'Der yon frükerem Dün= gen Ger noch alte Rräfte beftsht, Denn frifa Darf berfelbe nie gebüngt merben, weil er baburch einen unangenthnen bje=

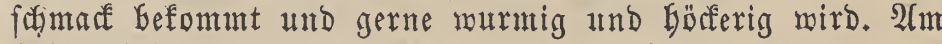
beften ftellt man bie Saat nach einem Negentage an, man legt ein paar Rettigferne entweder in Rillen vDer in Srütb=

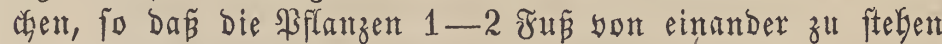
fonmen, und beberft fie mit Erbe. Sit ber Boben trorfent unt fant man einen Niegen nicht abraarten, fo füllt man Die Röcher, welche ben Samen aufnebmen follen, mit $\mathfrak{B a f f e r}$ an und fäet, wenn biefes in bie Erbe eingebrungen ift. Die

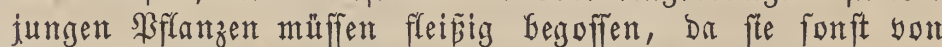
Den Errbflohen gefreffen merben. um. Santen zu erzitehen,

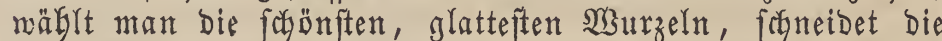

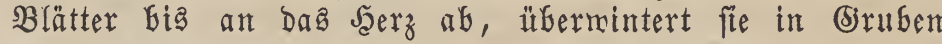
ober Sieffern, und verfecht fte im Mãrz 1 Jus meit yon einander entfernt inz freie Rand. Sux shlütyezeit müffen biefe Gamentpflanzen Der Eroflöbe und anberer Injeften we=

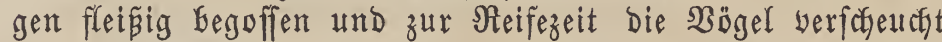
werben. Den Samen Drifdyt man fäuftg aus, bat fich je= Doch babei zu Güten, Durch zu ftarfez Drefchen benfelben zu zerbrürfen.

\section{(sigenithaften, গtuten, 2 (nwenoung.}

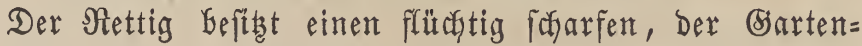
freffe ahnlidyen oft unangenefgmen (sieruch und einen webr

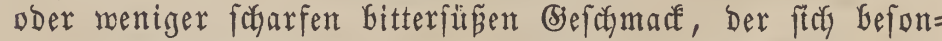

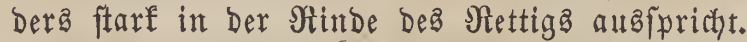

Die yormaltenden Beftandtheile Des Bettigs find fatarfeas, ätherifches Del.

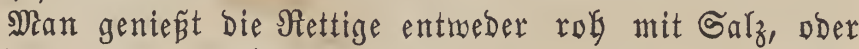
als Salat, als Zugeför zu Fleifh, jung aud gefocht und wie Spargel zubereitet. Der Nettig, mit Maße genoffen, ift ein gutes Mittel für fchwadye Mägen, ex mirft auflöfend und

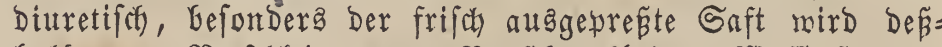
Galb gegen $\mathfrak{B e r f b l e i m u n g e n , ~ B r u f t f r a n f f e i t e n , ~ B a f f e r f u c h t e n , ~}$ Nieren = und Blafenfranffeiten und gegen Scorbut empfoglen;

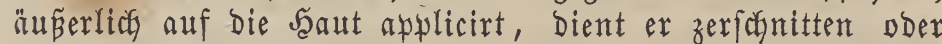
zerrieben als rotfmachendes Nittel. Die jungen Reime fön= nen als Salat und bie jungen Blätter als (semüfe genoffen werden. . IL und Die Blüthen merden Gäufig yon ben Bienen bejutft.

Man unterfocheibet als burch Sultur entftandene Spiel=

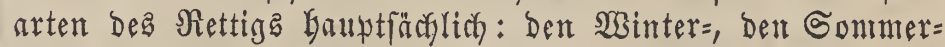
und bie Mionatrettige. 


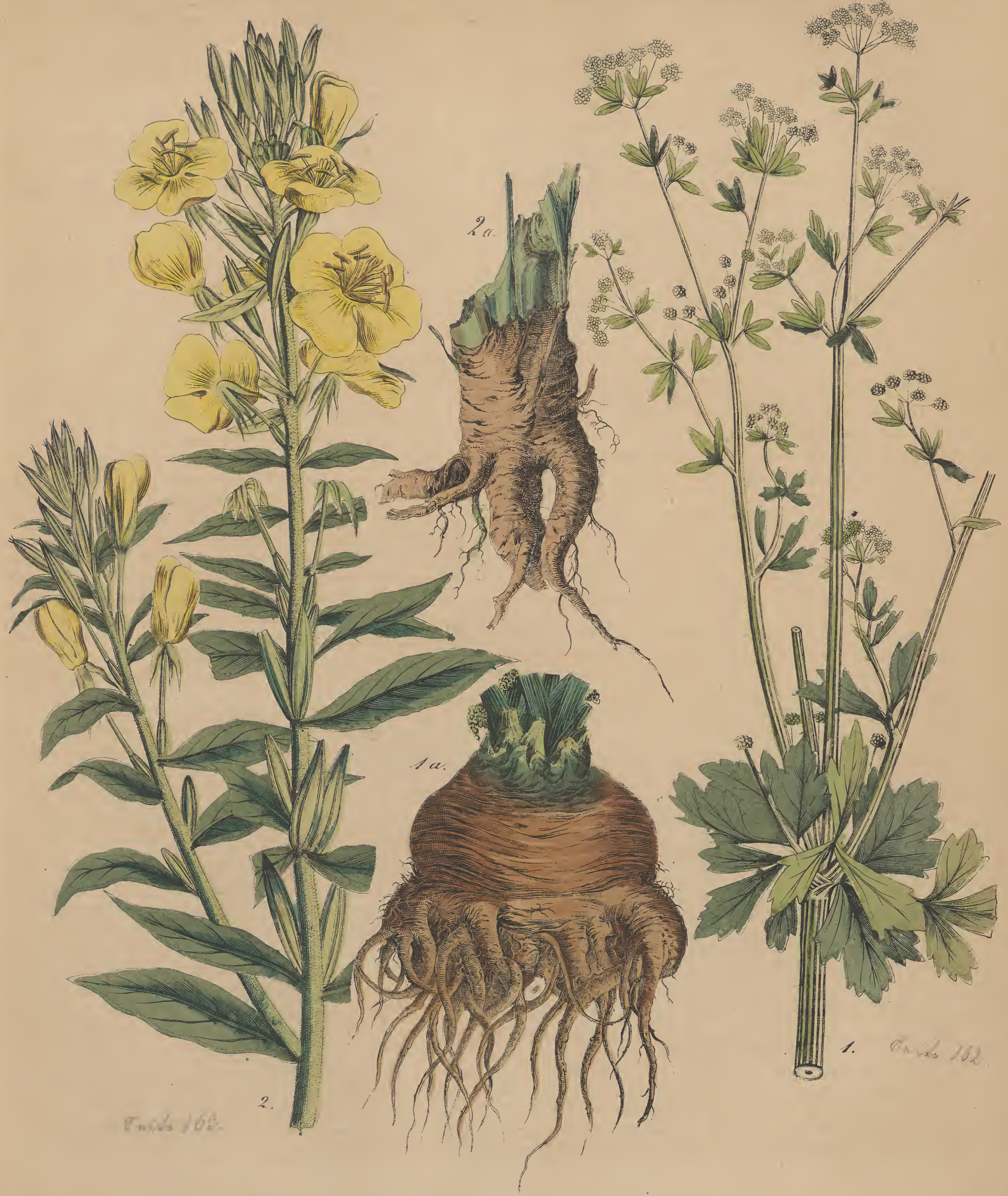




\section{Winterrettig.}

Raphanus sativus hiemalis.

Die $\mathfrak{B} u r z e l$ ift faft $2 j a ̈ g r i g$ und wirb oft $5-6$ und

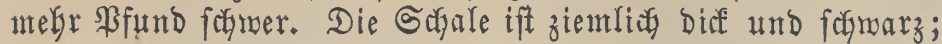

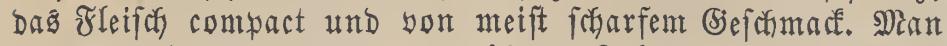
füet Den SWinterrettig nicht mobl yor Jokanni, weil er fonjt

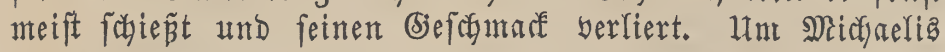
ninmt man bie Rettige aus Dem Rande, Da fie feinen Jroft ertragen, und fafneibet bas Rraut ab und aber mit SafD= nung bes Jeerzes, meil ite fonft pelzig werben, und werwabrt fite in Gruben ober auty in Sellern auf. Im Seller in Sand eingefdrlagen und zumeilen begoffen, treiben fëe Sproffen und Blätter, aus welchen man eimen zarten und woblfáme= ffenden Salat Gereiten fann. Sur Samenzudgt mägle man nur fajöne Winterrettige, mit ganz fanmarzer Schale - bie mit geflecter voer meifer ftnd zu verwerfen - weldfe man Den winter über forgfältig aufberwakrt und im Frübjabr auspflanzt. Der Sante bält fta 4-5 Sabre gut.

Der Winterrettig yaritrt weeder in Beziefung auf Form

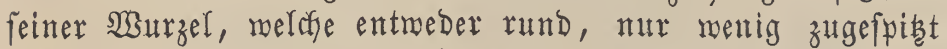
ober lang, fpindelförmig unb gefdunälzt ift.

a) Spindelförmige $\mathfrak{B}$ interrettige.

1) Errfurter fofwarzer Sinterrettig.

Ranger focharzer Erfurter Winterrettig, Ěrfurter ßettig, großer rübenförmiger WBinterrettig.

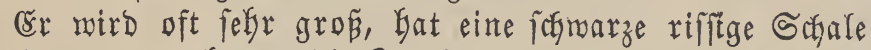
und einen angenefmen, bie Gedale aber eimen icharfbeisenden (Bejumarf, und ift einer ber beften Minterrettigforten.

b) $\Re u \mathfrak{n}$ be $\mathfrak{W}$ interettige.

1) Srymarzer runder Winterrettig.

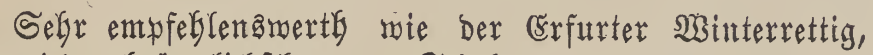
nit weicher Gräunlidyformarzer Sctyale.

\section{2) Sandrettig.}

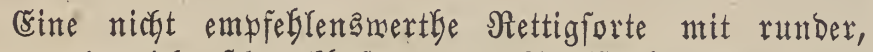
furzer und nidat fchuacthafter and bis SBeignadyten meift fchon pelzig merbender $\mathfrak{B u r z e l . ~ M a n ~ f a ̈ e t ~ b i e f e n ~ \Re e t t i g ~}$ erfit iut Juli.

\section{Sommerrettig.}

Raphanus sativus aestivus. Raphanus aestivus major.

(or ift meift fleiner, faftiger, weniger foctarf fonterfend, fchieşt auch feltener in Samen. Man ftecft die Sonmer=

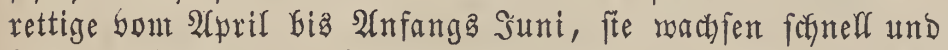
fönmen oft fochon im Sull benubl werben. Su Samen läät man einige Bjlanzen in \&ande fteben und fann int Dftober reifen Samen abnefmen, doer nimmt; menn bie Saat zu

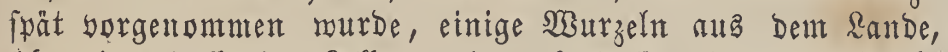
üfermintert fte in Refler und verjebt fte wieber in ₹rüb= jabr in's Freie. Der Sante Gleibt fo lange gut, mie Der yom Wsinterrettig.

a) Spindelformige Sommerrettige.

1) Ranger ficharzer Sommerrettig. merts.

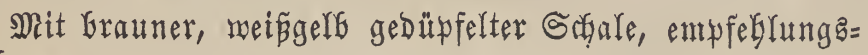

2) Ranger weíner Sontmerrettig.

Sefieñt leidgt, mit meiner Safale, weldye hie und ba weinglicty angeflogen ift.

b) $\Re u n d e$ Gommerrettige.

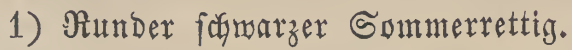

Nidft febr zu rübmen, da er gerne borzig wirb. Sagnle Dunferbraun.

2) Sirauer runder Sommerrettig.

Nit glatter brauner Schale.

3) Sumber meiner Sommerrettig.

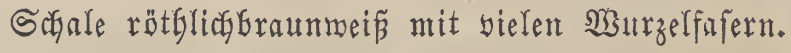

4) Runder rother ober violetter Sommerrettig.

Die Srgale ift meip̈braun, wird bie Dberbaut gejogabt, fo fiegt er roth alls.

\section{3. $\mathfrak{A}$ tittelrettig.}

2Munatrettig, Jaalbrettig, Baftardrettig, Wiener gelber

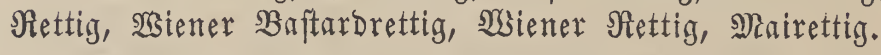

Die Mrittelrettige bilden Den Uthergang won Den Som= mer $=$ zu Den Mronatrettigen. Sie ftnd fleiner als erftere, gröper aber als lebtere, Gaben eine orfergelbe Scrjale und ein mildes angentelgmes Fleifdy.

1) Bielber runder Wienterrettig.

Mrit weip̈gelfer Scyale, wird felten pelzig.

2) Gelber langer fleinfrautiger 23 ienerrettig.

Sajale gelbianum.

\section{Altowatrettig.}

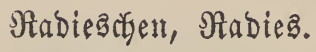

Die Nonatrettige Beftsen Das ntildefte Frleifa unter fämmtlichen Rettigiorten. Sie berlangen einen feuchten, gut gedüngten und verarbeiteten Boben und in $2(n f a n g$ einen rarmen, fontigen Standpunft. Man füet fe genöhnlias im Jrübjagr, iu $\mathfrak{A}$ pril; am aber den ganzen Sommer über

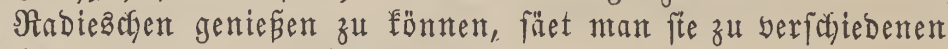
Beiten, yon 2-3 2 gorfen, bis 2lugut ober September und zwar fo, da fernt zu ftelen fonmen, bie zu bicht ftehenden müffen yer= zogen rerben. Itm früber Rabieschen zu befommen, macht man bie 2lusanat aucf ing Miftbeet. Sm Frübjagr lieben fite ein fonniges, int Sommer aber ein megr forattiges Rand. Orine Sauptfache bei Der Rultur Der Monatrettige, befonders aber Der im Soummer ausgefäeten, ift Daz fleípige Begießen Derfelfen, Denn baburdy mird nidft mur ifr Wachsthum be= Deutend befördert, fundern es merben aud bie ifnen fo ber= Derblichen Erdflabe afgelyalter. Wrent fte bas vierte Blatt angefegt baben, fo ftnd fie meift Grauchbar. Die frübege= fäeten fönnen nicht lange aufberablyt, ba fte Gald pelzig

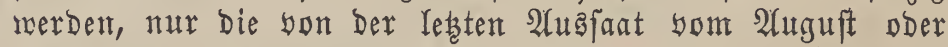
September laffen fref ziemlicly braudbar erbalten, indem man fie im Ditober aus Dem Rande nimmt und it einem falten Miftbeet ober in Seller in Crobe ober Sand bis über Den Wurzelgals einforlägt. Sur Samenzudat nimmt man etwa 
12 (ba bie 3uçt oft fegljălägt) Der grösten, hellften und glänzendften aus bem Rande, bringt fie einen ơn reit yon einander entrernt auf ein marmes Beet, afer nie in bie Näbe yon andern Nonatrettig=Sorten, und begieśt fate Gäuftis, und man befommt int gletifen Sommer nody reifen Samen; ift bie 2 usfant zul fpăt gemaed worben, fo übermintert man fie auf bie oben angegebente Wretife und verfest fie int ornüf= jabr in's Freie. Der Same bleibt 4 Jabre lang feimfähig.

Die Monatrettige ftnd, Gefonders in Frithjabre, roh

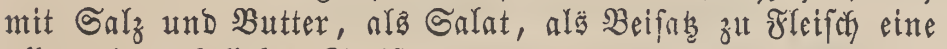
alfgenteine, beliebte Speife.

a) $\Re \mathfrak{n}$ des $\Re$ a diescden.

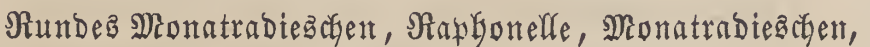
rother ober weiser runber Minatrettig.

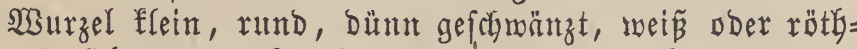
lief, mit fegr zarter Safale. Man' fann Dieje Spielart bont כrrübjalde bis zum berbfte anyffanzen.

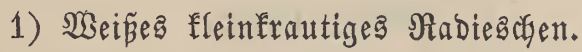

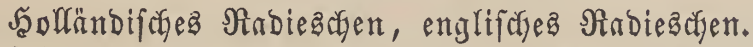

2tbart Des yorigen, eines bet frübeften; fte jitno meift 14 Tage früber als andere zu fertüsen tub taugen lyaupt= fächlich zu früfer Saat in's mititbeet.

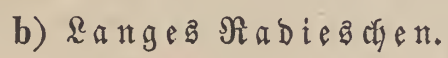

Ranges Mionatrabieżcten.

Wurzel länglich, meír, mit üfer ber (Erbe ftefendem, wurpur = oder rofenrothent Ropfe. Man fann fie gentesen, twenn fie bie Dicfe eines Fingers erreicht baben; ffe werben

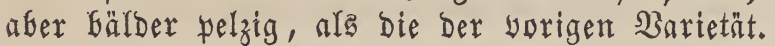

1) Bioletter langer Mionatrettig.

Bläuliç \ängliçrunder Monatrettig.

Selyr frith.

c) Forerlen $=\Re$ a biesa

W̧urzel fleị, länglicy, rothgeflertt.

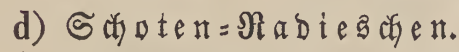

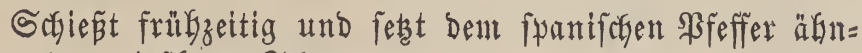
liche und geniep̧are Schoten an.

\section{Cochlearia. L.}

Armoracia. DeC.

Cochlear. DeC.

Jonopsidium. DeC.

Kernera. DeC.

Syfteme: Brachytophyta. Neck.

Cruciferae. Juss.

Cruciferae Alyssoideae. Vent.

Cruciferae Thlaspi. Adans.

Siliquosae. L.

Siliquosae Cochleariae. Rül.

Tetradynamae septatae. Rchbch.

Tetradynamia, Siliculosae. L.

Seldy 4brätterig, affallend. Relcbblätter aufreçt voer abftebend, eiförmig, megr vber weniger concay. SBlumen= frome 4blätterig, mebr ober weniger freufförmig. Blumen= blätter genagelt, berfebrt-eiförmig, ganzrandig. Staub=

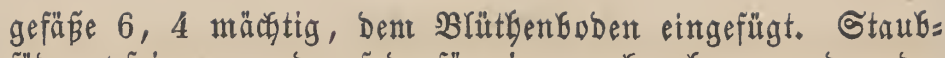
fäben yfriemen = ober fabenförntig, nact oben gerabe ober bie längern oberwärta reçtỏninfelig zur Seite gefnift und bann wieder auffteigend. Staubbeutel eiförmig, 2 fächerig. Stempel 1. Frudutfnoten runblich, 2 fücterig. Siriffel fels furz ober etwas werlängert, Gleift auf Der Scheidemand fieken. Narbe fopfförnig, ganz ober augigerandet. Sejötchen

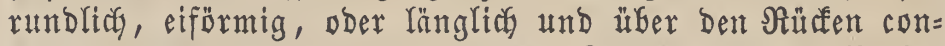
bex, DDer fugelf̈̈rmig, Gald yon ben Seiten, bald am $\Re$ türfen zufammengebrücft, 2flappig, 2 fäcterig. Santen 2 ober biele, in jebent rache 2reifig voer bidyt über einander zufantmen= gef̆äuft, bängend, glatt, punftirt, eimeif́logs.

\section{Cochlearia Armoracia. L.}

$$
\begin{aligned}
& \text { Cochlearia rusticana. Lam. } \\
& \text { variifolia. Salisb. } \\
& \text { Armoracia lapathifolia. Gilib. } \\
& \text { - rusticana. Fl. Wett. } \\
& \text { - sativa. Bernh. }
\end{aligned}
$$

Meerrettig, Märrettig, meerrettiges Röffelfraut.

Grand raifort, Cranson. (frattz.)

Horse - radish. (engl.)

Rafano, Ramolaccio. (ital.)

\section{Arten = (Sharakter.}

W3urzel $1 / 2-2$ 3oll biaf, oft einige Fú lang, biel= fäpfig, äftig ober einfach, malzenförmig, aupen gelblich,

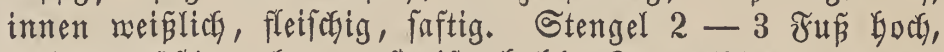
aufrecht, äftig, glatt, geftreift, bohl. Stengelblätter abmed)= felmb, faft fthend, fadmal, geftreeft-lanzetfförmig, beinake gleich breit, angetheilt Doer mefyr ober meniger eingefdyitten gefügt, oder gefeedert-getheilt, glatt, geabert, mit ftarfer Meittelrippe. WurzelGlätter $1-2$ ชuß lang und brüber, 4-7 3oll breit, ei-lanzettförmig, geftielt, geferbt, ftumtpf, glatt, glänzend, etreas runzlich und díf. Relch abftebend, Glap̧grün. Blumen givfelftändig, in langen, fălaffen Trau= ben ftehend, flein, weís voer etwas röthlich. Staubgefäpe Galb fo lang als bie Blumentrone. Staubfäben meiŕs, an Ränge nicht bebeutend werfochteden. Fruchtfnoten eiförmig, glatt, mit ber Scheiderwand gegen bie beiben längern Staub= fäber zugerwendet. Narbe fopfförmig, brüfț, gelblich. Schöt= chen flein, 2fächerig, eifürmig, ober elliptifch, 10-12 famig. Samen braun.

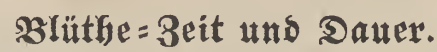 \\ Miat - כuli 4.}

\section{BorÉntmen.}

Man trifft Den \$eerrettig Gäufig in Deutfchland und

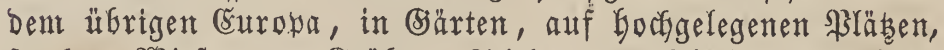

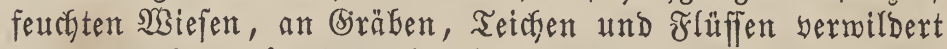
an; man baut ifn faft überall in sönten und auf Jelbern.

\section{Sultux.}

Der Meerrettig berfangt zu feinem wolfommenen Bes beifen eimen feudyten, locern, Gumubreicfen, Den berbjt zubor mit verrodetem $\mathfrak{s u l}$ mifte gebüngten, tief umgegrabenen ober rajolten, etras lefmljaltigen Boben; in feftent und

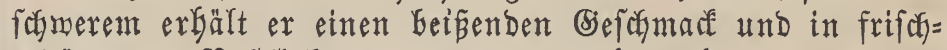

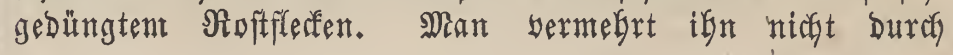




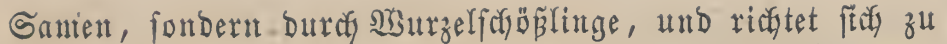

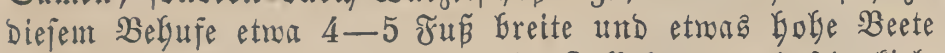
zu; in biefe legt man etma 6-10 Boll lange und feberfiel=

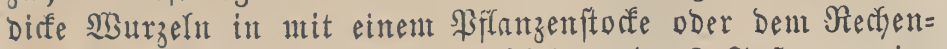

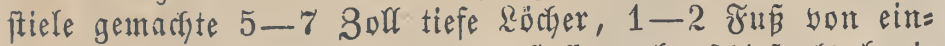
ander entfernt, utb zwar fo, baf fie methr fojief als hori= zontal in bie (5rbe zu liegen fontmen und dos Rronende nuch etwas aแs Derfelfen Kerausagt; Gierauf tritt utan bie Erbe um bie Whurzeln ber an, Damit fie gebörig yon ber= felben ungeben werben. Utm Jobanni etwa, wenn Der Meer= rettig einige Blätter getriefen Gat, nimut man die Errbe

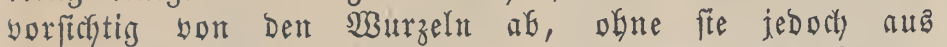
igrer Rage zu rünen, und fanteidet bie fleinern Seiten= wurzeft ab und brüfft bie Errbe roieber un fie an; biefes wieberkolt utan noch einigemal und erfält badurdy um fo gröpere und glättere Strngen.

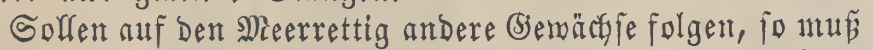
Der Boben tief und forgfültig umgetflügt, rajolt ober untgelgatet werben, weil Die bei Der Seerauzalyme Der Mieerrettig=Stangen

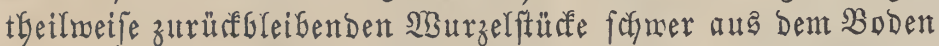
berauszubringen find, in benrjelben aber zurürfigelaffen, zum

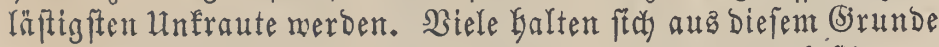
einige Jafre Jang eigens zun Neerrettig=2(nGau beftimmte Beete, welche aber nach Der erften Bflanzung, Den Serbft wor Der zmeiten, frifa und ftarf gedüngt und tief umge= graben werben inuffen. Srifeden ben Meerrettig andere (jie=

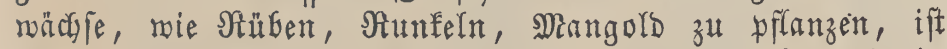
nidft anzuratben, weil foldye Dem Meerrettion nothmentig in feinem 2 sachst werflich, bent Meerrettig in Bärten berwilbern zu laffen, ba er Den Boben auperorbentlicy berunreinigt und erfegopft. Die im Früfjalgr gesflanzten 2 surzeln fann man foson im Jerbfte Genüben, Dber fe noch ein Safr liegen laffen, indem fate Dann biel ftärfer werden; fie aber 3 Sabre lang nicht benüben, ift nicht zu empfeblen, Da fe mit Dem Alter bart und ftrohig merden. - Der Meerrettig ift your 2 luguft bis zum שrüflinge, wo ex wieber in Trieb fommt, brauchbar. Da er gegen froble nicht empfindlich ift, fo fann man ifn wohl über den Winter im Rande laffen, nimmt, foyiel man für Den Winter etra bedarf, aus Dent Ranbe, fófteidet bie Sïpfe und Seitenmurzeln ab, bamit er ftef nicht treibe, und berwahrt ifn in Reflern ober Bruben. - Hm Närnberg, Errlangen, Ěrfurt und Sena wird Der Meerrettig iun Sropent angebaut und ein febr yortbeirbafter şandel mit ifm getrieber.

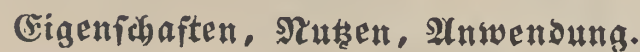

Der Meerrettig Gat, Gefonders frifo geriefen, einent ftarten, burchbringenden, flüchtig fadarfen, zu agränen rei= zenden (jeruch und einen brentenden, fojarfen, oft megr angenely fǖßlichen, ober mehr unangenelgm bittern $\mathbb{S}_{e}=$ ichmarf, meldye Eigenfdyaften bei Dem Esenuffe Deffelben zu= weilen augenbliafliche Stiche iut Gebirn berurjacten, fath aber Durch Rodyen zum grofen Theil berlieren.

Die yorwaltenden Beftandtyeile des Meerrettigs find

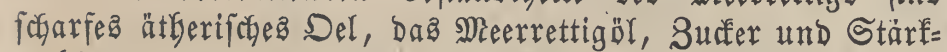
mebl. - 100 abeile frifeser Meerrettig entfalten nach (5)itret:

$$
\begin{aligned}
& \text { Aetberiface Del .. . . . . 0,06 }
\end{aligned}
$$

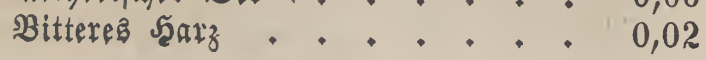

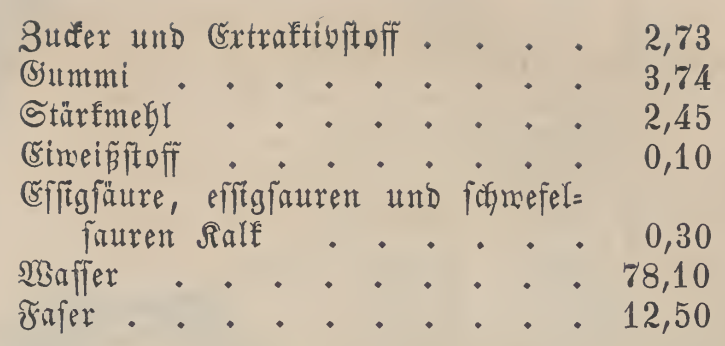

Man geniep̃t Den Meerrettig alz eine gefunde, Doch für

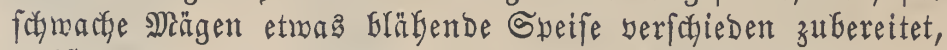
meift zerrieben, rug mit Effitg und 3urfer, 2lepfeln, ober mit Fleifchbrüge, Milch und zerftopenen Mandeln ober Ëiern

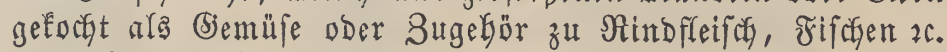
Mian benübzt $i \mathfrak{n}$ fermer als $\mathfrak{B}_{3}$ üze für andere Speifen, mie

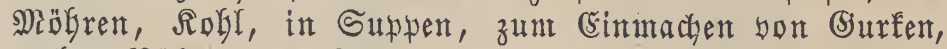

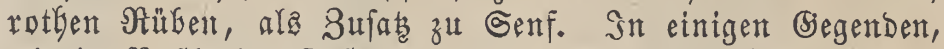

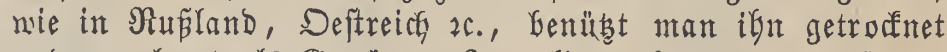
und gepulyert als (5ienürzze. Snnerlich gefraucht ntan ferner

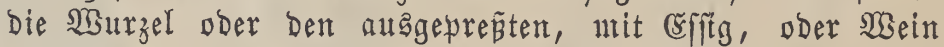
und 3urfer berfegten Saft gegen Scorbut, Safferfudten, (5icht, und mit Branntwein gegen Migenfrämpfe, und mit Bortbeil int $\mathfrak{A} u f g u f f e$ gegen Miundfäule, äuperlich allein ober in Serbinduitg mit Senf als fajnelf und farf rotgmadten= Des und reizendes, oft fogar Glafenerregendes Saautmittel. In einigen Segenden bient er Damen, welchen ifre Scaut nicht megr reizend und lebendig genug ift, mit Millch aufgegoffen als Sifminfmittel, und mit Weingeift gegen Reberfferfen. Die Blätter in geringer Menge anderem Futter beigemengt, bermefren bie Mitch Der Rühe.

\section{Allium. L.}

Anguinum. Don.

Cepa. Neck. Adans. Moench. Codonoprasum. Reichenb.

Moenchia. Medic.

Molium. Don.

Moly. Moench.
Ophioscorodon. Wallr. Porrum. Mill. Moench. Rhizirideum. Don. Saturnia. Maratt. Schoenoprasum. Kunth. Scorodon. Koch.
Syfteme: Alliaceae. Presl. Asphodeli. Juss. Coronariae Anthericeae. Rchbch. Coronariae Spathaceae. Spr. Lilia. Rül.

Liliaceae. Crantz.

Liliaceae Asphodeleae. Vent.

Liliaceae Hyacintheae. Endl.

Liliaceae Cepae. Adans.

Spathaceae. L.

Ymnadiphyta. Neck.

Hexandria, Monogynia. L.

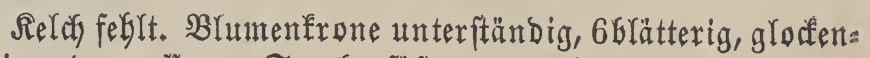
förmig ober offen. Staubgefäpe 6, auf Dem Orunde ber Blumenblätter angemacbjen. Staubfäben yfriemenförnig, oft mectfelameife breiter unb 3fpaltig, zumeilen am Brande in

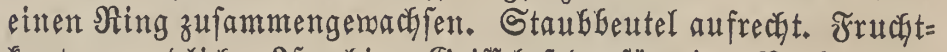
Enoten rundlich, 2 furchig. Eriffel fabenförutg. Narbe flein, 3 erfig ober 3lappig. Rapfel 3 fücherig, 3fnotig, rillig, jebes Fach 2 jantig, ober burth Berfümmerung 1 famig. Samen fantig. 


\section{Allium Cepa. L.}

Allium esculentum. Salisb.

Cepa vulgaris. Bernh.

Porrum Cepa. Reichenb.

$\beta$. Allium pauciflorum. Willd.

y. $\quad$ - Napus. Pall.

$\gamma$. - Cumaria. Hamilt.

ß. - proliferum. B. Mag.

(B)meine Smiebel, gemeiner Rauch, Sommerzmiebel, $8 \mathrm{i}=$ polle, genteine Rüctyenzmiebel, Bollen.

oignon, Common Onion. (entgl.)

Arten = (5̧arakter.

Die plattfugelige Zwiebel beftelyt aus biffen, fleifargigen

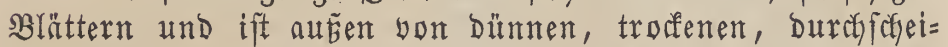

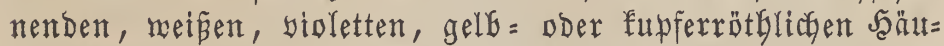

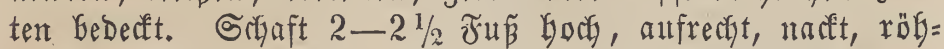
rig, Gobl, unten bauchig aufgetrieben. Blätter etwas fürzer als ber Schaft, hohl, zugefpist, 2zeilig, mechfelftünotg. Dolbe grofs, fugelförntig, vielGlüthig, hat yor ber sblütfe

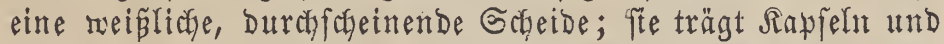

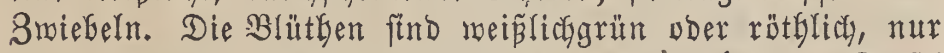
menig geöffnet. Staubfüben abmedsfelnd; 3theilig. Sapfel bielfamig.

\section{Blüthe = 3eit und จaนter. \\ รunt - 2 uguft. $\delta$.}

\section{Sorkommen.}

SGr Waterland ift Der Drient, Gei ung überalf in (bär = ten und Weinbergen angebaut.

\section{§ultux.}

Die Swiebel geräth an beften in einer warment Rage und in einem, fräftigen und locfern Boden; mur einen ma= gern Boben büngt inan und bebient ftedy bló gehörig zer= febten Dunges voer bringt aud frifdyen yor WBinter auf Das Rand, Da bie Bwiebeln friften Dung nicht ertragen, auth if es immer beffer, bas sand yor Dem Minter umzugraben. Bor Der Saat tritt ober walzt man ben $\mathfrak{B}$ Dben etwas an, bamit er länger feudft bleibe, bie 3miebeln weniger in bent= felben eindringen fönnen, Def̧balb auf Der Dberfläche des BDobens um fo gröper und früfer zeitig werben. 2 uf ein

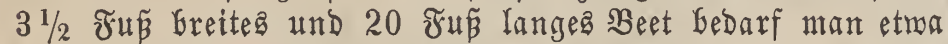
1/4 \$fund Samen zur 2Haşant. Den Samen făet man im Miärz, April, Mat ober, befonders menn man nur Stect= zmiebẹl für das nächfte Sabr kaben will, erft im Sunt, etmas bicht, am beften in etrag ergöbte seete, und bringt folchen mur oberf(äblidy in bie serbe, ober beffer, tritt ifn nur ein. Der Same braudyt meiftens 4-6 Wochen zum Reimen, es

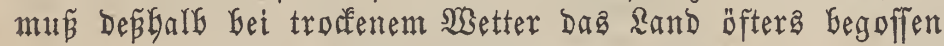
werben. Die jungen Bflanzen bat man forgfältig bom $\mathfrak{u} n=$ fraute zu reinigen und, menn fie an Drt und Steffe fleigen follen, bis auf 4-5 Solf yon einander zu verzieken. Mant berpflanzt auch bäuftg bie jungen 3niebeln, went fte ein paar sblätter angefetgt und die Diafe einer Schretbfeber er= reicft Gaben; fie follen baburdh gröper werben als biejentigen, reldye man auf Den Beeten fteben läbt. Beim $\mathfrak{B} e r$ eesen Dürfen nur bie SYurzelfajern ber Swiebel in ben Boben fommen, an bie man bie Erbe etwas andrüatt, bie Swiebel= chen felbft müffen auserbalb Deffelgen bleiben; nach einem
Regen, ober nachem man ben Boben gebörig angegoffen

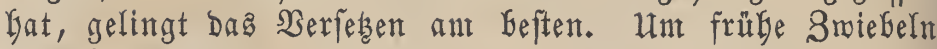
zu erbalten, fäet man. Ende Februars ober Anfangs Mårz Den Samen in mäpig warme Miftbeete, welche man bei mar= mer Witterung fleip̈ig lüftet, und verpflanzt fie, wie fo effen angegeben murbe; folche werben oft fogon im suli für bie Siuche braudjbar. Utm gröpere 3miebeln zu befonmmen, Darf man nur bie Crrbe ringsum yon Den 3 wiebeln bis an bie Wharzelfafern wegnelmen. Der Bebraud, gegen die Reife Der 3niebeln bie Blätter, bie fogenannten Scylotten, zu Boben zu treten vDer abzutnicfen, ift verwerffich. Die ium erften Jahre aus Samen gezogenen Sterfzmiebeln werden im

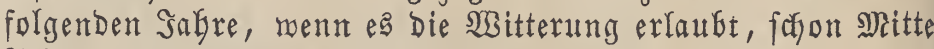
Februars in ein gutgedüngtes Rand und 8 Solf von einan= Der entfernte Furchen und in eitrer Entfermung bon $5-6$ 3oll berpflanzt und 1 3olf hoch mit Eroe beberft; zum 2 (uz $=$ yffanzen wäblt man am beften bie fleinften und fefteften Stedfarebeln. Die Bmiebelernte fälnt gemöhnlich in ben Águft ober September, wo alôbann bie Blätter gelb wer= Den und afferben; bei zu feftem und troffenent $\mathfrak{B}$ oben be= Dient man ftef zur Jerraßnalgnte Derfelben aus bem Rande eines Györzernen Spateris, wobei man fach hüte, bie Briebel zu Eefchabigen. Man fohneibet mun die Blätter etwa zur bälfte ab, Ginbet bie Smiebel, wenn man beren nidyt zul biele bat, mit ben Blättern zufammen und bängt fie auf, oder bringt fite an luftige Drte unter Dach, fofüttet fie 1 Fú boch auf und mentet fee pifter um. Heber Den Winter bemahrt man fte an froftfreien Drten, an beften in trodfe= nen Rammern auf, und bebecft fte bei zunebutender Rälte mit Stroly, alten Tüchern $2 c$. Die Bniebeln reiden nicht fo reicht burch orroft, und wenn fee auch gefrieren, fo läpt man fie yon ferbft mieber aufthauen, ofne fte yon ifrem sager zu Gringen. 2(ntch in Freien fann man bie Bmiebeln über= mintern, wenn ntan fte gut mit Ranb, Strob, Robe $2 c$. be= Decft, nur treifen fie Dann iut Frübjagre bald. Zur Gamen=

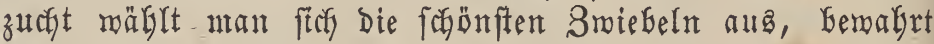
fite Den WBinter über auf bie angegebene Weife auf, und

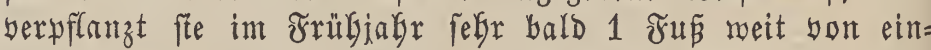
ander auf ein noch alte Siraft beftbendes Rand, pder fafon im Serbfte auf ein gefdüutes und fonniges Beet, unb bebecft fite mit $2 a u b$, in melch' lesterem Jalle man gemönnlich mefr unb beffern Samen erbält, doer aber man läßat bie Samen=

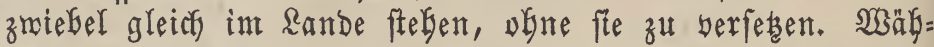
rend ber $\mathfrak{B}$ lüthezeit begieñt man Die Samenzmiebel einigemal und erfält dann meift in Septentber reifen Samen, meleher 2-3 Jabre lang feimfähig Gleibt.

\section{B̈igenfabaften, গtuten, Anwenoung.}

Die Bmiebel hat einen ftarfen, Durboringend ftecten= Dent, thränenerregenden (jeruch und einen fodarfen, füß̆lichen

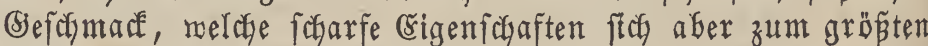
Theile Durch's Sochen ober 3 ujak bon Effitg berlieren.

Die yormaltenden $B$ eftandtgeile find: Scbleimzuner, flüch= tigez Det und Safmefel.

Die Brwiebel find näbrend, aber fchmer berbaulict, und

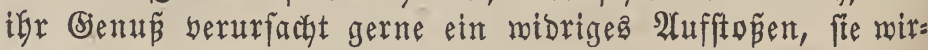
fen etmas reizend and barntreibend. Man verfpeist fie rob, wie in einigen füblichen Gegenden Črarapa', Der Tủrfei, Spanien, Jtalien $2 c_{.}$, allein, ober mit Sal 






Sują̧ zu Salaten, gebämpft in Suppen, in Saucen, zur

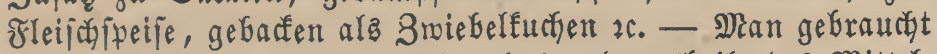
fie gefocht äuperlidy als erweidyendes und zertheilendes Mittel, befonders in Crntaplasumen, gegen befchmülfte, und roh mit Ejitig und Branntrein gegen $\mathfrak{B r a n d w u n d e n . ~}$

Durch Sultur find biele Barietăten entftanden, bie man nad ifrer Form, Der Saautfarbe und nach ifrer Rulturweife, nadj Begenden, wo fie befonbers bäuffig gebaut werben, unterichieben und eingetheilt hat. - Einige bon ifnen Gaben ein mildores, andere ein melgr beífendes Frletich, einige find Gartbarer, wie bie runden platten Sorten, andere weniger, wie bic Girnförmigen.

\section{Kothe Sommerzwiebel.}

Swird in einer fand $=$ und refmbaltigen Giartenerde oft felgr grof.

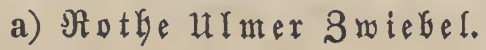

Rotbe fäarfite barte ulmer Smieber.

b) Dunfelrotbe ylattrunde Garte $B \mathfrak{a} \mathfrak{a} \mathfrak{n}=$ fondeiger 8 wiebel.

c) Bla sgelbe Golländifae 8 miebel.

\section{Gielbe Sommerzwiebel.}

Belfe Swieber.

Durd, Bermifajung bes Samenftaubz ber rothen und meisen Gorte entftanden und artet Gie und ba wieber in bie rotte ober meífe 3miebel aus.

a) Belbe fủ

b) Gerbe plattrunde Ropfzmiebel.

\section{Wrifre Sommerzwiebel.}

5ält fïn weniger lang als bie rotbe 3miebel, ift aber milder und weicher und geht leidft wieder in bie rothe über, meß̧halb beibe nicht zu nahe neben einander angebaut werben bürfen.

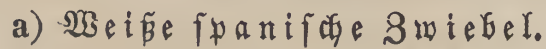

b) Sirbermeíse wattrunde, harteholran= Difue Ropfzmieber.

\section{Allium fistulosum. L.}

Cepa ventricosa. Moench

Allium sapidissimum. Pall

$\beta$. Allium altaicum. Pall.

$\gamma$. Allium ceratophyllum. Ledeb. Bess.

(Bemeine Winterzmiebel, lange fpanifche Smiebel, Jafobs: zmiebel, Schnittzmiebel, 3miebelröhrofen, emige Swiebel,

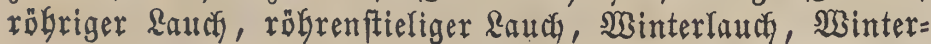
zmiebel, lauchige Winterzmiebel, Rörenlaucr.

Ciboule de St. Jacques, Oignette. (frattz.)

Welsh 0nion. (engl.)

\section{Arten = Charakter.}

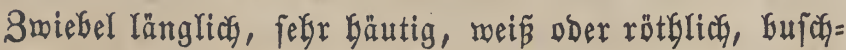

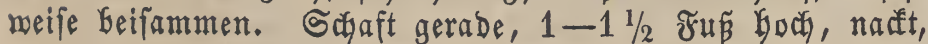
GoGl, fpindelförmig, in ber Mitte aufgeblafen, unten beblät= tert. Blätter röbrig, faft fo lang als ber Safaft, rund, Ealwer, bfonom. Pfanzenfunde.
Hfriemenfürmig, etwą bauctig. Dolbe biat, etwas längs

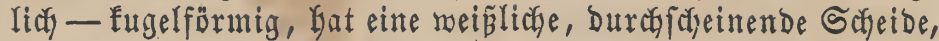

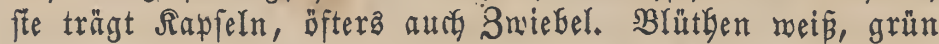
linirt. Staubfäben $2 \mathfrak{m a l}$ länger als bie firune, pfriemen= förmig, alffrectyt fteflend.

\section{Blüthe = 3eit uns Dauer.}

รuni - 2ługuft. 4 .

\section{3orkommen.}

Mian glaubt, fte fet in Sibirien einfleimifa, und mirb Gejonders in Deutidaland, England und Schmeden in (Sär ten gezogen.

\section{Sultur.}

Der Same wird Mitte Riprila ober erft nach Solganni auf ein warmes Beet gejäet; bie Bflanzen verjest man oft einigemal, und da fte nidht bejonders grop merben, $2-3$ in

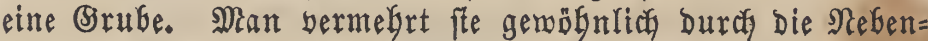
zmiebel, melaje bieje 2 art in Menge anjebt, unb verpflamzt Diefe im SeerGfte ober im Jrühiagr $10-12$ 3oll meit von einander in's Rand. Heber ben Binter läpt man fte meift im Boben, da fite gegen Rälte nicht empfindlich find, und verbraudyt fte yom ซrählinge an, und zwar bas ganze Sabr Gindurd. Der Same bleibt $3-4$ Salgre lang feimfäbig. Daz Hebrige mie beim Sommerzmiefel.

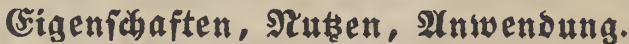

Die Winterzmiebel bat einen zmiebelartigen, füß̨liden Befechma und einen fobmachen, nidyt unangenebnen Beruch. Man gebraudyt fie wie bie borige, bauptiandblich aber bie Blätter ober Schoten, bie auch Den șinter über grün blei= Gen, frif̧ in Suppen z. Mhit Der äupern Sahale färbt man Dftereier gerb.

\section{Allium ascalonicum. L.}

Porrum ascalonicum. Reichenb.

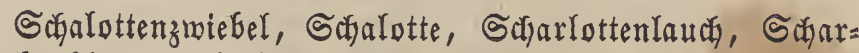

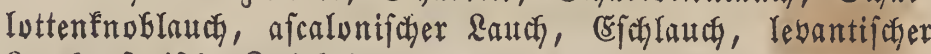
\&auch, fariface Smiefel.

Eschalotte. (franz.)

Shalot, Scallion, Ascalonian Garlick or Shalott. (entgl.)

Scalogno. (ital.)

\section{Arten = Çarakter.}

Smiebel flein, runblidy, ift aus mebreren veildyenblauen

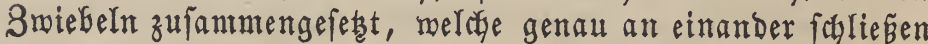
und bon gemeinfibaftlichen rothgelfen $\mathfrak{3} a \mathfrak{a}$ ten umgeben find. Schaft aufredst, nadet, rund, 1 ₹un boch. Blätter pfriemen= färnig, röbrig, meergrün. Dolde fopfföntig, fugelig, mit einer Gäutigen Scheibe. Blüthen violett und dunfel geftreift. Staubfüben bon Der Ränge Der Blumenblätter, abrechjelnd ftebend, fein 3tbeilig. Blübet felten bei uns und ber Same fommt nicht zur Nteife.

\section{Blütfe $=$ Beit $\mathfrak{\text { und }}$ Dauer.}

รันni - 2uguft. 4 .

\section{\$orÉmmen.}

SWurbe Durdi bie Rreuzfalder aus Der Stabt 2(ącalon

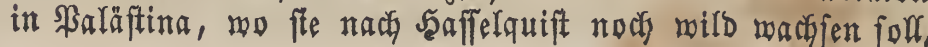




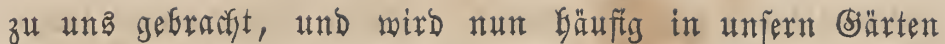
angebaut.

\section{Sinltut.}

Die Sifalottenzmiebeln berlangen eimen leidften, fandi= gen, trocferen und marmen boben unb wermefren fted in folchem oft ungemein ftarf. Man yffanzt fre burch Sarut fort, rozu ntan nur bie fleineren 3miebel nimmt. Diefe

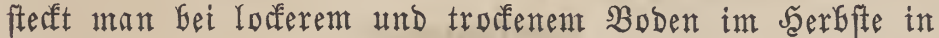
2 3oll tiefe rodyer ober Furchen, 5-6 -3oll weit yon ein= ander entfernt, in ein gut ungenrbeitetes sand und Derft fte

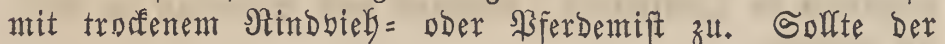
sboben fett fein, id müffen bie Röcher ober furdyen mit Sand aubigelegt werden, weil bie Sibalotten fonft faulen. Man fanm Die Swiebel auch erft int Jrüblinge legen, $\mathfrak{n} a=$ mentfich, went ber Boben mefre findig und falt ift, doch befommt nan yon Der Serbftpflanzung meift anjelgnlichere

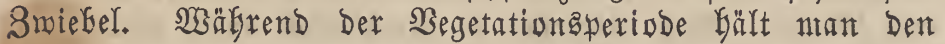
Boben jauber yout ltnfraut und forfert ifan zumetfen yoriteds= tig auf. Snt Suli, wenn bie Blätter anfangen gelb und welf zu roerden, nimmt man bie 8 miebel bet guter $23 i t t e=$ rung aนs bent Rande und läpt fie an einem luftigen, gegen

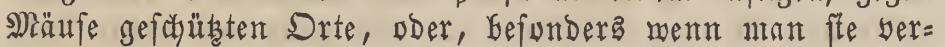
parfen und verjenden will, in Siefen, Saorden, über Dem Dfen ober Der DGftbörre troffinen und Gemahrt fe Den Win=

- ter über in froftfreien, aber nicht marmen Sanmern. Die gröpern Sagalottenzmiebeln gebraud man zum Beripeifen, Die Hleinern zum Stectent.

\section{(sigenidhaften, গtuten, Arnwendung.}

Die Sabalotenzmetebeln baben einen milden und febr angenegnen Biefdrmad, und werbent in Der Rüche bielfeitig, Gefonders zu Saucen, zum Spicfen ber Braten zc. vermendet.

\section{Allium Porrum. L. \\ Allium laetum. Salisb. \\ Porrum sativum. Mill. \\ Porrum commune. Reichenb. \\ $\beta$. Porrum sectile. Mill.}

Rauch, gemeiner Rauté), Stangenlauds, Sorrelauts,

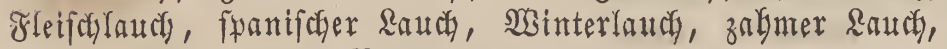
\$orre, SBinterporre, Forrey.

Porreau, Poireau, Porré. (frantz.)

Comon Leck. (engl.)

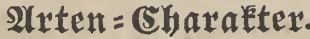

Swiebel flein, länglich, einfach, bäutig, wein. Sajaft

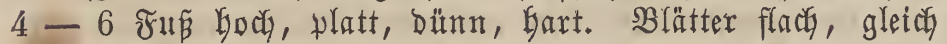
Ereit, etwas biff und faft gefielt, abmechfelnd, und an ber Baftz fcheidenartig. Dolde fugelfürntig. Blüttyen flein, röth=

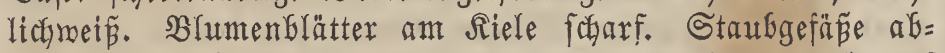
mechfelnd ftefjend, fein 2jpaltig. Rapjel eirund, ftumpf 3jeitig, mit etraz conbexen Flächen.

\section{Blüthe $=$ 3eit $\mathfrak{u n d}$ Dauer.}

$\mathfrak{s u t}-\mathfrak{s u l}, 4$.

\section{Syorkommen.}

W̧ächat in Der Schneiz in Weinbergen, überbaupt in

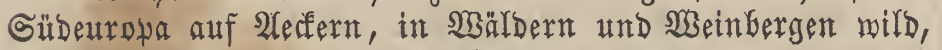
und twird bet unz büuftg in Gärten antgebaut.

\section{Sulttux.}

Man fäet ben Samen im 2ipril, nidyt zu bicht, in ein fonnig gelegenes Rand mit Yeidfter und, ba ber Raudy dent

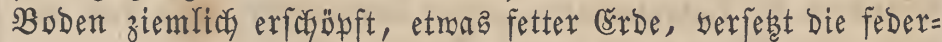
fielftarfen Pflanzen, nachdem man die Blätter und 3 urzel= fafern etwas abgeftuht lyat, in ein int Serbfte zubor gebüng=

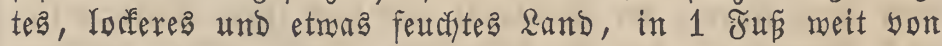
einander ftefende Neifen und 6-8 3oll meit yon einander entfernt, reinigt fie son Unfraut, begieß̧t und befart fie fpäter einigemale. Itm frübe Zmiebel zu ergalten, fäet man Den Samen int Februar in Mifteete, verfect bie jungen Şflanzen int Maa und Suni and begieśt fie Dann etras

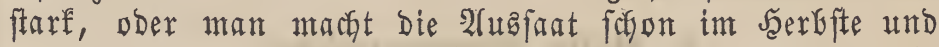

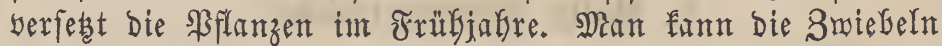

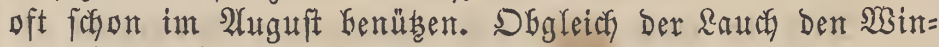
ter über wofl in Rande gelaffen werben fann, da er yon Der Räle nicht leidet, fo nimmt man ifn Loch gemöbnlicly im September aus demfelben und fahlagt ifn entreber im Jiefler in Sand ober im Sarten und zwar fo ein, baj bie Blätter etma 1 ซus unter bie (šrbe ober Den Sand zu lie= gen fommen, woburch fie einen mildern (sejchmate erfalten.

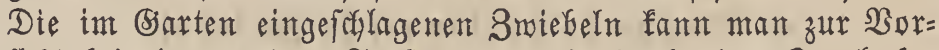
ficft bei eintretendem Froft noch mit Laub ober Stroh be=

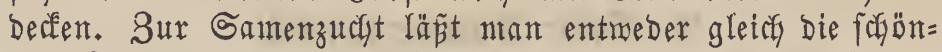
ften Bmiebeln int sande ftelyen, oder man beriegt fie im Jeerfite oder Frübjabre in ein anderes Rand. Der Sante

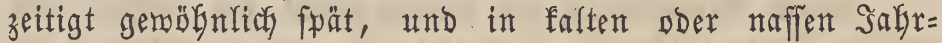

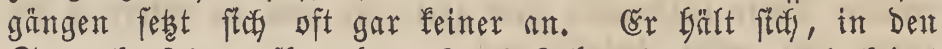
Samenfapfeln aufbemahat, $2-3$ Jabre lang gut und feimt oft figwer.

\section{(Sigenfachaften, stutsen, Anwensung.}

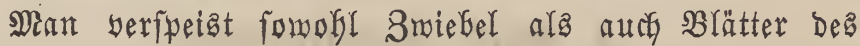

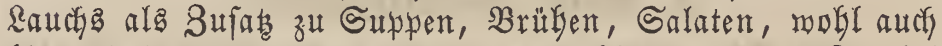

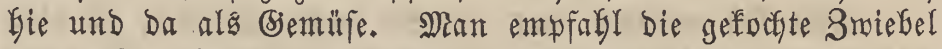
gegen Steinbefwnerben und Den Saft mit Şonig vermifd gegen Den $\mathfrak{B} i \tilde{\beta}$ giftiger Thiere.

Varietäten Dę ßorrelauchesิ ftut:

\section{Der Wintertaud. \\ 2. Der Sommerlauch.}

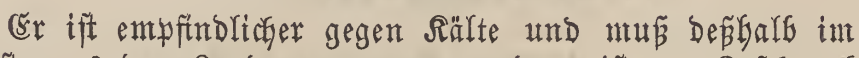
Seerbfte aนs Dem \&ande gendmmen merden, ift yon Gefichma milder.

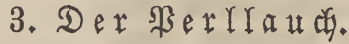

Allium ampeloprasum.

Berlfauth, Berlzmiebel, Sommerporre.

Die Smiebeln find flein, oft nur yon Der Bröpéper ber

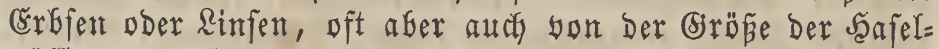

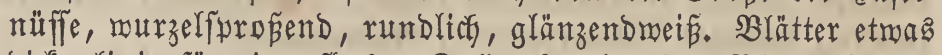
bief, Yinienförntig, ffach. Dolde fugelrund. Blumenfchetbe

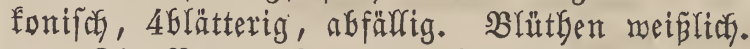

Die Serlzmiebelchen erfält man yon Dem genteinent

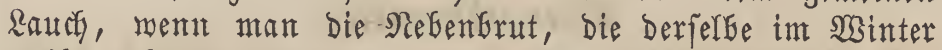
treibt, abnimmt, im Früblinge zeitig in's aand berpflanzt und ify Siraut im $\mathfrak{A}$ uguft, wenn fie in Samen treiben moffen, abforneidet, woburch ftch an Den Wurzeln bie run= ben perfenartigen Bwiebelchen bilden. Diefe legt man im 
Frübiature ober int Sertffte, Ende Septembera, in einter (Ent=

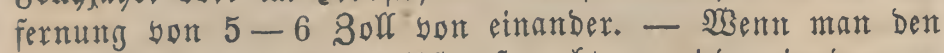
\$erlfauc Santen treiben läṕt, fo gefgt er mieber in ben ge= meinen Rauch itber.

Der Berlfauch Gat einen angenthmen und siel mildern

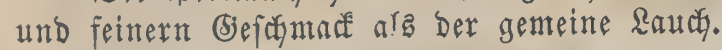

\section{Allium Schoenoprasum. L.}

Allium riparium. 0piz,

Allium tenuifolium. ? Salisb.

Cepa Schoenoprasum. Moench.

$\beta$. Allium reflexum. Dietr.

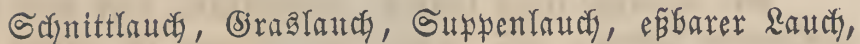
Bris̆anch, Infobazmiebel.

Ciboule. (franz.)

Cives. (entgl.)

Porro. (ital.)

\section{Arten $=$ (Sharater.}

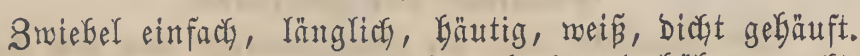

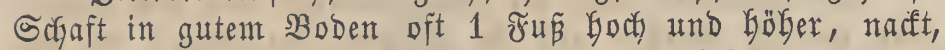
röbrig, an Der Baffa fadeidenartig, rajtgt. BBlätter aufrecht, grasgrün, röGrig, pfriemenförmig, rund, vit fo lang als Der Schaft. Dolde fopfï̈rntig, gebrängt, fteft in einer roth= geftreiften, eirunden Scheide. Blumenblätter find siolett doer rofa, Tanzettförmig. Staubräben fürzer als bie Bhlumen= blätter, einfach, ffriemenfürmig. Sapfel fugetrund. Samen fogmarz, fantig.

\section{3lüthe $=$ Seit uns $\mathfrak{D a u e r}$.}

Mai - September. 4.

\section{Borkommen.}

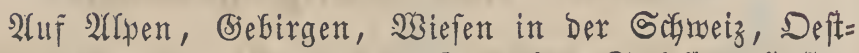
reich, Salzburg, Tyrol, Baiern, Schwaben, Schleften, Jeffen, auf bem Jarze und Sctyarzmalde wild und affgemein in (5)ärten fultivirt.

\section{Sultux.}

Der Schnittlaud gebeift an beften in einer warmen, fonnigen Rage und einem triebigen, lodfern und fanbigen Boben. Mlan bermelyrt ifu Durch Bertheilung ber Stöffe

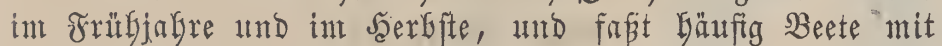
ify ein; nach 2-3 Safren berfest man ifh. Siegen Rälte ift Der Schnittlauch unempfindid. Se pfter man ifn abs: forneidet, Defto beffer gebeigt er, auch ift ifm bas Beftreuen

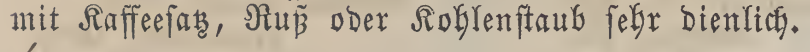

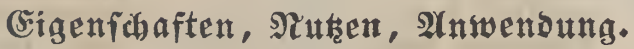

Man gentept bie 3miebel, bejonder aber bie zerichnit= tenten Blåtter in verjodiedenten Speifen, Suppen, Jemülen,

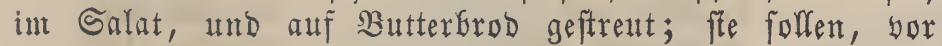
sijche gejpeist, 2Appetit erregen; auch mengt man fie zutwei= len Dent Futter für ganz junge Şügner bei.

\section{Allium sativum. L.}

Porrum sativum. Mill.

Snoblauth, zalmer Raudh, genteiner Snoblauch, Intopf= Iauch, Sinopfluch, gefauter Rauts, ftarfriectentoer Rauch.

Ail commun. (frintz.)

Garlick. (engr.)

Aglio. (ital.)

\section{Arten = Sharater.}

Die forwarzrothe 3wiebel beftegt aus melreren flei= nern, yon einer meiśn Scaut eingefbloffenen Bniebeln, Den fogenannten 8eken. Schaft $2-3$ Fú hoch, rund, glatt. Blätter fádeibig, lanzett-linienförmig, ganzrandig, abmectfelnd. Dolden fugelig, nit einer einblätterigen, Grei= ten und lang zugefpitenten Scheide. SBlütthen meiñlich, Gie und ba purpurroth. Staubjäben fefr lang, afmechfelnd, 3fpaltig. Einige Blüthenftiele tragen Dunfelrothe Brotebelchen,

\section{Blüthe $=$ Beit $\mathfrak{t}$ th Dauer.}

Iuni - $\mathfrak{s}$ li. 4 .

\section{3ortommen.}

Int Süben son Franfreich, Gicilien, und faft überall in (b)ärten und Şeinbergen angebaut.

\section{Sultux.}

Mian bermegrt Den Rnoblauch burch Die fleinern Smie= Geln ober Beben, welche man felgr zeitig int Jrübjagre rei= Genweife und $5-6$ 3olf meit you eimander ftecft. In Ginbigent Boben bütrfen bie 3wiebeln nttr ganz oberffächlich gelegt merben, meil fite fonft faulen. Int 2uguft, ment bie Blätter gelb merden, nimmt man ben Snoblaudy beraus,

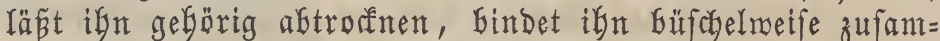
men und Gemalgrt ifn an troffenen Drten auf. Die Bwies beln Galten fich, geförig getroffret, 3 Jagre lang gut.

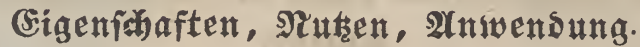

Der Inoblaudf beftest einen unangenebmen, Durcybrin= genden (berucf, Der lange an ber ßerfon, Die ifu genoffen bat, Gaftet, und einen eigenthümlitfen, fodarfen, geroürzbaf=

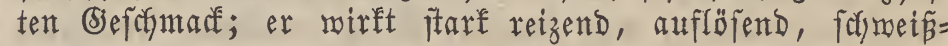
und urintreifend, frampf = und nurmwibrig, und wird in einigen Siegenden, wie in Spanien, Stalien, Ungarn, $\Re u \tilde{\beta}=$ land 2c. veripeist, befonders belieft ift fein (bienús aber bei

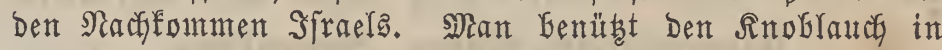

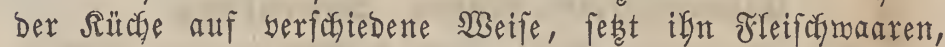

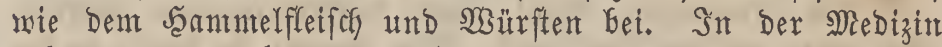
gefraucht man ifn gegen Waafferfuchten, yaffue Wainderbal=

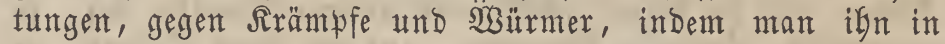
fleine Stüffe zerfdyntten und mit Del getränft, olne zu

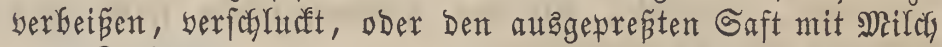
ober Bucfer bermifht genieǵt; aud fucht man fech burch in Dent Mund genommenen Rnvblauch gegen anftedfende Rranff=

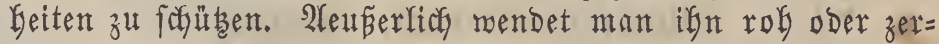

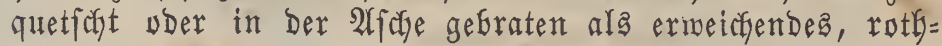
machendes und blajenziebendes Mittel an, fo Gei Zahnfobmer= zen, Denfelfen auf bie Jaaut gelegt ober in ben Mund ge= nomment, die Dämbfe eines Snoflautfanfguffes, weldye man an Den 2lfter gelyen lañt, DDer Derfelken in Rlyfteren mit Milus gefocht gegen Spulfroürmer, Den Saft gegen Flechiten und rheunatifche Hebelgörigfeit, auf Baummolfe getröpfelt

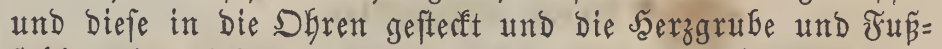
foflen eingerieben gegen Rrämpfe und Den Fuften Der Rin=

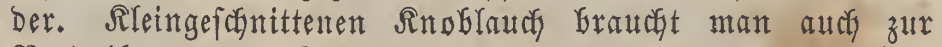
Bertreifung bon Schneifen, Sornmürmern und Eroflöben,

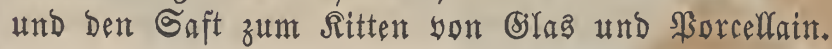




\section{Allium Scorodoprasum. L. \\ Allium arenarium. $\alpha$. $\beta$. Trev. \\ - carinatum. Schultz. \\ - obscurum. Bbrst. \\ Porrum Scorodoprasum. Reichenb.}

Sablangenfnoblauta, Bollenlauta, Sălangenlaud, Srabz=

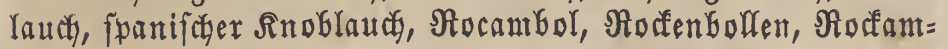
bolle, Roccambolfe.

Ait d'Espagne, Rocambole. (frattz.)

Rocambole Garlick. (entgl.)

\section{Arten = Charalter.}

3riebel auz melgreren fleinen, furzen und ftumpfen

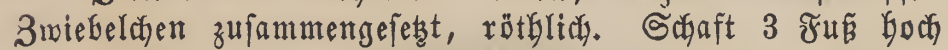
unb Darüber, fagl, vor ber Blütbezeit obett fothlangenförmig gebreft und umgebogen. Blätter flach, linienförmig, zuge= fpibt, mellenförmig feingeferft, am Rande und unten raug. Dolde fopf = und fugelförmig. Blüthen purpurröthlich; nadf Der Blüthe zeigen fitch gemöhnlid) ftatt ber Santen fleine

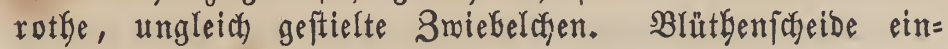
blätterig. Staubfäden 3 fpitigig.

\section{Blinthe $=$ 3eit und Dauter.}

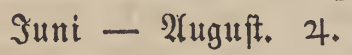

\section{3orkommen.}

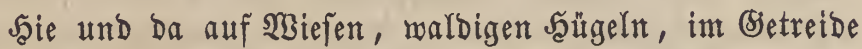
wild wachfend, in Deutfalland, Grefleften, Sachlen, Der $\mathfrak{B f a l}_{3}$, Thüringen, SSittenberg, Der Wetterau, Şommern, Srain, in Spanien, und bäufig in Sä̉rten angebaut.

\section{Sultur.}

Man legt bie fleineren Znotebeln im Dftober ober aud im שrübjakre in einen locfern, gut bearbeiteten Boben und fann fle meift foton im Sult ober $\mathfrak{Z}$ uguft ober im Septem=

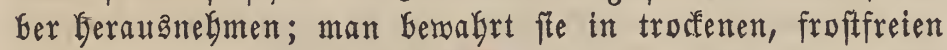
Ranmern auf. Die Zrwiebeln, bie fté an ber Dolde an= feken, fann man ebenfalls zur Bermebrung benühen, die aus folden gezogenen aber erft int zweiten Snbre gebraudden.

\section{Esigenfabaften, গtuţen, Atnwendung.}

Die Nocambole beftist einen Durchbringenden (seruch, aber einen milden Befchmax́. Nan benübt fie bäufig in ber Rüche, feht fie Salat, Solyl und andern Gemůfen bei, fo namentlich båufig in Sameden, auf ber Snfel Deland, in Dänentarf, Ungarn; mit Den Doldenzmiebeln fpicft man Wrildpret und $\mathfrak{a} a \mathfrak{m}$ elbraten.

\section{Allium proliferum. Schrad.}

Allium Cepa. Banks.

Allium Cepa. var. Ker. Schult.

Cepa prolifera. Moench.

Aegyptifice Smiebel, junge tragende Swiebel, fpropen= Der saudi.

Proliferous Garlick. (engr.)

\section{Arten = (Sharalter.}

Sahat 3 Fup boch, Gohl, röhrig, gebrebt, glatt, oben nacft. Blätter rund, Kobl. Die Dolde bat zwifanen ben geftielten, meiß̄en, grün gerippten Blüthen mebrere Bmiebeln, zmifoden biejen entfethen noch weitere Siengel, bie wieber

fleinete Snotebeläen tragen. Blütbenjayeiben mit 2 Goblen Slappen. Staubfäben länger als bie Blumenblätter, abmech= felnd ftuntpf, 3fpaltig. Staubbeutel grủn.

Blüthe $=$ Zeit und Datuer.

$\mathfrak{J u f i}-\mathfrak{A} u g u f t . \quad 4$.

\section{BorÉmmen.}

Nace Cinigen ift ifr $\mathfrak{B a t e r l a n d}$ Aleghpten, nach 2 Yndern Canaba, aber beibes mit menig Gerwibgeit, wirb biz jeşt noch nicht Gäuffig bei una angefaut.

\section{Sultux.}

Sie berlangt einen locfern, nabrbaften, aber nidgt frifa gebüngten Boben, und Dauert Den Winter int Freien auz. Die jungen Sroiebeln niumt man int Serbfte ab, berwahrt fie an einem froftfreien Drte auf und legt fie im $\widetilde{F}$ rabjabre. Sie ift felyr ergiefig.

\section{Sefdride ber 3wiebeln.}

Die Srwiebeln und ber Raud wurben yon ben 2 (eghp= tiern göttlich werefort und fie fofmuren bei ifnen; bei Den (5riecten murben die Berbrecter Durch 3roiebeln gereinigt; bie, welche folche genoffen Gatten, Durften nicht in ben Tem= pel ber Siöttermutter eintreten. Sie waren yorzuganeife ein Nabrungsmittel ber Sflaven, 2(rmen, Soldaten und Stjiffaleute.

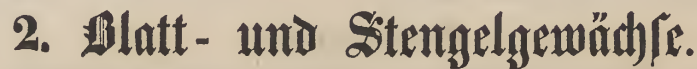

1tnter ignen verftelen mir foldye Bemäbre, beren Blatt=

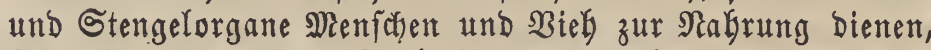
begreifen unter biefer 2lbtheilung bie Roblgemäatjle, Salat= und Sĭ̌chenfräuter.

\section{Brassica. L. Siebe Seite 24. \\ Brassica oleracea. L.}

Brassica arborea. Mill.

- botrytis. Mill.

- capitata. Hort.

- Erucoides. Horn.

- fimbricata. Hort.

- gongylodes. Mill.

- laciniata. Mill.

- muscovitica. Mill

- napobrassica. Mill.

- peregrina. Mill.

Semeiner Sobl, Sem

Cabbage. (engl.)

\section{Mrten $=$ Sharater.}

Die Swarzel ift rund, narbig und fleifchig. Die ganze Pfanze, Gefonders jung, glatt, graugrün Geduftet. Stengel verfocieben Koch, meift biff, aufrecht, im milben Suftande âtig, im fultibirten aber einfach, mit Sprofén und 2 (ugen 






ber frühern 2Uefte. Blätter grón, länglia, gegen bie Bafţ

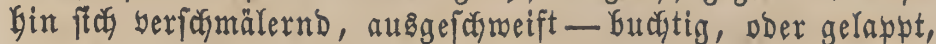
mebr ober weniger fteif, meift fleiforig und faftreids. Die WBurzelGlätter leierförmig, nie bia auf bie Mnittelrippe ein= geiănitten, fabl, bläuliç beduftet. Stengelblätter theilmeife ben Stengel umfaffend, anfthend, getwönlidy gleitjbreit, ober gegen bie Baftż Gin fich etwas berjüngend, bie oberften länglich berz $=$ lanzett = ober etwaz feilförmig. Sieldy bei= nale fo lang als bie Staubfäben, aufrecht, chlinbrifo, ge= fabloffen. Selchblätter fafnförmig, oben einmärts gebogen, faft gleichbreit, grủn, Gläuliç beduftet, oft aud bunfelgrün. Blütben fteben am Ěnde ber Stengel und Smeige in Trau= Gen oder Doldentrauben, find gros, ffach und meift belf=, zuweilen auch etwas bunfler gelb, fe ftrd yor bent völligen 2luf̣lüben fegr berlängert, fo daß̧ bie Blüthenfin̈pfe weit itber ben entfalteten $\mathfrak{B l u m e n}$ ftelen. Blumenblätter mebr ober weniger berlängert, länglidy - eiförmig, uneben, mit

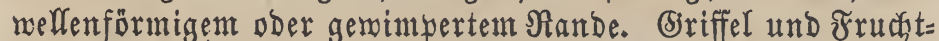
Enoten biaf, rund. Staubfäben gleichbicf, aufrect.: Narbe Galbfugelförmig, gelb. Bmifchen bem Selche und ben vier längern Gtaubfäben befinden fid vier Drüfen. Sifoten 3 Soll lang, aubzebreitet aufrecht, meift abftełend, runb, oft fnotig gegliebert, zumeilen faft 4 feitig, hie und ba bän= gend, glatt, mit einem runben, bicfen und furzen Briffel an ber Spike. Samen grof́, fugelig, mandymal effig ober etwas eingebrülft, glatt, bunfelbraum.

\section{Blintfe $=$ Beit und Dauter.}

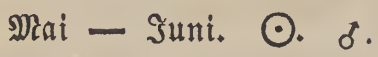

\section{3orkommen.}

Mian findet ben Sofhl wild in ơngland, Gejonberz um Dorfabire, Wallea, Cornmallez auf Rreibefelfen, an Den Rüften Der Normandie und in Briectenland, und fein $\mathfrak{A} \mathfrak{n}=$ bau in Gärten und auf Feldern ift affgemein berbreitet.

\section{Sultur.}

Der Sugl liebt einen locfern, fetten unb gut, aber

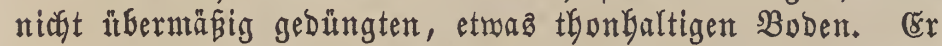
bird in nidyt zu frifós gebüngte Beete gefäet, wenig ober gar nicht, am wenigften aber mit saudfe begoffen, und bie jungen Sflanzen, wenn fte fröftig genug find, werben bei günftiger SBitterung am Geften 2 (bends nach ober voraus= fitchtlich furz yor eittem anthaltenden Negen regelmäpig yon einander entfernt, und. Damit fie in ifrem $13 a$ thathum nidft gefindert merben, nicht zu eng an einander berfest. Siele

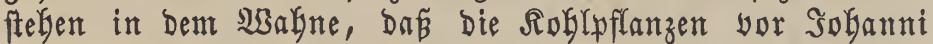
nieft berfest merben bürfen, und zwar aus bem Srunde, weil biefelben im anbern Falle bon ben (Erbflöfen vernichtet werben würben; biefe Meinung ift aber eine total irrige,

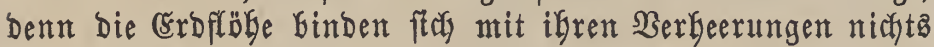
weniger als nur an bie Seit vor Sobanni, fondern fuchen bie Roflpflanzen ebenfo aud fpäter heim. Durch biefe ber= febrte 2 nfitht gefgt bäuftg ein groBer Theil Der Roblpflanzen zu Srunde, inbem fte Durdy biefes Dögern meift zum $\mathfrak{B e r}=$

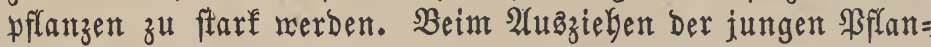
zen, zum Befhuf des Seriekens, fehe man Gauptjächlich

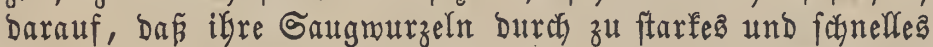

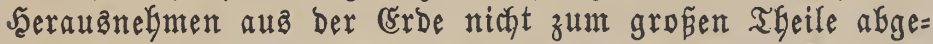
riffen werben, weil foldhe Bflanzen Dann oft lange fränfeln,

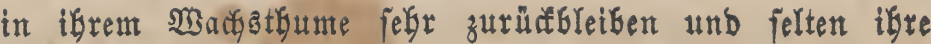
yollommene 2lubbiloung erlangen. 2im meiften Ieiden bie Saugmurzeln, menn man bie Sfilanzen bet zu trocenem,

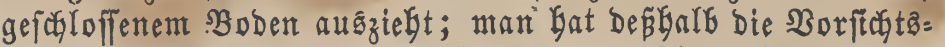

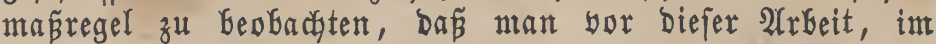

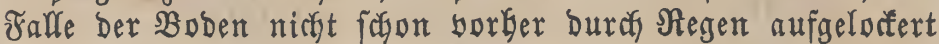
morben wäre, benfelben ftarf begieñt. Das Roch, in welches

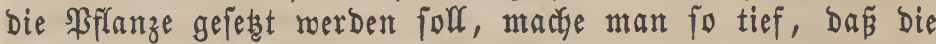
Erobe biz an bie Blătter berielben reidyt, ebenjo brülfe man die Erbe yom Stamme Der \$flanze an bis zur Murzel Ginab gehporig an. WWerben bie Suglpflamzen nur oberfläblich mit Der Murzel in Den Boben gebradt, fo faffen fie gemöhnlicf um, und rirb bie (rrbe nicht gleichförmig an bie Waurzel angebrürft, fo erbålt biefelbe menig ober gar feine feucdigtig= feit, und bie Pflanze ftirbt bann häuftg ab. Die Seblinge follen nun, zumal bet trodfener $\mathfrak{B}$ itterung, begoffen, einige Tage fpäter, furz yor eittem Regen, bebaf́t und angebäufelt werben.

Noch will ich auf zmei, in ber Bebandlungazmeife ber

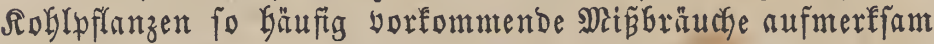
machen, welche oft allein an bem Mrieglitifen Der Roblpflan=

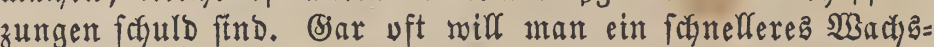

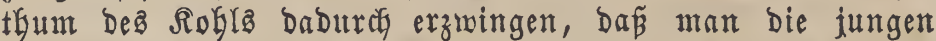

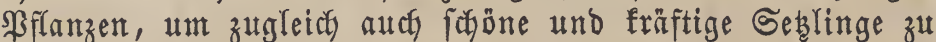
befommen, tüchtig mit Miftiaurde angiefst; Daburch bezmedt man nun aber Dasa Segentbeil, Denn ber Bildungätrieb biefer Bflanzen wird bann ein ganz anderer, fie vergeilen, fdyiesen

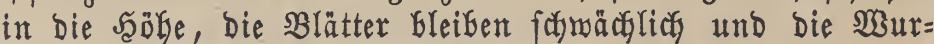
zeln befommen meift nur wenige ober gar feine Saugfajern, und bie \$flanzen berfütmmern ober fterben ganz ab, fobald fie in einen andern Boben verjegt werben. Ein weiterer

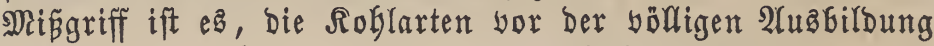
ifrer immern Theile abzublatten; Der Bilbungatrieb mirb $b a=$

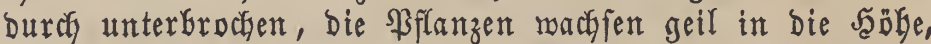

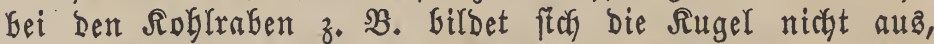

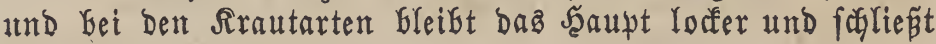
(tid) nie bolfommen.

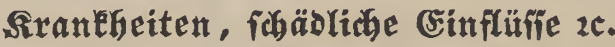

Unter ben Jnjeften, relche die Roblarten Gejonbers beintuchen, ftnd bie ärgften Freinde bie fogenannten Ero

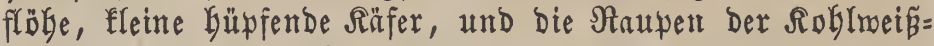
linge, ber meinen Schmetterlinge, welche leghtere ntan in Maffe in Soblgärten flattern fteht.

\section{Eigenforaften, গtuten, Anwenoung.}

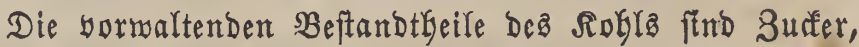
Schleint und fdyarfes ätherifdyes Del.

Sämmtliche Roblarten merben als (S) frifcyen Blätter mit Fett beftriçen, legt ntan auf Bejchmủre und yon Blafenpflafter wund gemachte Stellen ber Seaut.

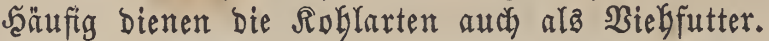

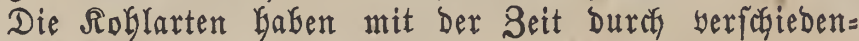

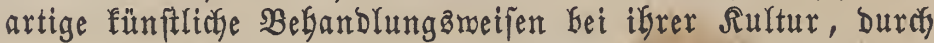

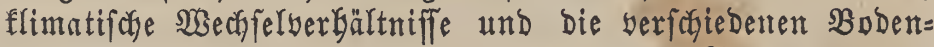
arten, in welchen foldge gebaut werben, in Form, fultur, Benübung 2c. vielfeitige Seränderungen erlitten, fo Dá es Gäufig fochierig ift, biefe neu entftandenen Spielarten mit

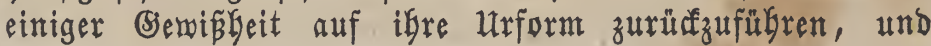




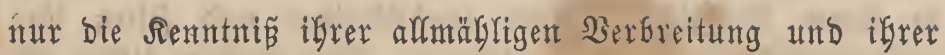

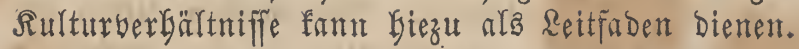

Itnterart.

\section{Brassica oleracea fruticosa.}

Strauchafol.

Stengel äftig, Golzig. Băätter geftielt, unten etwaß eingefornitten, Keflgrün. Die Sflanze Dauert Gäufig nelgrere Iabre.

\section{Miloex Straushoubl.}

Brassica oleracea fruticosa sylvestris. Brassica oleracea sylvestris. L. Brassica sylvestris. Mill.

Rangftändiger Mkerfofl, milder $\mathfrak{N}$ bl.

Chou sauvage. (firntz.)

Blätter gejtielt, Itntent etıas eingejçnitten, Gelfrrün, zuneilen rötglich, in feinen Saterlande ftraudartig.

(ङr ift an Den Seefüften Jranfreictis (bei Toulon), e̋ng=

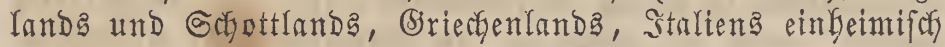
und wäçş Dafelgft in Menge auf Rreibefelfen.

Mian vermebrt biefen RoGl burch Samenableger und

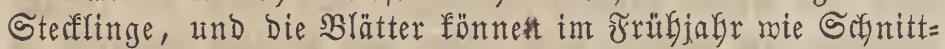

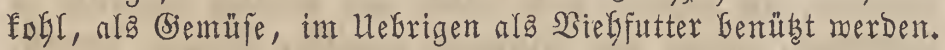

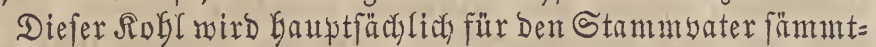
licher Rohlarten gefalten. (Eine Spielart biefes RoGla ift:

a) Dex barten=Straud of

Brassica oleracea fruticosa hortensis.

Berzweigter Staudenfogl, äftiger אofl yon ßoitou, auşoauernder Rofl yon Daubeton, gelber Blattfofl, emigę Blatteraut, eroiger $\mathfrak{R} 0 \mathfrak{f r}$.

Chou branchée, Chou vivace. (franz.)

Dem worigen faft ganz gleito. Stengel bolziger, ftärfer weräftelt. Blattftiele und Situsen bie und da violett.

Mefre in Jrantreich als Deutfaland angebaut. Da bieje Barietät mur felten blüft, alfo auch felten ober nur wenig Samen anfebt, fo bermegrt man fe Durdi 2lbleger; man fadreibet nänlich yon Suli bis 2 Infang Septembers bie jun= gen 3weige von ber SAflanje weg und berpflanzt diefe etwa 20 3oll yon einander entfernt in siartenteete. Biegen zroft ift er empftndlich und Gält debGalg bet unz ubber winter nicht wogl im Freien aus. Die jutgen Blätter, bie nan

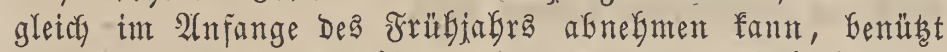
man mie Den 23 interfobl als Gemüfe. Diefer Jofgl hat mur injofern einigen $\mathfrak{B}$ erth, als er zu einer Beit Semilife Ytefert,

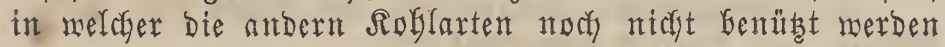
fönnen; er ift üt brigens ein fefr gutes $\mathfrak{S i e f}$ futter.

\section{Hnterait.}

\section{Brasica oleracea capitata.}

Ropffobl, Iraut.

Die Brätter Des Sopffahls fund naidy innen concay und liegen yor Dex Brïthe bicht auf einander, moburch fie einen

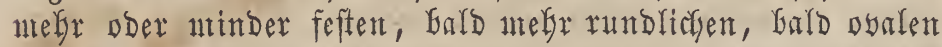

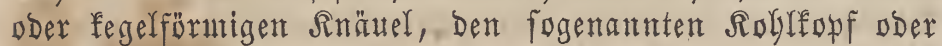
Dab Jallpt bilden.

SBie forgon oben beim Robl in arfgemeinen bemerft wurbe, serlangt auch Der Sopffohl, zumal bie gröberen Urten Defferben, einen rucern, fetten und gebörig gebüngten Boben, in geringent fetsen nur bie Saäupter fleiner Sorten an. - $\mathfrak{i n}$ Beziefung auf Den 2 (nbau unterfdyeidet man Sommer = und Sinterfiraut, und lesteres ift imnter lorferer als erfteres; Früflingsanbaut und ift biefer auch Der gebräuchlichfte. Das

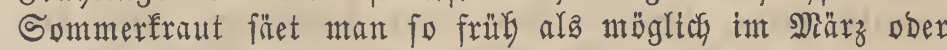
2lprif. Die Seblinge verwflanzt man am beften OEnde Mai's oder Suni's, und zwar bie Der mittleren Sorten in einer Ěntferung yon $2 \frac{1}{2}-2$ ₹̛ñ, Die Der gröperen aber $3-4$  rem Gingegen in fürzern 3mifchenräumen. Sft bas Sraut einigermapen berangewadifen, fo loffert man yon Seit zu Seit bie Erode auf und Gebäufelt Daffelbe. Bsefunde grüne Roblglätter bürfen nicht abgenommen werben, moljl aber gelbe und abfterbende. Die Şäupter fünnen, fobald fte bölfig ausegeradafen find, abgenommen merben, gemöbnlid fält aber Die Ernte in die Monate September und Dftober. Bum

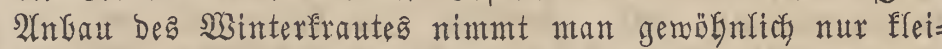

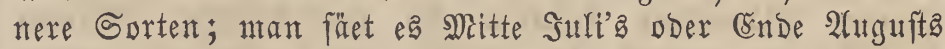

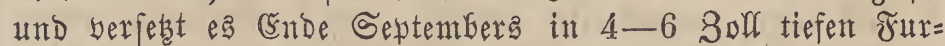
chen bis faft an bie Seerzblätter, entweder einzelm oder 2 bia

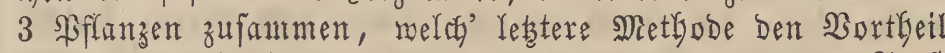

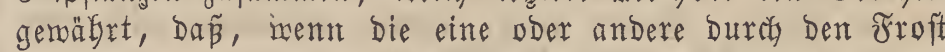

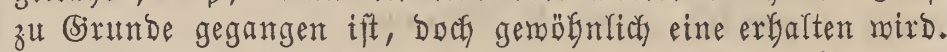
2luch ift es Deš Temperaturwecthiels megen anzuratben, bie

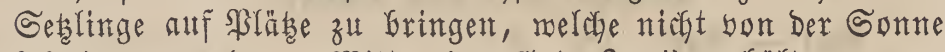
bejechienen werden. Mitte doer Ernde Sunt's erbält man ge= wöGnlich ausgerockjene Rrautgåupter. Man Durchwintert Das Rraut entmeder int Siller, indem man Die Stauden

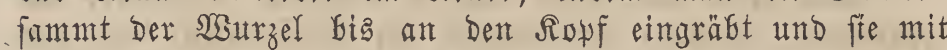
Ěrbjenftroly ober in sananglung biefes mit gemofylichem Stroly beberft, ober in Bruben, melche aber menigitens zmei

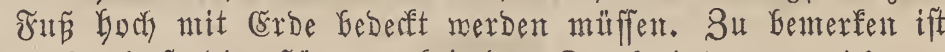

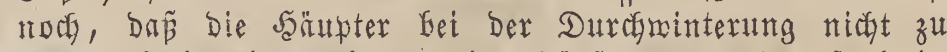
bicht auf einander gelegt werben bürfen und etwa faulende Blätter zu entfernen find. Bur Ganenzucht, went man je Diefe unternegmen will, bent man erbält meift mur wenig ober fachlechten Samen, ninnt man bie fräftigften sffranzen, weldye man im Seffer oder in Giruben übermintert und int Frübjabre mit eintretender warner Witterung berpflangt. Da Die Rrautblätter meift fegr diçt gefchlofien find, fo

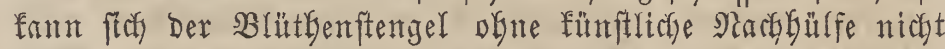
entmicfeln, man fpreitet Defifalb 8-14 Tage nach ber $\mathfrak{B e r}=$ yflanzung die B̉ătter aus einander, dDer madyt einten mäpig tiefen Rranzfolntit in bie Soblföpfe. Die Stengel madffen

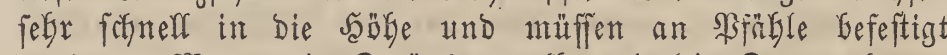
merben. Wenn bie Schotedyen gelf und bie Ganten braun

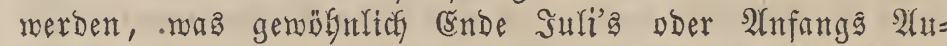

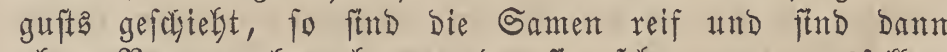
ofme Serzug afzutefnen, da fee fefr gerne aubfallen. Will man eine Ropffolfart fonftant erfalten, fo Darf in ifrer näcflifen Hutgefung yon feiner andern Art Gamen gezogen werden.

Dex Ropffogl felgft hat wieber biel Bartetäten, wont

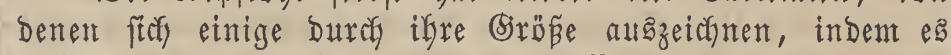

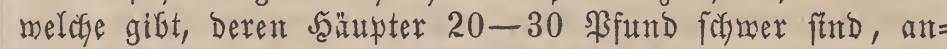
bere Dura ifre Gejtalt, mieder andere aber Durch ifre garbe. 
Die fleineren Ropffohlforten futb Den gröbern yorzuziefen, fie baben feftere Söpfe und find nteift biel zärter, ebenfo werben yon ben farbigen bie meib̆en Spielarten am meiften

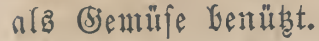

\section{Shlidhtex foblliopf.}

Brassica oleracea capitata laevis. Brassica oleracea capitata. L.

Stantu meift furz, marfig, oben berbist. Blintter glatt, längliç oder rund, Gilden einen runden ober oben zugefpilaten Ropf, fie find grün, meisfich ober roth.

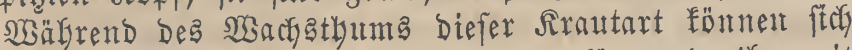
bie $\mathfrak{B l a ̈ t t e r ~ m e f g r ~ a u b d e l g n e n ~ u n d ~ m e r d e n ~ g l a ̈ t t e r , ~ b a ~ i f r e ~ m i t ~}$

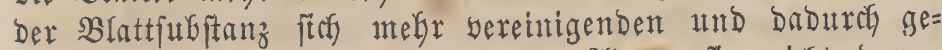
fornteibiger werbenden Rippen und 2ldern fie nicht baran bindern.

\section{Weink}

Brassica oleracea capitata alba. Rofptobl.

Chou pommé, chou Cabus, Cabus. (fianz.)

White Cabbage. (entgl).

Cavolo. (itar.)

Witkol. (j(t)wed.)

Sopf Doer Seaupt läntgliç ober rund, gemögnlich aber

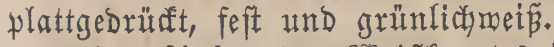

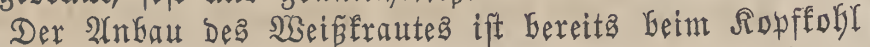
im Affgemeinen angegeben worden, und es gibt zerjonttten, mit $\mathrm{Sal}_{z}$ eingemadt, eines der Geliebfteften und verbreitet= ften Giemüle, Das Sauterfarat, Bettelfraut doer Schorbefraut, und wirb aud mit seffeg und Del als Srautfalat verfpeist. Die Blätter geben ferner ein gutes zutter, bejonders wenn

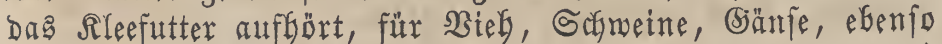
fann man bie Srrautftủnfe füttern; Gei größerem Borrath ftampft und falzt man Blätter und Strünfe für Den 2 Sinter

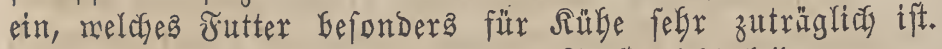
Diefe fann man, Da fte burch Den Froft nicht leiden, ganz gut überwintern, fte werden gefpalten ober zufantmengeftandft, rof Doer angebrügt gefüttert. - Der Same bleift 5-6 Saldre feimfähig und gibt mie aud Der übrigen Roblarten biel Del.

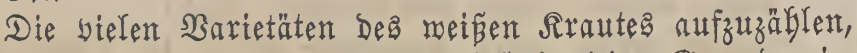
ift mir nicgt mögliay, indem man fajt in jeber biegend wie= ber eigente Sorten woer andere Benennungen antrifft, und

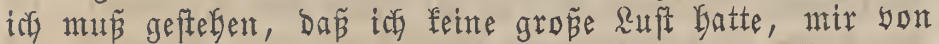

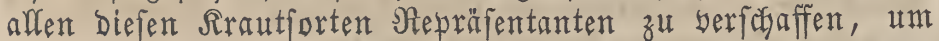
fie mit einander vergleicten zu fönnen; boch milf id eq

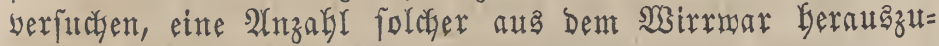
ziekgen und fite num futz aufzuzăblen.

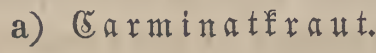

Brassica oleracea capitata flmbriata.

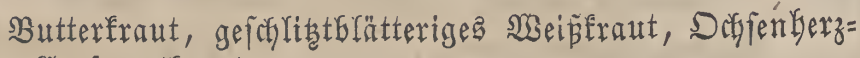
Eraut, Carbonatfraut.

Chou pommé hatif coeur de boeuf. (bei Straßßurg).

Strunt nieber, Blätter rund, mit zerfohlitetem doer ge=

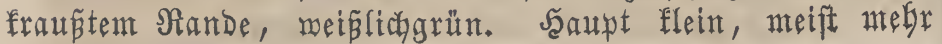
locter als feft, gleicht einigernapenen einem Dofjentherz.

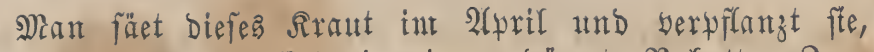

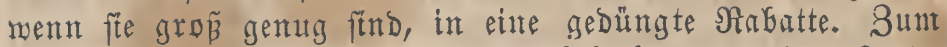
Heberwintern nimmt ntan fie Ende Dftobers aus Dem sambe und berwahrt fie int Siefler ober in tiefen Bruben, bie man Gebecft. Den Sament bezieft man gemblyntich aut LIfm. Diefes frraut ift fring und felgr gut.

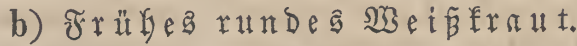 \\ Brassica alba praecox? Mill.}

Rleines frïles Rraut, plattgebrürfter Robl, rundes Jrubfraut, fleiner früfzeitiger 3 wergfofl, Erfurter fleines

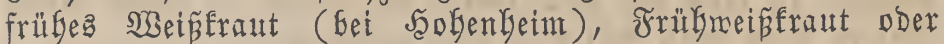
14lmex Weiphraut (bet Tübingen), 1trmer Jritbfraut (bei Sceilbronn), รrübrundfraut.

Chou deprimé ou aplati. (bei Strap̧burg.)

Strunf nieber, Ropf flein, mebr locter als feft.

Werlangt einen fefy guten $\mathfrak{B}$ oben und einen gegen $\mathfrak{R a ̈ l t e}$ gefchübten Standpunkt. Shan fäet es geröbnlich in 2 (utguft

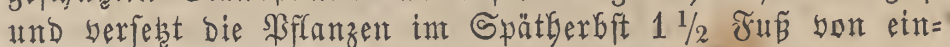
ander ins freie Rand, ober enger in ein faltes Mriftbeet,

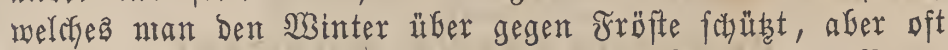

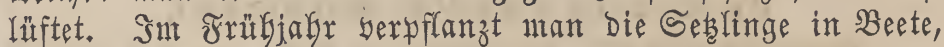
bie eine geichühte Rage baben, und fann bann meift čnbe

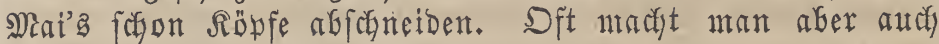
bie Saat erft im Februar ins Mifteet und verpflangt bie Seblinge, wenn fie gebörig erftarift ftnd, ing aand.

Diefea Siraut ift alfgemein zu empfeblen, ba ez nicht affein früh als Sauerfraut eingejchnitten werben fant, fon= bern auch ein fegr fohmadflaftes und frübes semüre riefert.

\section{c) (5)}

Brassica oleracea capitata alba compressa.

Brassica oleracea capitata serotina compressa major.

Brassica oleracea capitata canadensis.

Brassica oleracea capitata canadensis maxima.

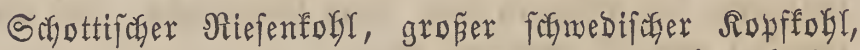
groper fonottiftyer Ropffogl, amerifantfoter Rugl, Greiter platter meífer Ropffofl, Centmerfpätfraut, groperer Brauns

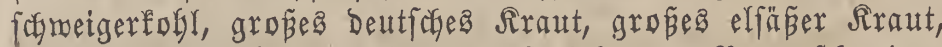

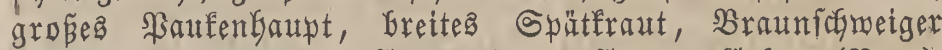

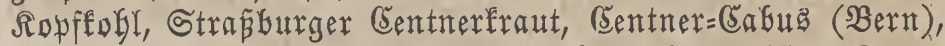

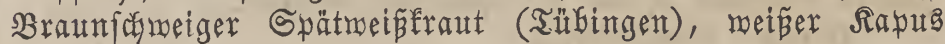

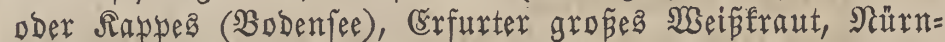

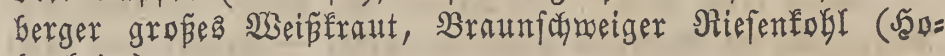
Genfeim).

Gros chou d'Allemagne, gros chou blanc d'automne, gros chou cabu ou quintau (Stıńburg).

Giant or Great Scotch Cabbage, The lauge Sided, Flat Cabbage, Flat topped Cabbage. (engr.)

(rine fefr grope Sorte, oft $1 \frac{1}{2}$ Fun in Durchmeffer,

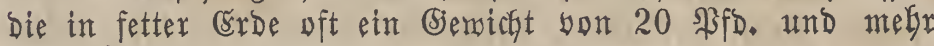
erreicht. Säapter rund, felgr feft.

Eine felgr beliebte Sorte, meldye fefr berbreitet ift, am

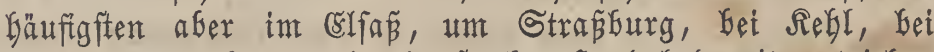
Conftarz angefaut and ein ftarfer Sandel bamit getrieben mirb. - Sie gebeift an beften in Nieberungen und in fettem, etwas feudeten SBoben; in magerem und trodfenem Boben mird baz fraut oyal und weniger anjefrilich. Man fäet bie Samen im 2 (pril auf ein warm gelegene Beet, 
Dber nocis Geffer in ein faltes Mliftbeet, ober auch auf einen Miffyaufen, Den man zuyor mit Erbe bedeft bat, und ver=

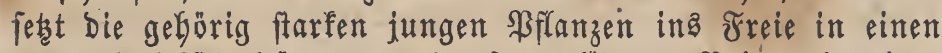
gut und frifdgebüngten und oft gepflügten 20 ben, in einer Entfermung yon 4 Duabratfú, und gieṕt fie bei trodfener Witterung gebörig an. Die Sirautländer bebauft man Den Sommer über zmeintal und behäufelt bie Sffanzen. - Wenn Das Siraut gebörig gebeitgen foll, fo burren feine andere Früchte bazmifichen gebaut merben. - 2 Auf biefes Rraut fann

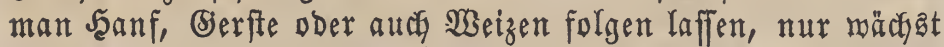
lebererer zu maft auf und lagert fid gerne. - $\mathfrak{T}$ uch biejen Samen fann man ächt aus $\mathfrak{H}$ Im beziekn.

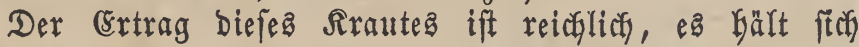
über Den Winter febr gut, ift ein fehr gutez Biehfutter, mergelt aber ben $B_{0 b e n}$ ziemlich ftarf aus.

Finige trennen Das Strap̧burger ober Braumidweiger Sraut yon ben Riejenfobl und ftelfen es als eigene Spiel= art auf, aflein und nur burch veridfiedene Sultur ober anderen Boben bie und ba ein anderes $2 \mathfrak{n}$ jegen zu befommen.

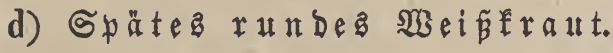

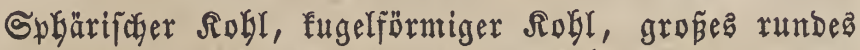
Sraut, breites Spätfraut, (Erfurter Sopffugl, grofer runber

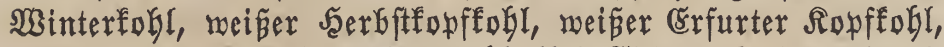

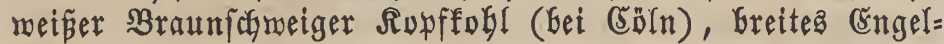
berger Sraut (Strap̈burg), Nändlinger Rraut (J̧eilbronn),

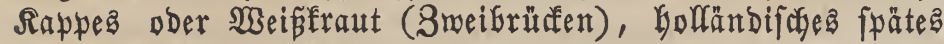

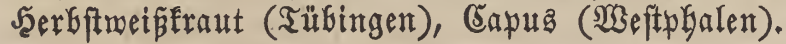

Chou sphärique. (firanz.)

Capuzzi (Benedig).

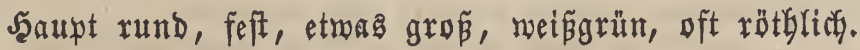
Strunf ftarf, Gocf.

Diefes Siraut ift am verbreitetfen. Man erziegt and behandelt die \$flanzen mie beim SRiejentokl. Sm Sftober fifnetbet man bie Săupter $\mathfrak{a b}$.

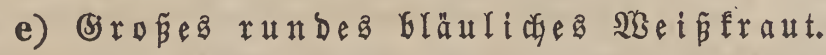

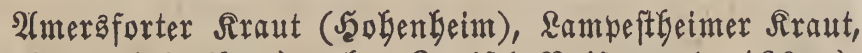

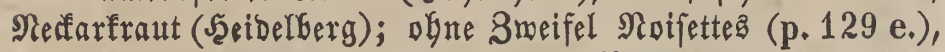

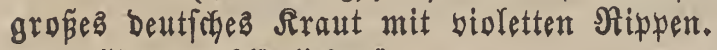

Sุăupter Glăuliăgrün.

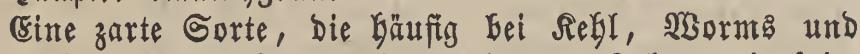
SRabolfzelf am sobenfee angebaut mird. - Sultut wie beim Riejenfogl.

\section{Woxkerkxaut.}

Brassica oleracea capitata elliptica. Brassica praecox Mill.

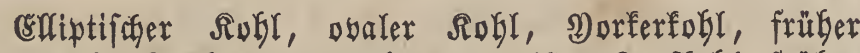

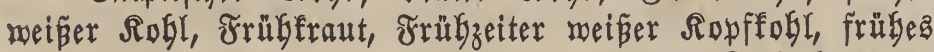
niedrigez Dorferfraut (Tübingen), Dorfer Burferfutfraut (bei Galem am Bobenfee).

Chou de York, chou pommé de York (Straf̧burg), chou elliptique. ( $\left(\mathfrak{t} \mathfrak{i n} \mathfrak{n}_{3}\right.$ )

Eearly Cabbage, Early Yorkshire. (engr.)

Strunf furz, Şaupt länglidy, oben ftunıf, meip̈grün, gemöbnlid locfer.

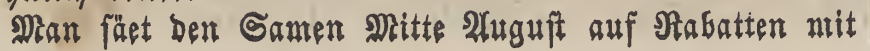

gutem $\mathfrak{B}$ oben und veriegt Die jungen Pflanzen im Dftober

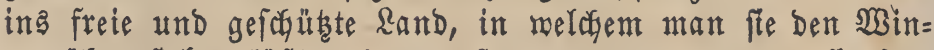
ter über fteben läst, ober verjeget man, wenn man fie frü= Ger benüben roill, eine $2 \mathfrak{n} z \mathfrak{g}$ l $\mathfrak{P f l a n z e n}$ in falte Miftbeete, melche ntan ben Winter über öfters lüftet. Man fäet biefes Sraut aud im Frübjahr in rarme Beete ober in Miiftbeete und verpflanzt bie Seblinge ing freie sand; auf bieje Ŝseife

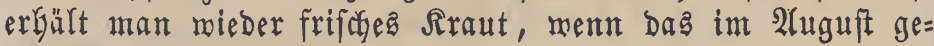

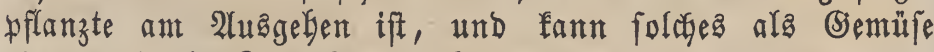
Dber audf als Gauerfraut gebraucten.

Die beften Samen erbălt man aus Straß̧burg. - Dả 2) orferfraut ift fegr frühe und von bejonderer bsüte.

Man hat yon bem Dorferfraut einige Varietäten, bie fith aber burch Nichta befonders bon einander untericheiden.

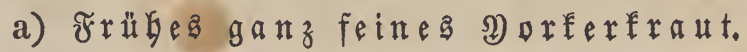
Säupter flein, aber fefr frübe.

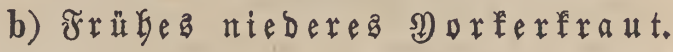

Utmgefehrt eiförmiger $\mathfrak{R}$ obl.

Chou abaré en oeuf. (firnmg.)

Strunf länger, Jaaut runber.

c) (5) rópes Doxfextrat.

(Gröperer, aber weniger früh.

d) 2(rrerfrübefte

Selgr gut, gibt aber beim Ëinmachen nidgt fégr aus.

\section{Budkexhutkŕxut.}

Brassica oleracea capitata pyramidalis. Brassica pyramidalis. Mill.

Gtrunf melgr niebrig ober hod, marfig. Şaupt lang, eiförmig, oben zugefpitst, feft, grün.

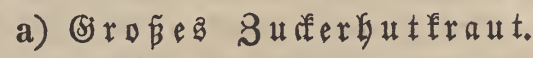

Filderipiberaut, 3uferbutfogl, groper Göbliger, bollich= ter Sưferkutfobl, Schmabentraut, Filderfraut (ㄲörttemberg), fpisig Filderfraut, fpikig Zưfergutfraut (Brei

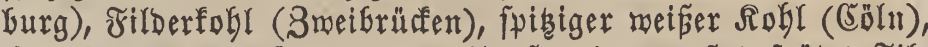
Spibfraut ober Spibcapus (Comftauz), grupece fpätę Fil = Derfraut.

Large hallow. Sugar loof-Cabbage. (etrgl.)

Diejes Rraut mirb bejonders bäufig in Württemberg auf Den fogenannten Fildern bei Ěchterbingen, M̈̈hringen, Baibingen, Nellingen 7c., in Der Nähe yon Stuttgart, im Remsthale zc. angebaut, in etwas gebirgigen 8egenden, wo ez beffer als andere אrautarten geräth.

Die Rultur ift bie gleithe mie beint runden Rraut.

Diefez Rraut Gerftet nicht, aber feine äuferen Blätter faulen gerne, wenn ea zulange ftefen bleibt.

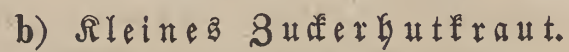

Brassica oleracea capitata pyramidalis alba.

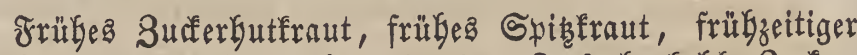

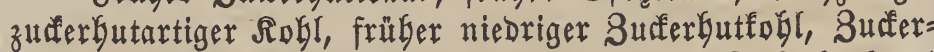

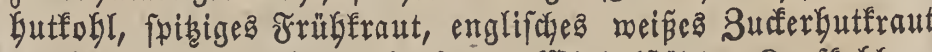

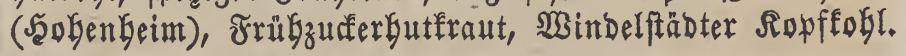

Chou pommé hatif en pain de Sucre. (jianz.)

Early Dwarf Sugarloof. (engl.) 
(ङః mirb meniger bäufig angebaut als bie borige Spiel= art, ฟaß̧t aud nur alz Frühfraut für (5ärtner.

Seine Şăupter find meí̈, feft und zart, etroas fleiner als voriges Sraut, wirb Gald feft; berftet aber leidgt, menn ę zu lange ftebt.

Man Gehandelt $e$ mie baz Dorferfant, Dem an Nubbarfeit gleidffommt.

\section{5. \#otbkraut.}

Brassica oleracea capitata rubra.

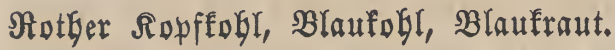

Chou rouge. (franz.)

Red Cabbage. (engl.)

Cavolo rosso. (ital.)

Strunf nieber. Röpfe flein, fegr feit, röthlidblau bia Glut= ober fodwarzroth, mit weipen ober Glauen Sloern, fidon Die Seblinge baben eine biolette Farbe. Der Same ift jobwarzbraun, Geinake runb, auf einer Seite eafig, yon ber (S)öpe eines gewöhnlichen Sterfnabelfnopfez.

Daz Rothfraut ift Gart und mird bäufig ala winter= fraut angebaut. Maan fäet yon ifam etra $1 / 4$ Roth alfein Dber im Semenge mit andern Rrautarten im März in ein

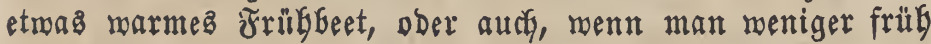

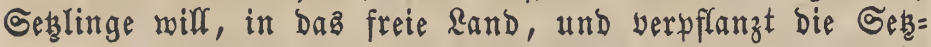
linge in einer (ङntfernung yon 2 Fus yon einander und in

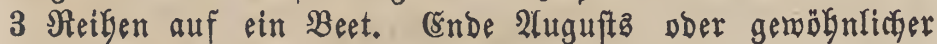
erit im September werben bie Röpfe Grauchbar und bürfen bann bez Schiepenz megen böbftenz noch 4 SBocjen auf

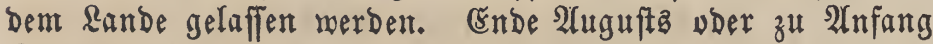
Septemberz beginnt man mit Der Şerbftaat, und die Sech= linge merben num entweber noch im Şerbjte, voer im Merz,

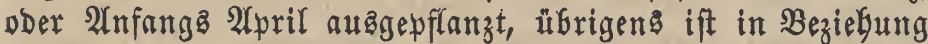

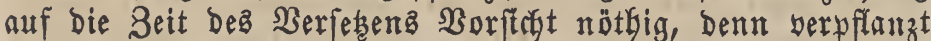
man bie Seblinge zu früh, fo madhen fie oft bor Eintritt Des Sinters zu ftarf und GrüFen bann im Jrübjakr, ftatt bäupter anzufeten, yff(anzt man fie bingegen zu fpät aub, fo erfrieren fie gerne über ben NBinter. Die Seblinge, weldye im Spätherbfte gemartyt merben, geben oft $6-8$

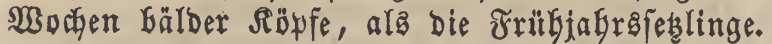

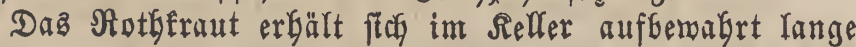

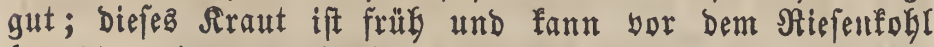
Genut werden. - Dieje Rrautjorte gibt gute, Duch bäufig

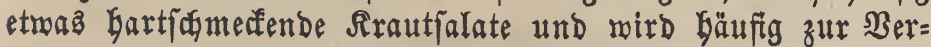
zierung anderex Eemüle Doer Salate benubt.

Die Barietäten Deß Blaufrautę find folgende:

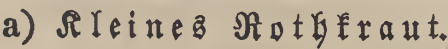

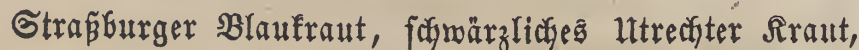
zmergartiger rother Ropffobl, rotber Ropffobl (C̈öln), hol=

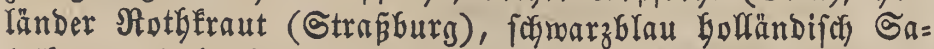

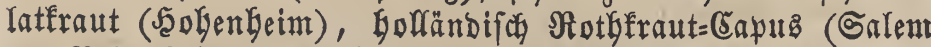
am Bobenfec), blutrothes Gollandifches nieberez Rraut. fidloffen.

Strunf niebrig. Şăupter flein, fämarzruth, feftge=

Şird nicht gar bäufig und roie daz

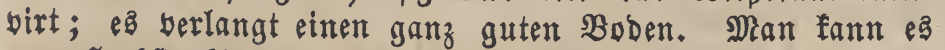
yom Saerbfte bia ins Frübjahr benuben als Galat, ober fein

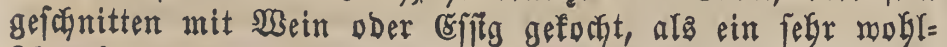

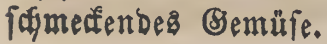

Ealmer, Bfonom. Ffrnzentunde.

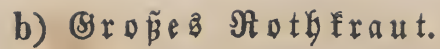

Hlmer Rothfraut, rother Ropfogl, rother Rappes,

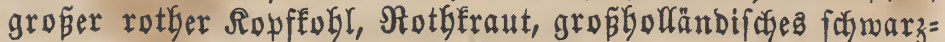
roth Sraut (Tübingen), holländifates gropes rotbez Rraut (Jablenbeim), rotber Capus (Conftanz).

Chou rouge. (frantz)

Red Cabbage. (entgl.)

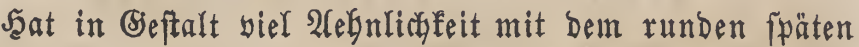

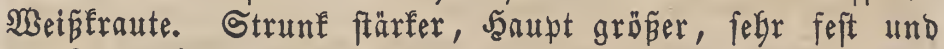
bie Farbe beller alz bei woriger Spielart.

WBirb Gäuftg, aber meift nur in bärten angebaut, unb ift etraz fpäter ala baz vorige. Man fäet ez im 2 (pril und fann ez vom Seerbfte an Den ganzen Binter alz Galat und Bemůje benuten. Bon $\mathfrak{A}$ lm beziegt mant febr guten Samen.

\section{Interart.}

Brassica oleracea sabauda.
Brassica oleracea capitata bullata.
Brassica oleracea viridis. 8. Mill.
Brassica oleracea sabauda. 1. Mill.
Brassica oleracea capitata crispa.

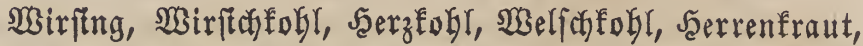

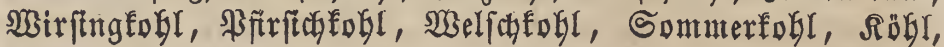

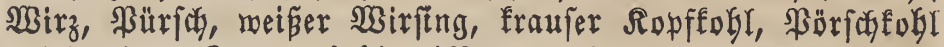
(Erfurt), Gavoberfobl (Norbdeutfaland), Rapfmirfing (รranffurt).

Chou pommé frisé, chou cloqués, chou de Milan, chou de Savoie, chou capus frisés, chou de Hollande. (fianz.)

Green Savoy. (engl.)

Verze. (ital.)

Savojkol. (fdtwed.)

Strunf furz, oben verdicft. Die Blätter find gerunzelt, frauz, lënglich, doér megr rund, meift ganzrandig. Die Şäupter nicht ganz gefdhloffen wie beim Sraute.

Die Bebandlung Des Wirftings ift faft ganz gleich mit Der bes Srautes. Mian pflanzt ifn, weil er fich weniger

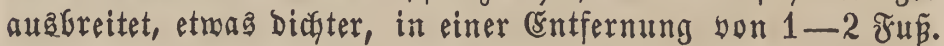
Man unterjocheibet früben und fpäten WBirīng, lebereren fäet man im Mai ober Juni inz Freie, erfteren fduon iun Februar und Mărz ins Jrübbeet. Man fann fee auch erft Ende Septembers fäen und überwintert fie im falten Miftecte ober im Freien. Die fpäte Saât Gat fleinere $\mathfrak{a} a \ddot{u p t e r, ~ b l e i=~}$

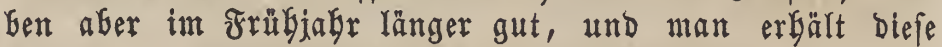

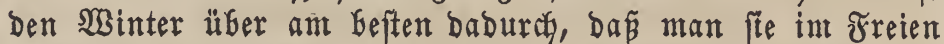
mit ber Sarzel und fefräg dicht an einander biaz an bie

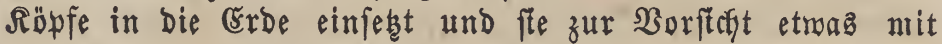

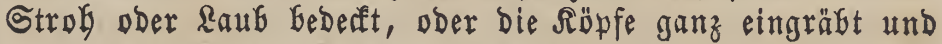
nur bie Strünfe aus bem Boden pekgen läp̃t. Dieje Heber= minterungarart ift immer beffer, ala bie im Selfer, weil fie in foldyem meift faulen. Sum Samenziegen mäblt man bie fefteften; fraufeften und gelgften Röpfe, werwakrt fe über

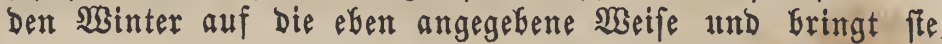
im Frübling in ein recht jonnigez Beet. Der Game bleift 4-5 Safre gut. - Sein Bebrauch alä Bemüpe ift bin= reichend befannt, er mirb aber auch in einigen begenden,

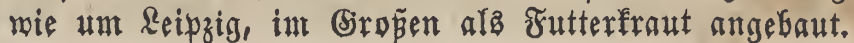




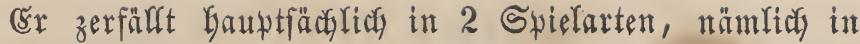
ben runben und langen Birfing.

\section{Rumoex Wixfing.}

Saupt rund, Gie und ba aud länglich, ftarf gelo, mit meift feft gefdoloffenem berz.

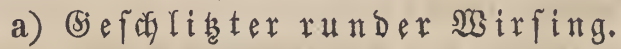

Carminatfögl (Täbingen).

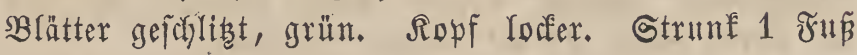
Hocty.

Wrird bie und ba in Württemberg fultivirt, ift aber nicht befonder empfeglengemerty.

\section{b) ซrüger runder SWirfing.}

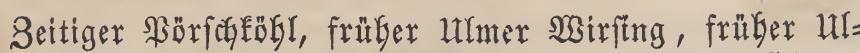

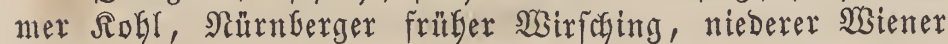

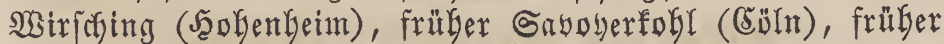

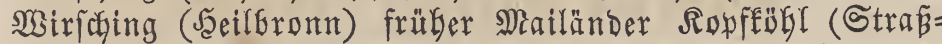
burg), früber niebriger $\mathfrak{R}$ opffogl (Täbingen und $\mathfrak{R} a \mathfrak{h r}$ ), früt= ber $\mathfrak{u l m e r}$ Siopfígl (Tüfingen).

Chou cloqué hatif. Petit chou frisé hatif. (frant.)

Strunf nieder, Saupt länglich, locfer, grün. Mlan füet ifn im rebruar und Miärz ins Miffteet und auf warme

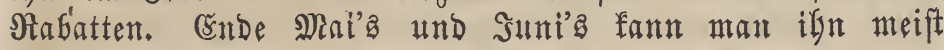
ficjon benuten.

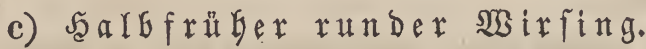

Meailänder Mittelfolyl, Mittelfofll (RaGr), Mittelnirfóding (Jeilbronn), Sommer = ober Mittelfopffofl (Tübingen), run=

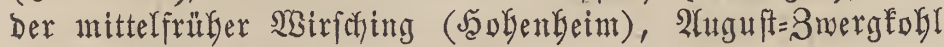
(Griem am sodenfee).

Chou de Wilan pommé d'été (Strẩ̆urg).

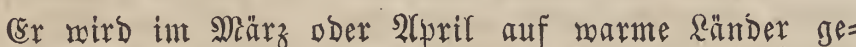
jäet und fpäter berfebst. Man fann ifn in berbfte gebrau= chen; roill man ifa noch früber haben, fo fäet man ign (Ende 2lugufts und verfest ifgn noch int Spätberbft, am beften in 3 Soll tiefe Furdfen, ober beffer noch, man Gringt die Prfanzen, meil fte Gei ftarfen $\mathfrak{W}$ inter gerne exfrieren,

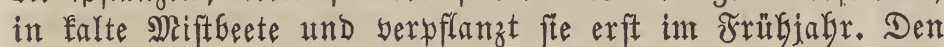
$23 i n t e r$ ủber müffen die Militbeete mo möglich eintigemal ge=

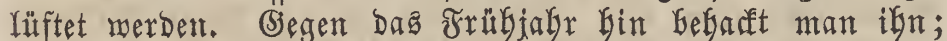
man befommt bei biefer behandungsmeife frübe bä̆uter.

d) Strofer rander SBiffing.

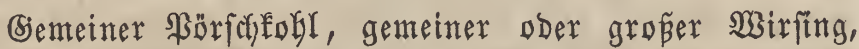

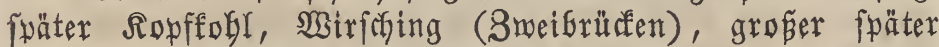

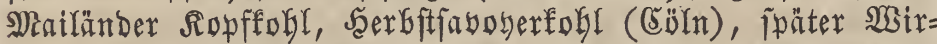

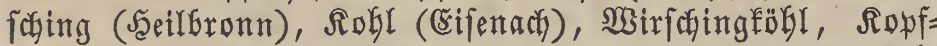
fohl (Salem am Bobenjee), groáer fpäter Sayoberfogl (Jabkentyeim).

Milan ordinaire, chou de Milan, chou de Milan pommć

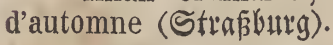

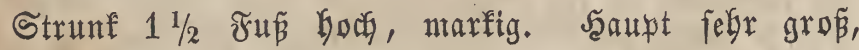
rund und länglich, aukẹn Dunfelgrün, innen gelb.

Der Same wird im 2lpril und Mai in gebüngtem $\mathfrak{B}:=$
Den auşgefäet. Sm Saerbft foblägt man ifu ein und beberft ifhn über ben Sinter mit Strol.

Diefer Rubl variint bäuftg, aber nidgt conftant.

e) Später runder Sistrfitg.

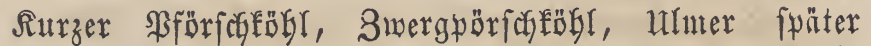
Whirfofing (Solfenbeim), grober fpäter Ropftobl (Tübingen), 3wergherztobl, Sancalier aus der Thouraine.

Chou pancalier à la feuille verte et frisée

Dem Galbfrüfen runden Wirnfing faft ganz gleich.

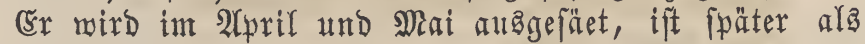
Der Galbfrübe runde Wirftng und fant yom Somnter bis faft zum Jribjabre benulgt werben.

f) (s) Brassica alba crispa. Bryant.

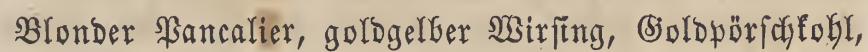
gelber Sayoberfobl, fwäter natürlidgelber Sayoberfogl (Tü= bingen).

Chou d'oré, chou à la grosse côte blond. (frant.)

Savoye Cabbage. (engr.)

Sat biel 2 (efnlich feit mit Dem borigen Robl, hat aber ein mely länglichea, lodferes Şaupt mit zärtern und gelb= grünen Blättern. Sonft gleicy mit Dem vorigen.

\section{Iangex $\mathfrak{M i x}$ [trig.}

Şaupt Iang, ftumpf, Iodfer. SBlätter lang, ftarf blafţ.

a) (5) ưner langer Writfing.

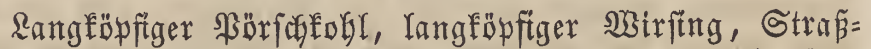

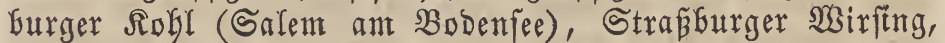

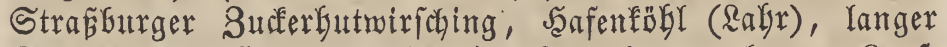

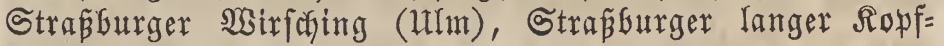
föbl (Tübingent).

Milan à tête longue, chou frisé en pain de Sucre d'hiver (Strapburg).

Strunf furz, Şaupt felyr lang, loffer. Blätter fdumal, ftarf Glafts, am SAande mach aupen untgefdagen.

SBirb Gauptfächlich in Den Straf̧burgern (5ärten fulti= birt. Mian jäet Den Gamen bon 2 lprif bis Miai. Dauer= Gaft über ben Winter und eir gefdyähtes (semüfe.

\section{Unterart.}

\section{Brassica oleracea acephala.}

Brassica oleracea non capitata.

Brassica oleracea. L.

Sobl, Minterfobl.

Chou cavalier, caulier. (franz.)

Kâl. (f̧đ) wed.)

Stengel boch, einfach, maxfig, an melchent fich eine Menge fleiner Sproffen und gropee, entweber fraufe ober glatte, ober auch eingefdanittene, gemöbnlich Gängende, ver= fofiedengefärote und am Ënde ber Stengel rofenartiggebildete Blătter Gefinden.

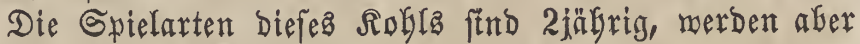
Durcha 2(bbrăttern 3-4jägrig, fie Dienen zur Nahrung Dę̧ Menfoden mie Des $\mathfrak{B i e f j e s . ~}$ 


\section{Nolenkobl.}

Brassica oleracea prolifera.

Brassica oleracea gemmifera. DeC

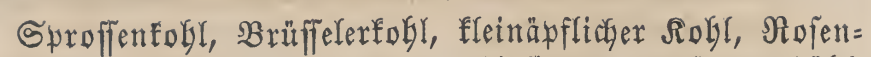

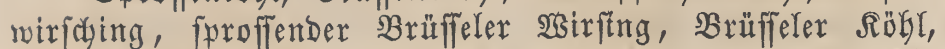
Sprufenfogl (Coln), Brüffeler Sproffen oder Rofenfübl (Tübingen), Stofenfögl (Salem am Bobenfee und Saben= heim).

Chou à jets, chou à jets et rejets, chou de Brusselles, chou

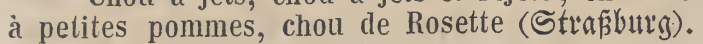

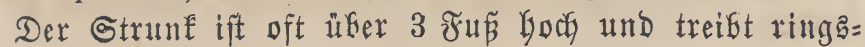
unt it Den Blattruinfelut eine Menge rofenartig gefoldoffener

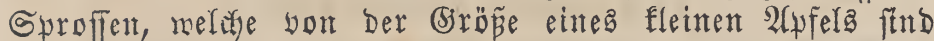
und aแล bicht iu= und übereitrander liegenden Blättern be= fteben. Blätter Glaftg. Die Sauptblätter fitnd an ibrer $\mathfrak{B a}=$ fiz gelappt, und fallen gemöhnfich bald ab.

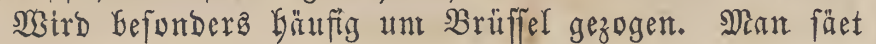

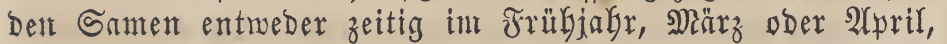

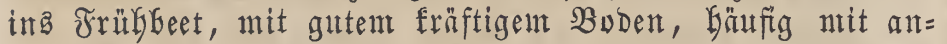
Dern Roblarten, und man fann in biejem ralle meift int

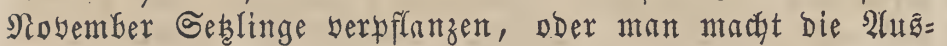
faat fwäter in ein fonnig gelegenea Beet und erfält bann in Sult ober 2 uguft Gethlinge. Rethtere müffen in einer

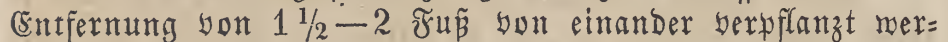

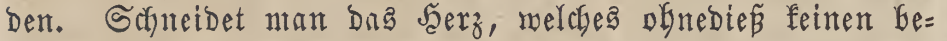
fonberen Saerth bat, ab, fo fommen bie Sproffen noch bief zalilreicher Gerbor. Man fann ben Mtofenfobl ganz wobl in Beete verfesen, bie fichn mit andern Bsemächfen angepflanzt find, wie in Rartoffelbeete zc., auch fann er im Spätherbft

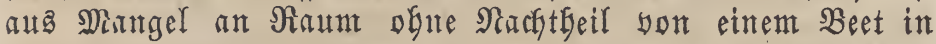

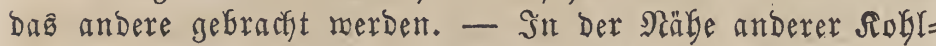
arten artet er gerne ala, Ceibet übrigens burch orröte felten, auch ift es yorfictstig, über Den WBinter bie Bffanzen etroa in bie (Erbe zu brüfen Dber in Rellern einzufdhlagen. Bur Sanenzucht läß̈t man mur fojönen, gefdloffenen Nofent= fogl fteben. Der Same bält fith 5-6 Jabre gut.

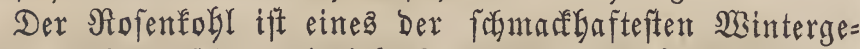
müfe und fann feiner Ěrgiebigfeit und Dauerbaftigfeit we= gen Den ganzen 2 sinter Durch Genutht werben.

\section{a) $\mathfrak{B}$ ielföpfiger $\mathfrak{R}$ olgr.}

Brassica oleracea capitata polycephala.

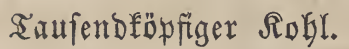

Chou à mille têtes, chou avec cent têtes. (frrant.)

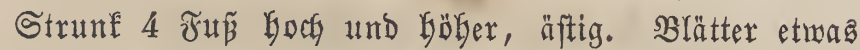
flein, zahlretç), längliç - eifürmig, ganzrandig unb Gelfgrün.

Erine Gujchige grofe Sorte, wirb im Jelde gebaut, ift ebenfalls dauerbaft über ben sionter, aber nicft Gefonders yon bieformar.

\section{2. 绝lattiobl.}

Brassica oleracea acephala vulgaris.

Stengel etwaz Goch, wben werbieft, marfig, Brätter eben, ganzrandig, längliçrund. B̉lattftiele geflügelt, bie Şerz: rofen offen, bie Stengelrofen flein. Blüthen fehr grof́. Die Sbläter biefer Roblarten fogliepen fich nidgt und werben neeift abgeblattet.

Dieje Soblarten nelymen faft mit jebem $\mathfrak{B}$ oben yorlieb; in gutgebüngtem Boben aufgewachfen, ift ifr Errtrag reich= ?
Yicyer, in magerent $\mathfrak{B}$ poen aber befommen bie $B$ lätter einen zarten (jefchmac. Die Sonmterfaat madyt man im Früb)= linge, fobrld es ber Boden und Die Witterung erlatben, und gemöbnlich in Beete, in weldyen yorker fochon andere Jrünte geftanden Gaben. Se nady Der Gröñe Der Gorten verpffanzt man bie Geblinge $1 \frac{1}{2}-2$ Jún yon eitrander ent= fernt und befarft fee einigemal ober bäufelt fie an. Doer man fäet den Blattfogl erft im Junt ober suli und ver= pflangt bie Seblinge in 2higuft und September auf afge= leerte Bnrtenbeete ober auf Stopwelfelder. Den $\mathfrak{B}$ inter über

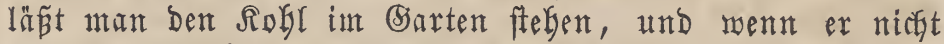
gerabe ganz ofne Schneedecfe bleibt, fo exfriert er aud nicht. Will nean ifn aber bennody yor der אälte bermabren, wo= Durch man denfelben zugleid aud etrab yor Den Saajen,

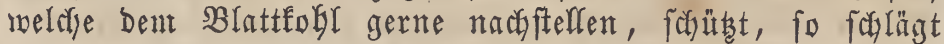
man ibn im Serbfte in eine gefortitste, aber forattige sage

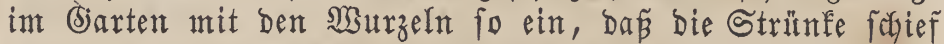
zu Yiegen fommen. - Sur Samenzud febt man bie frä $=$ tigften SPflanzen, nidgt aber blós Struñfe, mie es meift ge= fedebt, zeitigft in Das Samenbeet. Der Same erbält fich $5-6$ sakre.

Man fann Den Blattfogl Daz ganze Saly Gintourd be= nüben, fochon im Frübjakr fodneibet man bie jungen $\mathfrak{B}$ lätter und Stengelfproßen zu (Eemüfe und Salat ab, fpäter bie erftarften $\mathfrak{B l a ̈ t t e r , ~ u n d ~ i m ~}$ Binter bie ganze Sirone. - Die im Serbfte abgenommenen ålteren Blätter focten fich nicht

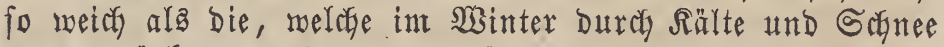
etwas mủrbe gemacht morben find.

$$
\begin{aligned}
& \text { a) (s) enteiner şlattogl. } \\
& \text { Brassica oleracea viridis. L. }
\end{aligned}
$$

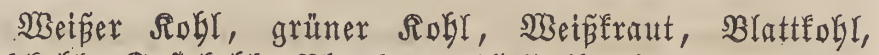
Miarftelgl, Baftefogl, siattfraut (Jectbelberg).

Chou blond, chou verd, chou commun. (frattz) belfgrün.

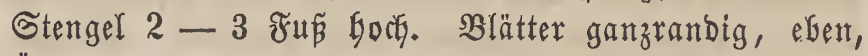

Jn Franfreich Gefonberz Gäufig angebaut, - Die $\mathfrak{A} u \xi=$

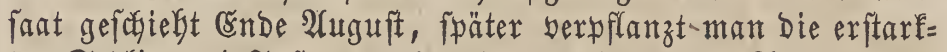

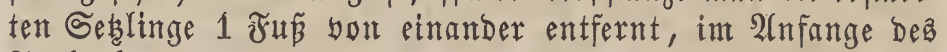
Jrübjabro fann man fajon mit 2 bblatten Geginnen zu bje=

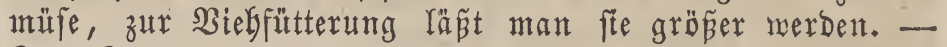
Sur Samenzud nimmt man bie Greitblätterigften Rulys= yflanzen, Glattet folche meniger ftarf ab, und im sult ge= wöGnlicf reift Der Same.

$$
\text { b) (5) rof }
$$

Breitrippiger. Winterfugl, dicfrippiger אuff, gelbeg Blattfraut, gelber Blattfogr.

Chou de Beauvais, Chou à large Côte. (firantz.)

Stengel ftärfer als bei ber yorigen Spielart. sblätter größer, birfgerippt, gelbgrün.

Da und bort in Deutfogland, Gäuftger in zranfreid fultivirt.

2rrtet germe auล, Gefonderş merben die Blätter bunflergrün.

\section{Raumkabl.}

Brassica oleracea arborea.

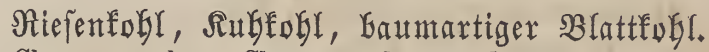

Chou en arbre, Chou cavaliers. (frattz.)

Collets. (in Flanderti.) 


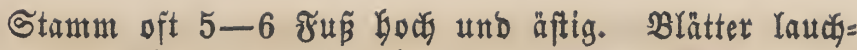
grün. Wirb bäufig 3-4 Salgre alt.

Wird Gauptäadlid in $\mathfrak{B}$ eftranfreid, zuntal int $D e=$ partentent ßą De Calaiz und in. Flanbern um Rifle und Tournag fultivirt.

Man fäet Den Ganten im Frǚlling und berpflanzt fite bei geböriger Stärfe in einer Entfermung yon 18 3oll yon einander. Bum 2 GGlatten für Den Sonmer jeboch madyt man Die Saat int Juni ober Auguft. Dieje Soblart bält zmar bäuftg ben $\mathfrak{B i n t e r ~ a u s , ~ e r f r i e r t ~ a b e r ~ b o c h ~ m e i f t ~ b e i ~ e i n e r ~}$ Sälte yon $12^{0}$.

Sie artet gerne befonders in ben Braunfogl aus. Bur Nabrung taugt biefer fobl nidgt biel, um fo mefr aber zu Biebfutter; Die Blätter vermegren bie Nilch Der Sübe, unb bie Strünfe werben zerfchnitten mit Scädfel gefüttert.

Eine Spielart Diefea Rogla ift:

\section{a) $\mathfrak{R}$ เ}

Flanbrifater Stengelfugl, rotber baumartiger Robl. (Sianz wie ber yorige, mur bie Blătter roth.

b) (s) meiner pommericter sobr.

Brassica oleracea sativa rubra aperta laevis.

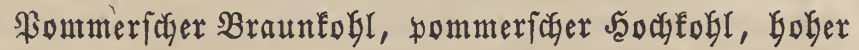

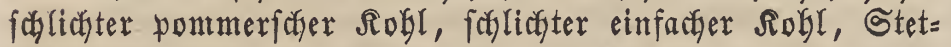

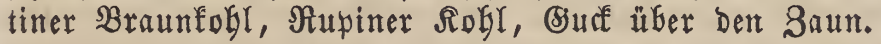

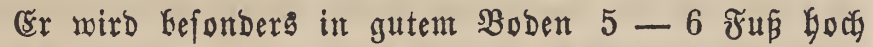

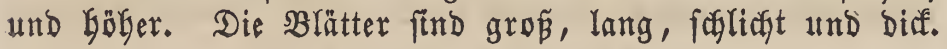

\section{UErünkngl.}

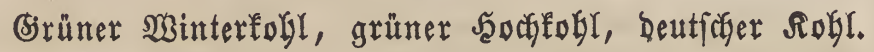

Stengel entrueder melgr Goch, ober megr nebrig. SBätter gemolgnlich uneben, tief eingefonnitten ober gefranzt, oft itarf fraus, grün, und ziemlich ftarf punftirt. Stengel und berzrofen zaflreich und offen.

Wenn man Den Sinunfobl früfe pflanzt, fo mirb er Gäker und treift mefre Spropen; regere merben aud zärter unb fämadfbafter, je offter man fie abfchneibet. Die älteren Blätter geben ein etwaz Gartes Gemüfe, wenn fie bor ben eintretenden zröften Genủht werben.

\section{a) Bsefdritglätteriger (s)}

\section{Brassica oleracea viridis.}

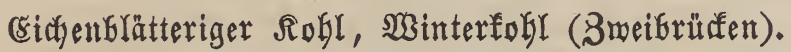

Chou à feuilles de chène, Chou verd feuilles de chêne. (franı.)

Blätter grủn, eben, glattranbig, bäufig tief eingefưnit= ten; Blattlappen ganzrandig.

Diefe Barietät fdeint zumeilen in ben $B$ raunfogl ober ben Sirauģogl übergefyen zu wollen, inbem bie Blattrippen zumeilen einen veilcyenblauen 2 nflug oder ein etros fraufez alnefgen ane

\section{b) Eseframzter (s) rüntol.}

Brassica oleracea sabellica non capitata.

Brassica oleracea sabellica. L.

Brassica oleracea selenisia. Mill.

Brassica sabellica. Suck.

Saerzfogl, গצirfoding, \$örichfogl, grüner Borecoli, grü= ner 2 Binterfogl (Deutfajlanb), Strauşogl, grofer norbifajer WBintertogl.

Chou fimbriè. Chou vert, Chou non pommè, Chou frangé. (franz.)

Green Borecole. (engl.)

Green kale. (iffottr.) grŭ̃n.

'Stengel meift hod\%. Blätter ganzrandig, ftarf gefranzt,

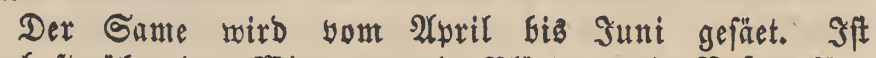

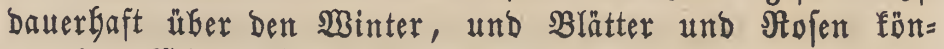
nen Den Winter Gindurç zแ Beműfe und $\mathfrak{B i e b f u t t e r ~ b e m t h t ~}$ werben.

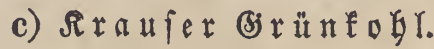 \\ Brassica Silenisia. L.}

Zeberfogl, Blumagefogl, grüner fraufer Winterfogl (Göln), Sïblfraut und SBinterföbl (Jaeibelberg), fraufer FeDerfohl, Subfobl (J̧obenteim).

Chou plume, Chou aigrette, Chou cavalier très frisé. (frantz.)

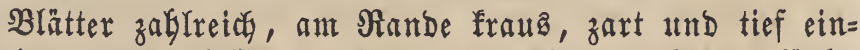

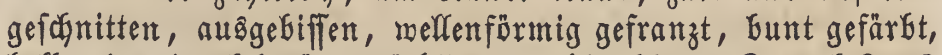
helf= ober bunfelgrün, rötblich, rötglichblau. Strunf $2-3$ Fus boch.

Wirb båuftg und wie ber borige fultivirt, nur will er einen beffern Boben. - Err ift beffer alß (semüfe benn ber borige, am meiften werben int Früblinge bie Stengetrofent gebraurst. (Er mird befonder ftarf un Leipzig gebaut.

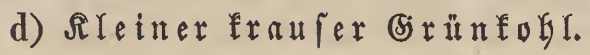

Barberwiffer Sogl, fleiner grüner Sobl, grüner Feder= fohl, fraufer niederer Sirünfobl (Jeamburg). borige.

Stengel 1-1 1/2 ₹̛́ boch, im Sanzen fleiner als ber Siejidmanaf.

Sebr bauerfaft im Winter. Blätter febr zart yon

\section{5. faraunkobl.}

Stengel und Blätter bunfelroth, theilą megr braum, theils melar violett angeflogen.

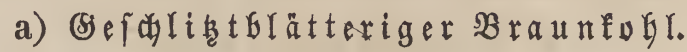
Brassica oleracea laciniata. $\mathrm{L}$.

Stengel und Blätter Dunfelroth und Gläuliç angeflogen. Eine nicht fonftante Spielart.

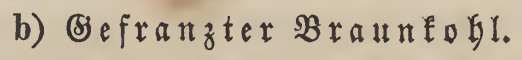

\$urpurrotber Borecoli, gefranzter Rogl, facttifiter

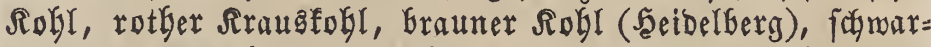
zer fraujer Sabhr (Nieberrbein), Glauer Winterfogl (J̧eil= Gronn), Braunfogl (Nordbeutichland).

Stengel und Blätter bunfelviolett.

Sälte fofabet ifm nidyt, er mú fogar burchfroren wer= Den, wenn er ein angenebm fohmerfendes bemulje geben foll. (beft gerne in Den Grünfogl ĭber.

\section{c) $\mathfrak{A} \mathfrak{r} \mathfrak{u} \mathfrak{f} \mathfrak{r} \mathfrak{B} \mathfrak{r a} \mathfrak{u} \mathfrak{n} \mathfrak{\mathfrak { b }} \mathfrak{l}$.}

Brassica oleracea Selenisia. L.

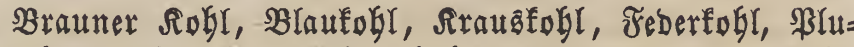
magefobl, rother sirabstobl, Gober fraufer Graumer sobl, 


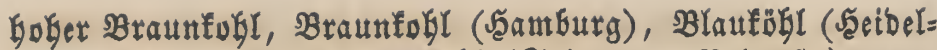
berg), Feber = ober Winterfogl (Salem am Bobenfee).

Chou plumage, Chou brun, Chou plume, Chou aigrette. (firat $\xi_{\text {. }}$ ) Borecole, Browncole. (ettgl.)

Stengel und $\mathfrak{B l a ̈ t t e r ~ D u n f e l r o t h , ~ i n ' s ~}$ Violette fọint= metnd, băufig bunfelblau.

Man fäet ifn im 2lpril; febr bauerbaft gegen Sălte.

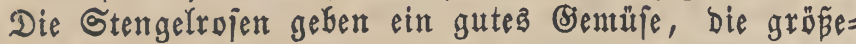
ren Blätter müffert übrigens burdgfroren werden.

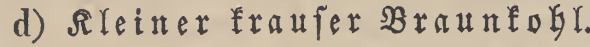 Brassica oleracea fimbriata pumila. Brassica fimbriata sibirica.}

Barbemiffer Sogl, niebriger Grauner Rugl, niebriger Braunfobl, niebriger fraujer Rogl, niebriger fraufer brauner SoGl, Dachaftogl, fleiner fraujer Barbeniffer Rokl, fraufer nieberer Dunferbrauner Blattfofl (Jamburg), Federfobl ( Wentime.

Sibirian Borecole, Curled Colewort; Scotch kale. (entgl.)

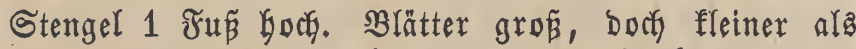
bei ber yorigen Spielart, febr fraus, bunfelroth.

Man fäet ben Gamen yont Mai - Juni und veriegt

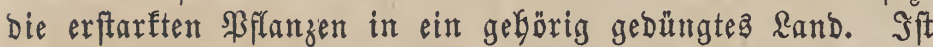
gegen אälte nicft empfindlich, da er meift yom Schnee be= befft mird, wirb in Gegentlyeil beffer, menn ex Durchfroren mirb, und gibt bann ein felfr angenefmes zartes Gemüfe.

\section{e) $\mathfrak{B} \mathfrak{u} \mathfrak{n}$ e $\mathfrak{r} \mathfrak{B} \mathfrak{x} \mathfrak{a} \mathfrak{n} \mathfrak{f} \mathfrak{b} \mathfrak{l}$.}

Brassica oleracea Selenisia foliis variegatis.

Franzöfiffher bunter Sobl, \$lumagefogl und bunter

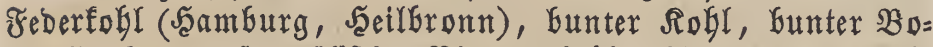

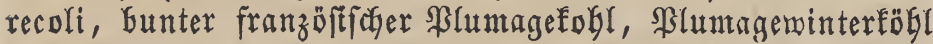
(Tübingen), Gunter Shlumagefohl (J̧ofengeim).

Blätter fø̆b̆ bunt, grün, ruth, violett, weiś, băuftg rojenfarbig und gelblich geflecft und geftreift, fonft beut fraujen Braunfogl ziemlich gleich.

Artet fegr gerne aus. Sur Samenzud lä̧̧ man bie Gunteften Sflanzen fteken. Eignet fied megr zur Sierde in

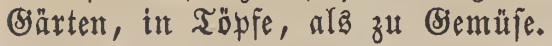

\section{Unterart.}

\section{Brasica oleracea hotrytis,}

Blumenfogl, Botrbtištogl.

Chou botrytis. (fiatz.)

Blätter lang, ganzrandig, hie und ba gefeedert. Blü= thenftengel fleifchig, bicht gebrängt beifanmen ftelend ober langgeftrefft mit fleifugigen monftröfen Blütbenföpfen.

\section{Blïthentwobl.}

Brassica oleracea cauliflora seu botrytis. DeC. Brassica cauliflora. Bryant.

Blumentohl, Traubenfobl, Siäfefogl (গärnberg), (Car=

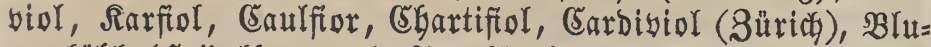
menfögl (J̧eibelberg und శranffurt).

Chou fleur. (fiantz.)

Colli -flower, Cauli -flower. (engl.)

Caboli nori. (ital.) Caoli fiori. (Bettebig.)

Blumkol. (Sd)weden.)

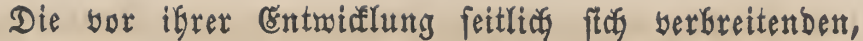
bichte Büfchel mathende Blütbenftiele und Blüthenfnogipen Gilben eine furze, fefte, fleifodige und gelblichmeíse Dolbent= traube, ben fogenannten $\mathfrak{R a ̈ z}$ Dber bie Blume. Die Blätter

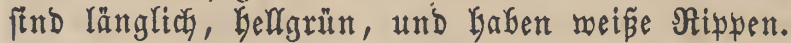

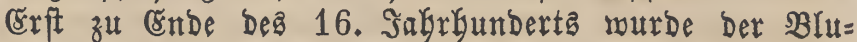
menfobl befannt. (Ér fam aแs 2leggpten über ben Drient

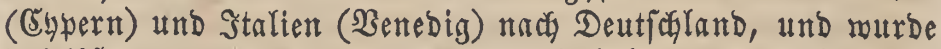

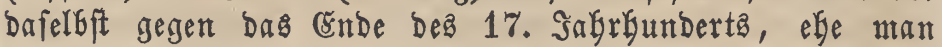
felbft mit feiner Samenzudft befannt war, aus italieniffyen ober chprifach Samen gezogen.

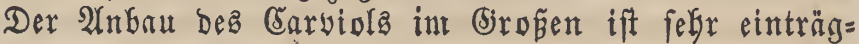
lich, wie z. $\mathfrak{B}$. um Erfurt, wo ein ftarfer Sandel mit ifm getrieben wirb.

Der Blütfenfogl gebeigt hur in einem tief und frifch untgegrabenen, megr füblen, frifo und ftarf gebüngten, aber nicht zut fetten, janbigen ober zu thonkaltigen 3 oben, am beften in gut ungearbeitetent アrajenboben und Gumusreichen, nieber gelegenen Nenbrüd,en und in einer bon Nord = und

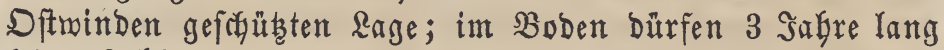
feine Soblarten gebaut worben fein. - Mit Dent 2 nbau, Der Gei biefer Roblart umftändlicher als bei allen andern ift, richtet man fich ganz nach ber Beit, in welcher man fte be= nithen wiff. Entweber fäet man biefen Robl Ěnde 2tprila, Mära oder Endo Mai's, und bann Den Sommerblumenfobl,

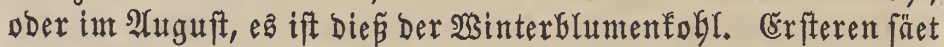
man um bie oben angegefene Seit in bie bazu vorbereiteten Beete und zwar felgr Dünn aus, bamit bie jungen Pflanzen um fo ftümmiger werben fönten, und bringt ben Samen nur oberffächlich unter bie Ěrde. Die Saat beberft man

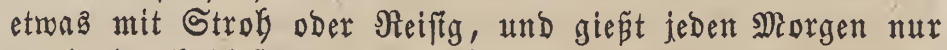
menig burch biefe Bebeifung binburdy. In $8-12$ Tagen

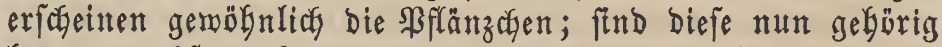
Gerangewadden, fo entfernt man entweber bie forwädjern und läp̧ nut bie fräftigern in einer Entfernung von $2-4$ Boll yon einander fteken, ober werjetst, ober was nody yor=

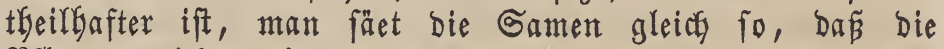
Pfflanzen nidgt melgr verzogen werben bürfen; in biefem Yesz=

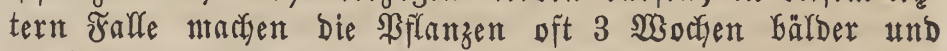

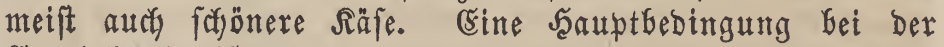

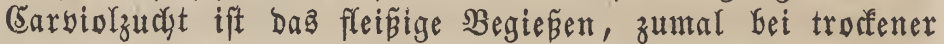

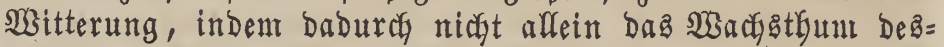
felben befördert wirb, fonbern auch feine Gauptjächlidfiten Freinde, bie Eroflöbe, yon ifm entfernt gefalten werben;

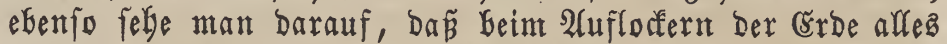

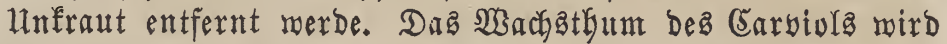

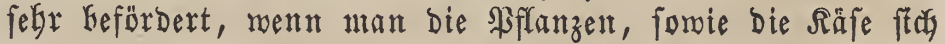
zu entruićeleln anfangen, mit guter Düngererbe ober, wenn Der Boben etwas mager ift, mit Raub=, bejonders Buthen=

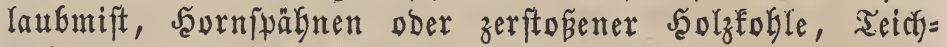
foflanm, umgift. WGas das Verpflanzen ber Seblinge be=

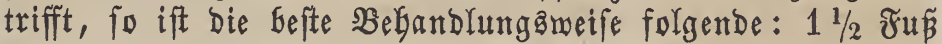
yon einnnder entfernt zieflet man in einem Beet brei, etraa $4-5$ 3oll tiefe Furchen, in reldye man mieber 10 8oll

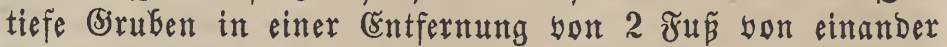
madf; biefe Erruben merben einige Tage lang wieberkolt

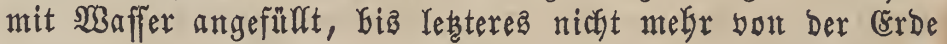
aufgenommen wirb, Gierauf gieşt man fte mit in $\mathfrak{\text { Waffer }}$ aufgelöвtem Sdyaf=, Safmeine= ober Taubenmift auf, füht 


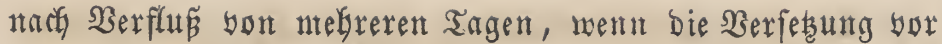
fect) gefen foll, bie Röber mit guter (5rbe wieber aus und bringt in Diejelben, und zwar biz an's $\mathfrak{g e r}^{2}$, bie zutor yorfectitig ats Dem Boben gefobenen Seblinge, und nun werben biefe ftarf angegoffen. Sind Die Pffanzen gegen baz

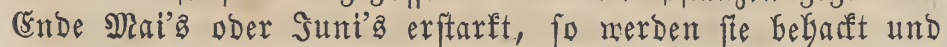
gefäufelt, aber mur in Dem Falle, Dá bieferfen in Furefen gepflamzt rourden ftrd, indem ambernfalls bie 1 Burzeln be= fääbigt und fich in Folge beffen nur unamjegnliche Räje entwicfeln würden; in ebenent Boben fetegende Carbiolpffan= zen werben weber befacft noch gefäufelt, fondern mur tief genug in Den Boben gebradyt und fwäter etwa anit Dünger= erbe ober Dung umgeben. Ěrfcheinen einntal die Blumen Des Carviols, fo werben bie Brätter bei trodfenter Şitterung,

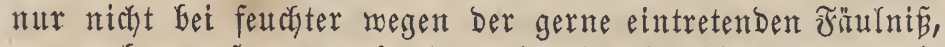

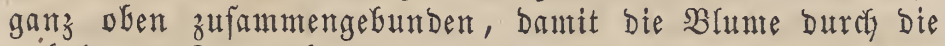
anbaltende Sonnenbibe nidbt in's Schiesen geräth. Wentiger

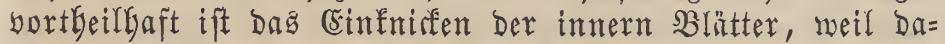
Durch bie \$flanze in iGren Trieb unterbrocten mird. S3ent nun im 2(uguft ober September bie Răfe yollfonmen aus=

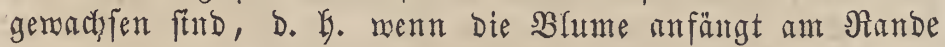
aus cinander zu geben, fo nimmt nan fie mit einem Theil Des Gtengela 3-4 Boll lang ab. Befbürig fultivirt erbal=

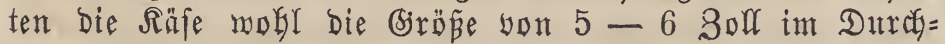
meffer. - Die şflanzen, welche erft (̌̈nde Mai's ausgefäet merben, werlangen einen melyr fojattigen und feuchten Stand= punft, unt fie yor Der meift fchun ftarf gemordeneat Sonnen=

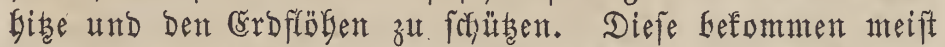

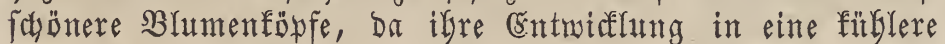
Beit fülft. Int Sftober und November merben bie Riñe Erauchbar. Die Siffanzen, Deren Säpfe fted nur mentig ent= wiefelt Kaben, werben, wenn bie Jröfte fich zeigen, jammt Den Wurzeln aus bem Rande gettonmen unb, wie wir foüter zeigen merben, ant froftfreien Drten aufberabrt. - Int ₹rüh $=$

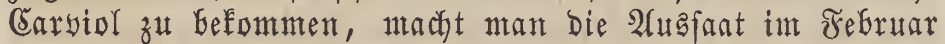
vber März in mäßig marme, aber ja nidyt. heipe Miftbeete, weldye man bei falter SBitterung, un bas Berzärteln ober Bergeilen Der Bflanzen zu berbüten, nur mit Miatten ober Brettern ftatt Der Fenfter Geberft. Mitte Alprils fann ntan gewöGnlid, die Siflanzen in's freie Rand verfesen, und gegent

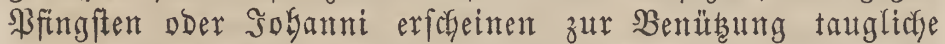
Siäje, welrbe jedoch, auker bei bejonders günftiger warmer SZitterung, felten bie Brröbe fpäter angebanter Siffanzen er= reichen. Eine meitere Früffultur=Methobe, bet melcher man nocf früber Garbiol ergält, ift biefe. Endoe 2lugufts ober Septembers fäet man Den Samen in falte Diffteete, Gegieśt mur ganz felten, verfect bie Siflanzen im Dftober, fomie fte einige : Blätter getrieben Gaben, etrwa didgt in andere, for EaYten Winden gefoühte und fonnig=gelegene Miftbeete, und gief́t fie bann nur mentig Dber nur einmal an, wenn aud gleich Der Boben ganz troden ift, Denn bei Siaffe faulen oder erfrieren fte germe. Tritt falte $\mathfrak{W}$ itterung eit , fo bebeft naan bie Slffanzen mit Streu 2c. Contmeder läpt man fie

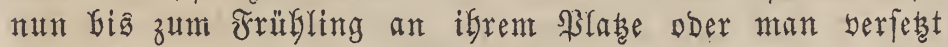
fite Mitte Fefrunrô in wärnere Mifteete, beberft fite mit

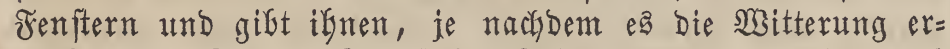
Jaubt, yon Zeit zu Zeit frifole suft. - Ëndich wäre noch Das Berfabren anzugeben, weldres bei Der Winterblumenfobl= pflanzung im Sluguft zu beobachten ift. Mian madgt bie

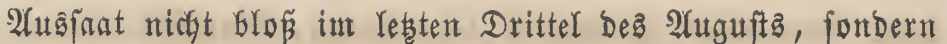
audy im 2 anfange und in Der Mitte Deffelben, $14 n$, wenn bie eine 3ucht feblfidlagen follte, Doch wenigftens bon ber

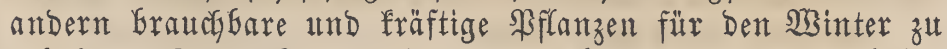
erbaltent. Diejer Saat foylägt ein ntebr magerer Boben beffer zut ars ein zut fefr gebüngter, bejonderz aber eine fonnige Lage Des Beetes. (Yine Beberfung ift fo rentig nöthig, als bei ber erft int Mai angeftellten Bffanzung. Man fäet bier

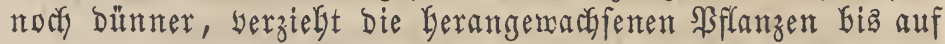
3 Soll yon einander, bebt fie romöglich mit demt Erbbaflen

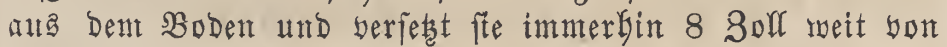
einatider, um fe int Frïhjagr fannt Dent (Erbballen aus= Geben zu fönmen, auf Daz Ueberwinterungagbeet, auf ein

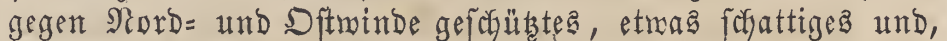

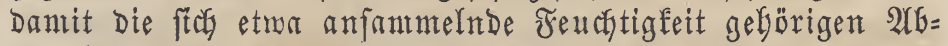
zug Grabe, etroas. Goch Yiegendes, bom ltnfraute gefäubertes Beet, und giē̈t Die Pffanzen nun an. Den SBinter juber bedürfen lestere feiner Bebeffung, auper gegen zu anbalten= Den Sonnenfidein, unt das Treiben berfelben zu berbindern. Solften fich die Gerwächfe Durch Rälte aus Dem sBoben heraus= gefdyoben Gaben; fo Drünft man bei eintretendent Thaunetter bie Groe wieber yorftchtig an fie nu. Bei günftiger SBitte=

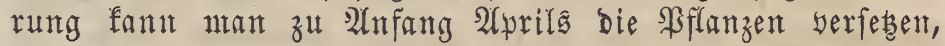

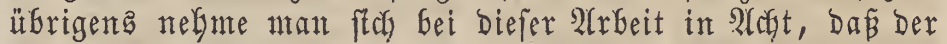
Bollen fter nidft won ben SWurzeln ablöfe, Denn nidyt genug fann bie Schomung Der jungen $\mathfrak{S}_{3}$ arzeln bei Der Carviol=

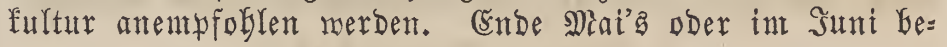

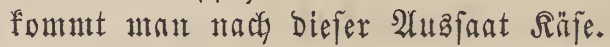

Die Samenzucht anbelangend, ift biefe eine febr miñ $=$ licke, bei meldyer felten biel Gerantafontmt, jeboch ift fite, Gefonders bet ber Carbiolpflanzung im Bropent, Durchaus nicht zat verwerfen, indent man yon Samenhänblern oft gans fojlecyte Wanare erbält. Den beften Samen beziegt man aus Erngland, und biefer ift auch borzugsneife zur 2ubfaat und fernern Samengeminnung zu empfeflen. Der Gommerfogl eignet fitch nisgt zut Samenzudyt, meil bie Samen int Spät= Gerbfte bei uns nicht megr reifen; ntan nimnt Dé̈galb zu biejem Zwerfe Den Samen you fräftigen, meiśen, flachen und bichtgefoldoffenen Räjen Des Minterblumentogla. - Mian bin= bet bie Sffanzen, weldye anfangen

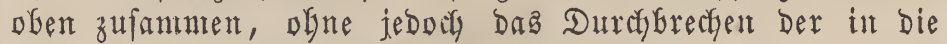

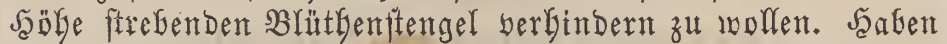
fted Stengel über bie Blätter herausigeforgben, jo unterftübt man fie Durch brei, in ein Dreieff um bie Bffanze herun= gefterfte niebere SFähle, melche man mit Sidnüren zc. um=

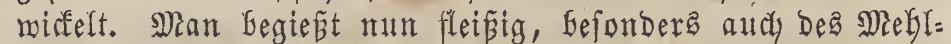
thaues und Der Eroffobe wegent. Die Samenftengel bricht man oben etma 1 Soll lang ab, ba bie oberften Schoten menig ober fallechten Samen geben und nur bent übrigen Die Nalgrung entziethen würden. Neif ftrd bie Schoten, wenn fie eine weiģliche Farbe unb Graune Rörner befommen; jest zieft man bie Samenftaude mit Der SBurzel aub und läpt fie int rreien in ber Eonne, ant beîten aufgelyängt, yollends reif werbent. Cén guter Same ift etwas fletuer als ber bez Rotherautes, runder und etrage Geflerbraun, und bleibt, wenn ex in Den Safoten aufferabart wird, $5-6$ Ialye feinffähig und gift eimen febr guten Saandelsarartifel af. Set

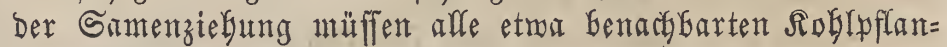
zen entfernt werben. - Noch Gleift unz Eintges za fagen 
übrig itber bie Heberwinterungąarten bes Sommer=Garbiols.

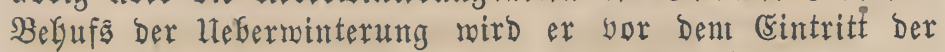

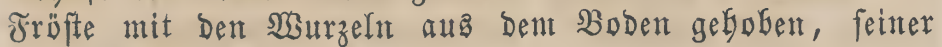
äunern Blätter beraubt, bie übrigen aber merden leirft zu= fanmengebunden, an einem froftfreien Sorte auf eigens bazu worbereiteten Rejerboira, ober in einent luftigen, aber gegen Jroft gefdühten, Gellen Relfer, Deffen Röcher bei gelinder switterung zu sffnen, bei falter aber und bor ber sadyt

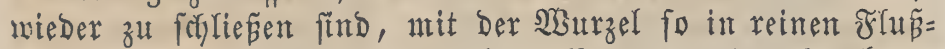

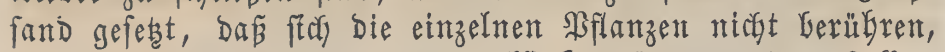
Dder utber ben 13 urzeln vermittelft Schnüren an Dem Reffer=

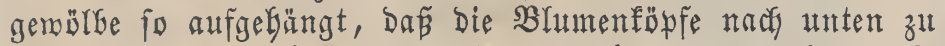
ftefen fonmen. Faulende Blätter melyne man gleich ab, und zur Benükung immer bie jüngften Säfe, überbarpt

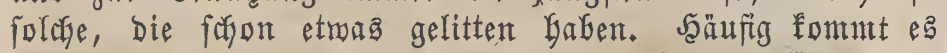
yor, bá bei eintretendent Frofte mande Carviolpflanze nux einen foglechten Sopf angefest Gat; im Rande fönnen num folche nicht melgr gelaffen merben, und ebenforwenig mag man

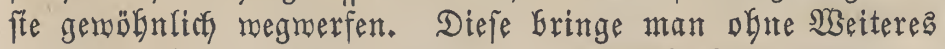
in Den Reller, felse fe yon Den anderen abgefondert mit Den

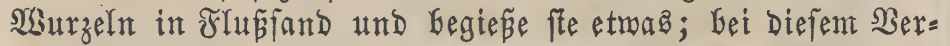

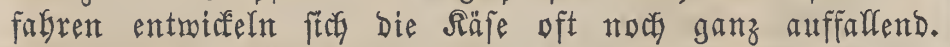
Auch bermefart man Den Carbiol im Freien in Sruben, welche nan mit einer bichten Rage bon Streu und Crobe und bieje

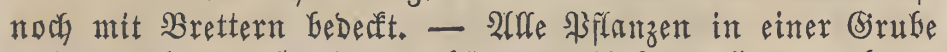

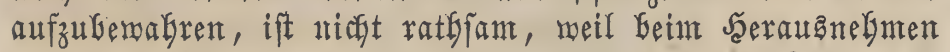
Der zu Genühenden bie jebesmal eindringende falte \&uft fohäb=

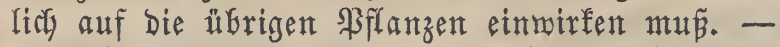

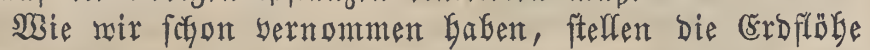
Dem Carviol fehr nach, und man befist berfofiedene Mittel, biefelben zu yertreiben. Unter die beften gefoüren inmer das fleip̧ige, aber feime Begiesenen Der Stauden, und zwar in Dent Manee, dá die Blätter faft fortwäbrend feucht erbalten wer= Den, wie auch Das lumpflanzen ber Carviolfeete mit Mionat= rettigen ober Sireffe, weldent Bembächfen bie Eroflöbe nody nefyr nachgefyen als Dem RoGl. Nicht aflein aber biefe Thiere

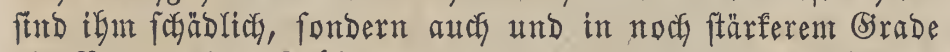

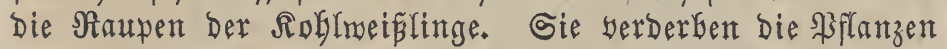

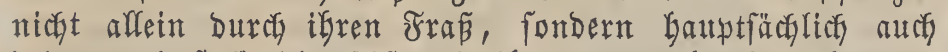

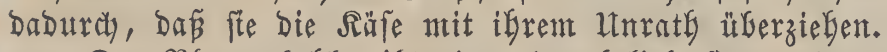

Der Blumentugl gibt eines Der Geliebteften und robl= fajmeçendften Bsemüfe, mie Sparger, in einer Butterfauçe, oder Srebsanace, in Fleifobrüle, als Galat, gebaden ober mit (crême überzagen.

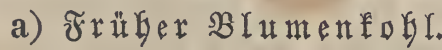

Zarter Blumenfobl, frügzeitiger Blumenfolyl, früber englifcher Carfiol, früber chprifcher Carftol.

Chou fleur tendre. (fianz.)

Earley. (engl.)

Der Same wirb yom Sanuar bis 2 (pril in falte Miift= beete gefäet, und die Pflatzen werben, wenn es Beit ift, erft wieder in falte Miffteete, Dann anf warme Beete ber= fert. Mian fann Den frülyen Carfiol aber aud fchon im Jerbfte fäen; in biefem ralle verfetst man die Pflanzen int

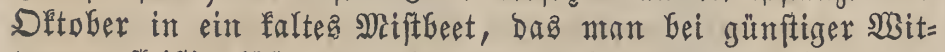
terung fleiṕig lüftet; im Sanuar treibt man bie \$llanzen in einem warmen Meiftbeet und berfest fie im orrübalgr, fobard fetne Jröfte mefr zu befürchten find, in's freie Rand.

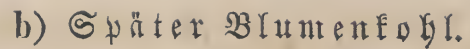

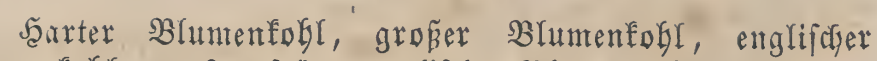

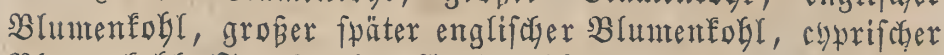

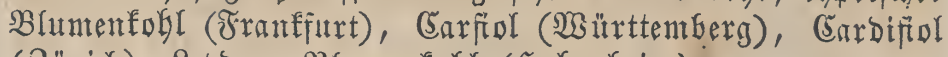
(Büridy), Reboner Bluntenfobl (Jabgenteim).

Chou fleur dur, Chou fleur d'Angleterre. (frantz.)

Sm Gianzen größer als der vorige, und reift fuäter.

Man fäet Den fpäten Blumenfobl entweder yont Mär

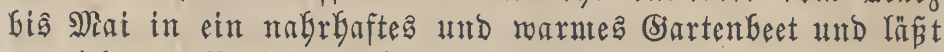
e马 nidyt am SBegieẩen feblen, man fann Dann im Jult bayon

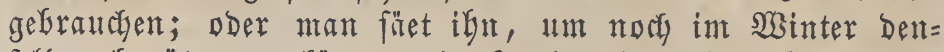

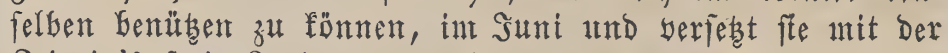
Seit in's freie Rand, aus welchem man fie im Dftofer wie= Der Gerausnintmt und in einem guten Sieffer einfoläğt, in weldyem fte bann Räfe anjeben.

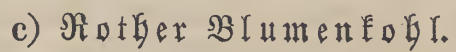

Blätter hie und da etwas eingefdynitten, Răfe rotb. Dauerbaft und ziemlicf früber.

\section{Spargelkobl.}

Brassica asparagoides. DeC. Brassica oleracea asparagoides. C. Bauh. Brassica oleracea botrytis cymosa.

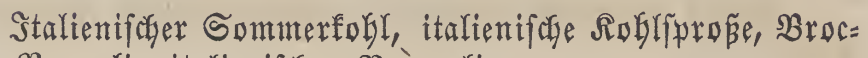
coli, Sroguli, italienifater Broccolt.

Brocoli. (engr.)

Die Strünfe Des Broccoli werden böber als beim ge= meinen Blüthenfolyl. Die $\mathfrak{B l u m e n f t e l e ~ u n d ~ B l a t t r i p p e n ~ f i n d ~}$ weniger ftarf. Blüthenftengel ausigebreitet, rißpenförmig. şätter bäuftg wellenförmig, etrwas geftedert.

2luch er foll aus Eypern zuerfit nach England gefommen fein and fita yon ba meiter berbreitet Gaben.

Man fäet Den Broccolifament gewöhnlich, aber fegr bünn, mit andern Solglarten in's Frülfbeet oder in'z freie Rand, und verpffanzt bie Seshlinge, wenn fie 8 Blätter Gaben,

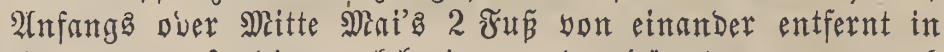
eimen etmas fanbigen, refmigen und gebüngten, menn aud etroa fdymeren Boben. Sach einiger Seit bebäufelt man bie Pflanzen und entfernt in ifrer Nähe, wie es fith von felbft

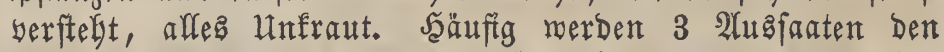
Sommer ủber, und zwar bie erfte, eben angegebene, Mitte

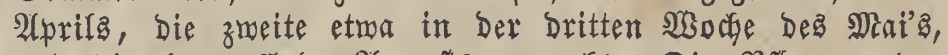

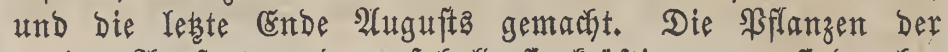

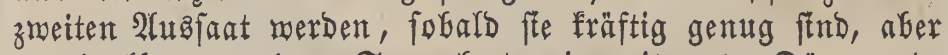
unmittelbar aus Dem Samenbeete, in mit guter Düngererde gefïlfte Töpfe gefest, an forattige Drte gebracht und yon Seit zul Beit begoffen. Findet man, Daf fie fortwadsfen, io febst man fie mit Den Töpfen etwa $3-4$ 3oll tief unb 2 Jus yon einander entfernt in das Rand und begiep̃t fie bei troffener SSitterung. Mit eintretendem Frofte bringt man fte mieber aus Dem $\mathfrak{a n d}$ e und an froftfreie Släbe, meldye

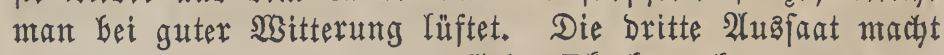
man in Räften, und gegen Ende Dftobers fann man ge: wöbnlich Seblinge auspplanzen.

um Samen zu ziehen, Fringt man meifi 3 Der fräf= tigften ßffanzen unter ein Sandglaz, begiest fie etwaz und 
läpt ifnen erfit Ruft zu, menn fee gebörig angemurzelt find. Der Same bleibt 5-6 Jahre lang gut.

In England mird die אultur Des Broccoli ftarf betrie= ben, und bie flimatifajen Verbältniffe biefes Randes fojeinen biefe auch mebr zu Gegünftigen als̄ bei uns. Die bei ung angeyflanzten Broccoliforten Gefommen geröbnlich erit im

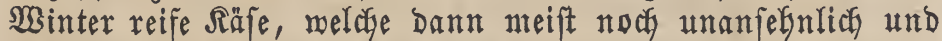

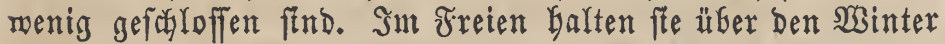

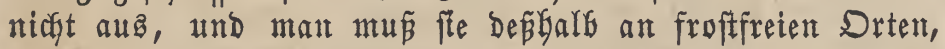
in Sellern z. aufberabren. Der 2 (nbau Des Broccoli bat alfo für bie Defonomie, wenigitens in unjern Begenden, wenig ober gar feinen $\mathfrak{\text { Serth. }}$

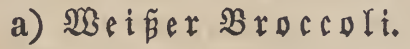 \\ Brassica italica alba.}

Şeiper gemeiner Broccoli, meiper Brofoli, italienificher

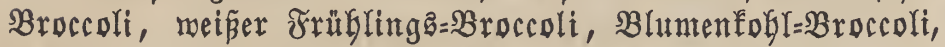
weíper neapolitanifder Broccoli, meífer Brodfelfobl (Tü= bingen).

Brassica blanche ou commune. (firanz.)

Stengel und Blume meís, rebtere faft ganz bon den langen formalen, flachen und biff geaberten Blăttern einge= fichloffen.

b) Selber $B$ roceori. RuGl.

Gelber römifăer Bruccoli, fofmefelfarbiger italienifader

Der vorigen Spielart gleich, mur bon Farbe gelber.

c) Bioletter Brocfoli.

Brassica oleracea asparagoides capensis.

Brassica italica purpurea.

Mialthejer Broccoli, purpurrotber rönifacer Broccoli, blauer Broccoli, purpurfarbener Rapfohl, römifuser Broc= coli (Tübingen), Jrübbrocculi romani (Galem am \$odenfee), früber rotber Spargelfobl, purpurfarbiger Sapplobl, Cap Brocoli.

Brassica violette, Brassica Malthe. (frntrz.)

Purple Cape. (entgl.)

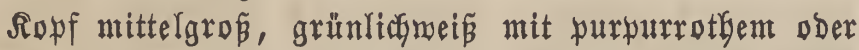
bunfelviolettem 2 nffug, meldye Farbe Durch's Rocten ver= fdymindet. SBlätter melfenförmig gelappt.

Man baut ifn als eine frübe Sorte bäufig in ơng= Iand, am meiften aber in Stalien an. Maan פai und Suni aus unb er Itefert vom September bia $D e=$ cember אiäfe.

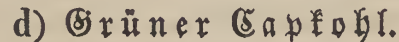

Green Cape. (entrl.)

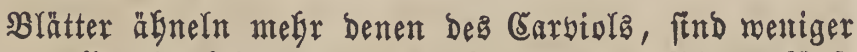
ftarf gemellt alz bei ber borigen Gurte. Die Blumenfäfe find größer, grünlidfuei fend etraz yon den Blättern bedecft. Baritrt mit vielen grop̃en, wellenfürmig aubgezacften, meiñaderigen Blättern Hnd fleinerent, aber feftem $\mathfrak{S}_{\text {ăfe. }}$

e) $\mathfrak{A} \mathfrak{h} \mathfrak{m}$ farbiger Spargelfohl.

Blätter breit, fegr auø̄gebreitet, meí geabert, biá,

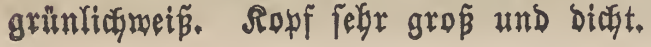

f) Spăter 8 werg= Spargelfugr.

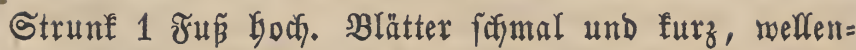
fôntig, ftarf aubgezadft, Dunfelgrủn, weís geabert Ropf purpurroth.

g) Sibirifder Spargelfogl.

Dänifater Spargelfobl.

Strunf purpurroth. B̉ätter lang, funnal, mellenförmig

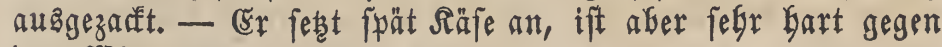
Den Winter.

\section{Hnterart.}

Brassica oleracea gongylodes.

Brassica oleracea caulo-rapa.

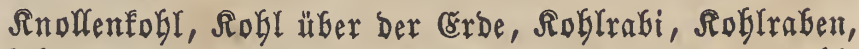
Dberfoblrabi, Rnopffoblrabi, Roblrübe üFer ber Errbe, Robl=

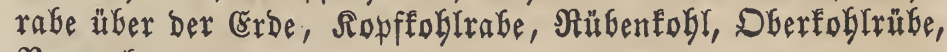
Napecole.

Chou rave. (franz.)

Turnep rooted Cabbage. (entrg.)

Kolrabi. (jd)wed.)

Die 23 urzel ift ftarf, äftig und Golzig. Der Stengel

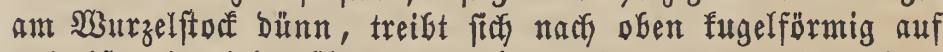
und ift mit vielen $\mathfrak{A}$ ugen verfefen. Die Blätter find glatt, getheilt, und fthen zerftreut auf Dent fnolfigen Theile bes

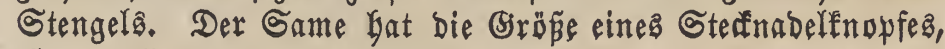
ift runblich und fidwarzbraun.

Der Roblrabi liebt einen gut verarbeiteten, frifachen,

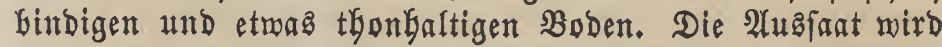
entweder in Mifftbeete ober in's freie \&and gemaift. Im erften

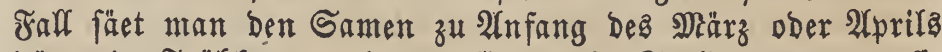
bünn in Frübbeete und verpflanzt bie Seflinge, wenn fie

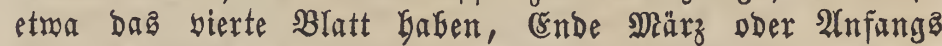
2laril in falte Beete, welche man bebecfen fann, ober im Mai 1 - 2 Jü won einanber entfernt in ein fonnig gele= genes Beet des (5artens. Ende Miai'z ober 2 Anfang Suni's erbält man yon ber Frübfaat nteift benubgare Snöpfe. Sn' Freie mirb bie Saat Enbe März ober im 2(pril borgenom= men. Da bie Roblrabi felten länger alb 2-3 Wodjen ifyren

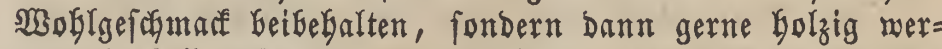
Den, fo jollen fie audy yon Riebgabern berfelben zu beridie= Denen Seiten aubgefäet werben, und zwar fann biés affe

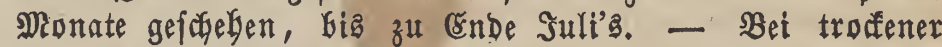
Witterung müffen fie fleísig begoffen merben, Damit fie nicht Golzig werben; aus eben biejem forrunbe bürfen fie niegt ab= geblattet werben, auEer wenn man fie aus bem \&ande nimmt, un fie für ben $\mathfrak{3}$ inter aufzubeben. Die Seblinge ber fpä=

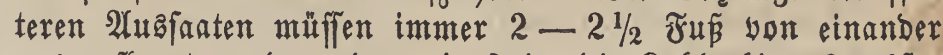
augigepflanzt werben, denn je freier bie Soblrabi aufwachjen

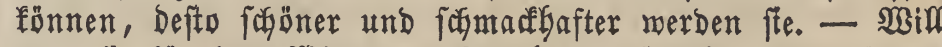
man fie für ben Winter aufbemalgren, fo thut man fie im Dftober aus bem Iande, nimmt ifnen bie slätter biả auf's

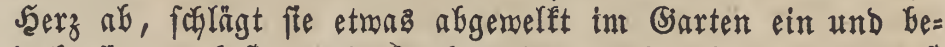

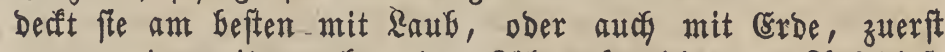
nur menig, mit zunehmender אälte aber biedter. 2łuf biefe

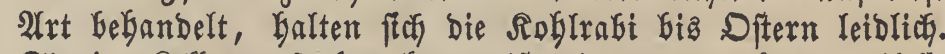
Sie im Reller aufzuberwabren, ift nicht anzuratben, weil fie

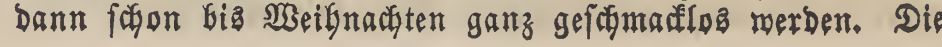








Bflamen, yon benen ntan Ganten geminnen mill, werben Den Sinter über eingeforlagen und fommenden Frübling in's Beet gejest. Der Roflrabi artet gerne in andere $\mathfrak{R}$ 'bl= arten aus und bildet Bajtarde.

Die jungen fleifdigen Stengelfnolfen, wie aur bie

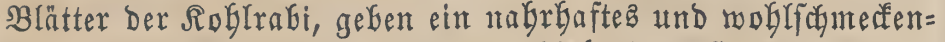
Dez (B)entüfe, meldyes aber feiner bläGenden SBirfung wegen eine gute Berbauungafraft berlangt. Die Rohrabi find ein

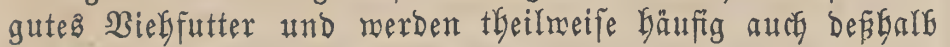
angefaut.

\section{Weine 隹ahliabe.}

Brassica oleracea gongylodes alba.

Strunf rübenartig. Blätter meişgrün.

a) Beneinex $\mathfrak{A}$ oflrabi.

(bemeinter grüner $\mathfrak{\Omega} 0$ Gltrafi.

Blätter flach. Die Snolfen find fehr grof́, länglicyrund und feft, mit bielen feften, meift bolzigen Fafern. Dient

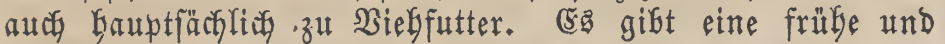
fpăte Sorte.

\section{b) Fra}

Die Sinopfe felten grö́per als 3 30W im Durefmeffer;

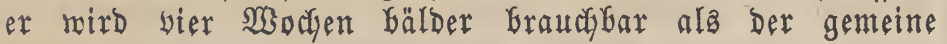
Roblrabi.

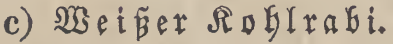

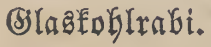

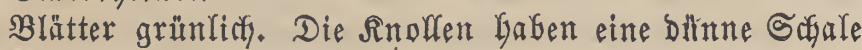
und ftnd roie auch bie Blattfiele meiplich, feltener etwaz siolett bebuftet. Sis empfieblt fich zur zrübzudgt und ift Dez meíren, milden Fleifdes wegen einer Der beften.

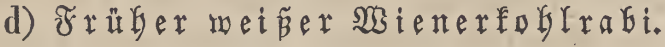

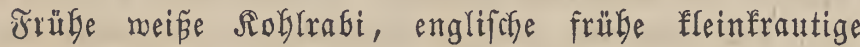

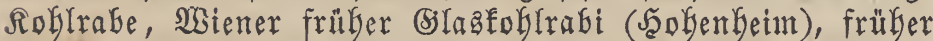
swienerfoflrabi (Jeamburg und am bodenfee), Frübfoblrabe (Jeeibelberg).

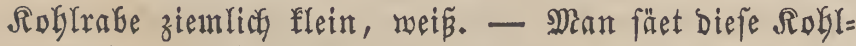
rabe int rebruar in's Miftbeet, Dber im Mãrz auf ein mar= mez Giartenteet, werfest die Pflanzen nachber und fann fe Dann yom alpril biz Juni benủsen.

\section{Alaue fioblrabe.}

Brassica oleracea gongylodes violacea.

Strunf und B̧ätter Glau.

a) Fräber brauer ablrabi.

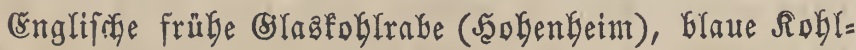
rabe, frủbe Eleine Roblrabi (Jeauburg und am $\mathfrak{B} \Delta$ denfee).

Blau und biolett. Alrtet bie und ba in bie meipe Sidfl= rabe สนติ.

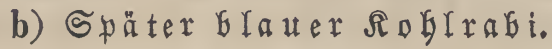

Biolette Roblrabe, Glaue Roblrabe (Seilfronn), fpäte

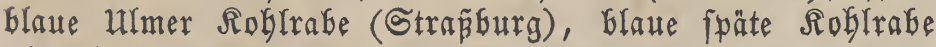
(Januturg, J̧okenteim).

Blau.

Entwer, bfonom. æFfnnzenfunde.

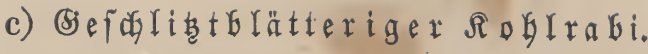

Blätter tief eingeldnitten, Glau.

d) $\mathfrak{B} \mathfrak{I} \mathfrak{a} \mathfrak{e} \mathfrak{x} \mathfrak{N} \triangleright \mathfrak{b} \mathfrak{I} \mathfrak{a} \mathfrak{b} \mathfrak{i}$.

Bioletter RoGlrabi, Glater Golländicher Rofitrabi.

Blattfitiele, Rippen und Rnöpfe röthlich oder violett. Die Ritolfen fommen etrą fpät, machfen aber bis zum

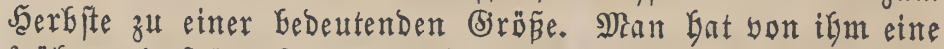
frübe und fpäte Sorte; diefe taugt melgr zur fpäteren $2 \mathfrak{n}=$ yflanzung, ba jie aucf bei ftarfer Saibe nicht fo feidgt bolzig rorb, jene mefr zur Frübfultur.

Diefer Ruglrabi wartirt in Der Form und ift bann ber

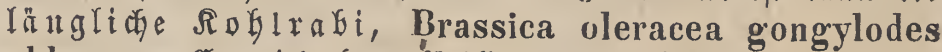

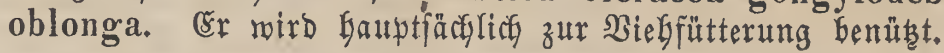

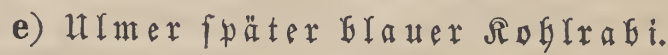

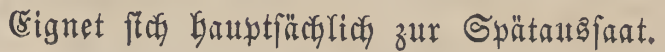

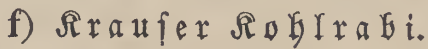

Chou rave crepu., (framz.)

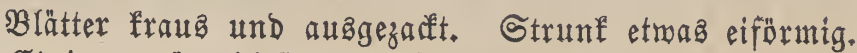

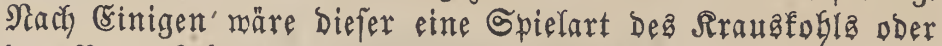
Dę B BraunfokI

\section{Brassica Napus, L. Siefle Seite $2 \%$}

Itnteratt.

\section{Brassica Napus pabularia.}

Brassica campestris pabularia.

Sdynittegl, Schnittëhl, Jrüblingăfohr, fraufer Schnitt= fobl, fraufer rotber Minterfoflrep: Gober Grauner fahlichter Schnittfobl (Joblenbeim).

Chou à faucher. (franz.)

SSแrzzelblätter zahlreich, langgeftielt, leterfürmig, einge= fchnitten, fraus, am Sande raug, rotg. - Er entftand ofne 3meifel Durch Vermengung Dez Blüthenftaubez Des Repfez und Der Rokitrübe.

Man fäet Den Sajnittfobl im Mărz in $6-10$ Boll yon einander entfernte Neiben, dDer noch in Maa, ober aud, ba er ben Winter aubbauert, im Serbfte. - $3 \mathfrak{u r}$

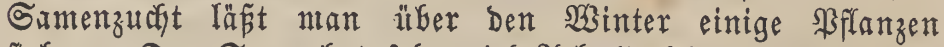
fteben. Der Same Gat fegr biel 2 eșnlich feit mit Dem Ear= biolfamen, melch' Yeterterem er auch bäufig betrügerifochermeife beigemengt wirb; er bleift 5-6 Jahre lang gut.

Der Schnittfobl gibt ein zartez angenefim formectendes (B)

Sine Spielart bon ifm:

Der fraubläterige ober geroblonlide Sontitiol

mil zartem, und Der

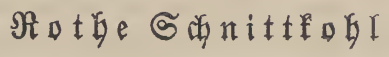

mit meniger zartem Fleifdse. 
Crambe. L.

Dendrocrambe. Dec.

Leptocrambe. DeC.

Sarccrambe. DeC.

Syfteme: Cruciferae. Juss.

Cruciferae Raphaneae. DeC.

Tetradynamae Synclistae Articulatae. Rchbch.

Tetradynamia, Siliculosa. L.

Selci) 4 blätterig, gegen die $\mathfrak{B a f t s}$ hin etwas ungleids. Relchblätter abftebend, länglich. Bluntenfrome 4blätterig, freuzförntg. SBlumenblätter ganzranbig, ungleidg: Stanb= gefǟe 6. Die 4 gröperen Staubfäben bäufig an Der Spibe gezafnt, pfriemenfürmig. Staubbeutel 2fächerig, eiförmig, einrärts gefebrt, jedes Fach fringt in einer Ràngâfpalte auf. Frudatenuten eiförmig. (Sirffel feglt oder ift nux febr furz. Sarbe fopfórmig. Sib̈̈trfen leberartig, 2glieberig, beifammenbleibend, 1 fächerig; Das untere berfüntmernd, ge= ftielt und fautenlos, Das obere etmas fugelförmig und 1 famig. Der Nabelftrang ift aufrect, an Der Spibe einmärtg gefo= gen, und trägt einen bängenden Santen. Die Samenlappen ftit birf, etmas blattartig, gefaltet und tief ausgerandet

\section{Crambe maritima. L.}

Meetfogl, Seefobl, gemeiner Meerfigl, Strandfobl. Crambe maritime. (finttz.)

Common sea Colewort. (engl.)

\section{Axten = (5)araktex.}

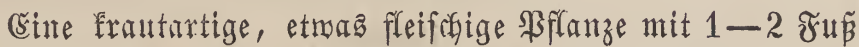
bohem, äftigem, fehr glattem Stengel, $2-3$ Fủ langen und 1 Juf breiten rundlichen, buditigen, meffenförmig ge= zähnten, fraufen und graugrünen Blättern, weisen, auf ãftigen Tratben ftebenden Blütben, ziemlidy groperm ei-fugel= förmigem, geftieltem und unberwebrtem Schötchen.

\section{şlüthe = Beit und $\mathfrak{D a u e r}$.}

Mai - Smin. 4.

\section{BorÉntmen.}

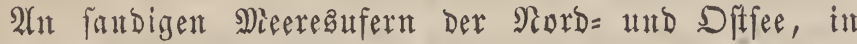

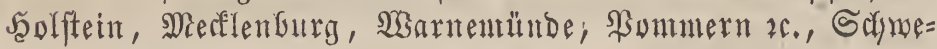
Den, Franfreich, England, Taurien.

\section{Sultux.}

Der Meerfobl mirb bei una leiber im banzen mur fel= ten angebaut, berbiente aber gerwíb megr Bearbtung, da ef fothon int Fefruar unb Miärz, alfo zu einer Zeit, wo bie Bafl anderer (Sientitfe noch fo gering ift, unt bei guter $\mathfrak{B}_{\rho}=$ Ganblung oft 20-30 Safire lang fenübt werben faun. In England roird ex in Gropen angebaut.

Ẽx liebt einen leichten, fanbigen, aber guten Boben, und wirb entreber in 2 Guguft ober Dftober, ober aber im Februar und März, menn Der SBoden noch yon ber MSinter= feuchtigfeit Durchbrungen ift, auggefäet;" gefdytebt aber bie Saat erft im 2ipril ober Mai, fo ift ea notgig, bie Samen= förner yon ifrer barten Sdfule zat befreien, weil fite andern= falls erft fpät in Gonner feimen mitrben. Den Samen felbft ftecft doer fäet ntan; erfterez ift befier, weil ntan $D a=$ Durch des Berfebens überboben ift. Man macht in einer

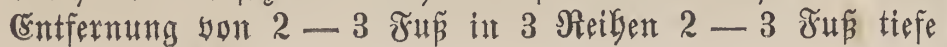

(Bruben und füflet biefelben bis zu $1 / 2$ Fun gegen bie DGer=

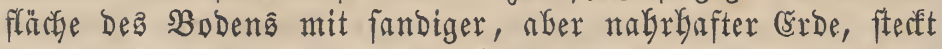
3-4 Sïrner in einem Dreierfe ober Sreife ein und Geberft

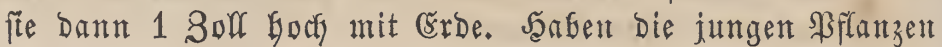
einmal das 4te 2 latt getrieben, fo vergieft man fie und läpt nur eine Pffanze ftetyen. Den Sommer üfer Gat man Darauf zu fehen, Dá Das Utnfraut nicft auffomme. Sind Die Pffanzen fräftig genug, und Dies werben fie int zweiten ober britten jeerffte, fo entfernt ntan bie etwa gelb gemor= Denen Blättex und bleicht nun yon Decentber an bie Bflan=

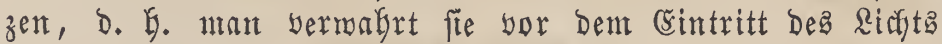
unb Der Ruft, und bringt zu Diefent Bebufe um jebe SFflanze

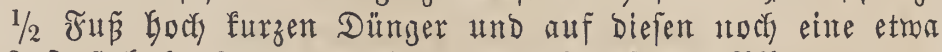

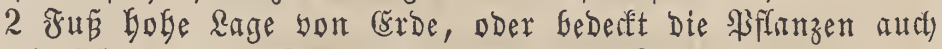

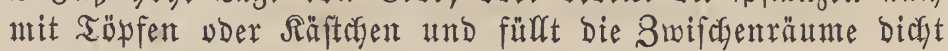
mit Pferdentift aus. (šnde Mianrz ober 2 lnfangs 2 (pril er=

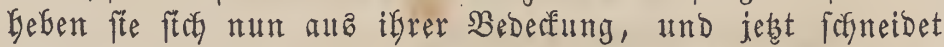
man bie 5-6 8oll hoben Syruffen bes Meerfolis mit einem guten Meffer af und bebeaft Gierauf Die \$flanzen auf's Nelle mit (Erbe. Wiegreremal fant man biés mieberbolen, autr)

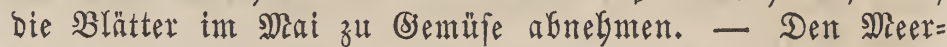
fobl vermelyrt man entweber aus den neuten Trieben ber

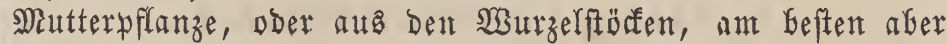
ziefgt man ifn immer aus bem Santen. Utm febr frübent Seefolgl zu geminnen, treibt man denfelbent entmeder int Freien, oder im 5aauje. Bunt Treiben int Jreien bederft man gegen bie Mitte Sanuar geförig erftarfte Sflanzen mit Tüpfen, und lebtere und bie Smifobentäume bicht mit Stroh und friffem \$fFerbemift, ober überbecft das ganze Beet

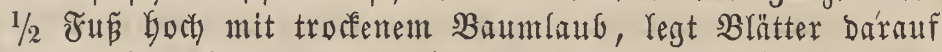
und auf Diefe nody eine ftarke Rage son Strofmift, auch $\mathfrak{m} u \tilde{B}$ Daß ganze $\mathfrak{B}$ eet mit $\mathfrak{B r e t t e r n}$ eingefajt merben. Schon nadi) $2-4$ Soodjen fann man bei biefer Befandlungämeife bie Sproffen abfannetben. WBifl man fich über ben SBinter gebärig mit Meerfogl berjeben, fo legt man 2 Beete bantit $\mathfrak{a n}$, Hnd zwar bab eine im-December, das andere aber int

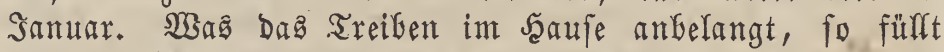

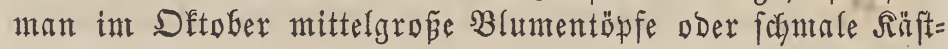
chen mit reichter und fandiger (Erbe, nachbem ntan zutyor

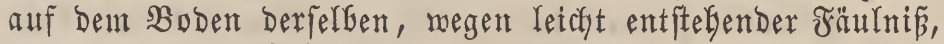
eime 1-2 3oll Goke Rage won fleimen Riefeln gebradht bat, und febt bann 2-3jägrige Seefoflpflanzen etwa 8 , 30ll yon einander entfernt in bieferben. Die röpfe läpt man im zreten an einent fodattigen Drte ftehen. Ronmen bie Sinterfröfte, fo ftellt mant fte in einent guten Reffer oder in ein faltes, aber froftfreeces Sinnmer an einen nicht zu bellen Drt, und bringt fte zux Treifzeit, etroa int December, in ein märme= res Rofal. Son Seit zu Seit, aber ja nicht bäufig, hat

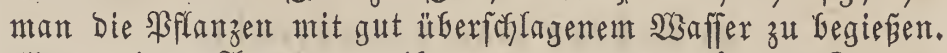
(sine weitere 2art, zu treiben, und zmar mefr int Gropenen, ift folgende: $2 \frac{1}{2}-3 \widetilde{F u} \tilde{\beta}$ breite Beete werben tief augge= graben und fatt ber Ěrbe mit feinem unb untermifostem Sande augigefülft, Düntger taugt meniger bazu, weil Durdf

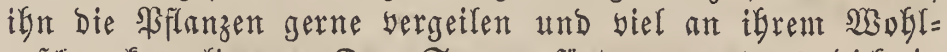

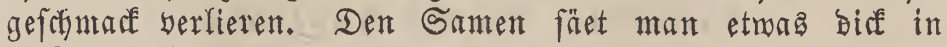
3 3oll tiefe Răngafurchen, und bie \$flanzen, wenn fte zum Berfeben tauglich ftnd, werben $6-7$ 3oll yon einander entfernt augsgepflangt und Den Sommer Gindurch mit ver= Dünter Sauche begulfen. Den WBinter Darauf, etwa im 
Nobember, fangt utan erft mit Dem Treifen an; man ver=

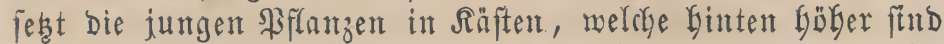

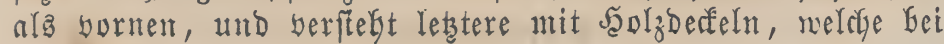
guter Witterung geoffinet werben, um \&uft und \&idbt ein= zulaffen. Treten שröfte ein, fo müffen bie Räften mit Stroly= matten zc. Gebecft merben, aud ift es rathjau, bie äupern \$3andungen ber Räften wenigftens mit (Erbe zu berbaumen. -

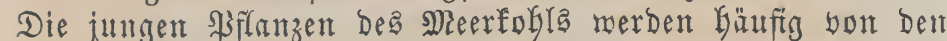
Erbfïben bernichtet. Der Game bleibt $3-4$ Jahre feimfübig.

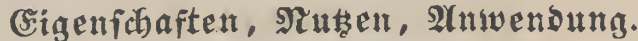

Die Stengelfuroffen bes Meerifobls find eitue felgr be= liebte Speife und weit zärter und wohlfogmedfender als die Spargeln, auch iß̧t mant bie jungen Blätter und bie Blatt=

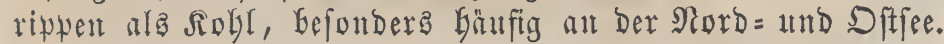

\section{Cirsium. Adans.}

Breea. Less.

Notobasis. Cass.

Cephalonoplos. Neck. DeC.

Chamaeleon. DeC.

Corynotrichum. DeC.

Epitrachys. DeC.

Eriolepis. Cass. DeC.

Lophiolepis. Cass. DeC.

\section{Odontolepis. Boiss.}

Onotrophe. Cass. DeC.

orthocentrum. Cass. DeC.

Serratula. L. DeC.

Xylanthema. Neck.

Syftente: Compositae capitatae. L.

Compositae Cardui. Adans. Loud.

Compositae Cynareae. Spr.

Compositae homoianthae. Spr.

Compositae Senecionideae. Less.

Siphoniphyta. Neck.

Synantherae Carduineae. Cass.

Syngenesia, Polygamia aequalis. L.

Slüthengüfle eifürmig, bauchig aufgetrieben, ziegelback= förmig, an ber Spite mit ffrientenförntig - Dornigen Relch)=

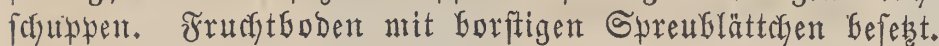
Samen berfegrt - eifürmig und etwas effig, nit federiger, an ber Bafts in einen abfäligen Ring berwadfener Sanar= frotte.

\section{Cirsium oleraceum, All.}

Cirsium variabile. Moench.

Carduus oleraceus. Pers.

Carduus acanthifolitus. Lam.?

Cnicus oleraceus. L.

Cnicus pratensis. Lam.

0notrophe oleracea. Cass.

Serratula oleracea. Poir.

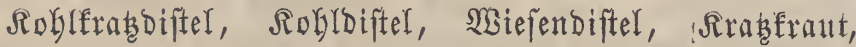
Biejenfohl, genteine Sirabbiftel, fohlartige Rrabbiftel, ge= niftartiges Srabfraut, wilbe Corbobenebifte, Diftelfobl, แnächter Saflor.

Quenoville Bomore. (franz.)

Pale flowerd Cnicus. (entgl.)

\section{Arten = Charater.}

Die ganze Bflanze ift faft glatt. Der Stengel $2-41 / 2$ శú hoch, meich, aufreect, einfach ober etwas äjtig unb geftreift. Blätter 6-12 Soll lang, zart, abmedjelnd, ftengelumfaffend, theilweife ungetbeilt oder balggeftedert, Gerablaufend geffedert, lanzettförnig, gelappt, melyr ober meniger eingefofnitten, gemimpert, fägenartig gezäbnt und mit fleinen frautartigen

Dornen verjeben, auf beiben Seiten glatt, an ben Ripwen Gie und Da furz begant, yon Farbe bellgrün ober audy

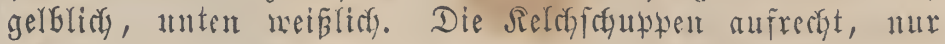
inenig abfekend, formal lanzetfförmig, Gaben einen furzen fadmachen, Gorftigen und weipflichen Dorn. Die B̧luntenförbe ftild gipfelftäloig, etwas äftig, und jebes cinzelne Rärbcten ift mit einem grofen eifürmigen, gemintperten, G Gattartigen und Glapgelfgrünlichen Derfblatte berfetgen. Die Blüthen fteben zu 3-4 beifamunen, ftnd felgr furg geftielt, 1 3oll Iang, weísgelb, feltener rötglicf. Frudgtfunten Gebaart. Die antheren Gaben am Srunde bemimperte Fortfätze.

\section{Blütfe $=$ Seit und $\mathfrak{D a u e r}$.}

\section{Juli - 2luguft. 4 .}

\section{3orEmmen.}

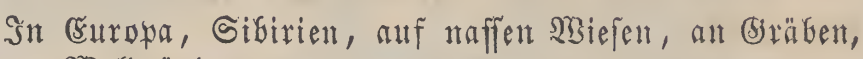
Bächen, $\mathfrak{B a l b r a ̈ n d e r n . ~}$

\section{(Eigenfabafter, গtuter, Antwenoung.}

Die jungen Blätter unb Stengel fönnen als Rofl ge= geffen werben und werben fo Gäufig in mörblicten añ Gentibt.

\section{Cirsium lanceolatum. Scop.}

Carduus lanceolatus. L. Cnicus lanceolatus. Willd. Eriolepis lanceolata. Cass.

Lophiolepis dubia. Cass.

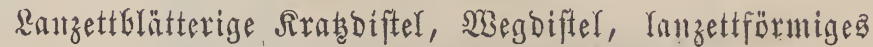
Rrabtraut.

\section{Arten = (5) rarater.}

Stengel aufreçt, ftarf, fantig, ftadyelig, äptig, $2-3$ Fun hoch und bäber, oben weif́lich filzig. Blätter lanzett= förmig, balbgeftebert, berablaufend, fchmal fieberförmig ge= Iappt, gezäbut, raub, unten wollig, ant Rande felgr borntg, bfen und unten grün. Relcly eifürmig, Gaudyig, ntit Ianzett= förmigen, abftegenden, etwas fpinnenmebenartig wolligen und Dornigen Schupken. SBlütgenfürbe grof́, aufresgt. Die $\mathfrak{B} l u ̈=$ then violettroth, Gie und ba weiglidy. Frutytboben mit langen Sprenblättchen. Strubgefäne fadenförmig. Samenfrome Inng und binfällig.

\section{Blüthe $=$ 3eit und $\mathfrak{S a u e x}$.}

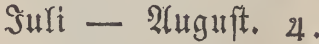

\section{Sorfommen.}

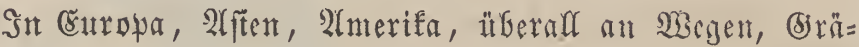

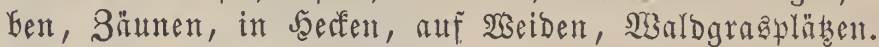

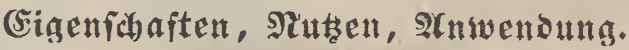

Die jungen bon Den Dornen befreiten Stengel geben ein fehr mogrfichuteffendes Giemutpe.

\section{Cirsium palustre. Seop.}

Carduus" palustris. L.

Cnicus palustris. Willd.

Onotrophe palustris. Cassin.

Cnicus palustri-tuberosus. Schiede. fraut.

Sumpfratediftel, Senffrabditel, fumpfliebendes Riak=

Mars Thistel. (entgl.) 
Arten = Ȩarakter.

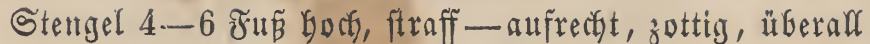
geflügelt und fehr ftachelig. Bäätter afwechjelnd, lanzettför= mig, theilmeife Galbgeftedert, bornig - gezähnt, unten ftart rauly, Gararig, bie ber Wurzel find geftielt. Sieldy länglich und bautsig aufgetriefen, mit ei-lanzettförnigen, anliegen= Den, ftachelfpibigen, grünen, bismeilen rötglichniolett ange= flogenen Reldfichuppen. Blüthen gipfelftändig, gegăuft trau= benartig ftebend, flein und purpurroth. Frudftfnoten anit geftreiften Spreublättçen. Şarafrome ungeftielt, Ginfälaig.

\section{Blüthe $=3$ eit utto Dauer.}

Suni - 2ugut. $\delta$.

\section{2orkomuten.}

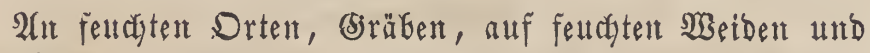
Walopläken.

(sigenfibaften, Nuten, Anwendung.

WBird wie bie yorige 2 rt benttht.

\section{Carduus. L. Spr.}

Clomium. Adans. Chromolepis. Cassin. Microcentrum. Cass. Platylepis. Cass. Stenolepis. Cass. Xylanthema. Neck.

Snftente: Cynarocephalae. Juss.

Compositae capitatae. L.

Compositae Cardui. Adans. Rül.

Compositae Cynareae. Spr.

Compositae homoiantheae. Rchbch.

Siphoniphyta. Neck.

Synantherae Carduineae. Cass.

Syngenesia, Polygamia aequalis. L.

Blätbengüfre eiförmig, ziegeldachförmig, batchig, mit Dornigen Relefichuppen. Jructfobent borftig ober zottig be= Gaart. Samen berfegrt-eiförmig, 4 fantig, Die Ranten aber undeutlich. Feberchen einfarb = Gaarig, auf einem abfallenden Ning fthent.

\section{Carduus nutans. L.}

\section{Carduus apenninus. Jan.}

Carduus montosus. Pollin.

$\beta$. Cnicus lucidus. Wall. biftel.

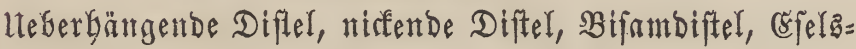

Musc Thistel. (engl.)

\section{Arten = Charakter.}

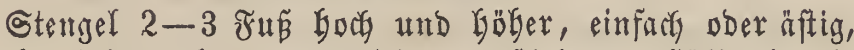

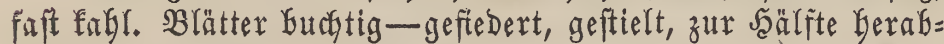
Iaufend, raubganrig und ftarf mit Dornen bejest. Seles grố, faft fugelförmig, ntit großenen, fanzettförmigen, fpinnen= mebenartig wolfigen unb ftare bornigen, aupen fparrig ab= ftegenden, innen aber aufiedgten Reldyfofupen. Blumenftiele weisfitzig. Die Blument felenen einzeln, an Der Spike Der Stengel, ftnd grof́, bice, niffend, purpurbiolett ober mefr fleifchfarben, feltener meiź. Der fllzige Relefüberzug riecht bifamartig. Samenfrone Gimfällig.
Blithe= 3eit uns Datter.

Juni - 2นuguft. $\delta$.

\section{Borfommen.}

2hu fanbigen, fteinigen Drten, WBegen, auf S(futt= Gäufen, Weiben, 2lecfern.

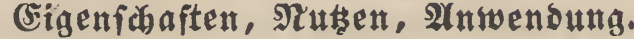

Benithung wie bei ben vorigen.

Carduus crispus. L.

Carduus acanthoides. Schl.

Carduus arctioides. Schl.

$\beta$. Carduus multiflorus. Gaud.

Carduus polyanthemus. Schl.

Arruife Difter.

Curled Thistel. (engl.)

Srrten = (E)arater.

Blătter längliç, Kernblaufend, halbgefiedert, doer aus: gefreffen Juthtig, ant Rande Dornig, oben Dunfelgrün, unten

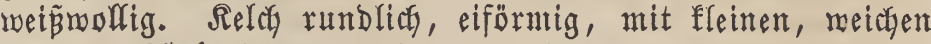
fparrig abftefenden, Dornigen und linien - yfriemenförmigen

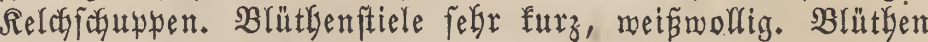
endftändig, gebäuft, violettroth, feltenter wein. Frachtboben Gorftig. Daz Jeberchen einfach Gaarig, mit abfälligent $\Re i n g$.

Blïthe = Beit und Dauex.

Juni - 2uguft. $\odot \cdot \sigma^{\pi}$.

\section{3ortommen.}

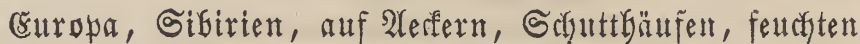

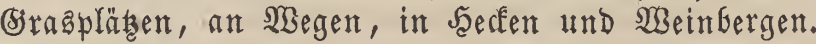

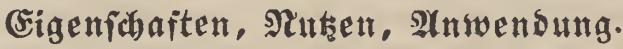

Wie Gei ben yorigen.

\section{Cynara. L. Spr.}

Snfteme: Compositae capitatae. L. Compositae Cardui. Rül.

Compositae Cynareae. Spr.

Compositae homoiantheae. Rchbch.

Cynarocephalae Carduaceae. Schultz.

Siphoniphyta. Neck.

Synantherae Carduineae. Cass.

Syngenesia, Polygamia aequalis. L.

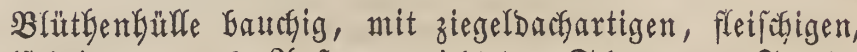

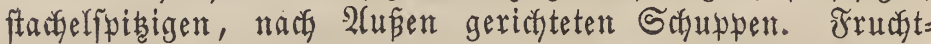
Goden mit borftigen Spreublättchen. Samen länglich-eirund. FeDerfrone ungeftielt.

\section{Cynara Cardunculus. L.}

Cynara sylvestris. Lam.

$\beta$. Cynara hortensis. Mill.

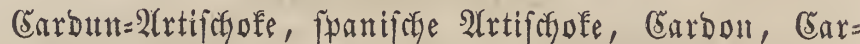
bome, fpanifale Cardone, fpanifdye Carbe.

Cardon d'Espagne. (finttz.)

Cardoon. (engl.)

\section{Arten = SGarater.}

Stengel über 5 ซ̛น 






bornig. Blüthen Dunfelblau, ebenio die Briffer. Staubgefüße graù. Schuppen eiförmig-länglich, mit ftadyeliger Spike, jonft ber gemeinen 2 rtifichofe ähnlich.

\&uguft $\sigma^{\pi}$.

\section{Blütfe $=$ Beit uno Dauer.}

\section{2ortommen.}

Sit Sildeuropa, Dem nörblichen Iffrifa, bet uns in (B)̋̈rten angebaut.

\section{Sultux.}

Die Carbonen berlangen einen leidyten, locfern, tiefs gegrabenen und gutgedungten Boben, und man fäet fie Durch 13 urzelfproffen werben fie feltener fortgepffangt - int 2łrif und Mai, indem nan in einer Ëntfernung yon 2 biz

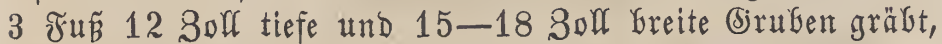
Diefe mit ganz serfaultem Pferbe = und Taubenmift ausfüllt, und in bieferben $3-4$ Samentönner etra 1 Soll tief ftecft,

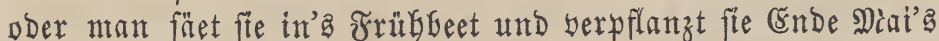
in'z Freie in ber angegebenen Ëntfermung. Son Den in's

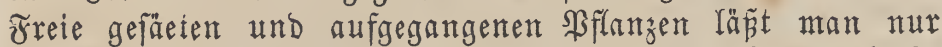

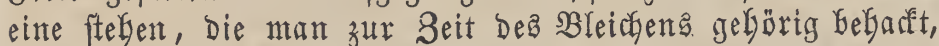
jätet und bejonders auch mit Dungwaffer begiest. - Um den Garbonen einen guten bjefdymate zu ertheilen, werden fie gebleicft, was man yom 2luguft bis Dftober unternimunt,

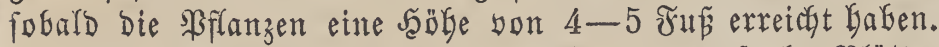
Man nimmt zuvor bie etras abgeftorbenen oder faulen Blätter $\mathfrak{a b}$, gipfelt auth bie gejumben Blätter, häufelt fe geförig an, umbindet nun bie ganze Bffanze mit Strof, fo daß̧ mux Die Spibe berfelben Gerausfteft, legt fie auf Den Boben und

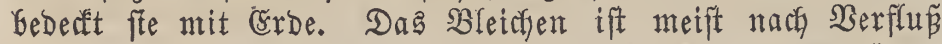
yon 14 Tagen vorüber, und man laffe Dann bie Sflanze aud nicht mefre länger beberft, indent fie fonft leidyt fault. Mit eintretendem Frofte nimmt man bie SFfanzen mit Dem Crobfafa aus Dem Rande und Gringt fte, nachbent man bie Blätter aufgerichtet und lorfer zugebunden hat, in ein trorfe=

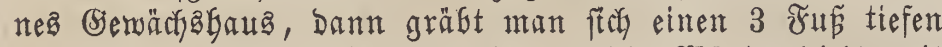

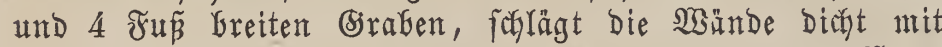
Strof aus, fteflt bie Carbonen reifenmeife an ben $\mathfrak{W a n}=$ Dungen des Esrabens auf, bringt auf biefe rweber Strof, Dann wieder Bffanzen, biz Der Graben auşgefüllt ift, doer fajlägt fie auch im Reller ein. Die oberften $\mathfrak{B}$ fätter Der Car= Donen läßst man aus Dent Boben berausfeben, bedectt fie aber Gei jebem eintretenden Siegen und orrofte. - Itm bie Car= Donen zu treifen, fäet naan fte fefon im Monate Samuar in Topfe, meldye man in ein warmes Nhiftbeet bringt und mit Zenftern beberft. Dit 2 Blättern verfebt man die jungen Sffamzen in gröpere Töpfe, Gringt biefe in ein anderes mar= mes und zuletet, monn bie Carbonen gebürig erftarft fend, in ein faltes Mriftbeet, welches ebenfalla Durch renfter ge= fadloffen mirb. Meift fann man bie fo gezogenten Carbonen bis Mai Genütent. - Bur Samenzudgt läß̄t man einige

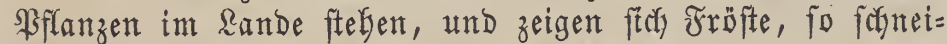
Det man die Brätter einige Sulf hod über Der Erobe ab,

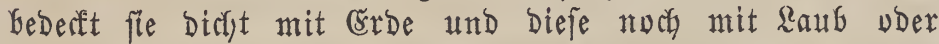
Strof. Der Same bleibt 6 Sabre und länger feimfäbig.

Eigenidyaften, গtuten, Anwendung.

Dian veripeiat yon ben Carbonen bie gebleichten max= figen Stengel, Blattrippen und Jaerzblätter mie die Spar= geln ober als Salat, auch die Wrurzeln fönnen genoffen werben. Die Blüthen gebraudyt man in Spanten uno Frant= reich zum Laben Der Mitha, und aus ber Samenfrone läpt fitch Difteltud werfertigen.

Barietäten Der Carbonen find:

1. (5) emetine Cardon= 2 rtifdyofe.

Baknte Sarbone, fyanifiche Carbone.

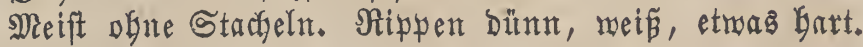
Schiept fefr idunelf.

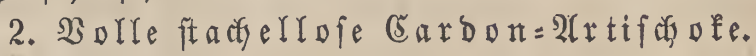

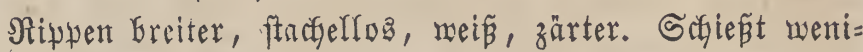
ger fofyelf.

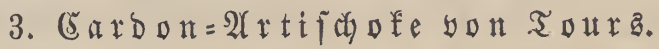

Ripyen fegr ftachelig, etmas rötglich, fonft wie bie Sorige.

\section{Artijdofenblätterige Cardone.}

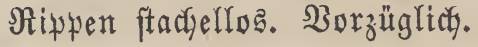

\section{Cynara Scolymus. I}

Cynara Cardunculus. L. var. Spr.

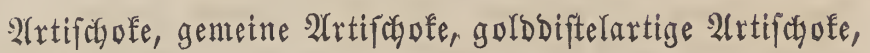
(jartenartif

Artichaut. (frantz.)

Common Artischoke. (engl.)

Carciofo. (ital.)

\section{Strten = Sharater.}

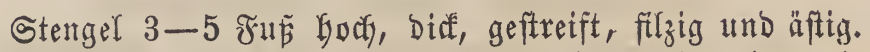
Blätter grós, abmechfelnd, tief eingefdyntten, Dornig, mit weififilziger Interfeite. Blüthen violettroth. S(ntheren am (5runde mit gemimperten Fortfäben. Sehuppen eirumb, flei= fartg, ausgefdnitten, fpitsig, badfiegelförmig über einanber riegend.

\section{Slitthe $=\mathfrak{Z e i t}$ and $\mathfrak{D a u e x}$.}

$\mathfrak{s u l i}$ - September. 4.

\section{\$ortommen.}

Sn Sicilien und Stalien zu ફূaufe, bei unz bäufig in (5)ärten angebaut.

\section{§ultur.}

Die Artifag fe liebt eiment fräftigen, fetten und etraz feuchten Boben; in einent naffen Boben faulen bie $\mathfrak{Y B u r z e l n}$ Den Minter über letcht. Ilm fie forfneller zum Wachjen zu bringen, mählt man einen thonigen, ftarl gebüngten, mit

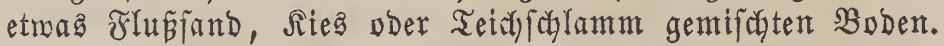
Man yflanzt bie Artifdy ofen Durch Sarurzelfproffen fort, fel=

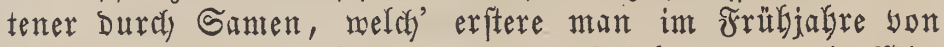

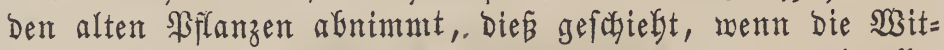
terung günftig ift, im Mionate März; man nimmt mit aller

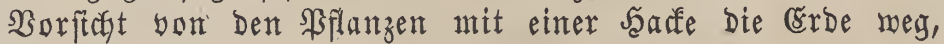
meil fter biele Rebenfproffen gebildet baben, won melcyen man nur die 2-3 febönten und geradeften Sproffen fteben läp̃t,

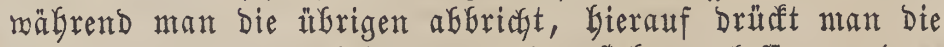
Erbe um bie 2-3 şflanzen, welche ftehen gelaffen merben, ftart an, bie abgenommenen $\mathfrak{3}$ urzelfproffen aber pflanzt.man in ein gut gearbeitetes Beet, wo man foron im berbfte grofe Blumenföpfe ernten fann, yorauge ge 
Sommer burthgemacht baben, andernfaffs erbält man fte erft int zweiten Sommer.

Die 2rtifchofen fetro fehr entufendlicty gegen Froft, geben meift auch in naffen Ragen zu Srunbe, Daber mant fie im Jerbfte augheben und an einent froftfreien Drte in Erobe voer

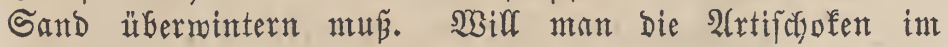
Jreien äberwintern, fo forneidet man in Dftober ober $\mathfrak{N}_{0}=$ vember bei trofferer Writterung bie äuneren grofen Blätter

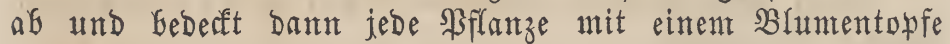

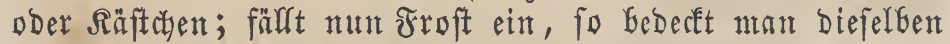
mit Stroh, Blättern und Dergleidyen. Aluch fann man bie Bflanzen vor Dem Erfrieren bewalyren, Daß̉ man im Serbite ebenfalfs bie Brätter und die jungen Sproffen biçt über Der

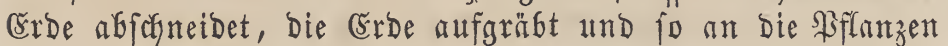

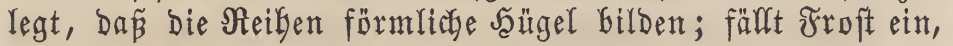

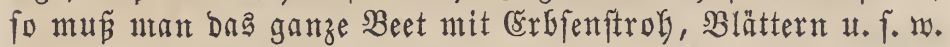
bedeffen. Mit Dünger Dürfent bie 2 rtiffyofen ntidyt Gebecft werden, indem fte fegr gerne faulen. Im Februar ober Wiärz mird Daz Stroh, bie Blätter, Errbe 26. mieber afge=

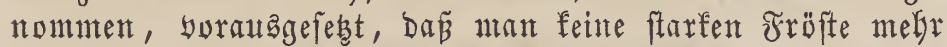
Gefürchtet. Bur Borfteryt fann man aud) yon ben Pflanzen, weldge Den SYinter über in sande fteben bleiben, einige Wourzelfproffen abnefgnen und fite in einent trodfenen Sieffer aufbemabren, und im Frübjakre fann man dann bie Sproffent

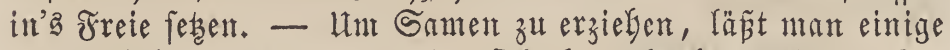
Söpfe fteben, welche man int Dftober abnegmen faut. Snt

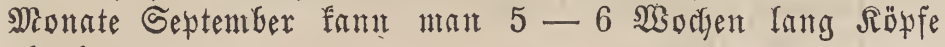
abnefmen.

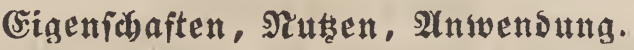

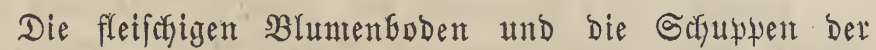
Bluntenderfe rerben gefotten und mit einer $\mathfrak{B}$ utterbrühe ge=

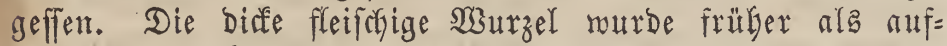
löfendes und Garntreibendes Mittel in ber $23 a$ ferfutht an= getwendet.

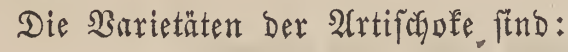

\section{Stachlige 2 rtifat ofe.}

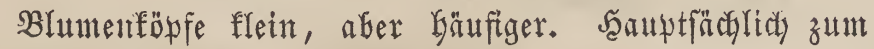
(rimmactyen bienlida.

\section{Bor tut the fra}

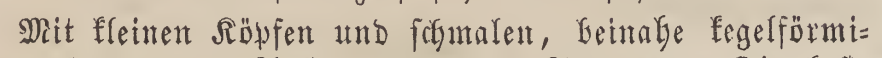
gen, grünen, mach 2 unen gefogenen Scfuppen. Die bejte Sorte.

3. Rothe $\mathfrak{A}$ tifichofe.

Biolette $\mathfrak{A}$ rtifoch ofe, Rugelartifadofe.

Nit gropen Blumenföpfen, Graunen, einnärtå geboge= แen Scfuppen und diffen; fleifüigen Blunenböben.

\section{Onopordon. L. Spr.}

\author{
Acanos. Adans.
}

Syfteme: Cynarocephalae. Juss.

Compositae capitatae. L.

Compositae Cardui. Rül.

Compositae Cynareae. Spr.

Compositae homoianthae. Rchbcl.

Siphoniphyta. Neck.

Synantherae Carduineae. Cassin.

Syngenesia, Polygamia aequalis. L.
Blumenfülle Gautigig, ziegeldachförmig. Reldyjchuppen ftachelfpitig, ftectyent. Jruchtboden zellig, etras ipreutg.

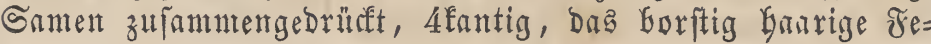
Derchen fitht auf einem abfälfigen Ninge.

\section{Onopordon Acanthium. S.}

\section{Acanos spina. Scop.}

$\dot{\gamma}$. Onopordon viride. Desf.

Irebabiftel, gemeine Rrebabiftel, Frauendiftel, MBeg=

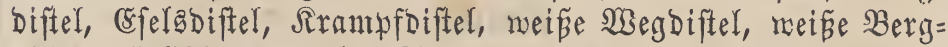
diftel., Jellblunte, wilde Sirtifordofe, genteinte Belfenflume.

Grand Chardon de Portugal, Epine blanche. (franz.)

Cotton Thistl Wolly onopordum. (entgl.)

\section{Arten = Sharakter.}

Watrzel 1 Fur lang und länger, yon Der Diffe eines Fingers, fpindelfürmig, faferig, aupen gelflich, innen weif. Der Stengel ift $3-6$ Jun God und höber, biff, äftig, Durch bie Gerablaufenden Blätter geflügelt, febr Dornig und meiffilzig, leghtere abwechfelnd, Gerablaufend, eiförmig, fpiţig, Guchtig=gezăhnt, fteif und fleifchig, meï̈lidygrau = filzig und an

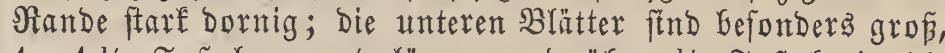

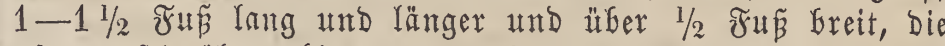
oberen focmäler, Gie und ba lanzettförntig und ungetbeilt. Der Selch 1-2 3oll breit, fugelförmig; bie Seldyfdruppen ftelgen ftarf abmärto und find an ifrer Spike mit ftarfen, gelben Dornen verfeben. Die Bhluthenftiele fund geflügelt ınd Dornig. Blüthen endfändig, aufredgt, bie Blüttychen gebrängt ftefend, röbrig, Glaz purpurroth, feltenter meif. Die Strubgefäpe fund herborftebend, Der Frudstgoden bienen= zellenförnig.

\section{Blüthe = Beit und $\mathfrak{D a u e r}$. \\ Suli - September. $\delta$.}

\section{3ortommen.}

In Ĕurowa, Norbafrifa, auf Srbuttgäufen, an şegen, in Şerfen.

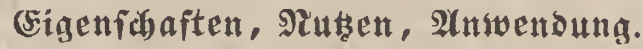

Die raurzel ift geruchlog und formerft bitterlich farzig, Das Sirut zientich bitter, berb und unangenefy frautartig, bie Samen milbe und ölig. Mian berfyeist bie jungen

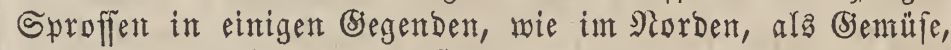
ebenfo, wie in Stalien Die Wurzeln und bie Frndetboden wie 2trtifchofen. 2lus ben Samen gewinnt man ein ntilbes, fettes und forger gerinnendes Del. Die Blätter benüht man zun Raben Der Milds. Die Saarffrone Der Samen fann,

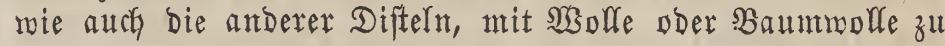
geringem sudje, Dem fogenannten Difteltucts, und zu Decfen verarbeitet merben. In frügen Seiten fpann und wob man Den fifzigen Heferzug biefer Diftel zu Rleibern. Den aus: gevreşten Saft gefraucht man als fpecifictes Mittel gegen

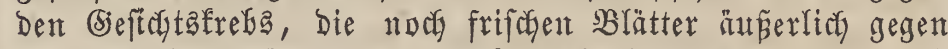

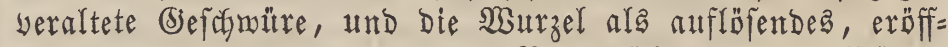

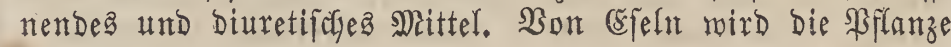
felgr gerne gefreffer. 


\section{Lappa. Adans. DeC.}

Arctium. L. Spr.

Snftellte: Cynarocephalae. Juss.

Compositae capitatae. L.

Compositae Cardui. Rül.

Compositae Cynareae. Spr.

Compositae homoianthae. Rchbch.

Siphoniphyta. Neck.

Synantherae Carlineae. Cass.

Syngenesia, Polygamia aequalis. L.

Blunenfülle fugelrund, ziegeldachförntig, ntit in einem furorpeligen atnd Gafenförmigen Dorn ftch endigenden Relds= facupen. Blumenboben Goritig, fprembabenartig, flach. Sa=

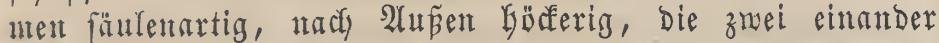
gegenüberftebenden Ranten find verwifest. Saarafrone einfach, fteif, zottig und gebreft bebart, fprenartig und fürzer ala Dif Fruift.

\section{Lappa major. Gaertn.}

Lappa Bardana. Moench.

Lappa glabra $\beta$. Lam.

Lappa officinalis. All.

Arctium Lappa. L.

Arclium majus. Schkr.

$\beta$. Arctium grandiflorum. Desf.

Rlette, genteine Rlette, officinelle Rlette, großje Rlette,

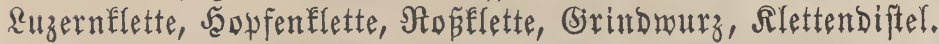

Bardane, Glouters. (Fianz.)

Common Burdock. (entgl.)

\section{Arten $=$ (S)arakter.}

Whurzel 1 Fúp lang und länger, etwas birf, cylindrifach - fpindelförmig, melyr einfach ober mentger äftig, aupen Dunfelgraubraun bis farmärzlidy, inmen meipfich, fónammig,

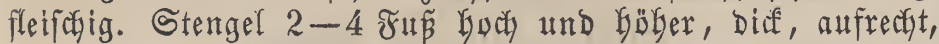
fteif, fehr äftig, gefurdst-geftreift und furzmolfig. Die 2lefte aufrecht und abrechfelnd. Blätter etinas biá, fteif, furzbegart, oben mefy ober weniger Dunfelgrủn, unten

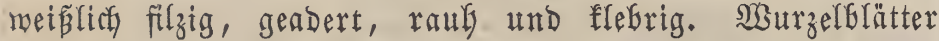

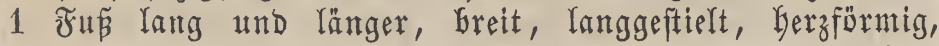
ftumpf und furz ftachelfpizig; Die Stengelflätter abwedgfelnd, oben fleiner, fürzer geftielt, bie und da eifürmig und ganz= randig, bie untern grö̈ern buchtig ober auch weflenfürmig gezalynt. Sieldy faft fugelig, Die unterften Releffchuppen ftnd

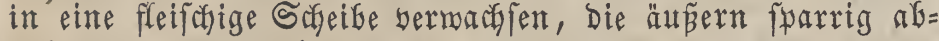
ftehend, gleich, röthlich angelaufen und gröB̈er als bie intern, restere linienlanzettförmis, in eime Siranne auslaufend und gleichfarbig. BBlumenftiele furz und filzig. B̧lumenfüpfe flein, flach, gipfel=, zuneilen auch achjelftändig, riapen-trau= benartig, zu $1-5$ gefnäult ftekend, fugelig. Blinthen röh= rig - tricgterfürntig, fuön roth, mit bunfelvioletten ober Glauen, etmas beraugeragenden Strubgefänen und 2tbeiltger, belfrotber Narbe. Samen etra 2 Rinten Yang, länglich, flach, erfig, oben etwaz breiter, belfgraubram, mit furzer, fteifer und abfallender baatfrone.

Mian Gat eine Barietät:

$$
\beta \text {. foliosa, Glätterige Rlette, }
$$

mit an Der Bafte reichblätterigen Selchen.

Blüthe $=$ Beit und Dauex.

suli - 2qugut. $0^{x}$.

\section{3orÉontmetr.}

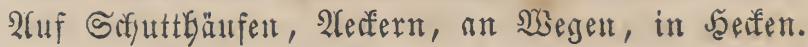

(sigenfáaten, stusen, Antwendung.

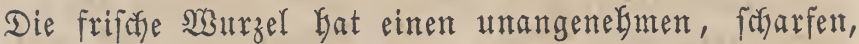
Dumpfitgen, faft narfotifchen (jeruch, Der fich aber Durch's Troffnen ober Ruchen gröptentEeila verliert, und einen fü $\tilde{B}=$

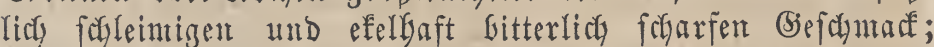
Das Rraut, befonders zerrieben, riecht noch roiderlicher und idsmeç̂t berb und falzig bitter; Die Santen bitter focharf ollig.

Die wormaltenden Şeftandtheile Der $\mathfrak{B a r z e l , ~ B l a ̈ t t e r ~ u n d ~}$ Samen ïnd: Burfer, Schleim, Gitterer Errtraftibftoff, Bierbe= fitof, und mach (butbourt biel Snulin, bie ber Samen biel fetteg Del.

Man iṕt yon ber Rlette bie jungen Sproffen und

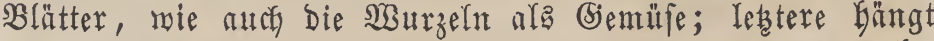
man auch, in Scheifen zerfachnitten und an F̈̈ben angereibr, gegen 2lugenentzündungen um ben Seals ober auf Den Naden.

\section{Sonchus, L. Spr.}

Anoleptus. DeC. Eusonchus. DeC.

Atalanthus. Don. DeC. Hieracium. Adans.

Snftente: Cichoraceae. Juss.

Compositae Cichoreae. Spr.

Compositae Hieracia. Rül.

Compositae homoianthae. Rchbch.

Compositae Lactucae. Adans.

Compositae semiflosculosae. L.

Glossariphyta. Neck.

Syngenesia, Polygamia aequalis. L.

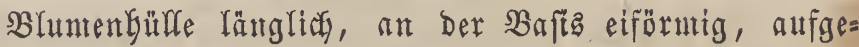
trieben, mit ungleidfen, ziegeldactspürmigen Reldyfduppen, bei Der Frudytreife ofien zufammenfchliesend. Frudstboden nact. Santen lünglid, auf beiden Seiten gleich und längągeftreift. Şarffrome furz, aufïmend, Gaarig, in einem ungolfemute= nen und abfälligen sRing fthend.

\section{Sonchus oleraceus, Willd.}

Sonchus ciliatus. Lam.

Sonchus asper. Gaertn.

Sonchus laevis. Vill.

Sonchus oleraceus. $\alpha . \beta$. L.

Hieracium oleraceum. Scop.

Bemüfediftel, Sänjediftel, Saudiftel, Dubiftel, Mitldy= biftel, genüfeartige Sänjebiftel, Reberdiftel, Machtelneizen,

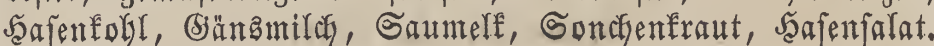

Laitron, Lasseron, Palais de Lièvre. (franz.)

Common Sowthistle. (entgl.)

\section{Axten = Eharater}

Wourzel fpinbelfärmig, äftig, ftarf fajerig und meiplick. Stengel 1-3 $\widetilde{F} u \mathfrak{s}$ hoch, aufrecht, etwas fteif, bäuftg äftig, Hund, glatt. Blätter längliç-eiförmig, nteift beflgrün. NGurzelblätter zart, oft auch etwas fteif, freiaförmig ftefend, leierfarotfägeförmig, ftarf fłachelfpibig bia ftectend, zumeiten aber auch wefhrlos, glatt, wben matt= ober etraas glänzend= grün, unten graugrür. Stengelblätter abmechfelnd, ftengel= umfaffend, bie obern oft ganzrandig, lanzettpfeilfürmig, bie 
Räpbchen lang zugefpib̧t, berlängert und frei. Der Relch chlindrifach aufgetrieben, megr ober weniger glatt ober etwas feinzottig behaart, nach Der Blüthe gefurcht-gerippt und pyramidenförnig. Die Seldafchuppen zaflreidy, ungleich Dads= ziegelförmig und fahmal. Die Blumenftiele faft glatt ober

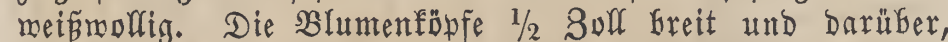
ftelyen ungleid, Dolden = ober büfchelartig, einzeln ober zu 2-3, aufrecft, und fend blägelf. Die Blúthdsen find gletch und liegen ziegeldachförmig. Der Bluntenbuben ift nacft. Der Samen flein, länglida =eifürmig, zujamnengedrǚft, ge=

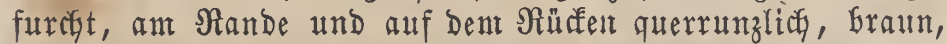
und, Die Saarfrone äuferft zart, fthend und weiñ.

Man fent bon biefer $\mathfrak{A f l a n z e} 3$ Spielarten:

$\alpha$. in tegrifolius, (S) $\mathfrak{n} z \mathfrak{z a n d i g e ~ ( 5 ) ~ a ̈ n f e d i f t e l . ~}$

Die Blătter find faft ganzranbig Dber nut fparfam ge= zabut ober bucfirg.

$\beta$. triangularis, Dreierfige (5) änfedifter.

Sonchus oleraceus $\beta$. laciniatus. Böningh.

Sonchus oleraceus. Fl. dan.

Blätter fachrotfägeartig leierförmig, und ber üuperfite sappen febr Greit und 3erfig.

$\gamma$. lacerus, Beforligte (s) änfedifter.

$\beta$. pinnatifidus. Günth.

Sonchus lacerus. Willd.

Die Blätter gefiedert-getheilt, Die Rapwen lamzettförmig, lang zugefpitat und affe gleidförmig.

\section{Blüthe = 3eit uns Dauer.}

Iuni - September. $\odot$.

\section{Borkommen.} Mauern.

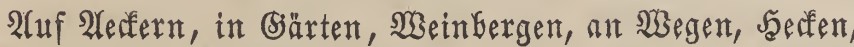

Eigenichaften, গtußzen, 2 (nwendung.

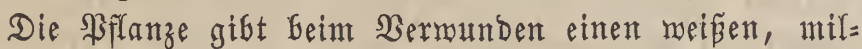
äigen, auperorbentlich bitter und efelfaft famerfenden Saft yon ftch. Sunge sBlätter Gaben einen frautartigen falzigen, ältere Dagegen einen berben bittern Bejechimarf. Die $23 u r z e t$ ift nod bitterer.

Die jungen Sproffen und Blätter biefer Pffanze Dienen ebenfalls, als Bemüfe, auch wird die \$iffanze yom $\mathfrak{B i e h}$ und yon (5)̈̈nen gerne gefreffen.

Den Miladaft der \&änfediftel mendete man früber gegen \&eberfrantheiten an.

\section{Spinacia, L. Spr.}

Syfteme: Aizoideae Atriplicineae. Rchbch. Atriplices. Rül. Juss.

Blita. Adans.

Chenopodeae. DeC. Spr.

Chenopodeae Atripliceae. Dumort.

Holeraceae. L.

Incompletae. Roy.

Sysellophyta. Neck.

Dioecia, Pentandria, L.

Banz getrennte Biefolechter.

Männliche $\mathfrak{B l u ̉ t h e : ~ R e l c h ~ 4 - 5 t h e i l i g , ~ m i t ~ c o n c a b e r , ~}$ länglichen, ftumpfen Rappen. Staubgefäpe 4 doer 5, länger als Der Sielog. Staubbeutel 2finöpfig.

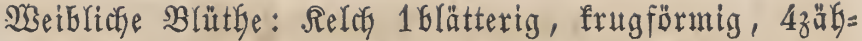
nig, Gleibend. Blumenfrone feglt. Frusteftenoten runblich, zufammengebrüaft. Briffel 4, baarfürmig. Naraben einfact. Samen yon bem vergärteten und unberänderten Relche ein= gefoldoffen, nur ein einziges Rorn.

\section{Spinacia oleracea. Willd.}

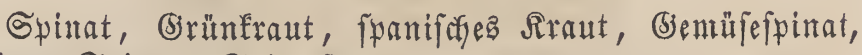
gemeiner Spinat, Spinetich.

Epinard. (firanz.)

Spinach, Spinage. (entgl.)

\section{Arten $=$ ÇGarakter.}

Stengel $1-3 \widetilde{\mho u} \tilde{B}$ hoch, aufrecft, äftig, edfig, glatt

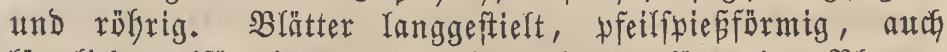
lănglid - eifürnig, ganzranbig, glatt, glänzend. Blumen flein, achfelftändig; bie männlichen fteGen aufrecht, rißpen= artig, fund 5tbeilig, belfgrünlid, mit 5 Staubgefüfen und 2 fächerigen Staubbeuteln; bie meiblichen fteben fnäulförmig, find 2-5fpaltig, bauchig, und fpäter noch melyr aufgetrie=

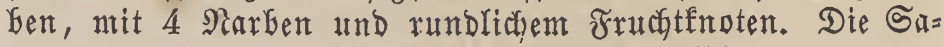
ment ftrd yon Der erfigen und vergrößerten Blume doer Dem Seldye eingefoldofien.

Man untericfeidet 2 Spielarten:

a. spinosa, Dorniger Spinat. Spinacia spinosa. DeC.

Die Samen find mit Dornen berfeb̧en.

$\beta$. inermis, $\mathfrak{B a f f e n l o f e r ~ S p i n a t . ~}$ Spinacia oleracea. $\beta$. L. Spinacia glabra. Mill. DeC. Spinacia inermis. DeC. Spinacia nobilis. Tabern.

Die Samen ohne Dornen. Blüthe = 3eit $\mathfrak{u n} \mathfrak{D a u e r}$.

$$
\text { Mai - Iuni. } \odot \text {. }
$$

\section{Sorḱmmen.}

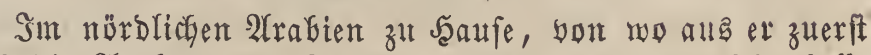
Durch bie 2lraber nach Spanten gebractst morben fein foll; rito überall in unfern bärten angebaut.

\section{Siultux.}

Whie fordon ofen gejagt murbe, bat ber Spinat $2 \mathfrak{B a}=$ rietäten, nämlich eine mit bornigen Samen, Der WBinter= fpinat, und eine mit glatten, ber Sommerfpinat, und auch Diefe Uariiren mieder mit Greitern Blättern. Der Spinat verlangt eine febr lockere, gut gebüngte und immer feucht

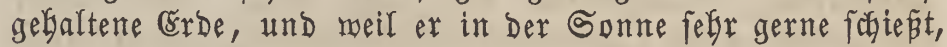
einen fohattigen Standpunft. Wian fäet itan faft zu jeber Seit, yom $\mathfrak{M} i a \mathfrak{r}_{z}$ an bis in Den Sftober, entweder aus Der

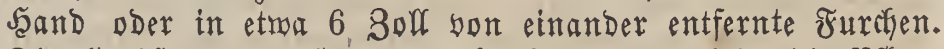
Die Serbftausfaat ift bie yortbeifkaftere, weil Da bie \$flan=

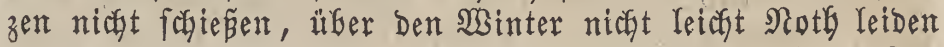

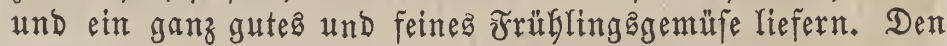
Samen nimmt man im Frübjabr yon Der Serbftausfaat, ntift fo gut ift Der yon ber Früblingąausfaat, and am beften yon ber glattjamigen und einer möglichft breitblätterigen Sorte. Der Spinatfamen Gleibt 4-5 Sabre feimfäbig.

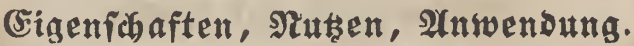

Der Spinat liefert ein alfgemein Gefannteb Semüfe; Dis 


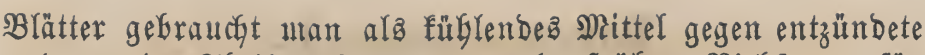
แnd munde Theile, fann auch als̄ früfez Biegfutter für Rindvieh und Srafe angebaut werben.

\section{Tetragonia, L. Spr.}

Ludolfia. Adans.

Tetragonocarpus. Commers. DeC.

Tetragonoides. DeC.

Snfteme: Aizoideae. Spr.

Ficoideae. Juss.

$\begin{array}{ll}\text { Fructiflorae. Roy. } & \text { Succulenta } \\ \text { Icosandria, Pentagynia. L. Seda. Rül. }\end{array}$

Relch fleifoctig, 3-5theilig, immen gefärbt. Irome feglt. Staubfäben biele, oft berfümntert. Die Steinfrucht fteht

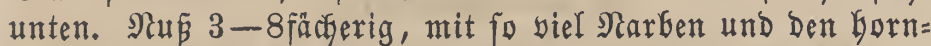
fürmigen Relchlappen gefrönt, je ein Samen, Der am Bipfel bängt.

\section{Tetragonia expansa. Ait.}

Tetragonia cornuta. Gärtn. Moench.

Tetragonia halimifolia. Forst.

Tetragonia japonica. Thunb.

Demidovia tetragonoides. Pall.

Neufeeländifäer Spinat, gemeine Biererfafrucht.

\section{Arten = Sharater.}

Stengel federfieldiaf, liegend, äftig, 2-3 ซur lang. Blätter $1-1 \frac{1}{2}$ Solf lang, faft 1 Solf breit, abmedffelnd, biff, graugrün, elliptifa-rautenförmig, faft berzförmig,

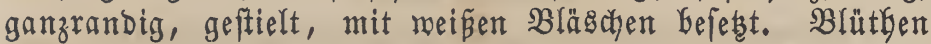
furzgeftielt, roinfelftändig, meift cinzeln, gelb, mit 16-20 Staubfäben. NuF fteinfart, freifelförmig, oben 4effig und 4färtjerig, mit 4-8 eiförnigen Samen.

2)

\section{Blithe $=$ Beit und $\mathfrak{D a u t}$.}

\section{3orkommen.}

Sn Neujeeland und Sapan, bei uns in (särten angebaut.

\section{ふultux.}

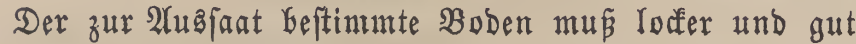
gebüngt fein und eine fonnige lage baben; man fäet bie

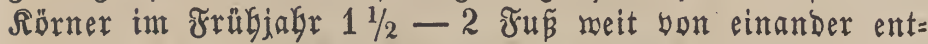
fernt. Die Seblinge werben yerpflamzt, fobald fie $3-4$ Blătter baben, und zwar jebet in megr fofattig gelegene

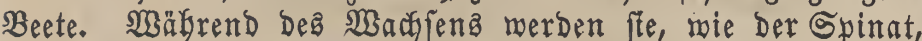
fleip̧ig begoffen. Wisenn bie Bmeige eine Ränge von $1-1 \frac{1}{2}$ $\widetilde{F} u \tilde{B}$ erreicht Gaben, fo werden fie ars braudbar über ben 2 ober 3 unterften afogefdnitten, und fie erfesen fich fegr fantell mieder. Will man diefes Bemüfe früber haben, fo mirb Die 2(uşaat in's Frübleet ober in Töpfe gemacht, welch'

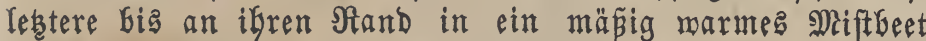
gefest werden.

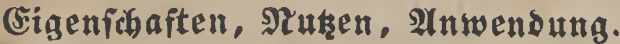

Der Same bleibt $3-4$ Jakre lang feimfräftig, bie jaftreichen fleifchigen und füblend foyntectenden Blätter geben

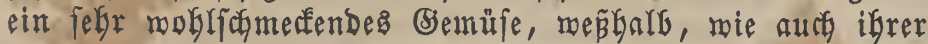

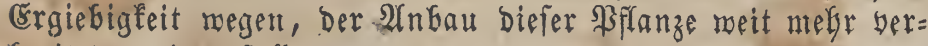
Greitet merben folfte.

Enrmer, bfonom. Pffanzentunde.

\section{Rumex. L. Spr.}

Acetosa. Neck.

Lapathum. Adans. Moench.

Syfteme: Incompletae. Roy.

Holoraceae. L.

Polygona. Adans, Juss.

Portulacaceae Polygoneae. Rchbch.

Vaginales. L.

- Hexandria, Trigynia. L.

Sieldy einfach, 6tbeilig, bleibend, bie 3 untern Rappen

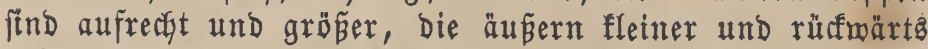
gebogen. Blumentrune febglt. Staubgefäße 6, paarmeife ben

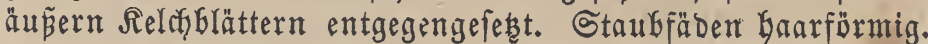
Staubbeutel länglich. Frudytfnoten 3ecfig. Briffel haarfür= wrig, furz, zuxủdfgebogen. Narben grof́, feberig. Frudyt 3erfig und yon ben untern zufammengangenden Reldalappen eingefogloffen; weldye befönt ober aud unbefönt ftnd.

\section{Rumex Patientia, L.}

Lapathum hortense. Lam. Moench.

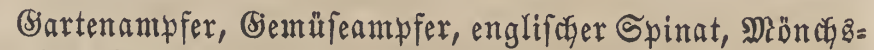
rhabarber, Gebuldfraut, ßatientafraut, gelinder Sartenampfer. Patience surette, Parelle des jardins. (finnz.)

Patientia Dock. (engl.)

\section{Arten = Sharafter.}

Şurzel gropa, biof, fajerig, fleipanig, aupen braun, innen fafrangelb, mit rötglicfen Stridfen. Stengel $2-6$

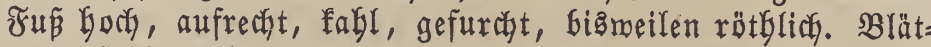
ter geftielt, abmechfelnd, breit-eilanzettförmig. Scheiden röbrig, bäutig, geftreift, Den Stengel feft umfwlię̧end. Die 3witterblütben find grünlich, fteben unterbrochen und quirl= förmig auf furzen Stielen in Trauben auf ben Spiben Der Hefte und Dez Stengelä. Die Durchmachfenden Decf́lätter fund bäutig und fobief abgeftubt. Die einzelne Sdumiele ift roth und fugelig Man findet auch meibliche Blütben, weline fürzer geftielt und fleiner find.

\section{Blüthe = Beit und Dauex .}

$$
\text { গuni - 2uguft. } 4 .
$$

\section{Boréommen.}

Sn Sübeuropa, Shmaben, Der Setterau, in Nafia

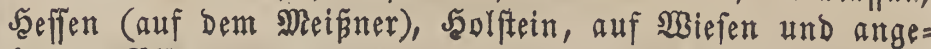
bauten slägen.

\section{Sultur.}

(̌rr liebt befonders einen fibattigen feuchten Slab. Man fäet Den Samen yom Meärz Gis in Den 2 luguft reifenmeije

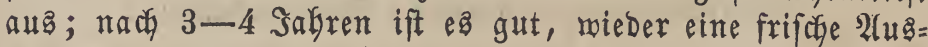

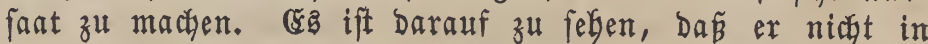
Samen fohieśe, weil er fonft ein läftiges und fodwer zu ber= tilgendes Unfraut mirb.

\section{Cigeniobaften, Nutsen, Anwenoung.}

Der Gante bleibt 2 Jahre gut. Die Blätter fochmerfen angenefyn fäuerlich und füblend. Der englifdye Spinat gibt

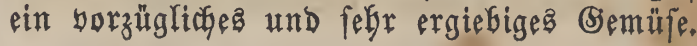




\author{
Rumex Acetosa L. \\ Acelosa magna. Gilib. \\ Acetosa pratensis. Mill. \\ Lapathum Acetosa. Scop. \\ Lapathum pratense. Lam. \\ $\beta$. Acetosa sterilis. Mill. \\ $\gamma$. Rumex sagittifolius. Campd.
}

(Broper Sauerámpfer, gemeiner Umpfer, Sauteranter, Wiefenfauerampfer, Wrarbjauterantpfer, Sauerfenf, Säuerling. Oseille ordinaire, Oseille des prés, 0seille commun, 0seille cultivée, Saliette, Vignette. (frinz.)

Common Sorrel, Meadow Sorrel. (engl.)

Acetoso. (ital.)

\section{Alrten $=$ ÇGarakter.}

SWurzel zậerig, gelb. Stengel $2-3$ Frü hoch, auf=

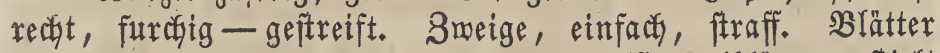
eilanzett - pfeilförmig, ganzandig, bie Mutrzelblätter geftielt und ftumpf, bie am Stengel ftiellos, fpibig und unfaffend. Scheiben bäutig, an গande gezägnt-borftig. Blütben grünlich, rötglich, Galbquirlfürmig ftebend. Die Ẽndtrauben Gaben geglieberte Stiele. Die eirunben Relchblätter find ganz: in Den männlicfen $\mathfrak{B l u ̈ t}$ then abftefyend, Gei ben weib= licfen zufammengeneigt. Sirone feglt. Staubfäben 6 , felgr furz, Gaarfürnig, im Blumenboben ftehend. Staubbeutel aufrecht, 2 fitöpftg. Dberer Fruchtfnoten 3erfig. Sriffel Gaar= förmig, zurüafgebogen. Narbe meiflich, federig. Samen 3ectig.

Es gift eine Narietät:

Rumex intermedius. DeC.

Rumex Acetosa $\beta$. crispa. L.

Rumex Acetosa $\beta$. auriculatus. Wallr.

mit jehr äptigen abftebenden 3reigen 'und geöbrten bibergi= renton Blatthaten.

Blütbe $=$ Beit and $\mathfrak{D a u t x}$.

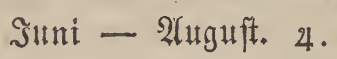

\section{Borḱmuten.}

Ĕurapa, Sibirien, auf Weiben, SWiefen, in Bras $=$ und DGftgärten, ȘGäldern; bie Spielart an büber gelegenen, troffenen Drten, auf foblecten, unfrudytbaren Wiejen. Der Sauerantefer mird audy in (bärten fultivirt.

\section{§ultux.}

Der Saueramyfer gebeigt wohl in jebent Boben und Standpunft. Selten zieft man ifn aus Samen, in melda

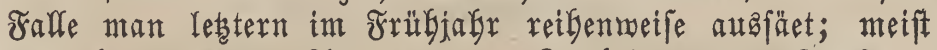
wermeght man Den 2(mpfer Durch Bertheilung Der Störfe.

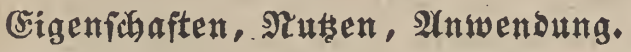

Die vormaltenden Beftandtheile Des Saueranteres find

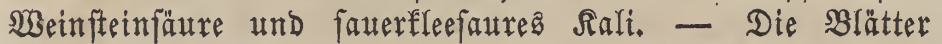

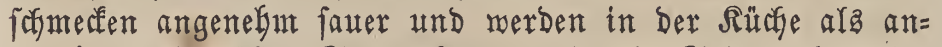
genefmes (semüfe, Suppenfraut und als Salat gebraucht;

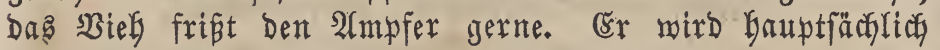
gegen Den Scorbut angemendet. Man bereitet auch Sauer= fleejalz aus ifm und geminnt aus 200 Şfund frifdyent Rraut etwa 16 Pfund Salz.
Rumex scutatus, L.

Acetosa scutata. Mill.

Lapathum scutatum. Lam.

$\beta$. Rumex glaucus. Jacq.

Rumex alpestris. Jacq.

Lapathum alpestre. Scop.

$\gamma$. Rumex hastaefolius. Bbrst.

$\delta$. Rumex luxurians. Hort.

$\varepsilon$. Rumex oxyotus. Campd.

- Acetosa romana. Blackw.

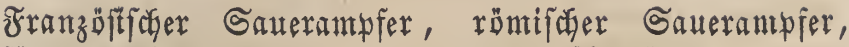

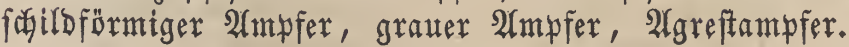

Oseille franche, 0seille ronde. (franz.)

French Sorrel. (engl.)

\section{Arten = CGarater.}

Manrzel friedjend, faferig. Stengel im $\mathfrak{A}$ nfange nieber: liegend, bann auffeigend, $1-2 \widetilde{F u} \mathfrak{b}$ god, geftreift, fabl, graugrün. Blätter langgeftielt, faft Deltafürmig, fpieß̋fürmig, graugrün; die $\mathfrak{W u r z e l b l a ̈ t t e r ~ e i f u ̈ r m i g , ~ e t w a s ~ g e i g e n f o ̈ r m i g , ~}$

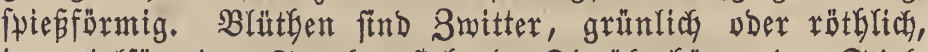
in quirffürmigen Trauben ftebend. Die überbängenden Stiele fteben zu 3-4 in einer băutigen Safeibe. Die Endrauben find nacft und jafaff. Die Rlappen ftnd beinake rund und ungleich. Staubfäden 5-15 an ber $3 a b l$.

\section{Blïthe $=$ 3eit und $\mathfrak{D a u e r}$.}

Mai - suli. 4 .

\section{3ortommen.}

In Mittel = unb Sübeuropa, bäufig in Deutrafiand ver= wildert, in Salleften, Deftreich, Salzburg, Baiern, Satwa=

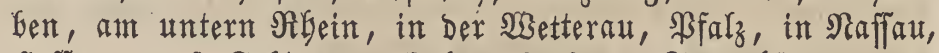
şeffen, auf Beftrgen, bohen zelfen, Schuttbäufen, an Mauern; wirb in Sä̈rten angebaut.

\section{§ultux.}

(Sigenichaften, গ⿰讠士

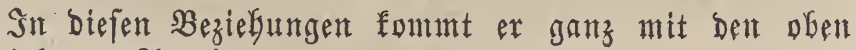
Gejariefenen 2 moberarten überein.

\section{Chenopodium. L. Spr.}

Syfteme: Aizoideae Atripliceae. Rchbch.

Atriplices. Rül. Juss.

Blita. Adans.

Chenopodeae. DeC. Spr.

Holoraceae. L.

Incompletae. Roy.

Pentandria, Digynia. L.

Selch 5theilig, auch 3theilig, Gleibend. Die Rapwen

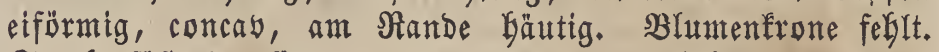
Staufgefäpe 5, fetsen in Dem Reldy und fteben ben Reldy= zipfeln gegenüber. Staubfäden pfriemenförmig. Staubbeutel runblich, 2fmotig. Fruchtfnoten runblich. Eriffel 2, ober 1 mit 2 Narben. Narben pfriemenfömig, fpib, baarig. Samen yon bem unberänderten Relche umgeben, magerecfit, felten aufrecht. Die äunere Samengaut hart, fnorpelig, braun ober fowmarz, wie innere fein. 
Chenopodium album. L.

Chenopodium Atriplicis. Heyn.

- candicans. Lam.

- concatenatum. Thuil.

- glomerulatum. Rchbch

- lanceolatum. Merat.

- leiospermum. DeC.

- paganum. Rchbch.

- $\quad$ salium. Hamilt.

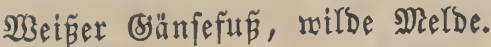

Anserine blanche. (franz.)

Common white goosefoot. (engl.)

Chenopodio bianco. (ital.)

\section{$\mathfrak{A r t e n}=$ (5)arakter.}

Die ganze Bffanze ift nefre Doer mentger weiflich be= ftäubt. Stengel $1-2$ J゙t aufrectst ober an ber Bafts nieberliegend, gefurcht. Die Sweige find zujammengefest und beflättert. Blätter abnedafelnd, geftielt, mebr ober meniger breit unb lang, rautenförmig-ei= förntig, ganzrandig, ober mebr ober weniger budutig gezalint und ausgebiffen, bie obern aber immer ganzrandig, länglich, lanzetfförmig. Blüthen fteben bicht in aufrecten 2refren. reldy 5ectig. Gancen ganz glatt und fein punftirt.

\section{Blüthe = Beit und Dauer.}

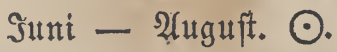

\section{3ortommen.}

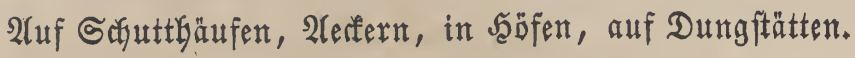

Sigenfibaften, stuten, anwenoung.

Die jungen Blätter Eenübt man mie Spinat and bie Wurzelfproffen wie Spargeln; auth wirb ber Same als (Sinke Genübt und zu Brod, yerbaden.

\section{Blitum. L. Spr.}

Orthosporum. Ledeb.

Syfteme: Atriplices. Rül. Juss.

Aizoideae Atripliceae. Rchbch.

Blita. Adans.

Chenopodeae. DeC. Spr.

Holoraceae. L.

Incompletae. Roy.

Sysellophyta. Neck.

Monandria, Digynia. L.

Relcy 4fualtig, freifuig, offen, Gleifent, mit eirunden, ftumpfen $\mathfrak{a}$ apen, won welden 2 bayon mebr abftefen. Blu= menfrome feblt. Staubgefäß 1, länger alô Der Relch. Staub= faben fadenförmig. Staubbeutel doppelt. Frudfffnoten eirund. Sriffel 2, aufrecht, nach 2üpen gefogen. Sarbe einfach. Rapfel Dünnbäutig, eirund, etrag plattgebrücft, meift yon bent beerenartigen seldye bebert. Same 1, beinabe fugelig.

\section{Blitum capitatum. L.}

Blitum virgatum. Schkr.

Morocarpus capitatus. Scop. Moench.

Atriplex sylvestris. Bauh.

Eroberipinat, Gdymintbere, gemeine Beermelde, fopfs

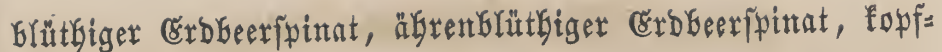
förmige Beermelde.

Berry headed strawerry Blite. (ettgl.)

\section{Sxten = Charafter.}

Şurzel fpindelförmig, unten etwas åftig, oben etwas röthlich. Stengel 1 J̛น

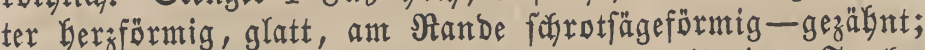
Blätterftiele 4-6 3olf lang; glatt, oben mit einer Jurade.

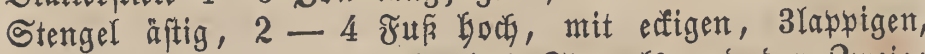
glatten $B$ lättern. $2(\mathfrak{m}$ Ernde Des Stengels und ber Zneige

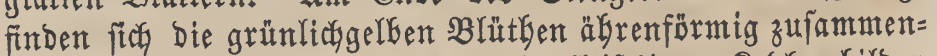
gebrängt und fteben aufrecht. Die fleifodigen Relda bilden rothe, uräbute Beeren.

\section{Slüthe = 3eit und Dauer.}

$\mathfrak{s u l t}-\mathfrak{A} \mathfrak{u g u f t . ~} \odot$.

\section{3orfommen.}

Sm füblidfen હuropa, in wärmeren Throl, bet แns piftera in Gärten angebaut.

\section{Sultux.}

Den Samen fäet man entweder im Seerbfte ober im

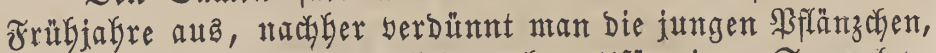
melefje ftì Durch bie länglichen, lanzettförmigen Samenlap= pen yon andern mit ignen aufmadefenden Eemädfen auga= zeictynen.

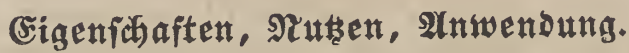

Die ßlätter fönnen als (semủie ftatt des Spinats ge= noffen werben, aud Genủbt man fie zu Salat. Dié mit fleifwigem rotfen Reldye. bebeciften Samen werben gendflen,

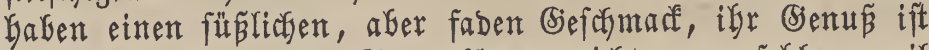
aber megen bet vielen Samenfürner nicht zu empfeblen, weil

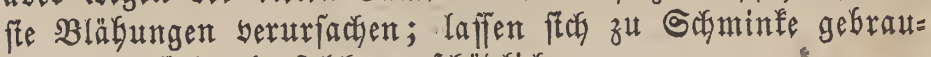
dyen unt ftrtb als foldye unichäblich.

\section{Blitum virgatum.}

\section{Blitum capitatum. Sturm.}

Monocarpus foliosus. Moench.

$\beta$. Blitum chenopodioides. Lam.

(S) meiner Ërobeerfintat, genteine Erobeernelbe, rutbent= förntige Beernelde.

Slender branch strawerry Blite. (entgl.)

\section{Arrten = (5)arater.}

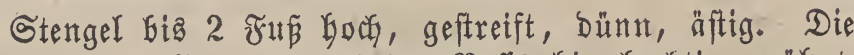

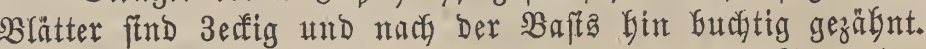
Die Blumentöpfaten fuben ofhe Dronung an Den Seiten ber rutbenförmigen, meiftens überfängenden, oder feitwärta ge= Gogenen 3weige. Die oberften Blumenföpife find beblättert. Die beerenartige Frucht ift erft grün, Dann Dunfelrotfo.

Mai - 2ugutt. $\odot$.

$$
\text { Blüthe }=\text { Beit and } \text { Santer. }
$$

\section{BorÉmmen.}

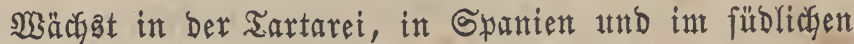

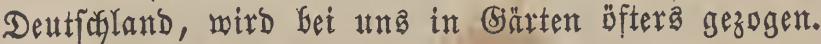

\section{Nultur.}

Eigenfadaften, stutuen, S(nwendung.

Sise bet ber yorigen 2 rrt. 
Blitum bonus Henricus. Meyer.

Agathophytum bonus Henricus. Mocq. Tand. Chenopodium bonus Henricus. L.

Chenopodium sagittatum. Lam.

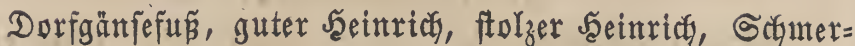

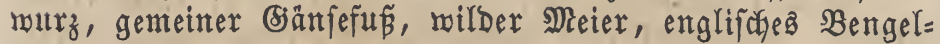

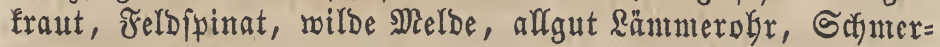

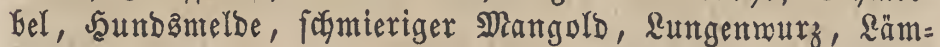
merfraut.

Toute bonne, Bon Henri. (franz.)

Mercury. (engl.)

Bono Enrico. (itar.)

\section{Arten = Sharalter.}

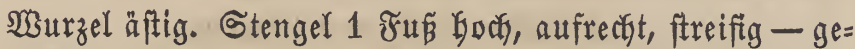
furcht, fabl, einfach, beftäubt. Blătter geftielt, abrocedfelnd, fabl, 3erfig- pfeilförntig, ganzrandig und bejonders an ifrer untern Fläche fodmierig beftäubt. Die Alefren find Didbt zu=

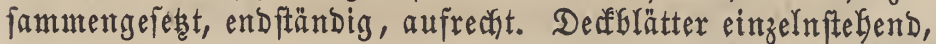
linienförnig. Selchabfuntte abgeftutet, an ber Spike 3zäh=

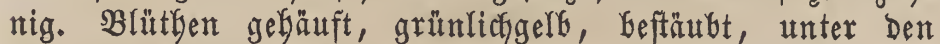
Swittern befunden fich biele meibliche. O5riffel $2-3$.

\section{Blüthe = Beit und Dauer.}

Mai - Suli. 4.

\section{3ortommen.}

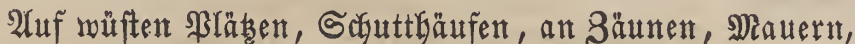
in (8ärten und Dörfern yon Europa und Sibirien.

(sigenfabaften, গtutzen, Anwendung.

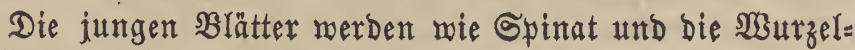
fproffen wie Spargelm benühts.

\section{Beta. L. \\ Siefre Seite 29.}

\section{Beta Cicla. L.}

Sielge Seite 30.

Unteraut.

\section{Beta Cicla alba.}

Wei ß̌et Mangold.

Sultux.

Siełe bei ben Sarietäter.

(sigenibaften, stuten, anvensung.

Der Same bleift 6-8 Jagre lang gut. Die Mangulde liefern ein befanntes biemüfe.

1. (B) e röbulicher Mangold.

(5x verlangt einen loffern, gutgebüngten $B$ Dben und

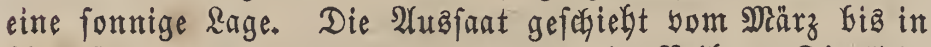

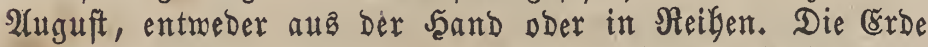
reinigt man gebörig bour ltnfraute unb begieşt ffeip̄ig.

Dą a minje bat feinen befondern $\mathfrak{B}$ oflgefdymaf und man verbeffert biefen geröbulich Durch Sutfun yon etwas Sauerampfer.

\section{Berber Sabetzer= Mangold.}

Rippenmangolb.

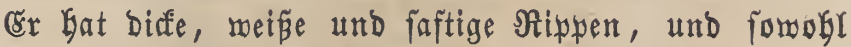

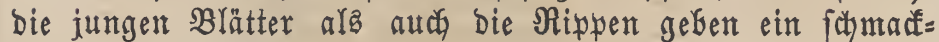
Gaftes Semüfe. Mrit ber 2(usfant biejer Sorte ricatet man ftch ganz nach Der Seit, in welcfjer man fte benühen will. Bum Sebraucte für bett Frübling fäet man ben Samen int ZYuguft, und zur Benübung für Den Şerbft und Sinter int

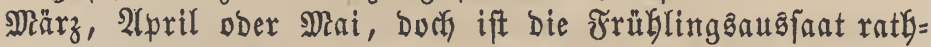
fanter, meil biefer Mangold ben WBinter über fegr gerne erfriert. Mean jäet Den Samen Dünn, am beften reifgenweije,

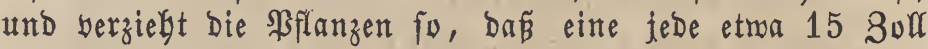

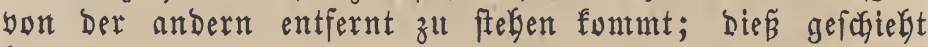
Gauptfäcblich, wenn man die jungen Manguldblätter wie Spinat gebrauchen wiff, ober und befonders zur Benübung Der Blattrippen, man berpflanzt bie fräftigften Seblinge auf ein anderes Beet in 3 Reiken und in einer Entfernung yon 2 Fũ von einander; in biefem lekteren Falle müifen bie

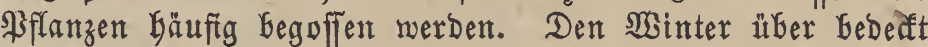
man fie mit Raub ober Streu, gebrauche jeboch bie Borfitht,

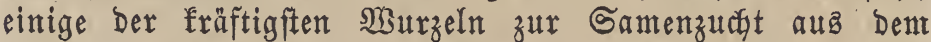
Ranbe zu nelymen und im Siller zu überwintern, Da bie ßffanzen im freien Rande erfrieren. - Die Samenftzonfe wer= Den an Stöbe gebunben und bie Gamen reifen meift int September, wo fte eime afrograue oder rötbliche Farbe be= fommen.

Atriplex. Spr. L.
Atriplexum, Rchbch
Euatriplex. Meyer.
Halimus. Wallr.
obione. Gärtn.
Schizotheca. Meyer.

Snfteme: Aizoideae Atripliceae. Rchbch. Atriplices. Rül. Juss.

Blita. Adans.

Chenopodeae. Spr.

Holoraceae. L.

Incompletae. Roy.

Sysellophyta. Neck.

Polygamia, Monoecia. L.

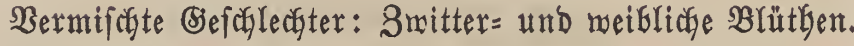

3witterglütge: Relry 5theilig, 5ectig, bleibenb. Blumen= frome fehlt. Staubgefäße 5, fleben Den Reldyzitpeln gegen= inber. Staubfäben yfriemenfürmig. Staubbeutel 2fmöpfig. Jrudftfnoten runblicf. (Sriffel 2, ober 1 mit 2 Narben. Narben pfriemenförmig, fpisig, haarig.

Beibliche Blüthe: Sielch 2fpaltig ober 2theilig, mit an= liegenden Seldylappen, weldye nady Der Blüthe ftedy vergrö̈B̈ern und bie Frueft bebecfen. Blumenfrone feglt. Fruedffnoten zujammengebrüfoft. Sriffel und Narben wie bei Der Bmitter=

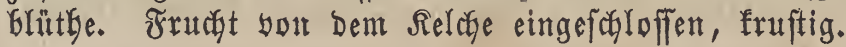

\section{Atriplex hortensis. L.}

Atriplex acuminata. Bbrst. ? Atriplex benghalensis. Hort. $\beta$. Atriplex ruberrima. DeC. 
(8artenutelbe, Ssemüremelbe, gebaute Meelbe, milber Gpi= nat, Buffermelde.

Arrache, Bonne Dame. (fitallz.)

Common garden Orache. (engl.)

\section{Arten = (5)araler.}

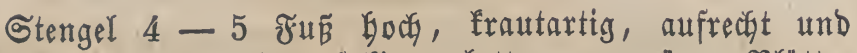
auşgebreitet—äftig, ftumpfeḉg, glatt, graugrủn. SBlätter matt gelblicfgrün, in Der Jugend etwa meblig beftäubt, glatt, Die obern länglich-4eçig, etwas fpief́förmig, bie un= tern grof, abmedffelnd, geftielt, berzförmig-3ecfig und ge= zäbnt. Blüthenäbren flein, gipfel = unb achfelftändig, zu= fammengefest. Die Blütben find flein, rein̈gelb. Frucht eiförnitg - runblis, flach, 3rippig, platt und yon nebartig geaberten, ganzranbigen, Gäutigen und glatten Feldegen $\mathfrak{u m}=$ geben.

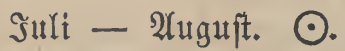

\section{\$orfommen.}

Эa Sübeurowa, Eriectentand, Sibirien und ber Tar= tarei einkeintijas, in Deutfaland aber verwildert, auf 2 Ceffern

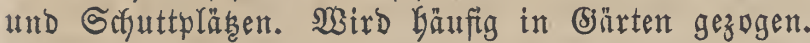

\section{Sitltur.}

Man fäet bie Gartenmelde mie ben Spinat int ornuly= linge Dünne auf gutgedüngten $\mathfrak{B}$ oden, an $\Re$ ändern von $\mathfrak{B e e}=$

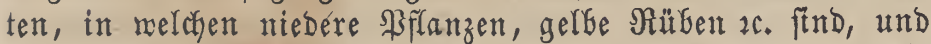
verziegt, went es Seit ift, bie \$fflanzen bis auf eine ént= fermung yon etra $1 \frac{1}{2}$ ₹̛ur yon einander. Berfeten Darf man bie jungen $\mathfrak{P f l a n z e n}$ nur fantmt Dem Ballen.

\section{Eigenfabaften, গutzen, צtnwendung.}

Das Sraut bat feinen Berudy, aber einen frautartig

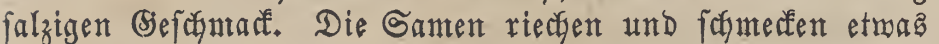
brenzlich und bleifen 2 Sabre lang feinfäbig. Man benübt fie mie ben Gpinat alş ઉ̉emüfe und Gäufĭg in Berbint= bung mit Spinat, Sauterampfer (mie bäufig in Franfretdi), Bwiebeln 2 .

Sie baritit:

Atriplex ruberrima. DeC. mit ganz rothen Stengeln, Blăttern und Trauben. Sie färbt bie Giemůfe roth.

\section{Atriplex Halimus. L.}

Chenopodium Halimus. Thunb.

Meérmelde, ftraucbartige Melde, Meerfortulaf.

Tall shrubby 0rache. (engl.)

\section{Arten = Sharater.}

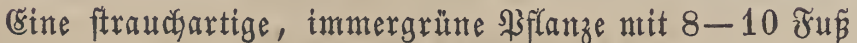

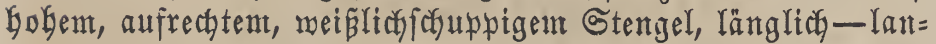
zettförmigen, ftumpfen, gegen Die Saftz bin fedmäler mer= Denden, ganzrandtgen, biffleifdyigen Blättern. Die fleinen Blüthen bilden rumbe snäuel und fteben riguenförmig. Die Rlappen ber Fructst find rauterförmig, ganzrandig und auf

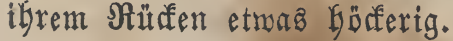

Stithe = 3eit und Daner.

$\mathfrak{J u l i}-\mathfrak{2}$ uguft. $ち$.

\section{Borénmen.}

Sn Sübeuropa, am Nittelmeer, im Srient, in Nord= ărif́a, ant Caps und in Neufolland, mird Gefonbers in Ěrigland, אolland und ßortugal angefaut, nut felten aber bei una.

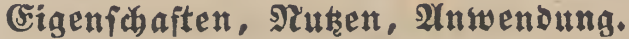

Die Blätter haben einen jäuerliçen, falzigen Befómad?. Mian fpeizt die Blätter ala Bemüle, fé und die jungen Stengel werben in Sadhand und Ëngland in Salz gelegt und als Salat, und in ßortugal bie jungen Sproffen wie bie Spargel genoffen.

\section{Atriplex portulacoides. L.}

Chenopodium portulacoides. Thunb.

Diotis portulacoides. Spr.

Halimus ? portulacoides. Wallr.

$\beta$. Halimus australis. Nees.

Sortulafmelde, portulafartige Melde.

Arroche pourpière. (ftattz.)

Dwarft shrubby 0rache. (engr.)

\section{Arten = (5)arakter.}

Wiurzel bielf́pwftg, treibt äftige, aufiteigende Stengel,

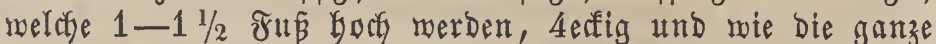
Bflanze beftäubt find. Blätter geftielt, entgegengefest, ber= feGrt eiförmig - lanzettförmig, ganzrandig, auf beiden Sei= ten weifigrün. Blütthen endftändig und ftef̧en gefäuft, trau= benartig. $\mathfrak{A} \mathfrak{m}$ Srumbe der abwechfelnden, einfachen ober verzmeigten 2lefte ift ein lanzettförmigea Decfflatt. Blütben flein, gelbGräunliç, faft alfe männlich ober meiblich, feltent

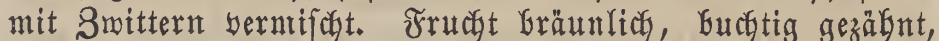
Der mittlere $3 a \mathfrak{h n}$ ift länger.

\section{Blütbe = 3eit uns Dauer.}

$$
\mathfrak{J u l i}-2 \mathfrak{A} \mathfrak{g} \mathfrak{u} \mathfrak{t} . \quad \text { ち. }
$$

\section{Borkommen.}

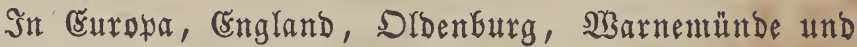
in 2 frifa an Seeufern, überbaupt an feudeten Drten.

\section{Sultur.}

Sn rauben und falten Elegenden Deutichlands ift eB in Betreff Dez $\mathfrak{B u c h j e z}$ und Der Dauer yon mefentlichem Nubert, wenn man fte in Töpfen erziegt und in einem Slabhaufe

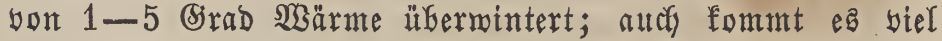
auf Den Standort und Boben an, wenn fte im Freten fräf= tig vegetiren folfen. Sie ertragen bas $\mathfrak{B} e r f e s e n$ im 2ulter Durcfaus nicht.

(igenfarten, Nuten, Anwendung.

Wird wie bie borigen Melden benüt, aurf merbent bie Blätter mie Čavern eingemadyt.

\section{Atriplex angustifolia. Smith.}

Atriplex patula. Pollich.

Atriplex virgata. Hoffm. Scop.

$\beta$. Atriplex erecta. Smith.

Schmalflütterige Mielde, wilde Mielde.

Arten $=$ (5)arakter.

Stengel frautartig, mit augebreiteten 2 (reften, B̧ätter 
Ianzettförmig, ganzranbig, geftielt; bie untern fpiesförmig, etwas gezalght, Die oberften linienförntig. 2Hehren flein, ent =

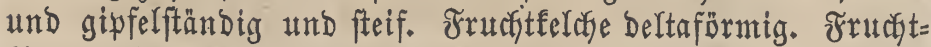

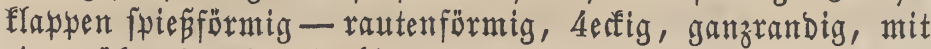
einer über bic Frucht Ginausagagenden Spibe.

$\mathfrak{s u l i}-\mathfrak{A}$ ugutt. $\odot$

\section{3lüthe = 3eit und Dauer.}

\section{3ortommen.}

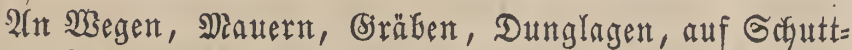
Gäufen, Rrautgärten.

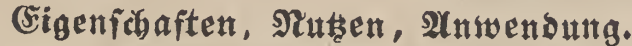

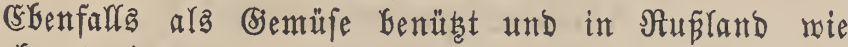
Sauerfraut eingemadyt.

\section{Portulaca. I. Sp. \\ Lemia. Vandel. \\ Merida. Neck. \\ Meridiana. L. Schrank.}

Syftemte: Diplosantherae. Roy.

Dodecandria, Monogynia. L.

Portulacaceae. Juss.

Succulentae. L.

Saxifragae. Roy.

Ypsoophyta. Neck.

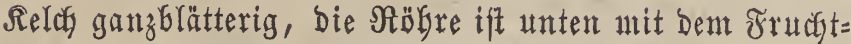
fnoten verwadefen wber beinake frei, Der Saum unterftändig voer. Gall oberftändig, 2 faltig, abfallend. Bhlumenfrone 4-6blätterig, hinfälig. Bluntenblätter entweder frei ober

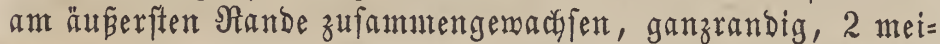

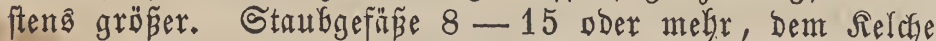
eingefügt. Staubfäben fabenfürmig. Staubbeutel 2fü dherig, 2fnutig. Stempel 1. Fruchtfnoten Galb unterftändig ober oberftändig, einfädjerig. Erriffel 1 , in $3-8$ fabenfürnige Bipfel getbeilt. Narben papillig, an Der snnenfeite ber Goriffelzipfel berablaufend, Siapfel eiförmig ober fugelig, Gäutig, 1 fächerig, bieljamig. Santen nierenfürmig, glatt, geftreift oder gefürnt, eimeingaltig.

\section{Portulaca oleracea. L.}

$\beta$. Portulaca sativa. Haw.

Portulaca latifolia. Hornem.

$\gamma$. Portulaca laevis. Hamilt.

Bemeinter Sortulaf, Giemüfeportulaf́, Soglportulaf, Burzelfraut, Brunzelfraut.

Pourpier. (fianz.)

Purslane, Purslain. (engl.)

\section{Arten = (5)arater.}

Stengel 1 Juf hoch, fultivirt oft 4 Fus boch, liegend, glatt, faf̣tig, äftig, bellgrün glänzend, bäufị rötblich ange= flogen. B̉ätter feilfürmig, gemöhnlich abmedyfelnd, amfthend, bis zur Spike ber 2lefte reichent, glatt, glänzento, bidé, faf = tig. Blüthen fleit, anfetzend, gefäuft, winfelftändig und glänzend gels. Relch, Blumenblätter und Staubfäben an ifrer

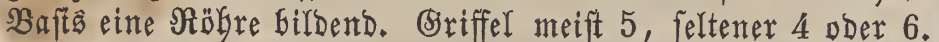

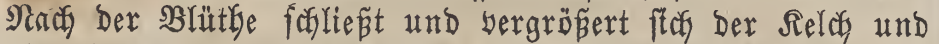
bie obere Sălffte deffelfen läst fich bei Der Samenreife won

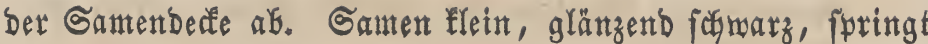
in Der Duere auf.

\section{Blütfe $=$ Beit und $\mathfrak{D a u e r}$.}

รunt - 2uguft. $\odot$.

\section{3oréntumen.}

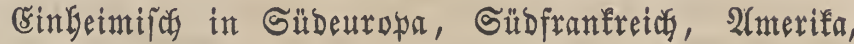
Ditindien, auf Jaba, bei uns auf bebauten und unbefauten

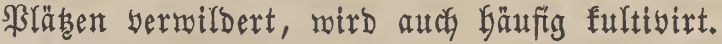

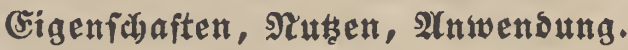

Nan benüht Den Bortulaf als bentüfe, Salat, zu Suppen, aud wendet man ibn gegen Den Scorbut an.

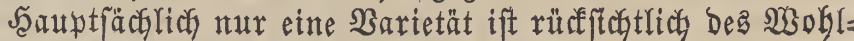

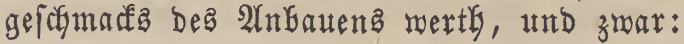

\section{Der gelbe $\mathfrak{A}$ ortulat.}

Sortulaf mit grofen gelben Blättern.

Der ßortulaf gebeigt am beften in eimer locfern, $\mathfrak{n a b r}=$

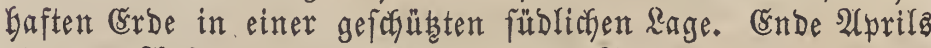
Dber zu $2 \mathfrak{n}$ fang Meat's fäet man Den Samen bünn aua, be= becft ifn leidft mit gereinigter Dungerbe und begiefst ifn im 2lnfang bäufig mit Braufe. SYBifl man bent \$ortulaf treiben, fo mirb er fichon im Samuar ober noch im März in Mift= beete gejäet, etwas angebrürft und mit Fenftern bebedft. Son

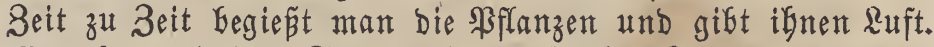
Man fammelt ben Ganten, fowie fich bie Samenfapfeln öff= nen, yon ben beften Stöffen, Yäpt ibn bis zur volffommenen Trodenfeit in Der Gonne liegen und enthürat ifn Dann. Der Same bleibt 2-3 Salyre feimfähig.

\section{Asparagus, L. Spr.}

Syfteme: Asparagi. Rül. Juss.

Asphodeleae. R. Br

Gonoophyta. Neck.

Hexandria, Monogynia. L.

Liliaceae Asphodeleae Asparageae. Endl.

Liliaceae Aspargi. Adans.

Lilia monopetala. Roy.

Sarmentaceae. L.

Sarmentaceae Asphodeli. Spr.

Sarmentaceae Smilaceae. Rchbch.

Relch feGlt. Blumenfrone unterftändig, walzig-glodéte förmig, 6fpaltig ober 6theilig, Die 3 innern Bipfel find an Der Spibe melgr umgebogen. Staubgefäße 6, Dem Rronen= grunde eingefügt. Staubfäden pfriemenfürmig. Staubbeutel

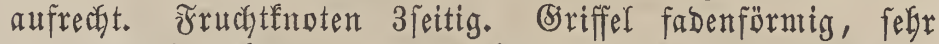
furz. Siarbe 3theilig. Die Blütyen oft getrennten Befollechta. Beere fugelfürmig, 3fächerig, jebe家 శach 2famig. Sament rund, imnent minfelig, glatt.

\section{Asparagus officinalis. L.}

Asparagus officinalis $\gamma$. altilis. Willd. Asparagus sativus. Mill.

$\beta$. Asparagus officinalis maritimus. $\mathrm{L}$. Asparagus maritimus. Mill.

Asparagus prostratus. Dumort.

Bemeine Spargel.

Asperges. (ftattz.)

Asparagus, sparrow-grass. (entgl.)

Spargio, Asparago. (ital.) 


\section{Arten = Sharater.}

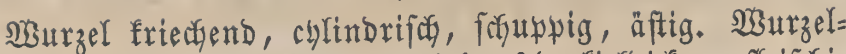

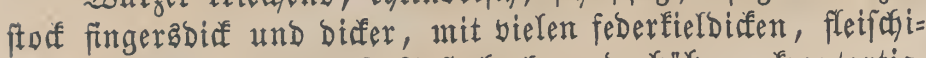

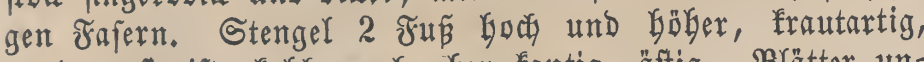
runb, geftreift, fabl, nacy oben fantig, äftig. B̧ätter un=

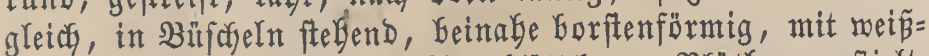
lidyer Spike und fleimen 2lfterblättchen. Blüthen geftelt, einzeln ober zu uelgreren in Den Blattwinfeln ftefend, gelb=

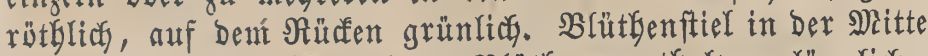
gegliebert. Die bängenden Blütben entbalten länglictse, ftumpfe Blättchen, weldye am Sirunde zufammenlyängen und weiß̧lich ausfeben. Blumenfrone 6theilig. In ber weiblidyen B̊lüthe trifft man nur Nubimente Der Staubfäben und 3 zurüffógebgene Narben an; in ber männlitben ift faum eine Spur eines (Eriffela. Beeren rund, erft grün, bann braun

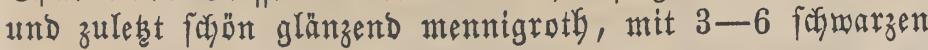
Samen.

\section{- Brintbe = 3eit und $\mathfrak{D a u e r}$.}

$$
\text { รัuni - งิuguft. } 4 \text {. }
$$

\section{SorÉomen.}

In Deutfahland bie und da werwitldert auf fandigen Alefern, am Sande Derjelben, auf trofenen $\mathfrak{B}$ tejen, in

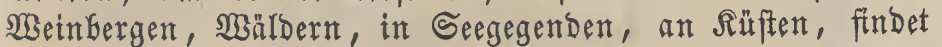

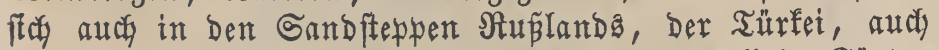
in Sibirien und Sapan, und mird faft überal in Särten angebaut.

\section{Sultux.}

Die Spargel werlangt einen reichten, ftarf gebüngten Boben und eine marme, fonnige und nad Süben freie Rage. Man bermegrt bie Spargeln Durdi SWurzeln, bie Spargel= flauen, doer Durch Samen. Mlan gräbt Das zur Spargel= Anlage beftinnte Beet im Gpätjalr, Ernde Septentbers oder $\mathfrak{A}$ (nfangs Dftobers, bei gutem $\mathfrak{B}_{\text {etter }} 2 \frac{1}{2}-3$ Fur tief aus,

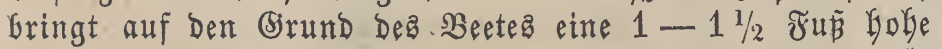

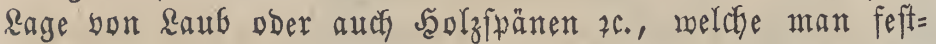
tritt, und bezeidjnet mun an Den längern Seiten dea Beete?

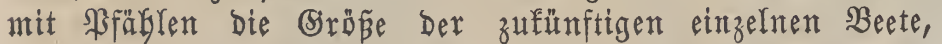

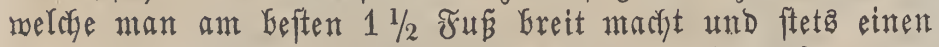

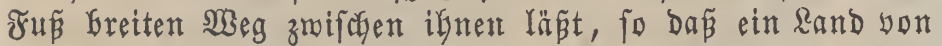

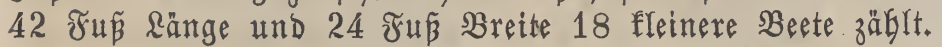
Man bringt mun etma eine 1 Fur bohe Rage yon burch=

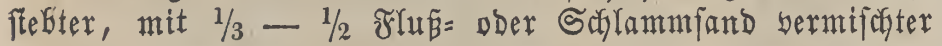
Erbe auf bie erfte Schichte, yun $\mathfrak{a} a b$, Gierauf eitre weitere

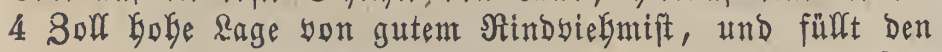

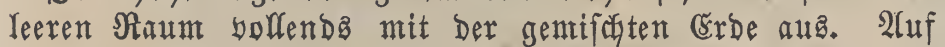
bieje Weife merben num fämmtlicje Beete zugerichtet, und

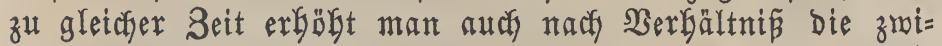

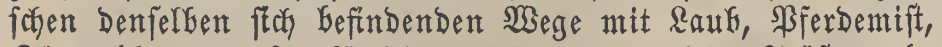

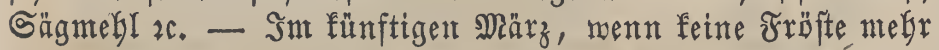

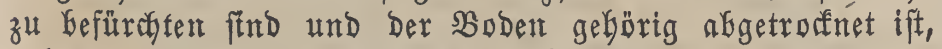
geht man mun an bas Regen Der Słargelflauen, woźu man auf Den oben angegebenen $\Re a u m$ etra 230 Stücfe bebarf und gejumbe 2 jäbrige, auch $3=$ und 1 jäbrige, am bejten Ulmer Spargelflauen wählt, won weldaen man wor bem Legen afles etro Berborbene mit einem guten Deffer ent=

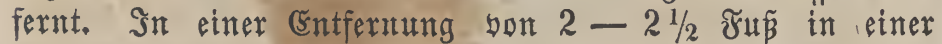

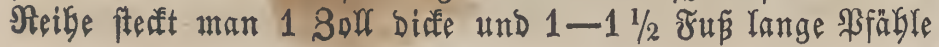

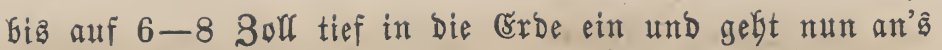
zmeite Beet, in welchem aber bie Pfähle fo eingeftect mer=

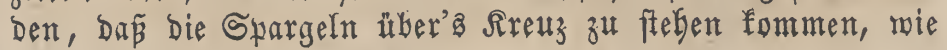

Die Spargelflauen legt man bei guter trodfener WSitterung

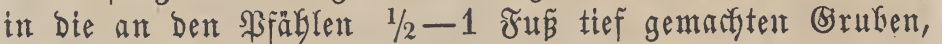

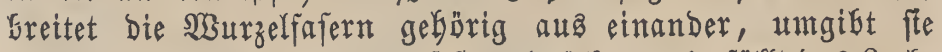

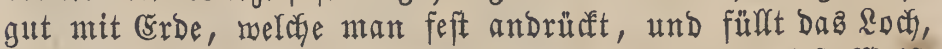

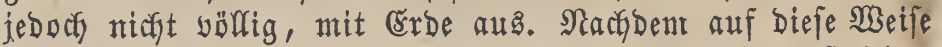

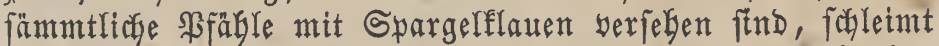
man biefelben, wenn Boben und Matterung nidgt oknebin fichon feucht find, fo lange mit waffer an, als bie ešrbe

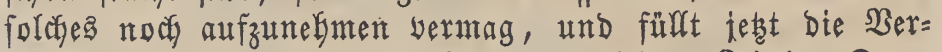
tiefung mit Errbe aus, und bringt zu gletcher Zeit Den Dung

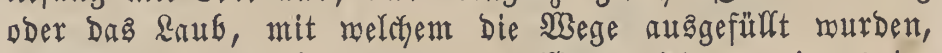

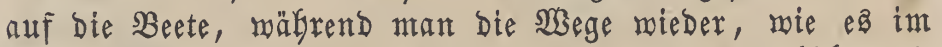
Serbfte gefdaly, mit frifdyem Dünger, Raub zc. ergägt und immer fefter eintritt. Waat fährt auf Diefe WBeife fo lange fort, bis bie Spargelfronen nady und nady eitte Deafe yon 8-10 3olf Rauberde erfalten Gaben, und füllt Dann nur afle 2 - 3 Sabre auf. - Die Spargelbeete müffen immer rein bont Itnfraute gefalten werben, zumal ba die Spargelin in Folge Deffelben einen unangenelymen (5ragigefonmat be= fommen. Fangen im Spätherbfte bie Spargerftengel an, ftch

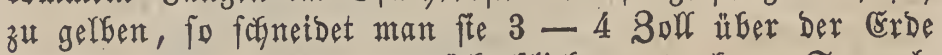
ab, ebenfo auch bie etra zurürfgebliebenen troctenen Spargel= ftumpfen.

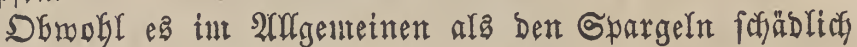
gefalten mird fo fann biés jedoch bet Der hier angefübrten Rultur ofine

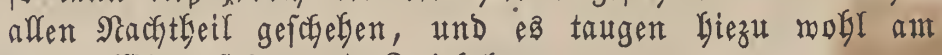
Geften SBinterfalat unb 3wiebeln.

Bei Der Spargelerzielyung aus Samen bereitet man fith bie Beete ganz, mie oben angegeben murbe. Den Samen nimmt man yon fogönen, fräftigen 4-5jälrigen Störfen, ftreift bie Beeren im September yon Den Stengeln ab, zer=

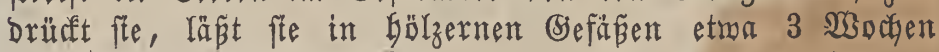
lang liegen, zerreibt biefelben und gieß̄t fte mit rsaffer an,

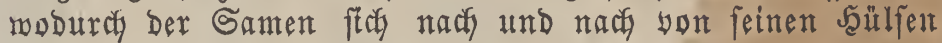
abroß̧t und zu Boben finft. Man breitet thn auf Tüchern,

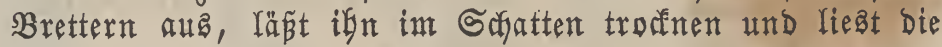

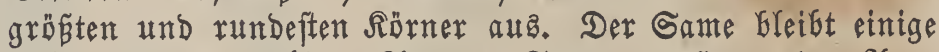

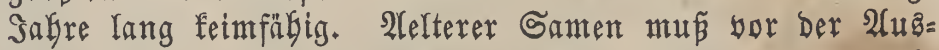
faat 8 Tage in Miftiaudide eingeweidyt merben. Man gräbt nun an jebem Bfable ein $3-4$ 3olf tiefez Rodh, fringt in diefes 3-4 Gamenfönner, Gedecft biefe 1 Solf hoch mit (Erbe und tritt biefe geförig an. Siemölntidy feinten bie Samen 3-4 2 bochen nach Der Saat, unb bann fünt man

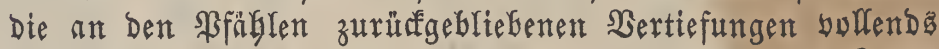

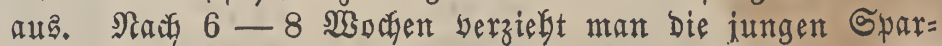
geln biz auf eine, und zmar bie fräftigfte.

Dbgleidy man bet biejer Rultur 2 Jahre länger, aljo 6 Jahre lang zumarten mun, bis man fté eines Extrags erfreuen fann, fo Gefomnt man Doch meit fräftigere Stöefe, als bei ber Bermehrung burch Spargelflauen.

Ham felgft Spargelflaulen zu ziełen, gräbt man (snde

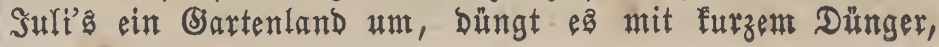




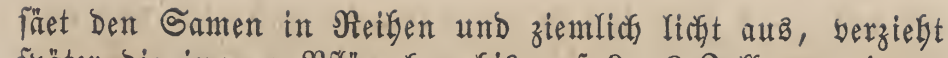
fpäter bie jungen Fffänzchen bis auf $9-8$ 30 ll von einan= Der und bededft fte über Den SBinter leicht mit Strub ober

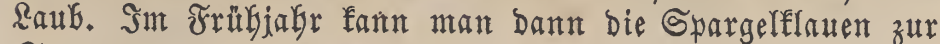
Spargelanlage bentüten.

Wir fonnten nun noch weitere Rulturarten Des Spar= gels anfütren, befdränfen uns aber Des Raumes regen auf biefe beiben und wohl entpfeblengmertheften yon chrift.

Utm fefr ftarfe und zarte Spargeln zu erbalten, ftellt man über fte, fobald fte aus ber Erbe Keraualommen, Töpfe mit einer Deffnung am Boben, weldfe man mit locferer

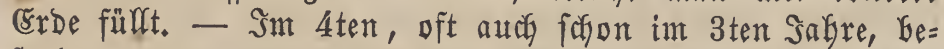
fonders wenn man anftatt 2jäbriger Spargelflauen 3jährige gelegt bat, fann man bie Spargeln ftechen, man eile jeboch nie mit Denfelben, fondern rarte rieber ein Jabr noch zu. (Bemöbnlich treiben bie Störfe 9-10 2Bochen lang ftechbare Spargeln, Doch ift es nicht ratgjam, ben Spargelftich zu

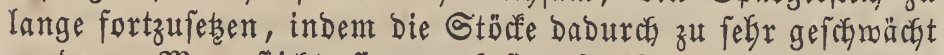
merben. Man fticht fite am beften orrülgmorgens, entblöß口 bie Spargelpfeifen yon Der Erbe, gebt mit einem ftarfen und langen Sartenmeffer Dirgt an Denfelben binunter und breft bann bas Mieffer; Dabet Güte man fted aber, bie Rrone zu beffäbigen, ba fie fonft leicht fault, ebenjo alle Spargeln abzufchneiden, fondern laffe an jebem Storfe $2-3$ ber fräf= tigften ftelyen unb büte fich ferner, bie benachbarten Sproffen abzutreten. - Crin Spargelbeet fann wobl 20 Salyre lang benủbt merden, übrigens folfte man je nach 14-15 Jahren mieber ein 2tes seet anlegen.

Dbgleich die Spargeln im erften Sabre feinen Ertrag geben, fo ift Derfelbe um fo beträchtlidaer im 4ten Jabre, indem ein Storf menigftenz 6 benubbare Spargelpfeifen treibt, und ift Der Spargelanbau, zumal in Der Sähe gróperer Stäbte, felgr einträglich.

\section{Srankbeiten, fchäblicbe Binflüfie.}

Sin Feind Des Spargels ift Der fogenannte Spargel= faffer, Lema asparagi. Bei faltem Jrühjahre fönnen bie zarten Sproffen auch mohl burch zröfte leiben, und eq́ ift befigals anzuratgen, diefelben mit Raub oder Stroh unber bie Nacist zu bebeffen, aber nicht zu berfäumen, fobald Mor= gens Das $\mathfrak{B}$ eet yon Der Sonne erwärmt wirb, bie Raubdecfe mieber abzunehmen, meil fonft bie Sproffen weis merben und viel an Beftymad werlieren.

Esa gibt melrere Spielarten:

$$
\text { 1. Weifer Spargel, }
$$

mit grünen Gpiken, wirb biffer ala ber forgende und wirb unten früber Gart.

2. ธpargel mit grünen $\mathfrak{3 u r z e l f y r o f f e n . ~}$ Sft bie zartefte Spielart.

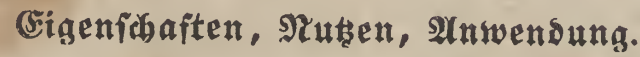

Die Spargeln find eine felr beliebte und gefunde Früb= lingsfpeife und man geniést fre als Bsemüfe, allein ober mit wiogren, jungen ङrbfen, als Salat, mit Bfeffer und Sal gebraten, in Butter gebarfen, bie אüpfe in \$afteten und Torten, auch merben bie Spargeln mit Esfifg und Del ein

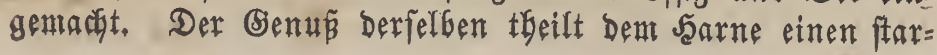

fen, beildsenartigen (s)erudf mit. - Den Samen benübste man auch fohon als Raffeefurrogat.

\section{Lactuca $\mathbf{L}_{\star}$}

Cyanoseris. Koch.

Mycelis. Cass. DeC.

Scariola. DeC.

Syfteme: Cichoraceae. Juss.

Compositae Cichoreae. Spr.

Compositae Hieracia. Rül.

Compositae Lactucae. Adans.

Compositae semiflosculosae. L.

Compositae homoianthae. Rchbch.

Glossariphyta. Neck.

Synantherae Lactucaceae. Cass.

Syngenesia, Polygamia aequalis. L.

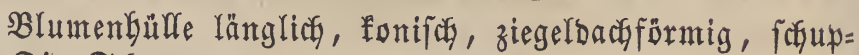
pig. Die Sdyuppen ungleich, lang zugeipist, etwas breit, am Rande troffen. Sriffel fo lang als bie Staubgefäß̈e. Rarbe zurüafgebogen. Fruchtboden nacft. Samen eiförmig, lang gefpikt, zufammengebrüdt, fein geftreift. Zebercfen ge= "ftielt, Gaarfürmig, befaart, meid, Gals verfonmindend.

\section{Lactuca sativa. L.}

Lactuca angustifolia. Lam.

Lactuca capitata. Hort.

Lactuca crispa. Roth.

Lactuca laciniata. Roth.

Lactuca longifolia. Lam.

Lactuca palmata. Willd.

Lactuca romana. Hort. Rattich.

Bartenjalat, Eartentattig, gemeiner Salat, Ropffalat,

Laitue ordinaire. (franz.)

Garden-Lettuce. (engl.)

\section{Arten $=(\mathbb{S h a x a l t e r}$.}

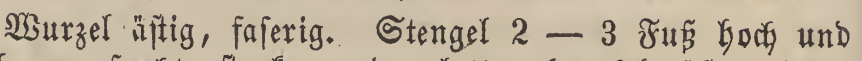
barüber, aufrecht, ftare, rumb, glatt, oben fekr äftig. Blät= ter meift rundlich, afwecffelnd, ganzrandig, ftengelumfaffend, zart = und theilmeife bucftig=gezăhnelt, glatt, faftig, bie untern fofrotfügeförmig - leierförmig, bie obern Gtengel= blätter Kerzförmig zugefpitht. SBlüthen am Ende Der Stengel in vielglütthigen, tiäpenartigen, flachen Dolden ftebent, find flein, mit Nebenblättchen verfeben, gelb. Sielda walzenfür=

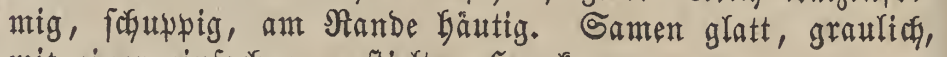
mit eimer einfachen, geftielten Saarfrone.

\section{Blüthe $=3$ eit uno : $\mathfrak{a u e r}$.$$
\text { Iuli - } \mathfrak{A} \text { uguft. } \odot
$$

\section{3orkommen.}

Da⿱ eigentlicfe Baterland Dezి Rattiga ift unbefannt, er mirb aber allgemein in (8ärten und auf Feldern angebaut.

\section{Sultux.}

Der Anbau Dez Galata ift affgemein befannt, und iaf will Gier nur einiges 2 Afgemeine üGer Denfelben und bas Eimzelne bei Den berfbiedenen Sorten berübren. Man ziegt Den Salat meift mit andern Gemächien in ein und bemfel= Gen Rande. (Ex fann meift fodon $6-8$ Woden nach ber 




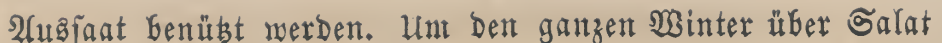
für bie Rürdye zu Gaben, mur man affe 14 Tage ein neuea

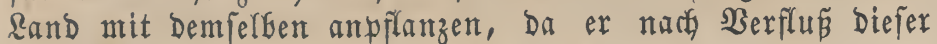

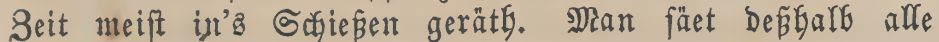
3 Siscenen Salatiamen auf ein fonnig gelegenes Beet, im Frübjugre int Februar, $\mathfrak{M a ̈ r} r$, meift in ein Frủbbeet, um entrober ben Rattich ober Stechjalat, ober Seblinge zu Sommerfobrifalat zu befummen. Diefe jungen Piflanzen ver= fest man 2 (nfanga Mia's und fann fie Dann Ende Suni's gebraudjen. Daß Moitere über Den Salat finden wir bei Den Früblings $=$, Sommer $=$ und $\mathfrak{W}$ Sinter $=$ Salaten.

Sur Samenzudyt läß̈t man einige, etra 8-12, făböne, fräftige Salatfiỏife im Rande fteben, forneibet bie Stengel, menn bie neiften Samen reif find, ab und bringt fie an einen fonnigen Srt, um alfe Samen bollends nachreifen zu Iaffen. Der Salatfamen Gleibt 4-5 Jafre lang gut.

\section{Srankbeiten, făblidbe Einflüfe ze.}

Der Galat mirb bauptfüblich von Den Roblmeipringen (Papilio brassica 1t. Papilio rapae) und yon Den (Erd = flöben und bent Meflthaue Geimgefucht. Das befte Mittel

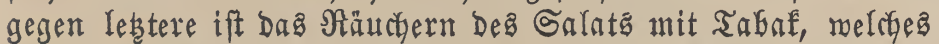
mittelf́t eigens bazu eingerichteter Blafebälge ober blectjerner Büchfen gefdyiebt. Ungünftige naffe Witterung zur Zeit, in welcher ber Samen reifen follte, berringert oft nicht unbe= beutend Den Errtrag an folchem.

\section{Eigenfabaften, গtuten, Anwenoung.}

Der Salat fognigt beim $\mathfrak{B e r w u n d e n ~ w a ̈ h r e n d ~ D e r ~ B l u ̈ t g e ~}$

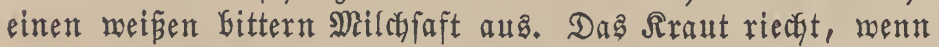
bie ßrfanze einmal gefdyoffen ift, frifory gerieben Dem Dpium ähnlicy marfotifas und formedt frautartig, falzig, bitter; bie Samen fumedfen ölig.

Die yormaltenden Beftandtgeile des Salata find: Nar= fotifa Gitterer Ěxtraftiuftoif; Der Samen Gat fettez Del.

Befannt ift ber alfgemeine Bebrauch Des Ratticha als

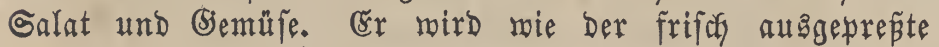
Saft alz Diätetifaces Mittel yerorbut.

Durch Sultur ftnd eine Hnzabl yon Salatiorten ent= ftanden, und wir fübren nur folche auf, fomeit fte uns be= fannt gemorben fitnd.

Man theilt Diefe Sorten gemöbnlich in Ropfialate und Bindfalate oder rönifaje, und biefe Geiden meder in Früly= lings: $=$, Sommer = und Sinterjalate ein.

\section{Nopfialat.}

Lactuca sativa capitata.

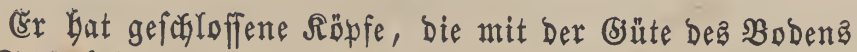

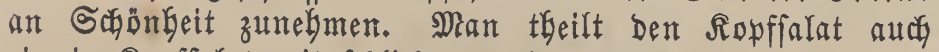
ein in Sopffalat mit forlichten und in folchen mit gefalteten und brittens mit fohraubenformig ftch fohliepenton Blättern.

\section{A. Jxühlings-fiopffalat.}

Den ซrrüblingåalatat făet man im ซebruar und Mărz in's Miftbeet ober in eine gutgebüngte, füblich gelegene $\Re_{a}=$ Gatte. Jam 2lpril werjeßzt man bie gebörig erftarften \$flanzen in ein gutgebủngtes Beet, etwa $8-9$ 3oWl, gröpere Gorten noch meiter yon einander entfent, orüft babei die ङrob um

Enimer, Bfonom. Franzenfunde.

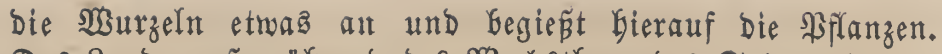

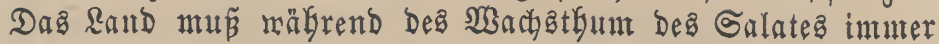
yon Seit zu Beit aufgelorfert merben.

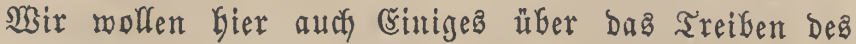
Ropfialates anfübren. Ulm ben ganzen Minter Salat fpeifen

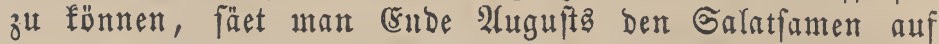

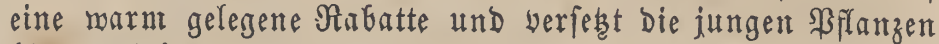
Gierauf in's Meiftbeet, in meldyent fie etwa in December zum Schlię̧en fonmen. Eine meitere Saat macht man zu 2 (nfang Nobembera, gleich in's Mriftbeet, in melchem ralle Der Salnt

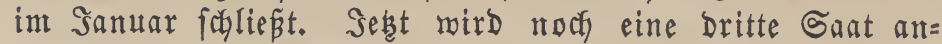
geftefft, und zwar yom Decentber bis Miärz. Bor biefer

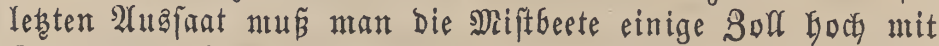
Düngererbe bebeffen und läpt bie Beete yorker erfalten, ehe man ben Samen fäet, meldhen man mit etwag Eroe über= ftreut. Die Miftbeete werben num mit Fenftern ober Bslocfen

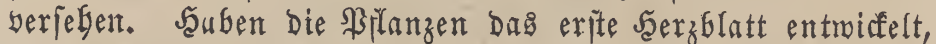
fo verfegt man fie im gleichen Beete big auf $1-2$ Soll yun einander, und folften bie Mififteete unter ber Seit er=

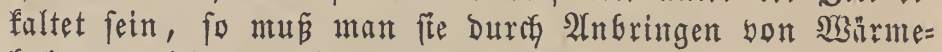
Galtern wieder mǟị erwärnten. Bei cintretender Rälte bebecft man bie Fenfter im 2 nfang nit leichten Strobbecten, Brettern 2C., fpäter aber mit ftärferen Strogmatten, jedoct fo, Dá bie Derfe nicht unmittelbar auf bie Jenfter, foudern auf untergeforobene Interlagen, wie Ratten 2c., zu liegen foumt, weif int erftern Frafle bie jungen Pflamzen gerne in

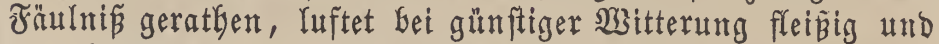

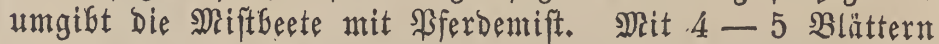
verfegt man fie in ein anderez, noch böber mit Düngererde bebefftes Miftbeet und in gehöriger (Entiernung bon einan= Der. Fängt ber Salat an Röpfe zu bilden, fo ninmt man bie Intern gelbwerdenden $\mathfrak{B}$ fätter ab and brügt bie Errbe gegen bie Salatitüfe an.

$$
\text { 1) Rothgelbex Ropfialat. }
$$

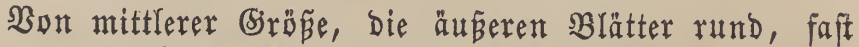

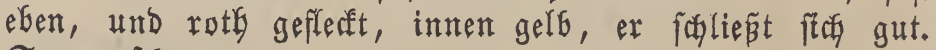
Samen fodmarz.

(rin angenelymer und zarter Salat.

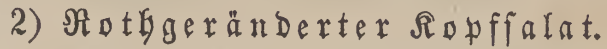

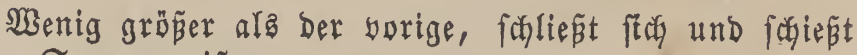
bald. Samen meip.

3) Spinatfalat.

Blätter faft ausigejdnttten wie Eichenblätter, welche fich

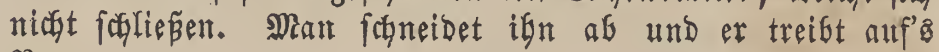
Neue.

4) Cichorienfalat. borigen.

Brătter fraua, cidorienartig. Das Hebrige mie beim

5) $\mathfrak{a} \mathfrak{a} g f \mathfrak{m}$ a

Schlieṕt langfam auf. Samen jubarz.

6) (S) meiner (s) ottefalat.

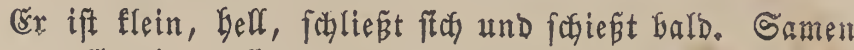
weis. - Er eignet fich vorzüglich zum Treiben.

7) (s) ottefalat mit fámarzem Samen. şlätter eben, fommt früb und fchiest nicht fo reidyt. 
8) Daułhine.

Sit febr grof́, etwas fract. Blätter beinabe glatt, oben

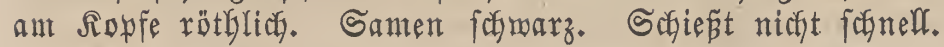

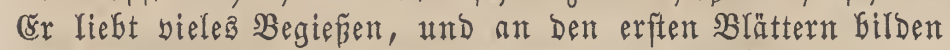
fich SBurzelforoffen, meldye entfernt werben müffent.

9) $\widetilde{S}$ teintowf.

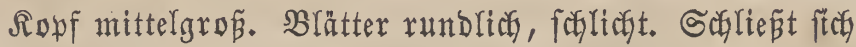

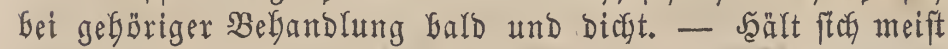
gut, gebt aber bei trodener 3 Bitterung aud gerne in Santen. Ex mirb Gauptfächlich bäuftg in Solland getrieben. Man fäet ighn nteift Dủnn aus.

Man fent 2 Barietäten yon ifm:

a) Selfer früber Steinfopf;

b) Srünẹ frủher Steinfopf.

\section{B. Sommex - fiopffialat.}

Man fäet ifn wie Den Jrüblingafalat, und erft im 2hpril, und zmar alle 14 Tage yon Neuem, menn man ben ganzen Sommer Gindurch Salat bafen mill. 2ln fleifigem Begiesen Darf man ez nicyt feblen laffen.

1) $\mathfrak{R} \mathfrak{i} \mathfrak{i} \mathfrak{r} \mathfrak{j} \mathfrak{l} \mathfrak{a}$.

(5roferer Deutfcher.

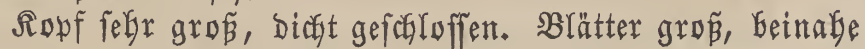
glatt, fómudiggrün. Samen meiß̄. - Selgr guter Salat.

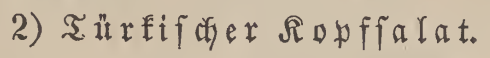

Whie Der yorige. Samen fabarz.

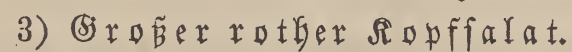

Räpfe fefr grof́, gelf und gelfrotf. Die äunern Brät= ter rund, Dunfelgrün, mit trübroth. Samen fţıarz. - Ner=

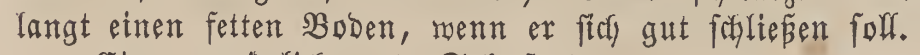

Eine worzüglich zarte Salatjorte.

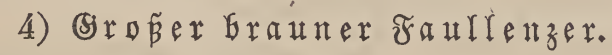

Siroper grauer Faullenzer.

Ropf felgr grof́, oben rotg. Blätter graulichgrün, mit Gellbraumen $\widetilde{F}$ leffer. Samen foymarz. - Der Ropf entmicfelt

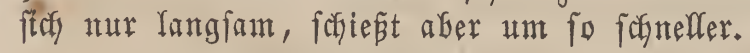

5) (5i) $\mathrm{D}$ Ber (b) $\mathrm{org}$.

Sopf bicht. Blätter helf, glatt. Samen meí⿱㇒㠯. - Ěine

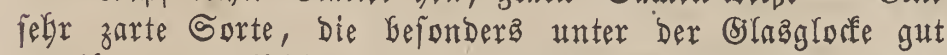
gebeift, wenn fleipig gelüftet und begoffen wird, aber fohnell

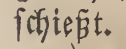

6) $\mathfrak{3} \in \mathfrak{i} \tilde{B} \in \mathfrak{r}$ (5) $ค$ org.

Ropf grof. Blătter gelfgrün, Gruchig, etmag fraub. Samen meî́.

Sebr angenebmer, zarter Salat.

7) B̆onder $\widetilde{J} \mathfrak{u}$ lfenzer.

Gelfer Sommerjalat.

Sopf etmą flach, bicht. Brätter eben, ftarf Glond. Sameก meiñ.

(ङ̌x bält fitch gut.

8) Berfailfer.

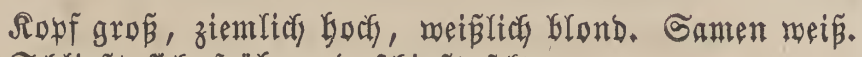

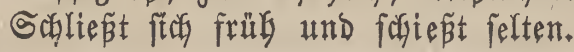

9) $\mathfrak{B} \mathfrak{l} \mathfrak{n} \mathfrak{b} \mathfrak{r} \mathfrak{B} \mathfrak{a} \mathfrak{a} \mathfrak{i} \mathfrak{a}$.

Gchlefticher 'Sommerfopfialat.

(̌ituer Der grö́pten. Rapf etwas hohl. Blätter ftarf gefaltet, Geffgrau, am Rande melfenförmig und röthlich. Samen weí́.

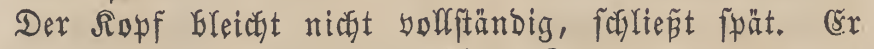
miff wie ausf Der folgende eine Yeicfte Dammerbe, wenn er gut gebeiben folf; auch mú man ifn Morgents und $2(6 e n d s$ Gegieñen, nur nicht ben Tag über, weil er fonft fferfig und faul mird.

Čine yortrefflicbe Sorte, Die aber einen reichten Boben berlangt, int andern ralle einen bittern beficfmade erbält; fault aud in naffen Sabrgängen gerne.

10) (B) elber $\mathfrak{B a} \pm \mathfrak{a} \downarrow \mathfrak{i} \mathfrak{a}$.

RoGlfalat.

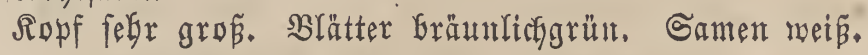

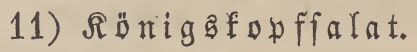

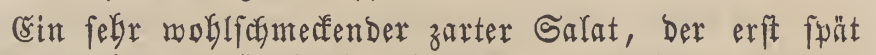
Gamen treibt und fleisig begoffen werden mún.

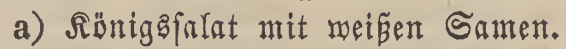

Die ăunern Blatter glănzendgrün, etmag blajtg. Sa= men weí́.

Diefer Ropffalat bält fich felyr lange, ift woblfathmedfend und zart.

b) Schmarzfamiger אänigşfalat. ไang $\mathfrak{2} \mathfrak{a m}$.

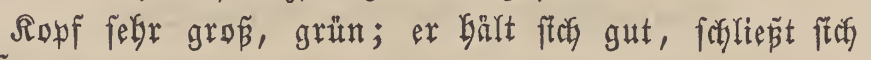

12) Dex Drollige.

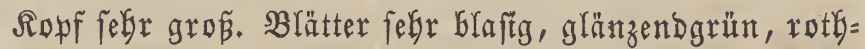

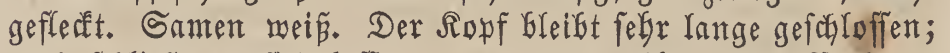
aud foylieşt er fich beffer, wenn man ign beim Derfesen tiefer fetht als bie andern Gorten.

13) Unterfebter blomber Sommerfopfiafat.

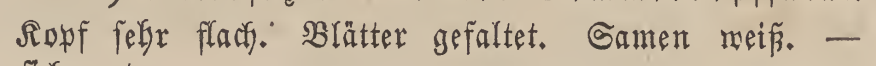
Jặlt ftefl gut.

14) Maltefer.

Bleidyt viel Dem Glunben Batavia; bie Blätter find aber Geller = grün und ebent. Samen meí̄.

15) (5) enuefer.

Man hat einige $\mathfrak{B a r i e t a ̈ t e n ~ y o n ~ i b m : ~}$

a) Siruner Benuefer.

Sopf gelb, hart. Blätter fraus und grün. Samen meí̄. werben.

(sr barf nur wenig begoffen, unt fo bifter aber befarft

b) Bglonder (sienuejer.

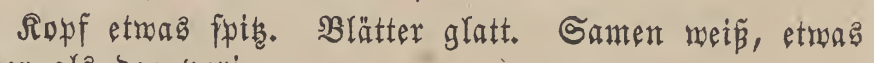
fleiner alz Der vorige.

c) Sidbgelfer (senutefer.

Ropf flach, oben rötgliał. Blătter glatt. Samen fodmars.

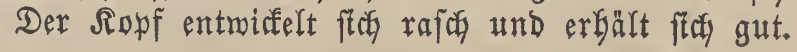

d) Nother (Benuefer.

Blätter fraus, roth und Graun. Samen formarz. (5r fablieșt fitu gut. 
16) $\Re$ otb falat.

Braumer Galāndifacter Salat, Hleiner Grauner Sommer=

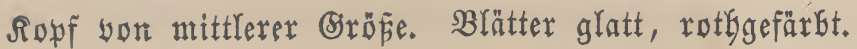
Santen fitmarz.

Sft eine raube Gorte, fohlieşt fich fpät, Dauert aber ben Winter über gut au?.

17) Ģe

Faft swie Der yorige.

18) $\mathfrak{A}$ u bertilferz.

Sopf felgr flein, gelb; bie äunern Blätter glatt, grün. Santen weín.

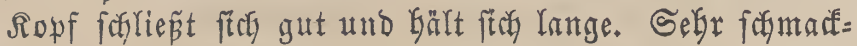
Gaft, wird aber jelten fultibirt.

19) Stalienifuex Salat.

Ropf Dicft. Blätter zart grün, roth gerändert. Samen finwarz.

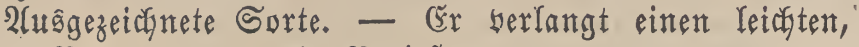
magern $\mathfrak{B}$ oben und menig $\mathfrak{B}$ egiep̃en.

20) (b) rüner $\mathfrak{x}$ erpignane.

Soxf felyr grón, fajön gelb. Blätter glatt, mit ftarfer Mittelripue. Gamen meíp.

(sin fehr famarffafter, zarter Salat, Der aud bei Geiner Witterung und in trodfenem Boben nicht leidyt foutepst.

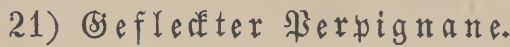

Die gropen $\mathfrak{B l a ̈ t t e r}$ gelb geffecte, fonft bem yorigen in $\mathfrak{U}$ (lem gleich.

22) Meterelfe.

Soyf gró, grünlidy, Glond. Santent meif́. Der Sopf entwirfelt fith langfam, fodiest fegr gerne.

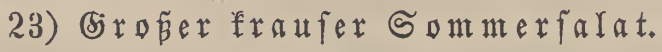

Blätter felyr fraua, gelblicfgrün. Samen meí̄. Sopf

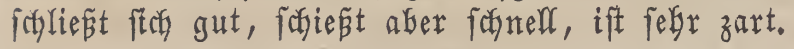

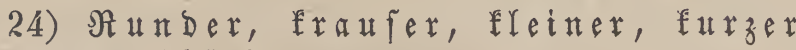
Treibjalat.

Blätter gelblichgrün. Samen weiß̄.

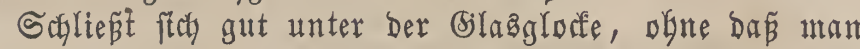
子u lüften nötfig Gätte.

25) B̧londer Berliner.

Ro⿲f fehr großa. Bătter zart grün, rötglià gerändert. Samen fobrarz.

Soblieft fith Gald.

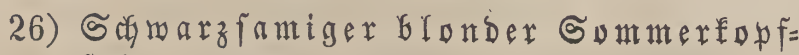
falat.

Ropf mittelgrofa, gelbliçblond.

27) $\mathfrak{B} \mathfrak{a} \mathfrak{a} \mathfrak{u} \mathfrak{m} e$.

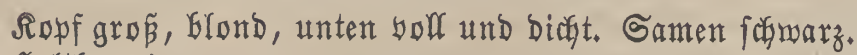
Scaltbar.

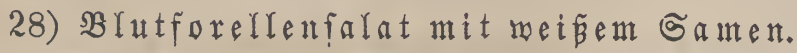
Blätter grün, rothgeflecft.

Solfte eigentlich nur im ₹rübling und Şerbfte ange=

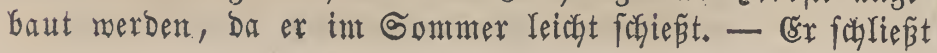

ftch wie ber folgende nur int Frübjagr und will einen zartent Boben.

29) Brutforellenfalat mit foduarzem Saneut. Stärfer geflefit als ber vorige, ift aud Dauerbafter, fonft ifm gleich.

30) Schedentap mit rei

Blätter fchlicut.

31) $\mathfrak{B}$ rauner $\mathfrak{B}$ erliner $\mathfrak{x}$ opfalat.

Sopf feft, fchiept aud bet trodener 2 itterung fpät und fann lange benubt werben.

32) $\mathfrak{P} \mathfrak{i} \mathfrak{h} \mathfrak{l} \mathfrak{a} \mathfrak{a} \mathfrak{a t .}$

Blätter runzlicy. Ropf groß̄. Samen fidyarzbraun. a) Sirüner Prablfalat.

Ropf etwas platt. Blătter weniger runzlich.

b) Bielger Srablialat.

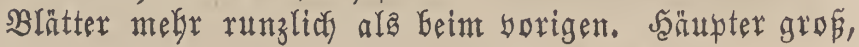
gelf.

33) $\mathfrak{B r i n z e n t o p f}$

Brinzenjalat.

(Brün, mit bielen gropenen und lleinen rotben glerfen. Samen Dunfelbraun.

Secht frülyzeitig Räpre an.

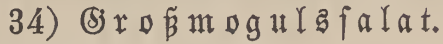

2lftatifacter Mlogul.

Jeeffrelts.

Sft eine Der beften Gorten, weldge einen guten Boben yerlangt, reitläuftg berpflanzt und bei trodfener $\mathfrak{X}_{3}$ itterung fleiß̧ig begoffen werden mus.

35) Sirofer arabifuex Ropfarat.

Wie beim borigen.

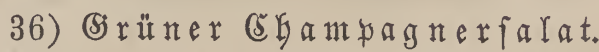

Ropf fadraubenförmig gefdyloffen, länglidy, boch.

Das Verpflanzen Deffelben Darf nidyt überfeben werden, weil er fonft ausartet. (Ex berlangt einen guten $\mathfrak{B}$ oben und öfters begoffen zut werben. Ěr bat einen angenebm füpen (B)efdumate.

37) (5)

(̌́twas geringer als Der yorige.

Von Geiben Yesetern Sorten fann man bie Stengel,

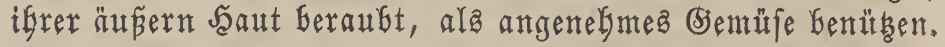

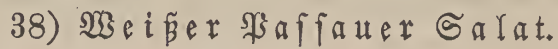

Blätter gefaltet, etwag gelb.

39) Mi @intrée.

Jranzfalat, Tobtentopf.

Ropf gró, gelb. Blätter menig aufgeblajen. Samen groś, perlfarbig, aud fchnarz.

Bintitrt:

a) Sroféer gelber fraufer Mintrée.

b) Rleiner rotbfantiger Miontrée.

\section{Wintex-finpfialat.}

Er folgt auf Den Gommerfalat und man fäet ign biz

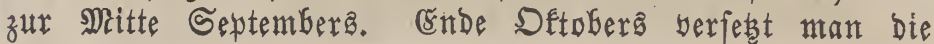
$26 *$ 


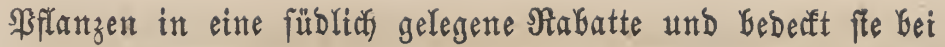
eintretender $\mathfrak{R a ̈ l t e ~ m i t ~ S t r o k m a t t e n , ~ S t r e u ~} 2$., lüftet aber

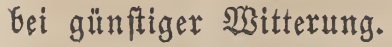

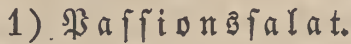

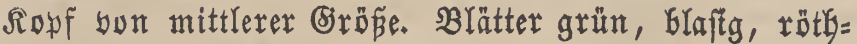
Yich geflefét. Santen meiñ.

Nur gefocht gut, wie faft alle Binterfopfialatiorten.

2) (5) e frefter $\mathfrak{B} \mathfrak{a}$ f fions

Blătter ganz rothgeflect, fonft bem sorigen ganz gleich.

3) Miufdelfalat mit weínem samen.

Blätter rund, eben, grün.

(Er ift bart, bitter, nur getocht geniebbar, aber febr bart gegen Siälte.

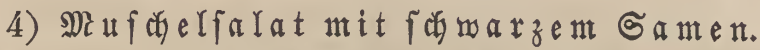

Bis auf Die Farke bes Samenz Dem vorigen gleid.

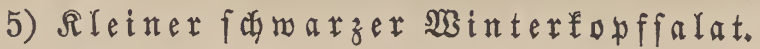

Samen fidnarz.

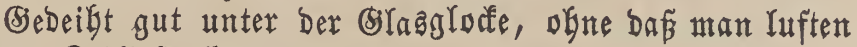
bürfte. Schließ̧t fitch ungerne.

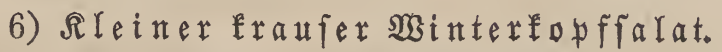

Samen fornary.

Wie ber vorige.

7) $\mathfrak{M o r i n e .}$

Samen reí́.

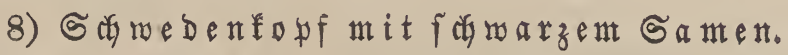

3̧t Dauerbafter als Der mit weínent Gamen.

\section{Fümifudet Salat.}

Bindjalat.

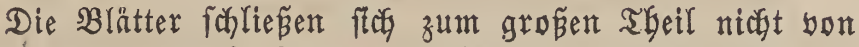
felgft in einen Sopf, fondern müffen wie ber Endinienfalat zufammengebunden merben. - Die Blätter Dürfen nur zu= fammengebunben werben, wenn fie ganz troffen find, und

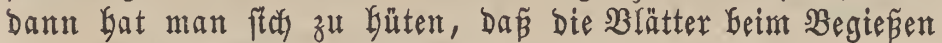
nicht gertäpt merden.

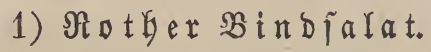

Notfjer röutifdyer Winterfalat.

Ropf nit gelfen Jaerz; Die äuneern Blătter rotf. Sa= men fotharar.

(豸ine febr zarte Sorte, bie aber, wenn fte, auf ungün= ftigem Slabe gebaut, gebunden wird, gerne zu Srande gebt.

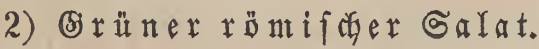

Srüner Gienüfegartenfalat.

๔ri ift flad), wird aber länger, fobald er aubartet. Sa= nten fodwarz.

(Ex wird am bäufigften angebaut, ba er gröb̆er und Gärter als bie andern Sorten ift und fith, olye gebunden berben zu mủffen, yon felfft fohlieşt.

3) B̧ londer Bindfalat.

Blonder römifcher Bemůjegartenfalat.

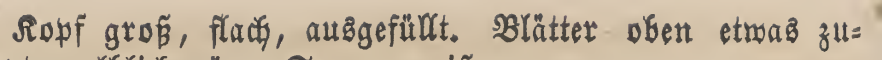

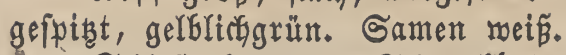

Schiét balb. - Sumadfarte Sorte.

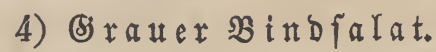

(Sroper grauer römifider Salat.

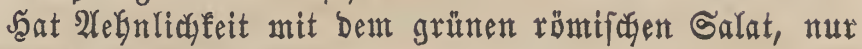
Dunfler gefärbt. Gamen meí̄.

(rine milde Salatiorte.

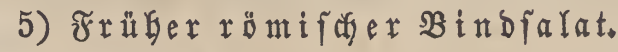

Früther grüner Bindfalat.

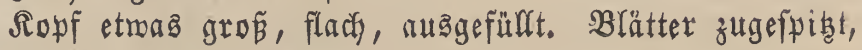
gelglidugrün. Samen weín.

(Ex fod lie

6) (5) $\mathfrak{x} \mathfrak{u}$ er $\mathfrak{x}$ interbind falat.

(5r gleidyt fo ziemlich bent grünen römifchen Salat, ift aber fleiner uno forliept fitch nidgt fo getne. Samen weif.

7) $\mathfrak{B} \mathfrak{u} \mathfrak{n}$ ter $\mathfrak{B} \mathfrak{i} \mathfrak{d}$ ja $\mathfrak{I} \mathfrak{a t}$.

Blutforellenbindjalat, fojleffrcher Galat.

Blätter rotbgefleft. Samen fojwarz.

(rr ift worzüglich und mildbe.

8) $\mathfrak{B} u \mathfrak{n}$ ter englifacr $B \mathfrak{i n} b$ jalat.

Die äuß̈eren 3 lätter haben mentiger biel Frlecten als bie yorige Sorte, um fo melyr aber bie innern Blätter. Sa= men weí̄.

Scyliept fich oft yon felfft.

9) $\mathfrak{2} \mathfrak{l} \mathfrak{b} \mathfrak{a} \mathfrak{\pi} \mathfrak{g} \mathrm{e}$.

Blätter fodmal zugeipicht, zart glatt, belfgrỉn, obent rötglich gefärbt. Samen meí̄. gerne.

Sefyr empfeflensmerthe Sorte, fofiest und fault aber

10) $\mathfrak{B} \mathfrak{l} \mathfrak{n} \mathfrak{d} \in \mathfrak{x} \mathfrak{A} \mathfrak{I} \mathfrak{g} \mathfrak{a} \mathfrak{g}$ e.

Sebr grof. Blätter biff, fett und gelb. Samen fămarz.

\section{Cichorium. I.}

Acanthophyton. Less. DeC.

Eucichorium. DeC.

Snfteme: Cichoraceae. Juss.

Compositae Hieracia. Rül.

Compositae Cichoraceae. Spr.

Compositae semiflosculosae. L.

Compositae Lactucae. Adans.

Glossariphyta. Neck.

Synantherae Lactucaceae. Cass.

Syngenesia, Polygamia aequalis. L.

Blüthendecfe geboppelt, bie äunere 5brütterig, fürzer als bie innere, bie lebtere 8blätterig, fonft malzenförmig. Die Schuppen an ber Safts verwachfen. Frudytboben bei= nabe nadft, fpreuartig. Samen zufamntengebriaft, fpikerfig. Febereffen anfthend, fürzer als bie Frudft, fohuppig, bie ein= zelmen Sdjuppen fteif, fammförmig.

\section{Cichorium Endivia, L.}

Cichorium pumilum. Jacq.

$\beta$. Cichorium crispum. Mill.

\%. Cichorium Cosnia. Hamilt. 
Orndivie.

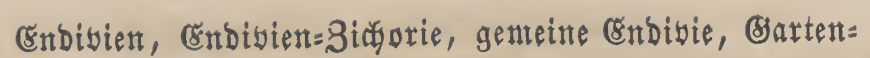

Endive chicorée des jardins. ( fłantz.)

Endive. (engr.)

\section{Srten = Sharater.}

Stengel 3 Fup boch und höger, aufrectyt, bie 2hefte fnieförnig gefogen. Blätter glatt, an ben Sippen und bem Rande zarthegaart und gemintpert, bie untern berfegrt-ei= förmig - länglida, fieberförmig zerriffen ober gezähnelt, bie obern \anzettförmig, ganzrandig. SBlumen in ben 2 ftwinfeln feGend, geftielt, Glau. Stiele gevaart, ungleidy lang, ber lăngere mit un๖olfommenen, meift mit 4 Blüthen.

Blütbe $=$ 3eit $\mathfrak{u n} \mathfrak{D}$ Dauer.

$$
\text { эult - 2uguft. } \odot \text {. } \delta \text {. }
$$

\section{Bortommen.}

In Sriectyenland, Sleinaften, Dftindien, Aeghpten, in Defterreidy in Der Nähe Der Siärten bermildert, und bäuftg fultivirt.

\section{Nultur.}

Der Ěndivien berlangt einen lorfern, gutgedüngten und Gearbeiteten Boben. Waan mactit wie beim Rattichfalat mely=

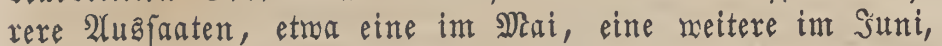
und eine Teşte im Suli ober 24uguft. Bei trocfener Witte= rung müffen bie aufgegangenen \$iffanzen fleişig begoffen

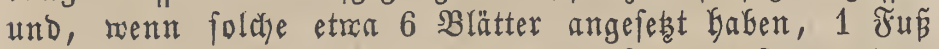

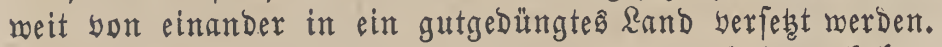

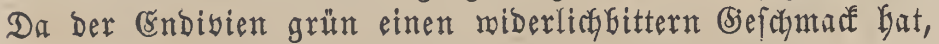
fo bleidgt man ifn, modurch er eine gelbe Farbe und einen befiern und zartern biefdynace erbält. Maan bindet nämlich, Gei trorfener Witterung, Die Blätter ber gebörig erftarften Bflanzen oben lorfer mit Baft zufanmen und läpt fte fo $3-4$ Woden lang ftefen. Einige Beit yorfer, ebe man Den $\mathfrak{B e r b a n d ~ Y o ̈ s t , ~ b a ̈ u f e l t ~ m a n ~ b i e ~ ( E r d e ~ n o c h ~ u m ~ d i e ~ S t o ̈ r f e ~}$

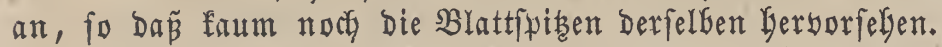
$\mathfrak{A}$ udy fann man $B$ lumentöpfe üGer Die Sffanzen fesen, ober biefelben in Bruben Yegen, mit Brettern GeDerfen und auf bieje noch eine Derfe yon SPferbemift bringen, ebenfo audy im Refler in Sand einfoylagen.

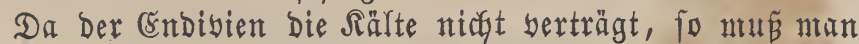
ifn im Spätherbfte gut afgetrorfnet aus Dent Rande nefmen und im Sieller in troftenem Sande einfolingen; wirb er int Seller nidgt trucfen gebalten, Doer ift Der Reller felbft feudid, fo fault ber Endivien founell.

Bur Samenzucht mählt man bie fraufeften Stöfe, burch=

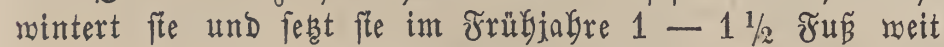
won eimander entfernt in guten $\mathfrak{B}$ oben. Sm Sult werbent bie Samenfapfeln braun und fönnen nun abgenommen werben. Säet ntan im ชrübjabre bald, fo fann man noch int Şerbfte Samen befommen. Der Erndivienfamen Gleibt 6 Sabre lang feimfäbig.

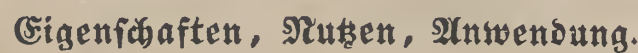

Mirb wie Der genteine Rattig als Salat und scentüe

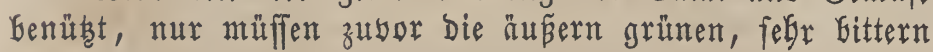
Blätter entfernt werben.

\section{Der Endivien Gat megrere Spielarten:}

1) Breitbrätteriger \&ே́bibien.

Blătter groß́, breit, glatt, oben breiter, zugerundet

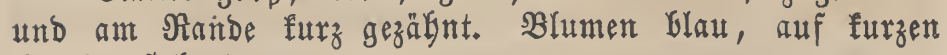
Stielen ftefend.

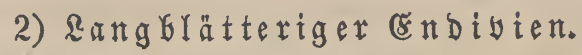

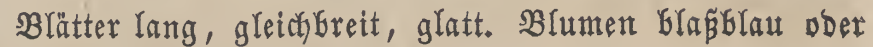
weín, melgr oder weniger geftielt.

3) $\mathfrak{A} \mathfrak{r} \mathfrak{a} \mathfrak{j} \mathfrak{e r}(\check{n} \mathfrak{d} \mathfrak{i} \mathfrak{i} \mathfrak{i} \mathfrak{n}$.

$\beta$. Cichorium crispum. Pers.

Endivia crispa. Bauh.

Blătter fraus, gefranzt. Blüthen einzelnftebend, geftielt.

a) Srroferer fraufer Endibien.

Blătter gefaclibt, faft gefiedert, etwas breit gelappt.

b) Sleituer fraufer Endibien.

Blattrippen grutr, veräftelt; gibt jegr forjöne Räpfe und mirb bep̧alb an bäuftgiten angebaut.

\section{Cichorium Intybus. I.}

Cichorium sylvestre. Lam.

$\beta$. Cichoreum Cicorea. Dumort.

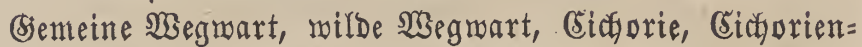

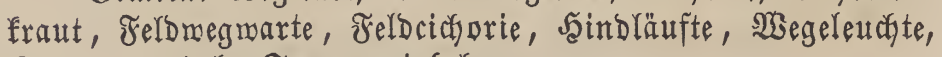
Sonnenmendel, Sonnenmirfel.

Chicorée sauvage. (firant.)

Succory, Cichory. (engl.)

Cicoria, Cicorea, Radicchia. (itar.)

\section{Mrten = (Sharakter.}

MBurzel 1-1 $1 \frac{1}{2}$ Fus lang, fpindelförmig, ofen äftig,

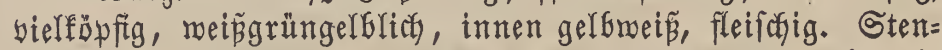
gel $2-4$ Fú hod, aufrecht, ecfig, fteif, etras raub, abs= rectifeln's äftig. Blätter Dunfelgrün, raug, oft audy glatt. Wurzelblätter freisförmig ftekend, geftielt, länglirg, lanzett= fürmig, fărotfägenförmig, gezafnt. Stengelblätter abwech= felnd, umfaffend, bie oberften ganz ungetbeilt und herzför= mig - lanzettförmig. Blumen Gimmelblau, grof́, faft ftielloz, eimzeln, auch gepaart in Den Blattminfeln ftegend. Seldef boppelt, ber innere walzíg, mit 8 foumalen, länglidsen, lanzettfürmigen Schuppen, Der äußere hat 5 , aber fürzere Schuppen. SBłumenfrome ffach, aus freisförnig georoneten Switterblütben zufammengefebt, weldae zungenförmig - ver= längerte, abgeftubte und 5zaknige slumenblättchen baben. Staubfäben 5, haarförmig, fehr furz. Staubbeutel in einem 5ecfigen, rofrigen oblinder vereinigt. Fruchtfnoten länglidy. (Briffel fadenfürmig, fo lang als bie Staubfäben. Nirben 2, zurüfgerollt. SBlumentoben beinake fpreuartig. Samen řlein, winflich, mit einer fleinen, unbeutlich Gaarigen, bei= nabe 5abnigen Samenfrone verfeken.

\section{Błüthe $=$ 3eit und Datter.}

$$
\mathfrak{s u l i}-\mathfrak{A} \mathfrak{u g u f t} \text {. 2. }
$$

\section{3orkmomen.}

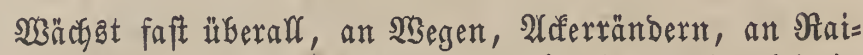
nen, auf trodenen Brağbläben, Sabutţäufen, und wird in bielen Biegenden angefaut. 


\section{Sultur.}

Die mildoe Crichorie mirb bauptfächlich ala Raffeepflanze

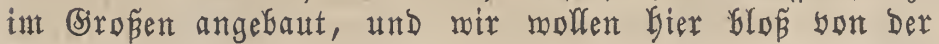
fultibirten Galatpflanze abgandeln.

Unt für ben Winter einen guten Galat yon bent $\mathfrak{B l a ̈ t =}$ tern zu bef́mmen, füllt mau אäftchen mit Sand an, fest in biefe bicht neben einander bie Cichorienmurzeln, bebefft bie Räftchen, bringt fte in's Simmer Ginter Den warmen Dfen und begiespt Den Sand, fo oft ex trofen mird, doer

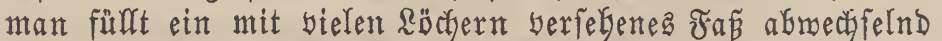
mit einer $\mathfrak{a g g e}$ Sand und wieder einer $\mathfrak{a} a g e$ Wurzeln, die mit ifren Sïpfen naif Dent Boben Des Jaffes fehen müffen,

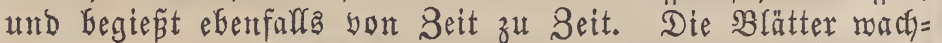
fen bier aus Den Röbern bervor und fönmen $3-4 \mathrm{mal}$ abs= genommen merden. Bei biejen beiden 2lrten Der Salatzud fterben itbrigeng bie Wurzeln ab.

Sur Samenzudyt nimmt man bie Eräftigften 2 surzeln, werwalgrt fite Den Winter über in Gruben ober Relfern, und

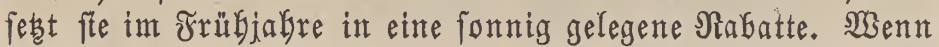
Der Samen reif ift, fo fahneibet man bie Samenftengel ab, läpt fie, büfchelmeife aufgeftellt ober,aufgebängt, an ber Gonne trodfen werben, brüfft Den Samen nachlyer aus, rei= night ifn und berwahrt ifh an einem luftigen, gegen Măuje gefduhtegten Drte auf. (Ex Gleibt 4 Jahre lang gut.

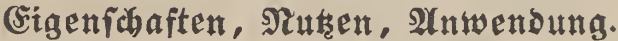

Die Wurzel Der fultibirten Bflanze ift wenig bitter, mefy fühlich fobleimig, als bie Der milden.

Man fant die fultisirten Wurzeln mie die Scorzonere

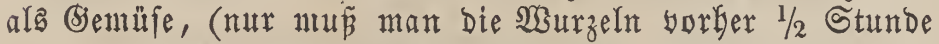
lang in Woaffer Yiegen laffen, Damit ifr bitterer Stoff aus= gezogen werbe) und gefocht und zerfechnitten als Galat be= nüben, auth mit anderem Mielle zu Brod berbačen.

Die Blätter, welche int Reller aus Den $\mathfrak{B}_{4}$ rzeln aus= machjen ober auf bie fchon oben befchriebene SBeife gezogen rerben, geben einen äuserft angenegmen, Dent Ëndivien ägn= licten Salat.

\section{Valerianella. Moench. DeC.}

Fedia. Gärt. Vahl

Odontocarpa. Neck.

Polypremum. Adans.

Syfteme: Aggregatae. Link. Whlbrg. Caprifoliaceae Valerianeae. Rchbch. Scabiosae. Adans.

Triandria, Monogynia. L.

Valerianeae. DeC.

Sield ganzblätterig, mit, oberftändigent, $3=$ und melgr= zälnigem, Gleibendem Saum und eirunder, eiförmiger ober

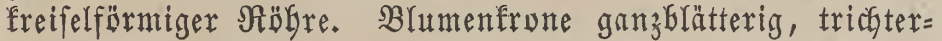
förnitg, 5ipaltig, regelmäpig, mit bberwärta erweiterter Nägre und ftumpfripfeligem, abftekenbem Saun. Staubge= fäse 3, unterbalf Der B̊lumenröbre eingefủgt. Staubäben baarförmig. Staubbeutel 2fächerig, runblich, einnärta ge= febrt. Stentwel 1. Fruchtfinsten 3fächerig, unterftändig. (5riffer 1, endfänoig, fabenfürmig. Narben 3, öfters bei=

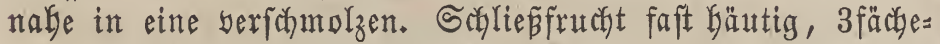
rig, mit bem Relchjaume gefrönt." Sament amgetelgrt, ei= meiplog.

Valerianella olitaria. Moench.

Fedia Locusta. Rchbch.

Fedia olitaria. Vahl.

Fedia striata. Steven.

Valeriana olitaria. Willd.

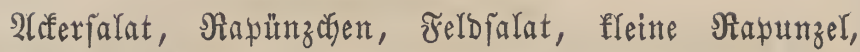

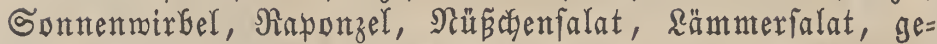

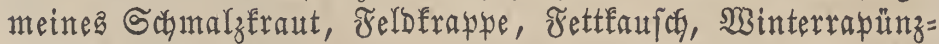
chen, Nüpchenfreffe.

\section{Arten = Sharakter.}

Stengel aufrecht, glatt, oben gabelförntig getbeilt. Blät= ter linien-zungenförmig, ganzrandig. Wanzzlblätter um= gefelgrt eiförmig - längliç ober feilförmig, glatt, gröper als bie etras gezähnten Stengelblätter. B̧lumen flein, mein, 5theilig. Gamen flein, rumblich, extig, bellgelb.

\section{Blütfre $=$ Zeit tno $\mathfrak{S a \mathfrak { e r }}$.}

2rpril - Mai. $\odot$.

\section{3ortommen.}

2uf Aectern, in Weinbergen, Sărten, unter bem Bie= treide, and bäuftg fultibirt.

\section{ßultur.}

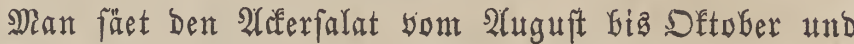
nicht zu bicht, und tritt ben Samen etmas ein; fpäter ift

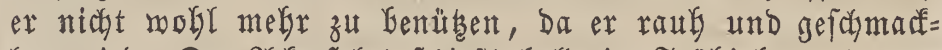

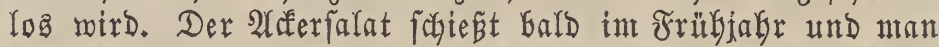
erfält bann leidgt Samen; bäuftg pflanzt er ftón aud won felbft fort.

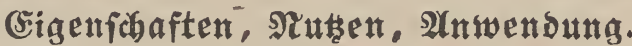

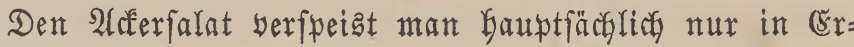
manglung eines andern Galats und bäuftg in Berbindung mit Rartoffeln.

Eine Barietät Des 2ldererfalata ift:

Der italienifue $\mathfrak{A} \mathfrak{d} \in \mathfrak{r} \mathfrak{a}$ lat.

\section{Lepidium. L.}

Brachypiptum. DeC.

Cardamon. DeC.

Cardaria. Desv. DeC.

Cardiolepis. Wallr.

Cynocardamum. Webb.

Dileptium. DeC.

Ellipsaria. DeC.

Snfteme: Antiscorbuticae. Crantz.

Brachytophyta. Neck.

Cruciferae. Juss.

Cruciferae Alyssoideae. Vent.

Cruciferae Lepidineae. DeC.

Cruciferae Thlaspi. Adans.

Siliquosac. L.

Siliquosae Cochleariae. Rül.

Tetradynamae septatae. Rchbch.

Tetradynamia, Siliculosae. L.

Relch 4blätterig, an ber Baftz böcferlos, abfalfend ober Gleibend. Relchblätter ziemrich aufrecht, abfelend, eiförmig, runbliç ober längliç. Bluntentrone 4blätterig, freuzför=

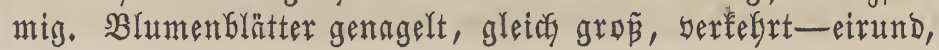


ober fpatelförnig, zumeilen fegr fämal, Staubgefäвe 6, 4 mächtig, Dem Blumentoden eingefügt. Staubräben baax= jörmig vber yfriemenförmig, zafnlob. Staubbeutel 2füdyerig, eiförmig, einuärts gefehrt. Stempel 1. Fruchtfnoten rund= lid ober eifürutig, entweber an' ber Spite ausgerandet ober niçt ausigerandet, 2fächerig. Siriffel berlängert, fadenför= mig, ober fegr furz, beinnlye feglend. Narbe funtuf ober fopfförnig. Schötchen feitlich zufammengebrünft, etmaz auf= getrieben voer flach, Kerzförmig, eirund ober länglidy, an Der Spite ausgerandet ober ganz, 2flappig, 2 fächerig. Sa=

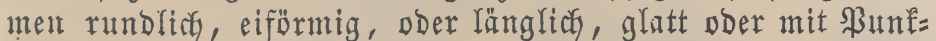

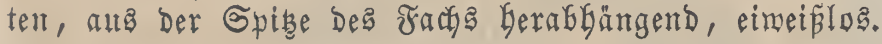

\section{Lepidium sativum. L.}

\author{
Arabis chinensis. Rottl. \\ Lepia sativa. Desv. \\ Nasturtium sativum. Crantz. Mönch. Vent. \\ Nasturtium crispum. Medic. \\ Thlaspi sativum. Cav. Poir. \\ Thlaspi Nasturtium. Berg. \\ Thlaspidium sativum. Spach.
}

(jiemeine Rreffe, gemeine Gartenfreffe, zabme Rreffe, gebaute Rreffe.

Cresson alenois. (franz.)

Garden or, Common Cress. (entgl.)

\section{Arrten $=\boldsymbol{G} \mathfrak{G a r a k t e r}$.}

Bflanze frautartig. Wourzel Dünn, fpindelförmig, faje:

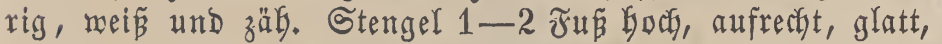

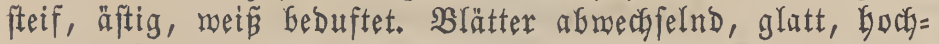

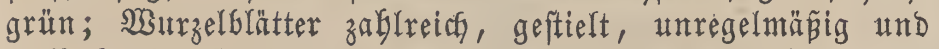
bielfach eingefofnitten, geffebert ober geftedert getheilt; bie obern Blätter uft 3 fpaltig; Die oberften faft ungetbeilt, an=

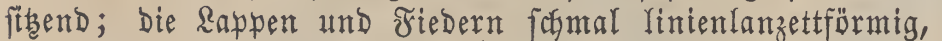
ftumpf, eingefonnitten doer ganzrandig. Die Blüthen fteben am Eride Der Stengel und Sweige in furzen Trauben, fitrd flein, 4blätterig, weiß̄. Staubfäben 6. Staubbeutel bid= rett. Selch Ginfällig. Sçütchen flein, glatt, fegr furz ge= ftielt, eiförmig-länglich, zufanmengebrü augigerandet, weiplich betbaut. Die Rlappen fiel-nacten= förmig, auf Dem Rürfen pfriemenfürmig. Samen 2, eiför= mig, zugefpidet, glatt, gelblicybraun.

\section{İni - Iuli. $\odot$.}

\section{Blüthe = $\mathbf{3}$ it $\mathfrak{u n d}$ Dauex.}

\section{Sorkommen.}

sn \$erfiten einkeimifor, fommt auch bie und ba in Deutfalamd auf Schuttgäufen, an seeffen bermildert bor, und mirb bäuftg in (5ärten angebaut.

\section{ßultur.}

Man fäet bie Sireffe in ein fonniges ober fadjattigez Rand, fobald ber Boben aufgegangen ift, fogar nuch auf ben Schnee, läß̧t Den Samen entreber gerabezu auf Der Ërbe liegen, ober Gebecft ifn aud nur leidyt mit folder;

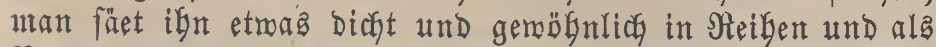
Nantenz̧üge. Meeift nimut nan bie Saat aber mit Ëintritt Des Frübjalgrs bor, und um Den ganzen Sommer mit Rreffe werieken zu fein, fäet man alfe Nonate frifch. Um frühe Sireffe zu befommen, fäet man fee im šamuar in Nifftbeete, etwa unter Den Carbiol, etras bicht, und man fann fie

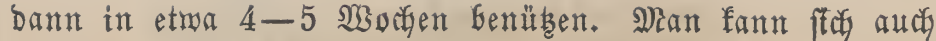
int Serbft und Şinter in warmen Simmern Rreffe ziehen, indem man folctye in Räften fäet.

\section{Eigenichaften, গtuten, Atmwenoung.}

Das frijche Rraut und die Samen Gaben, bejonders beim Berreiben, eimen ftarfen, flüchtig reizenden, bem Meer= rettig und Roffelfraut algnlichen (Seruch und einten beipend

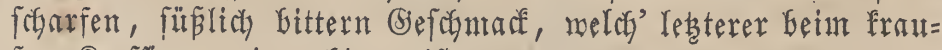
fen Rrefift meniger bitter ift.

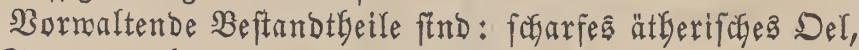
Der Samen enthält baneben noch Sableint.

Man gefraud bie Rreffe jung ala Galat pder ala ŞB̈rze zu Salat und andern Speifen, auf Butterbrod, zu Sirüuteriuppen, als Gemüpe mit Spinat, Saterampfer $2 C_{\text {. }}$ in ber Medicin als antifcorbutifdes, Garntreibendea, fobleim= auflöfendes und Den Afppetit reizendes Mittel. 2ilus dem Samen gewinnt man ein angenefint foumerfendez Del, relches

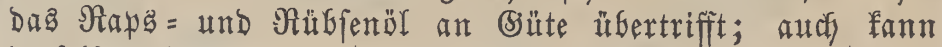
berfelfe mie Senf gebraucht werben.

(sine Varietät ift:

$$
\begin{aligned}
& \text { a) Die fra } \mathfrak{B} \mathfrak{b} \mathfrak{I} \text { tterige } \text { Ireffe. } \\
& \text { Lepidium sativum crispum. } \\
& \text { Nasturtium crispum. }
\end{aligned}
$$

(biefülute Nireffe.

Sie mirb in neter Beit fint alfgemeiner angebaut, als bie gemögntiche oder einfache Nireffe.

\section{Nasturtium. R. Br.}

Brachylobos. DeC.

Cardaminum. DeC.

Chrysoraphanus. C. A. Meyer.

Glandestinaria. DeC.

Snfteme: Antiscorbuticae. Crantz. Cruciferae. Juss.

Cruciferae Arabideae. DeC.

Cruciferae siliquosae. Spr.

Siliquosae. L.

Styridophyta. Neck.

Tetradynamae Siliquosae. Rchbch.

Tetradynamia, Siliquosae. L.

Relch 4brätterig, an ber Bạtz bäcferloa, abfallend. Relchblätter abftefbend, feltener aufrecht, eiförmig ober läng= Iich. Blumenfrone 4blätterig, freuzförmig, abfallend. B̉lu= menblätter genagelt, berfegrt - eirund, 'ganz, ftumpf Doer auşgerandet. Staubgefäpe 6, 4 mächtig, frei, lünger ober fürzer als bie Blätbe, Dem $B$ lüthenboden eingefügt. Staub= füben fabenförntig, zafmlos. Staubbeutel eiförmig, 2 fächerig, einnärta gefegrt. Stempel 1. Jruchtfonoten linealifo, eiför= mig ober fugelig, 2fächerig. Siriffel verlängert, Dünn, ober furz, Difflich, oder beinafe ganz fehlend. Narbe ftumpf, fopfig, ganz voer 2lappig. Schote 2fädyerig, 2flappig, rund= lich, Gäuftg fo furz als ein Schötchen, mit Dem furzen Briffel an Der Spike. Samen flein, ungerändert, unregel= măpig, 2reifig, gerabe anliegend.

\section{Nasturtium officinale. R. Br.}

Arabis nasturtium. Clairv.

Baumerta Nasturtium. Fl. Wett. 
Cardamine fontana. Lam.

Cardaminum Nasturtium. Moench.

Sisymbrium Nasturtium. L.

$\beta$. Nasturtium siifolium. Rehbch.

Nasturtium microphyllum. Rchbch.

Brunnenfreffe, officinelfe Brunnenfreffe, gemeine Brun=

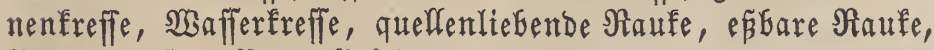
Braungierich, Braunfirich.

Cresson d'eau, Cresson de fontaine, Cailli. (Franz.)

Common Water-cress. (engl.)

Crescione. (ital.)

\section{Arten = Sharater.}

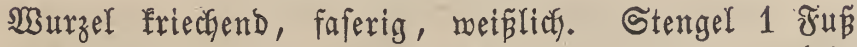

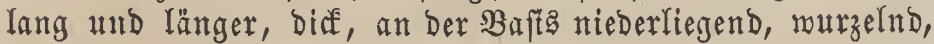
bann auffeigend, åftig, rund, gefurcht, glatt, hobl, faftig. Blätter ungleich-gefiebert, abwechfelnd, glatt, faftig, belf= grün; Fiederblättchen gegenüberftebend, anfthend, rundlich, ober eiförmig, ftumtyf, ftumbf ausgef dweift; bie crnbblätt= wen gröper, faft rundlich-berzfürmig. B̧lüthen am ěnde Der Stengel und 3meige in fleinen locfern Trauben und Doldentrauben ittekend, find flein, 4blätterig, meís. Die Relabblättchen ant Ranbe gelb. Staubfäben 6, ufriemenför= mig, aufrecht. Staubbeutel einfach, gelbroth. Fruchtfnoten länglidy, chlinbrifor. Briffel faum merflich. Narbe ftumpf.

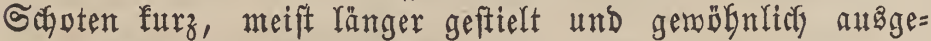
Greitet ftebend, etwas bouferig, glatt, nady unten fich nei= gend, aber nach oben gebogen. Samen zahlreidy, Hein, runblich, gelflicf.

\section{Blüthe = Beit und Dauex. \\ Mat - September. 4.}

\section{3orénmen.}

Man findet fie auper in (ruropa noch in 2 merifa,

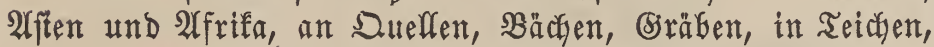
in tiefliegenden bemåfferten Gegenden, auf naffen MBiefen, und wird auch angebaut, befonders in Drebenbrunnen, bei Erfurt, in Thüringen.

\section{$\Re \mathfrak{M l t u x}$.}

Man fäet ben im Suli gefammelten Samen auf Dutell=

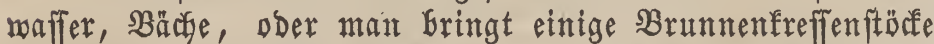
bafin, wo man fie ziefen will. Sefriert ea im sinter ftarf, fo Drücfit man Die Sfflangen mittelft Brettern unter Dab Sarfer, wobei fee bann nidyt yom Frofte leiben.

\section{sigenfaften, stutsen, צnwendung.}

Die frifchen $\mathfrak{B l a ̈ t t e r}$ entwidfeln zerriefen einen freffen= artigen, ftechenden Geruch und baben einen foharfen, Gittern (B)efdyma de.

Die vormaltenden Beftand theile find : fadarfes ätherifates Del und eifengrünender Gerbeftoff.

Die Brunnenfreffe bat gelind reizende, Garntreibende, auflöfende, antifcorGutiface Wirfungen. Mean benübt be=

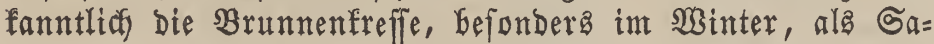
lat, auch als Bsemüfe, man madyt fte mit sfifts ein, gentest fee rub auf Butterbrod. Den Samen gebraudit man wie fodmarzen Senf.

\section{Cardamine. L.}

\section{Syfteme: Antiscorbuticae. Crantz.}

Cruciferae. Juss.

Cruciferae Arabideae. DeC.

Cruciferae Erucae. Adans.

Cruciferae Cheiranthoideae. Vent.

Cruciferae Siliquosae. Spr.

Cruciformes. Crantz.

Siliquosae. L.

Sisymbria. Rül.

Styridophyta. Neck.

Tetradynamae siliquosae. Rchbch.

Tetradynamia, Siliquosae. L.

Relch 4blätterig, abfallend. Relchblätter aufrecht vber etwas abftebend, eifürmig, länglidy ober Yineal-länglida, zumeilen mit einem furzen bä̈rndyen unter der Spike bejezt.

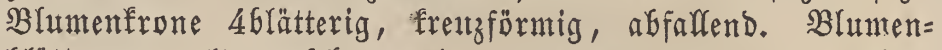
blätter genagelt, werfelyrt - eirund, felten fohmal lineal - feil= förmig, ganz, fefre ftumpf, garzrandig ober etras ausgese ranbet. Staubgefä́pe 6, 4 mächtig, p̈fters gleich lang, bem Błtütbenboben eingefügt. Staubfäben faben = ober pfriemen= fürmig. Staubbeutel eirunb ober länglich, 2fächerig, ein= wärta gefelgrt. Stempel 1. Frueftfnoten 2fächerig, limealifch. (E)riffel furz, Diff, Dber länger, Dünner, ftielrumb ober zu= fammengebrüaft, Yinealifa, zumeilen feblend. Narfe fopf: förmig Doer ftumpf, ganz ober augagerandet. Schote anfthend, rinienförmig, zujammengebrürét, 2ffappig, 2fächerig. Sanen eiförmig, ungerändert, in einer ßreibe liegend.

\section{Cardamine pratensis. L.}

\author{
$\beta$. Cardamine amara. Lam. \\ Cardamine dentata. Schult. \\ Cardamine buchtormensis. Willd. \\ Cardamine scaturiginosa. Whlbrg. \\ Cardamine uliginosa. Bbrst. \\ Cardamine sylvatica. Bess.
}

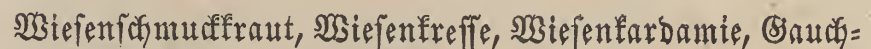
Glume, Rufufbblume. 7.3\% ,

Common Lady's smock. (engr.)

\section{Arten = Charater}

23urzel fofief, Göferig, ftarf befajert, faymukigmeís.

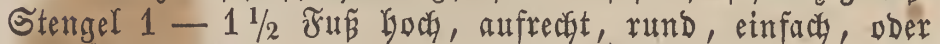
fparjam veräftelt, fteif, Dủnn, glatt. W3urzelblätter freißz= förmig ftebend, lang geftielt; Die Blättefen ungleich, nicht immer einamber gegenüber, fondern bäuftg auch abmechfelnd ftehend, rundlidf, 3lappig, hie und ba effig gezăgnt; die Stengelblätter abwechfelnd, geftedert-gefchlibt, febr furz geftielt, ausgeföblt, mit weiblicher Spike verfeben, glatt, ganzrandig; Die untern Stengelblättchen elliptifoy; bie obern fdymal lanzett = und linienfärmig. SBlüthen in unregelmă gen lorfern Doldentrauben und Trauben ftebend, fend 4blät= terig, Geffuiolettrötglich, oft megr rötglicf) ober mefr meís: lich, neçartig und Dunfler geabert. Blumenblätter an Der Spike oft mit einer feichten Einferbung verfeben. Sields

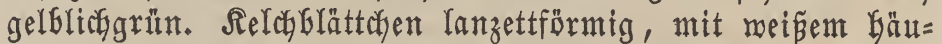
tigem Ranbe und eben folder Spibe, gemölbt. Staubbeutel länglidy - yfeilförmig. Narbe fapfförmig. Scyote lang, Dünn, lintenfürmig, etwab zufammengebrüct, glatt, nach vben augigebreitet, bei ber $\Re e i f e$ in 2 Rlappen auffpringent, meloh' restere ftod fpiralförmig aufrolfen. 
31.
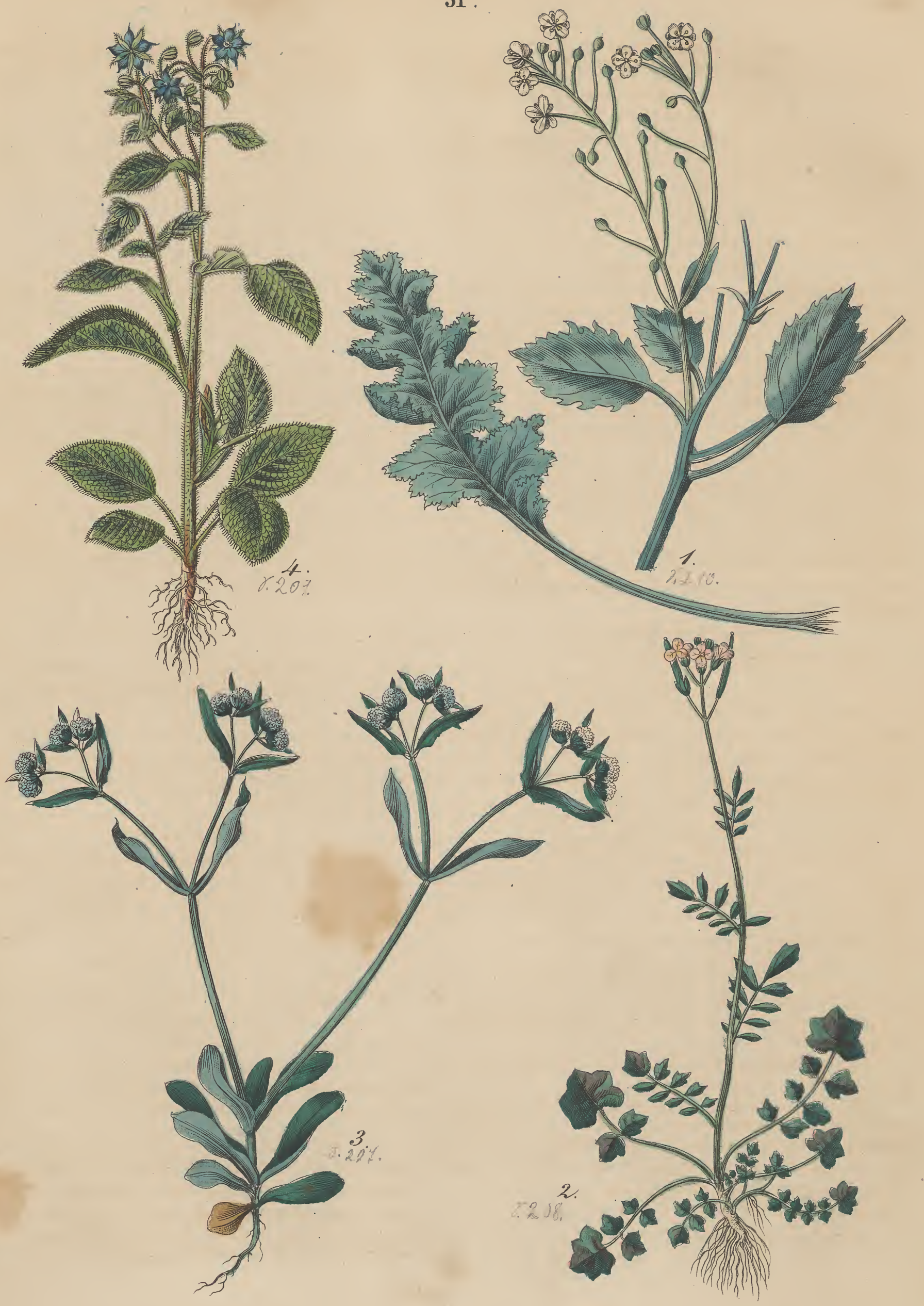

Bliithe = 3 eit แnv Dauer.

$2 \mathfrak{l p r i l}$ - Suni. 4.

\section{3ortommen.}

2(uf feuchten, aud troffenen Sibiefen, auf malbigen

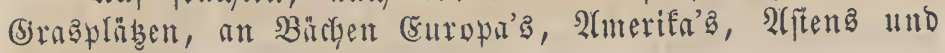
2lfrifa's.

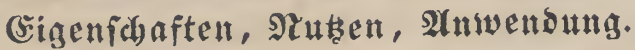

Die frifchen Blätter und Blïtyen Gaben Geint Berreibent

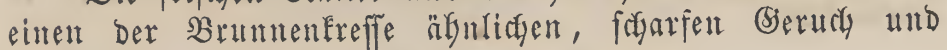
Gitterfdyarfen biefchmart.

Bormaltende Beftandfyeile: flürytig fogarfez Del und bitterer Ěxtraftioft off.

Man fann Daŝ Frant wie bie Bruntenfreffe benthken, fo Gauptfächlich in mördlichen (suropa, in Scymeden; aud in Der Mebicin wirb ea ebeño, jeboch ganz ferten, ange=

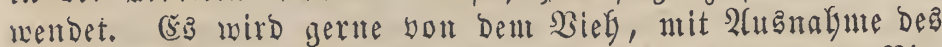
Bferdes, gefreffen. Die Blumen werben feeip̧ig won ben $\mathfrak{B} i e=$ nen befucyt.

\section{Borago. I.}

Psilostemon. DeC.

Trachystemon. Don.

Suftemte: Asperifoliae. L. Rül.

Asperifoliae Boragineae. Rchbch.

Asperifoliae Heliotropeae. Endl.

Boragineae. Adans. Juss.

Oligantherae pentandrae asperifoliae. Roy.

Pentandria, Monogynia. L.

Trachytophyta. Neck.

Reldy 1Glätterig, 5theilig, Gleibend. Reldazipfel lanzett= f̈̈rutig, und zmifchen biefen eiu B̈̈hndyen. Bluntenfrone 16rätterig, radförmig, meift uffen, mit furzer ßäbre, 5thei= ligent Saume und berfegrt-eirumben Bipfeln. Der Schlund burch ftumpfe, ausgerandete Silappen verfolifoffen. Staubge=

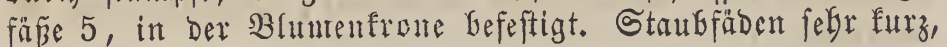
an ber 2 aftz freifelförmig, naci turen abgeftubt und von ba 2ipaltig. Staubbeutel lanzettförmig, an Der Spize ge= gramut, einen phramidalifshen Bsiffel Gildend. Srriffel mal= zig. Narbe ftumpf. Samen 4, eirund, an ber $\mathfrak{B a f t a}$ mulftig gerandet, ausigegöglt, in ber bäblung mit einem Gentral= feger.

\section{Borago officinalis. L.}

(5emeiuer Boretfd, officineffer Boretich, Borage, Sur=

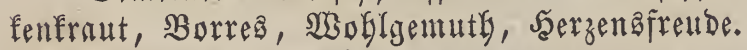

\section{Borage. (engl.) tre $31, f_{i \alpha} .4$.}

\section{Arten = Sharater. ?}

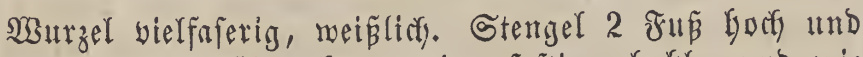
brüber, aufrecht, aftig, frautartig, faftig, hobl, und wie die ganze Bflanze Gorftig Gekart. Blätter grof́, länglials, eiförmig, etwas runzlich, bunfelgrün; die untern Blätter verfegrt - eiförmig, an Der Bafts verbünnt. B(üt tent fteben faft in Doldentrauben, find überfängend, fternförntis, 5thei= lig, in Golunde mit 5 fleinen 8ăbnen, fchön Kimmelblau, zuneilen auch rötglicf ober weiplich. Reldy auggebreitet. Samen länglich, rumzliç, fçmarzbraun.

Enrwer, benom. Spfnuzenfunde.
Blïthe = Beit und $\mathfrak{D a u e r}$.

Mai - September. $\odot$.

\section{Borkommen.}

Urfprünglidy einteimifa in Rleinaften, un 2Yleppo, auch in Sübeurowa, faft überall angebant, bäufig bermil=

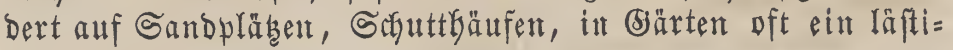
geß Unfraut.

\section{Sinltur.}

Man fäet Den Boretfch int FrüGjafr oder Seerbft, und er fommt in jebem Boben fort. W3enn Der Samen reif ift,

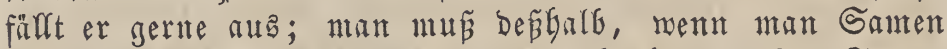
wiff, bie Boragenftengel nod grün abnefmen. Der Samen Gleibt 2 sabre feimfäbig.

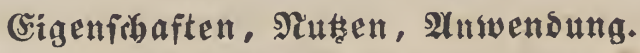

Die Buragen Gaben einen Galpeterisebalt, Die rảurzel fodmedft füb und bie $B$ lätter fdymeffen und riéchen gutfen= âfnlich.

Man fodyt bie jungen Blätter in Supyen, bemüfen,

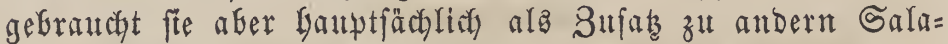
ten ober als Sugeför zu Fleif๘. Mnit Den Blumen färbt man Ejfitg Glau und fie geben mit 2llfolgol befandelt eine fighöne Radfarbe, auch werben fie fleişiy yon ben Bienen befucyt.

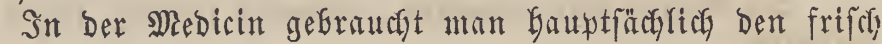

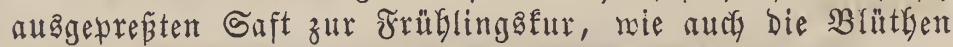
als berzftärfendes, und bie Blätter als füblendes, erfrifdyen=

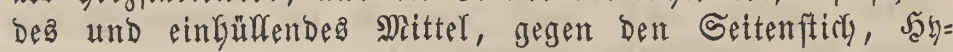
poifondrie 2 .

\section{Veronica. L.}

Aidelus. Spr.

Callistachya. Rafin.

Cochlidiospermum. Rchbch.

Diplophyllum. Lehm.

Eustachya. Rafin.
Hebe. Juss.

Leptandra. Nutt.

Omphalospora. Bess.

Piritia. G. Don.

Veronicastrum. Mönch.
Syftemte: Diandria, Monogynia. L.

Gentianeae. Spr.

Pediculares. Juss.

Personatae. L.

Personatae Pedicularinae. Rchbch.

Plasyrgophyta. Neck.

Rhinanthoideae. Vent.

Ringentes angiospermae. Roy.

Ringentes Veronicae. Rül.

Scrophularinae. R. Br.

Scrophularinae Veroniceae. Benth.

Veronicae. Cassel.

Selch 1 brätterig, $4-5=$, auth 2theilig, gleidy ober un= gleid) Yappig, Gleibend. B̧lumenfrone 1 blätterig, rabförmig, mit meift furzer $\Re$ b̆hre, meift flach berbreitetent, 4lappigent Saume; Der untere Raypen ift fleiner. Staubgefäpe 2, it Der Bfumenrögre eingefügt. Staubfäden lang. Staubbentel suffiegend, 2 fücherig. Fructetenten runblich. Siriffel faden= förmig, abmärts gebogen. Narbe einfach, ftumpf. Sinpfel bom Relife umichloffen, berfförmig ober eirund, zufaumen= gebrǚte, oben aufipringend, 2fächerig, megramig. Samen runbliat, auch nierenförmig, genabelt. 


\section{Veronica Beccabunga. L.}

Veronica limosa. Lejeun.

$\beta$. Veronica caroliniana. Poir.

Babbungen=(shrenwreiz, Badbunge, Babbohne, Suel=

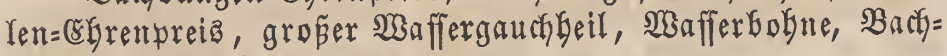
†umme, Runtedfe.

Veronique beccabunge. (fintz.)

Brooklime. (engl.)

\section{Arten $=$ (5)arakter.}

Die ganze Bfflanze ift glatt und fartig. Stengel rund, an Sirunde friechend, rourzeltreibend.: Blätter länglida, ge= ferbt, ftumpf, gegenüberftegend, furzgeftielt. 2(uz Den Blatt= winfeln entipringen die Blumentrauben, fite find einfach, 2-3ntal länger als die Blätter; Nebenblätter linienförmig, die untern etmas länger als die slumenftiele. Selth 4pal= tig. Srone Dunfelblau, im Saflunde meíp.

\section{$\mathfrak{B l i t}$ the $=$ 3eit und Dauer .}

Suni - September. 4.

\section{\$orEmmen.}

Şächôt in sächen, siruben, Suellen, in suropa, alten und 2 merifa.

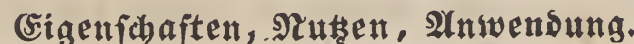

Die Blätter find geruchlog, fdymedfen famady, falzig und bitterlich.

Sm Früglinge werden die Blätter eingejamnelt und zu Salat benübt; aud mifat man fe mit andern Galaten unter Den jogenannten Sräuterjalat.

Die Blätter Gaben antifcorbutifde Wirfungen und wer Den mit andern Rräutern augigeprest und Der Saft roird getrunfer. 2(euperlicy merden fte ala Wunbfraut Genüht.

\section{Cochlearîa. L.}

Siefre Seite 166.

\section{Cochlearia officinalis, L.}

Cochlearia renifolia. Stock.

$\beta$. Cochlearia danica. Gunn.

$\gamma$. Cochlearia officinalis rotundifolia. Smith.

Cochlearia grönlandica. With.

2(echtes Röffelfraut, gemeines Röffelfraut, officinelleş

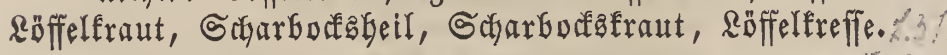

Cranson officinal, Herbe aux cuillers. (fianz.)

Spoon-wort, Common Scurry-grass. (engl.)

Coclearia. (ital.)

\section{Arten = (5)arafter.}

Wurzel fleit, faferig, äftig, roeiflich. Stengel mebrere,

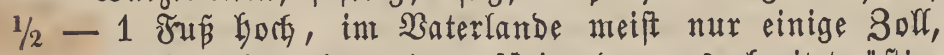
aufrect ober liegend und auffeigend, ausgebreitet äftig, ectig, glatt, faftig. şlätter etmaz diá, fleifuig, glatt, bellgrün; Sarzelblätter $1-1 \frac{1}{2}$ Soll breit, freisförntig ftebend, geftielt, rundlich berzförntig, etroas buchtig ober Geinake ganzrandig; Stengelblätter länglid, ftumpf, menig gezäbnt, die obern ftengelumfaffend, an der Bafta tfeilför= mig, die untern geftielt. Bblütben endftändig, in einfaçen loffern Trauben und Doldentrauben ftebend, 4 blätterig, meí̃. Blumenblätter noch einnal to lang als ber Relch, yer= febrt-eiförmig, ganzrandig. Relcblättcben abftebend, Gobl, binfällig. Staubfäden pfriemenförmig, fo lang als der Reld. Staubeutel ftumpf und zufammengebrüt. Frudtinoten Gerzförmig. Sriffel einfach, furz und bleibend. Narbe ftumpf, fopförmig. Sajötchen ei-fugelförutig, runzlich, aufgetrie= ben, 2fächerig, mit $4-5$ runblidjen, Graunen Samen in jedem Fande.

$$
\begin{aligned}
& \text { SBlüthe }=\text { Beit uno } \text { Dauter. } \\
& \text { April - Mai. } \odot . \delta \\
& \text { Borkommen. }
\end{aligned}
$$

Findet ftic an den Seeufern Norbeuropa's, ferner in Sibirien, Grönland, Spibbergen, zumeilen audy in funtpft= gen, fatjattigen Drten, an Salzquellen Deutichlands, in Schmaben, Batern, bei Nïrnberg, in Şolftein, Dldenburg, Pommern, Sannober, in Der Wetterau, in Franfreich, bäufig aud bei ung in Särten bermildert and fultibirt.

\section{Sultur.}

Das Roffelfraut gebeift am Geften in einem reichten, nabrbaften und füblen Boben und in einer fothattigen Rage, und man fäet es int Sommer gleich nach Der Reife Dę̇ Samens etmas meitläufig. Nach $4-5$ Tagen gebt Der Sa= men unter günftigen Verbältniffen getoöbnlich auf. Wäbrend Der Begetation Darf nant feglen Iaffen. Der Samen bleibt 2 Jabre lang gut.

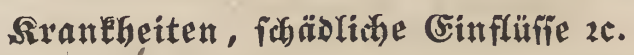

Die jungen Blätter ftnd befonder Den (srdflöben aus: gefetst.

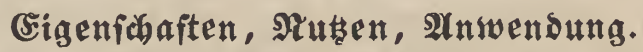

Die Şauptbeftandtheile Des Röffelfrautę ftno: fffarfea,

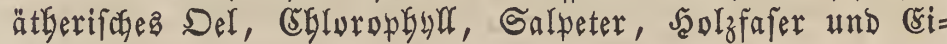
meipftoff.

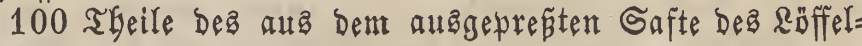
frautes erbaltenen (5xtrafts befteben nad SBraconnot aus: Braunem, füßem, nur in Geí̄em Noein= getif Yöaliçem Extraftioftoff . . 48,33 Nicht im Geipem Neingeift Iöălicher, Durch Serbeftoff fälbarer Materie . . 32,00 Bflanzenfaurem Rali . . . . . , 6,67 Sffanzenfaurem Salf . . . . . . . 8,67 Salziaurem und formefelfaurem sali und Berluft . . ..... 5,00

Das frifdye Röffelfraut und ber Samen, Gefonders aber Das erftere, geben beim Serreiben einen eigentbumlicten,

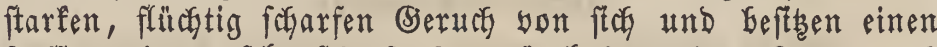
freffenartigen, febr fabarfen; genürzbaften, das אraut nod farzig bittern Sefofymad.

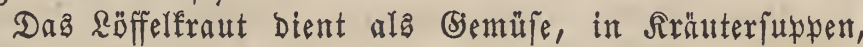
als 8 $u \mathfrak{a}$ zu Salaten, und mird flein zerfanitten auf $B$ utter= Grod und in Norben mit Molfen, faurer Milch, ober mit Salz eingemacht, genoffen.

(5) roirft ferner gelind reizend, Garntreibend und be= fonders antifcorbutifo ftnd Sraut und Samen. - Das Röfelfraut ift Gefonbers im Goben Norben faft unentbebrlia. 
Man gebraudyt bas frifdye Sraut als Salat $2 c$. , ben frifa

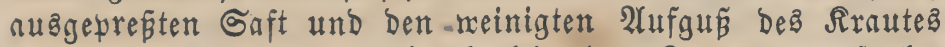
gegen Scorbut und bie ifn begleitenden Symptome, faules

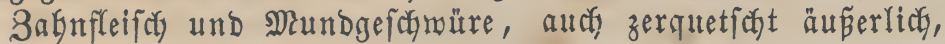
auf frorbutifale siefomulre gelegt, als surgelfraut.

Fü Schafe ift es ein nahrbaftes und gejundes Futter, auch werden bie Blüthen fleipig bon ben Bienen Fefuctyt.

\section{Petroselinum. Hoffm.}

Siekge Seite 161.

\section{Petroselinum sativum. Hoffm.}

Die Befbreifung bei ben 2 urzelgemäctjen, - wo mir Die Beterfftle als 2 Gurzelpeterftlie ermäbnt baben; Gier laffen wir nun bie Sultur ber Sräuterpeterftlie folgen.

\section{Sultur.}

Man făet bie ßeterfflie bald in đrübjabr, ober noch im Serbfte, etmas weniger bicht als bie Earartenfreffe, bäufig alz Ěnfaffung. Der Samen bleibt 3-4 Jahre gut.

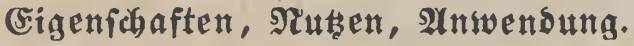

Daz Sraut ber ßeterftlie gefraudgt man in ber Sühe

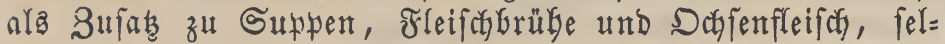

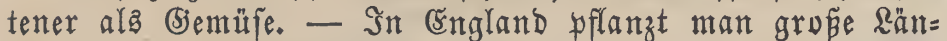
Dereien mit Beterfflie an und füttert bamit bie Sdjafe gegen daz Jaulwerben. Sie wirb auch gerne bon saafen und $\mathfrak{R} a=$ nindgen gefreffer.

Barietäten Der ßeterftlie find:

1) (5) aneine $\mathfrak{A} \mathfrak{a} u$ toeterfilie.

(Semeine Sifnittpeterfitie.

Sie wirb an bäuftgften angebaut, ift bie gleiche, wie bie gemeine ßeterftlie, wirb aber Segnitt= ober Rraut=ßeterftlie genannt, zum Unterfdyiebe bon ber gemeinen- Seterftlie, die Der $\mathfrak{B u}_{\text {urzel }}$ wegen angebaut wirb.

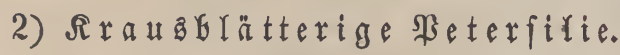

(5efüllte ßeterfitie.

Blätter vielfpaltig, geftäufelt.

Man gebraucht fie wie bie Borige, Gauptfäd blid aber

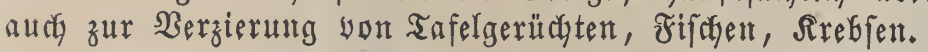

\section{Apium. L. \\ Siefre Seite 162.}

\section{Apium graveolens. L.}

\section{Befdrreibung Seite 162.}

Bei ben $\mathfrak{B u r z e l g e m a ̈ c h j e n ~ G a b e n ~ m i r ~ b i e ~ B a r i e t a ̈ t ~ S i n o f f e n = ~}$

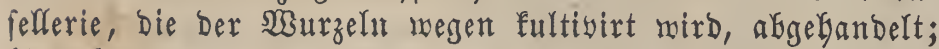
Gier fommen wir nun zut ber Barietät, bie igrer Blätter regen angebaut wird.

\section{Stengellëllerie.}

Sirautfelferie.

Er treibt bei geföriger Befandhung vift $8-10$ Boll Gobe Stengel. B̧lätter lang geftielt, forarf gezähnt, Gelfer= grür. NMurzel fleiner und äftiger als beim 2 Gurzelfellerie.

(85e utan die Seblinge im Frübjabr in's Rand ber= bflanzt, ift eas fefgr zu empfeblen, auf einent etra 4 ซus Greiten Rand gegen $3,4-5$ 3oll tiefe zurdjen zu zieflen,

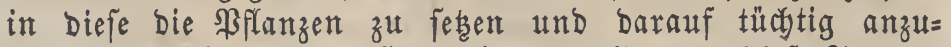

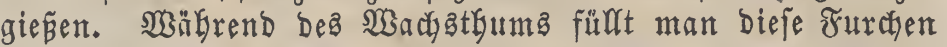
nach und nach mit (̌robe aus und befäufelt fie immer ftärfer, um îfe zu treiben und zugleich zu bleichen; yon biefem les= tern Gängt Gauptfächlich bie Stärfe und bäbe besె Stengel= fellerie ab. Das $\mathfrak{B}$ leicfen wirb fpäter noch, nachbem man bie Sffanzen im Serbfte aus bem Ranbe genommen hat, im sieller fortgejebt, indent man fee 2-3 3oll meit yon einan= Der faft Gorizoutal auf Groe ober Sant legt und fie mit foldjent 2-3 3oll how bebect.

Sur Gamenzudgt läp̆t man einige ber fobontrten Pflan= zen ium seande fteben, welche man natürfich nidyt zu befäu= feln Gat, und bebecft fee yor Eintritt bea Winters etwas mit $\Omega_{a} \mathfrak{b}$ ober Stroh.

Man, benủbt Den Stengelfellerie an Suppen, Fleifach zc. Eine 2 bart yon ifm:

a) Der italienifale Stengerferrerie.

Staubenfelferie.

ङri ift ber befte.

\section{Sdnntttiellexte.}

Sirauß̧blätteriger Sdynittfelferie.

Man fäet ifn im Jrühjahr in's Miftbeet und forneibet ifn wie Sifnittpeterling ab.

\section{Anthriscus, Pers. Sielye Seite 115.}

\section{Anthriscus Cerefolium. Hoffm.}

Cerefolium sativum. Bess.

Chaerophyllum Cerefolium. Crantz.

Chaerophyllum sativum. Lam.

Scandix Cerefolium. L. fraut.

Serbel, Rörbel, gemeiner Rerbel, Bartenferbel, Serbel=

Cerveuil commun. (ftant.)

Garden - chervil. (engl.)

\section{Strten = Charater.}

Stengel aufrecht, äftig, glatt. Blätter abftebend, bie vbern 2:, Die untern 3fach geftebert und länger geftielt. Błăttchen eiförmig, Kalbgefiebert und eingefdhnitten; bie Blatt= lappen etmas ftumpr. Blütben in Dolden ftefend, flein,

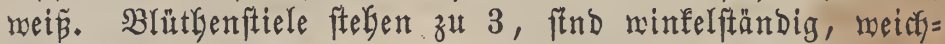
beGaart. Samen länglich, zart, fahmarzglänzend.

\section{Blithe $=$ Beit und Dauer.}

Mai - Suni. $\odot$. 


\section{3orkommen.}

WBächat in Sübeuropa, Franfreich 2c. mild, finbet ficts in Deutfdyland, in Weinbergen, an Bäuten 2c. Gie und da bermildert und wirb bänfig in (5)ärten angebaut.

\section{Siultur.}

Der Rerbel fommt faft in jebent Boden fort und lieft eine fontige Rage. Utut intmer frifogen unb zarten Serbel zu baben, fäet man ibn yom 2 quril an alfe 1.4 Tage auf'z Reue, und zwar im Sonnter nuf einen mebr fobattigen, im Frübling und Serbft aber auf einen fonnigen łlab. Ěr fäet fich bäur̉g aucl) felbft aus. Der Samen bleift $3-4$ Salgre gut.

\section{Cigeniabaften, গtuten, 2(nwendung.}

Das Serbelfraut bat beim Serreiben eiten farf aroma=

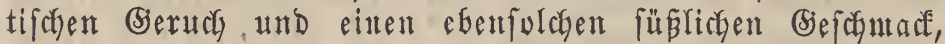
mirb Gauptfächlich zu Suppen, Den Serbelfuppen, zu $B$ rü= Getr, auch Salaten benübt.

Sindvieh, Schafe, Biegen freffen eas gerne, ßferbe nber werichmähen ęิ.

\section{Sedum. L.}

Anacamperos. Adans. Haw.

- Rhodiola. L.

Syfteme: Corniculatae, Crassulaceae. Rchbch.

Crassulaceae. DeC.

Decandria, Pentagynia. L.

Diplosantherae. Roy.

Seda. Adans.

Sempervivae: Juss.

Succulentae. L.

Succulentae b. Seda. Rül.

Synatrophyta. Neck.

Selds $5=$, audf 6 -7theilig, bleibend, mit fleifuigen, eirunden, elliptifchen, Janzettförntigen, fpisen oder ftumpfen Siłfeln. Blumenfrome $5=$, audi 6-7glätterig;, werwelfend. Blumenblätter agftebend, zugefpibst, ftadjelipitig ober ftumpf. Strubgefäßze 10, aud 12-14, Dent Reldegrunde eingefügt. Staubfädent driemenförmig. Staubbeutel 2 fächerig, rundliç. Sdhupen 5, eiförmig, abgeftuntpt, ganzrandig. Stempel 5. Fruchtfenoten frei, oberftändig, 1 f̈̈cherig. (Sriffel pfriemen= förmig, Gleibend. Narben ffein. Balgfapfeln 5, zufammen= gebrürft, zugefpist, 1 fădjerig, vielfamig. Samen flein, eimeingultig.

\section{Sedum reflexum. L.}

$\beta$. Sedum recurvatum. Willd.

$\gamma$. Sedum collinum. Willd.

Sedum elegans. Lejeun.

Sedum rupestre. DeC.

$\delta$. Sedum cristatum. Schrad.

Sedum crassicaule. Hortul.

Sebum.

Gelber Miauerpfeffer, Tripntidam, zurüfigefogenes

Tripemadam, Triquemadam, Reisinel. (franz.)

Yellow Stonecrop. (entgl.)

\section{Arten $=$ (5)araEter.}

Stengel nieberliegent, cylinbrifa, unbefant. Brätter bicht und zerftreut ftebend, ffriemenförnig, an Der Baftz abgelöst, fahl = ober röthlicfgrün, aufrecht, fleifafig, bie untern rüffuärtz gefrüumt. Blüthen faft in 2Afterbolben ftelyend, Geinulge ungeftielt, gels. Die Bnbl Der Seldyein= fallitte, Rromenblätter und Griffel wariirt yon 5-9. Die meiften Blumen baben 6 Seldyeinfdrnitte und 6 Yinien-lan= zettförntige, wertiefte und auลgebreitete Blumenbrätter, weldye mit Den Seldyeinfofnitten abrectjeln, 11-12-14 Staub= fäben und 6 Frudgtfnoten.

\section{Blüthe = 3eit uno $\mathfrak{D a u e r}$.}

Suni - Suli 4 .

\section{3ortommen.}

2luf bergigen, fonnigen $\mathfrak{B}$ räken, Mauern, in Sdywaben,

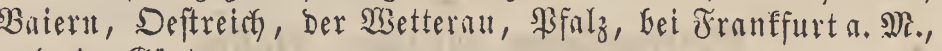
und in Gärten gezogen.

\section{Siultur.}

Die Tripunaant wurbe früber ftärfer angebant als gegen= wärtig. Sie werlangt einen troffenen $B$ oben und eine jonnige Rage, und wächşt am beften auf Mautern 2r. - Man vernelgrt

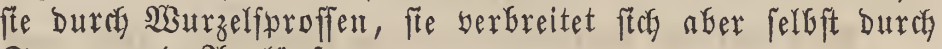

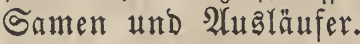

\section{Sigenfhaften, গ⿰ułen, Anivenoung.}

Die Pffanze Gat einen feyarfen befdyade. - Die Stengel Der jungen Pflnzen benübt nan in ber Süche zu Sräuterfuppen und Salaten; aud verwendet man bie Trip= mabaut zu Einfaffungen Der Rabatten.

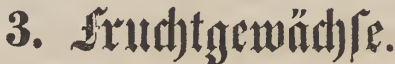

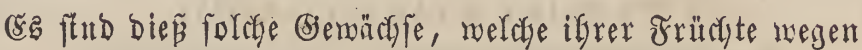
forwobl. zur Nabrung für ben Mienfchen als bie Thiete ange. zogen merden.

\section{Cucumis. L.}

Melo. Adans.

Rigocarpus. Neck.

Syfteme: Bryoniae. Adans.

Calyciflorae monopetalae. Roy.

Cucurbitaceae. L. Juss.

Monoecia, Monadelphia. L.

Sygalliphyta. Neck.

Männliçe Blüthen: Reld ganzblätterig, gloffig, mit

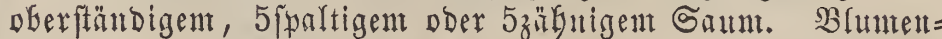
frone ganzblätterig, 5theilig, mit abftebendent eirunden oder länglid - eiförmigen, fpithen Bipfeln. Gtaubgefäß̨e 5, Dem Sielchloglunde eingefügt. Staubfäden furz, 3 brüberig, te 2 zufammengeradefen und ber 5te frei. Staubreutel an eir = ander liegend, je 2 zufammengerwaden und ber 5 te frei, 2fäd)erig, mit 2 Stachelfpisen gefrönt. Narben berfüntnert.

Weiblicfie Blütben: Relch ganjblätterig, mit beinabe fugeliger ober walziger, ober bent Frudytfuten eingefdulurter Rähre und oberfämbigen, 5fpaltigem ober 5 zäknigem, ab=

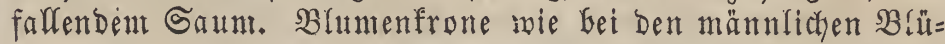
then, Nefenfäben 3, iber Dem Grunde Der Brume, oft 
32 .

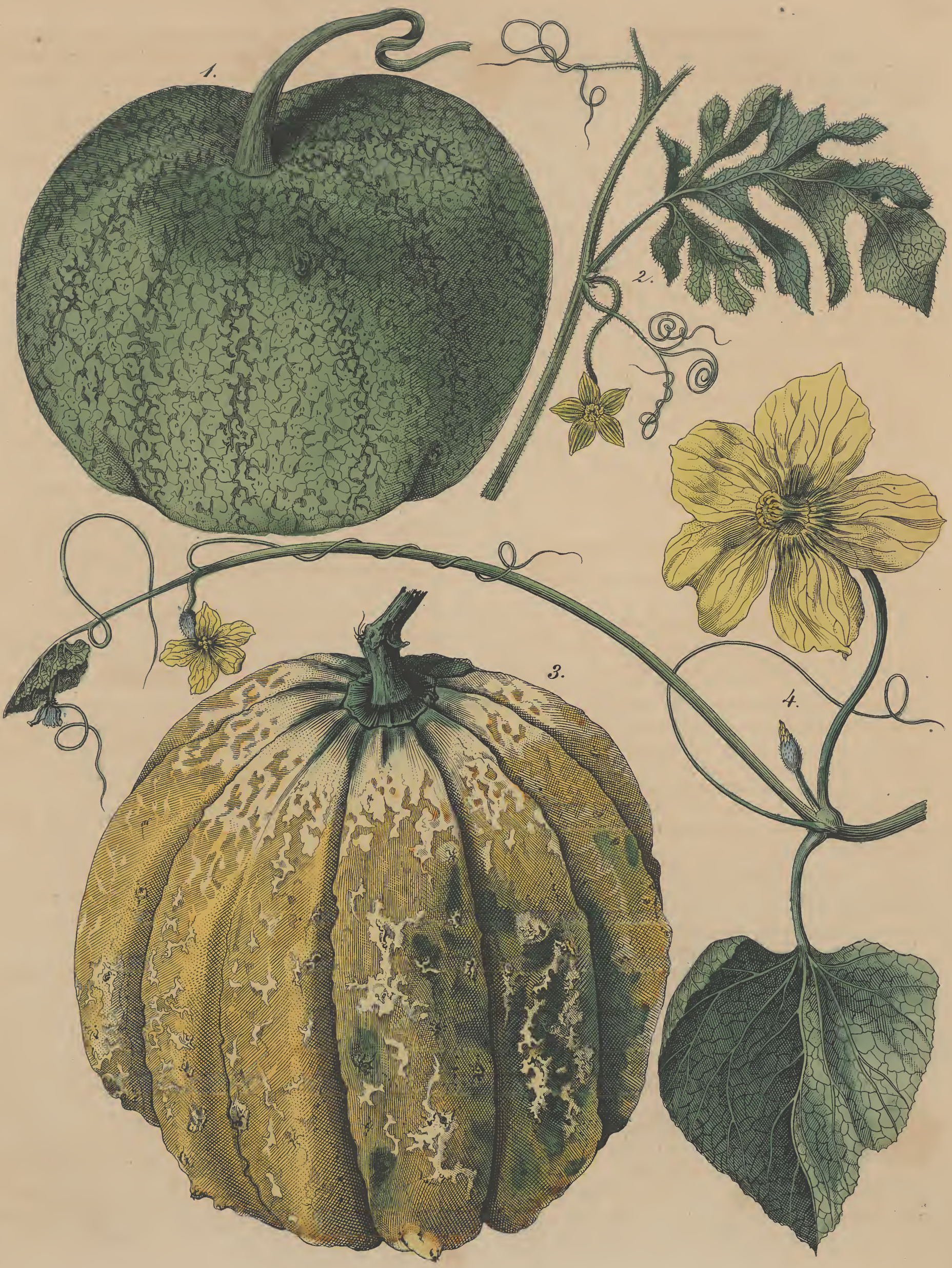



beinabe orüfenartig. Stempel 1. Jrưd̆tfnoten 3fätyerig, unterftändig. Briffer 1, furz. Narben verbicft, 2theilig.

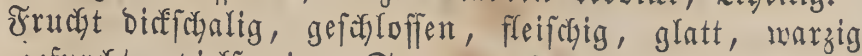
ober gefurdyt, vielfantig. Samen zufammengedrüct, yer=

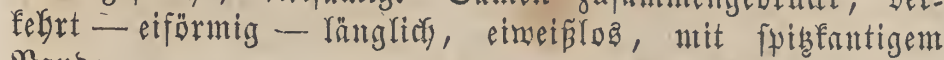
গRande.

\section{Cucumis sativus. L.} Birtife.

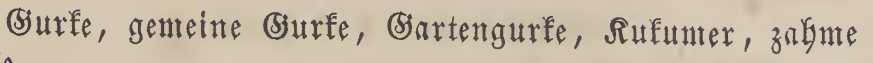

Concombre commun, Concombre cultivée. (finatz.)

Common Cucumber. (engl.)

\section{Arten = ÇGarakter.}

Die gemeine surfe hat wiel 2 efnlichfeit mit ber Nhe= lone. Stengel nieberliegend, treibt (5)abeln und ift mit

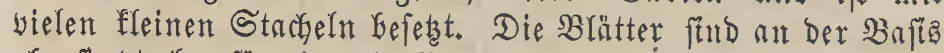
abgeftubt Gerzförnig, 5erfig, zugeipibt-gelappt, ungleich gezalint, etras rauk, hochgrün. Blüthen winfelftändig, zu

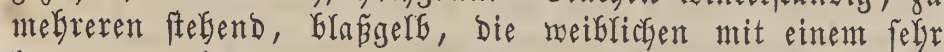

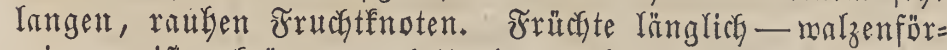
mig, meift gefrümmt, glatt ober megr ober meniger rauk= warzig, erft grün, mit ber Reife gelf, weiplict, vft melgr roth Doer braun, bielfamig. Samen faft mie bie ber Me= lonen, aber etwas fleiner und fanmäler.

\section{Blütbe = Beit und Dauer. \\ Mai - September. $\odot$.}

\section{\$orénmen.}

In Dftindien, ber Tartarei, und bei 1113 in aflen (3)ärten gezogen.

\section{ßưltux.}

Die Surfen Yieben einen lorfern, fetten und guten, be= fonders nit verrottetent Bferbemift gebüngten $\mathfrak{B}$ oben und eine warme gefdrthte Rage. N3as ifre fultur int Jreien

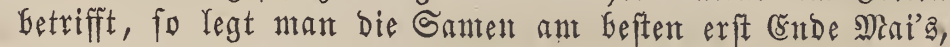
zunt Einntachen erft in Sunt, went Der Boben gefourig er= wärmt ift, in einen 30 ll tiefe Neiben ober Röcher, unb zwar in bie Reigen 5-6 3oll, in bie Röcter aber 2 Jup, $5-6$ Serne zufammten, weit yon einander entfernt. Die

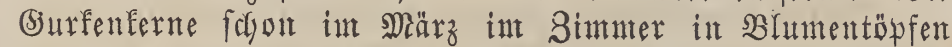
zu treiben, fann nicft befonders anempfoblent werben, Da Die Sflanzen, went fie auch mit einer biröße son 5-6 3olf int Mai in's freie Rand verfest werben, lange im Machs: thume fteben Gleiben und meift yon ben fpăter in's Freie gefäeten (surfen noch überbult werben. WBahrend der Bege= tation begię̧e man bie Surfen, bejondera igre Blätter, bäuftg mit Braure, unterlaffe es aber, an Den $\mathfrak{R} a n f e n$ etmaz abzubrecten. Da bie Burfen, Gefonders in naffen und farl=. ten Sahrgängen, bas Riegen auf ber feuchten und falten Erde nicht ertragen, fo ift bie Methode als eine fegr bor= theilgafte anzuratben, bie Burfen an Spalieren zu zielen. Man legt nänliç bie Rerne gleidy in bie Nähe yon fegr

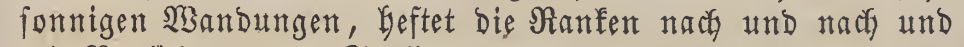
mit $\mathfrak{B o r f t a j t}$ an Das Spalier, und man wirb fich feine etwas größere Müke nicht reuen laffen Dürfen, indent man ftets große, foüne und roglfachnedfende surfen Daburch erziegt.

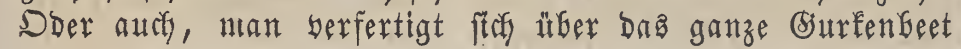

ein 1 Fú gores, aber liegendes Spalier yon Ratten und

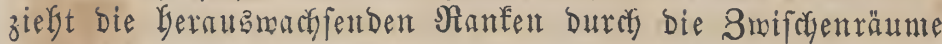
Derfelbett. - Bum Siüdengefraudf nimmt man bie Burfent im Suli und 2 (uguft unreif ab. Mlan treibt bie (5)urfent

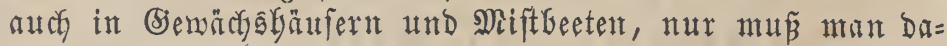

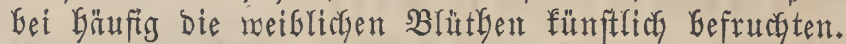

Bur Samenzudit nimmt nan nux yolffommene Frübte,

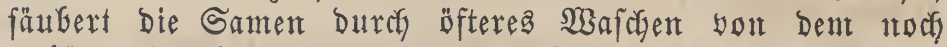
anfüngendent Fleifd)e und troffnet fte an ber Ruft. (Fin guter

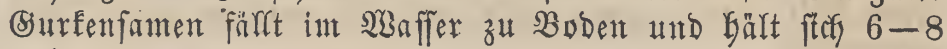
Salyre lang und länger.

\section{Sdbäslidue Einflüfie.}

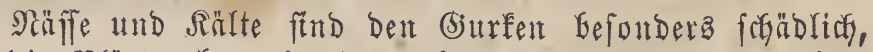

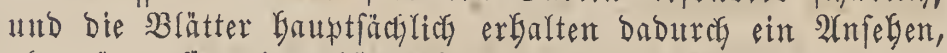
als mären fle mit meifem Strub beftreut.

\section{(Eigenfidaften, গtuten, 2umensung.}

Der (Burfenfaft bat eiten eigentbümlichen, frywadyen, nicht unangenebmen (5eruch und einen faden, wäferigen, füßlict) falzigen, etwas Gerben (befchmarf, und feine yorwal= tenden Beftandtgeile find: Burfer und einige Salze.

Nach 2. Straúp entgäl berfelbe in 100 Theilen: W3affer 96 , zmeierlei färbenden Grotraftioftoff, fticfitoffGaltige

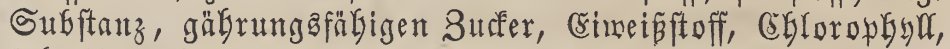
attheriftes Del und (Balluspäure eine Suur, effitgfaure, wein= faure, äpfelfaure, whosplorfaure, falzfaure und formefelfaure Kall $=$, $\mathfrak{i a l}=$ und Magnefta=Salze und Fafer. - Der Same

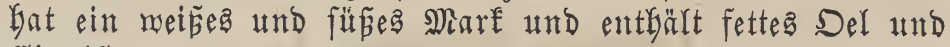
Ëimeiñ.

Armgemein befrant ift ber befrauch Der unreifen (sur= fen als Salat ober als Bentüfe. Da die Burfen zu Dent

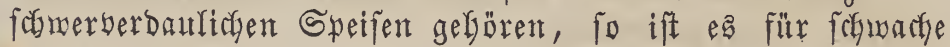
Miägen rathjam, yor Dem Sienuffe Der Sourfen den Saft nicht ganz auszudoütfen, foubern nody einen' Igeil Defferfent mitzugenię̄en.

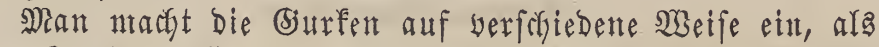
faure Burfen, Swaffer = oder Salzgurfen, wozu man bie größern Frübte mäblt, efe fee hobl werden und fefte Rerne Gefonmen, ntit Dill, Sauerfirfchen, SBeinblättern, Salz,

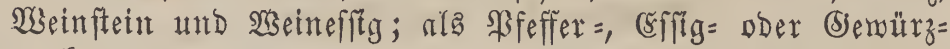
gutfen, wozu ntan bie fleinen, noch nteft ausigemachjenen

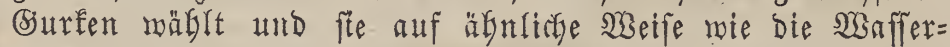
gurfen mit Dill, soorbeerblättern, Sfeffer, fuanifden ßfeffer= fichoten und andern Sienürzen einlegt; ferner als Senfgurfen,

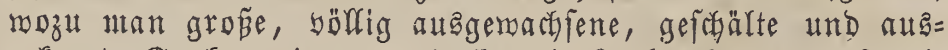
gefernte (S)urfen nimmt und fte mit Rorbeerblättern, fpani=

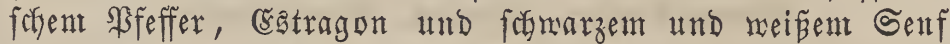
eimmadyt. - Dieje eingelegten Giurfen werben bäuftig als Bugebör zu Dodfenfleifch, Schinfen zr. genoffen.

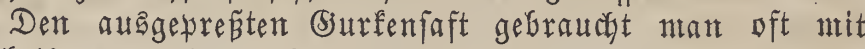
Bortbeil gegen eitrige Rungenformindfucht, auch als Sabn=

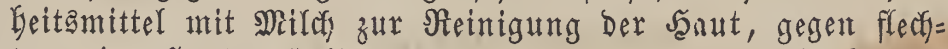

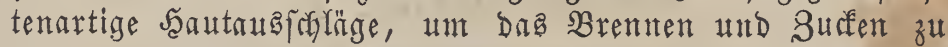

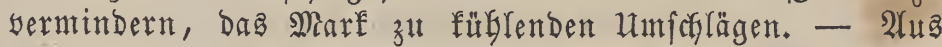

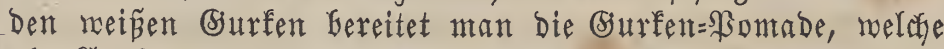

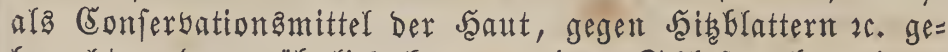
Graucht und gemöhnlicf furz yor Dent Schlafengeben einge= rieben wird. Die Sierne geben eine angenebme milatgige 
Crmulfton, und bie Sçale ber Siurfen fann man, in mäziger Siabe mit anderem Futter bermifot, Nindern uno Schneinen füttern.

Man Gat megrere Barietäten ber Gurfe:

1) (B) e me ine grüne (s) ưf

Santgurfe, gemeine rautge ftuctelige (Surfe, Surfe mit grüner Gifale.

Sie ift bie ant gemöhnlichiten angebaute Gurfe, bią zut ifrer $\Re e i f e$ grün, Dann gelb, und ift weniger gegen Froft empfindlich.

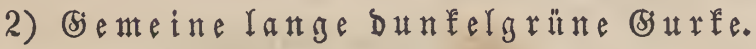

Salangengurfe (aber nicht bie eigentriche Salangen= gurfe Der Botanifer).

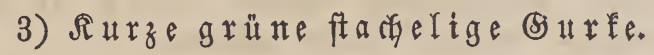

(b)ut zum (sinmacten.

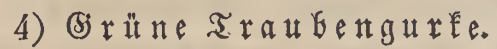

Bouquetgurfe.

Frücyte flein, 4-5 3oll lang, furz, Güichelweife bei= fammen ftekend.

Gebt frübe an und eignet fech Gejonders zum Treiben Itnd (sinutachen.

5) (5) it re mit weíner Schale.

Schale meíb, bei Heberreife audy gelblicf, und beim rinlegen ganz Durdyftedtig merbend.

\section{Cucumis flexuosus. L.}

$\beta$. Cucumis reflexus. Zeyh. Hort.

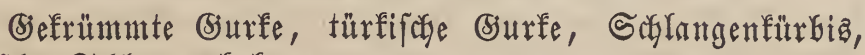
türfifche Gdylangenfufunter.

Concombre serpent. (frattz.)

Serpent Cucumber. Serpent Melon.(entgl.)

\section{Arten = Shauater.}

Blätter exfig, beinabe lappig. Frübte oft 10-15 3ull lang, walzenförmig, Gäuftg ftarf bin und ber gefogent.

\section{Blütbe = Beit und Sauer.}

Mrai - Juli. $\odot$.

\section{Borkommen.}

Sftinbien, in ber Tủrfei แnd 2 Trabien, audy bei unz in (3ärten angebaut.

\section{(Eigenfdaften, গtuthen, Atnwendung.}

Sie eignet fith ifrer wenigen Rerne megen bejonbers zum (sinmadfen und mird im Hebrigen wie bie gemeine Gurfe benübt.

\section{Cucumis Dudaim. I.}

Cucumis odoratissimus. Mönch.

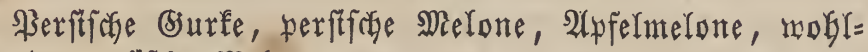
ricchende werfifiche Mielone.

Concombre de Perse. (frantz.)

Apple shaped Cucumber. (engr.)

\section{Arten = Erarahter.}

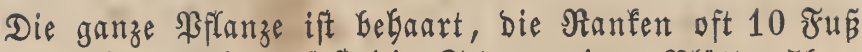
lang unb eben fo lang faft bie Seitenzmeige. Blätter 5laps= pig. Frücdte $6-8$ Soll lang, eiförmig, aud apfelförmig, flach gefurcht, im 2lnfang grün, gelblichbraun filzig, welch'

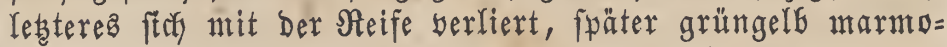
rirt ober geftricfelt. Der Stiel löst fich fuber bon ber Frudit $\mathfrak{a}$.

\section{Mai - Iuli. $\odot$.}

\section{Blüthe = Beit und $\mathfrak{D a u e r}$.}

\section{3ortommen.} (5ärten.

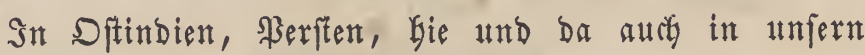

\section{ßulture.}

Vor bent Regen quellt man bie Serne einige Beit in Wanfer ein und forgt für eine recft fonnige Rage. Die meiblicyen $\mathfrak{B l u ̈ t}$ then zeigen ftef Mitte Mai's in Menge an ben Januptranfen, geben aber nicht immer Früchte; bie Blüthen an Den Seitenranfen Dagegen fesen gemölynlidy biele Früchte an, Deren einige dft fojon 2 hnfang Septemberz reifen.

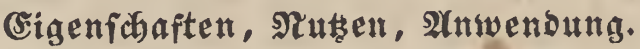

Die perfifdye burfe beftht einen Gerrlichen Woblgeruch, aber einen wiberlich fünen Mielonengefdymaf́; fie fann übri= gens als Salat berfpeiat, wie Siurfen eingemadyt ober wie Melonen Genủht werden.

\section{Cucumis Citrullus, Sering:}

Citrullus edulis. Spach.

Citrullus vulgaris. Schrad.

Cucurbita Anguria. Duch.

Cucurbita Citrullus. L.

Cucurbita pinnatifida. Schrank.

rienfürbia.

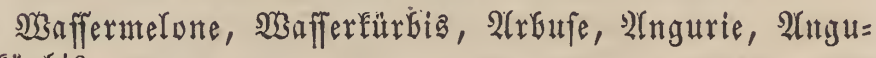

Pasteque, Melon d'eau. (ftatlz.)

Water melon. (entgl.)

Cocomero. (ital.)

\section{Arten $=$ Crarater.}

Blätter 3-5theilig, buchtig-gefiedert-getbeilt, abge= runbet-gelappt, rauh, fteif. Früchte grof mebr \$funde fchwer, fürbiąartig, elliptifch ober rund, glatt, fternförmig und 4effig, Dunfelgrün gefleceft, auch netgërnig

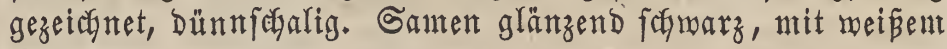
Rern.

\section{รuni - September. $\odot$. \\ Blüthe $=$ Beit $\mathfrak{t n} \delta$ Dauex .}

\section{3ortommen.}

$\mathfrak{A}$ frifa und Dftindien, und in vielen Eegenden, befon=

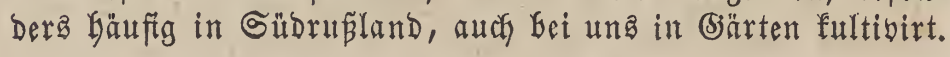

\section{§ultur.}

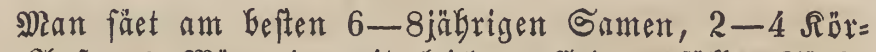
ner, $\mathfrak{A} \mathfrak{n}$ ang $\mathfrak{a}$ März in mit leichter Errde gefüllte Töpfe, meldye man barauf in ein Treibbanz ober in ein altes (5)ur= fenbeet fringt und etwaz feucht erfält. $\mathfrak{Z}$ (nfanga 2 (pril ver=

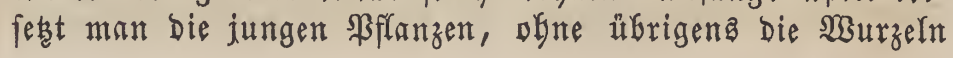




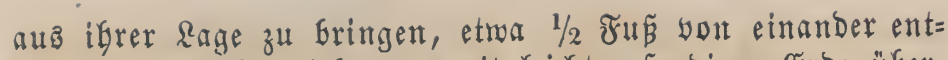
fernt in ein abgetriefenes, mit Yeichter fambiger crobe itber= Defftes und mit శenftern berfekenes Miftbeet. Später, wenn

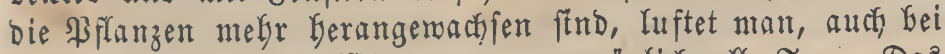
niwt ganz günftiger $\mathfrak{B i t t e r u n g , ~ w o ~ m o ̈ g l i c h ~ a l l e ~ T a g e . ~ D a s ~}$

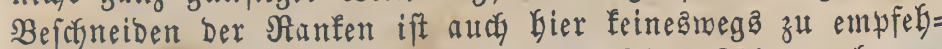
len. Mit bem Menate Suni, menn feine Rälte mebr zu Gefïrcften ift, ninmt man bie Fenfter ganz yon ben Beeten

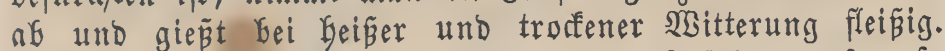
Sollten $\mathfrak{B l a ̈ t t e r ~ z u ~ b i e l ~ G c ̧ a t t e n ~ a u f ~ b i e ~ F r u ̈ c h t e ~ r e e r f e n , ~ f o ~}$

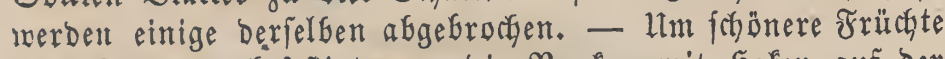
zu befommen, befeftigt man bie গanfen mit Şafen auf ber Errbe, welche nueift Mourzeln treiben. Bei biejer Befyand=

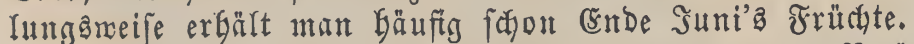

Die reifen Waffermelonen geben fich nie burch Berän= berung ber Farbe oder bes Beruchs zu erfennen, und fo

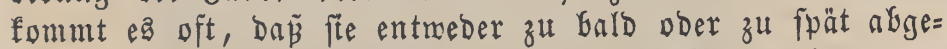
nommen merben, in melsh' beiben Frallen fie entweber ganz rauk und ungentéfGar, ober fagrammig und faftlos finb; bie Beften Rennzeidyen Der Reife find Dagegen ber hoble Ton, Den bie Früchte beim 2 Anflopfen yon fich geben, und baz Siniftern bei ftarfem Drufe, auch merben fte mit Der Neife

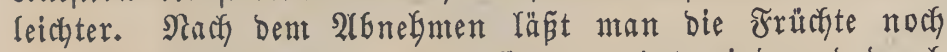
einige Tage liegen, eke man fte anmendet, inbem Daburch

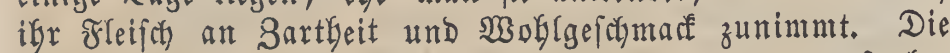
Fruble laffen fich nidat lange aufbemahren, fondern faulen bald.

\section{Eigenfabaften, Nutsen, Atnwenoung.}

Daz Fleifo, Der Sצaffermelone ift meidy, faftig, wäffe= rig, bunfelrofen= ober carmoiftntoth, und bat einen ange=

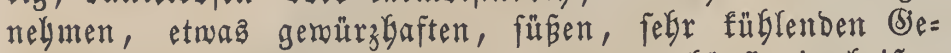

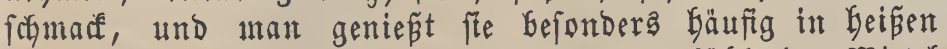

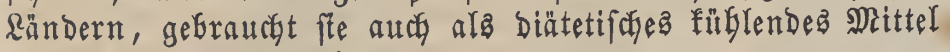
in Entzündungâfranf̧eiten.

\section{Cucumis Melo. L.}

$$
\begin{array}{cl}
\text { Cucumis } & \text { bucharicus. Hort. } \\
\text { - } & \text { Cantaloa. Hort. } \\
\text { - } & \text { erivanicus. "Hort. } \\
\text { - } & \text { maltensis. Sering. } \\
\text { - } & \text { reticulatus. Hort. } \\
\text { - } & \text { verruccosus. Hort. } \\
\text { - } & \text { viridis. Hort. } \\
\text { Melo vulgaris. Moench. }
\end{array}
$$

Melone, Melonengurfe.

Melon. (fianz.)

Common Melon. (entgl.)

\section{Sarten = Charater.}

Stengel lang, äftig, friechend ober ranfend, raul be=

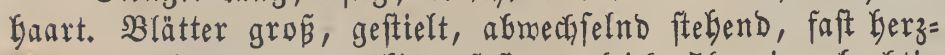
förmig, abgerundet-erfig, faft ungleich 5lappig, buchtig gezäbnelt, raug und Gorftig befaart. Blütben furzgeftielt, achfelftänbig, 5fpaltig, glorfenförmig, gelb, bie männlichen zu 4-5 ftefend. Die 3 Staubfäben zu einer $\Re$ öbre ber= bunben. Fruchtfnoten bicht Gebaart. Sriffel am Ende 3fpal= tig. Narbe 4erfig, ftarf auggerandet. Früdjte yon verfobie=

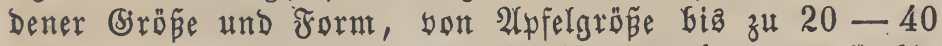
Pfund faber, in Berfien und Afghaniftan bat man fte biz

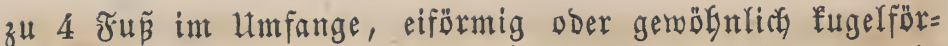
mig, oft auch platt, runzlich erfaben gerippt, glatt, marzig ober borftig. Samen flein, gegelt 4 Rinien lang und $1 \frac{1}{2}$ Sinie Greit, zufammengebrülf́t, glatt, eiförmig-länglich,

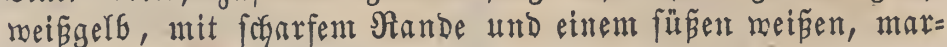
figen Rerme.

\section{Blüthe $=3$ eit und $\mathfrak{D a u e x}$.}

গuli - 2luguft. $\odot$.

\section{BorÉmmen.}

In 2 fiten, Dftindien, im Rande ber Ralmücfen, in

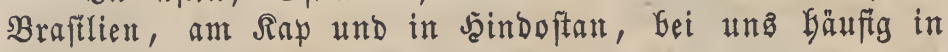
Miiftbeeten gezogen.

\section{sultur.}

Sm Sianzen gleidyt bie Melonenzudyt Der Der Burfen, nur baß in jeder Beziefung mefr 2lufmerffamfeit erforder= lich ift. Man legt die Nelonenferne im Mañ poer 2(pril in Töpfe im Simmer ober in Miftbeete, und luftet bet war= mer $\mathfrak{B}$ itterung zumeilen. Im Suni verfetzt man bie \$flan= zen, nadydem man fate vorftedtig mit bem Erbfalfen aubgeho= ben bat, in ein gefchühtez, recht fonnig an einer Mauer

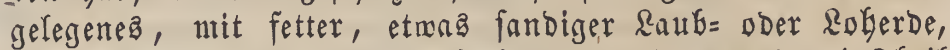
ober einer Nifchung yon 2 Theilen guter Jartenerbe, 1 Theil

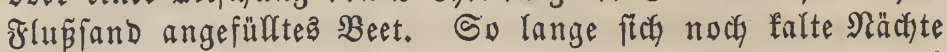
zeigen, überDerft nan bie Melonen mit Fenftern, Matten, auch

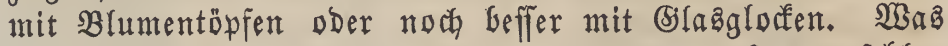
Daz Befuneiben bei ben Melonen anbelangt, fo empfeflen

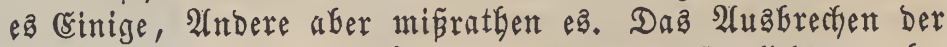
fogenannten tauben $\mathfrak{B}$ lütben, nämlid ber männlicten, anbe= langend, Güte man fter, biefes efer zu thun, als biefe bie meiblichen Gefruchtet Gaben, wenn man nicht bebeutenden

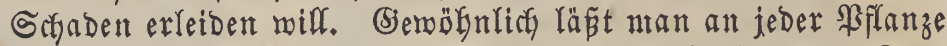
nur 2 Sauptranfen und bridht mit bem Errfcheinen ber $\mathfrak{R} n \mathrm{D}=$

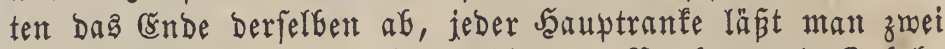

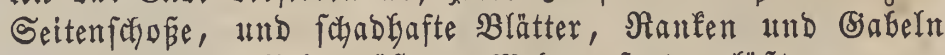
entfernt man. Bei gröseren Melonenforten lä̈̈t man au

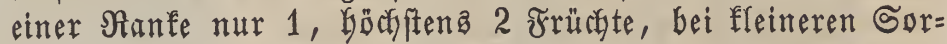
ten fann man megrere fteben laffen. Mit bem fortfdreiten=

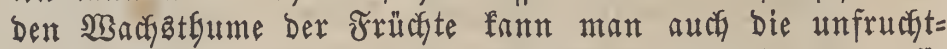

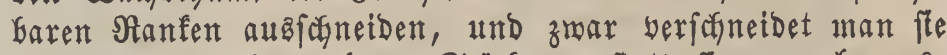
noch int Beete in mekrere Stühe, anftatt fie ganz heraus=

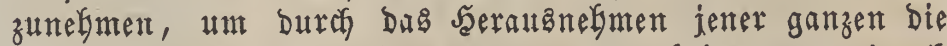
übrigen Nanfen niest in Unorbnung zu Gringen, woburion ber fünftige Ërtrag fefre verringert mürbe. Bei anbaltend

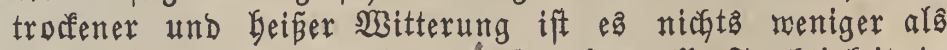
yortbeilgaft für bie Melonen," fite ofne affe Feuctigfigeit in bem troffenen $\mathfrak{B}_{\text {oden }}$ bis zum sroelfen fommen zu laffen;

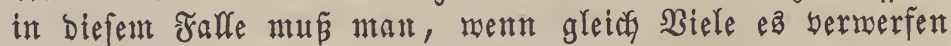

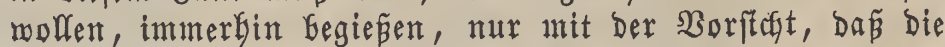

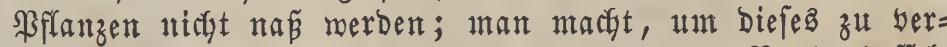

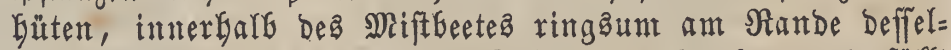
ben etwa 2 3olf tiefe und 4 3olf Greite bruben und füllt biefe fo lange mit $\mathfrak{B a f f e r}$ an, Gis man benterft, báz die Feudedtigfeit Das ganze Beet burchbrungen hat. Bu bemerfen ift nod, Daß bei marmer Witterung Die Mielonen ftetz ber Ruft ausigefest merben müffen. Giegen bie Reife ber Melu= nen unterlegt man, um $D a \xi$ Faulen berfelben zu verhüten, mit Brettern, Siegeln 26 , - Die Reife felbft fieft man an 
Dent buftigen, genürzbaften \$eruche, Der beränderten Farbe

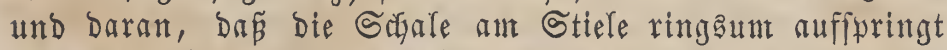
Doer menigftens dafelbft rifitg wirb. Man rechnet gemöhn= ricts yon Der Seit des Rernelegens bis zu Der Der Reife 100 Tage. - Einige ziefen Melonen auch in Simnter in

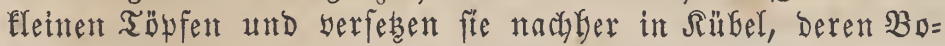
Den mit Subsünger belegt worben ift.

Die Melonen eignen ftef borzugameife zur Treiberei. Man legt int Februar $15-20$ 3jügrige Serne in einen

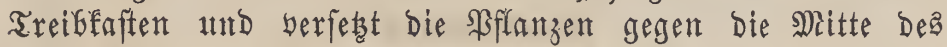

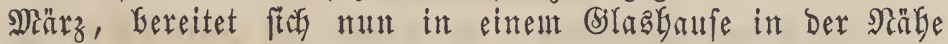

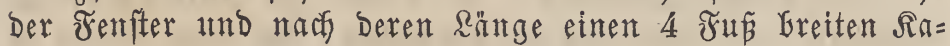
ften, in beat man frifoyen und waruten Sferbedung tritt und fol'cyen mit guter Bartenerbe überlegt, feht in biefen, nachbem fich bie Ëroe geförig erroärnt hat, bie Melonen:

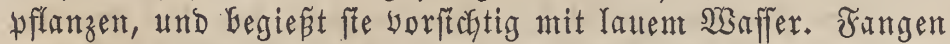

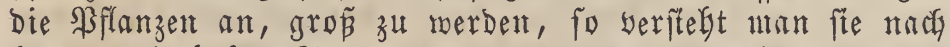
Ginten mit Goken Stangen, an melchen fe fterh Ginaufranfen

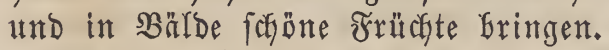

Crinige (5)ärtner pfropfen and Melonen auf Melonen, ober auf Jurfen, doer aud auf Rürbife, und bie Frind te follen baburch yief fafmarfbafter, fleiffy= und faftreicher merben.

Unm ferner befonders gute Melonen zu befommen, räth man, bie אäprner yor bem Ëinlegen in eitte Mifchung yon Sambeeraft, Miofdus, Binmt und Cardamomen zit Yegert.

Wenn bie Melonen abgenonmen fend, fo läst man fie noch einige Tage liegen, eke man fte Genüht, woburch fte nocf einen feinern und gemürzbaftern befchntaf erbalten. Der Same Gleift 5-6 Jabre gut.

\section{Grbäolidbe Sinflüfite.}

Rălte, Näffe und Winde fünd den Melomen noć weit gefübrlicfer als Den biurfen, und viele, oft alfe werben Daz Dopfer einer ungünftigen Witterung; e⿱ nichts thun, als bie Miftbeete gut zu verwabren. Ferner

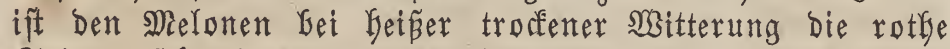

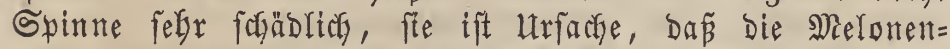
blätter fïcl zufanmentolfen und zerfchligen.

\section{sigenfabafen, গuten, Anwensung.}

Die Melonen Geftenen ein felgr angenebm aromatifas rie= ajendes und belifat und füв formedendes, fegr faftiges, zuffer=

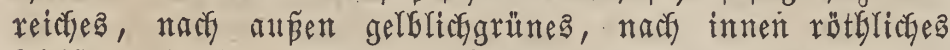
Fleifd und ein marfiges rotbes Bernebe, in welchent bie -

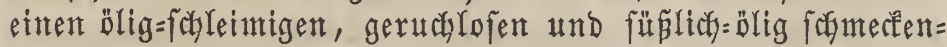
Den Siern einfolieñenden - Gamen Yiegen. Die Melonen find eine äußerft angenebm erqutifento und fullylende Speife, und man geniest fte meift in Stüffe zerfornitten rob, alfein ober mit Buffer, Simmt, auch, was zuträglicher für bie Bejuntb= beit ift, mit Bfeffer ober sngwer, in Keipent Rändern auth unreif, wie Surfen und mit Salz und Ëffitg eingentacht.

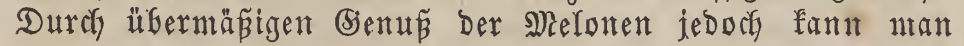
fïch, Befonders in füblictent Rändern, Yeidgt Diarrgöen, Rubr, Rolif zc. zuzieben. - Mian bereitet bie Melonen, um Den bermöhnten Saunten ber Menfechen noef megr zu fröknen, auf bie werfobiedenartigfte $23 e i f e$ zu, man macht fte fauer Dber für ein, man candirt fee, bereitet aus ifnen Melonen= mupe, Suppentorten $2 c$.

Mian verorbnet bie Melonen auch als diätetifctes Meittel,

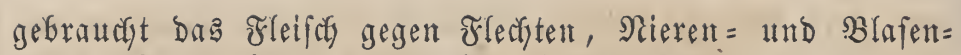
leiben, Gei Berbrenmungen, Suetichungen, gefodst zu erwei= chenden ltmifolägen, und igre Serne geben ebenfalfs eine Esnulfton, bie utan bet Entzündungen der Saanröbre, Blaje, Nieren, bei Sarnberfopfung anmendet.

Durry Rutur ftnd eine Menge yon Barietäten Der $\mathfrak{M}=$ lone Gerworgegangen, und ntan theilt fte ein in Cantalu= went, Nebutelonen unb in gereifte, geriefte oder geriefelte Melonen.

\section{Crntalupen.}

Florentiner Melone, Cantalupe. (Bon Cantalupi, einent Frleifen in 2 (ntcona.)

Melon de Florence. (firatz.)

Cantalup melone. (engl.)

Cantalupi. (itar.)

Frübyte fugelförmig, etwas wlattgebrürft, wit bielen S3arzen bebect, mit biffer Schale und Beidyungen auf ben

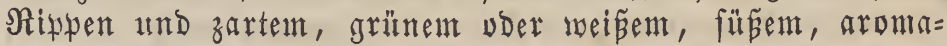
tifich riectyendent Fleifoche.

Sie verlangen zu threr Reife viel M̧ärnte ullo Nahrung.

a) (3) rüne (cantalupe.

Fritchte flein, oft melgr länglidy, vft melyr wlatt, mit einigen Warzen, zuweilen auth etwas gerippt. Schale wenig

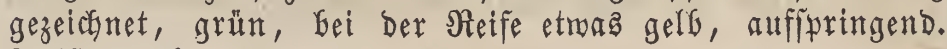

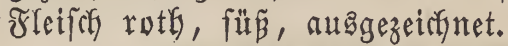

In falten (biegenden gebeigt fie felten, fpringt auch meift auf.

b) Sacharze (Cantarape.

Ștalienijade (Santalupe, Melone der Seiligen (in Stalien).

RTein, rund, Gäuftg unförmlich warzig, mit dunfel= bis folwarzgrüner, felgr biffer und fobmammiger Sajale und Dunfel= gelbem, Gerrlich und füpreinigt fanmedendent freifrye.

c) $D \mathfrak{i a n g e n t}=\mathfrak{C} \mathfrak{a} \mathfrak{t} \mathfrak{a} \mathfrak{l} \mathfrak{p} \mathfrak{e}$.

Drangenfarbige Cantalupe.

Ränglich, etwas brobirt, weniger warzig, bei ber ßeife gelb, nicht auffpringend; Fleifoh febr gut, aber wenig ge= würzbaft.

d) Frübe yerfirberte Drangen=

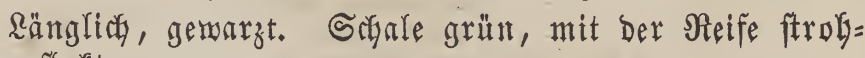
gers gefledt.

Sie ift fegr gut und befonders bauerhaft.

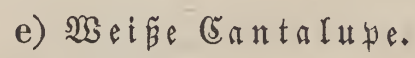

Erübte grus, rund, platt, warzig. Schale febr biff,

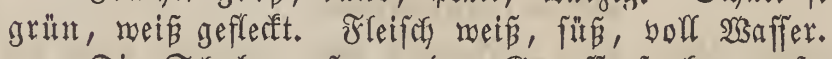

Die Sagale mús yor Dem Gentffe fauber entfernt wer= Den, fonft fochmerft bie Melone Gitter.

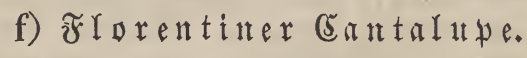

Siemlidf grofi, mit fegr biffer Sodyale und einen beli= faten gelGen ש̂Teiface.

\section{g) Słanifre (Eantalupe.}

Frudgt fein= und fleimwarzig. Schale ftrobfarbig. Fleifan

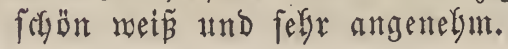







. 
h) Frăke fpaniface cantalupe.

Melone yon Balermo.

Frudyt jegr grof, fugelförmig. Scyale glatt, bünn und fdumal ftrohgelb geftreift. Fleifch Gellgrün, fefr faftig und moblichmerfend.

i) Prinz yon Dranien.

Frülge Golländifhe Cantalupe.

Frucht rund, gerippt. Fleifah gelb, fehr mohlfanmerfend. Steift frủbe.

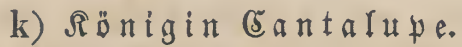

Rănglich, platt, warzig. Sçale im 2(nfang ganz grün, mit Der Reife ftrohfarbig, am Stiele netgartig und Dủnn gereift.

Segr gute Sorte, trägt frübe und Gäufig.

1) 8 werg $=(\mathfrak{a} \mathfrak{n} \mathfrak{t a l} \mathfrak{k}$ e.

Früchte fugelrund, glatt, fein= und bünnmarzig. Scfyale grün und ftrokgelb gereift.

Da. Diefe Sorte ftarfe, biffe, aber faum 1 Fun lange Ranfen treibt, fo Darf man fte, gebörig augsebreitet, nie

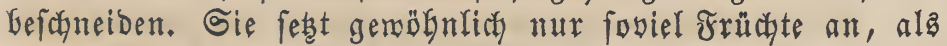
reifen fönnen.

m) Nothe Cantalupe.

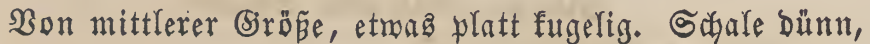

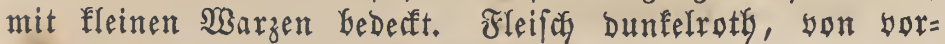
trefflictyem (jeffymatf.

n) Bjerippte (5antalape.

Sigale erbaben geftreift und baburch tief gefurdyt, grün,

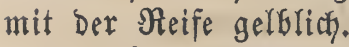

Segr gut.

\section{Aleb-Melomen.}

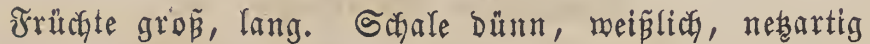

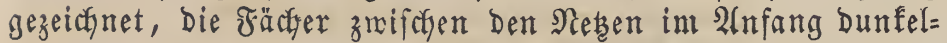
grün, fpăter gel6. Fleifch Diff, oraugegelb, faftig und wohl= fumerfend für.

\section{Grereifte Alelomen.}

Beriefte Dielonen, geriefelte Melonen.

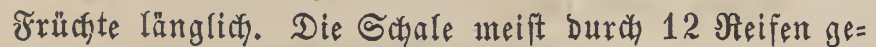

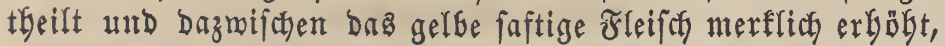
auch ganz bon Dem Marfe getrennt.

\section{Trichosanthes, Lindl.}

Eutrichosanthes. Wight. Arn.

Involucraria, Sering.

Snfteme: Bryoniae. Adans.

Calyciflorae monopetalae. Roy.

Cucurbitaceae. L. Juss.

Monoecia, Monadelphia. L.

Sygalliphyta. Neck.

Reldylappen borftenförmig. Blume 5theilig und geroim= pert. Staubfäben in 3 vermachfen. Erriffel 3ppaltig. Frucht länglich und 3 f̈̈cherig.

Entwer, benom. ஒPfanzentunde.
Trichosanthes Anguina. I.

Cucumis Anguinus. L.

Petola anguina. Mich.

$\boldsymbol{\beta}$. Trichosanthes Turolata. Hamilt.

Soldangengurfe, lange oftindifche (surfe.

\section{Arten = Ebarafter.}

Stengel 5eçig. Şlättex berfförmig, 3lappig und ge= zäbnt. ßanfen febr lang und gefpalten. SBlütben in lang= geftielten Trauben, langröbrig, weís. ซ̌rud̆t 3 , zumeilen $3 \frac{1}{2}$ ₹̛̣ lang, aber nur 2 Soll biff, walzig, nicht gerade, fondern fohlangenförmig gemunden, graulichgrün, Geftäubt, alt feuerroth, mit Dünner Saat, weldhe leidht zerreip̃t. $S_{a}=$ men belforaun, am Rande gezägnelt.

\section{Blütbe $=$ 3eit und $\mathfrak{D a u e r}$.}

Suni - September. $\odot$.

\section{SorÉmmen.}

CGina und Dftindien, bei unb bie und da in Bănten.

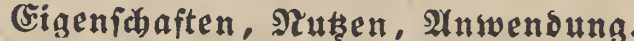

Die ganze $\mathfrak{B}$ fianze bat eitten unangenefmen Seruch und bittern (jefdynaff, ebenfo bie Frucht, welche aber, menn fie unreif gefocht mird, Das beišt, menn fte noch nicht vief ubber

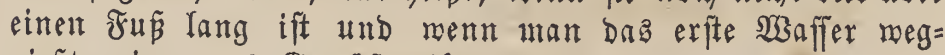
giefst, ein gutę Ssemůle gibt.

Sie wirft ftarf purgirend und man gebraucht fite deś Gall gegen Den Bandwurm.

\section{Cucurbita, L.}

Citrullus. Neck.

Pepo. Adans.

Syfteme: Bryoniae. Adans.

Calyciflorae monopetalae. Roy.

Cucurbitaceae. L. Juss.

Monoecia, Monadelphia. L.

Sygalliphyta. Neck.

Männliçe Blüthen: Relch ganzblätterig, 5fpaltig, mit pfriemenförmigen Bipfeln. Blunenfrone ganzblätterig, glocfen= förmig, 5fpaltig, igre Sipfel find in Der Inogpenlage am Rande eingefaltet. Staubgefäвe 5, Dem Srunde Der Blumen= frone eingefügt. Staubfäben unten 3 brüberig, je 2 zufam= mengewactyen, Der 5 te ift frei, Diff, oben 1 früberig ver= wachen. Staubbeutel 1 fäherig, ftumpf raalzenförmig. Narbe verfünmert.

W3eibliçe Blütgen: Relch ganzblätterig, mit eirunder RäGre und oberitändigem, 5 jpaltigen, abfallendent Saune. Blumenfrone wie bet Den männlichen $\mathfrak{B}$ lütthen. Nebenfüben

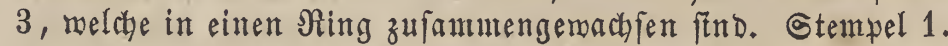
ঔruchtfnoten unterftändig, $3-5$ fächerig. Siriffel 3 fpaltig. Narben yerbift, lappig - 2ipaltig.

Frucht fugelig, ober birnförntig, gefchloffen, nicht auf= fpringend, 3 fächerig, vielfamig, und nit biffer Schale. Sa= men berfebrt - eiförmig, zufammengebrüaft, am Nande ber=

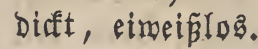

\section{Cucurbita Pepo. L.}

Cucurbita polymorpha oblonga. Duch. $\beta$. ? Pepo elongata. Haberl. 
Biemeiner Gartenfürbis, gemeiner Felbfübiz, gemeiner Sürbiz, Pfebenfürbiz, łepone, Babe, ßluber.

Potiron, Pepon. (fratz.)

Pumpkin gourd. (ettgr.)

\section{Arten = Sharakter.}

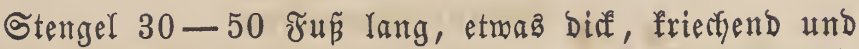
ranfend, åftig, ecfig, raub bis borftig, faftig, mit 3 jpalti= gen Bjabeln. Blătter grós, abuechfelnd ftebend, geftielt, Gerzförmig, ftumpf, 5lappig, gezähnelt, runzlich), fefgr rauh, Gockgrün. SBlüthen achjelftămbig, gefäuft ftehend, furz, trich= terförmig, Gochgelf. Die zrüchte erreichen oft eine anfegn=

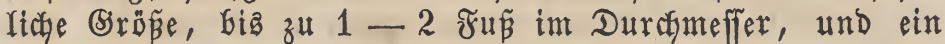
(5)endidyt oft bon 70 Pfund, fie fend entweder eiformig-läng= lich ober runblich ullo niedergebrüft, glatt, aucis gerippt, ober jelbft feinborftig, auch mit Waarzen, Roftflecfen werfeben, mefr ober meniger grün, mit ber Reife grün und gelb mar=

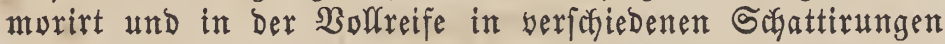
gelb, Gaben ein fegr faftreiches weipes Fleijon und viele $3 / 4$ 80W lange und 3 Rinien breite, glatte, berfegrt-eiför= mige und plattgebrüăte meí̄e Gamen mit aufgetriebenem Rande.

\section{Slütbe $=$ Beit and Dauer. \\ গuli - September. $\odot$.}

\section{S3orénmen.}

Snt Drient, in Dftinbien eintyeimifor, und Gäufig in (Bärten und $\mathfrak{B e i n b e r g e n ~ f u l t i v i r t . ~}$

\section{ßultur.}

Die Rürbife verlangen einen fetten, babei aber locfern, leichten und feucften Boben und eine fonnige Rage. Man baut fie am beftent mie bie Sourfen an, fäet fie meift Ende Alprila, nachdent nan die Rärner zuyor etwas in Şaffer eingeroeicht hat, in 2 3oll tiefe und 8 Fú bon einander

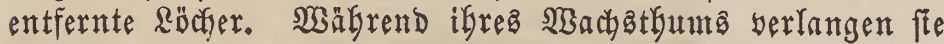
biel Feuchtigfeit. Seken fich einmal Früc cyte an, fo entfernt

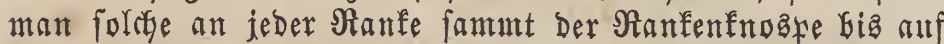
$2-3$, und menn bie Jrüchte grof́p gemorden find, fo wer = ftegt man fie mit Unterfagen und wentet fte auf biefen son Seit zu Seit um. Man ziegt die Rürbife Gäuftg an Spałer= mänden, Bäunen ober aud an Mauerabgängen. Die Reife Der Frucht läpt fich erfennen, wenn fie beim Anflopfen einen beffen Ton yon fich gibt. Der Game bleibt $6-8$ Jabre lang gut.

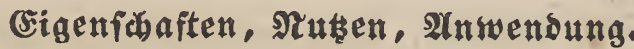

Der gemeine Rürbis enthält ein fodmammiges, meí̈ę und füpliches fleifon, melches in vielen Drten, bejonders auf bent Rande, als gejunde, menn auch gerabe nicht befon=

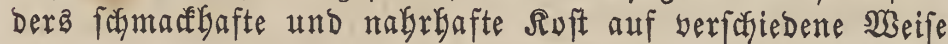

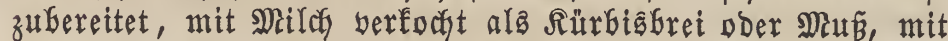

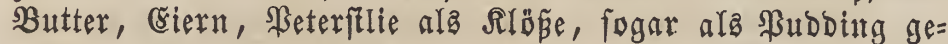
noffen mird. Rürbisffeifđ $(1 / 2$ zu 1 Megl) mit Mekgl ver=

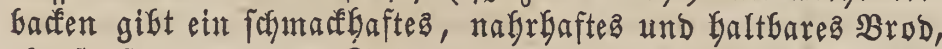
ebeño fest man Den Saft yon gefochten Räubifen $\mathfrak{B r o d}$ bei. Man bereitet aus bem Safte Surup, 3ưfer und Brannt= nein, fann bie jungen Rärbife, fobald bie slüthe weg ift, wie Gourfen mit Effitg einmaden und daz Fleifo, in lange Streifen gefdnitten, trodfnen und wie gedörrtes DGft ge=

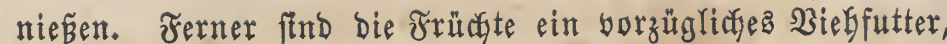

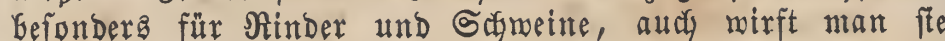
Sarpfen yor; aus ben - einen angenefnt, millo füß̨lich fofmeafenden und oligen Sern entbaltenden - Samen geminnt man ein Dem Baum = und Mandelöl ähnliçeả, milbeż und

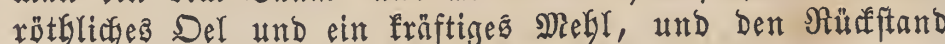
bei Der Delgeminnung benủbt man zur 2 iegfütterung.

Dfficinell find bie Samen, fie geben eine angenebme, milchige Emulfton. Die jungen Stengelfchöplinge fünnen

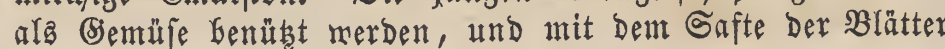
Geftreicht man $b_{a}$ Bieh, um ez gegen Fliegen, wie Bremt=

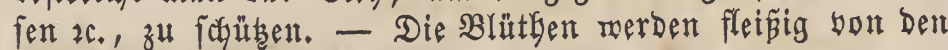
Bienen bejucht.

\section{Cucurbita maxima. Duches.}

Cucurbita Melopepo. L. var. Spr.

Cucurbita. Potiro. Pers.

Pepo macrocarpus. Rich.

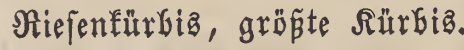

\section{Arten $=$ Cbarater.}

Blätter nieren - Gerzförmig, gezähnelt und ziemlich fteif= barig. Blumenfroue glocfenförmig, mit zurüffgefdlagenem ธăme.

\section{$\mathfrak{B l u ̈ t h e}=$ 及eit $\mathfrak{a n d} \mathfrak{D a \mathfrak { e x }}$.}

Suli - September. $\odot$.

\section{3ortommen.}

Sübafen, Dftindien, und ebenfalfs in unfern Bărten angebaut.

\section{(Eigenfidaften, গtuten, 2tnwenoung.}

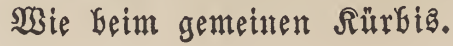

\section{Cucurbita Melopepo, L.}

Cucurbita polymorpha Melopepo. Duch.

Pepo Melopepo. Moench.

$\beta$. Cucurbita radiata. Hort.

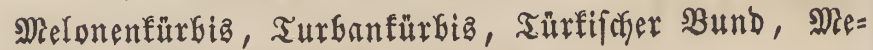
lonenpfebe, Schildopepone.

Pastisson, Bonet d'electeur. (framz.)

Squash gourd. (entgl.)

\section{Arten = Charakter.}

Blätter Gerzförmig, beinake fappenförmig und 5 lappig,

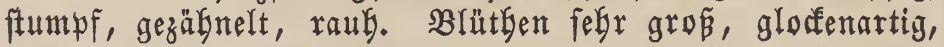

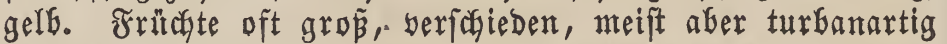
geftaltet, freifelfürmig, oben eingebrüaft, genabelt, gefurdit, über Der Jălfte gegen Die $\mathfrak{B a f t a}$ Gin Durch einen wulftigen ßand aufgetrieben.

\section{Blütbe = 3eit und $\mathfrak{D a u e r}$.}

suli - September. $\odot$.

\section{3ortommen.}

Dftindien, Dafelgft mie überhaupt im Drient, auch bet

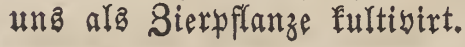

\section{నuttux.}

Man fultivint fie wie die Melonen. 


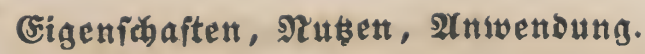

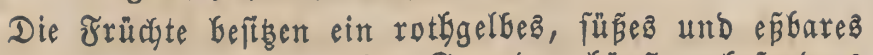

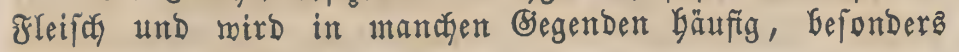
gebraten, genoffen.

Barietäten desิ Melonenfürbis find:

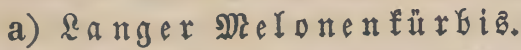

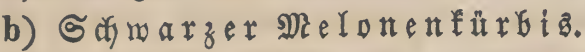

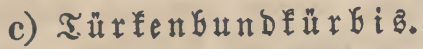
d) $\mathfrak{B} \mathfrak{i} \mathfrak{i} \mathfrak{a} \mathfrak{\mathfrak { f }} \mathfrak{u} \mathfrak{i} \mathfrak{b} \mathfrak{i}$ b.

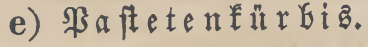

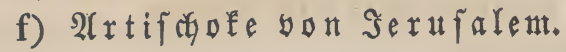

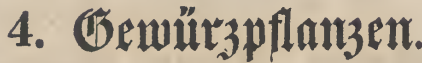

Saierunter werftehen wir foldye Bflanzen, bie ibrer Blätter, Blüthen und \&rüdfte wegen als (s)enürze angebaut werben.

\section{Origanum, L.}

Majorana. Moench. Benth.

Syfteme: Corytophyta. Neck.

Didynamia, Gymnospermia. L.

Labiatae. Juss.

Labiatae Nepeteae. Spr.

Labiatae Satureineae. Benth.

Ringentes gymnospermae. Roy.

Verticillatae. L.

Verticillatae Melissae. Rchbch.

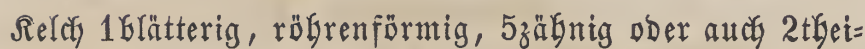
lig, ber Salund mit einem Barte yon Jaanen bejest. Blu=

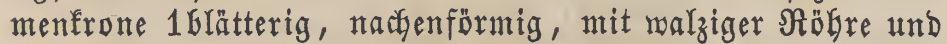
oberwärtz erweitert. Saum 2tippig; Dberlippe gerabe, aus= gerandet; Unterlippe abftebend, 3fpaltig, bie Sipfel ftumpf, beinabe gleich. Staubgefã einanber tretend, fo lang ober Yänger als bie B̊lumenfrome. Staubbeutel getrennt. Soriffel fadenförmig, fo lang als bie Staubfäben. Narbe gefpalten. Samen 4, glatt, abgerundet.

\section{Origanum Majorana. L.}

Origanum majoranoides. Willd. Origanum 0nites. L.

Origanum Wallichianum. Benth.

Majorana hortensis. Moench.

Majorana vulgaris annua. Moris.

B. ? Majorana crassa. Moench.

Majoran, SBurftfraut, gemeiner Majoran, Mairan, Mafferon, Somntermajoran, Majoranduften.

Mariolaine commune. (frattz.)

Sweet Majoran, Marjoran, Marsorum. (entgl.)

Majorana. (itar.)

\section{Arten = Charatter.}

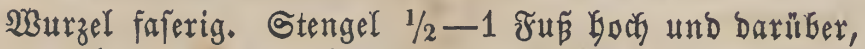

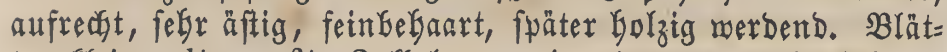
ter flein, $1 / 4-3 / 4$ 30ll lang, einander gegenüberftekend, efliptifa ober megr eifürmig, ftumpf, ganzrandig, melgr ober

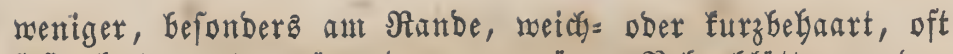
faft glatt, zart, grün Doer graugrün. Sebenblătter an ben Reldhen ziegeldadyförmig ftelyend, feinbefaart, graugrün, an

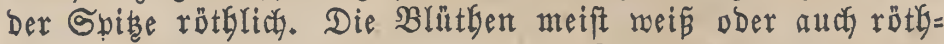
lid, am Ënbe Der Stengel und Der Zroeige bicht und meift zu 3 in fleinen runblichen, geftelten, etras undentlidfen, 4 [eitigen 2 elgrefen ftebend.

\section{Iuni - 2uguft. $\odot$.}

\section{Blüthe $=$ 3eit $\mathfrak{u n d}$ sauer.}

\section{3orkommen.}

Sm Drient, in ßalăftina, Dftindien, srieçenland, Bors tugal cinbeimifó und bei una in särten gebaut.

\section{నultux.}

Der Majoran wirb bei uns im Freien meift nutr alz

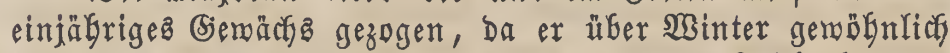
erfriert. Man fäet ben Samen entweder int Frühjakre auf ein fonnig gelegenes warmes Beet, in guten, leichten, etroa fandigen Boben, bedecfit ifn nur oberffächlich nit Errbe und Gält ifn etwas feucht, ober fäet ifn, Gefondera wenn man Samen ziehen will, Ënde 2 (ugut in ein Miftbeet, in $\mathfrak{B l u}=$ mentöpfe ober Räften, und berziegt bie jungen $\mathfrak{P f}$ fanzen $\{0=$

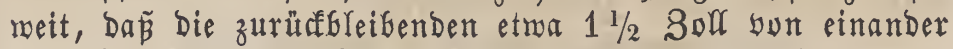
zu fteben fommen. Sm Syätberbfte, bei eintretender Rålte, bringt man bie Tüpfe in eine froftfreie אammer an's Ridht, begieß̧t folcte nur, wenn bie Erbe ganz trodfen gemorben ift, und nur fparjam, and luftet bei warmer $\mathfrak{W}_{\text {Bitterung. SD= }}$

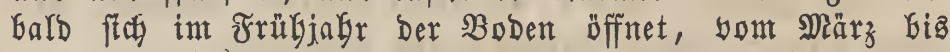
Miai, berpflanzt man bie Majoranftöf́chen in eine warnte

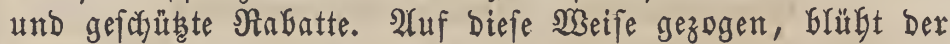
Majoran bald und feht auch meijt reife Samen an. Rebterer bleift 2, yöbftenz 3 sabre lang gut. - 3um 2rpotbefer= gefrauche barf man bas Rraut nicht bälder abfectneiden, als bis bie Blumenfnoßpen fith yolfommen augigebildet bafen.

\section{(rigenichaften, গ⿰ułen, A(nwenoung.}

Der Majoran hat einen ftarfen, gemürzlyaften Beruda, Der fich Duref's Troffnen nicht berliert, und einen angenely= men, arontatifochen und campheräbntiçen sefectmarf. Die yormaltenden Beftandtheile des Majoranz find: ätherifches Del und eifengrünender Berbeftoff. Das Rraut mur zum Berbraudye noch feinen geroürbaftell Berutch beftem, Darf nicht braun ober mit zu bielen Stengeln bermifabt fein. -

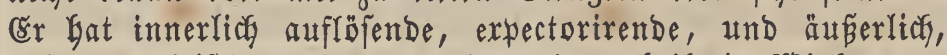
Gejonders frifo, gelind reizende und zertheilende Wrirfungen.

Man gebraudst ifn bäufig als Bemürze an Speifen,

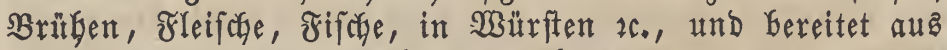
ifm für bie Tafel Den febr gemürzaften Meajoraneffitg. Die Blütben werben bäufig yon ben sienen bejucht.

\section{Origanum vulgare. L.}

Origanum orientale. Mill. Origanum stoloniferum. Bess. Origanum sylvestre. Blackw.

Origanum venosum. Willd. $\beta$. Origanum humile. Poir. \%. Origanum virens. Hffmsg. Link. Origanum oblongatum. Link. Origanum thymiflorum. Rchbch. 
Origanum viride. Willd.

$\delta$. Origanum vulgare prismaticum. Gaud.

Origanum capitatum. Willd.

Origanum creticum. DeC.

$\varepsilon$. Origanum nutans. Willd.

Bemeiner Doften, Grauner Doften, wilder Majoran, Bergmajoran, Felomajoran, WSalbmajoran, Woblgemuth, milde Dofte, SKaldodfte, Feldodfte, Drant, Dofant.

origant vulgaire. (firam.)

Common Majoran. (engl.)

\section{Arten $=$ Sharakter.}

Warzel friectyend, Golzig, aunen formärzlicy. Stengel $1-2 \mathfrak{F} u \tilde{B}$ boch, aufrecht, åftig, 4 feitig, bebant, bäufig roth angeflogen, mit gegenüberf́tebenden 3meigen. Blätter $1-1 \frac{1}{2}$ Soll lang und länger, gegenüberfétend, geftielt, breiteiförmig, ftumpf, ganzranbig, ober faum Gemerffar buchtig gezähnt, feinbefarart, faft glatt, geabert, butreffichtig punftirt, oben bunfel =, unten meí̄lidgrän. Seldy felgr furz. Blüthen am Ënde ber Stengel und Aefte in fleinen, riapen=

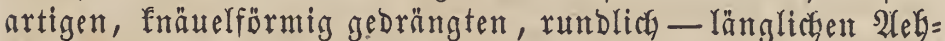
ren ftebend. Die Nebenblättclen ber Aebre länger als ber Relch), eiförmig, ftumpf, biolett ober Graunrotg. SBlumen= frome flein, aber länger als ber Selch, robrig, belfpurpur= roth, feltener meíb. Narbe 2fpaltig.

Blütfe $=3$ eit und Sauex.

\section{Juli - September. 4.}

\section{3orkonumen.}

$\mathfrak{A} \mathfrak{n}$ Zäunen, Şedfen, malbigen Şügeln, troftenen, ftei=

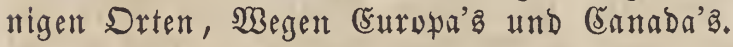

\section{હigenfdaften, Nutsen, Anwenoung.}

Die ganze $\mathfrak{B f l a n z e}$ bat einen angenelymen, burchbringend aromatifcten, najoranartigen (bieruch und einen falzig bittern, etwaz Gerbelt, brennend gervürzhaften Befdmarf.

Bormaltende Beftandtyeile fitnd: ätferifdyes Del und eifengrünender Berbeftoff.

Man benübt ben Doften gleich bent Miajoran alz Bese

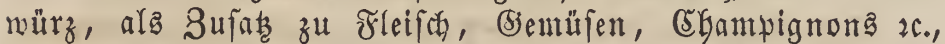
fo namentlich in Stalien, Sefweden zc. (Er ift ein fegr an= genebmes, bent dyineftichen Thee äGnliches Theefurrogat, wirb Gäufig bent Biere ftatt Des Sopfens beigentengt, und ertheilt Denffelben, wenn es mit ifm gäbrt, beraudbendere Erigen= f(c)after.

Man mendet ben Doften in ber Mebicin innerlich im

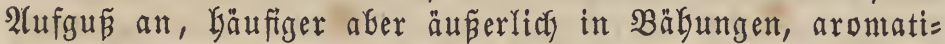
fduen $\mathfrak{B a ̈ b e r n , ~}$ Iräuterfiffen, und bas Doftenöl gegen fdymerz= Gafte Goble Bähne. Man legt ifn in Rleider, um Schaben

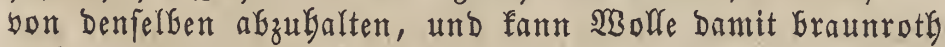
färben. Die Blütben geben ben Bienen gute und reichliche Rakrung.

Origanum creticum. L.

Origanum heracleoticum. Rchbch.

- hirtum. Link.

- latifolium. Mill.

- macrostachyum. Link. megastachyum. Link.

vulgare. $\beta$. Benth.

Cretifcher Duften, fwanifcher Şopfen, cretifcher Diptam, canbiffyer Doften, cretifher Majoran.

\section{Arten = Charatter.}

Stengel $1 \frac{1}{2}$ Fun gody, aufredyt, oben ñftig, beinabe Golzig. Blätter flein, 4-6 Rinien lang, gegenüberftebend, furzgeftielt, eiförmig, ganzranbig, raubbebaart, brüftg und graugrün. B̧ütben am Enbe Der Stengel und 3roeige ge= brängt, meift zu 3 in $3-6$ Rinien langen, 4 feitigen, gera= ben Aegren ftehend. SBlumenfrone flein, meiś; bie Neben=

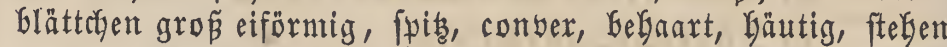

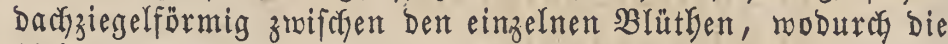
2lebren bas $\mathfrak{A}$ nfełen eines 5opfenzapfenz erbalten.

Blithe $=3$ eit und Dauer.

Эuli - 2 uguft 4 .

\section{3orÉntmen.}

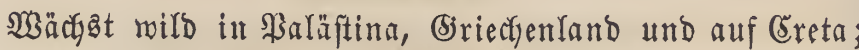
roirb bet uns bie und ba in (s)äten fultivirt.

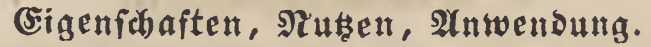

Sraut und Blumen Gaben einen angenelynen, bent ge= meimen Doften ägnlicten und genürzhaften (beruch und eitren Gitterlicyen, beisemb aromatifchen Bseichmad.

Borwaltende Beftandtbeile mie bei ben yorigen 2 arten.

Man Genübst ben cretifden Majoran wie ben gemeinen in Seablyaltungen und fest ign ebenfalls oft bem Biere bei. Dffecinelf fund bie Blumenähren, auch bereitet man aus ifnen ein forarfez, ätberijdes, campherbaltigez Del, das fwanifche 5oufenöl, weldyez man gegen Zahnjdymerzen und Răhnungen Der Bunge gebraucft.

\section{Rosmarinus. L. \\ Syfteme: Corytophyta. Neck Diandria, Monogynia. L. Labiatae. Adans. Juss. \\ Labiatae Monardeae. Bentlı. \\ Labiatae Salvieae. Spr. \\ Ringentes Gymnospermae. Roy. \\ Verticillatae. L. \\ Verticillatae Salviae. Rül.}

Selch 1Glätterig, röhrig, oben zufammengebrüdt, blei= Gend, im Sdylunbe nafet, 2lippig, bie untere ripue 2 fwaltig. Blumenfrone 1 blätterig, ungleidy, nachenförmig; $B$ lumen= röbre länger als ber Relch; Blumenrand 2lippig, bie obere sippe aufrecht, 2ipaltig und fürzer, bie untere zurürffiebogen,

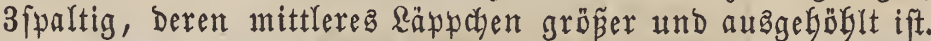
Staubgefüße 2. Staubfäben lang, yfrienenfürmig, mit einem gefrümmten 3akne berfeken und länger ala bie Dberlippe. Staubbeutel 1 fächerig. Siriffel fo lang alz die Staubräben. Narbe einfacts, fpisig. Samen 4, eirund, im Relcte.

Rosmarinus officinalis. L.

Rosmarinus latifolius. Mill.

$\beta$. Rosmarinus angustifolius. Mill.

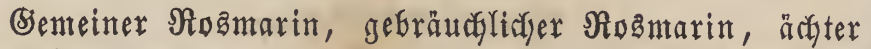
Ros̄marin.

Rosmarin des jardins. (frattz.)

Rosemary. (ettgl.)

Rosmarino, Ramarino. (ital.) 


\section{Arten = Gharakter.}

Strauch $3-5 \widetilde{\mho u} \mathfrak{B}$ bord, mit grauer, oft röthlidyer Ninde. B B Yätter ungeftielt, Yinien-lanzettförmig, ftumpf, fteif, mit einmärts gerolftent Rande, in Der Mitte gefurcht, gegenüberftebend, glatt, glänzend, biff, hart, immergrün, oben bunfelgrüı, unten meiffrizig. Die Blüttgen an ber Spitse ber jungen Bmeige in forlaffen Trauben ftelyend, Gla $\tilde{\beta}=$ bläulidà.

\section{Blüthe $=$ 3eit und Dauer. \\ 2Tpril - פłai. ち.}

\section{Borénumen.}

Srient, Norbafrifa, Sapan, Sildeuropa: Sftrien, Sta= lien, Spanien, fübliches ₹ranfreidy, Sdymeiz (2lartbal), auf (5ebirgen, Felfen und an Seefüften; bei uns in Sänten und Töpfen gezogent.

\section{Sultur.}

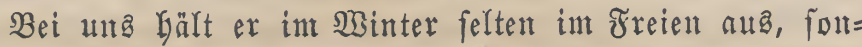
Detn แนผ Simmer ze. gefracht werben. Man wermegrt ign gemöhnlid, indem man im Sluguft abgefdynittene Sweige an einen forfat= tigen Drt einfteft.

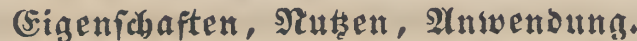

Das Rosmarinfraut Gat einen angenebmen, farfen, canthberartigen und gemürzbaften (S)eruty und einelt ftarfen, Galfamifa Gitterlichen, campherartigen biefchmad?.

Del.

Der bormaltende Beftandtheil Deffelben ift: ätherifdyea

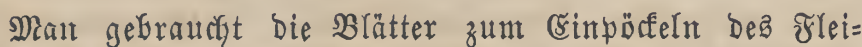

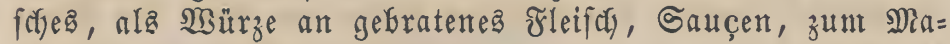
riniren yon Fifden, Schwarzwildopret 2 . - Der Rozmarin bat reizende, belebende, zertbeilende und fäulniánibrige (̧̌i= gemfdraften. Dfficinell ift daz Sraut. Man Gereitet aus ifm eit ätherifctues Del $2 c$.

Mau mendet Das Siraut felten innerlid, gegen Sanin=

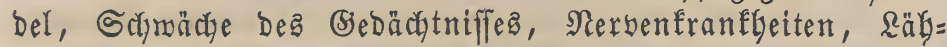
mungen, Diarrböen, Drüfengefdyủlfte, fondern meb̆r äน

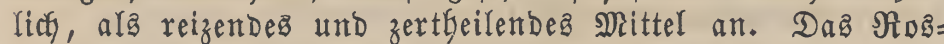
maringl gebraudyt man gegen fodmadye 2 (ugen, in bie Hungegend

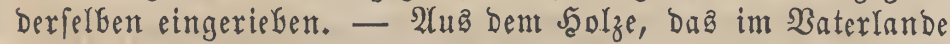

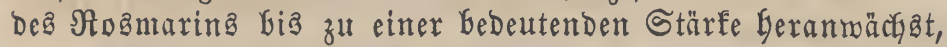
fann man mufifalifale Snftrumente verfertigen. - Sonft

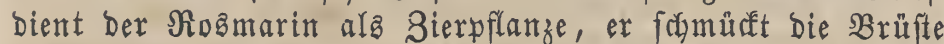
Der 2 erlobten und focdzeitägäfte und wirb in Tobtenfränze geflochten.

\section{Salvia, L. \\ Sieke Seite 120.}

\section{Salvia officinalis. L.}

Salvia chromatica. Hffmsg.?

Salvia grandiflora. Tenor.

Salvia papillosa. Hffmsg.?

$\beta$. Salvia aurita. Schult.

Salvia confusa. Benth.

(B) meine Salbei, gebräudylidye Salbei, ädste Salbei, (Bartenfalbei, Salfe.

Sauge commune. (fianz.)

Common Sage. (engl.)

\section{Arten = SGarafter.}

Pflanze ftrautyartig. Stengel einen Fuß Goch und barïber, äftig, 4erfig, bebaart. Blätter gegenüberftebeno, geftielt, ei= Innzettförmig, unten neb̧ซörmig, runzlich - geferbt, famnt= artig anzufüklen, graugrün. Relch aberig - geftreift, etmaz feinfehaart, brüftg, 5zätnig. Rebenblätter eiförınig, lang=

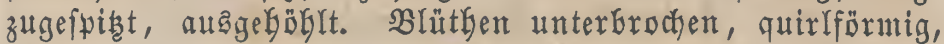
Güufig zu $6-8$ ftefend. Blumenfrone briffigt, mit ftchel= förmiger, convexer Sberlippe, fogon biolettflau ober meís. Sajlumb befarat. Staubgefäpe eingefdyloffen. Samen naft.

$\mathfrak{B}$ lüthe $=3$ eit $\mathfrak{u n d}$ Dauer.

รuti - รuli. ち.

\section{- \$orkommen.}

Sie ift im fübliçen und pftlichen હuropa, in Throl, Srain, Särnthen, Schleften 2c. cinkeimifa; mirb bei unz Gäuftg in (särten fultivirt.

\section{Sultur.}

Man yflanzt bie Salbei Durch Gamen ober burch Ber= theilung ber alten Störfe fort. Den Gamen fäet man in's

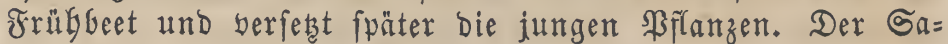
men bleigt 3 sagre lang gut.

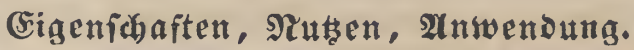

Die Galbeiblätter befiben einen angenefmen, aromati= fofen (beruch und einen geroürzbaften, camplerartigen, etwaz bittern und zufammenziehenden sejchmaff und bafen reizende (sigenfictaften.

Die vormaltenden Beftandtheife find: ätherifchez Del, Gitterer Extraftibftoff und Gierbeftoff.

Man Graucht Die Salbeiblätter in ber Rilche zum Braten

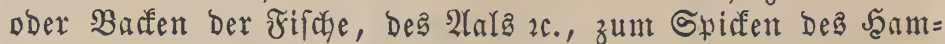
melsbraten, Sdyinfena, zu Sauçen, bafft fe mit siern, Sllöfen 2c., und bereitet einen Siüuterwein aแs ignen.

Dificinelf find bie Blätter und man bereitet aนs ifnen ein ätherifches Del, gebraucht fte in Der Mebicin, innerlich in Theeaufgüffen in Begrfiebern, gegen colliquative Schweise, MRundfăule, zu viełe Milch in Den Brŭften; ăunerlicy in

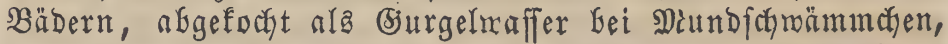
entzünolichen bealsaaffeftionen, bei Glutendem ober fcorbuti= foryem 3athnfeifatye.

Da⿱ Fleify yon Schafen, welche unter ifrem Futter yon ber Salbei zu freffen befommen hatten, foll fegr wogl= fobmedfend merden. Die Blüthen find ein gutes Sdyaffutter.

\section{Artemisia. L.}

Abrotanum. Bess. Absinthium. Adans. Dracunculus. Bess.

Snfteme: Compositae Anthemideae. Loud. Compositae Artemisiae. Rül. Compositae Eupatorineae. Spr. Compositae nucamentaceae. L. Compositae Senecionideae. Less. Compositae Tanacetae. Adans. Corymbiferae. Juss. Siphoniphyta. Neck. Synantherae Anthemideae Artemisieae. Cass. Syngenesia, Polygamia superflua. L. 
BlütGenberfe meift runblich, faft ei= ober fugelförmig, ziegelbachförnig - foduppig. Safuppen ungleich, gegen ein= anber gebogen. Frudetboden naeft voer Gaarig. Blüthen

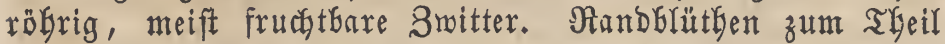
meiblicly. Samen eiförmig, länglich, načt. Feberchen feflt.

\section{Artemisia Dracunculus. L.}

0ligosporosus condimentarius. Cass.

$\beta$. Artemisia inodora. Willd.

Artemisia Redowskii. Ledeb.

Dragun Beifü, Efftragon, Raiferjalat, Dragun.

Tarragon. (engr.)

\section{Arten = C5araeter.}

Wrurzel weit friectend, fproffentreibend, äftig, faferig.

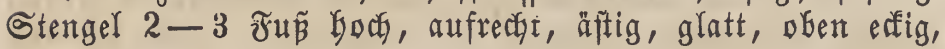
Gelfgrün, nit aufrechten, abmechfelnden Aeften. Blätter 1-2 Zull lang, ungeftielt, fahnal lanzettförmig, ganzran= big, mit etmas werbicftem Ranbe, etwas fçlaff, zart, oben fein geabert, Yebjaft grŭn. Sieleh glatt ober meidybefaart, Die obern Relchblättchen mit Durchjegeinendem, trocfengäutigem, weíslichent Rande. Blütben flein, furzgeftielt, je 2 auf

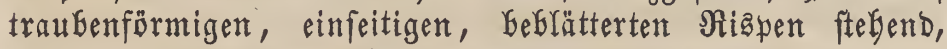
nickend, eiförmig, roftbraun. Blumenfdyeibe flach und faum etwas länger als der Selch.

\section{Bruthe $=\mathfrak{3 e i t}$ und $\mathfrak{S a u e x}$.}

Iuli - September. 4.

\section{\$orkommen.}

Sübeuropa, äftreichifches Rittorale, Sibirien, Tatarei; bet uns in Bå̃rten fultivirt.

\section{Sultur.}

ઉ̌r werlangt einen leidyten und fetten 2 oden. Da ber Dragun bet uns felten Samen befonmt, fo bermebrt man ifn Durch SBurzelauăläufer und Zertbeilung alter Stöbe und

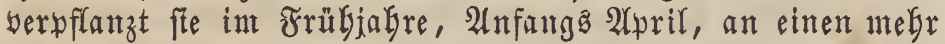
fadattigen, aber marmen Drt. Man Graudft Den Dragun nur afle 2-3 Salure zu berfetsen, büngt aber zmifchen Ginein

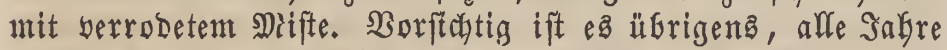
frifdje Şflanzen zu ziefben, weil in einent ftrengen oft alfe zu Srumbe geken. Im Nobember fohneidet man bas Rraut über bem $\mathfrak{B}$ oden af und bebefft bie Stüfe ben Winter über mit verrobetem Mifte, bamit fee im Fribling um fo foböner werben.

\section{ङigenfabaften, গtutsen, 2tuwendung.}

Der Dragun riecht audit in trodfenem 3uftande nocis lange angenebm und ftarf aromatifo, fohmećt beisend ge= würzbaft und nur wenig bitter.

Bormaltende Beftandtheile find: ätherifates Del und eifengrủnender Berbeftoff.

Sn Der Scatabaltung gefraucht man Dent Eftragon an

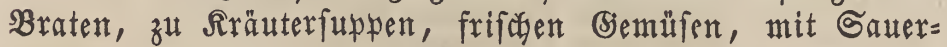
ampfer, Rerbel, Boragen, Sireffe, Bibernelle zc. zu Siräuter=

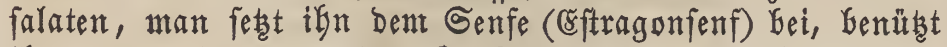
ifn zum Einmadjen der Siurfen und anderer Früchte in Efitg, Den Eftragonefitg, Vinaigre d'Estragon.

Dffecinel ift bas Rraut mit Den Blütbenfpisen, weldye man jeboch felten innerlich im 2 lufguffe gift. - Frifchea

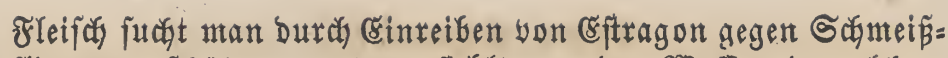
fliegen zu fodühen, auch empfieglt man bas NGaffer, in weldyem Dragunfraut einige Tage gelegen, gegen Eroflöbe.

\section{Artemisia vulgaris. L.}

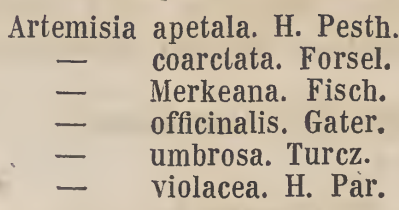

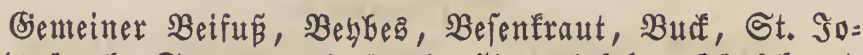

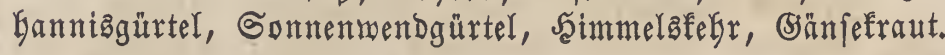
Artemise, Armoise. (frantz.)

Mugwort. (engl.)

\section{Arten = ErfaraEter.}

Sצurzel einige.30ll lang und federfiel= ober fingersbiá, äftig, faferig, fproffend, Gelfgraubräunliç. Stengel $3-6$ ₹un hoch, aufrecht, fteif, febra äftig, geftreift, glatt ober mur wenig filzig, unten oft faft fingerabiaf unb hăuftg rötglicf= violett angeflogen, mit abrechfelnd zerftreut ftebenden $\mathfrak{A}$ eften. Blätter abwedbfelno, ungeftielt, glatt, gefurdst, wben belfer= DDer bunfler $=$ grün, unten furz= und meifffilzig, ben Stengel etwas umfaffend, bie untern boppelt gefebert-getheilt, bie ofern gefiebert - getheilt; bie Rappen theilmeife eingeicfnit= ten, fahmach gezalgnt, lanzettförmig, oder feillanzettförmig, fpis; bie an Der Spibe dez Stengels ftebenden Blätter zum Theil ganzandig, linienlanzettförmig. Sieleh graumeiffilzig,

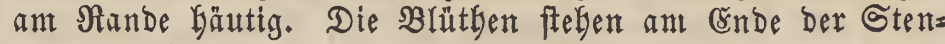
gel und Zimeige in $3-8$ furzgeffielten Sinäueln und in rişen $=$, faft äbrenartigen Trauben, ftnd $1-1 \frac{1}{2}$ Rinien lang und 1 Rinie breit, längliç=eiförmig, ober megr rund, aufrecht, faft fithend, filzig. Blumenftrabl 5blütbig. SBlumen= frone meißlich oder rötglichgelb. Fruedtboden nact.

Der $\mathfrak{B}$ eifup bariirt mit weißlichem und rothem Stenger, baber rotber und weißer Beifú; ferner gibt es noch zmei weitere Barietäten yon igm:

$$
\alpha \text {. foliosa, } \mathfrak{B} \mathfrak{I} \text { t t teriger } \mathfrak{B} \text { e } \mathfrak{f} \mathfrak{f} \tilde{b} \text {. }
$$

Die Blüthen flein, länglidy, in winfelftändigen, fpăr = lictjen Trauben.

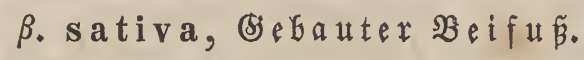

Blüt tyen ei=, faft fugelförmig, anfthend in wenigblüt $t=$ gen, ftumpfen Trauben.

\section{Sluthe = Beit und Dauer. \\ Suli - September. 4.}

\section{Bortommen.}

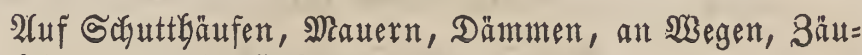

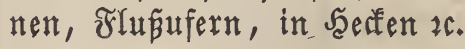

\section{હigenjabaften, গtüen, צnwenoung.}

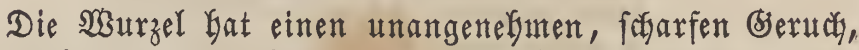
Der fied bei ber getrodfneten faft noch ftärfer entwirfelt und

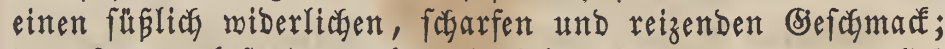
bas Siraut, Gefonders aber bie Blumen riechen, namentlid Geim Serreiben, angenebm gemürzhaft und fofmerfen aroma= tifa und etwas Gitter und berb. 
100 Theile trofene Şurzel befteben nady Samel und Sănefe aนs:

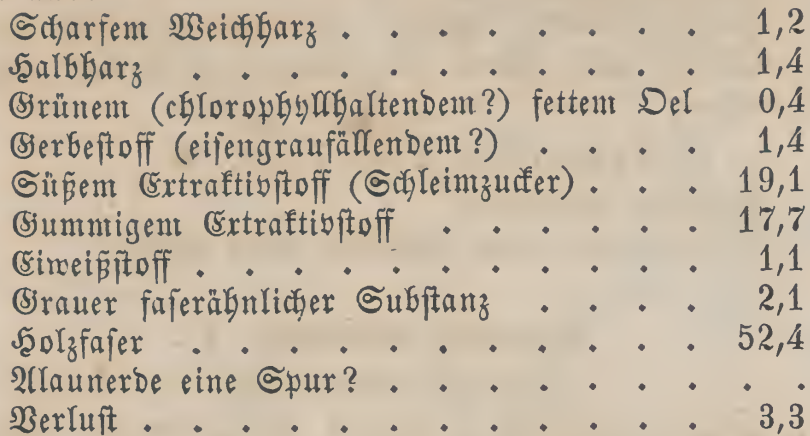

Man erbält aus ify 5 Procent foblenfauresa, fotmefel= jaures, falzfaures $\mathfrak{R a l i}$, falzfauren und foglenjauren $\mathfrak{i a l f}$, Eifenoryd und Riejelerde Kaltige 2afje.

Das Sraut hat zertheilende, ftărfende und fäulnismidrige (Eigenfdyaften.

Sn Der Rühe feģt man Stengel mit Dem Sraut $\mathfrak{B r a}=$ ten, zu bratenden Gänen und Ěnten, Ěierfuchen bei, $\mathfrak{b e}=$ nüht bie zarten $\mathfrak{B l a ̆ t t e r ~ a l s ~ B ̧ e m u ̃ f e . ~}$

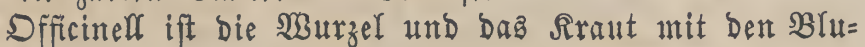
menfpisen; eritere gebraudst man in \$ulverform gegen Ěpi=

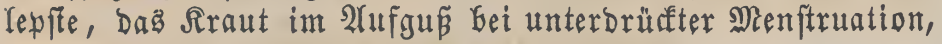
ủberbaupt bei ltntgätigfeit Der Gebärmutter.

AYuz Den filzigen Blumen und Blättern bereiten bie

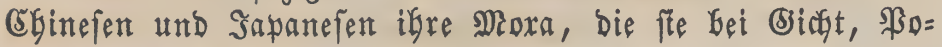

- Dagra zc. auf Der Jaaut abbrennen.

\section{(Gefraidete.}

Man legte früker Den Beifú in bie Srfukge, indem man glaubte, nicht zu ermüben.

\section{Artemisia Abrotanum. L.}

\section{B. Artemisia humilis. Mill.}

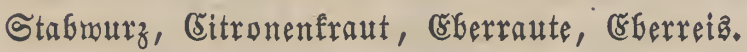
Common Southernwood. (engl.)

\section{$\mathfrak{A r t e n}=$ (Sharakter.}

Straudartige ßffanze. Stengel $2-3$ ซú lang, oft faft fingersbiaf, aufrecht, bolzig, graugrün, einfach, ober an Der Spibe mit furzen, rutbenförmigen, Giegfamen, oben ftarfelätterigen, frautigen, unten Golzigen, rothen Smeigen. Blätter büfchelförmig, afwechfelnd, zart boppelt gefédert, Geinake fadenförmig - zertbeilt, zart, etmas beftäubt, in ber Jugend weişlidy feibenartig Gebaart, fpäter bunfelgrün, bie oberften an ber Blüthe ftefenden oft einfact. Blüthen ftelgen an Der Spike Der Stengel und Sweige rißppenartig in wiel= blätterigen und einfeitigen 2 ebren ober Trauben, fend nidat zahlreich, flein, oft faum 1 sinie lang, furzgeftielt, abmärtz

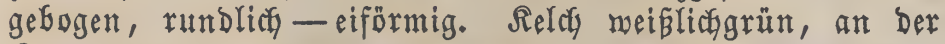

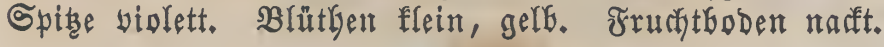

shäthe = 3eit und Dauex .

2luguft - Dftober. ち.

\section{3ortommen.}

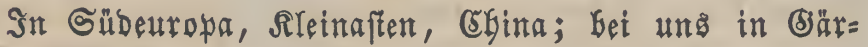
ten fultivirt.

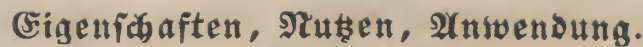

Das frifche und trodfene Rraut bat einen farfen, citro= nen= ober meliffenäbnlidfen, angenelgu Galfamifas gemürzbaf= ten Beruch und einen bitterlicfen, Grennemb aromatifhen (j)efdima

Bormaltende Beftandtheile ftnd: ätherifdyes Del, bitterer Ertraftigftoff und eifengrünender Berbeftoff.

Ěr wird in einigen (begenden, wie Der gemeine Beifǘ, als Gemürze benủht.

Dffïcinell ift Das Sraut mit Den Blunen; man gibt

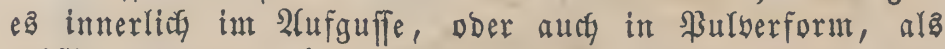
mäp̈ig reizendes, harn= und fohneiptreibendes Mrittel, ge=

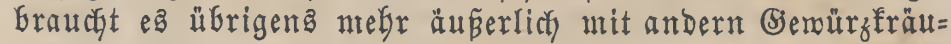

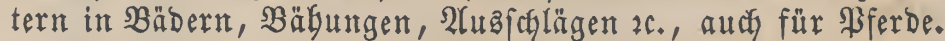
- Man fudft mit biefent Sraute aud bie Motten yon ben Rleidern abzulgalten.

\section{Ocimum. L.}

Gymnocimum. Benth.

Hierocimum. Benth.

0cimodon. Benth.

Syfteme: Corytophyta. Neck.

Didynamia, Gymospermia. L.

Labiatae. Juss.

Labiatae Ocimoideae. Benth.

Ringentes gymospermae. Roy.

Verticillatae. L.

Verticillatae Melissae. Rül.

Seld gloffenförmig, 5riefig, 2lippig, obere Rippe un= getbeilt, freiärund, untere 4 fpaltig. Blumenfrone nachen= förmig, 2lippig, obere Rippe 4fpaltig, bie untere ungetbeilt, ränger als die obere. Staubgefäße 4. Staubfäben gebogen, Die innern an ber Baftz mit einem 2tnbange. StaubbeuteI nierenförmig. Griffel fo lang als die Stauffüben. Narben fäblich, fpigig.

\section{Ocimum Basilicum. L.}

$\propto$. 0cimum pilosum. Willd. 0 cimum ciliatum. Horm. 0cimum hispidum. Lam. 0cimum minimum. Burm. $\beta$. 0 cimum anisatum. Hort. $\gamma$. Ocimum caryophyllatum. Roxb. 0 cimum integerrimum. Willd. 0 cimum lanceolatum. Schum.

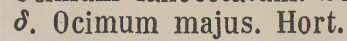
ع. 0cimum album. L. 0 cinum americanum. Jacq. 0cimum laxum. Vahl.

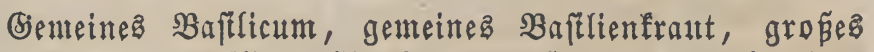
Baftlienfraut, Baftlie, Şirnfraut, oftindifder :

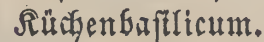

Frambasin du Perou. (fianz.)

Gommon sweet scented Basil. (engl.)

\section{Arrten = (5)aralter.}

Stengel 1 Fú boch unb Darüber, aufrect, äftig, mit frewzförmig gegenüberftebenden, auffteigenden Zweigen. Blät= ter geftielt, gegenüberftebend, glatt, eiförmig- länglich, bie Hnd ba etwa gefägt. Blütţen am Eัnde Der Stengel und 
3reige in quirlförmigen 2lebren flebend. Seldy fegr furz, gemimpert, Graunroth, bie ofere Relchlippe flach, freisför= mig, aufrecht, bie untere 4 fpaltig, fpisig. Blumenfrone berfebrt, bie obere Rippe furz, Greit, aufwärtz gerichtet, balb 4 jpaltig, bie untere viel länger, fhmäler, gefägt, ałwärtą

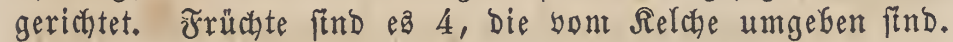
Samen flein, ftetfnabelfopfgrós, länglich - eiförmig, bunfel= Graulr.

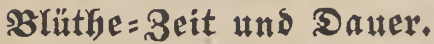

Suli - September. $\odot$.

\section{3orfommen.}

Oftindien, Berfeten, bei uns in Bärten und Töpen gezogen.

\section{ßultur.}

Man fäet Den Baftlicumfamen in Miftbeete ober im Sim= mer in Toppe, in locfere, gute und etmas feuchte (rrbe, ver= fest fie, menn fie $2-3$ 3oll hoch gemorden find, in eine warm gelegene Rabatte und gibt ilyen nadber einige Tage lang Schatten. Das Rraut ninumt man ab, menn Die Sflanze in yolfer Blüthe fteht, und läß̆̈t zur Samenzucht einige SPfanzen unverlest felen, yon meleben man nun im 2luguft reifen Samen nelgnen fann. Retzterer bleibt 2-3 Sabre gut.

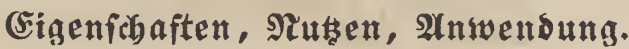

Die ganze Sflanze beftht einen eigentyümlidy burchbrin= genden, aber angenebm gemürzbaften Beruch, Der bura Troct= men Des Rrautes noch feiner roird, und einen etras fuhlend falzigen, aromatifusen (befdymarf; audy ber Santen riedyt und fümecft gemürzbaft.

Bormaltende Beftandtheile fund: ätherifues Del und eijengrünender Berbeftoff.

Man gebraucht Das Baftlicum, bejonders băufig in füb= lichen Ränderı und in Franfreidh, aIs Semoürz, zแ Suppen,

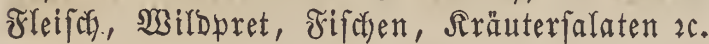

Difficinell ift Das Rraut, früber auch Der Samen. Sn= nerlich gibt man bas Rraut, jeboch nur jelten, im 2lufguffe,

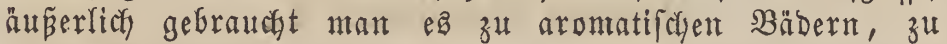

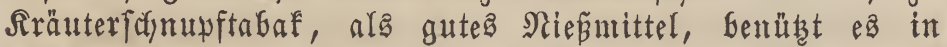
feinem Baterlande als Räucherungamittel und ftreut eB auf

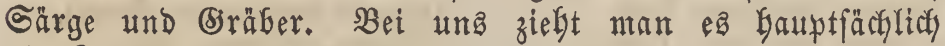

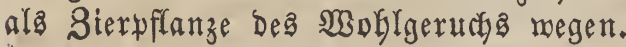

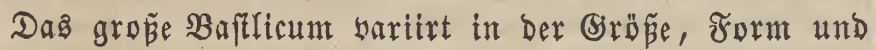
Farbe Der $\mathfrak{B l a ̈ t t e r}$ und $B$ lumen:

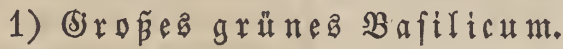
ocimum bullatum.

Blafenblätteriges $\mathfrak{B a f t l i c u m . ~}$

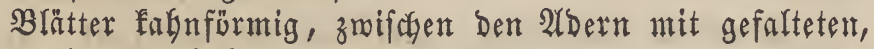
blajenartigen Erböhungen und Bertiefungen.

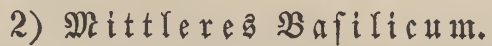

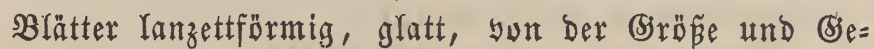
ftalt ber Birfenblätter, riecht tod angenefmer citronenartig alకె Dąิ 20rige.

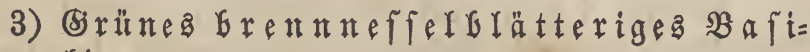
Iic $\mathfrak{H}$ m.

(Seruch befonders ftart unb angenebm gemürzhaft.
4) Scharzes $\mathfrak{B a f i l i c u m . ~}$

Nelfenbuftlicum.

NBie Dna Borige. Blätter aber füwarzbraum. Stengel und SBlütGen rotf. Sann ftatt Bimmt und Nelfen angemen= Dét werben.

5) (B) eftreifte $\mathfrak{B a f i l i c u m . ~}$

Bjeflectetes $\mathfrak{B a f t l i c u m . ~}$

Blätter Graun ober făntusig grün geflerft.

\section{Ocimum minimum. L.}

0cimum salinum. Molin.

Rleines Baftlicum, fleines Baftienfraut, bujaiges Bajtlicum.

Petit Basilic. (fl'inz.)

Bush-Basil. (engl.)

\section{Arten = (5Garakter.}

Dex yorigen Bffanze äbnlich, aber in alfen Theilen fleiner und meift you etras fugelförmiger Beftalt. Stengel $5-630 \mathfrak{l l}$ Goch, äftiger. Blätter flein, eiförmig, glatt, fpibig, ftetz ganzrandig und beflgrün. SBlütben in mefgr von

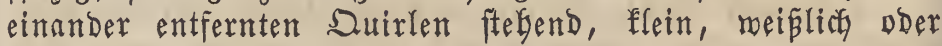
Glấ, doer rötglidy violett.

Blütbe $=$ Zeit und $\mathfrak{D a u e r}$.

suli - September. $\odot$.

\section{3ortommen.}

(Ceylon; bet uns mie bie vorige Specię in (särten und Töpfen gezogen.

\section{Rultux.}

Sm Serbfite fadneidet man bie Stengel ab und benabrt fie in Büfoldeln gebunden auf.

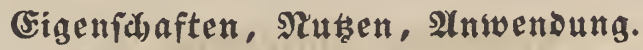

(beruch und Befchmar noch ftärfer und feiner als beim gemeiten Baftlcumfraut. Ěs wirb grün ober getrodinet an Suppen, Sauçen, Spannfucten, Säriten 2c. gebraucht und gibt einen wohlfchmedfenden, erwärmenden Thee.

Das Sraut ift ebenfalfs officinelf, meldyes auf gleiche Weife vermendet mird.

\section{Thymus, L.}

Maslichina. Adans. Benth.

Pseudothymbra. Benth.

Serpyllum. Pers. Benth.

Zygis. Pers.

Syfteme: Corytophyta. Neck.

Didynamia, Gymospermia. L.

Labiatae. Adans.

Labiatae Melisseae. Spr.

Labiatae Salviae. Rchbch.

Labiatae Satureineae. Benth.

Ringentes gymnospermae. Roy.

Verticillatae. L.

Verticillatae Melissae. Rül.

Relch 1blätterig, röGrenförmig, 2lippig, Dberlippe zu= rüff́gebogen, 3zäGnig, Utnterlippe mit 2 pfriemlichen Sipfeln. Bluntenfrone 16 lätterig, nachenförmig, 2lippig, obere Rippe gerabe, aubgerandet, untere 3fpaltig, ber mittlere - Bipfel 
34.







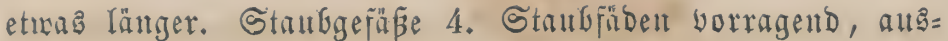
einanbergebend. Staubbentel getremut. Siriffel fo lang ala die Gtaufäden. Narben pfriemlidy, fpib, faft gleidy. Sa= men 4, beinnte fugelig.

\section{T'hymus vulgaris. L.}

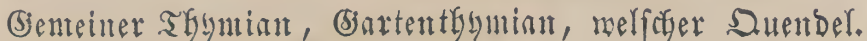
Commun Thym. (Franz.)

Common Garden-Thyme. (engl.)

\section{Arten $=$ (5)arater.}

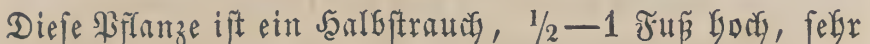
äftig, mit aufrechten, rumben, glatten, holzigen, Graunen, in ber Jugent 4erfigen, bicyt unb furz befaarten, meißslisjen Dber gelben 3weigen. Blätter $3-5$ Rinien lang, $1 / 2-1 \frac{1}{1} / 2$ Rinten Greit, gegenüberftebend, furzgeftielt, rintenförntig, ober eiförmig - länglich ober eilanzettförntig, etwaz ftumbf, ganz=

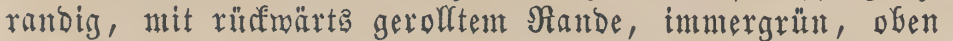
grubig, Dunfelgrün, unten zartbegaart, punttirt, weišgrau. Blütfen oben ant Stengel und Den Zweigen geroügnfidy in 10 bintfigen Duirlen und unterbrodjenen Trauben ober Telyren und Gaben fegr fleine, Ianzettförmige Nebenblättecten. Seldy geftreift, zottig und zart befaart und burd weiñe Saare gefoloffen, fobald fich früble gebildet Gaben. Blunenfrone nody einmal fo lantg als Der Seldy, mit ftumpfer Doerlipue

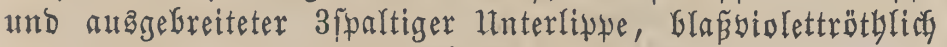

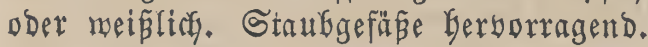

\section{$\mathfrak{B l u ̈ t h e}=\mathbf{3 e i t} \mathfrak{a n d} \mathfrak{D a u e r}$.}

$$
\text { গแni - 2ugut. ち. }
$$

\section{\$orénmen.}

In Sübeuropa, Spanien, Stalien, Sübranfreidy, bei Rarbonte, in Deftreich und in Sibirien, auf fteinigen (Sebirs= gen eintgeimifacy und bei uns in bärten angebaut.

\section{ßultur.}

Der Thymian follte alfe Saldre anz Samen gezogen merben, Da er nicht länger als 2 Jabre lang int Rande fteken folf. Der Gamen Gleift 2 Jabre feimfähig. - Das Rraut

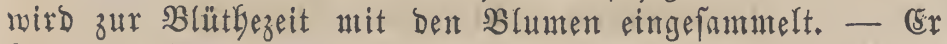
Gält ben Şinter int Jreien anb, riebt aber einen trofenen und etmas fteinigen Boben, in naffem und fettem geräth er

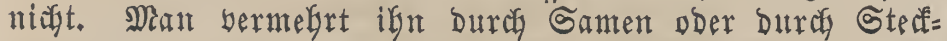
linge, Doer aber am beften buraif Bertbeilen alter Stöfét.

(igenifhaften, গtuen, Anwenoung.

Die ganze ßfflanze bat einen ftarfen, angenebmen, ge= mützbaften (Seruch unb beífend arontatifden, camplerartigen (ङ)ercymarf.

Borwaltende Beftandtyeile fand: ätherifaces Del und bierbeftoff?

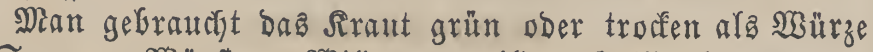

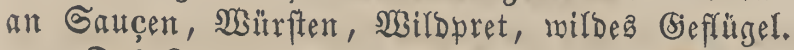

Das Rraut wirb in ber Nebicin gefraucht, wird felten innerlicy im $\mathfrak{Z}$ ufgü ober in \$ulberform angervendet, megr

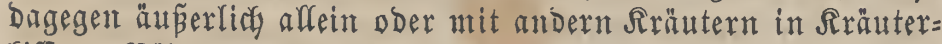
fiffen, Bäbern, Umpeslägen, aud Gat man yon ifnt ein ätbe= rifches Del.

In einigen sjegenden wajht man bie Fäffer mit eintem AGGube Des Thymiana, um Dem Weine einen angenegment Entwer, bfonom. গpfrnzenfunde.

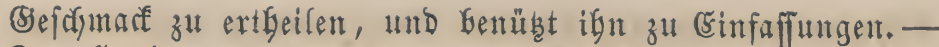
Der Jagnig, Den bie Bienen aแs ben BlütGen geminnen, ift geץchăbt.

\section{'Thymus Serpyllum. L.}

$\alpha$. Thymus arenarius. Bernh.

Thymus caucasicus. Willd.

- Chamaedrys. Fries. Rchbch.

- citratus. Dumort.

- citriodorus. Schreb.

- collinus. Bbrst.

- decumbens. Bernh.

- deflexus. Lejeun.

- elatus. Schrad.

- exserens. Ehrh.

- glaber. Mill.

- glabratus. Schult.

- humifusus. Bernh.

- includens. Ehrh.

- laevigatus. Vahl.

- lucidus. Willd.
Serpyllum vulgare. Blackw.

- effusus. Host.

- Kollmunzerianus. 0piz.

- lanuginosus, Schkr.

Thymus melissoides. Fisch. - procerus. 0piz. - rigidus. Rchbch. - serratus. 0piz. - subcitratus. Schreb. - sudeticus. 0piz. - sylyestris. Schreb.

$\beta$. Thymus Serpyllum montanus. Benth.

Thymus majoranaefolius. Desf.

- montanus. W. K.

- nummularius. Bbrst.

- ovatus. Mill.

- pseudoserpyllum. Rehbch.

- pulegioides. L. Rchbch.

Cunila thymoides. L.

Hedeoma thymoides. Pers.

Zizyphora thymoides. R. S.

Feldthmian, wilder Thymian, Suendel, Ruentein, Sitt= nelfe, Rundelfrant, Rumold.

Serpolet. (fraltz.)

Common Mother of Thyme, Wild Thyme. (engl.)

\section{Arten = Gharalter.}

NGurzel friechend. Stengel 3 80If bis 1 Fun goch, fehr äftig, nieberliegend, an Der Bafta etwas bolzig, ntit fraut= artigen, gegenüberftebenden und auffteigenden Dweigen. Blät= ter 3-6 Rinien lang, gegenüberftebend, febr furz geftielt, ei= Dber lanzetfförmig, ganzrandig, an ber Baftz meift ge= mintpert, eben, ftuntpf, oben feingrubig, rebbaft grün, unten fein und erbaben punftirt, Gellgrün. Blütfyen am Ende ber Sweige, meift georängt, in fleiten fopfförmigen Suirlen ftebend. Reldy yon weipen rauken Saaren berfoloffen, mit verfofieden gefürbtent Relchgrund. Blumentrone ein mentg gröper als bie beim yorigen Thymian, rofenroth, feltener mei $\tilde{\beta}$.

\section{Blüthe = Beit und $D a \mathfrak{a r}$.}

Iuni - September. 4.

\section{BorEommen.}

2luf Bergen, ફreiben, an troffenen, fonnigen Drten,

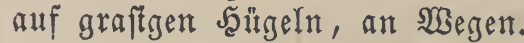

Der Duendel zerfänt in mebrere Barietäten, über beren Soentität man aber zum Theil nody nidyt ganz einig ift.

\section{$\alpha$. Thymus Serpyllum arenarius. Bernh.}

Sandtgumian.

Ëinige fteffer

\section{Thymus Serpyllum sylyestris}

als befondere Spielart auf und befdureiben fae:

Blätter eiförntig. Blütben größer als beim gemeinen Thymian, quirfepfförntig, mit 2 Gerborragenden Staub= gefüвеn.

Andere Gringen ben bier mit arenarius fynonymen Namen citriodorus ober subcitratus mit ber Benennung 29 
Thymus parviflorus, Thymus Serpyllum $\beta$. subcitratus, und befareiben bie Spielart:

Thymus Serpyllum citriodorus.

Citronenquendel, sitronenfraut.

Stengel 1-3 ซ̛ur lang, mehr ober meniger aufrect. Blätter etmas grof́, breit, eiförmig, beinabe glatt, an ber Bafts gemöhnlich gemimpert. Blumen ftehen in etwas ent= fernten, faft ärenartigen Suirlen, find flein und beftröth=

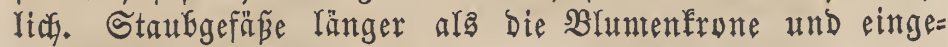
fdglofien, feblen auch bäufig.

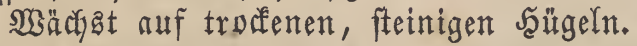

Der (Beruch ift fehr angenehm, citronenartig.

Wieder 2 ndere befdreiben:

Wrolliger Souendel;

Thymus lanuginosus,

ala Gejondere Spielart ober fogar 2rat. Die ganze Pflanze

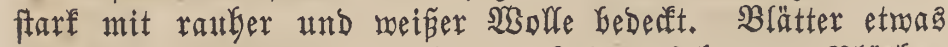

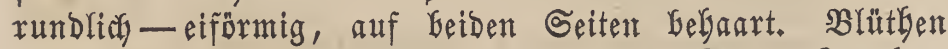
fopfförmig. Blunenfrone fo lang als Der Relch. Staubge= fä $\tilde{\beta}$ e eingefchloffen.

Şăchst auf hoben trodfenen Sebirgen.

$\beta$. Thymus Serpyllum montanus. Benth.

Bergthymian.

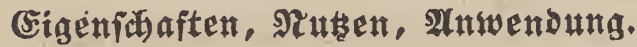

Der Suendel Gat einen angeneGmen, gemürzbaften, meit etwas citronenartigen (Seruch und einen Gerben, Gitterlichen,

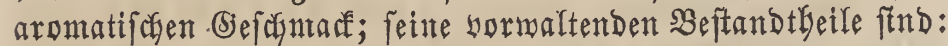
ätberifches Del, aber in geringerer Menge als beint genteinen Thymian, Gerbeftoff unb bitterer Extraftinftoff.

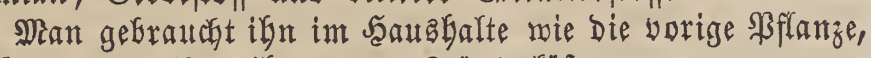
an Sauçen, mijø̆t ifn unter Rräuterfăfe 2 .

Dffictuell ift Das Sraut mit Den $B$ humen, welches man

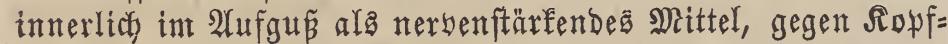
fochmerzen, som übermåäigen (S)enuffe Der Speifen und gei=

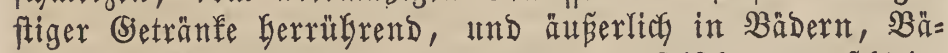

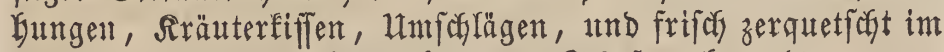
Biere gegen Die Drefferanflyeit Der Sedfafe gefraucht.

Die Blüthen ftnd ein gutes Bienenfutter und die Bie= nen bleiben gerne in mit bemfelben augegeftrictenen $\mathfrak{R}$ örben.

\section{Thymus angustifolius. Schreb.}

$$
\begin{aligned}
& \text { Thymus acicularis. W. K. } \\
& \text { - albidus. 0piz. } \\
& \text { - caespititius. Hffmsg. Lk. } \\
& \text { - ciliatus. Lam. } \\
& \text { - inodorus. Lejeun. } \\
& \text { - micans. Lowe. } \\
& \text { - nervosus. Gay. } \\
& \text { - odoratissimus. Bbrst. } \\
& \text { - repens. Lk. Hffmsg. } \\
& \text { - spinulosus. Tenor. } \\
& \text { - variabilis. Lk. Hffmsg. }
\end{aligned}
$$

Schmalglätteriger Suendel.

Narrow-leav'd Thyme. (engr.).

\section{Arten $=$ Sharakter.}

Bon Einigen Glós als Spielart Des gemteinen Suendels angejeben. Stengel bün, friefyend, meidjbehart. Blätter lanzettförmig, yornen Greiter, unten gewimpert. SBlüthen quirl-fopfföntig. Bluntenfrone etwas gró̧, lünger als ber Relch. Staufgefäße Kerausaragend und länger als bie Dberlippe Der Corolle.

\section{Blüthe $=$ Beit und $\mathfrak{D a u e r}$.}

Suni - September. 4.

\section{3oréommen.}

2uf fandigen Weiben und Esbenen.

Ěine $\mathfrak{B a r i e t a ̆ t ~ i f t : ~}$

$\alpha$. Thymus pulchellus. Böningh.

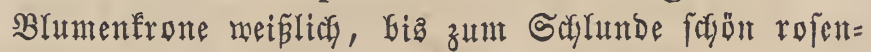
roth getüpfelt.

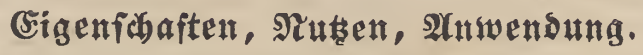

2IKe wie Geim Thymus Serpyllum.

\section{Calamintha. Moench. Acinos, Pers.}

Snftente: Corytophyta. Neck.

Didynamia, Gymnospermia. L.

Labiatae. Juss.

Labiatae Melisseae. Spr. Benth.

Ringentes gymnospermae. Roy.

Verticillatae. L.

Verticillatae Melissae. Rül.

Selch 1 blätterig, röbrenförmig, Gaudyig, 2lippig, obere sippe 3zägnig, untere 2fpaltig; Der Gchlund nit ober ofme Jaanfranz. Blumenfrone 1Glätterig, nachenfürmig, ntit bau= chiger $\Re$ b̆bre und 2lippigem Saum. Sberliphe furz, gerabe. Utnterlippe 3fpaltig; Sipfel flady, ftumuf, ungleich, Der mitt= lere Greiter, am Grande mit 2 bab̆fern. Staubgefäze 4. Staubfäben entfernt, gegen die Dberfipue bogig geneigt. Staubbeutel auf Die Staubfäden eingelenft. Briffel yon Der gleiçen Ränge ber Staubfäber. Sarbe 2fwaltig, ungleidy. Samen länglich, an beiden Enden abgerundet.

\section{Calamintha officinalis. Moench.}

Calamintha menthaefolia. Host.

Calamintha montana. Lam.,

Calamintha umbrosa. Rchbch.

Calamintha vulgaris. Sweet.

Nepeta intermedia. Lejeun.

Thymus Calamintha. Scop.

Thymus Moschatella. Pollin.

Thymus umbrosus. Spr.

$\beta$. Thymus calaminthoides. Rchbch.

Bergcalamintte, Bergmeliffe, Bergmünze, 2́fertbumian. Calamint. (franz.)

Mountain Balm. (engl.)

\section{Arten = Shaxakter.}

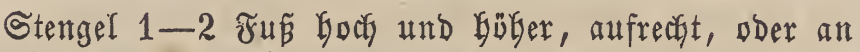
Der Bafti gefrümmt, äftig, 4erfig, Eekaart. Blătter 1-2 30 ll lang und 1-1 1/2 30l Greit, gegenüberftebend, geftielt, eiför= mig, ober beinalye berzförmig, ftumpf, geabert, gewöhnlich etroas ficharf gefangt, auf betben Seiten zottig Gebanat, Keblyaft grün. Brütfyen achfelftäutbig, in Afferbolden ftelyend, geftielt. BLuntenftiele gegenüberftebend, nteift funzzer ala die Blätter, bie obern etwas länger, oft faft gabelfürmig, 3theilig. 
Seldyägue zottig Gelgant unb Der Reldy burch Saare ber= fdoloffen. Bluntenfrome $5-7$ sinien lang, violettrotb.

Blithe $=$ 3eit und $\mathfrak{D a u e r}$.

Suli - September. 4.

\section{3ortommen.}

2uf Bebirgen, felftgen Şügeln, it Bebÿlzen Deutich=

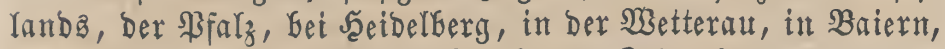
Deftreich, Der Sdymeiz, in Salzburg, Sdymaben.

\section{Eigenfidaften, গruzen, 2tnwendung .}

Gieruch gemürzbaft, meliffenartig; Dab sraut wax frü= Ger officineff und wirb wie bie 20 rigen benübt.

\section{Mentha。 L.}

Snfteme: Corytophyta. Neck.

Didynamia, Gymnospermia. L.

Labiatae. Juss.

Labiatae Menthoideae. Benth.

Labiatae Nepeteae. Spr.

Ringentes gymnospermae. Roy.

Verticillatae. $\mathrm{L}$.

Verticillatae Hyssopi. Rül.

Seld 1 blätterig, rögrenförmig, ober Geinake glodét = förmig, 5zäbnig. Błumtenfrone 16lätterig, triçterförmig, mit faft regelmägitgen, in 4 ftumpfe Rappen getbeiltem Saum, Der obere Rappen breiter und außggerandet. Staubgefäß̨e 4. Staubfäben gerabe, yon einamber entfernt. Staubbeutel eiför= mig ober runblich, 2 fnoppfig. Sriffel fo lang aro bie Staub= fäben. Starbe bfriemenförmig, gleidg. Samen 4, eiförntig.

\section{Mentha piperita, L.}

\author{
Mentha balsamea. Willd.? $\beta$. Mentha hirta. Willd. \\ Mentha glabrata. Vahl. Mentha hirsuta. $\delta$. Smith. \\ Mentha Hudsonii. Mirb. Mentha Pimentum. Nees v. Esenb. \\ Mentha kahirica. Forsk. $\quad y$. Mentha hircina. Hull. \\ Mentha officinalis. Hull. $\delta$. Mentha Langii. Steud.

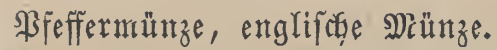 \\ Menthe poivrée. (iranz.) \\ Peper Mint. (engl.)
}

\section{Arten = Charakter.}

Wurzel bünn, wagrecht friecyend, oft etwaz 4erfig, äftig, mit fajerigen (5)iebern. Stengel $1-2$ ₹ur hoch und Dar= über, einfach ober äftig, 4ecfig, etroas rauf, befonderz an

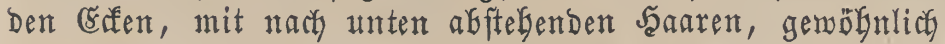
violettroth angeflogen, mit gegenüberftefenden, aufrecht-aus=

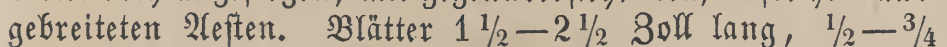
Soll breit, gegenüberftefend, geftielt, eilanzettformig, mekr fwis ober mekr ftumpf, oft ungleich, etwaz entfernt unb fecharf gefägt, auf beiben Seiten, zumal an ben $\Re$ tippen, zer= ftreut und furz betgart, oben theilmeife faft glatt, glänzend, lebgaft grün, unten ftarf und Gäufig rötglich gerippt unb geabert, Gelfgrün. Blütfen am Ende Der Stengel in 1-2 Boll langen und längern, und 4-6 Rinien breiten, etwaz ftumpfen, ralzenförmigen ober eiförmigen, oft faft fopfför= migen, bichten, unten unterGrochenen, vielglütfig (20)-quirl=

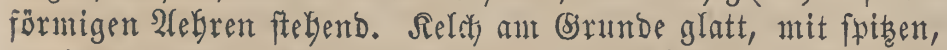

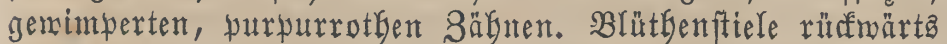
weidybefanrt. Blumenfrone flein, tridgterförntig, belfoiolett= rötglidy. Staubgefäß̋́ fürzer als bie Bluntenfronte, einge= idgloffen, yon einander entfernt ftefend. Die vernilderte

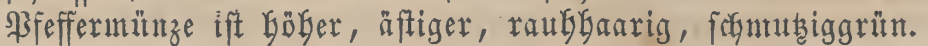

$$
\text { Blüthe = Beit und } \text { Dauer. }
$$

suli - September. 4.

\section{3ortommen.}

Findet fich an feuteften Drten in Ëurapa, in Eangland

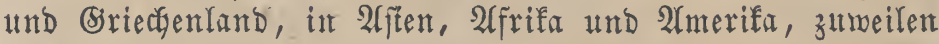
aud bei uns berwilbert unb wirb Gäufig in (särten angebaut.

\section{Sultur.}

Die Pfeffermünze gebeift am beften in leidfter Errde in eituer etwas fdyattigen Rage. Man fäet Den Samen im Märrz ober 2lpril, ober bermelyrt bie Sffanze auch int Jrübjabre

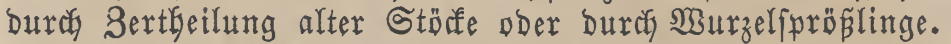

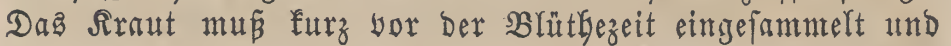
won ben Stengeln abgenommen werben.

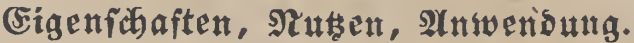

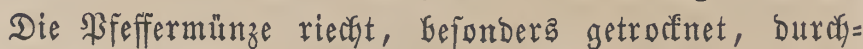
bringend und angenelgm gemürzhaft und fumesft int 2 (nfang Grennend aromatifch, campherartig, bann anthaltend fühlend; weniger ftarf ift (Seruch und biefdymaff bei ber berwilder= ten $\mathfrak{A}$ rt.

Bormaltende Beftandtheile ftnd: ätherifedes Del und eifengrünender Sierbeftoff.

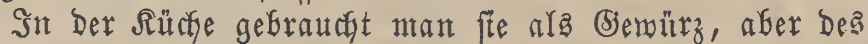

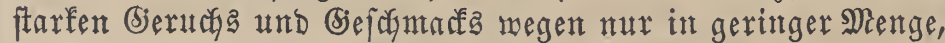
an Sräuterfuppen, Sauçen, Salaten, moburch biefe Gpeifen einen äน Det fie ferner zum Einntachen Der Efiẗggurfen, zum Einpöreln Des Frleifoces und Mariniren Der Fif che, und verfertigt aus ifr ben angenebm fámedfenden Bfeffermünzliqueur.

Sfficinell ift Das Siraut, weldaes flüchtig reizende, blä= Gungtreibende, magenftärfende und framipffitfende Ëigenfchaf= ten beftht. Mian gift es innerlich, neift in ageeaufgur, feltener in ßulberform, gegen Diarrgöen, berdorbenen und

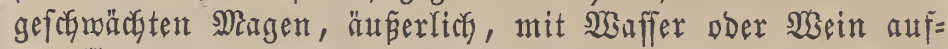
gegoffen, in Utmforlägen, Bädern.

\section{(seribidate.}

Die Sfeffermünze wurbe erft in ber Mitte be 18. Salyi= Gunderts als $2 \mathfrak{c}$ żneimittel burch die Ëngländer empfoljlen.

\section{Mentha crispa, L:}

Mentha aquatica $\gamma$. crispa. Benth.

Mentha crispula. Wender.?

Mentha piperita $\gamma$. crispa. Koch.

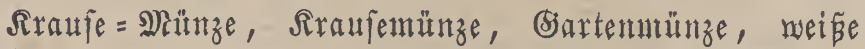

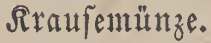

Menthe frisée d'Allemagne. (frantz.)

Curled Mint. (engr.)

\section{Arten = (5)arater.}

Whurzel fefr weit friectend, äftig, gegliebert, faferig,

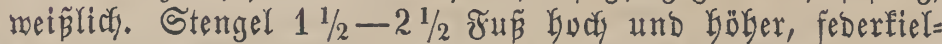
bicf, gerabe, eimfact) ober etwas äftig, 4ećfig, mit abmärtas= ftekenben, weiß̄en Saanren. Blätter gegenüberftebend, faft angeftielt und ftengeluntaffend, runblicf ober Yänglid, wber $29 *$ 
mely ober weniger zแgefpiţt, meift ftart wellenförmig-fraus, lang eingefdanitten gefägt-gezähnt, Dber weniger fraus und faft flach und nur ftumpf geferbt, oben gewöbnlicis fparjam und furz bebaart, rebgaft grün, unten runzlich, Dicht und

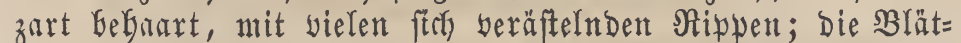
ter füblen ftety zart, faft flebrig an. Blüthen gipfelftändig, in längliabnalzig fegelförnigen ober fopfförmigen, Diçtent, aut Brumbe unterfrodyenen, vielglumigen, quirlförmigen 2leloren ftebend, find felyr furz geftielt und mit lanzettpfrie= menförmigen, filzigen und gemintperten Nebenblättçen befeht,

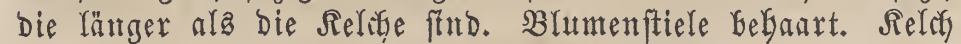

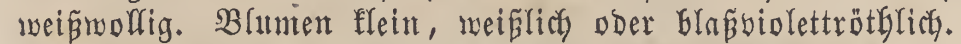
Staubgefäpe oft lürzer, oft länger, voer fo lang als bie Blumenfrone.

Einige Butanifer, wie Dierbach, Nees yon Ëenbef, Galten Die Sraufemünze nur für eine Splelart von Mentha sylvestris, 2(ndere als eine $\mathfrak{B a r i e t a ̆ t ~ y o n ~ M e n t h a ~ r o t u n d i - ~}$ folia.

\section{Blütbe $=$ Beit $\mathfrak{u n d} \mathfrak{D a \mathfrak { e r }}$.

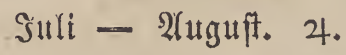

\section{2̧orkemmen.}

Şie und ba in Deutichland, am Şarze, in ber Sadyeiz, in Sibirien, an Bräben, und mirb bei unb in (Särten fultibirt.

\section{$\mathfrak{R u l t u x}$.}

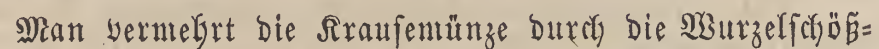
linge im zrübjabre und verpflanzt bie Störfe alfe 3 salure, meil fte zu ftarf matcfern. Nian fammelt bie Blätter, wenn Die $\mathfrak{B l u ̈ t h e n ~ b e g i n n e n , ~ f t c h ~ z u ~ D ̈ f f n e n . ~}$

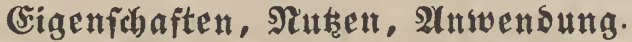

Die Rraufemünze Lat einen ftarfen, balfanif̧y gemürz= baften (berudy, Der leidyt Den Sopf einnimmt, und einen bitterlichen, Grennend gewürzbaften und bintennady ebenfalls etras füblenden befidmate.

Burwaltende Beftandtheile ftnd: ätherifacbes Del und eifengrünender Berbeftoff.

Man gebraudgt Die Sraufemünze in Der Sitche und Der Mebicin, mie bie Rfeffermunze, und Gereitet ebenfafls einen Riqueur, Den Sirafemünzgeift, auz ibr. Dfficinefl ift daz fraut. 2utf bem Rande gebraudgt man bie Blätter mit

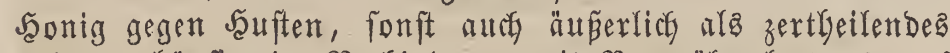
mittel, bäuftg in Berbindung mit Baumb̆l, legt ez auf gefchwolfene ober verbärtete Brüfte Der Rinbbetterinnen. Mant

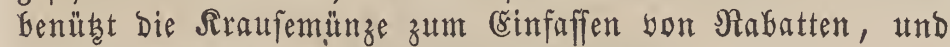
bie $\mathfrak{B l u ̈ t}$ tyen werben gerne yon ben $\mathfrak{B i e n e n}$ befucht.

\section{Mentha Pulegium. L.}

Mentha exigua. L.

Mentha simplex. Host.

Pulegium erectum. Mill.

Pulegium vulgare. Mill.

$\beta$. Mentha gibraltarica. Willd.

Mentha pulegioides. Rchbch.

Mentha tomentella. Link.

Mentha tomentosa. Sm.

Pulegium tomentella. Presl.

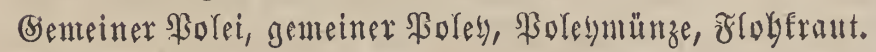
Pouliot. (frantz.)

Pennyroyal, Pudding-grass. (engl.)

\section{Arten = CGarakter.}

SZ3urzel weitfriedjend, äftig, fajerig, furoffend. Stengel

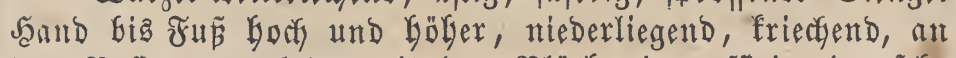
Der Bafta wwurzelnd, mit Der Blüthezeit auffteigend, fefr äftig, ftumpf 4fantig, furzbefaart, gemöbntich Graunrotb, mit gegenüberftebenden, aufredsten 3weigen. Sllätter $2-6$ Rinien lang ober etwas länger, geftielt, runbliç ober eiför= mrig, ftumעf, geferbt-gefägt, oft faft ganzrandig, unten bertieft getüpfelt, mit faft raubbelyarten ßippen. Blütben achfelftänbig, gegen bie Spibe Gin gebrängter und in zient= lich groben, bidgten, fugelförmigen, zaglreidyen Duirlen feebent, mit 4 geftielten, werfebrt - eif̈ormigen, vornen gejägten, rüct= märts gefogenen Nebenblättern, bie nur wenig grö̈er als bie Suirle find. Blütbyenftiele grauftzig. Selch nady Der Blüthe Durch feine ftch Geritgrende Saare verfochloffen, gefurcht, barzig junftirt, filzig. Sieldzzăgne gemintwert. BBlumenfrome Dopyelt länger als Der Seldy, ftarE zottig Gebarart, Gelluiolett

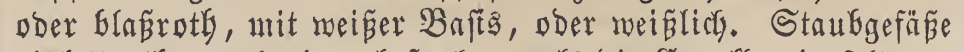
wiolettroth, nod einmal fo lang als bie corolfe, in feltenen ชäflen etwą färzer.

\section{Błäthe $=$ 3eit und Sauter.}

Suli - Septemtier. 4.

\section{3ortommen.}

2lu feudyten, nebern, öfters überfonemmen, zuweilen aber audy an trodfenen Drten in Deftreich, Baiern, Schma= ben, Der Wetterau, bei Franffurt, in Der Deerfaufts, in Salyefen, Der Sayweiz, Franfreich, England, und bei uns atcily in Särten gezogen.

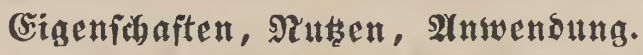

Das Flobfraut Gat eitten Durchbringenden, gewürzbaften, etwas unangenebmen Sieruch und etwas berben, bitterlicken, beipend aromatifosen, camplerartigen und im Mumbe eitue Süble Ginterlaffenden Befcyntadf.

Bormaltende Beftandtyeile find: ätherifctyes Del und eifengrünender Bierbeftoff.

Dfficinelf ift Das Rraut mit Den Blumen und nan ge= fraudyt es wie şfeffermünze als Siewürz, grün an siäuter=

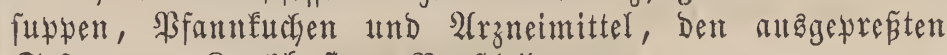
Snft gegen Reutbluften, Bruftleiden zc.

Man fudyte mit biefem fraut Flöbe und Rornmümmer zu bertreiben, inden man baffelbe in bie Betten Yeggte und Dantit räucherte.

\section{Hyssopus. L.}

Syfteme: Corytophyta. Nech.

Didynamia, Gymnospermia. L.

Labiatae. Juss.

Laciatae Nepeteae. Spr.

Ringentes gymnospermae. Roy.

Verticillatae. L.

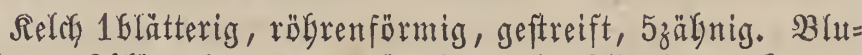
menfrone 2blätterig, nachenförntig, mit 2lippigent Snum; bie obere Rippe vorgeftreeft, eiförmig, 2fpaltig, flach; bie untere 3 fpaltig, Der mittlere Rappen verfefart-eiförmig und fely groṕ. Strubgefäße 4. Strubfäben berworgeftreeft, ge= rabe, oben aubeinandergebend. Staubbeutel getrennt. Striffel 
fo lang ala die Strubfäben. Narbe Hfriemenförmig, ipib. Gament 4, länglicis - eirund, gefielt.

\section{Hyssopus officinalis. L.}

Hyssopus alopecuroides. Fisch.

Hyssopus Fischeri. Hort.

$\beta$. Hyssopus myrtifolius. Desf.

Hyssopus ruber. Mill. Bernh.

$\gamma$. Hyssopus Schleicheri. G. Don.

Siopt.

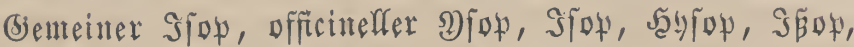

Hyssop. (entgl.)

Isopo. (ital.)

\section{Shten = Sharater.}

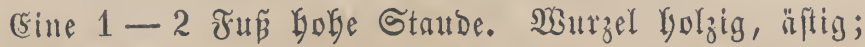
entweder fommen aus berfelfen einige aufredyte, einfadye doer

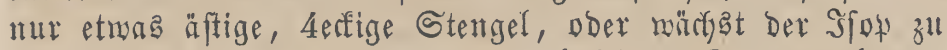
Daumengbiffem, runben, glattem, Golzigem Strauclye Geran, mit auggebreiteten 2hefter und aufrechten, 4erfigen, ganz furbharigen und biçt beblätterten Zweigen. B̧ätter $1-1 \frac{1}{2}$ 3olf lang, gegenüberftelend, ftiellos, fefmal ober lintenfan= zettförmig, ganzrandig, ftunty f, glatt, etwas fteif, auf bei= Den Seiten grubig punftirt, unten bon fleinen Drüfen etwas

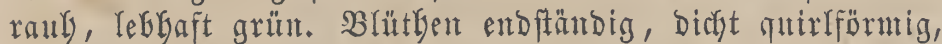
in unterbrochenen, einfeitigen, Geblütterten 2 (ebren. Bhumen= frome nachenfürmig, Glau doer biolett, feltener rotg does

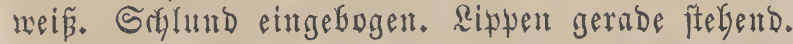

\section{Brithe $=$ 3eit uno Dauer .}

Suni - September. 5.

\section{3ortommen.}

Sn Sübentopa, mittüglichen Franfreich, auf trodfenen Şügeln, Nauern, zunt Theil in Deutfdyland, Deftreidy) (im (Engentbal), audy zumeilen berwildert in (särten, NGeinber= gen, und bei ung in bärten fultibirt.

\section{$\mathfrak{\text { Multur. }}$}

Der Dion serlangt eine leidyte, nabrafafte Erbe und

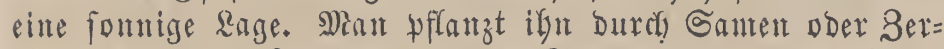
theilung älterer Störfe fort. Den Samen fäet man int $\mathfrak{A}$ pril ober Mai und werzieft fpäter bie zu bicht ftebenden \$ffanjen. Sm zmeiten Sabre mitfen Die Sffanzen berfegt merden. Das Sraut fammelt man furz yor ber $\mathfrak{B}$ lütbe ein. Der Santen bleibt 2 Jafre lang feimfäbig.

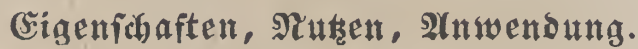

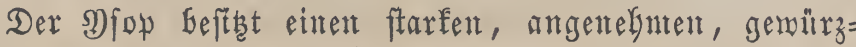
baften (5)eruch und einen Gitterlidyen, etwaz focharfen, aro=

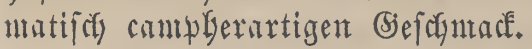

Vorwaltende Beftandtheile find: ätherifacas Del und eijengrütender bierbeftoff.

Sn Der Rithe gebraudebt man ign an Speifen, Saucen,

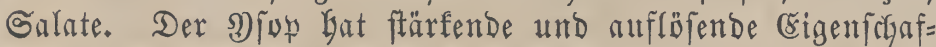
ten. - Dfficinell ift Daß Rraut, fritber auch ber Siment. Man gibt ez innerlidy im 2 Uffun als Thee gegen chroni=

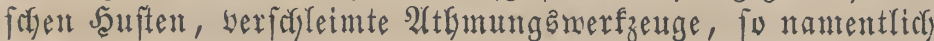

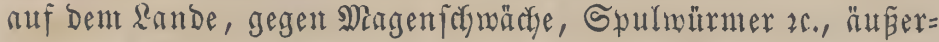

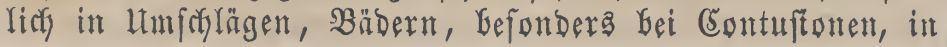

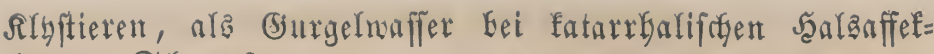
tionen, Sthutpfen.

Die Bienen gewinnen alls ben Blüthen viel Jannig. -

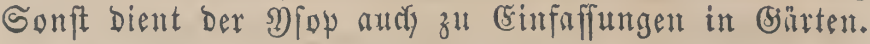

\section{Melissa. L.}

Syfteme: Corytophyta. Neck.

Didynamia, Gymnospermia. L.

Labiatae. Juss.

Labiatae Melisseae. Spr. Benth.

lingentes gymnospermae. Roy.

Verticillatae. L.

Verticillatae Melissae. Rül.

Selch 16 bätterig, rögrenfürmig, feitlich gefielt, 2lippig;

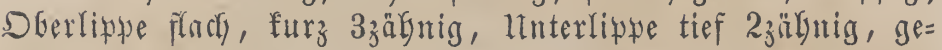
ftreift. Blumenfrone 1 blätterig, rögrenfürmig, mit 2lippi= gem Saume; Dberlippe in Der Witte gemölbt, augerandet und ftump gefielt, IInterlippe 3ppaltig. Die Rappen eirund, ber mittlere ift ber gräg̈te. Strubgefääe 4. Staubfäbent ent= fernt ftebend, unter Der Dberliphe mit ibren Staubbuteln zufanmengeneigt. Staubbentel getrennt. Soriffel yon der Rärge der Strubfäden. Sinbe ungleich gefpralten. Samen 4, oben ftump und abgerundet, undy unten formäler, mit weipent Niabelftricty.

\section{Melissa officinalis. L.}

\author{
Melissa corsica. Hortul. \\ - foliosa. 0piz. \\ - graveolens. Host. \\ - occidentalis. Rafin. \\ B. Melissa altissima. Sib. Sm. \\ Melissa cordifolia. Pers. \\ - hirsuta. Balb. Willd. \\ - romana. Mill. \\ - taurica. Hortul.
}

Bartenueliffe, officineffe Mefiffe, Citronenneliffe, Çi= tronenfraut.

Melisse des Jardins, Citronelle, Herbe de Citron. (frantz.)

Common Balm. (entgl.)

\section{Arter $=(5) a r a f t e r$.}

23urzel fdief laufend, äftig, fajerig. Stengel 1-2 ซur

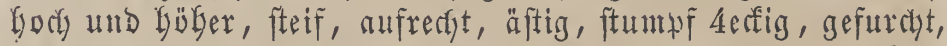
glatt ober mur wentg und fein begart, mit gegenüberfteben= ben, aufredyt ftef aubgreitenden Aleften. Blattftele gerwin= wert. Blätter $1 \frac{1}{2}-3$ Solf lang und $1-2$ Solf breit, lang= geftielt, geferbt-gefägt, runzlicf geabert, oben zerftreut furz=

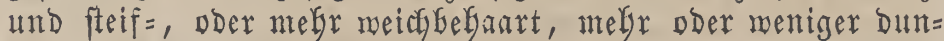
felgrün, unten faft glatt und befler =grün, bie an ben blü= Genden Zweigen ftely beftudenden Blätter funt eiförnig, etwas fpits, bie gröperen Stengelglätter bagegen Kerzeiförmig und melyr ftumpf. B̉lütben meift zu 6 oben in ben Blattroinfeln in oft faft Doldentraubenartigen, furzgeftielten $\mathfrak{x a l b q u i r l e n ~}$ ftebend, mit ganz furzen, lanzettförntigen und Geb̧anten Nebenblättcyen verfeben. Seldy offen, röbrig, geftreift, enfig, Gebaart und troffen. B̉lumenfrone flein, weiślidy, Gie und da rötglich angeflogen, yor bem Deffnen gelb, bie obere rippe rundlicf, 2fpaltig, mit grö̈erem, beinabe Gerzförmig runden mittlern Rapyen. Die Jrücyte zu 4 auf Dent Relchgrunde lie= gend, flein, eifürmig und formürzlich. 
Blüthe = Beit und Dauer.

Iuli - September. 4.

\section{\$̧ortommen.}

In Sübeuropa, Stalien, Frantretid, Der Schmeiz, Gie und ba audi in Deutichland, Deftreid, Gei zranffurt a. MT., in gebirgigen, waldigen bjegenden, in Biefürchen, und bei unz in Bärten angebaut.

\section{ßuttux.}

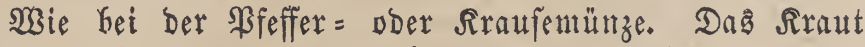
mú man furz yor Der $\mathfrak{B}$ łütbe einfammeln, bünn auzgge= breitet trodfuen laffen und an trofinen Drten gut berfogloffen aufbewayren.

\section{Eigenfádten, গtułen, 2tnwendung.}

Dab frifoge siraut riedgt ftarf und angenelym gemürz= Gaft, citronenartig, und fobmectt etmab berb bitter-aro= matificy.

Bormaltende Beftandtheile find: ätberifchez Del, Berfe= ftoff und bitterer Extraftivftoff.

Man fann es in Der Rücde ftatt Der Citronen alz Würze Den Speifen zufegen.

Dffectuell ift das Sraut, es wirft nerbenftärfend, frampf= ftiffend und carminatig, und man gebraudjt es im Theeauf= gun gegen $\mathfrak{B l a ̈ h u n g e n , ~ f d y m a c h e n ~ N a g e n . ~ D a s ~ C a r m e l i t e r = ~}$ waffer mendet utan innerlich ober äunerlid als Riectmittel ober Ëinreibung Gei Dhnmachten zc, an.

Die Meliffen ertheilen Dem Biere beraufdyende Esigen= fchaften. - Die Blüthen find cin gutes Bienenfutter.

\section{Satureja. L.}

Syfteme: Corytophyta. Neck.

Didynamia, Gymnospermia. L.

Labiatae. Juss.

Labiatae Satureineae. Benth.

Ringentes gymnospermae. Roy.

Verticillatae. L.

Selę) 1 blätterig, rährenförntig, 5 zaknig. Blumenfrone 16 lätterig, nachenförmig, mit malziger $\Re$ b̆he, 2lippig; obere Rippe ftumpf, mit einer Rerbe augerandet, gerabe burge= ftrefft, fpäter aufwärts gefrünumt; untere abftebend ober ab= wärta gebogen, 3laypig, bon ben ftumyfen Rappen ift ber mittlere ber größ̈te. Staubgefäpe 4. Staubfäben fabenfür= mig, entfernt, unter Der Dberlippe mit igren Spiten zu= famntengeneigt. Staubbeutel getrennt. Briffel fabenfürmig, io lang als bie Staubfäben. Sarbe gefpalten. Sament 4, ränglidi Doer eiförntig, oben abgerundet ober furz zugefpitst.

\section{Satureja hortensis. L. \\ Satureja viminea. Burm.}

Bartenjaturei, Bofnenfraut, şurfteraut, wilder Siop,

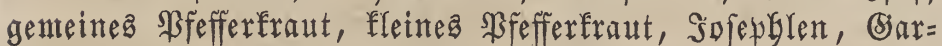
tempfefferfraut, $\mathfrak{R}$ ble, Sommerfaturei.

Sariette, Sardée, Savorée. (f'ranz.)

Savoury. (ettgl.)

Satureja. (ital.)

\section{Arten = Sharaeter.}

Wurzel fpindelig - äftig, befafert. Stengel 1 Fup bod

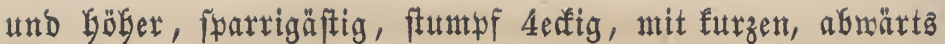
ftekenden, frummen Şaaren oder gegliederten 3 oriten und mit fitc in einent rectent $\mathfrak{S i n f e l}$ fich Durchfreuzenden Zwei=

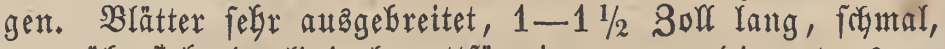
gegenüberftebend, linienlanzettförmig, ganzrandig, etwas ge= wimpert und wie bie Stengel befaart, etwaz biff, unten yertieft-punftirt. Blüthen achjelftändig, einzeln ober 2-8 auf 2 fterbolden ftebend, flein, Gellblau oder violett, zumei=

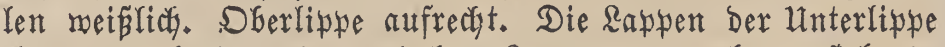
flact) altägebreitet, ber mittlere Rappen etwas berworftehend. Nebenbrätter länger ałz bie Sielcye. Samen flein, glänzend Graun.

\section{Blüthe $=$ Beit und Dauer . \\ suli - Geptentber. $\odot$.}

\section{3orÉmmen.}

Ŝn Taurien, Saufaften, Spanien, Stalien, int füblichen Jranfreich eingeintifø, in Deutfalland bäufig berwildert und in ธsärten fultivirt.

\section{Sultur.}

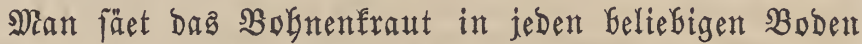
und auf ein marmes, fonnig gelegenes $B$ bet in Meärz ober Arpril; eine weitere Saat ift oft nicht nöthig, ba ftaf) baz Bobnenfraut burch ausaflemben Samen nteifit felgft fortpflanzt.

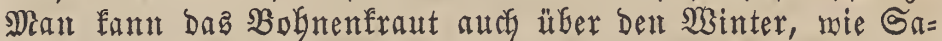
lat, in Miftbeeten zielyen, nur mú man Den Pffanzen biel Ruft und Richt gefen. - Man fofnetbet bie Eaturei furz yor ber Şüthe ab und trodfnet fte an Yuftigen, fdyattigen Drten. Der Samen bleibt uft faum 1 Jabr lang gut.

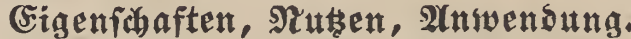

Der Bierud Des Bobnenfrauts ift ftarf angenehm ard =

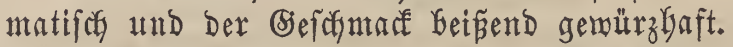

Bormaltende Beftandtyeife ftrtb: ätherifojes Del und eifengrünenter Bistbeftoff.

Man gefraucft ę̧ grün oder getrodfnet, ganz ober als Burver, zu Sirüterfupwen, Sauçen, Salaten, $\mathfrak{B u ̈ r t ̦ e n , ~}$ Bub=

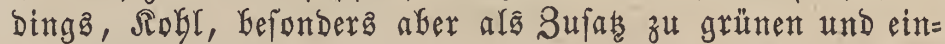
gemaiften $B$ ofnen.

Dfficinell ift Das Siraut mit ben $B$ lumen, welches man

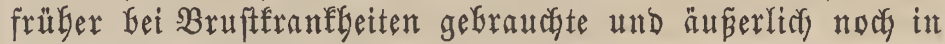
Bäbern 2c. anmenbet.

\section{Satureja montana $\mathbf{L}$.}

Satureja cuneifolia. Tenor.

Satureja juliana. Pall.

Satureja trifida. Moench.

Micromeria montana. Rehbch.

Bergpfefferfraut, SBinterbolnenfraut, Bergfaturei, $\mathfrak{B i n =}$ terfaturei, fpanifoger Thyntan.

Sariette vivace, Sariette de montagne, Savorée de montagne. (firttz.)

Mountain Savory. (engl.)

\section{Arten = Sharafter.}

Wurzel Golzig. Stengel äftig, 2 Fú Goch, etraa be=

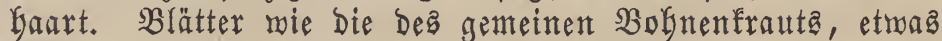
gemimpert. Blumen geftielte, Geinahe einfeitige, minfelf̂än= bige 2ffterdolden bildend. Selch mit langgefpiten, befaar= ten, ftechenden Ëinfdgnitten. Sironte weiś ober Glä́roth. 
Blütfe $=$ Seit und Dauer.

эuni - গuli 4 .

\section{Bortonumen.}

Tyrol, Rrain, Rärnthen, Sarbinien, und audy in un= fern (S)̆rten gezogent.

\section{నultux.}

Man vermefre die Bergfaturei burdy Samen ober Wur=

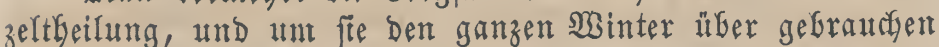
zu fănnen, nimnt man einige SFflanzen ntit Dent Erobalfen aแs bem Rande und febt fie in ein warntes sliftbet. Sie ift feldr bauerbaft und leibet aud in ftrengen Mintern nidgt reidgt. Der Gamen bleibt 4-5 Jagre lang feimfägig.

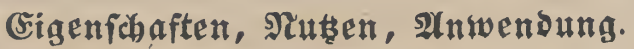

Wie bei ber $\mathfrak{B}$ origen.

\section{Lepidium. L.}

Sieke Seite 206.

\section{I.epidium latifolium. L.}

Cardaria latifolia. Spach.

Breitblätterige Rreffe, B̧fefferfraut.

Passerage. (finitz.)

Broad - leav'd Pepperwort. (entgl.)

\section{$\mathfrak{A} \mathfrak{x} \mathfrak{E n}=\mathbb{C} \mathfrak{S} \mathfrak{a r a E t e x}$}

Nauzel weitfriedyend, wuthernd, weiflidy. Stengel 2-5

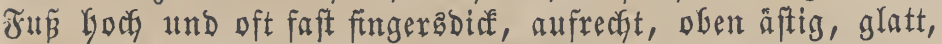
fteif, weiß̧lich befaart. SBlätter 6-10 3olf lang und 1-2 Solf breit, afwechelnd, geftielt, Gejonders lang geftielt aber bie unterften Blätter, eilanzettfürnig, fpibig - gefägt, oben ganzrandig, glatt, beinake lederartig fteif. Die silütyen end= ftänbig, felyr zablreich, in fleinen, bicften, riapenartigen, zuerft mebr frtäulförmigen Trauben ftebend, fie find flein

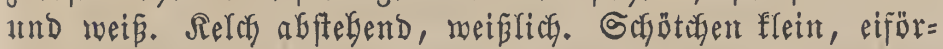
mig, rundlich, nicht augagerandet, mit gefielten Rlappen.

\section{Blütbe = 3eit und $\mathfrak{D a u e x}$.}

\section{รuni - 2uguft. 4.}

\section{\$20rEmmen.}

In England, Franfreidy, Der Sagneiz, bie und ba in Dentialand, in Safwaben, Dem babifaren Orerland, ber sibet= terau, in Baiern, Franfen, Sagleften, Sadjfen, Solftein, an fatattigen, feuditen und fetten Drten, auf Bebirgen und J̦ügeln.

\section{Sigenfidaften, Nutuen, $\mathfrak{A n w e n o u n g . ~}$}

Die ganze ßflanze, Gejonders aber Das אraut, Gat, zu= mal bein Derreiben einen ftarf freffenartigen Beruch und

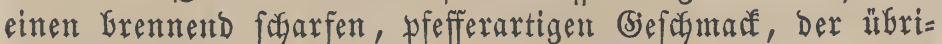
gens nicht nachbaltig ift. Beide Eigenforfaften berlieren fich Durch's Trofnen zunt grofen Theile.

Mian gebraucht es wie bie gemeine Sieffe und antatt

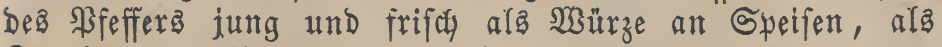

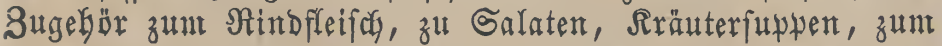

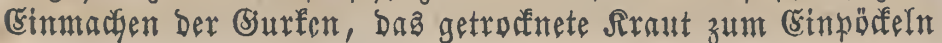

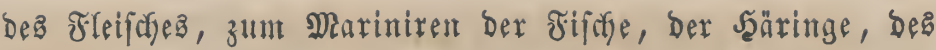
Rach

Das Sraut war früber gefrăudylid), es wirft anti= jcorbutifdy.

Lavendula, L.

Chaetostachys. Benth.

Fabricia. Adans.

Pterostoechas. Benth.

Spica. Benth.

Stoechas. Adans.

Syfteme: Corytophyta. Neck.

Didynamia, Gymnospermia. L.

Labiatae. Juss.

Labiatae Nepeteae. Spr. Rchbch.

Labiatae 0cimoideae. Benth.

Ringentes gymnospermae. Roy.

Verticillatae. L.

Verticillatae Hyssopi. Rül.

Relç 1 Glätterig, xöhrenfürntig, geftreift, 5 zăhnig. B̉u= menfrone 1 blätterig, nachenförmig, mit walziger $\Re$ ägre und 2lippigem Saume; die obere Rippe ffach, aużgerandet ober eingefanitten, gräser; bie untere fleiner, mit 3 ftumwfen Rapyen, yon meldyen ber mittlere größer ift. Staubgefäpe 4. Strubfüben in ber Reldyrägre eingefdoloffen, entfernt. Staub= Gentel beinabe nierenförmig. Siriffel fürzer als die Blumen= rökre. Narben eifürmig, ftumpf, gefpalten, an einanber lie= gend. Samen 4, länglidy, oben abgerundet.

\section{Lavendula spica, L.}

$\alpha$. Lavendula angustifolia. Bauh.

$\beta$. Lavendula latifolia. Bauh.

(3emeiner Ravendel, Ravandel, Spife.

Aspic. (finalz.)

Common Lavender. (entgl.)

\section{Arten $=$ (Sharater.}

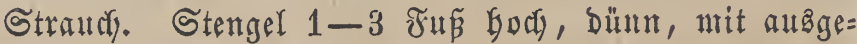
breiteten Sweigen; bie jährigen şlütbenzmeige frautartig, gerabe, aufrecht, einfach, 4effig, etwas raulg und fefr furz

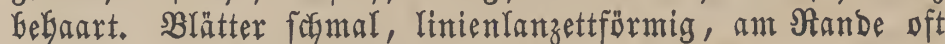
umgebogen, weif́lichgrün. Blüthen auf einfachen, an ber

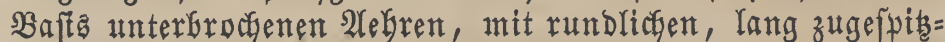
ten, geftreiften und bebaarten Nebenblättchen. Seldy geftreift, GeGaart, bläuliaj. Blumenfrone röhrig, 2lippig. Staubfäben

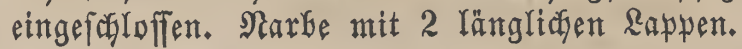

\section{Blüthe = 3eit und Dauex.}

Suni - Suli. ち.

\section{3ortommen.}

Sübeuroła, ซranfreich, Stalien, bei unz in Bäranten.

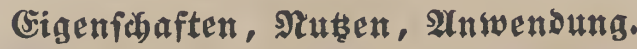

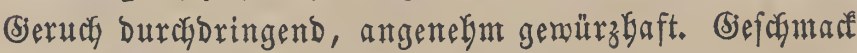
bitterlich beipend aromatifa.

Dfficinell ift bie Blütbe; man gebraucht fie felten inner= lich, megr äuferlich, als ein belebendes, ftärfendes und zer=

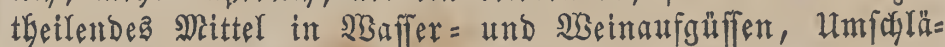
gen, Sֻafdungen, Bäbern, Siräuterfiffen. 
Die Błhutenftengel Kegt ntan zur Bertreibung Der Mrot= ten znifhen Rleiber und Wäfdye. Sonft bient ber Rabendel

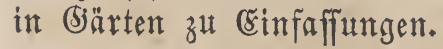

\section{Crocus. I.}

Syftente: Croci. Rül.

Coronariae spathaceae. Spr.

Denudatae. L.

Ensatae. L.

Irideae. Juss.

Lilia calyculata. Roy.

Liliaceae Irides. Adans.

Triandria, Monogynia. L.

Ymnodiphyta. Neck.

Sild) fegit. SBlumenfrone trichterfürmig, mit febr fan=

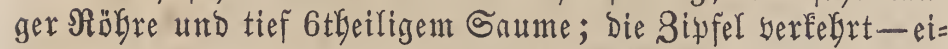

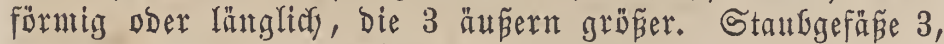
Der פ̧lumenröbre angebeftet. Staubfäbent pfrientenfürmig, fürzer als bie B̧umenfrone. Staubbeutel yfeifförmig, auf= recht. Frudiffnoten unter Der Bhuntenfroue, runblids. Griffel fabenförmig, fo lang alz bie Strubfäbent. Narbe tief 3fpal= tig, oben lappig. Rapfel eirutb, 3fontig, 3füdjetig, 3flap= pig, megrantig. Samen runblicy.

\section{Crocus sativus. I.}

Crocus hybernus. Frivald.

Crocus autumnalis. Smith.

Crocus officinalis. Pers. - fafran.

Aedyter Safran, zalmer Safran, Safranpflanze, Serbft=

Safran. (fraltz.)

Common Safran. (ettgl.)

Zafferano, Gruogo. (ital.)

\section{$\mathfrak{A}$ rten $=\mathbf{( S h a r a k t e r}$.}

Smiebel bicht, bon Graunen Sẳuten 1mutgeben, unten etroas abgeslattet, fajerig, trägt aber meift nocí $1-2$ flei= nere 3miebeln. Schaft furz, 3effig, unten yon einer Sdyeibe ungeben. Blätter grasartig, fpis, ant ßande aufgerold,

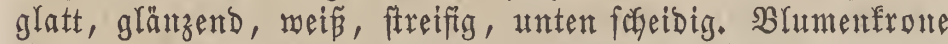
aufrecht, langrobrig, ober bem Frudstfnoten ftehend, violett. Staubgefäpe felyr lang. Narben 3. Der eigentlieje Safran linienförmig, fo lang ala bie Bluntenfrone, zufammengerolft, Glutroth und ftarfiechend. Fruchtfapiel 3 fächerig.

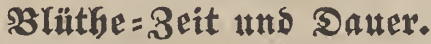

\section{September - Dftober. 4.}

\section{Eommen.}

Norbmeftliches 2lften, Serfen, auf Goben bebirgen und in einigen $\mathfrak{a} \mathfrak{a}$ bern, wie in Nieberöftreich, in ber Schweiz, felbft noch im Ërzgefirge auf Der böhnifiden Seite fultivirt.

\section{§ultux.}

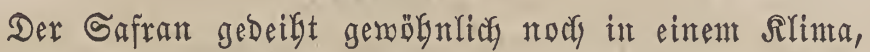

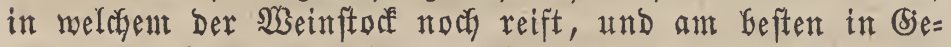
genden, meldye eine gejchübte, fonntge, gegen Mittag etmaz abbängige Rage baben, unb yerfangt einen fräftigen, humubs= reicfyen, lebmbaltigen, nicyt zu fandigen und binbigen ober zat naffen Boben, Der nie wie Torf = und Moorboden yom
Winterfrofte in bie Şäke gefoben und, wenn es nöthig ift,

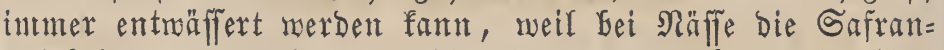
zwiebeln gerne faulen; un biés letztere zu serbüten, barf Der Safran auch nicht frifal gedüngt werben; mup Das Düngen aber bez zu magern Bobens megen Dentroch gefoheben, io bringt man int Serbite zutor geförig zergangenten Mifft ober Sontpolt unter ben $\mathfrak{B}$ oben. - Den Boben bearbeitet man mit Sefpanmerfzengen, ober mit Dem Spaten, ober mit beiben zugleich, bie Saatptfache dabei ift, Den Boben recht aufulorfern und won affem unkraute und Steinen zu reint=

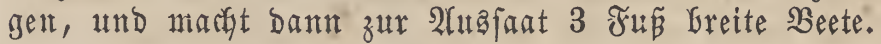

Mian fant Dent Safran auf fämmtliche Frürdste folgen

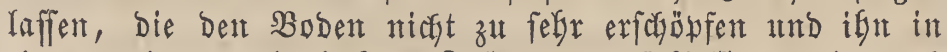
einem reinen und locfern Suftande zurüblaffen, wie nady

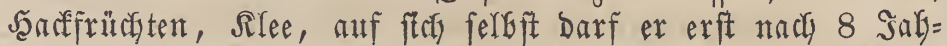
ren folgen. Man baut ifn in Gefondern \$lantagen, bie man ntit $\mathfrak{W a f f e r f u r c f i e n}$ yerfiegt, und Da er ben Boben nicht fonderlidf ausuagert, fo fant man jebe ambere Frudit nacts ibm bauter.

Man wermegrt ben Safran meift Durch Swiebelfrut, burch bie fogenaunten Riele, und rö̆lt bazu nur gefunde, mit ifren Sänten noch umgebene, mittelgrofae, aber nidyt lang zugefpibte Swiebeln, und reinigt foldye mit affer $2 o r=$

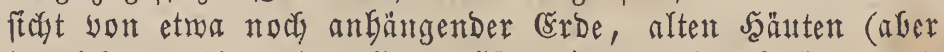
ja nicht yon beat eigentlichen Săuten), von ben Fafern, und yergeffe babei nicht, bas an ber untern Seite ftery befindende und eine Brabe beberfende Brättefen zu entfernen. - Die Safranzmiebel legt man, mit ber Spize genau nach oben,

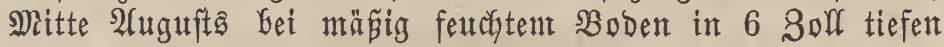
und 3-4 3oll yon einamber entfernten Reilyen, und eine jebe 3wiebel 3 3olf yon ber andern entfernt, und bederft

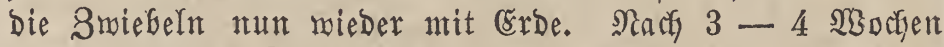

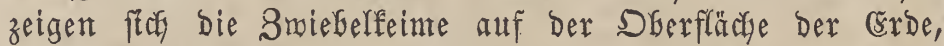

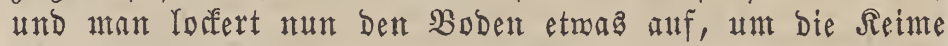
in ifrem Şerborfommen zu unterftühen, yorbandenes Unfraut mird entfernt. Int September doer Dftober treibt Der Safran in $\mathfrak{B}$ lätter und $\mathfrak{B}$ lütben und berlangt mun eine warme und troffene Witterung. - Da ber Safran ungleich blübt, fo Dauert bie Errnte immerbin einige, bei ganz günftiger WBit= terung 5 Tinge, ja nicht felten unter ungünftigen $\mathfrak{U}$ mftänden

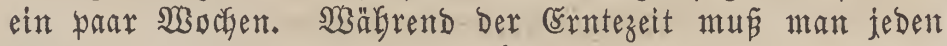
Morgen feine \$lantage Durabehen, um bie reif gemorbenen Blütben, wenn fte moch geferloffen und frifor ftets, abzu= neGmen. Bei biejer Yebtern 2lrbeit büte man fien aber, bie

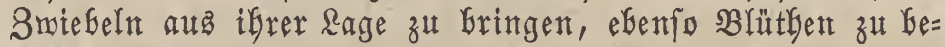

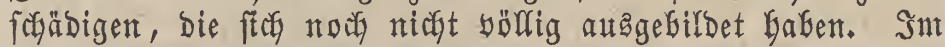
zroeiten Saljre nady der Ernte bat man zuerft Darauf zut

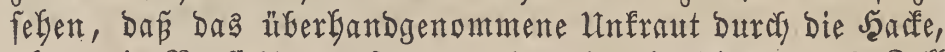

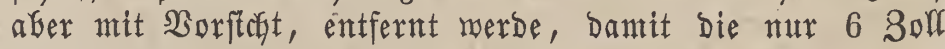
tief ftecfenden Smiebeln nicht werlebt werben. Die Blätter Des Gafrans bürfen nicht afgerweidet merben, fondern ntan Genüht foldge erft int folgenden Iafre um Sofanni, wo fie erft abfterben, zu Biebfutter. Wan foll von einer Safran= wlantage nicgt weiter als 3 šrnten nelmen, erftens meil bie Swiebeln immer weiter itber ftery machjen, fomit bie Bear= Geitung Dez Bobens immer mefy erfogweren, utd zmeitens weil bie Safranzwiebeln mebreren Siranfleiten auggefebt find;

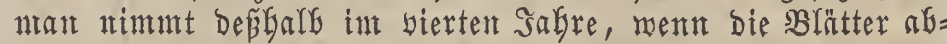
gemelft find, Die Zmiebeln mittelit eines Spatents aus Dem 
soben und berobart foldae, bis man fie mieber fezen wiff, an froftfreien, Iuftigen Drten auf. Die Swiebeln wermebren

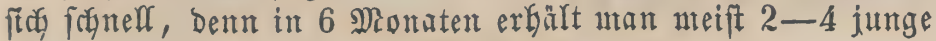
3riebeln, Dabei aber ftirbt die Mutterzmiebel ab.

Die Blütben Gringt man nun nidjt zu dicht in füblen

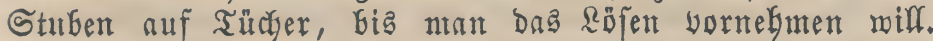

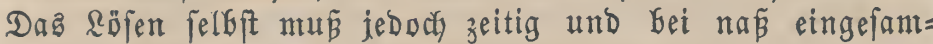
ntelten slütben gleich gefdyeben; nacjben biefes yorüber ift, fo fäumt man nidjt mit Dem Dörren Der Narben, weil fie fdnelf faulen; man Dört fie entweber, an eitem trofenen, fdyattigen Drte ausigebreitet und öfters umgerwendet, ober beffer Durds's Feuer in Saarfieben auf Serben Doer in eigens Dazu Geftimmten Defen. Heber Die Einridytung Diefer Defen und bie Bebanblung Des Gafrans beim Dörren frebe Siff=

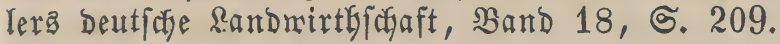

Der (Ertrag Des Gafrans int erften Jabre ift bom Dag= Deburget Miorgen oft faun 2 \$fund, fteigert ftcis aber int

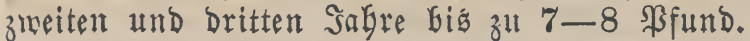

\section{Sxantheiten, făbäblibe Binflüfie.}

Die Safranzwiebeln ftnd Gauptfädalica 3 Rranfbeiten unterworfen, täulich Dem Brand, Der Fäulní̄ und Dem ในดริnuch fe.

Der Brand ober Tod beftelst in einer farmammigten Materie, bie fich nach und nach über bie ganze Swiebel ber= Greitet, Dann fich nach innen fortpflanzt und biefelbe zu (Srunde ridgtet; ntan erfennt Diefe Sranffeit im Sherbft, menn die Seime fommen, an fablen Slntgen und am ftcher=

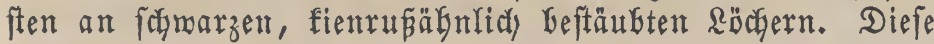
sranfbeit verbreitet fich auperorbentlicf fonelf, und nicht blos eine frante 3roiebel, fondern fogar nur Erbe, von ber Näbe einer foldben genommen und zu gefunden Swiebeln gebract, ftedt Diefe an. Man fann gegen diefe Srantbeit eigentlich nichts thun, als Die-3wiebeln aus Dem Rande neh)= melt und in ein anderes verpflanzen. Itm Das rafde Itnt= futgreifen Diejer Rranffeit zu verbüten, zieben (sinige auch

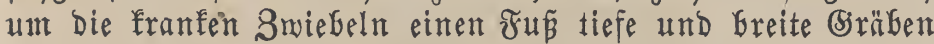

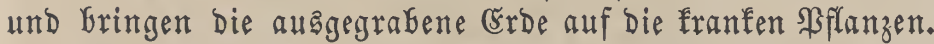
(rin Boben, Der franfe Swiebeln getragen Gat, bebilt ben Sranflyeitsftoff lange in ftch und er barf 15-16 Jahre lang mit feinen neuen Brobeln angepflangt roerben.

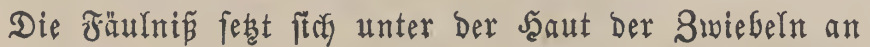
und ift äuperlich nicht zu bemerfen; un Diefer אranfbeit zu

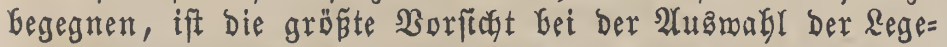
zrobern zu empreblen; foldse Smiebeln ftnd, wie fochon er= räknt, won ben alten 5 äuten gebörig zu reinigen und roeich

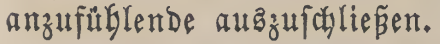

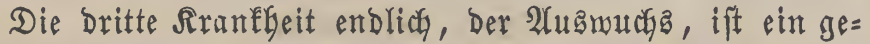
wöbnlicher, am untern Theile Der 3roiebel fte bildender, rübenförmiger sörper, ber fith afle Sïfte Der Swiebel an= eignet und fte auf foldabe Meife zu Srunde richtet. Diefe Sranfleit fommt feltener yor und es fofeint, Dá̧ fie auch

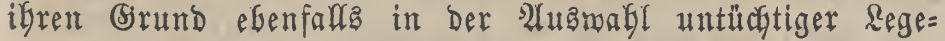
zmiebeln Gabe.

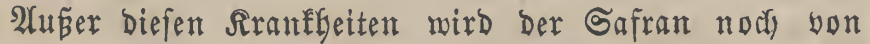
manderlei Feinden beimgefuryt, und febr gefäbrlich ift ifm

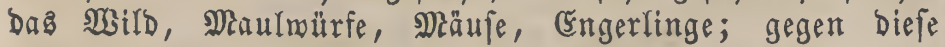
fucht man ftch Durd Einzäunungen, Durd eine fleisige und

Enfwer, Benom. spranzenfunde.
Ginlänglid tiefe Bearbeitung Dę B Bobens und Durdjziefen bon Gräben zu fởủen.

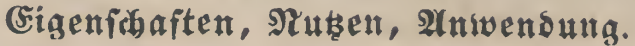

Der Safran, wenn er Die gegörigen Eigenfadyaften beftht und nicht mit andern Sngrebienzien, roie mit Dem $\mathfrak{B} e f r u d s=$

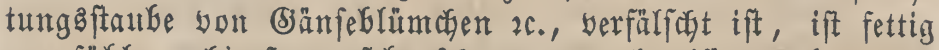
anzufüblen, biegiam, febr fonsoer zu pulveriftren, bat eime purpurrotbe, rotb und gelb abfärbende Farbe, einen Durcts= bringenden, betäubenden, gemürzbaften (5ierud und einen bitterlich flechenden, Galfamijalden siefantar.

Man gebraudgt Den Safran in einigen (5iegenden bäufig

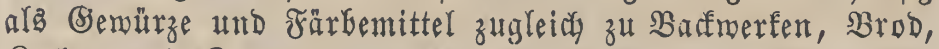
Ruchen und Suppen.

Der Safran ift ein Gefanntes 2 rzmeintittel, er wirft

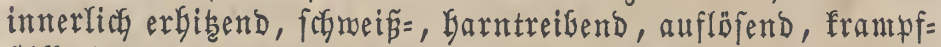
ftilfend, in gröpern (saben madyt er trunfen und erregt \$hantaften; äuferlic wirft er erweichend. Man gebraudst

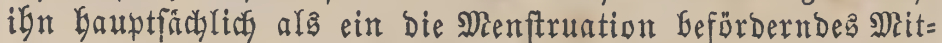
tel, bei fupbilitif dyen, nädytlidyen Inodfenfdynterzen, "̈uperlidy bei (sefdyüren, fcropbulöfen \&ugenentzündungen.

Man benutst Den Safran ferner in Der Malerei und Fårberei, die şlätter ftnd ein gutes Biebfutter und bie Blütben eine Sierde der särten.

\section{Capsicum. L.}

Syfteme: Arcytophyta. Neck.

Luridae. L.

Oligantherae pentandrae multiloculares, Roy.

Paucistamineae. Crantz.

Pentandria, Monogynia. L.

Solanaceae. Rül. Juss.

Solaneae. Endl.

Sielch 1 blätterig, 5 zälnig, Gleibend. Blumenfrone 1 blät= terig, rabförmig, mit furzer $\Re$ öbre und halb 5 fpaltigem, abite= bendent Saum, bie Bipfel fpibig. Staubgefäß̄e 5, ber Blu= menfrone eingefügt. Staubfäben furz. Staubbeutel länglidy, zufammenjaliejent, Der Ränge nach aufipringend. Frudgt= fnoten eirund. Erriffel fadenförmig. Narbe ftumpf. Beere trofán, 2-3fäberig, vielfanig. Samen nierenförmig, flach.

\section{Capsicum annuum. L.}

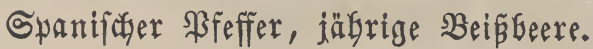

Long podded Capsicum. (engr.)

\section{Arten = (5harakter.}

Stengel frautartig, äftig, aufrecht, 1 Jus boch und Göber. Blätter eiförmig, zugefpid, glatt, langgeftielt. B̉lü= then einzeln ftefend, geftielt, meiz̄ ober gelblich. Kelch 5 fpal= tig, bleibend. Bhlumenfrome rabföntig. Frudyt oft 2 3oll lang, meift eiförmig - länglich, oft auch gebrungen, warzen= förmig, aufgeblafen, im 2lnfang grün, Dann mit fohwarzer Spibe, zulebt gelb, ober rotbgeidyerft, gemöhnlich aber ganz und fegün roth, innen mit einten lorfern Marf und vielen nierenförmigen, plattgebrücten, meísgelglidjen Samen ver= fehen.

$$
\begin{aligned}
& \text { Slüthe }=\text { Beit uno } \text { Dauer. } \\
& \text { Suli }-2 \text { 2uguft. } \odot .
\end{aligned}
$$


3orkonmen.

Sübamerifa, Braftlien, \$eru, Samaifa, Şeftindien, bei unz in (8ärten gezogen.

\section{Eigenfathaften, stuten, Anwendung.}

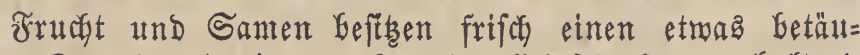
benden (Beruch und einen auserorbentlich fidarfen, anbaltend

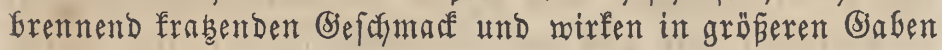
töbtlich giftig.

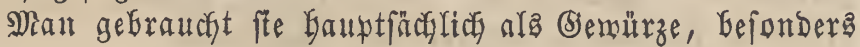
aber in Suldamerifa, Dftindien, in Spanien, Bortugal, Eng=

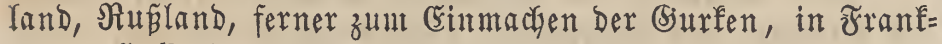

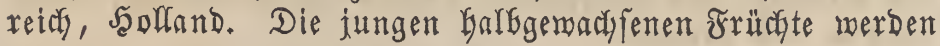
eingemacht und beripeist.

Sn Der Mebicin gefraud man fe innerlich gegen $\mathbb{R} a \mathfrak{a}=$ mungen, foblechte Derbauung, und äuserlid als rotgmachen= Des und blafenziebendes Mitter.

\section{Coriandrum. L.}

Syfteme: Pentandria, Digynia. L. Scadiophyta. Neck. Umbellatae. L. Umbelliferae. Juss.

Relă ganzblätterig, 5zähnig, Gleibend, mit oberftändi=

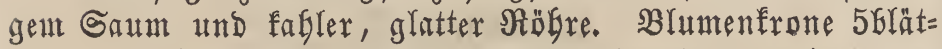
terig, abfälig. Blumenblätter gegen einander geneigt, wer= febrt-berzförmig, aużgerandet, mit einem einmärta gebo= genen, an Der Spide gezähnelten Bipfel; die äunere ber Sandbiüthen ift bebentend grö̈er, ftrablend, 2theilig. Staub= gefäß̧е 5, berlängert. Staubfäden fabenförmig. Staubbeutel

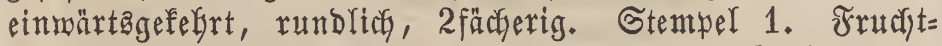
Enoten unterftandig, mit einem fegelförmigen Eriffelpolfter gefrönt, 2fäecherig. Soriffel 2, fabenförmig, lang, aufrechtabftebend. Narben fumpf. Spaltfrucht fugelig. Theilfribste Dicft, 9riefig. Samen umgefefret, eimeiphaltig.

\section{Coriandrum sativum. L.}

Coriandrum majus. Gouan.

$\beta$. Coriandrum microcarpum. DeC.

Coriander, gemeiner Coriander, grö́er ober zakmer Coriander, Wanzendiff, Sagmindelforn.

Coriandre. (fianz.)

Common Coriander. (engr.)

Coriandro. (itaf.)

\section{Shten = Charalter.}

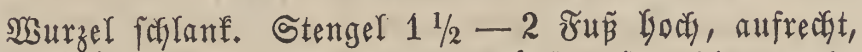
malzig, falli, oben äftig. Blätter leblgaft grün; bie grumb= ftändigen, melche bald verwelfen, find geftedert, bie Blättchen ftrd breit, rundlich, eingefchnitten gefügt; bie folgenden $B$ lät= ter boppelt geffebert, mit eirunden, an der sBafts berfounä= ferten, 3fpaltigen und eingefdyntttenen Blättchen; bie obern slätter 2-3fach geftebert, mit fámalen, ganzrandigen Feben. Dolden langgeftielt, flach, $3-5$ ftrahlig. Jaulfe 1 Glätterig

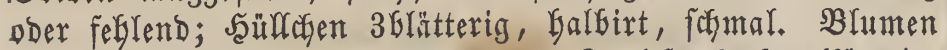

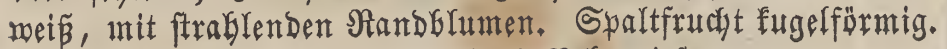
IGeiffrüchte mit 5 şaupt= und 4 Rebenriefen.

\section{Blüthe $=3$ eit und $\mathfrak{D a u t r}$.}

গuni - গuli. $\odot$.

\section{3ortommen.}

Sn Stalien zu Saatie, hie und ba in Deutiafand unter Der Saat berwildert, fonft Gäuftg, befonders in Thüringen, angebaut.

\section{Sultux.}

Der Coriander macht menig 2 ñprübre auf $\mathfrak{B}$ oben und Bebandlung, mur werlangt er zu feiner erften Entnuiffung viel Feuchtigfeit, Daker Das Feld yor Dem şinter gepflügt, im Frübjafr ftare abgeeggt und bann, renn folches abge= trodfnet, entweder breitwürfig oder gebriflt eingefäet mirb. Den Samen eggt man ffach unter und malzt ifm. Der Cov= riander reift ungleid und fält gerne aus, Daber man ifn mit Borftedt Gefandeln mus; er wirb mit ber Sidfel abge= fadnitten, auf Dem Felde in Fäffern augigeflopft und Dann auf einent luftigen $\mathfrak{B}$ oben aufGeroabrt.

Man recfnet yom Miorgen 4-6 Eentner Ertrag.

\section{(Eigenfidaften, Nuten, Anwendung.}

Die ganze Pflanze, mie aud ber frifue Samen, bat einten wibrigen, wanzenartigen (Serudy; Testerer berliert ben= felben Duref's Troffen und riedyt bann angenelyt und ge= mürzbaft. - Man brautht Den Samen ala Semürze an Spei=

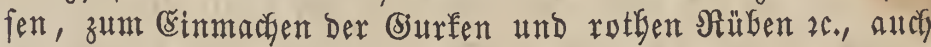

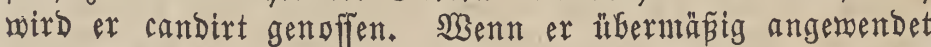
wird, wirft ex leicht betäubend und fann ftes fogar giftig ăunern. Den Bienen gift er biel Stoff zu Jennig.

\section{Carum. L. Siefre Seite 23.}

\section{Carum Carvi. L.}

Aegopodium Carum. Wibel. Apium Carvi officinale. Crantz.

Bunium Carvi. Bbrst.

Foeniculum Carvi. Link.

Lagoecia cuminoides. Willem.

Ligusticum Carvi. Roth.

Seseli Carum. Scop.

Seseli Carvi. Roth.

Sium Carvi. Bernh.

$\beta$. Pimpinella vaginata. Jan.

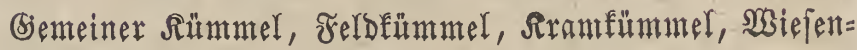
fümmel, Mattenfümmel, Sarbe, Rarbe.

Common Caroway. (engl.)

\section{Arten $=\mathbb{C}$ barater.}

Murzel fpindelförmig, auken gelb. Stengel 2 Fun boch und Darüber, äftig, gefurcht. SBlätter Doppelt geffebert, bie obern Blättcfen etwa länger und oft auch ftärfer getbeilt. Dolden an ber Spize Dez Stengels und Der Bmeige ftefento,

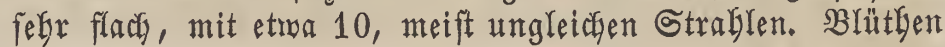

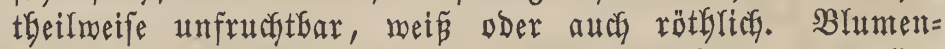
Grätter einmärtz gebogen, auszerandet. Samen länglich, etroas gefrünm, geftreift, grünliçbraun.

Mai. $\odot . \sigma^{\pi}$.

\section{Blüthe = 3eit und Sauer.}


3oréntmen.

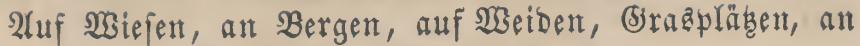
Af́errändern.

\section{Rultux.}

Obgleidy ber Sïmmel Gäufig mild mächast, fo mirb er bocis vielfăltig angebaut, indem feine Samen burch Rultur viel fräftiger und gemürzbafter werben. - Der Rïntnel ge*

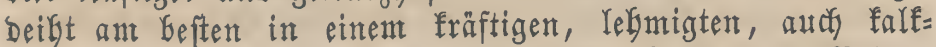
tnd mergelbaltigen, etras feudgten, unfrautreinen Boben, Der reeber zul bindig, nod zul leicht ift und frülyer gebörig mit Bferde= oder Schafmift gebünt worben war, auf nieber gelegenen, bुäufig überfofwemmten Feldern und in einem mebr feucteten Rlina. Der Rüntnel borb mur, nenn Der Boben zu mager fein follte, mit gépörig zergangentem Cont woft, Saglamm ober berbünnter und verfaulter Saudfe ge= Düngt, unter affen Unţtänden aber liebt er Dab Düngen mit

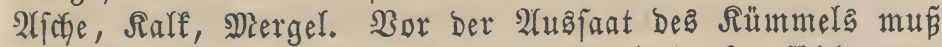
Der Boben gebörig mit ber E.gge unb şalze forgfältig yom Unfraute gereinigt werben.

Man fäet ben bolfommen frifden Samen im Jrübjabre, längftens bis 2(uguft, roomöglich bet etroas feuctster Mitte= rung, bamit er fodnelfer aufgegt, nicht zu bicht, entreber Ereitnürfig wie beint Rübfanten und bringt ben Samen nur flact) unter, boer man fäet ifn in 6-12 3oll yon einander

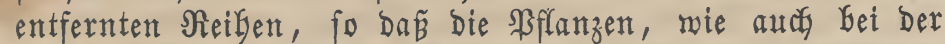
Greitmürfigen Saat, in einer Entfermung yon 6 20ll $z$ u fteben fonmen; lebtere Säeneife möbte Der erftern injofern worzuzieben fein, als ber Boben beffer aufgelocfert und reiner mird und Sefpanmmerfzenge dabei Genübt werden fönnen. Meler Soften verurfacht es, aber megr und befferen Sümmel erbält naan, wenn man ifan in Beeten erziegt und nachber beryflanzt; in biefem Falle fäet man Den Rünmel entweber in Frübjabr in 2 tpril ober auch im Serbfte in September in SFfanzenbeete ziemlich dicht, und verfetst, nachem man

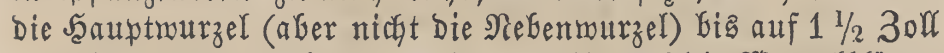

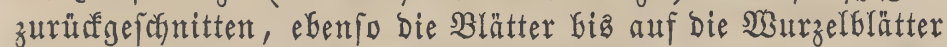
abgenommen, in 6-12 8oll yon einander entfernte Neigen, in einer Entfernung yon 6 3olf, bie im 2lprif gefäeten meift in Sunt ober Эult, und die im September gefäeten erft daz Jrilgtagr barauf.

Da Der Sïmmel noch in 2luguft gefäet werben barf, fo fann man ifn in Der Dreifelderwirtbjegaft nach Früchten, wie Neps 2c., Die bald afgeerntet merben und Den Boben in einem lorfern 3uftande Ginterlaffen, anbauen. Den Rüm= mel mit andern Eemädjen, wie Rein, Mobn, Mähren 2c., bermifud zu bauen, ift nicht zu empfeglen, und ez fann

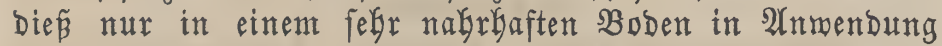
gebracht werben. Findet nan bei Der jungen Saat zu bicht ftebenbe Sflanzen, fo werziegt man foldye und yflanzt Rüfen

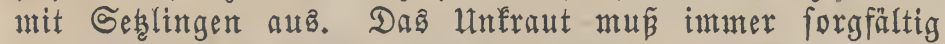
entfernt und Die \$flanzen bet trocfener Witterung, wo müg=

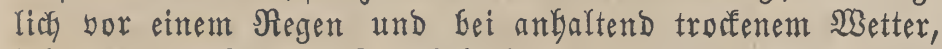
2lbends yon Beit zu Beit bef̧arft werben.

Da Der Riummel ungleich zeitigt, fo nimmt man eben bie Ernte bor, ment bie meiften Samen eine braungrün= lidye und bas Stroh eine bräunticţe Farbe befommen baben, zaubere aber bam nidjt mit Dem Einkeimfen, weil bie $\sigma_{a}=$ men fehr gerne ausfallen. Mhan nimmt bie Ernte Mlorgenz

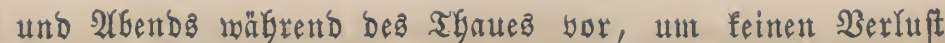
an Samen zu leiben. Whan läß̈t ifn, in Şaufen aufgeftellt, geförig abtroffnen und brifat ifn entweder auf einem Tuche ober zu Şauje auss. Den Samen reinigt man mun gebörig, fodüttet ign nicht zu bidgt auf einen luftigen Boben auf und wendet ifn zumeilen um.

\section{Cigenifhaften, গ⿰uțen, 2(nwenoung.}

Der Samen riedst und fowmecft eigenthitmlich genütry= Gaft, angenelgm. Eor ift ein faft überall bäufig angemen= Detes Gervürze, ntan berbaft ifg unter's Brod und anderez Bacfwerf, mifat ihn Răfe, verfogtedenen Speifen, Sauçen bei, bereitet einen $B$ ranntwein, Den Einfachen = und Dopyel= Sïmmel, aus ifnt, man gibt ifn auch Siüfen, wenn fee Glaute Milch geben. Die jungen Sproffen und Blätter mijcht

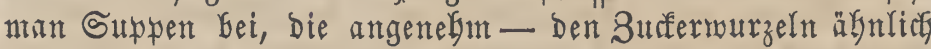

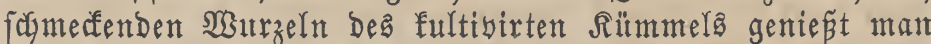

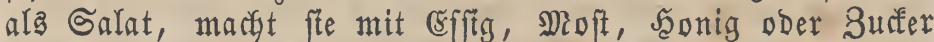
ein. Die Blätter find ein gutę Biebfutter, das Stroh fann ganz roogl Schafen gefüttert, im Uebrigen zu Streu benüht werben.

\section{Foeniculum. Adans.}

Syfteme: Pentandria, Digynia. L.

Scadiophyta. Neck.

Umbellatae. $\mathrm{L}$.

Umbellatae Cicutae. Adans.

Umbelliferae. Juss.

Umbelliferae Seselineae. DeC.

Seled ganzblätterig, mit eiförmiger, ftarf geftreifter,

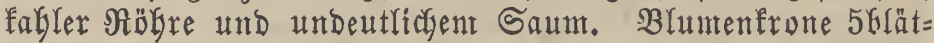
terig, abfalfend. Blumenblätter gleiç, rundlich, ganz, ein= gerollt, mit beinabe 4erfiger Spthe. Staubgefäßze 5, mit ben Bluntenblättern eingefügt. Staubfäben fabenförmig. Staubbeutel runblicy, 2 fächerig, eimbärta gefebrt. Stemt= pel 1. Frud flfnoten unterftändig, mit einem fegelförntigen Erriffelpolfter gefrönt, 2fächerig. Srriffel 2, fekr furz. Nar = ben ftumpf. Spaltfrudbt längliç. Theilfrüchte bicht, 5riefig. Sament ungefebrt, eirueiśbaltig.

\section{Foeniculum vulgare. Gaert.}

Foeniculum officinale. All.

Anethum foeniculum. L.

Ligusticum foeniculum. Roth.

Meum foeniculum. $\alpha$. Spr.

B. Tenoria romana. Schkr.

Foeniculum azoricum. Hort.

$\gamma$. ? Foeniculum rigidum. Brot.

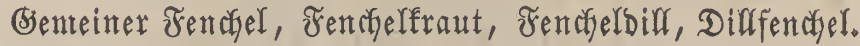
Common Fennel. (engl.)

\section{Arten $=$ Charakter.}

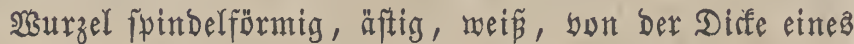
Fingerb.. Stengel $8 \widetilde{F u} \mathfrak{B}$ hoch, äftig, geftreift, glatt, grau= grün, yon Den Blatticheiden umgeber. Blätter groß̈, ungleich gefébert; Blättchen fein zertheilt, glatt, oben gefurcht, unten 3 ftreifin; Blatticheiden lang, rinnenförmig, geftreift, häutig gerandet, Graun. B̧lütben am Ende Des Stengels und ber

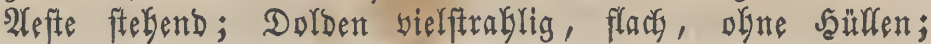


Blütthen grünlidaglb. Blumenblätter zujammenger oldt. Gamen eiförmig, 3rippig, mit băutigem Nantbe.

\section{Slüthe = 3eit uns Dauer.}

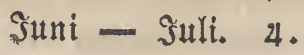

\section{Bortommen.}

In Sübeuropa, in Afien, bejonbers in ber taurifdyen

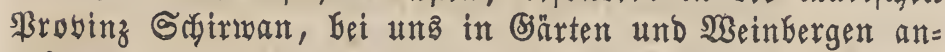
gebaut.

\section{sultur.}

Der Fenefel werlangt einen tiefgegrabenen, lockern, un= frautreinen, fräftigen, befonders mergel= oder falfealtigen Regmboben und ein warmez, etwas feuchtes Rlima. Der $\mathfrak{B} \mathbb{D}=$ ben mú mit $3-4$ ₹rurchen bearbeitet und gleidy bei ber erften $\widetilde{F} u r c t$ biel berfaulter Dünger intergebradgt werben. Man Gaut Den Fencfel in eignen \$lantagen, ba er im 3 ten bis 4ten Jahre erft recht ergiefig ift, läst ifg auf $\mathfrak{B o r}=$ frürefte, bie Den Boben nicht erfedöpfen, folgen, und Gaut auf ifn, Da er ben Boden fehr aubmergelt, nur noch orüchte, bie noch mit magerem Boben borlieb nelymen.

Man fäet ben zrenchel entmeder gleidy an Drt und Stelle

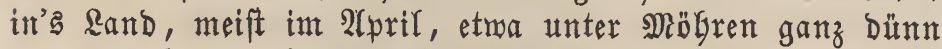
aus und bringt ikn nur flach unter, ober beffer, man fäet

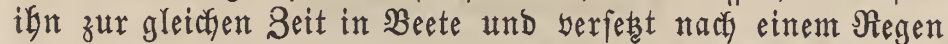
bie 3 - 4 3olf boken jungen Pflanzen in $1 \frac{1}{2}$ Fur yon

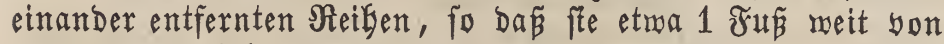
einander zut ftelyen fommen. - Die Frenchelernte fält in ben Auguft und September, und ba aucf Der Fendel ungleich reift, fo nimmt man nach und nach bie reifen Samendolden ab, und ber Fenchel fält gerne atta. Mian trodfnet ben Fendhel wie Den 2 ntiz auf luftigen Boben ober in ber Sonne, und reinigt ifn yor bent Gebrattche gegörig.

Der Errtrag Des Fenchels im erften Jabre itt gering, fteigert fich jeboch mit Den folgenden Sagren.

(sigenfdaften, গ⿰uten, 2 nwenoung.

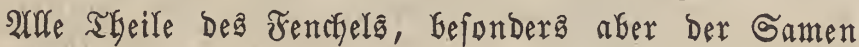

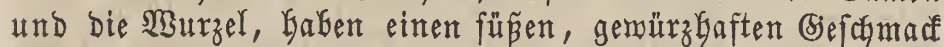
und einen ftarfen, angenebmen (5)eruch.

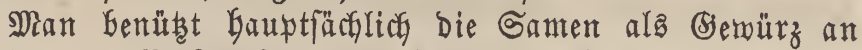
Speifen und Baftwerfen, bie Galbreifen Samendolden ober Glübenden Dolden zum sinmachen Der Siurfen, Die jungen Sieinte und jungen $\mathfrak{W u r z e l n ~ a l s ~ S a l n t ~ u n d ~ B e m u ̈ j e , ~ b i e ~ f l e i n ~}$ zerfodnittenen und eingemadyten Blätter als Beifac eingejal= zener Fif che, audf färben bie Blätter gebörig zubereitetez Tuch gelb. - Die Blüthen werben ftarf yon ben Bienen bejucht.

Man Gat einige Warietäten Dę̧ ซenchels:

1. Stalienifder fencher.

Foeniculum vulgare italicum.

Foeniculum dulce.

Bolognefer Fenchel, Beronefer Fenchel, füber Fendul.

Blätter baben mit ber nächitfolgenden 2 (rt eine gleiche Geftalt, aber-bie Blättçen fitnd viel länger, auch bie weípen Sanen find länger und etras zugefpitst.

2. De t $t$ 出er Fenct.

Foeniculum vulgare germanicum.

Nit zerftreuten Blättern, woyon bie fleineren $B$ lättodyen fürzer find und fitch mit vielen Gpiten endigen. Gamen furz.

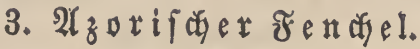 \\ Foeniculum azoricum.}

Süfer Bmergfentelel.

Samen gelblich und trumm gebogen. Stengel furz, breit, zartfeifohig, 9 3oll goch, und weldye, in ber Erbe gebleicht, man Speifen beimengt ober mit Efifg und \$feffer and Miebl zu Galat eimmadyt.

\section{Anethum. I.}

Syfteme: Pentandria, Digynia. L. Scadiophyta. Neck.

Umbellatae. L.

Umbelliferae. Juss.

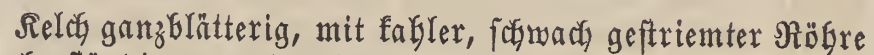
unb oberftändigem, undeuttlichem Gaum. Bluntenfrone 5blät= terig, abfallenb. Blumenblätter gleich, runblich, unaubge= ranbet, eingerollt, mit beinalye 4erfiger Spike. Staubgefä 5, ben Blumenblättern eingefügt. Staubfäben fabenförmig. Staubbeutel runblich, 2fächerig, eimmärta gefelgrt. Stem= pel 1. Frutiotfnoten unterftänbig, mit einem wlatten, ant Rande geferbten Griffelpolfter gefrönt, 2 fächerig. Eriffel 2, furz. Narbe ftumpf. Spaltfrudgt eiförmig, zufammengebrüdt, gerandet. Theilfrüç̧te biçt, 5ftriemig, nicht flaffend am Sande. Samen umgefelgrt, eimeiphaltig.

\section{Anethum graveolens, L.}

Anethum minus. Gouan.

Ferula graveolens. Spr.

Pastinaca Anethum. Spr.

Pastinaca graveolens. Bernh.

Selinum Anethum. Roth.

Difl, gemeiner Difl, Diffamen.

Common Dill. (ettgl.)

\section{2lvten = Sharater.}

SBurzel fpindelfürmig. Stengel $2-3$ Fú hoc und bäker, aufrecht, äftig, glatt, fabl, geftreift. Blătter 3 fach gefedert; Blättchen felgr fein, beinahe Gaarförmig getbeilt;

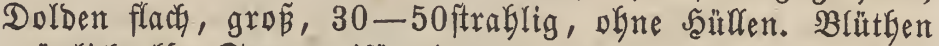
grünliçgelb. Samen eiförmig, plattgebrincft, Gräunliç, ant sande bäutig.

\section{Juni $-\mathfrak{s u l i .} \odot$.}

\section{Błüthe $=$ Zeit und $\mathfrak{D a u t e}$.}

\section{3̧oremtent.}

Sildeuropa, Spanien, Sortugal, Sonfantinopel, bei uns in Giärten und Feldern angebaut, Gie und ba auch ver= mildert.

\section{Eigenidbaften, গuten, 2 (nwendung.}

Die ganze \$rlanze, zumal ber Samen, bat einen eigen= thämrticyen, burchbringenden, faft unangenelgm gemürzhaften, etraa betäubenden Gieruch und Seformarf, und man gebraudst

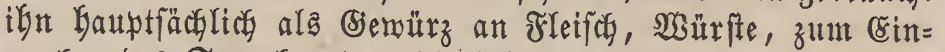
machen bes Gauterfrautes ; bie BYätter mit ben bünnen Sten= geln zum (sinmachen Der Gürfen; die zeridunttenen Blătter ftreut man auf Sauerfraut. 


\section{Pimpinella, L. \\ Sieğe Seite 139.}

\section{Pimpinella Anisum. L.}

Anisum officinale. Moench.

Anisum vulgare. Gaert.

Apium Anisum. Targ. Tozz.

Sison Anisum. Spr.

Tragium Anisum. Link.

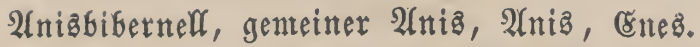

Anis, Anis commun des boutiques. (fratz.)

Anise. (engl.)

\section{$\mathfrak{A r t e n}=\mathbb{C}$ Garater.}

Wurzel fpindelförmig, faferig, meís. Stengel 1 Fuz Gocy und böber, aufredst, äftig, geftreift, bohr. Wuarzel= blätter runblich, 3fady eingeidynttten, bie Stengelglätter fieber= förutig getbeilt. Dolben bielftrablig, am Ende Der Stengel und 3rweige ftebend. Blüthen meí̈gelbliç. Blumenblättechen berzföornig, einuärta gebogen. Gamen flein, rundich, ge= ftreift, befarart, grüngelb.

গuli. $\odot$.

\section{Slütbe $=3$ eit und Dauer.}

\section{Sorkommen.}

fultibirt.

2legypten, Surien, bei una in Gäarten und Jelbern

\section{Sultur.}

Der $\mathfrak{A}$ inis will einen fräftigen, gebüngten, tief gegra= benen, locfern, bom Unfraute gereinigten, etwas feuchten, aber warmen $\mathfrak{B}$ oben, eine gejofühte, fonnige Rage und ein marmez, mäpig feuchtez, nicht aber zu feuchtes ober neb=

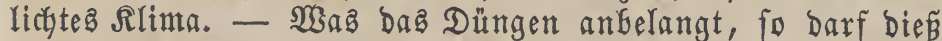
mur mit geförig zergangenem Compoft geforefen.

MRan fann ben 2 tris auf alle Früchte, die ben Boben nicht ausfaugen, Gauen, fo befonders nach Silee, und auf ifnt fann man, da er biele Bobenfräfte confumirt, auch nur Früchte folgen laffen, bie feines Gefonderz fräftigen $\mathfrak{B}$ doen

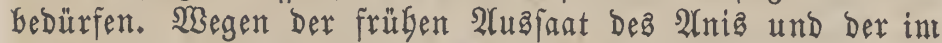
Jrübjabr noch borbandenen Winterfeuchtigfeit deg Bodena ift ea angemeffener, ben Boben fofon im beerbfte zur Sarat

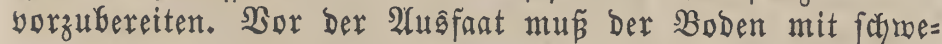
ren Eggen aufgelorfert merber. Sur 2Hąaat nimmt man nur gefunden und mefrjärigen Samen, welchen man feinez mur langfamen Seimens wegen finon Ende März poer Mitte

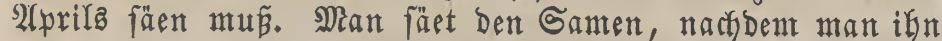
zuvor einige Tage in Waffer eingenveicft bat, ziemlich bünn, entweber Greitwürfig, ober beffer, in ßeifen, eggt iGn tief genug unter und üferfährt barauf ben Boben mit ber Walze.

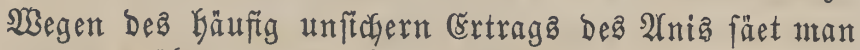
bäufig auch Miöhren unter ifn. Der 2(nis reift gemöhnlich im $\mathfrak{A}$ uguft, meift audi) ungleidy; Der Samen roird Dann

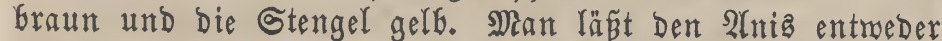
auf Dem Felde gebunden aufgeftellt Doer zu אূauje aufgebängt troffnen und brifdyt ifn bann bei troffener Witterung ober, weil er oft foctwer ausfäll, mit eintretendem orofte; ntan reinigt nun Den autgebrof(t)enen 2(niz Duref's Werfen und Giefen und läs̆t ign auf trofenen $B$ öben, bünn aufgefchüt= tet, yollends ausిtrodinen, inbem man ifn einigemal um= werndet.

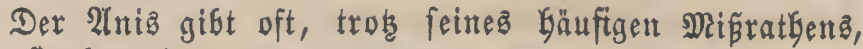
pinten ftarfen שrtrag.

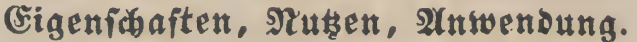

Der 2Tnis ift ein fefr beliebtes Bemürz, man gebraucht ifłn zum Einmadyen von Früchten, zu Den verfodiebenartig= ften Bactwerfen, zu Schiffz̧zoiebarf, Den fogenannten Sprin=

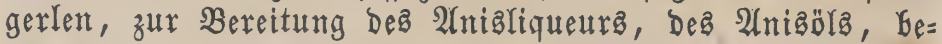

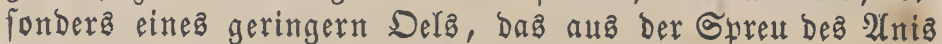
gewontuen und it einigen Begenden zum Brenten bentht mird. Das Struh ift ein gutea Biebfutter, Gefonders für

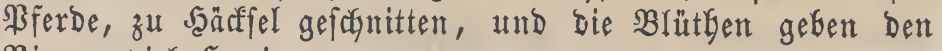
Bienen biel $\mathfrak{g}$ onig.

Nigella. L.

Erobatos, DeC.

Nigellaria. DeC.

Nigellastrum. Moench.

Snftente: Multisiliquae. L.

Polyandria, Pentagynia. L.

Polyantherae. Roy.

Ranunculaceae. Juss.

Synathrophyta. Neck.

Selch 5blätterig, abfallend, Die Reldbblätter genagelt, eirund, abfebend. Blumenfrome 5-10blätterig. Blumen= Glätter langgenagelt, 2lippig - 2theilig. Staubgefä záe zahl= reich, dem Blumenboden cingefügt. Staubfäben pfriemen= förmig. Staubbeutel eifürnig, ftachelfpib̧ig, 2fächerig. Stem= pel $5-10$, jelten weniger, bis 3 oder 2 , itsend. Die Frucht= fnoten an ber Bafts mit einander verwachfen, DDer bis zur Spite in einen verfochmolzen, jeder derjelben 1 fäederig. Boriffel pfriemenförmig, eefig, fahraubenförmig, gerabe, ausెmärta ge= frümmt. Narbe auf Der innern Seite Des Bsiffelą Der \&änge nach liegend. Sapfeln 2-12, yon Den Briffeln gefrönt, 1 fächerig, vielfantig. Santen 3ecfig, runzelig ober beförnt, ober zufammengebrüft แnd mit einem bäutigen frlügel um= zogen.

\section{Nigella sativa. I.}

\section{$\beta$. Nigella indica. Roxb.}

3ahmer Schwarzfümutel, gemeine Nigelle, zahme Nigelle, Narbenfame.

Nigelle des jardins, Poirorette toute epice. (frnttz.)

Small garden Fennel Flower. (entrl.)

\section{Arrten = (5)arafter}

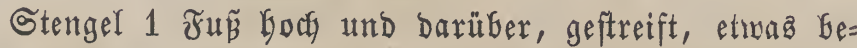
baart. Blätter 3 fach geftebert; Blättchen linienfürmig, fein=

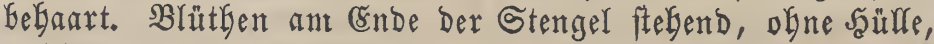

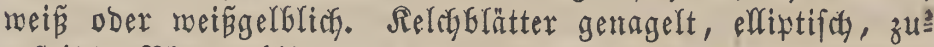
gefpięt; Blumenflätter 8 , genagelt, an Der $\mathfrak{B a f t z}$ nit einer Foniggrube. Staubfäben bläulicy. Staubbeutel grür. Sap= feln runblich, meidyftachelig, vielfamig. Samen flein, an beiben Endon zutgefpitht, exfig und forfwarz.

\section{Blütfoe $=$ Zeit und $\mathfrak{D a u e r}$.}




\section{\$ortommen.}

Sübeuropa, Aegypten, bei ung in Feldern und \&ärten fultibirt unb bäufig auch berwilbert.

(Eigenfaften, stuten, A(nwenoung.

Der Ganten mird in megreren Bsegenden ftatt bes Sînt= mels zur Speife bentüt; er riecht, befonders ment er zer=

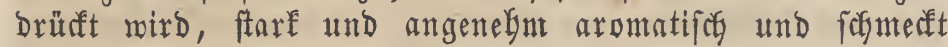
focharf aromatifich.

\section{Nilize.}

Unter ben silzen mirb bauptjädglich nur eine $\mathfrak{A}$ rt $\mathfrak{a n}=$ gebaut, bie übrigen werben größtentbeils im zreien einge= fantmelt und serfpeizt, ftnd aber eime fonwer verbaulicye Ruft.

Da unter biefer $2(b+b e i f u n g$ fith viele giftige Schnämme

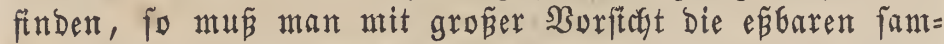
meln. Um feimer Sadje gewiffer zu fein, Daß̈ man feine

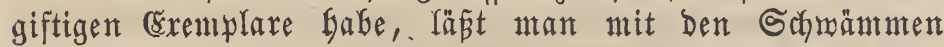
1-2 3roiebel mitfochen; Gleiben biefe weis, fo Gat ez feine (Sefald, werben fie aber fobmarz, fo ftnd bie Schmäntme giftig.

\section{Agaricus. L.}

Amanita. Per's. Adans.

Gelona. Adans. Lam. Juss. Dill.

Coprinus. Pers.

Kulma Adans.

Fungarius. Adans.

Lactarius. Pers.

Petrona. Adans,

Snfteme: Cryptogamia, Fungi. L.

Fungi. Juss.

Hymenomycetes, Pileati. Fries.

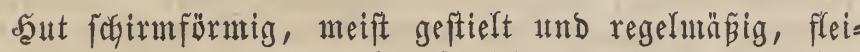

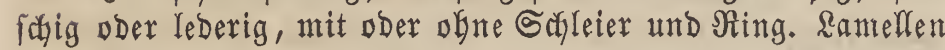
ftrablig, einfacts, meiftens mit fürzeren vermifcht, vermelfend ober zerfließ̧end, wenig mit bent saute berwactien, mit einer Schlauchichicft überzogen. Sporen geftielt, fugelig, elliptifad, edfig, glatt ober warzig, einen weichen Sern einfchließ̧end.

Agaricus campestris. L.

$$
\begin{array}{cl}
\text { Agaricus } & \text { edulis. Bull. } \\
\text { - } & \text { alutarius. Pers. } \\
\text { - } & \text { Pratella. Fl. Wett. } \\
\text { - } & \text { arvensis. Schaeff. } \\
\text { - } & \text { pratensis. Schaeff. } \\
\text { - } & \text { mylvaticus. Schaeff. } \\
\text { - } & \text { modestus. Batsch. } \\
\text { pollitus. Batsch. }
\end{array}
$$

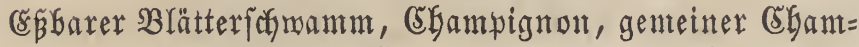

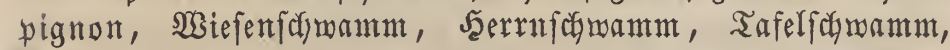

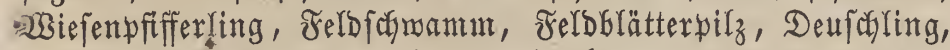
Trautichling, Șeiberling, Erogürtel, ङ̌Gegürtel, Brachmännlein.

Agaric comestible. (fratz.)

Mushroom, True Champignon. (engl.)

\section{Alrten = Sharater.}

Strunt 1-2 8oll boch, gegen $1 / 2$ 3oll ftarf, unten bünner, gerabe, bicht, etmas filzig, mit unvolftändigem

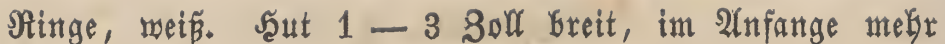
runb, fugelig, gejefloffen, oben glatt, fpäter gemölbt und zuletet nebr flach, genabelt, fochuppig ober etraa feidenartig,

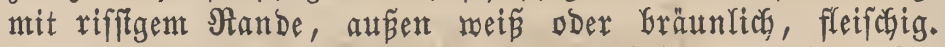
Die Ramellen fünd frei und gebrängt ftelend, aufgetriebent

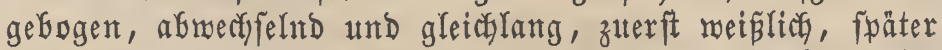
rofenfarbig ober fleifaroth, Dunfelroth und mebr Gerborfte= bend und zuletet bräunlich biz fohmarz und zufamutenge= f(d)

\section{Hogut - September. \\ Fungeit. \\ \$ortommen.}

2huf feutstent fetten 2 siejen, Feldern, SBeiden, Gejombers Bferbe = und Schafmeiden, in lichten Şäldern, zunal Esidjen= mäldern, Bsărten, Mrift= und alten Spargelbeeten, überbaupt gerne, wo Miift untergraben ift; in (Särten fünftlic erzeugt und bermefrt.

\section{Nultux.}

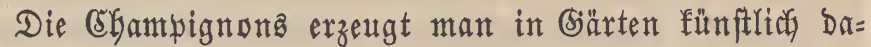
Durch, Dafi man Durch Bermifachng yon mefreren Dünger=

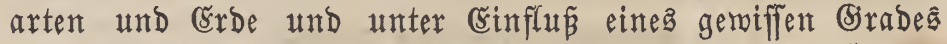
yon Şärme bie Brut, bas fogenannte Schmammmeís ober bie Brutfteine erziegt. - $\mathfrak{H m}$ Sdywammmei werfertigt man fich am beften im Nä̈rz, Mai, aud zur ?ototh int September, an einem trofenen, warnen, aber etwaz Dunfeln Drt, mit einer Temperatur yon $6-8^{0}$ গieaunur, ein Beet yon $\Re$ of́fugeln, bie man, bamit ften bie Maffe nicht zu febr erfibe, auf Das $\mathfrak{B}_{e}$ t bringt, bis fite eine Derfe yon $6-830 \mathfrak{l}$ goch Gilden, übericfüttet diefe nit etraa

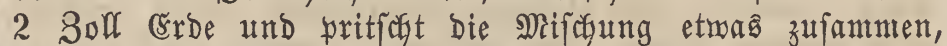
trägt nochmals Dung auf und auf biefen ebenjo wieber Errde, und fest biefes fo lange fort, bis bas Beet fertig ift. Man

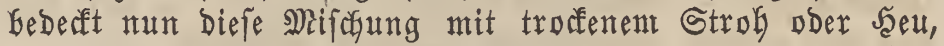
und feeft genau barauf, Dá̧ das Beet immer trodfen gefal=

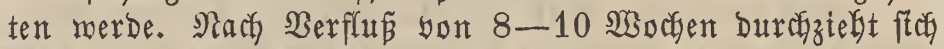

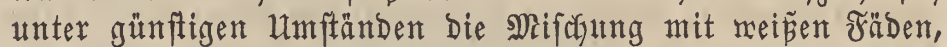
Dem Sajmammmeíf, und man begiefít nun das Beet etwas mit Yaumarment 2 affer. Nach 6-7 20 ochen erfocheinen meift

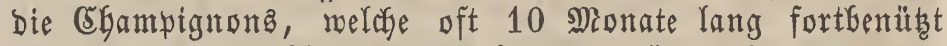
merben fönnet. $\mathfrak{A}$ trdere empfeglen zur Jerborbringung Der Brut eine andere Mififung, wie 1 Theil Pferbe=, 1 Theil Schafnift und 2 Theile Sulbmift, laffen foldye troden mer= Den und berfleinern fte faft biz zu Sulyer. Noch Andere Gringen in Beete 1 ชus

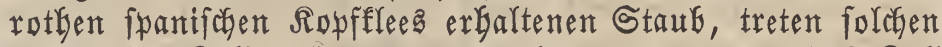
bis auf 8 3oll zufammen und legen Darauf nody 4 3oll goch Crrbe. - Soll fith bie Brut in Bälde und in gefäri= gem Srabe zeigen, fo hat bie Mrifolung immer eine Tent= beratur yon $12-14^{0}$ R. nöthig; aber aud unter biefen Utmftänden mus man oft Iange warten, bis fité eine folche Gildet. - Da man bäufig feine Schnammbrut Gaben fann, fo bereitet man ftch bie $\mathfrak{B}$ rutfteine. Man fnetet 1 Theil ftrof $=$

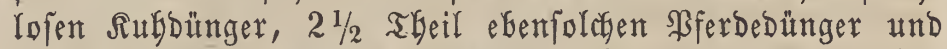
$1 / 2$ Theil Erobe, ober nady 2 trbern, 1 Theil Schafmift, 1 Theil

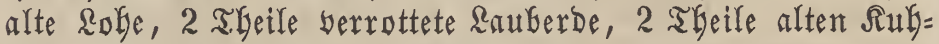
und 3 Theile Sferbemift, tücftig Durcfeinander und formt aus biefer Wiaffe fleine Barafteine; in biefe macht nan 1 3olf

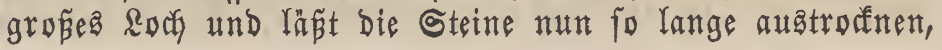


Gis fie bolffumuten erGärtet find, ba in benfelfen noch bor= Gandene Feurgtigfeit Der Brutbildung entgegentreten mürbe; ebenio bat man fich beim Trof́nen ber Brutfeine zu hüten,

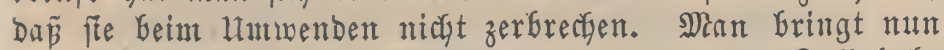
an eimeut vor Regen gefdübten Drt eine etwa 6 3oll bohe Rnge von langem, friffyem und warmem Pferbebung, legt auf biefe, nie aber bicht, un ber Wärme und bem Dampfe Des Dunges megr 3ugang zu vericfaffen, bie Brutiteitue, uachbem man ifre Röcher ganz mit Brut ausgefüllt Lat, und bebefft fie nun ringasum mit 6 soll bohem marmem Sferbe= mift. Bortheilfaft ift es, nach 14 Tagen noch eine neue 3 3oll bute Rage frifthen Prerbedüngers auf bie alten zu

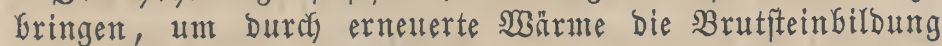
zu befwleunigen. Sind bie Brutfteine gänzlich von ber Brut Durchbrungen, fo berwakrt man fie an trocfenen Drten, in einem troffenen Reller ober warmen Binnter auf, wo fte fich, wenn fie nicht ber Sonne aubgefert merben, einige Sabre lang Galten.

Man fann fta bie Chantpignonbrut alt im Freien, wo fie wild madffen, in alten Wiftbeeten zc. verforaffen, wo man fie, wenn nan bie Erobe 2-3 :3oll tief aufgräbt, ars breite Fäben häuftg mit fugelförmigen $\Omega$ örperchen verfeben bemerft. Man gräbt fie im Spätfommer $2-3$ 3olf tief

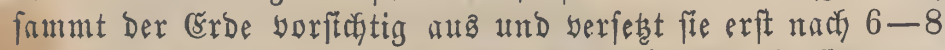
Şochen, oder beffer, fommendes Jrithjahr, damit fie zutor geförig austroctnen fönnen.

Man erziegt bie CGampignons in Räften, Rärben ober in eigenz bazu eingerichteten Miftbeeten. $2 a a z$ daz 区rzieben Der Safmänme in Rärben ober Răften anbelangt, fo bedarf man Deren, um immer Ghampignons haben zu fönnen, 3,

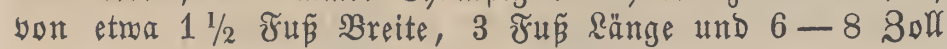
Tiefe, füllt fe nit einer Mifodung yon 1 Theil berfleiner=

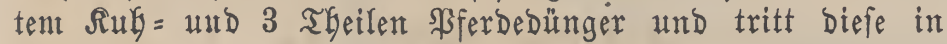
bie Rörbe ein. Nach 2-3 Tagen, menn fted Diefer Dung mefr erwärmt hat, zerbridgt man bie Brutfeine in $3-4$ Stüfe und legt biefe 1 Bolf yon einander entfernt oben bin auf Den Dünger, auf reldyem man fte einige Tage liegen Yäpt, biz Die Brut Der Brutfteine fich Dem Mifte etroa ntit= getfeilt Gat. Sit biefes gefdeben, fo bringt man noch eine Rage won 2 30 Wh friffyen Düngers auf bie Brutfteine und brülưt fie feft an. Nach 14 Tagen gemögnliç trägt man nun eine aage (5rbe $2 \frac{1}{2}$ 3olf Goch auf, welche ebenfalls

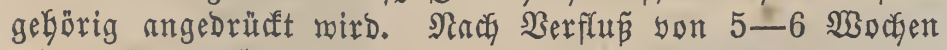
zeigen fich meiftens bie CGyampignonz, und man begiepst fie

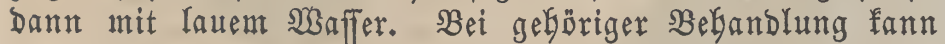
man 2 Monate lang Schmämme gebrauchen. Weitere Mie= thoden find, bie Siorbe ober Säften Gloz mit Strof zu be= leg̉en, Darauf bie Brutfteine und auf biefe (̌rbe zu Gringen,

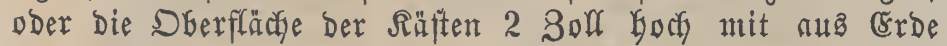
und Bferdebủnger beftehendem Compoft zu belegen. - Wsie oben fogn Gerübrt murbe, zieft man bie Cogampignons aud in Gefondern Miftheeten. Diefe fann man in falten und

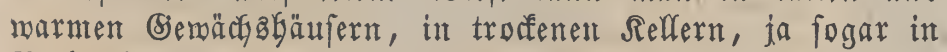

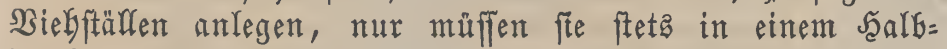
Dunfel gelegent feit. Sn bie meift bachrüfenartig eingeridj= teten Miftbeete bringt naan ganz furzen, gut Durchgearbeite=

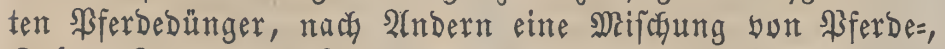
Rub $=$, Schaf= und Siegenmift, bebeaft bie farrägen Seiten 2-3 3olf goch mit Erob und ftefft in biefe, fobald bie gröpte Şiţe borüber ift, in einer Ëntfernung bon $5-6$ Soll

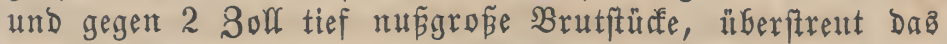
Beet nur leidyt nit Stroh and beipribt ea bie und ba mit lauem Săffer. Sn ein paar Monaten erbält man meift Champignonz. Ueber Den Sinter num man bie Beete forg=

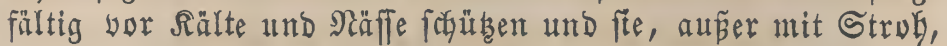
noch ntit Brettern und Pferbedünger bederfen.

(3)anz gut laffen fị bie Schmänme audy in Melonen= beeten ziełen, in weldye man, fobald im zrübjabre die ftärffte Jaibe vorüber, etwa 2 3oll grope Stïlfe Brut am. Nande Des Beetes 1-2 20II tief ftefft. Nachbem bie Melonen ge= erntet find, reinigt man Dab Beet yon Den $\mathfrak{B f f a n z e n t e f t e n , ~ D r u ̈ c f t ~}$ bie "(̌rbe feft au, begiepit fee etwas ftarf mit Der Braufe und beberft das Beet mit శrenftern.

Man nimnt bie Sffampignonz zum Rüchengebranche,

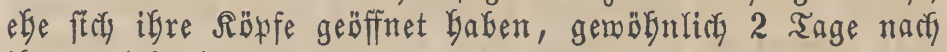
ibrem Errfyeinen.

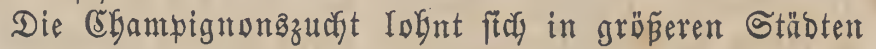
gut, indem foldye immer gut bezalit merben.

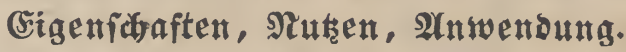

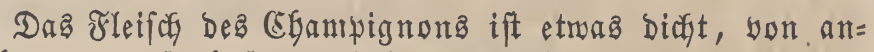

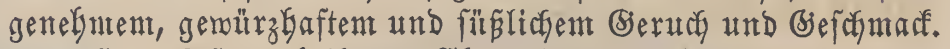

Jaatptbeftandtheil des Cbyampignons ift rungin.

Die Champignons merben bäufig als Delifateffe ver= fpeişt und fend, mäß̄ig genoffen, auch gefund; man gentepst fte gebraten, gebarfen, gebämpft, als Bugeunipe, mit Butter,

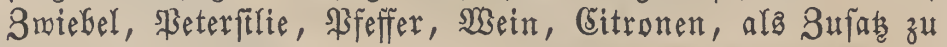

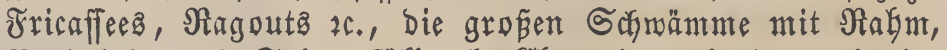
Brobrinde und Salz gefült aIs EGampignonbrod, verfertigt aus ifyen mit Trüffeln, Rfeffer, Nelfen, ßomeranzen dä

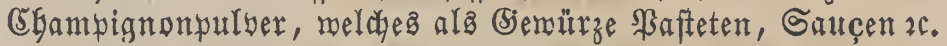
beigefest mird, reifhet fae, um fie aufuberwakren, an zäben an und trodfnet fie, Dder madgt fie mit Effifg, Galz und

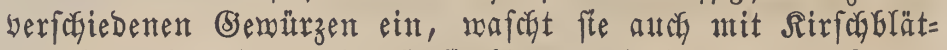

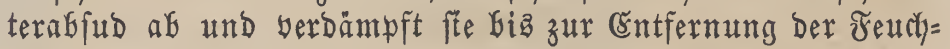

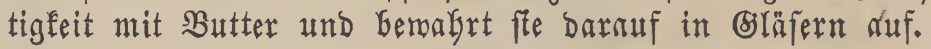

\section{Agaricus deliciosus. L.}

Agaricus Zonarius. Bolt.

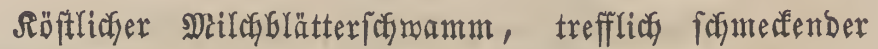

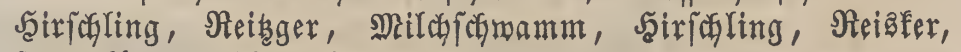

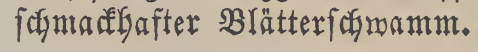

Agaric délicieux. (frantz.)

\section{Arten $=$ (SGaxakter.}

Strunf malzenförmig, grubig, bohl, mit fäleimiger Flüfittgfeit bebecft, Gellziegelroth, bäuftg Dunfelgeflect und meift in Der Erbe ftebend. Feut $2-4$ 3oll breit, in ber Mitte melyr ober mentger vertieft, 2(nfangs rund, glatt, fpäter raug, mit einmärtz gebogenem, ungetheiltem, glattem Fande, flebrig, wachgelb, ziegel= ober aud orange= biz braunroth, mit zaflreichen, Geffern und dunflern, freisför= migen, grünlichen Beichnungen, in Folge Der zerriffenen Sçleimbaut entftanden. Blättcyen gebrängt ftebend, flacd, äftig, berablaufend, gelblich ober ziegelroth.

Auguf - November.

\section{Frungzeit.}




\section{Borkommen.}

Man findet biejen Blätterjafmanm Gejonderz in troféc= nen Nabelgörzern, auf verfterften Nabelbaummurzeln, zmif dyen

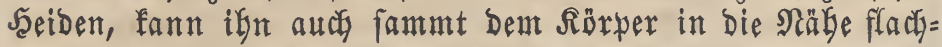
murzelnder Nabelgäume in Börten verpflanzen.

\section{(Sigenfachaften, গtuten,}

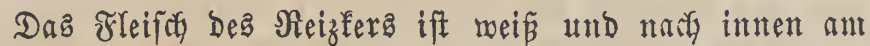
Rambe fafrangelb, und enthält eine etmas fajarfe, beim $2 e r=$

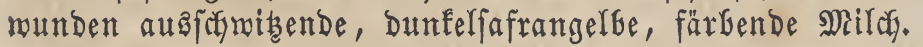

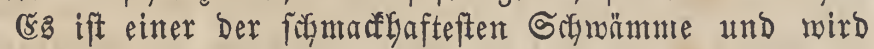
in mancyen Siegenden, wie im Norben, in Deutfelland, be= jombers im Thüringifasen, in Stalien, fonobl alz Reffer= biffen als auch als Roft genoffen. Der Neizfer ift felgr năby= rend, indem er afgefotten viel fefte Bafferte liefert. Man geniest ifn am Gäufigften gefalzen und banu geröftet, ober

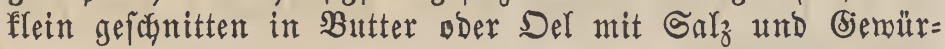

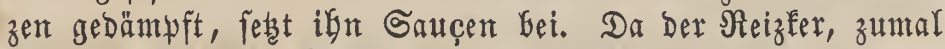
an einem marmen Drte, gerne einen fauren beffrmad $b_{e}=$ fömmt und fault, fo mú er frifangeg genoffen werben.

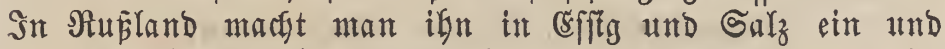

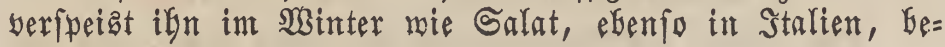
fonders in Benua, in Del.

\section{Agaricus lactifluus. L.}

$$
\begin{array}{cl}
\text { Agaricus } & \text { galarrhoeus. Fries. } \\
\text { - } & \text { subdulcis. Bull. } \\
\text { rubescens. Schaeff. }
\end{array}
$$

Brätling, ßBreitling.

Agaric douceatre. (franz.)

\section{Strten = Charakter.}

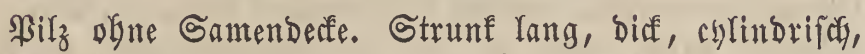

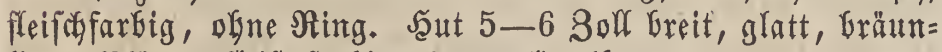
lid). Blätter fleifadfarbig oder goldogelb.

\section{Suli - Septemiber.}

$$
\text { Fungeit. }
$$

\section{3ortommen.}

Sit (ridjen $=$, Buchen $=$ und Birfenmäldern, bejondera bäufig in TGüringen.

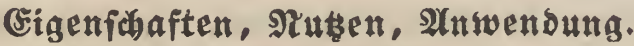

Der Brätling hat einen bein $\mathfrak{B e r l e b e n ~ r e i d y l i c h ~ a u s = ~}$

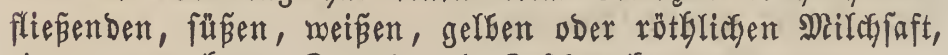
einen angenelgmen Beruch und Befergmar.

Seine bie und da fich fackalid zeigenden ssirfungen, bejonders wenn er in zu groper Menge genoffen roirb, ver= lieren fta zmar meift Durd Die Bubereitung in Der Rüche,

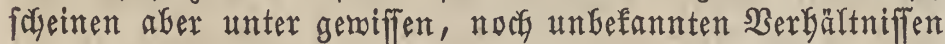
Doch giftige (rigenfdyaften anzutehmen. - Man bereitet fie

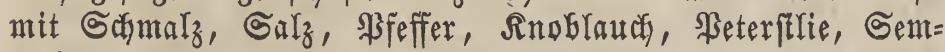
meln 2c. zu.

Man unterfđeibet 3 Barietäten Des Brätlingas:

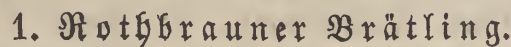

Agaricus lactifluus fulvens. Batsch.

Şeizenbrätling, Grauner Brätling.

Sุut gleich im Ânfang wertieft, gelb biz zimmtbraun,

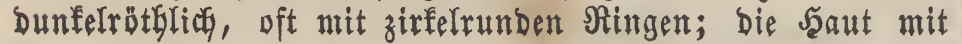

feinent Staube bebeeft, matt. Blätter meizengelb, an ver=

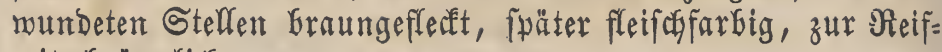
zeit brïunlicf.

Man findet biefe $\mathfrak{B a r i e t a ̈ t ~ y o m ~ S u l i ~ a n , ~ b a u p t f a ̈ c h l i c h ~}$

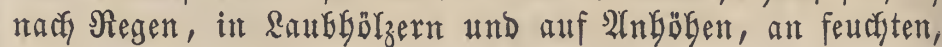
fdrattigen Stelfen.

Der Graune Brätring mirb am Gäufigften benübst, fein छleifdy ift fodmacflaft und zart.

$$
\begin{aligned}
& \text { 2. Sf old } \mathfrak{f} \mathfrak{x} a \mathfrak{t} \mathfrak{i} \mathfrak{i} g \text {. } \\
& \text { Agaricus lactifluus aureus. } \\
& \text { - ruber. Pers. }
\end{aligned}
$$

Strunf biłf. Şut int 2 (nfang fugelig, fafran= bia bunfels rotggelb, oft bräunlichiçwarz geffecft. Die Blätter am Sande forgun goldfarbig.

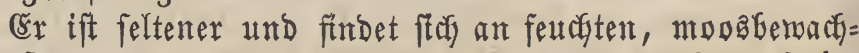
fenen Drten in fobattigen \$uchenwäldern; in troffenen Jabr= gången fef̧lt ex oft ganz.

Sein Fleiffy ift im 2 nnfange weip und mirb nady und

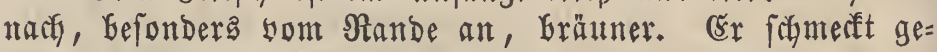
lind pfefferartig, füplias, aber nidyt fo zart als ber borige und folgende, und riecht angenebur.

\section{Silberbiatling. Agaricus lactifluus argenteus.}

WSeí̧er $\mathfrak{B r a ̈ t l i n g , ~ S c a b e r b r a ̈ t l i n g . ~}$

Strunf oft meiß̄lich bereift, in Der Sugend băuftg ganz

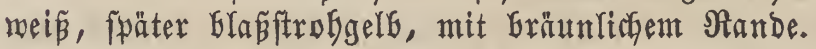

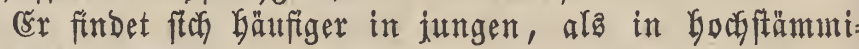
gen Birfen = und Butfenwäldern.

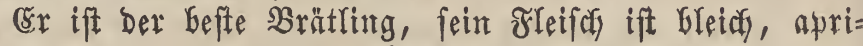
fofenartig, in Der Jugend febr zart und faftig.

\section{Agaricus integer. L.}




35.

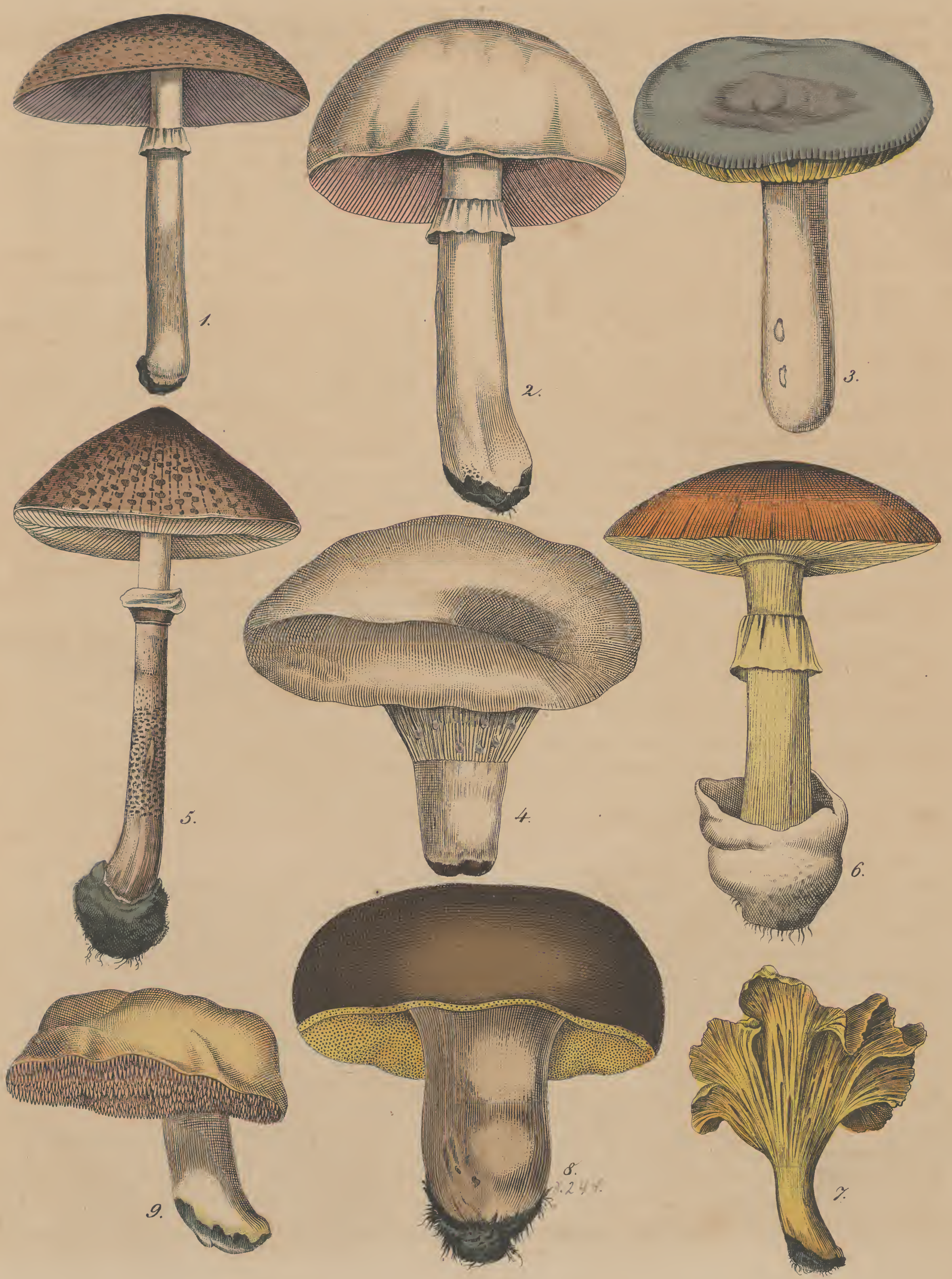



Agaricus pseudometicus. Secr. Agaricus crocinus. Röhl.

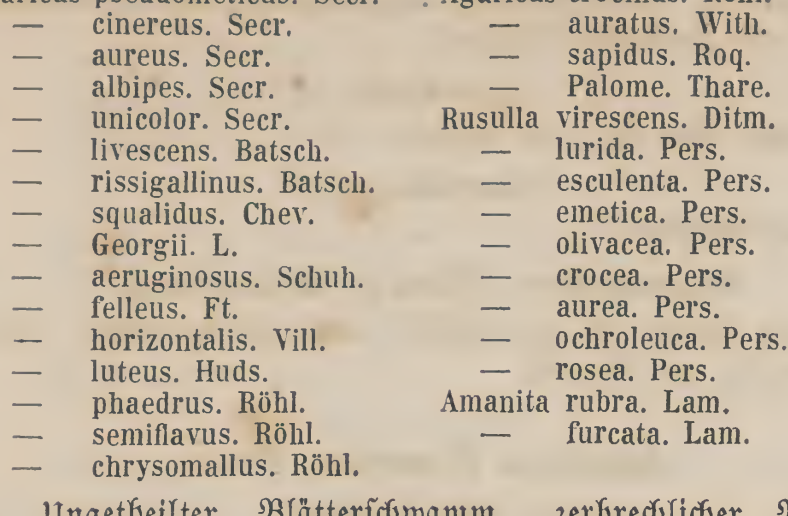

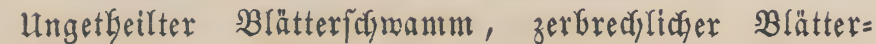
fămamm, (5örgenblätterfđnamm, gloffenförmiger slätter= fămamu, bioletter Blätterfdymanm, blutfarbiger Blätter= fdymamm, Tăubling, Speitüubling, rotber säubling, Sritn= ling, Sirunborf, Bläuling, Rötbling, Errauling, Rrenlling, ફ̇inderling, BBröbling, grüner B̊rätling, Speiteufel, BBrecf:= teufel.

Agaric émétique, Agaric sanguin, Blavet, Vert, Vert-bonnet, Verdette Iraux-cher, Crusagne, Palomet. (franz.)

Fungo posetto, Rossola, Verdone, Lardajola, Lumachino verde. (itar.)

\section{Arten $=$ (E)aralter.}

Strunf 1-3 3olf Gock, 1/2 und Drüber bicf, Dicht, runo, glatt, zumeilen gefrunmmt, unten etwas angefónollen, weiṕ biz gelblich, aura ba und bort rötblich angelaufen. Jat 1-5 3olf im Durameffer, jung runblicy, oben etroas flach, in Der Nitte concay, auf Der Dberfläde oft zerfalif= fen, mit ftarł einnärta gebogenem, gefurchtem, fpäter nulfti= gem, aud etras geftreiftem Rande; er nüancirt in Den verichiedenften Farben, in ber Jugent ift er meiftenz gelb und roth, ober audf grủn und blau angelaufen oder geflect, fpäter ift er braun, roth, rofenfarbig, violett, grủn, grau, reiṕ, und entyält diefe Farben in allen Stufen vernifat. Blätter gemöbnlias einfach, ungetbeilt, faft gleic groj und

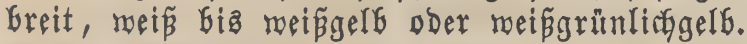

આuguft - Septemiber.

$$
\text { Fungezeit. }
$$

\section{М̧oríontmen.}

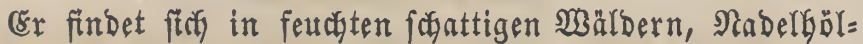
zern, Sebüfaen, im Diovfe und Raub, Gejonders nach mar= mem Regen.

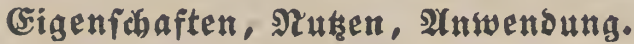

Der (Seruch Des Täubling ift meift unangenebm, und ber Gefdumaf megr ober weniger fararf bis brennend fdarf; er wirft unter gemiffen Itmftänden Grecten= und laxirenerre= gend, forargiftig und fann felbft Den Tod berbeifüren. Das J Fleifd ift in ber Jugend bidit und zart, aber obne Milchfaft, fpäter wirb ez fanmammig, zerbredylicd, trodfen, fault aud gerne bei feuchter Witterung.

Der berdindtigen Eigenfwaften ungeachtet wird biefer Schromm ebenfalls genoffen, und e⿱ follen für bie süche nur foldye exemplare gejammelt werben, bie feinen unange= nehmen (serud und feinen fifarfen sefchmaf beftben. Dan berfpeist Den Tăubling nur jung und ofne Strunf, Entwer, Bénom. ærfanzenfunde und aud ba bürfen fie nur mäpig genoffen werben, da ffe gute Berbauungąfräfte erforbern.

Te nads Dex berfaiebenen Farbe Des Sutes bat man auch Darietäten Dez Tăublingż aufgeftellt, berent einiger wir Gier ermähnen mollen:

\section{1. $\Re$ other $\mathfrak{x} \mathfrak{a} \mathfrak{u} \mathfrak{b} \mathfrak{i} \mathfrak{n} g$.}

Gelg pder roth, ober Geibe Farben gemifat.

Bon vint unterfocibet man mieber:

a) Den Şonigtảubling,

mit füpent Freifuce;

b) Den Frauentăufring,

melder Gauptfädylid yom 2infang Septembers bis mitte Dftobers innerbalb der fogenannten Frauentage gefammelt mird.

\section{2. $\mathfrak{B} \mathfrak{I a} \mathfrak{e} \mathfrak{x} \mathfrak{T} \mathfrak{a} \mathfrak{u} \mathfrak{b} \mathfrak{i} \mathfrak{n} g$.}

Şut bell, weildyen = biz fdyarzblau, mit weipem Strunf und weí̈en ober gelben Blättern.

Auf Malbwiejen, in Bucyentwäldern.

(5r) folf fifutadfafter und roniger bäufitg fifäblid fein als Der rotfe Tăubling.

\section{3. (B) $\mathfrak{x} \mathfrak{u} \mathfrak{n} \in \mathfrak{r} \mathfrak{T} \mathfrak{a} \mathfrak{u} \mathfrak{b} \mathfrak{l} \mathfrak{i n g}$.}

Strunt bäufig rotbgefledt. Saut auf ber Dberffäctye raug, foduppig, grün und grau, oft gelblic, Geller oder Dunfler grüngefledt.

Die Gchmảmmefammlex unterfadeiben nieber:

a) Den $\mathfrak{B}$ udtăubling.

Şut grũn, rotbgeflect. $B$ lätter dicf und fteif.

Findet fich megr in Buchentoaldungen.

b) Der ફ̌eibetäubling.

Sut graulich, etmas foruppig, mit fteifen, zerbrectlicyen,

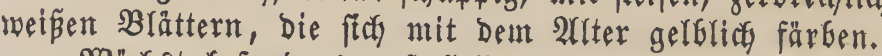

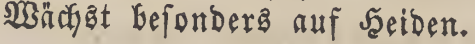
4. Cótronentäubling.
5. (๖)
6. $\mathfrak{R} \triangleright \mathfrak{b l e n t a ̈ u b l i n g . ~}$

\section{Agaricus piperatus, Scop. \\ Agaricus acris. Bull. \\ - amarus. Schaeff. \\ Fungus piperatus. C. Bauh.}

Pfefferblätteridumamm, Sfefferblättervilz, Bfefferfómamm,

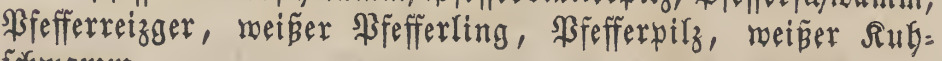
fofmanm.

Agaric poivré. (franz.)

\section{Arten = (5)arater.}

Strunf bia̛, furz, glatt, blaffftrobgelb. Şut glatt, im 2Ynfange erbaben, fpanter trichterförmig, fteif, oben meí̈lich Giz Glápgelb, mit zäber Rlebrigfeit bebecft und naftem Nande, fehr eng ftebenden, äftiggabelfürmigen, Geráblaufen=

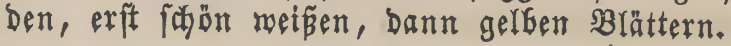

\section{శunozeit.}

Sommer und S.erbft. 
2orkemmen.

In Wăldern, zunal Buchenwäldern, aud Biefweiben. Eigenidaften, Nutuen, Atnwenoung.

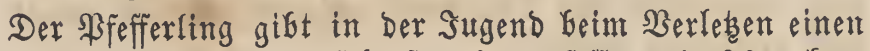
ganz weiken, bitteren und fegr fodarfen, yfefferartig fodmeden= Den Milajaft von ftch, und enthält nach Braconnot: flüch=

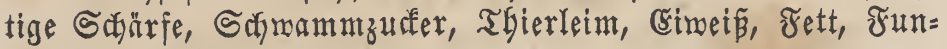
gin und megrere Salze.

Ex mirb ebenfalfs zu Den giftigen \$ilzen gerechnet und wirft brecten = und purgirenerregend, wird aber bennoch in

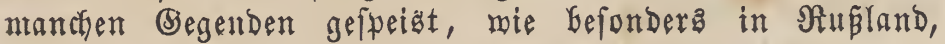
Preusen, wo man fte mit Salz in Făffer einmadyt.

\section{Agaricus mutabilis. Schaeff.}

Agaricus caudicinus. Pers. farmamm.

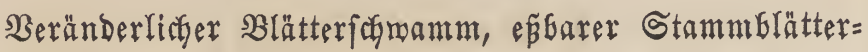

Agaric des troncs. (franz.)

\section{Arten $=$ Sharakter.}

Strunf bünn, fochuppig, rökrig, focharz mit abfälligem,

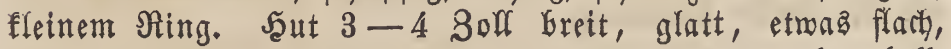
etraa fleifdig, mit einer $\mathfrak{B a r z e}$ im Mittelpunft, oben bell= zimmtbraum. Die sin̈tter didytftegend, etmas berablaufend, $\mathfrak{b l a u}, \mathfrak{r o f t}=$ ober fablfarbig.

Sommet แกd ફ̧erfft.

$$
\text { Fundzeit. }
$$

\section{3orÉmmen.}

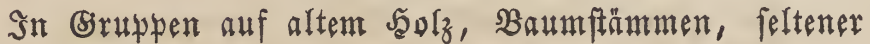
auf Der Crrbe.

\section{(sigenfdaften, Nuten, Anwendung.}

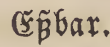

Diejer $\mathfrak{B i l}_{z}$ yaritit:

a) Agaricus caudicinus. Pers.

Agaricus mutabilis. Schaeff.

$$
\begin{aligned}
& \text { - ochroleucus. Vahl. } \\
& \text { - } \quad \text { annularius. Bull. } \\
& \text { - } \quad \text { polymorphus. Baumg. } \\
& \text { xylophilus. Bull. }
\end{aligned}
$$$$
\text { - truncigenus. Schrk. }
$$

Strunf jofuppig.

$$
\begin{aligned}
& \text { B) Agaricus denudatus. } \\
& \text { Agaricus mutabilis. Batsch. } \\
& \text { _ marginatus. Batsch. }
\end{aligned}
$$

Strunf glatt, mit W̧urzelfafern werfeben, oféergelb, roftarbig.

\section{Agaricus Oreades. Scop.}

Agaricus tortilis. DeC.

Bebrebter Blätterichmamm, Dreadenblätterichmamm, Nel= fentlätterpilz, Şerbftmouceron.

Agaric faux-mousseron. (frattz.)

2(rten $=$ ÇGarater.

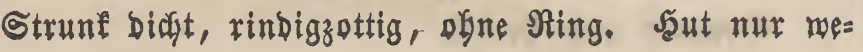

nig genabelt, zäbe, fleirchig, blapgelfroth, mit abfekenden, fablen und trurfenen $B$ lättern.

\section{Fundzett.}

Bon Mai bisz zunt Winter.

2U氏 Weiben.

\section{Bortemmen.}

Origenfahafen, গtusen, Antwenoung.

Das zleifon ift gemürzhaft und woblichmedend, bient als bemintz an Suppen.

\section{Agaricus Prunulus, Pers.}

$$
\begin{gathered}
\text { Agaricus albellus. Schaeff. } \\
\text { - } \text { Mouceron. Bull. } \\
\text { - } \quad \text { pallidus. Sowerb. }
\end{gathered}
$$

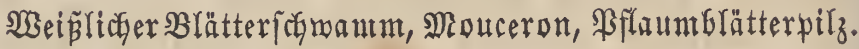
Agaric mousseron. (franz.)

\section{Alrten = Eharakter.}

Strunt biff, bidyt, an ber Bâtż zottig, gegen ben Şut Gin fth augbreitend. Saut beinafe flach, fahl, glatt, fleifethig, meís, mit lange Gerablaufenden, nach Ginten zugefpibten, etwas gebrängt febenden, exft meipen, fpäter fleifdrothen Blättern.

\section{Nom Fruffiatr bis zum \\ Jungzeit.}

\$ortommen.

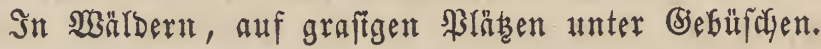

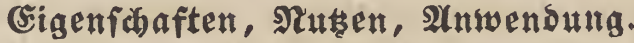

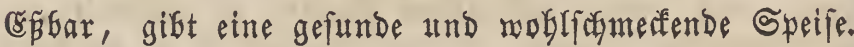

\section{Agaricus procerus. Scop.}

$$
\begin{gathered}
\text { Agaricus squamosus. Vitt. } \\
\text { - } \quad \text { colubrinus. Bull. } \\
\text { - } \text { antiquatus. Batsch. }
\end{gathered}
$$

Rangftieliger Blätterfadmamm, Sarajolfdymamm, Gober Blätterpilz.

Agaric élevé. (frantz.)

\section{Arten = çGarater.}

Strunf hoch, walzenförmig, Gobl, etroas faduplg, an Der Baptz fnollig, mit berweglichem stinge. Jaut genabelt, faguppig, braun, am Rande meisfaferig, mit entfernt fetefen= Den Blättern.

\section{Funozeit.}

Bom Sommer biz zum Winter.

\section{\$orkommen.}

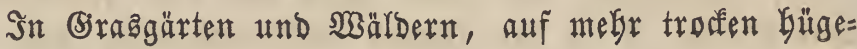
Yigen Wiefen.

\section{(Sigenidaften, Nuten, Anuendung.}

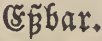

Man untericheidet eine Varietät:

a) Agaricus extinctorius. L., welcher ber Ring mangelt. 


\section{Agaricus ovoideus. DeC.}

Agaricus ovoideus albus. Bull.

Eiförmiger $\Re$ lätterfămamm.

Agaric oronge blanche. (Finnz.)

\section{Arten = Çarafter.}

Strunf biaf, bidat, aupen zottig, mit loderent $23 u l f t$.

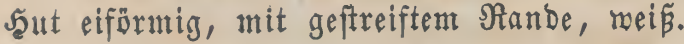

3u Eัnbe deตె Sommers.

\section{Fundzeit.}

\section{Szortemmen.}

Sie und ba in Deutfdland, ber Saymeiz, in Frant= reich, in Wălbern und Bebüfdren.

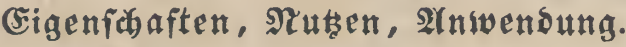

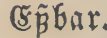

\section{Agaricus bombycinus. Schaeff.}

Agaricus leiocephalus. DeC.

Agaricus incarnatus. Batsch.

Amanita calyptrata. Lam.

Amanita denudata. Schrad.

Amanita incarnata. Pers.

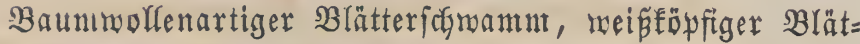
terfarramu, roolliger Blätterpily.

Agaric incarnat. (fintz.)

\section{arten = (5harafter.}

Strunf bidat, gefrummt, nady oben etwas yerbünnt, mit fdylaffem weitem Wulfte. Sut etwas genabelt, feiben=

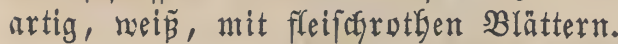

Serfit.

$$
\text { Funogeit. }
$$

\section{3orfommen.}

An Baumftämmen, yorzügliç am 2 Gorn.

cigenfidaften, গtutzen, Anwenoung.

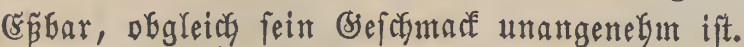

\section{Agaricus caesareus. Schaeff.}
Agaricus aurantiacus. Bull.
Agaricus speciosus. Gouan.
Amanita aurantiaca. Pers.
Amanita aurantia. Pers.
Amanita caesarea. Pers.

Saiferblättexpilz, Raiferforronmt, golbfarbiger Blätter= pilz, Eierfichamm, 5errnf chamm.

Agaric oronge. (franz.)

\section{Arten = Sharater.}

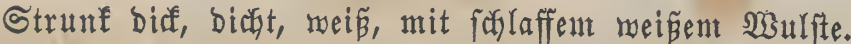
Şut im 2anfange Galbfugelförmig, fpäter genabelt, pomeran= zenfarbig, urit geftreiftem Rande und gelben Blättern.

Somnter und Sertft.

\section{Junozeit.}

\section{0rfommen.} reictis.

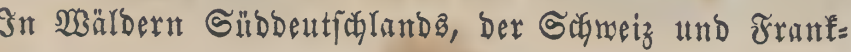

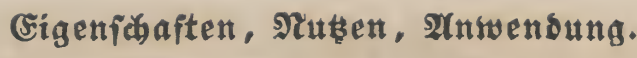

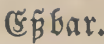

\section{Cantharellus. Adans.}

Merulius. Pers. Hall. Nees.

Snfteme: Cryptogamia, Fungi. L.

Fungi. Juss.

Hymenomycetes, Pileati. Fries.

Silz fleifodig ober bäutig, mit ober ohne Stiel, meift regelmäbig, okne Schleier. Lamellen gefaltet, fleifohig, ftrah= Yig, etwaz äftig, mit ftumpfer Scyneibe, itberall mit 4-6= fporigen Sdyläudyen bebect.

\section{Cantharellus cibarius. Fries.}

\author{
Agaricus Cantharellus. L. \\ Agaricus luteolus. Batsch. \\ Agaricus pseudounctuosus. Batsch. \\ Merulius Cantharellus. Pers. \\ Merulius cibarius. Pers
}

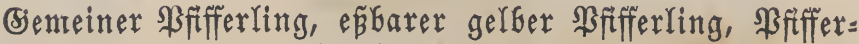

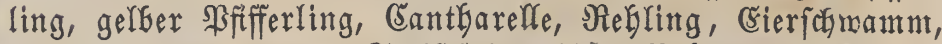

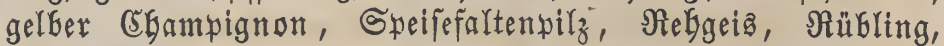

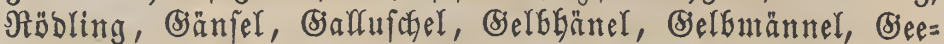
ricten, Beelögrtyen, Balögrchen, sfffer.

Cantharelle comestible. (fratz.)

\section{Alrten = (5łaraeter.}

Der $\Re i F_{z}$ ift mittelgró und burefans bottergelf. Strunf

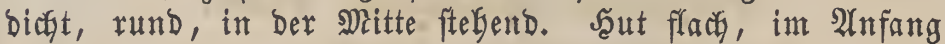
gewollst, nachber Gorizontal, und zulest eingebrübt, glatt, fleifchig, am Nande mellenförmig gelaupt, und hat ftatt ben Blättern Gervortretende, zur Sä̆lfte Gerablaufende 2ldern ober Falten.

Sommer und Şerbft.

$$
\mathfrak{F} \mathfrak{u n g} \mathfrak{z} \text { eit. }
$$

\section{Bortemmen.}

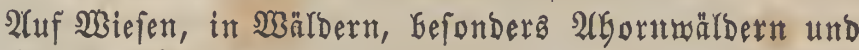
Nabelgölzern, bäufig und in Saaufen.

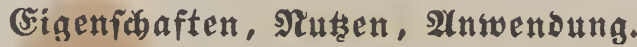

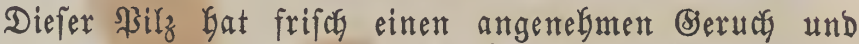

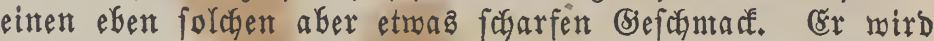
unter bie Delicaten Sdjränmme gezäglt, und flein zerfodnitten mit Salz, Ejftg, Znwiebeln, Butter gefdymort, genoffen. Gefannt.

(biftige Wirfungen find bon biefent Affferling nidut

\section{Polyporus, Fries.}

\section{Agaricon. Adans.}

Favolus. Beauv.

Microporus. Beauv.

Poria. Adans.

Syfteme: Cryptogamia, Fungi. L.

Fungi. Juss.

Hymenomycetes, Pileati. Fries.

Rilfe won berfatedener meift fefter Sufftanz, ftielloz $31 *$ 


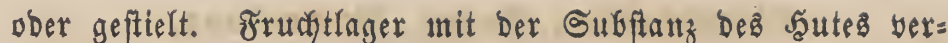
wachjen, rundliche söcher bildento, -in beren innerer flathe bie 4fporigen Baftbien fteken.

\section{Polyporus frondosus. Fries.}

Boletus frondosus. FI. Dan.

Boletus ramosissimus. Schaeff.

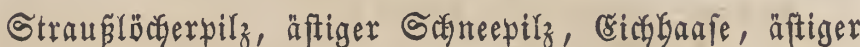
Röberifhanun, Gelaubter Rötherpil verling.

Polypore en bouquet. (fitatt.)

\section{Arten = Ebarater.}

Bilz feldr äftig, Durd bas Bujammenflięent ber Strunfe ziegeldachförmig zufammengebrängt, oft $1-1 \frac{1}{2}$ ₹ú boch und $1 \frac{1}{2}$ Fus breit, und $20-50$ \$fund fogwer. Strünfe feitenftändig, oft zujammengeroadgen, meişlich. Şüte meift nur Galb runzelig-gelappt, graubräunlich, mit feinen weís= lichen Boren.

\section{Áuguft - Dltober. \\ Fungzeit. \\ Bortommen.}

2lm ซ̌sue altex (ritren.

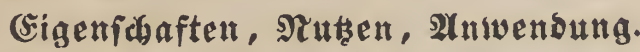

Diefer $\Re_{i l}$ wirb in manchen Bjegenden byäuftg genoffen,

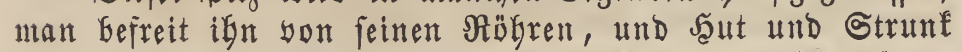

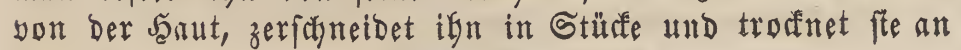
zäben gereigt.

\section{Polyporus squamosus, Fries. \\ Boletus juglandis. Schaeff \\ Boletus platyporus. Pers. \\ Boletus squamosus. Huds.}

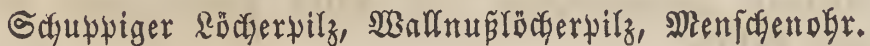
Polypore du noyer. (franz.)

\section{Arten= (Sharafter.}

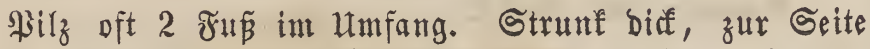
ftebend. Jaut borizontal ftebend, Greit, regelmäpig rund ober unregelmäñig, leberartig ober offergelb, braungelb geqdappt,

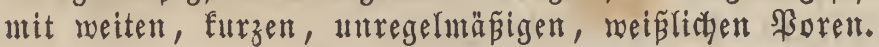

Sommer bis Jaerbft.

$$
\text { Funbzeit. }
$$

\section{S3ortommen.}

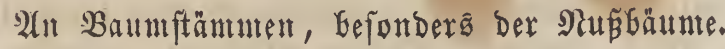

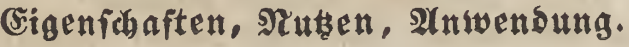

Der Schmamm verbreitet bei Der Fäulní̈ einen ftin=

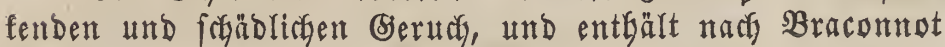
neben ben gerwöhnlichen Beftandtheilen der Schwämnte Gaupt=

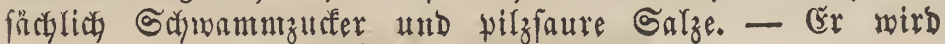
gegeffen.

\footnotetext{
Boletus. Dill.

Hypodrys. Pers.

Suillus. Mich.

Snfteme: Cryptogamia, Fungi. L.

Fungi. Juss.

Hymenomycetes, Pileati. Fries.
}

Bilz yon ঘeriffiebenter. Forn, meift regelmäsig, fleifdoig und ifrwammig, mit centralem Stiel. Şut ftegt wagrecht.

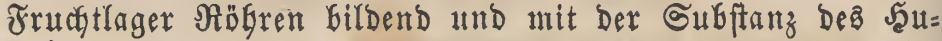

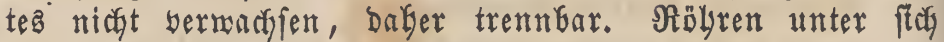
leidgt verbunden und 4 fporige Baftbien enthaltent.

\section{Boletus bovinus. L.}

Boletus mitis. Pers.

Boletus circinans. Alb. et Schw.

Boletus gregarius. Fl. Dan.

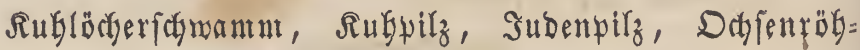
renpily.

\section{Arten = Charafter.}

Strunf in Der Mitte fteb̧end, dünn, glatt, rotbgelb. Jaut gepolftert, oben glatt, etwas flebrig, gelblidybraun bis rotgbraun. Soren zufammengefest, iun 2(nfang frymutgig= gelb, bann rotgbraun.

2)uguft - Dftober.

$$
\text { Fungeit. }
$$

BorÉntmen.

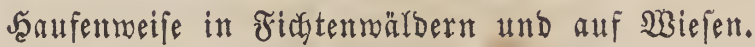

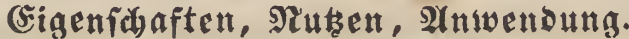

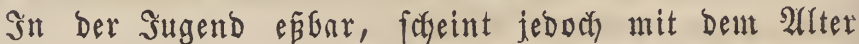

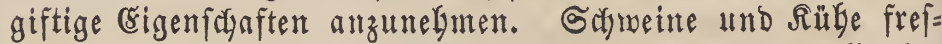
fen biefen Srymamm gerne, bie Milch Der Rethteren foll aber

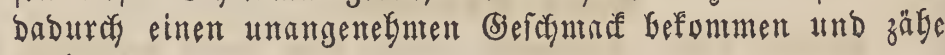
merben.

\section{Boletus edulis, Bull.}

Boletus dulcis. Pers.
Boletus umbrinus. Pers.
Boletus tuberosus. Pers.
Boletus bulbosus. Schaeff.
Boletus reticulatus. Schaefr.
Boletus crassipes. Schuh.

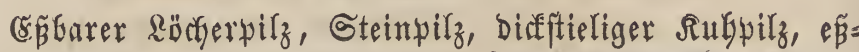

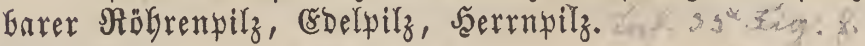

Bolet comestible. (frants.)

\section{$\mathfrak{A} \mathfrak{x t e n}=\mathbb{( S h a r a k t e r}$}

Strunf biff, zwiebelartig aufgetrieben, in ber Mitte ftelend. Şut erkaben gemölbt, oben glatt, fleifchig, braun= roth, unten heller boer bunfler gelb mit fleinen, balsgelös: ten, runblicten, weiñen und gelben łoren.

\section{Fungzeit.}

2luguft, Gepteniber, befonders nadj Regen.

\section{3ortommen.}

Sn Wä̆ldern, Gefonders in Gumuäreidyen Nabelfölzern, fegr Gäufig in Soigtlande und Erzgefirge.

\section{Eigenfäaften, Nuten, Anwenoung.}

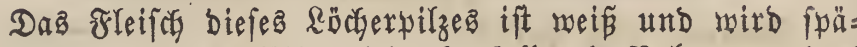
ter gelblich, und Der $\mathfrak{B i l}_{3}$ wirb ebenfalls als Nabrungşmittel Fenuht; mant trofinet ifn bäuftg für ben Winter. 

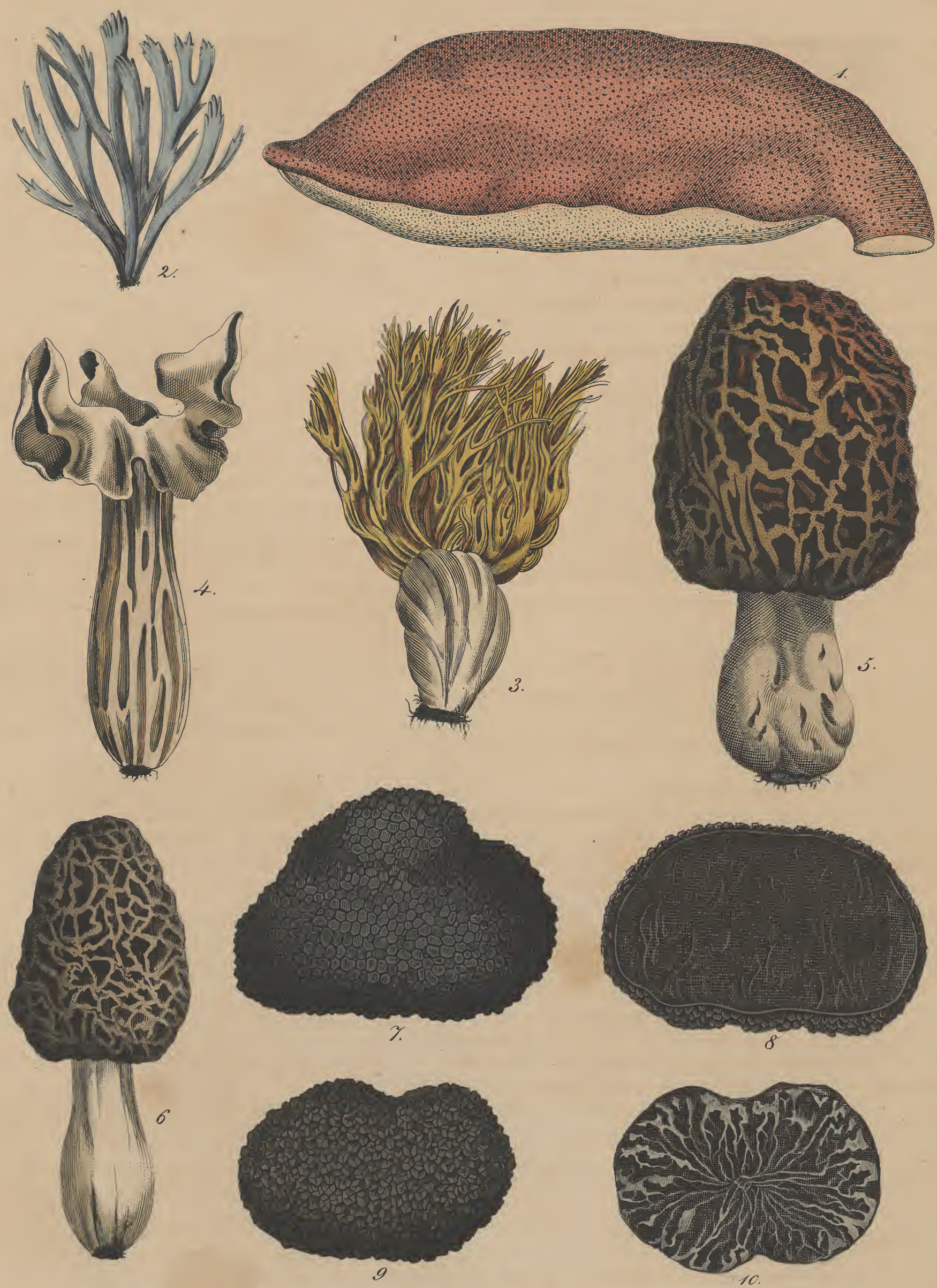



\section{Hydnum. L.}

Bidona. Adans. Martella Adans.

Echinus. Hall. Odontia. Pers.

Hericius. Juss. Somion. Adans.

Hericium. Pers.

Snfteme: Cryptogamia. Fungi. L.

Fungi. Juss.

Hymenomycetes. Pileati. Fr.

झłilz fleiffitg, mit ober obne Stiel. Fructlager unter= balb, fachelig. Die Stactieln find berichloffene Robren, melde aufergalb bie 4pprigen Baftoien tragen.

\section{Hydnum repandum. $\mathbf{L}$.}

Hydnum imbricatum. Willd.

Hydnum sinuatum. Bull.

Hydnum squamosum. Schaefi.

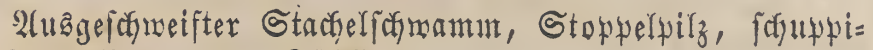
ger Stadyelfurwamnt, Süfling.

Hydne sinué. (franz.)

\section{Arten = Sharafter.}

Strunf biaf, unförmlich, meift in ber Mitte ftebend, glatt, blä̧gelb. Şut 2-6 Soll breit, unregelmäpig, aub= gefaneift, oben beinabe glatt, zerbrechlich, fleiffig, gelb ober roftfarben, auf ber untern Fläche mit ungleirben, theilweife röbrigen, Gellgelben ober graubräunlidyen Stadyeln berfeben.

Spätionmer bi: Serbft.

$$
\text { Fatudzeit. }
$$

\section{3orfommen.}

Sn Wäldern, Gefonders Nabelyölzern.

\section{(sigeniabaften, Stutien, 2tuvensung.}

Das Fleifd ift roblfafmedfend, Glägrelb, und ändert

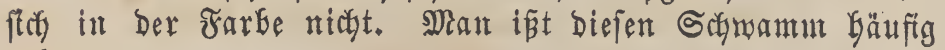
gebraten $2 c$.

\section{Hydnum Erinaceus. Bull.}

Hericium commune. Roq.

Hericium Erinaceus. Pers.

Manina cordiformis. Scop.

Jgelfogmamm.

Hérisson ordinaire. (firatz.)

\section{Arten = (5harater.}

Hilz grof, obne Strunf, berzförmig, fleiffig, weis. f̧ut faferig zerriffen, inten-gegittert, mit febr langen, bän= genden Stackelt.

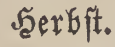

\section{Funozeit.}

\section{Yortommten.}

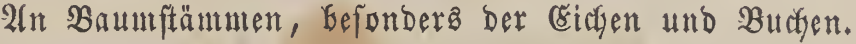
๕ebar.

\section{(sigenfidaften, Ntuen, artwenoung.}

\section{Fistulina, Bull.}

Buglossus. Whlbrg.

Snfteme: Cryptogamia, Fungi. L.

Fungi. Juss.

Hymenomycetes, Pileati. Fries.
Fruchtlager ifit auf Der Utnterjeite, erft warzig, bann

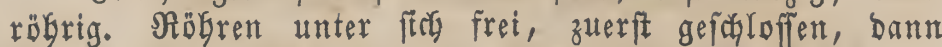
offen, iunen einfadie Sporen an Baftien tragend.

\section{Fistulina hepatica, Rabh.}

Fistulina buglossoides. Bull.

Boletus hepaticus. Lightf.

Boletus buglossum. Fl. Dan.

Reberfarbiger Bungenpilz, Reberfohmamm, słatjçwamm,

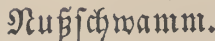

\section{Arten $=$ (5harakter.}

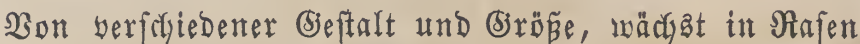
ober Gildet einzelne gerumbete, längliche, ausgefreitete, ein= factse Doer zerfonittene Rappen, Geinake ftielloz, zuerfit blut= roth, Dann rotgbraun, mit weiplichen ober gelglichen Räbren.

Spätfommer แก รุerbft.

$$
\text { Frungzeit. }
$$

\section{SorEommen.} ฟ̇allnüffe.

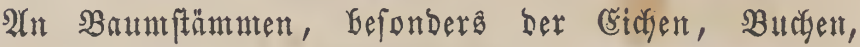

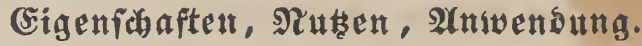

Das Jleifd ift in Der Sugent faftig, riecht angenebm und fafmedft fäuerlich. 3ur Seit ber Reife wirb er bolzig und ift bonn nicht mefr geniep̧bar.

\section{Helvella, L. \\ EIvella. L.}

Syfteme: Cryptogamia, Fungi. L. Fungi. Juss.

Hymenomycetes, Mitrati. Fries.

Morchellini, Helvellarii. Rchbch.

Strunf in Der Mritte fteGend. Şut aufgetrieben, unten concay, bben bucktig gefaltet, ant Nande und oben mit einer glatten Schmammbaut bederft, welche aus 8 pporigen Schln̈u= when beftegt.

\section{Helvella esculenta. Pers.}

Elvella Mitra. Schaeff.

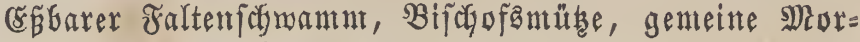
duel, Stodmorchel, Sumpfmorchel, Steinmorchel, Speife= morcher.

Helvelle comestible. (franz.)

\section{Arten = Cுyarakter.}

Strunf 4-8 Rinien ftarf, furz, edfig, bicht, Gobl,

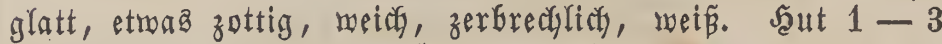
Soll biaf, werfateden geftaltet, aufgetrieben, abgerundet, wellenförmig gefaltet und gerunzelt, of̣t mit Dem SRande an ben Strunf angerondfen, Dunfel offerfarbig bis farmarzbraun.

Sim Frübjagr.

$$
\text { ঔunozeit. }
$$

\section{BorÉnmen.}

Sn trucfenen Bergwäldern, Nabelgölzern, auf Saltb= boden, an faulen Baumftänmen, befonder ną nach warmen ^egen. 


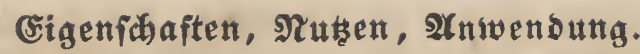

Diejer Srfmamm bejtht einen eigentbümlityen, reizen=

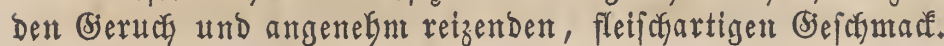

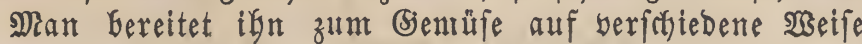
zu, Gratet, röftet, ober Gewahrt ifgn wie bie Morcheln ge= troffnet auf; nur múp man ifn fteţ frübe fammeln, ba er fwäter zut fegr won Injeften verborben ift.

\section{Helvella Infula. Schaeff.}

Helvella brunnea. Gmel.

Phallus triceps. Fl. Dan.

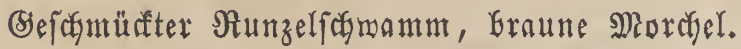

\section{Alten = Conarakter.}

Strunf faft eben, etraa biá, zottig, Gla gegefärbt. Şut berabbängend, gelappt, angemachjen, aufgeflafen, zimmt= bräunlich, unten etwas meichbehaart, meip̌lich.

Spätfonmer.

\section{Fundzeit.}

\section{3orkommen.}

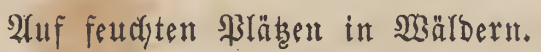

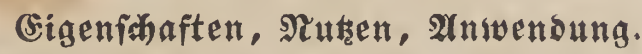
๕Ébar.

\section{Helvella Monachella. Fries.}

Helvella spadicea. Schaeff.

arten = Eharakter.

Strunf glatt, Gohl, meiñ, anfangs rund, bann zu= fammengebrürft. Şut herabbängend, gelappt, angemachjen, eben, Graunfchmärzlich.

J̧erbft.

\section{Fungeit.}

\section{Sorkommen.}

2luf fanbigen F̌eldern, an $\mathfrak{B a u m f t a ̈ m m e n . ~}$

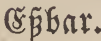

(sigenfabaften, stutsen, Alnwentung.

\section{Morchella. Dill.}

Phallus. L.

Phallo - Boletus. Michel.

Snfteme: Cryptogamia, Fungi. L.

Fungi. Juss.

Hymenomycetes, Mitrati. Fries.

J̧ut fugelig - glofenförmig ober walzenförnig, ange= wadhfen, machasartig fleifohig, aupen burch biele Falten in nebartige Bellen getbeilt und son Der Fruchtichichte ganz be=

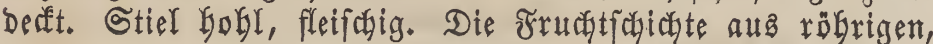
6-8fporigen Schläuchen beftefyend.

\section{Morchella esculenta. Pers.}

Morchella contigna. Tratt.

Boletus esculentus. Balt.
Phallus acuminatus. Batsch.

Phallus esculentus. L.

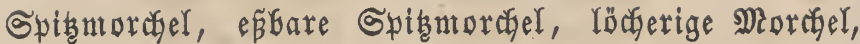
Morchelfdjwamnt, gemeine Miorchel, Doppelte Meaurache.

Morille comestible. (finttz.)

\section{Anten = Eharakter.}

Strunf 1-3 $80 \mathfrak{l}$ hocf, etwaz biaf, aufgetrieben, wal=

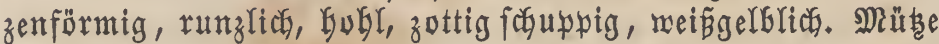
Dber Sat ober Segel eiförutig, etrag ftumpf, an ber $\mathfrak{B a f t z}$ angewachjen, aufgetrieben, neb̧artig zellig, wertieft und er= Gaben gerippt.

Frügiagr.

\section{Funofeit.}

\section{3ortommen.}

2huf Göber gelegenen Wiefen, Walbwiejen, in gebirgi= gen troffenen SBaldungen, an Bartenzäunen, zmifchen bor= nigen J̧erfen, auf Ralf= und Thonfoden, Roblenmeilern,

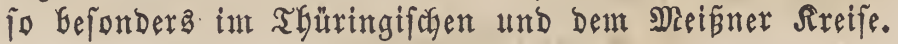

(sigenfuaften, গtuten, Antwenoung.

Die Spibmorchel hat einen angenelgmen (beruch und (5) fodmarf, und man braudat fie mie bie genteine Merdyel alz

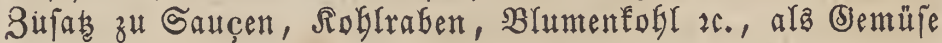
mit \$eterfflie zc., und bewahrt fte ebenfalls an zäben gereibt

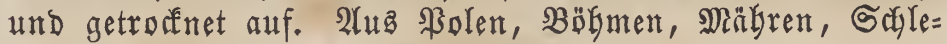
fien werden biele Mlurdyeln nad Deutfaland verfadicft. Man famntelt fie gemöbnlich in Mai.

Varietäten ber Spibmorchel ftnd:

$\alpha$. Morchella esculenta ovalis. Fries.

Ěifürmige Spibmorafyel.

Saut eiförmig.

$\beta$. Morchella esculenta rotunda, Fries.

Runde Spitimordfyer.

Jaut rund.

$\gamma$. Morchella esculenta conica. Fries. Conifare Spibmordyel. Şut fegelförmig.

$\delta$. Morchella esculenta fulva. Fries.

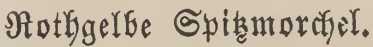
Ђ马ut rautenförmig.

$\varepsilon$. Morchella esculenta corrugata. Runzlitye Spitmorafel.

५. Morchella esculenta stipitata. Lenz. Ranggeftielte Spinmorcher.

Strunf Goch, um Das Doppelte länger ars Der faut.

\section{Morchella deliciosa. Fries.}

Morchella escuienta $\boldsymbol{\beta}$. grisea. Pers.

- esculenta var. vulgaris. Pers.

- esculenta var. $\gamma$. nova. Alb. et Schw.

- conica. Pers.

- costata. Schmidt et Kz. continua. Tratt.

Morater.

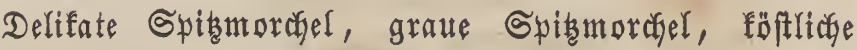
Morille délicieuse. (ftattz.) 
2rrten $=$ (5)arafter.

Strunf gleich, bünn, fleienartig, meip̈gelblicy. Şut 23 oll lang, $1 / 2$ 3oll breit, etwas malzenförmig, an ber Baftz feft verwadten, bie Bertiefungen länglica, fdymal, concat.

Sur erften Frübjafre.

Funozeit.

23orkommen.

Sn boger gelegenen DGftgărten, Walbmięuläzen.

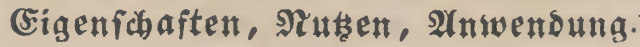

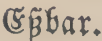

\section{Morchella patula. Fries.}

Helvella esculenta. Sowerby. Phallus patulus, Gmel.

Baftarbmorcyel, eimfache Mauradje, offene Morajel.

\section{Alrten = (Sharakter.}

Strunf God, fleienartig foduppig. Sat eiförmig - runb= lich, ftumpf conifis, rautenförmig, an ber Bafts frèt, gelb= rötglicf.

\section{Funozeit.}

2ipril und Mai.

\section{3ortommen.} (3räben.

Auf fettem $\mathfrak{B}$ oben, zuntal an fanbigen $\mathfrak{B a ̈ c b e n ~ u n d ~}$ ๕̧̋́ar.

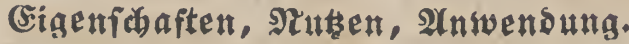

\section{Clavaria, Vaill.}

Coralloides. Tournef.

Sufteme: Cryptogamia, Fungi. L.

Fungi. Juss.

Hymenomycetes, Clavati. Fries.

Fleifarig, äftig, felțen einfacf. Reule meift nicht gejon= bert, walzig, glatt, won Der truffenen, wactsartigen, glanz=

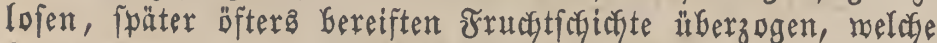
furze, feulige, an Der Spitge 4tyeilige Baftoien enthält.

\section{Clavaria coralloides. Bull.}

$$
\begin{gathered}
\text { Clavaria fastigiata. L. } \\
\text { - } \quad \text { flava. Pers. Schaeff. } \\
\text { - } \text { flavescens. Schaeff. } \\
\text { - } \quad \text { dichotoma. Schaeff. } \\
\text { Merisma flavum. Spr. }
\end{gathered}
$$

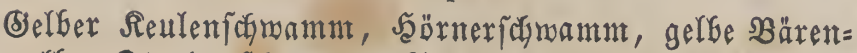
take, gelber Staudenfobmamm, Soraffemfidmanm, Biegenbart, Bonfabart, Coralfenfeulenfchnamm, Greiter Gujefiger Seulen: fमnamm.

Barbe de chèvre, Barbe de bouc, Pied de coq, Buisson, Ganteline, Tripette, Mainotte, Manine jaune. (franz.)

\section{2rten = Gharaeter.}

Bilz aufrecht, febr äftig, corallenartig gebildet, mit bichtem Freifa, wirb $3-5$ soll hoch und efenjo breit.
Strunf gegen 2 3olf biff, in zablreiche, ungleidge, unten einfuche, berbifte, aufrectite, rumbe, oben büfdelartige, $\mathfrak{a b}=$ geftumpfte, zerbrechliche, an ber furzen und fogarfen Spibe Gäufig in gelbliche 2lefte und fodlauchtragende 3reige aus= Iaufend.

Funbzeit.

Vom 2Hนguft bis Spätberb̂̃t.

3orkommen.

Su Wälbern, Gejonders in Nabelgölzern, auf ben flach

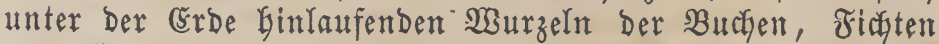
und Wachlyolderfträudye, bäufig im Erzgebirge.

$\mathfrak{\Omega u l t u x .}$

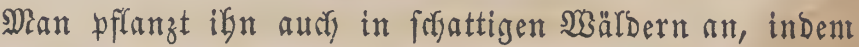
man an Den Wurzeln ber Nadelbăume bie Grrbe einige 3olf

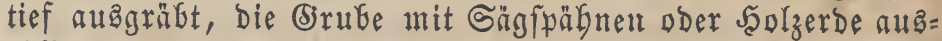
füft und bie Schrämme fanmt ber Erobe Darein feket.

Eigenfád aften, Nutaen, Anwendung.

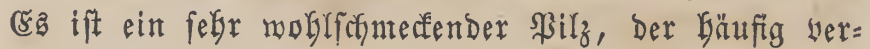

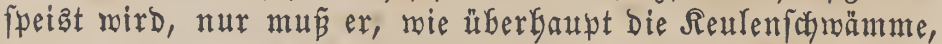
zeitig eingefammelt merben, meil er fonft fofmer verbaulich rird und gerne Erfbrecten $2 c$. erregt.

Clavaria Botrytis. Pers.

- Clavaria acroporphyria. Schaeff.

$$
\begin{aligned}
& \text { - } \quad \text { coralloides. Scop. } \\
& \text { - } \quad \text { rubeja. Wulf. } \\
& \text { - } \quad \text { Botrytis. Schaeff. }
\end{aligned}
$$

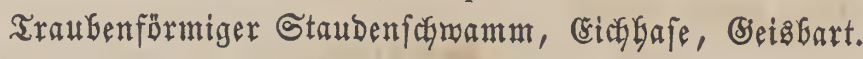
Clavarie botryde. (fianz.)

\section{Arten $=$ Sharalter.}

$\mathfrak{B i l}_{z}$ rafenartig, äftig, aufrecht, fleifodig, fleifachroth. Strunf febr biaf, mit furzen, flachgebrüdten, etmas geboge= nen, rumzligen, an ber Spibe gezăgnten, weífen oder fleifch= farbig gelblichen oder befunders an Der Spibe rotben afeften.

Gommer und ફeerbft.

$$
\text { Fumbzeit. }
$$

\section{2orÉnmen.} พ3ärอern.

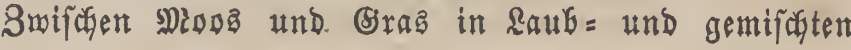
๔̧̌̉Gar.

\section{(̌igenithaften, গtuthen, Anwendung.}

Clavaria amethystina. Bull.

Clavaria purpurea. Schaeff.

Ramaria amethystina. Holmsk.

2(metgsft= Seulenfichamm.

Clavaire amethyste. (franz.)

\section{Arten = (SGaratter.}

Selgr äftig, violett, fpäter Graun, zulest fochmarz. 2lefte yerlängert, rundlich, glatt, ftumpf.

รุerตft.

Fundert.

\section{Sortommen.}

2Uf Bergmiejen, auf waldigen, feudyten 2(nböben. 


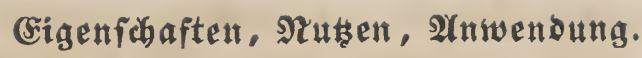

Şat einen fegr angenefment sefadmar.

\section{Peziza, Dill.}

Encoelia. Hill. Fungoides. Tournef.

Honsola. Adans.

0ctospora. Hedw.

Patella. Weber.

Pezica. Adans.
Phibalis. Wallr.

Pissidia. Adans.

Terana. Adans.

Trombetta. Adans.

Ugola. Adans.

Syfteme: Cryptogamia, Fungi. L. Fungi. Juss. Hymenomycetes, Cupulati. Fries.

Dïnnfleifdyige, Gizmeilen geftielte Pilze, yon beridyiede= ner Brö̈e. secher anfangz gefchloffen, bald geöffnet, oben Daz machsartige Fruchtlager tragend. Daz Fruchtlager ent= Gält röbrige Schläuche, bie nicht Gerbortreten und 6-8 ein= fache Sporen enthalten.

\section{Peziza cochleata. Huds.}

Peziza umbrina. Pers.

Röffelförmiger Relchfofmamm, löffelförntiger Becher= fohmamm, fobneffenfürmiger Becherfodmamm.

\section{Sarten = Sharaftex.}

\$ilz rajenartig, 1-2 3oll breit, fleiføig, im $2 \mathfrak{A}$ fang etwas fugelförmig, bann felchförmig gebrebt, aupen belf be= reif̆t, unten braun.

Sommer und ફૅerbft.

\section{Foundeit.}

\section{3̧orEmmen.}

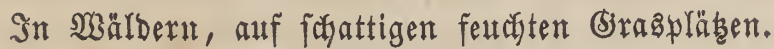

\section{(Eigenid)aften, stuten, Stnwenoung.}

şirb in manchen Begenden, wie in Frantreiff, gefpeiat.

Man Gat eine Barietăt:

$\alpha$. Peziza cochleata alutacea.

Peziza alutacea. Pers.

Peziza cochleata $\beta$. alutacea. Fries.

Tuber.

Aschion. Wallr.

Syfteme: Cryptogamia, Fungi. L. Fungi. Juss.

Gasteromycetes, Myxogastres. Fries.

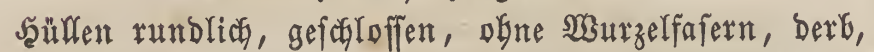
marzig, innen fleifaig, aberig marmorirt. Sabläufe rund=

lich, geftielt, unregelmäpig an ben 2lbern fitsend, $1-5$ ge= färbte Sporen enthaltend.

\section{'Tuber cibarium. Sibth.}

Lycoperdon gulosorum. Scop.

Lycoperdon Tuber. L.

Aschion nigrum. Wallr.

Tuber brumale. Mich.

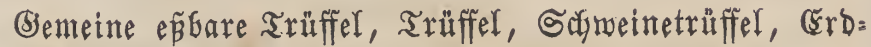
mordyel, Errogriefling, Eronü, Eroffhmamm.

Truffle commun des ragouts. (frattz.)

Truffle. (engl.)

\section{Arten = (5Garakter.}

Rutgelige Rnolfen, ofine Saurzel and Stiel, won ber

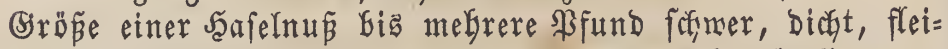

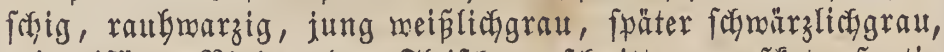

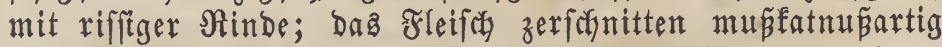
geabert, in ber Sugend weiplits, fpäter bunfel marmorirt.

\section{Fungeit.}

Man fammelt fie im Dftofer und December.

\section{\$orkommen.}

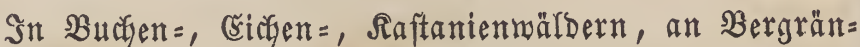
Dern, in Seeiden, 2-6 3olf tief unter ber Ěrbe, zumal auf troffenem, fandigem Boben, befonderb Gäuftg im Thüringi=

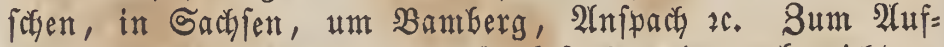
fuchen berjelben bebient man fth Gejonders dazu abgeridyteter J̧unde, ber Trüffelgunde, aud Der Gedmeine.

\section{Eigenforaften, গtuten, 2tnwenoung.}

Die Trüffeln Gaben einen eigentgümlichen, berichieben= artigen, Gäufig etwas endolauch = und mit ber Bolfreife urin= artigen Seruch, einen reizend füblictyen Befchmad und eine reizend ftimulirende Wirfung.

Sie werben als eine grope Delifateffe angejeben und als folche in bielen Biegendent Gäuftg beripeist. Man trodét= net fie auch in bünne slätter zerfodnitten und gebraudft fie

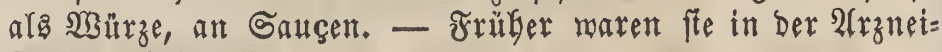
funbe gebräuchlich.

Barietäten Der Trüffel jutro:

$$
\text { 1. Schmarze Ix thffel. }
$$

Die gemolgnlicyite 2 rt.

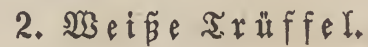

Tuber albidum.

2łu

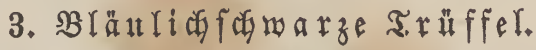

รnกen und außen fo gefärbt.

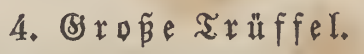

Siecht befonder nach Snoblaudd. 


\section{$\mathfrak{A l} \mathfrak{a} \mathfrak{d}) \mathfrak{t} \mathfrak{x} \mathfrak{a} \mathfrak{y} \mathfrak{e}$.}

3u Seite 96.

\section{Psamma. Beauv.}

Amagris. Rafin.

Ammophila. Host.

Sufteme: Achyrophyta. Neck.

Arundines. Rül.

Gramina. L.

Gramina avenacea. Spr.

Gramina agrostidea. Kunth.

Gramina digyna composita. Roy.

Gramina Poae. Adans.

Gramineae. Juss.

Triandria, Digynia. L.

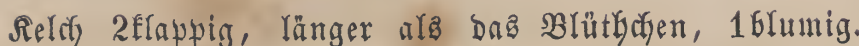
Rlapven zufammengebrünt, Ianzettförmig, unberwebrt; Die untere Rlappe fürzer als bie obere. Blüthctuen 2fpelzig, Teberig, an Der Baftz yon Jaaren umgeben, unbegrant; untere Spelze an Der Spike 2fpaltig, unter ber Spike fta anelfpitig, obere Spelze 2fielig, an ber Spibe 3 zäbnig. Decfipelzen 2. Jrudytfnoten fthend, fabl, einfädyerig. Grif= fel febr furz. Narben fäblicty, federig, feitmärta Gerbortre= tend. Samen bedect, frei.

\section{Psamma arenaria. R. et $\mathbf{S}$.}

Psamma littoralis. Beauv.

Psamma pallida. Presl.

Ammophila arenaria. Link.

Ammophila arundinacea. Host.

Arundo arenaria. L.

Arundo littoralis. Beauv.

Calamagrostis arenaria. Roth.

Phalaris Ammophila. Link.

Phalaris maritima. Nutt.

Sandrofr, Sanbried, Sandrohrgraz.

Sea-reed, Narram, Starr or Bent. (entgl.)

\section{Arten = Çharater.}

Wurzel weit friectend. Saaln $2-3$ Juß boch, auf= recht, zart geftreift, glatt, unten bie und ba äftig. Blätter

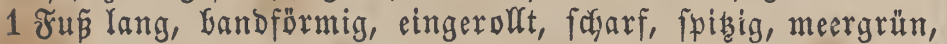
mit einem fefr langen Blatthäutchen. Nispe 6 8oll lang und brüber, aufrectit, äGrenförmig, gebrungen, oberkalb wer= ichmälert, furzäptig. 2lebrchen 6 Rinien lang. Rlappen lineal=laazettlich, fpis, fobarf punftirt, GelfgelG, mit einem grünen Siele, ober aud Geffriolett angelaufen; untere 1=,

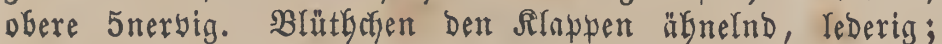
bie Şaare 3ntal fürzer als bie Spelzen; untere Spelze fo lang als bie untere Rlappe.

Juli, 2ługuft. 4.

\section{Blütbezeit und Dauer.}

\section{\$ัorénmen.}

2(ut Neereasfrande bes nörblidyen und füblichen Deutich= lands und hie und da an fandigen Drten, wie bei Stodf= Geint, Dresben, Darmftabt, Samburg, NBejel, Dorften.

Enfwer, bfonom. \$Fanjenfunde.
(Figenfichaften, গtuten, Anvenoung.

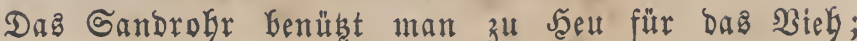

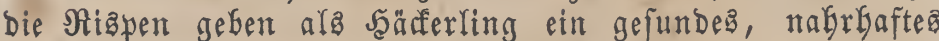
Futter für bie Sferde. Der Santen dea Sandrohrz fann zun Brobbarfen benudet reerben und gift alld ein gutes

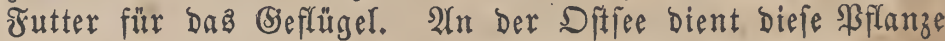
Gauptfächlidy zum Befeftigen bez Flugfandez, - und Durch die Alnpflanzung Derfelben werden Der See dft grope Strecten Landez abgewonnen. Ferner bient ez zum Dedfen Der Dächer

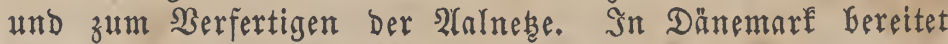
man bie fogenannten Rlärbürften aus igr.

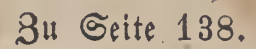

Symphytum. I.

Snfteme: Asperifoliae. L. Rül.

Asperifoliae Boragineae. Rchbch.

Asperifoliae Heliotropeae. Endl.

Boragineae. Adans. Juss.

Oligantherae pentandrae asperifoliae. Roy.

Pentandria, Monogynia. L.

Trachytophyta. Neck.

Relch ganzblätterig, 5theilig, Gleifend. Blumenfrone 1 blätterig, walzig, 5zägnig, abfalfend, mit glorfigem Saume und etras 5 fantiger $\Re$ ghre; ber Schlund mit 5 pfriem= lidben, brüftg = gezäGnelten, fegelfürmig zufammenichliēenden Dedfflappen gefoloffen. Staubgefäße 5, am Seglunde zmi= fichen Den Decfflappen befeftigt, frei. Staubjäben biaf, furz. Staubbeutel. fpibig, aufrectyt, 2fächerig, nach innen gefebrt. Stempel 1. Fruebtfnoten oberftänbig, 4theilig, 1 fädherig. Briffel 1, fadenförmig, lang, ungetheilt, Narbe fopftg, etraz 2fnotig. Samen 4, fdroarz, fuhief eirund; gegittert oder glatt und glänzend, an ber Baftz ausigeb̈̈Glt und bafelgft mit einem mulftigen Rande unrgeben.

\section{Symphytum officinale. L.}

Symphytum album. Hort.

Symphytum bohemicum. Schmidt.

$\beta$. Symphytum potens. Sibth. Schweig. $\gamma$. ? Symphytum datum. Tausch.

Beinmelf, Beimwurz, gebräuchlidger Beinnurz, gemeine Beinmurz, gemöbnliche Beinmurz, gemeine Malfmurz.

\section{Arten $=$ (Sharakter.}

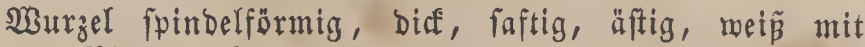

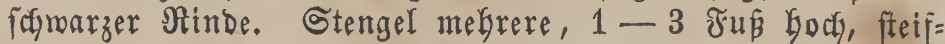
Gaarig, äftig, yon Den berablaufenden Blättern geflügelt. Blätter raubbaarig, bie murzelftändigen ei=lanzettförmig, ge= ftielt, fpisig, bie obern und Die blüthenftändigen lanzettlich, ftielfos. SBlütben in endftündigen, gepaarten, einfeitigen Trauber. Seldy abftebend oder aufrecht. SBlumenfrone län= ger als Def Reldh, Gångend, mit 5 ungejdylagenen Bäbuen, 
gelfricumeiñ. Staubbutel boppelt fo lang als ber Staubs: faben. Samen faymacl gegittert, glänzend.

Baritirt:

a. Symphytum.patens Sibth.

mit bleich rofenrother bis bunfel purpurrother Blumenfrone.

Blütbezeit uns Dauer.

Miai - $\mathfrak{u l i}, 4$.

\section{3orEmmen.}

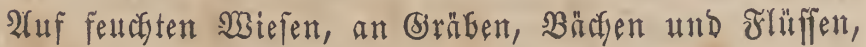
Gejonbers in 20 eidengebüfch.

\section{(sigenfáaften, গtuten, Anwenoung.}

Die Wurzel Der gemeinen Beinwurz enthält biel Graleint,

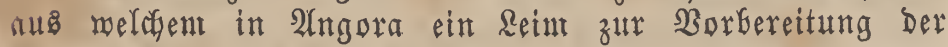
Sameelgaare zum Spinnen berfertigt mirb. Das Sraut und Die SNurzel ftut gerbeftoffyaltig. Die Blätter und Stengel geben ein Siebfutter; bie jungen $\mathfrak{B}$ lätter werben als Salat und Semüfe beripeist, in Salzburg in Sifmalz gebarfen und Dann als eine fräftige Speife genoffen.

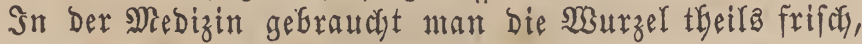

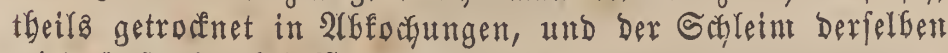

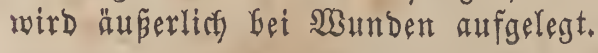

\section{$3 \mathfrak{u}$ Seite 209.}

\section{Montia. I.}

Cameraria. Dill.

Alsinoides. Vaill.

Syfteme: Anagallides. Adans.

Darinyphyta. Neck.

Ficoideae. Link.

Portulacaceae. Juss.

Succulentae Saxifragae. Rül.

Tricoccae. Roy.
Triandria, Trigynia. L.

Vagae. L.

Relch 2blätterig, Gleibend. Reldyblätter eirund, ftumpf= concab. Blumentrone 16lätterig, triduterförmig, 5theilig,

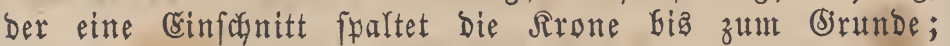
Sipfel concay, 2 berfelben gräper. Staubgefäpe 3, Dem Scglunde an Cirund der brei fleineren Sipfel eingefitgt. Staubfäden fabenförmig. Staubeutel eirund, 2 fücherig. Stentpel 1. Frudgtfnoten freifelfürmig, 1 fücherig. Soriffel furz. Narben 3feberig. Siapfel yom Gleifenden Selche um= fadloffen, freifelfürmig, 3füdterig, 3 jamig.

\section{Montia rivularis. Gmel.}

Montia aquatica major. Mich.

Montia major. Willd.

$\beta$. Montia fontana repens. Pers.

Montia fontana $\beta$. major. Koch.

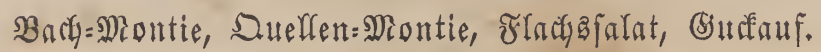

\section{Arten = $\mathbb{S}$ havakter.}

WBurzel faferig. Stengel 5 8oll lang und brüber, äftig, murzelnd. Bäntter entgegengefetst, ftiellos, länglich= eiförmig, unten yerfchmälert, ganzranbig, faftig. SBlunen flein, weis, einzeln voer in adjels und endftändigen Traut= Gen, 2-5Glüthig. Sapfel flein, 3flappig, freifelfürmig. Samen fegr feit förnigzgetüpfelt, glänzent.

\section{Slüthezeit und $\mathfrak{D a u e r}$.}

\section{Nai - September. 4.}

\section{Sorkonmen.}

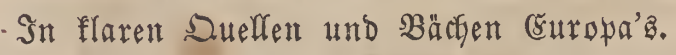

(sigenfachafen, Nuțen, Anwenoung.

Die Dueflen=Mentie wirb int SBinter in einigen (bese= genden, wie bauptfächlich int Thüringifchen, als Salat ge=

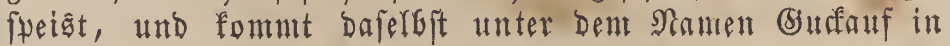
Jantider. 


\section{Eerklärutug oer Abbildungen.}

\section{Iafel 1.}

Jigut 1. Nothe Jrübtartoffer.

2. Bfäraer frübe belfrotbe Rartoffer.

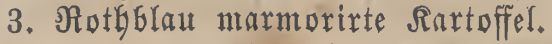

4. Beiß̧̧berget Rartoffel.

5. Sdjmarze Sartoffer.

6. Bişcuit = Rartoffel.

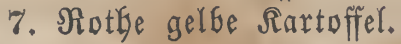

8. Platte meiß̨̌e Fritbfartoffel.

9. Surfenfintoffer.

10. Belbe Jrithfartoffel.

\section{Safel 2.}

Figur 1. Range rothe Nierenfartoffel.

2. Belbe Bapfenfartoffel.

3. झrei $\tilde{\beta}$ yon Jaglland.

4. Zưferfartoffer.

5. Sleine Schottlänber Siartoffer.

6. WSild Rartoffel.

7. Britterfartoffer.

8. \$rei

9. Preí̄ von Weftermald.

10. Blaue runde Rartoffel.

11. Rieine Skuf́fartoffer.

12. Bnobebelfartoffel.

13. Erobeerfartoffer.

\section{Safel 3 .}

Figut 1. Rerchenfartoffel.

2. Gute Speifefartoffer.

3. WSeí̄e Rartoffel.

4. Bontmeriche Rartoffer.

5. Wücthefelder Rartoffel.

6. Englifide Rartoffel.

7. Bielbe Satate.

8. Spanifate Rartoffer.

9. Blaue Şornfartoffel.

10. Grofóe Vieblartoffel.

\section{Tafel 4.}

Figur 1. Topinambur (Helianthus tuberosus L.).

1 a. Die Rnolle.

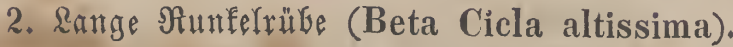

\section{זafel 5.}

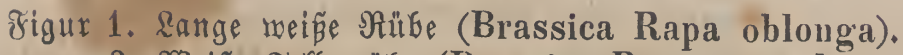

2. Weíne Tellerrübe (Brassica Rapa rotunda).

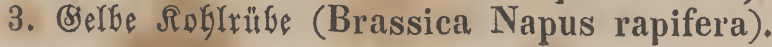

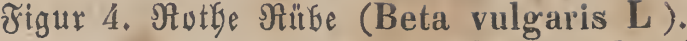

5. Rurze Runfelrübe (Beta Cicla altissima).

\section{Tafel 6.}

Figut 1. Sigmarzer genteiner Bartweizen (Triticum vulgare aristatum nigrum).

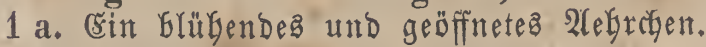

1 b. Briffel und Staubgefäpe.

2. W̧eí̧er genteiter Bartweizen (Triticum vulgare aristatum album glabrum).

3. Notger gemeiner Bartweizen (Triticum vulgare aristatum rubrum).

3 a. (Sin 2Aelgrchen yon Der fofmalen Seite.

4. Blauer gemeiner Bartweizen (Triticum vulgare spica laxa aristata coerulescente glabra).

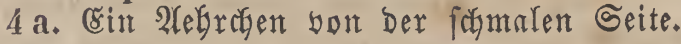

5. Rother jammtartiger gemeiner Bartmeizen (Triticum vulgare rufum velutinum).

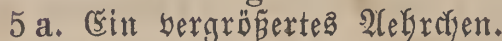

6. Brauner gemeiner Bartweizen (Triticum vulgare aristatum fuscum glabrum).

6 a. (⿶in $\mathfrak{A}$ efyrchen.

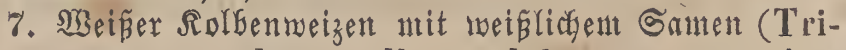
ticum vulgare album glabrum, seminibus albidis).

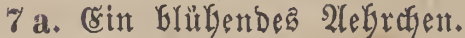

7 b. Sriffel und Staubgefäß̈e.

8. Miotber glatter Rolfenteizen (Triticum muticum rufum glabrum).

9. Brauner $\Re$ olbenmeizen (Triticum muticum rufum glabrum).

\section{Tafel 8.}

Figur 1. Rotfer fanmtartiger Rolfenweizen (Triticum muticum velutinum).

2. Blaue Spielart beş yorigen.

2 a. 2(efrethen yon burnen.

3. Weíner Rolfenweizen mit gelfem Samen (Triticum vulgare muticum album glabrum, seminibus aureis).

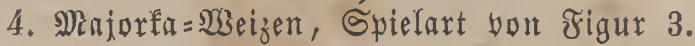

5. NGeifer fanmtartiger Rolbentweizen (Triticum vulgare muticum album velutinum).

6. Movaneizen, Spielart von Nr. 5 .

\%. W3inter=รgeltweizen (Triticum vulgare erinaceum hibernum).

7 a. (sin Grübendes 2febretien. 
Figut 8. Sommer=รgelmeizen (Triticum vulgare erinaceum aestivum).

9. S3einer fammtartiger Sgelweizen (Triticum vulgare erinaceum velutinum).

10. Binfelmeizen (Triticum compactum muticum).

11. Weiper fammtartiger englifuer 2 Seizen (Triticum turgidum album velutinum).

11 a. Čin blübendes 2 elyraten.

11 b. Staufigefäß̄e.

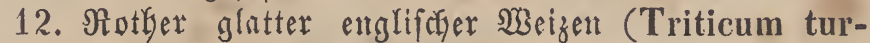
gidum rufum glabrum).

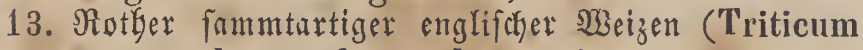
turgidum rufum velutinum).

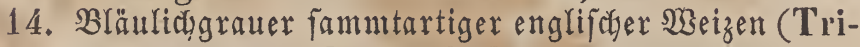
ticum turgidum subglaucum velutinum).

15. Blauer fammtartiger englifater $\mathfrak{B}$ eizen (Triticum turgidum violaceum velutinum).

16. Schwarzet fammtartiger engsiffyer Wreizen (Triticum turgidum nigricans velutinum).

\section{Safel 8.}

Figur 1. WBeiß̄er glatter $\mathfrak{W u n d e r m e i z e n ~ ( T r i t i c u m ~ t u r g i d u m ~}$ compositum album glabrum).

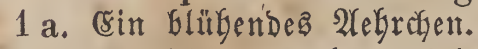

1 b. Deşgleiden, mekr entfaltet zur befferen Heberfict.

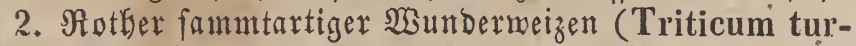
gidum compositum rufum velutinum).

3. Rother glatter $\mathfrak{V}$ underweizen (Triticum turgidum compositum rufum glabrum).

4. Weí̄er glatter Bartweizen (Triticum durum album glabrum).

5. Weip̃er fammtartiger $\mathfrak{B a r t w e i z e n ~ ( T r i t i c u m ~ d u r u m ~}$ albidum velutinum).

6. Notber glatter Bartweizen (Triticum durum rufum glabrum).

7. Nother fammtartiger Bartweizen (Triticum durum rufum velutinum).

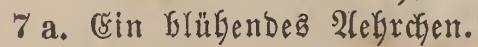

8. Błauer Bartweizen (Triticum durum bicolor).

8 a. (Ein 2 Aefretien.

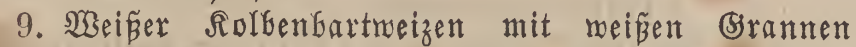
(Triticum durum compactum albidum glabrum, aristis albidis).

10. Weiñer fammtartiger Solbenburtweizen mit meinen (Srannen (Triticum durum compactum albidum velutinum, aristis albidis).

\section{Iafel 9.}

Zigur 1. Wheífer Diffähriger Rolbenbartweizen (Triticum durum compactum pyramidatum albidum glabrum).

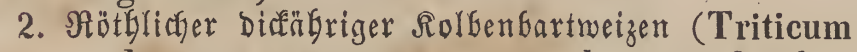
durum compactum pyramidatum subrufum glabrum).

3. DünnäGriger Rolbenbartmeizen (Triticum durum spica gracili).

4. Bemeiner polnifuer SIEfizen (Triticum polonicum vulgare).

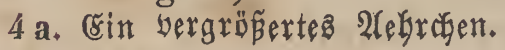

Figur 4 b. (J)iffel mit-ben Staubgefäв̈en.

5. Sanmtartiger polniffyer Weizen (Triticum polonicum velutinum).

6. Surzgegrannter polnifacer Meizen (Triticum polonicum aristis brevibus).

7. Rolfenartiger polnifcher SSeizen (Triticum polonicum compactum).

8. Wreí̄er Spelz (Triticum Spelta, spica mutica alba glabra).

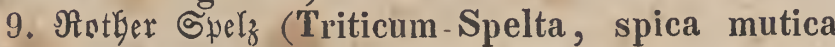
rufa glabra).

9 a. Čin geöffnetes 2fefretgen.

10. BBeiper (Srannenfpelz (Triticum Spelta, spica aristata alba).

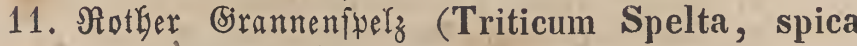
aristata rufa).

12. Bläuliçer (Brannenfpelz (Triticum Spelta, spica aristata coerulescente glabra).

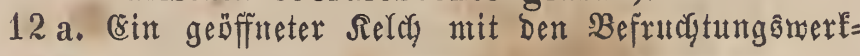
zeugen.

\section{Safel 10.}

ซ̛igur 1. 3 ei glabrum).

2. S3ei spica alba glabra ramosa).

3. Diçter meif́liçer (émnter (Triticum amyleum compactum albidum).

4. Stother glatter (Emmer (Triticum amyleum rufum glabrum).

5. Diçter rötgliçer Enmter (Triticum amyleum compactum rufum).

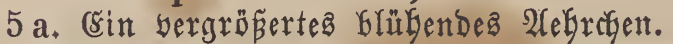

5 b. (Ein reifes 2(efriben.

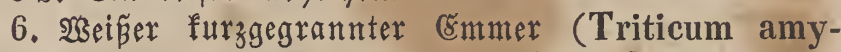
leum, spica submutica alba glabra).

7. Errofer meïer famntartiger Emmer (Triticum amyleum majus, album velutinum).

8. Weif́grauer fammtartiger Enmer (Triticum amyleum semicanum villosum).

9. Weiß̨er fammtartiger äptiger Emmer (Triticum amyleum, spica alba velutina ramosa).

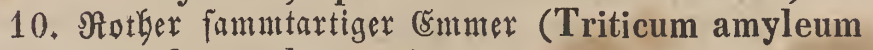
rufum velutinum).

\section{Tafel 11.}

Figur 1. Sawarzer fammtartiger (Entmer (Triticum amyleum atratum velutinum).

2. (̌inform (Triticum monococcum L.).

3. Bemeiner $\Re$ oggen (Secale cereale L.).

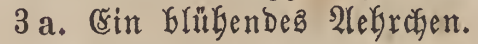

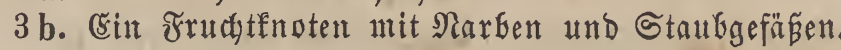

4. Gemeine Bierfte (Hordeum vulgare, spica flavescente).

5. Naritte gemeine Gerfte (Hor deum vulgare coeleste).

6. Surze Gläuliçe gemeine bierfte (Hordeum vulgare, spica brevi coerulescente).

7. Range fläuliche gemeine (5erfte (Hordeum vulgare, spica longa coerulescente). 
Figur 8. Sctmarze gemeine Serfte (Hordeum vulgare nigrum).

9. Surze 2zeilige Gierfte (Hordeum distichon, spica erecta).

\section{Tafel 12.}

Figur 1. Lange 2zeilige Bierfte (Hordeum distichon, spica elongata).

2. Nad te 2zeilige Berfte (Hordeum distichon nudum).

3. Range 6zeilige Sierfte (Hordeum hexastichon, spica longa).

4. Surze 6zeilige (5erfte (Hordeum hexastichon, spica brevi).

5. Bfautengerfte (Hordeum Zeocriton L.).

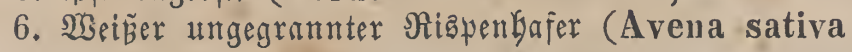
praegravis).

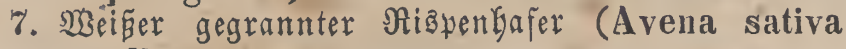
alba aristata).

7 a. Čin Glübendes 2lebratyen.

7 b. CEin reifes 2lefrecten.

8. FrüfGafer (Avena sativa praecox).

9. Rartoffelfafer (Avena sativa turgida).

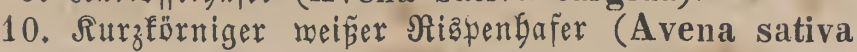
alba mutica, seminibus brevibus).

11. Dreifürniger Riąpentgafer (Avena sativa trisperma).

12. Belber ungegrannter Riąpentafer (Avena sativa aurea, glumellis muticis).

13. Belber gegrannter Riapenfafer (Avena sativa aurea, glumellis aristatis).

\section{Tafel 13.}

Figur 1. Brauner gegrannter ßispentafer (Avena sativa aristata, semine fusco).

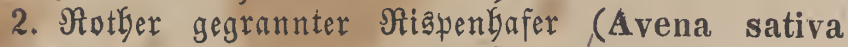
aristata, seminibus rubidis).

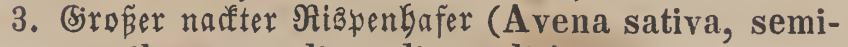
nibus grandiusculis nudis).

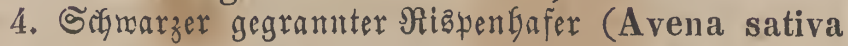
nigra).

5. WBeiper gegrannter Fahnenfafer (Avena orientalis alba aristata).

5 a. (Ein Glüfende 2 (e) elchen.

5 b. Ěin reifez $\mathfrak{A}$ efgrcfen.

6. 23einer nngegrannter Frahnentafer (Avena orientalis alba mutica).

7. Schraarzer gegrannter Falgnentyafer (Avena orientalis nigra).

8. Broferer naft tamiger שagnenfafer (Avena orientalis nuda, seminibus grandiusculis).

9. Sandfafer (Avena strigosa. Schreb.).

10. Narfter Feafer (Avena nuda. L.).

11. Surzer ફrafer (Avena brevis. Roth.).

12. Silberbafer (Avena argentea. Willd.).

13. Rispenfirfe (Panicum miliaceum. L.).

\section{Tafel 14.}

Figur 1. Staltenifate Şirje (Panicum italicum. L.).

2. 2(fferfuctsictymanz (Alopecurus agrestis. L.).

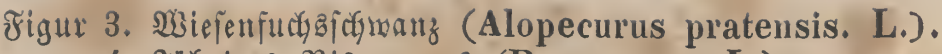

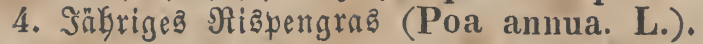

5. N̦iefenriąpengras (Poa pratensis. L.).

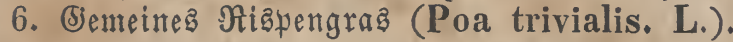

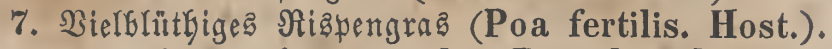

8. Fingerhunbzang (Cynodon Dactylon. Rich.).

9. SMeí̄er Wrindgalm (Agrostis alba. Schrad.).

10. (Bemeiner $\mathfrak{S}$ ind GaYm (Agrostis vulgaris. With.).

11. Nisiefenfiefdygraz (Phleum pratense. L.).

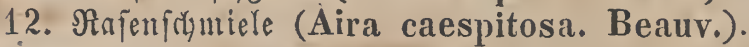

13. Sandrofigras (Psamma arenaria. R. et S.).

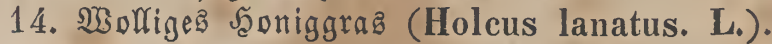

15. Wieicyę fantiggrą (Holcus mollis. L.),

\section{Safel 15.}

Jigur 1. Bolbhafer (Avena flavescens. L.).

2. Surzhariger Safer (Avena pubescens, Is.).

3. NBiefentafer (Avena pratensis. L.).

4. Felotreape (Bromus mollis. L.).

5. 2lffertreâpe (Bromus arvensis. L.).

6. Bemeines $\mathfrak{R a m m} \operatorname{mras}$ (Cynosurus cristatus. L.).

\%. (5emeines Rnauelgras (Dactylis glomerata. L.).

8. Schaffichingel (Festuca ovina. L.).

9. Jaartfdrmingel (Festuca duriuscula. L).

10. Wiefenfchmingel (Festuca pratensis. Huds.).

11. Roldhartiger Sdymingel (Festuca loliacea. L.).

12. Querfe (Triticum repens. L.).

13. (jemeiner Roldj (Lolium perenne. L.).

14. Wiefengerfte (Hordeum pratense. Huds.).

15. Eemeines Sittergras (Briza media. L.).

16. Sandfaargraz (Elymus arenarius. L.).

17. Semeines Ruchgras (Anthoxanthum odoratum.L.).

\section{Iafel 16.}

テigur 1. Mais (Zea Mays. L.).

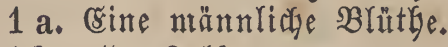

$1 \mathrm{~b}$. Ëin Rolben.

2. Buchreizen (Polygonum Fagopyrum, L.).

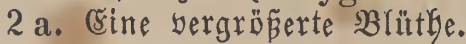

$2 \mathrm{~b}$. (sine Blüthe in natürliçer Eröß̈e.

2 c. Ein Gamen.

2 d. Dezgleithen vergröbert.

\section{Tafel 18.}

Figur 1. Blauer Steinflee (Melilotus coerulea. Lam.).

2. (Sezäbnter Steinflee (Melilotus dentata. Willd.).

3. Bemeiner Steinflee (Melilotus officinalis. Lam.).

4. Futterflee (Trifolium pratense sativum. Mill.).

5. Baftarbflee (Trifolium hybridum. L.).

6. Incarnatflee (Trifolium incarnatum. L.).

7. Mittlerer Rlee (Trifolium medium. L.).

8. Bergffee (Trifolium montanum. L.).

9. Iriectender Rlee (Trifolium repens. L.).

10. ^other Rlee (Trifolium rubens, L.).

11. Jaafenflee (Trifolium arvense. L.).

12. Bielber אilee (Trifolium agrarium. L.).

13. Fadenflee (Trifolium filiforme. L.).

14. Erb Geerflee (Trifolium fragiferum. L.).

15. Steinförmiger Rlee ('Trifolium stellatum. L.). 


\section{Safel 18.}

ซrigur 1. Bsenteine (5aigraute (Galega officinalis. L.).

2. Bortágrnflee (Trigonella Foenum graecum. L.).

3. (Ëpariette (Onobrychis sativa. L.).

4. Zaunnidfe (Vicca sepium. L.).

4a. Die Sifjote.

4 b. Der Santen.

5. Bmeifamige Rinfe (Ervım hirsutum. L.).

5 a. Die Sifute.

5 b. Der Sametr.

6. Bierfanige Rimfe (Ervum tetrispermum. L.).

6 a. Die Siflote.

6 b. Der Samen.

\section{Safel 19.}

Figur 1. Miefenfalbei (Salvia pratensis. L.).

2. (5emeine Beinwurz (Symphytum officinale. L.).

3. Spifmegerich (Plantago lanceolata. L.).

4. Semeine Gifafgarfe (Áchillea Millefolium. L.).

\section{Tafel 20.}

Figur 1. Bemeine Bokne (Phaseolus vulgaris. L.).

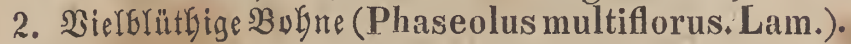

2 a. Det Samen.

3. Siemeine Grubolne (Vicia Faba, L.).

3 a. 2 Schoter.

\section{Safel 21.}

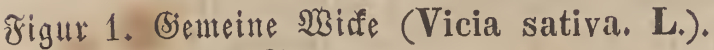

1 a. Die Sifute.

1 b. Der Samen.

2. Frugerfingte (Tetragonolobus siliquosus, Roth.).

2a. Die Schote geoffinet.

2 b. Der Samen.

\section{Tafel 22.}

Figur 1. Zuffererbfe (Pisum sativum sine cortice duriore).

2. Rimfe (Ervum Lens. L.).

2a. Die Sifjote.

2b. Der Samen.

\section{รafel 23.}

Figur 1. Meerrettig (Cochlearia Armoracia. L.).

1 a. Die Wurzel.

2. Selbe Mrähre (Daucus Carota. L.).

2 a. Die $\mathfrak{W u r z e l}$.

\section{รัafel 24.}

Zrigur 1. Bienteiner ßaftinaf (Pastinaca sativa. L.).

1 a. Die Burzel.

2. Spanifue Saferwurzel (Scorzonera hispanica.L.).

2. a. Die $\mathfrak{3}$ rzzel.

\section{safel 25.}

Figur 1. Sellerie (Apium graveolens. $L_{4}$ ).

1 a. Die Wurzel.

2. Schinfenturzel (Oenothera biennis. L.).

2 a. Die Wurzel.

\section{Safel 26.}

Figur 1. Benteiner Ralted (Allium Porrum. L.). 1 a. Die $\mathfrak{B l u ̈ t}$ the.

2. Bsemeiner 3wiebel (Allium Cepa. L.).

2 a. Die Blüt the.

7 3. Eismeiner Inoblanth (Allium sativum. L.).

3 a. Die Blüttge.

4. Schnittlaudy (Allium Schoenoprasum. L.).

\section{Tafel 28.}

శrigur 1. Ropffolgl (Brassica oleracea capitata).

1 a. હin 2 lüthenzmeig.

2. MBirfteblobl (Brassica oleracea sabauda).

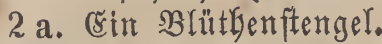

3. (Srünfolgl (Brassica oleracea sabellica).

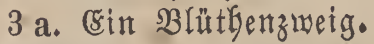

\section{safer 28.}

Figut 1. Bfumenfolyl (Brassica oleracea botrytis).

2. Spargeffofl (Brassica oleracea asparagoides).

2 a. હ̌in Blüttyenzmeig.

3. Inoffentubl (Brassica oleracea gongylodes).

3 a. Ěin Blüthenzmeig.

\section{Safel 29.}

Figur 1. (jemteine $\mathfrak{A}$ rtiffyofe (Cynara Scolymus. L.). 2. (Gardun=2(rtifegofe (Cynara Cardunculus. L.). 3. Benteine Ireffe (Lepidium sativum. L.).

\section{safel 30.}

Jigur 1. (jemeiner Galat (Lactuca sativa. L.).

2. (3) meine Spargel (Asparagus officinalis. L.).

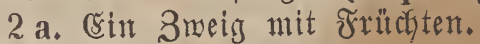

3. Brunnentrefie (Nasturtium officinale. R. Br.).

4. Roffelfraut (Cochlearia officinalis. L.).

\section{Tafel 31.}

Figut 1. Meerfolyl (Crambe maritima. L.).

2. WBiefenfreffe (Cardamine pratensis. L.).

3. 2leferfalat (Valerianella clitoria. Moench.).

4. Boprage (Borago officinalis, L.).

\section{Tafel 32.}

Figur 1. S3affermelone (Cucumis Citrullus. Sering.).

2. (Ein $\mathfrak{B l u ̈ t}$ hentzmeig.

3. Melone (Cucumis Melo, L.).

4. (sint Blütbenzmeig.

\section{Safel 33.}

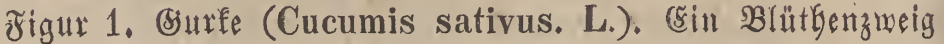
mit frifh angefeterter Frudyt.

2. Unreife Frucht.

3. গReife Frutert.

4. Sallangengurfe ('Trichosanthes Anguinea. L.). Tafel 34.

Figur 1. Bienteiner Råmmel (Carum Carvi. L.).

2. Coriander (Coriandrum sativum, L). 


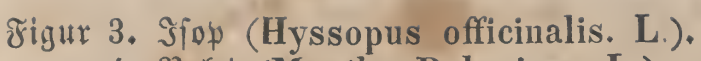

4. ßorei (Mentha Polegium. L.).

5. Baftlienfraut (Ocimum Basilicum.).

6. (Bartenmeliffe (Melissa officinalis. L.).

7. Rabendel (Lavendula spica, I.).

\section{Safel 35.}

Figur 1 11. 2. EGampignon (Agaricus campestris. L.), 3. Tänbling (Agaricus integer. L.).

4. Bfefferling (Ägaricus piperatus. Scop.).

5. \$arajolfigmamm (Agaricus procerus. Scop.).

6. Raiferifgramm (Agaricus caesareus. Schaeff.).

7. Pfifferling (Cantharellus cibarius. Fries.). ซigur 8. Röcherpilz (Boletus edulis. Bull.).

9. Stadjelifgmamm (Hydnum repandum. L.).

Tafel 36.

Frigur 1. Refberfofwamm (Fistulina hepatica. Rabh.).

2. 2(methyft=Reulenfdyanm (Clavaria amethystina. Bull.).

3. Belber Sentenfedmantm (Clavaria coralloides. Bull.).

4. (Semeine Mordyel (Helvella esculenta. Pers.). 5 11. 6. Spibmorifel (Morchella esculenta. Pers.). 7-10. Truffel (Tuber cibarium. Sibth). Figur 8

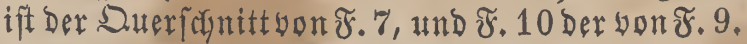

Abbot. Abbot. Adanson. Adans. Aiton. Ait.

Alhertini et Schweinitz. Alb. et Schw.

Allioni, All.

Anderson. And.

Andrzeiowsky. Andrz.

Arduino. Ard.

Arnott. Arn.

Aublet. Aubl.

Aubry. Aubry.

Baer. Baer

Balbis. Balb.

Baldinger. Balding.

Bang. Bang.

Banks, Banks.

Bartling. Bartl

Bastard. Bast.

Batsch. Batscli.

Bauhin. Bauh.

Baumgarten. Baumg.

Bavle-Barelle. Bayle.

Beauvois. Beauv.

Becker. Becker.

Beckmann, Beckm.

Bellardi. Bellard.

Bentham. Bentl.

Bergius. Berg.

Bernhardi. Bernlı.

Bertolini, Bertol

Besser. Besser.

Bieberstein. Bbrst.

Bivona-Bernardi. Bivon.

Blackwell. Blackw.

Boenninghausen. Boenningh. Boengh.

Boissieu. Boiss.

Bolton, Bolt.

Boucher. Bouch.

Brignoli Giovani, Brign.

Brittinger. Britting.

Brongnart. Brongn.

Brotero, Brot.

Brown R. R. Brown,

Bryant. Bryant.

Bulliard. Bull.

Burmann. Burm.

Cambessedes. Cambess.

Campdera. Campd.

Cassini. Cass. Cassin.

Cavanilles, Cav. Cavan.

Chevallier. Chev.

\section{Anmen Der amgeführten Autoren.}

Clairville. Clairv. Clarion. Clarion. Clemientey. Clem. Cornelissen. Corn. Coulter. Coult.

Crantz. Crantz.

Cullum. Cullum.

Curtis. Curt.

Cyrillo. Cyrill.

De Candolle. DeC.

Delarbre. Delarb.

Delile. Delil.

Desfontaines. Desf.

Desroussaux. Desr.

Desvaux. Desv.

Detharding. Dethard.

Dietrich. Dietrich.

Dillenius. Dill.

Ditmar. Ditm.

Don G. G. Don.

Duchesne. Duch.

Du Croz. Ducroz.

Dunieril. Dumeril.

Dumortier. Dumort.

Duval. Duval.

Ehrhart. Ehrlı.

Elliot. Ell.

Endlicher. Endl.

Escholz. Esch.

Fabricius. Fabr. Fabric.

Fischer. Fischer.

Fischer et Meyer. Fisch.

et Meyer.

Forskal. Forsk.

Forster. Forst.

Fries. Fries.

Frivaldsky. Frivald,

Gaertner. Gaertn.

Gallesio. Gall.

Gaterau, Gater.

Gaudin. Graud.

Gawler. Gawl.

Gay. Gay.

Gilibert. Gilib.

Giseke. Gisek.

Gmelin. Gmel.

Gorter. Gorter.

Gouan. Gouan.

Gray. Gray.

Gunner. Gunn.

Gussone. Guss

Haberle. Haberl.

Haenke, Haenk.
Haller. Hall.

Hamilton. Hamilt.

Hartmann. Hartm.

Haworth. Haw.

Hayne. Hayn.

Hedwig. Hedw.

Herrich-Schaeffer. Herr. Sch.,

Heyne. Heyne.

Hill. Hill.

Hoffmann. Hoffm.

Hoffmannsegg. Hoffmsg.

Holmskiold. Holmsk.

Hoppe. Hoppe.

Hornemann. Hornem.

Hornung. Hornung.

Host. Host.

Hudson. Huds.

Hull. Hull.

Jacquin. Jacq.

Jan. Jan.

Jaume Saint - Hilaire. Jaum.

Jussieu, Juss.

IKaempfer. Kaenupf.

Ker. Ker.

Kitaibel. Kit.

Knapp. Knapp.

Kocl. K. Koch.

Koeler. Koel.

Koerte. Koert.

Krombholz, Krombh,

Kuntl, Kunth.

Tuagasca. Lagasc.

Lamarck. Lam.

Lapeyrouse. Lapeyr.

Latour ette. Latour.

Ledebour. Ledeb.

Leers. Leers.

Lehmann. Lehm.

Lejeune. Lejeun.

Lenz. Lenz.

Lessing. Less.

Lestiboudois. Lest.

Leysser. Leyss.

Lightf oot. Lightf.

Link. Lk. Link.

Linné. L.

Lobel. Lobel.

Loiseleur Deslongchamps. Loisl.

Loudon. Loudon.

Lowe. Lowe.
Mann. Mann.

Maratti. Maratt.

Mazzucato. Mazz.

Medicus, Medic.

Meigen. Meig.

Meissner. Meissn.

Merat. Merat.

Merlet de la Boulage. Merlet.

Mertens et Koch. M. et K.

Meyer. Meyer.

Michaux. Michx.

Micheli. Mich. Michel.

Mieg. Mieg.

Miller. Mill.

Mirbel. Mirb.

Moench. Moench,

Molina. Molin.

Moquin. . Tandon. Moq.Tand.

Moris, Moris.

Morison. Morison.

Mühlenberg. Mhlbrg.

Murray. Murr.

Mutel. Mut.

Necker. Neck.

Nees von Esenbeck. Nees.

Nuttall. Nutt.

Dpiz. Opiz.

Ortega. Orteg.

Osbeck. Osb.

Otto. Otto.

Palìas. Pall.

Panzer. Panz.

Persoon. Pers.

Petermann. Peterm.

Petit Thouars. Pet. Thou.

Poiret. Poir.

Pollich. Pollich.

Pollini. Pollin

Pourret. Pourr.

Presl. Presl.

Pursh. Pursh.

Itabenhorst. Rabh.

Rafinesque - Schmaltz. Rafin.

Reichenbach. Rchbch.

Requien. Req.

Retzius, Retz.

Richard. Rich.

Rochel. Rochel.

Roehling. Roehl.

Roemer et Schultes. Roem, et Schult. Roques. Roq.

Roth. Roth.

Rottler. Rottl.

Roxburg. Roxb.

Royen. Roy.

Rüling. Rül.

Salisbury. Salisb.

Salzmann. Salzmı.

Savi, Savi.

Schaeffer. Schaeft.

Scheuchzer. Scheuchz.

Schiede. Schiede.

Sclikuhr. Schklrr.

Schlechtendal, Schlech. tend.

Schleicher. Schl. Schleich.

Schmidt. Sclimidt.

Schnidt et Kunze.

Schmidt et $\mathbf{K z}$.

Sclirader. Schrad.

Schrank. Schrank.

Schreber. Schreb.

Schübler. Schübler.

Schübler et Martens. Sclü̈bl. et Mart.

Schultes. Schult.

Schultz. Schultz

Schumacher, Schum.

Schweigger, Schweig.

Scopoli. Scop.

Secretan. Secr.

Seenus. Seen.

Seidl. Seidl.

Seringe. Sering.

Sibthorp. Sibth.

Sieber. Sieb.

Sievers. Siev.

Sinclair. Sincl.

Smith. Sm. Snuith.

Sobolewsky. Sobol.

Sowerby. Sowerby.

Spach. Spach.

Spenner. Spenn.

Sprengel. Spr. Spreng. 


\section{Lateinisches Register.}

\section{A.}

Abrotanum. Bess. 221.

Absinthium. Adans. 221.

Acanos. Adaus. 190.

spina. Scop. 190.

Acanthophyton. Less. DeC. 204

Acetosa. Neck. 193.

nıagna, Gilib, 194.

pratensis. Mill. 194.

romana. Blackw. 194

scutata. Mill. 194.

sterilis. B. Mill. 194.

Achillea. L. 114.

collina, $\beta$. Becker. 114 .

crassifolia. Hort. 114.

dentifera. $\varepsilon$. Rehbch. 114 .

gracilis. $\vartheta$ Rafin. 114.

Haenkiana. Tausch, 114.

in termedia. $\zeta$. Schleich.

Schult. 114.

magna. Haenk. 114.

Millefolium. L. 114 .

Millefolium. $\gamma$. crustata.

Rochel. 114.

occidentalis. $\eta$. Rafin. 114. polyphylla. $\delta$. Schleich, 114. seabra. Host. 114.

Seidlii. Presl. 114.

subhirsuta. Gilib. 114

sudetica. Opiz. 114.

sylvatica. Becker. 114.

Acinos. Pers. 226.

Acnogonum. Meissn. 85.

Acquartia. Jacq. 1.

Acrocentron. Cass. 114.

Acrolophus. Cass. 114

Adopagon. Neck. 158.

Aegopodium. L. 139.

Carum. Wibel. 234.

Podagraria. L. 139. ternatum. Gilib. 139.

A etheopappus. Cass. 114.

Aethiopis. Benth. 120.

Aethusa Meum. L. 138.

Agaricon. Adans. 243.

Agaricus. L. 238.

acris. Bull. 241 .

acutus. Schuh. 242.

aeruginosus. Schuh. 241.

albellus. Schaeff. 242.

albipes. Secr. 241.
Agaricus alutaceus. Vitt. Secr. Agaricus lactifluus argenteus. 240.

alntarius. Pers. 238.

amarus. Schaeff. 241 .

anuularius. Bull. 242.

antiquatus. Batsch. 242.

arvensis. Schaeff. 238.

aurantiacus, Bull, 243

aurantius. Secr. 240.

auratus. With. 241.

aureus. Secr. 241.

bifidus, Bull. 240.

bombycinus. Schaeff. 243.

caesareus. Schaeff. 243.

campanulatus. Pers. 240.

campestris. L. 238.

Cantharellus. L. 243 .

caudicinus. Pers. 242.

chioneus. Fries. 240.

chlorus. Secr. 240.

chrysomallus. Röhl. 241 .

cinereus. Secr. 241.

coeruleus. Pers. 240.

colubrinus. Bull. 242.

crocinus. Röhl. 241.

cyalloxanthus. Schaeff. 240.

delicatus. May. 240.

deliciosus. L. 239.

denudatus. 242.

edulis. Bull. 238.

emeticus. Schaeff. 240.

erosus. Poir. 240.

esculentus. Pers. 240.

exalbicans. Secr. 240.

extinctorius. L. 242.

fallax. Fries. 240.

felleus. Fries. 241.

flexuosus. Poir. 240.

fragilis. Fries. Secr. 240.

furcatus. Pers. 240.

galarrhoeus. Fries. 240.

galochrous. Fries. 240.

Georgii. L. 241.

graminicolor. Secr. 240

gregarius. Poir. 240.

griseus. Pers. 240.

heterophyllus. Secr. 240.

horizontalis. Vitt. 241.

inanis. Scop. 240.

incarnatus. Batsch. 213.

integer. L. 240 .

lacteus. Pers. 240.

\section{0.}

lactifluus L. 240.

lactifluus aureis. 240.

lactifluus fulvens. Batsch. 240.

leiocephalus. DeC. 243.

leucothejus. Fries. 240

Linnaei. Fries. 240.

licescens. Batsch. 241.

lividus. Secr. 240

Iuridus. Pers. Secr. 240.

luteolus. Batsch. 243.

luteus. Huds. 241 modestus. Batsch. 238.

Mouceron. Bull. 242.

mutabilis. Batsclı. 242

mutabilis. Schaeff. 242

nauseosus. Pers. 240

nitens. Schaeff. 240

nitidus. Pers. Fr. 240.

niveus. Pers. 240.

ochraceus. Pers. Secr. 240.

ochroleucus. Pers. Secr.

Vahl, 240.

ochrosulcatus. Secr. 240

olivaceus. Schaeff, 240 .

olivascens. Pers. 240

Oreades. Scop. 242.

ovoideus. DeC. 243.

ovoideus albus. Bull. 243.

pallidus. Sowerb. 242.

Palone. Thare. 241

paradoxus. Secr. 240.

pertinaceus. Bull. 240.

phaedrus, Röhl. 241.

piperatus. Scop. 241.

pollitus. Batsch. 238.

polynorphus. Baumg. 242.

Pratella. Fl. Wett. 238

pratensis. Schaeff. 238.

procerus. Scop. 242.

Prunulus. Pers. 242.

pseudoemeticus. Secr. 241.

pseudounctuosus, Batsch.

243.

pulcherrimus. Secr. 240.

purpureus. Schaeff. 240.

purpureo fuliginosus. Secr.

240.

purpureo lividus. Otto. 240.

rigidus. Poir. 240. marginatus. Batsch. 242.
Agaricus rissigallinus. Batsch. 241

rosaceus. Pers. 240 .

roseipes. Secr. 240.

roseogranulatus. Secr. 240.

ruber. Pers. Vitt. 240

rubescens. Schaeff. 240 .

russula. Scop. Poir. 240.

sanguineus.Vitt. Batseli .240.

sapidus. Roq. 241.

Schaefferi. Secr. 240:

semiflavus. Röhl. 24l.

sexampelius. Schaeff. 240.

Sowerbyi. Krombh. 242.

speciosus. Gouan. 243.

squalidus. Chev. 241.

squamosus. Vitt. 242.

sub dul cis. Bull. 240.

subobliquus. Poir. 240.

substypticus. Secr. 240.

suspectus. Poir. 240.

sylvaticus. Lest. 240.

sylvaticus. Schaeff. 238.

tortilis. DeC. 242.

truucigenus. Schrk. 242.

unicolor. Secr. 241.

vagus. Secr. 240.

versicolor. Secr. 240.

violascens. Secr. 240.

virens. Scop. 240

virescens. Schaeff. Vitt. 240.

vitellinus. Pers. 240.

xylophilus. Bull. 242.

zonarius. Bolt. 239.

Agassizia. Spach. 163.

Agathophytum bonus Henricus

Mocq. Tand. 196.

Agraulus. Beauv. 94

Agropyrum caesium. Presl. 110. caninum. R. S. 111. collinum. Opiz. 110. repens. Beauv. 110 . repium, Beauv, 110

Agrostis. L. 94.

alba. Balb. Loise. 95. alba. Schrad. 95

alba, var. $\beta$. Schrad. 96. alba. $\gamma$. Schrad. 96. alpina. Roth. 95. alpina. Savi. 95. ambigua. R. S. 95. argentea. Schleich. 95.
Agrostis aristata. Sincl. 95. atropurpurea. Hort. Rafin.

bermudians. Tuss. 89 . calamagrostis. Poll. 96. canina. With. 95. capillaris. Poll. 95. capillaris. Schkr. 95. coarctata. Ehrh. Hoffm. 95. compressa. Willd. 95. conferta. Willd. 95. cremenica. Bess. 95. decumbens. Gaud. 95. decumbens. Host. 95. diffusa. Host. 95. disticha. Schweig. 95. divaricata. Hoffm. 95 dubia. DeC. 95.

dulcis. Poir. 95. effusa. Poir. 94. flava. Fl. Dan. 95 . gigantea. Gaud. 96. gigantea. Roth. 95. gracilis. Kit. Schult. 95. hispida. Willd. 95. intermedia. Balb. 95. interrupta. Autor. 95. Kitaibelii. Schult. 95. linearis. Retz. 89. lithuanica. Bess. 95 . longearistata. $\gamma$. Aut. 95 . mutabilis. Knapp. Sibth. 95. neglecta. Schult. 95 . nigra. With. 95. obliqua Aut. 95. pallida. With. 95. palustris. Sincl. 95 . patula. Gaud. 95. pauciflora. Schrad. 95. polymorpha. Huds, 95. procumbens. R. S. 95. pumila. L. 95 .

purpurea, Beauv. Rchbch. 95.

purpurea. $\delta$. Gaud, 95. rivularis. Brot. 95. rubra. Whlbg. 95. rubra, $\beta$. L. 95. rubra. $\delta$. L. 95 . Spica venti. L. 95 . stellata. Willd. 89. stolonifera. L. 95 . 
Agrostis stolonifera, $\beta$. Leers. Allium laetum. Salisb. 170. 95.

stolonizans. Bess. 95.

straminea. Hartm. 95.

sylvatica. Host. L. 95.

sylvatica. Koel. Poll. 95.

sylvatica. $\gamma$. Poll. 95

sylvestris. FI. Dan. 95

stricta. Nitm. Gmel. 95.

tenella. Hoffm. 95.

tenuis. Sibth. 95.

trichotona. Ant. 95.

varia. Host. 95.

vernalis. Hort. Dorp. 95.

versicolor. Hort. Hafn. 95.

verticillata. Tluuil. 95.

vinealis. Schreb. 95.

violacea. Thuil. 95.

vivipara. Bivon. 95.

vulgaris. With. 95.

Aidelus. Spr. 209.

Aira. L. 98.

alpina. Roth. 98.

altissima. Moench. 98

aretica. $\gamma$. Spr. 98.

atrovirens. $\gamma$. Thuil. 102.

bottnica. $\zeta$. Lionk. 98.

breviaristata. Gilib. 98.

brevifolia. $\beta$. Burst. 98 .

caespitosa. L. 98 .

canescens, L. 98.

clavata. Gilib. 98.

coerulea. L. 102.

cristata, L. 101.

refracta. $\delta$. Cav. 98.

glauca. Hartm. 98.

gracilis. Trin. 101.

heloides. Brign. 91.

Holius mollis. Vill. 97.

miliacea. Lapeyr. 91.

mollis. Sclireb. 97.

natans. Wigg. 100 .

paludosa. Wibel. 98.

parviflora. Thuil. 98.

pumila. $\delta$. Pursh. 91.

subtriflora. Lagasc. 98.

vivipara. 98.

Airochloa cristata. Link. 101. gracilis. Link. 101.

Alchemilla. L. 138.

glaberrima. Schmidt. 138.

glabrata. Tausch. 138.

multicaulis. Tausch, 138.

palmata. Gilib. 138.

pratensis, Sclımidt. 138.

sylvestris. Schnidt. 138.

truncata. Tausclı. 138

vulgaris. L. 138.

vulgaris. $\beta$. glabra, 138.

vulgaris. $\gamma$. hirsuta. 138.

Allinm. L. 167.

altaicum. $\beta$. Pall. 169.

ampeloprasum, 170.

arenarium. $\alpha . \beta$. Trev. 172.

ascalonicum. L. 169.

carinatum. Schultz, 172.

Cepa. Banks. 172.

Cepa. L. 168.

Cepa. var. Ker. Schult. 172.

ceratopliyllum. $\gamma$. Ledeb.

Bess. 169.

Cumaria. $\gamma$. Hamilt. 168.

esculentum. Salisb. 168.

fistulosum. L. 169.

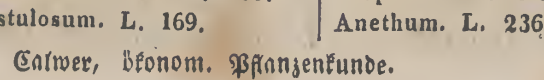
Napus. $\gamma$. Pall. 168.

obscurum, Bbrst. 172.

Porrunı. L. 170.

proliferum. Schrad. 172.

proliferum. $\beta$. B. Magn. 168

reflexum. $\beta$. Dietr. 171.

riparium. Opiz. 171.

sapidissimum. Pall. 169.

sativum. L. 171.

Sclioenoprasum. L. 171.

Scorodoprasunı. L. 172.

tenuifolium. Salisb. 171

Alopecurus. L. 88.

nequalis. Sobol. 88.

agrestis. L. 88 .

alpestris, $\beta$. Whlbg. 88 .

aristulatus. Miclix. 88

candicaus. $\gamma$. Salzm. 88 .

fulvus. Smitlı. 88.

geniculatus. L. 88 .

Spr. Trin. 88.

Konradii. Opitz. 88.

paludosus. Beauv, 88 .

paniceus. Fl. dan. 88 .

pratensis. L. 88 .

Mert. Koclı, 88.

scaber. Opiz. 88.

sericeus. Gaertn. 88 .

subaristatus. Pursh. 88.

trivialis. Seidl. 88.

villosus. Gilib. 88.

Alophium, Cass. 114.

Alsinoides. Vaill, 250

Amagris. Bafin. 249. Juss. Dill. 238.

aurautia. Pers, 243.

aurantiaca. Pers, 243.

caesarea. Pers. 243.

calyprata. Lam. 243.

denudata. Sclırad. 243.

incarnata. Pers. 243.

rubra. Lanı. 241

Anuarenus. Presl. 129.

agrarius. Presl. 134.

filiformis. Presl. 134

Amaxytis. Adans. 105.

Anulygonum. Meissı. 85.

Ammophila. Host. 249.

arenaria. Link. 249.

arundinacea. Host. 249.

Amoria. Presl. 129.

liybrida. Presl. 132.

repens. Presl. 132.

Andriscus elatior. Bess. 160.

Androcera. Nutt. 1 .

Andropogon. L, 80.

bicolor. Roxb. 80 .

niger. Kuntlı. 80.

sacharatus. Roxb. 81 .

Sorghum. Roth, Boxb. 80.

Anemagrostis. Trin. 94

nemochloa. DeC. 94.

Spica venti. DeC. 95.
Anethum foeniçulum. L. 235.

pauciflorum. $\beta$. Willd, 168.

geniculatus. Host. L, var.

myosuroides. Huds. Curt. 88.

pratensis spicis digitatis.

Alsine arvensis. Crantz. 121.

Amanita. Pers. Adans, Lam.

furcata. Lam. 241.

Anacamperos. Adans. Haw. 212.

Spica venti. Trin. 95. graveolens. L. 236. minus. Gouan. 236

Pastinaca. Wibel. 156.

Anguinum. Don, 167.

Anisactis. DeC. 153.

Anisum. Adans. 139.

officinale. Moench. 237.

vulgare. Gaert. 237.

Anogra. Spach. 163.

Anoleptus. DeC. 191.

Anosporum. Nees, 20.

Anthoxanthum. L. 113.

asperum. $\gamma$. Mann. 113.

odoratum. L. 113.

paniculatum. Hort. 113.

villosuu. $\beta$. Loisl. 113.

Anthriscus. Pers. 115. 211. Cerefolium. Hoffm. 211.

procera. Bess. 116. sylvestris. Hoffm, 116.

Anthyllis. L. 121.

affinis. Britting. 122.

alpestris. W. K. Rchibch, 122.

Dillenii. Schnlth. 122.

macrocephala. $\beta$. Wender. 122.

maritima. Schweig. 122.

rubicundà. Wender. 122.

rustica. Mill. 122.

rusticana. Wender. 122.

Tournefortii. Schult. 122.

Apera. Adans. 94.

Spica venti. Beauv. 95.

Aphaca. Adans. 21.

vulgaris. Presl. 134.

Apios. Moench. 23. americana. Corn. 23. tuberosa, Moench, 23.

Apiun. L. 161. 162. 211. Anisum. Turg. Tozz. 237. Carvi officinale, Crantz. 234. Celeri. Gaert. 162. crispum. $\beta$. Mill. 161. dulce. $\beta$. Mill. 162. graveolens: L. 162. 211. hortense Petroselinum ma

ximum. C. Bauh, 161. latifolium. $\gamma$. Mill. 161 . lusitanicum. $\delta$. Mill. 162. Petroselinum. L. 161 . Petroselinum rapaceum. 161 . rapaceum. $\gamma$. Mill. 162. romanum. $\varepsilon$. Znec. 161 . tuberosum. $\delta$. Bernlı. Desf. 161.

vulgare. Lam. I61.

Arabis chinensis. Rottl. 207. nasturtium. Ciairo. 207

Aragalus. Neck. 122.

Arctium. L. Spr. 191. Lappa. L. 19I. majus. Schkr. 191. grandiflorum. $\beta$. Desf. 191. Arenaria. Adans. 121. arveusis. Wallr. 121.

Arethryon. Raf. 20.

Armoracia, DeC, 166. lapatluifolia. Gilib. 166. rusticana. Fl, Welt, 165.
Antaurea. Neck. 114.

polyplıylla. W. K. 122.

Vulneraria. L. 122. graveolens rapaceunı. 162

Armoracia sativa. Berul. 166. Atriplex hortensis, L. 196. Arnoglossum. Endl. 116.

Arrhenatherum. Beauv. 96. avenaceum. Beauv. 96. avenaceum. $\beta$. R. S. 97. avenaceum. $\beta$. bulbosum. 97 . biaristatum. Peterm. 96. bulbosum. Presl. 96. elatius. Presl. 96. precatoriunı. Beauv. 97.

Artemisia. L. 221.

Abrotanum. L. 223.

apetala. H. Pestli. 222. coarctata. Forsel. 222. Dracunculus. L. 222. humilis. B. Mill. 223. inodora. $\beta$. Willd. 222. Merkeana. Fisclı, 222. officinalis. Gater. 222. Redowskii. Ledeb. 222. umbrosa. Turcz. 222. violacea. H. Par. 222. vulgaris. L. 222. vulgaris. $\alpha$. foliosa. 222. vulgaris. $\beta$. sativa, 222.

Arundo. L. 96 . arenaria. L. 249. calamagrostis. Light. Hnds. Suter. 96. canescens. Wigg. 96. colorata. Ait. 90. epigeios. L. 96. intermedia. Gmel. 96. littoralis. Beauv. 249. stricta. Gilib. 96.

Asclion. Wallr. 248. nigrum. Wallr. 248.

Asicaria. Neck. 85 .

Aspalathoides. DeC. 121.

Asparagus. L. Spr. 198. maritiuus. Mill. 198

officinalis. L. 198.

officiualis. $\beta$. maritimus. L. 198.

officinalis. $\gamma$, altilis. Willd. 198.

prostratus. Dumort. 198. sativus. Mill. 198.

Astragaloides Cicera. Moench. 122.

Astragnalus. L. 122.

Cicer. I. 122.

Cicer. B. miuor. 123.

glaucoides. Gmel. 123

glycyphyllos. L. 122.

glycyphyllos, $\beta$. pubescens. 122.

microplıyllus. Schübl. v.

Mart. 123.

minor. DeC. 123.

perennis. Moris. 23.

Pseudơcicer. $\beta$. Opiz. 123.

rotundifolius. $\beta$. Presl 122. sylvaticus. Thal. 22. vesicarius. Lam. 122.

Atalantluus. Don. DeC. 191 . Athamanta Meum. L. 138.

Atliyrus, Neck. 21.

Atriplex. L. Spr. 196. 
Arena sativá aristata, seminibus rubidis. 75 . sativa chinensis. 76 sativa flava glumellis aristatis. 75 .

sativa flava seu aurea, glumellis muticis. 75 .

sativa glumella alba mutica. 74.

sativa glumella nigra, aristata. Sering. 75.

sativa glumella nigra mutica. Sering. 75.

sativa nigra. L. 75 .

sativa nuda. 76 .

sativa praecox. 74.

sativa praegravis. 74 .

sativa, seminibus grandius-

culis nudis. 76 .

sativa trisperma. 74 .

sativa turgida. 74 .

sesquitertia. L. 99.

sesquitertia. Willd. 78.

spicata, Gilib. 99.

splendens, Aut. Gall. 99.

strigosa. Schreb. 77.

tartarica. Ard. 76 .

trisperma. Hort. 71.

unilateralis. Sering. 76.

vesca. Lobel, 71.

Avenella. Koch, 98.

Avicularia. Meissn. 85.

\section{IB.}

Banibusella. Rchbch.. 78.

Baldingera arundinacea. Dumort. 90.

colorata. Fl. Wett. 90.

Barba jovis. Adans. 121.

Bassovia. Aubl. 1.

Baumerta Nasturtium. Fl. Wett. 207.

Baumannia. Spach. 163.

Berula. Koclı. DeC. 159.

Beta. L, 29. 196.

altissima, Beckm, 30.

Cicla. L. 30, 196.

Cicla alba. 196.

Cicla altissima. 30.

crispa. $\beta$. Tratt. 29.

hortensis. Mill. 30.

rubra, C. Bauh. 29.

sativa. Bernh. 30.

vulgaris. L. 29.

vulgaris. L. var. 30.

vulgaris rubra major. 29.

Bidona. Adans. 245.

Bilderdykia convolvulus. Dumort. 119 .

Bistorta. Adans. L. 85.

Blitum. L. Spr. 195.

bonus Henricus. Meyer, 196.

capitatum. L. 195.

capitatum. Sturm, 195.

chenopodivides. $\beta$. Lam. 195.

virgatum. L. 195.

virgatum. Schkr. 195.

B oisduvalia. Spach. 163.

Boletus. Dill. 244.

bovinus. L. 244.

buglossum. FI. Dan. 245.

bulbosus. Schaeff. 244.

circinans, Albo et Schw, 244.
Boletus c ássipes. Schuh. 244. $\mid$ Brassica oleracea capitata 174, dulcis. Pers. 244.

edulis. Bull, 244.

esculentus. Balt. 246.

frondosus. Fl. Dan. 244. gregarius. Fl, Dan. 244. liepaticus. Lightf. 245. mitis. Pers. 244. juglandis. Schaeff. 244. platyporns. Pers. 244. ramosissimus. Schaeff. 244. reticulatus. Schaeff. 244. squanosus. Huds. 244. tuberosus. Pers. 244. unbrinus. Pers. 244.

Borago. L. 209. officinalis. L. 09 . Brachiaria. Trin. 78. Brachycerca. Presl. 21. Brachylobos. DeC. 207: Bracliypiptum. DeC. 206.

Brachypodium. Beauv. 110. caespitosum. R. S. 110. contractum. $\beta$. Presl. 110. loliaceum. Link. 108. pinnatum. R. S. 110. rupestre. R. S. 110. tenue. $\beta$. Beauv. 111. Brachystylis. DeC. 160 . Bradlea. Adans. 23.

Brassica. L. 24. 172. alba crispa. Bryant. 178. alba prnecox. Mill. 175. arborea, Mill. 172. asparagoides. DcC. 183. asperifolia. Lam. 27. asperifolia. $\gamma$. Lam. 24 . botrytis. Mill, 172

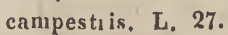
campestris Napobrassica. DeC. 27.

campestı is pabularia. DeC. 27. 185.

capitata. Hort. 172.

cauliflorn. Bryant, 181.

Erucoides. Horn. 172.

fimbricata. Hort. 172.

gongylodes. Mill. 172.

italica alba. 184.

laciniata Mill, 172.

italica purpurea. 184.

lapponica, 28.

maxima. Whistl. 26.

muscovitica. Mill. 172.

Napella. $\beta$. Vill. 24.

napobrassica. Mill. 172.

Napus. L. 27. 185.

Napus pabularia. 185.

Napus rapifera. 27.

oleifera. Moench. 27.

oleracea. L. 172.

oleracea. Spr. 27.

oleracea acephala. 178.

oleracea acephala vulgaris. 179.

oleracea arborea, 179.

oleracea arvensis. Lam. 27. oleracea asparagoides. C.

Baul. 183.

oleracea asparagoides capensis. 184.

oleracea botrytis. 181.

oleracea botrytis cymosa. 183.
175.

oleracea capitata alba. 175.

oleracea capitata alba com.

pressa. 175.

oleracea capitata bullata.

177.

oleracea capitata canadensis. 175. maxima. 175.

oleracea capitata crispa. 177.

oleracea capitata elliptica. 176.

oleracea capitata fimbriata.

175.

oleracea capitata polycephala. 179.

oleracea capitata pyramidalis. Mill. 176.

oleracea capitata pyranida-

lis alba. 176.

oleracea capitata serotina

compressa major. 175.

oleracea cauliflora seu botry-

tis. DeC. 181.

oleracea caulo-rapa. 184.

oleracea fiubriata pumila. 181.

oleracea fruticosa. 174.

oleracea fruticosa hortensis. 174.

oleracea fruticosa sylvestris. 174.

oleracea gemmifera. DeC. 179.

oleracea gongylodes. 184.

oleracea gongylodes alba. 185.

oleracea gongylodes oblonga. 185.

oleracea gongylodes violacea. 185.

oleracea laciniata. L. 180. oleracea Napobrassica Rutabaga. 28.

oleracea non capitata. 178. oleracea prolifera. 179

oleracea sabauda. 177.

oleracea sabauda. 1 Mill. 177.

oleracea sabellica. L. 180.

oleracea sabellica non capitata. 180 .

oleracea sativa rubra aperta

laevis. 180.

oleracea Selenisia. L. 180.

oleracea Selenisia. Mill. 180.

oleracea Selenisia foliis va-

riegatis. 181

oleracea sylvestris. L. 174.

oleracea viridis, 8 Mill. 177.

peregrina. Mill. 172.

praecox, Hort. 172.

praecox. Mill. 176.

pyramidalis. Hort. 172.

pyramidalis. Mill. 176.

Rapa, L. 24.

Rapa depressa. 26.

Rapa oblonga. DeC, 26. oleracea capitata canadensis

oleracea capitata laevis. 175 .

oleracea capitata rubra. 177. oleracea Napobrassica. L. 27.

oleracca sibirica. 181.

oleracea viridis. L. 179. 180.

Brassica Rapa rapifera, 24.

Rapa sativa minima. 27.

Rapa sativa oblonga. 26.

Rapa sativa oblonga, radice atro-punicea. 26.

Rapa sativa oblonga, radice candida. 26.

Rapa sativa oblonga, radice flavescente. 26.

Rapa sativa oblonga, radice punicea. 26.

Rapa sativa, radice brevi. 27.

Rapa sativa rotunda, 26.

Rapa sativa rotunda, radice candida. 26.

Rapa sativa rotunda, radice foris et intus flavescente. 27.

Rapa sativa rotunda, radice punicea. 26.

Rapa sativa rotunda, radice supra terram viridi. 27. rotunda. Mill. 172.

rubra. Hort. 172.

sabauda. Hurt. 172.

sabellica. Hort. 172.

sabellica. Suck. 180.

selenisia. Hort. 172.

Silenisia. L. 180.

sylvestris. Mill. 172.

viridis. Hort. 172.

tuberosa. Salisb. 24.

Brassiacastrum. ILink. 24.

Brela. Less. 187.

Briza. L. 102.

media. L. 102

monococcos. Lobel. 56.

tremula. Lam. Koel. 102.

virens. Bbrst. 102.

viridis. $\beta$. Pall. 102.

Bromus. L. 102.

agrarius. Hornung. 103.

agrestis. All. Host. 109.

altissimus, Gilib, 104.

altissinus. Weber. 109.

angustifolius. Schrank. 109.

aquaticus. Gmel. 108.

arenarius. $\delta$. Th. Desmas.

103.

arundinaceus, Roth. 108.

arvensis. Lam. Pollich, 109.

arvensis. L. 104.

arvensis. Weigel. 103.

asper. L. 109.

asper. Pollich. 109.

bohemicus. Schmidt. 110.

caespitosus. Host. 110.

ciliatus. Fisclı. 105.

commutatus. Schleich. 103.

compactus. $\gamma$. Hort. 103.

corniculatus. Lam. 110.

disticlius. Moench. 104

dumetorum. Lam. 109.

Ehrharti. Roem. 103.

elatior. Koel. 108.

elongatus. $\beta$. Gaud. 103.

enermis. L. 109.

erectus. Huds, 109.

erectus. $\beta$. arvensis. Huds. 104.

fragilis. Lam. 110 
Bromus vitiosus. Weig. 103. Buceras. Moench. 136. Foenum graecum. All. 136. Buda. Adans. 121.

Buglossus. Whilbrg. 245.

Bulbocastanum. Adans. DeC. 23.

majus. C. Bauh. 23.

Bunium Bulbocastanưm. L. 23. Carvi. Burst. 234. minus. Gouan. 23.

\section{C.}

Cabrera. Lagasc. 78.

Calamagrostis. Adans. Roth.96. arenaria. Rotlı, 249. Aruudo. Rotlı. 98. cauescens. Beauv. 96. colorata. Sibtl. 90.

Epigeios. Roth. 96. Hubneriana. $\beta$. Rchbelı. 96. lanceolata. With. DeC. 96. Leersii. Koel. 98. variegata. With. 90.

Calamintha. Moench. 226. nenthaefolia. Host. 226. moutana. Lau. 226. officinalis, Moench. 2?6. umbrosa. Rehbch. 226. vulgaris. Sweet. 226.

Calcitrapa. Juss. Gärt. 114.

Callicephalus. Meyer. 114.

Callistachya. Rafin. 209.

Colotheca. Beauv. 102.

Calylophis. Spaeh. 163.

Calymorplum. Presh 129.

Cambylorutis. Sering. 128.

Cameraria. Dill, 250.

Campella caespitosa. Link. 98.

Cantharellus. Adans. 243. cibarius. Fries. 243.

Capoecum. L. 233.

Capsicum annuum. L. 233.

Cardamine. L. 208.

amara. $\beta$. Lam. 208.

deutata, Schult. 208.

foutana. Lam, 208.

pratensis. L. 208.

scaturiginosa. Whlbrg. 208. sylvatica. Bess, 208. uliginosa. Bbrst. 208.

Cardaninum. DeC. 207. Nasturtium. Moench. 200.

Cardamon. DeC. 206.

Cardaria. Desv. DeC. 206. latifolia. Spach. 231.

Cardiolepis. Wallr. 206.

Carduus. L. Spr. 188. acanthifolius. Lam. 187. acanthoides. Schl. 188. apenninus. Jan. 188. aretioides. Schl. 188 crispus. I. 188. lanceolatus. L. 187. montosus. Pollin. 188. wultiflorus. $\beta$. Gaud. 188. nutans. L. 188 . oleracus. Pers. 187. palustris. L. 187. polyanthenus. Schl. 188. Carmelia. DeC. 120. Carota. DeC. 153. Carum. L. 23. 234.
Carum Bulbocastanun. Koch. 23.

Carvi. L. 234 .

Carvi. DeC. 23.

Catabrosa helodes. R. S. 91. pumila. R. S. 91 .

Caucalis Carota. Roth. 153

Celeri. Adans. 162.

Centaurea. L. 114.

affinis. $\xi$. Frivald, 116.

badensis. $\varepsilon$. Tratt. 115.

coriacea. $\delta$. W. K. 115.

decipiens. $\varepsilon$. Thuil, Pers. 115.

decunibeus. $\gamma$. Thuil. 115 . Jacea. L. 115 .

Jaceá $\beta$ decumbens 115 .

Jacea prandiflora, Gaud. 115.

italica. $\beta$. Lam, 115.

nollis. $\delta$. Schleich. 115.

nigra. Lam. 115.

prateusis. $\beta$. Thuil. 115.

Scabiosa. L. 115.

siuplex. Murr. 115.

sylvatica. Pourr. 115.

teuuifolia, $\gamma$. Schleich, 115.

Centaurinm. Cass. 114.

Cepa. Neek. Adans, Moench. 167.

prolifera. Moench, 172.

Schoeno prasum. Moench.

171.

ventricosa. Moencl., 169.

vulgaris. Bernl. 168.

Cephalonoplos. Neck. DeC. 187.

Ceranthera. Rafin, 1.

Cerefolium sativum. Bess, 211. sylvestre. Riv. 116.

Chaerophyllum. L. 160. alpinum. $\beta$. Vill. 116. bulbosum, L. 160 Cerefolium. Crantz. 211. magellense. $\gamma$. Tener, 116 . odoratun. Lam. 160. sativım. Lam. 211. sylvestre. L. 116. verticillatum. Pers. 160.

Chaetostacliys. Benth. 231.

Chamaeleon. DeC. 187 .

Chamaenerion. Adaus. 163.

Chartolepis. Cass. 114.

Chascolytrum. Desv. 102.

Cheirolophus. Cass. 114.

Chenopodium. L. Sp. 19 t album. L. 195.

Atriplicis. Heyn. 195.

bollus Henricus. L. 196. caudicans, Lam. 195. catenulatum. Schleich. 195. coneatenatum. Thuil. 195. glonerulatum. Rehbch. 195 Halimus. Thunl. 197. lanceolatum. Merat. 195. leiospermum. DeC. 195. paganum, Rchbch. 195. portulacoides. Thunl. 197. sagittatum. Lam. 196. salium. Hamilt, 195. viride. L. 195.

Chloris Cynodon. Trin. 89. maritima. Trin. 89.

Choretropsis. DeC. 114 .

Chromolepis. Cassin. 188.

Chronosenium. Sering. 129.
Chrysoraphanus. C. A. Meyer. 207.

\section{Cicer. L. 147.}

arietinum. L, 148 .

Lens. Willd. 148.

nigrum. $\beta$. Hort. 148.

physodes. $\beta$. Relibch, 148. sativum. 148.

sativum. $\gamma$. Schkr. 148.

Cicereala atrata. Moencli. 149.

Cichoreun Cicorea. $\beta$. Dumort. 205.

Ciclıorium, L. 204.

Cosnia, $\gamma$. Hamilt. 204.

crispum. $\beta$. Mill. 204.

crispum, $\beta$. Pers. 205.

Endivia, L. 204.

Jntybus. L. 205.

pumilum. Jacq. 204.

sylvestre. Law. 205.

Cicutaria bulbosa. C. Baul. 160.

Cirsium. Adans. 187. lanceolatum. Scop. 187. oleraceum. All. 187. palustre. Scop. 187. variabile. Moench. 187.

Citrullus. Neck, 217.

edul is. Spach. 214.

vulgaris. Schrad, 214.

Clavaria. Vaill. 247.

acroporphyria. Schaeff. 247. amethystina. Bull. 247. aurea. Schaeff. 247.

Botrytis. Pers. Spr. 247. coralloides. Bull. 247.

coralloides. Scop. 247.

diclotoma. Pers. 247.

fastigiata. L, 247.

flava. Pers. Scliaeff. 247.

flavescens. Schaeff. 247.

plebeja. Walf. 247.

purpurea. Schaeff. 247.

rubescens. Schaeff. 247.

Clomium, Adans. 188.

Clymenum. DeC. 21.

Cnicus lanceolatus. Willd. 187

lucidus. $\beta$. Wall 188

oleraceus, L. 187.

palustris. Willd. 187.

pratensis. Lam. 187.

Cnicus palustri-tuberosns. Schiede. 187.

Cochlear. DeC. 166.

Cochlearia. L. 166. 210.

Arnoracia, L. 166.

danica. $\beta$. Gunn, 210.

grönlandica. With. 210.

officinalis, L, 210 .

officinalis, $\gamma$. rotundifolia. 210.

renifolia. Stock. 210.

rusticana, Lam. 116.

variffolia. Salib. 166.

Cochlidiospermum, Rehbch. 209.

Codonoprasum. Rehbch. 167.

Coelorutis. Sering. 128.

Comostemum. Nees. 20.

Coprinus. Pers. 238.

Coralloides. Tournef. 247.

Coreopsis. Cass. 19.

Georgina nuda. Cass. 19.

Coriandrum. L, 234.

Coriandrum majus. Gollan. 234. umicrocarpum. $\beta$. Y) C. 234. sativum. L. 234.

Cornicina. DeC. 121.

Coronilla. L. 123.

varia. L. 123.

Coronopus. Endl, 116.

Corynephorus. Beauv. 98. canescens. Beauv. 98.

Corynotrichum, DeC, 187.

Crambe. L. 186 .

maritima. L. 186.

Cratericarpium. Spach, 163.

Crocodilium. Vent. 114.

Crocus. L. 232.

autumnalis. Smith. 232.

hybernus. Frivald. 232.

of ficiualis. Pers. 232.

sativus. L. 232.

Cucumis. L. 212.

anguinus. L. 217.

bucharicus. Hort. 215.

Cantaloa. Hort. 215.

Citrullus. Sering. 214.

Dudaim. L. 214.

erivanicus. Hort. 215.

flexuosus. L. 214.

maltensis, Sering. 21 i.

Melo. L. 215.

doratissinus. Moench 214

reflexus. $\beta$. Zeyh. Hort. 214.

reticulatus. Hort. 215.

saccharinus. Hort. 215

sativus. L. 213

verrucosus. Hort. 215.

viridis. Hort. 215.

Cucurbita. L. 217.

Anguria. Duch, 214.

Citrullus. L. 214.

maxima. Duch. 218.

Melopepo. L. 218.

Melopepo, L. var. Spr. 218.

Pepo. L. 217.

pinnatifida. Schrank. 214.

polymorpha Melopepo. Duch. 218.

polymorpha oblonga. Duch. 217.

Potiro, Pers. 218

radiata. $\beta$. Hort. 218 .

Cunila, thymoides. L. 225.

Cyanoseris. Koch. 200.

Cyanus. Gärt. 114.

humilis. Fl. Wett. 115.

Jacea. Fl, Wett. Baumg. 115. Scabiosa, Moench. 115.

Cynara. L. Spr. 188.

Cardunculus. L. 188

Cardunculus. L. var. Spr. 189.

hortensis. $\beta$. Mill. 188.

Scolymus. L. 189.

sylvestris. Lam. 188.

Cynocardanum. Webb. 206.

Cynodon. Rich. 89.

Dactylon. Rich, 89

linearis. Willd. 89

maritimus. H. B. 89. 
E.

Echinobrychis. DeC. 124.

Echinochloa. Beauv. 78. commutata. Schult. 89 composita. Prex. 89.

Crus-corvi. Beauv. 89. Crus-galli. Beauv. 89. Crus-pavonis. Schult. 89. echinata. Beauv. 89. hispida. Schult. 89 . intermedia. R. S. 80 .

Echinolaena erythrosperma. R. S. 80 .

Echinus. Hall. 245.

Ellipsaria. DeC. 206.

Elymus. L. 113 .

arenarius. L. 113

caninus. L. 111 .

caninus. $\beta$. Roth. Leers. 110. dunietorum. Hoffm. 110. europaeus. Willd. 113.

Elvella. L. 245.

Mitra. Schaeff. 245.

Emerus. Neck. Mill. Adans. 123.

Encoelia. Hill. 248.

Endivia crispa. C. Baulı, 205.

Enodium coeruleum. Gaud. 102 littorale, Relıbch. 102. sylvaticum. Link. 102.

Epitrachys. DeC. 187.

Erinacea. Adans. 121

Eriolepis. Cass. DeC. 187. Ianceolata. Cass. 187.

Erobatos. DeC. 237.

Eruca. DeC. 24.

Erucastrum. DeC. 24.

Ervilia. Link. 136.

Ervum. L. 136. 148.

Ervilia. L. 137.

filiforme. Roxb. 137. gracile. $\beta$. DeC. 137. hirsitum. L. 137.

Lens. L. 148.

longifolium. Tenor. 137.

plicatum. Moench. 137. sativa. Link. 137. tenuifolium. Lagase. 137. tenuissimun. Bbrst. 137. tetraspermum. L. 137.

Euatriplex. Meyer. 196.

Eubrychis. DeC. 124.

Euchaerophyllum. DeC. 160.

Eucichorium. DeC. 204.

Euheracleum. DeC. 120.

Eulathyrus. Ser. 21 .

Eulotus. Sering. 125.

Euphaseolus. DeC. 140.

Euscorzonera. DeC. 157.

Eusium. Koch. 159.

Eusonchus. DeC. 191.

Eustachya. Rafin. 209.

Eutrichosanthes. Wight. Arn. 217.

Eutriphyllum. Sering. 129.

\section{F.}

Faba. Adans, Juss, 135. major. Desf. 150. minor equina, C. Bauh. 150. sativa. Autor. 150. vulgaris. Mill. 150.
Fabricia. Adans. 231. Fagopyrum. Moench. Gaertı. 85.

carinatum. Moench, 119. esculentum. Moench. 85. saracenicum. Dumort. 85. tataricum. Gaertn. 87.

Fagotriticum, L. 85.

Falcatula. Brot. 136.

Favolus. Beauv. 243.

Fedia. Gärt. Vahı. 206.

Locusta. Rchbch. 206.

olitaria. Vahl. 206.

striata. Steven. 206.

Ferula graveolens. Spr. 236.

Festuca. L. 106.

adscendens. Retz, 108.

airoides. Lam. 91.

altissima, All. 108.

amethystina. Schleich. 106.

arenaria. 0sb. 107.

arundinacea. Schreb. 108.

aspera. M. K. 109.

asperrima. Hornem. 91.

baltica. Hornm, 107.

barbata. Schrank. 107.

bromoides. L. var. Spr. 110.

caesia. Smith. 106.

calamaria, Smith, 108.

calcarea. Tausch. 106.

cambrica. $\xi$. Huds. 107.

capillata. $\beta$. Lam. 106.

cinerea. Vill. DeC. 107.

coerulea. DeC. 102.

cristata. Vill. 101.

curtana, Autor. 106.

curtana, Lejeun. 107.

curvata. $\beta$. Antor. 108.

curvula, $\gamma$. Gaud. 106.

dactyloides. Roth. 101.

debilis. Schleich. 106.

decidua. $\beta$. Snith. 108.

dumetorum. L. 106، 107.

dunetorum. Rafin. 107.

dura. Host. 106.

duriuscula. L. 106. 107.

duriuscula. Pollisch. 106

duriuscula, Weihe. 107.

duriuscula. $\beta$. Whlbrg. 106.

duriuscula. $\varepsilon$. curvula. 107.

duriuscula, $\delta$. nemoralis.

107.

durinscula. $\beta$. subvillosa.

107.

duriuscula. $\gamma$. villosa. 107.

duriuscula, $\xi$. vivipara. 107.

duriuscula var, dumetorum.

Gaud. 107.

elatior. L. 108.

elongata. Elirh. 108.

erecta. Wolbr. 109.

Eskia. Lejeun. 106.

fluitans. Leers. 108.

fluitans. L. 93.

fluitans. $\gamma$. pratensis, Huds. 108.

gigantea. Vill. Sm. 108.

glabra. Lightf. 107.

glauca. Bbrst. 106.

glauca. Schrad. Lam. 106. glomerata. All. 105. lieterophylla. Haenk. 107. heterophylla. Spr. 106. heterophylla. Suter. 107.
Festuca heterophylla. Weihe, 107.

hirsuta. Host. 106.

hirta. Seen, 109.

hybrida. Brot. 110.

inernis. DeC. 109.

inermis. $\beta$. villosa. 110.

intermedia. R. S. 106.

intermedia, $\gamma$. Koel. 108.

involuta. Moench. Schleich. 106.

laevigata. Clairv, 106.

laevigata. Schleiclı. 106.

latifolia. Host. Willd. 108.

Lemanıii. Lejeun. 106.

Leysseri. Moench. 109.

linearis. Gilib. 110.

loliacea. Lam. 108.

loliacea. L. 108.

longifolia. Thuil. 106.

longifolia. Vivian. 106.

mouandra. Ell. 110.

montana. Savi. 109.

moutana. $\beta$. villosa. 109.

montis celtici. Delarb. 107.

multiflora. Hoffm. 107.

multiflora. $\delta$. Schleich. 106.

mutica. $\gamma$. Schleich. 106.

Myurus. L. 110.

nemorosa. Latour. 107.

nemorum. Leyss. 106. 107. nigra. Gilib. 106.

nutans. Moeneh, 111.

oraria, Dumort. 107.

ovina. L. 106.

ovina. Schrad. 106.

ovina, L. var. Trin, 106.

ovina. $\beta$. tenuifolia. 106 ,

o vina. $\beta$. villosa, Schrad. 106.

ovina. $\gamma$. villosa. 106.

ovina. $\delta$, vivipara. 106.

pallens. Host. 106. 107.

paludosa. Gaud. 106.

pauciflora. Schleiclı. 106.

Phoenix. Thuil. 108.

Phoenix. Vill. 108.

pinnata. Moench. Koel. 110.

poaeformis. Pers. 109.

poaeoides. Thuil. 109.

poliantha. Hrb. 107.

pratensis. Huds. Schrad, 108. pratensis. Schreb. 107.

pseudomyurus. $\beta$. Willem. 110.

pungens. Daval. Schult. 106.

ramosa. Cass. 110.

repens. Knapp. 107.

rubra. L. 107.

rubra. $\varepsilon$. Witl. 106.

rubra arenaria. Fries. 107.

rubra. $\varepsilon$. diversifolia. Gaud.

107.

rubra. $\gamma$. lanuginosa. 107. rubra. $\gamma$. lanuginosa. $M$. K. 107.

rubra. $\delta$. latifolia, 107.

rubra, $\delta$. megastachya, Gaud.

$$
107 .
$$

rubra. $\beta$. villosa. 107 .

rubra. $\beta$. villosa et subvil.

losa. M. K. 107.

rubra. $\varepsilon$. vivipara. 107.

siracusana. Jan. 107.

Festuca spadicea. Moench. 108. Hedysarum Onobrychis. L. 124. speciosa. Schreb. 109. stricta. Host. Gaud. 106. stricta. Schleicl. 107. strictifolia. Opiz. 106. sylvatica. Vill. 108. tenuifolia. Schrad. 106. trichophylla. Ducros. 107. triflora. Smith. 108. varia. Schleich. 107 villosa. Baer. 107. viridis. Panzer. 107. vivipara. $\delta$. Smitli, 106.

Festucarca Heisteri. Fabric. 93. Fibichia umbellata. Koel. 89. Fistulina. Bull. 245. buglossoides. Bull. 245. liepatica. Rabh, 245.

Flexularia. Rafin. 78.

Focniculum. Adans. 235.

azoricunt. Hont. 235. 236.

Carvi. Link. 234.

dulce. 236.

officinale. All. 235.

rigidum. $\gamma$. Brot. 235

vulgare. Gaert. 235.

vulgare gerinanicum. 236.

vulgare italicun. 236.

Foenugraecum. Adans. 135.

Foenum graecum officinale. Moench. 136.

Fragifera. Koch. 129.

Fungarius. Adans. 238.

Fungoides. Tournef. 248.

Fungus piperatus. C. Bauh 241.

\section{Cr.}

Galasia. Less. 157.

Galearia. Presl. 129.

fragifera. Presl. 134.

Galega. L. 123.

a fricana. $\beta$. Mill. 124.

officinalis. L. 124.

vulgaris. Lam. 124.

Gelasia. Cass. DeC. 157.

Gelona. Adans. 238.

Georgia. Spr. 19.

Georgina. Willd. 19. purpurea. Willd. 19. superflua. DeC. 19. variabilis. Willd. 19.

Glandestinaria. DeC. 207.

Glanduliloba. Rafin. 78.

Glyceria. Beanv. 93. aquatica. Whlbg. 94.

fluitans. R. Br. 93.

spectabilis. M. et K, 94 .

Glycine Apios. L. 23.

Godetia. Spach, 163.

Grammocarpus. Sering. 136. Koclı. 128.

Gynnocimum. Benth. 223.

Gymnosphace, Bentl. 120.

\section{H.}

Halimus. Waltr. 196. australis. $\beta$. Nees. 197. portulacoides. Wallr. 197.

Hamosa glyciplıylla. Medic. 122.

Harpostachys. Trin. 78. 
Hordeum hexastichon, Forsk. 62.

liexastichon. L. 67 .

Lexastichon, spica brevi. 68 .

hexastichon, spica longa. 68 . imberbe. $\gamma$. DeC. Schübl. 68 leporinum. $\gamma$. Link. 112. maritimum. Fl. Dan, Rotlı. 112.

naximum. Vill, 112. nulticaule. Hort. 62. murinum. L. 112. murinnm. $\beta$. L. 112. murinum. $\beta$. chileuse. Brongn. 112.

nigrum. Schübl, 66.

uigrum. $\gamma$. Willd. 62 . nodosum. L. 112.

nudum. Schübl. 69. plumosum. Gilib. 62. polystichum. Hall. 62. polystichum vermum. Moris. 65.

pratense. Huds. 112. ramosum seu frutescens. Viborg. 69. sanguin eum. Hort. 62. sativun. Pers. 62. secalinum. Sclireb. 112. sibiricum. B. Link, 42 . villosum. Moench, 113. vulgare. L. 62. vulgare, $\beta$. Lam. 67. vulgare hibernum. 65 . vulgare nigrum. 66. vulgare seminibus nigris. 66 . vulgare, seninibus nudis. 66 . vulgare spica brevi coeru. lescente. 66 .

vulgare, spica flavescente. 65.

vulgare spica longa coerulescente. 65 .

vulgare var. coeleste. L. 66 . vulgare var. $\beta$. seminibus vestitis. Sering. 66 . Zeocriton. L. 70.

Horninum. Benth, 120. pratense. Riv. 120.

Hyala ea. DeC. 114

Hydnum. L. 245.

Erinaceus. Bull, 245. imbricatum. Willd, 245. repandum. L. 245. sinuatum. Bull. 245. squa mosum. Schaeff. 245 .

Hydrochloa aquatica. Weber. 94.

coerulea. Hartm. 102

flnitáns. Hartm. 93.

Hymenobrychis. DeC. 124.

Hymenocarpus. Savi. Sering. 126.

Hymenocentron. Cass. 114 .

Hymenosphace. Benth. 120.

Hypodris. Pers. 244.

Hypophaestum. Gray. 114.

Hyssopus. L. 228.

alopecuroides. Fisch. 229.

Fischeri. Hort. 229.

myrtifolius. $\beta$. Desf. 229. officinalis. L. 229

ruber. Mill, Bernh. 229.

Schleicheri, $\gamma$. G, Don. 229. Ledebouria, Link, 139.
Jacea. Juss, Vent. 114 pratellsis. Cass. 115. Scabiosa. Lam. 115. Jueris. Adans. 206. Jchnantlus. Beauv. 78. Jnvolucraria, Sering. 217. Jonopsidium, DeC. 166. Jsachue. R. Br. 78 . Jschnanthus. Röm. Schult. 78.

\section{I.}

Kandis, Adans, DeC. 206. Kentia. Adans, 136. Kernera. DeC. 166. Knautia, DeC. 117. arvensis. Coult. 118.

Knavel. Adans. 137. annuum. Scop. 137. Kneiffia. Spach. 163.

Koeleria. Pers. 101. cristata. Pers. 101. gracilis. $\gamma$. Pers. 101. grandiflora, $\delta$. Bertol, 101. mollis. $\varepsilon$. Maun, 101.

Krokeria. Moench. 125.

Kulma, Adans. 238

\section{耳,}

Lactarius. Pers. 238.

Lactuca, L, 200.

Lägo ecia cuminoidcs. Willem. 234.

Lagopus. Sering. 119.

Lapathum. Adans. Moench. 193. Acetosa. Scop. 194. alpestre. Scop. 194.

liortense. Lam. Moen clı, 193. pratense. Lam. 194. sculatun. Lain, 194.

Lappa. Adans. DeC. 191. Bardana. Moeuch, 191. glabra. $\beta$. Lam. 191. major. Gaertn. 191. major. $\beta$. foliosa. 191. officinalis. All. 191.

Lascagrostis variegata. Meyer. 100.

Lasiospermum. Fisch. 157.

Lasiospora. Cass. DeC. 157.

Lasiospron. Benth. 140.

Lathyrus. L. 21. 134. 140. anpustifolius. Coes. 22. Aphaca. L. 134. attenuatus. Vivian. 22. Hallersteinii. $f$. Baumg. 135. Lens. Peterm. 148. montanus. Bernl. 22. oleraceus. $\beta$. Lam. 147. pratensis. L. 135. sativus. L. 149 . segetum. Lam. 134. semimaculatus. $\beta$. Hort. 149. semipunetatus. $\gamma$. Hort. 149. tuberosus. L. 22.

Lavauzia. Spach. 163.

Lavendula. L. 231. angustifolia. $\alpha$. Bauh. 231. latifolia. $\beta$. Bauh, 231. spica. L. 231 ,
Leipoteriun. Ded. 118. Lemia. Vandel. 198.

Lens. Sering. 136. esculenta. Moench. 148. sativa, Hall. 148. vulgaris. C. Baul. 145 . Lepia. Desv. DeC. 206.

Lepia sativa. Desv. 207. Lepidiastrum. DeC. 206. silipuosus. L. 152. tanricus. Hort. 125. tenuifolins. $\varepsilon$. Pollisch. 125. tenuis, Kit. 125. villosus. $\delta$. Thuil, 125

Lepidium. L. 206. 230. latifoliun. L. 231 . sativum. L. 207. sativum crispum. 207.

Leptandra. Nutt. 209. Lepteranthus. Neck. 114. Leptocrambe. DeC. 186. Leptospron. Benth. 140. Leucantlia. Gray. 114. Ligusticum capillaclum. Lam. 138.

Carvi. Roth. 234. foeniculum. Roth. 236. Meum. Crantz. DeC. 138. Podagraria. Crantz, 130. Loefflingia hispanica, Hort. 137. Lolium. L. 111. agreste. Hort, 111. annuum. Bernlt. 112 . arveuse. With, 112. asperum. Roth. 112. compositun. $\gamma$. Thuil. 111 . cristatum. Hort. Pers. 111. Halleri. Gmel. 111 . Iatum. Roth. 111. multiflorum. Koel. 112. perenne. L. 111. perenne italicum, 112 perenne Russelianun. 112 perenne Stickneyi. 112. perenne tenue. 112. perenne Witıwortii. 112. ramosum. Hort. 111. remotum. Hoffm. Schrank. temulentum. Huds. 112 , tenue. Bbrst. 112. tenue. L. 111 . vulgare. Host. 111.

Lophiolepis. Cass. DeC. 187. dubia. Cass. 114.

I ootea. Medic. 125.

Lotus. L, 125.

alpinus. $\varepsilon$. Schleich. 125. angustifolia. Lam. 200. arvensis. $\beta$. Schkr. 125. capitata. Hort. 200. ciliatus. $\gamma$. Tenor. 125. corniculatus, L. 125. corniculatus. $\alpha$. campestris. Wallr. 125.

corniculatus. $\gamma$, tenuifolius. Wallr. 126. crassifolius. $\eta$. Pers. 125 . crispa. Roth. 200. decumbells. Forst. 125. depressus. Willd, 125. Forsterie. Sweet. 125. humi fusus. Willd. 125 . laciniata. Roth. 200. Iongifolia, Lam. 200.

Lotus maritimus. L. 152. paluata. Willd. 200. pratensis. Mill. 152. riparius. Э. Pcrs. 125. romana. Hort. 200. sativa, L. 200. sativata capitata. 201. Ludolfia. Adans. 193. Lupinaster. Moenclı. 129. Lupsia. Neck. 114. Lupularia. Seriug. 126.

Lyclinoides. DeC. 117.

Lycoperdon gulosorum. Scop. 248.

Tuber. L. 248 .

Lycopersicum tuberosum. Mill. 1.

\section{NI.}

Macroptilinn. Benth. 140.

Mais. Mirb. Adans. 81.

Majorana. Moench. Benth. 219. crassa. $\beta$. Moench. 219. hortensis. Moench. 219. vulgaris annua. Moris. 219. Malabaila. Hoffu. 156.

Manina cordiformis. Scop. 245. Martella. Adans. 245.

Maslichina. Adans. Benth. 224. Mauchartia, Neck. 159.

Mays americana. Baumg. 81 . vulgare. Sering. 81 .

Zea. Gaertı. 81.

Medica. Mill. Adans, Lam. 126.

Medicago. L. 126. annularis. $\beta$. Bess. 127. corymbifera. $\beta$. W. L. $\mathrm{E}$. Schmidt. 127.

falcata. Lam. 127.

falcata. L. 127.

falcata. $\beta$. montaua, 127 .

falcata. $\gamma$. pratensls. 127 .

falcata. $\alpha$. riparia. 127.

falcata. $\delta$, versicolor. 127 .

lupulina. L. 127.

lupulina. $\delta$. corymbosa. Se. ring. 127 .

lupulina, $\gamma$. unguiculata, Sering. 127.

media. $\gamma$. Pers, 127. mniocarpa. Wallr. 127.

sativa. L. 126.

sativa var. flor. pallide. coeruleis. Willd. 127. Willdenowii. Merat. 127. Megapterium. Spach, 163. Melanoloma. Cass. 114.

Melica. L. 100.

altissima. $\beta$. Sobol, 94 amethistina. Pourr. 100. aquatica. Weber. 94.

ciliata. L, 100.

coerulea. L. 102.

cristata. Trin. 100.

divaricata. Meig Wenig. 102. Gmelini Roth. 101.

hirsuta. Koel. 101.

Lobelii. Vill. 101.

montana. Huds. 100.

nutans. Lan, 101.

nutans. L. 100.

provincialis. $\beta$. Clar. 100. uniflora, Retz. 101. 
Microcentrum, Cass. 188. Microchloe. Benth. 140.

Microlophus. Cass. 114.

Micromeria montana. Rchbch. 230.

Micropodium. DeC. 24

Microporus. Beauv. 243.

Microsphace. Benth. 120.

Miliaria. Trin. 78.

Miliarium effusum. Moench. 94.

Milium. L. 94.

attenuatum. $\beta$. Moench. 79. confertun. $\beta$. Mill. 94.

Crus-galli. Moench. 89.

Dactylon. Moencli. 89.

effusum. L. 94 .

esculentum. Moench. 79

panicum. Mill. 79 .

scabrum. Merlet. 94.

vernale. Van. Hall. 94.

Millefolium. Adans. 114.

Moenchia. Medic. 167.

Molinia. Koeler. 101.

altissima. $\beta$. Link. 102.

arundinacea. Sclirank. 102.

coerulea. Moench. 102.

coerulea major. 102.

littoralis. Host, 102.

sylvatica. Link. Wredow. 102.

varia. Schrank. 102.

variabilis. Wibel. 102.

Molium. Don. 167.

Moly. Moench. 167.

Montia. L. 250.

aquatica major. Miclı. 250.

fontana. $\beta$. repens. Pers. 250.

fontana. $\beta$. major. Kocl, 250 .

major. Willd. 250.

rivularis. Gmel. 250 .

Morchella. Dill. 246.

conica. Pers. 246.

contigua. Tratt. 246 .

continua. Tratt. 246

costata. Schmidt et Kz, 246 .

deliciosa. Fries. 246.

esculenta. Pers, 246.

esculenta. $\gamma$. conica. Fries. 246

esculenta. $\varepsilon$. corrugata. 246. esculenta. $\delta$. falva. Fries. 246.

esculenta. $\beta$. grisea. Pers. 246.

esculenta, $\alpha$. ovalis. Fries.

246

esculenta. $\beta$. rotunda. Fries. 246.

esculenta. $\zeta$. stipitata. Lenz. 246.

esculenta var. $\gamma$. nova. Alb. et Schw. 246.

esculenta var. vulgaris. Pers. 246.

patula. Fries. 247.

Morocarpus capitatus. Scop. Moench. 195.

Foliosus. Moench. 195.

Mycelis. Cass. DeC. 200.

Mygalurus caudatus. Link, 110 .

Myrrhis. Spr. 160.

Adans. 160.

foetens. Riv. 160.

odorata. Scop. 160.
Myrrhis sylvestris. Tour. 116. Mystyllus. Presl. 129.

\section{N.}

Napa oleifera. Spenn. 27.

Napus. Medic. Spenn. Spach.24. oleracea. Spenn. 172. Rapa. Spenn. 24.

Nasturtiun. Adans. Medic. 206. R. Br. 207.

crispun. Medic. 207. microphyllum. Relibeh. 208. officinale. $\mathrm{R}$. Br. 207. sativum. Crantz. Moench.

Vent, 207.

siifolium. $\beta$. Rchbch. 208.

Nepeta interncdia. Lejeun. 226

Nigella. L. 237.

indica. $\beta$. Roxb. 237.

sativa. L. 237.

Nigellaria. DeC. 237.

Nigellastrum. Moench. 237.

Notiospliace. Benth. 120.

Notobasis. Cass. 187.

Nycterium. Vent. 1.

\section{d.}

Obione. Gärtı. 196.

Ocimodon. Benth. 223.

Ocinum. L. 223

album. $\varepsilon$. L. 223

anericanum. Jacq. 223.

allisatum. $\beta$. Hort. 223.

Barrellieri. $\eta$. Roth. 223.

Basilicum. L. 223.

bullatum. $\zeta$. Lam. 223. 224.

caryoph yllatum. $\gamma$. Roxb.223.

ciliatum. Horm. 223.

cochleatum. Hort. Par. 223.

fimbriatum. Hortul. 223.

lispidum. Lam. 223

integerrimum. Willd. 223.

lanceolatum. Scham. 223.

laxum. Vahl, 223.

majus. $\delta$. Hort. 223.

medium. 9. Mill. 223.

ninimum. Burm. 223.

minimum. L. 224.

nigrum. Thouin. 223

peltatum. Hort. 223.

pilosum. $\alpha$. Willd, 223.

salinum. Molin. 224.

scutellaroides crispum.

Burn. 223.

thyrsiflorum. $\iota$. L. 223.

urticaefolium. Hort, 223.

Octospora. Hedw. 248 .

Odontia. Pers. 245.

Odontocarpa. Neck. 206.

Odontolepis. Boiss. 187.

Odontolophus. Cass, 114.

L. 163.

Oenothera. L. 163.

biennis. L. 163

Oenotherium. Sering. 163

Oligosporus. Cass. 221.

Oligosporosus condimentarius. Cass, 222.

Omphalospora. Bess. 209.

Onagra. Sering. Spach. 163.

biennis. Moencl., 163.

europaea. Spach. 163.
Onagra vulgaris. Spach. 163. Orthopogon hispidus. Spr. 89. Pastinaca sativa, L. 156. Onobruchus. Medic. 124. Retzii. Spr. 89.

Onobrychis. Gaert. 124.

sativa. $L$. 124.

sativa. $\beta$. subvillosa. DeC. 124.

sativa tatarica. Fisch, 124. Pachylophis. Spacl. 163.

spicata. Moencl. 124.

tanaitica. Fisch. 124.

viciaefulia. Scop. 124. vulgaris, Jaum. 124.

Onopordon. L. Spr. 190. Acauthium. L. 190. viride, $\gamma$. Desf. 190

Onotrople. Cass. DeC. 187. oleracea. Cass. 187 palustris, Cass. 187 Ophioscorodon. Wallr. 167.

Oplismenus. Beauv. 78.

Crus-galli. Kunth, 89

Crus-pavonis, Kr. B. 89

echinatus. Kuntlı. 89.

hispidulus. Kuntl. 89.

intermedius. Kunth. 80 .

muricatus. Kunth. 89

sabulicolus. Kunth. 89 .

Origanum. L. 219

capitatum, Willd. 220.

creticun. DeC. 220

creticum. L. 220.

lı racleoticum. Rchbcl. 220.

lirtum. Link. 220.

liumile. $\beta$. Poir. 219.

latifolium. Mill. 220.

macrostacliyum. Link. 220.

Majorana. L. 219.

majoranoides. Willd. 219.

megastachyum. Link. 220.

nutans, $\varepsilon$. Wild. 220.

oblongatum. Link. 219

Onites. L. 219.

orientale. Mill. 219.

stoloniferum. Bess. 219.

sylvestre. Blackw. 219 .

thymiflorum. Relıbch. 219.

venosum. Willd, 219.

virens. $\gamma$. Hffmsg. Link. 219.

viride. Willd. 220

vulgare. L. 219.

vulgare. $\beta$. Benth. 220.

vulgare. $\delta$. prismaticum.

Gaud, 220.

Walliclianum. Benth. 219

Ormycarpus. Neck. 164.

Orobus. L. 22

gracilis. Gaud. 22.

linifolius. Fl. Wett. 22.

pannonicus. Clus, 22

prostratus. $\gamma$. Host. 22.

tenuifolius, $\beta$. Roth, 22

tuberosus. L. 22.

tuberosus latifolius. Boenningh, 22.

tuberosus linifolius. Boenningh, 22.

tuberosus tenuifolius. Boen. ningh. 22.

tuberosus. $\beta$. tenuifolius. Willd. 22.

Orthocentrum. Cass. Dec. 187.

Ortlopogon. R. Br. 79.

Crus.galli. Spr. 89.

echinatus. Spr, 89

Orthosporum. Isedeb. 195.

\section{P.}

Panicum. L. Spr. 78. 89 asiaticum. Hort. 80 . asperrimuu. Lagasc. 79 attenuatum. Hort. 80 .

Burnanni. Bbrst. 89 . compactum. $\varepsilon$. Kit. 80 .

Crus-corvi. L. 89.

Crus-galli. L. 89.

Crus-pavonis, $\varepsilon$. Nees, 89

Dactylon. L. 89.

digitatum. Gilib. 89

dubium. Sieber. 89.

echinatum, Willd. 89 .

erytlirospermum. Hornem.

80.

germanicum. Host. 80 .

germanicum. $\gamma$. Willd. 80 .

glomeratum. Moench. 80.

liirtellum. Walt. 89.

hispidulum. $\zeta$. Retz. 89

hispidum. Forst. 89 .

lispidum. $\gamma$. Rhbrg. 89.

Hostii. Burst. 89.

indicum. Hort. 80 .

intermedium. $\eta$. Hornem. 80

italicum. L. 80 .

italicum var. seminibus au rantiacis. Sering. 80 .

lineare. Burnı. 89

macrochaetum. $\delta$. Jacq. 80 .

maritinum. $\beta$. Poir. 80 .

melfrugum. Hort. 80

miliaceum. L. 79 .

miliaceum glaucis seu val

vulis purpurascentibus. 80.

miliaceun semine albo. 80 . miliaceum semine luteo, seu flavo, seu stramineo. 79 . miliaceum seminibus nigres centibus, nigris et batiis 80.

Milium. Pers. 79 muricatum. Hornm. 89 muricatum. Mclix. 89. orizinum. $\beta$. Gmel. 89 oryzoides. Arduin. 89. pumiluın. $\zeta$. Link. 80. sabulicolum. $\delta$. Nees. 89 scrotinum. Hort. 80 . setarium. Hort. 80 . setosum. Hort. 80 .

sibiricum. Hort. 80 . stagninum. Host, 89 . Walteri. Pursh. 89.

Papyrus. Pet. Thou. 20 .

Paractaenum. Beauv. 79

Paramesus. Presl. 130.

Paspalum Dactylon. Lam. 89. praecox. Walt. 89. umbellatum. Lam. 89.

Pastinaca. L. 156. arvensis. Pers. 156 germanica. Moris. 156. graveolens. Bernh. 236 opaca. Bernh. 156. pratensis. FI. Dan, 156 
Phleum stoloniferum, $\gamma$. Host. 90.

tuberosum. Panz. 90.

villosum. $\beta$. Willd. 88.

villosum. $\varepsilon$. Opiz. 90.

Plirygia. Pers. 114.

Physocaulis. DcC. 160.

Pimpinella. L. 139. 237.

Adans. 118.

angelicaefolia. Lam. 139.

Anisum: L. 237.

austriaca. Mill. 139.

dissecta. Retz. 139.

hircina. Leers. 139.

laciniata. $\delta$. Thore. 139.

magna. L. 139.

magna $\delta$. dissecta. 139.

magna. $\beta$. floribus rubris. 139

magna. $\gamma$. orientalis. 139 major. Gouan. Mill. 139. niedia. $H_{\circ} \mathrm{ff} m .139$.

minor. Lam. 119.

officinalis. Gaert. 118. orientalis. $\gamma$. Gouan. 139 peregrina. Lejeun. 139. pratensis. Thuil. 139. rubra. $\beta$. Hort. 139. sanguisorba. Gaert. 119. Saxifraga. Scop. 139. tenuifolia. Schwgr. Koert. 139.

vaginata, $\beta$. Jan. 234.

Piptoceras. Cass. 114.

Piritia. G. Don. 209.

Pissidia. Adans. 248.

Pisum. L. 143.

Aplaca. Brot. 134 .

arvense. L. 147 .

baclium. Hort. 143.

borussicum. Hort. 143.

chlorospermum. Hort. 143.

coerulescens. Hort. 143.

excorticatum. Desf. 144.

fertile. Hort. 144 .

humile. Mill, 144 .

macrocarpum. Hort. 144.

macrospernum. Hort. 144 .

praecox. Hort. 144.

praecox anglicanum. 146.

prolificum. Hort, 144.

quadratum. Mill. 144.

quadratum majus. 146.

roseum. Hort. 144.

rugosum. Hort. 144.

saccliaratum. Hort, 144.

sativum. L. 143.

sativum. $\varepsilon$, arvense. Poir.

147.

sativum liortense. 146.

sativum sine cortice duriore. 145.

sibiricum. Hort. 144.

smyrnense. Hort. 144.

umbellatum. Mill. 144.

uniflorum. Hort. 144.

uniflorum. Moench. 147.

viride. Hort. 144.

zeylonicum. Hort. 144.

Plagiorutis. Sering. 128.

Plantago. L, 116.

bracteata. Moench, 117.

decumbens. Rehbch. 116

humifusa, Bernl. 116.
Plantago hungarică. $\beta$. Willd. 116

intermedia. Gilib. 117,

lanata. $\gamma$. Host. 116.

lanceolata. L. 116.

lanceolata. $\varepsilon$. lanuginosa. 116.

lanceolata, $\delta$. polystachya. 116.

lanceolata. $\beta$. sphaerostachya. 116.

lanceolata. $\gamma$. sylvatica. 116. lanceolata, $\varepsilon$, sylvatica. Pers. 116.

lanuginosa. Bast. 116.

linıosa. Kit. 117.

major. L. 117.

major. $\gamma$. brachystachya. 117. nuajor. $\beta$. leptostachya, 117. major. $\delta$. microstachya, 117. major. $\varepsilon$. phyllostachya. 117. major. $\eta$. polystachya. 117. major. $\zeta$. rhodostachya. 117. media, L. 117.

minima. DeC. 117.

nava. Tratt. 117.

nigricaus, $\delta$. Link, 116.

subsinuata. Hornm. 117.

Tabernae montani. Baumg.

117.

uliginosa. Sclımidt. 117.

Platylepis. Cass. 188.

Platylophus. Cass. 114. Platyspermum. Hoffm. 153.

Plectocephalus. Don. 114.

Plectranthus Barrelieri. Spr. 223.

Plethiosphace. Benth. 120. Plycnosphace. Benth. 120. Poa. Adans. 98. 102.

L. 91.

alpina. Pall. 92.

alpina. $\gamma$. Willd. 91.

altissima. Moench. 94.

anceps. $\beta$. Presl. 93.

augustifolia, L. 92.

angustifolia. S. 93.

angustifolia. $\alpha$. Huds. 91.

angustifolia. $\beta$. Huds. 91.

annua. L. 91 .

annua varia. Gaud. 91.

annua variegata. 91.

annua villosa. 91.

aquatica. L. 94 .

aristata. Leers. 101.

atrata. Pers. 108.

binervata. Ehrh. 108

botryoides. $\beta$. Trin. 93 .

bulbosa. L, 92.

bulbosa vivipara. 92. caespitosa. Poir. 91.

capillata. Merat. 106.

cilianensis. All. 92.

cinerea. Vill. 92.

coarctata. DeC. 9 l.

compressa. L. 93.

crispa. $\beta$. Thuil. 92.

cristata. With. Willd, 101

curvata. Koel. 108.

Dactylis. Trin. 105.

debilis. Thuil. 91.

depressa. Presl. 92

dubia. Leers. 92.

dubia. Suter. 91
Poa salebrosa. Panz. 91. scabra. Ehrh. 92.

scabra. Kit, 91.

Scheuchzeri. Suter. 91. serotina. Gaud. 93.

serotina. Sclirad. 91

setacea. Hoffm. 92.

setacea. Huds. 92 .

setacea. Koel. 106 .

strigosa. Hoffm. 92.

sulscoerulea. Snith. 92

subnuda. Gmel. 108.

sudetica. Schleich. 92.

supina. $\gamma$. Schrad. 91.

sylvatica. Koel. Pollich. 108.

tenuis. Vill. S1.

triangularis. Gilib. 91.

trinervata. Schrad. Willd.

108.

trivialis. Koel. 92.

trivialis. Leers. 91.

trivialis. Leyss. 92.

trivialis. L. 92. 93.

variegata. Hall. 91.

variegata. Lam. 92.

variegata. $\varepsilon$. Host. 91.

Villarsii. Gmel. 92.

viridis. Gilib. 92

Podagraria Aegopodium.

Moench. 139.

nemoralis. $\beta$. firmula, Gaud.

91.

nemoralis. $\eta$. glauca. Kunth.

91.

nemoralis. $\beta$. montana.Gaud. 91.

nemoralis rigidula. 91.

nemoralis. $\beta$. rigidula.Kunth. 91.

nemoralis. $\zeta$, sclıoenosperma.

Gaud. 91.

nemoralis uniflora. 91.

nemoralis vulgaris. Gaud. 91.

nitida. Lam. 101.

nutans. Gilib. 91.

paludosa. Beauv. 106

palustris. DeC. 91.

palustris. Roth. 93.

palustris. Timm. 92.

petraea. Bellard, 91

Phoenix. Scob. 108.

planiculnis. Weber. 93.

polynorpha. Wibel. 91.

pratensis. Leers. 91

pratensis. L. 92 .

pratensis. Poll. Rotll. 92.

pratensis anceps. 92 .

pratensis. $\gamma$. anceps. Gaud.

92.

pratensis angustifolia, 92.

pratensis. $\beta$. angustifolia.

Gaud. 92.

pratensis latifolia. 92.

pratensis. $\beta$. latifolia. Weihe.

92.

pratensis, var. With. 91. prolifera. Schmidt. 92 , pubescens, Lejeun. 92. pyramidata. $\beta$. Lam. 101. quadriflora. Moench. 108. rariflora. Desf. 91.

recta. Willd. 91 .

henana. Lejeun. 91.

riparia. Walff, 93.

sabauda. Vill. Schmidt, 108.
Podia. Neck. 114.

Polyacantha. Gray. 114.

Polyclada. DeC. 157.

Polygonum. L. Spr. 85. 119.

a viculare. L. 120 .

aviculare. $\beta$. littoralis. 120.

aviculare, $\delta$, polycnemum.

Rchbch. 120.

bistorta, L. 119.

bistortoides. Pursh. 119

centinodum, Lam. 120.

convolvulaceum. Lam. 119.

Convolvulus. L. 119.

ellipticum. Willd. 119.

erectum. $\beta$. L. 120.

Fagopyrum. L. 85.

humifusum. Sievers. 120.

monspeliense. Pers. 120.

neglectum. $\gamma$. Bess, 120.

oxyspernum, Ledeb. Bung.

120.

sin arum. Dev. 87.

tataricum. L. 87.

virgatum. Loisl. 120.

Polyporus. Fries. 243.

frondosus. Fries. 244.

squamosus. Fries. 244.

Poly premum. Adans. 206.

Poria, Adans. 243.

Porrum, Mill. Moencl, 167. ascalonicum. Rchbch. 169

Cepa. Rchbch. 168.

commune. Rchibch. 170

sativum. Mill. 170. 171.

Scorodoprasum. Rehbch, 172.

sectile. $\beta$. Mill. 170.

Portulaca. L, Spr, 198.

laevis. $\gamma$. Hamilt. 198

latifolia. Hornem. 198.

oleracea, L. 198.

sativa. $\beta$. Han. 198.

Poterium. L, 118.

glauce scens. $\beta$. Rchbch, 119.

guestphalicum. Boengh, 119.

Poterium polygamum. Lejeun. 119.

Sanguisorba, L. 119.

Psamna. Beauv. 249.

arenaria. Ret. S. 249.

littoralis. Beauv. 249.

pallida. Presl. 249.

Psephellus. Cass. 114.

Pterostoechas. Bentll. 231.

Pseudothymbra. Benth. 224.

Psilostemon. DeC. 209.

Psolanum. Neck. 1.

Psyllium. Neck. 116.

Pterolophus. Cass. 114.

Pulegium erectum. Mill. 228.

tomentella. Presl. 228.

vulgare. Mill. 228.

Pycreus. Beauv. 20.

TR.

Ramaria amethystina. Holmsk. 247.

Rapa, Adans. 24. 
Rusulla olivacea. Pers, 241. rosea. Pers. 241. virescens. Ditm. 241.

Rutidopoterium. DeC. 118.

\section{s.}

Salvia, L. 120. 221. agrestis. $\beta$. L. 120. aurita, $\beta$. Scliult. 221. chromatica. Hffmsg. 221. confusa. Bentli. 221. dumetorum. Andrz. 120. grandiflora. Tenor. 221. officinalis, L. 221. papillosa. Hffmsg. 221 . prateusis. L. 120. rostrata. $\gamma$. Sclimidt, 120 rubicunda. Wender. 120.

Sanguisorba. L. 118. altissima. $\beta$. Mill, 118. auriculata. All. Scop. 118. cordifolia. Opiz. 118. hispanica. $\delta$. Mill. 118. minor. Scop. I19. neglecta. $\varepsilon$. G. Don, 118. officinalis. L. 118. praecox. Bess. 118. sabauda. $\gamma$. Mill. 118 ,

Sarcirambe. DeC. 186.

Satureja. I. 230. cuneifolia. 'Tenor. 230. hortensis. L. 230 . juliana. Pall. 230. montana. L. 230. trifida. Moench. 230. vininea. Burm, 230.

Saturnia. Maratt. 167.

Scabiosa agrestis. Schmidt. 118. arvensis. L. 118 bohemica. Schmidt. 118. campestris. Bess. 118. canescens. Hort. taur. 118. collina. Sclimidt. Reg. 118. dubia. Moench, 118. hirsuta. Lapeyr. 118. hybrida. Bouch. 118. integrifolia. Rotl. 118. montana. Mill. 118. polymorpha. Schmidt. 118. pratensis. Sclimidt. 118. radiata. Schmidt. 118 stricta. Seidl. 118 trivialis. Schmidt. 118.

Scandalida, Adans. Medic. Neck. 152.

siliquosa. Scop. 152.

Scandix Bulbocastanum. Moench. 23. bnlbosa. Roth, Moench, 160. Cerefolium. L. 211. odorata. L. 160.

Scariola. DeC. 200.

Schedonorus altissimus. Beauv. 108.

arundinaceus. Dumort. 108. asper. Gaud. 109. calamarius. R. S. 108. curvatus. R. S. 108, dumetorum. Beauv. 107. elatior. Beauv. 108 erectus. Gaud. 109. giganteus. Graud. 108. glancus. Beauv, 106.
Schedonorus inermis. R. S. 109. Ioliac eus. R. S. 108. longifolius. Trin. 109. pratensis. R. S. 108. sylvaticus. Hopp. 108. Schizotheca. Meyer. 196.

Schoenoprasum. Kuntlı. 167. Sclaraea pratensis. Mill. 120

Scleranthus. L. 137

annuus. L. 137. collinus. $\beta$. Hornung. 137. Scorodon. Koch. 167.

Scorzonera. Lin. 157 angustifolia. $\beta$. Wohlg. Sclirad. 158. bohemica. Sclimidt. 158 denticulata. Lam. 157. edulis. Moench, 158. glastifolia. Willd. 158. graminifolia. Rotl. Hoffm. 158.

hispanica. I. 157. lispanica. $\beta$. Wallr. Koch. 158.

hispanica $\beta$. dentata. 157. montana. $\beta$. Mutel. 157. rumicifolia. Schleich. 157. sativa. Gater. 157.

Secale. L. Spr. 57.

barbatum. Moench. 57. cereale. L. 57. cereale aegyptiacun. 61 . cereale archangelicum. 61 . cereale compositum. DeC. 61 . cereale multicaule. 61 . cereale spica ramosa. Sering. 61 .

cereale wallachicunı. 61 . creticum. Sieb. 57. compositum. $\gamma$. Koch. 57. hibernum. C. Is. 57. spicis ramosis. Tenzel. 61. triflorum. Beauv. 57.

vernum. $\beta$. L. 57

Sedum. L. 212.

collinum. $\gamma$. Willd. 212 crassicaule. Hortul. 212. cristatum, $\delta$. Schrad. 218. elegans. Lejeun. 212. recurvatum. $\beta$. Willd. 212. reflexum, L. 212. rupestre. DeC. 212.

Selinon. Adans, 162.

Selinum Anethum, Roth. 236. Pastinaca. Crantz. 156. Seridia. Juss. 114.

Seridioides. DeC. 114.

Seriphida, Less. 221.

Seriphidium, Bess, 221.

Serpyllum. Pers. Benth. 224. vulgare. Blackw. 225.

Serratula. L. DeC. 187. oleracea, Poir. 187.

Seseli Aegopodiun, Moench. 139.

Carum. Scop. 234.

Carvi. Roth. 234.

graveolens. Scop. 162

Meum. Scop. 138.

Setaria. Beauv. 79

germanica, Beauv. R. S. 80 . italica. Beauv, 80

italica spica ininore. $R$, $S$. 80.
Setaria macrochaeta, Link. 80. Spinacia. L. Spr. 192. maritima. R. S. 80 .

Melinis. Link. 80 . muricata. R. S. 89. punila. Schult. 80 . rubicunda. Dumort. 80 .

Sinapis Rapa. Brot. 24.

Sisarum. DeC. 159.

Sison Anisum. Spr. 237. Podagraria. Spr. 139.

Sisymbrium Nasturtium L. 208. Sitospelos. Adans. 113.

Sium. L. 159.

Apium. Roth. 162. brevifolium. Hort. 159. Bulbocastanum, Spr. 23. Carvi. Bauli, 234. graveolens. Vest. 162. montanum. Kaempf. 159.

Ninsi. $\beta$. Burm. Thunb. 159. podolicum. Hort. 159.

Sisarum. L. 159 .

vulgare. Bernh. 139.

Solanuin. L. 1.

esculentum. Ncck. 1.

Parmenterii. Molin. 1 .

tuberosum. L. 1.

tuberosum esculentum. Bauli, 1.

Somion. Adans. 245.

Sonchus. L. Spr. 191. asper. Gaertn, 191.

ciliatus. Lam. 191

lacerus. Willd. 192.

laevis. Vill. 191.

oleraceus. Fl. Dan. 192

oleraceus. Willd. 191.

oleraceus. $\alpha$. $\beta$. L. 191.

oleraceus $\alpha$. integrifolius 192.

oleraceus $\gamma$. lacerus. 192. oleraceus $\beta$. laciniatus. Boenningl, 192.

oleraceus $\beta$. pinnatifidus. Guentlı. 192.

oleraceus $\beta$. triangularis. 192.

Sorghum. Moench. Pers. 80. album. Hort. 80. bicolor. $\beta$. Willd. 80 . medium. Hort. 80. nigricans. Hort. 80. nigrum. $\gamma$. R. S. 80 . pyramidale. Hort. 80 . saccharatum. Moench. Pers 81.

vulgare. Pers. 80.

Spergella. Rehbch. 121 .

Spergula. L. 121.

arvensis. L. 121 . geniculata. Pers. 121. maxima. Boenuingh. 121. refracta. Detlıard. 121. sativa. Boenningh, 121. viscosa. Dethard. 121. vulgaris. Boenningh, 121 . Spergularia arvensis. Cambess. 121

Sphaerostigma. Sering. 163. Sphondylium. Adans. Scop. Hoffm. 120.

branca. Scop. 121. Spica. Benth. 231.

Spilacron. Cass. 114. glabra. Mill. DeC. 192 inermis. DeC. 192. nobilis. Tubern. 192. oleracea. Willd. 192. oleracea. B. L. 192. oleracea $\beta$. inermis 192. oleracea $\alpha$. spinosa. 192 spinosa. DeC. 192. Spirocarpus, Sering. 126. Spizopoa. Dumort. 91 Stelephuros, Adans. 90. Stellaria arvensis. Scop. 121. Stenolepis. Cass. 188. Stenoloplius. Cass. 114. Stenopoa. Dumort. 91. Stizolophus. Cass. 114. Stoebe. Pers. 114. Stoechas. Adans, 231. Strophostyles. Ell. 140 . Suillus. Mich. 244.

Symphytum. L. 249. album. Hort. 249 elatum. $\gamma$. Tausch. 249. officinale. L. 249.

\section{$\eta \%$}

Terana, Adans. 248

Tetragonocarpus. Commers. DeC. 193.

Tetragonia. L. Spr. 193. cornuta. Gaertn. Moench. 193.

expansa. Ait. 193. halimifolia, Forst. 193 japonica. Thunb. 193.

Tetragonoides. DeC. 193 152 prostratus. Moench. 152. Scandalida. Scop. 152. siliquosus, Roth. 152.

Tetrataenium. DeC. 120.

Thlaspi. Poir. DeC. 206. Nasturtium. Berg. 207. sativun. Cav. Poir. 207.

Thlaspidium sativun. Spach, 207. Thymus, L. 224.

acicularis. W. K. 226 albidus. Opiz. 226. 226

Calamintha. Scop. 226 226.

cancasicus, Willd. 225 225.

ciliatus. Lam, 226. citratus. Dumort. 225. bohemicum. Schmidt, 249. patens. $\beta$. Sibth. Schweig.

Tenora romana. $\beta$. Sclikr. 235.

Tetragonolobus. Scop. Moenclı.

maritinus. $\beta$. Roth. 152. siliquosus, $\alpha$. glaber. 152 siliquosus $\beta$. pubescens. 152 .

Thymbra ciliata, Tenor. 226. angustifolius. Schreb. 226. arenarius. $\alpha$. Bernh. 225 . caespititius. Hffmsg. Link calaminthoides, $\beta$. Rehbch.

Chamaedrys, Fries, Rehbch. 
Trichodiunı. Mclıx. 94. rubruin. R. S. 95.

Trichogoninm. DeC. T*0

Triclolaena. Schrad. 79.

Trichosanthes. Lindl. 217. Anguina. L. 217.

Turobata. $\beta$. Hamilt. 217.

Trifoliastrum. Sering. 130. coeruleum. Moench. 129.

Trifolium. I. 129. affine. Lejeun. 133. agrarium. L, 134.

album. Crantz. 133. album. $\alpha$. $\beta$. Lam. 132. album. $\gamma$. Lam. 132. alpestre. Crantz. 133. altissimun. Loisl. 128. arvense. L. 133. arvense $\beta$. sylvaticum. 133. aureum. Poll. Vill. 134. bicolor. Moench. 132. campestre. Gmel. 134 . coeruleum. Willd. 129. controversum. Jan. 134 dentatum. W. K. 129. dubium. Abbot. 134. filiforme. L. 134.

filiforme, $\gamma$. microphyllum. Sering. 134.

filiforme $\beta$. multiflorum. DeC. 134.

flexuosum. Jacq. 133.

fragiferum. L. I34.

fragiferum $\beta$. proliferum. Bernh. 134.

germanicum. Smith. 128 gracile. $\beta$. Thuil. 133. hybridum. L. 132. incarnatum. L, 132. intermedium. Lapeỵr. 132. Lagopus. Neck. 133. lupulinum. Savi. 127. luteum. $\beta$. Lam. 134. lnxurians. $\beta$. Hort. Par. 132. medium. L. 133.

Melilotus coerulea. L. 129. Melilotus officinalis. L. 128. Melilotus vulgaris. Heyne. 128.

minus. Sın. 134.

Molinerii. $\beta$. Balb. 132. montanum. L. 133. officinale. Willd. 128. patulum. Tausch. 133. pectinatum. Willd. 133. Petitpierreanum. Hayne. 129. polyanthemum. Tenor. 132. pratense. L. 130. pratense. $\beta$. Gorter. 133. pratense $\beta$. sativum. 130 . procumbens. Huds. Curt. 134. procumbens. Pollich. 134. repens. L. 132 . rubens. Aubry, 132 rubens. L. 132. sativum. Mill, Rehbch. 130. stellatum. L. 133. strepens. Crantz. 134.

Trigonella. L. 136. coerulea. Sering. I29. Foenum graecum. L. I36. gladiata. Hort. 136. mniocarpa. Wallr. 127.

Triphylloides. Moench. 130.
Triphylioides pratense. Moench. 130. rubens. Moenclt. 132. Triplocantron. Cass. 114. Trisetum. Pers. Beauv. 70. argentenm. R. S. 78. distichophyllum. $\beta$. Trin. 78. flavescens. Beauv. 99 pratense. Pers. Nutt. 99. pubescens. R. S. 99. sesquitertiun. Beauv. 99 splendens. Presl. 99.

Triticum. L. 32, 110 . aestivum. 35. aestivum. L. 32 amyleum. Sering. 52. anyleum album glabrum. 52 . anyleum atratum velutinum. 55.

amyleum atratum velutinum ramosum. 56.

amyleum compactum albidum. 54.

amyleum compactum rufum. 54.

amyleum majus, album velutinum. 54.

amyleum rufum glabrum. 53. amyleum rufum velutinum. 55.

amyleum semicanum villosum. 55.

amyleum spica alba glabra raınosa. 53.

amyleum spica alba velutina ramosa. 55 .

amyleum spica aristata alba glabra. 52.

amyleum spica aristata atrata velutina. 55 .

anıleum spica aristata rufa glabra. 53.

amyleum spica rufa glabra

ramosa. 54 .

amyleum spica submutica alba glabra. 53.

amyleun, var. A. Sering. 52. amyleum, var. B. Sering. 53. amyleum, var. C. Sering. $\mathbf{5 5}$. ámyleum, var. D. Sering. 55 .

Arias. Lagasc. 50.

aristatun. Gisek. 32.

aristatum. $\delta$. Hall. 40.

arvense. $\alpha$. Schreb. 110

atratum. Host. 52.

atratum. Schuebl. 55

autumnale compactum aristatum. 39.

Bauhini, Lagasc. 44.

brachystachium. Lagasc. 44. bromoides. Web. Wibel. 110. caninum. Schreb. 111. caninum $\beta$. Gmelini. Ledeb. 111.

cereale. Schrank. 32.

Cevallos. Lagase. 48,50

Cienfuegos. Lagasc. 52. cochleare. Lagasc. 44. 47. compactum. 39. compactum. Host. 32 . compactum muticum. 40. compositum. L. 40.

dicoccum, Schrank. Schuebl. 52.
Triticum dicoccum album. Scliuebl. 52.

dicoccum rufum. Schuebl. 53. Duhamelianum, Mazz, 51. dumetorunı. $\gamma$. Sclıreb. 110 . durum. Desf. 44.

durum albidum velutinum. 45.

durum album glabrum. 45 . durum bicolor. 46.

durum compactum. $\mathbf{4 7}$

durun compactun albidum glabrum, aristis nigris. 47. durum conpactum albidum velutinum, aristis albidis, 47.

durum compactum album velutinum, aristis nigris. $\mathbf{4 7 .}$ durum compactum pyramida. tum albidum glabrum. 47. durum compactum pyramidatum subrufum glabrum. 48.

dnrum rufum glabrum. 46. durum rufum velutinum. 46. durum spica compacta. 47. durum spica gracili. 48 . durum spica laxa. 45 .

durum spica laxa alba glabra. 45.

dnrum spica laxa rufa glabra. 46.

durum spica rufa velutina. 46.

durum spica violacea glabra. 46.

durum versicolor. 46 . erinaceum. Hort. 32 . farreum. 52.

fastuosum. 45.

fastuosum. Isagasc. 44.

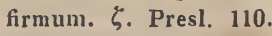

Forskahlei. Lagasc. 52.

Gaertnerianum. Isagase. 47, 52.

gracile. Del. 110.

glaucnm. Moench. 48.

hibernum, L. 38.

libernum. $\beta$. L. 32.

hordeiforme. Host. 44.

Hornemanni. Clemı. 56.

Hosteanum. $\delta$. Clenı, 32.

imbricatum. $\eta$. Lam. 110.

laevissimum. Hall. 48.

Leersianum, $\varepsilon$. Wulf. Sclireb. 110.

Linnaeanum. Lagasc. 40 .

majorcanum. 38

monococcum. L. 56

monococcum majus. Dume-

ril. 52.

muticum glumis villosis ci. nereis. 38.

muticum hibernum. Scliuebl. 38.

muticum rubrum glabrum. 38 . mutieum rufum glabrum. 39. muticum rufum velutinum. 39

patens. Brotz. 108

piunatum. Moench. 110.

platystachium. Lagasc. 44.

polonicum. L. 48.

polonicum. $\gamma$. Pers, 40.

Triticum polonicum aristis bre- $\mid$ Triticum turgidum spica arivibus. 50.

polonicum compactum. 50 . polonicum strictum. 50 .

polonicum velutinum. 49.

polonicum vulgare. 49.

pubescens. Bbrst. 56 .

quadratum, $\beta$. Mill. 40.

repens. L. 110

rufescens. Hort. 50.

sativunı, Lam, 32 .

sativum. $\beta$. Pers. 44.

sativum turgidum. Delil. 40.

sepium. Lam. 111.

sepium. Thuil. 110

Spelta. I. 50.

Spelta. Host. 52. 55

Spelta alba. Schuebl. 50.

Spelta nigrescens. Schuebl. 52.

Spelta rufa. Schuebl. 51 . Spelta, spica aristata alba. 51 . Spelta, spica aristata coerulescente glabra. 51 .

Spelta, spica aristata rufa. 51.

Spelta, spica mutica alba glabra. 50.

Spelta, spica mutica rufa glabra. 51.

Spelta, var. spica mutica coerulescente glabra. Sering. 51 .

subulatum. $\beta$. Schreb. 110.

tenue. Autor. 111.

teretiflorum. Wibel. 108

tomentosum. Bayle. 44 .

Trevisium. 45.

tricoccum. Schuebl. 53.

tricoccum. $\beta$. Schuebl. 52 .

turgidum. L. 40 .

turgidum album glabrum. 41 .

turgidum album velutinum.

41.

turgidum compositum. 43.

turgidum conıositum album glabrum. 43.

turgidum compositum rufum glabrum, 43.

turgidum compositum rufum velutiunm. 44.

turgidum nigricans veluti. nunı. 43.

turgidum rufum glabrum. 41. turgidum rufum velutinum. 42.

turgidum spica aristata alba glabra. 41

turgidum spica aristata alba glabra ramosa. 43.

turgidum spica aristata nigricaute velutina. 43.

furgidum spica aristata rufa glabra. 41

turgidum spica aristata rufa glabra ramosa. 43.

turgidum spica aristata rufa velutina. 42.

turgidum spica aristata rufa 
Tuber. Mich. 248. albidum. 248.

brumale. Mich. 248. cibarium. Sibth. 248.

Typhoides arundinacea. Moench. 90.

\section{U.}

Ugola. Adans. 248.

Urochloa, Beauv. 79.

\section{v.}

Valeriana olitoria. Willd. 206. Valerianella. Moench. DeC. 206. olitoria. Moench, 206.

Veronica. 209.

Beccabunga. L. 210.

caroliniana. $\beta$. Poir. 210.

limosa. Lejeun. 210.

Veronicastrum. Moench. 209.

Versicastrum. Sering. 130.

Verutina. Cass. 114
Verutum. Pers. 114.

Vicia. L. 135, 149.

alba, Moench. 149.

Cracca. L. 135.

Ervilia. Willd. 137. exstipulata. Gawl. 134.

Faba. L. 150.

Faba $\beta$. equina. Pers, 150. genella. Crantz, 137. glabra. $\delta$. Schl, 149. gracilis. Loisl. 137. lielvetica. Hort. 149. liirsuta. K. 137. lathyroides. Thomas, 149. laxiflora. Brot. 137. leucosperma. $\gamma$. Moench. 149. luganensis. Schl. 149. Mitclıelii. Rafin. 137. multiflora. $\alpha$. Lam. 135. ocliroleuca. $\beta$. Bast. 135. pusilla. Mhlbrg. 137. sativa. L. 149.

sativa biennis. 150 . sativa nemoralis. Pers, 149.
Vicia sativa $\alpha$. obovata. Sering. 149.

sativa $\varepsilon$. pygmaea. Sering. 149.

segetalis. $\beta$. Thuil. 149. sepium. L. 135.

tetrasperma. Schreb. 137.

Vicioides sepium. Moench, 135.

Vilfa alba. Beauv. 95. coarctata. Beauv. 95. divaricata Beauv. 95. gigantea. Beauv. 95. glaucescens. Presl. 95. lispida. Beauv. 95. linearis, Beauv. 89. neglecta. Beauv. 95. patula. Beauv, 95. punila. Beauv, 95. stellata. Beauv. 89. stolonifera. Beauv. 95. sylvatica. Beauv. 95. tenella. Beauv. 95. vulgaris. Beauv. 95. Virgaria. Trin. 79.
Vosacan. Adans. 17.

Vulneraria, Adans. 121.

Anthyllis. Scop. 122. heterophylla. Moench. 122. rustica. Lam. 122.

Vulpia, Gmel. 106.

Myurus. Gmel, 110.

psendomyurus. Rehbch, 110.

\section{W.}

Wiggersia sepium. FI. Wett.135.

Weingaertneria canescens. Bernh. 98.

Wendia. Hoffm. 120.

\section{X.}

Xylanthema. Neck. 187. 188. Xylopleurum. Spach. 163.

\section{Vis.}

Zea. L. Spr. 81 . alba. Mill. 81 .
Zea altissima. Gmel. 81. americana. Mill. 81. 85. amylea. Moris. 52.

Mais granis albis et albicantibus. 85 .

Mais granis rubris et pur. pureis. 85 .

Mais granis variegatis. 85 . Mais granis violaceis. 85 .

Mais minor. 85.

Mais praecox. 85 .

Mais spica exili. 85.

Mais spica ramosa, granis aureis. 85.

Mays. L. 81 .

minor. Gmel. 81 . praecox. Pers. 81. vulgaris. Mill. 81 . Wuerttembergicum, 52. Zeocriton. Beauv. 62. commune. Beauv. 70. distichum, Beauv, 68. murinum, Beauv. 112. 


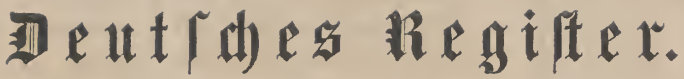

\section{A.}

थcterbofue. 150.

blnue bife. 151.

braue ettglijde. 151.

gröste. 151.

grof́e. 151.

treine. 151.

Eleinfte. 152.

rothbrithende. 151.

rothjnmige. 151.

(đ)wnrz jnmige. 151.

weíse ditfe. 151.

weise englifide. 151.

เขei⿱⺈⿵⺆⿻上丨. 151.

2(dererbje, bollänoiid)e. 146.

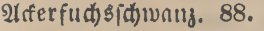

Ideergrns. 110.

Friedsettoes. 89.

Aderfirfe. 79.

शraferêlee. 133.

I(têtênüterid). 137.

Iferrol(d). 112.

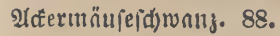

2ป屯ernแ. 22.

Ilferriedgrnz. 95.

2)

itnlieníicter. 206.

Aderfenbiofe. 118.

थderidmiele, gropee. 95.

hohe. 98.

I(téripnate. 121.

થd đerịnärfer. 121.

Ulferfteinffee. 129.

2lterftrnupgrns. 95.

भfertbyminn. 226.

Itêtereśpe. 104.

\&ferwife. 150.

Itcermind halm. 95. 98.

2temer. 52.

פffterblutétrut. 119.

Ugreftnimpfer. 194.

IIchemiftentrnut. 138.

2riptange. 204.

Gronder. 204.

21melforn 52.53.

İmer. 52.

มtmertortt. 52.

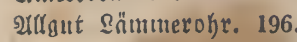

S(metyyftecurenidisnnm. 247.

2lmourettengras. $10 \%$.

भmpfer, gemeiner. 194.
İmpfer, grnuer. 194. fatilofürmiger. 194. 2(mn) 53.

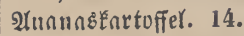

Angergrng. 91.

Ingerf́rnut. 120.

In ingeride. 30.

มngerie. 30.

21ngurie. 214.

Ingurienftirbis. 214.

Inis. 237.

Ilnibuibernell. 237.

भInis, gemeitter. 237.

Itpfelmelone. 214.

216ufe. 214.

Artiītule. 189.

gemeine. 189.

gurdoifternrtige. 189.

grüne franzülif de. 190.

ruthe. 190.

ipaniithe. 188.

ftndlige 190.

vivette. 190.

yon รerujntem. 219.

wilde. 190.

Irrtüffeln. 1.

श्रf(nit). 138.

2fiterbie. 147.

Iftynjer. 73.

Ituberviflers. 203.

Alugufthnfer. 74.

(d)warzer. 75

weiser frïhseitiger. 74.

2)

थusbredtererbje, englif(t)e. 147. exfurtiftce. 147.

früfzeitige. 146.

grope voer graue funnifate. 147.

I)\&ะ์ernerbfen. 146.

\section{3.}

Bnte. 218.

Bndtbothne. 210.

Bnd)bunge. 210.

Bnd) bringent (Ehrethrei:. 210.

Bn(t): Montic. 250.

Bndpumune. 210.

Bnđweizen. 108.

Bärenfup. 138. 3̧ñrengerfte. 65.

b̆̈rentatnue, gemeine. 121. unn̈at) 121.

Bärenichote. 122.

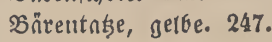

SB̆nf fend)el(wurz. 138.

Bärwurz, genteiner. 138. officinefler. 138.

Bntlenfrnut. 117.

Snifanif́lee. 129.

3กрnume. 203.

Barthnfer. 77. 99.

Bnetgrof́e. 70.

Bnettit). 121 .

Bartweizell. 35, 40. 44.

brnuer. 46.

blauer melifider. 46.

braumelíser. 46.

brnuner gemeiner. 36 .

eigentlidber. 45.

rötfricher bicfäthriger. 48.

rother gemeiner. 36 .

rother gintter. 36.46.

rother foumtnrtiger. 46.

rother fommtnetiger gemeiner.

36.

rother zottiger. 46.

fitwarjer gemeinet. 37.

weišer gemeilter. 35 .

weíser gerftenartiger. 45.

weišer glatter. 45.

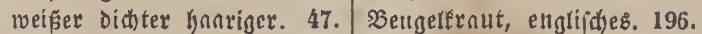

meišer fommtartiger. 45 .

weiß̈er foumtnrtiger gemeis

tier. 35.

weißßser zottiger. 45 .

Bnrtwifdynfer. 76.

Bafiticum, ornjenthlnttexiges. 224.

buiditges. 224.

gefledter. 224.

gemeines. 223.

geftreiftes. 224.

groß̌es grünes. 224

grînes brennnefielbrätteriges.

224.

fteines. 224.

mittleres. 224.

ithmarzes. 224.

Bnflitie. 223.

Bnfitienternut, gemteilles. 223.

grofes, 223.

freines. 224.
Bnftnrbgerfte. 112.

Bnftnrof́lee. 132.

Sofftnromordier. 247.

Bnftnrorettig. 165.

wiener. 165.

Baftnrofdiotenflee. 132.

Bntnten. 1.

Entnuin, Gronder. 202. getber. 202.

Sonte. 29.

B̊nuntétgl. 179.

vother. 180.

Bnurübe. 24.

Becterblume, gemeine. 119.

Becher fdwnmm; lb̈ffelf b̈rmiger. 248.

(d) ueftenfürmiger. 248.

Beermeroe, gemeine. 195.

fopfförmige. 195.

rutfenförunige. 195.

¿eifuñ, Grn̈tteriger. 222. gebnuter. 222. gemeiner. 222.

Beinneff. 249.

Beinwurz. 249.

gebrn̈uthlitit)e. 249.

gemeine. 249.

gewöburicte. 249.

Beiścully. 30.

Bei srübe. 30.

Bergeninminthe. 226.

Bergoiftel, weise. 190.

Bergerble, fnolige. 22.

Berggnižlee, groß̧er. 132.

Berggens, fndentantteriges. 106. fornälyriges. 113.

Berghnfer. 99.

Bergetee. 133 .

Berglujerne, getbe. 127.

Sergmijornil. 220.

Bergmelifie. 226.

Bergmünze. 226.

Bergufefferternut. 230.

Bergreitlgrn:. 102.

Bergrispengrns. 93

Bergfnturei. 230.

Bergidirf. 96.

Sersidiminger. 109.

sergthyminn. 226.

sergtrespe. 109.
Beißsbeere, jährige. 233.
Berlituer, Grunder. 203.

Berlinerrübe, Eleine. 27.

Beruffernut. 122.

Bejenernut. 222.

Beyber. 222

Biberuelle, grošce. 139.

italieni(d)e id)warze. 119.

fleine. 119.

twelide. 119.

Sienenéree. 132.

Bimbernelf, faride. 118.

situdinint. 204.

Glonder. 204.

bunter. 204.

bunter englif(t)er. 204.

frïker griner. 204.

frillyer römifater. 204.

grauer. 204.

rother. 204

Binfeetweizen. 39.40.

Binfentyntm. 102.

Sirogra:. 92.

Sirnzwieber, gerbe fïßse. 169

Bipnmoiftet. 188.

Sifamflee. 129.

Bijamtürbis. 219.

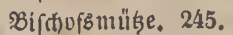

Bito̊nuttennturfer. 11

Btätterpils, gordforbiger. 243

yoljer. 242.

wolliger. 243.

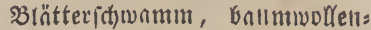
nrtiger. 243.

blutinrbiger. 241.

eifürmiger. 243.

efonner. 238.

gedrehter. 242. gloctenförmiger. 241 .

Inngitieliger. 242.

(t)mnathafter. 239.

ungetheilter. 241 .

veränderlid)er. 242.

violetter. 241.

meif́c̈upfiger. 243.

weiś(it)er. 242.

zertired)lict)er. 241.

Brăuring. 241.

Brnfenflee. 134.

Binttgerfte. 69.

SInttgewñđ) 172.

SBintteor). 179.

bnumnetiger. 179. 34 * 
Brnttugr, gerber. 174. 179. gemeiner. 179.

groforntetteriger. 179.

prnufer niederer dutfelernus ner. 181.

BIntiernut. 179.

getues. 179.

Emiger. 174.

Binufibgl. 181.

B̧rateohl. 177. 180.

Binufrenut. 177.

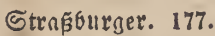

Stende. 85.

Blict. 56.

Sticten. 56.

Brüthenยัohr. 181.

SBlumentẻ hi. 181.

Błumentoh). 181.

.SBroccuti. 184.

(1)urifiter. 183

englipher. 183.

früher. 183.

frühyseitiger. 183.

grufer. 183.

grofer funter ellglifider. 183. hanter. 183.

Senoner. 183.

rother. 183.

ipäter. 183.

snrter. 183.

Blutforellenbind falnt. 204.

mit [dymarsem Samen. 203. nit weísem Snmen. 203.

Brutgnere. 120.

Biutflee. 132.

Brutếnut. 118. 120.

rnuthes. 119.

Brutiatwamm. 245.

Bofásunt. 247.

gratter. 98.

Pleiner. 106

Inuchbrätteriger. 158.

niederer. 149

porreblätteriger. 158.

purpurrother. 158.

rother. 107.

Botebryorn, gemeines. 136.

Soctshornétee. 136.

Sodencuglrabe. 27.

getbe ithwedict)e. 28. gemeitte meiše. 29.

meíse. 29.

rutrybaltige. 29.

(t)wediictse. 28.

sogne. 140.

arnbiidse. 143.

brnftinnijđe. 143.

breite fpanifde. 152.

bunte türsiidte. 143.

geneine. 140.

holye. 140

itntienifole. 142.

fleine ipanijite. 152.

Silingonter. 152.

niedrige. 142.

pertugiefift)e. 152.

römithe. 150.

rothionalige. 142.

(d)arfad)rothe, 143.

vieroututhige. 143.

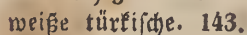

melictie. 140.142, 150.

willoe. 122

Bobnenfrnut. 230.
Bofnemivide. 150.

Bofrbtume. 23.

Buften. 168.

Buflentauth. 172.

Bornge. 209.

Borecoli, bunter. 181. orüner. 180. purpurrother. 180.

Boretid), gemeiner. 209. officineller. 209.

Burres. 209.

Borzdorfern̈pfel: Rartuffer. 13.

Borftif() winger. 107 .

Butrntisfofugl. 181.

Bounuetgurfe. 214.

Brnd)mänuteitt. 238.

Brndurï6e. 24.

Brn̈trilig. 240.

brnuner. 240.

grüner. 241.

rothernuner. 240.

meifer. 240.

Brnungieria). 208.

Brnunfirft. 208.

Brauntofl. 180. 181.

Gunter. 181.

gefranzter. 180.

geid)ligtblätteriger. 180.

hoher. 181 .

Éteiner frnufer. 181.

frnufer. 180.

nieoriger. 181.

pomiterider. 180.

Stettiner. 180.

Braunf(d)weigertohl, grofer. 175.

:Bred)bolyne. 142.

Brect)teufer. 241.

Breitring. 240.

ริrisเnu(). 171.

Srocculi. 183.

blanter. 184.

getbet. 184.

getber rỏmi(d)er. 184.

italienifder. 183. 184.

molthefer. 184.

purpurrother römijđer. 184.

römīa)er. 184.

violetter. 184.

weişer. 184.

weiser gemeiner. 184.

weiß̈er tenporitnnijder. 184.

Brodelerbjen. 146.

frülye. 146.

gelbe frügreife. 146.

bobe grüne. 147.

weišre. 146.

Broctelfobl, weiser. 184.

Bructuli, weis̄er. 184.

Brödring. 241.

ふ઼ru(t)hnfer. 99.

Brudbnfer. 99.

Brüfieterfoght. 179.

Brunnentrefie. 208. gemeine. 208.

offictnelle. 208.

Brufternut. 122.

Brunzelfrnut. 198.

Butt. 222

Budtüugring. 241.

But()weizen. 85.

gemeiner. 95.

gezn̈fuแter. 87.

fibirifoler. 87.

tartarifder. 87.
Bud)weisenfnbterig. 85.

Budininde. 119.

Büidelerbje. 147.

Buffoorne. 150.

gemeine. 151.

grủne mailändifđ)e. 152.

Bunt, thürtider. 218

Burgunderflee. 126.

Burgunderrübe. 30 .

Burzelernut. 198.

Buj bonne. 142.

Bufmeténrtoffer. 115.

Bufdumbre. 116.

Buidithininget. 108 .

ButterErnut. 175.

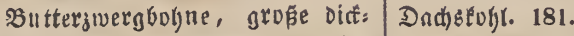

idotige, iveife fetne. 143. neue meise weiśitjutige. 143.

\section{(5.}

Cannriengrns, folfides. 88.

Enntnlupe. 216.

grorentiner. 216

frübe golln̈ndijde. 217.

frühe fpnnijde. 217.

gerippte. 217.

grüne. 216.

itnlieniijue. 216.

urangenfarbige. 216.

rotige. 217.

(i) warze. 216.

ipanifitte. 216.

weiśe. 216.

Enntntupen. 216.

Eantharefle. 243.

Enp \$roceuri. 184.

Enpłobl, grüner. 184.

ธேрив. 176.

rother. 177.

Earbonnternut. 175.

Enroe, ipnnifide. 188.

Enroifiur. 183.

Enrdiviol. 181.

Enroubenedilte, witde. 187.

Enrodll. 188.

Enrouns:Irtifdofe, gemeine. 189. wolle ftncherlofe. 189. voll Tours. 189.

Enroune. 188.

nxtij() o en

funnifide. 188. 189.

jofime. 189.

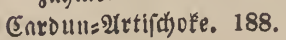

Enefiol. 183.

früler cyprifther. 183. früber englifđer. 183.

Enrmiuntétofl. 178.

Earminnternut. 175.

Enrotte. 153.

früne rotle. 156.

Enrvivr. 181.

Enulfior. 181.

Eentuerenbus. 175.

Eentmerfrnut, Strnofurgex. 175.

Centnerpötfrnut. 175.

Ehnungnguerialnt, get6er. 203. grüner. 203.

ङुnmpignun. 238.

getber. 243.

gemeiner. 238.

Ehartifior. 181.

Ehriftwurs. 22.

हstaprie. 205.

(̧iđ)orienfrentit. 205.

Eidjorienfant. 201.

Eitronenmetifie. 229.

Curinnder. 234.

gemeiner. 234.

grofer. 234.

zngmer. 234.

Dndtreesue. 105.

Dnhtie. 19

Darrarns. 97.

Douthine. 202.

Dnvid sfurn. 66.

Dnvideroggen. 66 .

Deviliding. 238.

Dictrübe. 30.

Dispenlynfer. 99.

Dill. 236.

Dillfendel. 235.

Diffonuen. 236.

Dinfere. 50. 56.

Dinferelfortl. 70.

Dintet, rother. 51.

Dinferiperzen. I11.

Dinfel, weíser. 50.

Difterte ofy. " 187.

Bifter, Ernuje. 188.

niftende. 188.

Dörithen. 27.

Dordenerbfe. 147.

Duride. 27.

Dorfe. 27.

Durt. 103. 111.

Dopant. 220.

cnlloijder. 220.

cretifder. 220.

gemeiner. 220.

Dofte, wilde. 220.

Dradenblut. 118.

Drachenimurg. 119.

Dragun. 222.

Drnétes= Éyre. 15.

Dreibintt. 130.

3rolliger. 202.

Dudiftel. 191.

Divelf. 104.

EGerrnute. 223.

ङ5 berreis. 223.

(Eterbje. 149.

હitronentrrnut. 223. 226. 229.

Citronenquendel. 226.

Eitronentäubring. 241.

CornIfenteurenfotwamm. 247.

Cornllenid)wamin. 247.

\section{จ.}

veridiedenfarbige. 19.

Deutfiter, groper. 202.

Difl, gemeiner. 236.

Dituteltweizell. 50. 111. gemeiner zueifübriger. 50.

Dinfer, werjher. 56.

Diptnin, cretiidjer. 220.

ïberbängende. 188.

Durfgänjefuв. 196.

Doften, brouner. 220.

Drngun:Beifuß. $2: 22$.

Dreimonntsunis. 85.

Dreidbohne, iveise. 143.

\section{ङ.}


Erofohirnbe. 27. gelve. 28.

weife. 29.

Eromnnder. 20.

Eromöhre. 122.

Erdmordel. 248.

Eronแ. 22. 248.

nแmerif̣nni|đe. 23. gemeine. 23.

Eropammertinge. 1.

Erortibe. 27.

(ExD/d)mnmm. 248.

Erotiffeln. 1.

Ertöfrelı 1.

Erue, vefhante. 137.

pnollige. 22.

Ervenliule. 137.

Erve, midennatige. 137.

(E) (d)(nud). 169.

Ejelsoiftet. 188. 190.

Esparfette. 124.

ât)rentrngetlde. 124.

getueine. 124.

Esper. 124.

EEpertlee. 124.

Eftrngut. 222.

\section{ซ.}

Fadenter. 134.

Fridergerfte. 70.

Fnfuentiffer. 76.

chinefíld)er. 77

groper nnatiomiger. 77.

fieiller unatfauniger. 78.

(đ) warzer. 76.

(d)warzer gegranutex. 76.

weif́er gegranuter. 76.

weif́rer ungegranuter. 76 .

Fnattenf(t)

Fnjeule. 140.

Fnulfenzer, Gronder. 202.

groper bramer. 202.

grof́er grauer. 202.

Fedtergerfte. 70.

Feoerfogl. 180. 181.

bunter. 181.

grüuer. 180.

ernuler. 180.

Feldblätterpil\}. 238.

Felocidorie. 205.

Zeldourt. 103.

zelodofte. 220.

Felderbfe. 144. 147. gemeine. 146.

Felognebe 114.

Felogemänfe. 1.

zelohnfer. 99.

Feloherbftrilue. 26.

Jeloflee. 132.133.

Feldernppe. 206.

Felofilmmer. 234.

Jeldërbis, gemeiner. 218.

Ferdinfe, gettreine bentitite. 149.

Ferdmnjornil. 2?0.

Felofnint. 206.

Feldicngioje. 118.

Feld (đ)

Felofpinnt. 196.

Feldifyminn. 225.

Feldtrespe. 103.

Feldwegmarte. 205.

Feldwiấe. 150.

Pleine gratte. 137.
Fender, njorifder. 236. sorognejer. 236.

Deutf(t)er. 236.

Fendideldial. 235.

Fendel, gemeiner. 235. itnlieniict)er. 236.

Fendielernut. 235.

Fend)el, rüser. 236.

şeronejer. 236.

wilder. 116.

รentri币. 79.

gemeitter hirfentragender. 79.

Fennidigrne. 89.

Fennid), welider. 80 .

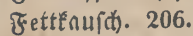

รeuerbolne. 143.

gemeine nit rother \$rïthe. 143.

gemeiue mit rother uto meiser stïthe. 143.

gemeine unit meiser Blittlye. 143.

Firdoertogr. 176.

Jirderếrnut. 176.

grofes fpñtes. 176.

pisisig. 176.

Jiloeripigkrnut. 176

Fingerpfennit). 89.

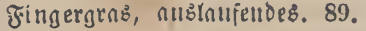
wurselfprofitides. 89.

Fingerfirfe. 89.

Fingerfundşgrns. 89.

Fioringrno: 95.

Find)

Fुnodergrns. 94.

FInmel. 102

Flectellbrume. 124.

Flectetlélee. 124.

F(eiid)Inแ(). 170.

Fritter(f)ell. 102.

Frittergrns. 102.

Floctenblume. gemeitte. 115. gemeine idunrze. 115.

Frobernut. 228.

Flottgrns. 93.

Frïgelerofe. 152.

Zrügeliळote, semeilte. 152.

f̧ughnfer. 99.

fauginnogrns. 113.

Fluthgrns. 93.

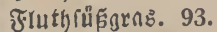

Fruttgrns. 88.

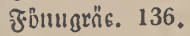

Fontnuellerbje. 146 .

Frnnjborne. 142.

Jranzerbje. 147.

Frnilinint. 203.

Jrnuenbis. 138.

Frnuendifter. 190.

ङrnuenmantel. 138.

Frnuentüuดring. 241 .

Frudtgewñd) je. 212.

Frübroceoli romnni. 184.

Jrübcarotte, engripd)e. 155. l)oländijđe. 155.

Eurge rothgetue guantndiate. 155.

Friligerbje. 146.

Friilggerfte 68.

Friilgnfer. 74 .

กแเ $\mathfrak{A}$ merif́n. 74.

กแร B) Beorgiett. 74.

nus \$pdovien. 74.
Griigenctoffern. 11.

Frübênatoffel, gelbe. 11.

prntte meińe. 11.

rotye, 11.

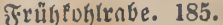

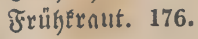

rundes. 175.

fuikgiges. 176.

Itfmer. 175.

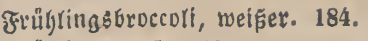

Fritilingesgerfte. 62.

Früblingšepfintat. 201.

Frülıühre. 155.

ร̛üłrübe. 26.

ङrüโxundซ́rnut. 175.

ซrülymeiffrnut. 175.

Friibsuaferbutfrnut. 176.

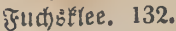

Fu(b)

gegliederter. 88.

geloer. 88.

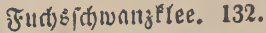

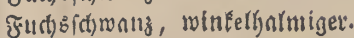
88.

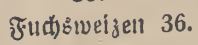

Fünfndernérnut. 116.

Fürfthnfer. 111.

Jutterbohne. 150.

Futtererbie. 147.

Juttergerfite. 68.

Jutterlinfer. 71.

Futterbnljuentopf. 124.

Jutterélee. 130.

Futterérñuter. 114.

Futterinefte, gemeitue. 124.

Futterrïbe, Innge. 26.

Futteridnucfentee, getteiner. 126.

Futter [d)minger. 108.

Futtertrespe. 108.

Futterwite. 150.

gervögntitite. 150.

grofe brnGanter. 150.

grofe englifthe. 150.

weise. 150.

\section{(3).}

(3)ด้อcleshnfer. 74.

(3)ีกреnmpfer. 119.

(3) ה̈njedifter. 191.

oreiectige. 192

gniljzrnidige. 192.

gemüjenrtige. 191

geid)liste. 192

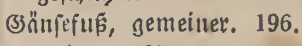
weiserer. 195.

(3)ลีnjęrnut. 222.

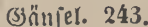

(3)กีn jelgrủn. 138.

(3)ีกเมี่เ(). 191.

(3) ถ̈แ (erich), grüแer. 138.

(3) nisbnet. 247.

ธ3กเร็แก๊. 139.

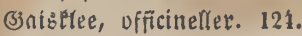
röthlicter. 132.

(3)

pificiulte. 124.

(3) nöhrden. 243.

(3)กโlu[d)er. 243.

(3) แแแแer. 48.

(3)ner. 48.

(5)กrbe. 234.

(3)

(3) r teltnutufer. 193.

getinder. 193.

Bsnrtenartifdupe. 189.

(3) artenlobule. 140.

groper. 150.

33ntens (Findivie. 205.

Binteller6je. 144.

grop̃e. 146.

grofe grülte. 147.

grose grïne franzofilide. 147.

orufe weis̄e. 147.

(3) nrtengewäd) 15.

(S)rtengurf́e. 213.

(5) กrtenbaferivurz. 157.

B) Brtenlynerwurzel. 157.

(5) ntenteretbel. 211.

Bartenéphr. 172.

(3) nutenfrefíe, gemeine. 207.

(ङ)

ङ̋ 3 rtenlnttig. 200.

ङ̧nrtentinje, groß̧e. 149.

(3)ntentuelde. 197.

(3) Artenuelifie. 229.

(5)

(3) irtenpeteritie. 161.

(3)artenpfefferérnut. 230.

(5)กtenrnyunzer. 163.

(3)rtentrettig. 164.

(3) nrtenfalnt. 200.

(3)ntentrirbei. 221.

(5)

(3)artenftraudefogl. 174.

(3)

(3) fltefugl. 179.

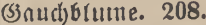

(5)

(3) ebirgshnfer. 75.

(3) dedidernut. 193.

(3)erlict)en. 243.

(3)etïhrditn. 243.

(3)

(3)

(5) elbrübe. 28.

(3) müienmufer. 193

(3)emüledifter. 191.

(S) emüiegnetenfalnt, Glonder rö: miider. 204.

grintuer. 204 .

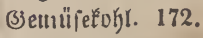

(3)

(s) emin| ieportulne. 198.

(3) emïeppiแnt. 192.

(3) enuejer. 202.

Grunder. 202

gologelber. 202.

grüner. 202.

rother. 202.

Bjeorgie, vern̈nderlid)e. 19.

(3) eorgitte, veridieden farbige. 19

(5) oorg, grofer. 202. weišer. 202.

(3)ernedsfrnut. 139.

(3)erfte. 62.

ñîtige ziveizeifige. 69.

กแI Sivrwesen. 68.

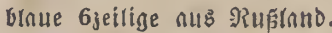
66.

getblidt) gemeitte. 65.

gemeille. 62.65.

genteine 4jeilige. 6 ? 
Brnunentiveisen, votfer gemeis ner. 36.

rother fomuntnrtiger. 36. weíser gemeiner. 35. meiśer foumntnrtiger semei: ner. 35.

(3) ragkirite. 93.

(3)rnsf́nöterid). 137

(3)กร์เกนส). 111. 171. 172.

(3)

(s) rautifaer. 77.

Birnuling. 241.

(3)rider. 85

(5)rieşgerfte. 66

(3) iffelgrns, puxpurfarbiges. 107.

(3)rindernut. 118.

(3) rinowurz. 191

Bsriser. 159.

(3)

(3rop, Snniferkelft. 138.

(3) rüblinge. 1.

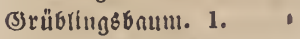

(5) rünboct. 241.

(3rïnfoly. 180.

gefrnizter. 180.

gejhligtorätteriger. 180.

freiner frnuler. 180.

Ernufer. 180.

Exnufer niederer. 180.

(5)rünf์́nแt. 192.

Bsrünling. 241.

(ङ)นึกโณกแ6. 136

(3)rübynfer. 78 .

tartarifder. 78

(5)rumbirne. 1.

Birundbirne. 1.

pf f̈̈rger. 12.

(3) Uțelrübe. 26.

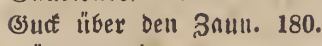

(3)inmer. 48.

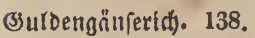

(5) ummer. 48.

(3)urfée. 213.

getritum mte. 214.

gemeine. 213.

gemeine grïne. 214.

gemeine rnnge ouneergrůne. 214.

gemeine rauke ftodiderige. 214. furze grüne ftadjelige. 214. rnnge oftilldirate. 217. init grütuer Sd)nale. 214. mit weišer Gđhnare. 214. perifiche. 214. türtif(t)e, 214 3nkme. 213.

(3)แrtenenentoffer. 11.

(3)utétufraut. 209.

\section{$\mathfrak{S}$.}

Şanrgras, quectenartiges. 111. Şnntútee. 133.

Şnber. 71 .

Şก Gerbrütring. 240.

Sonbergrne. 99.

Senberwurg, weibenblätferige. 158.

Şnoen. 85.

STafeturbig. 178.

Şafer. 71.

n̈gทutija)er. 76

n̈hriger. 99.

befaneter. 99
Şnfer, Ernutner. 75.

bunter. 75 .

chinefifdser. 76

Dopwerter. 74 .

Dreitürniger. 74.

DritthnrGbrütyiger. 78 .

feinbanriger. 99.

früber fdynazer nuts (3)eDt: gielt. 75.

gerblid)er. 99.

gebriaucflidter. 73.

gemeilter. 71. 73.

gemeiner obute (3)rnnell. 74.

geftreifter. 77.

gewöhnliøer grniter tweiser. 73.

glntter, 71.

glntter (if)warger, 75.

boher. 97.

f́teinfnmigex undter. 78.

Łurzähriger. 77.

furzer. 77.

furghnariget. 99.

uncter. 78.

orientnlifiter. 76 .

podolifłer. 76.

pornif(ber. 74.

pröhtiger. 74 .

rother. 75.

ruifificer. 76.

(d) wnarzer. 75.

fdiverer englif́cher. 74.

fibirifter. 76.

(pnnijder reider. 74.

tontnrifster. 78.

türţiıđer. 76.

ungarifsther. 76.

iveider. 99.

weichbnariger. 99.

weífer. 73.

weiser ungnxi/her. 74.

welicher. 76 .

wirber. 99.

zohimer. 71.

Şnfergrns. 97.

bnariges. 99

rotges. 99 .

Şก fermnete. 158.

Sุกferwurz, wnibgrätteriger. 158. wielentiebende. 158.

Şnfermursel, porreblätterige. 158.

funnifche. 157

witbe. 158.

wirde gelbe, 158.

Şกknenfeแnid). 89.

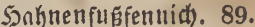

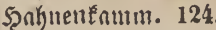

Şกฤแeแtépf. 124.

gemeiner. 124

Sonknenfpornfennidf. 89

Şnitretulelggrns. 91.

รุaintiepenguns. 91.

Sonrorettig. 165.

Şnumerforn. 70

S. Tnffétee. 128.

gelter. 128.

Snrtgrnz. 106.

Eleines. 107.

Snartidivinger. 107

5̧afentrod. 102.

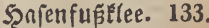

5̧njengrna. 102.

sonfenterte. 132. 133.
Sonfentlee, gebogener. 133.

rother. 132.

weiserer. 133.

Şกientofhl. 191.

Sonfentopf. 124.

Şnenpfötđen. 133

Sonjenfalnt. 191.

Şnusfaltshirje. 79

Shecternwide. 135.

Seidef́orn. 85.

gemeines. 85.

fibirift)e. 87.

windelldes. 119.

Sreidel. 85.

Sheiderfing. 238.

Seidetrübring. 241.

Şeiogrüze. 85.

Seilighell. 124.

Şeilfrnut, gemeines. 121

Seinrid), guter. 196.

ftorger. 196.

Seflolume. 190.

Seflertinfe. 149.

ร̧endelweís. 122.

Şengs. 92.

Şerbitgerfte. 68.

Şeroftéppffogl, weíser. 176.

Seerbftmouceroll. 242.

5อerfftrübr, Inแge. 26. range brane. 26.

Serbitinirnn. 232.

Sperbffinuoyertuogr. 178.

5eroftweisernut, Golnondif ipätes. 176.

Şerrenénatoffer. 12.

5jerrenfrnut. 177.

Şerrnpiry. 244.

Serruid)

Şergentefrettoe. 209.

5̧erźnentuffel. 11.

Şerzf́phr. 177. 180.

Shell, burgundiptaes. 127. griectilid). 136.

Spellinume, idinedifder. 127.

Speu, (it)medijates. 127. wírbes. 127. willoes heiliges. 127.

Simalnyngerfte. 66.

STimmelogerfte. 66 . grofe. 69.

zweizeirige. 69.

Şimmetšłelyr. 222.

Simmer इºrn. 66.

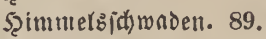

Simmelsthnu. 89. 93.

Şinderlilig. 241.

Sindräufte. 205.

Şirnérnut. 223.

şirjd)ling. 239.

treffitid fdimectender. 239.

Şirfdinfe. 14.9.

5itrdmingre. 156

Sirie, oeutidje. 80.

gelbe. 79.

gemeine mit getbem Somen. 79.

Şirfegrng. 89.

กแรึกebreitetes. 94

Şitrê, itnfienijat)e. 80.

Shirfenfend), Deutfiter. 80.

Şirie, ornugengerbe. 80.

(d) wกเż. 80.

weí̄e. 80.

weridue. 80.

Sirtengens. 90.

Şod) Eoghr, grüner. 180.

yommerider. 180.

Sörtterḱtee. 126

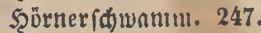

5̧onigerbfe. 135

5ृoniggrns, gemeines. 97.

indifates. 80.

weidjes 97.

molliges. 97.

Şonigftee. 125. 128, 132

Grnuer. 129.

5̧onigtñubling. 241.

Sonignidte. 135 .

STopfentree. 127.

getber. 134.

gemeiner. 134.

Eleiner gerber. 134.

Scopfenfrette. 191.

5.opfenluzerne. 127.

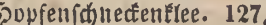

Szopfen, fpanifther. 220.

Sornenartoffer, Graue. 15.

rotye. 11.

meiśe. 11.

Sournflee. 125

5owaro sfartoffer. 15

ร̧แส์กuf. 250.

Sügerrohr. 96.

รุühnerfenuid). 89.

5̧ürjenfrüd)te. 140.

Şundegrns. 110.

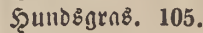

lleines. 95

rnukes. 105.

sulloshangras. 111.

5̧uกd smelde. 196

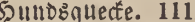

Şundsripp. 116.

Sounosidwan, buidhiger. 105.

Şund हnvizen. 111.

SoupW. 229.

ฐ.

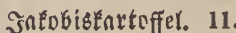

Эnétobsjwiebel. 169. 171.

Эnzell, gemeiner. 115.

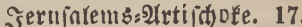

Эerujalemsgerite. 66 .

ร̌ruintems̊orn. 52, 53, 61, 66 .

รetTer. 139.

รgerfditunmm. 245.

Jgelweizen. 39.

mit selbem Snmell. 39

mit weistict)em Snmten. 39

weiser fammtnrtiger. 40 .

ฐmmuer. 52.

Fitcaruntétee. 132

รnhnunisobgne. 143

Snhannisforn. 61.

Эohantiisroggen. 61.

эofeprblume. 158 .

эoleptiten. 230.

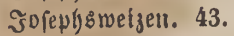

รipp. 229.

gemeiner. 229.

witider. 230.

รiopp. 229.

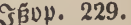

Эlloenpiry. 244.

sungfernbohne. 142. 143. 
Sieldithmamu, loffelfirmiger. 248.

Rerbet. 211.

erviger. 161.

gemeitner. 211.

Sierbelfernut. 211.

Reruerbjell. 146.

Rerugerfte. 62.65 .

Sieulenid)momm, Greiter Guidi: ger. 247.

getber. 247.

Sildererbie. 148.

Fid)er, gemeine. 148.

Ridertŕrnut. 123.

Ridterntrngant. 123.

Siđinerting. 148.

Rituer, puni/de. 149.

weiśe. 148.

iveise deutitie. 149.

witoe. 123.

3nfime. 148.

Rielgerfte. 68.

Sirếnménatoffer. 12.

Siridj6ohne. 142.

Sinquerítmaแım. 244.

תitebeforn. 61.

Sileber. 130.

Sitegeroggen. 61.

Silee, Graner emiger. 126.

brabanter. 130.

oreigrätteriger rother. 130.

englistier. 127.

erwiger. 126.

froenförmiger. 134.

feinfengeliger. 134.

freiptitrother. 132.

frůher. 133.

getber. 127. 134.

getber fđbebijater. 128.

getneiner. 130.

gezn̈fnter. 129

grnuer. 133.

groper. 130.

groferer meífer. 133.

grinituer. 133.

yolnändi i.jer. 130. 132.

fleitter. 132.

Eried)ender. 132.

mittlerer. 133.

rnuidender. 134.

röthlider. 132.

rother. 132.

rother friectiender. 134.

(d)wedifder. 127.

flétlinnifđer. 126

funnifder. 130.

fternfürmiger. 133.

tïrffif(d)er. 124. 130.

weiḱser. 132.

gurbfarbiger. 134.

meiser (đ)medicder. 128

welfher. 126. 130.

Fitette. 191.

Grätterige. 191.

gemeine. 191

gró̈e. 191.

officinelfe. 191.

Ricttendifter. 191.

Ritever. 130 .

Sitüge. 29.

Rlumperrůbe. 27.

Siumphnfer. 74.

Situmphirfe, getbe. 79. weiše. 80.
Situmprifbe. 27.

Situnererbje, grope. 146.

Riturferfoutnuelterbje. 146.

Snnuergras, getmeines. 105.

กิnnuel, jälyriger. 137.

Sineber, Innger. 121.

รีกัดชกนd. 171.

gemeiner. 171.

ipaniider. 172.

Snöterig, gemeines. 119.

tnrtarijifer. 87.

Sinotlen. 1.

Sindllengrn:. 97.

Snotlenilafer. 97.

Sinollenfohl. 184.

unter Det Erbe. 27.

Snollnubelli. 1.

Snoflenjellerie. 162.

rothgenderte. 163.

weiśe. 163.

Snollherbftrübe. 26.

Sinollwide, virginijate. 23.

Sillopfgrns. 105.

Sinopffohtrabi. 184.

Rnopf(aud). 171.

Sinopf(ud). 171.

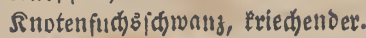
88.

ริnotengrกร. 92. 110.

ร๐bbีäpfe!. 11.

Rodrůbe, Iange. 26.

నื่น!. 177.

srüfieter. 179.

S̊̈gternut. 180.

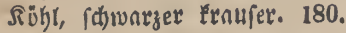

R̊̉̆bleingrns. 188.

R̈̈rbleingtrnut. 118.

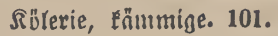

fummförmige. 101.

S̊Bte. 230.

Sönigin Enntnlupe. 217.

Rönigstopfinarnt. 202.

Rönigs farnt mit meisen Gamen. 202.

(fi) wnezzamiger. 202.

Sörber. 211.

Rörbetrübe. 160.

fibrbel, ppanifater. 161.

welfoer. 161.

wilder. 116.

wofiriedender. 161.

รỉrfel. 116.

Siofir. 178.

äftiger von ஒoitou. 174.

nmerifnniid)er. 175.

nilsonuernder von Dnubeton.

174.

Bnrdewifter. 180, 181.

brnuther. 180.

bunter. 181.

Dentidjer. 180.

Diffrippiger. 179.

Rohroifter. 187.

Sioht, eid)enbtätteriger. 180. ellintifder. 176.

Soflentäubring. 241.

Sobl, ewiger. 174.

frnmbiflicher bunter. 181.

frủher Ittmer. 178.

frủher meišer. 176.

frïhzeitiger zuderfyutartiger.

176.

gefrnnzter. 180.

senreiner. 172.
Siofl, gemeiner pommerider.180. grüner. 179

bofer frnujer Gramner. 180.

boljer (d)lichter pommer(b)er. 180.

f๋eiแลีpfliđer. 179.

Éreiner grüner. 180.

Fleiner fraujer \$ิnroenviffer.181.

(d)liđter. 175.

fiufrérntisoijter. 187.

Sivbr, niedriger Exnuner. 181.

niebriger Exnufer. 181.

nieoriger fraujer brnutter. 181.

ovaler. 176.

WInttgeorücter. 175.

Sivhrportulne. 198.

Softrabe. 27, 184.

blnue. 185

Glnue ipäte. 185.

englifate frübe fleinfrnutige. 185.

Rortrnbenjellerie. 163.

Sofirnbe, ipäte binue ltimer. 185.

liber ber Froe. 184.

unter ber Eroe. 27.

violette. 185.

เveí̄e. 185.

Siohtrabi. 184.

Graner. 185.

Glauer holfäldoifdier. 185.

früber Grnuer. 185.

frilher englifther. 185.

früger łleiner. 185

früber weişer. 185.

gemeiner. 185.

gemeiner grillter. 185.

geid) rigtbrätteriget. 185.

frnujer. 185.

ไänglider. 185.

Sü̈ter Grauer. 185.

แtrmer fpäter Grnuer. 185.

unter ber Erde. 27.

violetter. 185.

weíser. 185.

Rohireps. 27.

Sioll, rother Gnumartiger. 180.

Sioftrübe. 27.

eigentfict)e. 29.

getbe. 28.

gelbe runde. 28

gelbe (d)

getbe fpaniide. 28.

rïtljlidje. 29.

(f) we Diidie. 28.

liter Der Erde. 184.

unter Der Erde. 27.

พreí̄e. 29.

weí̧e unter fïh) wadjiente. 29.

Rohl, Rupiner. 180

Sohlfarnt. 202.

Siofl, fdjlidter einfadjer. 180. (d)ottifder. 180.

fhrwefelfarbiger italienijder. 184.

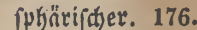

ipighiger weif́er. 176

Sobriprofe, italienifde. 183.

Rofl, Gtrnęurget. 178.

taujendebupiger. 179.

liber oer Erde. 184.

umgełefyrt eifürmiger. 176.

vielebufiger. 179.

weiśer. 179.

milder. 174.

Rorbentoartweisen. 47.

Düแnăhriger. 48 .

röthlider difälyriger. 48.

weiš̈er dictähryiger. 47.

weiser inmmtartiger mit

(d)warzen (3)rannen. 47.

weiśser fommtartiger mit

veísen B̋rnunen. 47.

weíser mit weípen Girnnnell.

$$
47 .
$$

Forbengrnb. 88

Jiotbentjir je, deutitie. 80.

grofe gelbe. 80.

fleine gelbe. 80.

ungegrannte. 80 .

violette. 80.

Rulbentieidgrns. 90

Sutbenmeizen. 37.

brnuer fammtnetiger. 39.

Grauner. 39.

rotter gintter. 38.

rother fammentiger. 39

weiser mit gelbem Snmen. 37.

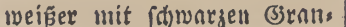
nen. 47.

weiserer mit meiślidem $\mathrm{S}_{n}$ : men. 37 .

weí̄er mit meístidjem $\mathrm{S}_{n}=$ men น. bräuntid)em Şalm. 37.

weíser fommtartiger. 38.

fiolrut. 28.

Sopfgerfte. 69.

Ropff́ree. 130.

getber. 125.

Sopfëbyl. 178

früber Mnirånoer. 178.

frülyer lllmer. 178

Strnf́burger Innger. 178.

Siopfétil. 174.

Srnunidyveiger. 175.

beeiter pratter weíser. 175.

Erfurter. 176.

früber niedriger. 178.

frühzeitiger weiser. 176

grofer arnbifter. 203.

grofer (d)ottifder. 175.

grofer fidmedifiter. 175.

grofer ipriter. 178.

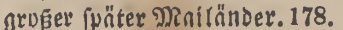

Exnuser. 177.

Siopféthirnbe. 184

Sopffogt rother. 177.

punter. 178.

weîีer. 175.

weifer Brnunitweiger. 176.

weí̄er Erfurter. 176.

ઝilndelftn̈bter. 176.

zwergartiger rother. 177

Sopf, fugelfürmiger. 176.

Sopfintat. 200. 201.

Grnuner Bertiner. 203.

getber holfändicher. 203.

groper rother. 202.

ranginu nufictlieśender. 201.

rotfigelber. 201.

ruthgern̈nderter. 201.

tilrefijder. 202. 


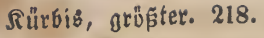
న̂uentein. 225.

Rugełartipdope. 190.

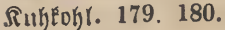

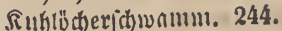

Silfpeterfirie. 116.

Rubpilz. 244.

Didatitieliger. 244.

Лuhidmanm, weiśer. 241.

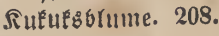

Sưfumer. 213.

Sîndelérnut. 225.

תuuefle. 225 .

Runotd. 225.

\section{2.}

En̈แแmertélee. 132.

\&ämumerf́rnut. 196.

عämmerinlnt. 206.

Eämmeriđ)พลกว. 133.

\&äu(t)eไgrns. 92.

Ennoroggenforn. 57.

Enildriedgins. 96.

Enudrohr. 96.

Ennorofrgrns. 96.

Enttich. 200.

\&aud. 170.

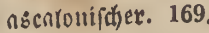

ę̧onrer. 171.

gebnuter. 171

gemeiner. 168. 170

reunntif(c)ex. 169.

rỏhrenftieliger. 169.

rühriger. 169.

ipanifiter. 170.

jprofiender. 172.

ftnrḱriedyelloer. 171.

3afmer. 170. 171.

Enurentiilentoffer. 11.

Envandel. 231.

gemeiner. 231.

Reberdifter. 191.

\&eberifinamm. 245.

Qeethardel. 98.

Rerdienénartoffer. 12.

Stebesgrns. 102

Rieidgrns, grop̈es, 90.

Sinje. 148.

Gefinnte. 137.

gemeine. 148. 149.

provencer. 149.

ppnnifaje. 149.

vierfnmige. 137.

vierfamige mirbe. 137.

zottige. 137.

zmeifnumige. 137.

Sinjenbiatterbje. 134.

Einientid)er. 148.

\&injenwicte, ถ̈ळte. 137.

rnuthe. 137.

vierfnmige. 137.

Röhervilz, Befnubter. 244.

esponrer. 244.

(む) uppiger. 244.

Ëb)eriđmanm, n̈ftiger. 244.

Ebfferternut, n̈()teg. 210.

gemeines. 210.

imeerrettiges. 166

officinelles. 210.

güfelf́refíe. 210.

\&üthe. 111.

Sb̈wenfuв, semeillet. 138.

Sbwentnppe 138.
Sord), nusbnuernort. 111. gemeiner. 111. rïßer. 111.

Sorderfartoffer. 12.

\&iimecte. 210.

\&ungeแmurg. 196.

\&uzerne. 126.

Deuticbe. 127

gerbe. 127.

(c)medifd)e. 127.

\&uzernertiee. 126.

\&uzerulfette. 191.

\section{ม्रT.}

MR̃nettig. 166

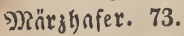

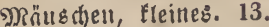

Mn̈uiegerfte. 112

roggennatige. 112.

ఇäujehafer. 99. 111.

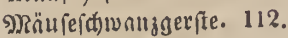

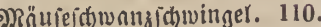

ग्रRngnznnbuhne. 152.

Mniexbie. 146.

volltragende gerbe engrifibe. 146.

Mnirnu. 219.

शRnirettig. 165

Mairübe. 26.

frïge grntte. 26.

rulloe gelbe. 27.

Mniz. 81.

amerif́nnijţer. 85.

blnuer gemeiner. 85 .

Guntforbiger. 85.

conndenjer. 81.

früber. 85.

gemeituer. 81 .

gemeiner groper. 81.

grofer. 85.

fleitler gelber. 85

mit äftiger 2 tehre. 85.

rotfer gemeiner. 85 .

weiser gemeiner. 85.

MRizufererbfe, frühe. 146.

Rajurn॥. 219.

cretificter. 220

Mnjornudoften. 219 getmeiner. 219. wirber. 220.

Majurénmeizen. 38.

Mnltefer. 202.

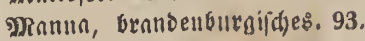
deutiches. 93.

श्रnnungens. 93. znl)แes. 89.

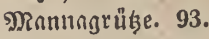

Ranunidyminger. 93.

Manid derénetoffer. 13

গRangelfernut. 119.

Manngold, gelleiner. 29. gemeiner weiper. 30. gewögntider. 196. (d) mieriger. 196. weiser. 30. 196. weiser öfreidifider. 30.

MRnngolorïbe. 29.

Rarienbohne. 143.

Mnrientenut. 138.

MRntienmanter. 138.

Mnrécohne, engrifide. 142.

Markerbje, engrifije. 147.

Sinights grope. 147.
Maxferbje, Rnights fleille. 147. Mohnms์ forll. 85.

MarEtéfil. 179.

Marotte, [ponificte. 147.

Mnfieron. 219

গ) Rnttentïlumer. 234.

Mautergerfte. 112.

MRnuerpfeffer, gelber. 212

Rnuertrespe. 105

MRurnd)e, eillfotbe. 247.

Mnurnathe, getteine. 246,

Manure. 153

MRazngnubuhne. 152.

Medel, grofer. 95.

Reert́uhr. 186.

gemeiner. 186

Inugitn̈uDiner. 174.

Meermelde. 197.

9)eerportulak. 197.

Jeerrettig. 166.

Megelérnut. 119

Mehrointer, rufifif(t)er. 55.

Reier, wirder. 196

Merde, gebnute. 197. porturnéntige. 197. (d) mnlbr"ntterige. 197. firnud)artige. 197. wiroe. 195. 196. 197.

Melilote. 128.

शerirotengrns. 113

Merilotentree, brnuer. 129. weiset. 128.

Retifie, officinelle. 229.

Relone. 215.

Melone der Seifigen. 216.

Melone, frorentiuex. 216.

Relone, gereifte. 217.

geriefelte. 217.

geriefte. 217.

perifictie. 214.

Relone won \$Brermo. 217.

פRerone, wogtriectiende perfifit) 214.

MRelonengutre. 215.

Meronenfürbi: 218

Innger. 219.

(d) wnizer. 219.

melonenufebe. 218.

Merotentétee. 128.

Menidiendhr. 244

Meterelle. 203

Midonxerbje. 147 bolnandifarte. 146.

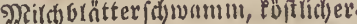
239.

Mild)bifter. 191.

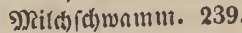

๓าi

Ritjgrns, gropes. 94

פRittelf́ul) 178

Macländer. 178

Mittelfopfoukt. 178

Mitterrettig. 165.

MRitte(wirfđing. 178.

Rodeforti. 61.

Mögre, frübe rothe. 156. gelbe. 153.

gemeine. 153.

getmeine gelbe. 155. geneine weí̄e. 155. gorogelbe. 155. ornilgegelbe. 155 rothe. 155.

Mebnchserjnbarber. 193.

פR०guk, afintijd)er. 203.

9)Rorrrübe. 153.

Rolinie, Grnue. 102

InI1ges. 166.

rundes. 166.

Monntrettig. 165.

rotfer. 166.

Monntsłlee. 126.

Montrée. 203 wollige. 97

M2ornübe. 153

Mooridumele. 98.

Modsweizen. 38. puptrid)e. 246.

robnerige. 246

offene. 247.

Murgenbnfer. 76 .

Rorgenftern. 158.

Murine. 204.

Mottentrnut. 128

शouceron. 242. irnuje. 227. Somell. 204.

Mutterínnut. 138.

Rutterwurz. 138.

Mnrrbe. 161 wirber. 116.

尺agelernut. 119.

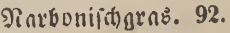

Sardeninme. 237.

RntterÉnterig. 119

Rnttermurz. 119.

Negerénartuffer. 12.

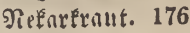

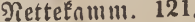
zngime. 237.

ఇiunfiéraut. 159

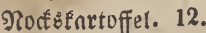

গudern. 1.

গีïßd)enfarnt. 206.

Monntrndics̊dell. 166.

bln̋ulich länglichrunder. 166.

vioretter rnuger. 166.

weifer runder. 166

groper gelber Ernujer. 203 fleiner rothénntiger. 203.

Roorbirfe, gemeine. 80

Morcher, Grnutue. 246 gemeine. 245. 246.

Mordinelictunmm. 246.

Münze, englifte. 227.

Muidueringt, mit (d)wnrzen

mit weísem Snnell. 204.

Musf́ntelferfenut, wildes. 120 .

Mnurthenferber. 161.

\section{2.}

Natttéerze, zweijährige. 163 গindtid)atten, ep̃onarer. 1.

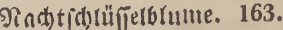

Singetwide, butte. 123.

शeger, frühe (đ)warje. 143

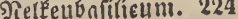

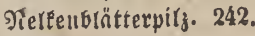

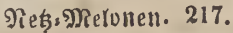

Siereutentuffer, Innge rotfe. 13.

Nigelle, gemeine. 237.

গonuenfleuper. 118.

Nuber, pommeriate, 12

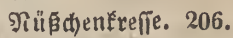

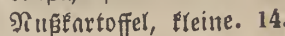

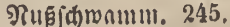




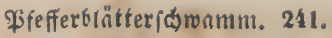
Pfeffertraut. 231. gemeines. 230. fleines. 230.

Pfefferting, weí̂́er. 241.

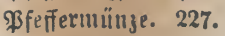

\$fefferpily. 241.

अfefferreizger. 241.

Pfefferidunam, 241.

Peifengrns, gemeines. 102.

\$fettuith. 79.

Ffennigbolye. 151.

IS feuniglinje. 149.

Pierdebohne. 150.

tleine. 151 .

Pferoegrns, weides. 97. wolliges. 97.

$\mathfrak{B}$ ferdeflee. 128

Fiffer. 243.

iffiferling. 243.

ef́barer gelber. 243.

gelber. 243.

getmeiner. 243.

Bfirfid)évirl, 177.

Pfinumblätterpil子. 242.

Pflüferbjen. 146.

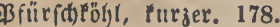

Pfundrafer, weiser. 74.

Pilje. 238.

Bimpinelle. 119

PIntterbie, Grattrofe. 134 e药are meí̄e. 149 selbe. 134 .

getlleine. 149.

fnurligte. 22.

अlattgerfte. 68.

Prumagef́ufr. 180, 181 ,

Gunter. 181.

bunter franzörijđ̆t)er. 181.

\$lumagewinterëbr. 181.

Pluker. 218.

\$örid). 177.

ஒ̈brfdéohl. 177. 180. gemeitter. 178.

langëp figer. 178.

Pỏrichtubrhl, zeitiger. 178.

Folei, semeiner. 228.

\$oley, gemriner. 228.

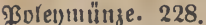

Porcellall6olne. 142.

\$orue. 170.

ஒordelnud. 170.

ßorrey. 170.

\$orjt. 121.

æortulné, gelber. 198. gemeiner. 198.

Porturne, mit groß̈en getben Blätterı. 198

\$ortuknemelde. 197.

अrablialnt. 203.

gelfer. 203.

ariiller. 203.

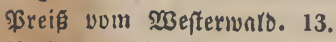

ஒreiß von Solfsuto. 13.

अreís von \$eru. 14.

\$rinz vou Dranietr. 217.

\$rinzentopf. 203.

Srinzenialnt. 203.

अrinzefínguitbobne. 143.

æroguri. 183.

Puxhafer. 77.

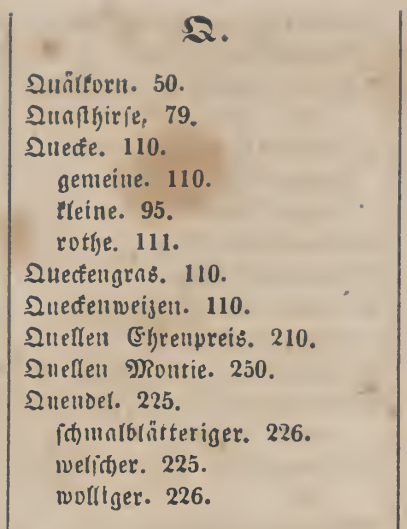

Rfeingerfte. 70.

Riedfrausgras. 94.

Riemengerfte. 70

Rie fentlee. 128.

golber. 128.

Riejentogl. 179.

braunidueiger. 175.

i由ottif(ber. 175

Riejentürbis. 218.

Riejenunis, vftindija)er. 85.

尺iejenidowinger. 108.

Riejentelisterorn. 85.

Riejenıudererbje. 146.

Siffell. 99.

Rippenunngurd. 196.

Risuell. 99.

\section{$\mathfrak{R}$.}

Rnbis. 98.

Rกดรgrne. 98

Rndie8. 165.

RRกDiezden. 165.

eligliid)es. 166.

ทolñntoict)er. 166

Ininges. 166 .

rundes. 166.

weises fleinfrnutiges. 166

Rniuljnfer. 99.

Ranger8. 30

Rnpecole. 184.

Rnutjonelle. 166

Rnpunzer. 206.

Rnpunjel, frnnzöriftie. 163.

getbe. 163.

fleine. 206.

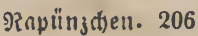

Rapunzeliellerie. 163.

Rapunjeftwarjel. 163.

Rnfenunnygrab, feillftes. 112.

Rnfenidduiele. 98.

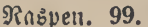

Raudhnfer. 77. 99 .

Rnufe, efpare. 208.

quellenliebende. 208.

Rnuide. 30.

RRกygrnz, englifties. 111.

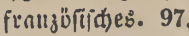

gróses. 97.

itnitentides. 112.

fleines. 111.

RuITels ellglifdes. 112.

Stictnen's engliithes. 112. Tुitfworths ellglifhes. 112.

Relygeis. 243.

Rehling. 243.

Reis, ñguptiches. 56. Deutidues. 70.

Reisbofne, ourdfidtige. 142.

Reisoinkel. 52. 53. n̈guptijder. 52.

ReiEgerite. 66, 70.

Reizler. 239.

Reikger. 239.

Rett' den Mnnn. 65.

Rettig. 164.

gegnuter. 164.

gemeiner. 164

Wiener. 165 .

खiener getber. 165.

Jnbmer. 164.

Rettungsmann. 65

Rhayontifa, 163

Rgnpontiffuntsel. 163.
Rišnengrns, didtrinpiges. 91 .

Düแunb(üthiges. 91.

ein brü thig ges. 91.

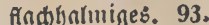

frud)tbares. 93.

geprestes. 93.

groses. 94.

jübriges. 91.

Pullfiges. 92.

fllotiges. 92.

meergrünes. 92.

(i) melenartiges. 101.

idivimmendes. 93.

fteifes. 91.

ftrnffes. 91.

vielbrïtbiges. 93.

zนโаmmengedrü đ̌tes. 93.

Rispentinfer. 71.

brauner gegrounter. 75 .

gelber gegraunter. 75 .

gelber ungegraluiter. 75 .

groper nnatter. ?6.

lurjërniger weíser. 74.

rother gegrounter. 75.

(t)marzer. 75.

(id) warzer gegraunter. 75.

(i) warser ungegraunter. 75 .

weiśer gegraunter. 73 .

weî́er ungegraunter. 74.

Rispentirfp, getmeine. 79 graule. 79.

(d)warge. 80.

Rucrmbot. 172.

Roccrinbolle. 172.

Rodell. 57.

Rudenbullen. 172

Rübring. 243.

Röhren(alld). 169

Röhrentily, ef́barer. 244.

Rübling. 29.

Roggell. 57.

n̈gyptifaer. 61. 66.

nxthangetip(t)er. 61

gemeiner. 57.

(ibirijat)er. 61.

tnurijder. 61.

tumelifider. 61.

vielälyriger. 61 .

wnIndiīder. 61.

ivt toer. 113

Roggengerfte. 67.

Roggenteril. 57.

Roggentre\&ue. 103.

Rohrglanzgrns. 90.

Rofrgens, groses. 94 getlleines. 92.

Rodtnmbolle. 172.

Röttlting. 241.
Rollgerite. 68

giojenterbfe. 147.

Rojentỉhl. 179.

ซrürit เer. 179.

Rofenfoft. 179.

Rojentuiriding. 179.

Rośunrill, äßt)er. 220. gebrïud)(iđ)er. 220 gemeiner. 220.

Rośohue, 150 .

R०ß̧grns. 97.

ynfernatiges. 97

yohes. 80.81.

Roślette. 191.

Ropripp. 116.

Rospicide. 150.

Rotabaga. 28.

Ruthgerite. 67.68.

SRothynfer. 111

Rotyernut. 177.

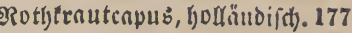

Rothernut, gropes. 177 .

holländes. 177.

fleitles. 177.

urmer. 177.

Rotel. 28.

Rud)gens, getbäbrigeb. 113. gelbes. 113 .

gemeines. 113.

woblriedendes. 113.

Rübe. 24.26.

nbgeplnttete. 26.

Gnirifide. 27.

brüfifeler gelbe. 27.

brififieter weise. 26

englifite. 28.

engrifde rumbe grünsopfige.

27.

englip̣) ruแbe grŭแrict)e. 27. engrifithe runde rothetonfige. 26. frübe glatte rotlje. 26. frithe glatte weise. 26. früge yolfäldịd)e. 26. gelbe. 27. 153.

gelbe bulländiad)e. 27.

gerbe inuge. 26.

gerbe rothe. 29.

getbe rullde. 27.

gerblidie. 27.

getleine rothe. 29.

gemeille weise. 24.

grofe rotije. 29.

grïne. 27.

grüne เuแbe. 27.

grünlide. 27.

Jettinger. 27.

Eleitie rothe. 29.

Eteine runde franzöfifd)e. 27. länglicthe. 26.

Innge. 26.

range getbe won syon. 26.

märtijđte. 27.

Rübettferbel. 160.

Rübentofy. 24. 27. 184.

rothbrätteriger. 29.

Rübenrettig. 164.

Rübe, Dttersberger. 27. panajdirt torn̈tterige Innge. 26. purpurrothe, "26.

rothe. 29.

rothe Innge. 26.

rothe runoe. 26.

rothêupige. 26.

Enrmer, öponom. SPfanzentunde.

rothidmarze Innge. 26. Sarbey, türtifice. 120.

35

Růbe, runbe. 26.

(4) wange fransörifide. 26.

idwarze wurzlige. 26.

Teltauter. 27.

weise. 24.

meiśe Innge. 26. 
Gorrey, witbe. 120.

EnIfe. 221.

Entziteinftee. 129.

Eammeténetuffer. 12.

Snummtweisen, rơther. 39.

Snnct:Эofnnuirguirter. 222.

Sanct: Petergarfte. 70.

Sinnct: :etersforn. 56.

Snilogerfte. 65.

Gnubgrns, Grnutb. 113.

Gnnognargrne. 113.

Snndhnfer. 77. 78.

Snndrettig. 165.

Ennoried. 249.

Snndrohr. 249.

Snindrohrarns. 249.

Snndipergel. 121.

Snndthyminn. 225.

Entrotrespe. 105.

Snndweisen. 113.

Snndwidtáburjue. 152.

Snnbohne, gemeine. 150.

Entibrud. 22.

Snudifter. 191.

Satmernmufer. 194.

fransobiict)er, 194.

groper. 194.

römifityer. 194.

Snuerírnut. 175.

Gnuerfenf. 194.

Snungens. 120.

Snupnitanie. 23.

Snumelt. 191.

Snumide. 150.

Snuoberfobl. 177.

früber. 178.

getwer. 178.

groper ppöter. 178.

fpäter nntürlidggerber. 178.

Scabiofe, falfote. 115.

Senbidienfiodenblume. 115.

Gđñfer. 145.

Sthäferftocterbfe. 147.

Sđnofiegerftee. 129.

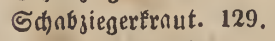

Sannfgarbe. 114.

gemeille. 114.

Sत) afgrne. 106.

Sthafferee. 132.

Sithuftinfe. 123.

Sतinfrien. 114.

Edinfripue. 114.

(S) nfidmillgel. 106.

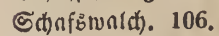

Sthnfzunge. 117.

S(t)rutute. 169.

Sduruttengrns. 92.

Gd)ntuttenjwieber. 169.

S(h)nrouctsheil. 210.

ธक)

Ed)artad) frant. 120.

Silyrten, wilde. 120.

S(t)nrteyernut. 120.

๔d) nrtottenfHoband). 169.

S(b)rruttenlnud). 169.

Stheer. 116.

Ethett. 124.

Sthiffisnrtuffer. 11.

ธतirbetee. 124.

Edititopepone. 218

Sdiutrunumzet. 163.

Solpperting. 244.

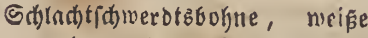
range sxeitiduobige. 142.
Gd) rningengrns. 157.

Sd) Inngengurfe: 214.217.

S(b) Inugenfinob(nud). 172.

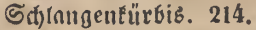

Sd)เnngenlúfumer, türsif(t)e. 214.

Sd)inngentand). 172.

Shlangenwurz. 119.

Sd) lnugemuarser. 157.

Sdlippenwurz. 119.

S(b)

Sd)mete, fried)ende. 95.

Бdmerbel. 196.

Sd)mernurs. 196.

Sn)miełe, brane. 102.

ornule. 98.

grnngrüne. 98.

S() minfeere. 195.

Sthminfborne. 140.

Scduedentilee, ornuer. 126.

groper gelber. 127.

hopfennrtiger. 127.

Eleiner gerber. 127.

(iid)elfrüdtiger: 127.

Sdineegrns. 110.

Sd)eepity, äftiger. 244.

Edyueideburne. 140.

Sđ̆nittëbr. 185.

Sd)nitféfl. 185

getwëhnulityer. 185.

Goher branner (d)ridter. 185. Ernusblätteriger. 185.

frnujer. 185.

rother. 185.

Sithitt(nut). 171.

Sdunttpeterifite, gemeine. 211.

Siduttfelferie. 211.

Ernusbrñtteriger. 211.

Sđuittzwicbel. 169.

Sdüngrn: 100.

Sdjotenflee, gefjönter. 125. getber. 152.

gemeiner. 125, 152.

vierediger. 152.

Sd)oten: Rndiesd)en. 166.

Sdjotenjudererbje, idwarze. 146.

St)ote, (t)warze. 146.

S(drotenerbje. 144.

Sd) wnbenfrnut. 176.

Sdirnbenneizen. 56.

ธत)wnden. 93.

fronefurter. 93.

Sd)wndengras. 93.

Sd)wärtrnut. 118.

(ङ) wanzbnfer. 99.

Sd)marjfümmel, zalfmer. 237.

Sd)narzminde. 119.

Sthwarzwurzel. 157. 158 groß̧Grätterige. 158.

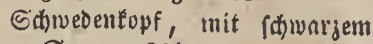
Snmen. 204.

mit weisem Samen. 203.

Sd)weinetrüffel. 248.

Sctwein fartoffel. 15.

Sthmeizermangold, gerber. 196.

ธ(t)weizerrübe. 26.

Saldwerdtbolne. 140. grope weíse. 142.

treine meišse. 142

Sd)werbt 3 udererøje. 146. grope. 146.

Schmerdtgmergoofine, frühe weišse Innge breitfdotige. 143.

Salmindelforn. 234.

Sdiwinger, anfredter. 109.
Gitwingel, blnugrůner. 106.

epsunrer. 93.

gefiederter. 110.

glntter. 109.

grannentojer. 109.

groferer. 108.

bärtlither. 107.

Garter. 107.

fléiner. 110.

furzgrnmiger. 109.

รnแอgeid) vänzter. 110.

rold)artiger. 108.

roulher. 109.

rofgrartiger. 108.

rother. 107.

(d)wimmender. 93.

jeegrütter. 106.

verfđiedenthantteriger. 107.

Gcorjonere. 157.

gebnute. 157.

gezninte. 157.

grofornttterige. 158

ipanifthe. 157.

แทก̈ธ่te. 158.

willoe. 158.

Sedum, zurürtgebogenes. 212.

Seelohl. 186.

Sellerint. 162.

Sellerie. 162.

Sellerie: Eppid). 162.

Senffrnbzoiftet. 187.

Gidelerbje. 146.

Sidjerḱlee. 127.

treiner. 127.

Siebenzeit. 129. 136.

Sitberbart. 98.

Silberbrätring. 240.

Siltbergrns. 98.

Sirberbnfer. 78.

Sinnu, getber. 138.

Siof. 80

Sijererbje. 148.

Sommerointel. 50.

Sommergerfte. 65.

gemeitte. 65

grope. 68.

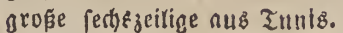
68.

pornifdse zuveizeilige. 69.

fanmaze fed) bzeilige gemeine. 68.

vierzeitige. 65.

zweizeilige. 68.

Sommer: Эgetweizen. 39.

Sommerfnnuel. 137.

SommerÉffl. 177.

itnlieni|jer. 183.

Soumertopfsugr. 178.

Sommerfopfinlat. 202

iकlefiliter. 202.

\{dimnesfnmiger Glonder. 203. unterjester bronder. 202:

Sommerfaud). 170.

Sommermnjorntl. 219.

Gommerporre. 170.

Somntertettig. 165.

grnuer runder. 165.

langer (f)warjer. 165.

lnuger meiser. 165.

rutioer rother. 165

runoer fdivanzer. 165.

runder weiser. 165.

violetter. 165 .

Sommertettige, runbe. 165. ipindelförmige. 165.

Sommerroggen r.us 2regypten. 61.

Gommerinfnt, gelber. 202. groper fronler. 203. Pleiller brnutuer. 203.

Sommerinturei. 230.

Sommerpelt. 50.

Sommerftnudenroggen. 61.

Sommerviehgrns. 91.

Eommerweijen nus ç

Sonmmermeizen nus Sicilien uno Nenper. 47.

Sommerweijen, weiser äftiger. 43.

SommerzuderEnrtoffer. 13.

Sommerzuieber. 168.

gcrbe. 169.

ruife. 169.

meí̈e. 169.

Sondenfrunt. 191.

Sonnenblume, findlige. 17.

Sunnenrofe, thonigte. 17.

Sonnenthnu. 138.

Gonnenuender. 205.

Eonnenuenogürtel. 222.

Sontmenmirbel. 205. 206.

Sorg. 80.

Surgigras. 89.

Gurghngras. 80.

Spätgerfte. 65.

Spätf́ntoffern. 12.

Spötérnut, Greites. 175, 176

Spätweíšrnut, Graunidgueiger. 175.

Spargerbohne, engrifige. 142. grnue enpiitite. 142.

Spargeterbie, witbe. 152.

Spargel, gemeine. 198.

Spnrgetétee. 126.

Spargetfufl. 183.

on̈nifther. 184.

frủher rotjer. 184.

rabmforbiger. 184.

fibirifdjer. 184.

Sparger, mit grïnell 20 urzer: iprofien. 200. weiser. 200.

Spectborne, bunte. 142.

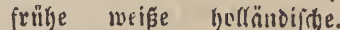
143.

weíse. 142.

Speisbolnne, bunte. 142.

Epeipfonttenpily. 243.

Speifepartoffer, gute 13

Speifemorder. 245.

Epeitñubling. 241.

Speiteufer. 241.

Spelz. 50.

n̈gyptijdjer. 53.

Gräulidbrnuner. 51.

Sperzreis. 56.

Spelz, rotyer. 51.

weífer. 50.

Sperbertrnut. 119 gerwö́fulides. 118.

Eperget, beutidjer. 121. weífer. 121. wirber. 121 


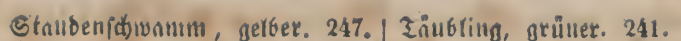
trnubenformiger. 247.

Stnudeniellerie. 211.

Stectinbe. 24. 27. grope gelve. 28. Inppländifかie. 27.

Steigbolyne. 140.

Gteintlee, ה̈ॐter. 128.

branter. 129. gelber. 127. 128.

getweituer. 128.

ufficinelfer. 128.

Petitpierrif(jer. 129

pisizer. 129.

ungarif(j)er. 129.

weiser. 128.132.

Steituppi. 202.

getber früber. 202.

grillter früfer. 202.

Steitnur(t)el. 245.

Eteinpir\}. 244.

Steinmide 122.

Eteligelbotine. 140.

Etengergenüh) 172.

Steligetelee. 126.

Stellgelforys, fannorifider. 180.

Steugetroggen. 57.

Etengeliellerie. 211.

itnfienifduer. 211.

Gternitrat. 138.

Gtiatrrübe. 27.

Sturfoblne. 142.

Stocterbie. 147.

Stufigerfte. 68.

Stofmorditel. 245

Stoppelpity. 245.

๔topperrübe. 24. 26.

Strnibgras. 113.

Strnitionfer. 113.

Strandetur. 186.

Strnß̈ellgrns, Preillez. 91.

Straud) Fofr. 174. wilber. 174.

ธtrnusgras, gemeimes. 95 . groper. 95.

Preines. 91.

เอeíse8. 95

wudierndes. 95.

Strnu(biö)erpiry. 244.

Stringel, gemtiller. 139

હtuppelrïbe. 24. 26.

Eņ̃̄⿻ 122.

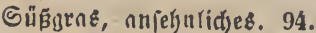
fluthendes. 93.

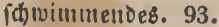

Gน̊ำ

Elip̈lee. 122.

gemeitter. 124.

Sï̈́ling. 245.

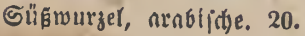
fnlidite. 22.

tildinnifict)e. 20.

Eilfforfengrens. 91.

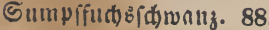

Sumpférngoifter. 187.

Sumpfmorther. 245.

Sumpfwillogarm. 95.

Suppentorn. 61.

Suppeninud). 171.

\section{$\mathfrak{3}$}

Tinubling. 241. ornuer. 241. rother. 241.

Injerfitionmm. 238.

Inlaverveveizen. 37.

Tnuneuthnfer. 76.

Inแแnenzanfenténrtuffel. 14.

Inppe. 138.

Inrtoffey. 1.

Znubenerbje. 147.

Tnubengerfte. 88.

Inubeninfer. 76.

Inubenforn. 111.

Inubentide. 150

Tnubhafer. 99. 104.

รnuโd. 111.

Enufendorntt. 114.

รnujendf́noten. 120

Inverid). 103.

Tellertübe. 26.

Teltorbernůbe. 27.

Pleine. 27.

Telutegrof. 120.

ริ)กugrne. 95.

Thnuroie. 138.

Thongerfte. 66.

รhyнtin, gemeilter. 225 optittoift)er. 223.

[unnifther. 230.

wiroer. 225.

కimothensogras. 90.

Timorijgarns. 90.

Ioderboryue. 152.

Suotentepf. 203.

รöberid. 103.

Iöfferdyell. 1.

Ioffern. 1.

Tonêterger. 116.

Zunfofrnut. 128.

Sopinambur. 17.

Topferbfe, grïue. 147.

Trngant, fleenrtiger. 122.

füper. 122.

Iraubellerbje. 147.

Iraubengurfe, grïne. 214.

Irnubenlyafer. 76.

TraubenÉogr. 181

Traubenenrtoffer. 15.

Trantfiling. 238.

Freibjarat, rmber frnuper flei: tier Eurzer. 203.

Tresue, nufrerbte. 109.

bife. 103.

Dünnểenige. 104.

feinlynarige. 103.

sefiederte. 110.

rnuke. 105.109.

parrige. 104.

tnilbe. 104.

traubennrtige. 103.

unfruditonre. 104.

vielbritthige. 103.

weidite. 103.

weidhyarige. 103.

Tresparns. 103.

Zrifthnfer. 99.

Tripmndam. 212.

Trogflee. 133.

Trommeliathangel. 11.5 .

Irüffer. 248.

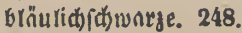

gemeine efsonre. 248.

groß̈e. 248. gemeine. 103.

trnubenflüthige. 103
Iriffer, fittuarje. 248. weíse. 248.

รunçersveijen. 42.

รินrbnแfủrbis. 218.

Türtentobyue. 143.

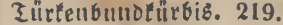

Iurueps, (t)wedifder. 28.

Turriips, englipde. 26.

11.

แtferrižpengrab. 93.

แแtirer tieben frraucumunter. 138. IInterfogirnve. 27.

unterfobirnbi. 27.

getbe. 28.

Ituterfohgrifbe. 27.

3.

Beits6ulne. 140

Benusuntel. 119.

Bergebrintt. 117.

Berinifler. 202.

Befen. 50.

Biehgrns, gemeines oreibrüthi= geb. 92.

вов́ев. 92, 94 .

fünf 6 hủtlyiges 92.

Enแumförmiges. 101.

Eleines. 91.

wonliges. 101.

Biegtentoffel, gruse. 15 ,

Bierectsfrumt, gemeine. 193.

Biperntwurzer, fjanijite 157.

Bitúbohne. 140.

Bugeryen. 135.

Bogelf̈uterig. 120.

Bugertueft. 153.

Bogernide. 135.

gerbe. 135.

getmeitue. 135

Eleine. 137.

23.

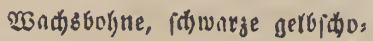
tige 142.

3ad)berb/e. 147.

20nd) tetweizen. 191.

Wुnizett. 32.

¿gniboofte. 220.

खुnroerbfe, enollige 22. breitflätterige. 22.

Dilunbrantterige. 22.

linientătterige. 22.

खुonroerve, Enoligte. 22.

खsarogrns, yanriges. 100.

Minlohnfer. 75.

W3arofirfe. 94.

豸̇ontohtriengras. 94.

Wandoélee, rangähriger, 132.

Wonromnjoran. 220.

Wुnloperlgens. 100.

Wnarorispengrab. 91 .

Bzarorohr. 102.

B̧arojarben. 120

W3nyb fauernunfer. 194

Bando idwinger. 108 .

33nlowicte. 22.

grope Glaue 135.

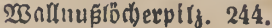

WnUtwurz, gemeine. 249.

Wontzenfernut. 125
20 nitzendill. 234.

פBnfierbolyue. 210.

ख্กnеreppit). 162.

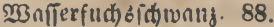

खुnfergnudbeil, groper. 210.

Bonijerf́refíe. 208.

D্กffertürbis. 214.

Bonfirmelone. 214.

Wniferriedgrns. 94.

Bnกtertübe. 24.

Bontertispengras. 94.

Bnกfirvieggrns, hohes. 94.

MPdielweizen. 41, 43

Wegoiftel. 187. 190.

weise. 190.

Begerratt. 117.

Wegebreit. 116. 117.

Pleiner. 116.

furjer. 117.

พ3egejens. 120.

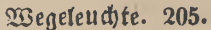

Żegeria), breitblantteriger. 117.

fleiner. 117.

mittlerer. 117.

rnuber 117.

rotjer 117.

wei Ber. 117.

Megetritt. 120.

gruper. 117.

Innzettolätteriger. 116.

fdumaler. 116.

juiésiger. 116

Beglnuf. 120.

Mुegroart, gemeine. 205.

wirloe. 205.

Weinfrıme. 163.

M̉eif́rnut. 175, $176,179$.

Errfurter gropes. 175.

Exfurter treines frïbes. 175. friifes rundes. I75.

gef

gropes rundes. 175.

gropes rundes bläulides. 176.

গürnberger grö́в丨. 175.

fuñtes ruibes. 175.

llimer. 175.

Beiß̄rïbe. 26

gelbe. 27.

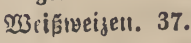

Mrizen. 32.

ägnptifd)er. 43.

äftige ellglifitoe. 43

nenbijdier. 43.

bräulidgrnuer fonnmtartiget eliglifder. 42

blauer gemeiner. 36.

Grnuer fonumintiger eng: rifd)er. 42.

cretifter. 40.

Definuer. 39.

bictähriger. 42.

einkoveniget. 56 .

ellglifiner. 40.

gegranuter. 35.

gemeiner. 32.

gemeiner mit grütem Sierne. 35.

gemelnet pornijiber 49.

bartjamiger. 44.

forbenartiger pornifder. 50.

friectender. 110.

furdgegennnter pornifder, 50.

Inngerorniger. 49.

sothringer. 48.

Beizen, pornifder. 48. 
wointerrapungeythen. 206. Winterrettig. 165. (5rfurter (d)marjer. 165. itfwnrzer runder. 165.

Miuterrettige, runde. 165. ipinderförunige. 165.

B্interroggengerfte, rect)szeitige. 67.

Dsinterrübe, (d)warje. 26.

Wointerintat, rother römijter. 104.

Minterinturei. 230.

Binteripely, fatmarjer nus Iffrién. 55

winterftnudenroggen. 61 .

Bistertręิpe. 111.

wiuterweizen, ה̈gypticher. 53. nrnbifiter. 44. getueiner. 38 .

3 interwicte. 150.

ख્ointerzivieber. 169. gemeine. 169. Inudbige. 169.

m̧irbelernut. 123.

Mirifing. 178, 180. friliger. 178 .

moirfainglofy. 178.

Wirliting, Innger Strnopurger. 178.

niederer $\dddot{3}$ siener. 178.

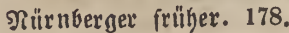
päter. 178. Llımer päter. 178.

M̧ir[i(d) Éthl. 177.

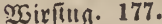

früher runder. 178. früber tlluer. 178. gelber ränglidłrunoer. 178. gemeiner. 178. gejdlitster runder. 178. gorogetber. 178. grof́er. 178. groß̧er runder. 178. grüner rnnger. 178 . yarbfrilyer runder. 178. Innger. 178.

langëbpfiger. 178. rutider. 178. runoer mitterfriffer. 178. Finter runder. 178. iprofiender Brüliferer. 179. Strą̧burger. 178. weíser. 177.

M̧infugfohl. 177.

ख̧irz. 177.

Bittwenfrume. 118.

Woblgenuffy. 209, 220.
M3orf: Flee. 127.

Wुolfbitiote. 122.

Wollorume, gemeine. 122.

Bouthergerfite. 70

Sounderhnfer. 74.

WutuderEtee. 128. gelber. 128.

พ豸แแ⿰亻⿻上丨eizell. 43. rotijer glatter. 43. roifer glatter viern̈hriger. 43. rother fammtnrtiger. 44. weiser glatter. 43.

ærundflee, getber. 122. gemeitur. 122.

B̉แndfrnut, gemeines. 122.

Wुurmivurz. 118

B̧urftérnut. 219. 230.

Murzer, gerfe. 153.

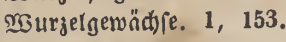

ख3urzelénftnnie. 23.

$\mathfrak{W}$ แrzetpeteriitie. 161.

Bourzerrapunzel. 163.

\section{Эy.}

2) orfertuhr. 176 -

3)ortertérnut. 176. nillerfrilifeftes. 176. frühes gnuz feines. 176. friilges niederes. 176. frülyes nieoriges. 176. gropess. 176.

3) Fop, officineller. 229.

\section{3.}

3apfellt́artoffel, gerbe. 14. 3nunidwinger. 108.

3numivide. 135.

3efrengne. 120.

Beilengerfte. 65 ,

3cileubnfer. 76.

Bellenbfume, gemeine. 190.

Belferie. 162.

Biegergerite. 68.

Siegenbart. 98, 247.

3iegenfurn. 136.

3iegenélee. 124.

3ipulle. 168.

Bipperleinfrnut. 139.

3ijererbje. 148.

3ittergrng, genteines. 102. mittreres. 102.

3ittertrespe. 110

3odoelhnfer. 76.

3uffernteniourzer. 161. 3ucterbohne, grose feine weise Inng: und oictichotige. 142. rotije. 142.

3uctererbje, ornunfönnige. 146. on̈niface. 146.

frübe weisoräfgende englifitge. 146.

grof́ brnแ und rothbrågende. 146.

grofe englifide. 146.

grop̧e yoln̈moifit)e. 146. grof̧e Exummithotige. 146 grof̧e fäbelformige. 146. grofe iveisbrügende. 146. grope weî́e 146.

Eleille goländifdue. 146.

it)ottijde grnue. 146. meişe grostïthige. 146.

3udererbfen. 145.

3udterhouiggrns. 81.

3uderhutéphr. 176.

früher niebrigex. 176. grofer hỏbliger, budid)ter. 176.

3ucterhutérnut. 176.

englif̧ues weisez. 176.

frütes. 176.

grofies. 176.

fleines. 176.

ipisig. 176.

2)orter. 176.

3udferbutwirfaing, S'trnß̧but: ger. 178.

3uctert́netoffer. 13.

3urtermerde. 197.

Sucternourbirie. 81 .

3uderpaftinate. 157.

3ucterpeterfiliennurzel. 161.

3ucterrïbdell. 159.

3ucferrübe. 30.

3ucterit)n̈fell. 145.

3uderfidoten. 145.

3ucterwurzer. 159.

3แđferwurzแert. 159.

3utergmergbohne, frühe gelbe. 143.

grose bidfajotige, weise feine. 143.

febr frufige Gunte. 143.

3ungenpiry, leberfarbiger. 245.

3reif́orn, ebles. 52.

3weimonntrettig. 165.

3wente, gefieberte. 110. gepinnte. 110.

3wergoofne. 142.

ornue mit weisen Fredten. 142.

Grnfirianifitye. 142. 3wergbohne, bunte fronsöfifhe biaffeiftige. 143.

englifide frübe. 143.

erbjennrtige. 143.

frïge gerbe. 143.

frübe gelbe, felyt volltragende. 143.

frübefte fohtwarge ficilinnild)e. 143.

frülge meiše. 143

gerbe 143

gerbe formarzgeffecte. 143.

fleine fdunarge. 143.

Łeine mei巨̄p. 143.

röthlict)e. 143.

rotrje weisgeftreifte. 143.

ftrohgerbe. 143.

frohgerbe mit brnunen 2 ugen. 143.

ftrot)gerbe mit gerben 2 ugen. 143.

meißge breithůrfige. 143.

meise molzenförmige. 143.

3wergcantalupe. 217.

3wergerbje, \$iifops. 147.

Siffows allerfrülefte. 147.

frübe. 147.

3wergfen丸t, füser. 236.

3werghergétol. 178.

3 wergétohr, fleimer früfsjeitiger. 175.

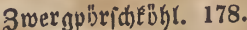

3ivergipargeltét, fpäter. 184.

3 mergneizet. 39.

3ıergzuctererbje, frifhe eng: liftoe. 146.

3mergzuder(‡)ote, frülye. 146.

3woieber, n̈gyptija). 172.

brapgerbe holläudifae. 169

Dunketrotye prattrunde barte

Srnutr(t)weiger. 169.

emige. 169.

gelbe. 169.

gemeine. 168.

3 miebergrns. 97.

treineb. 92.

3wietsel, junge tragende. 172.

3iviebelénrtoffer. 13.

3rvieber, range fpanifde. 169.

3wiebe(röhrct)en. 169.

Stvieber, rothe foürfite garte lltmer. 169.

rothe lufmer. 169.

3 mieberfante. 13.

3nieber, fi)rifde. 169.

weise funnifdse. 169.

Swittertntoffer. 15. 



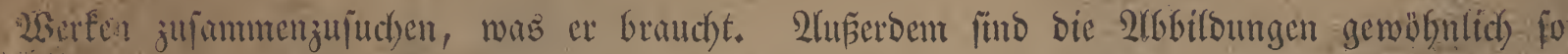

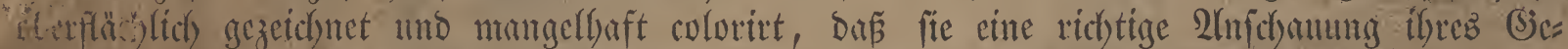

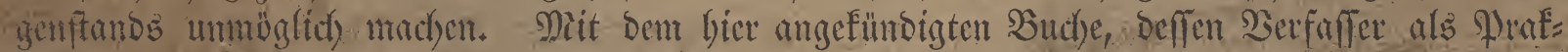

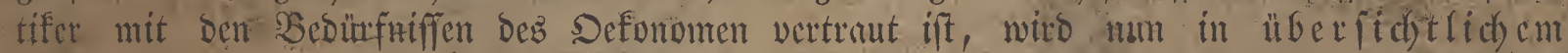
Zent uno naturgetreuen, porgfältig coloriten 2 bbiloungen zu äuserft billi gem Preife geboten, was von einer lanowirtbidaftlid)en Pflangenfunbe Deutichlantos inner: balb cines gegetenen Tabmens ermatet werben Eann. Daf́ es ber Serfaffer an eigenen Jorfdungen nitht bat feblen laffen, wiro man feine Mitbe baben berausjufinden.

Sm gleichen $\mathfrak{B e r l a g e}$ fino erfchienen:

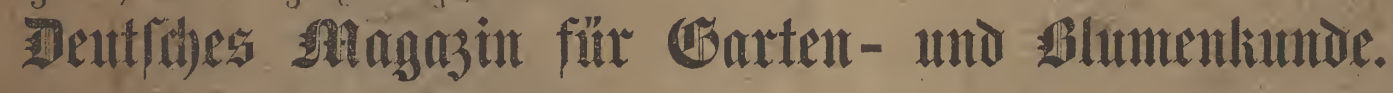

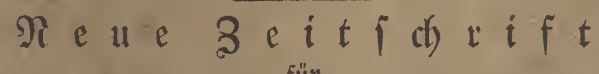

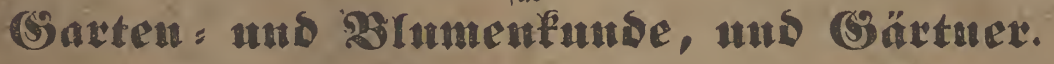

Jerausgegeben und rebigirt

Dilbelut teubert,

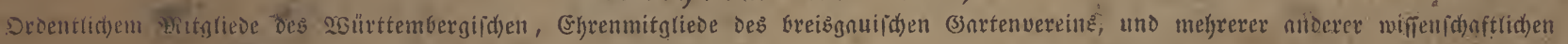
Bereine Mitglied.

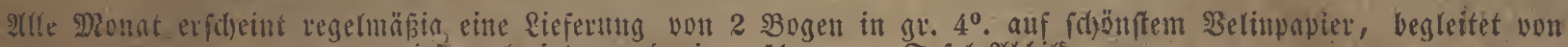

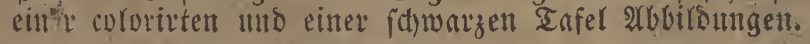

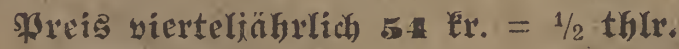

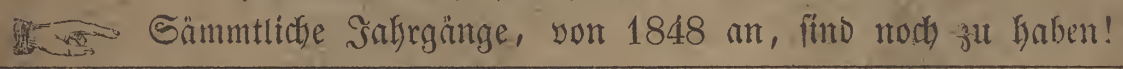

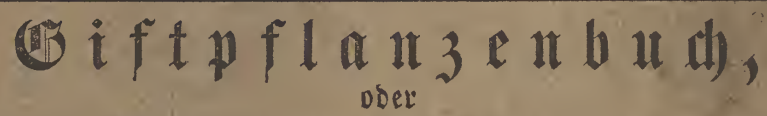

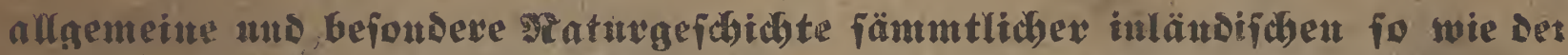

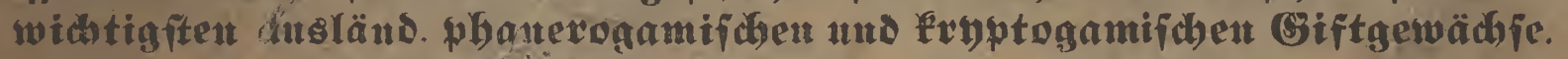

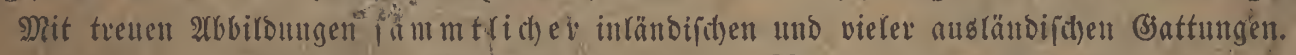

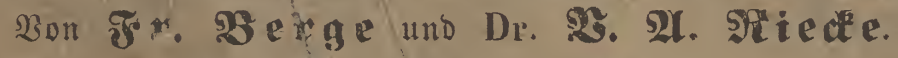

Mit 72 colorixten $\mathbb{C a f e} \mathfrak{n}$.

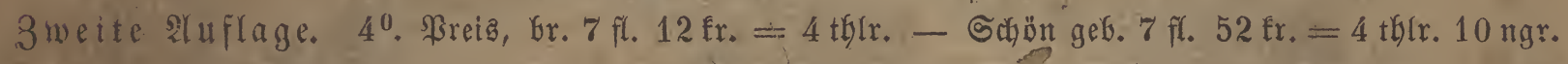

\section{Gdhuteterlingebudh,}

\section{oder \\ nllgemeine Anturgefóthte der Sodnmetterlinge und befondere oer curopäildiden Gonttungen.}

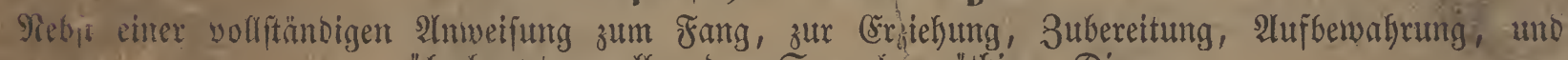
überhaupt zu alfen bem Sammles, nöthigen Dingen.

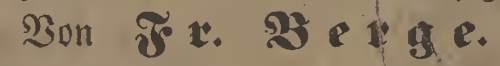

Bueite, völlig umgenrbeitete uno leht vermelnte Auflage.

Mit if (h): : 